HARALD GSCHWANDTNER

\title{
STRATEGEN IM \\ LITERATURKAMPF
}

THOMAS BERNHARD,

PETER HANDKE

UND DIE KRITIK
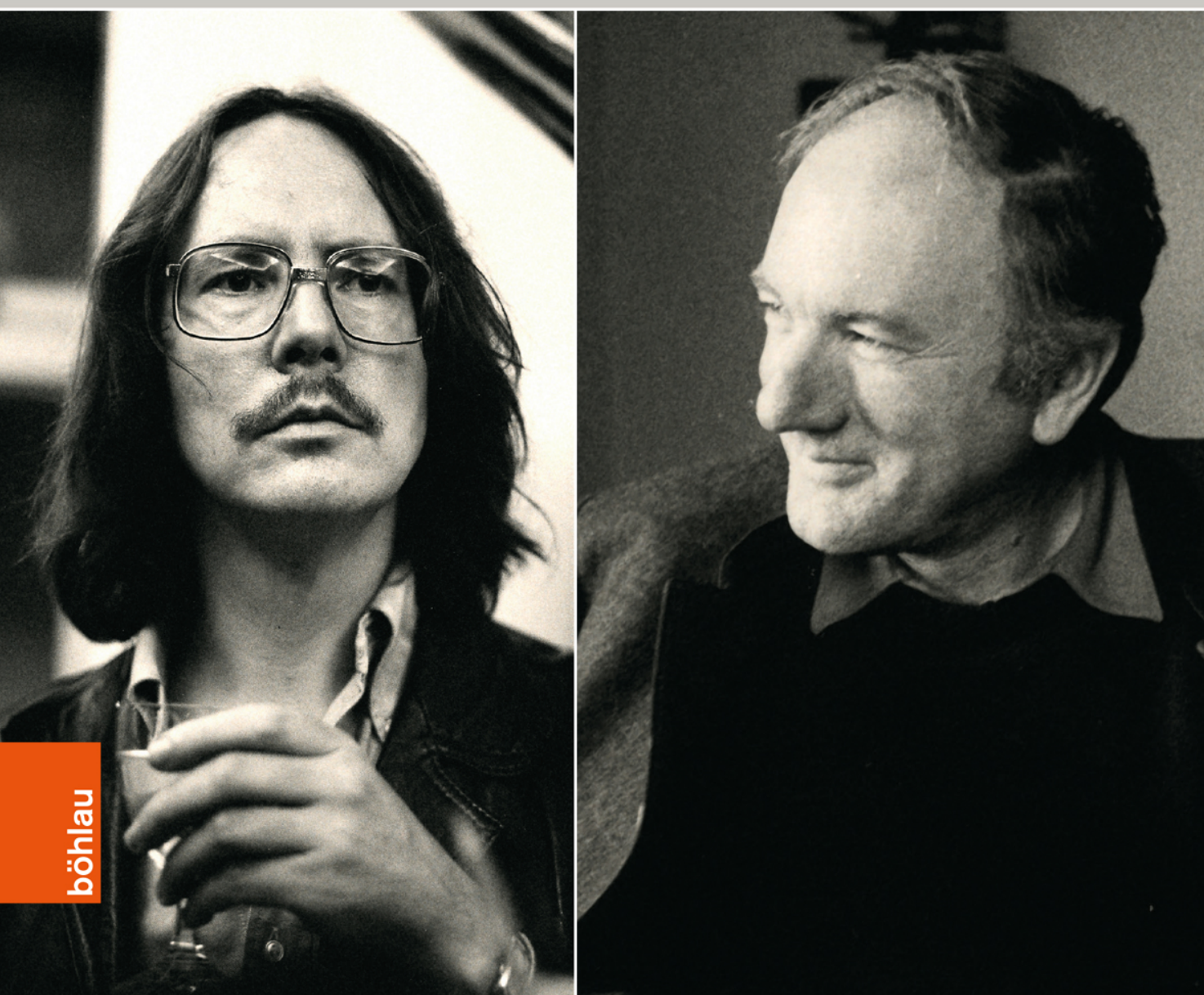
Literaturgeschichte

in Studien und Quellen

Band 31

Gegründet von

Klaus Amann,

Hubert Lengauer und

Karl Wagner

Herausgegeben von

Werner Michler und

Norbert Christian Wolf 


\title{
Harald Gschwandtner
}

\section{Strategen im Literaturkampf}

\author{
Thomas Bernhard, Peter Handke und die Kritik
}




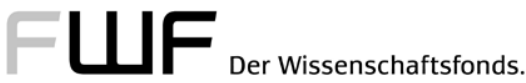

\section{Veröffentlicht mit Unterstützung des Austrian Science Fund (FWF): PUB 761-G}

Open Access: Wo nicht anders festgehalten, ist diese Publikation lizenziert unter der Creative-Commons-Lizenz Namensnennung 4.0; siehe http://creativecommons.org/licenses/by/4.0/

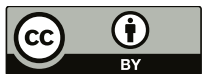

Die Publikation wurde einem anonymen, internationalen Peer-Review-Verfahren unterzogen.

Bibliografische Information der Deutschen Nationalbibliothek:

Die Deutsche Nationalbibliothek verzeichnet diese Publikation in der Deutschen Nationalbibliografie; detaillierte bibliografische Daten sind im Internet über https://portal.dnb.de abrufbar.

(C) 2021 by Böhlau Verlag GmbH \& Co. KG, Zeltgasse 1, A-1080 Wien

Umschlagabbildung: Foto Thomas Bernhard: ( Erika Schmied (Residenz Verlag GmbH, Salzburg/Wien); Foto Peter Handke: @ Brigitte Friedrich/SZ-Bild/picturedesk.com

Korrektorat: Volker Manz, Kenzingen

Satz und Layout: büro mn, Bielefeld

Druck und Bindung: Finidr, Český Těšín

Vandenhoeck \& Ruprecht Verlage | www.vandenhoeck-ruprecht-verlage.com

ISBN (Print) 978-3-205-21230-0

ISBN (OpenAccess) 978-3-205-21231-7 


\section{INHALT}

VORWORT

I „SCHREIBEN IST EIN FÜNFKAMPF“: EINE ART EINLEITUNG

II „ICH KANN MICH DAMIT SCHWER ABFINDEN“: KRITIK DER KRITIK ALS WERKPOLITIK .............................. 27

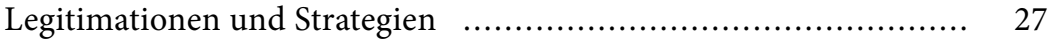

Einsprüche gegen die Kritik: eine verbotene Übung (Verstörung) $\quad \ldots \quad 34$ „Über diesen Roman wären nicht so viele böse Worte zu verlieren ...": Handkes Hornissen nach Princeton ................. 39

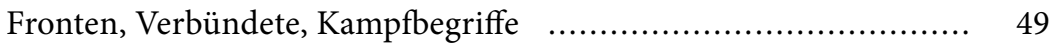

Ein Buch „rehabilitieren“? (Die Hornissen, Der Hausierer) ......... 55

III UNFREUNDLICHE BETRACHTUNGEN: EINWÄNDE GEGEN DIE LITERATURKRITIK $\ldots \ldots \ldots \ldots \ldots \ldots \ldots \ldots . . \ldots 6$

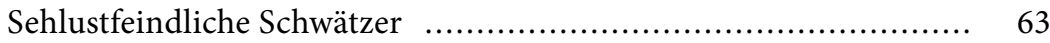

Vom Zeitungswahnsinn bedroht (Wittgensteins Neffe, Nachmittag eines Schriftstellers) ................ 70

„vollkommen humorlos und blöd“:

Bernhard und die Literaturkritik

„Vom peinlichsten Lob bis zum bösartigsten Verriß“:

Bernhard liest Rezensionen (Frost)

„unbeholfener lyrischer Unsinn“: Bernhard redigiert eine Kritik mit einem Exkurs zu Elias Canetti

„ekelhaft ekelhaft ekelhaft“: Kritiken auf der Bühne (Der Ignorant und der Wahnsinnige, Minetti, Über allen Gipfeln ist Ruh)

Von der Dürre der Theaterkritik oder:

Landwirte und Rezensenten

Nur selten ein Sommerhemd: Handke liest Rezensionen

Literaturkritik als ,leeres Geschäft':

Handkes Vorarbeiten im Radio 
„Ihr wart Vollblutschauspieler“:

Handke und die Phrasen der Kritik (Publikumsbeschimpfung) $\quad$...... 126

„Solche Wörter sollte man euch verbieten“ oder:

Erstsprache vs. Zweitsprache

Einwenden und Hochhalten:

Handkes Rede gegen die Literaturkritik

"MEIN FEIND IN DEUTSCHLAND“:

PETER HANDKE VS. MARCEL REICH-RANICKI

Princeton 1966 und die Folgen

Poetik und Polemik oder: Das Problem der ,Natürlichkeit 150

Die „ästhetischen Gewissensbisse“ des Peter Handke

(Wunschloses Unglück)

Schleichende Eskalation: die 1970er Jahre

(Die linkshändige Frau, Das Gewicht der Welt)

„schiefe Bilder und preziöse Vergleiche“ (Langsame Heimkehr) $\quad$.... 170

Die Bestie von Puyloubier (Die Lehre der Sainte-Victoire) $\quad$............ 175

Mit Cézanne gegen die Hunde (Die Lehre der Sainte-Victoire) ...... 183

Im Bunde? Reich-Ranicki, Bernhard und Unseld .................... 189

Schnüffeln und Verreißen (Mein Jahr in der Niemandsbucht) ........ 204

Unversöhnt: letzte Gefechte

(In einer dunklen Nacht ging ich aus meinem stillen Haus)

V „ES SIND AUCH ANDERE SÄTZE MÖGLICH“: PETER HANDKES GEGENMODELLE ZUR ZEITGENÖSSISCHEN LITERATURKRITIK _.. 221

„Aber ich bin kein Kritiker“ …....................................... 221

Ein Leseerlebnis beschreiben: Handke rezensiert Hermann Lenz $\quad \ldots \quad 228$ Abenteuergeschichte der Lektüre:

Handke liest Bernhards Verstörung …................................ 239

„Kritik, die zugleich eine Form der Begeisterung ist“:

Helmut Färber

„Haben Sie das gehört?":

Wolfgang Bauer, The Beatles, Gert Jonke 
„wirklich unorthodox“: Handke über/mit Ödön von Horváth

Keine Axt für das gefrorene Meer in uns:

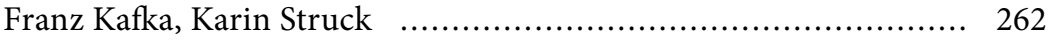

Der Autor als Kritiker: ein Rollenkonflikt? ....................... 266

VI „ZEITUNGSG'SCHICHT'LN“:

THOMAS BERNHARD ALS LITERATURKRITIKER ................... 273

Vor eines Dichters Grab: Johannes Freumbichler ................... 273

„Ich glaube, da liegen die Wurzeln“:

Bernhard als Gerichtsreporter ................................... 284

„Kanzlist, Kofferträger und Kunstkritiker“ “....................... 289

„Zuchtvoll und klar“: Bernhard als Literaturkritiker

im Salzburger Demokratischen Volksblatt ......................... 293

Verschweigen und Verzeihen: Bernhard und der „NS-Parnaß“ ..... 305

„Traumfabrik“ und „Ro-Ro-Ro-Kost“: Kino und Taschenbuch .... 314

Alte Zöpfe, neue Pferde ........................................ 322

„Was in den guten Jungen nur gefahren sein mag?“:

erste Polemiken ............................................... 329

„Ich kann kein Buch besprechen“:

Absagen und Stellvertretungen (Alte Meister, Auslöschung) ......... 333

VII REZENSIONEN, DIE KEINE SIND:

KRITIK UND SELBSTKRITIK BEI THOMAS BERNHARD ............ 343

Vorgeschichten einer Polemik: Bernhard vs. Bruno Kreisky ....... 343

Politische Polemik als Literaturkritik

(Gerhard Roth, Peter Turrini) ................................ 357

„ein wirklicher Dichter“: Kreisky verteidigt Handke ............... 362

The Return of the Critic oder: Ausweitung der Kampfzone ........ 369

Bernhard als Kritiker seiner selbst (Korrektur) .................. 372

Zwischen „Geisteskunst“ und "Selbstkorrektur“:

Szenen prekärer Autorschaft (Korrektur, Am Ortler) .............. 379

Vom „Streben nach eigener Billigung“

(Der Untergeher, Der Theatermacher) ............................. 386 


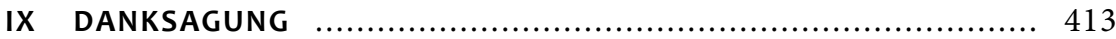

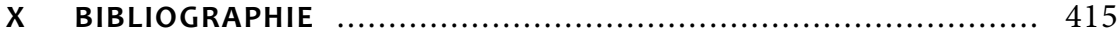

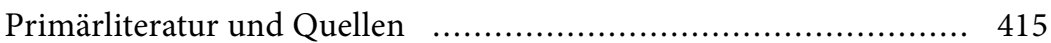

Literatur- und Kulturtheorie ...................................... 433

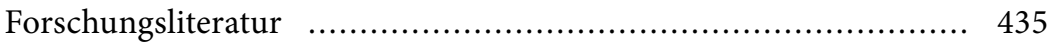

Rezensionen, Presseberichte, Journalistisches $\quad \ldots \ldots \ldots \ldots \ldots \ldots \ldots \ldots . \ldots . \ldots 4$

Fernsehsendungen, Audiovisuelle Medien, Webpages ............. 469

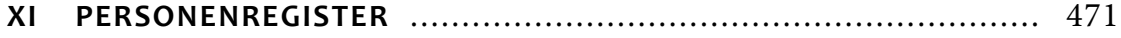




\section{VORWORT}

Als Peter Handke im Oktober 2019 von der Schwedischen Akademie der Nobelpreis für Literatur zuerkannt wurde, war die vorliegende Dissertation bereits seit einem guten halben Jahr abgeschlossen und wenige Monate zuvor an der Universität Salzburg approbiert worden. Im Zuge der neu aufgeflammten Diskussionen um Handkes ,Jugoslawien-Texte wurde auch das Verhältnis des Autors zur Literaturkritik, zum Feuilleton und zum Journalismus im Allgemeinen erneut verhandelt: Worin liegt das Eigenrecht der Literatur begründet, wenn es um die Kommentierung aktueller politischer und gesellschaftlicher Konflikte geht, und wie unterscheidet sie sich von der Sprache des von Handke vielfach geschmähten Journalismus? Welche Formen öffentlicher Kritik an einer Person sind zulässig, und welche überschreiten, wie auch immer man Maß nimmt, den Bereich des Vertretbaren? Sind in der Berichterstattung über einen Schriftsteller Werk und Person tatsächlich sinnvoll zu trennen, und hat nicht gerade Peter Handke - ähnlich wie Thomas Bernhard diese Trennung im Lauf seiner Karriere wiederholt, ja nachgerade programmatisch unterlaufen? Petitionen für und gegen Handke wurden in diesem turbulenten Literatur-Herbst 2019 lanciert, in den Feuilletons deutschsprachiger, aber auch internationaler Zeitungen, Zeitschriften und Online-Medien stritt man heftig über das Werk des österreichischen Autors, besonders aber über sein öffentliches Auftreten, etwa über seine Rede beim Begräbnis von Slobodan Milošević im Jahr 2006.

2010 hatte Handke in einem Gespräch mit den beiden Journalisten Hubert Patterer und Stefan Winkler geäußert, der Nobelpreis sei „etwas ungeheuer Politisches“ und bedeute im Grunde den „Tod der Literatur“: „Das passt nicht zu mir.“” Einige Jahre später antwortete er anlässlich der von ihm kritisierten Verleihung des Nobelpreises an die weißrussische Schriftstellerin Swetlana Alexijewitsch auf die Frage, ob er damit rechne, den Preis eines Tages selbst zu erhalten: „Das ist eine alberne Frage, und meine Antwort kann nur noch alberner sein: Ich verdiene ihn nicht, weil er sinnlos ist. “2 Nun, im Oktober 2019, sah Handke sich selbst mit der politischen Dimension des Nobelpreises konfrontiert - und damit, bei diversen Gelegenheiten öffentlich Rede und Antwort stehen zu müssen: Das

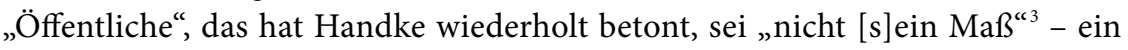
Umstand, der im Zuge der Debatten erneut deutlich zutage trat.

1 Peter Handke im Gespräch mit Hubert Patterer und Stefan Winkler. Graz: Edition Kleine Zeitung 2012, S. 23.

2 Heinz Sichrovsky: Der König der Niemandsbucht. [Gespräch mit Peter Handke.] In: News, Nr. 2, 16.1. 2016, S. 84-89, hier S. 89.

3 Peter Handke: Vor der Baumschattenwand nachts. Zeichen und Anflüge von der Peripherie 2007-2015. Salzburg, Wien: Jung und Jung 2016, S. 243. 
Für die Fragestellung der vorliegenden Arbeit hätten die Kontroversen zweifellos eine Menge neuen Materials geboten. Zugleich aber hätten sie deren Rahmen gesprengt, zumal die Diskussionen um Handkes Beziehung zu Serbien und zum ehemaligen Jugoslawien weit mehr berühren als das Verhältnis von Literatur und Journalismus, etwa die komplexe politische Geschichte des Balkans in der zweiten Hälfte des 20. Jahrhunderts und ihre mediale, wissenschaftliche und juristische Aufarbeitung. Gleichwohl seien eingangs zwei aktuelle Beispiele erwähnt, die das Fortwirken der behandelten Thematik im Schreiben, in der poetologischen Reflexion und im öffentlichen Auskunftgeben Peter Handkes belegen.

Im November 2019, also im unmittelbaren Vorfeld der Nobelpreis-Verleihung, betonte Handke in einem Gespräch mit Ulrich Greiner, man dürfe zwar „den Journalismus nicht generell verachten“, beharrte aber zugleich auf einem fundamentalen Unterschied zwischen literarischem und journalistischem Schreiben: „Die literarische Sprache ist die natürliche, sie ist die Sprache des Menschen, des Gefühls, der Vernunft, sie ist ursprünglichste, nachhaltigste Sprache. Die Sprache des Journalismus ist eine künstliche, beigebrachte, schulische. “4 Handke, der sich erfreut darüber zeigt, dass Greiner „nicht nur ein Kritiker“, sondern auch „ein Leser“ sei, ${ }^{5}$ greift hier einen altehrwürdigen Topos auf, der sich auf Johann Georg Hamanns Rede von der Poesie als „Muttersprache des menschlichen Geschlechts" ${ }^{\text {“6 }}$ zurückführen lässt und sich seit vielen Jahrzehnten, mit wechselnder Intensität und Schärfe, wie ein Generalbass durch Handkes Werk zieht: Es handelt sich um einen grundlegenden, nicht selten zu Wut und Hass eskalierenden Vorbehalt gegenüber dem ,Journalistischen', der nicht nur die tendenziöse und sprachlich unsensible Berichterstattung über politische Konflikte betrifft, sondern auch das journalistische Schreiben über Literatur, die Literaturkritik und ihre Spielarten.

Die Verleihung des Nobelpreises hat Peter Handke nicht dazu bewogen, diese lange gehegte Feindschaft ruhen zu lassen - ganz im Gegenteil. Noch in der Anfang 2020 erschienenen, aber bereits im Frühjahr 2019 verfassten Erzählung Das zweite Schwert stellt er einen Mann ins Zentrum, der auszieht, um an einer Journalistin Rache zu nehmen, die einst Falschmeldungen über seine Mutter verbreitet hat: Die als „Maigeschichte“ camouflierte Streitschrift wendet sich nicht nur gegen die „Myriaden öffentlich agierender Frauen“, die dem Erzähler

4 Ulrich Greiner: „Spielen Sie jetzt Tribunal?“ [Gespräch mit Peter Handke.] In: DIE ZEIT, Nr. 48, 21.11. 2019, S. 61-62, hier S. 62.

5 Ebd.

6 Johann Georg Hamann: Aesthetica in nuce. [1762] In: J. G. H.: Sämtliche Werke. Hg. v. Josef Nadler. Bd. II: Schriften über Philosophie / Philologie / Kritik. 1758-1763. Wien: ThomasMorus-Presse 1950, S. 195-217, hier S. 197. 
ein Gräuel sind, ${ }^{7}$ sondern auch gegen den Journalismus und die „Zeitungen“ in toto, die er, bewusst auf Differenzierungen verzichtend, zum „Gipfel der Gewalttätigkeit“ und zum „größte[n] Unheil“ „auf dem Erdkreis“ erklärt.

Seiner Aversion gegenüber dem Journalismus und dessen Akteurinnen und Akteuren wird Peter Handke, von dem seit Mitte der 1960er Jahre weit über 100 gedruckte Interviews erschienen sind und der es durchaus verstanden hat, mit den Mechanismen medialer Aufmerksamkeit zu spielen, wohl auch zukünftig (literarisch) Ausdruck verleihen. Während Thomas Bernhards Kritiker- und Zeitungsschelten - sieht man von Unpubliziertem aus dem Nachlass ab - abgeschlossen, gesammelt und sorgsam dokumentiert vorliegen, kann sein österreichischer Antipode dieser Rubrik seines Euvres noch die eine oder andere Volte hinzufügen.

Salzburg, Juni 2020

7 Peter Handke: Das zweite Schwert. Eine Maigeschichte. Berlin: Suhrkamp 2020, S. 95.

8 Ebd., S. 73. 


\section{I „SCHREIBEN IST EIN FÜNFKAMPF“: EINE ART EINLEITUNG}

In einem Beitrag zum Almanach des Salzburger Residenz Verlags hat Alois Brandstetter Anfang der 1980er Jahre seine Situation als Autor mit jener seines Vaters verglichen: So wie dieser als Bäcker überzeugt gewesen sei, negative Reaktionen auf seine Ware seien nicht auf deren Qualität, sondern auf seine politischen Ansichten zurückzuführen, so denke er mitunter, „daß dem oder jenem Kritiker eigentlich weniger mein Buch als meine Nase nicht gefällt“: „So macht man bei sich bisweilen auch aus einem sachlichen Gegner einen persönlichen

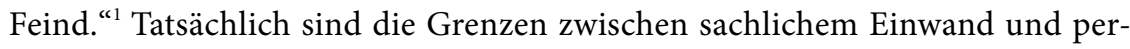
sönlicher Idiosynkrasie im Verhältnis von Kritikerinnen und Kritikern einerseits und Autorinnen und Autoren andererseits oft fließend, wobei Entsprechendes auf beiden Seiten zu beobachten ist: „Man wird“, so Brandstetter weiter, „nicht weit fehlgehen, wenn man annimmt, daß auch den Kritikern, den unbestechlichen, so wenig das Menschliche fremd ist wie den Autoren, die um Anerkennung ringen. “2

Widmet man sich der Beziehung von Schriftstellerinnen und Schriftstellern zur Literaturkritik, dann betritt man ein umkämpftes Feld, in dem seriöse Verhandlungen über ästhetische Fragen nicht selten in persönliche Gehässigkeiten übergehen; für „Prozesse der literarischen Kommunikation zwischen Kritikern, rezensierten Autoren und anderen Adressaten der Kritik“ spielen, so Thomas Anz, die „Emotionen der Beteiligten eine erhebliche Rolle“.3 Gerade der Umstand, dass die einen coram publico über die Arbeiten der anderen urteilen, birgt ein enormes Konfliktpotential, das sich im Laufe der Literaturgeschichte immer wieder in heftigen Kontroversen entladen hat. Die Institution der Literaturkritik ist ohne die Gegenrede der Autorinnen und Autoren, die sie fehlender ästhetischer Sensibilität bezichtigen und ihr Blindheit, Unsinnlichkeit, Hochmut und Präpotenz vorwerfen, kaum zu denken.

Ein ums andere Mal haben sich Schriftstellerinnen und Schriftsteller gegen Urteile der Literaturkritik zur Wehr gesetzt und pointierte, meist wenig schmeichelhafte Bilder des derart attackierten Berufsstandes entworfen: Heinrich Heine

1 Alois Brandstetter: Selig sind die Feindseligen, fertig sind die Friedfertigen. In: Mein(e) Feind(e). Literaturalmanach 1982. Hg. v. Jochen Jung. Salzburg, Wien: Residenz 1982, S. 29-32, hier S. 29.

2 Ebd.

3 Thomas Anz: Werten und Fühlen. Zur Rationalität und Emotionalität literaturkritischer Kommunikation - am Beispiel von Marcel Reich-Ranicki. In: Literaturkritik heute. Tendenzen Traditionen - Vermittlung. Hg. v. Heinrich Kaulen u. Christina Gansel. Göttingen: V\&R unipress 2015, S. 13-25, hier S. 14. 
etwa soll die Kritiker mit Eunuchen verglichen haben, die über einen Mann spotten, weil er ein buckeliges Kind gezeugt hat. ${ }^{4}$ Das dem begnadeten Polemiker Heine zugeschriebene Bonmot zeigt exemplarisch, dass in den entsprechenden Kontroversen oft mit harten Bandagen gekämpft und vor der aggressiven Schmähung des jeweiligen Gegners nicht zurückgeschreckt wird. „[J]ener parasitären Kategorie Mensch“, „die wie winzige Milchegel an den Zitzen der Kunst hängen“, konnte auch der 2005 verstorbene österreichische Schriftsteller Wolfgang Bauer wenig abgewinnen: „Am unteren Ende“ der „gefräßigen Traube, die sich von der

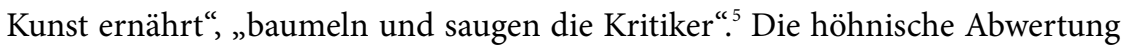
der Kritiker erhält aber zugleich die Andeutung einer positiven, ja notwendigen Funktion der attackierten Spezies: „Sie sind unruhig wie kleine Kinder; während sie ihre Magermilch schreiend kotzen und auch sonst viel Wind machen, tun sie der Kunst weh. Durch ihr Geschrei machen sie aber viele Leute auf die Kunst aufmerksam. “6 Obschon die unter starken Schmerzen gemolkene Kunst im Magen der Kritiker zur sehr viel weniger schmackhaften „Magermilch“ verkommt, deutet sich in Bauers provokanter Fabel doch ein symbiotischer Gewinn aus dieser vorderhand asymmetrischen Beziehung an. Aller Geringschätzung zum Trotz war ihm durchaus bewusst, dass das Greinen der Kritiker für die ,Ökonomie der Aufmerksamkeit` (Georg Franck) im literarischen Feld ein nicht unwesentliches Element darstellt.

Die Verachtung der Literaturkritik ging und geht bei vielen Autorinnen und Autoren mit einer nicht unerheblichen Sensibilität für deren Einschätzungen einher, hängen alle „Künstler“ doch, wie der französische Soziologe Pierre Bourdieu betont hat, so stark wie „[n] ur wenige soziale Individuen“ „in dem, was sie sind, und in ihrem Bild von sich selbst von der Vorstellung ab, die sich die anderen von ihnen machen".7 Ganz in diesem Sinne hat Max Frisch in seiner

4 Vgl. Franz Schuh: All you need is love. Notizen und Exzerpte zur (Literatur-)Kritik. In: F. S.: Schreibkräfte. Über Literatur, Glück und Unglück. Köln: DuMont 200o, S. 24-114, hier S. 34 f.; auch in: Lauter Worte über Worte. Runde und spitze Gedanken über Sprache und Literatur. Hg. v. Christoph Gutknecht. München: C. H. Beck 1999, S. 125. Leider bleiben Schuh und Gutknecht eine Quellenangabe schuldig.

5 Wolfgang Bauer: Manche Künstler sind Dichter. In: 25 Jahre Residenz Verlag. Zeitgenössische Literatur. Literatur für Zeitgenossen. Almanach für Literatur und Kunst 1981. Salzburg, Wien: Residenz 1981, S. 29-34, hier S. 30; auch in: W. B.: Werke in sieben Bänden. Hg. v. Gerhard Melzer. Bd. 6: Kurzprosa, Essays und Kritiken. Mit einem Nachwort v. Rolf Schwendter. Graz, Wien: Droschl 1997, S. 97-99, hier S. 97. Zum Kontext vgl. Hermann Schlösser: „Milchegel an den Zitzen der Kunst“. Autoren als Gegner der Literaturwissenschaft. In: Konflikte - Skandale Dichterfehden in der österreichischen Literatur. Hg. v. Wendelin Schmidt-Dengler. Berlin: Erich Schmidt 1995, S. 280-290, bes. S. 288-290.

6 Bauer: Milchegel an den Zitzen der Kunst (Anm. 5), S. 30.

7 Pierre Bourdieu: Künstlerische Konzeption und intellektuelles Kräftefeld. In: P. B.: Kunst und Kultur. Kunst und künstlerisches Feld. Schriften zur Kultursoziologie 4. Hg. v. Franz Schultheis u. Stephan Egger. Berlin: Suhrkamp 2015, S. 7-49, hier S. 17. 
1965 gehaltenen Rede zur Verleihung des Schiller-Preises folgende Überzeugung festgehalten: „Wir, deren Beruf unweigerlich mit öffentlicher Selbstpreisgabe verbunden ist, sind in bedenklichem Maße angewiesen auf oder doch anfällig für Lob, Ehrung als Erholung von jenem Zweifel, der die Öffentlichkeit nichts angeht. “8 Die vorliegende Arbeit unternimmt den Versuch, das Spannungsfeld zwischen Literatur und Literaturkritik, zwischen ästhetischer Produktivität, poetologischer Reflexion und kritischer Rezeption, am Beispiel von Thomas Bernhard und Peter Handke genauer zu erkunden.

Wenige Autorinnen und Autoren sind, so Wendelin Schmidt-Dengler, „über das Ghetto des Innerliterarischen hinaus in Österreich so nachhaltig wahrnehmbar und wirksam geworden “ wie Bernhard und Handke. ${ }^{9}$ Sie setzten wichtige Impulse für die Herausbildung neuer und innovativer literarischer Verfahren, standen aber auch in besonderer Weise im medialen Rampenlicht, waren Gegenstand von und Akteure in intensiv geführten Debatten, die im Feuilleton angesehener Tages- und Wochenzeitungen und in auflagenstarken Boulevardmedien gleichermaßen ausgefochten wurden. Für ihren gemeinsamen Verleger, Siegfried Unseld, war schon früh klar, „wie stark die Stellung von Bernhard und Handke ist“: „,[D]iese beiden charakterisieren im Augenblick die österreichische Literatur, jedenfalls was die jüngere Generation betrifft", konstatiert er 1975 in einem internen Reisebericht. ${ }^{10}$ Indes war Bernhard und Handke stets bewusst, dass, wie es der elf Jahre jüngere Handke 1972 im Gespräch mit Franz Hohler formuliert hat, „grad bei Literatur ein Ruhm Kritik erst richtig provoziert".11 Die Popularität und mediale Sichtbarkeit der beiden Autoren mag zur „Polarität der Einschätzungen “12 in Bezug auf ihre Arbeiten erheblich beigetragen, die Gräben zwischen harscher Ablehnung und begeisterter Zustimmung - sowohl beim allgemeinen Lesepublikum als auch in der Riege der Kritikerinnen und Kritiker - noch vertieft haben.

Peter Handke galt manchen Kommentatoren, zumal jenen, die dem frühen ,Hype um seine Person skeptisch gegenüberstanden, von Anfang an als „Hätschelkind der Kritik ${ }^{* 13}$ Andere sahen ihn als einen Autor, der sich gerade trot $z$ der Widerstände

8 Max Frisch: Schillerpreis-Rede. [1965] In: M. F.: Öffentlichkeit als Partner. Frankfurt a. M.: Suhrkamp 1967, S. 90-99, hier S. 90.

9 Wendelin Schmidt-Dengler: Bruchlinien II. Vorlesungen zur österreichischen Literatur 1990 bis 2008. St. Pölten, Wien: Residenz 2012, S. 13.

10 Siegfried Unseld: Reisebericht Wien, 15-18. Mai 1975. In: Thomas Bernhard/S. U.: Der Briefwechsel. Hg. v. Raimund Fellinger, Martin Huber u. Julia Ketterer. Frankfurt a. M.: Suhrkamp 2009, S. 468.

11 Franz Hohler: Ist Ihnen oft langweilig? Fragen an Peter Handke. [24.5.1972] In: F. H.: Fragen an andere. Bern: Zytglogge 1973, S. 19-39, hier S. 35.

12 So der Kommentar in Thomas Bernhard: Erzählungen. Mit einem Kommentar v. Hans Höller. Frankfurt a. M.: Suhrkamp 2001, S. 101.

13 Hans Bertram Bock: Im Taumel der Fremdheit. Interview mit dem Schriftsteller Peter Handke. In: Nürnberger Nachrichten, 27./28. 8.1977. 
der Literaturkritik habe durchsetzen können. Obgleich mit Christel Terhorst zu konstatieren ist, dass „der Aufstieg Handkes zu höchster literarischer Prominenz“ „[o]hne die lebhafte und andauernde Resonanz in der Tageskritik [...] nicht denkbar gewesen wäre", 14 wurde der früh auch ökonomisch erfolgreiche und weit über den engeren Bereich des Literarischen hinaus bekannte Autor von der Kritik mitunter „hart hergenommen ${ }^{15}$ Manche Journalistinnen und Leserbriefschreiber hegten die Überzeugung, der shooting star des Literaturbetriebs habe nur mit der Schützenhilfe des Feuilletons "hochkommen“ können, ${ }^{16}$ das seiner kalkulierten Selbstinszenierung als Outsider des Literaturbetriebs auf den Leim gegangen sei. „Handkes Image“ beruhe, so Peter Hamm, in den 196oer Jahren einer seiner vehementesten Kritiker, „primär darauf, daß er es versteht, als Außenseiter aufzutreten - ohne einer zu sein; wäre er einer, fände er gewiß kein Forum für seinen Auftritt. “17

Schon in den ersten Jahren von Handkes schriftstellerischer Karriere standen sich ablehnende und euphorische Stimmen diametral gegenüber, wobei die spezifisch literarische Ambition seiner Arbeiten mitunter in den Hintergrund trat, aber umso vehementer gegen die Positionen des anderen Lagers agitiert wurde (s. Kap. II). „Indem man ihn verriß oder beweihräucherte, wurden zugleich unterschwellig Positionskämpfe in der Literaturkritik ausgetragen. ${ }^{18}$ Das Bild, das man sich von seiner Arbeit gemacht habe, sei, wie Handke wiederholt festgehalten hat, von Anfang an ganz wesentlich von den Urteilen der Literaturkritik beeinflusst und damit in gewisse Bahnen gelenkt worden, was nicht selten die Lektüre der Texte selbst ersetzt habe: „Ich bin sicher, daß niemand es liest“, so der Autor 1973 mit Blick auf seinen sieben Jahre zuvor erschienenen Debütroman

14 Christel Terhorst: Peter Handke. Die Entstehung literarischen Ruhms. Die Bedeutung der literarischen Tageskritik für die Rezeption des frühen Peter Handke. Frankfurt a. M. u.a.: Lang 1990, S. 244.

15 Volker Hage: Warum nicht wie Balzac? Peter Handkes Die Geschichte des Bleistifts und Phantasien der Wiederholung. In: The German Quarterly 63 (1990), S. 412-420, hier S. 412.

16 So ein Leserbrief von Dr. Hermann Stolz: Böses Ende. In: Der Spiegel, Nr. 24, 8. 6. 1970, der vor allem die „Halb- und Ganzlinks-Gazetten“ dafür verantwortlich macht.

17 Peter Hamm: Der neueste Fall von deutscher Innerlichkeit: Peter Handke. In: konkret, Nr. 12, 2.6.1969, S. 42-45, hier S. 42.

18 Manfred Durzak: Peter Handke und die deutsche Gegenwartsliteratur. Narziß auf Abwegen. Stuttgart u. a.: Kohlhammer 1982, S. 13. Durzak stellte dieses Schema des „Freund-Feind-Denken[s]“ indes auch bei Handke selbst fest: Literaturkritik nehme der Autor lediglich „in Kategorien von grundsätzlicher Zustimmung oder Verrat" wahr (ebd., S. 13 f.). - Handke hat Durzaks stellenweise polemische Abrechnung mit Werk und Person des Autors mit einiger Verwunderung zur Kenntnis genommen: Durzak sei, so Handke 1988 im Gespräch mit André Müller, „einer von diesen Winkelschreibern, die schwerhörig sind vom Echo der anderen. Also das hat mich schon leise gewundert, denn es gehört doch eine gewisse kriminelle Energie dazu, das zu können.“ (André Müller: Im Gespräch mit Peter Handke. Weitra: Bibliothek der Provinz 1993, S. 90) 
Die Hornissen: „Es fragt mich auch niemand nach diesem Buch. Es werden nur Urteile, diese Verrisse, wiedergegeben. ${ }^{\text {“19 }}$

1994 hat Karl-Markus Gauß Handkes polarisierende Wirkung in der Literaturkritik anlässlich des Erscheinens von Mein Jahr in der Niemandsbucht pointiert zusammengefasst:

Seit seinen frühen Büchern und ersten Auftritten scheint Peter Handke nur Verehrer und Verächter zu haben, Gefolgsleute, die ihrem Meister lesend überallhin nachzufolgen bereit sind, und Feinde, die sich die Mühe der Lektüre vornehmlich deshalb machen, um sich zuverlässig über den Autor ärgern zu können. Indes die einen nicht ablassen, ihn zu lieben, egal zu welchen neuen Ufern er aufgebrochen ist, können die anderen nicht aufhören, ihn zu hassen, selbst wenn er literarisch längst nicht mehr dort steht, wo sie ihn vermuten. ${ }^{20}$

Die Rezeption in Tages- und Wochenzeitungen schwankte „oft zwischen ehrfürchtiger Wertschätzung und beleidigter Ablehnung“; ${ }^{21}$ „Befürworter und Gegner" trugen „die immer gleiche Fehde mit den immer gleichen Argumenten aus", ${ }^{22}$ wobei sich mit der Zeit - etwa zwischen Sigrid Löffler und Marcel Reich-Ranicki im Literarischen Quartett - eine Art von „Sprachspiel mit starren Ritualen und mit fester Rollenverteilung “ herausbildete. ${ }^{23}$ Handke selbst stand diesem „Kritikspiel“, 24 ja vor allem dem „Ausspielen des einen gegen

19 Dieser Teil eines 1973 geführten Interviews wurde erstmals in Durzak: Peter Handke und die deutsche Gegenwartsliteratur (Anm. 18), S. 52, gedruckt.

20 Karl-Markus Gauß: Vorort-Vermessung und Reiseroman. In: profil, Nr. 46, 14. 11. 1994, S. 86-88, hier S. 86. - „[K] aum ein anderer Autor“ habe, so Herwig Gottwald: Mythos und Mythisches in der Gegenwartsliteratur. Studien zur Christoph Ransmayr, Peter Handke, Botho Strauß, George Steiner, Patrick Roth und Robert Schneider. Stuttgart: Heinz 1996, S. 35, „derart gegensätzliche, oft emotional gefärbte Bewertungen“ seines Werks erfahren, „die von schroffster Ablehnung bis zu emphatischer Zustimmung reichen“.

21 Thorsten Carstensen: Romanisches Erzählen. Peter Handke und die epische Tradition. Göttingen: Wallstein 2013, S. 97.

22 Uwe C. Steiner: Literatur als Kritik der Kritik. Die Debatte um Peter Handkes Mein Jahr in der Niemandsbucht und die Langsame Heimkehr. In: Deutschsprachige Gegenwartsliteratur. Wider ihre Verächter. Hg. v. Christian Döring. Frankfurt a. M.: Suhrkamp 1995, S. 127-169, hier S. 127.

23 Ebd., S. 141. Dazu auch Wilfried Barner: Zwischen unübersichtlichem Überfluß und unverhoffter „friedlicher Revolution“. Literarisches Leben im Westen. In: Geschichte der deutschen Literatur von den Anfängen bis zur Gegenwart. Bd. XII: Geschichte der deutschen Literatur von 1945 bis zur Gegenwart. Hg. v. W. B. München: C. H. Beck²2006, S. 797-813, hier S. 803.

24 Peter Handke: Gurken und Kiefern, Äpfel und Schnee. Laudatio zum Hermann-Lenz-Preis an Jürgen Becker. [2006] In: P. H.: Meine Ortstafeln. Meine Zeittafeln. 1967-2007. Frankfurt a. M.: Suhrkamp 2007, S. 272-279, hier S. 274. 
den anderen“, 25 stets distanziert und misstrauisch gegenüber, und er versuchte dagegen sowohl durch entschiedenen Widerspruch als auch mit einer eigenen Idee literaturkritischen Schreibens anzutreten (s. Kap. V).

In jenen Jahren, in denen Bernhard und Handke mit ihren Debütromanen Frost (1963) und Die Hornissen (1966) als vielversprechende Autoren der Frankfurter Verlage Insel und Suhrkamp reüssierten, kamen die zählebigen Debatten über Maßstäbe, Verfahren und gesellschaftliche Bedingungen der Literaturkritik $^{26}$ eben neu in Schwung. Der 72-jährige T. S. Eliot hatte im Juli 1961 an der University of Leeds eine "Convocation Lecture“ mit dem Titel To Criticize the Critic gehalten, aber auch zahlreiche jüngere Autorinnen und Autoren machten sich nun auf, die Institution der Literaturkritik selbst kritisch zu befragen und deren Autorität in Zweifel zu ziehen. Handke gehörte zu dieser neuen, der Provokation keineswegs abgeneigten Generation, und er bemängelte bereits im Dezember 1964 in einem seiner ersten Rundfunkfeuilletons die „automatisiert“ und „mechanisch“verwendeten „Bewertungsworte“ der Literaturkritik. Wenn er schließlich am Ende seiner Metakritik in Aussicht stellte, dass im Schreiben über Literatur „auch andere Sätze möglich“ seien, ${ }^{27}$ setzte er damit nicht nur den Auftakt für ein dauerhaft belastetes Verhältnis zur Literaturkritik, sondern plädierte darüber hinaus „für eine andere Auseinandersetzung mit Literatur“, die sich in seinem eigenen Euvre bis heute nachverfolgen lässt. ${ }^{28}$ Während Bernhard nur am Beginn seiner schriftstellerischen Laufbahn (1952-1955) im engeren Sinne als Kritiker tätig war, hat Handke sich seit Mitte der 196oer Jahre - allen Vorbehalten gegenüber der „Rolle des Kritikers“ ${ }^{\text {“9 }}$ zum Trotz - regelmäßig als „Begleitschreiber ${ }^{\text {“30 }}$ fremder Texte eingebracht und sich, über den konkreten Einzelfall hinaus, mit verschiedenen Formen kritischen Schreibens auseinandergesetzt.

Peter Handke verstand sein Schreiben über die Texte anderer nicht bloß als „Freundschaftsdienst“ für Schriftsteller, ${ }^{31}$ mit denen er persönlich in gutem

25 Peter Handke: Nachmittag eines Schriftstellers. Erzählung. Salzburg, Wien: Residenz 1987, S. 37.

26 Vgl. dazu etwa Wolfgang Albrecht: Literaturkritik. Stuttgart, Weimar: Metzler 2001, S. 85-97.

27 Peter Handke: „Bücherecke“vom 21. 12. 1964. In: P. H.: Tage und Werke. Begleitschreiben. Berlin: Suhrkamp 2015, S. 189-197, hier S. 190.

28 Karl Wagner: Handkes Endspiel. Literatur gegen Journalismus. In: Mediale Erregungen? Autonomie und Aufmerksamkeit im Literatur- und Kulturbetrieb der Gegenwart. Hg. v. Markus Joch, York-Gothart Mix u. Norbert Christian Wolf. Tübingen: Niemeyer 2009, S. 65-76, hier S. 70.

29 So der Abschnitttitel in Peter Handke: Ich bin ein Bewohner des Elfenbeinturms. Frankfurt a. M.: Suhrkamp 1972, S. 191-207.

30 Dazu ausführlich Lothar Struck: Der Begleitschreiber. Einige Bemerkungen zum Kritiker und Leser Peter Handke. In: L. S.: Erzähler, Leser, Träumer. Begleitschreiben zum Werk von Peter Handke. Mit einem Vorwort v. Klaus Kastberger. [Klipphausen]: Mirabilis 2017, S. 13-27.

31 Peter Handke: Des Privatdetektivs eigener Fall. Über Peter Stephan Jungk und seinen Roman Tigor. [1992] In: P. H.: Langsam im Schatten. Gesammelte Verzettelungen. 1980-1992. Frankfurt a. M.: 
Einvernehmen stand (z. B. Wolfgang Bauer, Nicolas Born, Klaus Hoffer, Gert Jonke und Hermann Lenz), sondern er hat im Lauf der Jahre über eine Vielzahl deutschsprachiger und internationaler Autoren - nur äußerst selten Autorinnen $^{32}$ - publiziert, sie ausführlich rezensiert, in kurzen Notizen auf sie aufmerksam gemacht, sie in Vor- und Geleitworten gewürdigt und in Reden und Laudationes seiner lesenden Zuneigung versichert. Die Bände, die Handkes zunächst verstreut erschienene Arbeiten zur Literatur versammeln, ${ }^{33}$ zeigen ihn als einen Autor mit beeindruckendem Lektürepensum und mit eigensinnigem Blick auf Themen, Formen, Sujets und Verfahren seiner schreibenden Kollegen. ${ }^{34}$ Neben Texten zu Schriftstellern des 19. Jahrhunderts (Franz Michael Felder, Franz Grillparzer, Adalbert Stifter, Christian Wagner u. a.) finden sich viele Arbeiten zu fremdsprachigen Autoren, etwa zu John Cheever, Nathaniel Hawthorne, Iasushi Inoue, Philippe Jaccottet, Gustav Januš, Kito Lorenc, Miodrag Pavlović, Tomas Tranströmer oder Dragan Velikić. Der darin zum Ausdruck kommende Impuls zur Vermittlung zwischen verschiedenen Sprach- und Kulturräumen geht mit Handkes Tätigkeit als Übersetzer aus dem Amerikanischen, Englischen, Französischen, Griechischen, Lateinischen und Slowenischen Hand in Hand.

„Die Literaturkritik, diese erste Instanz in der Rezeption zeitgenössischer Literatur, ist seit sieben Jahren mit der Produktion dieses Autors konfrontiert", hält die Lektorin Anneliese Botond 1970 in einem ersten Materialienband zum Werk Thomas Bernhards fest: „Sie war sehr bald von gegensätzlichen Positionen, Attraktionen und Irritationen, bestimmt. Zustimmung und Ablehnung waren nicht ohne Pathos. ${ }^{\text {35 }}$ In der ersten Hälfte der 1950er Jahre hatte Bernhard als

Suhrkamp 1992, S. 172-181, hier S. 172: „Daß ich zu Peter Stephan Jungks Buch Tigor etwas schreibe, ist ein Freundschaftsdienst. Aber wer sagt, daß von einem Freundschaftsdienst nicht auch ein Dritter etwas haben kann - im Fall hier dieser und jener Leser?“

32 Neben dem 1975 im Spiegel veröffentlichten Radikal-Verriss von Karin Strucks Die Mutter hat Handke nur wenige Arbeiten über Schriftstellerinnen verfasst; Ausnahmen bilden die Texte über Patricia Highsmith (Die privaten Weltkriege der Patricia Highsmith, 1975), Marguerite Duras (Die Hexenmeisterin, 1992) und Friederike Mayröcker (Fragment zu Friederike Mayröcker, 2009).

33 Es handelt sich dabei um die folgenden Bände, die jedoch auch andere Textsorten sowie Beiträge zur bildenden Kunst, zu Film und Musik enthalten: Ich bin ein Bewohner des Elfenbeinturms (1972), Als das Wünschen noch geholfen hat (1974), Das Ende des Flanierens (1980), Langsam im Schatten (1992), Mündliches und Schriftliches (2002), Meine Ortstafeln. Meine Zeittafeln (2007), Tage und Werke (2015).

34 Vgl. dazu Karl Wagner: Handke als Leser. In: lesen.heute.perspektiven. Hg. v. Eduard Beutner u. Ulrike Tanzer. Innsbruck u. a.: StudienVerlag 2010, S. 140-149, sowie den zuletzt erschienenen Sammelband: Die tägliche Schrift. Peter Handke als Leser. Hg. v. Thorsten Carstensen. Bielefeld: transcript 2019 (darin besonders die überaus instruktive Einleitung des Herausgebers).

35 Anneliese Botond: Schlußbemerkung. In: Über Thomas Bernhard. Hg. v. A. B. Frankfurt a. M.: Suhrkamp 1970, S. 139-141, hier S. 139. 
Literatur- und Kulturjournalist für das Salzburger Demokratische Volksblatt gearbeitet und dabei eine Vielzahl heute kaum mehr bekannter Artikel verfasst (s. Kap. VI); ab dem Zeitpunkt der Veröffentlichung von Frost im Jahr 1963 seine noch deutlich konventionelleren Gedichtbände hatten 1957/1958 wenig Beachtung gefunden - stand er selbst im Fokus literaturkritischer Debatten, die mitunter heftig und emotional geführt wurden:

Und irgendwie ist das Buch erschienen und auch Kritiken. Aber sonst befriedigt es einen ja nicht, denn die eine widerspricht der anderen, und letzten Endes durchschaut man ja als halbwegs intelligenter Mensch auch schon, was das für Geisteskinder sind. Weil da im Grunde nichts dahinter ist und lange Kritiken nicht einen Satz beinhalten, der den Rezensenten persönlich wirklich betrifft, wo man das Gefühl hat, der hat das wirklich mit Interesse gelesen. Das wird ja alles nur geschäftsmäßig aufgefaßt, der bespricht das und fertig. Das ist für den so ein ganz primitives, lebenserhaltendes, familienerhaltendes G'schäft. Und dann sitzt man da, mit diesen Kritiken und dem Buch, und weiß auch nimmer, wie ist das Buch, ist es überhaupt was oder so und so weiter. ${ }^{36}$

Der Bereich der literarischen Produktion ist in Bernhards Selbstauskünften eng mit jenem der literaturkritischen Rezeption verknüpft. Er hat wiederholt darauf insistiert, dass seine Arbeiten meist „völlig abgelehnt ${ }^{\text {“37 }}$ worden seien, diese Ablehnung aber zugleich als Motor der eigenen Kreativität beschrieben und in seinen Prosa- und Theatertexten die „Situation des Künstlers in einer verständnislosen Umwelt ${ }^{\text {“38 }}$ erzählerisch und dramaturgisch ausgestaltet; in Der Ignorant und der Wahnsinnige (1972) und Minetti (1976) hat er gar Figuren beim Lesen von Theaterkritiken auf die Bühne gestellt (s. Kap. III). Gleichwohl sah sich Bernhard - ebenso wie Handke - mit dem Vorwurf konfrontiert, von der Literaturkritik allzu freundlich behandelt zu werden, zumal er mit seiner Provokationsästhetik und seinen öffentlichkeitswirksamen Rundumschlägen die mediale Erwartungshaltung oftmals nicht irritiert, sondern nachgerade erfüllt habe. Peter Rühmkorf, der ihm nicht eben wohlgesonnen war, hat in seinen Tagebüchern das „zum Fußaufstampfen ständig bereite[ ] Drohverhalten“ Bernhards

36 Kurt Hofmann: Aus Gesprächen mit Thomas Bernhard. Wien: Löcker 1988, S. 49 f. Gegen die Publikation dieses Bandes hat Bernhard Einspruch erhoben, weil es sich „um zusammenmontierte Bruchstücke aus einer Reihe von älteren Radio-Interviews“ handelte, die er in dieser Form nicht schriftlich publiziert sehen wollte; von einem Gerichtsverfahren sah der gesundheitlich schon schwer angeschlagene Autor im Herbst 1988 jedoch ab (Andreas Razumovsky: Mist, Most. Bernhard gegen Löcker. In: Frankfurter Allgemeine Zeitung, 18. 11. 1988).

37 Hofmann: Aus Gesprächen mit Thomas Bernhard (Anm. 36), S. 48.

38 Willi Huntemann: Artistik und Rollenspiel. Das System Thomas Bernhard. Würzburg: Königshausen \& Neumann 1990, S. 27. 
kritisiert, weil es „den Masochismus der szenebegleitenden Feuilletons immer heimlich mit einkalkuliert“ ${ }^{\text {" }}$

Indes hat Bernhard seine charakteristische, „mit Exzeß und Hyperbel arbeitende Schmäh-Rhetorik“" ${ }^{* 0}$ eben mit besonderer Verve und Ausdauer auch gegen die Literaturkritik, deren Akteure sowie einzelne „grauslige[ ] Kritiken “41 in Stellung gebracht. Der Empörung über das „Zeitungsgewäsch“ (TBW 20, 163 ${ }^{42}$ ) steht dabei die fortwährende Beteuerung gegenüber, sich um die literaturkritische Einschätzungen des eigenen Werks eigentlich nicht zu kümmern, ja sie selbstbewusst zu ignorieren: „Die Rezensionen nahm er belustigt hin“, notiert Siegfried Unseld im Juli 1983 nach einem Treffen mit Bernhard, „er beschäftigte sich zehn Minuten damit, und dann meinte er, das genüge nun doch wohl. Das Positive sei langweilig und biete nichts Neues, das Negative träfe ihn nicht, weil es falsch sei. “" Zwar lernte er, so der Bernhard-Biograph Manfred Mittermayer, „mit den Jahren, souveräner [...] mit kritischen Reaktionen umzugehen“, zeigte sich aber doch „immer wieder zutiefst von diesen verletzt “ ${ }^{44}$ Als Herausforderung erweist sich dabei stets aufs Neue die Frage einer, angemessenen' Antwort auf kritische Urteile, etwa die Entscheidung zwischen dem direkten, ad personam geführten Gegenangriff als Beweis eigener Stärke einerseits und der betonten Selbstbeherrschung als Akt besonnenen Gleichmuts andererseits.

Die vorliegende Arbeit zeichnet Thomas Bernhards und Peter Handkes vielschichtige, von der Forschung bislang nicht ausreichend gewürdigte Auseinandersetzung mit der Literaturkritik nach; sie versucht dabei insbesondere zu zeigen, wie eng die jeweiligen Aversionen der beiden Autoren mit ihrem eigenen Schreiben, mit der literarischen Ästhetik ihrer eigenen Arbeiten in Verbindung stehen - nicht nur im Sinne der instinktiven Zurückweisung kritischer Urteile,

39 Peter Rühmkorf: Tabu I. Tagebücher 1989-1991. Reinbek b. Hamburg: Rowohlt 1995, S. 31; die Passage findet sich auch in ders.: In meinen Kopf passen viele Widersprüche. Über Kollegen. Göttingen: Wallstein 2012, S. 29.

40 Pierre Bourdieu: Praktische Vernunft. Zur Theorie des Handelns. Frankfurt a. M.: Suhrkamp 1998, S. 93.

41 Niklas Frank: Ansichten eines unverbesserlichen Weltverbesserers. [Gespräch mit Thomas Bernhard.] In: stern, Nr. 24, 4. 6.1981, S. 160-162, hier S. 162.

42 Die Wendung stammt aus Bernhards Theaterstück Elisabeth II. (1987). Seine Werke werden im Folgenden nach der im Suhrkamp Verlag erschienenen 22-bändigen Werkausgabe (hg. v. Martin Huber u. Wendelin Schmidt-Dengler. Frankfurt a. M., Berlin: Suhrkamp 2003-2015) zitiert und mit der Sigle „TBW“, Band- und Seitenzahl im Fließtext ausgewiesen. - Die Bücher Peter Handkes hingegen werden, da eine vollständige Werkausgabe zum Zeitpunkt der Abfassung dieser Arbeit noch nicht vorlag - die 2018 erschienene 14-bändige Handke Bibliothek ist als bloße Leseausgabe konzipiert -, nach den Erstausgaben zitiert.

43 Unseld: Reisebericht Salzburg, 26.-29. Juli 1983. In: Bernhard/Unseld: Der Briefwechsel (Anm. 10), S. 676.

44 Manfred Mittermayer: Thomas Bernhard. Eine Biografie. Salzburg, Wien: Residenz 2015, S. 14. 
sondern auch, mit Gérard Genette gesprochen, „im Dienst einer besseren Rezeption der Texte“: ${ }^{45}$ Gerade Handke sah sich von negativen Besprechungen seiner Bücher dazu herausgefordert, die poetologischen Prinzipien seines Schreibens mit Nachdruck zu verteidigen und öffentlich Einspruch gegen die feuilletonistische Behandlung seiner Bücher zu erheben (s. Kap. II). Damit gerät nicht nur „die Rezension als möglicher Ort der Polemik“ in den Blick, ${ }^{46}$ sondern ein weitaus größerer, für die Mechanismen und Kräfteverhältnisse im literarischen Feld überaus aufschlussreicher Kommunikationszusammenhang. Bernhard und Handke haben, wie im Folgenden gezeigt werden soll, im Laufe ihrer schriftstellerischen Karriere die diversen „kommunikativen Optionen kritischen Replizierens ${ }^{\text {“47 }}$ ausgelotet und sich dabei als veritable „Stratege[n] im Literaturkampf“ erwiesen. ${ }^{48}$ Mit dieser aus Walter Benjamins Die Technik des Kritikers in dreizehn Thesen (1928 im Band Einbahnstraße gedruckt) entlehnten Wendung gerät zum einen die agonale Qualität der geschilderten Auseinandersetzungen zwischen Autoren und Kritikern in den Blick, zum anderen aber auch ein weit über den Einzelfall hinausweisendes Moment künstlerischer Selbstbehauptung: Bernhard und Handke zeigten sich nicht nur als gewiefte Taktiker, die in konkreten Situationen mit geschickten publizistischen Manövern (re)agieren oder selbst in der „Rolle des Kritikers“ auftreten, sondern ebenso als weitsichtige Strategen. ${ }^{49}$

45 Gérard Genette: Paratexte. Das Buch vom Beiwerk des Buches. Mit einem Vorwort v. Harald Weinrich. Frankfurt a. M.: Suhrkamp 2001, S. 10.

Ulrich Rüffer: Benjamins Programm der Kritik. In: Walter Benjamin. Profane Erleuchtung und rettende Kritik. Hg. v. Norbert W. Bolz u. Richard Faber. Würzburg: Königshausen \& Neumann ${ }^{2} 1985$, S. $34-40$, hier S. 34 .

47 Carlos Spoerhase: Ausweitung der literarischen Kampfzone: Was die Geschichte der aufklärerischen Rezensionskultur die aktuelle Reflexion über Literaturkritik lehren könnte. In: Zeitschrift für Germanistik. N. F. 19 (2009), H. 1, S. 171-178, hier S. 175.

48 Walter Benjamin: Einbahnstraße. [1928] In: W. B.: Gesammelte Schriften. Unter Mitwirkung v. Theodor W. Adorno u. Gershom Scholem hg. v. Rolf Tiedemann u. Hermann Schweppenhäuser. Bd. IV.1. Hg. v. Tillman Rexroth. Frankfurt a. M.: Suhrkamp 1972, S. 83-148, hier S. 108.

Zur Differenzierung von ,Taktiken' und ,Strategien' vgl. auch die Überlegungen von Michel de Certeau: Kunst des Handelns. Berlin: Merve 1988, S. 23-26. - Michael Opitz: Literaturkritik. In: Benjamin-Handbuch. Leben - Werk - Wirkung. Hg. v. Burkhardt Lindner. Unter Mitarb. v. Thomas Küpper u. Timo Skrandies. Stuttgart, Weimar: Metzler 2006, S. 311-332, hier S. 316, zufolge zeichnet Benjamin den Kritiker ,als Taktiker auf dem Feld der literarischen Auseinandersetzungen“, der zugleich „einem strategischen Plan“ folge. Wiederholt hat sich Benjamin, so Opitz, einer „militärische[n] Terminologie“ bedient (ebd., S. 319), um Phänomene und Mechanismen intellektueller und literaturpolitischer Fehden zu beschreiben. - Auf genauere Erläuterungen von Benjamins literaturkritischem Profil und dessen diskurshistorische Kontextualisierung muss an dieser Stelle verzichtet werden. Vgl. dazu neben dem instruktiven Handbuch-Artikel von Opitz die einschlägigen Arbeiten von Heinrich Kaulen: „Die Aufgabe des Kritikers“. Walter Benjamins Reflexionen zur Theorie der Literaturkritik 1929-1931. In: Literaturkritik - Anspruch und Wirklichkeit. DFG-Symposion 1989. Hg. v. Wilfried Barner. 
Entscheidende methodologische Einsichten und theoretische Konzepte verdankt die Dissertation der Kultursoziologie Pierre Bourdieus, auf die ich im weiteren Verlauf ein ums andere Mal rekurrieren werde. In Die Regeln der Kunst (1992 im franz. Original, 1999 in dt. Übersetzung) hat Bourdieu die „Kämpfe um die Durchsetzung“ einer legitimen „Definition“ von Literatur als zentralen Motor der Veränderung im literarischen Feld charakterisiert, ja den „Kampf selbst" als das "generierende und vereinheitlichende Prinzips dieses ,Systems"“ beschrieben.$^{50}$ Erst die „Tatsache, an dem Kampf beteiligt und Gegenstand oder Anlass von Kämpfen, Angriffen, Polemiken, Kritiken, Einverleibungen usw. zu sein“, verbürge, so Bourdieu, die legitime "Zugehörigkeit“ zum literarischen Feld. ${ }^{51}$ Im Folgenden soll gezeigt werden, dass der Literaturkritik in diesen Kämpfen eine ganze zentrale Funktion zukommt - einerseits als Ziel der polemischen Distinktion von jenen Instanzen, die der „Bewahrung“ der "geltenden Konventionen " zuzurechnen sind, ${ }^{52}$ andererseits aber auch als Experimentierfeld und Reflexionsmedium eigener Positionierungen.

Wiederholt werde ich dabei die von Stephen Greenblatt erteilte Lizenz zum „Einsatz von Anekdoten ${ }^{453}$ in Anspruch nehmen, jene „fragmentarische Methode, die auf dem Prinzip der Repräsentation basiert “. ${ }^{\star 54}$ Ich habe versucht, anhand ausgewählter Konstellationen zentrale Konfliktlinien im Verhältnis von Literatur und Literaturkritik zu präparieren und nachzuzeichnen, um mithilfe dieser „anekdotische[n] Technik ${ }^{\text {“55 }}$ die Beziehung Bernhards und Handkes zur Institution der Kritik und zu ihren Akteuren zu erhellen. Mit einem solchen Ansatz geht, so Greenblatt, auch die Entscheidung einher, „wenige Abschnitte mit großer Leidenschaft, Wachsamkeit und einfühlsamem

Stuttgart: Metzler 199o, S. 318-336, und Alexander Honold: Der Leser Walter Benjamin. Bruchstücke einer deutschen Literaturgeschichte. Berlin: Vorwerk 82000.

50 Pierre Bourdieu: Die Regeln der Kunst. Genese und Struktur des literarischen Feldes. Frankfurt a. M.: Suhrkamp 1999, S. 355 u. 368.

51 Pierre Bourdieu: Das literarische Feld. Kritische Vorbemerkungen und methodologische Grundsätze. In: P. B.: Kunst und Kultur (Anm. 7), S. 309-337, hier S. 316. - Wenn hier von Schriftstellern als "Strategen im Literaturkampf “ gesprochen wird, ist freilich mit Pierre Bourdieu zu ergänzen, dass strategisches Handeln im literarischen Feld nicht mit „zynische[r] Berechnung“ und „bewußte[m] Streben nach Maximierung des spezifischen Profits“ gleichzusetzen ist: „Die Strategien, die ich meine“, so Bourdieu, „sind Handlungen, die sich objektiv auf Ziele richten, die nicht unbedingt auch die subjektiv angestrebten Ziele sein müssen." (Pierre Bourdieu: Soziologische Fragen. Frankfurt a. M.: Suhrkamp 1993, S. 113)

52 Bourdieu: Die Regeln der Kunst (Anm. 50), S. 370.

53 Stephen Greenblatt: Erich Auerbach und der New Historicism. In: S. G.: Was ist Literaturgeschichte? Mit einem Kommentar v. Catherine Belsey. Frankfurt a. M.: Suhrkamp 2000, S. 73-100, hier S. 79.

54 Ebd., S. 81.

55 Ebd., S. 87. 
Verständnis aufzufassen " ${ }^{56}$ während auf eine Gesamtschau der kritischen Positionen zu den beiden Autoren und eine umfassende Rekonstruktion sämtlicher Konflikte mit der Literaturkritik bewusst verzichtet wird. Zudem bin ich mir mit dem Wiener Essayisten Franz Schuh darüber im Klaren, „daß das Thema ,Literaturkritik' Züge von Unerschöpflichkeit hat und daß ich daher in meinen bescheidenen schöpferischen Ausführungen nur einige Punkte berühren, einige Spots auf eine ohnedies überbelichtete Branche werfen kann". ${ }^{57}$

„Ja, Schreiben ist ein Fünfkampf“, hat Handke 2010 im Band Ein Jahr aus der Nacht gesprochen festhalten, ohne diese ,Aufwachnotiz' näher zu erläutern; ${ }^{58}$ in ihr deutet sich an, dass der Benjamin'sche „Stratege im Literaturkampf“, zumal unter den medialen Bedingungen der Gegenwart, mit einer Vielzahl publizistischer Techniken und generischer Formen hantieren muss, um seine Position im literarischen Feld zu definieren und von konkurrierenden Akteuren abzugrenzen. ${ }^{59}$ Im Gegensatz zu verdienstvollen Arbeiten wie jener von Gerhard Pfister, der am Beispiel einzelner Publikationen Handkes akribisch deren Rezeption rekonstruiert und analysiert hat, ${ }^{60}$ möchte ich die Perspektive erweitern, um die Auseinandersetzung mit der Literaturkritik als einen zentralen Aspekt auktorialer ,Werkpolitik' zu beschreiben. Wenn Steffen Martus in seiner wegweisenden Studie ,Werkpolitik ' nicht zuletzt als eine Form der „Aushandlung[ ] von Mächtigkeit" charakterisiert, ${ }^{61}$ so gerät damit ein vielstimmiges Ensemble von Genres und Praktiken in den Fokus, die an der Durchsetzung und Positionierung einer dezidiert neuen Schreibweise im literarischen Feld mitwirken. Bernhard und Handke haben auf je charakteristische Weise hervorgehoben, dass und auf welche Weise sich ihre Vorstellung von Literatur sowohl von den Vorläufern als auch von ihren unmittelbaren Konkurrenten im literarischen Feld unterscheidet; er schreibe, so Bernhard 1976 mit Blick auf seine Arbeiten für das Theater, „nicht, wie normale Leut' Stücke schreiben“ (TBW 22.2, 84).

56 Ebd., S. 96.

57 Schuh: All you need is love (Anm. 4), S. 41.

58 Peter Handke: Ein Jahr aus der Nacht gesprochen. Salzburg, Wien: Jung und Jung 2010, S. 215.

59 Einen ersten Versuch, dieses komplexe Zusammenspiel zu beschreiben, habe ich, mit Blick auf Gérard Genettes Konzept des Para-, Epi- und Peritextes, im folgenden Aufsatz unternommen: Peter Handkes epitextuelle Werkpolitik. In: Paratextuelle Politik und Praxis. Interdependenzen von Werk und Autorschaft. Hg. v. Martin Gerstenbräun-Krug u. Nadja Reinhard. Wien: Böhlau 2018, S. 271-292.

60 Vgl. Gerhard Pfister: Handkes Mitspieler. Die literarische Kritik zu Der kurze Brief zum langen Abschied, Langsame Heimkehr, Das Spiel vom Fragen, Versuch über die Müdigkeit. Bern u. a.: Lang 2000.

61 Steffen Martus: Werkpolitik. Zur Literaturgeschichte kritischer Kommunikation vom 17. bis ins 20. Jahrhundert. Mit Studien zu Klopstock, Tieck, Goethe und George. Berlin, New York: de Gruyter 2007, S. 13. 
Gerade bei Handke ging die Suche nach und die Erprobung von noch nicht konventionalisierten Schreibverfahren mit dem Interesse an den literarischen Innovationen anderer Autoren einher: „Hier, bei Konrad Bayer, scheint sich, endlich, eine neue Literatur anzubahnen“ ${ }^{62}$ hält Handke im September 1966 im Jahr seiner ersten Buchveröffentlichungen - in einem Rundfunkfeuilleton über Bayers der kopf des vitus bering fest. Wenige Monate zuvor hatte er in seiner Princetoner Polemik gegen die grassierende „Beschreibungsimpotenz" kritisiert, dass ein gewichtiger Teil der zeitgenössischen Literatur sich zwar pflichtgemäß vom Traditionellen und Althergebrachten distanziere, aber - und hier fällt die Diktion des jungen Handke mit jener der Bourdieu'schen Kultursoziologie in eins - noch keine eigene "neue[ ] Position“ etabliert habe. ${ }^{63}$ Sein Anspruch an das eigene Schreiben, den er etwa im mittlerweile kanonisch gewordenen Essay Ich bin ein Bewohner des Elfenbeinturms (1967) formuliert hat, deckt sich dabei mit dem Anspruch an fremde Texte, die er selbst als Kritiker - u. a. für den Spiegel und die ZEIT - in Augenschein nahm. Die „Tatsache, dass Handke sein Schreiben seit den eigenen literarischen Anfängen beständig und eingehend theoretisch reflektiert hat ${ }^{\text {“ }}{ }^{64}$ ist nicht zuletzt seiner langjährigen Arbeit als Literaturkritiker geschuldet (s. Kap. V).

Die vorliegende Studie hat sich zum Ziel gesetzt, die bislang bloß angedeutete Beziehung zwischen literarischem Schreiben, poetologischer Reflexion und kritischer Kommentierung aus einer kultursoziologischen Perspektive näher und anhand zahlreicher Mikro-Konstellationen in den Blick zu nehmen. Scharmützel und regelrechte Fehden mit einzelnen Kritikern - etwa Handkes jahrzehntelanger Konflikt mit Marcel Reich-Ranicki (Kap. IV) - sollen nicht als literaturbetrieblicher gossip verharmlost, sondern in ihrer, werkpolitischen sowie poetologischen Bedeutung ernst genommen und, basierend auf einem breiten Sample von Materialien, im Detail rekonstruiert werden. Stärker als bislang wird dabei die Verhandlung des Konzeptes, (Literatur-)Kritik' auch in fiktionalen Texten thematisiert: Immer wieder haben Bernhard und Handke, zumal im Kontext autofiktionaler Schreibprojekte, in ihrem Werk die exponierte Position des Künstlers in der Öffentlichkeit reflektiert und sich dabei mit der Praxis und den Aporien des Urteilens auseinandergesetzt: Seine Bilder seien, so lässt Bernhard den Maler Strauch in Frost (1963) sagen, ,immer gut kritisiert

62 Peter Handke: Die Wörter als Wirklichkeit. [1966] In: P. H.: Tage und Werke (Anm. 27), S. 12-16, hier S. 15 f.

63 Im Wortlaut: Peter Handkes, Auftritt' in Princeton und Hans Mayers Entgegnung. [1966] In: Text + Kritik (51989), H. 24, S. 17-20, hier S. 18. Vgl. dazu zuletzt die erhellenden Ausführungen von Jörg Döring: Peter Handke beschimpft die Gruppe 47. Siegen: universi 2019.

64 Stefan Hofer: Funktion - Peter Handke. In: Systemtheoretische Literaturwissenschaft. Begriffe Methoden - Anwendungen. Hg. v. Niels Werber unter Mitarb. v. Maren Lickhardt. Berlin, New York: de Gruyter 2011, S. 135-146, hier S. 136. 
worden“, nur ihn selbst hätten sie niemals zufriedenstellen können: „Im Grunde ist niemand kritisch, und heute sind die Leute, die sich mit Kunst beschäftigen, so kritiklos wie zu keiner Zeit. Vielleicht irritierte mich die Kritiklosigkeit der Kritiker, und ich wurde deshalb kein guter Maler?“ (TBW 1, 140) Mit Konstellationen wie dieser gerät im letzten thematischen Abschnitt der Arbeit (Kap. VII) die Idee einer von den Instanzen der etablierten Literaturkritik unabhängigen ,Selbstkritik' in den Fokus, bevor der Epilog (Kap. VIII) noch einmal nach dem produktiven Potential der Auseinandersetzungen zwischen Literatur und Literaturkritik fragt. 


\section{II „ICH KANN MICH DAMIT SCHWER ABFINDEN“: KRITIK DER KRITIK ALS WERKPOLITIK}

\section{Legitimationen und Strategien}

Polemisches Sprechen und Schreiben hat, selbst wenn das Objekt der Polemik explizit benannt wird, nicht selten mehrere Adressaten, und es weist, zumal in seiner ästhetisch produktiven Form, über das Verhältnis zwischen ,Angreifer und ,Angegriffenem ' hinaus. Peter von Matt hat in diesem Sinne am Beispiel Lessings und Heines betont, dass der „wahre Adressat“ polemischer Schriften in vielen Fällen „der Leser“ bzw. „das Publikum“ sei, welches „das Hin und Her“ der Argumente "genußvoll“ verfolge; der Leser oder die Leserin sei demnach, so von Matts Fazit, „die eigentliche Waffe des Polemikers“. Wie im Rahmen der vorliegenden Arbeit anhand ausgewählter Konstellationen um Thomas Bernhard, Peter Handke und die Literaturkritik gezeigt wird, erweisen sich die Netze polemischer Kommunikation als überaus komplex und lassen sich, will man der Produktivität des Agonalen im literarischen Feld auf die Spur kommen, kaum je auf die Konfrontation zweier Akteure reduzieren.

Bringt etwa ein Autor wie Peter Handke zur Bestimmung seines eigenen Schreibprojekts die Unterscheidung zwischen Literatur und „Nicht-Literatur“, zwischen Schriftsteller und „Nicht-Schriftsteller“, 3 zwischen Büchern und „UnBüchern“" ins Spiel, liegt es nahe, eine zumindest zweifache Adressierung dieser Statements zu konstatieren: Sie können einerseits, mit Pierre Bourdieu gesprochen, als ostentative „Exkommunikationen “5 aus dem Bereich des Literarischen begriffen werden, für die der „Kampf um symbolische Macht und kulturelle Legitimität" eine entscheidende Rolle spielt. ${ }^{6}$ Die Denunziation richtet sich also

1 Peter von Matt: Grandeur und Elend literarischer Gewalt. Die Regeln der Polemik. In: P. v. M.: Das Schicksal der Phantasie. Studien zur deutschen Literatur. München, Wien: Hanser 1994, S. $35-42$, hier S. $41 \mathrm{f}$.

2 Peter Handke: Am Felsfenster morgens (und andere Ortszeiten 1982-1987). Salzburg, Wien: Residenz 1998, S. 452.

3 Peter Handke: Phantasien der Wiederholung. Frankfurt a. M.: Suhrkamp 1983, S. 90.

4 Peter Handke: Mißglückte Heimat. [2004] In: P. H.: Meine Ortstafeln. Meine Zeittafeln. 1967-2007. Frankfurt a. M.: Suhrkamp 2007, S. 341-345, hier S. 345.

5 Pierre Bourdieu: Das literarische Feld. In: P. B.: Kunst und Kultur. Kunst und künstlerisches Feld. Schriften zur Kultursoziologie 4. Hg. v. Franz Schultheis u. Stephan Egger. Berlin: Suhrkamp 2015, S. 339-447, hier S. 363.

6 Nach Markus Joch und Norbert Christian Wolf: Feldtheorie als Provokation der Literaturwissenschaft. Einleitung. In: Text und Feld. Bourdieu in der literaturwissenschaftlichen Praxis. Hg. v. 
direkt an die Autorinnen und Autoren einer solchen „Nicht-Literatur“, die - aus Sicht des Polemikers - zentrale Anforderungen an ihre Texte im Sinne einer ästhetischen oder moralischen Norm nicht erfüllen. Geht man von einer solchen manichäischen Unterscheidung aus, hat dies in weiterer Konsequenz zur Folge, dass den Verfassern von „Un-Büchern“ der Status als legitime Akteure im literarischen Feld aberkannt wird - von Matt spricht hier von einem nicht bloß in Kauf genommenen, sondern beabsichtigten „Akt der sozialen Tötung“?

Andererseits lassen sich entsprechende Urteile, die den Texten anderer Autoren ihren Literatur- bzw. Kunstcharakter und damit den Verfassern die „Bezeichnung Schriftsteller überhaupt ${ }^{\text {“8 }}$ absprechen, auch auf jene Institutionen beziehen, denen derlei Ordnungs- und Klassifizierungslizenzen gewöhnlich vorrangig zugestanden werden: Noch im April 2012 hat Peter Handke in Bezug auf Werke, die aus Schreibschulen hervorgegangen sind, eine Trennung zwischen ,Literatur und ,Nicht-Literatur' vorgenommen, wobei sein Ressentiment durchaus kulturkonservative Züge offenbart: „Das ist keine Literatur. Den Kritikern würde ich daher auch nahelegen, in den Feuilletons wirklich zu trennen, was Literatur ist und was nicht. Das sollen sie endlich wieder machen! ${ }^{“ 9}$ Handkes Einwand richtet sich hier nicht bloß gegen die Autoren selbst, sondern ausdrücklich auch gegen das Feuilleton, das keinen Mut zu einer strikten Trennung mehr aufbringe.

Taxieren und kritisieren literarische Autoren in unterschiedlichen Kontexten - in Interviews, Reden, Essays, Rezensionen, aber auch in fiktionalen Genres - die Legitimität konkurrierender Schreibprojekte oder hinterfragen die bestehende Wertschätzung kanonisierter Texte, stehen diese Statements gleichzeitig in einem wiederum distinktiven Bezug zu den Rede- und Schreibweisen der „Klassifizierungsexperte $[\mathrm{n}]^{\text {“10 }}$ in Literaturkritik und Literaturwissenschaft. Oder mit anderen Worten: Interpretiert man polemische Attacken gegen Konkurrenten und Traditionen in den medialen Kanälen des Literatur- und

M. J. u. N. C. W. Tübingen: Niemeyer 2005, S. 1-24, hier S. 23, findet dieser „Kampf “ nicht zuletzt an der „Schnittstelle zwischen Literatur und Nicht-Literatur“ - und damit im hier skizzierten Spannungsfeld - statt. Dazu ausführlich Pierre Bourdieu: Die Regeln der Kunst. Genese und Struktur des literarischen Feldes. Frankfurt a. M.: Suhrkamp 1999, S. 353-360. Zum „Terminus ,Literatur““ als umkämpftem „Ehrenbegriff“vgl. auch Stephen Greenblatt: Erich Auerbach und der New Historicism. Bemerkungen zur Funktion der Anekdote in der Literaturgeschichtsschreibung. In: S. G.: Was ist Literaturgeschichte? Mit einem Kommentar v. Catherine Belsey. Frankfurt a. M.: Suhrkamp 2000, S. 73-100, hier S. 95.

7 von Matt: Grandeur und Elend literarischer Gewalt (Anm. 1), S. 35.

8 Bourdieu: Die Regeln der Kunst (Anm. 6), S. 353.

9 Peter Handke/Thomas Oberender: Nebeneingang oder Haupteingang? Gespräche über 50 Jahre Schreiben fürs Theater. Berlin: Suhrkamp 2014, S. 54.

10 Sigrid Löffler: Die versalzene Suppe und deren Köche. Über das Verhältnis von Literatur, Kritik und Öffentlichkeit. In: Literaturkritik. Theorie und Praxis. Hg. v. Wendelin Schmidt-Dengler u. Nicole Katja Streitler. Innsbruck, Wien: StudienVerlag 1999, S. 27-39, hier S. 29. 
Kulturbetriebs auch und im Besonderen als Bestreben, Deutungen über den ,Wert' und ,Unwert' kultureller Produkte durchzusetzen - und damit den Sprecher oder Schreiber selbst als reliable Beurteilungsinstanz zu positionieren -, gerät ein solches Agieren fast zwangsläufig in Konflikt mit jenen Institutionen, „die literarische Texte, Autoren und andere Phänomene der Literatur kommentier[en] und bewerte[n]“."

Diese Konstellation ist etwa auch in Thomas Bernhards 1984 erschienener Abrechnung mit dem Literatur- und Kulturbetrieb Österreichs, Holzfällen. Eine Erregung, zu beobachten. Der in sicherer Distanz zu den anderen Gästen in einem Ohrensessel postierte Erzähler unterscheidet zunächst mit souveräner Geste zwischen „Künstler“ und „Nichtkünstler“, um im nächsten Atemzug zu beschreiben, wie er reagiere, wenn er „heute einen sogenannten bedeutenden oder berühmten Namen in der Zeitung lese“ (TBW 7, 84). Der Bezug der persönlichen Unterscheidung zwischen ,Kunst ‘ und ,Nicht-Kunst' zu dem seiner Meinung nach verfehlten Klassifizierungsauftrag der Presse ist evident. Immer wieder wird in Holzfällen der Kontrast zwischen der „Distinktions- und Klassifikationswut “" ${ }^{\text {12 }}$ des Erzählers und der Wertschätzung, die den attackierten Personen im Literatur- und Kulturbetrieb entgegengebracht wird, deutlich. Seine Angriffe richten sich nicht nur gegen die Nähe der Kulturschaffenden zum Feld der Macht - „verabscheuungswürdige Staatsanbiederungskunst“, „Anbiederung an den Staatsapparat", „Staatspfründnerexistenzen“ (TBW 7, 157f.) -, sondern eben auch gegen eine fatale Allianz von Kunst und Journalismus; eine „kleine positive Zeitungsbesprechung“ oder „ein paar dumme lobende Erwähnungen“ (TBW 7, 63) hätten bei vielen, die er im Laufe des Abends polemisch ins Visier nimmt, zur unproduktiven Selbstzufriedenheit geführt. Ingeborg Bachmanns Bemerkung in einem Essayfragment zu Thomas Bernhards Literatur, wonach das „Unglück der Kritik“ womöglich darin bestehe, „daß ihr jedes Gefühl für Rang fehlt “' ${ }^{13}$ hätte Bernhard wohl vorbehaltlos unterschrieben.

Auf die skizzierte doppelte Adressierung deutet auch eine Bemerkung in Pierre Bourdieus Die Regeln der Kunst hin: Der Soziologe beschreibt die „Konkurrenzkämpfe“ um das „Monopol literarischer Legitimität“ nicht bloß als Verhandlungen darüber, „wer Schriftsteller ist“, sondern auch über die heikle Frage,

11 Herbert Jaumann: Literaturkritik. In: Reallexikon der deutschen Literaturwissenschaft. Neubearbeitung des Reallexikons der deutschen Literaturgeschichte. Bd. II: H-O. Hg. v. Harald Fricke. Berlin, New York: de Gruyter 2007, S. 463-468, hier S. 463.

12 Karl Wagner: Holzfällen als Selbstdemontage. Eine Lektüre nach den Skandalen. In: Thomas Bernhard. Persiflage und Subversion. Hg. v. Mireille Tabah u. Manfred Mittermayer. Würzburg: Königshausen \& Neumann 2013, S. 107-117, hier S. 113.

13 Ingeborg Bachmann: Watten und andere Prosa (über Thomas Bernhard). In: I. B.: Kritische Schriften. Hg. v. Monika Albrecht u. Dirk Göttsche. München, Zürich: Piper 2005, S. 453-457, hier S. 455. 
wer ,aus eigener Machtvollkommenheit darüber befinden kann, wer Schriftsteller ist “; ${ }^{14}$ das Problem der Legitimation erweist sich also insbesondere als Problem der Legitimationsinstanz. Spricht demnach Peter Handke in einer im März 1987 verfassten, aber erst nach Bernhards Tod publizierten Notiz seinem schärfsten Konkurrenten den Status als ernstzunehmender Autor ab, indem er dessen Texte zur „Nicht-Literatur“ erklärt, ${ }^{15}$ dokumentiert dies nicht nur den schwelenden Konflikt zwischen den beiden Schriftstellern, den Handke schon im vorangegangenen Herbst öffentlich angeheizt hatte: „Was der Thomas Bernhard macht, in Ehren, aber für mich ist das keine Literatur. ${ }^{\text {“16 }}$ Neben der naheliegenden Deutung als Einsätze im Kampf zwischen zwei Akteuren im literarischen Feld, die eine im Laufe der Jahre sorgsam kultivierte gegenseitige Aversion verband, sind solche Invektiven eben auch als pointierte Beiträge zu einer grundlegenderen Diskussion um Wert und Bewertung literarischer Texte zu verstehen. Handkes Bemerkung lässt sich zudem auf den von ihm konstatierten Umstand beziehen, Bernhard sei ein Liebkind der Literaturkritik und verdanke seinen Erfolg zuallererst dem Einfluss professioneller Leser, wie Handke bereits 1972 André Müller gegenüber mit einer zweifachen polemischen Volte festgestellt hatte: „Der Thomas Bernhard, der hat viel Erfolg bei den Literaturkritikern, was eventuell daher rührt, daß durch das, was er schreibt, die Existenz der Literaturkritiker befriedigt wird in diesem miesen Gefühl, Literaturkritiker zu sein. ${ }^{\text {17 }}$

Der Eintrag von Herbert Jaumann im Reallexikon der deutschen Literaturwissenschaft definiert Literaturkritik als ,jede Art kommentierende, urteilende, denunzierende, werbende, auch klassifizierend-orientierende Äußerung über Literatur“, worunter nicht zuletzt die prekäre Bestimmung dessen falle, „was

14 Bourdieu: Die Regeln der Kunst (Anm. 6), S. 354.

15 Vgl. Handke: Am Felsfenster morgens (Anm. 2), S. 452: „Jetzt weiß ich: Literatur muß einen Duft haben, freiwerdend nur durch den freien Leser (und Nicht-Literatur, wie die von Thomas B., hat keinen Duft)“. In einer 1987, also zu Lebzeiten Bernhards, in den manuskripten publizierten Fassung des Notats hatte Handke den Verweis auf seinen Konkurrenten noch unterdrückt: „Jetzt weiß ich: die Literatur muß einen Duft haben, nur durch das Lesen freiwerdend; Nicht-Literatur ist daran zu erkennen, daß sie keinen Duft hat" (Peter Handke: Am Felsfenster, morgens. In: manuskripte 27 [Oktober 1987], H. 97, S. 3-9, hier S. 3).

16 Sigrid Löffler: Der Mönch auf dem Berge. [Gespräch mit Peter Handke.] In: profil, Nr. 47, 17.11. 1986, S. 98-102, hier S. 102. Handkes Aussagen hatten zuerst, am 25.11.1986, einen Beschwichtigungsbrief Siegfried Unselds an Bernhard zur Folge, in dem er „die Äußerungen des ,Mönchs auf dem Berge“ [...], wenn sie so gefallen sind“, als „töricht, dumm, unverzeihlich, geschmacklos“ bezeichnete (Thomas Bernhard/Siegfried Unseld: Der Briefwechsel. Hg. v. Raimund Fellinger, Martin Huber u. Julia Ketterer. Frankfurt a. M.: Suhrkamp 2009, S. 760), sowie gegen Ende des Jahres eine an Handke gerichtete Ermahnung des gemeinsamen Verlegers (vgl. Peter Handke/Siegfried Unseld: Der Briefwechsel. Hg. v. Raimund Fellinger u. Katharina Pektor. Berlin: Suhrkamp 2012, S. 526).

17 André Müller: Im Gespräch mit Peter Handke. Weitra: Bibliothek der Provinz 1993, S. 43. 
jeweils als ,Literatur ' gilt“. ${ }^{\text {18 }}$ Wenn nun die Rezension von Handkes Debütroman Die Hornissen (1966) in der Saarbrücker Zeitung demonstrativ mit dem Titel Was man heute Literatur nennt überschrieben ist, kann dies als anschauliches Beispiel dafür gelten, dass in der literaturkritischen Wertung - zumal bei der Etablierung innovativer Erzählverfahren - nicht nur die Qualität eines Textes innerhalb des Literatursystems auf dem Spiel steht, sondern auch der Zutritt zu jenem Bereich, der sich überhaupt ,Literatur' nennen darf. ${ }^{19}$ Als entscheidenden Aspekt für die Aushandlung „,iterarischer Legitimität" hat Bourdieu in diesem Zusammenhang das „Monopol“ beschrieben, „mit Fug und Recht sagen zu können, wer sich überhaupt Autor nennen darf" - d. h. auch: wessen Texte überhaupt als ,Literatur' gelten dürfen. ${ }^{20}$ Dass Autorinnen und Autoren solch apodiktische Bestimmungen über die Frage, welche Texte zum jeweiligen Zeitpunkt den Status eines ,literarischen Kunstwerks' für sich beanspruchen können, oft nicht kommentarlos hinnehmen und stattdessen Rolle und Funktion der journalistischen gate keeper selbst kritisch hinterfragen, überrascht kaum.

Wiederholt hat Handke ein demonstratives „Nein zu Handke“ ${ }^{\text {“21 }}$ vonseiten der Literaturkritik mit einem selbstbewussten, Nein zu dieser Kritik' beantwortet und seine Gegner bei verschiedenen Gelegenheiten als „Trupp gravitätisch-nichtsnutziger Barbaren “22 oder als bloße „Öffentlichkeitsagenten ${ }^{\text {“23 }}$ bezeichnet. Die Fronten dieser Auseinandersetzung zwischen Autor und Feuilleton werden im Zuge der vorliegenden Arbeit anhand exemplarischer Konstellationen rekonstruiert.

18 Jaumann: Literaturkritik (Anm. 11), S. 463; zur Definition von,Literaturkritik‘ vgl. auch Brigitte Schwens-Harrant: Literaturkritik. Eine Suche. Innsbruck u. a.: StudienVerlag 2008, S. 49-56.

19 Dieter Hasselblatt: Was man heute Literatur nennt. In: Saarbrücker Zeitung, 9./10. 7. 1966. Zwar ist der Rezensent, mit Verweis auf Goethes Aufsatz Literarischer Sansculottismus (1795), der Überzeugung, „daß einem einzelnen Opus nicht die Gesamtanlage einer Literatursituation angelastet werden dürfe“, er dekretiert jedoch gleichzeitig im Namen einer normativen Gattungspoetik: „Was Handke schreibt, ist kein Roman.“ (Ebd.) - Vgl. als Beispiel eines ähnlichen Verfahrens eine Besprechung von Handkes zweitem Roman Der Hausierer, die ebenfalls bereits im Titel ihre Stoßrichtung offenlegt, durch Wolfgang Ignée: Handkes Nicht-Buch. In: Christ und Welt, 10.10.1967.

20 Pierre Bourdieu: Das literarische Feld. Kritische Vorbemerkungen und methodologische Grundsätze. In: P. B.: Kunst und Kultur. Kunst und künstlerisches Feld (Anm. 5), S. 309-337, hier S. $329 \mathrm{f}$.

21 So der Titel einer weiteren Rezension zu Handkes Debütroman: Jürgen Lütge: Nein zu Handke. In: Münchner Merkur, 9.7.1966.

22 Peter Handke: Einwenden und Hochhalten. Rede auf Gustav Januš. [1984] In: P. H.: Langsam im Schatten. Gesammelte Verzettelungen. 1980-1992. Frankfurt a. M.: Suhrkamp 1992, S. 125-135, hier S. 128.

23 Peter Handke: Wie ein Letzter ein Erster; Lob eines „Kritikers“. Zu Helmut Färber. [1994] In: P. H.: Mündliches und Schriftliches. Zu Büchern, Bildern und Filmen. 1992-2002. Frankfurt a. M.: Suhrkamp 2002, S. 39-65, hier S. 45. 
Dabei stehen weniger die Debatten um Handkes ,Jugoslawien-Texte' im Mittelpunkt, die im Zuge der Verleihung des Literatur-Nobelpreises im Herbst 2019 erneut mit großer Vehemenz geführt wurden, ${ }^{24}$ sondern vor allem die ebenso emotionalen Verhandlungen über literarische Formen, Tendenzen und Bewertungskriterien. In diesem Zusammenhang lässt sich eine „erstaunliche Vernetzung des literarischen mit dem kritischen Diskurs“ ausmachen, ${ }^{25}$ die sowohl für die Akkumulation der knappen ,Ressource' Aufmerksamkeit im literarischen Feld als auch für die Durchsetzung und poetologische Flankierung der eigenen Schreibregel von zentraler Bedeutung ist.

In der Folge soll gezeigt werden, wie gerade die Auseinandersetzung mit literaturkritischen Sprachcodes und Bewertungssystemen als zentraler Aspekt einer umfassenden Distinktionspraxis, einer "Selbstprofilierung durch Widerspruch“, ${ }^{26}$ $\mathrm{zu}$ verstehen ist. Für die beiden untersuchten Autoren ist dabei eine sehr unterschiedliche Intensität und Charakteristik auszumachen: Thomas Bernhard hat zwar wiederholt ein unzureichendes Verständnis und eine mangelnde Wertschätzung seiner Prosatexte und Theaterstücke im Feuilleton moniert und dies schon Ende der 1950er Jahre auf das „Fehlen auch nur einer einzigen Kritikerpersönlichkeit in Österreich“ (TBW 22.1, 577) zurückgeführt; er ist jedoch mit wenigen Ausnahmen kaum je selbst als poetologisch ambitionierter und versierter Kommentator in Erscheinung getreten. Jene frühen Texte, die aus seiner Rezensionstätigkeit für das Demokratische Volksblatt, die Salzburger Nachrichten und die Wiener Furche in der ersten Hälfte der 1950er Jahre hervorgegangen sind, bieten kaum Belastbares für eine stringente Auseinandersetzung mit Aspekten literaturkritischen Wertens; sie sind, wie Christian Klug schon früh gezeigt hat, „arm an Kriterien, so daß kein Hintergrund einer theoretisch reflektierten Ästhetik oder Poetik erkennbar wird“. ${ }^{27}$

24 Vgl. dazu exemplarisch Ulrich Breuer: Parasitenfragen. Medienkritische Argumente in Peter Handkes Serbienreise. In: Mediensprache - Medienkritik. Hg. v. U. B. u. Jarmo Korhonen. Frankfurt a. M. u. a.: Lang 2001, S. 285-303; Martin Sexl: Literatur als Bildkritik. Peter Handke und die Jugoslawienkriege der 1990er-Jahre. In: Kriegsdiskurse in Literatur und Medien nach 1989. Hg. v. Carsten Gansel u. Heinrich Kaulen. Göttingen: V\&R unipress 2011, S. 89-106; Jürgen Brokoff: „Ich wäre gern noch viel skandalöser“. Peter Handkes Texte zum JugoslawienKrieg im Spannungsfeld von Medien, Politik und Poesie. In: Peter Handke. Stationen, Orte, Positionen. Hg. v. Anna Kinder. Berlin, Boston: de Gruyter 2014, S. 17-37.

25 Uwe C. Steiner: Literatur als Kritik der Kritik. Die Debatte um Peter Handkes Mein Jahr in der Niemandsbucht und die Langsame Heimkehr. In: Deutschsprachige Gegenwartsliteratur. Wider ihre Verächter. Hg. v. Christian Döring. Frankfurt a. M.: Suhrkamp 1995, S. 127-169, hier S. 127.

26 Otto Lorenz: Die Öffentlichkeit der Literatur. Fallstudien zu Produktionskontexten und Publikationsstrategien: Wolfgang Koeppen - Peter Handke - Horst-Eberhard Richter. Tübingen: Niemeyer 1998, S. 167.

27 Christian Klug: Thomas Bernhards Arbeiten für das Salzburger Demokratische Volksblatt 1952 bis 1954. In: Modern Austrian Literature 21 (1988), H. 3/4, S. 135-172, hier S. 145. Dazu ausführlich Kap. VI. 
Peter Handke hingegen gehörte schon im Zuge seiner Etablierung im literarischen Feld zu jenen Autoren, die, zumal in den ersten Jahren ihrer schriftstellerischen Laufbahn, die Rechtfertigung ihrer spezifischen Schreibweise gerade durch die exzessive „Kommentierung eigener wie auch fremder Texte “ betrieben, um, so Otto Lorenz, „die Differenz zu Vorgängern und Mitkonkurrenten kenntlich [zu] machen “. ${ }^{28}$ Die ab Ende 1964 verfassten Rundfunkfeuilletons für das steiermärkische Regionalradio stellten dafür ein wichtiges Übungsfeld dar, auf dem Handke das Wechselspiel von Rezensieren und (verdeckter) poetologischer Selbstreflexion erproben konnte. Als nachgerade prototypischer „Stratege im Literaturkampf “29 hat Handke in der Folge ein ganzes Ensemble unterschiedlicher Genres in Stellung gebracht und deren mitunter virtuoses Zusammenspiel im Sinne einer vielschichtigen ,Werkpolitik' ausgestaltet.

Die Polemiken gegen die Institution der Literaturkritik sind dabei, wie ich zu zeigen versuche, eng mit seiner eigenen Rezensionstätigkeit verknüpft, die sich betont von etablierten Formen der Kritik distanziert. Kommentiert Handke Bücher von Kolleginnen und Konkurrenten, erweisen sich die Besprechungen, die Lobreden ebenso wie die Verrisse, nicht selten als poetologische „Statement[s] in eigener Sache“. ${ }^{30}$ Wenn Handke etwa 1965 in der Wiener Literaturzeitschrift Wort in der Zeit und in der „Bücherecke“ des steiermärkischen Regionalradios über das „sprachliche Verfahren“ und die ästhetischen Bauprinzipien von Ror Wolfs Fortsetzung des Berichts referiert, werden damit ein Stück weit auch die literarischen Arbeiten des Rezensenten selbst vorbereitet. ${ }^{31}$ Die Verhandlungen über das ästhetische Potential ,fremder' Texte sind, ebenso wie die Invektiven gegen die Maßstäbe und Kriterien der zeitgenössischen Literaturkritik, stets auf das eigene Schreiben, auf die Verfahren eigener literarischer Arbeiten bezogen.

28 Otto Lorenz: Pro domo - Der Schriftsteller als Kritiker. Zu Peter Handkes Anfängen. In: Literaturkritik - Anspruch und Wirklichkeit. DFG-Symposion 1989. Hg. v. Wilfried Barner. Stuttgart: Metzler 1990, S. 399-414, hier S. 399 f.

29 Walter Benjamin: Einbahnstraße. In: W. B.: Gesammelte Schriften. Unter Mitwirkung v. Theodor W. Adorno u. Gershom Scholem hg. v. Rolf Tiedemann u. Hermann Schweppenhäuser. Bd. IV.1. Hg. v. Tillman Rexroth. Frankfurt a. M.: Suhrkamp 1972, S. 83-148, hier S. 108; dazu u.a. Wolfgang Albrecht: Literaturkritik. Stuttgart, Weimar: Metzler 2001, S. 92-94; Lorenz: Pro domo (Anm. 28), S. 403.

30 Anna Estermann: Vom „bloß sprachlichen“ zu einem „allumfassenden Realismus“. Handkes ,realistic turn' um 1970. In: Schreiben als Weltentdeckung. Neue Perspektiven der Handke-Forschung. Hg. v. A. E. u. Hans Höller. Wien: Passagen 2014, S. 97-134, hier S. 107; vgl. ebd., S. 127, Anm. 49.

31 Peter Handke: Ror Wolf: Fortsetzung des Berichts. In: Wort in der Zeit 11 (1965), H. 3, S. 59-6o, hier S. 59; vgl. Peter Handke: „Bücherecke“ vom 26. 4. 1965. In: P. H.: Tage und Werke. Begleitschreiben. Berlin: Suhrkamp 2015, S. 211-217, hier S. 211 f. - Zur Zeitschrift Wort in der Zeit als Rezensionsorgan vgl. Wolfgang Hackl: Kein Bollwerk der alten Garde - keine Experimentierbude. Wort in der Zeit (1955-1965). Eine österreichische Literaturzeitschrift. Innsbruck: Institut für Germanistik 1988, S. 156-168. 


\section{Einsprüche gegen die Kritik: eine verbotene Übung (Verstörung)}

In seiner Dankesrede zur Verleihung des Franz-Kafka-Preises im Jahr 1995 hat Christoph Ransmayr die Einmischung eines Autors in die Diskussion über sein Werk als vergebliche Mühe beschrieben: „Jeder Versuch, seine Erzählung zu begleiten, ihr nachzugehen, um sie vor dem Schlimmsten zu bewahren, wäre so erschöpfend wie hoffnungslos", so Ransmayr, denn was der Autor geschrieben habe, könne "nirgendwo klarer und stärker sein als im Inneren seiner

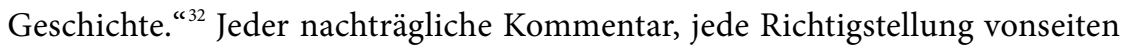
des Autors mache die Sache nicht besser; die veröffentlichten Bücher seien, selbst wenn ihnen das ,Schlimmste' drohe, ihrem Schicksal zu überlassen. Dieses Pensum einer stoischen Haltung gegenüber kritischen Kommentaren haben Thomas Bernhard und Peter Handke wiederholt nicht erfüllt, vielmehr die Auseinandersetzung mit Kritikern und Kritiken zur pointierten Positionierung und zur Verteidigung ihrer Texte genutzt.

Jene gelassen-souveräne Haltung, die Bernhard sich 1977 im ,Nachtgespräch mit Peter Hamm in Erinnerung an die Kritiken seiner ersten Gedichtbände attestiert hat - „mein Gott, war'n halt Kritiken, und die guten waren halt wunderbar und die schlechten waren halt schlecht, nicht?" (TBW 22.2, 109) -, kann jedenfalls nicht als Regel gelten, meldete sich der Autor doch im Laufe der Jahre mehrmals als „Anwalt seiner Bücher ${ }^{\text {“33 }}$ zu Wort: Bereits in seinem ersten erhaltenen Leserbrief - einer Textsorte, mit der er ab Mitte der 1970er Jahre zusehends virtuos die öffentliche Aufmerksamkeit auf sich lenken sollte - ignorierte Thomas Bernhard jenes ungeschriebene Gesetz literarischer Kommunikation, demzufolge es sich bei der „öffentliche[n] Antwort auf Kritiken“ um eine „im Prinzip verbotene Übung "handle ${ }^{34}$ - begeht doch ein „Schriftsteller, der seinen Kritiker kritisiert, [...] leicht einen Fauxpas. ${ }^{{ }^{335}}$ Unter dem Titel Theater am Tonhof hatte der Chefredakteur der Wiener Wochenpresse und spätere Hörfunk- und

32 Christoph Ransmayr: Die Erfindung der Welt. Fragen, Antworten. In: C. R.: Die Verbeugung des Riesen. Vom Erzählen. Frankfurt a. M.: S. Fischer 2003, S. 15-22, hier S. $21 \mathrm{f}$.

33 Clemens Götze: „Ein Autor ist etwas ganz und gar erbärmliches und lächerliches“. Autorschaft als Inszenierung bei Thomas Bernhard. In: Theorien und Praktiken der Autorschaft. Hg. v. Matthias Schaffrick u. Marcus Willand. Berlin, Boston: de Gruyter 2014, S. 419-437, hier S. 432; ebenso in ders.: „Mit allen Anzeichen der Empörung“. Thomas Bernhard als Leserbriefschreiber. In: Text + Kritik ( $\left.{ }^{4} 2016\right)$, H. 43, S. 52-65, hier S. 62.

34 Gérard Genette: Paratexte. Das Buch vom Beiwerk des Buches. Mit einem Vorwort v. Harald Weinrich. Frankfurt a. M.: Suhrkamp 2001, S. 337. Zur „öffentliche[n] Widerrede, die den Kritiker zur Rede stellt", vgl. auch Franz Schuh: All you need is love. Notizen und Exzerpte zur (Literatur-)Kritik. In: F. S.: Schreibkräfte. Über Literatur, Glück und Unglück. Köln: DuMont 2000, S. 24-114, hier S. 103.

35 Steiner: Literatur als Kritik der Kritik (Anm. 25), S. 132. 
Fernsehintendant des ORF, Wolf In der Maur, im August 1960 eine Aufführung von Bernhards Kurz-Oper Köpfe sowie seiner Einakter Frühling, Rosa und Die Erfundene am Kärntner Tonhof ablehnend besprochen. Gerhard Lampersbergs „serielle Musik“ und „Thomas' [sic] Dichtungen“ hätten das Publikum „eher ratlos“ zurückgelassen (zit. nach TBW 22.1, 837). Außerdem wirft In der Maur sowohl dem Autor als auch dem Komponisten vor, für eine bloß sekundäre, epigonale Modernität zu stehen, wobei avantgardistischer Anspruch und künstlerische Wirklichkeit auseinanderklafften:

Beide schwören darauf, daß das, was sie machen, nicht bloß modern, sondern schlechthin Gegenwartskunst sei. Beide wandeln dennoch auf Pfaden, die seit den frühen zwanziger Jahren immer wieder von experimentierfreudigen Künstlern und deren Epigonen mit Ausdauer eingeschlagen wurden, ohne indessen zu ,bleibenden Werten zu gelangen. (zit. nach TBW 22.1, 837)

Bernhard replizierte in der folgenden Ausgabe der Wochenpresse mit einem Leserbrief auf den seiner Meinung nach „merkwürdigen Bericht“, der nicht nur sachlich inkorrekte Angaben zu seinen Publikationen beinhalte, sondern auch eine Äußerung zur „Gegenwartskunst“ wiedergebe, die er so nie getätigt habe: „[I]ch habe mich zu der ,Darbietung“ auf dem Tonhof in weiser Voraussicht überhaupt nicht geäußert, geschweige denn eine Pubertätsbehauptung, wie die mir von Ihrem Rezensenten ,in den Mund geworfene, aufgestellt." (TBW 22.1, 631) Zur Verteidigung der eigenen künstlerischen Arbeit zögert Bernhard indes nicht, die Verantwortung für ein etwaiges Misslingen der Aufführung auf andere Beteiligte abzuwälzen; „daß die Darstellung auf der ,Bühne ' mit dem Text nur mehr sehr wenig zu tun gehabt hat“, sei jedenfalls „nicht Schuld des erst zur Premiere erschienenen verblüfften Autors“ gewesen (TBW 22.1, 631). ${ }^{36}$ Der Leserbrief kann folglich auch als Dokument der allmählichen Entzweiung von Lampersberg und Bernhard gelesen werden, ${ }^{37}$ als Hinweis auf die demonstrative Emanzipation des jungen Autors von den Orten und Netzwerken seiner frühen literarischen und intellektuellen Sozialisation. Gut zwanzig Jahre später sollte Bernhard in Holzfällen (1984) mit der Charakterisierung des Protagonisten Auersberger als „Komponist in der Webern-Nachfolge“ (TBW 7, 11), der als "steiermärkische[r] Epigone“ in ebenjener „Webernachfolge steckengeblieben“ sei (TBW 7, 62), die von Wolf In der Maur formulierte Kritik an der ,epigonalen

36 Vgl. dazu auch den Kommentar in TBW 22.1, 836 f., sowie die Dokumentation in: Sehr geschätzte Redaktion. Leserbriefe von und über Thomas Bernhard. Hg. v. Jens Dittmar. Wien: Edition S 1991, S. 17-20.

37 Vgl. Wieland Schmied: Auersbergers wahre Geschichte und andere Texte über Thomas Bernhard. Ein Alphabet. Vorwort v. Hans Höller. Weitra: Bibliothek der Provinz [2014], S. 18-20. 
Avantgarde` am Tonhof schließlich noch einmal explizit gegen seinen früheren Freund und Förderer Gerhard Lampersberg wenden. Eine gerichtliche Auseinandersetzung und ein kurzfristiges Verbot der Auslieferung von Holzfällen in Österreich war die Folge.

Könnte Bernhards Intervention in der Wochenpresse mit Gérard Genette noch als eine jener ,Gegendarstellungen' gelten, die dann „legitim“ sind, „wenn sie auf als verleumdend empfundene oder auf mangelhafter Lektüre beruhende Kritiken“ reagieren, ${ }^{38}$ trifft dies auf seine am 29. Mai 1967 im Spiegel veröffentlichte Leserbriefreplik jedenfalls nicht zu:

Mein nächstes Buch lassen Sie bitte gleich von einem natürlich auch in Oberösterreich geborenen oder ansässigen Schimpansen oder Maulaffen besprechen.

Ohlsdorf (Österr.)

Thomas Bernhard (TBW 22.1, 633)

Einen knappen Monat zuvor hatte der österreichische Schriftsteller Herbert Eisenreich im Spiegel Bernhards zweiten Roman Verstörung zumindest ambivalent besprochen: Zwar gehöre, so Eisenreich, der erste Abschnitt des Bandes „in jede Muster-Sammlung moderner deutscher Prosa“ und stelle eine „glänzend gelungene[ ] Einstimmung in die Thematik" universellen menschlichen Leides dar, der zweite, mit „Der Fürst“ überschriebene Teil des Romans jedoch enttäusche die Erwartungen des geneigten Lesers. Der Rezensent konstatiert in Verstörung einen „, antirationale[n]“, „, antizivilisatorische[n] “ und „antiurbane[n] Affekt“, der „im politischen Bereich die Wurzel jedes (grünen, braunen, roten oder sonstigen) Totalitarismus" darstelle ${ }^{40}$ - ein Vorwurf, der die Rezeption von Bernhards Büchern in der Folge dauerhaft begleiten sollte:

Es wimmelt in diesem Buch von (noch dazu völlig unmotivierten) Invektiven gegen Idee und Realität des demokratisch organisierten Staates, die sich von denen gewisser ahistorisch denkender bundesdeutscher Jungdichter nur durch das bessere Deutsch unterscheiden. Mit Thomas Bernhard ist inmitten der dezidiert urbanen Literatur Österreichs wieder einmal der Urwald ausgebrochen. ${ }^{41}$

38 Genette: Paratexte (Anm. 34), S. 338.

39 Vgl. dazu noch Bernhards Brief an Karl Ignaz Hennetmair vom 4. 5. 1968: „Die Sache ist die, dass ich in Ohlsdorf vernarrt bin. Auch in Österreich, aber alles ist nur von Affen bevölkert. Marke Orang-Utan.“ (Thomas Bernhard/Karl Ignaz Hennetmair: Ein Briefwechsel. 1965-1974. Kommentiert v. Peter Bader in Zusammenarbeit mit K. I. H. Weitra: Bibliothek der Provinz 1994, S. 115)

40 Herbert Eisenreich: Irrsinn im Alpenland. Über Thomas Bernhard: Verstörung. In: Der Spiegel, Nr. 19, 1. 5.1967, S. 164-166, hier S. 164.

41 Ebd. 
Eisenreich misst in der Folge die literarische Figur des Fürsten Saurau und „seine über 140 Seiten ausgegossene psychische Diarrhöe“ an der Wirklichkeit - und kommt zu dem Schluss, dass Bernhard es, ähnlich der „ganzen gegenstandslosen (und deshalb sich, irrtümlich, für modern haltenden) Literatur“, nicht vermocht habe, „Wahrheit“ zu schildern. ${ }^{42}$

Wenige Tage nach Erscheinen der Besprechung im Spiegel riet Siegfried Unseld in einem Brief an Bernhard ausdrücklich, „sich von den Kritiken nicht beirren“ zu lassen, obschon er selbst „das Ausmaß der Ablehnung von ReichRanicki und Eisenreich nicht ganz verständlich finde“ ${ }^{43}$ Die Suhrkamp-Lektorin Anneliese Botond hatte dem Autor bereits eine Woche zuvor, unmittelbar nach der Lektüre von Eisenreichs Rezension, mitgeteilt, diese habe sie „ganz entsetzlich deprimiert, und ich hatte nur noch den einen Gedanken, dass es Ihnen nicht ebenso geht“. Sie sei jedoch überzeugt,

[d]ass weder ein denkender noch ein nicht-denkender Mensch eine solche Rezension schreibt, allenfalls einer, der etwas vom Tisch fegen möchte, möglichst ohne es anzulangen; dass der Herr Eisenreich Ihnen mit geschwungenem Prügel das Rezept einbläuen möchte, wie Sie sich ehestens und mühelos auf das ,urbane EisenreichTaschenformat reduzieren können. ${ }^{44}$

In der Gegenüberstellung der beiden Solidaritätsbekundungen von Botond und Unseld zeigen sich nicht zuletzt die unterschiedlichen Tonlagen von Lektorin und Verleger; ganz offensichtlich imponierte Botonds energische Parteinahme Bernhard mehr als die Diplomatie Unselds - das Ausscheiden der Lektorin aus dem Verlag sollte ihn zweieinhalb Jahre später schwer treffen. ${ }^{45}$

42 Ebd., S. 166. Vgl. zu Eisenreichs Rezension auch Franz Josef Görtz: Hier spukt natürlich Beckett. Thomas Bernhard und die Kritik. In: Text + Kritik (1974), H. 43, S. 36-44, hier S. 40 f.

43 Unseld an Bernhard, 8. 5. 1967. In: Bernhard/Unseld: Der Briefwechsel (Anm. 16), S. 54. ReichRanickis Rezension war wenige Tage vor jener Eisenreichs in der ZEIT erschienen. Vgl. Marcel Reich-Ranicki: Konfessionen eines Besessenen. In: DIE ZEIT, Nr. 17, 28. 4. 1967.

44 Anneliese Botond an Thomas Bernhard, 1.5.1967. In: Anneliese Botond: Briefe an Thomas Bernhard. Mit unbekannten Briefen von Thomas Bernhard. 1963-1971. Hg. v. Raimund Fellinger. Mattighofen: Korrektur 2018, S. 111.

45 Vgl. Bernhard an Botond, 7. 12.1969. In: ebd., S. 171: „Noch habe ich die Tatsache, dass Sie aus dem Verlag weggegangen sind, nicht begriffen. Ich durfte mir die Beschäftigung mit dieser Tatsache nicht erlauben. " Zur Wertschätzung Bernhards für Anneliese Botond vgl. Manfred Mittermayer: Thomas Bernhard. Eine Biografie. Salzburg, Wien: Residenz 2015, S. 147; Raimund Fellinger: Thomas Bernhard als Menschenfänger? In: Text + Kritik ( $\left.{ }^{4} 2016\right)$, H. 43, S. 7-9; sowie Bernhards Brief an Unseld, 11. 5. 1969. In: Bernhard/Unseld: Der Briefwechsel (Anm. 16), S. 110: „Meine Lektorin A. B. ist der Pfahl, an den ich Schaf mich gern, meine ganze Schriftstellerei, anbinde."Vgl. auch die Ausführungen in Raimund Fellinger: Nachwort. In: Botond: Briefe an Thomas Bernhard (Anm. 44), S. 193-200, bes. S. 197-200, der Botonds Rolle als Vermittlerin 
In seiner unmittelbaren Antwort auf Unselds Beschwichtigung gab Bernhard sich noch souverän: Zwar gebe es, so Bernhards apodiktische Feststellung am 18. Mai 1967, „überhaupt nur dumme, darunter aber verheerend ganz dumme Kritiker", aber er lasse sich von den negativen Rezensionen seines nach dem Debüt Frost (1963) zweiten, erneut im Insel Verlag erschienenen Romans mit Sicherheit „nicht irritieren“, sondern werde vielmehr „arbeiten, nichts als arbeiten und mein lebenslängliches Vergnügen daran haben“: „Ich finde, die Kritiker, ob dumm oder nicht, haben sich von meinem Buch aufregen lassen, das ist der Sinn eines solchen Buches. “46

Umso mehr sorgte Bernhards Replik, in der er Eisenreichs „Urwald“-Vorwurf in verknappter Form gegen den Kritiker wendet und einen „Schimpansen oder Maulaffen“ für eine zukünftige Rezensionstätigkeit im Spiegel vorschlägt, für Irritationen bei seinem Verleger: Noch am Tag der Publikation des Leserbriefs forderte Unseld Bernhard nachdrücklich auf, angesichts von kritischen Reaktionen auf seine Bücher Contenance zu bewahren - ein fürsorglicher Hinweis, der zweifellos auch im Sinne des Suhrkamp'schen Credos, nicht bloß Bücher, sondern Autoren zu verlegen ${ }^{47}$ und dabei deren öffentliches Auftreten in die verlagsseitige Werkpolitik einzukalkulieren, zu verstehen ist: „Bitte, reagieren Sie in der Öffentlichkeit nicht auf die Kritik, die an Ihnen geübt wird. Ihr ,Spiegel'-Brief könnte wie ein Bumerang auf Sie zurückschlagen. Man darf so nicht reagieren und muß seinen Übermut bezähmen. “ ${ }^{48}$ Szenen einer solchen verlegerischen Appeasement-Politik sollten sich in der Folge regelmäßig wiederholen, etwa in Unselds diplomatischem Beschwichtigungsbrief nach der skandalträchtigen Verleihung des Österreichischen Staatspreises im März 1968, in dem er seinem Autor nahelegte, „zunächst überhaupt keine Notiz von der Sache [zu] nehmen“, um die Fronten nicht weiter zu verhärten:

zwischen Autor und Verleger hervorhebt: „Den Spagat, den ein Lektor aus prinzipiellen Gründen zu meistern hat zwischen der Loyalität zum Verlag und der Loyalität zum Autor, gab Botond auf zugunsten letzterem, ohne illoyal Position gegenüber dem Verleger Siegfried Unseld zu beziehen - eine Artistik, möglich allein durch ständige intellektuelle und psychische Anspannung.“ (Ebd., S. 199) Ohne dass ihr Name genannt wird, findet Botond auch in Bernhards Meine Preise als Helferin in finanzieller Not Erwähnung (vgl. TBW 22.2, 377 f.).

Bernhard an Unseld, 18. 5. 1967. In: Bernhard/Unseld: Der Briefwechsel (Anm. 16), S. 56.

So „beschränkte sich der Suhrkamp-Verlag nicht auf die Publikation einzelner Bücher, sondern beanspruchte die ,Gesamtphysiognomie eines Schriftstellers zu präsentieren - durch sukzessive Veröffentlichung aller Bücher dieses Schriftstellers, die zumeist durch preiswerte Taschenbuchausgaben einem breiten Publikum zugänglich gemacht wurden und durch kompakte Werkausgaben für die wissenschaftliche Rezeption zugänglich blieben. " (Lorenz: Die Öffentlichkeit der Literatur [Anm. 26], S. 45) Vgl. dazu Siegfried Unseld: Die Aufgaben des literarischen Verlegers. In: S. U.: Der Autor und sein Verleger. Vorlesungen in Mainz und Austin. Frankfurt a. M.: Suhrkamp 1978, S. 9-64, bes. S. 36.

Unseld an Bernhard, 29.5.1967. In: Bernhard/Unseld: Der Briefwechsel (Anm. 16), S. 57 f. 
Das moralische Recht für Ihre Rede ist ganz auf Ihrer Seite, und ich stehe hier hinter Ihnen. Sie sollen aber nicht verkennen, daß Sie mit Ihrer Rede Gefühle anderer verletzt haben. [...] Also, seien Sie stark, ziehen Sie sich auf sich selbst zurück, schreiben Sie das Buch. Alles andere ist unwichtig. ${ }^{49}$

\section{„Über diesen Roman wären nicht so viele böse Worte zu verlieren ...“: Handkes Hornissen nach Princeton}

Bereits ein Jahr zuvor hatte der Verleger mit Peter Handke eine vergleichbare Diskussion geführt: Als der Autor sich am 22. März 1966 bei Siegfried Unseld für die Zusendung der ersten Besprechung zu seinem Debütroman Die Hornissen bedankt, zeigt er sich auch von deren stilistischer Qualität angetan: „Die Kritik in der ,FAZ“ hat mir sehr gefallen, sie ist, glaube ich, auch gut geschrieben. “ ${ }^{\text {“ }}$ Tatsächlich schien Helmut Scheffels Rezension in der Frankfurter Allgemeinen Zeitung vom 15. März 1966 einen vielversprechenden Auftakt für Handkes Wahrnehmung als neuer Suhrkamp-Autor im deutschen Feuilleton zu bilden, positionierte der Kritiker Handkes Roman doch nicht nur als legitimen Erben einer innovatorischen Kunsttradition, sondern attestierte ihm darüber hinaus eine nachgerade wegweisende Funktion für die aktuelle Entwicklung der Literatur: Der Roman sei zwar, so Scheffel, der schon 1959 Roland Barthes' Le degré zéro de l'écriture für den Hamburger Claassen Verlag ins Deutsche übersetzt hatte $^{51}$ und mit den literarischen und literaturtheoretischen Debatten der Zeit vertraut war,

49 Unseld an Bernhard, 18. 3. 1968. In: ebd., S. 71 f. Zur Kontroverse Bernhard/Eisenreich vgl. auch: Sehr geschätzte Redaktion (Anm. 36), S. 21-25.

50 Handke an Unseld, 22.3. 1966. In: Handke/Unseld: Der Briefwechsel (Anm. 16), S. 32. - Noch Mitte der 1970er Jahre erinnerte sich Handke im Gespräch mit Manfred Durzak mit Wohlwollen an diese erste wertschätzende Analyse seines Debütromans. Vgl. Manfred Durzak: Für mich ist Literatur auch eine Lebenshaltung. Gespräch mit Peter Handke. [1973] In: M. D.: Gespräch über den Roman. Formbestimmungen und Analysen. Frankfurt a. M.: Suhrkamp 1976, S. 314-343, hier S. 316; dazu Adolf Haslinger: Peter Handke. Jugend eines Schriftstellers. Salzburg, Wien: Residenz 1992, S. 106, der „die erste Kritik von Helmut Scheffel“ als „eine der sachlichsten und besten zu diesem Roman“ einordnet.

51 Vgl. Roland Barthes: Am Nullpunkt der Literatur. Objektive Literatur. Aus dem Französischen v. Helmut Scheffel. Hamburg: Claassen 1959. Vgl. zu Scheffels Rolle für die Rezeption des Strukturalismus und des nouveau roman in Deutschland Clemens Özelt: Klangräume bei Peter Handke. Versuch einer polyperspektivischen Motivforschung. Wien: Braumüller 2012, S. 87: „Scheffel war [...] durch seine Übersetzungen von Robbe-Grillets erzähltheoretischen Arbeiten, Roland Barthes [sic] Am Nullpunkt der Literatur und zahlreichen Texten von Michel Butor bereits 1966 soweit mit den Problemen, Fragestellungen und Perspektiven des Nouveau Roman vertraut, um Handkes Auseinandersetzungen entsprechend würdigen zu können.“ 
keine ganz leichte Lektüre, aber eine lohnende. So wie es sich gelohnt hat, unsere Sehweise beim Betrachten von Bildern seit einer Reihe von Jahrzehnten zu ändern und neu einzuüben. Ein Roman, der uns als erkennende Wesen in Frage stellt, ein Autor, der weiß, worauf es ankommt, und der Grundlagenforschung betreibt. Man vertraue sich ihm an. ${ }^{52}$

Das Buch, dem Scheffel einen „weit über dem Durchschnitt liegenden Rang“, besonders ,in der Nutzung sprachlicher Möglichkeiten“, bescheinigt ${ }^{53}$ war zum Zeitpunkt der Rezension noch gar nicht in den Buchhandlungen erhältlich; erst am nächsten Tag berichtet Unseld seinem Autor von „ersten Bindemuster[n]“ der Hornissen und „letzte[n] Änderungen, die die Farbe des Rückenschildes und des Kopfschnitts betrafen“" ${ }^{54}$ Dem Brief vom 16. März 1966 legte Unseld bereits Scheffels "gute Besprechung" bei und bestätigte außerdem die Einladung Handkes zum Treffen der Gruppe 47 in Princeton. Er habe Hans Werner Richter, den spiritus rector der Gruppe, gebeten, den Suhrkamp-Debütanten in die USA einzuladen: „Hoffentlich können Sie es einrichten, es wäre sehr schön, wenn wir

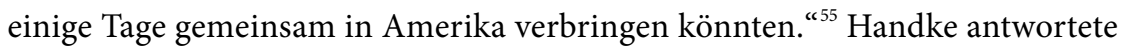
umgehend, zeigte sich mit Blick auf die künftige kritische „Reaktion“ auf das eben erschienene Buch zuversichtlich und dankte Unseld herzlich dafür, die Einladung nach Princeton in die Wege geleitet zu haben: „Ich werde alles daran setzen, daß ich kommen kann. Ich glaube, es ist fast sicher. Ich freue mich sehr auf diese Reise, ich war noch nie in den Vereinigten Staaten. ${ }^{\text {“56 }}$

Alle folgenden, erst knapp zwei Monate später einsetzenden Besprechungen der Hornissen erschienen bereits unter dem Eindruck jenes vielbeachteten Auftritts in Princeton vom April 1966, der das Image des Autors im Feuilleton nachhaltig prägen und damit auch Rezeption und Rezensionspraxis seiner literarischen Werke nur zu deutlich beeinflussen sollte, wie Handke 1973 im Rückblick beklagt hat: „Nur bei der Rezension in der FAZ war nur das Buch da und der Autor noch nicht. Bei allen andern Rezensionen dieses ersten Buches wurde die

52 Helmut Scheffel: An der Erfahrungsgrenze. Die Hornissen - Der erste Roman von Peter Handke. In: Frankfurter Allgemeine Zeitung, 15.3.1966.

53 Ebd. Zu Scheffels Rezension vgl. auch Christel Terhorst: Peter Handke. Die Entstehung literarischen Ruhms. Die Bedeutung der literarischen Tageskritik für die Rezeption des frühen Peter Handke. Frankfurt a. M. u. a.: Lang 1990, S. 44-46. - In seinem letzten Rundfunk-Feuilleton für Radio Steiermark würdigte Handke im September 1966 den von Scheffel aus dem Französischen übertragenen Band Zeit und Raum bei Marcel Proust von Georges Poulet (vgl. Peter Handke: „Bücherecke“ vom 12.9.1966. In: P. H.: Tage und Werke (Anm. 31), S. 281-283, hier S. $282 \mathrm{f}$.).

54 Unseld an Handke, 16.3. 1966. In: Handke/Unseld: Der Briefwechsel (Anm. 16), S. 31.

55 Ebd., S. $31 \mathrm{f}$.

56 Handke an Unseld, 22.3.1966. In: ebd., S. 33. 
Geschichte von Princeton ausführlich dagegen gehalten, ausgespielt. ${ }^{457}$ In einem offenen Brief an Günter Grass, im Oktober 1966 in der Münchner Abend-Zeitung veröffentlicht, hat Handke selbst die Einschätzung formuliert, dass seine provokante Intervention vor der versammelten Riege der deutschen Literaturkritiker der „Beurteilung meiner Arbeiten nur geschadet" habe, was er freilich nicht auf eine verfehlte, Öffentlichkeitsarbeit 'seinerseits, sondern zuallererst auf einen „Mangel an Differenzierung" aufseiten der „Kritiker" zurückführt. $^{58}$

Tatsächlich kam ab Mai 1966 kaum eine Besprechung seines Debütromans ohne einen Hinweis auf Handkes Einmischung bei der ersten Jahrestagung der Gruppe 47 in den Vereinigten Staaten aus: „Den Rezensenten [...] stand Peter Handkes Princeton-Auftritt farbiger vor Augen als der Roman“, so Adolf Haslinger; „es gelang ihnen nicht, sich bei der Lektüre des Werks vom Medien-

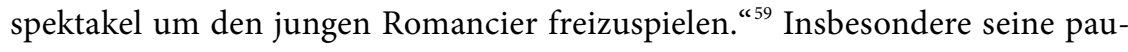
schale Polemik gegen die ,Beschreibungsimpotenz' der zeitgenössischen Literatur wurde in zahlreichen Besprechungen der Hornissen aufgegriffen und gegen Handkes Roman in Stellung gebracht, dem man nun umso nachdrücklicher eigene erzählerische Schwächen und Langatmigkeit attestierte. Verhalf die Aufmerksamkeit, die ihm ob des rasch mythisierten Verstoßes gegen die Gruppenregeln zuteilwurde, Handke einerseits zu einer außergewöhnlichen publizistischen Resonanz,

57 Durzak/Handke: Für mich ist Literatur auch eine Lebenshaltung (Anm. 50), S. 316. Vgl. dazu Lorenz: Pro domo (Anm. 28), S. 409 f.; Georg Pichler: Die Beschreibung des Glücks. Peter Handke. Eine Biografie. Wien: Ueberreuter 2002, S. 66 f.; ebenso Hans Höller: Peter Handke. Reinbek b. Hamburg: Rowohlt 2007, S. 32: „Die Kritik hat sich zunächst wenig für den Roman interessiert. Erst nach Handkes, Auftritt' in Princeton wurde er in vielen Zeitungen besprochen. Der Tenor der Rezensionen: Sprachexperiment, formal überanstrengt.“

Peter Handke: Bitte kein Pathos! In: Abend-Zeitung, 22./23.10.1966. Adolf Haslinger: „Achtung, Hornissen!“ Zu Peter Handkes früher Prosa. In: Peter Handke. Die Langsamkeit der Welt. Hg. v. Gerhard Fuchs u. Gerhard Melzer. Graz, Wien: Droschl 1993, S. 95-113, hier S. 108; vgl. Terhorst: Die Entstehung literarischen Ruhms (Anm. 53), S. 39 f. u. 46-48. Dazu auch Garvin H. C. Perram: Peter Handke. The Dynamics of the Poetics and the Early Narrative Prose. Frankfurt a. M. u. a.: Lang 1992, S. 87: „It would seem that much of the early critical response to Peter Handke's works was in itself more a response to Handke's statements on literature at the Princeton conference than an objective response to the works themselves.“ - Vgl. z. B. Josef Laßl: Das Zucken der leblosen Dinge. In: Oberösterreichische Nachrichten, 14. 5. 1966; Lütge: Nein zu Handke (Anm. 21); Hasselblatt: Was man heute Literatur nennt (Anm. 19); Jakov Lind: Zarte Seelen, trockene Texte. In: Der Spiegel, Nr. 29, 11. 7. 1966, S. 79; Helga Meister: Enttäuschte Erwartungen. In: Düsseldorfer Nachrichten, 1. 10. 1966. - Zehn Jahre später hat Rolf Michaelis: Ohrfeigen für das Lieblingskind. Peter Handke und seine Kritiker. Eine Beispielsammlung. In: Text + Kritik ( $\left.{ }^{3} 1976\right)$, H. 24/24a, S. 80-96, hier S. 82, konstatiert, dass ,auch heute noch Kritiker mit der fast immer böswillig ironischen Erinnerung an jene Szene beginnen“, und sich ausgehend davon die Frage gestellt, „auf welchem Niveau sich die dichtungswissenschaftliche oder nur journalistische Beurteilung literarischer Texte hierzulande bewegt". 
die durch die Premiere der Publikumsbeschimpfung noch verstärkt wurde, führte sie andererseits dazu, dass die literarische Faktur der Hornissen, etwa ihr spezifischer Einsatz in der Diskussion um den ,Neuen Realismus', tendenziell weniger intensiv beachtet wurde. Während der Princetoner „Mediencoup “60 und seine Nachwehen ganz wesentlich zur plötzlichen Prominenz Handkes beitrugen - und er diesen Rückenwind durchaus für sich zu nutzen verstand -, standen sie der unvoreingenommenen Rezeption seiner literarischen Arbeiten zugleich im Weg. ${ }^{61}$

Seine Publicity geriet dem jungen Schriftsteller dabei schnell zum Vorwurf: „Über diesen Roman wären“, so Hellmuth Karaseks exemplarische Einschätzung im Feuilleton der Süddeutschen Zeitung,

nicht so viele böse Worte zu verlieren, gälte der Autor nicht seit seinem Auftritt in Princeton bei der Gruppe 47 als eine Art Jung-Siegfried, der den Drachen einer Erzählmaschine, die nichts zu sagen habe, mutig (wenn auch wenig artikuliert) zum Zweikampf herausforderte. Nach der Lektüre der ,Hornissen` weiß man wenigstens, daß Handke mit exakt den gleichen Waffen kämpft, wie diejenigen Erzähler, bei deren Prosa ihm zu Recht der Kragen platzte. Handke hat sich in Princeton in das eigene Hornissennest gesetzt. ${ }^{62}$

Ganz ähnlich argumentierten andere prominente Literaturjournalisten in Deutschland, etwa Fritz J. Raddatz, der Handke in den Frankfurter Heften bescheinigte, dass sein „kritischer Anspruch“, den er in Princeton wortmächtig formuliert habe, „leider durch seine eigene literarische pop-Collage nicht erfüllt werde“; der Roman Die Hornissen strande „an haargenau jenem Riff“, „das Handke nun als so gefährlich charakterisierte: eine bloße Deskriptionsprosa, kühl dargeboten, vertrauend darauf, daß die Phänomene sich selber erklären “. ${ }^{63}$ Der Debütant hatte in seinem vielzitierten Statement nach Hermann Peter Piwitts Lesung von einer Krise der „deutschen Prosa“ gesprochen, die ihr „Heil“ gegenwärtig „in einer bloßen Beschreibung“ suche und dabei eine veritable „Beschreibungsimpotenz“

60 Heribert Tommek: Der lange Weg in die Gegenwartsliteratur. Studien zur Geschichte des literarischen Feldes in Deutschland von 1960 bis 2000 . Berlin, Boston: de Gruyter 2015, S. 133.

61 In seiner Ökonomie der Aufmerksamkeit hat Georg Franck sich ausführlich mit dem problematischen Verhältnis zwischen Qualität und Quantität von Aufmerksamkeit beschäftigt - etwa damit, „daß es bei der Beachtung, die bezogen wird, nicht gleichgültig ist, von wem sie kommt“ (Georg Franck: Ökonomie der Aufmerksamkeit. Ein Entwurf. München, Wien: Hanser 1998, S. 116). Vgl. auch ebd., S. 79-84 u. 121-126 sowie zur „Selektivität im Umgang mit empfangener Aufmerksamkeit“S. 217 f.

62 Hellmuth Karasek: Handke, wo ist dein Stachel? In: Süddeutsche Zeitung, 25./26. 6. 1966.

63 Fritz J. Raddatz: Die Bilanz von Princeton. [1966] In: Die Gruppe 47. Bericht - Kritik - Polemik. Ein Handbuch. Hg. v. Reinhard Lettau. Neuwied, Berlin: Luchterhand 1967, S. 241-247, hier S. $244 \mathrm{f}$. 
offenbare $;{ }^{64}$ nun wurde ihm dieser Vorwurf von vielen Kritikern postwendend zurückgereicht. Er habe sich, so der Tenor zahlreicher Kommentare im Frühjahr 1966, in den Hornissen gerade jener Verfehlungen schuldig gemacht, die er in Princeton so vehement und pauschal kritisierte.

Bereits eine Woche vor Karaseks Rezension in der Süddeutschen Zeitung hatte sich Handke mit der dringlichen Frage an Unseld gewandt, was „man“ gegen die seiner Einschätzung nach „unsensibel, unintelligent, gehässig geschriebenen Kritiken“ seines Buches „unternehmen könnte“; denn er lasse sich „Schwächen“ nur in jenen Fällen „gern nachsagen“, „wenn sich die Besprechung dem Niveau meines Buches anpaßt ${ }^{\text {“65 }}$ - ein Kriterium, das Handke in vielen Rezensionen seines Debüts offensichtlich nicht erfüllt sah. Schon in seinem Princetoner Statement, das im Gefolge von Erich Kubys großer Spiegel-Story zum Literaturbetriebsereignis stilisiert werden sollte, ${ }^{66}$ attestierte Handke den Literaturkritikern der Gruppe 47, mit einem „überkommene[n] Instrumentarium“ zu hantieren, das sich bestenfalls noch zur Erschließung ästhetisch konventioneller Texte eigne:

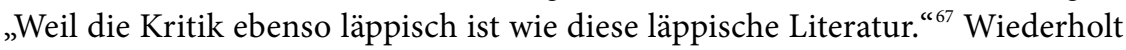
von Gelächter und Zwischenrufen unterbrochen und wohl nicht zuletzt deshalb eher tastend als selbstbewusst sprechend, ${ }^{68}$ formulierte Handke zunächst recht

64 Im Wortlaut: Peter Handkes, Auftritt` in Princeton und Hans Mayers Entgegnung. In: Text + Kritik ( $\left.{ }^{5} 1989\right)$, H. 24, S. 17-20, hier S. 17.

65 Handke an Unseld, 20. 6. 1966. In: Handke/Unseld: Der Briefwechsel (Anm. 16), S. 34. - 1968 hat Martin Walser in einer Reflexion über die Tätigkeit des Kritikers dies ähnlich pointiert formuliert: „Schließlich möchte man in der Beschreibung der eigenen Mängel wenigstens das Niveau gewahrt sehen, auf dem man diese Mängel selbst zur Schau stellte." (Martin Walser: Tagtraum, daß der Kritiker ein Schriftsteller sei. In: Kritik - von wem / für wen / wie. Eine Selbstdarstellung deutscher Kritiker. Hg. v. Peter Hamm. München: Hanser 1968, S. 11-14, hier S. 11)

66 Vgl. Erich Kuby: Ach ja, da liest ja einer. In: Der Spiegel, Nr. 19, 12. 5. 1966, S. 154-165. Handke antwortete mit einem satirischen Leserbrief. Vgl. Peter Handke: Pantoffeln. In: Der Spiegel, Nr. 22, 23. 5. 1966.

67 Handke: Im Wortlaut (Anm. 64), S. 18. Vgl. Terhorst: Die Entstehung literarischen Ruhms (Anm. 53), S. 11: „Handke opponierte nicht allein gegen die vorgetragene Literatur, sondern auch gegen die Art von Kritik, wie sie von professioneller Seite während der Tagung geäußert wurde."

68 Vgl. Karl Wagner: Handke und die Gruppe 47. In: Zwischen Aufbegehren und Anpassung. Poetische Figurationen von Generationen und Generationserfahrungen in der österreichischen Literatur. Hg. v. Joanna Drynda. Frankfurt a. M. u. a.: Lang 2012, S. 121-132, hier S. 125, sowie Helmut Böttiger: Nach den Utopien. Eine Geschichte der deutschsprachigen Gegenwartsliteratur. Wien: Zsolnay 2004, S. 48 f.: „Die Stimme war schütter, manchmal drohte sie gar zu versagen, und anfangs stotterte und stocherte es [sic] zwischen den eigentlich äußerst geharnischten Aussagen herum. “ - Der Mitschnitt der Lesungen und der anschließenden Diskussionen ist auf der Website des Department of German an der Princeton University verfügbar; vgl. https://german.princeton.edu/department/about/resources/gruppe-47-recordings (Stand 
allgemeine, für viele offenbar nicht eindeutig zuordenbare Einwände gegen eine „ganz, ganz unschöpferische Periode in der deutschen Literatur“. ${ }^{69}$ In der Folge setzt er die diagnostizierte Konventionalität und die fehlende innovative Potenz der Gegenwartsliteratur mit der intellektuellen Trägheit der Literaturkritik in Beziehung. Tauche nämlich „eine neue Sprachgestik“ im Feld der Literatur auf, reagiere die Kritik reflexhaft mit „Beschimpfungen“ und dem Vorwurf der ,Langweiligkeit‘ oder gehe lediglich „auf gewisse einzelne Sprachschwächen“ ein, „die sicher noch vorhanden sein werden“ ${ }^{70}$ Eine eingehende und vorurteilsfreie Prüfung neuer Textverfahren und avancierter Zugänge finde jedoch nicht statt, während Altbekanntes mit bewährten Maßstäben gemessen werde.

Handke skizziert ein Klima der Innovations- und Experimentierfeindlichkeit, an dem die kritischen Instanzen und meinungsbildenden Foren der literarischen Öffentlichkeit eine Mitschuld trügen. Vor Hans Werner Richters erstem Ordnungsruf, es sei „hier nicht üblich“, „eine literarhistorische Rede“ zu halten, betont er noch einmal explizit die doppelte Adressierung seines Einspruchs: „Das Instrumentarium der Kritik ist genau dieser Literatur adäquat, die hier im Vorgang ist. ${ }^{\text {“71 }}$ Handkes Princetoner Intervention gegen die ,Beschreibungsimpotenz' forderte folglich nicht nur die zeitgenössischen Autoren und ihr Verständnis von Literatur heraus, ${ }^{72}$ sondern auch und im Besonderen die vor Ort anwesenden und die Diskussionen dominierenden Kritiker. ${ }^{73}$ Als Volte gegen deren begriffliches und methodisch-theoretisches „Instrumentarium“ konzipiert, die die „Literaturkritik als veraltet verhöhnt" ${ }^{\text {74 }}$ stellten Handkes pointierte Äußerungen eine ,Provokation der Kritik‘ in einem doppelten Sinne dar: einerseits als gezielte Infragestellung der textanalytischen Kompetenz der etablierten Instanzen

14. 10. 2020); die bislang ausführlichste Interpretation der Tonbandaufnahmen hat Jörg Döring: Peter Handke beschimpft die Gruppe 47. Siegen: universi 2019, bes. S. 59 ff., vorgelegt.

Handke: Im Wortlaut (Anm. 64), S. 17.

Ebd., S. 18 .

71 Ebd.

72 Dass sich Handkes Angriff weniger gegen etablierte Gruppe-47-Autoren wie Günter Grass richtete, sondern zuallererst gegen die (vergleichsweise jungen) Verfechter eines, Neuen Realismus im Umkreis der ,Kölner Gruppe (Dieter Wellershoff, Nicolas Born u. a.), hat Estermann: Vom „bloß sprachlichen“ zu einem „allumfassenden Realismus“ (Anm. 30), bes. S. 98 f., gezeigt.

73 Vgl. Lorenz: Pro domo (Anm. 28), S. 408; Werner Graf: Peter Handke und seine Kritiker. Zu Motiven der Rezeption von Gegenwartsliteratur. In: Literatur für Leser 27 (2004), H. 2, S. 89-101, bes. S. 100; Norbert Christian Wolf: Autonomie und/oder Aufmerksamkeit? Am Beispiel der medialen Erregungen um Peter Handke, mit einem Seitenblick auf Marcel Reich-Ranicki. In: Mediale Erregungen? Autonomie und Aufmerksamkeit im Literatur- und Kulturbetrieb der Gegenwart. Hg. v. Markus Joch, York-Gothart Mix u. N. C. W. Tübingen: Niemeyer 20o9, S. $45-63$, hier S. 50 f.

74 Gabriele Feulner: Mythos Künstler. Konstruktionen und Dekonstruktionen in der deutschsprachigen Prosa des 20. Jahrhunderts. Berlin: Erich Schmidt 2010, S. 223. 
der Gruppe 47, andererseits als öffentlich geführte Attacke, die zwangsläufig eine Reaktion vonseiten der angegriffenen Kritiker herausforderte. ${ }^{75}$

Es liegt also durchaus nahe, Handkes Diktum von der ,Beschreibungsimpotenz' nicht nur auf die Verwendung literarischer Verfahren im Kontext eines terminologisch umkämpften ,Neuen Realismus' zu beziehen, ${ }^{76}$ sondern auch auf die mangelnde Fähigkeit der attackierten Kritiker, diese Verfahren vorurteilsfrei und mit adäquaten Mitteln zu beschreiben - gerade in jener (aus dem Rückblick) finalen Phase der Gruppe 47, in der die Riege der ,Berufskritiker zunehmend an Einfluss und medialer Aufmerksamkeit gewonnen hatte:

From the early 1950 os on, professional critics became quasi group members, ultimately including critic-celebrities such as Marcel Reich-Ranicki, Fritz Raddatz, Hans Mayer, and Walter Jens. [...] Some members bemoaned the invitation of professional critics, because their presence put an end to the intimate workshop atmosphere. ${ }^{77}$

Hatten Walter Jens und der spätere „Professor-Autor-Dichter ${ }^{\text {“78 }}$ Walter Höllerer sich zu Beginn ihrer Partizipation noch vor allem als literarische Autoren verstanden, entwickelte sich spätestens mit der regelmäßigen Einladung von Joachim Kaiser, Marcel Reich-Ranicki und Hans Mayer Ende der 1950er Jahre eine zunehmend mächtige Kritiker-Fraktion innerhalb der Gruppe 47 heraus. ${ }^{79}$ Während dieses vergleichsweise kleine ,Lager', zu dem etwa noch Reinhard Baumgart und Fritz J. Raddatz zu zählen sind, immer mehr die Diskussionen im Anschluss an die Lesungen dominierte, brachten sich die Autoren selbst zusehends seltener in die Gespräche ein: ${ }^{80}$ „Hat die Kritik in der Gruppe zunächst den Charakter

75 Vgl. dazu auch die Notiz zu Handke im Tagungsbericht von Dieter E. Zimmer: Gruppe 47 in Princeton. In: DIE ZEIT, Nr. 19, 6. 5. 1966: „Es war ein Aufstand gegen so gut wie alles, was sich an Literatur und Kritik auf dieser Tagung präsentiert hatte, nicht sehr artikuliert zwar, selber Geschimpf, doch radikal gemeint."

76 Vgl. dazu Rolf G. Renner: Peter Handke. Stuttgart: Metzler 1985, S. 25, sowie ausführlich Estermann: Vom „bloß sprachlichen“ zu einem „allumfassenden Realismus“(Anm. 30), S. 97-102.

77 Kristin Rebien: Gruppe 47: Literature, politics, and the political economy of postwar publishing. In: German Life and Letters 62 (2009), H. 4, S. 448-464, hier S. 459. Vgl. auch Jörg Magenau: Princeton 66. Die abenteuerliche Reise der Gruppe 47. Stuttgart: Klett-Cotta 2016, S. 125 f., sowie die Erinnerungen von Reinhard Baumgart: Damals. Ein Leben in Deutschland. 1929-2003. [München]: Hanser 2003, S. 230, der vom „Vorherrschen der eloquent virtuosen Profikritik, nach jeder Lesung zelebriert vor allem vom Quintett Jens, Kaiser, Höllerer, Reich-Ranicki und Hans Mayer", schreibt.

78 Friedrich Christian Delius: Als die Bücher noch geholfen haben. Biografische Skizzen. Berlin: Rowohlt 2012, S. 46.

79 Vgl. Helmut Böttiger: Die Gruppe 47. Als die deutsche Literatur Geschichte schrieb. München: DVA 2012, S. $265 \mathrm{f}$.

80 Vgl. ebd., S. 272; Rebien: Gruppe 47 (Anm. 77), S. 459. 
von Werkstattgesprächen, in denen sich die Autoren gegenseitig zu helfen versuchen, so erhält sie durch diese Kritiker zunehmend Merkmale einer richtenden Instanz. " ${ }^{81}$ Zahlreiche Autoren äußerten angesichts dieser Entwicklung ihren Unmut über die Herrschaft der „Kritiker der ersten Reihe“; ${ }^{82}$ Hubert Fichte schlug im November 1964 Hans Werner Richter gar ein eigenes Treffen als ausgewiesene „Tagung der Kritik“ vor, bei der die Kriterien der Kritiker auf dem Prüfstand stehen müssten: „Es würde hart zugehen - aber es wäre eine Wohltat für den deutschen literarischen Betrieb und würde vielleicht vermeiden, daß die Hohlheit weiteren Raum gewinnt. “83

Für Handke, der sich schon 1964 bis 1966 in Rundfunkfeuilletons für das Landesstudio Steiermark parallel zur eigenen schriftstellerischen Arbeit einer kritischen Sichtung jeweils aktueller literarischer wie theoretischer Positionen gewidmet hatte, führte die beschriebene Entwicklung außerdem zu einer im Grunde unzulässigen und unfruchtbaren Arbeitsteilung zwischen Schriftstellern und professionellen Kritikern, wie sie - freilich unter ganz anderen ideologischen und literaturtheoretischen Prämissen - Georg Lukács Ende der 193oer Jahre als Symptom kapitalistischer Logiken im Literaturbetrieb beschrieben hatte. ${ }^{84}$ In seiner im Anschluss an die Tagung publizierten Rückschau auf die Ereignisse hat Handke betont, die Gruppe 47 zwar „wenig“ gekannt zu haben, jedoch „neugierig

81 Oliver Pfohlmann: Literaturkritik in der Bundesrepublik. In: Literaturkritik. Geschichte Theorie - Praxis. Hg. v. Thomas Anz u. Rainer Baasner. München: C. H. Beck ${ }^{4} 2007$, S. 160-191, hier S. 163. Vgl. ebd., S. 168. Handke hat fast 50 Jahre später in einem Gespräch mit Julia Encke die Kommunikationssituation zwischen Autoren und Kritikern bei den Treffen der Gruppe 47 folgendermaßen beschrieben: „Und wie die erste Reihe, wo die Kritiker saßen, mit diesen Autoren umgegangen ist, das hat mich empört. Das ging doch nicht, dass man sie heruntermachte und mit ihnen redete als wären sie Schulbuben. Ich habe es verachtet, wie Reich-Ranicki und Walter Jens da ihre Schnöseleien brüllten.“ (Julia Encke: Schimpfen ist ein Ausdruck von Hilflosigkeit. [Gespräch mit Peter Handke.] In: Frankfurter Allgemeine Sonntagszeitung, Nr. 41, 11. 10. 2015, S. 53) Vgl. dazu auch Handkes Äußerung im Gespräch mit seinem Biographen Malte Herwig: „Wie können diese drei Leute, die zumindest ich verehrt hab damals - Grass, Johnson, Weiß [sic] -, wie können die sich von diesen Jammergestalten wie dem Reich-Ranicki, der kräht und schreit und die Menschen niedermacht ..." (Malte Herwig: Meister der Dämmerung. Peter Handke. Eine Biographie. München: DVA ²010, S. 143).

82 Delius: Als die Bücher noch geholfen haben (Anm. 78), S. 36.

83 Hubert Fichte an Hans Werner Richter, 8. 11. 1964. In: H. W. R.: Briefe. Hg. v. Sabine Cofalla im Auftrag der Stiftung Preußische Seehandlung und der Textkritischen Arbeitsstelle der Freien Universität Berlin. München: Hanser 1997, S. 538.

84 Vgl. Georg Lukács: Schriftsteller und Kritiker. [1939] In: G. L.: Schriften zur Literatursoziologie. Hg. v. Heinz Maus u. Friedrich Fürstenberg. Neuwied, Berlin: Luchterhand 41970, S. 198-212, bes. S. 198 f. - Varianten dieser Deutung finden sich in den zeitgenössischen Debatten etwa bei Peter Hamm: Der Großkritiker. Literaturkritik als Anachronismus. In: Kritik - von wem / für wen / wie (Anm. 65), S. 20-39, hier S. 20: „Hinter all dem steht das Problem der kapitalistischen Arbeitsteilung, die auch aus den Schriftstellern und Kritikern Spezialisten gemacht hat.“ 
auf die Lesungen in Princeton und noch neugieriger auf die Kritik der Lesungen“ gewesen zu sein. ${ }^{85}$ Tatsächlich bezieht Handke im Laufe seines Essays - zunächst unter dem plakativeren Titel Beschreibungsimpotenz in der Zeitschrift konkret gedruckt, die dem politisch linken Spektrum zuzurechnen war - wiederholt die Instanz der Literaturkritik in seine Formulierung eines Ungenügens mit ein: So würden nicht nur in einer „neu aufkommenden Art von Literatur [...] Dinge beschrieben, ohne daß man über die Sprache nachdenkt" ${ }^{\text {"86 }}$ auch die Kritik sei nicht in der Lage, die von Handke geforderte, theoretisch informierte Reflexion über die Zusammenhänge von Sprache und ,Wirklichkeit', ja von signifié und signifiant im Sinne de Saussures zu leisten:

Es wird vernachlässigt, daß die Welt nicht nur aus den Gegenständen besteht, sondern auch aus der Sprache für diese Gegenstände. [...] Anstatt so zu tun, als könnte man durch die Sprache schauen wie durch eine Fensterscheibe, sollte man die tückische Sprache selber durchschauen und, wenn man sie durchschaut hat, zeigen, wie viele Dinge mit der Sprache gedeht [sic] werden können. Diese stilistische Aufgabe wäre durchaus, dadurch, daß sie aufzeigte, auch eine gesellschaftliche. / In Princeton nun mußte ich hören, wie sehr das sogenannte gesellschaftliche Engagement des Schriftstellers von den Kritikern in der Gruppe 47 an den Objekten gemessen wurde, die er beschreibt, und nicht an der Sprache, mit der er diese Objekte beschreibt. ${ }^{87}$

In einem von Horst Ziermann herausgegebenen Dokumentationsband zu den Diskussionen um die Gruppe 47 wurde Handkes Polemik unter dem Titel Für eine neue Literatur kurz darauf erneut, aber deutlich gerafft abgedruckt; einige jener Passagen, die sich der Literaturkritik widmen, fielen dabei den Kürzungen zum Opfer. ${ }^{88}$ Als die Gruppe 47 im Oktober 1967 in der oberfränkischen Pulvermühle ihr letztes Treffen abhielt, begründete Handke seine Absage - Richter hatte ihn trotz seiner Skepsis gegenüber dem jungen Autor erneut eingeladen - ausdrücklich

85 Peter Handke: Zur Tagung der Gruppe 47 in USA. [1966] In: P. H.: Ich bin ein Bewohner des Elfenbeinturms. Frankfurt a. M.: Suhrkamp 1972, S. 29-34, hier S. 29; Erstdruck in konkret (Nr. 6, 1966) unter dem Titel Beschreibungsimpotenz. Zur Tagung der Gruppe 47 in USA.

86 Ebd., S. 29.

87 Ebd., S. 3o f. Vgl. zu diesem Aspekt im Kontext der Princetoner Tagung Magenau: Princeton 66 (Anm. 77), S. 142. - Gerhard Pfister: Handkes Mitspieler. Die literarische Kritik zu Der kurze Brief zum langen Abschied, Langsame Heimkehr, Das Spiel vom Fragen, Versuch über die Müdigkeit. Bern u. a.: Lang 2000, S. 287 f., hat mit Blick auf die literaturkritische Rezeption Handkes konstatiert, dass „[d]ie grösste Zahl der Kritiker [...] nach wie vor die Texte darauf hin [betrachte], was sie an Realität abbilden, nicht, wie sie Realität bilden.“ (Herv. H. G.)

88 Vgl. Peter Handke: Für eine neue Literatur. In: Gruppe 47. Die Polemik um die deutsche Gegenwartsliteratur. Eine Dokumentation. Hg. v. Horst Ziermann. Frankfurt a. M.: Wolter Editionen 1966, S. 51-54. 
damit, im Rahmen der Deutschen Theaterwoche in Stockholm „wieder den Reden einiger Kritiker zugehört“ zu haben: „Jetzt ist mir klar, daß ich einfach nicht zur Tagung kommen kann, obwohl ich doch ganz gern einige Leute getroffen hätte. ${ }^{\text {c }} 9$

Nun darf freilich nicht unterschlagen werden, dass Handke mit seinem öffentlich artikulierten Einspruch gegen die zeitgenössische Literaturkritik und seinem Zweifel an deren analytischem Instrumentarium im literarischen Feld der 196oer Jahre keineswegs auf einsamem Posten agierte. Ein verbreitetes „Unbehagen an Praxis und gesellschaftlicher Funktion der Kritik ${ }^{“ 90}$ war, wie einschlägige Debatten zeigen, bereits vor Handkes Polemik gegen die kritischen Instanzen der Gruppe 47 und das von ihnen repräsentierte literarische Establishment allenthalben festzustellen gewesen. ${ }^{91}$ Theodor W. Adorno hatte, wenngleich unter anderen historischen Prämissen, schon Anfang der 1950er Jahre einen „Verfall der literarischen Kritik“ beklagt, der ein Symptom des „zugleich desorganisierten und epigonalen Bewußtseinszustands" im postnazistischen Deutschland sei. ${ }^{92}$ Nun, ein gutes Jahrzehnt später, meldeten sich in Zeitschriften wie konkret und anderen alternativen Foren zahlreiche junge Autorinnen und Autoren in dieser Causa zu Wort und diagnostizierten im Zusammenhang eines engagiert-emanzipatorischen Verständnisses von Literatur diverse „Mängel der gegenwärtigen Literaturkritik“.93 Für das 1965 von Hans Magnus Enzensberger ins Leben gerufene Kursbuch etwa wurde in der programmatischen „Ankündigung einer Zeitschrift“ nicht nur eine grundlegende Offenheit für „neue[ ] Poesie und neue[ ] Prosa“ als Losung ausgegeben, sondern auch das Feld der Literaturkritik explizit thematisiert:

89 Peter Handke an Hans Werner Richter, 22. 9. 1967. In: Richter: Briefe (Anm. 83), S. 651, Anm. 2. $\mathrm{Zu}$ Handkes Rolle bei der Deutschen Theaterwoche Stockholm 1967 vgl. den Kommentar in Handke/Unseld: Der Briefwechsel (Anm. 16), S. 87, Anm. 1; zu Handkes Absage an Richter vgl. Böttiger: Die Gruppe 47 (Anm. 79), S. 409 f.

90 Pfohlmann: Literaturkritik in der Bundesrepublik (Anm. 81), S. 169.

91 Eine (zum Teil retrospektive) Übersicht über die Debatten bietet der folgende Band: Kritik der Literaturkritik. Hg. v. Olaf Schwencke. Stuttgart u. a.: Kohlhammer 1973, der aus dem im Frühjahr 1971 veranstalteten Kolloquium an der Evangelischen Akademie Loccum hervorging und bereits in den einleitenden Bemerkungen des Herausgebers von einer persistenten „Krise der Literaturkritik in Deutschland“ (ebd., S. 14) handelt. Der Band enthält zahlreiche Beiträge prominenter Kritiker, darunter Lothar Baier, Heinrich Vormweg und Klaus Stiller, aber - für das damalige intellektuelle Establishment durchaus bezeichnend - keinen einzigen Text einer Autorin, Literaturkritikerin oder Philologin.

92 Theodor W. Adorno: Zur Krisis der Literaturkritik. [1952/1953] In: T. W. A.: Noten zur Literatur. Hg. v. Rolf Tiedemann. Frankfurt a. M.: Suhrkamp 1981, S. 661-664, hier S. 661 u. 663. Zu Adornos Thesen vgl. Albrecht: Literaturkritik (Anm. 29), S. 86; Lorenz: Pro domo (Anm. 28), S. $403 \mathrm{f}$.

93 So der Titel eines einschlägigen Artikels von Peter Schneider: Die Mängel der gegenwärtigen Literaturkritik. In: Neue deutsche Hefte 12 (1965), H. 107, S. 98-123. Dazu auch Albrecht: Literaturkritik (Anm. 29), S. 90 f. 
Da das Kursbuch keine Beschränkung der Gegenstände, von denen es handelt, kennt, wird auch von Büchern darin die Rede sein. Die Zeitschrift versteht sich jedoch nicht als Vehikel für Rezensionen, die Noten verteilen wollen. Die üblichen literarischen Zwistigkeiten, denen kein anderes als ein rein lokales Interesse zukommt, können anderswo ausgetragen werden. ${ }^{94}$

Das ,Übliche“ wird an dieser Stelle ausdrücklich zum Problem, das herkömmliche und mit dem Ballast bildungsbürgerlich-selbstreferenzieller Gravität beladene Genre der ,Rezension' zum - in einem dezidiert progressiven publizistischen Forum - unerwünschten Ingrediens erklärt. Programmatiken wie diese können als Beispiel dafür dienen, dass - mit Daniela Strigl gesprochen - die Rede von der „Krise der Kritik“ mitunter Züge einer „Strategie“ trägt, „aus der der Kritiker der Kritik den Distinktionsgewinn eigener Überlegenheit bezieht “ 95

\section{Fronten, Verbündete, Kampfbegriffe}

Handkes polemische Intervention gegen die etablierte Literaturkritik, sein „Zweifel an der Leistungsfähigkeit der literarischen Tageskritik “96 ist folglich auch und gerade im Kontext einer Mitte der 196oer Jahre proliferierenden Diskussion über deren Status und Praxis zu verstehen. Die spezifische theoretische Ambition von Handkes Einsatz in dieser zunehmend heftiger geführten Auseinandersetzung wird dabei erst vor dem Hintergrund anderer, in den intellektuellen Debatten der Zeit artikulierter Verabschiedungen der Institution ,Literaturkritik' ersichtlich. Dass im August 1968 im Kursbuch für das kommende Heft der Zeitschrift ein Text Handkes mit dem verheißungsvollen Titel Grablegung der Rezension angekündigt wurde, der dann in der berühmten Nummer 15 allerdings nicht erschien, ${ }^{97}$ kann einerseits als exemplarischer Hinweis auf die Einbettung von Handkes Polemiken in zeitgenössische diskursive Formationen gelten: Seine ungeschriebene Grablegung hätte sich im Umkreis einschlägiger Todesanzeigen, die Autor, Literatur und anderen

94 N. N.: Ankündigung einer neuen Zeitschrift. In: Kursbuch 1 (10. 6. 1965), H. 1, S. 1-2, hier S. 2.

95 Daniela Strigl: Alles muss man selber machen. Biographie, Kritik, Essay. Graz, Wien: Droschl 2018, S. 52. Dazu auch Gunther Nickel: Krise der Literaturkritik. Historische Dimensionen eines aktuellen Themas. In: Kaufen! statt Lesen! Literaturkritik in der Krise? Im Auftrag der Deutschen Literaturkonferenz hg. v. G. N. Göttingen: Wallstein 2006, S. 5-19.

96 Terhorst: Die Entstehung literarischen Ruhms (Anm. 53), S. 40.

97 Die Ankündigung findet sich im unpaginierten Anzeigenteil von Kursbuch 14, im Anschluss an die „Redaktionellen Anmerkungen“. Vgl. dazu Karl Wagner: Handkes Endspiel. Literatur gegen Journalismus. In: Mediale Erregungen? (Anm. 73), S. 65-76, hier S. 69; Henning Marmulla: Enzensbergers Kursbuch. Eine Zeitschrift um 68. Berlin: Matthes \& Seitz 2011, S. 189 u. 362 , Anm. 640. 
liebgewonnenen Instanzen bürgerlicher Kultur ab 1967 demonstrativ das letzte Geleit geben wollten, jedenfalls gut ausgemacht. ${ }^{98}$ Andererseits erhellt eine kontrastive Lektüre von Handkes Texten mit den im Umfeld des Kursbuchs ventilierten politisch-literaturästhetischen Positionen aber auch eine veritable Unvereinbarkeit der jeweiligen Argumentationen: ${ }^{99}$ Walter Boehlich, kurz zuvor noch Lektor im Suhrkamp Verlag, konstatiert in seinem Manifest Autodafé, das im November 1968 als unpaginierter ,Kursbogen' im Gegensatz zu Handkes Grablegung den Weg in die 15. Nummer des Kursbuchs fand, den Tod einer „bürgerliche[n] Kritik“, die die „bürgerliche[ ] Literatur" stets „schulterklopfend begleitet" habe; ${ }^{100}$ sein Einspruch zielt also, ebenso wie jener Handkes, auf eine unheilvolle, weil sich bloß selbst bestätigende Allianz von Literatur und Kritik ab.

Doch während Boehlich die Ohnmacht der traditionellen Kritik ausdrücklich mit deren Unfähigkeit in Verbindung bringt, „zu verstehen, daß es einen politikfreien Raum nicht länger gibt “ ${ }^{101}$ ist es Handke gerade nicht um die Politisierung der Literaturkritik zu tun. Boehlichs Vorstellung einer Kritik, die „endlich die gesellschaftliche Funktion jeglicher Literatur als das Entscheidende versteht und damit die künstlerische Funktion als eine beiläufige erkennt ${ }^{\text {“ }}{ }^{102}$ steht Handke mit seiner ,Kritik der Kritik' diametral gegenüber. Für ihn speist sich das „Übel der Literaturkritik“ - so Handke schon 1964 in einem seiner ersten

$98 \mathrm{Zu}$ den damit einhergehenden Diskussionen bzw. zur Frage, ob im Kursbuch 15 tatsächlich der ,Tod der Literatur' ausgerufen wurde, vgl. Marmulla: Enzensbergers Kursbuch (Anm. 97), S. 187-19o u. 36o f., Anm. 630; zum „Tod der Kritik“ vgl. auch Oliver Pfohlmann: Kleines Lexikon der Literaturkritik. Marburg: LiteraturWissenschaft.de 2005, S. 53 f.; Delius: Als die Bücher noch geholfen haben (Anm. 78), S. 82-88; siehe außerdem Baumgart: Damals (Anm. 77), S. 203: „Das Selbstvertrauen, mit dem unsere neue Literatur Ende der fünfziger Jahre aufgebrochen war, schien verbraucht, schien brüchig, ja krank geworden."

99 Zur Auseinandersetzung Handkes mit literaturästhetisch-politischen Positionen aus dem ,Thinktank' des Kursbuchs vgl. Norbert Christian Wolf: Pop, Ästhetik und Politik 1969 - und ihr Nachspiel: Handke gegen/mit Jelinek. In: Literatur - Politik - Kritik. Beiträge zur Österreichischen Literatur des 20. Jahrhunderts. Hg. v. Harald Jele u. Elmar Lenhart. Göttingen: Wallstein 2014, S. 141-151.

100 Walter Boehlich: Autodafé. In: Kursbuch (November 1968), Nr. 15, Kursbogen [unpag.]. Auch in: Texte zur Theorie der Literaturkritik. Hg. v. Sascha Michel. Stuttgart: Reclam 2008, S. 236-239. Vgl. dazu Sibylle Cramer: Literaturkritik. In: Machen - Erhalten - Verwalten. Aspekte einer performativen Literaturgeschichte. Hg. v. Burckhard Dücker. Göttingen: Wallstein 2016, S. 61-68, hier S. 67: „Die Kassandrarufe aus [den] eigenen Reihen, die seit Walter Boehlichs Autodafé an Zahl, Wut und Ernst zugenommen haben, sind ein Symptom für die in der InfotainmentGesellschaft drohende intellektuelle Selbstabschaffung der Literaturkritik."

101 Boehlich: Autodafé (Anm. 100), [unpag.].

102 Ebd. Vgl. zur Argumentation Boehlichs Marmulla: Enzensbergers Kursbuch (Anm. 97), S. 192 f., sowie ders.: Veränderung um 68. Enzensberger, die anderen und Peter Handke. In: Peter Handke. Analyse du temps. Hg. v. Mireille Calle-Gruber, Ingrid Holtey u. Patricia Oster-Stierle. Paris: Presses Sorbonne Nouvelle 2018, S. 227-238, hier S. 232 f. 
Rundfunkessays ${ }^{103}$ - nicht primär aus deren „fadenscheinig gewordene[m] Kunstwerk-Begriff“, 104 sondern sie erweist sich als Problem mangelnder Sensibilität für die genuin literarische Funktion und Faktur eines Textes. Ein gemeinsamer Gegner hat in der bewegten Zeit der 196oer Jahre keineswegs einen Schulterschluss der jungen Autoren zur Folge, ganz im Gegenteil. ${ }^{105}$

Die hier nur in Ansätzen skizzierten publizistischen Kämpfe um Aufgaben und Verfahrensweisen von Literatur und Literaturkritik wurden nicht einfach entlang klar definierter Fronten - hier Schriftsteller, dort Kritiker - geführt. ${ }^{106}$ Vielmehr versuchten sich die Protagonisten der ideologisch heterogenen Fraktion der ,Kritiker der Kritik ${ }^{`}$ im Sinne einer Konkurrenz innerhalb der , häretischen ' Opposition ${ }^{107}$ auch und im Besonderen voneinander abzugrenzen, um die Legitimität der je eigenen Position zu unterstreichen. Grundsätzlich verwandte Ambitionen bedeuteten keineswegs ein kooperatives und geschlossenes Projekt einer neuen Generation von Autoren, sondern führten in der gesellschaftlich-kulturellen Umbruchsituation der zweiten Hälfte der 196oer Jahre vielmehr zu komplexen ideologischen Verscherungen und erbitterten Grabenkämpfen - mit wechselnden Allianzen und teils von verschiedenen Seiten vereinnahmten theoretischen Gewährsleuten. 1968 veröffentlichte Peter Hamm im Hanser Verlag eine Anthologie zur Lage der Literaturkritik in Deutschland und stellte bereits in seiner „Vorbemerkung“ ein verbreitetes „Mißtrauen gegen Kritik und Kritiker“ fest, das sich ganz grundsätzlich gegen deren „Anspruch“ richte, „Urteile anzugeben“ ${ }^{108}$ Diese Situation

103 Peter Handke: „Bücherecke“ vom 21.12. 1964. In: P. H.: Tage und Werke (Anm. 31), S. 189-197, hier S. 190. Dazu auch Kap. III, Abschnitt „Literaturkritik als ,leeres Geschäft': Handkes Vorarbeiten im Radio“.

104 Boehlich: Autodafé (Anm. 100), [unpag.].

105 Vgl. dazu auch Delius: Als die Bücher noch geholfen haben (Anm. 78), S. 85; Lorenz: Die Öffentlichkeit der Literatur (Anm. 26), S. 51. Zu den diesbezüglichen Diskussionen und ideologischen Differenzen vgl. etwa das folgende, 1969 aufgezeichnete Interview: Hartmut Sander/ Horst Tomayer: Subversive Dialoge. Peter Handke über Berliner Subkultur. In: Abend-Zeitung, 1. 8.1969.

106 Dabei ist zu bemerken, dass auch die Riege der Kritiker keineswegs eine in sich homogene Clique darstellte, was nicht zuletzt mit unterschiedlichen, Generationen' zu tun hatte. Das Ungenügen an der Literaturkritik hatte sich Anfang der 196oer Jahre noch vorrangig an konservativen AltKritikern wie Friedrich Sieburg (1893-1964) entzündet - wofür die ,Gartenzwerg-Affäre' als anekdotische Verdichtung gelten kann (vgl. Pfohlmann: Literaturkritik in der Bundesrepublik [Anm. 81], S. $161 \mathrm{f}$.). Die Angriffe von Handke und anderen jungen Intellektuellen richteten sich bereits gegen eine neue, im Kontext der Gruppe $47 \mathrm{zu}$ Macht und Einfluss gekommene Generation, von der nur Hans Mayer $\left({ }^{\star} 1907\right)$ ein Geburtsdatum vor 1920 aufwies: Marcel Reich-Ranicki $\left({ }^{\star} 1920\right)$, Walter Höllerer $\left({ }^{*} 1923\right)$, Walter Jens $\left({ }^{*} 1923\right)$, Joachim Kaiser $\left({ }^{*} 1928\right)$, Reinhard Baumgart $\left({ }^{*} 1929\right)$.

107 Vgl. zum kultursoziologischen Begriff der ,Häresie` Bourdieu: Die Regeln der Kunst (Anm. 6), S. 322.

108 Peter Hamm: ,Kritik muß sein' Vorbemerkung. In: Kritik - von wem / für wen / wie (Anm. 65), S. 7-10, hier S. 7 f. Der Umschlag des Bandes zeigt eine Karikatur des Kritikers als Hund - ein 
führen Hamm und andere Beiträger des Bandes nun jedoch nicht - wie Handke auf Phänomene einer Ungleichzeitigkeit zwischen der Entwicklung literarischer Verfahren und deren kritischer Kommentierung zurück, vielmehr verstehen sie ihre spezifische „Kritik der Kritik“" ${ }^{109}$ vor allem als Ideologiekritik der Kritik unter eindeutig politischen Vorzeichen. Demnach lasse sich „die etablierte Literaturkritik“ nirgends leichter „als reaktionär und anachronistisch decouvrieren“ als in ihrem traditionellen Verständnis von ,Geist" und ,Kultur', das die gesellschaftlichen Voraussetzungen dieser Begriffe vernachlässige. ${ }^{110}$ Als Gegenentwurf zeichnet Hamm - mit Bezug auf Bertolt Brecht - die progressive Rolle eines „dialektisch-materialistisch [...] argumentierende[n] Kritiker[s]“, der sich von der überkommenen Erscheinungsform des „idealistisch reagierende[n]“ Kritikers emanzipiere. ${ }^{11}$

Dass die Fraktion der stärker politisch argumentierenden Akteure Handke nicht als einen der ihren verstand, den „politisch unzuverlässigen Jungstar“ ${ }^{\text {“112 }}$ vielmehr als Teil des Problems interpretierte, sollte sich im Jahr darauf nur zu deutlich zeigen: In seiner scharfen Polemik gegen Handke, dessen wachsende „Publicity“ sowie die Gruppe der „Handke-Fans“, ja der „Handke-Gemeinde“"113 erklärte Peter Hamm im Juni 1969 in der Zeitschrift konkret diesen zum „ideologischen Feindbild“.114 Handkes „zwanghafte Artistik“ lasse nicht nur auf ein

Bild, das im Laufe der vorliegenden Arbeit, wenn Peter Handkes Kontroverse mit Marcel ReichRanicki im Mittelpunkt steht, noch eine wichtige Rolle spielen wird. Dazu Kap. IV, Abschnitte „Die Bestie von Puyloubier“ und „Mit Cézanne gegen die Hunde“.

109 Yaak Karsunke: Uralte Binsenwahrheiten. In: Kritik - von wem / für wen / wie (Anm. 65), S. 45-48, hier S. 47. Zu Karsunkes Thesen vgl. die „Diskussionsnachzeichnung“ eines 1971 geführten Podiumsgesprächs: Braucht die Literatur Kritik und das Publikum den Kritiker? Streitgespräch zwischen Yaak Karsunke, Dieter Wellershoff und anderen. In: Kritik der Literaturkritik (Anm. 91), S. 74-80.

110 Hamm: Der Großkritiker (Anm. 84), S. 33.

111 Ebd., S. 36.

112 Herwig: Meister der Dämmerung (Anm. 81), S. 128.

113 Peter Hamm: Der neueste Fall von deutscher Innerlichkeit: Peter Handke. In: konkret, Nr. 12, 2.6.1969, S. 42-45, hier S. 42; erneut abgedruckt in: Über Peter Handke. Hg. v. Michael Scharang. Frankfurt a. M.: Suhrkamp 1972, S. 304-314. Als Kommentar zu Hamms Attacke vgl. B. S.: Peter Handkes Drinnen- und Draußenwelt. In: Theater heute (1969), H. 7, S. 4.

114 Wagner: Handke und die Gruppe 47 (Anm. 68), S. 122. Zur Rekonstruktion dieser Kontroverse vgl. Michaelis: Ohrfeigen für das Lieblingskind (Anm. 59), S. 84-86, der eine allgemeine „Barriere ideologischer, materialistisch-marxistischer Kritik“ beschreibt, „gegen die sich Handkes Werk während der Zeit der linken Träume, der Studenten-Unruhe durchsetzen mußte“ (ebd., S. 87). Dazu auch Karl Wagner: Der Popstar im Elfenbeinturm. Kontexte zu Handkes ,Auftritt' in Princeton. In: Dichterdarsteller. Fallstudien zur biographischen Legende des Autors im 20. und 21. Jahrhundert. Hg. v. Robert Leucht u. Magnus Wieland. Göttingen: Wallstein 2016, S. 175-190, hier S. 189: „Es ist bezeichnend für Handke, dass er am Höhepunkt seiner Popularität den politischen Jargon der diversen Emanzipationsdiskurse rückhaltlos der Sprachkritik 
„totale[s] Desinteresse an allem Gesellschaftlichen“ schließen und zeuge von einer Vernachlässigung der „Klassenfrage“; ${ }^{115}$ sie arbeite außerdem auf fatale Weise den „Literatur-Makler[n]“, ja am Ende auch den „Kritiker[n] “ zu. ${ }^{116}$ Die argumentativen Verfahren von Hamms unter dem Titel Der neueste Fall von deutscher Innerlichkeit publiziertem Beitrag und Handkes zwei Wochen darauf veröffentlichter Replik, in der er wiederum Hamms Position als „Ausläufer eines verkommenen Feuilletonismus" charakterisiert, ${ }^{117}$ legen nahe, sie als (terminologisches) Ringen um eine spezifische Deutungshoheit im literarischen Feld zu verstehen - stellen doch, so Pierre Bourdieu, die „meisten Begriffe, mit denen die Künstler und die Kritiker sich selbst oder ihre Gegenspieler definieren“, „Waffen und Einsätze in den zwischen ihnen ausgetragenen Kämpfen dar“. ${ }^{118}$ Indem Hamm und Handke sich wechselseitig vorwerfen, die Diktion des jeweils anderen stehe in engem Konnex zum von beiden bekämpften „Feuilletonismus“, wird die positive wie negative Besetzung von „Kampfbegriffe[n] ${ }^{“ 119}$ als zentraler Aspekt im Spiel der Distinktionen evident. Nicht von ungefähr stellte Hamm einer neuerlichen Gegendarstellung zu Handkes Text im nächsten konkret-Heft vom 30. Juni 1969 eine Liste mit Begriffen und Phrasen voran, die Handke in seiner Replik verwendet hatte: „Solche Wörter, Metaphern, Vergleiche, Adjektive, Denkfaulheiten läßt Peter Handke nur sich selbst durchgehen. “ ${ }^{120}$ Auch der Vorwurf, es handle sich bei Hamms Argumenten um „letzte Ausläufer eines verkommenen Feuilletonismus“, findet sich in der von Hamm zusammengestellten Liste der Handke'schen „Denkfaulheiten“ - ein weiteres Indiz dafür, dass es sich hier um ein stark umkämpftes Begriffsfeld in einer ohnehin intensiven, aufgeheizten Debatte handelte. ${ }^{121}$

aussetzt und solcherart in neue Kontroversen gerät, die damals vielfach unter der Opposition Formalismus vs. Marxismus geführt werden. "Handke selbst hat dazu im Abstand mehrerer Jahrzehnte im Sinne einer polemischen Reprise geäußert: „Ich war ja nie Achtundsechziger. Ich war ja das rote Tuch von denen. ,Literatur ist tot', hat der Scharlatan Enzensberger gesagt, der sich als Dichter ausgibt und nie im Leben ein wirkliches Gedicht geschrieben hat. Für mich sind das meine Feinde. Und wo das hingeführt hat, hat sich später ja auch gezeigt. Von [Daniel] Cohn-Bendit bis Joschka Fischer." (Peter Handke im Gespräch mit Hubert Patterer und Stefan Winkler. Graz: Edition Kleine Zeitung 2012, S. 22)

115 Hamm: Der neueste Fall von deutscher Innerlichkeit (Anm. 113), S. 44 f.

116 Ebd., S. 44.

117 Peter Handke über Peter Handke. In: konkret, Nr. 13, 16.6.1969, S. 51. Erneut abgedruckt in: Über Peter Handke (Anm. 113), S. 314-319.

118 Bourdieu: Die Regeln der Kunst (Anm. 6), S. 466.

119 Ebd.

120 Peter Hamm: Der Dramaturgie dritter Teil oder das denkfaule Genie. In: konkret, Nr. 14, 30.6.1969.

121 Vgl. dazu bereits den Schlagabtausch ein halbes Jahr zuvor: Peter Handke: Totgeborene Sätze. Kunst als Ware. In: DIE ZEIT, Nr. 49, 6.12.1968 vs. Peter Hamm: Versäumte Solidarität: Eine 
Darüber hinaus wird in Auseinandersetzungen wie diesen auch der legitime Bezug auf historische wie zeitgenössische philosophische Diskurse und Denkschulen verhandelt: In einer als Gedicht ausgewiesenen Liste „[z]itierfähige[r] Namen im Kulturbetrieb" hat Peter Handke als Replik auf Peter Hamms sich nacheinander auf Marx, Brecht, Karl Kraus, Benjamin und Barthes berufende Polemik dessen rhetorische Technik des ostensiven wie extensiven name droppings karikierend vorgeführt. Handkes Liste verzeichnet sowohl Adorno, Barthes, Brecht und Godard als auch Lenin, Malcolm X, Mao und Karl Marx. ${ }^{122}$ Auf die theoretischen Entwürfe Roland Barthes' etwa bezogen sich Handke und Hamm gleichermaßen, sie funktionalisierten die Thesen des französischen Kulturtheoretikers aber jeweils in ihrem Sinne und brachten sie dabei ein ums andere Mal auch gegen den jeweils Anderen in Stellung. ${ }^{123}$

Anhand der Kontroverse zwischen den späteren Weggefährten Hamm und Handke lässt sich exemplarisch zeigen, wie Akteure im literarischen Feld die eigene Position durch beständige Umgruppierungen und Neuordnungen etablierter Hierarchien und Verteilungsstrukturen zu stärken und zu plausibilisieren versuchen: einerseits durch den Vorwurf, der Gegner agiere konservativ und unreflektiert reaktionär, andererseits durch die Einschreibung der eigenen Praxis in eine ehrenwerte Genealogie kritischen Bewusstseins. ${ }^{124}$ Dass Hamm nur ein Jahr, nachdem er Hellmuth Karasek vorgeworfen hatte, in Handkes Lager ,übergelaufen zu sein, ${ }^{125}$ Die Angst des Tormanns beim Elfmeter (1970) zum

Erwiderung auf Peter Handkes Aufsatz „Totgeborene Sätze“. In: DIE ZEIT, Nr. 50, 13. 12. 1968.

122 Peter Handke über Peter Handke (Anm. 117), S. 51. Zur Praxis des name droppings im Kulturbetrieb vgl. auch Peter Handke: Namen als Beweise. In: Das große Eierbuch. Hg. v. Ulrich Raschke u. Heinz Jacobi. Frankfurt a. M.: Euphorion 1970, [unpag.], wo die Liste aus der Polemik gegen Hamm geringfügig verändert noch einmal abgedruckt wurde; im Vergleich zur ursprünglichen Aufzählung kamen John Lennon, Claude Lévi-Strauss, Herbert Marcuse und Andy Warhol neu hinzu, während Adorno und Ernst Bloch wegfielen.

123 Vgl. etwa Peter Handke: Marcel Reich-Ranicki und die Natürlichkeit. [1968] In: P. H.: Ich bin ein Bewohner des Elfenbeinturms (Anm. 85), S. 203-207, hier S. 205 f.; Hamm: Der Großkritiker (Anm. 84), S. 32; ders.: Der neueste Fall von deutscher Innerlichkeit (Anm. 113), S. 44; Hamm: Der Dramaturgie dritter Teil (Anm. 120). - Selbst Marcel Reich-Ranicki: Lauter Verrisse. Mit einem einleitenden Essay. München: Piper 1970, S. 40 u. 177, nennt Barthes als Gewährsmann. Zu Handkes Barthes-Rezeption vgl. Kap. IV, Abschnitt „Princeton 1966 und die Folgen“.

$124 \mathrm{Zu}$ erwähnen ist, dass Hamm wenige Monate vor seiner harschen Polemik, im März 1969, in einer Kritik zu Handkes Stück Das Mündel will Vormund sein (bei Hamm fälschlich „Das Mündel will Vormund werden“) zwar ebenfalls Einwände erhoben, diese sich jedoch auf die Theaterästhetik eines konkreten Textes und nicht auf Handkes Image oder seine ideologische Position bezogen hatten. Vgl. Peter Hamm: Nackte Schauspieler, stummes Stück. In: Neues Forum 16 (März 1969), H. 183/I, S. 183-184.

125 Hamm: Der neueste Fall von deutscher Innerlichkeit (Anm. 113), S. 43: „Hellmuth Karasek meinte, bevor er zu Handke überlief, in einer Kritik des Romans, Die Hornissen', daß Handke sich stets ,den Eindruck erschleicht, vollkommen up to date zu sein." Hier wird von Hamm 
„ohne Einschränkung“ Besten erklärte, „das in deutscher Sprache seit Thomas Bernhards ,Verstörung ' und ,Ungenach' geschrieben wurde “126 - und Handke Unseld bat, diesen Satz für eine Werbeanzeige in der ZEIT zu verwenden ${ }^{127}$-, soll an dieser Stelle nur als Indiz für die Schnelllebigkeit forcierter Positionierungen in dieser Übergangszeit verzeichnet werden - und als Beispiel für das im Bereich der Handke-Leser nicht eben seltene Phänomen einer „überraschenden Konversion[ ] "vom Feind zum Freund (und umgekehrt). ${ }^{128}$

\section{Ein Buch „,rehabilitieren“? (Die Hornissen, Der Hausierer)}

Doch zurück ins Jahr 1966: Dass das deutsche Feuilleton, dem er kurz zuvor pauschal vorgeworfen hatte, auf einem recht bescheidenen theoretischen Niveau zu operieren, nach dem Auftritt in Princeton fast einhellig negativ über seinen Debütroman Die Hornissen urteilte, ja ihm ausgerechnet vorwarf, selbst ein Exemplar jener „,Schreibmusterliteratur“ “ vorgelegt zu haben, „gegen die er auf der Princeton-Tagung der Gruppe 47 in vielberedetem Alleingang polemisiert hat" ${ }^{129}$ wollte Handke nicht auf sich sitzen lassen. Im bereits zitierten Brief an Unseld vom 20. Juni 1966 zeigte er sich über die Reaktionen in diversen Tageszeitungen und Zeitschriften enttäuscht, ja erregt: „Ich weiß nicht, ob Sie mich verstehen werden: aber ich kann mich damit schwer abfinden. “ ${ }^{130}$ Rezensionen wie jene von Wolfgang Werth in der ZEIT und Heinz Piontek in der Welt könne er nicht akzeptieren und wolle im Gegenzug zeigen, dass deren negative Urteile „verlogen und leichtfertig“ seien: „Gern würde ich einen ,großen“ Artikel gegen all diese Kritiker schreiben, die die Konsumliteratur, zum Beispiel die Romane eines Günter Grass, zur literarischen Norm erheben wollen. Andererseits möchte ich mein Buch rehabilitieren. ${ }^{\text {131 }}$ Nachgerade paradigmatisch wird

jene Dichotomie skizziert, die die Handke-Rezeption der folgenden Jahrzehnte entscheidend prägen sollte: Man könne nur für oder gegen Handke sein.

126 Peter Hamm: Handke entdeckt sich selbst. In: Neues Forum 17 (März 1970), H. 195/I, S. 253-255, hier S. 254; er bemüht am Ende gar Kafkas Bild des Buches als „Axt für das gefrorene Meer in uns“ (ebd., S. 255).

127 Vgl. Handke an Unseld, 24. 6. 1970. In: Handke/Unseld: Der Briefwechsel (Anm. 16), S. 177 f.

128 Michaelis: Ohrfeigen für das Lieblingskind (Anm. 59), S. 81. Vgl. Wagner: Handkes Endspiel (Anm. 97), S. 68; ders.: Handke und die Gruppe 47 (Anm. 68), S. 122. - Die Entwicklung von Hamms Arbeiten zu Handke lässt sich im Band Peter Handke und kein Ende. Stationen einer Annäherung (Göttingen: Wallstein 2017) nachvollziehen.

129 Wolfgang Werth: Schreibmuster. Peter Handkes Erstlingsroman Die Hornissen. In: DIE ZEIT, Nr. 25, 17.6.1966.

130 Handke an Unseld, 20. 6.1966. In: Handke/Unseld: Der Briefwechsel (Anm. 16), S. 34.

131 Handke an Unseld, 20. 6. 1966. In: ebd., S. 35. - Auf die Rezension von Wolfgang Werth erhob dann nicht Handke selbst öffentlich Einspruch, sondern der Suhrkamp-Lektor Chris Bezzel, 
hier die doppelte Begründung von Handkes Verteidigungsbegehren deutlich: zum einen der Wunsch, durch entsprechende Hinweise eine adäquate (und wertschätzende) Interpretation der eigenen Texte zu gewährleisten, die die Urteile der „verlogen und leichtfertig“ agierenden Kritiker nachhaltig korrigiert; zum anderen die Idee einer Richtigstellung, die über das konkrete Buch und die Person Handkes hinausgeht und den größeren Zusammenhang zeitgenössischer Literatur und nicht zuletzt die Frage im Blick hat, welche Maßstäbe kritischanalytischer Bewertung dieser Literatur angemessen wären.

Umgehend antwortete Unseld am 22. Juni 1966 seinem Autor, dessen erstes Bühnenstück Publikumsbeschimpfung zwei Wochen zuvor in Frankfurt unter der Regie von Claus Peymann Premiere gefeiert und Handkes Rolle als aufsehenerregender rising star der Gegenwartsliteratur befestigt hatte, und riet ihm - wie ein Jahr danach Thomas Bernhard in der Causa Verstörung - mit Nachdruck von seinem Vorhaben ab: „Es ist völlig sinnlos, auf Kritiken direkt zu reagieren. [...] Ich möchte Ihnen also dringend raten, ja, ich flehe Sie an, nichts gegen diese Kritiken zu schreiben, am besten überhaupt nicht auf sie zu reagieren [...]. “132 Unselds beschwichtigender Appell sollte jedoch weitgehend folgenlos verhallen: Zwar verfasste Handke in der Folge keinen ",großen' Artikel gegen all diese Kritiker“, wie er ihn seinem Verleger zuvor noch in Aussicht gestellt hatte - bestenfalls wäre der Essay Marcel Reich-Ranicki und die Natürlichkeit (1968) als ein solcher zu verstehen -, er replizierte allerdings in den nächsten Jahren wiederholt in Leserbriefen und paratextuellen Kommentaren auf negative Urteile der Literaturkritik. Sehr viel expliziter als Bernhard nutzte Handke diese Erwiderungen dabei nicht nur zur aggressiven Verteidigung seines Textes - in einem Brief an Unseld sollte Bernhard Mitte der 1980er Jahre seine Bücher als „Kinder“ bezeichnen, die von ihrem „literarischen Vater[ ]“ vor "grober Misshandlung zu schützen“ seien,$-{ }^{133}$ sondern er verwendete sie auch zur forcierten Propagierung seiner literarischen Praxis sowie seiner poetologischen Position.

Die am 11. Juli 1966 erschienene Rezension von Jakov Lind über die Hornissen parierte Handke in einer Vorbemerkung zum Abdruck des ersten Kapitels aus dem für 1967 angekündigten zweiten Roman Der Hausierer in der Zeitschrift Akzente mit souveräner Geste: Lind hatte Handkes Debütroman im Spiegel bescheinigt, sich in „pedantisch aufdringlichen Beschreibungen von Details“ zu

der die Hornissen betreut hatte (vgl. den Kommentar ebd., S. 37, Anm. 3).

132 Unseld an Handke, 22. 6.1966. In: ebd., S. 39.

133 Bernhard an Unseld, 19. 11. 1984. In: Bernhard/Unseld: Der Briefwechsel (Anm. 16), S. 713. Vgl. zu dieser Konstellation Götze: „Mit allen Anzeichen der Empörung“ (Anm. 33), S. 62, sowie bereits Bernhards Brief an Unseld vom 23. 2.1980. In: Bernhard/Unseld: Der Briefwechsel (Anm. 16), S. 588: „Der Roman soll auch heuer gar nicht veröffentlicht sein, ich beschwörte mutwillig ein Massaker, in welchem sich meine Kinder gegenseitig umbringen, herauf." 
erschöpfen, und in der Folge eine ganze „Generation junger Schriftsteller“ eines unproduktiven ,introvertierten Herumkramens “ bezichtigt, das sich bevorzugt in Varianten von „Harfezupfen und Schalmeienblasen“ ergehe, statt mit „Emotion“ und „Erregung“ einer „robusten Maskulinität“, die er gegen das ,Schöngeistige der Handke-Generation setzt, Ausdruck zu verleihen. ${ }^{134}$ Interessanterweise bringt Lind diese von ihm diagnostizierte Fehlentwicklung der Gegenwartsliteratur in einen direkten kausalen Nexus mit der literaturkritischen Praxis von „Mayer, Reich-Ranicki, Jens, Höllerer, Baumgart und Kaiser“, verdanke man deren „Formalität“ und „literarische[m] Preußentum“ doch den Umstand, „daß sich heute ,die Jungen' mit Stilübungen und Schriftgeplätscher beschäftigen “. ${ }^{135}$ Linds Insultation hätte Handke wohl kaum empfindlicher in seinem Selbstverständnis und in seinen Ambitionen treffen können: Hatte er sich in seinem Statement in Princeton und seiner ,Nachschrift' in konkret gerade gegen diese ,läppischen Kritiker gerichtet, denen er jegliches Sensorium für innovative Textformen und „neue Sprachgestik[en] “136 absprach, zeichnete Lind ihn nun - durchaus perfide - als Produkt von deren ästhetischen Präferenzen.

Bedenkt man die Tragweite von Jakov Linds Kritik, reagierte Handke in den Akzenten beinahe überraschend abgeklärt: „Zu einer programmatischen Erklärung über meine Arbeit bin ich im Augenblick nicht aufgelegt“, setzt Handke unaufgeregt ein, um seinen Kontrahenten sogleich en passant einer konservativen Fraktion zuzuschlagen, die das innovative Potential von Handkes Schreiben nicht wertzuschätzen imstande sei: „Was Jakov Lind sagt, sagt er halt. Den Fortgang der Literatur wird er nicht aufhalten. ${ }^{“ 137}$ Handke verfolgt hier jene Strategie, die Pierre Bourdieu in Die Regeln der Kunst als wichtiges Grundmuster der Entwicklung im literarischen Feld beschrieben hat: Indem er die Ästhetik des

134 Lind: Zarte Seelen, trockene Texte (Anm. 59), S. 79. Vgl. ebd.: „Handkes Buch regt zu einer allgemeinen Frage an: Was ist von einer Literatur ohne Themen und was von einer Sprache zu halten, die es fertigbringt, gleichzeitig wortreich und nichtssagend zu sein? Ich bin nicht sicher, ob man, wie es seit Jahr und Tag in der Gruppe 47 behauptet wird, nur den Stil und nichts als den Stil beurteilen soll. Das mag dem Germanisten genügen, ein normaler Mensch [!] aber will etwas erfahren, möglichst etwas Interessantes, oder zumindest von irgend etwas berührt, betroffen werden.“ Magenau: Princeton 66 (Anm. 77), S. 180, bezieht Linds Verriss auf Handkes Princetoner Polemik, die eine „versteckte Selbstkritik“ im Sinne einer „verborgene[n] Einsicht ins eigene Unvermögen“ vorgestellt habe.

135 Lind: Zarte Seelen, trockene Texte (Anm. 59), S. 79. Gleichzeitig verteidigt Lind die Kritiker gegen Handkes pauschale Vorwürfe, treffe diese doch „die geringste Schuld am allgemein festzustellenden Unbehagen gegenüber der zeitgenössischen Literatur“ (Terhorst: Die Entstehung literarischen Ruhms [Anm. 53], S. 47).

136 Handke: Im Wortlaut (Anm. 64), S. 18.

137 Peter Handke: Wenn ich schreibe. In: Akzente 13 (1966), H. 5, S. 467. In der Debatte zwischen Handke und Lind meldeten sich auch andere Schriftsteller, etwa Adolf Muschg, zu Wort. Vgl. Adolf Muschg: Ein Brief. In: Akzente 13 (1966), H. 5, S. 478-479. 
Kontrahenten „in die Vergangenheit“ verweist, bezieht er selbst die Position des „Neuankömmling[s]“, der bestrebt ist, die Differenz zwischen seiner eigenen Kunstauffassung und jener des (auch biologisch) älteren Lind zu betonen. ${ }^{138} \mathrm{Nicht}$ nur die „Abwertung der bestehenden kulturellen Werte“ ist Boris Groys zufolge „ein notwendiger Aspekt des innovativen Gestus “ ${ }^{139}$ sondern auch die Deklaration und Denunziation des Bestehenden als Vergangenes, als nicht mehr Zeitgemäßes.

In kondensierter Form formuliert Handke in der Folge eine poetologische Standortbestimmung, die die grundlegenden Positionen seiner Essays Die Literatur ist romantisch (1966) und Ich bin ein Bewohner des Elfenbeinturms (1967) zusammenführt und integrativ verdichtet. Wie in anderen Fällen fordert auch hier der Widerspruch zur Zuspitzung des eigenen Standpunkts heraus, erweist sich der Dissens als Motor distinkter Selbstbeschreibung:

Sicher ist, daß Lind und seinesgleichen, engagiert wie sie sind, bis in alle Ewigkeit kritiklos die literarischen Formen jener Gesellschaft verwenden werden, die sie zu kritisieren glauben. Ich selber bin nicht engagiert, wenn ich schreibe. Ich interessiere mich für die sogenannte Wirklichkeit nicht, wenn ich schreibe. Sie stört mich. Wenn ich schreibe, interessiere ich mich nur für die Sprache; wenn ich nicht schreibe, ist das eine andere Sache. [...] Es wäre mir widerlich, meine Kritik an einer Gesellschaftsordnung in eine Geschichte zu verdrehen oder in ein Gedicht zu ästhetisieren. Das finde ich die scheußlichste Verlogenheit: sein Engagement zu einem Gedicht zu verarbeiten, Literatur draus zu machen, statt es gerade heraus zu sagen. Das ist Ästhetizismus, und diese Art von Literatur hängt mir zum Hals heraus. Ich schreibe von mir selber. ${ }^{140}$

Sind Linds Besprechung und Handkes Replik, in der er dessen ÄsthetizismusVorwurf postwendend an den Rezensenten zurückreicht, auch als Symptome eines grundlegenden Konflikts zwischen verschiedenen Schriftstellergenerationen über den Status des ,Neuen' zu interpretieren - Lind war gut 15 Jahre älter -, richtete sich Handkes nächste ,Gegendarstellung' demonstrativ an einen Altersgenossen: Hans Christoph Buch, Jahrgang 1944, der 1966 mit dem Prosaband Unerhörte Begebenheiten sein erstes Buch ebenfalls bei Suhrkamp veröffentlicht hatte. Er wurde Ende 1967 vom Spiegel in einer der Rezension vorangestellten biographischen Skizze als „einer der jüngsten unter den Autoren der sich jetzt etablierenden Nach-Graß-Generation [sic]“ eingeführt und anschließend auf Handkes zweiten Roman Der Hausierer , losgelassen'. Schon mit dem ersten Satz

138 Bourdieu: Die Regeln der Kunst (Anm. 6), S. 254; dazu auch Nina Birkner: Vom Genius zum Medienästheten. Modelle des Künstlerdramas im 20. Jahrhundert. Tübingen: Niemeyer 2009, S. 9.

139 Boris Groys: Über das Neue. Versuch einer Kulturökonomie. München: Hanser 1992, S. 63.

140 Handke: Wenn ich schreibe (Anm. 137), S. 467. 
der Besprechung stellt Buch deren polemischen Impetus klar, indem er Handkes rege Publikationstätigkeit spöttisch kommentiert: „Wenn Produktivität das

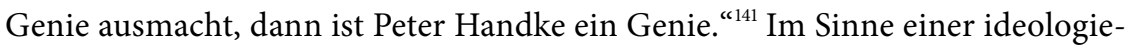
kritischen Lektüre von Handkes Roman versucht Buch im weiteren Verlauf der Rezension, den „affirmativen Charakter, das Nirgendwo dieser Prosa“ offenzulegen; denn sein - Buchs - „Schrecken“ habe nichts mit dem „abstrakten Schema des Schreckens“ im Hausierer zu tun: „mein Schrecken betrifft Bolivien und Vietnam, er betrifft auch Los Angeles und West-Berlin. ${ }^{\text {" }}{ }^{42}$

Diese Steilvorlage vonseiten seines politisch engagierten Kontrahenten wusste Handke geschickt zu nutzen, und er quittierte Buchs Verriss in einem Leserbrief an den Spiegel mit unverhohlenem Sarkasmus:

Ich bitte um Erbarmen und Geduld für mich. Ich habe den affirmativen Charakter meiner Arbeiten nach der Lektüre der Besprechung des Romans „Der Hausierer“ sofort erkannt. Ich habe bist jetzt im Dienst der herrschenden Ideologie gearbeitet. [...] / Ich werde mich ändern. Mit meiner nächsten literarischen Arbeit werde ich mich gegen die herrschende Ideologie stellen. Der affirmative Charakter meiner Arbeiten wird sich in einen negierenden Charakter verwandeln. Mit meiner nächsten Arbeit werde ich die bestehenden Zustände verändern wollen. [...] Gerade habe ich mir schon ein Plakat mit dem Bild Che Guevaras beschafft und es in meinem Zimmer an die Wand geklebt, und wenn heute abend die Tagesschau Bildberichte aus Vietnam bringt, werde ich mir überlegen, wie ich aus diesen Bildern Literatur machen kann. ${ }^{143}$

In dieser Konstellation, in der ,Ideologie‘ und ,Affirmation` zu brisanten Schlagworten werden, zeigt sich eine schon am Beispiel der Konfrontation von Handke und Hamm beobachtete und allgemein für Teile der frühen Handke-Kritik

141 Hans Christoph Buch: Tot und sauber aufgeräumt. In: Der Spiegel, Nr. 52, 18. 12. 1967, S. 118-120, hier S. 118.

142 Ebd., S. 120. Vgl. dazu Perram: Peter Handke (Anm. 59), S. 90: „It is quite obvious that Buch is criticizing Handke because he has, by implication not taken on the role of documentator of the then current ,real' fears and terrors of our civilization." Macht man sich ein Stück weit Handkes Perspektive zu eigen, lässt sich Buchs Ansatz als „Gesinnungskritik“ einordnen, die Pfohlmann: Kleines Lexikon der Literaturkritik (Anm. 98), S. 22, folgendermaßen definiert hat: „Pejorative Bezeichnung für eine engagierte Kritik bzw. literaturkritische Position, der bei der Beurteilung von literarischen Werken eine bestimmte politische oder moralische Haltung oder Intention des Autors wichtiger ist als das Vorhandensein formal-ästhetischer Qualitäten, die also besonders auf die politischen Funktionen der Kritik rekurriert.“

143 Peter Handke: Charakter-Studie. In: Der Spiegel, Nr. 4, 22.1.1968. Vgl. dazu bereits seine Äußerung in Hans Bertram Bock: „Ich wollte immer Kommunist werden“. AZ-Gespräch mit dem BeatAutor Peter Handke. In: Abend-Zeitung, 8./9. 7. 1967: „Ich möchte kein Stück über Vietnam oder Ausschwitz schreiben. Moralische Entrüstung ökonomisch zu verwerten, finde ich peinlich.“ 
charakteristische Frontstellung: Hans Christoph Buch - der einige Monate vor seiner Hausierer-Kritik F. C. Delius um die Zusendung von ,Mao-Bibeln` bat, weil dieser in London dazu leichter Zugang hatte ${ }^{144}$ - vertritt dabei die Position einer linken Kulturkritik im Umkreis der Studentenbewegung, der Handke Ende 1968 in der ZEIT vorwerfen sollte, allein durch die sprachliche Machart ihrer Stellungsnahmen „Denkkrämpfe ${ }^{\text {“145 }} \mathrm{zu}$ verursachen. Auf Buchs Vorwürfe reagiert Handke nicht nur - wie im Fall seines Konflikts mit Peter Hamm - mit der Schärfung seiner Argumentation, sondern auch mit dem ironischen Eingeständnis, bislang „l'art pour l'art produziert“, ${ }^{146}$ ja sich auf einem literarischen Irrweg befunden zu haben: ein wirkungsvolles rhetorisches Verfahren, das Peter von Matt in seiner Charakterisierung literarischer Polemiken als „subtile[s] Gefüge der wechselnden Tonarten“ beschrieben hat. ${ }^{147}$ Seine Ankündigung, künftig „ein anderes Vokabular [zu] gebrauchen“, "148 ist dabei weniger als Diskussionsangebot und Zugeständnis an Buch im Sinne einer „wirkliche[n] Kommunikationssituation“ zu verstehen; vielmehr richtet sie sich zuallererst an ein Publikum, an eine literarische Öffentlichkeit: „Ziel ist nicht, daß der Angegriffene seine Meinungen überprüfe, sondern daß der Leser sein Verhalten dem Angegriffenen gegenüber verändert. " ${ }^{149}$ Handkes zwischen wütendem Protest und Ironie changierende Repliken auf die Vorwürfe von Hamm und Buch waren dabei Teil jener „vehemente[n] Gegenkritik pro domo “, ${ }^{150}$ die seine zu dieser Zeit bereits beträchtliche mediale Resonanz noch weiter verstärkte.

Auf die Rezension seiner Erzählung Die Angst des Tormanns beim Elfmeter in der ZEIT vom 24. April 1970 antwortete Handke drei Wochen später mit einem Leserbrief, in dem er die Besprechung von Marianne Kesting als „ahnungslos und achtlos“ bezeichnete ${ }^{151}$ und sich in der Folge zu einer „Richtigstellung

144 Vgl. Delius: Als die Bücher noch geholfen haben (Anm. 78), S. 66. Wenig später nahm Buch jedoch von der radikalen Politisierung der frühen Jahren Abstand, wie etwa in seinem Aufsatz Von der möglichen Funktion der Literatur im Kursbuch (Nr. 20 [1970], S. 42-52) zum Ausdruck kommt; vgl. dazu auch Marmulla: Enzensbergers Kursbuch (Anm. 97), S. $196 \mathrm{f.}$

145 Handke: Totgeborene Sätze (Anm. 121).

146 Handke: Charakter-Studie (Anm. 143).

147 von Matt: Grandeur und Elend literarischer Gewalt (Anm. 1), S. 39.

148 Handke: Charakter-Studie (Anm. 143).

149 von Matt: Grandeur und Elend literarischer Gewalt (Anm. 1), S. 42.

150 Lorenz: Die Öffentlichkeit der Literatur (Anm. 26), S. 195.

151 Peter Handke: Peter Handke und der Monteur. In: DIE ZEIT, Nr. 20, 15. 5. 1970; die Rezension von Marianne Kesting erschien unter dem Titel: Mord und Verfolgung. Ein umfunktionierter Kriminalroman von Peter Handke. In: DIE ZEIT, Nr. 17, 24. 4. 1970. Vgl. zu dieser Kontroverse ausführlich Norbert Christian Wolf: „Die beginnende Schizophrenie“ eines Tormanns. Handkes Erzählung und die Pathographien aus Klaus Conrads Gestaltanalyse des Wahns. In: Schreiben als Weltentdeckung (Anm. 30), S. 165-200, bes. S. 187-190. 
irreführender Behauptungen“ genötigt sah. ${ }^{152}$ Siegfried Unseld stellte er dieses Mal bereits vor vollendete Tatsachen:

Vielleicht hast Du meine Entgegnung in der ,Zeit' gelesen. Ich meinte, zu widersprechen, und zwar auf genaue und ernste Weise, sei einmal nötig, sonst glaubt man, mit all meinen Prosaarbeiten so oberflächlich umspringen zu können. ${ }^{153}$

Neben solchen Scharmützeln um gelegentliche „Rezensionsrezensionen “154 entwickelte sich zwischen Handke und dem wohl prominentesten Kritiker Deutschlands nach 1945, Marcel Reich-Ranicki, bald ein Verhältnis „unerbittliche[r] Gegnerschaft “: ${ }^{155}$ eine Literaturfehde im besten Sinne, die von beiden Seiten in einer Mischung aus immer wieder neu angefachter Angriffslust und schmerzhafter Kränkung über viele Jahrzehnte in diversen medialen Kanälen der literarischen Öffentlichkeit geführt wurde - und im Grunde, trotz sanfterer Töne gegen Ende, erst mit dem Tod des Kritikers im Sommer 2013 zu einem Abschluss kam. Die Kontroverse zwischen Peter Handke und Marcel Reich-Ranicki wird in Kapitel IV dieser Arbeit als exemplarischer Kampf zweier wirkmächtiger Strategen im Fokus stehen.

152 Ebd., S. 171. Es greift zu kurz, in Handkes Antwort auf Kestings Rezension - wie dies Manfred Durzak: Peter Handke und die deutsche Gegenwartsliteratur. Narziß auf Abwegen. Stuttgart u. a.: Kohlhammer 1982, S. 14, tut - bloß eine „beleidigte[ ] Entgegnung[ ]“ zu sehen.

153 Handke an Unseld, 22. 5. 1970. In: Handke/Unseld: Der Briefwechsel (Anm. 16), S. 173. Vgl. ebd.: „Ich muß im übrigen zugeben, daß ich einige Wut habe wegen einiger achtloser Besprechungen wie der von M. Kesting. " Mehr als drei Dezennien später, in seinem Todesjahr 2002, sprang Unseld seinem Autor schließlich als Reaktion auf eine Kritik von Denis Scheck in der Frankfurter Allgemeinen Zeitung, der Handke u. a. als „Autorenluder“ tituliert hatte, selbst mit einem Leserbrief zur Seite. Vgl. ebd., S. 723-725.

154 Carlos Spoerhase: Ausweitung der literarischen Kampfzone: Was die Geschichte der aufklärerischen Rezensionskultur die aktuelle Reflexion über Literaturkritik lehren könnte. In: Zeitschrift für Germanistik. N. F. 19 (2009), H. 1, S. 171-178, hier S. 171.

155 Wagner: Handkes Endspiel (Anm. 97), S. 70. 


\title{
III UNFREUNDLICHE BETRACHTUNGEN: EINWÄNDE GEGEN DIE LITERATURKRITIK
}

\author{
Sehlustfeindliche Schwätzer
}

Im postum publizierten Berliner Journal hat Max Frisch im Frühjahr 1973 Rezensionen als „lesenswert wie Börsenkurse“ bezeichnet. In der kurzen Notiz geht er von der feuilletonistischen Rezeption des gerade erschienenen Arbeitsjournals von Bertolt Brecht aus, um in weiterer Folge die Erwartungshaltung der Kritik allgemein skeptisch in den Blick zu nehmen: „Was genau unter Privat zu verstehen ist, muss keiner von ihnen definieren; man weiss schon so ungefähr, was verlangt ist, was hingegen ganz und gar schmählich, und handkehrum ihr Entzücken: Man darf wieder Ich sagen, weil Peter Handke es gewagt und gekonnt hat. “1 Der Schweizer Schriftsteller - auf den Wunschloses Unglück „den grössten Eindruck gemacht“ hatte, weil der „Virtuose“ Handke nun „plötzlich [...] etwas zu melden“ habe, sodass er, Frisch, sich „nicht mehr frage, warum ich lese ${ }^{\text {“2 }}$ - spielt mit dem Vergleich von Literaturkritik und Börsenkurs auf gleich zwei vermeintliche Probleme der Branche an: zum einen auf die eingeschliffenen Muster und Ressentiments der Literaturkritik, die sich um die Reflexion ihrer Analysekategorien nicht ausreichend kümmere und deshalb kaum erkenntnisfördernde oder gar lesenswerte Texte hervorbringe; zum anderen auf das ökonomische Kalkül (Stichwort Bestsellerliste), das in einem kapitalistisch organisierten Kulturbetrieb hinter weiten Teilen des Literaturjournalismus stehe. Beide Vorwürfe begleiteten und begleiten die Geschichte der Literaturkritik seit langer Zeit. ${ }^{3}$ Sie zählen, wie sich an vielen Beispielen zeigen lässt, zum fixen Repertoire, zum Generalbass

1 Max Frisch: Aus dem Berliner Journal. Hg. v. Thomas Strässle unter Mitarb. v. Margit Unser. Berlin: Suhrkamp 2014, S. 80.

2 Ebd., S. 27. Handke indes zeigte sich, geht man nach einer Notiz von Siegfried Unseld, wenig später von Frischs Erzählung Montauk wenig begeistert: „Sehr kritische Äußerung über die gespielte Ehrlichkeit von Frischs ,Montauk'““ (Siegfried Unseld: Reisebericht Paris, 20./21. November 1975. In: Peter Handke/S. U.: Der Briefwechsel. Hg. v. Raimund Fellinger u. Katharina Pektor. Berlin: Suhrkamp 2012, S. 296)

3 Vgl. Oliver Pfohlmann: Kleines Lexikon der Literaturkritik. Marburg: LiteraturWissenschaft.de 2005, S. 31 f.: „Zu den immer wieder gegen die Kritik erhobenen Vorwürfen gehören Käuflichkeit bzw. Korruption, fehlende ästhetische Maßstäbe, Parteilichkeit, illegitime Machtanmaßung, die Vernichtung von Autorenexistenzen, der elitäre Ausschluss breiter Publikumsschichten, populistische Simplifizierung, die Dominanz ästhetischer, ethischer oder politischer Maßstäbe." Zur „Kritik der Institution Literaturkritik“ vgl. grundlegend Wolfgang Albrecht: Literaturkritik. Stuttgart, Weimar: Metzler 2001, S. 85-97. 
einer ,Kritik der Kritik. Legionen von Autorinnen und Autoren haben sich ihr auf die eine oder andere Weise und mit wechselnder Vehemenz angeschlossen.

Thomas Bernhard und Peter Handke sind nicht nur in konkreten Einzelfällen als Anwälte und Verteidiger ihrer Veröffentlichungen aufgetreten, sondern haben darüber hinaus grundlegende Einwände gegen das ,Handwerk' der Kritikerzunft im Allgemeinen artikuliert. Wiederholt beklagten die beiden Autoren die uninspirierte und unsensible Rezeption ihrer Bücher im deutschsprachigen Feuilleton: „Schauen Sie sich die Leute an, die drüber schreiben“, rät Bernhard 1986 dem Journalisten Werner Wögerbauer, um dann aus seiner Antipathie keinen Hehl zu machen und ein physiognomisches Zerrbild der "primitive[n]“ Kritiker zu entwerfen:

Das sind nur ordinäre, primitive Kasperln, geschmacklose außerdem, die keine Ahnung von dem haben, was sie beschreiben und lesen. Keine Ahnung, mit was sie eigentlich umgehen. Wenn's heiß wird, ziehn s' den Rock aus, sitzen mit dicken Bäuchen und Hosenträgern verschwitzt da, sind ganz vulgär, saufen eine Flasche nach der andern, net, verbrüdern sich mit Krethi und Plethi. Das ist eine üble Meute. Wurscht, wie sie heißen. (TBW 22.2, 293)

Zwei Jahre zuvor hatte Bernhard die biedere Existenz literarischer Autoren in ähnlichem Duktus mit den Mitteln der Satire gezeichnet: „Es wird doch fast nur wertloses Zeug g'schrieben, von Leuten, die irgendwo in einer Gemeindewohnung sitzen, eine Rente haben, und da stehen die Hauspatschen, und dann haben sie Zettelkästen, und dann machen sie halt Bücher, so wie Näherinnen nähen." (TBW 22.2, 268 f.) Dieses Bild ließ er kurz darauf seinen Protagonisten Reger, den er durchaus gerne als Sprachrohr eigener Agenden in Anspruch nahm, in Alte Meister (1985) in leichter Variation wiederholen: „Sie sitzen in Wiener

4 Die Passage findet sich auch in Kurt Hofmann: Aus Gesprächen mit Thomas Bernhard. Wien: Löcker 1988, S. 99 f. Bernhards Beschreibung des dickbäuchigen und trinkfreudigen Kritikertypus korrespondiert mit Goethes berühmtem Spott-Gedicht auf die Rezensenten von 1774, in dem das lyrische Ich einen „Kerl zu Gast“ hat, der sich zunächst „satt“ frisst, um anschließend „[ü]ber mein Essen zu raisonnieren“: „Die Supp hätt können gewürzter sein, / Der Braten brauner, firner der Wein. / Der tausend Sackerment! / Schlagt ihn tot den Hund! Es ist ein Rezensent.“ (Johann Wolfgang Goethe: [Da hatt ich einen Kerl zu Gast]. In: J. W. G.: Sämtliche Werke nach Epochen seines Schaffens. Münchner Ausgabe. Hg. v. Karl Richter in Zusammenarb. mit Herbert G. Göpfert u. a. Bd. 1.1: Der junge Goethe. 1757-1775. Hg. v. Gerhard Sauder. München: Hanser 1985, S. 223-224, hier S. 223f.) Zu Goethes Gedicht vgl. auch Kap. IV, Abschnitt „Schnüffeln und Verreißen“. - Auf die wiederholte Denunziation „körperfixierter Dumpfheit“ (im Gegensatz zur ,genialische[n] Einsamkeit“ des Schriftstellers) in Bernhards Werk hat Franz M. Eybl: „Wenn das Werk lacht, weint der Dichter“. Thomas Bernhards poetologische Maskeraden. In: Dichterdarsteller. Fallstudien zur biographischen Legende des Autors im 20. und 21. Jahrhundert. Hg. v. Robert Leucht u. Magnus Wieland. Göttingen: Wallstein 2016, S. 157-174, hier S. 162, hingewiesen. 
Gemeindewohnungen oder in kärntnerischen Gelegenheits- und Verlegenheitshuben oder in steiermärkischen Hinterhöfen und schreiben Mist, den epigonalen, stinkenden, kopf- und geistlosen österreichischen Schriftstellermist, sagte Reger, in welchem die pathetische Dummheit dieser Leute zum Himmel stinkt, so Reger." (TBW 8, 137) Selbstaussagen des Autors und fiktionale Texte greifen hier wie an zahlreichen anderen Schauplätzen des Bernhard'schen Euvres ineinander; sie wirken an der Denunziation und Abwertung konkurrierender Akteure im literarischen Feld mit, wobei die entsprechenden Invektiven wiederum der distinktiven Werkpolitik des Autors zuarbeiten.

In allen drei zitierten polemischen Texten geht Bernhard vom Vorwurf provinzieller, ästhetisch rückständiger Kleingeistigkeit aus und unterstellt, dass äußere Erscheinung und Lebensstil von Autoren und Kritikern mit der Qualität ihrer intellektuellen und künstlerischen Hervorbringungen korrespondieren. Diese Rhetorik der „soziale[n] Diskriminierung“ und „Klassenverachtung“, aus der Pierre Bourdieu zufolge eine Vielzahl polemischer Texte im künstlerischen Feld ihren Impuls bezieht, ${ }^{5}$ ist bei Bernhard überaus aufschlussreich, hatte er sich doch selbst aus materiell bescheidenen, zudem alles andere als bildungsbürgerlichintellektuellen Verhältnissen stammend im Literaturbetrieb etabliert. Die Polemiken gegen das Kleinbürgerlich-Provinzielle ${ }^{6}$ sind stets auch als Kommentare zur eigenen, zwar zunächst mühsam, aber schließlich erfolgreich verlaufenen Karriere, zur Sozialisation des 1931 geborenen Autors im Feld der Nachkriegsliteratur Salzburgs, Österreichs und schließlich des gesamten deutschsprachigen Raums zu verstehen.

Wer „über einen kleinbürgerlichen Habitus verfügt“, rekapituliert Bourdieu 1983 eine Aussage von Karl Marx, der habe auch „Grenzen seines Hirns, die er nicht überschreiten kann ". Im Bewusstsein seiner eigenen sozialen und familiären Herkunft hat Bernhard, das bezeugen seine heftigen Attacken gegen Proletariat, Provinzialität und Kleinbürgertum, zeitlebens mit der soziologischen Einsicht

5 Pierre Bourdieu: Die Regeln der Kunst. Genese und Struktur des literarischen Feldes. Frankfurt a. M.: Suhrkamp 1999, S. 360. Zum Vorwurf der „Kleinbürgerlichkeit“ gegen bestimmte Akteure, Praktiken und Kunstrichtungen vgl. Pierre Bourdieu: Rede und Antwort. Frankfurt a. M.: Suhrkamp 1992, S. 168. Zur allgemeinen kulturgeschichtlichen Dimension siehe den folgenden Sammelband: Kleinbürger. Zur Kulturgeschichte des begrenzten Bewußtseins. Hg. v. Thomas Althaus. Tübingen: Attempto 2001.

6 Vgl. Karl Wagner: „Er war sicher der Begabteste von uns allen“. Bernhard, Handke und die österreichische Literatur. Wien: Picus 2010, S. 22 f.; Alfred Pfabigan: Motive und Strategien der Österreichkritik des Thomas Bernhard. In: Thomas Bernhard. Gesellschaftliche und politische Bedeutung der Literatur. Hg. v. Johann Georg Lughofer. Wien u. a.: Böhlau 2012, S. 35-48, hier S. 44 .

7 Pierre Bourdieu: Mit den Waffen der Kritik ... In: P. B.: Satz und Gegensatz. Über die Verantwortung des Intellektuellen. Berlin: Wagenbach 1989, S. 24-36, hier S. 26 f. 
gerungen, wonach eine weitgehende „Analogie“ zwischen „Lebensstil und künstlerischem Stil ${ }^{\text {“ }}$ besteht. Er hat sich in diesem Zusammenhang mit Nachdruck dagegen zur Wehr gesetzt, von den Ausgangsbedingungen seines Milieus im selben Maße determiniert und gehemmt zu werden, wie er dies am Beispiel seines Großvaters Johannes Freumbichler hatte beobachten können; auch in dieser Hinsicht kann Freumbichler als „wichtige Folie für Bernhards Schreiben“, konkret für dessen Entwurf von Autorschaft, gelten. ${ }^{9}$ Die Faszination des Enkels für die Lebenswelt der Aristokratie und des intellektuellen Großbürgertums ist die Kehrseite und negative Entsprechung seiner Distinktion vom vielbeschworenen „Herkunftskomplex“ (TBW 9, 158), an dem sich Bernhard beharrlich abgearbeitet hat.

Die Images des vulgären, dickbäuchigen Kritikers auf der einen und des kleinbürgerlichen Zettelkastenautors auf der anderen Seite, die Bernhard in den zitierten Interviews spielerisch und mit erkennbarer Lust an der Denunziation lanciert hat, arbeiten mit an einer umfassenden Abwertung der literarischen bzw. literaturkritischen Praxis der Geschmähten. Bernhards Polemiken tragen, zumal in den späteren Jahren seines Schaffens, oft das Gewand der Satire, büßen im Zuge der humoristischen Zuspitzung ihre konkrete Treffsicherheit aber noch stärker als bisher ein. Namentlich seine Vorhaltungen gegenüber der Institution der Literaturkritik, die im Folgenden rekapituliert werden sollen, offenbaren selbst dort, wo sie von einer gewissen Akribie der Auseinandersetzung zeugen, eine (bei Bernhard hinlänglich bekannte) Neigung zur undifferenzierten Verallgemeinerung und Übertreibung. ${ }^{10}$ Ein gerade fertiggestelltes Theaterstück warte, so der Autor im Dezember 1981 in einem Brief an Siegfried Unseld, in dem er die bei Suhrkamp verlegte Werkgeschichte seines CEuvres als „vollkommen überflüssige Scheusslichkeit“ bezeichnet, „darauf, wie alle anderen, völlig missverstanden zu werden. Ich habe mich mit der Dummheit der Beurteiler abgefunden. " ${ }^{11}$ Knapp vier Jahre später hat sich Bernhards Aggression gegen im Grunde alle anderen

8 Ebd., S. 27.

9 Bernhard Judex: Der Schriftsteller Johannes Freumbichler. 1881-1949. Leben und Werk von Thomas Bernhards Großvater. Wien u. a.: Böhlau 2006, S. 223.

10 Vgl. dazu bereits Sigurd Paul Scheichl: Nicht Kritik, sondern Provokation. Vier Thesen über Thomas Bernhard und die Gesellschaft. In: Annali. Studi Tedeschi 22 (1979), H. 1, S. 101-119; später, um nur ein weiteres Beispiel zu nennen: Josef Donnenberg: Thomas Bernhards Zeitkritik und Österreich. In: Literarisches Kolloquium Thomas Bernhard. Materialien. Hg. v. Johann Lachinger u. Alfred Pittertschatscher. Weitra: Bibliothek der Provinz 1994, S. 53-72. Willi Huntemann: Artistik und Rollenspiel. Das System Thomas Bernhard. Würzburg: Königshausen \& Neumann 1990, S. 204, hat für Bernhards Polemiken ganz allgemein festgestellt: „Das Bernhardsche Schimpfen glänzt durch seine Rhetorik, die Inhalte sind sekundär und austauschbar, was in zunehmender Tendenz für die späteren Werke überhaupt gilt."

11 Thomas Bernhard an Siegfried Unseld, 17. 12. 1981. In: T. B./S. U.: Der Briefwechsel. Hg. v. Raimund Fellinger, Martin Huber u. Julia Ketterer. Frankfurt a. M.: Suhrkamp 2009, S. 644. 
Akteure im literarischen Feld auf die folgende Formel kondensiert, die strukturell von ferne an die doppelte Polemik - als Autoren- und Kritikerschelte - des jungen Peter Handke in Princeton erinnert: „Lauter kitschiger und kopfloser Schmarren wird gedruckt“, so Bernhards Brief an seinen Verleger vom 1. August 1985, „das ist über so viele Jahre schon deprimierend. Die Schriftsteller sind kunstlose Dummköpfe und die Kritiker sentimentale Schwätzer. “12

Handkes Einwände gegen die Literaturkritik erweisen sich bereits auf den ersten Blick als differenzierter - gerade sein früher Essay Marcel Reich-Ranicki und die Natürlichkeit (1968) argumentiert, ungeachtet seiner polemischen Agenda, auf hohem literaturtheoretischem Niveau. ${ }^{13}$ Im Gegensatz zu Bernhard seltener auf pauschale Diffamierungen beschränkt, konstatierte Handke gleichwohl seit langer Zeit und in immer neuen Anläufen ein fundamentales Unvermögen vieler Kritiker, literarische Texte in ihrer spezifischen künstlerischen Logik zu begreifen. Das „Kulturgeschwätz deutscher Feuilletonisten “14 reizte ihn bei vielen Gelegenheiten zum entschiedenen Widerspruch. Zudem hat Handke ein ums andere Mal gegen die Literaturkritiker den Vorwurf der Unsinnlichkeit erhoben, die mit einer Unfähigkeit zur vorurteilsfreien Lektüre einhergehe: „Sehlustfeindlich“ zu sein, hat er in diesem Sinne Mitte der 1980er Jahre dem „Feuilleton“ in toto attestiert. ${ }^{15}$ Handkes Neologismus korrespondiert mit einer Klage, die der Autor in gleich mehreren Notaten seiner Journalbände festgehalten hat: „So viele, die über Bücher schreiben (sich auslassen?), machen diese, gerade die wesentlichen, fürs erste unleserlich “16

Die literaturkritische Kommentierung von Büchern eröffne, so Handke, ihm und anderen Lesern in vielen Fällen keine Zugänge zum Text, keine Wege zu dessen individueller Aneignung, sondern verhindere oft das unbefangene Erlebnis der Lektüre: „Manchmal denke ich auch, daß das Lesen eine Sache von Leuten geworden ist, die den anderen das Lesen immer mehr unmöglich machen", schreibt Handke am 7. Mai 1974 an Hermann Lenz. Während der Lektüre von Franz Nabls Die Ortliebschen Frauen sei ihm, so Handkes Brief an Lenz, bewusst

12 Bernhard an Unseld, 1. 8.1985. In: ebd., S. 726.

13 Vgl. Norbert Christian Wolf: Autonomie und/oder Aufmerksamkeit? Am Beispiel der medialen Erregungen um Peter Handke, mit einem Seitenblick auf Marcel Reich-Ranicki. In: Mediale Erregungen? Autonomie und Aufmerksamkeit im Literatur- und Kulturbetrieb der Gegenwart. Hg. v. Markus Joch, York-Gothart Mix u. N. C. W. Tübingen: Niemeyer 2009, S. 45-63, hier S. 53: „Jenseits der Polemik [...] besticht Handkes metakritische Diagnose durch ihr sprachliches und intellektuelles Niveau sowie durch ein literaturtheoretisches Problembewusstsein, das man in Reich-Ranickis Rezensionen vergeblich suchen wird."

14 André Müller: Im Gespräch mit Peter Handke. Weitra: Bibliothek der Provinz 1993, S. 54 f.

15 Peter Handke: Am Felsfenster morgens (und andere Ortszeiten 1982-1987). Salzburg, Wien: Residenz 1998, S. 284.

16 Peter Handke: Gestern unterwegs. Aufzeichnungen November 1987 - Juli 1990. Salzburg, Wien: Jung und Jung 2005, S. 57. 
geworden, „was doch alles an Wichtigem und eigentlich Unverlierbarem [...] verloren geht“, weil das Feuilleton nur die ausgetretenen Pfade der hinlänglich kanonisierten und mit Aufmerksamkeit gewürdigten Literatur beschreite, aber keinen Sinn für Entdeckungen und vorderhand,Abseitiges ' mehr habe. ${ }^{17}$ Die Literaturkritik mache, wie der Autor moniert, nicht aufmerksam auf Bücher und Autoren, schon gar nicht auf vergessene oder noch nicht entdeckte: „Das Problem ist, daß die, die über Bücher schreiben, diese schon längst nicht mehr brauchen", so Handke im Journal Am Felsfenster morgens, das in den Jahren, in denen der Autor mit seiner Tochter Amina am Salzburger Mönchsberg wohnte, entstanden ist. ${ }^{18}$ Für seine eigene Tätigkeit als Rezensent hingegen, die in Kapitel $\mathrm{V}$ in den Blick genommen wird, formulierte er wiederholt den Anspruch, etwas über die besprochenen Bücher „zu schreiben, das wirklich Lust zum Lesen macht“, wie er Lenz im März 1975 aus Paris mitteilt. ${ }^{19}$ Mit „Lust“ und mit der sinnlichen Erfahrung von Lektüre konnte er die Riege der etablierten Kritiker und ihre Texte nicht in Verbindung bringen.

Handkes Diagnose, wonach die „schlechte[ ] Sprache“ des Journalismus eine „Weltverschließende[ ] Macht“ darstelle, ${ }^{20}$ wird indes stets durch das Positivbild eines ernsten und freien Lesens sowie eines immer wieder aufs Neue begeisterten Sprechens und Schreibens über Literatur begleitet: „Es gibt noch Bücher zu lesen jenseits der Zeitungen. “21 Die „Serie von negativen Bestimmungen“, mit der das Zeitunglesen bei Handke im Laufe der Jahrzehnte belegt wird, steht, so Karl Wagner, in „scharfe[m] Kontrast zum Selbsterlebnis im Lesen“.22 Die Lektüre im emphatischen Sinn - das „Lesen als Mitbuchstabieren, Entdecken, Welt- und

17 Peter Handke an Hermann Lenz, 7. 5. 1974. In: P. H./H. L.: Berichterstatter des Tages. Briefwechsel. Hg. u. mit einem Nachtwort versehen v. Helmut Böttiger, Charlotte Brombach u. Ulrich Rüdenauer. Mit einem Essay v. Peter Hamm. Frankfurt a. M., Leipzig: Insel 2006, S. 49.

18 Handke: Am Felsfenster morgens (Anm. 15), S. 14.

19 Handke an Lenz, 14.3. 1975. In: Handke/Lenz: Berichterstatter des Tages (Anm. 17), S. 68 f.

20 So der Nachvollzug der Handke'schen Position bei Roland Borgards: Sprache als Bild. Handkes Poetologie und das 18. Jahrhundert. München: Fink 2003, S. 41.

21 Peter Handke: Was ich nicht sagte. Eine Entgegnung auf die Kritik am Heinrich-Heine-Preis. [2006] In: P. H.: Tage und Werke. Begleitschreiben. Berlin: Suhrkamp 2015, S. 32-34, hier S. 33 f. Vgl. auch das folgende Notat in Peter Handke: Phantasien der Wiederholung. Frankfurt a. M.: Suhrkamp 1983, S. 41: „Wenn ich Goethe lese, habe ich auch Lust zu den eigenen Sachen (auch diese nachzulesen); er macht sie nicht nichtig, wie das so viele Zeitungssätze tun“. Vgl. dazu Thorsten Carstensen: „Ich muß zu Meinesgleichen!“ Lesen, Ahnenkult und Autorschaft bei Peter Handke. In: Die tägliche Schrift. Peter Handke als Leser. Hg. v. T. C. Bielefeld: transcript 2019, S. 9-40, hier S. 26: „Das Lesen wirkt in Handkes Texten als Gegenmittel zu jener beschleunigten Übermittlung von Nachrichten, als deren Sinnbild der Autor immer wieder die Tageszeitung angeführt hat.“

22 Karl Wagner: Handkes „Der Roman des Lesens“. In: Texttreue. Komparatistische Studien zu einem masslosen Massstab. Hg. v. Jürg Berthold u. Boris Previšić. Bern u. a.: Lang 2008, S. 173-181, hier S. 177. Zu Handkes Lektüre-Emphase vgl. auch ders.: Handke als Leser. In: lesen.heute. 
Selbsterforschen“23 - bleibt dem abseits der ,Aktualitäten', abseits der schnelllebigen Artikel zum Tag veröffentlichten Buch vorbehalten. Wenn der Autor am 14. November 1986 notiert: „Noch einmal zum Zeitunglesen: das Lesen versäumen“, ${ }^{24}$ verweist er damit nicht nur auf ein Problem der Zeitökonomie - mehr Zeitungslektüre bedeutet weniger Zeit für das Lesen von Literatur -, sondern trifft auch eine Unterscheidung zweier miteinander unvereinbarer Lektüreweisen: eine strikte, zum Manichäischen tendierende Differenzierung, die für Handke - bis heute - eine wichtige Rolle spielt: „Unheimlich und unappetitlich sind die Allesleser (die Zeitschriften genauso lesen wie Bücher, Bücher genauso wie Zeitungen) “. ${ }^{25}$ Mit Nachdruck hat Handke nicht erst im Kontext der Diskussionen um seine Haltung zum Jugoslawien-Krieg, sondern schon früher auf dem „Unterschied zwischen journalistischer und literarischer Sprache“ ${ }^{\text {26 }}$ bzw. auf dem „Unterschied zwischen Journalismus und Schriftstellertum “27 beharrt. Insbesondere der ,Aktualitätszwang' des Journalismus steht dabei, wie die Forschung gezeigt hat, mit Handkes Ideal des „Schärfen[s] der Aufmerksamkeit für die Einzelheiten durch die verlangsamte Lektüre“ in Widerspruch. ${ }^{28}$ „Die Zeitungen sind, haben von vornherein eine Aktualität", hält er in diesem Sinne im Juni 1988, unterwegs im Friaul, an der Grenze zu Jugoslawien, fest; „das Buch, auch

perspektiven. Hg. v. Eduard Beutner u. Ulrike Tanzer. Innsbruck u. a.: StudienVerlag 2010, S. 140-149.

23 Peter Handke: Fragment zu Friederike Mayröcker. [2009] In: P. H.: Tage und Werke (Anm. 21), S. $47-48$, hier S. 47.

24 Handke: Am Felsfenster morgens (Anm. 15), S. 418.

25 Handke: Phantasien der Wiederholung (Anm. 21), S. 85.

26 Peter Handke: Ein Brief. [2006] In: P. H.: Tage und Werke (Anm. 21), S. 41-42, hier S. 41f. Auch an einer zentralen Stelle gegen Ende der vieldiskutierten Winterlichen Reise (1996) hat Handke den Unterschied zwischen literarischer und journalistischer Welterschließung hervorgehoben: „Meine Arbeit ist eine andere. Die bösen Fakten festhalten, schon recht. Für einen Frieden jedoch braucht es noch anderes, was nicht weniger ist als die Fakten." (Peter Handke: Eine winterliche Reise zu den Flüssen Donau, Save, Morawa und Drina oder Gerechtigkeit für Serbien. Frankfurt a. M.: Suhrkamp 1996, S. 133)

27 Rosina Katz-Logar: „Literatur ist wie ein Schlager“. [Gespräch mit Peter Handke.] In: Kleine Zeitung, 17. 5. 2007. Vgl. auch Adolf Haslinger: In treusorgender Ironie. In: Peter Handke/A. H.: Einige Anmerkungen zum Da- und zum Dort-Sein. Ehrendoktorat an Peter Handke durch die Universität Salzburg. Salzburg, Wien: Jung und Jung 2004, S. 13-34, hier S. 24: „Was ihn dabei zum Gegenentwurf reizt, ist [...] die von Meinungen, Stellungnahmen, Informationen verstellte Welt, jene der täglichen Schrift, des Journalismus und des gedankenlosen, ahnungslosen Geplappers.“ Noch in seinem bislang letzten Journalband notiert Handke 2011: „Meinungen, Meinungen, immer nur Meinungen! Auf die Almen mit euch, damit ihr das Erzählen lernt" (Peter Handke: Vor der Baumschattenwand nachts. Zeichen und Anflüge von der Peripherie. 2007-2015. Salzburg, Wien: Jung und Jung 2016, S. 148).

28 Heiko Christians: Der Roman vom Epos. Peter Handkes „Poetik der Verlangsamung“. In: Hofmannsthal. Jahrbuch zur europäischen Moderne 10 (2002), S. 357-389, hier S. 382. 
bloß ein Satz, ein Absatz, eine Seite, dagegen ist etwas zu Aktualisierendes - zu Erarbeitendes ${ }^{\text {“ } . ~}{ }^{29}$ Das , Aktuelle ' aus Politik und Zeitgeschehen und das erst nach und nach ,Zu-Aktualisierende' der Literatur stehen bei Peter Handke seit jeher in einem spannungsreichen Verhältnis.

\section{Vom Zeitungswahnsinn bedroht (Wittgensteins Neffe, Nachmittag eines Schriftstellers)}

Was Bernhard und Handke jedenfalls eint, ist ein schwieriges, von vielerlei Faktoren beeinflusstes Verhältnis zum Medium der Zeitung. Dabei spielt das Interesse an der journalistischen Wahrnehmung und Kommentierung des eigenen Schreibens - die Suche nach dem eigenen Namen, nach Rezensionen eigener Werke bei der Zeitungslektüre -, eingestanden oder nicht, eine wichtige Rolle. „Wenn Sie heute eine Zeitung aufmachen, lesen Sie fast nur vom Thomas Mann irgendwas. Jetzt ist der schon dreißig Jahre tot, und immer wieder, ununterbrochen, das ist ja nicht zum Aushalten", klagt Thomas Bernhard im zitierten Gespräch mit Werner Wögerbauer (TBW 22.2, 289). Der Blick in die Zeitung, ins Feuilleton, kontrolliert und taxiert die Verteilung der Aufmerksamkeit im literarischen Feld, nimmt wohlwollend zur Kenntnis oder beanstandet die Präsenz anderer, vermeintlich weit weniger diskussionswürdiger Akteure: Bernhard habe „nur Zeitung g'lesen, damit er schaut, ob er drinnen steht“, so Franz Josef Altenburg, ein Weggefährte des Autors in einem, Zeitzeugengespräch' mit Krista Fleischmann. ${ }^{30}$ Wenn statt Thomas Bernhard Thomas Mann Erwähnung fand, war das dem Autor ein fortwährendes Ärgernis.

Das Problem ist dabei, wie es scheint, stets ein doppeltes: zunächst der Wunsch nach angemessener Wertschätzung und positiver Bestätigung durch das Feuilleton angesehener, überregional bedeutender Zeitungen und Zeitschriften, zugleich aber auch das Bedürfnis, nicht $\mathrm{zu}$ einem „Gefangene[n] der Redakteure ${ }^{\text {(311 }} \mathrm{zu}$

29 Handke: Gestern unterwegs (Anm. 16), S. 201.

30 Krista Fleischmann: Franz Josef und Christa Altenburg. In: K. F.: Thomas Bernhard - Eine Erinnerung. Interviews zur Person. Wien: Edition S 1992, S. 111-122, hier S. 119; dazu auch Joachim Hoell: Thomas Bernhard. München: dtv 200o, S. 120. In seiner Ökonomie der Aufmerksamkeit hat Georg Franck ein „Zählwerk“ beschrieben, das fortwährend „registriert, wieviel [Aufmerksamkeit] die anderen verdienen“: „Im Reden über Dritte ist, offen oder versteckt, immer auch die Rede davon, ob zuviel oder zu wenig Aufhebens um sie gemacht wird, ob sie die Beachtung verdienen, die sie finden, oder ob ihnen schon zuviel der Ehre zuteil wird, wenn man über sie spricht. [...] Wir vergleichen, wenn wir uns über Dritte unterhalten, ganz unwillkürlich deren Einkommen mit unserem eigenen." (Georg Franck: Ökonomie der Aufmerksamkeit. Ein Entwurf. München, Wien: Hanser 1998, S. 115)

31 Peter Handke: Nachmittag eines Schriftstellers. Erzählung. Salzburg, Wien: Residenz 1987, S. 36. 
werden, ja sich dem „Kreislauf aus Einordnungen und Urteilen“, "32 wie es in Handkes Nachmittag eines Schriftstellers (1987) heißt, ein für alle Mal zu entziehen. Dementsprechend ist der Protagonist der Erzählung, nachdem er zuvor geglaubt hatte, in einer Zeitung auf „, seinen Namen“ gestoßen zu sein, „[a]nders als früher“ nicht enttäuscht, sondern „erleichtert“, „sich geirrt zu haben“. ${ }^{33}$

Die Konsequenz einer solchen Verweigerung wäre die demonstrative Nichtbeachtung der journalistischen Kommentierung der eigenen Bücher, die Konzentration auf das Schreiben als erfüllende, selbstgenügsame Tätigkeit, ohne an den daraus erwachsenden Debatten zu partizipieren, ja ohne sie auch nur wahrzunehmen. „Erfolg wäre, wenn ich mein Manuskript einem Verleger schicke und der nicht lang fragt; er setzt es, druckt es, das finde ich eigentlich schon den ganzen Erfolg“, so Bernhards Beteuerung im Sommer 1980: „Es würde mir genügen, möglichst korrekt mit möglichst wenig Druckfehlern, möglichst einfach, ohne graphische Kinkerlitzchen gedruckt zu werden. Und daß ich leben kann. Alles andere brauch' ich nicht. Das ist mir eher immer grauslich, was nachher kommt." (TBW 22.2, 179 f.) Bereits 1971 hatte er sich André Müller gegenüber in ähnlicher Weise geäußert: „Wenn man das dann gedruckt sieht, als Buch, mit einem Deckel, schön gebunden, das gefällt mir. Aber eigentlich ist es dann schon vorbei. Von mir aus müßte von jedem Buch nur ein einziges Exemplar gedruckt werden: für mich. “" ${ }^{34}$ Ganz deutlich steht diese Haltung, die ein Schreiben um des Schreibens willen im Blick hat, mit dem Wunsch nach Anerkennung und Wirkung des eigenen Tuns, nicht zuletzt in der Literaturkritik, in Widerspruch. Das „Ausstrahlen, und zwar nicht nur weltweit, sondern universell“ (TBW 22.2, 320), das Bernhard 1986 als Maxime seiner Autorenexistenz formuliert hat, ist, wie ihm selbst bewusst war, nicht ohne die Kräfte, Akteure und Mechanismen des literarischen Feldes zu bewerkstelligen. Wer von sich reden machen will, von dem muss zunächst einmal die Rede sein. ${ }^{35}$

"Zeitungen haben mich immer fasziniert, von meiner Jugend bis heute. Es ist mir kaum erträglich, einen Tag ohne Zeitung zu verbringen“, so Bernhard im letzten ausführlichen Gespräch, das zu Lebzeiten des Autors publiziert wurde (TBW 22.2, 336); „die regelmäßige Lektüre von Zeitungen, der er sich mit Vorliebe im Kaffeehaus hingab“, sei, so der Bernhard-Biograph Manfred Mittermayer,

32 Ebd., S. $36 \mathrm{f}$.

33 Ebd., S. 37.

34 André Müller: Im Gespräch mit Thomas Bernhard. Weitra: Bibliothek der Provinz 1992, S. 24.

35 Oder, wie Otto Lorenz: Pro domo - Der Schriftsteller als Kritiker. Zu Peter Handkes Anfängen. In: Literaturkritik - Anspruch und Wirklichkeit. DFG-Symposion 1989. Hg. v. Wilfried Barner. Stuttgart: Metzler 1990, S. 399-414, hier S. 400, festhält: „Literatur wie Literaturkritik stellen Öffentlichkeit nicht autonom her, sondern gehen, auch wenn die Autoren das gern abstreiten, aus ihr hervor." 
eine seiner „größten Leidenschaften“ gewesen. ${ }^{36}$ Auch viele Protagonisten seiner Bücher sind passionierte Zeitungsleser, wenngleich sich diese Begeisterung nicht selten als veritable Hassliebe äußert: „Die Station ist der einzige Ort, wo es Sinn hat, hinzugehen, denn da gibt es Zeitungen“ (TBW 1, 237), weiß schon der Maler Strauch, dessen Äußerungen ein junger Famulant in Bernhards Prosadebüt Frost (1963) akribisch dokumentiert; die Lektüre der Zeitungen gehört zu den wenigen verbliebenen Freuden des Misanthropen.

Auf vielfältige Weise sind die Schicksale von Bernhards Figuren immer wieder mit dem Medium der Zeitung verbunden, ${ }^{37}$ etwa auf besonders tragische Weise in der 1965 publizierten Erzählung Der Zimmerer: Gleich eingangs heißt es dort von dem eben aus der Haft entlassenen Zimmermann Winkler, „die Zeitungen“ hätten über ihn „vor fünf Jahren, während der Dauer seines Prozesses, unglaublich viel Ordinäres und Abstoßendes“, geschrieben (TBW 14, 76). Dass

36 Manfred Mittermayer: Thomas Bernhard. Frankfurt a. M.: Suhrkamp 2006, S. 97. Vgl. auch die Aufzeichnungen von Rudolf Brändle: Zeugenfreundschaft. Erinnerungen an Thomas Bernhard. [1999] Frankfurt a. M.: Suhrkamp 2001, S. 65: „Schon in Grafenhof hat Thomas jede Zeitung, deren er habhaft werden konnte, von A bis Z verschlungen. Diese Angewohnheit entwickelte sich im Lauf seines Lebens zu einer wahren Sucht [...]. “ Ebenso ambivalent liest sich dies in den Erinnerungen von Camillo Schaefer: Wir haben uns gegenseitig angeschwiegen. In: Was reden die Leute. 58 Begegnungen mit Thomas Bernhard. Aufgezeichnet v. Sepp Dreissinger. Salzburg, Wien: Müry Salzmann 2011, S. 156-160, hier S. 159: „Er hat mit einer fast manischen Lesegier die Zeitungen verschlungen. Man hat den Eindruck gehabt, er kommt nicht wegen des Vergnügens her [ins Café Bräunerhof], sondern erfüllt irgendwelche Pflichten. “- In Meine Preise berichtet Bernhard davon, dass Hedwig Stavianicek ihn während seines Klinikaufenthalts auf der Wiener Baumgartner Höhe Mitte der 1960er Jahre „jeden Tag“ mit „mehreren Kilogramm Zeitungen“ versorgt habe (TBW 22.2, 377), an einer anderen Stelle der autobiographischen Erzählung ist von einem „von mir zum Zwecke des Zeitungslesens täglich aufgesuchten Kaffeehaus in Gmunden“ die Rede (TBW 22.2, 436 f.). Im Gespräch mit Hellmuth Karasek und Erich Böhme hat Bernhard in zeitlicher Nähe zu Meine Preise und mit Blick auf seinen angeschlagenen Gesundheitszustand geäußert: „Wenn ich eingehen würde, also wenn ich draufgehen würde, wenn ich mich nicht mehr bewegen könnte, dann würde ich es wahrscheinlich ideal finden, im Kaffeehaus zu sitzen bei zugezogenen Vorhängen. Aber nicht so weit zugezogen, daß man nicht mehr lesen kann. Es wäre schön, die Welt nur noch aus der Zeitung zu erfahren. Dann lese ich nur noch die Welt aus der Zeitung." (TBW 22.2, 170)

37 Vgl. dazu auch die Beispiele in Franz M. Eybl: Thomas Bernhards Stimmenimitator als Resonanz eigener und fremder Rede. In: Kontinent Bernhard. Zur Thomas-Bernhard-Rezeption in Europa. Hg. v. Wolfram Bayer. Wien u. a.: Böhlau 1995, S. 31-43, hier S. 36 f., sowie die Ausführungen zur Bedeutung von Printmedien in Bernhards Stücken bei Clemens Götze: „Die eigentliche Natur und Welt ist in den Zeitungen“. Geschichte, Politik und Medien im dramatischen Spätwerk Thomas Bernhards. Marburg: Tectum 2009, S. 113-122. Julia Kerschner: Autodidaktik, Artistik, Medienpraktik. Erscheinungsweisen des Dilettantismus bei Karl Philipp Moritz, Carl Einstein und Thomas Bernhard. Göttingen: V\&R unipress 2016, S. 351, zufolge nehmen zahlreiche Protagonisten in Bernhards Stücken ,ihre Umwelt in erster Linie vermittelt über Zeitungen wahr“. 
er sich, nach dem Ende seiner Haftstrafe mut- und obdachlos herumstreifend, „in einem Hohlweg bei Wimsbach“ ausgerechnet „mit mehrere[n] große[n] Zeitungen“ zudeckt, ja selbst in der Wohnung seiner Schwester, „[d]a keine Decke vorhanden war“, „mit ein paar alten Ausgaben des ,Linzer Volksblattes“ vorlieb nehmen“ muss (TBW 14, 9o f.), ${ }^{38}$ unterstreicht die Tragik seiner Existenz. Ein Urteil über ihn ist, nicht nur vonseiten der Justiz, sondern auch von der Presse, längst gesprochen - sich vom, wie es in Der Untergeher (1983) heißt, „Zeitungsbestätigte[n]“ (TBW 6, 39) im Sinne der normativen Kraft des Faktischen zu lösen, gelingt dem Delinquenten nicht.

„Wir haben selbst schon jahrelang keine Zeitung mehr gelesen“, berichtet hingegen der namenlos bleibende Erzähler von Midland in Stilfs (1969) über eine abgeschieden, ja „absolut isoliert“ in einem Bergdorf lebende Gruppe von Menschen, „weil wir die Zeitungslektüre, in die wir jahrzehntelang vernarrt gewesen sind, von einem Augenblick auf den anderen verabscheuten, uns nicht mehr gestatteten“. Nur einer von ihnen, Roth, hält noch „Kontakt“ zur „Welt“ und liest „im Tal unten die Zeitung“; es ist ihm freilich streng untersagt, „uns eine Zeitung herauf zu bringen“ (TBW 14, 127 f.). Verstößt jedoch der Engländer Midland, der die Abgeschiedenen episodisch besucht, gegen das strenge Gebot, sie nicht mit Zeitungen zu versorgen, dann „stürzen“ sie sich „darauf wie nach der Zeitungslektüre Ausgehungerte“ (TBW 14, 128), wie rückfällig gewordene Süchtige.

Gerade in späteren Texten Bernhards erscheint der Abschied von der Zeitungslektüre als Teil einer Abkehr von alten Gewohnheiten, von einer in der Vergangenheit liegenden Existenzweise: „Die billigen Methoden haben sich alle abgenützt“, heißt es dementsprechend in Beton (1982),

Besuche, Zeitunglesen etcetera, auch die Lektüre der sogenannten höheren Literatur hat nicht mehr die Wirkung, die sie einmal gehabt hat. Wir fürchteten aufeinmal das Geschwätz, vor allem das, das die sogenannten bekannten und berühmten, aber um so widerlicheren Journalisten des Feuilletons ununterbrochen schwätzen. Und von diesem widerlichen Geschwätz haben wir uns jahrelang, jahrzehntelang zudecken lassen. (TBW 5, 95)

In der im gleichen Jahr wie Beton veröffentlichten Erzählung Wittgensteins Neffe, die vielfältige Bezüge zur Biographie Bernhards aufweist und durchaus als Fortführung der autobiographischen Pentalogie verstanden werden kann, berichtet das Text-Ich von dem Entschluss, „einen Aufsatz über die Mozartsche Zaide, der

38 Es handelt sich dabei um eine Zeitung, in der am 17.7.1954 auch eine Erzählung Thomas Bernhards, Der Untergang des Abendlandes, erschien (vgl. TBW 14, 493-499, sowie den Kommentar ebd., 579) und die zudem im Band Der Stimmenimitator als fiktive Quelle einer anekdotischen Miniatur erwähnt wird (vgl. TBW 14, 312 f.). 
in der Neuen Zürcher Zeitung angekündigt gewesen war“, zu lesen (TBW 13, 259). Gemeinsam mit Paul Wittgenstein und einer weiteren Freundin begibt sich der Erzähler in der Folge, ausgehend vom Ohlsdorfer Vierkanthof des Autors, auf einen Road-Trip durch das Alpenvorland, zunächst in die knapp 8o Kilometer entfernte „sogenannte weltberühmte Festspielstadt“ Salzburg, sodann ins deutsche Bad Reichenhall und zurück ins oberösterreichische Bad Hall, schließlich nach Steyr und Wels. Nirgends ist das Schweizer Blatt erhältlich, der Zeitungskauf scheitert bei allen Anläufen: „Wenn wir nicht total erschöpft gewesen wären, wären wir sicher auch noch nach Linz und nach Passau, vielleicht auch noch nach Regensburg und nach München gefahren, und schließlich hätte es uns auch nichts ausgemacht, die Neue Zürcher Zeitung ganz einfach in Zürich zu kaufen, denn in Zürich, so denke ich, hätten wir sie mit Sicherheit bekommen." (TBW 13, 259 f.) Während der Erzähler der Überzeugung ist, die österreichischen Zeitungen seien im Grunde „überhaupt keine Zeitungen“, sondern „nur tagtäglich millionenfach erscheinende unbrauchbare Klosettpapiere“ (TBW 13, 291), ${ }^{39}$ hält er die Neue Zürcher Zeitung als Medium bürgerlicher Kultur und feuilletonistischer Dignität in Ehren, zumal sie für ihn einen Gegenpol zum provinziellen Österreich und zur hiesigen ernüchternden Presselandschaft repräsentiert:

[A]n der Tatsache, daß wir in so vielen angeblich so wichtigen Orten die Neue Zürcher Zeitung nicht bekommen haben, selbst in Salzburg nicht, entzündete sich unser aller Zorn gegen dieses rückständige, bornierte, hinterwäldlerische, gleichzeitig geradezu abstoßend größenwahnsinnige Land. Wir sollten uns nur immer da aufhalten, wo wir wenigstens die Neue Zürcher Zeitung bekommen, sagte ich und der Paul war absolut meiner Meinung. (TBW 13, 261) ${ }^{40}$

39 Vgl. dazu Bernhards Bemerkung im Interview mit Krista Fleischmann von 1986: „Aber bei zwanzigtausend Romanen im Jahr und fünf Millionen Gedichten ist ja abzusehen, was das für einen Sinn hat. Für die Papierfabriken, weil die mit den Klorollen ja nicht ausgelastet sind, also müssen auch Bücher gedruckt werden. Das wäre ja überhaupt eine angenehme Vorstellung von Literatur, daß man das einfach runterreißt und liest und sofort hineinschmeißt. Das Furchtbare ist ja dann, daß die Leute die Bücher in [sic] die Wand stellen und daß das dann Jahrzehnte herumsteht und nur stinkt.“ (TBW 22.2, 311) Auch in anderen Zusammenhängen hat Bernhard Gedrucktes mit Toilettenpapier verglichen, so etwa Anfang 1986 in seiner brieflichen Philippika gegen Marianne Fritz' bei Suhrkamp publizierten Monumentalroman Dessen Sprache du nicht verstehst: „Hätten Sie doch anstatt den Unsinn von Frau Fritz, nur eine dreitausend Blätter lange Klopapierrolle gedruckt und unter dem Suhrkampsignet herausgegeben, Sie wären auch damit ins Buch der Rekorde gekommen." (Bernhard an Unseld, 19. 1. 1986. In: Bernhard/Unseld: Der Briefwechsel [Anm. 11], S. 744)

40 Vgl. die folgende Stelle in Beton: „Wenn ich die ekelhaften Zeitungen, die bei uns erscheinen, die gar keine Zeitungen sind, nur Schmutzblätter, die von geldgierigen Emporkömmlingen herausgegeben werden, nicht mehr lesen muß, wenn ich das, was mich hier umgibt, nicht mehr sehen muß! sagte ich mir." (TBW 5, 93) 
Zwar habe er, so der Erzähler, den Aufsatz „bis heute“ nicht gelesen und „naturgemäß ohne diesen Aufsatz überlebt“: „Aber im Augenblick hatte ich geglaubt, ihn haben zu müssen." (TBW 13, 261) Die mit feinem Humor geschilderte Episode verweist beispielhaft auf Bernhards - trotz einschlägiger Invektiven gegen das (österreichische) Pressewesen - lebenslange Faszination für das Medium der Zeitung: ein Medium, das ihm immer wieder als zentraler Aktionsort seiner polemischen, Öffentlichkeitsarbeit ${ }^{{ }^{41}}$ dienen sollte. Bernhards vielschichtige Werkpolitik ist kaum ohne diesen Aspekt, ohne die Kollaboration nicht nur verschiedener Genres und Textsorten, sondern auch verschiedener medialer Kanäle zu denken.

In einer Passage von Der Atem (1978), die seinen Aufenthalt in einem Lungensanatorium in Großgmain schildert, hat Bernhard die Ambivalenz von Lust und Abscheu als „lebenslänglichen Mechanismus“ beschrieben:

Auch hatte ich mit der Zeit wieder Lust bekommen, Zeitungen zu lesen, wenngleich ich von dieser Lektüre immer gleich abgestoßen gewesen war, was aber nicht verhindern hatte können, daß ich schließlich wieder jeden Tag von neuem in ihnen gelesen habe, schon damals war ich ganz und gar diesem alltäglich sich wiederholenden, jetzt, wie ich weiß, lebenslänglichen Mechanismus verfallen gewesen, Zeitungen zu besorgen und zu lesen und von ihnen immer abgestoßen zu sein. (TBW 10, 299)

Diese Ambivalenz, das Spannungsverhältnis zwischen nachgerade fanatischem Interesse und tiefsitzender Aversion, hat Bernhard auch literarisch fruchtbar gemacht: sei es in der Figur des Immanuel Kant im gleichnamigen, 1978 uraufgeführten Stück - „Zeitlebens bin ich gegen die Zeitungen / zeitlebens habe ich sie in mich hineingefressen“" (TBW 17, 109) -, im Erzähler von Holzfällen (1984), den die Zeitungslektüre im Kaffeehaus zwar zunächst beruhigt, der sich „von diesen schamlosen Blättern“ aber wenig später , angewidert“ zeigt (TBW 7, 66), oder im alten Misanthropen Herrenstein, der sich in Elisabeth II. (1987) über die Wiener Tageszeitung Die Presse echauffiert, um sogleich, wie dies für Bernhards Protagonisten nicht unüblich ist, vom Einzelfall seines eigenen Missvergnügens an der Presse auf die Gesamtheit aller Leserinnen und Leser sowie aller Zeitungen zu schließen:

Das ist es ja

das mich ärgert

ein so fürchterliches Blatt

und ich lese es täglich

so geht es doch allen Leuten

41 Vgl. Michael Billenkamp: Thomas Bernhard. Narrativik und poetologische Praxis. Heidelberg: Winter 2008, S. 20. 
mit allen Blättern

sie sind schauerlich

und werden doch gelesen (TBW 20, 208)

Wenige Monate vor der Publikation von Elisabeth II., am 20. Februar 1987, wandte sich Bernhard mit einem Leserbrief an das „Sehr geehrte[ ] Feuilleton“ der Süddeutschen Zeitung, um einige seines Erachtens falsche Angaben in einer Opernkritik zur Aufführung von Peter Ronnefelds Nachtausgabe zu korrigieren (TBW 22.1, 686). Nach umfänglichen Erläuterungen, die unter anderem seine eigene Karriere als Sänger zum Gegenstand haben, schließt Bernhard den Leserbrief mit einer für den vorliegenden Zusammenhang charakteristischen Wendung: Er bezeichnet die Süddeutsche als eine „schauerliche“ Zeitung, die ihm freilich „jeden Tag ein ganz und gar singuläres Vergnügen“ bereite (TBW 22.1, 688). ${ }^{42}$ Die geschilderte Zwiespältigkeit des Autors mit Blick auf Feuilleton und Zeitung findet hier, ironisch getönt, ihren exemplarischen Ausdruck.

Thomas Bernhards Begeisterung für das Medium Zeitung hat Peter Handke nie geteilt - ganz im Gegenteil: Beinahe sein gesamtes Werk, die poetologischselbstreflexiven wie die fiktionalen Texte, durchzieht die nachdrückliche Warnung vor den negativen Einflüssen des Journalismus. Sich selbst hat er Mitte der 1970er Jahre im Journalband Die Geschichte des Bleistifts als einen „,om Zeitungswahnsinn Bedrohte[n] " charakterisiert. ${ }^{43}$ Das Interesse des Autors, dessen Vorbehalt sich auf Printmedien und Television gleichermaßen erstreckt ${ }^{44}$ gilt dementsprechend nicht neuen „Empfangsschirme[n] für Nachrichten“, sondern „Nachrichtenabhalteschirme $[\mathrm{n}]]^{\text {“ }}{ }^{45}$ die den ruhebedürftigen poeta vates vor den Zumutungen medialer Dauerinformation bewahren. ${ }^{46}$

42 Vgl. dazu: Sehr geschätzte Redaktion. Leserbriefe von und über Thomas Bernhard. Hg. v. Jens Dittmar. Wien: Edition S 1991, S. 170-177; Manfred Mittermayer: Thomas Bernhard. Eine Biografie. Salzburg, Wien: Residenz 2015, S. 109 f., bzw. den Kommentar in TBW 22.1, $882 \mathrm{f}$.

43 Peter Handke: Die Geschichte des Bleistifts. Salzburg, Wien: Residenz 1982, S. 24.

44 Vgl. dazu, ohne Handkes Auseinandersetzung mit dem Fernsehen hier genauer verfolgen zu können, den ,Zwillingsaphorismus' im Journalband Phantasien der Wiederholung: „Die Literatur setzt mir die Lesebrillen auf “vs. „Das Fernsehen brennt mir die Seele aus“ (Handke: Phantasien der Wiederholung [Anm. 21], S. 89 f.); siehe auch Handke: Am Felsfenster morgens (Anm. 15), S. 14: „Zeitgenössisches Schattendasein: vor dem Fernseher“.

45 Handke: Die Geschichte des Bleistifts (Anm. 43), S. 201. Entsprechend vermerkt Handke noch gut drei Jahrzehnte später in einer ,Aufwachnotiz' des Bandes Ein Jahr aus der Nacht gesprochen eine, so hat es den Anschein, wünschenswerte Vorstellung, womit nicht zuletzt die andauernde Bedeutung dieser Antipathie in Handkes Werk und Denken dokumentiert ist: „Guten Morgen, liebe Hörer: Hier ist der Saarländische Rundfunk mit keinen Nachrichten“ (Peter Handke: Ein Jahr aus der Nacht gesprochen. Salzburg, Wien: Jung und Jung 2010, S. 180).

46 Zu Handkes „Habitus des, poeta vates“ vgl. Herwig Gottwald/Andreas Freinschlag: Peter Handke. Wien u. a.: Böhlau 2009, S. 87 f., hier S. 87: „Handke stilisiert sich selbst - analog zu 
„Wie schon so oft sagte er sich“, heißt es vom Protagonisten der Erzählung Nachmittag eines Schriftstellers, der mit seinem Autor viele charakterliche Züge und biographische Details teilt, „daß er mit dem Zeitungskauf nun seinen ersten Fehler beging, und nahm sich vor, das Ganze nur durchzublättern, möglichst noch im Gehen, und dann in einen Papierkorb zu stecken“. Denn: „Schon der Anblick der Schlagzeilen machte ihn kurz sprechunfähig; zu dem Gruß des Verkäufers gelang ihm gerade noch ein Nicken. ${ }^{(47}$ Seine Befürchtungen, die sich an den umgehend bereuten Erwerb einer Tageszeitung knüpfen, bewahrheiten sich wenig später: „Mit dem ersten Satz, den er las, hörte in ihm sofort jede Art von Denken auf. Er pflegte sich selber einzureden, er sei zur Zeitungslektüre verpflichtet, um informiert zu sein. [...] In Wahrheit jedoch war sein Blättern in den Zeitungen eine Sucht. “ ${ }^{48}$ Das Eingeständnis, einer ,Zeitungssucht ${ }^{`}$ zu unterliegen, veranlasst den Schriftsteller auf seinem Fußmarsch durch die Stadt Salzburg schließlich zu dem „Gelöbnis“, bis zum Abschluss seiner ,jetzigen Arbeit [...] keine Zeitung mehr auf[zu]schlagen “49 - ist er doch der Überzeugung, dass „die Möglichkeit, neu anzufangen " ${ }^{50}$ ein radikales Abstandnehmen von der Sprache des Journalismus, eine Form der Enthaltsamkeit gewissermaßen, voraussetzt: „Es war, als habe er durch das Zeitungslesen den Gesichtskreis verloren; schon

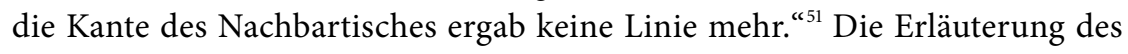
eigenen Schreibens wird hier und auch an anderen Stellen in Handkes CEuvre, zumal in den metafiktionalen Reflexionstexten und in den Journalbänden, mit der Benennung der Widerstände und ,Feinde dieses Schreibens verknüpft. Handkes Poetik gewinnt ihre Konturen nicht zuletzt aus einer distinktiven Setzung: „Die geschriebene, gedichtete Sprache erhält die Sprache. Die journalistische Sprache erhält die eigene Sprache nicht. ${ }^{452}$

„Nachher Zeitungslektüre“, notiert Handke unter dem Datum 24. Oktober 1976 im Band Das Gewicht der Welt, „und dabei die Empfindung, all die Sätze da auf

seinen Hauptfiguren - zu einem in metaphorischem und geographischem Sinn an ,Rändern` lebenden Dichter, der sich dem Medienrummel, der Betriebsamkeit westlicher Zivilisation, der Tagespolitik und vielen modernen Lebensformen bewusst verweigert [...]. Zu diesem MotivKomplex vgl. auch den einschlägigen Sammelband: Peter Handke. Poesie der Ränder. Hg. v. Klaus Amann, Fabjan Hafner u. Karl Wagner. Wien u. a.: Böhlau 2006.

Handke: Nachmittag eines Schriftstellers (Anm. 31), S. $28 \mathrm{f}$.

Ebd., S. 33. Wagner: Handkes „Der Roman des Lesens“ (Anm. 22), S. 177, spricht in diesem Zusammenhang von der „Hartnäckigkeit des Lasters“, das dazu führe, dass sich der Autor und seine Protagonisten immer wieder dem Medium Zeitung aussetzen (um dies kurz darauf ein ums andere Mal zu bereuen).

49 Handke: Nachmittag eines Schriftstellers (Anm. 31), S. 49.

50 Ebd., S. 48.

51 Ebd., S. 38.

52 ... und machte mich auf, meinen Namen zu suchen. Peter Handke im Gespräch mit Michael Kerbler. Klagenfurt: Wieser 2007, S. 20. 
dem Papier seien so entstanden, wie durch das Hineinhauchen von Besoffenen in den Testsack sich dieser dunkel färbt. ${ }^{\text {(53 }}$ Und kurz darauf, im Besonderen auf die Akteure des journalistischen Betriebs gemünzt: „Dem Journalisten zuhören: als würde einem das Lebensgefühl ganz und gar durch seine Rede entzogen, bis zur völligen Wesenlosigkeit, gerade dadurch, daß er die ganze Zeit dieses Lebensgefühl im Mund führt “ ${ }^{54}$ Als wirke dessen Sprache kontagiös, als stelle sie ein ansteckendes Übel dar, formuliert Handke hier nicht nur eine Kritik an den Schreibweisen des Journalismus, sondern deutet darüber hinaus den verheerenden Effekt der inkriminierten „Rede“ auf seine eigene Existenz als Autor, auf seine dezidiert, dichterische' Sprache an; „immer häufiger die Idee“, heißt es in Das Gewicht der Welt weiter, „daß die Nachrichtenwelt [...] einem das Bewußtsein vom eigenen Leben nimmt “. ${ }^{55}$

Auch das in den 1980er Jahren entstandene Journal Am Felsfenster morgens, das die Entstehung der Wiederholung (1986) und anderer Texte begleitet und kommentiert, durchziehen Beobachtungen, die nicht nur Handkes „Verachtung des Zeitungslesens ${ }^{\text {“56 }}$ dokumentieren, sondern auch von einem grundlegenden Gefühl der Bedrohung der eigenen schriftstellerischen Praxis durch die Sprache der Zeitungen handeln. Die Notate, die sich nachgerade leitmotivisch durch den gesamten Band ziehen, können hier lediglich in einer knappen Auswahl wiedergegeben werden: „Schrumpfherz vom Zeitunglesen: welker, schwerer, blutleerer

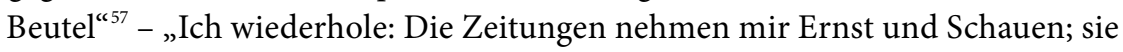
nehmen mir, mit all den, ernsteren' Nachrichten, den ersten Blick (seit 1 Woche habe ich keine Zeitung gelesen) ${ }^{\text {“58 }}$ - „Durch die Beschäftigung mit dem Bekannten (Zeitung) versäume ich das Benennbare; ich kann, im und nach dem Zeitunglesen, nicht mehr benennen ${ }^{\text {“59 }}$ - „Beim Zeitunglesen entfällt mir, augenblicks, alles, worüber ich mich gerade noch gefreut habe “. 60

Im Zentrum von Handkes Notaten steht die Beobachtung, durch die Formelhaftigkeit der Pressesprache in seiner Profession als Autor behindert und geschwächt zu werden. Es handelt sich dabei um ein Phänomen, das er auch an anderen Schriftstellern, an Konkurrenten im literarischen Feld feststellen

53 Peter Handke: Das Gewicht der Welt. Ein Journal (November 1975 - März 1977). Salzburg: Residenz 1977, S. 264.

54 Ebd., S. 279.

55 Ebd., S. 291. Vgl. dazu auch Peter Handke/Peter Hamm: Es leben die Illusionen. Gespräche in Chaville und anderswo. Göttingen: Wallstein ${ }^{2}$ 2008, S. 68: „Das vermeide ich seit zwanzig Jahren; vor dem Ans-Schreiben-Gehen Zeitung zu lesen.“

56 Wagner: Handke als Leser (Anm. 22), S. 144.

57 Handke: Am Felsfenster morgens (Anm. 15), S. 47.

58 Ebd., S. 100.

59 Ebd., S. 117.

60 Ebd., S. 143. 
zu können meinte. Schon im Essay Zur Tagung der Gruppe 47 in USA, im Juni 1966 als Rechtfertigung und Nachbetrachtung seines Princetoner Auftritts in der Zeitschrift konkret veröffentlicht, hatte Handke Walter Höllerer, „,von dem man doch einige gute Gedichte kennt“, vorgeworfen, „in der Prosa einfach die Sprache Sprache sein [zu] lassen“ und „wie ein Reporter“ zu schreiben, was die in Princeton vorgelesene Geschichte „unrein“ gemacht habe: „[A]lle Worte und Wendungen waren gedankenlos hingeschrieben. “61 Seine Abneigung gegenüber den „Zeitungsschriftstellern“, die, wie er 1977 in einer äußerst zwiespältigen Laudatio auf Herbert Achternbusch formuliert, als handle es sich um eine schwer zu kurierende Erkrankung, „das Meinen haben“, 62 hat Handke immer wieder zu pointierten Distinktionsgesten Anlass gegeben. Dabei geht die Kritik an den Schreibverfahren anderer Autorinnen und Autoren stets mit der Reflexion der eigenen Arbeit Hand in Hand: „Aus dem Urteilen und Meinen zieh dich zurück in die Unschuld des Erzählens, wie in den Epikurschen Garten“, hält er Anfang August 1989 in St. Moritz im Journalband Gestern unterwegs fest, um einige Monate später auf dem Weg durch Frankreich zu ergänzen: „Gegen all das Meinen und Urteilen (meines), mit dem ich mir im Älterwerden häßlicher und häßlicher, hassenswerter und hassenswerter werde, möchte ich, drängt es mich, eine regelrechte Wallfahrt zu unternehmen “63

Nimmt man Handkes Kommentare zur österreichischen Gegenwartsliteratur in den Blick, dann fällt auf, dass er sich im Zeichen der Unterscheidung zwischen Literatur und Journalismus von ganz unterschiedlichen, kaum auf einen gemeinsamen literarästhetischen Nenner zu bringenden Autorinnen und Autoren distanziert hat: Sein Verdikt trifft Thomas Bernhard, dem er 1986 im Gespräch mit Herbert Gamper vorwarf, er schreibe so, „wie wenn ein

61 Peter Handke: Zur Tagung der Gruppe 47 in USA. [1966] In: P. H.: Ich bin ein Bewohner des Elfenbeinturms. Frankfurt a. M.: Suhrkamp 1972, S. 29-34, hier S. 33.

62 Peter Handke: Zu Herbert Achternbusch. [1977] In: P. H.: Das Ende des Flanierens. Frankfurt a. M.: Suhrkamp 1980, S. 101-105, hier S. 101. Als schriftstellerisches Gegenprogramm, das sich für ihn aus seinen ernüchternden Wahrnehmungen zum Problem des ,Meinens' ergibt, skizziert Handke im März 1977, also im Jahr der Achternbusch-Laudatio, auf der vorletzten Seite des Journalbandes Das Gewicht der Welt das folgende Vorgehen: „Das Betrachten so lange aushalten, das Meinen so lange aufschieben, bis sich die Schwerkraft des Lebensgefühls ergibt“ (Handke: Das Gewicht der Welt [Anm. 53], S. 324). Zum Gegensatz von ,Meinen' und ,Erzählen` bei Handke vgl. Katrin Kohl: Poetologische Metaphern. Formen und Funktionen in der deutschen Literatur. Berlin, New York: de Gruyter 2007, S. 373 f.; Wagner: Bernhard, Handke und die österreichische Literatur (Anm. 6), S. 42. - Dass „Urteil und Meinung in den Erzählungen Stifters“ „kaum vorhanden“ seien, kann in diesem Zusammenhang etwa als ausdrückliches Lob gelten (Peter Handke: Einige Bemerkungen zu Stifter. [1991] In: P. H.: Langsam im Schatten. Gesammelte Verzettelungen. 1980-1992. Frankfurt a. M.: Suhrkamp 1992, S. 55-57, hier S. 56).

63 Handke: Gestern unterwegs (Anm. 16), S. 435 u. 510. 
Spiegelreporter als Schriftsteller auftritt" ${ }^{64}$ ebenso wie Eva Menasse. Von seinem Biographen Malte Herwig auf die Autorin und Journalistin Menasse angesprochen, zeigte sich Handke 2009 jedenfalls wenig begeistert: „Die hat vor ein paar Jahren so ein Buch über den Vater geschrieben“ - gemeint ist der Roman Vienna (2005), einer der stilprägenden Familienromane des 21. Jahrhunderts. „Das fing so an: ,Mein Vater war eine Sturzgeburt.' Da habe ich gedacht, das sind so richtige Zeitungssätze. “65 Im selben Jahr hat Handke seinem Vorbehalt in einem Gespräch mit Klaus Kastberger und Elisabeth Schwagerle ein weiteres Mal Ausdruck verliehen:

Die meisten Autoren schreiben inzwischen wie Journalisten. Schon beim ersten Satz denkt man, das könnte auch in der Zeitung stehen, und so geht das dann weiter. Für mich ist Schreiben Forschung, dabei weiß ich nicht, wo man hinkommt. Und was man weiß, vergisst man. Naja, das ist für mich ein großes Problem, viele Autoren heute zu lesen. Es ist schon im Voraus alles klar, die Konstruktion ist klar, die Sätze sind kurz geworden, das ist sehr seltsam. Ich kann keine kurzen Sätze lesen, das ist so eine Krankheit von mir, scheint's. ${ }^{66}$

Die entsprechende Kritik trifft mitunter auch Autoren, die er außerordentlich schätzt, etwa Tolstoi, der in Krieg und Frieden, so Handke in einem Gespräch aus dem Jahr 2009, zwischenzeitlich zum „Zeitungsschreiber“ mutiere. ${ }^{67}$ Wer sich im literarischen Schreiben an den Duktus des Journalismus annähere, korrumpiere

64 Peter Handke: Aber ich lebe nur von den Zwischenräumen. Ein Gespräch, geführt von Herbert Gamper. Zürich: Ammann 1987, S. 93.

65 Malte Herwig: Meister der Dämmerung. Peter Handke. Eine Biographie. München: DVA 22010, S. 30o. - Es handelt sich dabei tatsächlich um den ersten Satz von Menasses Roman; siehe Eva Menasse: Vienna. Roman. Köln: Kiepenheuer \& Witsch 2005, S. 9. Dazu ausführlicher Harald Gschwandtner: „Fontane hat das vielleicht noch gekonnt“. Familiennarrativ und Gattungspolemik bei Peter Handke. In: Familie und Identität in der Gegenwartsliteratur. Hg. v. Goran Lovrić u. Marijana Jeleč. Frankfurt a. M. u. a.: Lang 2016, S. 199-218. Zu Menasses Roman hat sich Handke bereits 2008 in einem Interview abschätzig geäußert. Vgl. Christine Eichel: „Der Zorn verraucht, das Feuer bleibt.“ [Gespräch mit Peter Handke.] In: Cicero online, Februar 2008, http://www.cicero.de//der-zorn-verraucht-das-feuer-bleibt/38460 (Stand 20.12. 2015).

66 Klaus Kastberger/Elisabeth Schwagerle: „Es gibt die Schrift, es gibt das Schreiben. “ Peter Handke im Gespräch. In: Peter Handke. Freiheit des Schreibens - Ordnung der Schrift. Hg. v. Klaus Kastberger. Unter Mitarb. v. Clemens Özelt. Wien: Zsolnay 2009, S. 11-30, hier S. 13. Vgl. auch seine Äußerung in Ulrich Weinzierl: „Serbien soll Weltmeister werden“. [Gespräch mit Peter Handke.] In: Welt am Sonntag, Nr. 24, 13.6.2010, S. 68: „Die Schriftsteller werden wie alle, wie Journalisten.“

67 Ulrich von Bülow: „Wait and see!“ Peter Handke im Gespräch. In: Das stehende Jetzt. Die Notizbücher von Peter Handke. Gespräch mit dem Autor und Essays von U. v. B. Marbach a. N.: Deutsche Schillergesellschaft 2018, S. 5-63, hier S. 34. 
sein schriftstellerisches Ethos, sei das „Erzählen“ doch, wie es im Versuch über die Müdigkeit (1989) heißt, die „ursprünglich am meisten von Meinungen freie[ ], weitherzigste[ ] Weise zu reden“ ${ }^{68}$

Mit Nachdruck hat sich Handke gegen die „heteronomen Zwänge[ ], die auf die künstlerischen Felder heute seitens des journalistischen Feldes und des Feldes der Macht einwirken", 69 zur Wehr zu setzen versucht, hat darauf insistiert, die ,Geistlosigkeit ${ }^{70}$ der journalistischen Meinungsführer von der sprachlichen Sensibilität literarischen Erzählens zu unterscheiden. Obgleich seine Reflexionen zu diesem Komplex mitunter apodiktisch anmuten und einen gewissen Hang zur polemischen Zuspitzung verraten, ${ }^{71}$ zeigen sie dessen ungeachtet ein hohes Problembewusstsein für den Status literarischen Schreibens und sprachlicher Weltaneignung in der Informations- und Mediengesellschaft des späten 20. bzw. frühen 21. Jahrhunderts. Immer wieder sind Handkes Invektiven gegen den Einbruch journalistischer Verfahren ins Literarische zudem mit dem Vorwurf an die Schriftsteller verknüpft, als, geschäftige ${ }^{72}$ und ,geschäftstüchtige ' Autoren heteronomen Prinzipien zu folgen und ihr Schreiben, auf bessere Marktchancen und

68 Peter Handke: Versuch über die Müdigkeit. Frankfurt a. M.: Suhrkamp 1989, S. 29. Zur Stellung des ersten Versuchs im Werkzusammenhang vgl. Dominik Srienc: „Aber das Schreiben war Existenz non plus ultra“. Peter Handke, der Bleistift und der Versuch über die Müdigkeit. In: Peter Handke. Stationen, Orte, Positionen. Hg. v. Anna Kinder. Berlin, Boston: de Gruyter 2014, S. 153-171.

69 Wolf: Autonomie und/oder Aufmerksamkeit? (Anm. 13), S. 63, mit Bezug auf Bourdieus Literatursoziologie. Vgl. auch ebd., S. 49, über „Handkes offensichtliches Ansinnen, den [...] wachsenden Einfluss des journalistischen Feldes auf andere, vordem autonomere Felder kultureller Produktion zu konterkarieren“, sowie sein Bestreben, „der Funktionsweise des immer stärker ausschließlich den Anforderungen eines homogenisierenden Massenmarktes unterworfenen journalistischen Feldes ein konträres künstlerisches Kalkül entgegenzusetzen, das auf Autonomie pocht".

70 Vgl. Peter Handke: Am Felsfenster, morgens. In: manuskripte 27 (Oktober 1987), H. 97, S. 3-9, hier S. 9: „Nichts Geistloseres als Meinungen“ (10.5.1987), zuvor bereits: „Die meisten, die für Zeitungen schreiben, kann ich mir nicht schreibend vorstellen, nur diktierend“ (3. 5.1987); beide Notate wurden in die Buchfassung des Journals, Am Felsfenster morgens (1998), nicht aufgenommen.

71 Nicht selten geht Handkes Medienschelte in eine umfassende Zivilisationskritik über. Vgl. Thorsten Carstensen: Romanisches Erzählen. Peter Handke und die epische Tradition. Göttingen: Wallstein 2013, S. 31 f.: „Handkes Erneuerung der epischen Tradition wird begleitet von einer - mitunter plakativ übersteigerten - Kritik an der postmodernen Lebenswelt“, etwa vom Widerstand „[g] egen die Akzeleration des Alltagslebens“. Dazu außerdem Christians: Der Roman vom Epos (Anm. 28), S. 373 f. Auch Ilma Rakusas lesenswerter Essay Lamgsamer! nimmt auf Handkes Poetik Bezug; vgl. Ilma Rakusa: Langsamer! Gegen Atemlosigkeit, Akzeleration und andere Zumutungen. Graz, Wien: Droschl 52008, bes. S. 32-34.

72 Vgl. dazu bereits den Mitte der 196oer Jahre gegen Martin Walser erhobenen Vorwurf in Peter Handke: „Bücherecke“ vom 5. 7. 1965. In: P. H.: Tage und Werke (Anm. 21), S. 225-232, hier S. 225: „Martin Walser ist unter den jüngeren deutschen Autoren in seinem Metier der geschäftigste." 
Verkaufszahlen schielend, zu ,verraten'. Die „Journalisierung“ der Literatur, die Robert Musil schon Mitte der 1920er Jahre diagnostiziert und beklagt hatte, die Gefahr, dass „die Literatur der Literaten“ durch jene der Journalisten „ersetz[t]“ werde, ${ }^{73}$ beschäftigt Peter Handke jedenfalls seit langer Zeit.

\section{„vollkommen humorlos und blöd“: Bernhard und die Literaturkritik}

Noch in seinem vorletzten Brief an Siegfried Unseld vom 20. November 1988 in jener Zeit, als die Beziehung zwischen Verleger und Autor so sehr auf dem Spiel steht wie selten zuvor - hält Bernhard zur skandalumwitterten Aufführung seines Stücks Heldenplatz am Wiener Burgtheater fest: „Leider sind alle Kritiken Blödsinn, weil die Leute sich nie die Mühe machen, das Buch zu lesen, sie schauen ja nicht einmal wirklich hinein; aber das bin ich gewöhnt. Die Zukunft wird gerade dieses Stück als ein ganz besonderes erkennen und mir in allen Punkten rechtgeben. “74 Man muss Bernhard hier eine gewisse Triftigkeit seiner Einschätzung zugestehen, hatten sich doch große Teile der Diskussion um Heldenplatz in der (Boulevard-)Presse an mutwillig ausgewählten und aus dem Zusammenhang gerissenen Textpassagen entzündet, während deren Funktion im dramaturgischen Gesamtgefüge des Stücks geflissentlich ignoriert wurde. ${ }^{75}$

73 Robert Musil: Der „Untergang“ des Theaters. [1924] In: R. M.: Gesammelte Werke. Hg. v. Adolf Frisé. Bd. II: Prosa und Stücke. Kleine Prosa, Aphorismen. Autobiographisches. Essays und Reden. Kritik. Reinbek b. Hamburg: Rowohlt 200o, S. 1116-1131, hier S. 1128.

74 Bernhard an Unseld, 20.11. 1988. In: Bernhard/Unseld: Der Briefwechsel (Anm. 11), S. 802. Im gleichen Brief teilte er Unseld seinen Entschluss mit, ein weiteres Buch im Residenz Verlag zu veröffentlichen (In der Höhe. Rettungsversuch, Unsinn). In seinem Antworttelegramm vom 24.11. formulierte Unseld seine endgültige Kapitulation: „lieber herr bernhard / ich habe gestern ihren brief vom 20. november erhalten. fuer mich ist eine schmerzensgrenze nicht nur erreicht, sie ist ueberschritten. nach all dem, was in jahrzehnten und insbesondere in den beiden letzten jahren an gemeinsamem war, desavouieren sie mich, die ihnen gewogenen und fuer sie wirkenden mitarbeiter, und sie desavouieren den verlag. ich kann nicht mehr. / ihr siegfried unseld“ (ebd., S. 805). In der Folge kam es aber noch zu einem letzten persönlichen Gespräch der beiden in Salzburg, zwei Wochen vor Bernhards Tod (vgl. dazu den Kommentar ebd., S. 806-811).

75 Vgl. Billenkamp: Thomas Bernhard (Anm. 41), S. 389: „In Bernhards Spätwerk, das belegen die Skandale zu Holzfällen, Alte Meister und Heldenplatz, wird jede Aussage seiner Figuren zu einer persönlichen Stellungnahme des Autors simplifiziert." Siehe schon Huntemann: Artistik und Rollenspiel (Anm. 10), S. 195: Die in Heldenplatz „von der fiktiven Figur Professor Schuster betriebene Österreichbeschimpfung entfachte, von der Presse vorab in Ausschnitten veröffentlicht, bereits vor der Uraufführung Entrüstungsstürme, als sei sie vom Autor selbst, außerhalb eines fiktiven Kontextes, geäußert worden. “Zur Rekonstruktion des Konflikts vgl. Oliver Bentz: Thomas Bernhard - Dichtung als Skandal. Würzburg: Königshausen \& Neumann 20oo; Robert Weninger: Wien: Heldenplatz. Viel Ärger um Thomas Bernhard. In: R. W.: Streitbare Literaten. 
Dennoch sticht in Bernhards Brief an Unseld erneut die Apodiktik seiner denunziatorischen Feststellung ins Auge: Nicht eine erhebliche Anzahl von Kritiken oder bestimmte meinungsbildende Zeitungen, etwa die auflagenstarke KronenZeitung, fallen unter sein vernichtendes Urteil, lediglich „Blödsinn“ von sich zu geben, sondern eben ausnahmslos „alle Kritiker“.

„Höre ich meinen Namen aus dem Rundfunk“, schreibt Bernhard bereits im Herbst 1972, einige Monate nach dem Salzburger, Notlicht-Skandal' um Der Ignorant und der Wahnsinnige, an Unseld, „sehe ich mich im Dreck liegen, lese ich meinen Namen in der Zeitung, glaube ich, ich bin in einer Kloake. ${ }^{\text {c76 }}$ Ein ums andere Mal hat der Autor festgehalten, seit Beginn seiner schriftstellerischen Laufbahn von einer breiten Front der Kritik abgelehnt worden zu sein - auch wenn sich dieser Befund bei der Relektüre der zeitgenössischen Rezensionen der Prosaarbeiten und Bühnenstücke Bernhards kaum verifizieren lässt. Zwar fanden einzelne Texte nur wenig positive Resonanz bei den Literatur- und Theaterkritikern (etwa die Wiener Uraufführung der Berühmten 1976), von einer einhelligen Ablehnung seiner Literatur im Feuilleton kann jedoch, wie in der Folge an einem Beispiel gezeigt werden soll, nicht die Rede sein. Vielmehr erwarben sich im Laufe der Jahre zahlreiche bedeutende und einflussreiche Kritiker wie Günther Blöcker, Benjamin Henrichs, Karin Kathrein oder Marcel Reich-Ranicki große Verdienste um die Durchsetzung seines Werks. Sie trugen ganz wesentlich zur Popularisierung von Bernhards Literatur im deutschsprachigen Raum bei.

Kontroversen und Eklats in der deutschen Literatur von Adorno bis Walser. München: C. H. Beck 2004, S. 118-132; Martin Huber: Was war der „Skandal“ an Heldenplatz? Zur Rekonstruktion einer österreichischen Erregung. In: Thomas Bernhard. Gesellschaftliche und politische Bedeutung der Literatur (Anm. 6), S. 129-136; außerdem den Kommentar in Thomas Bernhard: Heldenplatz. Mit einem Kommentar v. Martin Huber. Berlin: Suhrkamp 2012. Zur Konzentration auf die „weit ausholenden Tiraden gegen Österreich“ in der Rezeption von Bernhards Spätwerk bei gleichzeitiger Vernachlässigung der „dichterische[n] Qualität“ der jeweiligen Texte jetzt auch Axel Diller/Manfred Mittermayer: Rezeption der Prosa im deutschen Sprachraum. In: Bernhard-Handbuch. Leben - Werk - Wirkung. Hg. v. Martin Huber u. M. M. Unter Mitarb. v. Bernhard Judex. Stuttgart: Metzler 2018, S. 478-483, hier S. 479.

76 Bernhard an Unseld, 22.11.1972. In: Bernhard/Unseld: Der Briefwechsel (Anm. 11), S. 329. Lassen Bernhards Kritikerschelten dabei auch nichts an Deutlichkeit vermissen, agitierte er doch nicht mit der gleichen rhetorischen Derbheit wie der 13 Jahre jüngere Peter Turrini, mit dem Bernhard seit den späten 1950er Jahren bekannt war: „Damit ist der Kritiker nur noch einem hauptberuflich tätigen Onanisten vergleichbar, der es im Laufe von zehn fleißigen Jahre auf mehr als fünfzig Arten des Wichsens gebracht hat. [...] Wer die Ausscheidungskämpfe siegreich besteht und seinen Kollegen immer um zwei Tropfen voraus ist, der darf sich Großkritiker oder Großwichser oder Juror des Berliner Theatertreffens nennen. " (Peter Turrini: Kulturkritik. [1974] In: P. T.: Mein Österreich. Reden, Polemiken, Aufsätze. Darmstadt: Luchterhand 1988, S. 27-39, hier S. 30 f.) Zu Turrinis Konflikten mit der Literaturkritik vgl. Franz Schuh: All you need is love. Notizen und Exzerpte zur (Literatur-)Kritik. In: F. S.: Schreibkräfte. Über Literatur, Glück und Unglück. Köln: DuMont 200o, S. 24-114, hier S. 36-41. 
Dankbarkeit oder das Eingeständnis, von anderen Akteuren des literarischen Feldes Hilfe und Unterstützung erhalten zu haben, waren von Bernhard jedoch nicht zu bekommen. So wie er immer wieder auf der Existenz einer „grundsätzlich feindlichen Einstellung fast der gesamten Lebensumgebung "ihm gegenüber insistierte, ${ }^{77}$ unterstrich er auch die angeblich feindliche Einstellung fast aller Kritiker mit großer Regelmäßigkeit. Hier wie dort handelt es sich um die Stilisierung eines Autors, der wiederholt betont hat, die Kraft für sein Schreiben aus dem ,Widerstand', aus der ,Verteidigung' zu gewinnen - und an diesem ,Widerstand zu wachsen: „Es sind lauter Widerstände von Anfang an“, heißt es exemplarisch im 1970 von Ferry Radax gedrehten Film-Monolog Drei Tage, „wahrscheinlich schon immer gewesen. [...] Das Gehirn braucht Widerstände.“ (TBW 22.2, 57) Weil ihm „Widerstände“, so Bernhard weiter, „alles bedeuten“, wird das andauernde „Zur-Wehr-Setzen“ im Selbstverständnis des Autors zur Leitvorstellung seiner Poetik (TBW 22.2, 62 f.). ${ }^{78}$ In diesem Narrativ, das Bernhard bei verschiedenen Gelegenheiten und in diversen Textsorten ausgestaltet hat, würde das Ausbleiben der Widerstände, würde das Fehlen der Feinde die Produktivkräfte des Autors ganz wesentlich schwächen.

Sich von den Kritiken seiner Bücher, seien sie positiv oder negativ, im Grunde nie verstanden zu fühlen - diesen Eindruck hat Thomas Bernhard wiederholt geäußert: „Ich habe, glaube ich, noch nie etwas gelesen, wovon ich denken konnte: Das ist gut so, genau das denke ich“, so der Autor 1978 im Gespräch mit Nicole Casanova (TBW 22.2, 148). ${ }^{79}$ Mehrmals hat er diesen Umstand, nach den Gründen für das angeblich weitverbreitete Unverständnis befragt, auf die mangelnde musikalische Sensibilität der Kritikerriege zurückgeführt, die nicht in der Lage sei, die „Zwischentöne“ seiner Texte wahrzunehmen. Dies habe, wie Bernhard im Interview mit Armin Eichholz betont, zu einer einseitigen Lektüre seines Werks und zu einer entsprechenden Wahrnehmung seiner Person beigetragen: „Aber die Zwischentöne - wer versteht denn das heut? Brauchen S’ bloß die Kritiken lesen - wenn ich mir das anschau', ist das vollkommen humorlos und blöd.

77 Mittermayer: Thomas Bernhard [2015] (Anm. 42), S. 358.

78 Vgl. in diesem Zusammenhang, um nur ein weiteres Beispiel zu nennen, auch Bernhards Äußerung im Gespräch mit Rudolf Bayr über die biographischen Voraussetzungen des 1975 publizierten Bandes Die Ursache: „Ich glaube, irgendeinen Fußtritt, und zwar einen ganz entscheidenden, muß jeder im Leben bekommen. Oder eine Ohrfeige, die einen gleich aus dem Haus und über die Straße hinaushaut. Sonst geht das nicht. Das ist notwendig, da bin ich ganz überzeugt." (TBW 22.2, 71)

79 Dazu Bernhards anschließende Einschränkung: „Aber zweifelsohne gibt es dieses Gefühl gar nicht. Wenn jemand ganz genau die Gedanken eines anderen wiedergeben könnte, dann müßte er schweigen, weil er sonst vollständig aufgesaugt und verschlungen würde. Dann geht man weg, man rettet sein Leben, indem man sich in die Lüge und die Oberflächlichkeit flüchtet, wie ein Ertrinkender, der kämpft, um dem Strudel zu entkommen.“ (TBW 22.2, 148f.) 
Wer weiß, was sie alle von mir erwarten ... Daß i a schwarz' Kreuz trag', daß i umfall' ..." (TBW 22.2, 85) Nicht nur würden die Kritiker wie andere, nicht-professionelle Leser bei der Lektüre seiner Bücher von der fatalen Ausweglosigkeit der geschilderten Welt umstandslos auf Psyche und Lebensrealität des Autors Bernhard schließen. ${ }^{80}$ Sie seien, so Bernhard, darüber hinaus nicht in der Lage, die Feinheiten seines Prosarhythmus und der musikalischen Strukturen seiner Theaterstücke zur Kenntnis zu nehmen.

Im ,Nachtgespräch' mit Peter Hamm - 1977 in Ohlsdorf geführt, aber erst 2011 veröffentlicht - hat der Autor sich ausführlicher dazu geäußert und, in der Sache durchaus ernsthaft, Fortbildungsmaßnahmen für die kritisierten Kritiker angeregt:

Ja, ich sehe die Prosastücke wie die Stücke als Partituren. Die Kritiker aber sehen nur die Singstimme oder den Klavierauszug, und dadurch geht bei ihnen immer alles daneben, weil sie das Ganze nicht sehen. Sie sehen nur den Auszug und die Oberstimme. Und das ist für mich immer der Ruin, und deshalb hab' ich eigentlich noch nie das gelesen, was das treffen würde, nicht? Ob jetzt positiv oder negativ, das ist ganz wurscht. Der Literaturkritiker müßte eigentlich auch um die drei Jahre in die Musikhochschule gehen, finde ich. Literatur hat ja sehr viel damit zu tun. Und wer das nicht macht, der ist einfach degradiert von vornherein. (TBW 22.2, 111)

Bei einer anderen Gelegenheit, in einem zunächst in Le Monde publizierten, ein Jahr darauf im Suhrkamp-Spectaculum auf Deutsch erschienenen ${ }^{81}$ Interview mit dem französischen Journalisten Jean-Louis de Rambures, attestiert Bernhard

80 Vgl. die einschlägige Passage im ersten Gespräch mit Krista Fleischmann, Monologe auf Mallorca (1981): „[I]ch bin wahrscheinlich lebenslänglich der negative Schriftsteller. [...] Weil die Leut” sagen, ich bin ein negativer Schriftsteller, und ich bin aber gleichzeitig ein positiver Mensch." (TBW 22.2, 191f.) Ähnlich hatte sich Bernhard bereits 1977 gegenüber Peter Hamm geäußert: „Ich bin ja nicht todesverfallen, die Kritik, die so was immer wieder behauptet, ist ja ein Blödsinn. Wer dem Tod verfallen ist, könnte so nie schreiben." (TBW 22.2, 118) Im 1978 geführten ORF-Interview mit Brigitte Hofer hat Bernhard das ,Zurechtrücken` journalistischer Kommentare zudem als nicht unwesentlichen Antrieb für die Publikation seiner autobiographischen Bücher ins Spiel gebracht: „Ich mein', wenn ich die Zeitungen aufmach', stehn da über mich die unmöglichsten Sachen, und , mein Weg geht dorthin und dahin' und alles, was Tod betrifft und Leben und Philosophie und einfaches Leben und hin und her, das ist alles falsch bis jetzt. Und dann kommt der Moment, wo einem vor dieser Sache graust, und dann setzt man sich selber hin und versucht, das mehr oder weniger ins Authentische zu bringen." (TBW 22.2, 138)

81 Der Kommentar der Werkausgabe unterschlägt den deutschsprachigen Druck zu Lebzeiten und nennt Sepp Dreissingers Sammelband Von einer Katastrophe in die andere (1992) als Ersterscheinungsort des Interviews auf Deutsch (vgl. TBW 22.2, 517). Vgl. jedoch Jean-Louis de Rambures: Thomas Bernhard im Gespräch mit Le Monde. In: Spectaculum 39. Sechs moderne Theaterstücke. Frankfurt a. M.: Suhrkamp 1984, S. 242-245. 
dieses Defizit 1983 im Besonderen den bundesdeutschen Rezensenten und weist zudem darauf hin, dass die Fokussierung vieler Kritiker auf die histoire seiner Texte den Blick auf den discours, auf das „Wie“ seines Erzählens verstelle:

Ja, was ich schreibe, kann man nur verstehen, wenn man sich klarmacht, daß zuallererst die musikalische Komponente zählt und daß erst an zweiter Stelle das kommt, was ich erzähle. Wenn das erste einmal da ist, kann ich anfangen, Dinge und Ereignisse zu beschreiben. Das Problem liegt im Wie. Leider haben die Kritiker in Deutschland kein Ohr für die Musik, die für den Schriftsteller so wesentlich ist. (TBW 22.2, 250) ${ }^{82}$

Ähnliche Beobachtungen sollte einige Jahre später, in affirmativem Rekurs auf Bernhard, aber poetologisch deutlich versierter, auch Elfriede Jelinek formulieren:

Diese Art Literatur, die sich mit der Sprache selbst beschäftigt, im Anschluss an den frühen Wittgenstein und vor allem in der Nachfolge der Wiener Gruppe, der ich samt Artmann, Jandl und Mayröcker eigentlich das allermeiste verdanke, ist typisch österreichisch. Ich habe das Gefühl, die Deutschen verstehen nicht wirklich, was ich schreibe, oder nur wenige von ihnen. Sie haben eine ganz andere literarische Tradition, eben die realistische, erzählerische. Als hätte es nicht schon die BrechtLukács-Realismusdebatte gegeben. Sie erzählen immer wieder vor sich hin. Dazu kommt, dass ich Musikerin bin und eher lautlich, musikalisch die Sprache auf ihren Ideologiecharakter abklopfe, wie ein Arzt einen Brustkorb. ${ }^{83}$

Sie habe, so Jelinek, „immer darunter gelitten, dass die Leute an meiner Arbeit nur die Oberflächenstrukturen gesehen haben, sozusagen nur die Melodie, nicht die harmonische Verarbeitung der Melodie“ ${ }^{84}$ Ganz analog zu Bernhard besteht Jelinek darauf, „eine Zwischenform zwischen Komponieren und Schreiben“ zu betreiben, die bei nicht entsprechend sensibilisierten Lesern - und man kann diesen ,Leuten' auch hier die Riege der Kritiker zurechnen - für Unverständnis und Irritation sorge: „Das geht sicher so weit, dass Leute, die sich nie mit Musik beschäftigt haben, sofern es die überhaupt noch gibt, weil sich ja jeder

82 Vgl. dazu auch das Interview mit Werner Wögerbauer aus dem Jahr 1986, wobei man sich der beständigen Ironisierungstendenzen von Bernhards Gesprächsduktus stets bewusst bleiben muss: „Könnte ein deutscher Autor so schreiben? / Na sicher nicht, Gott sei Dank. Die Deutschen sind ja unmusikalisch, das ist ja ganz etwas anderes." (TBW 22.2, 290)

83 Andreas Puff-Trojan: „Vielleicht sind ja doch die Alpen schuld“. Gespräch mit Elfriede Jelinek. In: Frankfurter Rundschau, 13.10. 2004.

84 Frido Hütter: „Ich schulde so vielen so vieles“. Nobelpreisträgerin Elfriede Jelinek über die Hoffnung auf Rückkehr zur Normalität und den Zusammenhang von Text und Musik. In: Kleine Zeitung, 10.10. 2004. 
mit Musik zudröhnt, gar nichts [mit meinen Arbeiten] anfangen können. Für die ist es wahrscheinlich ein leeres Rauschen. Das rauscht dann an ihnen vorbei. Es erscheint ihnen als unsinnig. ${ }^{85}$ Bei Bernhard wie bei Jelinek lautet der Vorwurf an die Kritik, diese sei aufgrund ihres eingeschränkten Sensoriums für künstlerisch-artistische Ausdrucksformen nicht in der Lage, die jeweiligen Texte in ihrer ästhetischen Komplexität - also nicht nur auf der Inhaltsebene wahrzunehmen und zu würdigen: „Der Geist bleibt immer auf der Strecke“, wie Bernhard 1987 im letzten ausführlichen Interview mit einem etwas plakativen Bild für das Verhältnis von Literatur und Kritik konstatiert, „[d]er Geschmack bleibt auf der Strecke. Die Poesie bleibt auf der Strecke. Darüber reiten die Kolonnen von Redakteuren und Kritikern hinweg. Sie gehen über alle Leichen, die irgend etwas Schöpferisches machen.“ (TBW 22.2, 336 f.) Dem „berühmten Kritiker" Joachim Kaiser, 1970 gemeinsam mit Bernhard bei einem feierlichen Festakt ausgezeichnet, gesteht Bernhard in Meine Preise Anfang der 1980er Jahre zwar „musikwissenschaftliche[ ] Kenntnisse“, einen „verblüffenden geballten Kenntnisreichtum“ zu: „Von Literatur“ jedoch, so das harsche Fazit, „versteht Kaiser nichts“ (TBW 22.2, 440).

„vom peinlichsten Lob bis zum bösartigsten Verriß“:

Bernhard liest Rezensionen (Frost)

Warf er den bundesdeutschen Kritikern also mehrheitlich vor, die musikalische Qualität seines Schreibens nicht entsprechend anzuerkennen, war es um Bernhards Meinung zur Situation der Kritik in seinem Heimatland keineswegs besser bestellt. Schon in einer frühen Literatur-Polemik hatte Bernhard im Oktober 1959 „das Fehlen auch nur einer einzigen Kritikerpersönlichkeit in Österreich“ beklagt; er sei, wie er in der autobiographischen, gleichwohl in der dritten Person Singular verfassten Skizze Junge Köpfe für das Magazin Morgen schreibt, „wütend“ über diesen Umstand (TBW 22.1, 577). Gemeinsam mit der mangelnden Selbstkritik der Wiener Autorenszene ergebe dieses Defizit des hiesigen Literaturbetriebs eine fatale Kombination:

85 Hans-Jürgen Heinrichs: Wo nichts ist, kann nichts vergeudet werden. Gesellschaft und Obszönität, Lust und Schreiben, Männer und Frauen: Elfriede Jelinek im Gespräch. In: Frankfurter Rundschau, 4.3.200o. Zur Bedeutung der Musikalität bei Bernhard und Jelinek vgl. jetzt Rita Svandrlik: Das Zusammenwirken von Lust und Unlust beim Lesen von Elfriede Jelinek und Thomas Bernhard. In: Figurationen 15 (2014), H. 2, S. 83-98, bes. S. 97, sowie allg. den Sammelband: Sprachmusik. Grenzgänge der Literatur. Hg. v. Gerhard Melzer u. Paul Pechmann. Wien: Sonderzahl 2003, darin die Beiträge von Martin Huber, Gudrun Kuhn und Manfred Mittermayer (zu Bernhard) sowie Gerhard Fuchs und Pia Janke (zu Jelinek). 
Die Wiener sieht er nicht liebenswürdig, sondern von der Unfähigkeit, sich selbst zu kritisieren, berauscht. Diese Beobachtung trifft auch die jungen und zäh älter werdenden Literaten dieser Stadt, die, Epigonen von Natur aus, in den Kaffeehäusern bei lebendigem Leib vermodern. Keiner Hymne und keines Intellekts fähig, beweihräuchern sie sich gegenseitig an den Extratischen und in den Spalten der schmutzigsten, witzlosesten und unbedeutendsten Zeitungsblätter der Welt. (TBW 22.1, 577)

Bernhards Suada, in der er sein eigenes Schreiben, als Gegenentwurf zu den denunzierten Zeitgenossen, in der Tradition von Dostojewski, Hamsun und Thomas Wolfe als radikale Abkehr vom Herkömmlichen verortet, verrät noch eine gewisse stilistische Unbeholfenheit - und ein nicht unerhebliches Maß an Prätention. Sie nimmt gleichwohl eine Behauptung vorweg, die der Autor später mit Blick auf sein Prosadebüt Frost (1963) erneut vehement vertreten sollte: Der österreichische Kulturbetrieb entbehre nicht nur einer ernstzunehmenden „Kritikerpersönlichkeit“, sondern er verschließe sich, folgt man Bernhards Narrativ, zudem aus Eigendünkel allen Impulsen von außen. ${ }^{86}$ Die Rezeption von Frost habe, so Bernhard im Abstand von knapp zwei Jahrzehnten im erst postum veröffentlichten Prosatext Meine Preise, „Vom peinlichsten Lob bis zum bösartigsten Verriß“ gereicht (TBW 22.2, 384). Carl Zuckmayers euphorische Rezension in der ZEIT, die für seine Durchsetzung im literarischen Feld eine nicht unerhebliche Rolle spielte, hebt Bernhard ausdrücklich hervor. Tatsächlich eröffnete Zuckmayers Besprechung des Romans „einen Reigen enthusiastischer Rezensionen im deutschsprachigen Feuilleton“, die sich „von der Neuartigkeit und der Intensität dieser Literatur fasziniert ${ }^{\text {“87 }}$ zeigten; die Rezeption des Buches in Tagesund Wochenzeitungen hat von "Zuckmayers überaus positive[r] Rezension“ und vom „Konsekrationskapital des im deutschsprachigen Raum so renommierten Autors“ jedenfalls stark profitiert. ${ }^{88}$

86 Eine Einschätzung, die, zieht man etwa die Aktivitäten der Wiener Avantgardeformation um Friedrich Achleitner, H. C. Artmann, Konrad Bayer, Gerhard Rühm und Oswald Wiener in den 1950er Jahren in Betracht, die sich intensiv um einen Anschluss an internationale Strömungen bemühten, nur bedingt überzeugen kann, zumal sich auch einige konservative Akteure des Kulturbetriebs, u. a. Heimito von Doderer und Hans Sedlmayr, für die junge Autorengeneration einsetzten. Sedlmayr verfasste 1958 ein Vorwort zu Artmanns med ana schwoazzn dintn. gedichta r aus bradnsee, Doderer ein Jahr später ein Geleitwort zur Gemeinschaftsproduktion von Achleitner, Artmann und Rühm, zum Lyrikband hosn rosn baa. - Zur Bedeutung der Wiener Gruppe für die österreichische Literaturgeschichte vgl. exemplarisch den Sammelband: verschiedene sätze treten auf. Die Wiener Gruppe in Aktion. Hg. v. Thomas Eder u. Juliane Vogel. Wien: Zsolnay 2008.

87 Günther Stocker: Bernhard und die literarische Landschaft Österreichs der 1950er und 1960er Jahre. In: Bernhard-Handbuch (Anm. 75), S. 296-301, hier S. 299.

88 Michael Billenkamp: Provokation und posture. Thomas Bernhard und die Medienkarriere der Figur Bernhard. In: Mediale Erregungen? Autonomie und Aufmerksamkeit im Literatur- und 
In Österreich jedoch habe Frost, so Bernhards bitteres Resümee, „nicht eine einzige positive Besprechung gehabt, im Gegenteil“; das Buch sei, wie er noch an einer weiteren Stelle des Textes betont, "gleich bei seinem Erscheinen ausnahmslos von allen österreichischen Zeitungen heruntergemacht worden“. Zudem seien die Besprechungen „nicht an gehöriger Stelle“ erschienen, „wie ich es mir vorgestellt hatte, sondern irgendwo links oder rechts unten, wo die Nichtswürdigkeiten und die Verachtung von jeher ihren Platz haben“ (TBW 22.2, 414) ${ }^{89}$ Außerhalb Österreichs sei Frost und ganz allgemein sein frühes Prosawerk indes sehr viel freundlicher und wertschätzender aufgenommen worden. Einen Beleg für diese Behauptung sah Bernhard etwa in der Zuerkennung eines Arbeitsstipendiums zum Julius-Campe-Preis im Jahr 1964, dessen Umstände er ebenfalls in Meine Preise behandelt, wobei er erneut die Dichotomie zwischen Deutschland und Österreich ins Spiel bringt: „Aus Hamburg habe ich den Preis bekommen, aus Hamburg, aus Hamburg, dachte ich immer wieder und ich verachtete die Österreicher insgeheim, die mir bis dahin noch niemals auch nur die Spur einer Anerkennung gezeigt hatten. Von der Nordsee herunter war die Kunde gekommen, von der Binnenalster!“ (TBW 22.2, 398) ${ }^{90}$ In einem nicht datierten Gespräch mit dem Journalisten Kurt Hofmann hat Bernhard noch einmal auf die ungleiche Behandlung seines Debütromans in der österreichischen und deutschen Literaturkritik hingewiesen:

[A]ls ,Frost' erschien, ist es ja hier sowieso völlig abgelehnt worden. Ich weiß noch, daß die Leut', die heute noch fesch drauflos schreiben, alle geschrieben haben, das ist eine Talentprobe, doch wir werden nie mehr was davon hören, von diesem Jüngling da in Salzburg. Es ist ja wurscht, jeder kann ja schreiben, was er will. Ermutigend war es nicht. Wenn nicht draußen [!] ein paar Kritiken erschienen wären, die an sich auch blöd waren, aber groß aufgemacht, wär's vielleicht schiefgegangen. ${ }^{91}$

Kulturbetrieb der Gegenwart. Hg. v. Markus Joch, York-Gothart Mix u. Norbert Christian Wolf. Tübingen: Niemeyer 2009, S. 23-43, hier S. 31. Zuckmayer hatte bereits Bernhards Großvater Johannes Freumbichler durch Vermittlung und Fürsprache unterstützt. Vgl. Caroline Markolin: Die Großväter sind die Lehrer. Johannes Freumbichler und sein Enkel Thomas Bernhard. Salzburg: Otto Müller 1988, S. 133-139.

89 Der Kommentar der Werkausgabe verzeichnet lediglich die Rezensionen in der Süddeutschen Zeitung (Otto F. Beer), der ZEIT (Carl Zuckmayer) und der Weltwoche (Urs Jenny) und geht auf die Rezeption in Österreich nicht genauer ein (vgl. TBW 1, 354 f.); zur Rezeption von Frost vgl. auch Mittermayer: Thomas Bernhard [2015] (Anm. 42), S. 153 f.; Andreas Gößling: Frost. In: Bernhard-Handbuch (Anm. 75), S. 37-46, bes. S. 37 u. 43.

90 Vgl. dazu Brigitte Prutti: Festzertrümmerungen. Thomas Bernhard und seine Preise. Bielefeld: Aisthesis 2012, S. 96: „Der parodistische Tonfall in der zitierten Passage kontrastiert die Offenbarung aus dem Norden mit der Verkennung des Propheten im eigenen Land. [...] Keine Erhöhung durch Andere ohne das Pendant der Verachtung von Anderen, gegen die sie sich vollzieht.“ Hofmann: Aus Gesprächen mit Thomas Bernhard (Anm. 4), S. 48. 
Was Bernhard hier mit dem Brustton der Überzeugung und der Verve des auf Differenzierung wenig bedachten Polemikers konstatiert, hält einer Überprüfung allerdings nicht einmal in Ansätzen stand. Von einer , ausnahmslosen' Ablehnung seines Romans in der österreichischen Presse kann keineswegs die Rede sein; vielmehr äußerten sich die führenden Zeitungen in Wien und in den Bundesländern fast durchwegs positiv über Bernhards Debüt. Was die Forschung zur autobiographischen Pentalogie längst im Detail herausgearbeitet hat, ${ }^{92}$ ist auch für die Erinnerungen in Meine Preise zu betonen: Sie sind in einem erheblichen Maß durch Stilisierung und der erzählerischen Struktur geschuldete Dramatisierung geprägt. ${ }^{93}$ Die „bösartige[ ] Verleumdung“, der Bernhard in der Zeit der Abfassung von Meine Preise seine „Existenz als Schriftsteller in Österreich [...] von Anfang an“ ganz grundsätzlich ausgesetzt sah, die vollständige „Ignoration“, unter der er, „solange“ er „schreibe und veröffentliche“, leide (TBW 22.1, 665), war immer auch das Produkt einer betont einseitigen Wahrnehmung seiner Rezeption. Zuletzt hat der Wiener Germanist Günther Stocker darauf hingewiesen, dass Bernhards Werk zwar stets „umstritten“ gewesen sei, gleichzeitig jedoch „von Beginn an Institutionen und Personen [...] sein Schaffen und dessen Verbreitung“ - etwa durch wohlwollende Rezensionen, aber auch durch Publikations- und Auftrittsmöglichkeiten - „nachhaltig förderten“ ${ }^{94}$ Die Schilderung des eigenen Werdegangs, die mitunter an die „Leidenskataloge einer Passionsgeschichte“ erinnert, weist bei Bernhard stets ein erhebliches Maß an "Selbststilisierung“ auf; ${ }^{95}$ sein Verhältnis zur Literaturkritik bildet dabei keine Ausnahme.

92 Vgl. dazu bereits die Untersuchung von Reinhard Tschapke: Hölle und zurück. Das Initiationsthema in den Jugenderinnerungen Thomas Bernhards. Hildesheim u. a.: Olms 1984; für die spätere Forschungsdiskussion seien nur die folgenden drei Aufsätze exemplarisch genannt: Walter Pape: „Mich interessiert nur mein Körper und mein Kopf und sonst gar nichts“. Erzählerische und autobiographische Subjektivität bei Thomas Bernhard. In: Geschichte und Vorgeschichte der modernen Subjektivität. Hg. v. Reto Luzius Fetz, Roland Hagenbüchle u. Peter Schulz. Bd. 2. Berlin, New York: de Gruyter 1998, S. 1174-1197; Manfred Mittermayer: „Der Wahrheitsgehalt der Lüge“. Thomas Bernhards autobiographische Inszenierungen. In: Spiegel und Maske. Konstruktionen biographischer Wahrheit. Hg. v. Bernhard Fetz u. Hannes Schweiger. Wien: Zsolnay 2006, S. 79-94; Olaf Kramer: Wahrheit als Lüge, Lüge als Wahrheit. Thomas Bernhards Autobiographie als rhetorisch-strategisches Konstrukt. In: Rhetorik und Sprachkunst bei Thomas Bernhard. Hg. v. Joachim Knape u. O. K. Würzburg: Königshausen \& Neumann 2011, S. 105-122.

93 Dazu ausführlich Clemens Götze: Der geehrte Autor und die Kunst der Invektive. Zu Thomas Bernhards Meine Preise. In: Studia austriaca 20 (2012), S. 55-84; Martin Huber: „beinahe alles falsch"? Dichtung und Wahrheit in Thomas Bernhards Meine Preise. In: Text + Kritik ( $\left.{ }^{4} 2016\right)$, H. 43 , S. $10-28$.

94 Stocker: Bernhard und die literarische Landschaft Österreichs (Anm. 87), S. 298.

95 Wolfram Bayer: Das Gedruckte und das Tatsächliche. Realität und Fiktion in Thomas Bernhards Leserbriefen. In: Thomas Bernhard. Beiträge zur Fiktion der Postmoderne. Londoner Symposion. 
„Auf Anhieb ein Kunstwerk von hohen Graden zu schaffen“, sei „jungen Schriftstellern nur in raren Ausnahmefällen, die wir alle kennen, man denkt an Rimbaud, Grabbe, Kleist, Hölderlin, Lenau, Trakl, beschieden“, so der Rezensent der Wiener Furche, Johann A. Boeck, und er setzt nachgerade euphorisch hinzu: „Einen solchen Ausnahmefall schuf Thomas Bernhard“ ${ }^{96}$ Die „leidenschaftsheiße[ ] Sprache“ des 1963 im Insel Verlag publizierten Debüts Frost besitze, wie es abschließend mit großer Emphase heißt, „eine in der jüngeren deutschen Prosa selten auch nur annähernd erreichte Stoßkraft“ ${ }^{\text {97 }}$ Die aus der Süddeutschen Zeitung übernommene Besprechung von Otto F. Beer bescheinigt dem jungen Autor in Neues Österreich, „sich mit diesem Romanerstling ungemein kräftig eingeführt und als ein Menschengestalter von unverwechselbarer Originalität ausgewiesen“ zu haben, ${ }^{98}$ während die Salzburger Nachrichten ihm trotz Einwänden im Detail „erstaunliche[ ] Begabung“ attestierten ${ }^{99}$ und das Salzburger Volksblatt das Buch ungeachtet der wenig schmeichelhaften Zeichnung der ländlichen Bevölkerung im Salzburger Pongau ebenfalls freundlich aufnahm:

Thomas Bernhard malt grau in grau: Und dennoch nimmt seine minuziöse Schilderung des Auslöschens eines Außenseiters, eines Abseitigen des Lebens, mit beklemmender Intensität gefangen. Der Dichter Thomas Bernhard schreibt einen ungekünstelten, wie mit unbewußter Sicherheit zupackenden Stil. Er erzählt in einer Sprache, die keine Umwege geht. Sein erster Roman schon ist kein Buch unter vielen. ${ }^{100}$

Hg. v. Wendelin Schmidt-Dengler, Adrian Stevens u. Fred Wagner. Frankfurt a. M. u. a.: Lang 1997, S. 1-23, hier S. 14.

96 Johann A. Boeck: Die bitteren Träume. In: Die Furche, 19.10.1963. - Dieser und die folgenden Rezensionsbelege stammen aus der Mediendokumentation des Siegfried-Unseld-Archivs im Deutschen Literaturarchiv Marbach.

97 Ebd.

98 Otto F. Beer: Der innere Frost. In: Neues Österreich, 7.9.1963. Zuerst erschienen als ders.: Endspiel im Salzburgischen. In: Süddeutsche Zeitung, 17./18. 8. 1963. Dazu Anneliese Botonds Brief an Thomas Bernhard vom 21. 8.1963, unmittelbar nach Erscheinen der Rezension: „Ich hoffe, das Lob, das die Presse, zuletzt die ,Süddeutsche Zeitung' Ihrem Roman zollt, wird sie beflügeln.“ (Anneliese Botond: Briefe an Thomas Bernhard. Mit unbekannten Briefen von Thomas Bernhard. 1963-1971. Hg. v. Raimund Fellinger. Mattighofen: Korrektur 2018, S. 24) Der Name Otto F. Beers findet sich bereits in einem frühen journalistischen Beitrag des Rezensenten Thomas Bernhard, der für das Demokratische Volksblatt eine Veranstaltung im Salzburger „Amerika-Haus" besucht hatte (27. 2. 1954), bei der das von Beer ins Deutsche übertragene Stück Ah, Wilderness! von Eugene O’Neill in einer „Leseaufführung“ präsentiert worden war (TBW 22.1, 341); 1987 kommentierte Bernhard in einem Leserbrief an die Süddeutsche Zeitung einen dort veröffentlichten Bericht Beers über die Wiener Aufführung von Peter Ronnefelds Oper Die Nachtausgabe (vgl. TBW 22.1, 686-688).

99 A. H.: Thomas Bernhards „Frost“ der Einsamkeit. In: Salzburger Nachrichten, 21. 12. 1963.

100 haku: „Frost“ überm Pongau. In: Salzburger Volksblatt, 21./22.12.1963. 
Waren in der sozialistischen Arbeiter-Zeitung, in den Oberösterreichischen Nachrichten und - der einzig wirkliche Verriss - in der Klagenfurter Neuen Zeit auch kritische Stimmen zu vernehmen, überwog doch eindeutig das Wohlwollen für den jungen Schriftsteller. Selbst konservative Kritiker wie Josef Laßl lobten, trotz Skepsis gegenüber der formalen Gestaltung, den „tiefen sittlichen Ernst“ des Textes. ${ }^{101}$ „[M] an wird sich seinen Namen merken müssen “ ${ }^{\text {“102 }}$ - darüber waren sich beinahe alle Rezensenten in österreichischen Tageszeitungen und Zeitschriften einig, so auch Claus Pack in seiner ausführlichen Besprechung in der Wiener Presse, die Bernhard, geht man nach einem Brief an Peter Schünemann, ${ }^{103}$ selbst angeregt hatte:

In diesem ersten Roman beweist Thomas Bernhard eine vielversprechende epische Begabung. Das Wechselspiel von Reflexion und dramatischem Geschehen in der inneren Form des Buches, das in der äußeren die Entwicklung seines Helden nachzeichnet, den Knoten schürzt, verdichtet und löst, verrät einen Schriftsteller, der sich ernste Gedanken über Formprobleme und sein Metier macht. [...] Die unbezweifelbare Kraft und wilde Musik, die aus diesem Roman strömen, die Bildwelt, die eindringlich haften bleibt, und das Ethos, das aus ihm spricht, lassen von Thomas Bernhard in der Zukunft entscheidendes erwarten. ${ }^{104}$

Dass man von solchen positiven, ja aufmunternden Reaktionen in Meine Preise nichts liest, ist weniger der unvollständigen Erinnerung Bernhards als vielmehr der Stilisierung seines autobiographischen Narrativs geschuldet. Dieses entwirft die Etablierung des Autors im literarischen Feld als Kampf gegen den beharrlichen Widerstand eines reaktionären Kulturbetriebs. Die Siegfried Unseld in Aussicht gestellte Ergänzung seiner Autobiographie durch die Bände „Der

101 Josef Laßl: Thomas Bernhard: Frost. In: Österreichischer Rundfunk. Radio Salzburg, 8. 2. 1964 [Rundfunkmanuskript im Siegfried-Unseld-Archiv]. Womöglich stammt auch die anonym erschienene Besprechung in den Oberösterreichischen Nachrichten vom 6.7.1963 von Laßl, da hier ebenso vom „sittlichen Ernst“ und einem noch nicht vollends ausgereiften „formale[n] Können“ die Rede ist und Laßl regelmäßig als Rezensent für die Zeitung tätig war. - Zu Bernhards langjähriger Bekanntschaft mit Laßl vgl. Kap. VI, Abschnitt „,zuchtvoll und klar‘: Bernhard als Literaturkritiker im Salzburger Demokratischen Volksblatt“.

102 wj: Thomas Bernhard: Frost. In: Österreichisches Kulturwort. Zeitschrift für Kultur und Wissen (Februar 1964), [unpag.].

103 Vgl. den Brief von Thomas Bernhard an Peter Schünemann, 2. 2.1963. In: Botond: Briefe an Thomas Bernhard (Anm. 98), S. 13, Anm. 1, in dem Bernhard den Verlagsmitarbeiter um die Zusendung von Frost-„Leseexemplare[n]“ nicht nur an Gerhard Fritsch, Carl Zuckmayer und Wolfgang Kraus, sondern eben auch an Claus Pack bittet. Bernhard kannte Pack wohl schon aus den 1950er Jahren; jedenfalls nennt er ihn in einem 1956 erschienenen Beitrag als talentierten Buchillustrator (vgl. TBW 22.1, 564).

104 Claus Pack: Bewältigung des Vergangenen. In: Die Presse, 13. 7.1963. 
Gerichtsreporter“ und „Der Beginn des Schriftstellerischen“105 hätte wohl diesen Kampf zum Gegenstand gehabt und den Bericht vom Weg ,in die entgegengesetzte Richtung" (TBW 10, 114), den Bernhard in Der Keller in vielfacher syntaktischer Variation gestaltet hat, auf seinen frühen künstlerischen Werdegang ausgedehnt. Sich gegen den ,jahrelangen Morast aller Kritiker ${ }^{“ 106}$ behauptet zu haben, wie Bernhard 1975 in einem Brief an Unseld schreibt, spielt für dieses Narrativ eine zentrale Rolle, sind doch die Kritiker es, die als „Türsteher ${ }^{\ll 107}$ ganz wesentlich über die Zulassungsbedingungen und Wertmaßstäbe im literarischen Feld entscheiden. ${ }^{108}$ Überprüft man Bernhards Behauptung, wonach sich gerade in Österreich eine Phalanx von Kritikern von Anfang an gegen ihn gestellt habe, an den historischen Dokumenten, kann von einer solchen einhelligen Gegnerschaft jedenfalls nicht die Rede sein - zumal, wenn man die Rezeption von Frost mit der drei Jahre später deutlich kritischeren, ja oftmals polemischen Aufnahme von Peter Handkes Debütroman Die Hornissen im deutschsprachigen Feuilleton vergleicht. ${ }^{109}$

Der zitierte Brief an Peter Schünemann vom 2. Februar 1963 zeigt außerdem, dass sich Bernhard bereits vor der Veröffentlichung von Frost um eine positive Resonanz im Feuilleton bemühte. Er regte dabei nicht nur die Versendung von Rezensionsexemplaren an diverse Kritiker an, sondern gab Schünemann gegenüber auch freimütig zu, sich aus taktischen Gründen mit diesen in gutes Einvernehmen setzen zu wollen: „Die ganze Presse ist ein grosser Schmarrn - aber man muss es ihr nicht laut sagen. Man muss sich auch nicht, weil man überall vorlaut ist, immer überall alles vermasseln. ${ }^{\text {“110 }}$ Gezielt um die Gunst einzelner Kritiker zu werben - etwa des FAZ-Journalisten Andreas Razumovsky, der ihm „bei Tisch“ versichert habe, „den Roman besprechen“ zu wollen - sei zwar „blöd, wie fast alles“, aber, so Bernhard weiter, auch „wirksam“: „Der Welt muss man ja so kom-

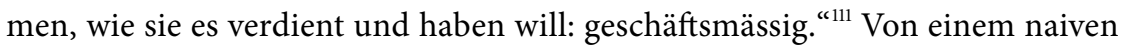
Debütanten, über den die etablierten Kritiker erbarmungs- und verständnislos herfallen, kann hier kaum die Rede sein; das ,allgemeine Besprechungsgewitter“,

105 Unseld: Reisebericht Salzburg, 24.-26. Juli 1980. In: Bernhard/Unseld: Der Briefwechsel (Anm. 11), S. $597 \mathrm{f}$.

106 Bernhard an Unseld, 22. 7. 1975. In: ebd., S. 48o.

107 Daniela Strigl: Alles muss man selber machen. Biographie, Kritik, Essay. Graz, Wien: Droschl 2018, S. 65.

108 Vgl. Bourdieu: Die Regeln der Kunst (Anm. 5), S. 357 f.; Carolin John-Wenndorf: Der öffentliche Autor. Über die Selbstinszenierung von Schriftstellern. Bielefeld: transcript 2014, S. 27.

109 Vgl. Kap. II, Abschnitt „,̈̈ber diesen Roman wären nicht so viele böse Worte zu verlieren ...‘: Handkes Hornissen nach Princeton“.

110 Bernhard an Schünemann, 2. 2.1963. In: Botond: Briefe an Thomas Bernhard (Anm. 98), S. 13, Anm. 1.

111 Ebd., S. 14, Anm. 1. 
das der Autor auf Frost niedergehen sah (TBW 22.2, 384), war bei Weitem nicht so verheerend, wie er es im Nachhinein dargestellt hat. Zum einen reagierten die meisten Rezensenten in österreichischen Zeitungen und Zeitschriften positiv und wohlwollend auf sein erstes Prosabuch, zum anderen setzten sich österreichische Autorenkollegen - neben Carl Zuckmayer etwa der zwei Jahre jüngere Humbert Fink - in bundesdeutschen Medien für Bernhard ein: „Dieser ,Frost ist ein Debüt“, heißt es in Finks ausführlicher Besprechung in der Deutschen Zeitung, „das zweifellos Genie verrät; es ist der Prosatext eines jungen Autors, der uns von der Zukunft dieses Autors überzeugt“."112

Womöglich hatte Bernhard bei seinem Kommentar zum fatalen „Besprechungsgewitter" aber auch - stärker als die unmittelbare Rezeption von Frost in den Jahren 1963/1964 - die Ereignisse im Anschluss an die Verleihung des Österreichischen Staatspreises am 4. März 1968 vor Augen, jene Veranstaltung also, die den endgültigen „Einzug der Person Bernhards ins öffentliche Bewußtsein“ markierte. ${ }^{113}$ Bernhards Preisrede über den „Requisitenstaat“ Österreich, „der von einem ahnungslose[n] Volk“, von „Geschöpfe[n] der Agonie“ bewohnt werde (TBW 22.2, 23), wurde von vielen, zumal von anwesenden Politikern, als offene Insultation des Landes verstanden und erfüllte damit, so Josef Donnenberg, den „Tatbestand eines öffentlichen Ärgernisses“. ${ }^{114}$ Im Anschluss an die Preisverleihung, deren Umstände Bernhard gleich in mehreren Varianten literarisch gestaltet und stilisiert hat (u. a. in Wittgensteins Neffe und Meine Preise), wurde nicht nur die Zeremonie zur Überreichung des Anton-Wildgans-Preises, der Bernhard ebenfalls zugesprochen worden war, abgesagt; auch die Salzburger Politik wurde auf den Autor und sein Buch aufmerksam. (Der Österreichische Staatspreis war Bernhard nicht für den aktuellen Roman Verstörung aus dem Jahr 1967, sondern eben für Frost verliehen worden.) Hatte die Salzburger Lokalpresse Frost im Jahr des Erscheinens, wie oben zitiert, noch positiv aufgenommen, waren die Passagen über Weng, den „düsterste[n] Ort“, den der Erzähler „jemals gesehen habe“ (TBW 1, 10), nun Gegenstand einer Anfrage im Salzburger Landtag.

„Tatsächlich erschreckt mich diese Gegend“, so der Famulant am Beginn seiner Aufzeichnungen aus dem Salzburger Pongau, „noch mehr die Ortschaft,

112 Humbert Fink: Auf der Spur des Malers Strauch. Thomas Bernhards Debüt als Erzähler. In: Deutsche Zeitung und Wirtschaftszeitung, 24./25. 8.1963.

113 Wendelin Schmidt-Dengler: Der Übertreibungskünstler. Studien zu Thomas Bernhard. Wien: Sonderzahl 1986, S. 96.

114 Donnenberg: Thomas Bernhards Zeitkritik und Österreich (Anm. 10), S. 55. Zu Bernhards Reden vgl. Anne Ulrich: „Ich bin kein Redner und ich kann überhaupt keine Rede halten“. Thomas Bernhard und seine Preise. In: Rhetorik und Sprachkunst bei Thomas Bernhard. Hg. v. Joachim Knape u. Olaf Kramer. Würzburg: Königshausen \& Neumann 2011, S. 45-62, sowie jetzt auch Harald Gschwandtner: Journalistisches, Reden, Interviews. In: Bernhard-Handbuch (Anm. 75), S. 270-278, hier S. 270-272. 
die von ganz kleinen, ausgewachsenen Menschen bevölkert ist, die man ruhig schwachsinnig nennen kann. Nicht größer als einen Meter vierzig im Durchschnitt, torkeln sie zwischen Mauerritzen und Gängen, im Rausch erzeugt. Sie scheinen typisch zu sein für das Tal.“ Nicht nur die „Landschaft“ sei von ausgesuchter „Häßlichkeit“, auch ihre Bewohner werden in Bernhards Roman nicht eben freundlich gezeichnet (TBW 1, 10 f.). Ein Monat nach der skandalträchtigen Preisverleihung in Wien brachten Abgeordnete der Volkspartei im Salzburger Landtag eine Anfrage an Landeshauptmann Hans Lechner (ÖVP) ein, weil sie in Bernhards Frost Landschaft und Einwohner des Pongaus verunglimpft sahen. Ohne sich des fiktionalen Charakters des Textes bewusst zu sein, erkannten sie in der Schilderung der örtlichen Verhältnisse eine „in der Literatur der Gegenwart einzig dastehende Entgleisung und Brüskierung eines Teiles der Salzburger Bevölkerung “. 115 Landeshauptmann Lechner gab daraufhin zu Protokoll, dass er bereits im für die Verleihung zuständigen Unterrichtsministerium Protest eingelegt habe; die Auszeichnung sei, so habe man ihm mitgeteilt, „in gänzlicher Unkenntnis der örtlichen Gegebenheiten“ erfolgt. ${ }^{116}$ Was die Kenntnis der „örtlichen Gegebenheiten“ an der Wertschätzung eines literarischen Kunstwerks geändert hätte, blieb in der entsprechenden Landtagsdiskussion freilich im Dunkeln. Am 17. April, also gut eineinhalb Monate nach der Preisverleihung, nahm auch ein Leserbrief eines Oberschulrats namens Hans Müller in den Salzburger Nachrichten an den „Beleidigungen unseres Bergvolkes“ in Frost Anstoß. ${ }^{117}$ Die zweite Welle der Rezeption des Buches in Salzburg war - befördert von der ÖVP, die offenbar mit Blick auf die anstehende Landtagswahl bemüht war, sich als ,Heimatpartei ${ }^{\text {zu }}$ profilieren ${ }^{118}$ - sehr viel unerfreulicher und emotionaler. Es liegt durchaus nahe zu vermuten, dass Bernhards Erinnerung an die ,bösartigen Verrisse' seines Debüts von diesen Vorkommnissen überlagert wurde.

„unbeholfener lyrischer Unsinn“: Bernhard redigiert eine Kritik mit einem Exkurs zu Elias Canetti

Ein anschauliches Beispiel für Bernhards Einwände gegen die literaturkritische Kommentierung seiner Bücher bietet ein Dokument, das im Zusammenhang der Reihe „Autoren diskutieren mit ihren Kritikern“ entstanden ist, die im November

\footnotetext{
115 Zit. nach: Mittermayer: Thomas Bernhard [2015] (Anm. 42), S. 189; vgl. dazu auch die Schilderung in Herbert Moritz: Das Milieu der Gerichtsberichte hat ihn beeinflusst. In: Was reden die Leute (Anm. 36), S. 44-51, hier S. 49.

116 Zit. nach: Mittermayer: Thomas Bernhard [2015] (Anm. 42), S. 190.

117 Zit. nach: Sehr geschätzte Redaktion (Anm. 42), S. 30.

118 Vgl. Mittermayer: Thomas Bernhard [2015] (Anm. 42), S. 190.
} 
1968 in der Berliner Akademie der Künste organisiert wurde. Ziel dieses Veranstaltungsformats war es - als Gegenentwurf zum Modus der Gruppe 47, die ein Jahr zuvor in der oberfränkischen Pulvermühle ihr letztes Treffen abgehalten hatte nicht eine Ad-hoc-Kritik zu einem erstmals gelesenen Text zu liefern, sondern auf der Basis eines vorab bekannten Lesetextes und eines ebenfalls schriftlich vorliegenden Kommentars ein Gespräch zwischen Schriftstellern und Kritikern zu initiieren. Die Autoren hatten die Möglichkeit, sich auf der Bühne gegen die Argumente der Journalisten zu verteidigen, ja selbst Einwände gegen die Praxis der Kritiker zu erheben. Die sonstige „Asymmetrie [...] im Verhältnis von Literatur und Kritik“119 sollte damit ein Stück weit ausbalanciert werden. Zudem durften die Gespräche - auch darin unterschied sich das Format von jenem der Gruppe 47 - über den konkreten literarischen Text hinaus auch grundlegende poetologische Fragen berühren. Jedem literarischen Autor wurde ein Kritiker zugeteilt, die einzelnen Paare im Vorfeld mit den Beteiligten abgesprochen. ${ }^{120}$ Waren bei den ersten beiden Terminen der Reihe am 3. und 10. November 1968 u. a. Bernhards Landsleute Oswald Wiener und Barbara Frischmuth auf- bzw. gegen Karl Heinz Kramberg und Wolfgang Werth angetreten, hatte man für die dritte und letzte Ausgabe Thomas Bernhard und den streitbaren Rolf Dieter Brinkmann eingeladen. Die Rolle der Kritiker sollten Rudolf Hartung und Marcel Reich-Ranicki übernehmen, wobei Letzterer gleich mit beiden Autoren des Abends in Konflikt geriet. ${ }^{121}$

Das Typoskript von Hartungs mit „Thomas Bernhard“ überschriebenen Ausführungen, die sich zu großen Teilen auf die Erzählung Ungenach (1968) beziehen und später die Grundlage für Hartungs Rezension im Deutschlandfunk bilden sollten, ${ }^{122}$ hat sich in Bernhards Nachlass erhalten. Es weist eine Vielzahl handschriftlicher Anmerkungen des Autors auf, die den Duktus, die Terminologie und die konkreten Textbeobachtungen Hartungs kritisch reflektieren. Sie bieten einen aufschlussreichen Einblick in das, was man im Sinne einer auktorialen Werkpolitik als Verteidigung der eigenen Poetik gegen externe Festlegungen und Deutungen beschreiben kann. Während Bernhard die Literaturkritik sonst meist in toto als unzulänglich und gedankenlos denunziert, ohne dieses Urteil im Detail zu belegen - „Wie Sie ja wahrscheinlich, sicher wissen, gibt es ja überhaupt nur dumme, darunter aber verheerend ganz dumme Kritiker“, so Bernhard etwa ein

119 Uwe C. Steiner: Literatur als Kritik der Kritik. Die Debatte um Peter Handkes Mein Jahr in der Niemandsbucht und die Langsame Heimkehr. In: Deutschsprachige Gegenwartsliteratur. Wider ihre Verächter. Hg. v. Christian Döring. Frankfurt a. M.: Suhrkamp 1995, S. 127-169, hier S. 139.

120 Vgl. zum Modus der Veranstaltung Raimund Fellinger: „Ich bin kein Teppichknüpfer“. In: Berlin, 17. November 1968. Autoren diskutieren mit ihren Kritikern. Thomas Bernhard diskutiert mit Rudolf Hartung. Mattighofen: Korrektur 2017, S. 35-39, hier S. 35.

121 Vgl. Kap. IV, Abschnitt „Im Bunde? Reich-Ranicki, Bernhard und Unseld“.

122 Vgl. Fellinger: „Ich bin kein Teppichknüpfer“ (Anm. 120), S. 36. 
Jahr zuvor in einem Brief an Unseld ${ }^{123}$-, setzt er hier an einzelnen Formulierungen Hartungs an und unterzieht sie einer kritischen Prüfung.

Noch über dem Titel von Hartungs Typoskript vermerkt Bernhard mit blauem Kugelschreiber: „Was soll ich dazu sagen? Es ist eine dieser vielen Kritiken, die keine Kritiken sind“, um dem immerhin 17 Jahre älteren Kritiker gleich eingangs „totale Ratlosigkeit“ zu bescheinigen, die er „aber“ - so Bernhards konzilianter Nachsatz - „nicht ohne Ehrgeiz“ festzuhalten versucht habe: „Aber bitte! Ich habe mir natürlich ein paar Notizen zu diesen Zeilen gemacht, gestern Nacht, im Hotel, gegenüber dem Kanzler, es war eine so schöne Stimmung. “ Und er platziert noch vor die erste Zeile der Rezension, als Abschluss seiner subversiven ,Rahmenerzählung', die Formel: „Also schreibt Herr Hartung“, setzt dahinter einen Doppelpunkt und lässt - es liegt nahe, das annotierte Typoskript auch als Aushandlung von Diskurshoheit zu betrachten - erst jetzt den Kritiker selbst zu Wort zu kommen. ${ }^{124}$ In der Folge nimmt Bernhard an inhaltlichen Ungenauigkeiten der Rezension Anstoß und kritisiert einzelne Formulierungen Hartungs als „Phrase“ ${ }^{125}$ „Herumgerede“, „unbeholfene[n] lyrische[n] Unsinn“" ${ }^{126}$ ja fühlt sich von „grauenhafte[n] Ausdrücke[n]“ des Kritikers „an liturgische Volkstümelei“ erinnert. ${ }^{127}$ Er dokumentiert sein - dem Leser von Hartungs raunendunkonkretem Text heute durchaus begreifliches - Unverständnis an manchen Stellen durch Fragezeichen, kapituliert vor einer besonders erratischen Passage des Kritikers mit einem lapidaren „Diesen Satz verstehe ich nicht ", ${ }^{128}$ um auf den letzten Seiten des Typoskripts die Frequenz von Kommentaren wie „Unsinn“, "dumm“, „bedeutungsschwanger, skurril“ und „Gefasel“ noch einmal zu erhöhen. ${ }^{129}$

Erweisen sich auch nicht alle Einwände Bernhards als gleichermaßen stichhaltig - etwa wenn er Hartung vorhält, Ungenach als „Erzählung“ zu bezeichnen, obgleich die Erstausgabe selbst den Text ausdrücklich als eine solche ausweist ${ }^{130}-$, so zeigen seine über das siebenseitige Typoskript verteilten Kommentare doch auf anschauliche Weise, wie ernst und genau Bernhard die Sache nahm: „Die ewigen Beispiele, ohne die die Kritiker Luft sind“" ${ }^{131}$ merkt er an einer Stelle an, an der Hartung Bernhards Schreiben mit Franz Kafka in Verbindung bringt, und

123 Bernhard an Unseld, 18. 5. 1967. In: Bernhard/Unseld: Der Briefwechsel (Anm. 11), S. 56.

124 Rudolf Hartung: Thomas Bernhard. Mit handschriftlichen Kommentaren von Thomas Bernhard. [Faksimile u. Transkription] In: Berlin, 17. November 1968. Autoren diskutieren mit ihren Kritikern (Anm. 120), S. 7/20.

125 Ebd.

126 Ebd., S. 11/24.

127 Ebd., S. 13/26.

128 Ebd., S. 15/28.

129 Ebd., S. 17-19/30-32.

130 Ebd., S. 7/20. Vgl. Thomas Bernhard: Ungenach. Erzählung. Frankfurt a. M.: Suhrkamp 1968.

131 Hartung: Thomas Bernhard (Anm. 124), S. 11/24. 
scheint Handkes Vorbehalte gegen literaturhistorische Vergleiche, das „Elend des Vergleichens “, 132 durchaus zu teilen. Nachdem er schließlich den letzten Satz Hartungs („Immer steht dieses Erzählen Bernhards in der Gefahr, von diesem grundlosen Grund verschlungen zu werden oder ihm nicht mehr entringen [sic] zu können") mit mehreren horizontalen Strichen und einer Wellenlinie markiert hat, was wohl als Hinweis auf eine gewisse Irritation zu verstehen ist, setzt er an das Ende des Manuskripts: „Jetzt habe ich Angst, ich kann nichts dafür ... Kein Wort mehr ... ${ }^{133}$ Die Ablehnung weiterer Diskussionen fand in Bernhards Weigerung, gemeinsam mit den beiden Kritikern und Rolf Dieter Brinkmann auf der Bühne Platz zu nehmen, ihre Fortsetzung. ${ }^{134}$ Seine eingehende, das Typoskript energisch mit Kugelschreiber bearbeitende ,Kritik der Kritik' war kein Angebot für einen darauf folgenden Austausch, sondern im Grunde, ganz im Stile Bernhards, ein apodiktisches Schlusswort.

In einem Brief an Rudolf Hartung versuchte Elias Canetti kurz darauf, den mit ihm in freundschaftlichem Einvernehmen stehenden Kritiker zu beruhigen: „Das Verhalten Bernhards“ sei, so der Brief vom 20. Dezember 1968, „leider charakteristisch für ihn. Ich kenne ihn ganz gut, er verträgt überhaupt keine Kritik. “135 Canetti mutmaßt in weiterer Folge, Bernhard sei womöglich durch „die Anwesenheit des R.-R. irritiert gewesen“, zumal es sich bei diesem um einen „geistig [...] schwer erträgliche[n] Menschen[en]“ und „ahnungslose[n] Schulmeister" handle, um Hartung am Ende für das erlittene Unrecht zu bedauern und ihn von aller Schuld an dem Konflikt freizusprechen:

Aber Ihre Sätze über Bernhard, die Sie im Brief zitiert haben, sind maßvoll, treffend und wahr, und er weiß es. Ich glaube, es muss ihre Wahrheit sein, die ihn so getroffen hat. Er gerät dann gleich in Panik und reagiert wie in Todesgefahr. Mir hat es schrecklich leid getan, dass Sie das erleben mussten, denn welcher Kritiker wäre gerechter und gewissenhafter als Sie. ${ }^{136}$

132 Peter Handke: Verdrängt das Kino das Theater? Das Elend des Vergleichens. In: protokolle (1969), S. 228-236; erneut gedruckt in P. H.: Ich bin ein Bewohner des Elfenbeinturms (Anm. 61), S. $65-77$.

133 Hartung: Thomas Bernhard (Anm. 124), S. 19/32.

134 Dafür war wohl nicht zuletzt der kurz zuvor erschienene Verriss Reich-Ranickis über Ungenach in der ZEIT verantwortlich. Vgl. dazu Fellinger: „Ich bin kein Teppichknüpfer“ (Anm. 120), S. 38 .

135 Elias Canetti an Rudolf Hartung, 20. 12. 1968. In: Elias Canetti: Ich erwarte von Ihnen viel. Briefe 1932-1994. Hg. v. Sven Hanuschek u. Kristian Wachinger. München: Hanser 2018, S. 315.

136 Ebd. Zum spannungsreichen Verhältnis zwischen Canetti und Reich-Ranicki vgl. Sven Hanuschek: Elias Canetti. Biographie. München, Wien: Hanser 2005, S. 541 f. u. 679 f. Als ReichRanicki Canettis autobiographische Bände Die gerettete Zunge (1977) und Die Fackel im Ohr (1980) kritisch besprach, verhöhnte ihn der Autor in mehreren Briefen als „noch beschränkter, 
In den folgenden Jahren sollte sich das Verhältnis zwischen Bernhard und Canetti, das als „Versprechen einer großen, ungewöhnlichen Freundschaft“ begonnen hatte, ${ }^{137}$ zusehends verschlechtern. Hatte sich Bernhard 1966 noch als Jurymitglied des Bremer Literaturpreises für die Vergabe der Auszeichnung an Canetti eingesetzt ${ }^{138}$ und vier Jahre später Siegfried Unseld die Aufnahme von Canettis philosophischem Hauptwerk Masse und Macht in die „Bibliothek Suhrkamp“ empfohlen, ${ }^{139}$ entwickelte sich mit den Jahren zwischen Bernhard und Canetti ein Konflikt, der im Grunde, wie nicht selten im Literaturbetrieb, auf Neid und gekränkter Eitelkeit beruhte - und das auf beiden Seiten. ${ }^{140}$

In Meine Preise hat Bernhard darüber geklagt, im März 1968 nicht mit dem Großen Österreichischen Staatspreis für Literatur, sondern nur mit dem „sogenannten Kleinen Staatspreis“ ausgezeichnet worden zu sein. Lediglich den „Staatspreis für Romane“ - so die korrekte Bezeichnung der Auszeichnung - zu erhalten, habe er als „Demütigung“ empfunden (TBW 22.2, 408 f.). ${ }^{141}$ Der Große Österreichische Staatspreis für Literatur ging in diesem Jahr indes ausgerechnet an Elias Canetti. ${ }^{142}$ Kurz darauf wiederholte sich die Situation unter gegenteiligen Vorzeichen: Dass dem 26 Jahre jüngeren Bernhard 1970 (und damit zwei Jahre vor Canetti) der Georg-Büchner-Preis zuerkannt wurde, stellte für den arrivierten Autor einen veritablen Affront dar. ${ }^{143}$ Im selben Jahre notierte er mit einiger Verbitterung, Bernhard stehe zusehends unter dem „Einfluss“ Samuel Becketts,

als ich dachte“, seine Rezensionen als „dumm und ordinär“ bzw. als „armselige Elaborat[e]“ (Canetti: Ich erwarte von Ihnen viel [Anm. 135], S. 560, 629 u. 633).

137 Prutti: Festzertrümmerungen (Anm. 90), S. 33.

138 Vgl. die Schilderung von Prutti (ebd., S. 93-95); Mittermayer: Thomas Bernhard [2015] (Anm. 42), S. 160. Bernhard hat auf diesen Umstand in Meine Preise hingewiesen (vgl. TBW 22.2, 393 f.).

139 Vgl. Unseld: Reisebericht Schweiz-Österreich, 14.-21. Juni 1970. In: Bernhard/Unseld: Der Briefwechsel (Anm. 11), S. 179: „Zwei Empfehlungen von Thomas Bernhard für die Bibliothek Suhrkamp: Canetti, eine Auswahl aus , Masse und Macht', eventuell auch das Ganze prüfen. [...] Ferner würde Thomas Bernhard gerne eine Auswahl der Gedichte von Trakl für die Bibliothek Suhrkamp vornehmen."

140 Eine Rekonstruktion der Beziehung der beiden Autoren liefert Hanuschek: Elias Canetti (Anm. 136), S. 582-587; die folgenden Ausführungen stützten sich ganz wesentlich auf diese Biographie. Vgl. dazu auch Prutti: Festzertrümmerungen (Anm. 90), S. 32-36.

141 Brigitte Prutti hat die Hintergründe der Preisverleihung im Detail aufgearbeitet und dabei u. a. gezeigt, dass Bernhards Vorwurf, den ,kleinen Staatspreis" „über dreißig“ bekommen zu haben, sei „eine ungeheure Gemeinheit“ und „Unverschämtheit“ der Jury gewesen (TBW 22.2, $411 \mathrm{f}$.), mit der tatsächlichen Vergabepraxis nicht in Einklang zu bringen ist, lag Bernhard im Alter von 37 Jahren doch statistisch unter dem Durchschnitt von 39,5 Jahren für die Zeitspanne 1950-1969 (vgl. Prutti: Festzertrümmungen [Anm. 90], S. 119).

142 Vgl. ebd., S. 113.

143 Zur Vergabe des Büchner-Preises an Canetti vgl. Judith S. Ulmer: Geschichte des Georg-BüchnerPreises. Soziologie eines Rituals. Berlin, New York: de Gruyter 2006, S. 252 f. 
„der meinen verdeckt“; ${ }^{144}$ Canetti sah sich als Mentor und Vorbild des nunmehr gefeierten Autors nicht ausreichend gewürdigt. „Die Preise, die ich habe“, so Bernhard im August 1972 im Gespräch mit Karl Ignaz Hennetmair, „bekommt man gewöhnlich erst, wenn man ein Canetti ist. “145

Anfang 1976 schließlich kulminierte die allmähliche Entfremdung der beiden in einem öffentlich ausgetragenen Konflikt. Canetti wurde im Januar 1976 die Ehrendoktorwürde der Universität München verliehen. Er hielt in diesem Rahmen eine programmatische Rede über den Beruf des Dichters, deren kritische Ausführungen Bernhard auf sich und seine Poetik beziehen musste: ${ }^{146}$

$\mathrm{Zu}$ den Worten, die während einiger Zeit in hilfloser Ermattung darniederliegen, die man mied und verheimlichte, durch deren Gebrauch man sich zum Gespött machte, die man solange entleerte, bis sie verschrumpft und häßlich zur Warnung wurden, gehört ,Dichter؛ Wer sich auf die Tätigkeit, die wie immer weiterbestand, dennoch einließ, nannte sich ,Jemand, der schreibt..$^{\text {147 }}$

Im 1970 von Ferry Radax produzierten Filmmonolog Drei Tage hatte Bernhard betont, „kein Schriftsteller“ zu sein, „ich bin jemand, der schreibt ... “ (TBW 22.2, 59). Zwei Jahre später trug eine von Rudolf de le Roi herausgegebene Anthologie den Titel Jemand der schreibt; sie enthielt neben dem einschlägigen Abschnitt aus Drei Tage auch einen Beitrag von Canetti. ${ }^{148}$ Nach einem Seitenhieb auf jene Autoren, die wie Enzensberger und Boehlich Ende der 196oer Jahre die „kleinliche

144 Elias Canetti: Das Buch gegen den Tod. Mit einem Nachwort v. Peter von Matt. München: Hanser 2014, S. 138: „Jeder fragt mich nach Thomas Bernhard, jeder will wissen, was ich von ihm halte. Ich lobe und erkläre ihn, ich suche ihn allen nahezubringen, ich erhebe [!] ihn zu meinem Schüler und natürlich ist er's [...]. Die Verwicklung alles dessen, was bei Bernhard von mir kommt, mit Beckett, ist merkwürdig und offenkundig. Sie ist etwas zu einfach, um mir wirklich zu gefallen. So muß ich hier, für mich, feststellen, daß ich ihn zu sehr verteidige, aus einer Art von Großmut. Ich bin nicht ganz sicher, ob er sie verdient.“ (Ebd.) - Dazu Karl Wagner: Echo. (Nach-)Hall: Beckett, Bernhard, Handke. In: Ein Zoll Dankfest. Texte für die Germanistik. Konstanze Fliedl zum 6o. Geburtstag. Hg. v. Susanne Hochreiter u.a. Würzburg: Königshausen \& Neumann 2015, S. 227-244, hier S. $231 \mathrm{f}$.; zu den literarischen Einflüssen Canettis auf Bernhard vgl. Mittermayer: Thomas Bernhard [2015] (Anm. 42), S. 149 f.

145 Karl Ignaz Hennetmair: Ein Jahr mit Thomas Bernhard. Das versiegelte Tagebuch 1972. St. Pölten u. a.: Residenz ${ }^{5} 2014$, S. 348 (Eintrag v. 17. 8.1972).

146 Dass sie eindeutig so intendiert waren, zeigt etwa ein Brief Canettis an Hans Bender, 3. 2. 1976. In: Canetti: Ich erwarte von Ihnen viel (Anm. 135), S. 523: „Sie [i.e. die Münchner Rede] ist mir sehr wichtig, aber es könnte sein, dass Ihnen manches daran missfällt (z. B. der Angriff auf Thomas Bernhard zu Beginn).“

147 Elias Canetti: Der Beruf des Dichters. Münchner Rede, Januar 1976. In: E. C.: Das Gewissen der Worte. Essays. München: dtv 1978, S. 257-267, hier S. 257.

148 Jemand der schreibt. 57 Aussagen. Hg. v. Rudolf de le Roi. München: Hanser 1972, S. 64-67 (Thomas Bernhard: In der Finsternis wird alles deutlich) u. S. 68-72 (Elias Canetti: Wortanfälle). 
Meinung“ vertreten hätten, „daß alle Literatur tot sei“, kommt Canetti in seiner Münchner Rede noch einmal auf den namentlich nicht genannten Thomas Bernhard zurück: Dieser habe zwar „bittere und sehr begabte Bücher“verfasst und es „als ,Jemand, der schreibt' sehr bald zu Ansehen“ gebracht; nun aber tue er das,

was früher Dichter zu tun pflegten: statt zu verstummen schrieben sie dasselbe Buch immer wieder. So verbesserungsunfähig und todeswürdig die Menschheit ihnen erschien, eine Funktion war ihr geblieben: ihnen zu applaudieren. Wer dazu keine Lust verspürte, wer die immerselben Ergüsse satt hatte, war doppelt verdammt: einmal als Mensch, damit war es schon nichts, und dann als einer, der sich weigerte, die endlose Sterbesucht dessen, der schrieb, als das Einzige anzuerkennen, das überhaupt noch von Wert war. ${ }^{149}$

Canettis Attacke ließ an Deutlichkeit und Angriffslust wenig zu wünschen über gerade der Vorwurf, es bei aller Negation und „Sterbesucht“ am Ende doch auf den Applaus des Publikums abgesehen zu haben, wog im Kontrast zu Bernhards künstlerischem Selbstverständnis besonders schwer. Der derart Angesprochene revanchierte sich am 27. Februar 1976 mit einem Leserbrief in der ZEIT, die drei Wochen zuvor auch Canettis Rede gedruckt hatte: ${ }^{150}$ Der neue Ehrendoktor der Universität München habe zwar, so Bernhard, mit dem Roman Die Blendung (1935) vor vielen Jahren „eine begabte Talentprobe“ abgeliefert, als „Aphorismusagent der Jetztzeit“ jedoch „durch Inkonsequenz konsequent sein Niveau verloren“, wovon seine Festrede beredtes Zeugnis ablege: Seinem Kontrahenten attestiert er in seiner Replik, „als eine Art Schmalkant und Kleinschopenhauer“ eine hochgradig lächerliche Figur zu sein, und verhöhnt Canetti als „Spätlingsvater[ ] und skurrilen Torschlußphilosophen“ (TBW 22.1, 646). Auf eine öffentliche Erwiderung sollte Canetti verzichten - „ein solches Maß von Niedertracht ist nur durch Schweigen zu strafen “151 -, in der ZEIT jedoch nahmen zahlreiche Leserinnen und Leser ihn gegen Bernhards wüsten Angriff in Schutz. ${ }^{152}$ Einen

149 Canetti: Der Beruf des Dichters (Anm. 147), S. 257.

150 Vgl. Elias Canetti: Der Beruf des Dichters. In: DIE ZEIT, Nr. 7, 6. 2. 1976, S. 35-36.

151 Elias Canetti an Wolfgang Frühwald, 20.5.1976. In: Canetti: Ich erwarte von Ihnen viel (Anm. 135), S. 538.

152 Vgl. dazu: Sehr geschätzte Redaktion (Anm. 42), S. 67-70. Zu den Kalamitäten um Canettis Rede und Bernhards Reaktion vgl. auch die Notiz in Unseld: Begegnung mit Thomas Bernhard in Salzburg am 10. Mai 1976. In: Bernhard/Unseld: Der Briefwechsel (Anm. 11), S. 502 f., sowie Hans Bender/Elias Canetti: Briefwechsel. 1963-199o. Hg. v. Hans Georg Schwark u. Walter Hörner. Aachen: Rimbaud 2016, S. 59-65. - Eine Dokumentation des Konflikts findet sich in Manfred Mittermayer, Lächerlich, charakterlos, furchterregend. Zu Thomas Bernhards Rhetorik der Bezichtigung. In: Rhetorik und Sprachkunst bei Thomas Bernhard. Hg. v. Joachim Knape u. Olaf Kramer. Würzburg: Königshausen \& Neumann 2011, S. 25-44, hier S. 30 f. 
bereits formulierten Brief an Bernhard schickte Canetti Anfang März 1976 nicht ab, bewahrte ihn aber - „als Zeichen dafür, wie mir wirklich zumute war" ${ }^{153}$ wie schreibt - bei seinen Unterlagen auf.

Auch zu einer persönlichen Aussprache der beiden kam es in der Folge nicht. In einem Brief an Hans Reiss vom 30. März 1976 hielt Canetti fest, Bernhard habe die „harte Kritik an ihm in meiner Rede [...] offenbar schwer getroffen. Es zeigt sich, in seiner Reaktion, dass er gar nichts gelernt hat. Meine Kritik war eine prinzipielle und richtete sich gegen die gewissenlosen Lobhudler des Todes, die sich in der neueren Literatur immer breiter machen. “154 Während Canetti auf eine Entschuldigung wartete und seinen Kontrahenten selbst in privaten Aufzeichnungen schmähte, ${ }^{155}$ war Bernhard nicht bereit, persönlich Abbitte zu leisten: „Den moralischen Mut, sich bei mir zu entschuldigen, bringt er nicht auf“, so Canetti im Januar 1977 an Wolfgang Kraus, den Bernhard zuvor gebeten hatte, Canetti sein Bedauern über den öffentlich ausgetragenen Konflikt zu versichern: „Ich habe es nicht anders erwartet. “ ${ }^{156}$ Kurz darauf kam Bernhard in einem ausführlichen Filminterview mit Norbert Beilharz erneut auf das angespannte, von seiner Seite stets ambivalente Verhältnis zu Canetti zurück: Angesprochen auf schreibende Zeitgenossen, berichtete er davon, dass er bei seiner sporadischen Lektüre von Gegenwartsliteratur stets auf Canetti zurückkomme, der am Ende „doch alle überragt“: „Eine Hassliebe wahrscheinlich, aber das entspricht meiner Mentalität - und es geschieht ihm recht. “157 Die Zuerkennung des Nobelpreises für Literatur im Jahr 1981 stellte für Canetti wohl auch angesichts seines Konflikts mit Bernhard, der selbst auf diese höchste Auszeichnung

153 Canetti: Das Buch gegen den Tod (Anm. 144), S. 170. Der Brief findet sich abgedruckt ebd., S. 169. Dort heißt es etwa: „Ich habe Sie hart kritisiert, und Sie schlagen nun besinnungslos um sich. [...] Sie reagieren immer blindwütig auf Kritik. Da ich aber kein Zeitungsschmierer bin, dachte ich, daß ein harter Stoß von mir, den Sie in Wirklichkeit ganz anders sehen als in Ihrer Schimpftirade, Sie zur Besinnung bringen könnte. Sie haben niemand, der Ihnen die Wahrheit sagt, ist sie Ihnen gleichgültig geworden?"

154 Elias Canetti an Hans Reiss, 30. 3. 1976. In: Canetti: Ich erwarte von Ihnen viel (Anm. 135), S. 536.

155 Vgl. Elias Canetti: Aufzeichnungen 1973-1984. München, Wien: Hanser 1999, S. 27: „Er wendet sich gegen alles, was nicht er ist.“ - „Er hat eine unreine Haut und hält sich für den Gekreuzigten. Der Reliquiensammler seiner Lodenmäntel und Wanderschuhe.“ - „Um Geld schimpft er ausführlicher.“ - Bernhard wiederum antwortete im Sommer 1976 in einem Interview auf die Frage, ob er daran interessiert sei, einmal die Rede zur Eröffnung der Salzburger Festspiele zu halten: „Nein! Das hat sogar der Canetti nicht gemacht.“ (TBW 22.2, 90)

156 Elias Canetti an Wolfgang Kraus, 4. 1. 1977, zit. nach: Hanuschek: Elias Canetti (Anm. 136), S. 587. Zu Bernhards vielfältigen Beziehungen zu Kraus vgl. jetzt Stefan Maurer: Wolfgang Kraus und der österreichische Literaturbetrieb nach 1945. Wien u. a.: Böhlau 2020.

157 Norbert Beilharz: Die Feuer- und die Wasserprobe. Gespräch mit Thomas Bernhard, Saarländischer Rundfunk 1978. In: https://www.youtube.com/watch?v=oktFW5KOFjM (Stand 14. 10. 2020), 12:00-12:15. 
spekuliert hatte, ${ }^{158}$ eine Genugtuung dar. Noch anlässlich der Diskussionen um die Uraufführung von Heldenplatz wird er an Cilli Wang schreiben, er halte Bernhard „für gewissenlos und für einen grundschlechten Menschen ${ }^{\text {“. }} .{ }^{159}$ Wie andere Beziehungen Thomas Bernhards zu konkurrierenden Akteuren im literarischen Feld - allen voran zu Peter Handke - endete auch diese unversöhnt.

\section{„ekelhaft ekelhaft ekelhaft": Kritiken auf der Bühne (Der Ignorant und der Wahnsinnige, Minetti, Über allen Gipfeln ist Ruh)}

Polemische Bezugnahmen auf Feuilleton und Kritik finden sich auch an zahlreichen Stellen in Thomas Bernhards Theatertexten. So setzt die Bühnenhandlung von Der Ignorant und der Wahnsinnige, 1972 bei den Salzburger Festspielen uraufgeführt, unmittelbar mit der Lektüre von Opernkritiken ein: „Hören Sie / was über die Premiere geschrieben wird / es handelt sich / um ein unsterbliches Werk / ein Genie etcetera" (TBW 15, 227), berichtet der Doktor dem fast erblindeten Vater der gefeierten Sopranistin, die an diesem Abend zum 222. Mal die Partie der Königin der Nacht in Mozarts Zauberflöte singen und anschließend alle weiteren Engagements und Verpflichtungen absagen wird: „Die Stimme Ihrer Tochter", so der Doktor mit prüfendem Blick in die Zeitungen, „die perfekteste einerseits / makellos andererseits / und die Technik / jedes zweite Wort ist das Wort authentisch / jedes dritte Wort das Wort berühmt" (TBW 15, 227). Ist er eben noch damit beschäftigt, die euphorischen Premierenberichte zu sichten und die häufigsten Lobesworte zu zählen - „,neunzehnmal das Wort stupend“ (TBW 15, 227) -, wirft er die Zeitungen gleich darauf angewidert zur Seite: „Immer der gleiche Dreck / einen Menschen wie mich ekelt noch immer / vor dem täglichen Empfindungsreichtum des Feuilletonismus“ (TBW 15, 229).

158 Vgl. Prutti: Festzertrümmerungen (Anm. 9o), S. 7, 36, 57 u. 72 f. - In dem im April 1981 - also einige Monate vor der Nobelpreis-Verleihung an Canetti - gedruckten Stück Über allen Gipfeln ist Ruh trifft „ein Brief aus Stockholm“ an den erfolgreichen Schriftsteller Moritz Meister ein (TBW 18, 175); da er in der Folge jedoch nicht geöffnet wird, „bleibt unklar, ob ihm auch der Nobelpreis für Literatur zugesprochen worden ist“ (Nina Birkner: Vom Genius zum Medienästheten. Modelle des Künstlerdramas im 20. Jahrhundert. Tübingen: Niemeyer 2009, S. 234). Vgl. zu Bernhards Reflexionen über den Nobelpreis auch Hennetmair: Ein Jahr mit Thomas Bernhard (Anm. 145), S. 406, 459 f., 481 u. 556, sowie Hofmann: Aus Gesprächen mit Thomas Bernhard (Anm. 4), S. 93: „Ich war schon zweimal für den Literaturnobelpreis vorgeschlagen [...]. Nur, ich würd' ihn ja gern kriegen, um ihn dann nicht anzunehmen, aber man kann nicht ablehnen, was man nicht bekommt.“

159 Elias Canetti an Cilli Wang, 16.12.1988. In: Canetti: Ich erwarte von Ihnen viel (Anm. 135), S. 744 . 
Der Zusammenbruch der Sopranistin aufgrund von „Erschöpfung / nichts als Erschöpfung" (TBW 15, 328) ist nicht zuletzt auf die akkumulierte Erwartungshaltung zurückzuführen, die in den gleich eingangs verlesenen Kritiken ihren exemplarischen Ausdruck findet. Die Superlative der Opernkritik werden durch den alkoholkranken, vom Erfolg seiner Tochter abhängigen Vater und insbesondere durch den dubiosen Doktor noch verstärkt, obgleich die beiden vorgeben, die gefeierte Sängerin vor der „schmutzigen Öffentlichkeit / vor ihrer tödlichen / Inkompetenz" „abschirmen“ zu wollen (TBW 15, 326 f.). Ständig dem Anspruch genügen zu müssen, als perfektionierte „Koloraturmaschine“ (TBW 15, 227) so zu singen, „wie noch keine vorher / gesungen hat" (TBW 15, 314), geht schließlich über ihre Kräfte, ja trägt ganz wesentlich zu ihrem Zusammenbruch bei ${ }^{160} \mathrm{In}$ Der Ignorant und der Wahnsinnige wird das Drama der virtuosen Künstlerin, die „Deformation des Menschen durch die Kunst ${ }^{\text {" }}{ }^{161}$ als ein Scheitern sowohl an ihrem privaten Umfeld als auch an den Mechanismen des Opernbetriebs geschildert. ${ }^{162}$

In Minetti, der 1976 in Stuttgart uraufgeführten Hommage an den von Bernhard verehrten Schauspieler Bernhard Minetti ${ }^{163}$ dem er später auch das Stück Einfach kompliziert (1986) widmen wird, hat der Autor dem skizzierten Konflikt eine neue Wendung gegeben: Hier ist es eine Künstlerfigur, die gegen Ende ihres Lebens anhand gesammelter Kritiken auf ihre wechselvolle Karriere zurückblickt. Bernhard versah das Stück, in Anlehnung an Joyces Portrait of the Artist as a Young Man, mit dem Untertitel „Ein Porträt des Künstlers als alter

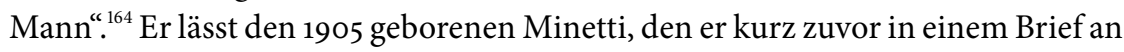
Henning Rischbieter als „elementaren Geistestheaterkopf“" ja als „,wahrscheinlich

160 Vgl. Herbert Gamper: Thomas Bernhard. München: dtv 1977, S. 115.

161 Mittermayer: Thomas Bernhard [2006] (Anm. 36), S. 112.

$162 \mathrm{Zu}$ den überzeugendsten Deutungen des Stücks gehören die folgenden beiden Forschungsbeiträge: Christian Klug: Thomas Bernhards Theaterstücke. Stuttgart: Metzler 1991, S. 227-253; Jean-Marie Winkler: Bernhard als Anti-Mozart. Einige Thesen zum Stück Der Ignorant und der Wahnsinnige als Kontrafaktur der Zauberflöte. In: Bernhard-Tage Ohlsdorf 1996. Materialien. Hg. v. Franz Gebesmair u. Alfred Pittertschatscher. Weitra: Bibliothek der Provinz [1998], S. 206-218.

$163 \mathrm{Zu}$ Thomas Bernhards Verhältnis zu Bernhard Minetti vgl. Marek Podlasiak: Das Geistesduo - Thomas Bernhard und Bernhard Minetti. In: Im Wechselspiel der Kulturen. Festschrift für Karol Sauerland. Hg. v. Maria Gierlak, Małgorzata Klentak-Zabłocka u. Leszek Żyliński. Toruń: Wydawnictwo Uniwersytetu Mikołaja Kopernika 2001, S. 95-103; Mittermayer: Thomas Bernhard [2015] (Anm. 42), S. 279-282; dazu auch das Spiegel-Interview mit Hellmuth Karasek und Erich Böhme aus dem Jahr 1980 (vgl. TBW 22.2, 173). Wiederholt hat Bernhard betont, beim Verfassen seiner Stücke „, auf Zuschauer nie einen Wert g’legt“ und diese „nur für Schauspieler und ganz bestimmte Schauspieler g'schrieben“ zu haben (TBW 22.2, 265).

164 Vgl. Hans Höller: Thomas Bernhard. Reinbek b. Hamburg: Rowohlt 1993, S. 122, der nicht nur den Bezug zu Joyce unterstreicht, sondern Minetti zudem als „romantische[s] Märchen eines ausgestoßenen Künstlers“ beschreibt. 
größten [...] lebenden [...] Schauspieler" bezeichnet hatte (TBW 22.1, 642), ${ }^{165}$ als greisen, schon zur senilen Lächerlichkeit neigenden Mimen auftreten. Bernhard Minetti sollte - Ironie der Geschichte - den Autor allerdings um fast zehn Jahre überleben: Noch 1998, wenige Monate vor seinem Tod, stand der Schauspieler auf der Bühne des Berliner Ensembles.

Bernhards Bühnenfigur Minetti teilt zwar einige biographische Merkmale mit dem realen Schauspieler gleichen Namens, ist aber weit davon entfernt, ein Biopic zu sein. ${ }^{166}$ In einem Hotel an der Atlantikküste wartet Minetti vergebens auf den Direktor des Flensburger Theaters, räsoniert über die Erfolge und Misserfolge seiner Laufbahn sowie seine Lebensrolle des King Lear, wobei „Perfektomanie“ und "pathologische[ ] Exzentrik“ des gealterten Schauspielers zusehends zutage treten. ${ }^{167}$ Er fühlt sich in Bezug auf seine Lebensleistung verkannt. Ganz ähnlich wie Bernhard im autobiographischen Band Der Keller (ebenfalls 1976 erschienen) definiert Minetti seine Kunst als bewusste Entscheidung für die „entgegengesetzte Richtung“, eine Haltung, die ihm, so der Mime, stets „Einsamkeit“,

165 Vgl. dazu auch den ersten Satz von Bernhards in einer Festschrift zu Siegfried Unselds 60. Geburtstag (Der Verleger und seine Autoren, 1984) gedrucktem Beitrag: „Wenn Shakespeare der größte Dichter und Minetti der größte Schauspieler, dann ist Unseld der größte Verleger.“ (TBW 22.1, 626) Siehe auch Bernhards Bemerkungen in Hofmann: Aus Gesprächen mit Thomas Bernhard (Anm. 4), S. $81 \mathrm{f}$.

166 Vgl. Gabriella Rovagnati: King Lear als Obsession: Minetti von Thomas Bernhard. In: G. R.: Studien zur österreichischen Literatur: Von Nestroy bis Ransmayr. Frankfurt a. M.: Lang 2016, S. 299-306, hier S. 300; Podlasiak: Das Geistesduo (Anm. 163), S. 101-103. Alfred Barthofer: King Lear in Dinkelsbühl. Historisch-Biographisches zu Thomas Bernhards Theaterstück Minetti. In: Maske und Kothurn 23 (1977), S. 159-172, hier S. 162, hat indes auf die Nähe der Bühnenfigur Minetti weniger zu seinem Namensvetter Bernhard Minetti als zu Werner Krauß hingewiesen, der „im Jahre 1959 unmittelbar nach einer ,Lear'-Aufführung des Wiener Burgtheaters“ verstarb. Zu den biographischen Parallelen zwischen der Dramenfigur und Krauß in Bernhards Theatertext vgl. ebd., S. 161-172. Barthofer verweist dabei mehrmals auf „das Spielverbot, das Werner Krauß nach dem Ende des Zweiten Weltkrieges drei Jahre lang vom Theater fernhielt und seelisch tief verwundete“ (ebd., S. 162), sowie auf die „Gefühlslage [...], in der sich der ,größte Schauspieler dieses Zeitalters` zwischen 1945 und 1950 befunden haben dürfte, als er von der Bühne verbannt war und nur in kleinen Provinzstädten arbeiten durfte“ (ebd., S. 171), verschweigt jedoch geflissentlich den Grund dafür, nämlich Krauß’ Rolle im Kulturbetrieb des Dritten Reichs. Siehe dazu den Eintrag in Ernst Klee: Das Kulturlexikon zum Dritten Reich. Wer war was vor und nach 1945. Frankfurt a. M.: S. Fischer 2009, S. 304-305; zur Diskussion um die historische Referenzierung der Bernhard'schen Bühnenfigur Minetti vgl. jetzt Mittermayer: Thomas Bernhard [2015] (Anm. 42), S. $281 \mathrm{f}$.

167 Rovagnati: King Lear als Obsession (Anm. 166), S. 305. Sandra Heinrici: Maskenwahnsinn. Darstellungsformen des Wahnsinns im europäischen Theater des 20. Jahrhunderts. Bonn: Bouvier 2008, S. 109 f., zufolge findet im Zuge des Stückes „, bei Minetti neben einer Bestandsaufnahme seines Lebens auch ein Prozess der Selbstbewusstwerdung statt, insofern als er nach und nach seine Selbsttäuschung, die in einem Prolongieren der Vergangenheit in die Gegenwart besteht, zu erkennen scheint." 
„Unverständnis“ und „Ablehnung“ eingebracht habe (TBW 17, 25). Wie andere Protagonisten in Bernhards Prosa- und Theatertexten kann Minetti sich indes nicht von den Bewertungen seiner Kunst durch andere, durch die Instanzen der Kritik zumal, lösen: „Seit dreißig Jahren“ trägt er einen Koffer bei sich, in dem sich nicht nur „die Maske des Lear / von Ensor“ befindet, sondern auch „mehrere Zeitungsausschnitte / mich betreffend / Rezensionen / Artikel über mich“ (TBW 17, 39). ${ }^{168}$ Immer wieder „öfnet“ Minetti, wie die Regieanweisungen verraten, „den Koffer und entnimmt ihm verschiedene alte Zeitungen“ (TBW 17, 47), zitiert in der Folge aus diesen - „Einer unserer größten Schauspieler / der sich an diesem Abend wieder / ein Denkmal gesetzt hat" -, um sie schließlich „plötzlich" mit dem Ausruf „Genug / ekelhaft ekelhaft ekelhaft" wieder in den Koffer zu stopfen; jedoch nur, um gleich darauf erneut „einen Pack anderer Zeitungen heraus[zuholen]“ (TBW 17, 47 f.). Noch gegen Ende der dritten und letzten Szene konstatiert der Schauspieler mit Blick auf sein Gepäckstück: „Wir sind dreiBig Jahre / zusammengeblieben / der Koffer und ich" (TBW 17, 63). Obgleich Minetti in allen Artikeln, insbesondere in den Berichten über die juristischen Auseinandersetzungen mit dem Lübecker Theater, zuallererst „Verdrehungen und Verleumdungen“ (TBW 17, 48) wahrnimmt, kann er sich doch nicht von ihnen trennen. Das Taxieren der eigenen Geltung in der Theaterkritik ist für ihn ganz offensichtlich von essentieller Bedeutung, auch wenn er den bewertenden Instanzen des Feuilletons demonstrativ den Respekt verweigert.

Hanna Klessinger hat mit Blick auf Bernhards Theaterästhetik von vielfältigen Formen der „Metatheatralität“ gesprochen ${ }^{169}$ von der Thematisierung der Institution ,Theater' und der Reflexion des Dispositivs ,Bühne‘. In Minetti zeigt sich diese Dimension einerseits in der „prononcierte[n] Intertextualität ${ }^{\text {“170 }}$ des Stücks (in Bezug auf Shakespeares The Tragedy of King Lear); andererseits ergeben sich ,metatheatralische' Effekte aber auch und insbesondere im Zuge der Auseinandersetzung mit den Verlockungen und Gefahren der Kritik - nicht abseits, sondern eben auf der Bühne. Der Schauspieler Minetti, der den Schauspieler Minetti spielt, führt dabei im Sinne der Bourdieu'schen,Selbstobjektivierung ${ }^{\text {c171 }}$ auch die

168 Vgl. Heinrici: Maskenwahnsinn (Anm. 167), S. 113: „Die alles überlagernde Vergangenheit wird auch durch den Koffer symbolisiert, der Minettis angeblich [?] von Ensor hergestellte LearMaske und Rezensionen seiner früheren Auftritte sowie Artikel über seine Vertreibung aus dem Theater und somit im übertragenen Sinne alles, was seine Identität ausmacht, enthält.“ Zur Bedeutung der Rezensionen vgl. auch ebd., S. $124 \mathrm{f}$.

169 Hanna Klessinger: Postdramatik. Transformationen des epischen Theaters bei Peter Handke, Heiner Müller, Elfriede Jelinek und Rainald Goetz. Berlin, Boston: de Gruyter 2015, S. 22.

170 Martin Brunkhorst: Minetti oder Beckett und Bernhard. In: Beckett und die Literatur der Gegenwart. Hg. v. M. B., Gerd Rohmann u. Konrad Schoell. Heidelberg: Winter 1988, S. 175-189, hier S. 175 .

171 Vgl. Bourdieu: Die Regeln der Kunst (Anm. 5), S. 54 f. 
künstlerischen Herausforderungen des Autors Bernhard - der im Laufe seiner Karriere nicht selten den Autor Bernhard gespielt hat ${ }^{172}$ - vor Augen.

Der Erzähler des 1967 veröffentlichten Prosatextes Ist es eine Komödie? Ist es eine Tragödie?, der kurz darauf von einem melancholischen cross dresser angesprochen wird, disponiert die einleitenden Abschnitte einer großen „Studie über das Theater" (TBW 14, 35) nach dem folgenden Schema: „Erster Abschnitt DIE SCHAUSPIELER, zweiter Abschnitt DIE SCHAUSPIELER IN DEN SCHAUSPIELERN, dritter Abschnitt DIE SCHAUSPIELER IN DEN SCHAUSPIELERN DER SCHAUSPIELER usf.“ (TBW 14, 36) Diese Staffelung, die zugleich den Fokus auf den Moment des Spiels in der Erfüllung der eigenen sozialen Rolle legt, ist für Bernhards Konzeption von Autorschaft und Künstlertum von zentraler Bedeutung. Sie kehrt im Titel des Theaterstücks Ritter, Dene, Voss (1984) ebenso wieder wie im fortgesetzten Vexierspiel zwischen Autor- und Figurenrede in den Prosatexten der 1980er Jahre: ein Spiel, das sich immer wieder aufs Neue um Identität und Nicht-Identität, um den Gegensatz von literarischer Rolle und , authentischem' Sprechen dreht. ${ }^{173}$ Der Schauspieler Minetti wird in diesem Zusammenhang, gerade beim Lesen der ihn betreffenden und taxierenden Kritiken auf der Bühne, zu einer über den Einzelfall hinausweisenden Reflexionsfigur für Probleme künstlerischer Selbstbehauptung und künstlerischen Selbstbewusstseins. Ein, wie Bernhard 1975 in Bezug auf den Schauspieler Minetti doppelsinnig formuliert hat, , uns tatsächlich auf die Nerven gehende[r] Künstler" zu sein (TBW 22.1, 642), kann mit gutem Recht ebenso als Anspruch und Pensum seiner eigenen Idee von Autorschaft interpretiert werden. ${ }^{174}$

Auch im sechs Jahre nach Minetti, im Juni 1982, bei den Ludwigsburger Festspielen uraufgeführten Theaterstück Über allen Gipfeln ist Ruh ist der Status, der der Kritik zugesprochen wird, ein zumindest ambivalenter. „Nicht nur mit den Kritikern in Deutschland ist es eine fatale Sache / Sie loben und sie verdammen / und sie wissen niemals was sie loben / und was sie verdammen / sie haben keine Ahnung von ihrem Gegenstand / wie Stieglitz sagt“" (TBW 18, 184), zitiert der gealterte, längst umfassend konsekrierte Schriftsteller Moritz Meister die Hauptfigur seiner eben abgeschlossenen Tetralogie. Der Romancier und sein

172 Zur „Kunstfigur“ Bernhards vgl. schon Schmidt-Dengler: Der Übertreibungskünstler (Anm. 113), S. 94, sowie nun umfassend Clemens Götze: „Die Ursache bin ich selbst!“ Thomas Bernhards inszenierte Autorschaft am Beispiel seiner (Film-)Interviews. In: Thomas Bernhard. Gesellschaftliche und politische Bedeutung der Literatur (Anm. 6), S. 357-371. Eine prägnante Reflexion über diesen Aspekt findet sich auch in Leonhard Fuest: Kunstwahnsinn irreparabler. Eine Studie zum Werk Thomas Bernhards. Frankfurt a. M. u. a.: Lang 2000, S. 303-306.

173 Siehe dazu etwa aktuell den erhellenden Aufsatz von Nicolas Pethes: „glauben Sie mir“. Die Ausweitung der literarischen Kampfzone in Thomas Bernhards Interviews, Briefen, Preisreden und Feuilletonbeiträgen. In: Text + Kritik ( $\left.{ }^{4} 2016\right)$, H. 43, S. 126-139.

174 Zur selbstreflexiven Dimension von Minetti vgl. auch Heinrici: Maskenwahnsinn (Anm. 167), S. $131 \mathrm{f}$. 
Protagonist Stiglitz teilen die Vorbehalte ihres Autors Thomas Bernhard, zweifeln wie er an der Kompetenz und am Sachverstand der Rezensenten, zumal, wie Meister selbstbewusst feststellt, nur wenige Kritiker in der Lage seien, sein Werk „in seiner Komplexität zu verstehen ${ }^{\text {“175 }}$ Von einer jungen Germanistin, Fräulein Waldenfels, auf die Einschätzungen der „maßgeblichen Kritiker“ angesprochen (TBW 18, 183), zeigt Meister sich gleichwohl „,erstaunt“ darüber, „daß die Kritiker tatsächlich zu solcher Beobachtung fähig sind“, hätten doch „die meisten“, so die Erfahrung des selbstbewussten Autors, „niemals die Fähigkeit tiefer in ein Werk einzudringen" (TBW 18, 183). Wie in anderen Künstlertexten Bernhards verrät die zumeist abwertende Beschäftigung mit der Literaturkritik, wie Nina Birkner überzeugend dargelegt hat, auch in Über allen Gipfeln ist Ruh indirekt, doch überdeutlich die „Abhängigkeit des Künstlers von dieser Definitionsmacht“ ${ }^{\text {“ }}{ }^{176}$ Meister betont zwar, dass „ein schöpferischer Künstler“, „je früher“ er sich „klarmach[e]“, dass die Kritiker „keine Ahnung von ihrem Gegenstand“ hätten, desto besser mit deren Urteilen umgehen könne (TBW 18, 184), muss jedoch im weiteren Verlauf des Stücks eingestehen, wie stark seine Existenz als Autor mit der Aufmerksamkeit und dem Wohlwollen der Kritiker in Beziehung steht:

Tatsächlich sind die Zeitungen mein Schicksal

gäbe es die Zeitung nicht ich existierte gar nicht

das kann wohl jeder Schriftsteller von sich sagen

wenn er ehrlich ist

Gäbe es kein Feuilleton

es gäbe gar keine Schriftsteller

Das Feuilleton ist gut sagen sie

wenn sie darin gelobt werden

das Feuilleton ist schlecht

werden sie kritisiert

so einfach ist das (TBW 18, 222) ${ }^{177}$

175 Birkner: Vom Genius zum Medienästheten (Anm. 158), S. 228.

176 Ebd., S. 235.

177 Zur zuletzt zitierten Passage vgl. auch Bernhards eigene Äußerung im ,Nachtgespräch` mit Peter Hamm (hier in Bezug auf die Rezeption seiner frühen Lyrikbände): „Zum Teil wird so ein erster Gedichtband nicht wahrgenommen und zum andern, mein Gott, war'n halt Kritiken, und die guten waren halt wunderbar und die schlechten waren halt schlecht, nicht?" (TBW 22.2, 109) - Es handelt sich dabei um einen stehenden Topos in der Reflexion über das Verhältnis von Autor und Kritik. Vgl. dazu bereits die Bemerkungen in Georg Lukács: Schriftsteller und Kritiker. [1939] In: G. L.: Schriften zur Literatursoziologie. Hg. v. Heinz Maus u. Friedrich Fürstenberg. Neuwied, Berlin: Luchterhand ${ }^{4} 1970$, S. 198-212, hier S. 211: „Für den Schriftsteller ist im allgemeinen eine ,gute' Kritik jene, die ihn lobt oder seine Nebenbuhler herunterreißt; eine ,schlechte jene, die ihn tadelt oder seine Nebenbuhler fördert.“ 
Die „Kritiker“ hätten, so Meister, „schon viele Genies vernichtet“, ja er selbst hätte sich, „, [w]enn es nach den Kritikern gegangen wäre“, „längst umbringen müssen“ (TBW 18, 183f.). Erst im fortgeschrittenen Alter habe er die uneingeschränkte Gunst der Rezensenten genossen - der Nachvollzug der eigenen Laufbahn indes bleibt für den gesetzten,Großschriftsteller ' weiterhin auf die historischen Urteile der Literaturkritik bezogen, sie stellen einen wesentlichen Bezugspunkt seines auktorialen Selbstentwurfs dar:

Ich selbst habe inzwischen eine harte Haut

und mein Blick ist immer nur auf den Gegenstand gerichtet

und heute kann ich nicht klagen

[...]

es wird seit Jahren nur Positives über mich geschrieben

seit ich fünfundsechzig gewesen bin kein verletzendes Wort mehr

lese ich meinen Namen in der Zeitung

ist er immer mit einem hochachtenden Lob verbunden

das beflügelt natürlich

ja hätte ich früher ein solches Echo gehabt

wer weiß was ich noch alles vollbracht hätte (TBW 18, 184f.)

Hier wie auch in anderen Theatertexten stellt Bernhard die Sensibilität des Künstlers ins Zentrum des dramaturgischen Konflikts. Im 1981 unter der Regie von Claus Peymann bei den Salzburger Festspielen erstmals aufgeführten Drei-Personen-Stück Am Ziel etwa - einem, so Siegfried Unselds Chronik-Notiz, „Stück über das Schöpferische des Schriftstellers “"178 - lässt er ganz in diesem Sinne und mit Blick auf die Gefährdung der künstlerischen Existenz die Mutter dem jungen Schriftsteller gegenüber äußern:

Ich kann mir denken

daß es sehr gefährlich ist

einen solchen wie man sagt

durchschlagenden Erfolg zu haben

bei einem solchen unberechenbaren Publikum

bei einer solchen ja tatsächlich immer unberechenbaren Kritik

Ein dramatischer Schriftsteller

eine Natur die doch menschenscheu ist

plötzlich mit Beifall überschüttet

Auch das ist eine Rücksichtslosigkeit (TBW 18, 327)

178 Unseld: Chronik [Salzburg, 7. 8. 1981]. In: Bernhard/Unseld: Der Briefwechsel (Anm. 11), S. 637. 
Die Abhängigkeit von der Gunst des Publikums wie von jener der Kritik wird in Bernhards Theatertexten immer wieder als prekäre Herausforderung des darstellenden Künstlers thematisiert. Sie verweist dabei auf einen grundlegenden Aspekt künstlerischer Produktivität, der für das Werk des Autors insgesamt, explizit thematisiert wie implizit verhandelt, von zentraler Bedeutung ist: Der Genuss des „Besprechungsmenu[s], das auf eine Veröffentlichung folgt “, ${ }^{\text {"179 }}$ birgt stets die Gefahr, den Organismus des Künstlers aus dem Gleichgewicht zu bringen - sei es durch zu süße Worte oder durch zu stark gewürzte Urteile.

1986 hat Bernhard dem geschätzten Schauspieler Bernhard Minetti mit Einfach kompliziert ein weiteres Theaterstück gewidmet: „Für Minetti“ ist in der Erstausgabe noch vor dem Motto aus Shakespeares Richard III. auf einem eigenen Blatt zu lesen; ${ }^{180}$ in der Uraufführung am Schillertheater Berlin (Regie Klaus André) übernahm Minetti die Hauptrolle. Siegfried Unseld notierte in seiner Chronik nach der ersten Lektüre, er sei „zum ersten Mal tief enttäuscht“ von einem Manuskript des Autors; es handle sich bloß um einen „müde[n] Aufguß“ früherer Theaterarbeiten. ${ }^{181}$ Auch wenn der Protagonist von Einfach kompliziert lediglich den Namen „Er“ trägt, spinnt Bernhard darin die Geschichte des Schauspielers aus Minetti weiter: ${ }^{182}$ Ein laut Regieanweisung „alter Schauspieler“ lebt abgeschieden von der Welt und ihren Zumutungen. Er versucht sich anfangs an kleineren Reparaturen in seinem verwahrlosten Zimmer, reflektiert seine prekäre Künstlerexistenz und gedenkt wehmütig seiner einstigen Bühnenauftritte. ${ }^{183}$ Indem er mit der Krone Richards III. vor dem Spiegel posiert und überzeugt ist, diese sitze erst „richtig“, „wenn der Kopf blutet“, imaginiert er sich als leidenden Christus, als Schauspieler mit der Dornenkrone (TBW 20, 31), weiß jedoch gleichzeitig über seine eigene „Überheblichkeit / Selbstüberschätzung“ (TBW 20,

179 Bernhard an Unseld, 18. 5. 1967. In: ebd., S. 56.

180 Thomas Bernhard: Einfach kompliziert. Frankfurt a. M.: Suhrkamp 1986, S. [5].

181 Unseld: Chronik [15. 7. 1985]. In: Bernhard/Unseld: Der Briefwechsel (Anm. 11), S. 724; vgl. dazu auch Huntemann: Artistik und Rollenspiel (Anm. 10), S. 213 f.

182 So war „Er“ wie „Minetti“ etwa „[i]mmer wieder in Prozesse verwickelt / aber nie eingesperrt“ (TBW 20, 58); daneben hat Bernhard auch Elemente seiner eigenen Biographie in die Figur des Schauspielers in Einfach kompliziert eingearbeitet: „Im Thüringer Wald / haben sie mich drei Monate / allein gelassen / sich nicht um mich gekümmert / und ich war noch nicht elf Jahre alt / Wir verzeihen ihnen nicht / dazu sind wir nicht befähigt / den Eltern ist nicht zu verzeihen / Das Geborenwerdenverbrechen ist nicht zu verzeihen“ (TBW 20, 37). Zu den lebensgeschichtlichen Implikationen dieser Stelle vgl. Mittermayer: Thomas Bernhard [2015] (Anm. 42), S. 55 f.

183 Vgl. zu dieser Grundkonstellation bei Bernhard Hans Höller: Selbstporträts des Künstlers als alter Mann. Zu typischen Figuren bei Thomas Bernhard, Franz Grillparzer und Adalbert Stifter. In: Bernhard-Tage Ohlsdorf 1999. „In die entgegengesetzte Richtung“. Thomas Bernhard und sein Großvater Johannes Freumbichler. Materialien. Hg. v. Franz Gebesmair u. Manfred Mittermayer. Weitra: Bibliothek der Provinz [200o], S. 201-214. 
26) nur zu gut Bescheid. Während Bernhard Minettis problematische Rolle im Kulturbetrieb des Dritten Reichs in Minetti fast vollständig ausgespart hat (und auch sonst offenbar nie daran Anstoß nahm ${ }^{184}$ ), findet sich in Einfach kompliziert doch eine kurze Passage, die diese Dimension zumindest erahnen lässt. Wie beiläufig erwähnt die Figur des greisen Schauspielers „Memel Etsch Belt“ (TBW 20, 28) und spielt damit auf die erste, von den Nationalsozialisten vornehmlich verwendete Strophe des Deutschlandlieds an. Die drei Flüsse, die neben der Maas im Deutschlandlied des August Heinrich Hoffmann von Fallersleben genannt werden, verweisen in der Lesart des Dritten Reichs auf dessen raumgreifende Expansions- und Großmachtsphantasien. Bernhard Minetti hatte dem NS-Staat jahrelang als willfähriger, auf der „Gottbegnadeten-Liste“ des Regimes geführter Künstler gedient. ${ }^{185}$

Wichtiger für den vorliegenden Zusammenhang aber sind jene beiden, zunächst eher unscheinbaren Stellen, an denen auch in Einfach kompliziert Zeitungen zum Thema werden. Anders als in Minetti scheint sich der gealterte, mittlerweile 82-jährige Schauspieler nicht mehr mit den Kritiken seiner Auftritte auseinanderzusetzen; er hat zwar aus Gewohnheit noch eine Zeitung „abonniert“ (TBW 20, 32), studiert dort aber lediglich die „Stellenangebote“ (TBW 20, 29). Am Ende breitet er, wie es in der Regieanweisung heißt, „ein großes Stück Zeitungspapier" auf dem Tisch aus, um es als Unterlage zum Schneiden von Käse zu verwenden (TBW 20, 58): Die Abhängigkeit von den Urteilen des Feuilletons, die den Schauspieler in Minetti an- und umtreibt, die ihn am Leben hält und

184 Auch über Paula Wessely, die im Dritten Reich an zahlreichen NS-Propagandafilmen mitwirkte, hat Bernhard sich - ganz anders als Elfriede Jelinek - stets wertschätzend geäußert (vgl. TBW 22.2, 266 f.). Ein Jahr vor der Uraufführung von Jelineks Burgtheater (1985) nimmt der Erzähler von Holzfällen (1984), Bernhards Abrechnung mit dem österreichischen Kulturbetrieb, „die Wessely“ ausdrücklich von seinem „ganz besonderen Haß“ auf die „Burgschauspieler“ aus; er habe sie vielmehr - ebenso wie Käthe Gold - „zeitlebens innig geliebt“ (TBW 7, 20). - Bruno Ganz hatte Paula Wessely 1973 als Generalin in der Uraufführung von Die Jagdgesellschaft vorgeschlagen; Bernhards Schilderung in Wittgensteins Neffe (1982) zufolge kam die Besetzung nur aufgrund einer Intrige der Burgtheater-Schauspieler gegen Ganz nicht zustande: „In dem Augenblick, in welchem der Auftritt des Bruno Ganz durch die Gemeinheit seiner Wiener Kollegen unmöglich gemacht worden war, hatte sich auch die Paula Wessely, meine erste und einzige Generalin, aus dem Projekt zurückgezogen“ (TBW 13, 302). Vgl. dazu ausführlicher TBW 13, 300-304, sowie den Kommentar in Bernhard/Unseld: Der Briefwechsel (Anm. 11), S. 345. Zur differierenden Beschäftigung Bernhards und Jelineks mit Paula Wessely vgl. Karl Müller: Die Theaterkonzepte Thomas Bernhards und Elfriede Jelineks im Vergleich. In: Thomas Bernhard Jahrbuch 2004, S. 91-116, hier S. 96, der auch Jelineks „Verwunderung“ über Bernhards unbedarften Umgang mit Wessely dokumentiert.

$185 \mathrm{Zu}$ Minettis Rolle im NS-Kulturbetrieb vgl. Klee: Das Kulturlexikon zum Dritten Reich (Anm. 166), S. 371, sowie Helmut Lethen: Die Staatsräte. Elite im Dritten Reich: Gründgens, Furtwängler, Sauerbruch, Schmitt. Berlin: Rowohlt 2018, S. 39-41. 
gleichzeitig Quelle seines Unglücks ist, ist in Einfach kompliziert einem resignativen Desinteresse gewichen. Nur bei der Zubereitung einer einfachen Jause, so legt es der Text nahe, findet die Zeitung noch Verwendung.

\section{Von der Dürre der Theaterkritik oder: Landwirte und Rezensenten}

Bereits am 3. November 1976 hatte sich Bernhard in einer Diskussion zur Situation des Gegenwartstheaters in der Frankfurter Allgemeinen Zeitung pointiert zu Wort gemeldet. Der Essay mit dem Titel Ist das Theater nicht mehr, was es war? richtet sich allerdings - anders als seine Polemik gegen das Salzburger Landestheater Mitte der 1950er Jahre (vgl. TBW 22.1, 411-413) oder die geplante „wissenschaftliche Arbeit“ (TBW 14, 35) in Ist es eine Komödie? Ist es eine Tragödie? - nicht vorrangig gegen das Niveau des zeitgenössischen Theaters, ${ }^{186}$ sondern gegen die „sogenannten Theaterkritiker“, die sich mit „furchtbar verzerrter Kompetenzmiene [...] die Köpfe darüber zerbrechen, ob und in was für einem katastrophalen Ausmaß eine Dramendürre in Deutschland herrsche“ (TBW 22.1, 613):

Die Theaterkritiker und die sogenannten Theaterkritiker haben immer und lebenslänglich von der sogenannten Theaterdürre gelebt wie die Bauern und die sogenannten Landwirte von der Getreidedürre, und die Bauern und die sogenannten Landwirte werden auch in Zukunft und wahrscheinlich, wenn nicht alles täuscht, nicht nur wie seit, sondern tief in alles künftige vernünftige oder unvernünftige Menschengedenken hinein von der einträglichen Behauptung, es herrsche eine Getreidedürre, existieren wie die Theaterkritiker von der Behauptung, es herrsche eine Theater-, genauer, eine Theaterstückdürre. (TBW 22.1, 611)

Der von Bernhard angestrengte Vergleich zwischen Landwirtschaft und Theaterbetrieb - den er aus einem FAZ-Diskussionsbeitrag von Karlheinz Braun, dem früheren Leiter des Suhrkamp-Theaterverlags und langjährigen Geschäftsführer des Verlags der Autoren, aufgreift ${ }^{187}$ - mag hinken und nur eingeschränkt stichhaltig erscheinen, zumal ,Dürre' die physische Existenz in dem einen Bereich auf ganz andere Weise bedroht als in dem anderen. Er stellt jedoch, humoristisch

$186 \mathrm{Zu}$ Bernhards Auseinandersetzung mit „zeitgenössischen Theaterdiskurse[n]“vgl. Verena Meis: Bernhard und das Theater der 1970er und 1980er Jahre. In: Bernhard-Handbuch (Anm. 75), S. 302-306.

187 Vgl. Michael Töteberg: Die Dürre der Theaterlandschaft. Polemische Anmerkungen, gestützt auf Zahlen, Daten und Statistiken. In: Text + Kritik (1988), Sonderbd. „Bestandsaufnahme Gegenwartsliteratur“, S. 61-66, hier S. 65. 
aufgeladen, einen wichtigen Angelpunkt der Argumentationsführung des Aufsatzes dar, indem Bernhard durch die Gleichsetzung von Getreide- und Theaterdürre den Vorrang der künstlerischen Diskussionen gegenüber den agrikulturellen provokant in Zweifel zieht: „[D]ie Bauern und die sogenannten Landwirte und die Theaterkritiker und die sogenannten Theaterkritiker zwischen Flensburg und Bozen haben viel mehr gemeinsam, als sich ein einfacher feuilletonistisch verdorbener und verunstalteter Kopf ausmalen kann oder denken läßt.“ (TBW 22.1, $613)^{188}$ Dass sowohl die „Produkte der Bauern“ als auch jene der „Theaterkritiker“ mitunter zu Magenverstimmungen führen (TBW 22.1, 611), lasse, so Bernhard, auf Ähnlichkeiten in den beiden Feldern schließen. Hier wie dort gehorche die Rhetorik der ,Dürre einem Kalkül, das nicht die Verbesserung der Qualität der Produkte, sondern den Gewinn der "Getreide- wie der Feuilletonsilobesitzer“ (TBW 22.1, 613) im Blick habe. Bernhard, der schon 1968 die „agronomische[ ] Schläue“ seines Verlegers mit „Bewunderung“ zur Kenntnis genommen hatte ${ }^{189}$ und als seine Berufsbezeichnung wiederholt „Landwirt“ angab, ${ }^{190}$ wusste, wovon er sprach. $^{191}$

Nach etwa einem Drittel des Beitrags fällt Bernhard ein vorläufiges, für beide Bereiche gleichermaßen vernichtendes Urteil, das in einem etwas zwielichtigen Binnenreim kulminiert: „Der Ruf nach der Gesundheitspolizei dröhnt uns ja tatsächlich fortwährend in den Ohren, und mit den Vergifteten der Bauern und der sogenannten Theaterkritiker sind die Spitäler überfüllt. Es ist ganz einfach und überall zwischen Flensburg und Bozen zum Kotzen!“ (TBW 22.1, 611 f.) Die

188 Huntemann: Artistik und Rollenspiel (Anm. 10), S. 195, zufolge ist Bernhards Beitrag zur Dürre dermaßen „stilisiert“, dass er als konkreter Diskussionsbeitrag „nicht mehr ernstzunehmen“ sei.

189 Bernhard an Unseld, 22. 7. 1968. In: Bernhard/Unseld: Der Briefwechsel (Anm. 11), S. 8o.

190 Vgl. die Abb. in Hennetmair: Ein Jahr mit Thomas Bernhard (Anm. 145), S. 216. Siehe auch Unseld: Reisebericht Israel-Iran-Ägypten, 29. April - 12. Mai 1977. In: Bernhard/Unseld: Der Briefwechsel (Anm. 11), S. 516: „Das Zusammensein mit Thomas Bernhard war ungemein freundlich. Er nahm auch an Exkursionen teil, aber freilich reichte die Basis seiner Gemeinsamkeitsbereitschaft nicht allzu weit. Er zog sich gerne auf sich zurück, mit dem Hinweis, daß sein Beruf (in seinem Paß steht als Beruf ,Landwirt') langen kulturellen Exkursionen nicht standhält." Dazu Janko Ferk: Bauer Bernhard. Beamter Kafka. Dichter und ihre Zivilberufe. Wien u. a.: Styria premium 2015, S. 115-129, bes. S. 126 f., sowie die Erinnerungen von Rudolf Asamer: In zwanzig Minuten war der Verkauf abgeschlossen. In: Was reden die Leute (Anm. 36), S. 136-139.

191 Einige Jahre später wird der Musikphilosoph Reger in Alte Meister (1985) Martin Heidegger als „urdeutsche[n] Philosophiewiederkäuer“, ja als „unablässig trächtige Philosophiekuh“ bezeichnen, „die auf der deutschen Philosophie geweidet und darauf jahrzehntelang ihre koketten Fladen fallen gelassen hat“: „Heute ist Heidegger noch immer nicht ganz durchschaut, die Heideggerkuh ist zwar abgemagert, die Heideggermilch wird aber noch immer gemolken“ (TBW 8, 56 f.). Die Herabstimmung der Bedeutung des polemisch attackierten ,hohen' Gegenstands funktioniert auch hier über den Vergleich mit der Sphäre des Agronomisch-Ruralen. Der Begriff des „Philosophiewiederkauer[s]“ (TBW 13, 71) wiederum findet sich bereits in Ja (1978). 
Einschätzung mancher Kritiker, wonach sich das Theater Mitte der 1970er Jahre in einer veritablen Krise befand, kontert Bernhard mit dem - durchaus zutreffenden - Hinweis, wonach die Rede von der Krise des Theaters dessen Geschichte und Entwicklung bereits seit langer Zeit begleitet und damit an Triftigkeit eingebüßt habe - eine Beobachtung, die er mit Verweisen auf Alfred Kerr und Robert Musil, „die beiden eitlen heroischen Theaterberserker“ (TBW 22.1, 612), untermauert. Die „Einträglichkeit dieser Behauptung“, der Umstand, dass die Kritiker „ihre Dürre immer recht gut verkauft“ hätten (TBW 22.1, $612 \mathrm{f}$.), habe dazu beigetragen, dass die Diagnose noch immer fröhliche Urständ feiere. Zudem hatte Bernhard seit der Hamburger Uraufführung von Ein Fest für Boris im Juni 1970 mit Der Ignorant und der Wahnsinnige (1972), Die Jagdgesellschaft (1974), Die Macht der Gewohnheit (1974), Der Präsident (1975), Die Berühmten (1976) und Minetti (1976) eine ganze Reihe von Bühnenstücken vorgelegt, die er keineswegs unter das Verdikt der Dürre gestellt sehen wollte. Seine Polemik war also durchaus auch als eine Intervention pro domo zu verstehen.

Gleichwohl stellen Bernhards Äußerungen weniger einen Kommentar zum zeitgenössischen Theater als vielmehr zur eingeschliffenen Rhetorik der Theaterkritik dar, für die er die damaligen Debatten im Feuilleton der Frankfurter Allgemeinen Zeitung als symptomatisch anführt:

\begin{abstract}
Aber hier geht es nicht darum [...], meine Bewunderung für diejenigen als Hymnus ans Feuilleton der F. A.Z. festzunageln, die aus der Dürre ihr großes Geschäft und ihren legendären Lebenszweck ziehen, ich bin kein Theaterluther, und dazu fehlt mir auch der dazu unbedingt notwendige Ernst [!], aber es ist schon erschreckend und es macht einen schon frösteln, wenn ein Kopf in der F. A.Z. lesen muß, wie sich ein paar andere Köpfe in der F. A. Z. mit von Dürreangst furchtbar verzerrter Kompetenzmiene [...] die Köpfe darüber zerbrechen, ob und in was für einem katastrophalen Ausmaß eine Dramendürre in Deutschland herrsche. Und in Österreich und in der Schweiz selbstverständlich. (TBW 22.1, 613)
\end{abstract}

Die historischen Bezugspunkte seiner Überlegungen bleiben indes, wie öfter bei Bernhard, relativ indifferent. Die Stelle aus einem Text Robert Musils etwa, die er vorgibt, „wörtlich“ zu zitieren (TBW 22.1, 612), lässt sich in dessen Schriften, selbst mithilfe der digitalen Klagenfurter Ausgabe, nicht nachweisen. Zwar ist in Musils Essay Der „Untergang“ des Theaters, 1924 im Neuen Merkur erschienen, von einer „Theater- und Bildungskrisis“ die Rede, ${ }^{192}$ nicht jedoch von der

192 Musil: Der „Untergang“ des Theaters (Anm. 73), S. 1126. Töteberg: Die Dürre der Theaterlandschaft (Anm. 187), S. 65, vollzieht Bernhards Einschätzung zustimmend nach, bleibt einen konkreten Musil- bzw. Kerr-Beleg aber ebenso schuldig: „Bauern und Theaterkritiker hätten, im Schatten von Getreidesilos und Stadttheatern, ihr Gerede von der Dürre immer gut verkauft. 
zitierten ,Dürre‘ des Theaters (nur vom „dürren Verstandesunterricht des Schultyrannen ${ }^{\text {“193 }}$ ). Zudem weist Musil in seinem Essay, ganz gegen Bernhards Lesart, gleich eingangs darauf hin, dass er an den „Zustand“, „den sie den Untergang des Theaters nennen“, nicht "glaube“, weil es sich um den „latente[n] Zustand eines Daueruntergangs“ handle, in dem sich das Theater „seit Menschengedenken häuslich eingerichtet" habe. ${ }^{194}$ Wie in anderen Reflexionen Bernhards, die sich explizit mit literarischen und/oder philosophischen Positionen auseinandersetzen, kann man guten Gewissens davon ausgehen, dass er nur wenig Zeit mit intensivem und philologisch akkuratem Quellenstudium verbracht hat - dem polemischen Drive seiner „wütende[n] Suada“ ${ }^{195}$ tut dies freilich keinen Abbruch, zumal er ja selbst listig bekennt, sein Statement lasse den für eine Feuilletondebatte „unbedingt notwendige[n] Ernst“ vermissen (TBW 22.1, 613): eine Geste, die die eigene Überlegenheit wie die Distanzierung vom Gegenstand der Debatte gleichermaßen suggeriert.

Bemerkenswert und aufschlussreich ist Bernhards Essay Ist das Theater nicht mehr, was es war?, der mit zahlreichen rhetorischen Figuren und Wiederholungsstrukturen arbeitet, indes noch aus einem weiteren Grund, der für die Analyse polemischen Agierens im literarischen Feld von nicht unwesentlicher Bedeutung ist: Weil die für ihn attraktive Position des polemischen Kommentators bereits von den Kritikern besetzt ist, die den Zustand des Theaterbetriebs beklagen, überzeichnet Bernhard deren kritische Einwände, um sie im Gestus des Satirikers zu desavouieren. So treibt er die Phrase, wonach das Theater nicht mehr sei, wie es einmal gewesen', virtuos auf die Spitze:

Aber das Theater und insbesondere das Drama war ja, behaupte ich, schon zu Lebzeiten der griechischen Tragiker nicht mehr das, was es einmal war, auch zu ihren (der griechischen Tragiker) Zeiten herrschte absolut eine Dürre, und es herrschte schon die Dürre des Dramas, bevor überhaupt ein einziger Mensch, ein einziges Gehirn, ein einziger Kopf (welch ein Wahnsinn!) auf die Idee gekommen war, ein Drama zu schreiben und ein Theater zu machen. (TBW 22.1, 612 f.)

Bernhard hat recht: Von der ,Dürre des Dramas heute‘ schrieben bereits in den zwanziger Jahren Robert Musil und Alfred Kerr.“

193 Musil: Der „Untergang“ des Theaters (Anm. 73), S. 1126. Auf diese Stelle in Musils Essay verweist auch der Kommentar in TBW 22.1, 819. Zum Verhältnis von Bernhard und Musil vgl. jetzt Marion Schmaus: Literarische Rezeption. In: Robert-Musil-Handbuch. Hg. v. Birgit Nübel u. Norbert Christian Wolf. Berlin, Boston: de Gruyter 2016, S. 825-854, hier S. 842-844.

194 Musil: Der „Untergang“ des Theaters (Anm. 73), S. 1116 f. Zu Musils Tätigkeit als Theaterkritiker vgl. Oliver Pfohlmann: Literatur- und Theaterkritik. In: Robert-Musil-Handbuch (Anm. 193), S. 414-429, sowie die grundlegende Studie von Nicole Streitler: Musil als Kritiker. Bern u.a.: Lang 2006.

195 Töteberg: Die Dürre der Theaterlandschaft (Anm. 187), S. 65. 
Am Ende wiederholt Bernhard den bereits zuvor lancierten Vorwurf an die Kritiker, durch die fortwährende Diagnose einer „Dürre“ des Theaters im Grunde nur ihre eigene Legitimation als Kritisierende festigen und bestätigen zu wollen, und fordert die Leser seiner Polemik dazu auf, ihnen nicht allzu viel Gehör zu schenken: „Die Bauern und die sogenannten Landwirte und die Theaterkritiker und die sogenannten Kritiker ziehen (siehe Kerr und Musil!) am gleichen Strang: an der Dürre. Und wenn sie nicht gestorben sind, ziehen sie noch daran. Laßt sie ziehen!“ (TBW 22.1, 614) ) $^{196}$

Nicht nur diese letzte sprachspielerische Volte, die an die Schlusspointen eines Karl Kraus erinnert, ${ }^{197}$ zeigt, dass Bernhards Diskussionsbeitrag - wie auch andere polemische Texte des Autors - der formalen Poetizität gegenüber der Stringenz der Argumentation den Vorrang einräumt. Die „Wörter und ihre Zusammensetzung, ihre Bedeutung, ihre äußere und innere Form“ sind, mit Roman Jakobson gesprochen, „nicht nur indifferenter Hinweis auf die Wirklichkeit“, sondern sie haben „eigenes Gewicht und selbständigen Wert“. ${ }^{198}$ Als „Wortkunstwerk[e]“199 sind Bernhards Polemiken stets ,überstrukturiert', gehen weit darüber hinaus, Missstände zu benennen und Gegner zu denunzieren. Sie sind - auch und gerade dort, wo ihre konkrete Stoßrichtung oder ihre argumentative Substanz diffus bleibt - Texte von eigenem ästhetischem Wert, als polemische Beiträge immer auch poetische Artefakte, wobei sich die beiden Aspekte nicht trennscharf voneinander scheiden lassen.

1961984 hat Bernhard in einem Gespräch mit Krista Fleischmann das Bild von der ,Dürre“ des Theaters affirmativ aufgegriffen, wenn er „Wüste und Dürre auf dem Burgtheater“ beklagt: „Das Burgtheater ist ja wie so eine Sahelzone, wo alles dürr ist, ausgetrocknet, kaputt, und da gehen diese zwei [Käthe Gold und Paula Wessely] immer noch frei herum auf dieser toten Wüste.“ (TBW 22.2, 266) Im Laufe des Gesprächs erweitert Bernhards das Bild auf komödiantische Weise: „Man geht hinein, man fahrt dort hin, man bucht quasi eine Safari im Burgtheater und geht hin, und es sind keine Tiere da, es wachst nichts, es brüllt nichts, keine Giftschlangen, gar nichts, völlig leer. Da geht man wieder heraus und sagt, na ja also wenn's nur Wüste ist, brauch' ich ja nicht hingehen. Es ist wüst und leer. Nur so manchmal hört man so alte Schreie von Schakalen, aber auftreten tun keine mehr dort." (TBW 22.2, 267) Schließlich greift Bernhards WüstenVerdikt auch auf die Salzburger Festspiele über, wobei er die Entwicklung des Theaterbetriebs mit den Veränderungen von Vegetationszonen kurzschließt: „Na ja, Salzburg ist genauso eine Wüste. Es gibt ja in der Welt auch mehrere Wüsten, also gibt's halt in Wien eine, und Salzburg, das wird auch immer mehr zur Wüste. Steppe ist es ja schon jahrzehntelang, und jetzt wird's wahrscheinlich von der Steppe zur Wüste umkippen." (TBW 22.2, 267)

197 Vgl. exemplarisch Kraus' Glosse, die im Rahmen seiner publizistischen Auseinandersetzung mit der Wiener Kriegsausstellung 1916 entstanden ist: Karl Kraus: Es zieht! In: Die Fackel (2. 8. 1916), H. $431-436$, S. 109.

198 Roman Jakobson: Was ist Poesie. [1934] In: R. J.: Poetik. Ausgewählte Aufsätze 1921-1971. Hg. v. Elmar Holenstein u. Tarcisius Schelbert. Frankfurt a. M.: Suhrkamp 1979, S. 67-82, hier S. 79.

199 Ebd. 
1980 in einem Interview mit dem Spiegel nach Erfahrungen mit der Literaturkritik befragt, antwortete Bernhard lapidar, ohne sich in der Folge genauer zu erklären: „Zwischen grauenhaft und ganz lustig.“ (TBW 22.2, 169) Ebenso wie der Schlusssatz von Ist das Theater nicht mehr, was es war? - „Laßt sie ziehen!“ (TBW 22.1, 614) - suggeriert auch diese Sentenz eine Souveränität und Distanz gegenüber den Einschätzungen der Literaturkritik, die Bernhard, allen Erfolgen im Feuilleton und aller öffentlichen Konsekration zum Trotz, nie dauerhaft aufrechterhalten konnte; zeitlebens spielten sie, mochte er sie für noch so ,dumm ' und ,skurril' halten, für den künstlerischen Selbstentwurf des Autors eine zentrale Rolle.

\section{Nur selten ein Sommerhemd: Handke liest Rezensionen}

Wie Thomas Bernhard hat auch Peter Handke, was die literaturkritische Wahrnehmung seiner Bücher betrifft, selten von positiven Erfahrungen berichet. In einer Reportage, die im Frühjahr 1987 von einen Besuch bei Handke am Salzburger Mönchsberg berichtet, hält Heinz-Norbert Jocks in aller Kürze fest: „Natürlich hat Peter Handke ein gespanntes, in Wahrheit vielleicht sogar gestörtes Verhältnis zur Kritik. “200 Zwar war der Auftakt mit Helmut Scheffels Besprechung der Hornissen - sie habe ihm „sehr gefallen, sie ist, glaube ich, auch gut geschrieben “201 - ein vielversprechender, Handkes Rezensionslektüren fielen in der Folge jedoch eher selten so erfreulich aus: „Am schönsten fand ich, was [Reinhard] Baumgart in der Süddeutschen Zeitung schrieb“, lässt Handke seinen Freund Alfred Kolleritsch 1972 nach der Veröffentlichung von Der kurze Brief zum langen Abschied wissen: „Eins der wenigen Male, daß ich mich in einer Rezension

200 Heinz-Norbert Jocks: Ein Märtyrer unter Erzählzwang. Sonntagnachmittag eines Autors. Bei Peter Handke in Salzburg. In: Stuttgarter Zeitung, 28. 3. 1987. Dazu auch Gerhard Pfister: Handkes Mitspieler. Die literarische Kritik zu Der kurze Brief zum langen Abschied, Langsame Heimkehr, Das Spiel vom Fragen, Versuch über die Müdigkeit. Bern u. a.: Lang 200o, S. $66 \mathrm{f}$.

201 Handke an Unseld, 22.3. 1966. In: Handke/Unseld: Der Briefwechsel (Anm. 2), S. 32. Einige Jahre später ist Handke noch einmal auf diese erste Rezension zurückgekommen: „Bevor die komische Rede in Princeton geschah, gab es eine große Rezension in Deutschland, das war die Rezension von Helmut Scheffel in der FAZ. Es war eine eingehende und wirklich beschreibende, einen Autor vorstellende Rezension, die auch - das darf man jetzt nicht auslassen, ohne daß ich mich damit brüsten will - auf der ersten Seite der Literaturbeilage erschien. " (Manfred Durzak: Für mich ist Literatur auch eine Lebenshaltung. Gespräch mit Peter Handke. [1973] In: M. D.: Gespräch über den Roman. Formbestimmungen und Analysen. Frankfurt a. M.: Suhrkamp 1976, S. 314-343, hier S. 316) Zu Scheffels Hornissen-Rezension vgl. Kap. II, Abschnitt „Über diesen Roman wären nicht so viele böse Worte zu verlieren ...': Handkes Hornissen nach Princeton“. 
ein bißchen wiedererkannte. “202 Euphorische Meldungen über die journalistische Kommentierung seiner Bücher, wie die folgende vom Juni 1975, blieben in der Minderzahl: „In ,Le Monde‘ erschien eine sehr schön geschriebene Besprechung von ,Wunschloses Unglück', über die ich sehr froh war - ich kaufte mir sofort ein Sommerhemd! ${ }^{“ 203}$ Nur sehr selten habe er beim Lesen einer Rezension den Eindruck, „that this critic has a sympathetic understanding of what I have written“, so Handke Ende der 1970er Jahre im Gespräch für eine amerikanische Zeitschrift: „That is very, very good for one who writes. “204

Deutlich öfter finden sich Berichte über ernüchternde Erfahrungen mit den Kritiken eigener wie fremder Texte: Von der Besprechung eines seiner Bücher sei er, wie Handke im August 1974 an Nicolas Born schreibt, regelrecht „angewidert" gewesen:

Oft ist mein Impuls, zurückzuschreiben, bitte nichts mehr über mich zu verfassen. Dann kommt mir das zu aufwendig vor, und ich nehme mir vor, es demjenigen einmal mündlich zu sagen, und wenn ich ihn dann sehe, kommt es mir wieder zu aufwendig vor ... Es gibt wahrhaftig keinen, der über Literatur schreibt, dem ich auch nur einen Atemzug lang vertraue. ${ }^{205}$

Borns ernüchterten Hinweis auf einen boshaften Verriss seines Romans Die erdabgewandte Seite der Geschichte - „Den Artikel im Spiegel wirst Du ja wohl gelesen haben, von diesem hämischen Nagetier Schober “206 - beantwortete Handke im Herbst 1976 postwendend mit aufmunternden Invektiven gegen den Kritiker: „Bei Schober habe ich nicht einmal den Kopf geschüttelt. Er ist eine der wirklich von außen und innen tristen Gestalten, mit denen der Kulturbetrieb ja vollgestopft ist und die ihre dauernde schlechte Laune als kritische

202 Peter Handke an Alfred Kolleritsch, 31.3. 1972. In: P. H./A. K.: Schönheit ist die erste Bürgerpflicht. Briefwechsel. Salzburg, Wien: Jung und Jung 2008, S. 56. Eine fast wortgleiche Äußerung Handkes findet sich in Volker Hage: Die Fiktion ist nötig. [Gespräch mit Peter Handke, März 1972] In: V. H.: Die Wiederkehr des Erzählers. Neue deutsche Literatur der siebziger Jahre. Frankfurt a. M. u. a.: Ullstein 1982, S. 111-121, hier S. 118: „Was Baumgart jetzt über ,Der kurze Brief zum langen Abschied' geschrieben hat in der ,Süddeutschen', fand ich schön. Das war eines der ersten Male in meinem Leben, daß ich mich wiedererkannt habe. Da ist man irgendwie froh drüber. Wenn woanders geschrieben wird, das sei großartig und toll, macht mich das dagegen ganz unzufrieden."

203 Handke an Unseld, 15. 6. 1975. In: Handke/Unseld: Der Briefwechsel (Anm. 2), S. 291.

204 June Schlueter: An Interview with Peter Handke. [1979] In: Studies in $20^{\text {th }}$ Century Literature 4 (1980), H. 1, S. 63-73, hier S. 71 f.

205 Peter Handke an Nicolas Born, 28. 8. 1974. In: N. B., P. H.: Die Hand auf dem Brief. Briefwechsel 1974-1979. In: Schreibheft (2005), H. 65, S. 3-35, hier S. 6.

206 Born an Handke, 11. 10. 1976. In: ebd., S. 16. 
Haltung verkaufen. “ ${ }^{\text {207 }}$ Freilich ist die Verständigung der beiden Autoren über den missliebigen Kritiker, den Handke einige Jahre zuvor noch als Mitarbeiter einer Zeitschrift gewinnen wollte, ${ }^{208}$ in diesem Fall durchaus heikel: Siegfried Schobers Rezension im Spiegel polemisiert nicht nur vehement gegen Borns Buch - so ist etwa von „verpoetisierte[m] Literatenwehweh“ ${ }^{\text {“209 }}$ die Rede -, sondern sie beginnt auch mit folgendem Satz: „Über weite Strecken liest sich dieser Roman wie eine unglückselige Epigonenvariante einiger Standardmotive Peter Handkes, die der schon größtenteils überwunden hat. “ ${ }^{210}$ Dass Handke den Roman seines Freundes in der ZEIT selbst ambivalent besprochen hatte, ${ }^{211}$ kam nicht unbedingt erleichternd hinzu. Zwar attestierte Born seinem ungleich prominenteren, aber fünf Jahre jüngeren Kollegen, einen „ungeheuer gute[n], genaue[n] und hellsichtige[n] Aufsatz" über Die erdabgewandte Seite der Geschichte geschrieben zu haben, „dem ich weder mit Lob noch mit Dank gerecht werden kann", ${ }^{212}$ er musste aber auch die „Einschränkungen“ Handkes zur Kenntnis nehmen. ${ }^{213}$ Angesichts eines gemeinsamen Außenfeinds jedoch versicherte Handke dem zerknirschten Freund seine nachdrückliche Solidarität: „Was für eine Horde von Gesindel“, hatte er schon gut eineinhalb Jahre zuvor Alfred Kolleritsch als Aufmunterung nach einer negativen Rezension mit auf den Weg gegeben. ${ }^{214}$

In Fällen wie diesen birgt die Doppelrolle als Autor und Kritiker ein gewisses Konflikt- und Irritationspotential in sich. Gleichwohl hat gerade sie sich bei Handke als produktiv im Sinne der Reflexion über das Verhältnis von Literatur und Kritik erwiesen - ein Verhältnis, mit dem er sich intensiv (und sehr viel eingehender als sein Antipode Bernhard) beschäftigt hat. Von seiner „Ideal“-Vorstellung, Kritiker sollten „im Bestfall genaue Leser“

207 Handke an Born, 14.10.1976. In: ebd.

208 Vgl. Handke/Unseld: Der Briefwechsel (Anm. 2), S. 104, 117 u. 121-124. Zu Handkes Zeitschriftenprojekt vgl. Kap. V, Abschnitt „,Kritik, die zugleich eine Form der Begeisterung ist': Helmut Färber".

209 Siegfried Schober: Schriftsteller intim. Nicolas Born: Die erdabgewandte Seite der Geschichte. In: Der Spiegel, Nr. 41, 4. 10.1976, S. 230-231, hier S. 231.

210 Ebd., S. 230.

211 Vgl. Peter Handke: Gegen den tiefen Schlaf. Nicolas Borns zweiter Roman: Die erdabgewandte Seite der Geschichte. In: DIE ZEIT, Nr. 42, 8.10.1976; wieder abgedruckt in P. H.: Das Ende des Flanierens (Anm. 62), S. 107-119.

212 Born an Handke, 11. 10. 1976. In: Born/Handke: Die Hand auf dem Brief (Anm. 205), S. 16.

213 Ebd., S. 15. Erst später, nach Borns Tod, hat Handke den Freund auch literarisch als „eine[ ] meiner Instanzen“ bezeichnet (Handke: Gestern unterwegs [Anm. 16], S. 76).

214 Handke an Kolleritsch, 23. 1. 1975. In: Handke/Kolleritsch: Schönheit ist die erste Bürgerpflicht (Anm. 202), S. 81.

215 Die vollständige Passage lautet: „Kritiker sind ja im Bestfall genaue Leser. Zumindest ist das mein Ideal.“ (Müller: Im Gespräch mit Peter Handke [Anm. 14], S. 65) 
all die Jahre ebenso wenig abgewichen wie von der Überzeugung, dass literarische Autoren selbst als Kritiker - oder besser: als über ihre Lektüreerfahrungen schreibende Leser - taugen. „Du schaffst es“, schreibt er am 7. Oktober 1986 als Dank für Hermann Lenz' Rezension der Wiederholung an den befreundeten Autor, „ein Buch darzustellen, so, daß es sich erst öffnet und aus dem Zeitungsgeraschel hervortritt als ein Ding für sich. “216 Und ein halbes Jahr später, mit Blick auf Lenz' Besprechung von Nachmittag eines Schriftstellers: „Ich bewundere Dich, daß Du über Bücher schreiben kannst, und noch mehr dafür, wie Du das Wesentliche an einer Sache findest und es zugleich dann nur andeutest, so daß der Zeitungsleser auf die Spur kommen kann, von selber “.217 Dieser Idealform der Kritik, der es gelingt, sich vom sonstigen „Zeitungsgeraschel“ freizuspielen und die Leserinnen und Leser der Zeitung zur eigenen, aufmerksamen Lektüre anzuregen, haben, folgt man Handkes einschlägigen Notizen und Äußerungen, im Laufe seiner schriftstellerischen Karriere nur wenige Rezensionen entsprochen. Seinen daraus resultierenden „Bedenken gegen die geläufige Literaturkritik“218 hat er nicht selten pointiert Ausdruck verliehen, ja sein Schreiben mitunter als bewussten Gegenentwurf zum Mindset der tonangebenden Kritiker in Stellung gebracht: „Es wendet sich“, so Handke 1982 anlässlich der Salzburger Uraufführung des Theaterstücks Über die Dörfer, „aggressiv gegen den Schwindel dieser Existenz, in der die meisten Kulturjournalisten dahinvegetieren. “219

In der Folge werden Stationen dieses konfliktträchtigen Verhältnisses kursorisch in den Blick genommen, bevor ich im fünften Kapitel dieser Arbeit Handkes Gegenentwürfe zur etablierten Praxis der Literaturkritik nachzuzeichnen versuche. Sie sind als produktive Erweiterungen seiner Diagnosen zu verstehen, als Vorschläge für andere Formen und Ausprägungen der Literaturkritik.

\section{Literaturkritik als ,leeres Geschäft': Handkes Vorarbeiten im Radio}

Handkes Beschäftigung mit der Institution ,Literaturkritik', mit ihren Mechanismen, ihrem Vokabular, ihren Argumentationsverfahren und nicht zuletzt mit ihrer Selektionsfunktion im literarischen Feld reicht bis in die Anfänge seines Schreibens zurück. Sie beginnt bereits deutlich vor seinen vielzitierten Princetoner Invektiven von 1966 - Invektiven, die sich, wie bereits gezeigt wurde, nicht

216 Handke an Lenz, 7. 10.1986. In: Handke/Lenz: Berichterstatter des Tages (Anm. 17), S. 221.

217 Handke an Lenz, 11. 5. 1987. In: ebd., S. 232 f.

218 Georg Pichler: Die Beschreibung des Glücks. Peter Handke. Eine Biografie. Wien: Ueberreuter 2002, S. 59.

219 Renate Poßarnig: „Ich möchte nicht verehrt werden“. [Gespräch mit Peter Handke.] In: stern, Nr. 40, 30. 9. 1982. 
nur gegen die ,Beschreibungsimpotenz' der Autorinnen und Autoren, sondern auch gegen die in der Gruppe 47 praktizierte Form der Literaturkritik wendeten. ${ }^{220}$ Die von Handke für das steiermärkische Regionalradio gestaltete „Bücherecke“Sendung vom 21. Dezember 1964 widmet sich gleich eingangs, noch bevor Cesare Paveses Roman Der schöne Sommer vorgestellt wird, einer Art von ,Metakritik: Nach der Wiedergabe der ersten Sätze des Romans tritt der Rezensent gewissermaßen einen Schritt zurück und fragt danach, wie denn in der Folge über das vorliegende Buch zu reden sei:

Es stellen sich nun nach der Lektüre des Buches sogleich viele Worte zur Wahl. Gedankenlos fallen einem für die Sprache des Romans etwa die Worte ,klar', , anmutig', ,einfach, , streng, ,sparsam ' und ,schlicht' ein; ebenso automatisch kommen die Worte für die Wiedergabe der erzählten Geschichte: Entwicklung, Mädchen, Sommer, Frau, Liebe, Erfahrung, Enttäuschung. ${ }^{221}$

In der zweiten zitierten Aufzählung klingt die strukturale Erzähltextanalyse an, wie sie Vladimir Propp in seiner Morphologie des Märchens (1928) entworfen hat; sie korrespondiert mit Handkes eigenen Arbeiten der 196oer, die, wie Der Hausierer, die „Erzählgrammatik“ bestimmter Genres offenzulegen versuchen. ${ }^{222}$ Primär wendet sich die Kritik des jungen Rezensenten aber gegen die ,Gedankenlosigkeit‘ einer journalistischen Sprache, die auf literarische Texte mit automatischen Reflexen und nicht mit individueller analytischer Akribie reagiere: „Darauf kann sich jeder, der dies hört“, so Handke in Bezug auf die genannten Begriffe, „wohl ohne Mühe seinen Reim machen: sowohl weiß er, was geschieht, als auch weiß er, wie das Geschehen erzählt wird. “223 Aus dieser Beobachtung leitet der Autor fundamentale Einwände gegen die zeitgenössische Literaturkritik ab, wobei nicht unterschlagen werden darf, dass Handke diese Einwände selbst in einem Sub-Genre der Literaturkritik, der Rundfunkrezension, artikuliert:

220 Vgl. Kap. II, Abschnitt „,Über diesen Roman wären nicht so viele böse Worte zu verlieren ...‘: Handkes Hornissen nach Princeton“, sowie Kap. IV, Abschnitt „Princeton 1966 und die Folgen“.

221 Peter Handke: „Bücherecke“ vom 21. 12. 1964. In: P. H.: Tage und Werke (Anm. 21), S. 189-197, hier S. 189. Dazu und zum Folgenden vgl. auch Lothar Struck: Der Begleitschreiber. Einige Bemerkungen zum Kritiker und Leser Peter Handke. In: L. S.: Erzähler, Leser, Träumer. Begleitschreiben zum Werk von Peter Handke. Mit einem Vorwort v. Klaus Kastberger. [Klipphausen]: Mirabilis 2017, S. 13-27, bes. S. 17-19.

222 Alexander Honold: Der Erd-Erzähler. Peter Handkes Prosa der Orte, Räume und Landschaften. Stuttgart: Metzler 2017, S. 19. Vgl. die Charakterisierung seines Romans Der Hausierer in Peter Handke: Ich bin ein Bewohner des Elfenbeinturms. In: P. H.: Ich bin ein Bewohner des Elfenbeinturms (Anm. 61), S. 19-28, hier S. 28.

223 Handke: „Bücherecke“ vom 21.12.1964 (Anm. 221), S. 189. 
Indes sind alle diese Vokabeln so nichtssagend, wie sie gedankenlos sind. Die Literaturkritik wertet, für die Bewertung aber besteht in der Sprache nur ein begrenzter Vorrat von Worten; dieser Vorrat schießt automatisch in die Gedanken, wenn die Sprache des zu beurteilenden Textes beurteilt werden soll: das ist es, was die Literaturkritik oft zu einem leeren Geschäft macht. Sowohl die Worte für die Beschreibung einer Geschichte als auch die Bewertungsworte für die Sprache dieser Geschichte sind mit der Zeit automatisiert worden; dazu kommt noch, daß für einen Autor je bekannter er ist, desto mehr Eigenschaftsworte gängig sind, die mechanisch bei der Erwähnung des Autors in den Sinn kommen. ${ }^{224}$

Zwar betont Handke, dass das von ihm skizzierte „Übel der Literaturkritik“ ein „natürliches“ sei und deshalb im Grunde auch nicht als „Übel“ gelten könne; ${ }^{225}$ gleichwohl bestehe, so der junge Rezensent in seinem ersten literaturkritischen Radiofeuilleton, ein fundamentaler Missstand im Bereich des Sprechens und Schreibens über Literatur, der nicht nur das verwendete Vokabular und das analytische Instrumentarium der Kritiker selbst, sondern das gesamte Kommunikationssystem des Literaturbetriebs betreffe:

[E]s ist die Natur der Kritik, zu bewerten; die Bewertungsworte aber sind von Natur aus abstrakt, das heißt, sie tragen in sich keinen Begriff von dem, was sie bezeichnen; sie dienen nur als Hilfsmittel oder als Hinweise; was ihnen trotzdem zu einer Wirkung verhilft, ist die Gewöhnung des Zuhörers; es geschieht nämlich, daß auf die Nennung des automatisch gesagten Wortes, etwa die Sprache sei dicht, in dem Zuhörer ebenso von selber eine Wertvorstellung von dem Kritisierten entsteht. Im eigenen Lesen wird dann der leere Hinweis, die Sprache sei dicht, sozusagen mit Begreifen gefüllt. ${ }^{226}$

Handke deutet also an, dass nicht die Wortwahl der Kritiker (es handelt sich in diesen Jahren fast ausschließlich um Männer) allein zum Automatismus tendiert; vielmehr ließen aus dem Formelvorrat der Kritik kompilierte Sätze auch eine standardisierte Vorstellung über den besprochenen Gegenstand bei den Leserinnen und Lesern der Rezension entstehen. Er sei, so Handke, durchaus in der Lage, einen nach dem skizzierten Kritik-Schema gebauten Satz über Paveses Roman anzufertigen, und er liefert in der Folge die Probe aufs Exempel. Er beschließt seine programmatischen Überlegungen zur Praxis der Literaturkritik jedoch mit der pointierten Ankündigung eines Alternativmodells, die eine ,andere' Literaturkritik in Aussicht stellt: ${ }^{27}$

224 Ebd., S. 189 f.

225 Ebd., S. 190.

226 Ebd.

227 Vgl. Kap. V, Abschnitt „Ein Leseerlebnis beschreiben: Handke rezensiert Hermann Lenz“. 
So wäre es nun kein Unding, aus den anfangs aufgereihten banalen Worten, die nach dem Lesen des Buches automatisch gekommen sind, einen ebenso banalen Satz zu bilden, diesen zum Beispiel: „Pavese erzählt im ,Schönen Sommer ' die alte Geschichte eines Mädchens, das zur Frau wird und dadurch die Welt gleichsam mit anderen Augen zu sehen beginnt; die Sprache der Geschichte ist so einfach und straff, daß eine Sinnfälligkeit der Ereignisse erzeugt wird, die beinah auf der Zunge zu schmecken ist." Es sind auch andere Sätze möglich. ${ }^{228}$

Die Rundfunkfeuilletons, die Handke in den nächsten gut eineinhalb Jahren für die Sendung „Bücherecke“ verfasst, sind als erste Versuche zu verstehen, dem von ihm diagnostizierten Automatismus der Kritik im beständigen Bewusstmachen der Problematik auszuweichen. Nicht nur lobt er darin Autoren, die es zuwege bringen, ,jede literarisch vorgepauste Schablone zu vermeiden“, wie dies seines Erachtens bei Julien Greens Aufbruch vor Tag der Fall ist, ${ }^{229}$ sondern er problematisiert darin immer wieder auch Formen der „bewertenden Sprache “. 230 Er tut dies freilich, ohne selbst vor harschen Urteilen zurückzuschrecken, etwa wenn er die umfassende „Harmlosigkeit“ des aktuellen S. Fischer-Programms ${ }^{231}$ bemängelt oder die Kleine Prosa des rumänischen Autors Tudor Arghezi als „laxe Satiren“ bezeichnet, „,in denen eine Banalität die andere jagt“; ${ }^{232}$ die dem Format inhärente Kürze drängt auch den Rezensenten Handke zu pointierten, weniger auf Differenzierung denn auf Effekt bedachten Formulierungen.

Selbst in kurzen Skizzen, die ein Buch lediglich in Ansätzen vorstellen, kommt Handke dabei auf das Problem der kritischen Beschreibungssprache zurück, wie an einem signifikanten Beispiel verdeutlicht werden soll:

Bohumil Hrabal ist dagegen harmloser [als Vĕra Linhartovás Geschichten ohne Zusammenhang], obwohl in seinen Tanzstunden im Vordergrund viel Böseres geschieht. Geschichte gibt es eigentlich keine: die Tanzstunden für Erwachsene und Fortgeschrittene bestehen vielmehr aus aneinandergereihten assoziativen Anekdoten eines alten Mannes, der über irgendeine junge Person seinen Redefluß ausgießt. Das

228 Handke: „Bücherecke“vom 21.12.1964 (Anm. 221), S. 190. Zur Bedeutung der Pavese-Rezension in Handkes Auseinandersetzung mit der Literaturkritik vgl. jetzt Wolfgang Hackl: Zwischen Theaterereignis und Theaterbluff. Handkes Publikumsbeschimpfung und sein Anfang als Dramatiker. In: „Das Wort sei gewagt“. Ein Symposium zum Werk von Peter Handke. Hg. v. Attila Bombitz u. Katharina Pektor. Wien: Praesens 2019, S. 148-162, hier S. 157 f.

229 Peter Handke: „Bücherecke“ vom 18.1. 1965. In: P. H.: Tage und Werke (Anm. 21), S. 198-203, hier S. 200.

230 Peter Handke: „Bücherecke“ vom 29.3.1965. In: ebd., S. 204-210, hier S. 204.

231 Handke: „Bücherecke“ vom 5.7.1965 (Anm. 72), S. 230.

232 Peter Handke: „Bücherecke“ vom 4. 4. 1966. In: P. H.: Tage und Werke (Anm. 21), S. 274-280, hier S. 279. 
Eigenschaftswort „,saftig“ steht zur Verfügung, andere würden vielleicht sagen: „fabulierfreudig“ und „bunt“: ganz nach Belieben. Ein Ereignis ist das Buch nicht, aber jedenfalls ein Vergnügen. ${ }^{233}$

Anlässlich der Besprechung von Friedrich Hackers Monographie Versagt der Mensch oder die Gesellschaft?, die sich „Probleme[n] der modernen Kriminalpsychologie“ widmet, ${ }^{234}$ hat Handke im Februar 1966 seine Vorbehalte noch einmal, obgleich hier am Beispiel wissenschaftlicher Prosa, pointiert zusammengefasst. Seine Position ist an dieser Stelle wohl auch seiner eingehenden Beschäftigung mit Roland Barthes' Begriff der Kritik geschuldet:

Es wird frisch draufloskritisiert, ohne daß man beachtet, daß die Ausdrucksweise der Kritik oft gar nichts mehr besagt, vielmehr sich schon eingebürgert hat und demgemäß konventionell ist. Die Kritiker haben gleichsam die Funktion des allgegenwärtigen Erzählers im traditionellen Roman eingenommen; sie lassen außer acht, daß auch die Wendungen der Kritik nicht ohne Selbstkritik auf die Materie angewendet werden können. Ohne Reflexion der Kritik über ihre eigenen Ausdrucksmittel wird sie sich im Kreis drehen müssen. ${ }^{235}$

Wie in späteren polemischen Einlassungen zu diesem Thema zeichnet Handke die Kritiker hier als Leser, die auf literarische Texte mittels eines eingespielten Sets an „Bewertungsworte $[\mathrm{n}]{ }^{\text {“236 }}$ reagieren und sich genuin neuen ästhetischen Verfahren gegenüber reserviert zeigen. Bezieht man Handkes Argumentation auf die Modellbildungen der Literatursoziologie, dann entspricht sie strukturell jener Opposition, die Pierre Bourdieu in Anlehnung an Max Webers Religionssoziologie zwischen ,Priestern' und ,Zauberern' (bzw. in alternativer Übersetzung: zwischen ,Priestern' und ,Propheten') skizziert hat: Der Zauberer spricht sich als Anwärter im literarischen Feld, der noch über wenig symbolisches Kapital verfügt, vehement gegen „die Routine und Schablonenhaftigkeit“ der Priester aus, kritisiert ihre „pedantische Ignoranz und kleinmütige Bedenklichkeit“" 237 um sich selbst bzw. seine eigene Position als Überwindung und Negation des Bestehenden, des Konventionellen zu postulieren. Handkes Einwände gegen konkurrierende

233 Ebd., S. $278 \mathrm{f}$.

234 Peter Handke: „Bücherecke“ vom 21. 2. 1966. In: P. H.: Tage und Werke (Anm. 21), S. 266-273, hier S. 267.

235 Ebd., S. 268. Zu Handkes Auseinandersetzung mit Roland Barthes vgl. Kap. III, Abschnitt „Princeton 1966 und die Folgen“.

236 Handke: „Bücherecke“ vom 21.12.1964 (Anm. 221), S. 190.

237 Pierre Bourdieu: Künstlerische Konzeption und intellektuelles Kräftefeld. In: P. B.: Kunst und Kultur. Kunst und künstlerisches Feld. Schriften zur Kultursoziologie 4. Hg. v. Franz Schultheis u. Stephan Egger. Berlin: Suhrkamp 2015, S. 7-49, hier S. 39. 
Autorinnen und Autoren einerseits und gegen maßgebende Kritiker andererseits gehen dabei Hand in Hand: Er adressiert seine Kritik an den „Automatismen der Darstellung“ sowie seinen Anspruch, „eine schon automatisch reproduzierbare Methode wieder produktiv zu machen“, "238 an beide Gruppen gleichermaßen.

Zudem lässt sich bei der Lektüre der Rundfunkfeuilletons Folgendes feststellen: Tauchen Handkes Überlegungen zum „neue[n] Realismus“ als „,cinema verité der Literatur“, die er in der „Bücherecke“-Sendung vom 4. April 1966 angestellt hat, ${ }^{239}$ zweieinhalb Wochen später beinahe wortgleich in der Princetoner Polemik gegen die ,Beschreibungsimpotenz $z^{\prime}$ auf ${ }^{240}$ - was nicht zuletzt ein bezeichnendes Licht auf die behauptete Spontaneität seines Statements wirft ${ }^{241}$-, so sind auch seine Äußerungen zur Literaturkritik und zu ihren Akteuren nicht als Ausdruck eines impulsiven, aus dem Augenblick geborenen Unwillens über den Verlauf der Gruppe-47-Tagung zu werten. Sie waren vielmehr, so Alfred Holzinger, sein Auftraggeber und Förderer im steiermärkischen Rundfunk, „begründet durch das vorausgehende schriftstellerische Arbeiten und Überlegen in Graz“. Der Vergleich zwischen Radiofeuilleton und Princetoner Polemik zeigt, wie Holzinger ausführt, in mehrerlei Hinsicht eine „Kontinuität seines ästhetischen Urteilens “ ${ }^{242}$ Handkes literaturkritische,Gesellenstücke ' waren indes an der Peripherie des deutschsprachigen Literaturbetriebs gesendet worden; die über ein Jahr vor dem Auftritt in Princeton formulierten Einwände erregten demnach keine größere mediale Aufmerksamkeit, ihre Reichweite blieb überschaubar. ${ }^{243}$

238 Handke: Ich bin ein Bewohner des Elfenbeinturms (Anm. 222), S. 28.

239 Handke: „Bücherecke“ vom 4. 4.1966 (Anm. 232), S. 276.

240 Vgl. Im Wortlaut: Peter Handkes ,Auftritt' in Princeton und Hans Mayers Entgegnung. In: Text + Kritik ( $\left.{ }^{5} 1989\right)$, H. 24, S. 17-20, hier S. 17: „Es wird überhaupt keinerlei Reflexion gemacht. Es wird eine Philosophie vorgegeben, eine Weltanschauung vorgegeben, in der man so tut, als gäbe es nur die Beschreibung von Einzelheiten und Vorgängen. Und das ist auch eine Art cinéma verité der Literatur, nach meiner Ansicht.“

241 Vgl. dazu etwa die Erinnerungsbände von Reinhard Baumgart (Damals. Ein Leben in Deutschland, 2003) und Friedrich Christian Delius (Als die Bücher noch geholfen haben. Biographische Skizzen, 2012; Die Zukunft der Schönheit. Erzählung, 2018), in denen die Episode ausführlich thematisiert wird.

242 Alfred Holzinger: Peter Handkes literarische Anfänge in Graz. In: Peter Handke. Hg. v. Raimund Fellinger. Frankfurt a. M.: Suhrkamp 1985, S. 11-24, hier S. 23. Zu Handkes, Öffentlichkeitsarbeit‘ der frühen Jahre vgl. auch meine Überlegungen in: Peter Handkes epitextuelle Werkpolitik. In: Paratextuelle Politik und Praxis. Interdependenzen von Werk und Autorschaft. Hg. v. Martin Gerstenbräun-Krug u. Nadja Reinhard. Wien: Böhlau 2018, S. 271-292; zu Holzingers Rolle im Grazer Literaturgeschehen vgl. Manfred Mixner: Das Forum Stadtpark Graz und der ORF eine Erinnerung an Alfred Holzinger. In: Literatur in Graz seit 1960 - das Forum Stadtpark. Wien, Köln: Böhlau 1989, S. 13-20.

243 Gleichwohl lässt sich an ihnen ablesen, „wie der Jurastudent und nur im kleinen Kreis bekannte Schriftsteller schon damals seine Position als Autor theoretisch unterbaute" (Holzinger: Peter Handkes literarische Anfänge [Anm. 242], S. 18). 
Obschon er bereits hier pointiert gegen eine Literaturkritik Stellung bezogen hatte, die „zu einem leeren Geschäft“ verkomme sei, ${ }^{244}$ schufen erst seine im Spiegel und in anderen auflagenstarken Printmedien kolportierten Invektiven gegen die „läppische“ Literaturkritik ${ }^{245}$ das Image des jugendlichen Polemikers Peter Handke; erst sie machten die maßgeblichen Akteure im literarischen Feld auf ihn aufmerksam.

Wie in anderen Fällen gilt auch hier: Polemische Attacken benötigen eine geeignete mediale Plattform, einen medialen Resonanzraum, wollen sie die Deckung ihrer Adressaten mit einem Wirkungstreffer ins Wanken bringen. Man kann dies am ,Verpuffen' von Bernhards Politischer Morgenandacht exemplarisch beobachten, die 1966, in der Wiener Zeitschrift Wort in der Zeit publiziert, kaum für Aufregung gesorgt hatte, während seine inhaltlich vergleichbare StaatspreisRede wenig später einen Skandal nach sich zog. Freilich ist zu bedenken, dass dem Auftritt Handkes im literarischen Feld dank der weitgehenden Unsichtbarkeit seiner literaturkritischen,Gesellenstücke‘ ein veritabler Überraschungseffekt eigen war, durch den die Princetoner Polemik desto stärker als neue und diskussionswürdige Position wahrgenommen wurde. Wenn Bourdieu konstatiert, die Struktur des literarischen Feldes und die Möglichkeiten der in ihm möglichen Positionsnahmen hänge ganz wesentlich „von dem Raum bereits vollzogener Positionierungen $a b$ “ ${ }^{246}$ so wäre hier zu ergänzen, dass der Coup eines Newcomers auch und im Besonderen davon lebt, dass sein Akteur noch weitgehend unbekannt und damit schwerer auszurechnen ist.

\section{„Ihr wart Vollblutschauspieler“: Handke und die Phrasen der Kritik (Publikumsbeschimpfung)}

Die Auseinandersetzung mit der Praxis der Literaturkritik wurde indes nicht nur in öffentlichen Statements, poetologischen Reflexionen, privater Korrespondenz oder in Genres der Literaturkritik selbst ausgefochten, sondern fand und findet bei Handke bis heute auch in den literarischen Texten selbst statt. Werden die einschlägigen Passagen in Die Lehre der Sainte-Victoire (1980) und Mein Jahr in der Niemandsbucht (1994) an anderer Stelle noch ausführlich ins Blickfeld gerückt, ${ }^{247}$ soll im Folgenden kurz Handkes erstes, im Juni 1966 im Frankfurter Theater am Turm uraufgeführtes Bühnenstück im Mittelpunkt stehen. Die

244 Handke: „Bücherecke“ vom 21.12.1964 (Anm. 221), S. 190.

245 Handke: Im Wortlaut (Anm. 240), S. 18.

246 Bourdieu: Die Regeln der Kunst (Anm. 5), S. 370.

247 Vgl. Kap. IV, Abschnitte „Die Bestie von Puyloubier“, „Mit Cézanne gegen die Hunde“ und „Schnüffeln und Verreißen“. 
Publikumsbeschimpfung, die das Verhältnis von Bühne und Zuschauerraum, ${ }^{248}$ von Repräsentation einer Handlung und deren passiver Konsumierung performativ infrage stellt, ist in seiner selbstbewussten Erprobung einer damals neuen Theaterästhetik auch auf das Vokabular der Theaterkritik bezogen, indem die Sprecher des Stücks die Zuschauer im Saal mit ausgewiesenen „Kritiker-Phrasen“249 adressieren. Das Spiel mit den Wendungen und sprachlichen Stereotypen der Kritik ist ein wesentlicher und signifikanter Teil der Beschimpfungskaskaden, es stellt ein zentrales Element in der Architektur der Publikumsbeschimpfung, die Handke seinem Verleger als „mein erstes und mein letztes“ Stück angekündigt hatte, ${ }^{250}$ dar: „Auf der Suche nach vernünftigen Wörtern und Sätzen, die man zu Leuten sprechen könnte, die im Theater sitzen“, schreibt Handke Anfang 1967 in einem offenen Brief an Henning Rischbieter, „sind die Wörter und Sätze der ,Publikumsbeschimpfung' entstanden. “251

Zunächst, noch bevor die eigentliche ,Beschimpfung` einsetzt, werden die Zuschauer von der Bühne herab mit Charakterisierungen bedacht, die dem Verriss-Repertoire der Theaterkritik entlehnt sind bzw. die Negation, die Verkehrung journalistischer Lobrede darstellen:

Aber Sie sind nicht abendfüllend. Sie sind ein dramaturgischer Fehlgriff. Sie sind nicht lebensecht. Sie nicht theaterwirksam. Sie versetzen uns in keine andere Welt. Sie bezaubern uns nicht. [...] Sie unterhalten uns nicht köstlich. Sie sind nicht spielfreudig. [...] Ihr Debut ist nicht überzeugend. Sie sind nicht $d a$. Sie lassen uns die Zeit nicht vergessen. Sie sprechen nicht den Menschen an. Sie lassen uns kalt. ${ }^{252}$

Nachdem die Sprecher schließlich kurz vor Ende des Stücks den Beginn der ,Beschimpfung' angekündigt haben, ${ }^{253}$ wird das Sprachmaterial der Theaterkritik noch einmal explizit aufgenommen und mit der Attacke gegen das Publikum

248 Otto Lorenz: Literatur als Widerspruch. Konstanten in Peter Handkes Schriftstellerkarriere. In: Text + Kritik ( $\left.{ }^{5} 1989\right)$, H. 24, S. 8-16, hier S. 13, spricht von der Aufhebung der „Akteur/ Zuschauer-Trennung“ in der Publikumsbeschimpfung als Teil von Handkes „Lust am Widerspruch“. Zur Poetik der Publikumsbeschimpfung vgl. Klaus Kastberger: Lesen und Schreiben. Peter Handkes Theater als Text. In: Die Arbeit des Zuschauers. Peter Handke und das Theater. Hg. v. K. K. u. Katharina Pektor. Salzburg, Wien: Jung und Jung 2012, S. 35-48, hier S. 36 f.

249 N. N.: Handke: Unerschrocken naiv. In: Der Spiegel, Nr. 22, 25. 5. 1970, S. 174-190, hier S. 183.

250 Handke an Unseld, 21. 10. 1965. In: Handke/Unseld: Der Briefwechsel (Anm. 2), S. 17.

251 Peter Handke: Briefe über Theater (1). In: Theater heute (1967), H. 2, S. 37.

252 Peter Handke: Publikumsbeschimpfung. In: P. H.: Publikumsbeschimpfung und andere Sprechstücke. Frankfurt a. M.: Suhrkamp 1966, S. 5-48, hier S. 25.

253 Vgl. ebd., S. 43 f.: „Zuvor aber werden Sie noch beschimpft werden. / Sie werden beschimpft werden, weil auch das Beschimpfen eine Art ist, mit Ihnen zu reden. Indem wir beschimpfen, können wir unmittelbar werden. Wir können einen Funken überspringen lassen. Wir können den Spielraum zerstören. Wir können eine Wand einreißen. Wir können Sie beachten.“ 
verschränkt: „Ihr wart Vollblutschauspieler. Ihr begannet verheißungsvoll. Ihr wart lebensecht. Ich wart wirklichkeitsnah. Ihr zoget alles in euren Bann. Ihr spieltet alles an die Wand. Ihr zeugtet von hoher Spielkultur", heißt es da, bevor der Text wieder in die Schmähung der Zuschauer als „Gauner“, „Schrumpfgermanen“ und „Ohrfeigengesichter“ abzweigt. ${ }^{254}$ Diese Struktur kehrt in den folgenden Passagen des Stücks wieder: Auf die Beteuerung der Sprecher, es habe sich beim anwesenden Publikum um „eine Bombenbesetzung“, „die Idealbesetzung“ gehandelt, deren „Tragik [...] von antiker Größe“ gewesen sei, setzt erneut die Beleidigung als „Miesmacher“, „Nichtsnutze“ und „Auswürfe der Gesellschaft“ ein. ${ }^{255}$ Das eingeschliffene Vokabular der Theaterkritik, das einem Ensemble attestiert, „wie aus einem Guß“ agiert zu haben, wird um die aggressive Denunziation als „Tröpfe“, „Flegel“ und „Liederjahne“ - ja, historisch prekär, als „Saujuden“ und „Genickschußspezialisten“ gleichermaßen - ergänzt, ${ }^{256}$ bevor schließlich eine einzige Kritikerfloskel am Beginn eines Absatzes eine ganze Sturzflut an Beschimpfungen unterschiedlichster Provenienz zur Folge hat:

Ihr seid profilierte Darsteller, ihr Maulaffenfeilhalter, ihr vaterlandslosen Gesellen, ihr Revoluzzer, ihr Rückständler, ihr Beschmutzer des eigenen Nests, ihr inneren Emigranten, ihr Defätisten, ihr Revisionisten, ihr Revanchisten, ihr Militaristen, ihr Pazifisten, ihr Faschisten, ihr Intellektualisten, ihr Nihilisten, ihr Individualisten, ihr Kollektivisten, ihr politisch Unmündigen, ihr Quertreiber, ihr Effekthascher, ihr Antidemokraten, ihr Selbstbezichtiger, ihr Applausbettler, ihr vorsintflutlichen Ungeheuer, ihr Claqueure, ihr Cliquenbildner, ihr Pöbel, ihr Schweinefraß, ihr Knicker, ihr Hungerleider, ihr Griesgräme, ihr Schleimscheißer, ihr geistiges Proletariat, ihr Protze, ihr Niemande, ihr Dingsda. ${ }^{257}$

254 Ebd., S. 45. Vgl. dazu Klessinger: Postdramatik (Anm. 169), S. 147, Hackl: Zwischen Theaterereignis und Theaterbluff (Anm. 228), S. 155 f., sowie zuletzt auch Jörg Döring: Peter Handke beschimpft die Gruppe 47. Siegen: universi 2019, S. 103: „In dem Stück beschimpfen die Schauspieler das Publikum, benutzen dafür aber [...] litaneiartig ihre Lieblingsphrasen aus dem Katalog einer abgestandenen Theaterkritik."

255 Handke: Publikumsbeschimpfung (Anm. 252), S. 45.

256 Ebd.

257 Ebd., S. 46 f. Vgl. Klessinger: Postdramatik (Anm. 169), S. 152: „Die einzelnen Abschnitte der Beschimpfung sind zunächst zweigeteilt: Sie beginnen jeweils mit einer lobenden Abendkritik, in der die theateranalytischen Begriffe auf das Publikum bezogen werden [...]. Ganz unvermittelt münden die Abschnitte in Schimpfwörter: Es beginnt zunächst mit einem einzelnen ,ihr Rotzlecker' und ,ihr Gernegroße. Im Folgenden reihen sich an das Lob bereits drei, vier Schimpfwörter, und so nimmt von einem Absatz zum folgenden das Kritikerlob ab und die Reihe der Beschimpfungen wächst, bis zuletzt nur noch Schimpfwörter aufeinanderfolgen." 
Noch im letzten längeren Textblock des Stücks werden neben der „schleichende[n] Pest“, den „Schwangerschaftsunterbrecher[n]" und dem „verrottete[n] Bürgertum“ auch die "Charakterdarsteller", die „Menschendarsteller", ja die "Meilensteine in der Geschichte des Theaters" ins Visier genommen. ${ }^{258}$ In jenem Stück, dessen Methode Handke zufolge darin bestand, „daß alle Methoden bisher verneint wurden “, ${ }^{\text {‘ } 259}$ stellt der junge Autor im Zuge seiner Reflexion des Theaters in actu auch die journalistischen Klischees des Sprechens über diese Institution und ihre ästhetischen Prinzipien infrage. Er problematisiert das Vokabular der Literatur- und Theaterkritik jedoch - anders als in den Rundfunkfeuilletons nicht, indem er dessen Konventionalität und Phrasenhaftigkeit beschreibt und eine andere Form des Sprechens über künstlerische Artefakte in Aussicht stellt ”Es sind auch andere Sätze möglich ${ }^{1260}$-, sondern er vollzieht diesen Einspruch gerade durch die ostentative Verwendung der entsprechenden Formeln in einer "genuin theatrale[n] Situation", nämlich auf der Bühne. ${ }^{261}$

„Solche Wörter sollte man euch verbieten" oder:

Erstsprache vs. Zweitsprache

Im bereits zitierten Brief an Henning Rischbieter hat Peter Handke, einige Monate nach der Uraufführung der Publikumsbeschimpfung, seine Vorbehalte gegenüber der Institution des Theaters ein weiteres Mal mit einem negativen Urteil über die Theaterkritik verschränkt: Weil diese sich oft „menschlich-persönlich statt sachlich“ geriere, „nicht informativ, sondern vertraulich-privater Tip“ sei, könne sie keine präzise formale Analyse der Stücke liefern: „Man beschreibt (auch Ihre Zeitschrift [i.e. Theater heute]) Stücke, als ob sie Wirklichkeit wären, und erledigt in trägen Metaphern dann die Form dieser Stücke, als ob Was und Wie zwei Welten wären. ${ }^{\text {“262 }}$ Die erstarrte Metaphorik des Sprechens über das Theater habe, wie Handke in diesem dichten, in der Forschung jedoch wenig beachteten Text ausführt, ganz wesentlich zum gegenwärtigen Dilemma des Theaterbetriebs und zu seiner eigenen „Aversion“ diesem Betrieb gegenüber beigetragen:

[D] as war es auch noch, was mich am Theater und am Gerede vom Theater gestört hat: die Metaphorik. Sogar Ihre Zeitschrift, wenn auch mit recht effektvollem Jargon, sucht ihr Heil in der Bildersprache, wenn die Bilder eines Stücks schon beschrieben

258 Handke: Publikumsbeschimpfung (Anm. 252), S. 47.

259 Handke: Ich bin ein Bewohner des Elfenbeinturms (Anm. 222), S. 27.

260 Handke: „Bücherecke“ vom 21. 12.1964 (Anm. 221), S. 190.

261 Klessinger: Postdramatik (Anm. 169), S. 141.

262 Handke: Briefe über Theater (1) (Anm. 251), S. 37. 
sind und es jetzt gerade um die formale Struktur eines Stückes geht. Man setzt nur neue Metaphern an die Stelle der alten und gewinnt dadurch wenigstens eine gewisse Anschaulichkeit für die Leser. Aber es fehlt sehr viel an Reflexion über Formen. ${ }^{263}$

Handkes ,Kritik der Kritik' geht hier ein weiteres Mal mit seinen poetologischen Reflexionen Hand in Hand. Sowohl in der Literatur- bzw. Theaterkritik als auch in der zeitgenössischen Literatur nimmt er eine fehlende Aufmerksamkeit für sprachlich-formale Fragen wahr, unter der die Präzision der Beobachtungen, aber auch die Möglichkeit einer produktiven, d.h. „sensibler, empfindlicher, genauer “264 machenden Vermittlung von Erfahrungen zu leiden habe:

Die begriffliche Eindeutigkeit wird ersetzt durch so sinnlose Wörter wie ,vergeistigend; ,dicht', ,flach', ,tief', , geschlossen', ,große Linie' (zum Teil aus Ihren eigenen Arbeiten). Diese Art von Kritik, das ist das schlimme, verläßt sich immer auf die schon fertige Meinung des jeweils Lesenden von z.B. der großen Linie, ist in der Regel also faul, ändert nicht die Voraussetzung für diese Meinung [...]. Auf diese Weise sind auch ursprünglich präzise Begriffe zu Bildern geworden wie etwa das ,Modell‘ oder der ,Realitätsbezug' oder die ,Sozialstudie. ${ }^{\text {(25 }}$

So wie Handkes „Geschichtskritik“ im Grunde eine „Diskurskritik“ vorstellt, ${ }^{266}$ indem sie die Konzepte der sprachlichen Repräsentation von Historie hinterfragt und mitunter polemisch zur Diskussion stellt, opponieren auch Handkes Einwände gegen die Literaturkritik nicht zwangsläufig gegen das Metier an sich, sondern gegen bestimmte Ausprägungen dieser Kritik, gegen deren „Brachylogien $^{\text {“267 }}$ und Sprachregelungen. In seinen Notizbüchern, die Handke in Auswahl als ,Journalbände' publiziert hat, hält er in unregelmäßigen Abständen Beobachtungen über das Vokabular der Literaturkritik fest; ${ }^{268}$ in Interviews, Reden und anderen öffentlichen Statements hat er es wiederholt einer kritischen Prüfung unterzogen - etwa wenn er 2006 im Gespräch mit Ulrich Greiner auf „wertvolle“ Lektüre der letzten Zeit zu sprechen kommt, um sich sogleich selbst zu korrigieren und im nächsten Schritt in die Offensive überzugehen: „Wertvoll ist ein dummer Ausdruck, ich weiß, aber immer noch besser als das, was ihr

263 Ebd.

264 Handke: Ich bin ein Bewohner des Elfenbeinturms (Anm. 222), S. 26.

265 Handke: Briefe über Theater (1) (Anm. 251), S. 37.

266 So Fabjan Hafner: Peter Handke. Unterwegs ins Neunte Land. Wien: Zsolnay 2008, S. 152.

267 Wendelin Schmidt-Dengler: Literaturwissenschaft und Literaturkritik. In: Literaturkritik. Theorie und Praxis. Hg. v. W. S.-D. u. Nicole Katja Streitler. Innsbruck, Wien: StudienVerlag 1999, S. 11-25, hier S. 15.

268 Vgl. etwa Handke: Das Gewicht der Welt (Anm. 53), S. 99: „Aus einer Kritik: ,Das ist mehr als ein großes Stück Literatur.' Was ist mehr als ein großes Stück Literatur?“ 
Kritiker immer sagt, ,wunderbar‘ oder ,großartig‘. Solche Wörter sollte man euch verbieten. “269

Die „polemischen Absetzbewegungen“ Peter Handkes von den „Methoden“ der „Literaturkritik“ ${ }^{270}$ seine „Bemerkungen über die unterentwickelte Kritik im deutschsprachigen Raum“ ${ }^{\text {“271 }}$ sind Teil eines umfassenden Misstrauens, das neben dem Feuilleton auch die akademische Literaturwissenschaft, den „Universitätsstumpfsinn “ ${ }^{\text {272 }}$ und die „verlogene[ ] Gravitätik der Germanistik“273 miteinschließt. Dem „Worteklauben“ der Philologien hat er ein ums andere Mal, und nicht selten mit polemischer Schlagseite, das, forschende Erzählen' vorgezogen, das es - ganz anders als die Wissenschaft - Autor und Leser ermögliche, „unvergleichlich frei ums Herz" zu werden. ${ }^{274}$ Sowohl die von Handke formulierten Forderungen an „ordentliche“ und „außerordentliche Germanist[en]“, 275 adäquate Instrumentarien zur Beschreibung literarischer Texte zu entwickeln, als auch seine Gleichsetzung des „Professorenhaften“ mit dem „Klassizistischen “276 zeugen von der angesprochenen Skepsis. Dem „Schwindel der Zu-Ende-Denker “277 hat Handke, nicht nur in der Rede zur Verleihung des Georg-Büchner-Preises im Jahr 1973, die „begriffsauflösende[ ] und damit zukunftsmächtige[ ] Kraft des poetischen Denkens“, ja das „hoffnungsbestimmte poetische Denken“ gegenübergestellt. ${ }^{278}$

269 Ulrich Greiner: Ich komme aus dem Traum. Gespräch mit Peter Handke. In: DIE ZEIT, Nr. 6, 2. 2. 2006, S. 53-54, hier S. 53. Vgl. dazu auch Handkes 2015 publizierte Reflexionen über drei Bücher von Dragan Aleksić, Xaver Bayer und Dag Solstad: „Keine Sorge: Es sei hier fern, die drei fraglichen Bücher in einen Himmel zu heben. ,Meisterwerke, ,wunderbare;, ,unvergleichliche', , atemberaubende', ,epochale', gibt es ja heutzutage in Fülle und Hülle; tagtäglich kommen ein paar frische dazu." (Peter Handke: Drei Zitterer an der homerischen Quelle. [2015] In: P. H.: Tage und Werke [Anm. 21], S. 165-186, hier S. 166 f.)

270 Rolf G. Renner: Peter Handke. Stuttgart: Metzler 1985, S. 24.

271 Clemens Özelt: Klangräume bei Peter Handke. Versuch einer polyperspektivischen Motivforschung. Wien: Braumüller 2012, S. 89.

272 Handke an Kolleritsch, 17.5 1976. In: Handke/Kolleritsch: Schönheit ist die erste Bürgerpflicht (Anm. 202), S. 99.

273 Handke an Lenz, 18.11. 1975. In: Handke/Lenz: Berichterstatter des Tages (Anm. 17), S. 9o. Auch Bernhard ist wiederholt gegen die Literaturwissenschaft zu Felde gezogen. Vgl. etwa seine abschätzige Bemerkung in einem Interview mit Kurt Hofmann: Aus Gesprächen mit Thomas Bernhard (Anm. 4), S. 96: „Germanisten werden die Leut' ja nicht aus Liebe zur Dichtung oder Kunst, sondern weil ihnen alle anderen Möglichkeiten als Chauffeur, Bäcker oder Schlosser völlig verwehrt sind. Oder weil sie stinkfaul sind oder zu eingebildet, um irgend so einen Beruf auszuüben."

274 Peter Handke: Mein Jahr in der Niemandsbucht. Ein Märchen aus der neuen Zeit. Frankfurt a. M.: Suhrkamp 1994, S. 224.

275 Handke/Hamm: Es leben die Illusionen (Anm. 55), S. 117.

276 Ebd., S. 107.

277 Handke: Das Gewicht der Welt (Anm. 53), S. 301.

278 Peter Handke: Die Geborgenheit unter der Schädeldecke. [1973] In: P. H.: Als das Wünschen noch geholfen hat. Frankfurt a. M.: Suhrkamp 1974, S. 71-80, hier S. 76 u. 80. 
Seine Einwände gegen die Methoden und Verfahren der Literaturwissenschaft haben Teil an jener „anhaltenden atmosphärischen Störung“ zwischen Autoren und Philologen, die Hermann Schlösser in einem pointierten Beitrag festgestellt und an zahlreichen Beispielen vorgeführt hat. ${ }^{279}$

Im Gespräch mit Herbert Gamper hat Handke Mitte der 1980er Jahre selbstbewusst der Hoffnung Ausdruck verliehen, „die Germanisten, oder die Erforscher der Texte“, könnten gerade an seinen Texten „ein neues Herangehen lernen“, „ihr Fach und ihre Methoden neu überdenken“, zumal es sich um einen „doch ins Stocken geratenen Berufsstand“ handle. ${ }^{280}$ Der "Zweitsprache“ der Literaturwissenschaftler, die mit der „Erstsprache umspringt“, wie er im Februar 1982 an Hermann Lenz schreibt, ${ }^{281}$ ist Handke über all die Jahre mit Argwohn begegnet. Dieser Argwohn gegenüber der „Syntax des Wissensgetues“282 geht mit einer großen Sympathie für das ,Ahnen' als Gegenentwurf zum selbstsicheren Wissen einher: „Mit dem, was ich weiß“, heißt es in Die Geschichte des Bleistifts (1982), „kann ich so selten enthusiastisch sein; wohl aber mit dem, was ich ahne; deswegen will ich nicht zu viel wissen“. 283 Der "Ton des Wissens“ erscheint ihm, wie er in Am Felsfenster morgens (1998) notiert, als „eine scheußliche Leier“, die sich vom „Tonfall[ ] des Suchens und Ahnens in der Poesie und im poetischen Erzählen“ radikal unterscheidet. ${ }^{284}$ Diese Differenzierung zwischen ,Wissen " und ,Ahnen', die Handkes gesamte Wissenschaftskritik - nicht nur jene der Literaturwissenschaft - prägt, ist für seine poetologischen Reflexionen von entscheidender Bedeutung. ${ }^{285}$ Sie spielt, um zur Literaturkritik zurückzukehren, auch in Notate wie das folgende hinein, das der Autor im Dezember 1987 auf einer Reise durch Griechenland festgehalten hat: „So vieles Schreiben über Bücher (,Kritik'): Nach den alten Ahnungslosen, die das Beiwort, alt' nicht verdienen, kommen die jungen Ahnungslosen, für die entsprechend das gleiche gilt“. ${ }^{\text {“28 }}$,Ahnungslos` zu sein meint hier weniger, dass es jemandem an Wissen mangelt, sondern verweist zuallererst auf das Fehlen eines Sensoriums für poetische Texte.

279 Hermann Schlösser: „Milchegel an den Zitzen der Kunst“. Autoren als Gegner der Literaturwissenschaft. In: Konflikte - Skandale - Dichterfehden in der österreichischen Literatur. Hg. v. Wendelin Schmidt-Dengler. Berlin: Erich Schmidt 1995, S. 280-290, hier S. 280; Schlösser versammelt darin Attacken auf die Germanistik von Autoren wie Wolfgang Bauer, Elias Canetti, Kasimir Edschmid und Helmut Eisendle.

280 Handke: Aber ich lebe nur von den Zwischenräumen (Anm. 64), S. 239 f.

281 Handke an Lenz, 23. 2. 1982. In: Handke/Lenz: Berichterstatter des Tages (Anm. 17), S. 169.

282 Handke: Am Felsfenster morgens (Anm. 15), S. 412.

283 Handke: Die Geschichte des Bleistifts (Anm. 43), S. 34.

284 Handke: Am Felsfenster morgens (Anm. 15), S. $412 \mathrm{f}$.

285 Ulrich von Bülow: Spinoza-Lektüren. In: Das stehende Jetzt (Anm. 67), S. 125-147, hier S. 133, spricht in diesem Zusammenhang von Handkes ,weitreichende[r] Skepsis gegenüber der Wissenschaft“.

Handke: Gestern unterwegs (Anm. 16), S. 47. 


\section{Einwenden und Hochhalten: Handkes Rede gegen die Literaturkritik}

„Lieber würde ich die Maultrommel schlagen oder die Mundharmonika blasen als über Literatur reden“, beginnt Handke am 23. Juni 1984 in Avignon seine Laudatio auf Gustav Januš anlässlich der Verleihung des Petrarca-Preises. ${ }^{287}$ „Und lieber würde ich über Literatur reden als über das gegenwärtige Geschäft, den gegenwärtigen Umgang, den gegenwärtigen Handel mit der Literatur“; jedoch müsse davon „auch einmal die Rede sein“: „Ich schwinge mich also auf und beginne meine Ehrung des Poeten - denn diese soll bei allem doch die Hauptsache sein - mit einer kurzen Beschreibung meiner Sicht der gegenwärtigen deutschen Literaturszenerie. ${ }^{\text {“288 }}$ Es handelt sich um Handkes vielleicht schärfste Abrechnung mit dem Literaturbetrieb, insbesondere mit dem Primat der Ökonomie im literarischen Feld, dem Handke vorwirft, die Sensibilität für Ästhetik zusehends unterminiert zu haben. Gustav Januš' Gedichte hatte Handke ein Jahr zuvor in der „Bibliothek Suhrkamp“ dem deutschsprachigen Lesepublikum vorgestellt. ${ }^{289}$ Seine Avignoner Lobrede auf den slowenischen Dichter wird indes von einer Abrechnung präludiert, die beinahe die Hälfte des gedruckten Textes einnimmt. Die Ehrung für den „Altersgenosse[n]“ ${ }^{\text {290 }}$ und ehemaligen Mitschüler Handkes im Tanzenberger Stiftsgymnasium, den der Laudator mit der Rilke'schen Wendung vom ,sachlichen Sagen' zum exemplarischen „Dichter“ erklärt, ${ }^{291}$ gerät dabei beinahe in den Hintergrund.

287 Peter Handke: Einwenden und Hochhalten. Rede auf Gustav Januš. In: P. H.: Langsam im Schatten (Anm. 62), S. 125-135, hier S. 125. Die Datierung folgt dem Kommentar in Handke/ Unseld: Der Briefwechsel (Anm. 2), S. 470 f.

288 Handke: Einwenden und Hochhalten (Anm. 287), S. 125.

289 Vgl. Gustav Januš: Gedichte. 1962-1983. Aus dem Slowenischen v. Peter Handke. Frankfurt a. M.: Suhrkamp 1983. In der Folge setzte Handke seine Tätigkeit als Übersetzer von Januš mit mehreren Lyrikbänden im Salzburger Residenz Verlag fort: Wenn ich das Wort überschreite (1988); Mitten im Satz (1991); Der Kreis ist jetzt mein Fenster (1998). Zu Handkes Beschäftigung mit Januš vgl. Höller: Peter Handke. Reinbek b. Hamburg 2007, S. 101 f., sowie die Kontextualisierung bei Fabjan Hafner: Zwischen Herkunft und Ankunft. Peter Handke übersetzt. In: Peter Handke. Freiheit des Schreibens - Ordnung der Schrift (Anm. 66), S. 73-86, bes. S. 82; ders.: Peter Handke. Unterwegs ins Neunte Land (Anm. 266), S. 166-171.

290 Peter Handke: Zu Gustav Januš, ,Gedichte 1962-1983؛ [1983] In: P. H.: Langsam im Schatten (Anm. 62), S. 109-111, hier S. 110.

291 Handke: Einwenden und Hochhalten (Anm. 287), S. 135: „Wir nennen Gustav Januš einen Dichter, weil er an keiner Stelle meint, sondern stets sachlich sagt." Im Gedicht an die Dauer verwendet Handke die Sentenz vom, sachlichen Sagen' mit Blick auf Johann Wolfgang Goethe: "Goethe, mein Held / und Meister des sachlichen Sagens" (Peter Handke: Gedicht an die Dauer. Frankfurt a. M.: Suhrkamp 1986, S. 12); sie stammt aus einem Brief Rainer Maria Rilkes an seine Frau Clara vom 19.10.1907. Vgl. Sascha Löwenstein: Poetik und dichterisches Selbstverständnis. Eine Einführung in Rainer Maria Rilkes frühe Dichtungen (1884-1906). Würzburg: Königshausen \& Neumann 2004, S. 224. Zur Bedeutung dieser Wendung bei Handke siehe auch 
Handkes zunächst in der ZEIT gedruckte Rede setzt nach der Exposition sogleich im Brustton der Verdammung ein, um anschließend die Ausführungen zum Zustand von Literaturbetrieb und Literaturkritik ausdrücklich als „Tatversuch“ anzukündigen. Sein „Hang zu scharfer Polemik“ ${ }^{292}$ den der Handke-Biograph Malte Herwig hervorgehoben hat, tritt hier in besonders prägnanter Weise hervor, weshalb der Text der Rede ausführlicher gemustert werden soll. Er sehe dort, so Handke,

wo einmal vielleicht Leidenschaft, Liebe, Erschütterung, Ernst, Zorn und heiterer, genauer Streit spielten, ein finsteres, jämmerliches, schamloses, beschämendes Geschiebe, Gedränge und Gerempel von Machthaberei, Schlagworten in jedem Sinn, Begrifferücken, Spiegelfechterei, Spitzfindigkeit - mit einem Wort: den so totalen wie totalitären Vordergrund, welcher nicht einmal beklagenswert ist, bloß zu verachten. Die Verachtung freilich sträubt sich gegen den Ausdruck, drängt zum Verschweigen und will doch nicht tatenlos bleiben: das ist ihr und das ist mein Problem. So sind die nun folgenden Worte ein Tatversuch. ${ }^{293}$

Sind die konkreten Adressaten seiner Polemik eingangs nur vage zu erkennen, bleiben also die Objekte der „Verachtung“ vergleichsweise schwach konturiert, greift der Redner kurz darauf „[e]ine der Gewohnheiten [...] des heutigen Feuilletons“ als Beispiel heraus. ${ }^{294}$ Es sei dort Usus, „die unterdrückten, verfolgten, zum Schweigen gezwungenen Künstler in den totalitären Staaten jenen in den sogenannten freien Ländern gegenüberzustellen“. Dieses „Ausspielen“, das Mitte der 1980er Jahre zuallererst auf die Frontstellung der beiden dominierenden politischen Machtsysteme in Ost- und Westeuropa zu beziehen ist, beruhe jedoch, so Handke weiter, auf einer falschen Annahme, nämlich auf der Prämisse eines strengen Antagonismus zwischen ,freien' und ,unfreien' Staaten:

In der sogenannt freien Welt geht es, jedenfalls was die Literatur betrifft, auch totalitär zu, wenngleich auf eine andere Weise als in der augenfälligen Kerkerwelt. Die Verfolgung, die Unterdrückung, die Korrumpierung, das Mundtotmachen, das Totmachen von Schriftstellern geschieht hier - ich kann nicht sagen: „bei uns“ - nur heuchlerischer, heimtückischer, gauklerischer und, wenn sich das Wort steigern ließe: faustrechthafter. ${ }^{295}$

Norbert Christian Wolf: Der „Meister des sachlichen Sagens“ und sein Schüler. Zu Handkes Auseinandersetzung mit Goethe in der Filmerzählung Falsche Bewegung. In: Poesie der Ränder (Anm. 46), S. 181-199.

292 Herwig: Meister der Dämmerung (Anm. 65), S. 114.

293 Handke: Einwenden und Hochhalten (Anm. 287), S. 125.

294 Ebd., S. 126.

295 Ebd. 
Erst jetzt führt Handke die Kritiker explizit als Adressaten seiner Auslassungen an, wobei sich, wie ein späterer Hinweis nahelegt, hinter der namentlich nicht genannten Zeitung die Frankfurter Allgemeine Zeitung verbirgt, deren Literaturressort in diesen Jahren von Marcel Reich-Ranicki geleitet wurde. ${ }^{296}$ Handke greift, so hat es den Anschein, Bertolt Brechts vielzitierte Überlegungen zum „Zerpflücken von Gedichten“ auf, die die analytische Sezierung literarischer Texte offensiv legitimiert - „Wer das Gedicht für unnahbar hält, kommt ihm wirklich nicht nahe. In der Anwendung von Kriterien liegt ein Hauptteil des Genusses. Zerpflücke eine Rose, und jedes Blatt ist schön. “ ${ }^{\text {297 }}$-, um sie im Bild vom zerkrümelten Brot ins Gegenteil zu wenden:

Fast tagtäglich nimmt es sich in der Zeitung, welche sich so viel darauf einbildet, der Literatur einen besonderen Raum zu geben, ein junger oder alter Wicht, der weder ein so schönes Wort wie „jung“ oder „alt“ je verdienen wird, heraus, mit ein paar vollkommen vordergründigen, Satz für Satz durchschau- und vorhersehbaren Standardkniffen ein Buch, wie es auch sei, in ein Nicht-Buch zu zerkrümeln, vergleichbar mit einem Kerl, der, ohne es zu wissen, was er tut, ein Stück Brot zerkrümelt, bis es nicht mehr Brot ist, und dafür auch noch bezahlt und dafür vielleicht auch noch in seiner Abendkneipe belobigt wird: „Den hast du aber prachtvoll fertiggemacht!“298

296 Vgl. ebd., S. 127, wo von „jene[r] Zeitung,für Deutschland““ die Rede ist - der vollständige Titel der FAZ lautet Frankfurter Allgemeine. Zeitung für Deutschland. In seinen Jugoslawien-Texten hat Handke erneut vehement gegen die FAZ Stellung bezogen; vgl. Peter Handke: Abschied des Träumers vom Neunten Land. Eine Wirklichkeit, die vergangen ist: Erinnerung an Slowenien. Frankfurt a. M.: Suhrkamp 1991, S. 31 f.: „Noch im nachhinein bleibt es frecher Unsinn, wenn der mit Informationen prunkende, dabei großmäulig-ahnungslose, Spiegel' in seiner Titelstory Jugoslawien ein ,Völkergefängnis? heißt, und wenn die Finstermännerriege der deutschen ,Frankfurter Allgemeinen' einen ihrer erfahrungslosen Maulhelden von der Kärntner Grenze reportieren läßt, die deutschen Österreicher dort hätten mit ihrer slowenischen Minderheit immer in gutem Einvernehmen gelebt“. Vgl. auch die in der Winterlichen Reise formulierten Vorwürfe gegen die „Tendenzkartätschen“ und „Haßleitartikler[ ] der FAZ“, der er attestiert, ein „Serbenfreßblatt“ zu sein (Handke: Eine winterliche Reise zu den Flüssen Donau, Save, Morawa und Drina oder Gerechtigkeit für Serbien [Anm. 26], S. 15, 33 u. 125). Dazu Handkes nachträglicher Kommentar im Gespräch mit Willi Winkler: „Über die Jahre habe ich mit zunehmender Empörung verfolgt, wie die Frankfurter Allgemeine vorgegangen ist, auch der Spiegel und Le Monde. [...] Was diese drei Organe gemacht haben, ist und bleibt kriminell. Das ist auf andere Weise auch kriegsverbrecherisch." (Willi Winkler: Ich bin nicht hingegangen, um mitzuhassen. Peter Handke antwortet seinen Kritikern. In: DIE ZEIT, Nr. 6, 2. 2. 1996, S. 47-48, hier S. 47)

297 Vgl. Bertolt Brecht: Über das Zerpflücken von Gedichten. [1937/1939] In: B. B.: Werke. Große kommentierte Berliner und Frankfurter Ausgabe. Hg. v. Werner Hecht u. a. Bd. 22: Schriften 2. Teil I. Berlin u. a.: Aufbau/Suhrkamp 1993, S. 453-454. Den Hinweis darauf verdanke ich Werner Michler.

298 Handke: Einwenden und Hochhalten (Anm. 287), S. 126. 
War Thomas Bernhard im November 1978 eine „Bücherverbrennung“ angesichts der Angriffe auf seine Person (im Rahmen einer abgebrochenen Lesung an der Universität München) als ,ein geradezu symbolischer Akt" erschienen, ${ }^{299}$ bedient sich Handke im Folgenden eines ähnlich absurden Vergleichs, um das destruktive Moment der Literaturkritik durch eine historische Analogie zu erhellen: „Hört auf, von der Bücherverbrennung der Nationalsozialisten zu reden - ihr tut das gleiche immer noch, auf eure Weise, unauffälliger, aber genauso vorsätzlich, und kommt dazu straflos davon. ${ }^{\text {¿300 }}$ Obschon diese Ebene des Vergleichs in der Folge beiseitegelassen wird - nur der Vorwurf des ,Totalitarismus' taucht erneut auf -, bleibt der Ton der Rede doch aggressiv, wobei Handke auch vor harschen Invektiven nicht zurückschreckt:

Der sogenannte „Raum“, den jene Zeitung „für Deutschland“ angeblich den Büchern gibt, ist das Gegenteil von einem Raum: Er ist ein stickiges, luftloses Henkerstübchen, vollgepfercht mit bieder-wahnsinnigen Unholden und ihren ehrsüchtigen, selbstvergessenen Mietlingen. Kritiker zu sein könnte ein guter, lehrreicher, Vergnügen bescherender Beruf sein; eine genaue, erzählende, aufschlüsselnde und wiederum verschlüsselnde Besprechung eines Buches, ob mit Liebe oder mit Zorn verfaßt, zu lesen, hat mir schon oft Freude gemacht, oft das Hirn zum Glühen gebracht, ja mich sogar gerührt und begeistert. Aber es gibt schon lange kaum Kritiker mehr - nur noch gutbezahlte Angestellte, die sich aufspielen, und immer für sich selber, und immer gegen jemand andern; und die hellen Streitspiele sind zum bloßen GegeneinanderAusspielen verkümmert. ${ }^{301}$

In der Denunziation des Status quo scheint - wie so oft in Handkes Polemiken als Gegenbild das Ideal eines „genaue[n], erzählende[n]“ Rezensierens durch, das den Beruf des Kritikers zu einem positiven, ja lustvollen Tätigwerden im Namen der Literatur werden ließe. Anstatt die emotionale Affektion beim Lesen („Liebe“, „Zorn“, „Freude“ etc.), anstatt das ,Erlebnis der Lektüre‘ zu beschreiben, seien die prominenten Kritiker im Feuilleton der FAZ mit der Demonstration von Deutungsmacht und literaturbetrieblicher Ranküne beschäftigt. Drei Jahre

299 Bernhard an Unseld, 29. 11. 1978. In: Bernhard/Unseld: Der Briefwechsel (Anm. 11), S. 550: „Ich glaube, der Schritt von der gewalttätigen Behinderung einer (in diesem Falle meiner) mit dem umgekehrten Gastrecht geohrfeigten Person - und die Unterdrückung war ja mehr oder weniger eine brutal-physische, wie Sie gesehen haben - bis zur Vernichtung dieser Person (und ihrer Arbeit), ist kurz. Dagegen wäre die Bücherverbrennung ein geradezu symbolischer Akt.“ Franz Xaver Kroetz und seine „Leute“, die er für die Störung der Münchner Lesung verantwortlich machte, erinnerten Bernhard „an die Münchner Nazis“. Vgl. dazu den Kommentar ebd., S. 547-551.

300 Handke: Einwenden und Hochhalten (Anm. 287), S. 126 f.

301 Ebd., S. 127. 
später wird Handke in Nachmittag eines Schriftstellers (1987) von seinem durch die Stadt Salzburg gehenden Alter Ego schreiben, dieser habe zwar „manchmal erfahren, daß auch die Kritik eine Kunst für sich war“; „die große Regel“ auf den Seiten des Feuilletons jedoch sei, „im besten Fall, das ausgefüllte Schema oder, im schlechtesten, ein Falschspiel, bei dem die Lust an der Sache längst gewichen war den raschen durchschaubaren Hintergedanken“ - „statt Kritik zu schaffen“, werde, so der Erzähler von Nachmittag eines Schriftstellers, „Winkelpolitik“ betrieben. ${ }^{302}$ Ganz in diesem Sinne argumentiert der Autor auch in Einwenden und Hochhalten:

Lest, Leute, daraufhin in dem besagten Machtblatt eine sogenannte Buchkritik: in fast jedem Fall wird da weder ein Buch sichtbar, noch wird eine Besprechung zur Lehre, sondern, Satz um Satz, das Ausspielen, dieses gegen jenen, jenes gegen diesen, zum Skandal: der totale, totalitäre Vordergrund. Würde das Wünschen helfen, so wäre folgendes mein Wunsch: eine Wiederholung, eine Erneuerung, eine Wiederbelebung der Haltung Walter Benjamins. ${ }^{303}$

Kann bereits dieser „Wunsch“ als Seitenhieb gegen Marcel Reich-Ranicki gelten dieser hatte dem Kritiker Benjamin vorgeworfen, aufgrund „seiner extremen Ichbezogenheit“ „zu sehr poetischer Denker“ gewesen zu sein ${ }^{304}$-, kulminiert Handkes Philippika gegen die Ausprägungen des Literaturbetriebs schließlich in der Kritik an einem Format, das Reich-Ranicki als prominentes Jurymitglied von 1977 bis 1986 ganz wesentlich mitgeprägt hat: am Klagenfurter Ingeborg-Bachmann-Preis. ${ }^{305}$

302 Handke: Nachmittag eines Schriftstellers (Anm. 31), S. 35.

303 Handke: Einwenden und Hochhalten (Anm. 287), S. 127.

304 Marcel Reich-Ranicki: Walter Benjamin. Der poetische Denker. [1972] In: M. R.-R.: Die Anwälte der Literatur. Stuttgart: DVA 1994, S. 227-236, hier S. 235. Vgl. Reich-Ranickis Erläuterung ebd., S. 234 f.: „In der Kritik kommt es nicht darauf an, selber dichterisch zu denken, sondern das Dichten und Denken anderer zu erkennen und zu überprüfen, zu zeigen und einzuordnen.“ Zu dieser Konstellation vgl. auch Kap. V, Abschnitt „Der Autor als Kritiker: ein Rollenkonflikt?“.

305 Vgl. Doris Moser: Der Ingeborg-Bachmann-Preis. Börse, Show, Event. Wien u. a.: Böhlau 2004, S. 185 f.: „Marcel Reich-Ranicki spielte vermutlich die wichtigste Rolle im Aufbau dessen, was Klagenfurt als Schlagwort im Lexikon des Literaturbetriebes heute bezeichnet, denn ReichRanicki ließ sein Kapital von Anfang an für den Wettbewerb arbeiten [...]. Reich-Ranicki hat den Wettbewerb maßgeblicher mitbestimmt als seine Kollegen aus den anderen Feuilletons, er nimmt [...] daher eine Position ein, die zwischen Management und Marketing anzusiedeln wäre." Gerade an dieser Ökonomisierung des Literaturbetriebs, für die Reich-Ranicki als charakteristisches Beispiel dient, nimmt Handkes Rede denn auch konkret Anstoß. Zur „Ablehnung der gesamten Veranstaltung durch Autorenpersönlichkeiten wie Peter Handke und Gerhard Roth“ vgl. die kursorischen Bemerkungen ebd., S. 251, 278 f. u. 348 (Zit.); Handkes Januš-Rede 
Statt sich Benjamins Haltung als Kritiker ${ }^{306}$ zum Vorbild zu nehmen, werde „schon seit geraumer Zeit einmal im Jahr in einer südlichen Stadt meines Heimatlandes Österreich das minderwertigste, schändlichste, menschenunwürdigste Spektakel abgehalten“, das nur scheinbar „im Namen und unter dem Zeichen der Kultur" stehe. ${ }^{307}$ Wohl auf Bachmanns berühmte Erzählung Jugend in einer österreichischen Stadt anspielend, wenn er davon spricht, dass in Klagenfurt „in allen Straßen, auf allen Plätzen, unter jedem Baum [...] immer noch und für immer die unschuldig-wissenden Augen der Ingeborg Bachmann aufgeschlagen sind“, ${ }^{308}$ bezeichnet Handke den unlauteren „Wettbewerb des Geistes“ als „niedrig und erniedrigend“ für die Autorinnen und Autoren. ${ }^{309}$ Während ein „Wettbewerb der Körper“ „etwas sehr Schönes“ sein könne, erscheine ihm ein „Wettbewerb der Rede schon [...] fragwürdiger, angewiesen auf Suggestion, immer behaftet mit dem Makel des Nachgeschmacks“; einem „Wettbewerb des Geistes, der Poesie“ jedoch kann Handke definitiv nichts abgewinnen, „sofern er nicht, wie im antiken Griechenland, vom Volk selbst entschieden wird: da hätte auch ich Lust, teilzunehmen und mit der Sprache meinen Weitsprung zu zeigen, mich zu freuen am Sieg, und mich zufriedenzugeben damit, der Besiegte zu sein. “ ${ }^{310}$

Bei den Juroren des Bachmann-Preises handle es sich, so Handkes Vorwurf, um „ein[en] Trupp gravitätisch-nichtsnutziger Barbaren, vor denen ein paar arme, eifrige, beflissene Talente erzittern wie damals die gesamte Kärntner Bevölkerung vor den Türken“. ${ }^{311}$ Dem Prinzip der Assoziation folgend weitet Handke seine

wird zwar im Literaturverzeichnis von Mosers Studie angeführt, spielt im Zuge ihrer Untersuchung aber keine Rolle.

306 Vgl. etwa Gérard Raulet: Einbahnstraße. In: Benjamin-Handbuch. Leben - Werk - Wirkung. Hg. v. Burkhardt Lindner. Unter Mitarb. v. Thomas Küpper u. Timo Skrandies. Stuttgart, Weimar: Metzler 2006, S. 359-373, hier S. 362, der hervorhebt, „daß Benjamin die traditionelle Kunstkritik für überholt und den neuen Erfahrungsbedingungen unangemessen hält" - und damit zentrale Einwände mit Handke teilt.

307 Handke: Einwenden und Hochhalten (Anm. 287), S. 127.

308 Ebd., S. 128.

309 Ebd., S. 129.

310 Ebd., S. 128 f.

311 Ebd., S. 128. Fast wortgleich findet sich diese Attacke in einem gut einen Monat nach der Januš-Laudatio geführten Interview, dessen Wortlaut Handke später in einem offenen Brief in Teilen dementiert hat: „Waren Sie einmal beim Klagenfurter Literatur Wettbwerb [sic]? Haben Sie gesehen, wie da vor einem Trupp gravitätisch daherschreitender nichtsnutziger Barbaren ein paar eifrige, beflissene Talente herumkriechen? Finster! Gruselig! Das ist doch Kulturabtreibung. In der Kultur herrscht das reine Faustrecht.“ (Lothar Schmidt-Mühlisch: Macht der stinkenden Fäulnis. Wider die Abtreibung der Kultur - Ein Welt-Gespräch mit Peter Handke. In: Die Welt, 27.7.1984) Der Interviewer ist in seiner Antwort auf Handkes Dementi auf die Übereinstimmung zwischen den Aussagen im Welt-Gespräch und der Januš-Rede ausdrücklich 
Anklage zunächst auf die Nichtbeachtung zweier für ihn wichtiger Schriftsteller (Hermann Lenz und Ernst Meister) im Kreis der Gruppe 47 aus, um am Ende des Absatzes auf den umfassenden Betrug an den Leserinnen und Lesern, den die Literaturkritik sowie die Ein- und Ausschließungsmechanismen des Literaturbetriebs zu verantworten hätten, zu sprechen zu kommen:

Die so oft nostalgisch heraufbeschworene, selige Gruppe 47 schon war vielmehr ein unseliges Übel, in dem die Literatur beschnitten wurde zu einem Flachding aus Meinung, Trend, Jargon und Sprachpolizei; für immer wird unverzeihlich bleiben, daß der deutsche Epiker Hermann Lenz und der deutsche Lyriker Ernst Meister - für mich ebenbürtig der Ingeborg Bachmann und dem Paul Celan - von den Ausschließungs- oder Einlaßverwahrungsriten jener sitzriesigen Kleinbürger, aus denen sich die Gruppe vor allem rekrutierte, um das Gelesenwerden, um jede Antwort, um ihre Recht betrogen worden sind. Und betrogen sind auch wir, die Leser. Dafür wird es nie eine Lossprechung geben. ${ }^{312}$

Es hat den Anschein, als handle es sich bei dem Verhalten der „aus ihren Kummerlöchern herbeigereisten Feder- und Mikrophonfuchser“, der „selbsternannten Kunstschöffen “" 313 um ein Kapitalverbrechen, für das Vergebung ob der Schwere des Delikts unmöglich ist. Die Ausrufung eines ,Wettbewerbs' der Literatur sieht Handke dabei als symptomatischen Beleg einer Fehlentwicklung, die dazu geführt habe, dass Hierarchisierung und Quantifizierung dem Bekenntnis zur eingehenden und genauen Lektüre vorgezogen werde.

Nun hebt Handke nach dem ausufernden, nicht eben festlichen ,Einwenden' endlich mit dem ,Hochhalten' des an diesem Tag mit dem Petrarca-Preis bedachten Gustav Januš an, den er schon ein Jahr zuvor als einen der beiden

eingegangen: „In diesem Gespräch sagten Sie ja prinzipiell gar nichts anderes als das, was Sie an anderer Stelle auch geäußert haben. Darf ich Sie an Ihre Rede anläßlich der Verleihung des Petrarca-Preises erinnern? Dort [...] steht fast wörtlich das gleiche, was Sie mir [...] gesagt haben. “ (Lothar Schmidt-Mühlisch: Rolle rückwärts aus einer hellen, heiteren, scharfen Unterhaltung. In: Die Welt, 6.9.1984)

312 Handke: Einwenden und Hochhalten (Anm. 287), S. 128. Diesen Vorwurf hat Handke im zitierten Interview mit Schmidt-Mühlisch wenig später erneuert: „Nehmen Sie mal die ,Gruppe 47, die sich nach dem Krieg anmaßte, Richter über die deutsche Literatur zu sein. Jämmerlich! Zwei der größten deutschen Dichter, Hermann Lenz und Ernst Meister, haben die bei ihrem Unterliga-Spiel glatt übersehen. Die paßten nicht in ihr, Vernunft'-Konzept. Da wurde eine ganze literarische Generation zu einem Flachholz zurechtgeschnitten. Meinung, Trend, Jargon - das waren die Kriterien, nach denen diese Versammlung von Kleinbürgern ihren literarischen Schrebergarten vermaß.“ (Schmidt-Mühlisch/Handke: Macht der stinkenden Fäulnis [Anm. 311])

313 Handke: Einwenden und Hochhalten (Anm. 287), S. 129. 
„exemplarische[n] Schriftsteller" Sloweniens vorgestellt hatte ${ }^{314}$ - um schließlich, am Ende der Rede, auf „Maultrommel“ und „Mundharmonika “, 315 die beiden eingangs gegenüber dem Sprechen über Literatur präferierten Instrumente, zurückzukommen. Erst die Entladung des Zorns im ersten Teil der Rede ermöglicht die freundliche und wertschätzende Laudatio auf das „Absichtslose“, das "Eigen-Mächtige“ von Januš Schreiben, das Handke erneut im Kontrast zur "herrschende[n] Literatur unseres Jahrhunderts" profiliert. ${ }^{316}$ Das ,Hochhalten ist bei Handke - hier wie auch in anderen Fällen - ohne die Kontrastfolie des polemisch Abgewerteten kaum zu denken.

314 Handke: Zu Gustav Januš, ,Gedichte 1962-1983' (Anm. 290), S. 110.

315 Handke: Einwenden und Hochhalten (Anm. 287), S. 135.

316 Ebd., S. $133 \mathrm{f}$. 


\title{
IV „MEIN FEIND IN DEUTSCHLAND“: PETER HANDKE VS. MARCEL REICH-RANICKI
}

\author{
Princeton 1966 und die Folgen
}

Im Herbst 1966, wenige Monate nach der Tagung der Gruppe 47 in Princeton, hob Peter Handke aus der Riege der Literaturkritiker, die er großteils für „indiskutabel“ hielt, Marcel Reich-Ranicki gleich an erster Stelle als negatives Beispiel hervor. ${ }^{1}$ Ebenso kann der knapp zwei Jahre darauf in den Grazer manuskripten veröffentlichte Essay Marcel Reich-Ranicki und die Natürlichkeit als Beleg dafür gelten, dass Handke schon damals eine ausgeprägte Aversion gegen den ,Großkritiker' hegte. ${ }^{2}$ Mag für diese auch (gegenseitige) persönliche Antipathie eine Rolle gespielt haben, so fußte der Konflikt der beiden Kontrahenten doch zuallererst auf einer Unvereinbarkeit ihrer jeweiligen ästhetischen Konzepte. ReichRanickis Ideal eines organischen Kunstwerks, das seine Faktur geschickt zum Verschwinden bringt, standen die literarischen Verfahren und theoretischen Positionen in Handkes Frühwerk diametral entgegen. Dem Vorwurf Handkes, Reich-Ranicki „verniedlich[e]“ das „erkennbare Machen von Literatur“, „,indem er dafür das beliebte Wort ,Basteln“ verwendet ", 3 ist ein grundlegender Antagonismus im literarischen Feld der späten 196oer und frühen 1970er Jahre eingeschrieben. Die sorgsam gepflegte, immer wieder aufs Neue geschürte Feindschaft sollte lange Zeit andauern. In gewisser Weise kann sie als paradigmatisch für die schwierige Beziehung von Autor und Kritiker, für das „spannungsreiche[ ]

1 Peter Handke: Bitte kein Pathos! In: Abendzeitung, 22./23. 10. 1966: „Sie wissen, daß ich kein Feind der Gruppe bin, nicht sein kann, weil ich zu wenig von ihr weiß. Ich finde nur die meisten Kritiker in ihr (Marcel Reich-Ranicki, Joachim Kaiser, Walter Jens, Hans Mayer) indiskutabel." Von den etablierten ,Groß-Kritikern' der Gruppe fehlt in Handkes Aufzählung lediglich Walter Höllerer - diesen hatte Handke allerdings bereits in Princeton im Anschluss an dessen Lesung als „völlig geistlos“ attackiert (Audioaufzeichnung der Lesungen und Diskussionen der Gruppe-47-Tagung in Princeton 1966. In: Princeton University Department of German, https:// german.princeton.edu/department/about/resources/gruppe-47-recordings [Stand 14. 10. 2020], Lesung Höllerer, Wortmeldung Handke, 20:53-21:37).

2 Vgl. Peter Handke: Marcel Reich-Ranicki und die Natürlichkeit. In: manuskripte (1968), H. 22, S. 40-41; durch den raschen Wiederabdruck im ,Handke-Reader' (1969) sowie die Aufnahme in den Band Ich bin ein Bewohner des Elfenbeinturms (1972) wurde er bald einem größeren Publikum bekannt; vgl. Prosa, Gedichte, Theaterstücke, Hörspiele, Aufsätze. Frankfurt a. M.: Suhrkamp 1969, S. 288-291; Ich bin ein Bewohner des Elfenbeinturms. Frankfurt a. M.: Suhrkamp 1972, S. 203-207. In der Folge wird er aus dem am weitesten verbreiteten Band Ich bin ein Bewohner des Elfenbeinturms zitiert.

3 Handke: Marcel Reich-Ranicki und die Natürlichkeit (Anm. 2), S. 204. 
Verhältnis[ ] von Literatur und (journalistischer) Literaturkritik“ überhaupt gelten. ${ }^{4}$ Sie geht jedoch, das lässt sich schon eingangs sagen, weit über das übliche $\mathrm{Ma} ß$ der eingespielten Gegnerschaft zwischen beiden Fraktionen hinaus - es lohnt sich, ihr im Detail nachzuspüren, nicht zuletzt deshalb, weil in ihr ein zentraler Aspekt von Handkes streitbarer Werkpolitik besonders prägnant zum Ausdruck kommt.

Die Konfliktgeschichte reicht, wie erwähnt, zurück bis in die Phase von Handkes Etablierung im literarischen Feld, und der ikonische Chronotopos ,Princeton 1966' spielt dafür eine entscheidende Rolle. Im Frühjahr 1966 agitierte Handke im Rahmen der Tagung der Gruppe 47 - schon fast am Ende des Lesungsprogramms - öffentlichkeitswirksam gegen die proliferierende ,Beschreibungsimpotenz' von Literatur und Literaturkritik. Der 23-jährige Schriftsteller war von Hans Werner Richter als vielversprechender Suhrkamp-Debütant und als Vertreter einer neuen Autorengeneration zu diesem ersten Treffen der Gruppe auf amerikanischem Boden eingeladen worden; Siegfried Unseld hatte sich mit Nachdruck für ihn eingesetzt. Noch vor seiner Philippika im Anschluss an Hermann Peter Piwitts Lesung stelle Handke, dessen erstes Buch Die Hornissen kurz zuvor erschienen war, einen Abschnitt aus seinem aktuellen Romanprojekt Der Hausierer der kritischen Gruppenöffentlichkeit vor - und stieß mit seiner spröden formalistischen Variation des Kriminalromangenres ${ }^{5}$ besonders bei Reich-Ranicki auf wenig Gegenliebe: In seinem typischen, mit den Jahren zum Markenzeichen geronnenen Sprachgestus konstatiert Reich-Ranicki gleich zu Beginn seiner Wortmeldung, Handkes Text habe ihn „gelangweilt“, „ohne dass es

4 Karl Wagner: Handkes Endspiel. Literatur gegen Journalismus. In: Mediale Erregungen? Autonomie und Aufmerksamkeit im Literatur- und Kulturbetrieb der Gegenwart. Hg. v. Markus Joch, York-Gothart Mix u. Norbert Christian Wolf. Tübingen: Niemeyer 2009, S. 65-76, hier S. 7o. Vgl. dazu die Ergänzung von Norbert Christian Wolf: Autonomie und/oder Aufmerksamkeit? Am Beispiel der medialen Erregungen um Peter Handke, mit einem Seitenblick auf Marcel Reich-Ranicki. In: ebd., S. 45-63, hier S. 58: „Die individuelle Idiosynkrasie zwischen einem Autor und seinem Kritiker lässt sich aber nicht allein auf diese allgemeine Opposition reduzieren [...]; sie wird im Gegenteil immer auch durch spezifische Mikrokonstellationen begünstigt oder unwahrscheinlich gemacht, durch den spezifischen Literaturbegriff und den intellektuellen Habitus der beteiligten Personen, wie das ganz anders geartete Verhältnis zwischen Peter Handke und Sigrid Löffler veranschaulicht.“

5 Vgl. zum literarischen Verfahren des Hausierers Linda C. DeMeritt: Handkes Antigeschichten. Der Kriminalroman als Subtext in Der Hausierer und Die Angst des Tormanns beim Elfmeter. In: Experimente mit dem Kriminalroman. Ein Erzählmodell in der deutschsprachigen Literatur des 20. Jahrhunderts. Hg. v. Wolfgang Düsing. Frankfurt a. M. u. a.: Lang 1993, S. 185-203. Karl Wagner: Handke und die Gruppe 47. In: Zwischen Aufbegehren und Anpassung. Poetische Figurationen von Generationen und Generationserfahrung in der österreichischen Literatur. Hg. v. Joanna Drynda. Frankfurt a. M. u. a.: Lang 2012, S. 121-132, hier S. 126, hat den Roman als „strukturalistische[ ] Hardcore-Übung“ bezeichnet. 
mich interessierte“, um verdeutlichend hinzuzufügen: „Überhaupt nicht hat’s mich interessiert. “6 In der Folge unterstreicht Reich-Ranicki, zeitweilig unterbrochen und wohl auch angefeuert von Gelächter aus dem Publikum, sein Desinteresse an Handkes Text und bezeichnet dessen sprachanalytische Auseinandersetzung mit der Produktivität einer literarischen Gattung als bloßen „Manierismus“, ja als im vorliegenden Fall gescheiterte „Schreibweise“:

Es ist natürlich richtig, was hier gesagt wurde, dass es eine solche Schreibweise gibt. Es gibt sie, nur die Frage ist, ob sie was taugt. Und wenn man sagt, dies sei ein Kriminalroman, und das Kriterium ist hier wörtlich gebracht worden, weil man nicht weiß, worum es geht, nun, dann möchte ich behaupten, dass das noch kein ausreichendes Kriterium ist. Man weiß sehr oft bei schlechten Sachen nicht, worum es geht, und es sind deswegen noch keine Kriminalromane. Dieses Prinzip der Hauptsätze wird verteidigt. Ja, natürlich kann man aus Hauptsätzen, Aussagesätzen, eine Erzählung bauen, und kann machen, dass sich aus diesen Hauptsätzen ein einziger großer Potentialis ergibt. Er ergibt sich hier meiner Ansicht nach nicht. Ich glaube nicht an diese Schreibweise, wie sie hier vorgeführt wurde. Ich glaube, dass das Ganze in einem sehr, sehr primitiven und, trotz allem, was hier gesagt wurde, eigentlich sehr altmodischen Manierismus landet. [...] Mich hat es gelangweilt. ${ }^{7}$

6 Audioaufzeichnung Princeton 1966 (Anm. 1), Lesung Handke, Wortmeldung Reich-Ranicki, $37: 35-37: 42$.

7 Ebd., 38:05-39:05. Vgl. zu den Reaktionen auf Handkes Lesung Helmut Böttiger: Die Gruppe 47. Als die deutsche Literatur Geschichte schrieb. München: DVA 2012, S. 391 f.; Jörg Magenau: Princeton 66. Die abenteuerliche Reise der Gruppe 47. Stuttgart: Klett-Cotta 2016, S. 142. Zur Wiederkehr dieses Bewertungsmusters vgl. Thomas Anz: Werten und Fühlen. Zur Rationalität und Emotionalität literaturkritischer Kommunikation - am Beispiel von Marcel Reich-Ranicki. In: Literaturkritik heute. Tendenzen - Traditionen - Vermittlung. Hg. v. Heinrich Kaulen u. Christina Gansel. Göttingen: V\&R unipress 2015, S. 13-25, hier S. 17: „Reich-Ranickis Wirkungsargumente verwenden, soweit sie sich auf Unlustgefühle beim Lesen beziehen, mit Vorliebe Wörter wie ,langweilen' oder ,ermüden.“ - Auf eine Anfrage des Residenz Verlags für einen Anthologie-Beitrag antwortete Reich-Ranicki 1984 denn auch entsprechend: „Lieber Herr Jung, / Sie möchten gerne wissen, wie die Literatur aussehen sollte, die ich mir für die Zukunft wünsche. Hier meine Antwort, die hochmütig klingen mag, indes, Sie können es mir glauben, ganz und gar aufrichtig ist: Ich wünsche mir eine Literatur, die mich nicht langweilt." (Marcel ReichRanicki: Erst die Poesie, dann die Theorie. In: Was Kritiker gerne läsen. Literaturalmanach 1984. Hg. v. Jochen Jung. Salzburg, Wien: Residenz 1984, S. 99-101, hier S. 99) - Vgl. dazu Anton Thuswaldner: Österreichische Verhältnisse. In: Deutschsprachige Gegenwartsliteratur. Wider ihre Verächter. Hg. v. Christian Döring. Frankfurt a. M.: Suhrkamp 1995, S. 108-119, hier S. 111: „Wo früher die mühsame Suche nach Argumenten Zustimmung oder Ablehnung für andere überprüfbar machte, zählt heute das saloppe und beiläufig fallengelassene Wort. Noch nie ist eine Floskel vom Typus, Das langweilt mich!' eine literaturkritische Kategorie gewesen, mittlerweile sind solch subjektive, nicht weiter begründeten oder begründbaren Phrasen Allgemeingut geworden $[\ldots]$.. 
Eine Ad-hoc-Verteidigung war Handke aufgrund des etablierten Reglements der Gruppe 47 verwehrt: Wie später bei den Klagenfurter „Tagen der deutschsprachigen Literatur“, die Reich-Ranicki von 1977 bis 1986 ganz wesentlich prägen sollte, ${ }^{8}$ hatten die lesenden Autorinnen und Autoren nicht die Möglichkeit, direkt auf die Kommentare der Kritiker zu antworten, sondern mussten Lob und mitunter fundamentale Einwände duldsam und schweigend über sich ergehen lassen. ${ }^{9}$ Allerdings nahm Handke in der Folge Reich-Ranickis Bemerkung, sich bei der Lesung aus dem Hausierer vor allem "gelangweilt“ zu haben, in seiner Princetoner Einrede gegen die „Beschreibungsimpotenz“ auf, um sie als Beleg für seine These, wonach die Kritik ihr Sensorium für innovative erzählerische Artikulationsformen eingebüßt habe, anzuführen: Es sei, so Handkes verdecktes Revanchefoul an Reich-Ranicki, eines der eingeschliffenen Reaktionsmuster der Literaturkritik, auf irritierende Leseerfahrungen mit der Bekundung zu antworten, man habe den Text für „langweilig“ befunden:

Wenn nun eine neue Sprachgestik auftaucht, (Zwischenruf: Psst!) so kann die Kritik nichts anderes, vermag die Kritik nichts anderes, als eben zu sagen ... entweder zu sagen, das ist langweilig, sich in Beschimpfungen zu ergehen, oder auch eben auf gewisse einzelne Sprachschwächen einzugehen, die sicher noch vorhanden sein werden. ${ }^{10}$

Handkes Protest beschränkte sich in der Folge nicht auf die pauschale Abwertung der Kritiker, die „das sogenannte gesellschaftliche Engagement des Schriftstellers [...] an den Objekten“ statt „an der Sprache, mit der er diese Objekte beschreibt", gemessen hätten, ${ }^{11}$ sowie die bereits eingangs zitierte Nennung ReichRanickis als ,indiskutablen' Kritiker in seinem offenen Brief an Günter Grass in der Münchner Abendzeitung. Mit einigem zeitlichen Abstand richtete er sich

8 Vgl. dazu detailliert Doris Moser: Der Ingeborg-Bachmann-Preis. Börse, Show, Event. Wien u. a.: Böhlau 2004; zum Vergleich von Gruppe 47 und Ingeborg-Bachmann-Preis ebd., S. 56-61.

9 Vgl. zu dieser Regel etwa Magenau: Princeton 66 (Anm. 7), S. 43, 173 u. 190; Reinhard Baumgart: Damals. Ein Leben in Deutschland. 1929-2003. [München]: Hanser 2003, S. 243. Zum Modus der ,mündlichen Sofortkritik' vgl. Wolfgang Albrecht: Literaturkritik. Stuttgart, Weimar: Metzler 2001, S. $57 \mathrm{f}$.

10 Im Wortlaut: Peter Handkes, Auftritt' in Princeton und Hans Mayers Entgegnung. In: Text + Kritik (51989), H. 24, S. 17-20, hier S. 18. - Noch in Die Lehre der Sainte-Victoire (1980) hat Handke auf diesen Vorwurf angespielt: „Nur einmal, wie von mir gelangweilt, hielt er ein, blinzelte heuchlerisch zur Seite“ (Peter Handke: Die Lehre der Sainte-Victoire. Frankfurt a. M.: Suhrkamp 1980, S. 57). - Zuletzt hat Jörg Döring: Peter Handke beschimpft die Gruppe 47. Siegen: universi 2019, S. 39-57, 70 u. $101 \mathrm{f}$, darauf hingewiesen, dass Handkes Princetoner Polemik ganz wesentlich mit den Reaktionen auf seine eigene Lesung in Beziehung stand.

11 Peter Handke: Zur Tagung der Gruppe 47 in USA. [1966] In: P. H.: Ich bin ein Bewohner des Elfenbeinturms (Anm. 2), S. 29-34, hier S. 30 f. 
in einer Besprechung von Reich-Ranickis Band Literatur der kleinen Schritte (1967) - also in der Rezension einer Rezensionssammlung - zudem ausführlich gegen dessen konkrete literaturkritische Praxis sowie dessen Status als vermeintliche Leitfigur der Literaturkritik im deutschsprachigen Raum. Seinem Freund Alfred Kolleritsch ließ Handke den Artikel am 4. März 1968 zur Publikation in den manuskripten zukommen: „Ich schicke dir einen Text über Reich-Ran. mit, vielleicht kannst Du was anfangen, er wird im Westdeutschen Rundfunk gesendet werden. ${ }^{\text {"12 }}$ Unter dem Titel Marcel Reich-Ranicki und die Natürlichkeit erschien der Text im Frühjahr 1968 im 22. Heft der Zeitschrift, das - die räumliche Nähe zu den Schreibweisen der österreichischen Avantgarde ist hier durchaus signifikant - auch die letzte Folge von Oswald Wieners Romanprojekt die verbesserung von mitteleuropa enthielt, dessen fortschreitende Veröffentlichung in den manuskripten den jungen Handke, ebenso wie die Arbeiten Konrad Bayers, „stark beeindruckt“ hatte, ${ }^{13}$ obgleich er sich später den Vertretern der Wiener Gruppe gegenüber reservierter zeigte. Adolf Haslinger berichtet gar davon, dass Handke Kolleritsch bei „Korrektur und Redaktion“ von Wieners die verbesserung von mitteleuropa für die Publikation in den manuskripten "stundenlang“ unterstützt hat. ${ }^{14}$

Reich-Ranicki - Ende der 196oer Jahre Kritiker der ZEIT in Hamburg - war sowohl in der Gruppe $47^{15}$ als auch in den Diskussionen über Rolle und Aufgabe der Literaturkritik immer mehr zu einer polarisierenden Figur geworden. Während Autoren und Essayisten ganz unterschiedlicher politischer Couleur seinen Erfolg als exemplarisches Symptom einer „Misere unserer Literaturkritik“

12 Peter Handke an Alfred Kolleritsch, 4. 4. 1968. In: P. H./A. K.: Schönheit ist die erste Bürgerpflicht. Briefwechsel. Salzburg, Wien: Jung und Jung 2008, S. 21. Über eine Sendung des Beitrags im Westdeutschen Rundfunk ist in den vorliegenden Ausgaben des Textes nichts vermerkt; in einem weiteren Brief an Kolleritsch vom 20.12.1968 verweist Handke erneut auf die vorherige Veröffentlichung im Rundfunk: „Was ich über Reich-Ranicki und Thomas Bernhard geschrieben habe, ist vorher auch schon entweder im Rundfunk oder in einer Zeitung gedruckt, aber erst in den ,manuskripten' hat man davon gehört." (Ebd., S. 23) Handkes Bemerkungen zu Bernhards Verstörung jedenfalls wurden am 9.10.1967 im Format „Kulturelles Wort“ im Hessischen Rundfunk (Redaktion: Adolf Frisé) gesendet (vgl. den entsprechenden Beleg im Siegfried-Unseld-Archiv, DLA Marbach, Handke Allg.).

13 Rolf G. Renner: Peter Handke. Stuttgart: Metzler 1985, S. 25; vgl. dazu Helmuth Kiesel: Geschichte der literarischen Moderne. Sprache - Ästhetik - Dichtung im zwanzigsten Jahrhundert. München: C. H. Beck 2004, S. 459. Ob Wiener aber tatsächlich „Handkes Vorbild“ war, wie Ingrid Gilcher-Holtey: 1968. Eine Zeitreise. Frankfurt a. M.: Suhrkamp 2008, S. 77, schreibt, halte ich für fraglich.

14 Adolf Haslinger: Peter Handke. Jugend eines Schriftstellers. Salzburg, Wien: Residenz 1992, S. 118.

15 Vgl. Thomas Anz: Marcel Reich-Ranicki. München: dtv 2004, S. 77f.; Uwe Wittstock: Marcel Reich-Ranicki. Die Biografie. München: Blessing 2015, S. 174-176. 
ausmachten, ${ }^{16}$ galt anderen sein Anspruch, der Kritik mittels Popularisierung ein neues und breiteres Publikum zu erschließen, gerade als Chance für die notwendige Revitalisierung des Rezensionsbetriebs. ${ }^{17}$ An seiner literaturkritischen Praxis entzündeten sich vielfältige Debatten, zumal Reich-Ranicki die Rolle des umstrittenen und streitbaren Kritikers bewusst kultivierte und zelebrierte. Bereits vor Handkes polemischer Attacke im Frühjahr 1968 wurde ReichRanicki eine „totale Abwesenheit jeglichen Stilgefühls“ ebenso vorgeworfen wie ein überschaubares ästhetisches Sensorium: „Seine Intelligenz arbeitet prompt und zuverlässig wie eine nicht allzu komplizierte Maschine", so der Publizist und Schriftsteller Franz Schonauer 1965, „doch graphisch dargestellt, ergäbe das Gesamtresultat seiner kritischen Bemühungen eine erstaunlich flache Kurve. ${ }^{\text {“18 }}$ Bei seinem Angriff auf Reich-Ranicki und dessen „Kritikschablonen ${ }^{419}$ konnte Handke demnach - nicht nur im Kreis seiner Altersgenossen, die sich wie er vom literarischen Establishment und dessen Akteuren abzuheben suchten - „mit dem stillen Einverständnis zahlreicher vorsichtigerer Kollegen und Kolleginnen rechnen“ ${ }^{20}$ Mit den Jahren, in denen die Popularität des Kritikers zusehends über den engeren Kreis des Literaturbetriebs hinaus anwuchs, sollte sich, so der US-amerikanische Germanist Peter Demetz, das „Reich-Ranicki bashing“ gar zu einem „popular sport“, ja zu einem „established literary genre“ entwickeln, das gerade ,among the younger generation" Zustimmung und Verbreitung fand. ${ }^{21}$

Indes ist erneut zu betonen, dass, um nur ein Beispiel zu nennen, mit Hans Christoph Buch und Peter Handke zwei Anwärter im literarischen Feld - Jahrgang 1942 bzw. 1944 - ihre jeweilige Aversion gegen den ,Großkritiker'von gegensätzlichen ästhetischen wie ideologischen Positionen aus artikulierten: Während Buch seine Vorbehalte gegen Reich-Ranickis literaturkritisches „System[ ] der ,schönen Stellen “ ${ }^{\text {222 }}$ mit einer „materialistische[n] Kritik am

16 Hans Christoph Buch: Kritik der kritischen Kritik. Über Roland Barthes. [1969] In: H. C. B.: Kritische Wälder. Essays - Kritiken - Glossen. Reinbek b. Hamburg: Rowohlt 1972, S. 69-75, hier S. 70.

17 Vgl. Wittstock: Marcel Reich-Ranicki (Anm. 15), S. 17. - Wittstock etwa schreibt von ReichRanickis Ziel einer „möglichst effektvolle[n], publizistisch wirksame[n] Kritik“ (ebd., S. 177). Dazu auch ders.: Die Demokratisierung der Literaturkritik. In: Marcel Reich-Ranicki: Kritik als Beruf. Drei Gespräche, ein kritisches Intermezzo und ein Porträt. Hg. v. Peter Laemmle. Frankfurt a. M.: S. Fischer 2002, S. 135-138.

18 Franz Schonauer: Marcel Reich-Ranicki: Literarisches Leben in Deutschland. In: Neue deutsche Hefte (1965), H. 108, S. 161-167, hier S. 164.

19 Handke: Marcel Reich-Ranicki und die Natürlichkeit (Anm. 2), S. 203.

20 Wolf: Autonomie und/oder Aufmerksamkeit? (Anm. 4), S. 53.

21 Peter Demetz: On Marcel Reich-Ranicki. In: German Literature, Jewish Critics. The Brandeis Symposium. Hg. v. Stephen D. Dowden u. Meike G. Werner. Rochester: Camden House 2002, S. 289-302, hier S. 289.

22 Buch: Kritik der kritischen Kritik (Anm. 16), S. 71. 
Strukturalismus“, ${ }^{23}$ namentlich an Roland Barthes, verbindet, fungieren für Handke gerade Barthes' Mythen des Alltags als kulturtheoretischer Bezugspunkt, ja der Semiotiker selbst als Kronzeuge und intellektuelle Instanz für seine Attacke gegen Reich-Ranicki. Im Natürlichkeits-Essay zitiert Handke zustimmend eine Passage des Kapitels „Stumme und blinde Kritik“ aus den Mythen des Alltags, die 1964 in deutscher Übersetzung von Helmut Scheffel in der „edition suhrkamp“ erschienen waren und die Handke ein Jahr darauf in einer „Bücherecke“-Sendung ${ }^{24}$ vorgestellt hatte:

„Warum erklärt die Kritik von Zeit zu Zeit ihre Ohnmacht oder Verständnislosigkeit?“ schreibt Roland Barthes in den Mythen des Alltags: „... es geschieht gewiß nicht aus Bescheidenheit; niemand fühlt sich wohler als jemand, der bekennt, daß er nichts vom Existenzialismus begreift, und niemand ist selbstsicherer als ein anderer, der verschämt eingesteht, daß er nicht das Glück habe, in die Philosophie des Außerordentlichen eingeweiht zu sein ...": das trifft, mit veränderten Themen, auf Reich-Ranicki zu. ${ }^{25}$

23 Ebd., S. 69.

24 Vgl. Peter Handke: „Bücherecke“ vom 11. 10. 1965. In: P. H.: Tage und Werke. Begleitschreiben. Berlin: Suhrkamp 2015, S. 240-248, hier S. 240-243.

25 Handke: Marcel Reich-Ranicki und die Natürlichkeit (Anm. 2), S. 205 f. Die zitierte Passage findet sich in Roland Barthes: Mythen des Alltags. Deutsch v. Helmut Scheffel. Frankfurt a. M.: Suhrkamp 1964, S. 33: „Warum erklärt die Kritik von Zeit zu Zeit ihre Ohnmacht oder ihre Verständnislosigkeit? Es geschieht gewiß nicht aus Bescheidenheit, niemand fühlt sich wohler als jemand, der bekennt, daß er nichts vom Existentialismus begreift, niemand ist ironischer und niemand ist also selbstgewisser als ein anderer, der verschämt eingesteht, daß er nicht das Glück habe, in die Philosophie des Außerordentlichen eingeweiht zu sein“. - Zu Handkes Beschäftigung mit den Mythen des Alltags vgl. bereits N. N.: Handke: Unerschrocken naiv. In: Der Spiegel, Nr. 22, 25. 5. 1970, S. 174-190, hier S. 187; später Christoph Bartmann: Suche nach Zusammenhang. Handkes Werk als Prozeß. Wien: Braumüller 1984, S. 88-92; Otto Lorenz: Die Öffentlichkeit der Literatur. Fallstudien zu Produktionskontexten und Publikationsstrategien: Wolfgang Koeppen - Peter Handke - Horst-Eberhard Richter. Tübingen: Niemeyer 1998, S. 195 f.; Carsten Zelle: Parteinahme für die Dinge. Peter Handkes Poetik einer literarischen Phänomenologie (am Beispiel seiner Journale, 1975-1982). In: Euphorion 97 (2003), H. 1, S. 99-117, hier S. 102. - Auch in einer 1969 erschienenen Kritik hat Handke explizit auf Barthes' Mythen des Alltags hingewiesen: „Godard zeigt, daß auch die Dinge und Phänomene Sprache sind, daß sie etwas ,sagen', wie Roland Barthes es schon in den ,Mythen des Alltags' formulierte, als er das Plakat beschrieb, das einen Afrikaner unter der Trikolore zeigte“ (Peter Handke: Ah, Gibraltar! Die 19. Internationalen Filmfestspiele Berlin 1969. In: DIE ZEIT, Nr. 28, 11. 7. 1969). Peter Hamm: Der neueste Fall von deutscher Innerlichkeit: Peter Handke. In: konkret, Nr. 12, 2. 6. 1969, S. 42-45, hier S. 45, hatte kurz zuvor die Mythen des Alltags gegen Handke in Stellung gebracht: „Was theoretisch zu dem kleinbürgerlich elitären Bewußtsein, das sich in solchen Zeilen ausplappert, zu sagen wäre, hat Roland Barthes in seinen ,Mythen des Alltags' unten den Stichworten ,Das Weder-Noch` und ,Die Tautologie` beschrieben; [...] er hilft sich, ob er politisch oder literarisch argumentiert, immer wieder mit, jener mythologischen Figur, die 
Versucht Handke, seine Einwände gegen den Kritiker durch die Berufung auf Barthes' einschlägige Beobachtungen zu plausibilisieren und zu stützen, sind die Arbeiten von Barthes und Reich-Ranicki für Hans Christoph Buch Symptome eines ähnlichen Problems. ${ }^{26}$

Dass den Angriffen gegen Reich-Ranicki mitunter antisemitische Ressentiments beigemischt waren, die den Holocaust-Überlebenden in besonderer Weise trafen, gehört - das darf an dieser Stelle nicht unterschlagen werden - zur ideologischen Signatur der Jahrzehnte nach dem Ende des Zweiten Weltkriegs, die eminente Ungleichzeitigkeiten in der Reflexion und Aufarbeitung des nationalsozialistischen Erbes offenbarten. ${ }^{27}$ Handkes Attacke gegen Reich-Ranicki in der Lehre der Sainte-Victoire (1980), die auf ein "Getto“ anspielt, in dem der KritikerHund ,jedes Rassenmerkmal verlor[en]" habe, erweist sich vor diesem Hintergrund als hochgradig problematisch. ${ }^{28}$ Die Verwendung des Begriffs dokumentiert

darin besteht, zwei Gegensätze aufzustellen, den einen mit Hilfe des anderen ins Gleichgewicht zu bringen und sie dann beide zu verwerfen' (Barthes); und erst recht sucht er stets Zuflucht bei Tautologien, also bei jenem Verfahren, das darin besteht, dasselbe durch dasselbe zu definieren (ein Film ist ein Film, die Bühne ist die Bühne) und damit das Rationale, das einem Widerstand leistet, zu unterdrücken.“ Auf diese beiden rhetorischen Figuren, „Tautologie“ und „Weder-Noch-Kritik“, hatte Handke: „Bücherecke“ vom 11.10.1965 (Anm. 24), S. 243, in seiner frühen Rundfunkrezension von Barthes' Buch besonders hingewiesen. Zur Kontroverse zwischen Hamm und Handke vgl. Kap. II, Abschnitt „Fronten, Verbündete, Kampfbegriffe“. Nach Otto Lorenz: Pro domo - Der Schriftsteller als Kritiker. Zu Peter Handkes Anfängen. In: Literaturkritik - Anspruch und Wirklichkeit. DFG-Symposion 1989. Hg. v. Wilfried Barner. Stuttgart: Metzler 1990, S. 399-414, hier S. 407, geht Handke von einer „von Wittgensteins Sprachspiel-Konzept und Roland Barthes' Mythen-Theorie instruierten Grundüberzeugung“" aus, wonach „Literatur, die nicht unbedacht mit Sprachkonventionen umgeht, zum ideologiekritischen Werkzeug taugt“; gerade dieses ideologiekritische Potential stellte Hans Christoph Buch dem Semiotiker Barthes jedoch in Abrede.

27 Dazu Wittstock: Marcel Reich-Ranicki (Anm. 15), S. 251-253; Franz Schuh: All you need is love. Notizen und Exzerpte zur (Literatur-)Kritik. In: F. S.: Schreibkräfte. Über Literatur, Glück und Unglück. Köln: DuMont 2000, S. 24-114, hier S. 98-100.

28 Handke: Die Lehre der Sainte-Victoire (Anm. 10), S. 58. - Zum Antisemitismus-Vorwurf gegen Handke vgl. Christian Luckscheiter: Das Blau des Himmels über dem Hôtel Terminus. Peter Handke und der Nachkrieg. In: Peter Handke. Stationen, Orte, Positionen. Hg. v. Anna Kinder. Berlin, Boston: de Gruyter 2014, S. 39-55, hier S. 39 f.; André Müller: „Ein Idiot im griechischen Sinne“. [Gespräch mit Peter Handke.] In: Die Weltwoche, Nr. 35, 30. 8. 2007, S. 52-57, hier S. 56 f. Zur zitierten Stelle in der Lehre auch Wolf: Autonomie und/oder Aufmerksamkeit? (Anm. 4), S. 56 f., Anm. 55. - Irritierend wirkt Handkes Untergriff nicht zuletzt angesichts seiner eigenen insistierenden Auseinandersetzung mit dem Verhältnis von Täterschaft und Opfer gerade in der Langsame-Heimkehr-Tetralogie. Vgl. z. B. Peter Handke: Langsame Heimkehr. Erzählung. Frankfurt a. M.: Suhrkamp 1979, S. 99: „Er [...] war vielleicht schwach, aber ein Nachkomme von Tätern, und sah sich selber als Täter; und die Völkermörder eines Jahrhunderts als Ahnherren.“ - Oder, in den Notizen der späten 1980er Jahre: „Bedenk immer wieder, daß dein Geschichtserlebnis das des Völkermordes an den Juden ist“ (Peter Handke: Gestern unterwegs. 
den Grad der Unversöhnlichkeit, den das Verhältnis zwischen Handke und Reich-Ranicki zu diesem Zeitpunkt erreicht hatte (was die Sache nicht besser macht); umso verstörender ist es, dass Handke vierzehn Jahre später, in seinem vielgelobten Opus magnum Mein Jahr in der Niemandsbucht (1994), erneut in abschätziger Weise auf die Verfolgungserfahrung des Kritikers im Zweiten Weltkrieg Bezug genommen hat.

So mächtig ging das Verstehen um, daß die Meinungsmacher in den Zeitungen für Deutschland mit ihrer Hirnschwellsprache fürs erste hinter ihren Büroscheiben tonlos allein blieben und mein einstiger Feind, weiter aktiv bei seinem Bücher-Vernehmen und -Ausschnüffeln, für seine Wortspektakel keine Gaffer mehr fand und erstmals, außerhalb seines Ghettos, zu Gängen verurteilt war in die von ihm verabscheute Natur, wo ihm seinesgleichen aus jeder Blume und jedem Busch nichts als die eigene Fratze entgegenstierte. $^{29}$

Reich-Ranicki selbst hat die Praxis mancher Gegner, seine Vergangenheit im Warschauer Ghetto ostentativ hervorzuheben, wiederholt und vehement als Form eines perfiden Antisemitismus kritisiert. ${ }^{30}$ Hier geht es längst nicht mehr

Aufzeichnungen November 1987 - Juli 1990. Salzburg, Wien: Jung und Jung 2005, S. 218). $\mathrm{Zu}$ diesem schwierigen Komplex Hans Höller: Peter Handke. Reinbek b. Hamburg: Rowohlt 2007, S. 106-108.

29 Peter Handke: Mein Jahr in der Niemandsbucht. Ein Märchen aus der neuen Zeit. Frankfurt a. M.: Suhrkamp 1994, S. 929 f. - Vgl. Volker Hage: Das Zittern der Gräser. In: Der Spiegel, Nr. 45, 7.11.1994, S. 242-243, hier S. 243: „Als wäre nicht ohnehin deutlich, wer dieser Kritiker [...] sein soll, gibt es - nicht zum erstenmal bei Handke - eine überflüssige Anspielung auf Marcel Reich-Ranickis Prägung durch das Warschauer Ghetto.“ - Dazu Uwe C. Steiner: Literatur als Kritik der Kritik. Die Debatte um Peter Handkes Mein Jahr in der Niemandsbucht und die Langsame Heimkehr. In: Deutschsprachige Gegenwartsliteratur (Anm. 7), S. 127-169, hier S. 146-148.

30 Vgl. N. N.: „Mir soll der Mund verboten werden“. Marcel Reich-Ranicki über seine Popularität, sein Selbstverständnis und die Vorwürfe gegen ihn. In: Süddeutsche Zeitung, 17. 6. 1994: „Wenn es heißt, ,Der Jude und Kritiker, vom Ghetto geprägt fürs ganze Leben', dann ist das schon, Stürmer“. Vgl. auch die Kritik von Jochen Hieber: Staunen und Raunen. Peter Handkes neuer Roman und die deutsche Literaturkritik. In: Frankfurter Allgemeine Zeitung, 19. 1. 1995: „Handkes Haßsprache, die im Roman und im Zusammenhang mit Reich-Ranicki auch fahrlässig und infam den Begriff ,Ghetto verwendet, fand vor kurzem in einem Interview des Autors im ,Stern' einen Tiefpunkt, der an schlimmste deutsche Zeiten erinnert: ,weil man dem nichts übelnehmen kann', steht da über den ,Feind' zu lesen, ,weil er selber das Grundübel ist'. Die nationalsozialistische Kampfpresse benutzte das Wort beständig: ,Der Jude ist das Grundübel der Welt.““ Die Passage im stern, auf die Hieber rekurriert, lautete folgendermaßen: „In der ,FAZ` wurde ein Jahrzehnt lang jedes einzelne meiner Bücher zerfleddert wie von Strauchdieben. Und er war der Oberstrauchdieb. [...] Ich nehme das den ,FAZ'-Leuten fast noch übler als ihm, weil man dem nichts übelnehmen kann, weil er selber ein Grundübel ist. Als er selber nicht 
um die Sache der Literatur, um die Verteidigung poetischer Verfahren gegen einen unverständigen oder missliebigen Kritiker; vielmehr verweisen Beispiele wie diese auf die Bereitschaft zur sprachlichen Eskalation, die in öffentlichen Debatten allenthalben und zum Schaden aller Beteiligten anzutreffen ist.

\section{Poetik und Polemik oder: Das Problem der ,Natürlichkeit‘}

Anhand des Essays Marcel Reich-Ranicki und die Natürlichkeit lässt sich zeigen, dass Handkes Polemiken gegen die gängige Praxis der Literaturkritik nicht bloß als Zurückweisung ablehnender, weil ästhetisch , unsensibler' Urteile über seine Bücher zu verstehen sind. Sie haben darüber hinaus eine wichtige Funktion sowohl für die poetologische Selbstreflexion als auch - mit Gérard Genette gesprochen - für die Sicherstellung einer „relevanteren Lektüre “31 seiner eigenen Texte. Handkes Einspruch gegen bestimmte Verfahren der Kritik und seine Forderungen an eine neue, der zeitgenössischen Literatur adäquate Beschreibung von avancierten Texten sind stets mit seinen Überlegungen zur Ästhetik des literarischen Schreibens selbst, zumal des eigenen Schreibens, verknüpft. Aus dieser Warte erhalten Handkes Einwände gegen Reich-Ranicki als Person, als „unwichtigste[n], am wenigsten anregende[n], dabei am meisten selbstgerechte[n] deutsche[n] Literaturkritiker seit langem “ ${ }^{32}$ erst im Verbund mit den parallel dazu formulierten Einwänden gegen die von Reich-Ranicki propagierte literarische Ästhetik und deren Akteure ihre volle polemische Sprengkraft. ${ }^{33}$

Es liegt nahe, Handkes pointierte Besprechung von Reich-Ranickis Literatur der kleinen Schritte in den manuskripten nicht zuletzt als Fortführung und Zuspitzung früherer essayistischer Positionen zu beschreiben. ${ }^{34}$ Zentrale Aspekte

mehr schrieb, haben sich, FAZ'-Leute dazu hergegeben, in seinen Diensten meine Bücher anzufaulen. Nie werde ich ihm auch nur das Kleinste verzeihen können.“ (Sven Michaelsen: „Ab und zu sticht mich ein Teufelchen“. [Gespräch mit Peter Handke.] In: stern, Nr. 52, 22. 12. 1994, S. 124-130, hier S. 126)

31 Gérard Genette: Paratexte. Das Buch vom Beiwerk des Buches. Mit einem Vorwort v. Harald Weinrich. Frankfurt a. M.: Suhrkamp 2001, S. 10.

32 Handke: Marcel Reich-Ranicki und die Natürlichkeit (Anm. 2), S. 206.

33 Vgl. dazu grundlegend Lorenz: Die Öffentlichkeit der Literatur (Anm. 25), S. 194-197.

34 Vor allem in Zur Tagung der Gruppe 47 in USA (1966) und Ich bin ein Bewohner des Elfenbeinturms (1967), aber auch in den Rundfunkessays für die Sendung „Bücherecke“ des Landesstudios Steiermark aus den Jahren 1964 bis 1966. Karl Wagner: Handkes Arbeit am 19. Jahrhundert: Roman- und Realismuskritik. In: Die Dinge und die Zeichen. Dimensionen des Realistischen in der Erzählliteratur des 19. Jahrhunderts. Hg. v. Sabine Schneider u. Barbara Hunfeld. Würzburg: Königshausen \& Neumann 2008, S. 403-412, hier S. 408, hat Marcel Reich-Ranicki und die Natürlichkeit als „nachgereichte[ ] Polemik“ zu Handkes in Princeton lancierten Argumenten bezeichnet. 
wie die Diagnose einer Abnützung literarischer Verfahren durch „Wiederholung und Verbrauch“" ${ }^{35}$ die deutlich auf die theoretischen Konzepte des russischen Formalismus (v. a. Boris Eichenbaum und Viktor Šklovskij) rekurriert, ${ }^{36}$ und die Problematisierung der Fallstricke, realistischen' Schreibens sind hier wie dort von entscheidender Bedeutung. Hatte Handke zunächst vergleichsweise abstrakt den Zusammenhang zwischen literarischer, Manier' und literaturkritischer Unbedarftheit ins Visier genommen, um deren jeweilige Klischees aufzudecken, steht im Natürlichkeits-Essay mit Marcel Reich-Ranicki ein prominenter Vertreter jener „normative[n] Literaturauffassung“ im Fokus, der der Autor schon in Ich bin ein Bewohner des Elfenbeinturms (1967) vorgeworfen hatte, avancierten literarischen Verfahren nicht gerecht werden zu können. ${ }^{37}$

Seiner einleitend formulierten Absicht, den Kritiker nicht „beschimpfen“, sondern vielmehr auf dessen „kritische[ ] Modelle [...] aufmerksam“ machen zu wollen, ${ }^{38}$ bleibt Handke in der Folge weitgehend treu, obschon die Idee einer analytischen Durchdringung mitunter von polemischen Volten unterlaufen wird. Am Beispiel der ,Natürlichkeit', die er als eines von Reich-Ranickis „heftiggebrauchten Lobeswörter[n] “ registriert, führt Handke - auch hier geschult an Šklovskij und Eichenbaum - die Aporien eines naiven Realismusverständnisses, wie er es dem Kritiker attestiert, vor:

Daß auch die realistische Methode nicht Natur, sondern gemachtes Modell ist, daß sie am Beginn ihrer Verwendung gekünstelt und gebastelt gewirkt hat und nur durch den Gebrauch und die Gewöhnung natürlich erscheint, will er nicht merken. [...] ReichRanicki will es nicht merken, daß jede literarische Methode, solange sie noch etwas taugt, künstlich erscheint, indem sie sowohl den Vorgang des Schreibens als auch das Geschriebene als Gemachtes, Nicht-Natürliches, als Gegenwirklichkeit, in jedem Moment kenntlich macht: er hält einen richtigen erzählenden Satz, niedergeschrieben, für das natürlichste Ding auf der Welt; aber einen Satz, der, niedergeschrieben,

35 Handke: Marcel Reich-Ranicki und die Natürlichkeit (Anm. 2), S. 204.

36 Vgl. dazu Michael Linstead: Outer World and Inner World. Socialisation and Emancipation in the works of Peter Handke, 1964-1981. Frankfurt a. M. u. a.: Lang 1988, S. 19-27; Garvin H. C. Perram: Peter Handke. The Dynamics of the Poetics and the Early Narrative Prose. Frankfurt a. M. u. a.: Lang 1992, S. 66, 80, 113-116, 129 u. 249-254; vgl. zuletzt auch Harald Gschwandtner: Peter Handkes epitextuelle Werkpolitik. In: Paratextuelle Politik und Praxis. Interdependenzen von Werk und Autorschaft. Hg. v. Martin Gerstenbräun-Krug u. Nadja Reinhard. Wien u. a.: Böhlau 2018, S. 271-292, bes. S. 276-279. Handke hatte sich in den „Bücherecke“-Sendungen vom 11.10.1965 und 17.1.1966 mit großem Interesse auf Šklovskij, Eichenbaum und Roman Jakobson berufen. Vgl. Handke: Tage und Werke (Anm. 24), S. 243 f. u. 264.

37 Peter Handke: Ich bin ein Bewohner des Elfenbeinturms. [1967] In: P. H.: Ich bin ein Bewohner des Elfenbeinturms (Anm. 2), S. 19-28, hier S. 26.

Handke: Marcel Reich-Ranicki und die Natürlichkeit (Anm. 2), S. 203. 
kenntlich macht, daß ein richtiger erzählender Satz, kaum niedergeschrieben, das künstlichste Ding auf der Welt ist, beschimpft er als „modernistisch“, obwohl doch gerade dieser Satz vom natürlichsten Ding auf der Welt redet. ${ }^{39}$

Jene Literatur, die Reich-Ranicki als ,natürlich` oder ,realistisch' beschreibe und bevorzuge, mache keineswegs ,eine Wirklichkeit [...] sichtbar“;" vielmehr werde, so Handke, „die Verlogenheit einer sich als natürlich gebenden Literatur“ kenntlich, „die jeden Satz als naturgegeben hinnimmt ${ }^{\text {“41 }}$ und die linguistische Unterscheidung von signifié und signifiant, von Bezeichnetem und Bezeichnendem, geflissentlich ignoriert: „Es wird nämlich verkannt, daß die Literatur mit der Sprache gemacht wird, und nicht mit den Dingen, die mit der Sprache beschrieben werden“, hatte er bereits 1966 im Anschluss an die Princetoner Tagung sowohl den Autoren als auch den Kritikern zum Vorwurf gemacht. ${ }^{42}$ Reich-Ranicki war für ihn schon damals ein charakteristischer, wenn nicht der charakteristische Vertreter dieser Haltung.

Zwei Jahre später beschreibt Handke den Kritiker nun als Agenten einer unterkomplexen Vorstellung von Literatur, der zudem auf ungebührliche Weise mit seiner theoretischen Unbedarftheit kokettiere:

Reich-Ranicki kann man mit Einwänden nicht kommen: er kennt die alte List, sich dumm zu stellen, weil er nicht argumentieren kann. [...]. „Ich gestehe“, leitet er dann in der Regel seine Sätze ein. Nachdem er aber seine Verständnislosigkeit eingestanden hat, zieht er über das Nichtverstandene her. ${ }^{43}$

Handke verweist hier auf eine taktische Finte des Kritikers, eine Rhetorik, die schon Roland Barthes in den Mythen des Alltags ins Visier genommen hatte:

$[\mathrm{M}]$ an hält sich für so intelligent, daß das Eingeständnis des Nichtverstehens die Klarheit des Autors in Frage stellt, nicht aber die der eigenen Vernunft. Man spielt Beschränktheit, und das geschieht, um das Publikum leichter zum protestierenden Aufschreien zu bewegen und es so auf vorteilhafte Weise von einer Gemeinsamkeit der Ohnmacht zu einer solchen des Einverständnisses zu bringen. ${ }^{44}$

39 Ebd., S. 204f. Zum Aspekt der ,Natürlichkeit‘ bei Reich-Ranicki vgl. Franz Josef Czernin: Marcel Reich-Ranicki. Eine Kritik. Göttingen: Steidl 1995, S. 60; Jan Wiele: Poetologische Fiktion. Die selbstreflexive Künstlererzählung im 20. Jahrhundert. Heidelberg: Winter 2010, S. 202.

40 Handke: Marcel Reich-Ranicki und die Natürlichkeit (Anm. 2), S. 205.

41 Ebd.

42 Handke: Zur Tagung der Gruppe 47 in USA (Anm. 11), S. 29.

43 Handke: Marcel Reich-Ranicki und die Natürlichkeit (Anm. 2), S. 205.

Barthes: Mythen des Alltags (Anm. 25), S. 33. 
Ein Beispiel dafür findet sich auch in Reich-Ranickis Statement nach Handkes Princetoner Lesung aus dem Manuskript des Hausierers: Den Hinweis eines Vorredners auf die Bedeutung des Grazer ,Forum Stadtpark' für die literarische Sozialisation Handkes konterte der Kritiker süffisant mit dem Geständnis, er sei „kein Kenner des Grazer Inventionismus“, um angestachelt durch Gelächter aus dem Publikum hinzuzufügen: „Ich gebe zu, dass mir die Theorie dieses Grazer Inventionismus nur sehr oberflächlich bekannt ist. ${ }^{\text {“ }}{ }^{45}$ Noch vier Jahrzehnte später sollte Handke in einer Laudatio auf Jürgen Becker diese rhetorische Operation, ohne den Namen Reich-Ranickis zu nennen, als Untugend der Literaturkritik verzeichnen: „Ein letztes Mal jetzt noch ,der Kritiker‘: Zu dessen Rolle gehört es, oder hat es gehört, sein Sichmokieren, Ablehnen, Nichtverstehen einzuleiten mit einem ,Ich gestehe. “ ${ }^{46}$ Reich-Ranickis gerne für sich in Anspruch genommene Sentenz, die er in Die Literatur der kleinen Schritte seinem Aufsatz über Friedrich Sieburgs „exemplarisches Scheitern als Literaturkritiker“ vorangestellt hatte - „Ein Literaturkritiker, der etwas taugt, ist immer eine umstrittene Figur ${ }^{\text {47 }}$-, quittiert Handke am Ende seines Essays mit der spielerischen Freude des Polemikers: „Von mir aus ist Reich-Ranicki unumstritten. “ ${ }^{48}$

Bemerkenswert ist freilich, dass Reich-Ranicki Handkes Essay kurze Zeit später, 1970, als einzigen ,Fremdtext' in seine programmatisch zu verstehende Sammlung Lauter Verrisse aufnahm. ${ }^{49}$ Es dürfte, so Reich-Ranickis Biograph Uwe Wittstock, in der Geschichte der Literatur tatsächlich „nur selten den Fall gegeben haben, dass ein Autor eine derartige fundamentale Polemik gegen die

45 Audioaufzeichnung Princeton 1966 (Anm. 1), Lesung Handke, Wortmeldung Reich-Ranicki, 37:20-37:35. Dazu auch Reich-Ranickis nachträgliche Skepsis im Hinblick auf die Wirkung der österreichischen Avantgarde-Strömungen nach 1945: „Gerhard Rühm und Oswald Wiener und die Grazer Gruppe. Ich weiß schon, das sind dringend nötige, wichtige Erscheinungen der Gegenwartsliteratur. Aber so sehr viel ist daraus nicht geworden, glaube ich." (Marcel ReichRanicki: Der doppelte Boden. Ein Gespräch mit Peter von Matt. Zürich: Ammann 1992, S. 142)

46 Peter Handke: Gurken und Kiefern, Äpfel und Schnee. Zu Jürgen Becker. In: Sinn und Form 58 (2006), H. 6, S. 800-807, hier S. 803; wieder abgedruckt in: P. H.: Meine Ortstafeln. Meine Zeittafeln. 1967-2007. Frankfurt a. M.: Suhrkamp 2007, S. 272-279, hier S. 275. Vgl. dazu auch Michaelsen/Handke: „Ab und zu sticht mich ein Teufelchen“ (Anm. 30), S. 128: „Aber er ist so stolz auf seine Beschränktheit. Das ist der Skandal.“

47 Marcel Reich-Ranicki: Friedrich Sieburg: Verloren ist kein Wort und Nicht ohne Liebe. In: M. R.-R.: Literatur der kleinen Schritte. Deutsche Schriftsteller heute. München: Piper 1967, S. $247-256$, hier S. 255 u. 247 .

48 Handke: Marcel Reich-Ranicki und die Natürlichkeit (Anm. 2), S. 207. Zum Problem der ,unumstrittenen' Instanz Reich-Ranicki vgl. Schuh: All you need is love (Anm. 27), S. 62 f. u. 70 f.

49 Vgl. Peter Handke: Marcel Reich-Ranicki und die Natürlichkeit. In: Marcel Reich-Ranicki: Lauter Verrisse. Mit einem einleitenden Essay. München: Piper 1970, S. 167-171; in der „[e]rweiterte[n] Neuausgabe" von Lauter Verrisse aus dem Jahr 1984 fehlt Handkes Polemik; stattdessen findet sich darin nun die vernichtende Besprechung von Handkes Erzählung Die linkshändige Frau (1976). 
eigene Arbeit“ so „bereitwillig weiterverbreitet hat", ${ }^{\text {"50 }}$ ohne sie im Zuge dessen durch eine entschiedene Gegendarstellung einzuhegen und zu entkräften. In der ausführlichen Einleitung des Bandes begründet Reich-Ranicki seine Entscheidung folgendermaßen:

Ein Gebot der Fairness schien es mir daher, diese Sammlung, die achtzehn Verrisse enthält, mit einem Verriß meiner eigenen Arbeit abzuschließen: Ich habe (wenn auch nicht ohne Überwindung) den schärfsten und radikalsten ausgewählt, den ich finden konnte. Peter Handke und dem Suhrkamp-Verlag sei für die Abdruck-Genehmigung bestens gedankt. ${ }^{51}$

Noch in seiner 1999 erschienenen Autobiographie Mein Leben hat Reich-Ranicki die Aufnahme von Handkes „schärfste[r] und radikalste[r] kritische[r] Verurteilung meiner eigenen Arbeit“ in den Band Lauter Verrisse als „Beitrag zum Gespräch über deutsche Literatur und Kritik in jenen Jahren “ bezeichnet. ${ }^{52}$ Eine Deutung, wonach „Reich-Ranickis Feindschaft“ gegenüber Handke auf dessen „Satire über das naive Realismus- und Natürlichkeitsgetue des Starkritikers zurück[gehe] “53 verschreibt sich vor diesem Hintergrund zu stark der Perspektive des Schriftstellers, obschon das vermeintliche Diskussionsangebot des ,Großkritikers' hier wohl zuallererst dessen souveräne Position der Stärke demonstrieren sollte: Nur wer sich seiner Sache ausreichend sicher ist, lässt seinen Widersacher auf diese Weise als Gegenstimme zu Wort kommen. An Selbstbewusstsein mangelte es dem Kritiker jedenfalls nicht.

Zuletzt ist auch folgendes Detail in Lauter Verrisse zu erwähnen, das ein etwas anderes Licht auf die ,Bereitwilligkeit' des Kritikers wirft: Im Dezember 1967 hatte Reich-Ranicki in einer Rezension von Martin Walsers Die Zimmerschlacht angemerkt, Walser habe „jene Konsequenz gefehlt, die man einem Bühnenautor wie Peter Handke nicht absprechen kann“, was man mit einigem guten Willen als positive Resonanz auf Handkes Theaterarbeiten deuten kann. ${ }^{54}$ Im Wiederabdruck der Besprechung von 1970 jedoch ergänzte der Kritiker die Passage um eine Parenthese, die die Distanz zu Handke betont: Walser habe „jene Konsequenz gefehlt“, heißt es nun, „die man einem Bühnenautor wie Peter Handke, was immer man von seinen Arbeiten denken mag, nicht absprechen kann“. ${ }^{\text {" }}$

50 Wittstock: Marcel Reich-Ranicki (Anm. 15), S. 250 f.

51 Marcel Reich-Ranicki: Nicht nur in eigener Sache. Bemerkungen über Literaturkritik in Deutschland. In: M. R.-R.: Lauter Verrisse (Anm. 49), S. 7-45, hier S. 45.

52 Marcel Reich-Ranicki: Mein Leben. Stuttgart: DVA ${ }^{3} 1999$, S. 444.

53 Höller: Peter Handke (Anm. 28), S. 45 f.

54 Marcel Reich-Ranicki: War es ein Mord? Martin Walsers Zimmerschlacht in München inszeniert von Fritz Kortner. In: DIE ZEIT, Nr. 50, 15.12.1967.

Reich-Ranicki: Lauter Verrisse (Anm. 49), S. 146. 
Reich-Ranickis fast durchwegs negative Rezensionen zu Handkes Büchern - eine Ausnahme bildete sein wohlwollender Kommentar zum Versuch über den geglückten Tag (1991) im Literarischen Quartett, und auch die Tormann-Erzählung (1970) und den Kurzen Brief zum langen Abschied (1972) scheint er einigermaßen geschätzt zu haben $^{56}$ - waren zwar von persönlicher Antipathie geprägt, die durch die Widerreden des Autors noch zusätzlich Nahrung erhielt. Sie können aber, wie mir scheint, kaum auf die polemische ,Urszene' des Jahres 1968 reduziert werden, zumal der Kritiker diese recht abgeklärt zu entschärfen verstanden hatte. Obschon auf einem persönlichen Konflikt fußend, der mit der ersten Konfrontation in Princeton 1966 seinen Ausgang nahm, sind Reich-Ranickis Verrisse von Handkes Texten doch einem bestimmten, gleichwohl zu dieser Zeit ästhetisch überholten Konzept von Literatur verpflichtet, das ihm auch in anderen Fällen - und zum Missfallen zahlreicher Autorinnen und Autoren - als Maßstab seiner Kritiken diente. ${ }^{57}$ Franz Josef Czernin hat dies, selbst ohne besondere Sympathie für Handkes „Gegenpolemik“ ${ }^{“ 58}$ Mitte der 1990er Jahre mit wenig schmeichelhaftem Unterton pointiert zusammengefasst:

Reich-Ranickis Kritiken sind viel systematischer, als er ahnt und wissen will; seine Form literaturkritischer Vernunft hat so viel Methode wie nur irgendein Wahn. Daß er selbst das Systematische häufig als für den Kritiker schädliche Befangenheit bezeichnet, verschlägt dabei nichts. Das ist nur die bezeichnende Geste des antitheoretischen Pragmatikers, der seine Theorieblindheit damit bezahlt, daß er von bestimmten Annahmen geleitet wird, ohne es wahrhaben zu wollen. ${ }^{59}$

56 In seiner Kritik von Wunschloses Unglück bezeichnete Reich-Ranicki 1972 Die Angst des Tormanns beim Elfmeter immerhin als „durchaus beachtlich[ ]“, den Kurzen Brief als zumindest „stellenweise virtuos[ ]“ (Marcel Reich-Ranicki: Die Angst des Peter Handke beim Erzählen. In: DIE ZEIT, Nr. 37, 15. 9.1972).

57 Perram: Peter Handke (Anm. 36), S. 74, hat dies auf eine wohl zu einfache Formel gebracht: „Marcel Reich-Ranicki's critiques are conservative; his favourite target is the avant-garde." Überzeugender scheint hingegen seine kurz darauf formulierte Einschätzung des Kritikers: „Handke does fail to point out that Reich-Ranicki is in many ways an astute critic. Much of what he has to say about literature demonstrates his ability to accurately perceive the nature and complexity of a work. However, this obvious ability tends to dangerously obscure the fact that he has subordinated his perception to a rigid, and in many ways, outmoded system of criticism and evaluation." (Ebd., S. 79) - Vgl. dagegen Lorenz: Die Öffentlichkeit der Literatur (Anm. 25), S. 19, der betont, Reich-Ranicki habe als Literaturkritiker „entschieden subjektiv“ geurteilt, „dabei aber keinen festen literarästhetischen Standpunkt“ eingenommen; ebenso argumentieren Volker Hage/Mathias Schreiber: Marcel Reich-Ranicki. Köln: Kiepenheuer \& Witsch 1995, S. 115: „Ein geschlossenes System, eine umfassende Theorie wird man bei ihm nicht finden. Damit möchte er auch gar nicht dienen."

58 Czernin: Marcel Reich-Ranicki (Anm. 39), S. 53. Handke biete als Gegenentwurf zu den „Klischees Reich-Ranickis vor allem eine Reihe von Antithesen“ auf, „die insofern selbst klischeehaft sind, als sie als unvermittelte Behauptungen jenen Reich-Ranickis einfach entgegengesetzt werden" (ebd.). Ebd., S. 18. 
Dass das problematische Verhältnis zwischen Autor und Kritiker mit der gönnerhaften Geste Reich-Ranickis, d. h. dem Abdruck von Handkes Essay in Lauter Verrisse, keineswegs in Entspannung übergegangen, sondern bestenfalls ein zeitweiliger Waffenstillstand erreicht worden war, sollte sich bald zeigen. Habituelle Prägungen wie literaturästhetische Positionen der beiden Kontrahenten erwiesen sich weiterhin als inkompatibel: Weder hatte sich an Handkes Aversion gegen die von Reich-Ranicki verkörperte, traditionellen Realismuskonzepten verpflichtete Literaturkritik etwas geändert, noch an Reich-Ranickis Ablehnung betont autoreflexiver Schreibweisen, wie sie Handke zu dieser Zeit in immer neuen Anläufen erprobte. Obschon der Autor Ende der 1960er Jahre allmählich von den experimentellen Schreibverfahren früherer Prosa- und Theaterarbeiten Abstand nahm, ja seinem Verleger Unseld Die Angst des Tormanns beim Elfmeter (1970) gar als „klassische[ ] ruhige[ ] Prosa, wie Kleist oder Stifter “60 ankündigte, spielte die offene Reflexion und Thematisierung der eigenen literarischen Verfahren weiterhin eine wichtige Rolle in Handkes Texten. Ein zentrales Element seiner Poetik sei es, so Handke 1974 im Gespräch mit Günther Nenning, nicht nur die Verwendung von Sätzen und Satzmodellen im Schreibprozess kritisch zu reflektieren, sondern „die Reflexion“ auch „zugleich mit dem Satz" explizit vorzuführen. ${ }^{11}$ Reich-Ranicki hingegen waren, wie selbst Thomas Anz in seiner weitgehend hagiographischen Darstellung des Kritikers konstatiert, „[p]oetologische Metareflexionen“ ganz grundsätzlich „verhasst“62 - eine fundamentale Diskrepanz im Literaturverständnis der beiden Akteure, die bei nächster Gelegenheit zu neuen Konfrontationen führen sollte.

\section{Die „ästhetischen Gewissensbisse“ des Peter Handke (Wunschloses Unglück)}

Am 15. September 1972 veröffentlichte die ZEIT mit der Besprechung von Wunschloses Unglück - unter dem prägnanten Titel Die Angst des Peter Handke beim Erzählen - Reich-Ranickis erste Printrezension eines Buches des mittlerweile 29-jährigen Autors; an ihr lassen sich die skizzierten Konfliktlinien beispielhaft nachvollziehen. Handke hatte die Erzählung Anfang des Jahres unter dem Eindruck des Freitods seiner Mutter niedergeschrieben: Er habe sich, so die bekannte

60 Peter Handke an Siegfried Unseld, 20.5. 1968. In: Peter Handke/Siegfried Unseld: Der Briefwechsel. Hg. v. Raimund Fellinger u. Katharina Pektor. Berlin: Suhrkamp 2012, S. 93.

61 Günther Nenning: „Schreiben, intensiv wie im Traum!“ [Gespräch mit Peter Handke.] In: Neue Freie Presse (1974), H. 8, S. 7.

62 Anz: Marcel Reich-Ranicki (Anm. 15), S. 159. - Stephan Porombka: Gemengelagen lesen. Plädoyer für einen kulturwissenschaftlichen Umgang mit Literaturkritik. In: Zeitschrift für Germanistik. N. F. 15 (2005), H. 1, S. 109-121, hier S. 113, Anm. 22, spricht mit Blick auf Anz' Reich-RanickiBiographie von einem „die Autobiographie des Kritikers paraphrasierende[n] Portrait“. 
Wendung zu Beginn des Buches, „an die Arbeit machen“ wollen, „bevor das Bedürfnis, über sie zu schreiben, das bei der Beerdigung so stark war, sich in die stumpfsinnige Sprachlosigkeit zurückverwandelt, mit der ich auf die Nachricht von dem Selbstmord reagierte. “63 Überzeugt davon, dass die „Darstellung eines Frauenlebens“ nur mittels der „Bewusstmachung der Schablonen, mit denen eine Vita produziert wird“, 64 gelingen kann, beschreibt der Ich-Erzähler das Problem einer Literarisierung biographischer Realität als beständige „Gefährdung seines literarischen Unternehmens“, ${ }^{\text {" w }}$ weil man sich „auf der Suche nach Formulierungen“ schon zwangsläufig „von den Tatsachen“ entferne:

Nun ging ich von den bereits verfügbaren Formulierungen, dem gesamtgesellschaftlichen Sprachfundus aus statt von den Tatsachen und sortierte dazu aus dem Leben meiner Mutter die Vorkommnisse, die in diesen Formeln schon vorgesehen waren; denn nur in einer nicht-gesuchten, öffentlichen Sprache könnte es gelingen, unter all den nichtssagenden Lebensdaten die nach einer Veröffentlichung schreienden herauszufinden. ${ }^{66}$

Erst über den dabei konstatierten Grad der Abweichung vom etablierten narrativen Schema werde, so die Argumentation, die individuelle Prägung des einzelnen Lebens erkenn- und damit auch beschreibbar: „Ich vergleiche also den allgemeinen Formelvorrat für die Biographie eines Frauenlebens satzweise mit dem besonderen Leben meiner Mutter; aus den Übereinstimmungen und Widersprüchlichkeiten ergibt sich dann die eigentliche Schreibtätigkeit. ${ }^{\text {“67 }}$ Das ostentative „Vermeiden der üblichen Phraseologie ${ }^{\text {“68 }}$ biographischen Schreibens wird so zum Leitprinzip von Handkes Wunschlosem Unglück.

Diesem selbstreflexiven, die Bedingungen des Schreibens fortwährend hinterfragenden literarischen Verfahren vermochte Reich-Ranicki nur wenig abzugewinnen; von einer „beinahe lobenden Rezension“" ${ }^{69}$ kann, denke ich, kaum

63 Peter Handke: Wunschloses Unglück. Erzählung. Salzburg, Wien: Residenz 1972, S. 7.

64 Wagner: Handkes Arbeit am 19. Jahrhundert (Anm. 34), S. 409.

65 Peter Pütz: Peter Handke. Frankfurt a. M.: Suhrkamp 1982, S. 54; vgl. auch Renner: Peter Handke (Anm. 13), S. 85, sowie zur Gesamtanlage von Wunschloses Unglück Volker Bohn: „Später werde ich über das alles Genaueres schreiben“. Peter Handkes Erzählung Wunschloses Unglück aus literaturtheoretischer Sicht. In: Germanisch-Romanische Monatsschrift 26 (1976), S. 356-379.

66 Handke: Wunschloses Unglück (Anm. 63), S. $42 \mathrm{f}$.

67 Ebd., S. 43. Dazu die immer noch erhellende Deutung bei Pütz: Peter Handke (Anm. 65), S. 55.

68 Werner M. Bauer: Die deutschsprachige Literatur Österreichs nach 1945. In: Literaturgeschichte Österreichs von den Anfängen im Mittelalter bis zur Gegenwart. Hg. v. Herbert Zeman. Graz: Akademische Druck- und Verlagsanstalt 1996, S. 511-563, hier S. 552.

69 Clemens Özelt: Klangräume bei Peter Handke. Versuch einer polyperspektivischen Motivforschung. Wien: Braumüller 2012, S. 94, Anm. 247. 
die Rede sein. ${ }^{70}$ Nicht nur attestiert er dem Autor in einem Schnelldurchlauf durch das bisherige Euvre, mit Die Hornissen und Der Hausierer im Grunde „indiskutable Prosa“ vorgelegt zu haben, sondern konstatiert auch ein Scheitern seines aktuellen Erzählprojekts, das nach dem Kurzen Brief zum langen Abschied (1972), „seinem auf jeden Fall besten Buch", schritt in Handkes künstlerischer Entwicklung darstelle: Der Autor habe sich, so Reich-Ranicki, zwar mittlerweile von seiner früheren „hochgestochene[n] Wichtigtuerei" verabschiedet, seine Texte litten gleichwohl noch immer an einem Übermaß unfruchtbaren „Theoretisieren[s]“: „[I]mmer wieder" zeigten sich in Wunschloses Unglück „allerlei Hemmungen und Skrupel eines Schriftstellers“, "der leider allzuviel theoretisiert und der sich offenbar sehr ängstigt, was er schreibt, könne als unmodern abgetan werden. ${ }^{\text {“72 }}$ Dementsprechend stößt sich der Kritiker gerade an jenen metanarrativen Passagen der Erzählung, die seine Hoffnung, Handke sei nun (endlich) „, an einer mehr oder weniger realistischen Schilderung gelegen“, nur zu deutlich enttäuschen mussten. ${ }^{73}$ Nimmt man die abschließende Wendung der Rezension in den Blick, kann sie freilich auch in toto als verspätete - und im Vergleich zum selbstbewussten Wiederabdruck 1970 weniger konziliante - Antwort auf Handkes Natürlichkeits-Essay verstanden werden. In einer für seine literaturkritische Praxis typischen Verquickung von Autor-Psychologie und bildungsbürgerlichem Klassiker-Zitat ${ }^{74}$ konstatiert Reich-Ranicki im letzten Absatz:

Wenn er nur seine ästhetischen Gewissensbisse und seine vielen theoretischen Hemmungen überwinden wollte und unverkrampft und natürlich erzählen könnte. Denn

70 Vgl. dazu, mit genauem Blick auf die konträren ästhetischen Positionen der beiden Akteure, Perram: Peter Handke (Anm. 36), S. 77: „Reich Ranicki's critique of Handke's Wunschloses Unglück [...] contains ample material to justify Handke's attack on Reich-Ranicki's critical method.“

71 Reich-Ranicki: Die Angst des Peter Handke beim Erzählen (Anm. 56). In den Sammelband Entgegnung. Zur deutschen Literatur der siebziger Jahre (1979) hat Reich-Ranicki die Rezension unter dem leicht abweichenden Titel Die Angst des Dichters beim Erzählen (S. 315-322) aufgenommen.

72 Reich-Ranicki: Die Angst des Peter Handke beim Erzählen (Anm. 56). Werner Graf: Peter Handke und seine Kritiker. Zu Motiven der Rezeption von Gegenwartsliteratur. In: Literatur für Leser 27 (2004), H. 2, S. 89-101, hier S. 95, der an mancher Stelle zu emphatisch Partei für Handke ergreift, spricht allgemein von einer verbreiteten „Theoriefeindlichkeit“ der HandkeRezeption im Feuilleton.

73 Reich-Ranicki: Die Angst des Peter Handke beim Erzählen (Anm. 56).

74 Reich-Ranickis Anspielung auf die letzte Strophe von Schillers Bürgschaft könnte auch als Replik auf die adaptierte Gretchen-Frage in Handkes Essay gedeutet werden, wo es heißt: „Zu seinen wohl wichtigsten Kritikschablonen gehören die normativen Sätze über die Wirklichkeit: die Prüfungsfrage für die Schriftsteller lautet: ,Nun sag, wie hast du's mit der Wirklichkeit?"“ (Handke: Marcel Reich-Ranicki und die Natürlichkeit [Anm. 2], S. 203) 
die Natürlichkeit, sie ist doch kein leerer Wahn. Nur daß in der Literatur die Natürlichkeit nicht von selber kommt. Sie setzt viel Arbeit voraus und etwas Mut. ${ }^{75}$

Die Rezension bestätigt damit nicht zuletzt Handkes einstige Beobachtung, wonach der Kritiker „[f] ormalistische Methoden beim Schreiben“ grundsätzlich „nicht gelten“ lasse: „Er hält sie nicht für Probleme der Literatur“, so Handke 1968 in den manuskripten, „sondern für private Schwierigkeiten des Literaten, mit denen, der Leser" nicht behelligt werden möchte. ${ }^{\text {"76 }}$ Reich-Ranickis autoritativer Fingerzeig an Handke, wonach „in der Literatur die Natürlichkeit nicht von selber“ komme, ja „viel Arbeit“ und „etwas Mut“ erfordere, illustriert die rhetorische Finesse des Kritikers, kontert er doch Handkes Vorwurf von 1968, er könne Literatur nur als „etwas Entstandenes“, nicht aber als „etwas Gemachtes“ begreifen, ${ }^{77}$ gerade durch den Hinweis auf die mangelnde literarische Kunstfertigkeit des Autors: „Die Pointe dieser Polemik besteht darin, dass gerade die ästhetische Verweigerung gegenüber dem Erwartungshorizont eines an Formexperimenten uninteressierten Publikums als mutlos gescholten wird. ${ }^{\text {“78 }}$ Ohne ernsthaft auf Handkes literaturtheoretisch ambitionierte Argumentation einzugehen, sieht sich Reich-Ranicki ganz offensichtlich kraft seines Amtes im Recht. ${ }^{79}$

\section{Schleichende Eskalation: die 1970er Jahre (Die linkshändige Frau, Das Gewicht der Welt)}

Der Grundstein für die literarische Fehde der beiden Akteure, in der für Handke die beherrschende Position des Kritikers im deutschen Feuilleton zusehends zum Problem wurde, war damit endgültig gelegt, obgleich Reich-Ranicki im selben Jahr Handkes Erzählung Das Umfallen der Kegel von einer bäuerlichen Kegelbahn (1969) noch in die Anthologie Verteidigung der Zukunft aufnahm - eine

75 Reich-Ranicki: Die Angst des Peter Handke beim Erzählen (Anm. 56).

76 Handke: Marcel Reich-Ranicki und die Natürlichkeit (Anm. 2), S. 204. Vgl. dazu Wolf: Autonomie und/oder Aufmerksamkeit? (Anm. 4), S. 54, Anm. 44: „Der Rezensent misst Handkes Erzählverfahren also just an jener traditionellen Poetik, von deren Naturalisierungstendenz sich das besprochene Buch gerade reflexiv absetzt, und befindet es in der Folge - kaum überraschend - als ungenügend.“

77 Handke: Marcel Reich-Ranicki und die Natürlichkeit (Anm. 2), S. 203; vgl. ebd., S. 203 f.: „ReichRanicki betrachtet die gemachte Literatur als ein Stück Natur. Ähnlich wie die Vögel in jener antiken Anekdote pickt er nach den ganz naturgetreu gemalten Trauben auf dem Bild von den Trauben. [...] Reich-Ranicki pickt nach Wörtern wie nach der Wirklichkeit.“

78 Wolf: Autonomie und/oder Aufmerksamkeit? (Anm. 4), S. 54. Zum Aspekt der, Kunstfertigkeit bzw. des ,Handwerklichen' bei Reich-Ranicki vgl. Czernin: Reich-Ranicki (Anm. 39), S. 21-52.

Vgl. Lorenz: Die Öffentlichkeit der Literatur (Anm. 25), S. 220. 
Entscheidung, die er einige Zeit später demonstrativ revidieren sollte. ${ }^{80}$ ReichRanickis hämische Rezension von Wunschloses Unglück hatte bei Handke Spuren hinterlassen: Im Gespräch mit Manfred Durzak ereiferte er sich Ende 1973, anlässlich der Verleihung des Georg-Büchner-Preises, über die „Lebenshaltungen, die zum Beispiel aus Rezensionen sprechen. Das sind Menschen, mit denen ich nie ein Wort sprechen könnte, mit denen ich nichts Gemeinsames, keine Erinnerung austauschen könnte. ${ }^{81}$ Handke führt seinen Gegenspieler namentlich als Beispiel für diese weitreichende wie tiefsitzende Antipathie an: „Ich könnte nie mit diesen Menschen verkehren, ich könnte kein einziges menschliches Wort mit ihnen wechseln, auch mit R.-R. nicht. Das sind halt fremde Menschen." ${ }^{82}$ Auch hinter der Antwort auf Heinz Ludwig Arnolds Frage, wie sehr der Autor sich über Kritik an seinen Büchern ärgere, kann man den ungenannten Kontrahenten vermuten:

Ich habe schon manchmal, wenn ich so etwas lese, die Lust zu körperlichem Einschreiten: daß ich dem einfach eins reinhauen möchte. Aber ich möchte nicht antworten; meine Reaktionen haben sich mit der Zeit reduziert auf Gewaltvorstellungen, die ich aber eh nicht ausführe. ${ }^{83}$

Abseits solcher Gewaltphantasien stand Mitte der 1970er Jahre eine professionelle Zusammenarbeit zwischen dem Autor und dem Kritiker durchaus im Raum: Bereits im Juni 1974 hatte Handke anlässlich von Franz Kafkas 50. Todestag einen kurzen Beitrag über den Prager Schriftsteller im Feuilleton der Frankfurter Allgemeinen Zeitung veröffentlicht. ${ }^{84}$ Deren Literaturredaktion wurde seit 1973 von Marcel Reich-Ranicki geleitet; er versuchte gleich von Beginn seiner Tätigkeit

80 Siehe Peter Handke: Das Umfallen der Kegel von einer bäuerlichen Kegelbahn. In: Verteidigung der Zukunft. Deutsche Geschichten seit 1960. Hg. v. Marcel Reich-Ranicki. München: Piper 1972, S. 358-368. Auf die späteren Auflagen der Anthologie wird im Laufe dieses Kapitels im Abschnitt „Im Bunde? Reich-Ranicki, Bernhard und Unseld“ noch genauer eingegangen.

81 Manfred Durzak: Für mich ist Literatur auch eine Lebenshaltung. Gespräch mit Peter Handke. [1973] In: M. D.: Gespräch über den Roman. Formbestimmungen und Analysen. Frankfurt a. M.: Suhrkamp 1976, S. 314-343, hier S. 330. Das Gespräch wurde 1973 in Auszügen in der ZEIT gedruckt; die Äußerungen über Reich-Ranicki fielen dabei den Kürzungen zum Opfer und wurden erst 1976 in dem zitierten Band veröffentlicht.

82 Ebd., S. 330 f. Vgl. dazu die spätere Äußerung Helmut Heißenbüttels, eines weiteren Intimfeindes von Reich-Ranicki: „Ich kann nicht mehr mit ihm, mit einem Mann seiner Denkungsweise, reden.“ (Helmut Heißenbüttel: Nachruf bei Lebzeiten. In: Text + Kritik [1988], H. 10o, S. 26-28, hier S. 28)

83 Heinz Ludwig Arnold: Gespräch mit Peter Handke. In: Text + Kritik ( $\left.{ }^{3} 1976\right)$, H. 24/24a, S. 15-37, hier S. 34.

84 Vgl. Peter Handke: Gewaltiger als alle Handlungen. In: Frankfurter Allgemeine Zeitung, 1. 6. 1974. Zum Kontext vgl. Reinhard Urbach: Die Rezeption Franz Kafkas durch die jüngste österreichische 
an, über den engeren Kreis der Kritiker hinaus namhafte Akteure des Literaturund Kulturbetriebs als freie Mitarbeiter zu gewinnen, so etwa Golo Mann und Peter Rühmkorf, die in der Folge regelmäßig Beiträge für die $F A Z$ verfassten, ${ }^{85}$ aber auch Elias Canetti, dessen Absage, nicht zuletzt angesichts früherer Verrisse Reich-Ranickis über Canettis Bücher, recht harsch ausfiel:

Ich dachte, Sie wissen, dass ich nicht für Zeitungen schreibe. Sie haben schon so früh meine Außenseiter-Natur erkannt, und jetzt, mit 68, soll ich das plötzlich ändern? Ich kann nur schreiben, was ich von mir aus schreiben muss, und nicht Vorschläge zum Schreiben von außen entgegennehmen. Bei der Vorstellung, dass ich anlässlich irgendeines 100. Geburtstags etwas schreibe, muss ich lachen (so wie Sie bei der Lektüre von „Masse und Macht“). Und dann noch über Hofmannsthal, der mir nie etwas bedeutet hat, den ich im Gegenteil für maßlos überschätzt halte! ${ }^{86}$

Anfang 1975 erkundigte sich Reich-Ranicki bei Handke, ob er Interesse daran habe, einen Aufsatz über Thomas Mann für die Zeitung zu verfassen. Handke zögerte jedoch: Er habe, so der Autor am 30. Januar 1975, bei seinem Kafka-Text „bemerkt, dass es eher unglückselig ist, irgendetwas, auch nur Artikelchen, so ,nebenbei' zu schreiben“; außerdem sei seine Thomas-Mann-Lektüre „über zehn Jahre her“. ${ }^{87}$ Als Alternative bot er Reich-Ranicki die Einleitung zu einem Band mit Erzählungen des österreichischen Autors Franz Nabl, der im Salzburger Residenz Verlag vorbereitet wurde, als Vorabdruck an: „Anfang März, oder Ende Februar, werde ich Ihnen den Aufsatz dann schicken. ${ }^{* 88}$ Handke hatte Nabl bereits ein Jahr zuvor

Literatur. In: Franz Kafka. Eine Aufsatzsammlung nach einem Symposium in Philadelphia. Hg. u. eingel. v. Maria Luise Caputo-Mayr. Berlin, Darmstadt: Agora 1978, S. 183-193, hier S. 183 f.

85 Vgl. den Einladungsbrief vom 11.3.1974. In: Golo Mann/Marcel Reich-Ranicki: Enthusiasten der Literatur. Ein Briefwechsel. Aufsätze und Portraits. Hg. v. Volker Hage. Frankfurt a. M.: S. Fischer 2000, S. 19 f., sowie Marcel Reich-Ranicki/Peter Rühmkorf: Der Briefwechsel. Hg. v. Christoph Hilse u. Stephan Opitz. Göttingen: Wallstein 2015.

86 Elias Canetti an Marcel Reich-Ranicki, 30.12.1973. In: Elias Canetti: Ich erwarte von Ihnen viel. Briefe 1932-1994. Hg. v. Sven Hanuschek u. Kristian Wachinger. München: Hanser 2018, S. 46of. In seiner 1999 erschienenen Autobiographie hat Reich-Ranicki Canettis Brief in Auszügen wiedergegeben (vgl. M. R.-R.: Mein Leben [Anm. 52], S. 453). Dazu Sven Hanuschek: Elias Canetti. Biographie. München, Wien: Hanser 2005, S. 568, der moniert, der Kritiker habe den Brief durch Kürzungen mit Absicht „,öllig entstellt“, um Canetti in einem schlechten Licht dastehen zu lassen.

87 Peter Handke an Marcel Reich-Ranicki, 30. 1. 1975. In: Deutsches Literaturarchiv Marbach, Handschriftensammlung, A: Reich-Ranicki, HS.2003.0002.00240. Für die Genehmigung zur Verwendung dieses und der folgenden beiden Briefe danke ich Peter Handke sehr herzlich.

88 Ebd. Es handelt sich um den folgenden Band: Franz Nabl: Charakter. Der Schwur des Martin Krist. Dokument. Frühe Erzählungen. Hg. v. Peter Handke. Salzburg: Residenz 1975; darin findet sich Handkes auf „Februar, März 1975“ datierter Essay Franz Nabls Größe und Kleinlichkeit (S. 5-24) sowie ein Erinnerungstext von Gerhard Roth (S. 149-154); Handkes Essay 
im Almanach des Residenz Verlags als zu Unrecht vergessenen Schriftsteller hervorgehoben und gewürdigt. ${ }^{89}$ Dass er sich um das Andenken des Anfang 1974 im Alter von 90 Jahren verstorbenen Autors kümmerte, nahmen auch Schriftsteller einer älteren Generation wohlwollend zur Kenntnis: „Eine gute Fügung scheint es mir", schreibt Elias Canetti am 25. Dezember 1974 an dessen Witwe Ilse Nabl, „dass Peter Handke einen Band Erzählungen im Residenz Verlag herausgibt. Die Jungen wollen es von einem der Ihren hören, wie bedeutend ein Dichter ist. ${ }^{“ 90} \mathrm{Als}$ die Stadt Graz kurz nach dem Tod Nabls einen nach ihm benannten Literaturpreis stiftete, war Canetti der erste Preisträger. ${ }^{91}$

Reich-Ranicki lehnte Handkes Vorschlag aber mit Hinweis auf die mangelnde Bekanntheit Nabls in der Bundesrepublik ab - ein Einwand, der bei Handke auf wenig Verständnis stieß, zumal er davon überzeugt war, am Beispiel des Schriftstellers ein über den Einzelfall hinausreichendes Problem künstlerischer Existenz geschildert zu haben:

Lieber Marcel Reich-Ranicki,

daß Sie den Aufsatz über Franz Nabl nicht haben wollten, dagegen ist nichts zu sagen. Der Grund freilich, er wäre in Deutschland fast unbekannt, hat mir nicht eingeleuchtet. Man hätte ja eine kurze Vorstellung und Geschichte seines Werkes in der deutschen Öffentlichkeit (+ die Geschichte seines Vergessenwerdens) vorausschicken können und der Konflikt, den ich an Franz Nabl klarzustellen versucht habe (der Schriftsteller und die vorgegebenen normativen Systeme von Erleben), scheint mir nicht gar so speziell zu sein. Nun, das alles ist nicht so wichtig ... ${ }^{92}$

wurde 1980 in den Band Das Ende des Flanierens (S. 22-37) aufgenommen. - Vgl. Handke an Unseld, 7. 3. 1975. In: Handke/Unseld: Der Briefwechsel (Anm. 60), S. 281: „Den Aufsatz über Franz Nabl habe ich gestern fertiggekriegt; er ist ziemlich lang geworden, etwa 14 Seiten ... Ich werde ihn in der nächsten Woche an die ,FAZ` schicken. “ - Zu Handkes Beschäftigung mit Franz Nabl vgl. Norbert Gabriel: Peter Handke und Österreich. Bonn: Bouvier 1983, S. 38-41.

89 Vgl. Peter Handke: Österreich und die Schriftsteller. In: Literatur im Residenz Verlag. Almanach auf das Jahr 1974. Salzburg: Residenz 1974, S. 57-61; mit verändertem Schluss und einer Widmung für Alfred Holzinger wurde der Text 1980 in den Band Das Ende des Flanierens (S. 18-21) aufgenommen.

90 Elias Canetti an Ilse Nabl, 25. 12. 1974. In: Canetti: Ich erwarte von Ihnen viel (Anm. 86), S. 494. $\mathrm{Zu}$ Canettis Wertschätzung für Franz Nabl vgl. auch den Eintrag in Elias Canetti: Das Buch gegen den Tod. Mit einem Nachwort v. Peter von Matt. München: Hanser 2014, S. 132. Zu Nabls ,Wiederentdeckung' durch eine neue Autoren-Generation vgl. Wendelin Schmidt-Dengler: Franz Nabl und die Literaturgeschichte. In: Über Franz Nabl. Aufsätze, Essays, Reden. Hg. v. Kurt Bartsch, Gerhard Melzer u. Johann Strutz. Graz u. a.: Styria 1980, S. 9-27, hier S. 14 f.

91 Vgl. Hanuschek: Elias Canetti (Anm. 86), S. $515 \mathrm{f}$.

92 Peter Handke an Marcel Reich-Ranicki, 29. 4. 1975. In: Deutsches Literaturarchiv Marbach, Handschriftensammlung, A: Reich-Ranicki, HS.2003.0002.00240. Vgl. dazu auch Peter Handke an Wolfgang Schaffler, 8. 4. 1975. In: Literaturarchiv Salzburg (LAS), Archiv des Residenz Verlags: 
Handkes Brief vom 29. April 1975 steigert sich im weiteren Verlauf vom Ausgangspunkt des ,Geschäftlichen' unversehens zum erneuten Angriff auf den Adressaten. Der Plan, sich für das literarische Werk seines Freundes Hermann Lenz einsetzen zu wollen, ${ }^{93}$ wird von der Vorstellung, dies im Forum der FAZ, d.h. in zweifelhafter Gesellschaft zu tun, getrübt:

Es ist im Insel-Verlag ein neues Buch von Hermann Lenz, „Neue Zeit“, erschienen. Das Buch sagt mir zu, es gibt in mir aber auch Widerstände dagegen. Ich werde eine „Besprechung“ schreiben und würde die Ihrer Zeitung überlassen - nur verdrießt es schon ein bißchen, daß ich von Ihrer Vorstellung von Literaturkritik wieder abhängig wäre und mich also freiwillig in die Höhle des Marders begäbe. ${ }^{94}$

Bereits diese Formulierung, die auf das wenig schmeichelhafte Tier-Porträt in der Lehre der Sainte-Victoire vorausweist (dort wird ebenso von einem Marder die Rede sein), kann als veritable Insultation des Kritikers gelten. Im letzten Teil seines Briefes macht Handke seine Einwände gegen Reich-Ranickis literaturkritische Praxis auch an einem aktuellen Beispiel fest:

Gestern las ich, was Sie zu Rolf Dieter Brinkmann und seinem Tod schrieben. ${ }^{[95]}$ So recht es war, daß da was Langes über diesen poetischen Menschen stand, so unangenehm berührt war ich doch, daß Sie ihm den Ausspruch mit dem Niederschießen jetzt noch vorwerfen. Das war nichts Gemeines, Widerwärtiges, sondern eine hilflose Formulierung eines fleischlichen Ekels, die ich wohl begreifen und immer noch nachfühlen kann, wenn ich mir die Versammlung der in strotzender Routine röchelnden Sekundärliteraten vorstelle, die ihren Frieden mit der Welt sehr vorschnell abgeschlossen haben oder dies zumindest materiell erfolgreich vortäuschen. ${ }^{96}$

„Reich-Ranicki von der FAZ meint, Nabl sei zu wenig bekannt in der BRD, als daß man in einer Zeitung so einen Aufsatz bringen könnte - und so sei es mehr ein Artikel für eine ,Zeitschrift. Ich hab' noch nicht widersprochen ...“

93 Dazu ausführlich Kap. V, Abschnitt „Ein Leseerlebnis beschreiben: Handke rezensiert Hermann Lenz".

94 Handke an Reich-Ranicki, 29.4.1975 (Anm. 92).

95 Es handelt sich dabei um den folgenden Beitrag: Marcel Reich-Ranicki: ... aber ein Poet war er doch. Zum Tod des Rolf Dieter Brinkmann. In: Frankfurter Allgemeine Zeitung, 28. 4. 1975, einen Nachruf auf den am 23. 4. 1975 bei einem Verkehrsunfall getöteten Autor. Darin findet sich etwa die folgende psychologisierende Analyse des Schriftstellers: „Nicht Kraft oder Selbstbewußtsein oder Übermut ließ er erkennen, sondern Unsicherheit und Schwäche, Hilflosigkeit und Ohnmacht. Die brutale Aggressivität zeugte ebenso von panischer Angst wie von Geltungssucht. Brinkmann war ein verwirrter Rebell, der sich in die Rolle eines provozierenden Berserkers geflüchtet hatte. Da er nicht anders mit seiner Umwelt fertig werden konnte, versuchte er es als wild um sich schlagender Anarchist."

Handke an Reich-Ranicki, 29.4.1975 (Anm. 92). 
Handke bezieht sich hier auf eine Episode aus dem Jahr 1968, die dazumal für einige Aufregung im Literatur- und Kulturbetrieb gesorgt hatte: Rolf Dieter Brinkmann hatte bei einer Veranstaltung der Berliner Akademie der Künste mit der Vorstellung gespielt, den missliebigen Kritiker auf offener Bühne mit einem Maschinengewehr niederzuschießen. ${ }^{97}$ Indem er Reich-Ranicki mitteilt, er könne Brinkmanns damaligen „Ekel“ angesichts der „in strotzender Routine röchelnden Sekundärliteraten“ durchaus nachvollziehen, wiederholt Handke gewissermaßen dessen sechs Jahre zurückliegende Attacke - und rechnet den Adressaten seines Briefes auf diesem Umweg zur Riege der routinierten und „materiell erfolgreich[en]“ Journalisten. „Es ist schade“, so Handkes Fazit in seinem Brief vom 29. April 1975,

daß Sie über Brinkmann in Schemata wie Reife x Unreife schreiben ... Es lag mir daran, Ihnen das zu sagen, eher traurig, und enttäuscht. Beim Tod Brinkmanns habe ich einen Verlust gespürt und spüre ihn immer noch. Wann kann man das sagen? Viele Grüße,

Ihr

Peter Handke ${ }^{98}$

Die lose Arbeitsbeziehung der beiden war ein gutes Jahr später immer noch intakt (ein Beitrag über Heimito von Doderer für die FAZ war in Planung), bis sich Handke im Juni 1976 angesichts eines Artikels von Reich-Ranicki über Wolfgang Koeppen ein weiteres Mal zu einer polemischen Attacke herausgefordert sah einer Attacke, die zum endgültigen Bruch zwischen den beiden Kontrahenten führte. Das Schriftbild des im Nachlass des Kritikers im Deutschen Literaturarchiv in Marbach erhaltenen Briefes verweist nur zu deutlich auf die Erregung, ja auf den heiligen „Zorn“99 seines Verfassers:

97 Vgl. die Dokumentation von Raimund Fellinger: „Ich bin kein Teppichknüpfer“. In: Berlin, 17. November 1968. Autoren diskutieren mit ihren Kritikern. Thomas Bernhard diskutiert mit Rudolf Hartung. Mattighofen: Korrektur 2017, S. 35-39. - Dirk Niefanger: Rolf Dieter Brinkmanns Poetik der Selbstinszenierung. In: Medialität der Kunst. Rolf Dieter Brinkmann in der Moderne. Hg. v. Markus Fauser. Bielefeld: transcript 2011, S. 65-82, hat darauf hingewiesen, dass, weil Tonband- oder Videoaufzeichnungen der Veranstaltung fehlen, „geradezu erschreckend unterschiedliche Varianten“ (S. 68) der Brinkmann'schen Äußerung kursieren. Er deutet diese aber - im Gegensatz zu Reich-Ranicki - als „weder barbarisch noch gefährlich“, „sondern schlicht als eine wohl überlegte medial abgestimmte Selbstinszenierung" des Autors (S. 71). Vgl. dazu Wittstock: Marcel Reich-Ranicki (Anm. 15), S. 252; Andrea Bandeili: Rolf Dieter Brinkmann und Peter Handke um '68. Der Skandal als Akt der Revolte? In: Skandalautoren. Zu repräsentativen Mustern literarischer Provokation und Aufsehen erregender Autorinszenierung. Bd. 2. Hg. v. Andrea Bartl u. Martin Kraus. Unter Mitarb. v. Kathrin Wimmer. Würzburg: Königshausen \& Neumann 2014, S. 53-67.

98 Handke an Reich-Ranicki, 29. 4.1975 (Anm. 92).

99 Peter Handke: Das Gewicht der Welt. Ein Journal (November 1975 - März 1977). Salzburg: Residenz 1977, S. 260. - Unter dem Datum des Briefes an Reich-Ranicki selbst findet sich nur 
Lieber Marcel Reich-Ranicki,

was Sie über Wolfgang Koeppen geschrieben haben, hat mich in seinem so völlig künstlichen, leeren Klappentext-enthusiasmus [sic] so elend gestimmt, daß ich nichts zu Doderer für Ihre Zeitung schreiben kann. ${ }^{[100]}$ Was so ganz und gar unkritisch, als typisches (in der Literaturkritik typisches, übliches, hysterisches) Ausspielen einer Figur gegen andre, an Koeppen ta in diesem Fall, und nicht nur bei von Ihnen, sondern von allen Toastern, da geschieht, wird diesem ernsthaften, aber meist doch nur rhetorischen, anempfindenden Schriftsteller nur schaden. Mich hat bei Ihrem so durchschaubar emphatischen Gehudel jedenfalls derart die Wut gepackt, daß meine Unbehaglichkeit Ihnen (d.h. Ihren Äußerungen) gegenüber schtagartig in die Gewißheit einer notwendigen dauernden Unversöhnlichkeit mit einem für meine Augen so offensichtlich nur lavierenden, sich für sich selber in seinen Arbeiten positionspolitisch opportun verhaltenden, nie eine kleine Überraschung oder gar Offenbarung oder Leidenschaft in seiner Spracharbeit zeigenden Kritiker mir ein für alle Male ktar geworden umgeschlagen ist. Daß davon mein Respekt für den Raum, den Sie in Ihrer Zeitung der poetischen Existenz, so lächerlich diese auch (mir auch) oft scheint, ist und wird, gewähren, nur teilweise berührt wird, möchte ich doch zufügen.

Ihr Peter Handke ${ }^{101}$

Handke hatte sich, folgt man zwei Notaten im Journalband Das Gewicht der Welt, bereits an Vorarbeiten zu einem Doderer-Essay gemacht, ${ }^{102}$ las noch nach der Abfassung seines ,Wut-Briefs' die Strudlhofstiege und bekräftigte Hermann Lenz gegenüber, "große Achtung und Zuneigung “ für Doderer zu empfinden. ${ }^{103}$

ein Eintrag über das anger management seiner Tochter: „Wenn A. auf Leute Wut hat, hat sie Lust, ihnen etwas zu rauben“" (ebd., S. 201).

100 Es handelt sich um folgenden Beitrag in der Wochenend-Beilage der FAZ, in der sich neben ReichRanicki auch Peter Demetz, Peter Härtling, Horst Krüger, Siegfried Lenz und Hans Mayer anlässlich von Koeppens 70. Geburtstag zu Wort meldeten: „Daß Wolfgang Koeppen zu den bedeutendsten deutschen Schriftstellern der Gegenwart gehört, ja, daß er vielleicht der originellste Prosapoet, der vorzüglichste Stilist unserer zeitgenössischen Literatur ist - diese Behauptung wird die meisten Leser verwundern. Und doch gleicht sie nur einer kühnen Banalität." (Marcel Reich-Ranicki: Der Dichter der aggressiven Resignation. In: Frankfurter Allgemeine Zeitung, 19. 6.1976)

101 Peter Handke an Marcel Reich-Ranicki, 23. 6. 1976. In: Deutsches Literaturarchiv Marbach, Handschriftensammlung, A: Reich-Ranicki, HS.2003.0002.00240.

102 Vgl. Handke: Das Gewicht der Welt (Anm. 99), S. 172 (27.5. 1976) u. 177 (31. 5. 1976): „Und doch: Doderer lesen und denken: Ach, diese ideale Welt! (Ein Seufzer der Sehnsucht)“ - „Doderer: Es ist vielleicht ganz gut, wenn jemand beim Schreiben nicht mehr viel Sehnsucht spürt, sondern nur die Erinnerung daran als Energie für seine Figuren verwendet“.

103 Peter Handke an Hermann Lenz, 30. 9. 1976. In: P. H./H. L.: Berichterstatter des Tages. Briefwechsel. Hg. u. mit einem Nachwort von Helmut Böttiger, Charlotte Brombach u. Ulrich Rüdenauer. Mit einem Essay v. Peter Hamm. Frankfurt a. M.: Insel 2006, S. 102; von der Lektüre der Strudlhofstiege zeugen mehrere Passagen in Handke: Das Gewicht der Welt (Anm. 99), S. 226, 229 
Die Publikation eines Aufsatzes in der FAZ kam jedoch - wenig überraschend nicht mehr zustande.

Stattdessen veröffentliche Reich-Ranicki am 9. Oktober 1976, also knapp vier Monate nach Handkes privater Attacke, mit der Rezension von Die linkshändige Frau (1976) seinen bislang schärfsten Verriss zu einem Buch des Autors. Wie des Öfteren geht er auch hier vom Urteil anderer Kritiker aus, um sich von deren positiver Einschätzung des Handke'schen Werks zu distanzieren: „Die Leser vor diesem Büchlein warnen zu wollen“, heißt es gleich eingangs,

wäre abwegig. Denn zum Widerspruch oder gar zur Aufregung gibt es hier nicht den mindesten Grund. Und nur weil die Erzählung ,Die linkshändige Frau' von dem beliebten und auch in mancherlei Hinsicht repräsentativen Nachwuchsdichter [seinen ersten Roman hatte dieser bereits zehn Jahre zuvor vorgelegt; H. G.] Peter Handke stammt, müssen wir auf dieses erstaunlich harmlose Prosastück, das schon von einigen Rezensenten mit Andacht analysiert wurde, etwas näher eingehen. ${ }^{104}$

„Nachlässig“ und „schlecht formuliert“ zähle Handkes Erzählung zu jenem „Mumpitz, der Tiefsinn vortäuscht und in Deutschland immer beliebt war und ist“. Reich-Ranicki vergleicht Die linkshändige Frau in der Folge maliziös mit den Liebesromanen und „der Welt der Hedwig Courths-Mahler“, ${ }^{105}$ und er charakterisiert Handkes bewusstes Spiel mit trivialen Erzählmustern unreflektiert als Defizit des Buches. ${ }^{106}$ Der Kritiker rückt die Erzählung Handkes, der schon 1973

u. 231 (24./26./28. 9.1976); zu den Wasserfällen von Slunj vgl. ebd., S. 311-313 (Februar 1977). Auch in anderen Textsorten hat sich Handke auf Doderers Werk als Vergleichspunkt bezogen, etwa in der 1976 veröffentlichten Rezension zu Nicolas Borns Roman Die erdabgewandte Seite der Geschichte (P. H.: Das Ende des Flanierens. Frankfurt a. M.: Suhrkamp 1980, S. 107-119, bes. S. 117) oder 2005 in einem Interview mit Heinz-Norbert Jocks: Geglückte Tage, unterwegs. Im Gespräch: Peter Handke erzählt vom Reisen allein, von Nomaden und Nesträubern. In: Freitag, Nr. 42, 21. 10. 2005, S. 3. - Vgl. dazu jetzt Helmut Moysich: Rück mir auf den Leib, Du stille Welt. Poetisch-existentielle Verwandtschaften zwischen Peter Handke und Heimito von Doderer. In: Die tägliche Schrift. Peter Handke als Leser. Hg. v. Thorsten Carstensen. Bielefeld: transcript 2019, S. 163-177.

104 Marcel Reich-Ranicki: Unser junger Handke und die alte Hedwig. In: Frankfurter Allgemeine Zeitung, 9.10.1976.

105 Ebd.

106 Vgl. die Rekonstruktion in Wolf: Autonomie und/oder Aufmerksamkeit? (Anm. 4), S. 54 f.; zur Rezeption des Bandes auch Christel Terhorst: Peter Handke. Die Entstehung literarischen Ruhms. Die Bedeutung der literarischen Tageskritik für die Rezeption des frühen Peter Handke. Frankfurt a. M. u. a.: Lang 1990, S. 4; Anz: Marcel Reich-Ranicki (Anm. 15), S. 135 f. Peter Demetz: On Marcel Reich-Ranicki (Anm. 21), S. 300, zählt „disqualifying the shoddy and trivial“ zu dessen zentralen Anliegen, unterschlägt aber, dass der Kritiker sich - etwa im Fall Elfriede Jelineks für die literarische Funktionalisierung des Trivialen als Verfahren der ästhetischen Moderne wenig aufgeschlossen gezeigt hat. - In einem Beitrag für die Suhrkamp-Zeitschrift Dichten und 
mit dem renommiertesten Literaturpreis Deutschlands, dem Georg-BüchnerPreis, ausgezeichnet worden war, in die Nähe der Werke einer Schriftstellerin, die - in der Terminologie der Bourdieu'schen Kultursoziologie - eindeutig dem „Subfeld der Massenproduktion“ zuzurechnen ist. ${ }^{107}$ Die Fallhöhe zwischen dem Status eines bereits früh umfassend konsekrierten Autors, zu dessen künstlerischem Ethos es gehörte, mit jedem Buch eine „neue Möglichkeit“ des Erzählens zu erkunden, ${ }^{108}$ und der mit dem Vergleich mit Courths-Mahler angedeuteten literarischen Banalität und Nachfrageorientierung ist denkbar groß. Gerade weil der „Grad der faktischen oder vermeintlichen Abhängigkeit von Publikumsgeschmack, Erfolg, Wirtschaft “, so Bourdieu, ${ }^{109}$ im literarischen Feld ein zentrales Kriterium der Hierarchisierung und Bewertung darstellt, ist Reich-Ranickis Bemerkung nicht bloß ein beiläufig gestreutes Bonmot, sondern attackiert ganz grundlegend Handkes Konzept von Autorschaft. Dem denunziatorischen Vergleich mit der Trivialautorin ist nicht nur der Vorwurf inhärent, unter seinem ,Niveau' zu arbeiten, sondern auch die Anschuldigung, sich dem kommerziellen Erfolg (mit Bourdieu: dem „Prinzip der externen Hierarchisierung ${ }^{\text {“110 }}$ ) verschrieben zu haben. In Reich-Ranickis Besprechung ist - im Wissen um Handkes brieflichen Vorwurf, der Kritiker verhalte sich „in seinen Arbeiten“ meist "positionspolitisch opportun“ - ein gerüttelt Maß an revanchistischem Zorn zu vernehmen. Der Bruch zwischen den beiden war damit wohl endgültig vollzogen; die Erwartung künftiger „Unversöhnlichkeit“, der Handke in seinem letzten Brief Ausdruck verliehen hatte, war der Kritiker ohne Zögern zu erwidern bereit.

Nach dem Verriss der Linkshändigen Frau in der FAZ musste Siegfried Unseld seinen Autor damit vertrösten, dass „Reich-Ranickis verantwortungslose Kritik [...] neue, verantwortungsvolle auf den Plan rufen“ werde. ${ }^{111}$

Trachten hatte Handke 1967, mit Blick auf seinen Roman Der Hausierer, die Absicht festgehalten, „ein darstellungsschema aus der ,trivialliteratur' wieder wirklich [zu] machen“ (Peter Handke: Über meinen neuen Roman Der Hausierer. In: Dichten und Trachten 29 [1967], S. 27-29, hier S. 28), und sich im Essay Ich bin ein Bewohner des Elfenbeinturms (1967) mit dem Absinken künstlerischer Methoden in die „Trivialkunst“ beschäftigt (Handke: Ich bin ein Bewohner des Elfenbeinturms [Anm. 37], S. 21). Zu Handkes Arbeit mit ,trivialen` Kunstformen vgl. Norbert Christian Wolf: High and Low: Mediale Dominanzbildungen bei Peter Handke. In: Der neue Wettstreit der Künste. Legitimation und Dominanz im Zeichen der Intermedialität. Hg. v. Uta Degner u. N. C. W. Bielefeld: transcript 2010, S. 77-97.

107 Pierre Bourdieu: Das literarische Feld. In: P. B.: Kunst und Kultur. Kunst und künstlerisches Feld. Schriften zur Kultursoziologie 4. Hg. v. Franz Schultheis u. Stephan Egger. Berlin: Suhrkamp 2015, S. 339-447, hier S. 347.

108 Handke: Ich bin ein Bewohner des Elfenbeinturms (Anm. 37), S. 22.

109 Pierre Bourdieu: Das literarische Feld. Kritische Vorbemerkungen und methodologische Grundsätze. In: P. B.: Kunst und Kultur (Anm. 107), S. 309-337, hier S. 332.

110 Bourdieu: Das literarische Feld (Anm. 107), S. 347.

111 Unseld an Handke, 18. 10. 1976. In: Handke/Unseld: Der Briefwechsel (Anm. 6o), S. 311. 
Versehen mit dem Datum 21. bzw. 24. Oktober 1976 finden sich in Handkes Journalband Das Gewicht der Welt zwei Einträge, die man wohl guten Gewissens in diesen Zusammenhang stellen darf: „Schwierig: im Zorn trotzdem die Beherrschung nicht verlieren (als sei das nur in alten Romanen möglich gewesen)“ - „Feinde: kein Impuls mehr, sie zu beschimpfen, zu bekämpfen, zu vernichten - nur noch die Befürchtung, sie könnten mich überleben: die schändlichste Niederlage“.112 Ja, auch die am 29. Oktober skizzierte „Amoklaufphantasie am Nachmittag“, die sich gegen willkürlich ausgewählte Personen und Objekte wendet, weil der Autor seine „Wut nicht auf denjenigen richten“ kann, „der sie ausgelöst hatte“, kann man in diesem Kontext lesen; „im Bewußtsein, daß gegen den Auslöser keine Tätlichkeit, nicht einmal eine Äußerung mehr möglich war“, projiziert er seine Gewaltphantasien „auf eine fremde Frau, der ich ein Messer hineinrennen wollte“, und „auf ein Schaufenster, das ich auf der Stelle eintreten wollte ${ }^{\text {“ }}{ }^{113}$ Der Journalschreiber wird, so hat es den Anschein, vor allem von der Aussichtslosigkeit seines Widerstands geplagt, empfindet er doch gleich darauf eine „völlige Schwächlichkeit, eine den Körper und die Seele ganz entleerende Schwachheit und Ohnmacht “ ${ }^{114}$ Im Rückblick hat Handke wiederholt über das Gefühl der Hilflosigkeit angesichts einzelner ablehnender Rezensionen berichtet, die ihn nachhaltig aus der Fassung, aus der Balance gebracht hätten.

Hermann Lenz versicherte dem jungen Freund kurz darauf, am 3o. Oktober, seine Solidarität gegen die „Saubande“ der Rezensenten, zu der er ausdrücklich Reich-Ranicki rechnete. Auslassungen im 2006 edierten Briefwechsel der beiden Autoren lassen erkennen, dass hier Deftigeres zu Lebzeiten des Kritikers nicht gedruckt werden sollte. ${ }^{115}$ In seiner Antwort vom 9. November bezieht sich Handke auf Lenz' Polemik: „Die Kritik von Reich-Ranicki hat mich natürlich wütend gemacht, aber nicht betroffen (betroffen höchstens darüber, wie solche Figuren existieren können, ohne sofort von sich aus abzustinken) “ ${ }^{116}$

Wenig später folgte in einem Artikel zur Frankfurter Buchmesse 1977 die nächste Spitze des Kritikers: An Peter Handke, der wie Botho Strauß einmal „eine große Hoffnung unserer Literatur“ gewesen sei, könne man den „Verfall eines Talents“ beobachten, „dessen Größenwahn jegliche Selbstkontrolle ausgeschaltet hat“: „Nach der liederlich-kitschigen Erzählung ,Die linkshändige

112 Handke: Das Gewicht der Welt (Anm. 99), S. 260 u. 265. Dazu der Kommentar in André Müller: Im Gespräch mit Peter Handke. Weitra: Bibliothek der Provinz 1993, S. 66. Zur Deutung dieses Satzes vgl. jetzt Karl Heinz Bohrer: Mit Dolchen sprechen. Der literarische Hass-Effekt. Berlin: Suhrkamp 2019, S. 437.

113 Handke: Das Gewicht der Welt (Anm. 99), S. 270.

114 Ebd.

115 Lenz an Handke, 30. 10. 1976. In: Handke/Lenz: Berichterstatter des Tages (Anm. 103), S. 103.

116 Handke an Lenz, 9. 11. 1976. In: ebd., S. 105. 
Frau' offeriert er nun ein Journal mit dem anspruchsvollen Titel ,Das Gewicht der Welt', das spontane Aufzeichnungen zweckfreier Wahrnehmungen enthält. “"17 Aus seiner vehementen Ablehnung des kurz zuvor im Salzburger Residenz Verlag erschienenen Bandes Das Gewicht der Welt machte Reich-Ranicki keinen Hehl. Ihm galt, ebenso wie anderen Rezensenten, ${ }^{118}$ die radikale Introspektion des Journals, die „Reportage eines Einzel-Bewußtseins, veröffentlicht als Buch“, als Irrweg eines narzisstischen Autors, die von Handke forcierte „Befreiung von gegebenen literarischen Formen“ als bemühter, aber unproduktiver Ansatz. ${ }^{120}$

In einer Notiz zu einem Gespräch mit Peter Handke im Juni 1978 hielt Siegfried Unseld die tiefsitzende Verletzung des Autors gerade angesichts von ReichRanickis Kritik der Linkshändigen Frau fest, die gut eineinhalb Jahre nach der Veröffentlichung offensichtlich immer noch sehr präsent war:

Und dann, nach einigen Gläsern Wein, äußerte sich bei ihm ein Haß gegen die Bundesrepublik, ein Land, das zu nichts mehr fähig sei, ein Kadaver, eine vom Erdbeben verwüstete Gegend. [...] Und sofort fügte er hinzu: in der Bundesrepublik ist Größe nicht mehr möglich. Auslösender Moment für diesen Haß ist die Behandlung seiner ,Linkshändigen Frau', die Behandlung des Buches durch die ,FAZ' und die Behandlung des Filmes durch die Kritiker. ${ }^{121}$

Ende der 1970er Jahre schließlich sollte sich das Verhältnis zwischen Handke und Reich-Ranicki in einer Weise zuspitzen, die deshalb besondere Aufmerksamkeit verdient, weil die Eskalation der Beziehung zwischen Autor und Kritiker mit einer grundlegenden Neuausrichtung von Handkes Schreiben zusammenfällt. Sie verläuft zudem parallel zur Entzweiung zwischen Handke und Thomas Bernhard, dessen autobiographische Bände Reich-Ranicki im April 1978 $\mathrm{zu}$ „den großen literarischen Dokumenten unserer siebziger Jahre“ rechnete. ${ }^{122}$

117 Marcel Reich-Ranicki: Deutsche Literatur 1977. Ein Überblick aus Anlaß der Frankfurter Buchmesse. In: Frankfurter Allgemeine Zeitung, 13. 10. 1977.

118 Vgl. etwa Ulrich Greiner: Peter Handke und das Glücksgefühl, eine Flasche Mineralwasser anschauen zu können. In: Frankfurter Allgemeine Zeitung, 11. 10. 1977; Hans Christoph Buch: Der vollkommene Schauspieler. Über Peter Handke: Das Gewicht der Welt. In: Der Spiegel, Nr. 37, 5. 9. 1977, S. 197-201; Reinhold Tauber: Ein Talent macht Pause. Ein „Journal“ läßt erkennen: Peter Handke tritt auf der Stelle. In: Oberösterreichische Nachrichten, 5. 10. 1977.

119 Handke: Das Gewicht der Welt (Anm. 99), S. 6.

120 Ebd., S. 5. Vgl. dazu Hage/Schreiber: Marcel Reich-Ranicki (Anm. 57), S. 108: „Das Skizzenhafte und Ungeordnete dieses Werks [i.e. Das Gewicht der Welt] war Reich-Ranickis Sache nicht.“

121 Unseld: Peter Handke, 23. Juni 1978. In: Handke/Unseld: Der Briefwechsel (Anm. 6o), S. 346 f.

122 Marcel Reich-Ranicki: In entgegengesetzter Richtung. [1978] In: M. R.-R.: Thomas Bernhard. Aufsätze und Reden. Mit Fotografien v. Barbara Klemm. Zürich: Ammann 1990, S. 43-58, hier S. 58 . 
Während der Kritiker Bernhards Literatur nach anfänglicher Skepsis mehr und mehr für sich entdeckte, verschlechterte sich Handkes Verhältnis zu den beiden zusehends - und nachhaltig.

\section{„schiefe Bilder und preziöse Vergleiche“ (Langsame Heimkehr)}

Im Vorfeld der Publikation der Erzählung Langsame Heimkehr, dem ersten Band der gleichnamigen Tetralogie, notiert Siegfried Unseld im Juli 1979, der Autor habe sich sowohl gegen einen „Klappentext“ als auch gegen die „übliche Werbung“ ausgesprochen - „keine Anzeigen mit blöden Texten“; außerdem fordere Handke, so der Bericht des Verlegers, ein „Verbot aller Rezensionen, insbesondere von M. R.-R. ${ }^{123}$ Langsame Heimkehr erschien in der Folge tatsächlich ohne Klappentext; wenig überraschend konnte sich Handke aber weder mit seinem allgemeinen noch mit dem persönlichen Rezensionsverbot für Reich-Ranicki durchsetzen. ${ }^{124}$ Nach ersten negativen Besprechungen, die sich, wie etwa Urs Jenny im Spiegel, am pathetischen Duktus von Handkes Erzählung stießen, ${ }^{125}$ teilte dieser seinem Verleger am 15. Oktober 1979 mit, die Kritiken hätten ihn „traurig gemacht“, er habe seine Hoffnung auf „ein verborgenes Großes Volk von Lesern" aber noch nicht aufgegeben. ${ }^{126}$ Kurz darauf hatte sich allerdings bis zu Handke herumgesprochen, dass auch Reich-Ranicki eine Besprechung von Langsame Heimkehr vorbereitete: In einer ausführlichen Notiz zu einem Besuch in Handkes Salzburger Domizil hält Unseld fest: „Peter Handke: er ,laboriert` an den Kritiken herum. Daß MRR schreiben will, versteht er überhaupt nicht, er habe das auch gar nicht gewollt. “127

123 Unseld: Chronik, Juli 1979. In: Handke/Unseld: Der Briefwechsel (Anm. 60), S. 367. Unselds Chronik-Eintrag endet mit dem für die Beziehung des Verlegers zu seinem Autor bezeichnenden Satz: „Man muß schon von seiner Sache überzeugt sein und sich stark fühlen, um da nicht umzukippen." (Ebd., S. 368)

124 Auch sein,Werbungsverbot' blieb wirkungslos, wie u. a. Unselds Brief vom 27. 8. 1979 zeigt. Vgl. ebd., S. $368 \mathrm{f}$.

125 Vgl. Urs Jenny: Ein Messias der Natur. In: Der Spiegel, Nr. 41, 8. 10. 1979, S. 247-249, hier S. 249 : „[N]ie war man so sehr wie hier (wo doch Hinwendung zum Nächsten das Credo ist) Zuhörer eines sehr kühnen und sehr selbstseligen Selbstgesprächs, in sauerstoffarmen Kunsthöhen, fern und ein bißchen zu schön.“ Vgl. zur negativen „Kritik an Sprache und Stil“ von Handkes Erzählung Gerhard Pfister: Handkes Mitspieler. Die literarische Kritik zu Der kurze Brief zum langen Abschied, Langsame Heimkehr, Das Spiel vom Fragen, Versuch über die Müdigkeit. Bern u. a.: Lang 2000, S. 128-130.

126 Handke an Unseld, 15. 10. 1979. In: Handke/Unseld: Der Briefwechsel (Anm. 60), S. 384.

127 Unseld: Salzburg, 5.-6. November 1979. In: ebd., S. 385; vgl. zur Rezeption der Langsamen Heimkehr auch Handkes nachträglichen Kommentar in einem 1988 geführten Interview: „Am Anfang war eigentlich so eine gutmütige Ratlosigkeit, bis auf ein oder zwei Kritiker, die gleich 
Unter dem Titel Peter Handke und der liebe Gott wurde Reich-Ranickis Rezension am 17. November 1979 im Feuilleton der Frankfurter Allgemeinen Zeitung veröffentlicht. Genüsslich wärmt der Kritiker darin seine bereits früher formulierten Einwände gegen Handke und dessen Leserschaft auf: Hatte er 1972 anlässlich der Besprechung der Erzählung Wunschloses Unglück abschätzig festgestellt, dass die „Handke-Euphorie [...] von pensionsreifen Germanisten bis zu zarten Gymnasiastinnen“ reiche, ${ }^{128}$ modifiziert er dieses Spektrum sieben Jahre später nur geringfügig, um die „Handke-Euphorie, die um 1970 epidemisch um sich griff und ebenso betagte Philologen wie zarte Teenager befiel“, erneut als veritable Fehlleistung des Literaturbetriebs und als „mysteriöses Phänomen“ zu beschreiben. ${ }^{129}$ Im Rückblick auf dessen schriftstellerische Laufbahn zeichnet der Rezensent Handke noch einmal als „Trotzköpfchen“ der deutschen Literatur, dessen Prominenz nicht auf die Qualität der bislang vorgelegten literarischen Arbeiten, sondern auf die geschickte Vermarktungsstrategie des jungen Autors und seines Verlags zurückzuführen sei. Zudem setzt er das erzählerische Verfahren von Handkes Die linkshändige Frau ein weiteres Mal mit Courths-Mahler in Beziehung, deren als ,Groschenhefte' aufgelegte Romane sich andauernder Popularität erfreuten: „Das Prosastück ,Die linkshändige Frau' (1976), angeblich eine ,Erzählung', doch in Wirklichkeit der schludrig geschriebene Entwurf eines Filmdrehbuchs“, heißt es in der Rezension, „nähert sich bedenklich der Welt der Hedwig Courths-Mahler. “130

Zunächst richtet sich Reich-Ranicki in seiner maliziösen Besprechung von Langsame Heimkehr aber gegen jene Vertreter seiner eigenen Zunft, die Handkes Arbeiten in den vergangenen Jahren, trotz dessen augenfälliger „Produktionskrise“, „meist kniend, also in einer Position, die weder das Denken noch das Schreiben begünstigt“, rezensiert hätten. ${ }^{131}$ Handke wird gleich eingangs

drauflosgehämmert haben. “ (Konrad Funcke: Wir müssen fürchterlich stottern. Die Möglichkeit der Literatur - Gespräch mit dem Schriftsteller Peter Handke. In: Süddeutsche Zeitung, 23. 6. 1988)

128 Reich-Ranicki: Die Angst des Peter Handke beim Erzählen (Anm. 56).

129 Marcel Reich-Ranicki: Peter Handke und der liebe Gott. Zu der Erzählung Langsame Heimkehr. In: Frankfurter Allgemeine Zeitung, 17. 11. 1979. Zur Konstanz bestimmter Themen und Urteile in der Handke-Rezeption vgl. Pfister: Handkes Mitspieler (Anm. 125), bes. S. 276 f., sowie zuletzt Alexander Honold: Der Erd-Erzähler. Peter Handkes Prosa der Orte, Räume und Landschaften. Stuttgart: Metzler 2017, S. 106, Anm. 2.

130 Reich-Ranicki: Peter Handke und der liebe Gott (Anm. 129). Der Kritiker hat die Autorin wiederholt als abschreckendes Beispiel trivialen Erzählens angeführt; vgl. etwa Reich-Ranicki: Der doppelte Boden (Anm. 45), S. 47: „Statt [...] nach des Tages Arbeit, wie es sich gehört, das Land der Griechen mit der Seele zu suchen, warfen sich die schamlosen Leser an den Busen verschiedener Damen - von Eugenie Marlitt und Nataly von Eschstruth bis zur Hedwig Courths-Maler [sic].“

131 Reich-Ranicki: Peter Handke und der liebe Gott (Anm. 129). Vgl. ebd.: „So befindet sich Handke nun schon seit Jahren in einer Produktionskrise, über die nichts hinwegtäuschen kann - am wenigsten die emsigen Bemühungen seiner Paladine. Während diese auch seine 
als Liebkind von Literaturkritik und Germanistik apostrophiert, denen er „bequeme Objekte der Interpretationskunst“ geliefert habe. Reich-Ranicki ist dabei bemüht, sich vom literaturkritischen Mainstream, der Handkes Bücher bis zuletzt „andächtig rezensiert“ habe, abzugrenzen; er selbst habe, wie er nicht müde wird zu betonen, schon früh die Schwächen des Autors erkannt und hervorgehoben. ${ }^{132}$ Der Kritiker zeigt sich in der Folge ob der „dürftige[n] Handlung“ der Erzählung enttäuscht - „Was in diesem Buch geschieht, läßt sich rasch andeuten, denn es geschieht nur sehr wenig“ -, moniert, dass der Protagonist des Buches, Valentin Sorger, gemessen an den Standards realistischen Erzählens unzureichend geschildert wird, ${ }^{133}$ und kann dies folgerichtig nur als Defizit wahrnehmen: „Ob dieser Mann jung oder alt, dünn oder dick ist, wissen wir nicht; über seine Herkunft, seine Nationalität und ähnliche vielleicht nicht ganz unwichtige Umstände finden wir in dem Buch keinerlei Auskünfte. “134 Schließlich steigert sich die Rezension zum polemischen Verriss, der dem Autor „intellektuelle[ ]“ wie „künstlerische[ ]“ Unzulänglichkeit attestiert. Handkes vermeintliche „Hinwendung zu Gott“ beschreibt Reich-Ranicki als Symptom literarischen Scheiterns:

[D]er beschwörende Prediger und raunende Heilsverkünder Handke schreibt - von wenigen schönen Passagen abgesehen - eine hochpathetische, angestrengte und umständliche Prosa, deren schiefe Bilder und preziöse Vergleiche die Dürftigkeit der Gedanken nicht verbergen können, hingegen auf unbeabsichtigte Weise ihrer Konfusion entsprechen. ${ }^{135}$

Ja, Reich-Ranicki sieht den Autor der Langsamen Heimkehr seiner literarischen Ambition gleich auf mehreren Ebenen nicht gewachsen:

Das sich wandelnde Verhältnis denkender Zeitgenossen zum Glauben ist wahrlich ein großes, ein gewaltiges Thema, immer wieder der literarischen Darstellung wert. Doch wer Handkes frühere Bücher nüchtern gelesen hat, den kann es nicht wundern, daß ein solches Thema seine Möglichkeiten übersteigt - die künstlerischen wie die intellektuellen. ${ }^{136}$

offensichtlichen Niederlagen in heimliche Siege ummünzen möchten, ist er selber auf der Suche nach einem Ausweg."

132 Ebd.

133 Zum, Realismus-Problem ' in der Rezeption von Langsame Heimkehr vgl. den aufschlussreichen Kommentar in Pfister: Handkes Mitspieler (Anm. 125), S. 144-157, zu Reich-Ranicki dabei insbes. S. $147 \mathrm{f}$.

134 Reich-Ranicki: Peter Handke und der liebe Gott (Anm. 129).

135 Ebd.

136 Ebd. 
Die Besprechung schließt mit dem süffisanten Hinweis, Langsame Heimkehr sei „das seit Jahren erste Buch Peter Handkes, das sich auf keiner Bestsellerliste findet. Man sage nicht, bei uns gäbe es keinen Fortschritt. “137 Das neueste Buch Handkes erreiche, so lautet Reich-Ranickis Insinuation, nun nicht einmal mehr die dem Autor einst gewogenen Leserinnen und Leser. Während der Kritiker im Sommer 1979 die Lyrik der bis zu diesem Zeitpunkt weitgehend unbekannten Autorin Ulla Hahn für sich entdeckt hatte und in und mit der FAZ mit Nachdruck für sie eintrat, ${ }^{138}$ war Handke mit dem Verriss der Langsamen Heimkehr endgültig zur persona non grata in der Frankfurter Redaktion geworden.

Bei diversen Gelegenheiten sollte der Kritiker in den folgenden Jahren die Einschätzung wiederholen, Handke habe sich Ende der 1970er Jahre auf ,religiöse Literatur 'kapriziert ${ }^{139}$ und damit endgültig die Schärfe des Verstandes eingebüßt sowie den Anschluss an eine ernstzunehmende Gegenwartsliteratur verloren. Gut eineinhalb Jahre nach seiner Rezension von Langsame Heimkehr nahm Reich-Ranicki längere Passagen aus ihr in seine ebenfalls in der FAZ gedruckte Abhandlung Gibt es eine neue Innerlichkeit? auf, um anhand des bei Handke „reichlich verwendete[n] sakrale[n] Vokabular[s]“ zu veranschaulichen, „daß die Innerlichkeit in unserer Epoche“ zumeist „mit künstlerischer Qualitätseinbuße, ja mit literarischem Verfall zu tun hat “. ${ }^{\text {140 }}$ Fest steht: Selbst im Kontext einer äußerst „kontroversen Rezeption“ ${ }^{141}$ der Erzählung im deutschsprachigen

137 Ebd. Wolf: Autonomie und/oder Aufmerksamkeit? (Anm. 4), S. 55, Anm. 49, zufolge zeigt Reich-Ranickis Rezension von Langsame Heimkehr „seine völlige Verständnislosigkeit gegenüber maßgeblichen Errungenschaften der literarischen Moderne“.

138 Vgl. Joachim Wittkowski: Das souveräne Bekenntnis zu sich selbst. Notizen zu einem,Fall‘ der bundesdeutschen Literaturkritik. In: Text + Kritik (1988), H. 100, S. 59-65.

139 Eine Diagnose, die schon 1979 auf einer sehr selektiven Lektüre der Langsamen Heimkehr beruht, da der Text auf der Distanz zu Formen traditioneller Religiosität und institutionell abgesicherten Glaubens beharrt: „Es verlangte ihn wohl nach einem auf etwas gerichteten Glauben, ohne daß er sich einen Gott je denken konnte; aber in Zeiten der Bedrängnis merkte er, daß er - bloß zwanghaft? - geradezu flehentlich immer einen Gott mitdenken wollte. (Zuweilen wünschte er sich, fromm zu sein - was ihm nie gelang; er war dann aber sicher, daß, die Götter ‘ ihn verstanden.)“ (Handke: Langsame Heimkehr [Anm. 28], S. 17) - Zur Reaktion der Literaturkritik auf den Komplex ,Metaphysik/Religion' in Langsame Heimkehr, die die Unterscheidung von Autor und Figur mitunter geflissentlich ignorierte, vgl. Pfister: Handkes Mitspieler (Anm. 125), S. 134-144; Graf: Peter Handke und seine Kritiker (Anm. 72), S. 93 f.

140 Marcel Reich-Ranicki: Gibt es eine neue Innerlichkeit? In: Frankfurter Allgemeine Zeitung, 6.6.1981; zit. nach: M. R.-R.: Nichts als Literatur. Aufsätze und Anmerkungen. Stuttgart: Reclam 1990, S. 78-85, hier S. 85. Die oben bereits zitierte Stelle aus der Besprechung von Langsame Heim$k e h r$ wird darin nur geringfügig variiert: „Handke, der in den späten sechziger und den frühen siebziger Jahren ein wichtiger Vertreter der jungen Literatur war, schreibt, seit es sein Ehrgeiz ist, sich als Heilsverkünder zu betätigen, eine angestrengte und hochpathetische Prosa. Ihre schiefen Bilder und preziösen Vergleiche können die Dürftigkeit seiner Gedanken nicht verbergen.“

141 Pfister: Handkes Mitspieler (Anm. 125), S. 120. 
Feuilleton markierte Peter Handke und der liebe Gott eine extreme Variante der Ablehnung, die einen Widerspruch des derart Attackierten nachgerade provozierte. Öffentlich schwieg der Autor jedoch einstweilen.

Mitunter sei ihm, so Handke knapp zwei Wochen später in einem Brief an Hermann Lenz, „auch das Böseste ganz recht; als ob es dazugehört. Ob’s mich weiterbringt, das weiß ich freilich nicht. “142 Lenz riet seinem Freund postwendend, sich „vorzustellen, wie man dem Schreiber bei der nächsten Gelegenheit gegen das Schienbein treten wird“, seine Aggression ansonsten aber für sich zu behalten; er war sich freilich bewusst, dass „Nichtbeachtung“ mitunter „am mühsamsten zu erlernen“ ist: „Schade, dass man nicht stumpfsinniger wird, zumindest gegenüber so etwas. ${ }^{\text {"143 }}$ Handke verzichtete in der Folge zwar einstweilen auf eine öffentliche Entgegnung, ${ }^{144}$ widmete sich im Frühjahr 1980 im Zuge der Niederschrift von Die Lehre der Sainte-Victoire aber einer neuen, zunächst verdeckten Form der polemischen Erwiderung: Er ließ den Kritiker dabei, wie im Folgenden im Detail gezeigt wird, nach seiner Erwähnung in den experimentellen Deutschen Gedichten von 1969 ein weiteres Mal in einem dezidiert literarischen Text auftreten. ${ }^{145}$

In Langsame Heimkehr hatte Handke seinen Protagonisten Sorger „die Kraft zu einer bleibenden Versöhnung“ an sich wahrnehmen lassen, die auf „Harmonie“, „Synthese“ und „Heiterkeit“ gerichtet sei. ${ }^{146}$ Reich-Ranickis Rezension, die die Erzählung mit Bezug auf Passagen wie diese als ärgerliche „Erbauungsliteratur“ diskreditiert hatte, ${ }^{147}$ hebelte das in Langsame Heimkehr skizzierte, gleichwohl als stets gefährdet geschilderte Ideal der Konzilianz und Friedfertigkeit nachhaltig aus. Wiederholt hat Handke auf diesen Widerstreit in seiner charakterlichen

142 Handke an Lenz, 29.11. 1979. In: Handke/Lenz: Berichterstatter des Tages (Anm. 103), S. 139.

143 Lenz an Handke, 10. 12. 1979. In: ebd., S. 140. In Lenz’ Äußerung zu Reich-Ranickis Besprechung wurden, so der Kommentar, „[z]wei Worte aus Gründen des Persönlichkeitsschutzes getilgt“ (ebd., S. 344).

144 Er hatte sich die entsprechende Zurückhaltung bereits einige Jahre zuvor auferlegt: „Ich würde das [i.e. eine Antwort auf negative Kritiken zu schreiben] nicht mehr machen. " (Durzak/ Handke: Für mich ist Literatur auch eine Lebenshaltung [Anm. 81], S. 330)

145 In einem der Briefumschläge des 1969 ausgelieferten Buches Deutsche Gedichte (erschienen im Frankfurter Euphorion Verlag) befand sich eine Liste mit dem Titel „Prominente Kritiker empfehlen neue Bücher“, in der u. a. der folgende Eintrag verzeichnet war: „MARCEL REICHRANICKI: Alfred Polgar: Auswahl / Er war ein Grandseigneur der deutschen Prosa." Das von Handke verwendete Zitat stammt aus Marcel Reich-Ranicki: Alfred Polgars sanfte Gewalt. Eine neue Auswahl seiner Prosa aus vier Jahrzehnten. In: DIE ZEIT, Nr. 24, 15. 6. 1968. Daneben finden sich auf der gefalteten A4-Seite auch knappe Buchempfehlungen von Helmut Heißenbüttel (über Gisela Elsner), Urs Jenny (über Hubert Selby), Walter Jens (über Hubert Fichte) und Rolf Michaelis (über Peter O. Chotjewitz).

146 Handke: Langsame Heimkehr (Anm. 28), S. 140.

147 Reich-Ranicki: Peter Handke und der liebe Gott (Anm. 129). 
Disposition hingewiesen: „Die Aggressionen, der Zorn und der Haß sind in mir sehr stark. Das ist ein grober Widerpart zu meinem starken Bedürfnis nach Friede und Versöhnung, was für mich das geltende Gesetz ist. Aber die Energie, um dieses Gesetz zu formulieren, bekomme ich nur von meiner Aggressivität. “148 Reich-Ranickis Besprechung von Langsame Heimkehr führte zu einer nochmaligen Verschärfung des Konflikts zwischen den beiden Kontrahenten, den Handke nun auf das Feld des fiktionalen Schreibens, d. h. auf sein heimatliches Territorium lenkte.

\section{Die Bestie von Puyloubier (Die Lehre der Sainte-Victoire)}

Handkes Arbeit an dieser Erwiderung ist in den Werkmaterialien zur Lehre der Sainte-Victoire, die im Deutschen Literaturarchiv in Marbach aufbewahrt werden, dokumentiert: In ersten Entwürfen zum Kapitel „Der Sprung des Wolfs“, entstanden Ende März 1980, hatte Handke noch die Initialen Reich-Ranickis („MRR“) notiert, diese im Zuge der weiteren Ausarbeitung der Passage aber wieder gestrichen. ${ }^{149}$ Der explizite Verweis ist in der publizierten Fassung des Textes vollständig getilgt: Dass das „Erlebnis mit ,meinem“ Hund“150 am Rande der Ortschaft Puyloubier auch das belastete Verhältnis von Autor und Kritiker reflektiert und literarisch in Szene setzt, behielt Handke zunächst für sich. ${ }^{151}$ In zeitgenössischen Rezensionen des Buches ebenso wie in ersten Forschungsarbeiten zur Lehre taucht kein Hinweis auf diese Lesart auf; auch der attackierte Kritiker meldete sich vorerst nicht selbst zu Wort. Allerdings bezeichnete Franz Josef Görtz, ein enger Mitarbeiter Reich-Ranickis, den Band in der FAZ als

148 Renate Poßarnig: „Ich möchte nicht verehrt werden“. [Gespräch mit Peter Handke.] In: stern, Nr. 40, 30. 9. 1982. Zu diesem Konflikt, auch in der erzählerischen Anlage der Lehre der SainteVictoire, vgl. Martina Kurz: Bild-Verdichtungen. Cézannes Realisation als poetisches Prinzip bei Rilke und Handke. Göttingen: Vandenhoeck \& Ruprecht 2003, S. 55; zum Problem des Hasses in Handkes Texten, besonders im Journalband Das Gewicht der Welt, jetzt grundlegend Bohrer: Mit Dolchen sprechen (Anm. 112), S. 428-441.

149 Vgl. dazu den detaillierten Kommentar von Christoph Kepplinger-Prinz. In: Handke online, http://handkeonline.onb.ac.at/node/355 (Stand 14.10. 2020).

150 Handke: Die Lehre der Sainte-Victoire (Anm. 10), S. 53.

151 Eine Anekdote am Rande: Gerade in den Wochen, in denen Handke an der Lehre der SainteVictoire schreibt, teilt Siegfried Unseld Thomas Bernhard die aktuellen Rückmeldungen auf die Ankündigung der „Neuen Folge“ der „edition suhrkamp“ mit; die kritische Aufnahme der neuen Reihe im Feuilleton beschreibt Unseld als das Gebell von Hunden: „Ich höre gerne, daß Sie so konzentriert an Ihren Arbeiten sitzen; ich tue das auch. Die Neue Folge der edition suhrkamp ist angekündigt; die Hunde bellen, die Karawane aber zieht weiter." (Siegfried Unseld an Thomas Bernhard, 4.3. 1980. In: T. B./S. U.: Der Briefwechsel. Hg. v. Raimund Fellinger, Martin Huber u. Julia Ketterer. Frankfurt a. M.: Suhrkamp 2009, S. 589) 
"dürftige Skizze über das Besondere und das Allgemeine", Handke selbst als einen „Propheten“ und „empfindsamen Zeitgenossen“, der seinen literarischen Zenit längst überschritten habe; Görtz verriss Handkes Lehre der Sainte-Victoire also gewissermaßen stellvertretend für seinen Vorgesetzten. ${ }^{152}$

Reich-Ranicki selbst konstatierte in einem Kommentar zu den aktuellen Programmen deutscher Verlage lediglich, es handle sich ganz allgemein um einen „schlechte[n] Bücherherbst", in dem sogar die „,bewährten Autoren“ wie Jurek Becker, Hans Magnus Enzensberger oder Adolf Muschg nur mittelmäßige Werke vorgelegt hätten. ${ }^{153}$ Ohne Handkes neuestes Buch mit einem Wort zu erwähnen, kann er sich einen Seitenhieb doch nicht verkneifen: Der rezente Erfolg des Frankfurter Suhrkamp Verlags und seines Verlegers Siegfried Unseld habe dazu geführt, dass dieser sich „alles leisten“ könne:

[W]enn er Lust hätte, auch eine Ludwig-Ganghofer-Gesamtausgabe. Oder die Gesammelten Werke von Peter Rosegger. Ich sehe sie schon vor mir: acht Bände in Leinen und gleichzeitig eine Werkausgabe in der edition suhrkamp, ausgestattet von Willy Fleckhaus, mit einem Vorwort von Peter Handke (das sich allerdings als eine Nacherzählung des Buches Als ich noch ein Waldbauernbub war erweisen wird) und mit einem Essay über die Heimatliteratur von Martin Walser, einer Arbeit aus dem Jahre 1976, in der sich kein Wort über Rosegger findet. ${ }^{154}$

Karikiert Reich-Ranicki hier vorderhand die Programmplanung des Suhrkamp Verlags, der aufgrund seines Erfolgs und des Renommees seiner Autoren sogar mit einer Ganghofer- oder Rosegger-Ausgabe reüssieren könne, ist die von ihm skizzierte editorische Dystopie vor allem ein Anlass zur erneuten Stichelei gegen Handke. Mit dem fingierten Titel des Vorworts, der Handkes 1968 publizierten Lektürebericht Als ich "Verstörung" von Thomas Bernhard las aufgreift, spielt der

152 Franz Josef Görtz: Wallfahrt eines Propheten. Peter Handkes Die Lehre der Sainte-Victoire. In: Frankfurter Allgemeine Zeitung, 16.12.198o. Ein gutes Jahrzehnt später hat Handke diesen Stellvertreterangriff im stern-Gespräch mit Sven Michaelsen als gängige Praxis dieser Zeit moniert: „Als er [i. e. Reich-Ranicki] selber nicht mehr schrieb, haben sich ,FAZ'-Leute dazu hergegeben, in seinen Diensten meine Bücher anzufaulen. Nie werde ich ihm auch nur das Kleinste verzeihen können.“ (Michaelsen/Handke: „Ab und zu sticht mich ein Teufelchen“ [Anm. 30], S. 126)

153 Marcel Reich-Ranicki: Der Kaiser ist nackt oder: Über den Herbst unserer Bücher. In: Frankfurter Allgemeine Zeitung, 17.10.1980; zit. nach: M. R.-R.: Nichts als Literatur (Anm. 140), S. $66-77$, hier S. 71.

154 Ebd., S. 7o. Traut man den Memoiren von Friedrich Christian Delius: Als die Bücher noch geholfen haben. Biografische Skizzen. Berlin: Rowohlt 2012, S. 52, hatte Handke 1966 im Anschluss an die Princetoner Tagung „auf dem Empire State Building“ in New York nicht nur sich selbst als „den neuen Kafka“ ausgerufen, sondern auch Günter Grass „als ,den besseren Ganghofer“" abgekanzelt. 
Kritiker auf die in Wunschloses Unglück (1972) geschilderte Herkunft des Autors aus einfachen Verhältnissen an. Wenn Reich-Ranicki ausgerechnet Handke als potentiellen Verfasser des Vorworts nennt, ist das zudem als eine Spitze gegen dessen Affinität zu einer Literatur des ländlichen Raums zu verstehen - Handke hatte Mitte der 1970er Jahre Erzählungen des österreichischen Autors Franz Nabl im Residenz Verlag herausgegeben, Reich-Ranicki den Abdruck von Handkes Vorwort in der FAZ, wie bereits zitiert, mit Blick auf die mangelnde Bekanntheit Nabls in Deutschland abgelehnt. Handke galt dem Kritiker wohl seitdem als Statthalter von Autoren wie Rosegger oder Nabl im zeitgenössischen literarischen Feld. ${ }^{155}$

Die Lehre der Sainte-Victoire tauchte 1980 im offiziellen Suhrkamp-Herbstprogramm nicht auf. Überdies hatte der Verlag auf Wunsch Handkes keine Rezensionsexemplare des Buches versendet. ${ }^{156}$ Wie schon bei Langsame Heimkehr war dem Autor daran gelegen, sich den Abläufen und Konventionen des Literaturbetriebs demonstrativ zu verweigern: „Er will viele Leser, aber keine professionellen" ${ }^{157}$ hatte Siegfried Unseld im April des Jahres in seinem Reisebericht festgehalten. Die Idee, die Lehre der Sainte-Victoire durch den Verzicht auf Rezensionsexemplare der literaturkritischen Kommentierung zu entziehen „Und ich bitte noch einmal, zu beachten, daß es keine Besprechungsexemplare geben soll, für niemanden“ ${ }^{\text {“158 }}$-, ließ sich freilich nicht realisieren: Die „stille Programmatik “159 des Buches stieß im Feuilleton auf geteiltes Echo; scharfzüngige Bemerkungen wie jene von W. Martin Lüdke, man werde „sich halt daran gewöhnen müssen, Handke und seinen Heiligenschein künftig immer zusammen zu sehen“, ${ }^{160}$ waren keine Seltenheit. Lüdke äußerte freilich auch die Vermutung,

155 In seiner Vorbemerkung zur Neuausgabe von Franz Michael Felders Autobiographie bezieht sich Handke 1985 u. a. auf den „Waldbauernbub Peter Rosegger“ (Peter Handke: Zu Franz Michael Felder. In: Franz Michael Felder: Aus meinem Leben. Mit einer Vorbemerkung v. Peter Handke u. einem Nachwort v. Walter Methlagl. Salzburg, Wien: Residenz 1985, S. 5-6, hier S. 5).

156 Vgl. N. N.: Geheim-Werk von Peter Handke. In: Der Spiegel, Nr. 37, 8. 9. 1980, S. 184. Der Vorwurf, den Manfred Durzak: Peter Handke und die deutsche Gegenwartsliteratur. Narziß auf Abwegen. Stuttgart u. a.: Kohlhammer 1982, S. 13, darauf aufbauend konstruiert hat, ist durchaus perfide, weil er die Verweigerung Handkes gerade als größtmögliche Affirmation deutet: „Die Tatsache, daß Handke seinem Verlag untersagte, Rezensionsexemplare seines Buches, Die Lehre der Sainte-Victoire` zu verschicken, daß er sich jegliche Werbung für die ,Linkshändige Frau' verbat, sind ja nur indirekte Bestätigungen der übergroßen Bedeutung, die der Literaturbetrieb für ihn hat. Und prompt haben sich diese Restriktionen ja auch eher verkaufsfördernd als -hemmend ausgewirkt."

157 Unseld: Reisebericht, 5./6. April 1980. In: Handke/Unseld: Der Briefwechsel (Anm. 60), S. 399.

158 Handke an Unseld, 5. 8.1980. In: ebd., S. 416.

159 Uwe Schultz: Die Suche nach dem reinen Augenblick. Peter Handke: Die Lehre der SainteVictoire. In: Hannoversche Allgemeine Zeitung, 11. 10.1980.

160 W. Martin Lüdke: Der heilige Handke? Peter Handkes erzählende Poetik Die Lehre der SainteVictoire. In: Frankfurter Rundschau, 25.10.1980. 
Handke habe „sein Buch gar nicht um jeden Preis der Kritik entziehen“ wollen, „ihn interessiert diese Kritik einfach nicht (mehr) ${ }^{\text {“ } 161}$ Nicht wenige Rezensenten sahen in der "Selbstbefragung des Schriftstellers ${ }^{\text {“162 }}$ auch einen weiteren Schritt Handkes in seiner Abkehr vom zeitgenössischen Literaturbetrieb: „Der Schriftsteller hat dieses Buch und möglicherweise auch manche seiner früheren, dieses aber speziell, so geschrieben, weil alle anderen Schriftsteller ihre Bücher so schreiben, wie er sie nie schreiben würde", so Gunter Schäble im Spiegel. ${ }^{163}$ Schäble macht Handke somit dessen zu offensichtliches Bemühen, anders schreiben zu wollen als „alle anderen Schriftsteller“, zum Vorwurf. Seine Kritik trifft sich jedoch recht genau mit einem entscheidenden Antrieb von Handkes literarästhetischem Neuansatz im Umfeld und im Nachhall von Langsame Heimkehr: nicht mehr "das Kind seiner Zeit zu sein", ${ }^{164}$ sondern seine Poetik ganz bewusst als provokativen, weil betont anachronistischen Gegenentwurf zum Status quo des literarischen Feldes zu verfolgen. Handke suchte, wie Otto Lorenz anschaulich gezeigt hat, zumal im Kontext der Neuausrichtung seines Schreibens Ende der 1970er Jahre „konsequent individualistisch seinen eigenen Weg“; seine „literarische Methode“ definierte er dabei stets „in kritischer Abwehr von bereits festgeschriebenen Konventionen". ${ }^{\text {“ } 165}$

Erst im März $1989^{166}$ hat Handke in einem ausführlichen Gespräch mit André Müller in der Hamburger ZEIT bekannt, als "kleine Bosheit“ in die Lehre der Sainte-Victoire „ein langes Kapitel über den Kerl aus Frankfurt" eingearbeitet zu haben, „wo er als Hund auftritt“. Auf Müllers Nachfrage, ob er damit ReichRanicki, der bereits zuvor Thema des Gesprächs gewesen war, meine, bestätigt Handke dies: „Ja, das hat mir unglaubliches Vergnügen bereitet. ${ }^{\mathrm{c} 167}$ - Eingebettet

161 Ebd.

162 Sigrid Löffler: Erdforschung. In: profil, Nr. 41, 6.10.1980, S. 61.

163 Gunter Schäble: Vom Himmel durch die Welt zur Helle. In: Der Spiegel, Nr. 50, 8.12.1980, S. 213-216, hier S. 215.

164 Peter Handke: Aber ich lebe nur von den Zwischenräumen. Ein Gespräch, geführt von Herbert Gamper. Zürich: Ammann 1987, S. 125.

165 Lorenz: Die Öffentlichkeit der Literatur (Anm. 25), S. 167.

166 Das Interview fand bereits am 15. Oktober 1988 statt. Vgl. die Angabe in Müller: Im Gespräch mit Peter Handke (Anm. 112), S. 59. Hatte Reich-Ranicki womöglich schon vor der Publikation des Gesprächs im März 1989 von Handkes Äußerungen Wind bekommen? In einem Fragebogen der ZEIT beantwortete er den Punkt „Was verabscheuen Sie am meisten?“ jedenfalls schon Ende 1988 mit: „Zur Zeit: Unversöhnlichkeit, die von verletzter Selbstliebe herrührt, und Rachsucht, die mit maßlosem Ehrgeiz zu tun hat.“ (Grn [i. e. Ulrich Greiner]: Marcel Reich-Ranicki geht und bleibt. In: DIE ZEIT, Nr. 1, 30.12.1988, S. 44)

167 André Müller: Wer einmal versagt im Schreiben, hat für immer versagt. [Gespräch mit Peter Handke.] In: DIE ZEIT, Nr. 10, 3.3.1989, S. 77-79, hier S. 79. In der Folge zit. nach: Müller: Im Gespräch mit Peter Handke (Anm. 112), S. 57-102, hier S. 88. Zur Aufdeckung des ReichRanicki-Bezugs im vierten Kapitel der Lehre der Sainte-Victoire vgl. auch die Schilderung in 
in die kontemplative Schilderung einer Wanderung, zeichnet Handke in der Fiktion der Lehre der Sainte-Victoire Reich-Ranicki in der Figur einer blutrünstigen Dogge als papierverschlingendes Untier, „die Gier und zugleich die Unlust in Person“. ${ }^{168}$ Schon in Das Gewicht der Welt (1977) hatte Handke die Begegnung mit einem Exemplar dieser Hunderasse geschildert, bei der er „nach dem Notizbuch wie nach einer Waffe" getastet habe; ${ }^{169}$ in Langsame Heimkehr tauchen die Tiere mehrmals nicht als loyale und zutrauliche Begleiter des Menschen, sondern als „Symbol[e] des Unheils“ auf. ${ }^{170}$ Nun, in der Lehre der Sainte-Victoire, rückt Handke dem Hund tatsächlich schreibend zu Leibe. Hermann Lenz jedenfalls gratulierte umgehend und wohl im Wissen um den Subtext der geschilderten Hunde-Episode: „Den Höllenhund [...], den macht Dir neben vielem anderen $[. .$.$] niemand nach. { }^{~} 171$

In der südlichen Provence auf den Spuren von Paul Cézanne unterwegs, trifft der autornahe Erzähler, der schon seit Kindertagen einen „unüberwindlichen Widerwillen gegen die meisten Hunde“ hegt, auf eine schwarze Dogge: In dem großen Hund, der hinter einem Zaun auf dem Gelände einer Kaserne lauert und schon eingangs als „Bestie“ apostrophiert wird, erkennt er augenblicklich nicht bloß einen unberechenbaren Angreifer, sondern seinen „Feind“ ${ }^{172}$ Sogleich gesellen sich weitere Hunde zu ihrem vermeintlichen „Leithund“; bellen die anderen Tiere des Rudels jedoch „eher temperamentlos und rhetorisch“, fühlt sich der Erzähler von deren Anführer ausdrücklich „gehaßt“:

Sein Körper wirkte bunt, während Kopf und Gesicht tiefschwarz waren. „Sieh dir das Böse an“, dachte ich. Der Schädel des Hundes war breit und erschien trotz der hängenden Lefzen verkürzt; die Dreiecksohren gezückt wie kleine Dolche. Ich suchte

André Müller: Das Schreien. Über Marcel Reich-Ranicki. [2002] In: A. M.: „Sie sind ja wirklich eine verdammte Krähe!“ Letzte Gespräche und Begegnungen. Mit einem Vorwort v. Elfriede Jelinek. München: LangenMüller 2011, S. 160-168, hier S. 166-168.

168 Handke: Die Lehre der Sainte-Victoire (Anm. 10), S. 59. Als Interpretation der Episode vgl. jetzt die lesenswerte Darstellung von Honold: Der Erd-Erzähler (Anm. 129), S. 197-201.

169 Handke: Das Gewicht der Welt (Anm. 99), S. 316. Dazu noch die Bemerkung in Ulrich von Bülow: „Wait and see!“ Peter Handke im Gespräch. In: Das stehende Jetzt. Die Notizbücher von Peter Handke. Gespräch mit dem Autor und Essays von U. v. B. Marbach a. N.: Deutsche Schillergesellschaft 2018, S. 5-63, hier S. 9: „Damals habe ich kleine Notizbücher gezogen wie eine Art von Waffe. Wie im Western James Stewart, oder wer auch immer, plötzlich einen Revolver zieht.“

170 Alexander Huber: Versuch einer Ankunft. Peter Handkes Ästhetik der Differenz. Würzburg: Königshausen \& Neumann 2005, S. 234. Vgl. ebd.: „Überall im Text trifft man auf Hunde, sei es vereinzelt, sei es als Meute. Sie sind Symbole des drohenden Nichts, selbst im Detail.“

171 Lenz an Handke, 17. 8. 1980. In: Handke/Lenz: Berichterstatter des Tages (Anm. 103), S. 147.

172 Handke: Die Lehre der Sainte-Victoire (Anm. 10), S. 54 u. 56. 
die Augen und traf auf ein Glimmen. [...] Sein Leib war kurzhaarig, glatt und gelbgestromt; der After markiert von einem papierbleichen Kreis; die Rute fahnenlos. ${ }^{173}$

Die Konfrontation von Mensch und Hund erweist sich in der Folge nicht bloß als beiläufige Episode, vielmehr als sorgsam durchkomponierte und anspielungsreiche Verteidigung einer Poetik, als Kampf gegen einen Kontrahenten, von dem man erzählen muss, um über ihn hinwegzukommen: „Ich kann nicht weiter, ehe ich den nicht los bin. “ ${ }^{174}$ Die Unvereinbarkeit im Habitus und die gegensätzlichen literarischen Ästhetiken der beiden Antagonisten werden von Handke in einer Vielzahl von Details ins Spiel gebracht: ${ }^{175}$

Als der böse Lärm wieder einsetzte, verschwand die Landschaft in einem einzigen Strudel aus Bombentrichtern und Granatlöchern. [...] Danach stand er still drohend und las aufmerksam und lange in meinem Gesicht, doch einzig nach Zeichen der Angst und der Schwäche. Ich begriff: Er meinte gar nicht mich-im-besonderen, sondern sein Blutdurst war hier auf dem Territorium der Fremdenlegion, wo nur mehr das Kriegsrecht galt, auf jeden dressiert, der, unbewaffnet und ohne Uniform, bloß war, der er war. (Wenigstens einen müßte es doch geben, der unbewaffnet bliebe, schrieb diesbezüglich einmal ein solch ein bloßes Ich.) Er, der Wachhund, im Gelände; und ich im Gefilde (für das er naturgemäß keine Augen hatte, weil das Wirkliche für ihn einzig sein Sperrgebiet war) $\left[\ldots . .{ }^{176}\right.$

Der Hinweis, wonach auf dem „Territorium“ der gegenwärtigen Konfrontation „nur mehr das Kriegsrecht“ gelte, verweist auf den existentiellen Ernst der Situation. Die abschließende Wendung über den Wirklichkeitsbegriff des ,Wachhundes' lässt sich mit Reich-Ranickis gängiger Praxis in Beziehung setzen, „die künstlerische Gestaltung literarischer Figuren an seinen Vorstellungen eines adäquaten Verhaltens in der Realität“ zu messen; ${ }^{177}$ ganz in diesem Sinne

173 Ebd., S. $56 \mathrm{f}$.

174 Ebd., S. 53.

175 Vgl., v. a. mit Blick auf Handkes Poetik der Naturräume, Kurz: Bild-Verdichtungen (Anm. 148), S. 99.

176 Handke: Die Lehre der Sainte-Victoire (Anm. 10), S. 56-58.

177 Wolf: Autonomie und/oder Aufmerksamkeit? (Anm. 4), S. 55, Anm. 48. Vgl. dazu auch Huber: Versuch einer Ankunft (Anm. 170), S. 218: „Der Hund steht [...] für die Übermacht des Realitätsprinzips des Bösen über das Idealitätsprinzip der Kunst." Eine noch einmal anders akzentuierte Lesart schlägt Hans Höller: Geschichtsbewusster Kosmopolitismus. Peter Handkes Raum-Poetik. In: Der Dichter als Kosmopolit. Zum Kosmopolitismus in der neuesten österreichischen Literatur. Hg. v. Patricia Broser u. Dana Pfeiferová. Wien: Praesens 2003, S. 51-66, hier S. 62 f., vor, der in der Hunde-Episode der Lehre der Sainte-Victoire das „friedliche[ ] Weltgesetz“ des Autors „einer äußersten Re-Realisierung ausgesetzt“ sieht. 
hat sich auch der Erzähler der Kindergeschichte (1981), des dritten Teils der Langsame-Heimkehr-Tetralogie, polemisch von den „Realitäts-Tümler[n]“ und „Wirklichkeitler[n] “ distanziert. $^{178}$

Die selbstbewusste Formulierung einer neuen Poetik - Handke kündigte Unseld die Lehre als „Essay“, aber auch als „,Manifest“ an ${ }^{179}$-, die das individuelle ,Recht zu schreiben' zu ergründen versucht, ${ }^{180}$ geht mit der aggressiven Verteidigung des eigenen Schreibens gegen den literaturkritischen „Leithund“ Hand in Hand. Bei dessen "großspurige[r] Krakelschrift“, mit der er "sozusagen einen öffentlichen Machtbereich abgesteckt hatte", handelt es sich bei genauerem Hinsehen um getrocknete Kothaufen. ${ }^{181}$ Das Schreiben des anderen wird mit diesem Vergleich aus dem Bereich des Fäkalen ostentativ entwürdigt und delegitimiert. Die Verbindung von poetologischem Entwurf und kämpferischer Bewahrung dieses Entwurfs gegen ein feindliches Prinzip, wie sie hier zu beobachten ist, ist charakteristisch für Handkes mehrstimmige Werkpolitik: „Für mich war diese Erzählung oder Essay zugleich ein Manifest und eine Drehscheibe für meine

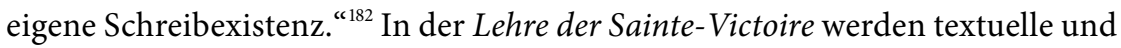
paratextuelle Funktionen miteinander verschränkt, wobei diese Amalgamierung von Text und Paratext einer spezifisch erzählerischen Inszenierung folgt.

Obschon das Kapitel „Der Sprung des Wolfs“, wie Anne-Kathrin Reulecke herausgearbeitet hat, auch ohne den Bezug zu Marcel Reich-Ranicki eine wichtige Schaltstelle des Buches markiert, weil es ein „retardierendes Moment in der Annäherung an Cézannes Kunst" vorstellt und zudem die Rolle des Bösen in der Natur reflektiert ${ }^{183}$ kommt seine poetologische, ja werkpolitische Sprengkraft erst dann vollends zur Geltung, wenn man es als Allegorisierung des Konflikts zwischen Autor und Kritiker in den Blick nimmt - zumal, wie noch zu zeigen ist, auch der Cézanne-Bezug selbst dieser Lesart zuarbeitet. Handkes Ausweitung

178 Peter Handke: Kindergeschichte. Frankfurt a. M.: Suhrkamp 1981, S. 86 f.

179 Handke an Unseld, 22.3. 1980. In: Handke/Unseld: Der Briefwechsel (Anm. 6o), S. 392.

180 Vgl. Handke: Die Lehre der Sainte-Victoire (Anm. 10), S. 68-72. Vgl. Roland Borgards: Sprache als Bild. Handkes Poetologie und das 18. Jahrhundert. München: Fink 2003, S. 36 f.; Honold: Der Erd-Erzähler (Anm. 129), S. 208 f.

181 Handke: Die Lehre der Sainte-Victoire (Anm. 10), S. 59.

182 Funcke/Handke: Wir müssen fürchterlich stottern (Anm. 127).

183 Anne-Kathrin Reulecke: Geschriebene Bilder. Zum Kunst- und Mediendiskurs in der Gegenwartsliteratur. München: Fink 2002, S. 67: „Der Erzähler anthropomorphisiert das Tier, indem er dessen Verhalten als kriegerischen Angriff gegen sich persönlich deutet [...]." Vgl. zur Funktion des Kapitels in der Architektur der Lehre der Sainte-Victoire ausführlich ebd., S. 67 f.; Huber: Versuch einer Ankunft (Anm. 170), S. 246-250; Tanja Angela Kunz: Sehnsucht nach dem Guten. Zum Verhältnis von Literatur und Ethik im epischen Werk Peter Handkes. Paderborn: Fink 2017, S. 210 f.; sowie Ulrich von Bülow: Spinoza-Lektüren. In: Das stehende Jetzt (Anm. 169), S. 125-147, hier S. 142 f., der die Episode mit Handkes Spinoza-Rezeption um 1980 in Beziehung setzt und dafür stichhaltige Belege in den Notizbüchern des Autors anführt. 
der Kampfzone, seine extension du domaine de la lutte, hat ganz wesentlich dazu beigetragen, dass der Grad der Animosität zwischen den Akteuren der beiden Professionen in diesem Fall weiter über das übliche Maß hinausgeht.

Es bleibt indes unklar, ob Reich-Ranicki den camouflierten Angriff Handkes in Die Lehre der Sainte-Victoire als solchen bereits 1980 zur Kenntnis nahm. Die Rezensenten anderer Zeitungen grübelten über die „Funktion des bösen Hundes“ in der Erzählung ${ }^{184}$ und identifizierten ihn, wie Jürgen Jacobs im Kölner Stadt-Anzeiger, mit dem ,radikal Bösen ; ${ }^{6}{ }^{185}$ keiner von ihnen bezog sich jedoch auf den polemischen Subtext der Puyloubier-Episode. Auch W. G. Sebald, mit dem Handke in sporadischem Briefkontakt stand, ${ }^{186}$ behandelte Mitte der 1980er Jahre in einem Essay die „Konfrontation mit dieser unsäglichen Kreatur“, ohne die literaturbetrieblichen Implikationen der Episode zu berühren. Den aggressiven Hund charakterisiert er „als das traditionelle Symbol saturnischer Melancholie“, ${ }^{187}$ bezieht die Begegnung mit der Dogge also auf ihre mythengeschichtliche und literaturhistorische Dimension, nicht auf den Konflikt zwischen Handke und Reich-Ranicki. ${ }^{188}$ Darüber hinaus hat Sebald erstmals auf die intertextuellen Bezüge des Kapitels „Der Sprung des Wolfs“ zu Dantes Divina Commedia hingewiesen, die zuletzt Claudia Albes im Detail erläutert und aufgeschlüsselt hat. ${ }^{189}$

184 So Schäble: Vom Himmel durch die Welt zur Helle (Anm. 163), S. 214.

185 Vgl. Jürgen Jacobs: Lehren von der großen Harmonie des Daseins. Der Schriftsteller Peter Handke auf dem Weg zum Landschaftsmaler. In: Kölner Stadt-Anzeiger, 2.10.198o.

186 Einige Briefe aus den Jahren 1983 bis 1991 finden sich in den Beständen des DLA Marbach.

187 W. G. Sebald: Helle Bilder und dunkle. Zur Dialektik der Eschatologie bei Stifter und Handke. In: W. G. S.: Die Beschreibung des Unglücks. Zur österreichischen Literatur von Stifter bis Handke. Salzburg, Wien: Residenz 1985, S. 165-186, hier S. 182.

188 Pütz: Peter Handke (Anm. 65), S. 114, beschreibt in seiner Handke-Werkbiographie 1982 die „roheste Brutalität einer Hundebestie, deren maulaufreißendes, weltverschlingendes Brüllen als Ausdruck äußerster Gefährdung ertönen muß - ein paar Seiten Handkescher Prosa übrigens [...], die ihresgleichen in der deutschsprachigen Literatur der Gegenwart suchen. “ Auch andere Germanistinnen und Germanisten nahmen von der verfremdeten Bezugnahme auf die Handke/Reich-Ranicki-Fehde in der Lehre vorerst keine Notiz; Thomas K. Thornton: Die Thematik von Selbstauslöschung und Selbstbewahrung in den Werken von Peter Handke. Frankfurt a. M. u. a.: Lang 1983, S. 118, etwa liest sie lediglich als „Projektion der eigenen Innenwelt zum objektiven Äußeren“.

189 Vgl. Sebald: Helle Bilder und dunkle (Anm. 187), S. 182 f.; Claudia Albes: Erzählen - Argumentieren - Beschreiben. Zur Theorie und Interpretation moderner Prosatexte am Beispiel von Peter Handkes Lehre der Sainte-Victoire. Trier: Wissenschaftlicher Verlag Trier 2013, S. 414-416. Dazu schon die Andeutungen bei Hans-Ulrich Treichel: Auslöschungsverfahren. Exemplarische Untersuchungen zur Literatur und Poetik der Moderne. München: Fink 1995, S. 217. 


\section{Mit Cézanne gegen die Hunde (Die Lehre der Sainte-Victoire)}

In seiner Rede zur Verleihung des Franz-Kafka-Preises hatte Handke im Oktober 1979, parallel zur Veröffentlichung von Langsame Heimkehr, sein Dasein als „Schreibender" in der Tradition literarischer Klassizität neu zu legitimieren versucht. ${ }^{190}$ Dem „entschieden hoffnungslosen Kafka“ hatte er dabei sein Ideal einer „eher bilderleere[n], von Detail und Fabel befreite[n] Heiterkeit“ gegenübergestellt, ${ }^{191}$ das, so Handkes abschließende Wendung, die bestärkende „Zuneigung“ der Leser brauche. ${ }^{192}$ In einer Phase der „krisenhafte[n] Transformation einer vormals erfolgreichen Schreibregel ${ }^{\text {“193 }}$ der Bestärkung durch wohlmeinende Leser im Besonderen bedürftig, hatte Reich-Ranickis vernichtende Rezension für Handke eine schwerwiegende Irritation bedeutet. Er habe sie, nach der Überwindung des „furchtbare[n] Problem[s] beim Schreiben von Sorgers Geschichte ${ }^{\text {“ }}{ }^{194}$ als elementaren Angriff auf seine Existenz als Autor erlebt, wie Handke im Rückblick zu Protokoll gegeben hat:

Ja, mich hat, was der schreibt, vor zehn Jahren, das gebe ich zu, sehr beschäftigt, weil er dachte, nun hätte er mich endgültig zur Strecke gebracht. Da habe ich mir gesagt, na, jetzt werden wir mal schauen. Ich glaube, daß ihm der Geifer noch immer von den Fangzähnen tropft. ${ }^{195}$

Hier ist ein zentraler Punkt formuliert, der sich auch in späteren Kommentaren Handkes über seinen Kontrahenten und vor allem über dessen Kritik an Langsame Heimkehr findet: Hatte Handke Mitte der 1970er Jahre die Klagen von Autoren, ein Kritiker habe sie „zerstört“, noch zu „bloße[r] Theatralik“ erklärt, weil der Kritisierte damit lediglich beanspruche, „in der Klageposition seinen Lebensinhalt zu finden“, 196 machte er Reich-Ranicki nach dem polemischen Verriss seiner

190 Peter Handke: Rede zur Verleihung des Franz-Kafka-Preises. [1979] In: P. H.: Das Ende des Flanierens (Anm. 103), S. 156-159, hier S. 158.

191 Ebd., S. 157.

192 Ebd., S. 159.

193 Karl Wagner: Die Tetralogie Langsame Heimkehr (1979-1981). [2005] In: K. W.: Weiter im Blues. Studien und Texte zu Peter Handke. Bonn: Weidle 2010, S. 81-88, hier S. 84; vgl. dazu auch Höller: Peter Handke (Anm. 28), S. 86-90.

194 Peter Handke: Die Geschichte des Bleistifts. Salzburg, Wien: Residenz 1982, S. 128.

195 Müller: Im Gespräch mit Peter Handke (Anm. 112), S. 89.

196 Arnold: Gespräch mit Peter Handke (Anm. 83), S. 35 f. Handke rekurriert an dieser Stelle auf Karin Struck, deren Roman Die Mutter er Anfang 1975 im Spiegel negativ rezensiert hatte. In einem Brief an Handke zeigte sich Struck daraufhin über die „einen Menschen vernichtende[ ] Rezension“ ihres Buches enttäuscht; zit. nach: Malte Herwig: Meister der Dämmerung. Peter Handke. Eine Biographie. München: DVA ²010, S. 300. Vgl. dazu auch Kap. V, Abschnitt „Keine Axt für das gefrorene Meer in uns: Franz Kafka, Karin Struck“. 
Erzählung gerade dies zum Vorwurf: Der Kritiker sei darauf aus gewesen, ihn als Schreibenden zu ,vernichten. „Es gab eine Zeit, in der ich von konvulsivischem Widerwillen befallen wurde, sobald dieser Mann nur in Erscheinung trat. Er hat über Jahre versucht, mich zu vernichten. Er hatte die Illusion, das zu können. “197 Im Gespräch mit André Müller hat Handke auf diese Erfahrung existentieller Bedrohung mit nicht eben feiner Klinge reagiert, was Reich-Ranicki wenige Jahre später in seiner Autobiographie, wohl nicht ganz zu Unrecht, als ungebührliche Entgleisung auffassen sollte: „Was in der Literatur herumkrabbelt, das möchte man alles vernichten“, ${ }^{198}$ lautet der Satz, mit dem Handke das Gespräch auf die entsprechende Passage der Lehre der Sainte-Victoire und die Person des Kritikers lenkte; und gleich darauf: „Ich kenne viele, die finden ihn amüsant. Die haben gar keinen Stolz. Die sagen, wenn der einmal stirbt, wird man das sehr bedauern. Dem kann ich nun nicht beipflichten. “199

Die Imagination des toten Kritikers, der in der deutschen Literatur bekanntlich zahlreiche weitere „Mordlüste“ und „Todeswünsche “ folgen sollten, ${ }^{200}$ findet sich bereits in der Lehre der Sainte-Victoire selbst, wissen doch die beiden Kontrahenten, Mensch und Hund, ab einem bestimmten Zeitpunkt, dass sie „auf ewig Todfeinde“ sein würden: „[J]a, jetzt trachtete er mir nach dem Leben; und auch ich wollte mit einem Machtwort ihn tot und weg haben. ${ }^{\text {201 }}$ Der Erzähler fühlt sich „[s] prachlos vor Haß“, aber „zugleich schuldbewußt“, weil er „[f]ür das, was [er] vorhabe“, nicht hassen dürfe ${ }^{202}$ - ist sein „Ideal“ doch, wie er im weiteren Verlauf der Lehre formuliert, „seit je der sanfte Nachdruck und die begütigende Abfolge einer Erzählung ${ }^{\text {“ }}{ }^{203}$ Bei einem erneuten Weg über den Berg ist der

197 Müller: Im Gespräch mit Peter Handke (Anm. 112), S. 65.

198 Ebd., S. 88.

199 Ebd., S. 89. Vgl. Reich-Ranicki: Mein Leben (Anm. 52), S. 446: „Meinen Tod wünschte auch Peter Handke, jedenfalls würde er ihn nicht bedauern: In seinem aus dem Jahr 1980 stammenden Buch ,Die Lehre der Sainte-Victoire‘ stellt er mich als bellenden und geifernden,Leithund dar, ,in dem sich gleichsam etwas Verdammtes umtrieb' und dessen, Mordlust' vom Getto noch verstärkt worden war." Vgl. dazu Anm. 28-30.

200 Daniela Strigl: Platzanweiser im circus maximus? Traum und Wirklichkeit der Literaturkritik. In: Literatur und Kritik (2001), H. 353/354, S. 24-30, hier S. 27. Auf die diversen „literarischen Phantasien vom Tod des gehassten Kritikers" Marcel Reich-Ranicki, von Helmut Heißenbüttel über Martin Walser bis Christa Reinig, verweisen Anz: Marcel Reich-Ranicki (Anm. 15), S. 150-155, Zit. S. 151, und Wittstock: Marcel Reich-Ranicki (Anm. 15), S. 251-253.

201 Handke: Die Lehre der Sainte-Victoire (Anm. 10), S. 60.

202 Ebd., S. 6of.

203 Ebd., S. 99. Vgl. dazu auch Handkes Äußerung in Krista Fleischmann/Peter Handke: Ein Gespräch über das Schreiben und die Kindergeschichte. In: Die Rampe (1981), H. 2, S. 7-15, hier S. 9 f.: „Wie ich schon in der ,Langsamen Heimkehr' geschrieben habe, ich glaube an die Geschichte als eine friedensstiftende Form. [...] Ich will die Geschichte der friedlichen Menschen schreiben, daraus die Kraft gewinnen." 
Hund schließlich nicht mehr zu sehen, „oder er lag als Lehmklumpen in einem Hohlweg “ ${ }^{204}$ Erst im zeitlichen Abstand ist der Erzähler in der Lage, im Glauben an seine „Unverwundbarkeit“ auf seiner poetischen Methode zu beharren, „den Coup [zu] wagen und aufs Ganze [zu] gehen“: „Und ich spürte die Struktur all dieser Dinge in mir, als mein Rüstzeug. TRIUMPH! dachte ich - als sei das Ganze schon glücklich geschrieben. ${ }^{\text {"205 }}$ Hier werden nicht nur Konzeption und Entstehung des Textes in die Narration einbezogen, sondern Handke verschränkt den Aspekt der Werkgenese auch mit der Imagination einer kritischen Instanz, gegen die sich die Lehre als Antizipation der Ablehnung bereits vorab wendet.

Dass Handke den verhassten Kritiker in der Lehre der Sainte-Victoire, also in der Landschaft Paul Cézannes, ausgerechnet als Hund auftreten lässt, ist - geht man nach den Erinnerungen des Malers und Kunsttheoretikers Émile Bernard (1868-1941) - womöglich kein Zufall, sondern bereits im historischen Bezugssystem der bildenden Kunst angelegt. Der 1906 verstorbene Cézanne habe, so Bernard, über Jahre am Sujet einer Apotheose des Eugène Delacroix gearbeitet, auf deren Entwürfen neben Camille Pissarro und Claude Monet auch „ein bellender Hund abgebildet gewesen sei“, der nicht nur „ein Symbol des Neides darstellte“, sondern auch „die Kunstkritik symbolisieren sollte“: ${ }^{206}$

Er plante, eine Apothéose de Delacroix zu malen, und zeigte mir die Skizze dazu. Der Meister der Romantik war dargestellt, wie er von Engeln, von denen der eine seine Pinsel, der andere seine Palette hielt, tot emporgetragen wird. Darunter dehnte sich eine Landschaft aus, in welcher Pissarro an seiner Staffelei vor dem Motiv stand. Zur Rechten war Claude Monet und im Vordergrund Cézanne, von hinten gesehen, mit einem großen Barbizonhut auf dem Kopf, einen Spieß in der Hand und einer Jagdtasche an der Seite. Zur Linken befand sich Herr Choquet, der den Engeln applaudierte. Endlich präsentierte ein bellender Hund (das Symbol des Neides, nach Cézanne) in einem Winkel die Kritik. ${ }^{207}$

204 Handke: Die Lehre der Sainte-Victoire (Anm. 10), S. 111.

205 Ebd., S. 115 f. Zu dieser Passage vgl. die Interpretation von Johanna Bossinade: Moderne Textpoetik. Entfaltung eines Verfahrens. Mit dem Beispiel Peter Handke. Würzburg: Königshausen \& Neumann 1999, S. 152. Mehr als drei Jahrzehnte später hat Handke die Wendung in seinem bislang letzten Journalband erneut aufgegriffen, wo es in einem 2014 festgehaltenen Notat heißt: „Schreiben, Tun: aufs Ganze gehen.“ (Peter Handke: Vor der Baumschattenwand nachts. Zeichen und Anflüge von der Peripherie. 2007-2015. Salzburg, Wien: Jung und Jung 2016, S. 317)

206 Reulecke: Geschriebene Bilder (Anm. 183), S. 68, Anm. 61. Dieser Deutung des Hundes folgt, bezugnehmend auf Bernard, auch Oskar Bätschmann: Ausstellungskünstler. Kult und Karriere im modernen Kunstsystem. Köln: DuMont 1997, S. 109: „[...] und der bellende Hund - der Neid - soll die Kritik darstellen.“

207 Emile Bernard: Erinnerungen an Paul Cézanne, 1904-1906. [1907] In: Gespräche mit Cézanne. Hg. v. Michael Doran. Deutsch v. Jürg Bischoff. Zürich: Diogenes 1982, S. 68-106, hier S. 92. 
Cézanne konnte dem Bild zeitlebens nicht mehr seine endgültige Gestalt geben, er sah sich, so der Kunsthistoriker Oskar Bätschmann, zwei Jahre vor seinem Tod gezwungen, den über lange Zeit gehegten Traum aufzugeben, das Gemälde noch auszuführen. ${ }^{208}$ Auf der kleinformatigen Ölskizze Apothéose de Delacroix, die sich heute im Pariser Musée d'Orsay befindet, ist der Hund neben den anderen genannten Figuren zu sehen, er befindet sich jedoch keineswegs, wie Bernard behauptet, „in einem Winkel“, sondern vielmehr an der Seite Cézannes. ${ }^{209}$

Steht die Parallelsetzung der beiden animalischen Kunstkritik-Allegorien bei Cézanne und Handke somit unter einem gewissen Vorbehalt, weil Bernards Kommentar in diesem Detail nicht mit den überlieferten Entwürfen der Apothéose übereinstimmt, verfolgen bildende Kunst und Literatur hier doch ähnliche Ziele. Wie die Lehre der Sainte-Victoire liefert auch die viele Jahrzehnte zuvor entstandene Apothéose de Delacroix den Entwurf eines positiven Traditionsbezugs: „[D] urch die gute Arbeit bin ich endlich wieder den Vorfahren angeschlossen und kann mich mit ihnen denken; auch mit den Künstler-Vorfahren“, hatte Handke gegen Ende der 1970er Jahre im Journal Die Geschichte des Bleistifts notiert. ${ }^{210}$ Cézannes Allegorisierung des Kunstsystems durchaus vergleichbar, schildert die Lehre der Sainte-Victoire als poetologische Programmschrift das Verhältnis der künstlerischen Generationen als harmonische und wertschätzende translatio, wobei das „Bemühen“ des Erzählers, „sich seiner Legitimation als Schriftsteller zu vergewissern“, 211 ausdrücklich mit dem in der Geschichte des Bleistifts beteuerten „Bedürfnis nach einem Lehrmeister “ ${ }^{212}$ korrespondiert. Der Erzähler der Lehre, der schon im ersten Satz des Buches davon berichtet, sich nach seiner Rückkehr nach Europa der „tägliche[n] Schrift“ gewidmet und „vieles“ neu gelesen zu haben, ${ }^{213}$ zeigt sich im weiteren Verlauf der Handlung als genauer Leser, der in der Lektüre immer auch den Anschluss an künstlerische Tradition und vorbildliche Texte - etwa Adalbert Stifters Bergkristall - sucht.

Reulecke: Geschriebene Bilder (Anm. 183), S. 61, zeichnet Cézanne als bildenden Künstler, der sich „gegen die etablierte Kunstkritik“ gewendet habe. Nicht zuletzt deshalb habe er „jungen Künstler[n]“ und Autoren, „die die offiziellen Instanzen des Kunstbetriebes und die zunehmende Verdinglichung der Kunstwerke im Zusammenhang des kapitalistischen Kunstmarktes in Frage stellen“, als Leitfigur gedient (ebd.).

208 Vgl. Bätschmann: Ausstellungskünstler (Anm. 206), S. 109.

209 Eine Reproduktion der Skizze findet sich u. a. ebd., S. 110.

210 Handke: Die Geschichte des Bleistifts (Anm. 194), S. 114.

211 Ellen Dinter: Gefundene und erfundene Heimat. Zu Peter Handkes zyklischer Dichtung: Langsame Heimkehr. 1979-1981. Köln, Wien: Böhlau 1986, S. 153.

212 Handke: Die Lehre der Sainte-Victoire (Anm. 10), S. 33.

213 Ebd., S. 9. 
Dem Hund, der Ellen Dinter zufolge die „Störanfälligkeit“" ${ }^{\text {214 }}$ und Gefährdung der Handke'schen Poetik symbolisiert, kommt dabei die Rolle des stumpfsinnigen Widersachers zu, mit dem kein Einvernehmen möglich ist; „entschlossen “215 gegen ihn vorzugehen, erweist sich für den Erzähler als Notwendigkeit, um das eigene Schreibprojekt angesichts fundamentaler Einwände der Literaturkritik zu verteidigen. Gerade die Ablehnung durch die Bestie von Puyloubier, die Auseinandersetzung mit dem Feind, nährt am Ende die Überzeugung, „unversöhnt“ auf dem richtigen Weg zu sein:

Wohl auch müde von dem vielen Gehen, schlief ich kurz ein. Ich träumte von dem Hund, der sich in ein Schwein verwandelte. So, hell, fest und rundlich, war er keine Spottgeburt eines Menschen mehr, sondern ein Tier, wie es sein sollte; und ich gewann es lieb und tätschelte es - erwachte jedoch unversöhnt, und, nach dem Worte des Philosophen, „durch erkennende Orgien gereinigt für die heilig seienden Werke“. 216

Ein Jahr darauf, in der 1981 als dritter Band der Tetralogie Langsame Heimkehr publizierten Kindergeschichte, setzt Handke hündische Animalität und öffentliches Sprechen und Schreiben erneut miteinander in Beziehung. Die stark autobiographisch geprägte Erzählerfigur verleiht nicht nur ihrer Abneigung gegen die „Von überallher“ auf sie eindringende „Drohnensprache eines Blechernen Zeitalters“ Ausdruck; „all die in den öffentlichen Diskussionen, in den Tagblättern und im Fernsehen, aber auch in den neuen Büchern [...] umlaufenden zeitgebräuchlichen Ausdrücke“ hätten darüber hinaus, so die Wahrnehmung des Erzählers, „das Niederschmetternde, Banalitätsstinkende, Seelenmörderische, Gottlose, Nervtötende, Hirnrissige von Hundenamen“.217

Die typographische Hervorhebung des Begriffs im Text deutet eine Signifikanz an, die über die Einzelstelle hinausweist: Wiederholt taucht der Hund bzw. das Hündische bei Handke als feindliches Prinzip auf, das im Verdacht steht,

214 Dinter: Gefundene und erfundene Heimat (Anm. 211), S. 121.

215 Handke: Die Lehre der Sainte-Victoire (Anm. 10), S. 59.

216 Ebd., S. 61 f. Albes: Erzählen - Argumentieren - Beschreiben (Anm. 189), S. 416, zufolge handelt es sich bei der zitierten Sentenz um einen Ausspruch des Vorsokratikers Demokrit von Abdera. Zur traumhaften Verwandlung des Hundes in ein Schwein vgl. Reulecke: Geschriebene Bilder (Anm. 183), S. 68, sowie Thorsten Carstensen: Romanisches Erzählen. Peter Handke und die epische Tradition. Göttingen: Wallstein 2013, S. 231: „Was wie ein kindischer Akt der Verzauberung anmutet, ist tatsächlich ein dringend notwendiger Reinigungsvorgang: Der Hund muss aus dem Bild entfernt werden, weil er die als unschuldig vorgestellte Natur zu kontaminieren droht." Dazu auch von Bülow: Spinoza-Lektüren (Anm. 183), S. 142.

217 Handke: Kindergeschichte (Anm. 178), S. 64. 
Leben und Schreiben zu gefährden. ${ }^{218}$ Das Hündische, das Kläffen des Hundes, ist zudem gleich in mehreren Werken Handkes mit einem bestimmten Sprachund Denkgestus verknüpft. ${ }^{219}$ Der emphatische Schlussmonolog der Nova im 1982 bei den Salzburger Festspielen uraufgeführten, dramatischen Gedicht' Über die Dörfer - mit dem Theaterstück fand die Tetralogie ihren Abschluss - fordert sein Publikum denn auch ganz in diesem Sinne dazu auf, sich nicht „als die Hunde“ zu gebärden, „bei deren Anblick sofort die Phantasie erstirbt“ ${ }^{“ 220}$ In Korrespondenz zum kritischen „Allesfresser“ ${ }^{\text {“221 }}$ in der Lehre könnte man auch die folgende Passage in Novas Monolog am Ende des Stücks auf diesen thematischen Komplex beziehen: „Beweist, gegen den Allesverschlinger, mit euren Mitteln, unseren menschlichen Trotz!“"222 Wenn Handke kurz darauf „Schwarzer Hund, notdurftverrichtend an weißer Birke“ in seinem (erst 1998 als Buch publizierten) Salzburger Journal Am Felsfenster morgens notiert, ${ }^{223}$ liegt es nahe, das nur grob skizzierte Natur-Bild auch als erneute Inszenierung der Konfrontation von Kritiker und Autor zu lesen: Die aus Kot gebildete „Krakelschrift ${ }^{\text {“224 }}$ des Hundes aus der Lehre wird im scharfen Kontrast zwischen hellem Baum und dunklem Tier aufgenommen und aktualisiert.

Demgegenüber steht das Wunschbild gleichmütigen Erduldens, wobei das Vertrauen auf die eigenen Stärken die destruktiven Energien entkräften soll: „Der schwarze Dobermann mit seinen knickenden Beinen / mag mir jetzt ruhig in den Kniekehlen schnüffeln “225 heißt es 1986 im Gedicht an die Dauer: ein Mantra des selbstbewussten Voranschreitens. Im Versuch über die Müdigkeit (1989) wiederum berichtet der Autor-Erzähler wie beiläufig vom zeitweisen Ausbleiben der „übliche[n] Hundeangst“ ${ }^{226}$ Noch in den Aufwachnotizen Ein

218 Vgl. Leopold Federmair: Die Apfelbäume von Chaville. Annäherungen an Peter Handke. Salzburg, Wien: Jung und Jung 2012, S. 61, der einen „Angsthass gegen Hunde, der sich [...] durch Handkes Werk zieht", konstatiert; dazu ausführlich die textnahe Interpretation von Huber: Versuch einer Ankunft (Anm. 170), S. 218-223 u. 243-254, der von einer „Leitmotivtechnik“ (ebd., S. 244) Handkes in Bezug auf das ,Hündische' spricht.

219 Folgt man dem Publizisten Franz Schonauer in seiner Einschätzung, wonach sich ReichRanicki durch eine „fast automatisch zu nennende Reaktion auf Literatur" ausgezeichnet habe (Schonauer: Marcel Reich-Ranicki [Anm. 18], S. 163), ließe sich Handkes Identifizierung des Kritikers mit dem Hündischen auch als hintersinnige Aktualisierung der Pawlow'schen Konditionsexperimente verstehen.

220 Peter Handke: Über die Dörfer. Dramatisches Gedicht. Frankfurt a. M.: Suhrkamp 1981, S. 104.

221 Handke: Die Lehre der Sainte-Victoire (Anm. 10), S. 59.

222 Handke: Über die Dörfer (Anm. 220), S. 105.

223 Peter Handke: Am Felsfenster morgens (und andere Ortszeiten 1982-1987). Salzburg, Wien: Residenz 1998, S. 53.

224 Handke: Die Lehre der Sainte-Victoire (Anm. 10), S. 59.

225 Peter Handke: Gedicht an die Dauer. Frankfurt a. M.: Suhrkamp 1986, S. 45.

226 Peter Handke: Versuch über die Müdigkeit. Frankfurt a. M.: Suhrkamp 1989, S. 61. 
Jahr aus der Nacht gesprochen (2010) spukt die Figur eines Hundes, der die arglistige Gefährdung des Schreibens verkörpert, durch Handkes Aufzeichnungen: „Wie am Ende des Kapitels den Hund vermeiden?“ - ,Ihn überspringen“'.227 Und auch jene Szene der Erzählung Der Große Fall (2011), in der der Schauspieler "in einer stillen Straße" plötzlich „ein wüstes Bellen und Knurren“ vernimmt und „unversehens eine ganze hundertköpfige, wie tausendschwänzige Hunderotte ${ }^{\text {“228 }}$ auf sich zuschießen sieht, kann im Sinne dieses Schreckbildes, das immer auch ein Bild der Selbstbehauptung gegenüber dem Feind ist, interpretiert werden. ${ }^{229}$

\section{Im Bunde? Reich-Ranicki, Bernhard und Unseld}

Noch vor der Publikation der Lehre der Sainte-Victoire im September 1980 hatte sich Reich-Ranicki im Frühling des Jahres an einer demonstrativen Tilgung seines Kontrahenten versucht - einer Tilgung, die im Übrigen zeigt, wie sehr die Zusammenstellung von Anthologien Aufschluss geben kann über Machtverhältnisse, über Ein- und Ausschließungsmechanismen im literarischen Feld. Wie bereits erwähnt, hatte der Kritiker 1972 Handkes Das Umfallen der Kegel von einer bäuerlichen Kegelbahn neben Prosatexten von Peter Bichsel, Ernst Bloch, Jürg

227 Peter Handke: Ein Jahr aus der Nacht gesprochen. Salzburg, Wien: Jung und Jung 2010, S. 36.

228 Peter Handke: Der Große Fall. Erzählung. Berlin: Suhrkamp 2011, S. 259 f.

229 Wenn davon die Rede ist, der Schauspieler habe ,in Gedanken an die Sage von dem altgriechischen Schauspieler und Sänger (Name? ,weiß nicht mehr'), welcher von solch einer Meute zerrissen worden war" (ebd., S. 260), seinen Weg fortgesetzt, verknüpfte Handke die Episode in Der Große Fall mit der Figur des antiken Sängers Linos: „Linos war nach einer merkwürdigen Sage der Argiver ein Knabe, der, von göttlichem Stamm entsprossen, unter Lämmern bei Hirten aufwuchs und von wüthenden Hunden zerfleischt wurde [...]. Daß später aus Linos auch ein Sänger gemacht wurde, einer der ältesten Aöden, der mit Apollo selber einen Wettstreit beginnt und den Herakles im Zitherspiel unterweist, war ein sehr natürlicher Irrtum; es blieb indeß auch da die Vorstellung, daß Linos erschlagen worden sei, und man muß wohl annehmen, daß in dem alten Gesange selbst von Tod und Untergange die Rede war." (Karl Otfried Müller: Geschichte der griechischen Literatur bis auf das Zeitalter Alexanders. Nach der Handschrift des Verfassers hg. v. Eduard Müller. Erster Band. Breslau: Josef Max und Komp. 1841, S. 29) Zu diesem literatur- und mythengeschichtlichen Komplex vgl. Georg Heinrich Bode: Geschichte der Hellenischen Dichtkunst. Zweiter Band: Geschichte der Lyrischen Dichtkunst der Hellenen bis auf Alexandros den Grossen. Erster Theil: Ionische Lyrik, nebst Abhandlungen über die ältesten Kultus- und Volkslieder und über die Tonkunst der Hellenen. Leipzig: Köhler 1838, S. 84 f., Anm. 1. - Vom Gesang des Linos ist auch in der homerischen Ilias die Rede: „Und inmitten von ihnen schlug ein Knabe die Leier / Hell mit lieblichem Ton, die schöne Weise des Linos / Singend mit zarter Stimme; die anderen stampften im Tanze, / Jauchzten melodisch dazu und hüpften dabei mit den Füßen." (Homer: Ilias. Übersetzung, Nachwort u. Register v. Roland Hampe. Stuttgart: Reclam 1979, S. 295 [Achtzehnter Gesang, V. 569-572]) 
Federspiel, Fritz Rudolf Fries, Wolfgang Koeppen und Wolf Wondratschek als Beispiel für das Jahr 1969 in der Anthologie Verteidigung der Zukunft abgedruckt. In die um einige Texte erweiterte Neuauflage von 1975 nahm Reich-Ranicki Handkes Erzählung erneut auf. ${ }^{230}$ In der dritten, erneut um die aktuellen Jahrgänge ergänzten Ausgabe von 1980 jedoch fehlt Handkes Erzählung als einziger Text der früheren Ausgaben: Während alle anderen Beiträge der 196oer Jahre in der gleichen Reihenfolge enthalten sind, wurde lediglich Handkes Das Umfallen der Kegel von einer bäuerlichen Kegelbahn kommentarlos gestrichen; auf Fries' Der Seeweg nach Indien folgt nun direkt Wondratscheks Off limits, die Paginierung verschiebt sich für die anschließenden Texte entsprechend der Länge der getilgten Handke-Erzählung um zehn Seiten. ${ }^{231}$ Der Autor scheint für den Kritiker zu diesem Zeitpunkt, also noch eindeutig vor der Publikation der Puyloubier-Episode, längst zu einer veritablen persona non grata geworden zu sein; während Reich-Ranicki andere Autoren, mit denen er im Clinch lag, ${ }^{232}$ sogar neu in die Anthologie aufnahm, versuchte er gegen seinen Intimfeind Handke durch einen Akt demonstrativer De-Kanonisierung vorzugehen.

Anfang der 1980er Jahre griff der Konflikt zwischen Handke und ReichRanicki schließlich auch auf das Verhältnis des Autors zu seinem Verleger über. Handke hatte Siegfried Unseld schon im März 1980, noch während der Arbeit an der Lehre der Sainte-Victoire, wie beiläufig angedeutet, er habe ,in den letzten Monaten viel über das Verhältnis des Verlags zu seinem Autor" nachgedacht: „Wir werden vielleicht darüber reden. ${ }^{“ 233}$ In seinem Reisebericht vom 5./6. April des Jahres hält Unseld schließlich einen heftigen Wutausbruch seines Autors in einem Salzburger Restaurant fest:

230 Vgl. Peter Handke: Das Umfallen der Kegel von einer bäuerlichen Kegelbahn. In: Verteidigung der Zukunft. Deutsche Geschichten seit 1960. Hg. v. Marcel Reich-Ranicki. München, Zürich: Piper ${ }^{2}$ 1975, S. $358-368$. Zum Abdruck von Handkes Erzählung in diversen Anthologien vgl. Clemens Özelt: Durch die Lupe? Peter Handkes Kurzprosa (Noch einmal für Thukydides, Begrü$\beta$ ung des Aufsichtsrats). In: Schreiben als Weltentdeckung. Neue Perspektiven der Handke-Forschung. Hg. v. Anna Estermann u. Hans Höller. Wien: Passagen 2014, S. 73-95, hier S. 83 u. 93 f.

231 In den Angaben am Ende des Bandes findet sich dazu folgende, einen wesentlichen redaktionellen Akt aussparende Information: „Die zuerst 1972 veröffentlichte Anthologie Verteidigung der Zukunft erschien 1975 in einer ergänzten Ausgabe (damals kamen die Geschichten für die Jahrgänge 1973, 1974 und 1975 hinzu) und wird jetzt abermals erweitert. Für die Jahrgänge 1976 bis 1980 wurden die Geschichten von Hugo Dittberner, Renate Schostack, Hans Joachim Schädlich, Hermann Burger, Hans J. Fröhlich und Jurek Becker hinzugefügt. / Frankfurt/M., im April 1980" (Verteidigung der Zukunft. Deutsche Geschichten 1960-1980. Hg. v. Marcel Reich-Ranicki. München: dtv 1980, S. 532). Im Impressum ist „Juni 1980“ als Erscheinungsdatum angegeben.

232 Vgl. Hermann Kinder: Schweine-Bande. In: Text + Kritik (1988), H. 10o, S. 30-36, hier S. 32 f.

233 Handke an Unseld, 22.3.1980. In: Handke/Unseld: Der Briefwechsel (Anm. 60), S. 393. Dazu Unseld im Reisebericht, 5./6. April 1980: „Das mußte ein Alarmsignal sein und war wohl auch so gemeint." (Ebd., S. 397) 
[I]ch merkte, wie dann [...] eine Stauwand in ihm brach. Und dann kam es auch heraus: Er ,haßte` unsere, und er meinte damit meine, ,verbrüdernde, zersetzende, krebserregende' Umarmung mit den Medienpäpsten. Es war ja klar, wer gemeint war, obschon er den Namen nicht aussprechen kann. [...] Vielleicht müßten wir sie machen, aber er wolle das nicht, und deswegen meinte er, ein Selbstverlag sei für ihn doch das beste. Und als Höhepunkt seiner Anklage kam der Vorwurf, daß ich mich an der besagten Festschrift beteiligt hätte. Ich verneinte dies, aber er glaubte es nicht. Er wisse ganz genau, daß ich beteiligt sei. Ich sagte ihm, das Buch käme ja im nächsten Monat heraus und er würde sehen: kein Beitrag von mir. ${ }^{234}$

Bei jener „Festschrift“ handelt es sich um den Band Literatur und Kritik, den Walter Jens 1980 anlässlich von Reich-Ranickis 6o. Geburtstag herausgab. Er enthielt, trotz Handkes gegenteiliger Vermutung, zwar zahlreiche Artikel literarischer Kolleginnen und Kollegen, von Martin Walser über Siegfried Lenz bis Sarah Kirsch, aber keinen Beitrag des Verlegers. ${ }^{235}$

Die sich anbahnende Krise war damit aber keineswegs abgewendet, zumal Handkes Misstrauen gegenüber der Loyalität seines Verlegers auf einer fatalen Entdeckung beruhte: „Ich betrat das Haus des Verlegers, und der Stuhl, auf dem ich saß, war in meinem Wahn oder Nichtwahn noch heiß von dem Kritiker, der fünf Minuten vorher da war, auf Vernichten aus“, hat Handke sich noch 2004 im Zuge einer Rede in memoriam Siegfried Unseld erinnert. ${ }^{236} 1979$, im Jahr der Publikation von Langsame Heimkehr, war Handke in Unselds Büro auf ein Widmungsexemplar des Reich-Ranicki-Bandes Entgegnung gestoßen, in dem der Kritiker die vernichtenden Besprechungen von Wunschloses Unglück und Die linkshändige Frau erneut abgedruckt hatte. ${ }^{237}$ Handke deutete den Umstand, dass Unseld und Reich-Ranicki miteinander in freundlichem Einvernehmen

234 Unseld: Reisebericht Salzburg, 5./6. April 1980. In: ebd., S. 400.

235 Vgl. Literatur und Kritik. Aus Anlaß des 6o. Geburtstages von Marcel Reich-Ranicki hg. v. Walter Jens. Stuttgart: DVA 1980. Dazu weiter Unseld: Reisebericht Salzburg, 5./6. April 1980. In: Handke/Unseld: Der Briefwechsel (Anm. 60), S. 400: „Er glaubte es nicht. Es dauerte wieder eine halbe Stunde, bis er sich ausgeredet hatte, ich konnte ihn gewiß mit meinem Einreden nicht überzeugen, aber vielleicht hatte er etwas mehr Verständnis für meine Haltung."

236 Peter Handke: Vom Singular und vom Plural. Rede zur Verleihung des Siegfried-Unseld-Preises am 28. September 2004 im Holzhausenpark. In: P. H.: Meine Ortstafeln. Meine Zeittafeln (Anm. 46), S. 425-430, hier S. 427.

237 Vgl. Marcel Reich-Ranicki: Entgegnung. Zur deutschen Literatur der siebziger Jahre. Stuttgart: DVA 1979, S. 315-322 (Die Angst des Dichters beim Erzählen) u. 322-329 (Wer ist hier infantil?). In die Neuauflage des Bandes von 1981 wurde unter dem Titel Sein Weg zu Gott zusätzlich die Besprechung von Langsame Heimkehr aufgenommen. Vgl. ders.: Entgegnung. Zur deutschen Literatur der siebziger Jahre. Erweiterte Neuausgabe. Stuttgart: DVA 1981, S. 403-411. 
standen, als hinterhältigen Verrat des Verlegers. ${ }^{238}$ Im Februar 1981 eskalierte der Konflikt schließlich in einem wütenden Brief Handkes, dessen „gnadenlose Generalabrechnung “239 noch deutlicher als ein Jahr zuvor die Ankündigung enthielt, den Verlag zu verlassen - eine Drohung, die der Autor freilich nie wahr machen sollte:

Lieber Siegfried (immer noch),

die Zeit der Lügen muß ein Ende haben. Schon an jenem Tag vor zwei Jahren, als ich am Frühstückstisch in Frankfurt in dem Sammelwerk des übelsten Monstrums, das die deutsche Literaturbetriebsgeschichte je durchkrochen hat, die Widmung an Dich, meinen Verleger, gelesen habe (als Vorsatzblatt zu den nackt mordlustigen Artikeln über ,Wunschloses Unglück' und ,Die linkshändige Frau'): ,In alter Verbundenheit', da hätte ich die Pflicht vor mir und dem, was mir noch vorschwebt, gehabt, für immer meine Arbeiten aus Deiner sogenannten Obhut zu nehmen. [...] Unsere Wege trennen sich hiermit, unwiderruflich. ${ }^{240}$

Im Abstand von mehr als drei Jahrzehnten, im Oktober 2012, hat Handke sich in einem Interview mit der Süddeutschen Zeitung noch einmal zu diesem Konflikt und seinen Hintergründen geäußert:

Das war ein völlig sinnloser Amoklauf, aber er hat mich, so blöd dialektisch das klingt, auch befreit. Was Reich-Ranicki zu Langsame Heimkehr geschrieben hat, war nackter Vernichtungswille. Er wollte mich weghaben. Und am nächsten Tag hat Siegfried Unseld ihn empfangen, ihn bewirtet. Ich fühlte mich verraten und musste einen Auslauf suchen aus mir. Da habe ich eben losgelegt. Ich bedaure das nicht. ${ }^{241}$

Reich-Ranicki wiederum hat diese Szene am Schreibtisch des Verlegers, deren Nachwehen 1981 beinahe zum Bruch zwischen Handke und dem Suhrkamp Verlag

238 Ein Detail am Rande: Als Reich-Ranicki 1984 in der FAZ eine Würdigung zu Unselds 6o. Geburtstag druckte, sparte er Handke in seiner Liste bedeutender Suhrkamp-AutorInnen demonstrativ aus: „Ziffern allein besagen im Verlagsgewerbe doch nicht viel, es gehören die Namen dazu. Hier sind sie: Brecht, Hesse und die Marieluise Fleißer, die Kaschnitz, Nossack, Koeppen und Frisch, Eich, Huchel, Celan und Krolow, Peter Weiss und Hildesheimer, Uwe Johnson, Martin Walser, Enzensberger und Thomas Bernhard.“ (Marcel Reich-Ranicki: Siegfried Unseld oder Die Wollust am Buch. [1984] In: M. R.-R.: Lauter Lobreden. Stuttgart: DVA 1985, S. 116-121, hier S. $117 \mathrm{f}$.)

239 Herwig: Meister der Dämmerung (Anm. 196), S. 291.

240 Handke an Unseld, 25. 2. 1981. In: Handke/Unseld: Der Briefwechsel (Anm. 6o), S. 431 f.

241 Malte Herwig/Sven Michaelsen: „Ich wäre liebend gern ein Böser“. [Gespräch mit Peter Handke.] In: Süddeutsche Zeitung Magazin, Nr. 42, 19.10. 2012, S. 52-57, hier S. 53. 
geführt hatten, einige Jahre später im Gespräch mit Peter von Matt selbst weiter tradiert: „Handke war und ist natürlich gekränkt und beleidigt. Und irgendwann hat er in der Wohnung seines Verlegers Siegfried Unseld ein Buch von mir mit einer Widmung für ihn, Unseld, gefunden. Er hat wohl damals verlangt, er sollte die Beziehung mit einem so schrecklichen Kritiker sofort abbrechen." ${ }^{242}$ Erneut bekundete Reich-Ranicki bei dieser Gelegenheit, sich für die Literatur des „angeblich so fabelhaften Handke“ nur eingeschränkt begeistern zu können. Selbst das vermeintliche Lob für dessen Sprechstücke der 196oer Jahre entpuppt sich dabei als hintersinnige Abwertung:

Offen gesagt: Mich hat dieser außerordentlich erfolgreiche Schriftsteller nie sonderlich beeindruckt. Interessiert haben mich seine früheren Einakter wie Publikumsbeschimpfung, Weissagung oder Hilferufe. Das war, glaube ich, hochbegabtes Studententheater. [...] In den siebziger Jahren habe ich zwei Bücher von ihm entschieden abgelehnt: Die linkshändige Frau und Langsame Heimkehr. Man warf mir vor, ich hätte keinen Sinn für den angeblich so fabelhaften Handke. In der Tat interessieren mich seine Bücher immer weniger. ${ }^{243}$

Der Vorwurf, als Autor auch ökonomisch erfolgreich zu sein, der Topos des ,Desinteresses' sowie das Beharren darauf, mit seiner Skepsis gegen den Mainstream der Literaturkritik anzuschreiben: Reich-Ranickis Äußerungen im Gespräch mit Peter von Matt fügten den bekannten Einwänden nichts wesentlich Neues hinzu; sie waren im Grunde eine Reprise seiner Besprechungen der 1970er Jahre.

„Seit zwölf Jahren“ habe er, so der Kritiker weiter, „nichts mehr über ihn geschrieben“. ${ }^{244}$ Tatsächlich war mit dem Verriss von Langsame Heimkehr auch die letzte Printrezension eines Handke-Buches aus der Feder Reich-Ranickis erschienen. Der Bekanntheitsgrad des Kritikers als „national figure ${ }^{\text {“245 }}$ und Ins$\tan z$ des Literaturbetriebs hatte durch seine Präsenz im öffentlich-rechtlichen Fernsehen stark zugenommen; die im Literarischen Quartett lancierten Verrisse und Lobreden erreichten ein beachtlich großes Publikum. ${ }^{246}$ Ein knappes Jahr vor

242 Reich-Ranicki: Der doppelte Boden (Anm. 45), S. $10 \mathrm{f.}$

243 Ebd., S. 10.

244 Ebd.

245 Demetz: On Marcel Reich-Ranicki (Anm. 21), S. 291.

246 Zu Reich-Ranickis Rolle im Literarischen Quartett vgl. Peter Sprengel: Der Authentizitätsdiskurs der literarischen Moderne. Von Heinrich Heine bis Hubert Fichte, mit einem einleitenden Exkurs zum „Literarischen Quartett“. In: Das Authentische. Referenzen und Repräsentationen. Hg. v. Ursula Amrein. Zürich: Chronos 2009, S. 53-65, bes. S. 53-56. Vgl. außerdem Steiner: Literatur als Kritik der Kritik (Anm. 29), S. 138 f.; zu den Diskussionen über das Literarische Quartett allg. s. Albrecht: Literaturkritik (Anm. 9), S. 6o f., sowie Sibylle Cramer: Literaturkritik. 
dem Start des Quartetts - die erste Sendung wurde im März 1988 ausgestrahlt hatte Handke in einem Journaleintrag vom 29. April 1987 bereits vielsagend und klar referenzierbar festgehalten: „,Sich ein Buch vornehmen', sagte gestern abend im Fernsehen der in der Rolle eines Kritikers auftretende Wahnsinnige: Wenn ich mir ein Buch vornehme ... “. ${ }^{247}$ Am Vorabend des Eintrags hatte die ARD die Dokumentation Der Literaturpapst. Auseinandersetzungen mit dem Kritiker Marcel Reich-Ranicki (Regie: Martin Lüdke) erstmals ausgestrahlt. ${ }^{248}$ Handkes Notat war demnach eine unmittelbare Reaktion auf das Gesehene.

Im Oktober 1989, ein halbes Jahr nach Erscheinen des ZEIT-Interviews mit André Müller, folgte der erste Angriff Reich-Ranickis auf Handke im Literarischen Quartett. Bereits einleitend spottete er über „das große[ ] Werk“ Handkes, weil dieses nur „31 Maschinseiten Manuskript“ umfasse, ${ }^{249}$ unterbrach in der Folge Sigrid Löfflers Vorstellung des Buches mehrmals mit despektierlichen Einwürfen - „ich meine, das ist doch Schwachsinn, das ist doch schrecklich“250 und machte sich, an die passionierte Handke-Leserin Löffler gewandt, erneut

In: Machen - Erhalten - Verwalten. Aspekte einer performativen Literaturgeschichte. Hg. v. Burckhard Dücker. Göttingen: Wallstein 2016, S. 61-68, hier S. 65, über die Rolle des „zum Entertainer aufgestiegenen Kritiker[s]“; Baumgart: Damals (Anm. 9), S. 198, hat Reich-Ranickis Auftritte im Fernsehen als „ein mimisches, gestisches, hochtheatralisches eher als argumentatives Ereignis“ bezeichnet.

247 Peter Handke: Am Felsfenster, morgens. In: manuskripte 27 (Oktober 1987), H. 97, S. 3-9, hier S. 8; in der 1998 erschienenen Buchfassung wird das Kritiker-Zitat abschließend mit dem Wort „Drohung“ versehen: „Wenn ich mir ein Buch vornehme‘: Drohung“ (Handke: Am Felsfenster morgens [Anm. 223], S. 471). Vgl. dazu noch Peter Handke/Peter Hamm: Es leben die Illusionen. Gespräche in Chaville und anderswo. Göttingen: Wallstein ${ }^{2} 2008$, S. 164 f., wo Handke im Gespräch mit Peter Hamm die Kritik an Reich-Ranickis Vokabular und Rollenverständnis mit der Apotheose einer anderen (d. h. seiner) Idee von Literatur kontrastiert: „Wenn der große Bücher-sich-Vornehmer, wie er sich selbst nennt, da in Deutschland, über Günter Grass sagt, keiner beherrsche die deutsche Sprache so wie Günter Grass, dann weiß ich schon: Also, wenn einer die deutsche Sprache ,beherrscht', da kann nicht viel in dem Buch leben, in Büchern leben. Die Sprache soll leben! Leben und leben lassen. Und rhythmisieren. Und Luft durchgehen lassen."

248 Vgl. Gesellschaft für Exilforschung: Nachrichtenbrief 1984 bis 1993 mit Gesamtregister. Bd. 1. Redaktion: Ernst Loewy. München u. a.: Saur 1995, S. 162.

249 Marcel Reich-Ranicki: Peter Handke, Versuch über die Müdigkeit im Literarischen Quartett [ZDF], Sendung Nr. 7, 12.10.1989. In: https://www.youtube.com/watch?v=DC9sROSoPoo (Stand 14.10.2020), 23:29-23:40. Eine vollständige Transkription der Sendung findet sich in: Das Literarische Quartett. Gesamtausgabe aller 77 Sendungen von 1988 bis 2001. 3 Bde. Berlin: Directmedia 2006, hier Bd. 1, S. 181. - Ansätze zu einer linguistischen Analyse der Debatte zu Versuch über die Müdigkeit hat Susanne Pütz: „Das Literarische Quartett“ Elite-Show oder Show-Elite. In: Arbeitshefte Bildschirmmedien (1990), H. 21, S. 16-63, hier S. 29 f., vorgelegt.

250 Reich-Ranicki: Peter Handke, Versuch über die Müdigkeit (Anm. 249), 25:25-25:30; vgl. Das Literarische Quartett. Bd. 1 (Anm. 249), S. 181. 
über die Handlungsarmut eines Handke'schen Textes lustig: „Sagen Sie mal, was steht in dem Buch drin? Obwohl ich's gelesen habe, hätte ich's gern von Ihnen gewusst. “251 Hatte Reich-Ranicki gar jene kurze Szene, in der, an Robert Musils Hasenkatastrophe erinnernd, ein "grazile[r], edelköpfige[r] Hund“ einen wehrlosen Hasen zur Strecke bringt, bevor dieser „blutnaß“, mit „,erschlaffende[n] Pfoten, noch ein wenig zuckend“, vom Ort der Gewalt weggebracht wird, ${ }^{252}$ auf sich bezogen, und das womöglich zu Recht? Hellmuth Karaseks Hinweis, er habe im Versuch über die Müdigkeit eine „fast Thomas Bernhard'sche Stelle“ entdeckt, quittierte Reich-Ranicki jedenfalls umgehend und energisch mit der Ermahnung, Karasek solle „die Namen großer Schriftsteller nicht unnütz im Munde führen“. ${ }^{253}$ Bernhard, wenige Monate zuvor verstorben, stand bei ReichRanicki sehr viel höher im Kurs als dessen Antipode; der Kritiker spielte die beiden Autoren des Öfteren zu Ungunsten des Jüngeren gegeneinander aus.

Es lohnt sich, die Beziehung zwischen Bernhard und Reich-Ranicki als Kontrastfolie kurz genauer in den Blick zu nehmen. Zunächst durchaus skeptisch, weil „Bernhards Reflexionen“, so Reich-Ranickis Besprechung von Ungenach (1968), „meist zwar radikal, aber zugleich etwas banal“ seien $^{254}$ und der Autor zudem an einem „Mangel an schriftstellerischer Selbstdisziplin“ laboriere, ${ }^{255}$ brachte er Thomas Bernhard und dessen Literatur im Laufe der Jahre immer größere Sympathie entgegen. Bereits 1965 hatte er den Autor gebeten, eine in der Neuen Rundschau publizierte Erzählung in die Anthologie Erfundene Wahrheit aufnehmen zu dürfen: „[W]enn Ihnen meine Erzählung ,Der Zimmerer“ gefallen hat, so möchte ich sie Ihnen gerne für ein Buch, das Sie im Piper-Verlag herausgeben, überlassen“, willigt Bernhard am 19. März 1965 brieflich ein. ${ }^{256}$ In einem

251 Reich-Ranicki: Peter Handke, Versuch über die Müdigkeit (Anm. 249), 24:00-24:07; vgl. Das Literarische Quartett. Bd. 1 (Anm. 249), S. 181.

252 Handke: Versuch über die Müdigkeit (Anm. 226), S. 63 f.

253 Reich-Ranicki: Peter Handke, Versuch über die Müdigkeit (Anm. 249), 32:19-32:27; vgl. Das Literarische Quartett. Bd. 1 (Anm. 249), S. 183 f.

254 Marcel Reich-Ranicki: Finstere Wollust aus Österreich. Die Erzählungen des Thomas Bernhard. In: DIE ZEIT, Nr. 43, 25.10.1968.

255 Marcel Reich-Ranicki: Leichen im Ausverkauf. In: DIE ZEIT, Nr. 51, 19. 12. 1969. Der Autor neige, so Reich-Ranicki mit Blick auf Bernhards Publikationen des Jahres 1969 (Watten bei Suhrkamp, An der Baumgrenze bei Residenz sowie Ereignisse im Verlag des Literarischen Colloquiums), zu „leichtfertige[m] Publizieren“, was zum Gestus eines „Erzähler[s], der sich offenbar gegen fixe Ideen und Obsessionen wehren muß und der seine Ziele mit monomanischer Unbedingtheit verfolgt", in Widerspruch stehe.

256 Thomas Bernhard an Marcel Reich-Ranicki, 19.3. 1965. In: Deutsches Literaturarchiv Marbach, Handschriftensammlung, A: Reich-Ranicki, HS.2003.0002.00153: „Ich arbeite jetzt an einer Prosaarbeit, die mich, ausser, wenn ich mich dagegen wehre, vollkommen in Anspruch nimmt, und habe keine Zeit, andere kürzere Stücke anzuschauen und eventuell zu korrigieren und so muss ich es beim Zimmerer lassen." Siehe Thomas Bernhard: Der Zimmerer. In: Erfundene 
Porträt zum 70. Geburtstag Hans Erich Nossacks, Anfang 1971 in der ZEIT veröffentlicht, merkte der Kritiker freilich noch an, „die virtuose Verwendung der indirekten Rede“ sei „bei Bernhard längst zur ermüdenden Manier erstarrt“ ${ }^{257}$ Auch im Rückblick hat sich Reich-Ranicki über die frühen Bücher Bernhards wenig begeistert geäußert und den autobiographischen Erzählungen sowie der Prosa der $1980 e r$ Jahre stets den Vorrang eingeräumt. ${ }^{258}$

Er habe, so der Kritiker in seiner Autobiographie Mein Leben, mit Bernhard immer wieder „entspannte und angenehme Plaudereien“ gehabt: „Ich habe ihn mehrfach getroffen: in Berlin, in Frankfurt und in Salzburg und einmal, im August 1982, im oberösterreichischen Ohlsdorf. “259 Seine Gespräche mit Bernhard hätten zwar, wie Reich-Ranicki in einem 1990 publizierten Band schreibt, „in der Regel nicht viel ergeben“, seien aber gerade deshalb „angenehm“ gewesen, „weil wir niemals auch nur erwähnten, was wir beruflich machten: Ich wollte nichts über seine Arbeit erfahren, und auch er stellte keine Fragen, die auf Literatur oder Kritik abzielten. ${ }^{\text {260 }}$ Nachdem er, eigenen Angaben zufolge, die autobiographischen Bände Bernhards „begeistert besprochen“ hatte, ${ }^{261}$ äußerte sich Reich-Ranicki im Laufe der 1980er Jahre wiederholt positiv über Neuerscheinungen des Autors, sowohl über Wittgensteins Neffe (1983) als auch über Holzfällen (1984): ${ }^{262}$ Obschon „die

Wahrheit. Deutsche Geschichten seit 1945. Hg. v. Marcel Reich-Ranicki. München: Piper 1965, S. 477-493. Als die Anthologie 1972 auf zwei Bände (Erfundene Wahrheit. Deutsche Geschichten 1945-1960 und Verteidigung der Zukunft. Deutsche Geschichten seit 1960) erweitert wurde, ersetzte Reich-Ranicki den Zimmerer durch Die Mütze (1967). - Für die Genehmigung zum Abdruck des Bernhard-Briefes an Reich-Ranicki danke in Peter Fabjan.

257 Marcel Reich-Ranicki: Der hanseatische Poet. [1971] In: M. R.-R.: Entgegnung [1979] (Anm. 237), S. $42-46$, hier S. 45 .

258 Vgl. Hans Haider: Die kleine Fehlbarkeit des Literaturpapstes? [Gespräch mit Marcel ReichRanicki.] In: Die Presse, 16.8.1994.

259 Reich-Ranicki: Mein Leben (Anm. 52), S. 443.

260 Marcel Reich-Ranicki: Nachwort. In: M. R.-R.: Thomas Bernhard (Anm. 122), S. 95-103, hier S. 102. Vgl. Reich-Ranicki: Mein Leben (Anm. 52), S. 443: „Bernhard gehörte zu den nicht wenigen Schriftstellern, die Literatur schufen [...], die sich aber für Literatur nicht sonderlich interessierten." Bernhards Freund und Weggefährte Wieland Schmied hat den Verlauf der Gespräche mit Reich-Ranicki folgendermaßen interpretiert: „Er mußte sich gegen das Unbekannte wappnen. Damals erzählte er mir: ,Mit Reich-Ranicki habe ich nur über Würste gesprochen, als ich ihn getroffen habe. 'Er wollte einem Gespräch über Literatur ausweichen, damit sich nicht plötzlich herausstellt, daß er gar nicht so viel weiß wie der andere. Dieser Möglichkeit ist er entgangen, indem er über banale Dinge des alltäglichen Lebens gesprochen hat, wie zum Beispiel davon, was er gerne ißt." (Wieland Schmied: Auersbergers wahre Geschichte und andere Texte über Thomas Bernhard. Ein Alphabet. Vorwort v. Hans Höller. Weitra: Bibliothek der Provinz [2014], S. 57)

261 Reich-Ranicki: Mein Leben (Anm. 52), S. 443.

262 Vgl. Marcel Reich-Ranicki: Thomas Bernhards Bolero. Österreichs großer Einzelgänger wird von Buch zu Buch besser: Holzfällen. Eine Erregung. In: Frankfurter Allgemeine Zeitung, 22. 9. 1984. 
Stücke gegen Ende schwächer" geworden seien, ${ }^{263}$ habe er sich, zumal mit Blick auf die Prosa, mehr und mehr zu einem „Bernhard-Enthusiast[en]“ entwickelt, so der Kritiker im bereits zitierten Gespräch mit Peter von Matt: „Manche leiden an der Prosa Thomas Bernhards, ich gehöre zu jenen, die sie geradezu genießen. “264 Und er gesteht dem Autor im weiteren Verlauf des Interviews ausdrücklich eine Sonderstellung im literarischen Feld zu: „Das Manische bei Bernhard, das Insistierende, das sich in Sprache umsetzt, das in seinem Tonfall, in seinem Satzbau spürbar wird, sein bitterer, grimmiger Humor, sein Katastrophismus - das alles ist

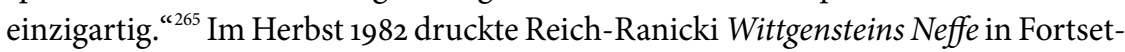
zungen im Feuilleton der $F A Z$, was den Leserkreis der autobiographischen Erzählung deutlich erweiterte; 2002 nahm er neben Werken von Fontane, Goethe, Kafka und Joseph Roth schließlich auch Bernhards Holzfällen in den Kanon der zwanzig seines Erachtens wichtigsten Romane der deutschen Literaturgeschichte auf. ${ }^{266}$

Bernhard und Reich-Ranicki waren sich am 17. November 1968 anlässlich der bereits erwähnten skandalträchtigen Veranstaltung in der Berliner Akademie der Künste begegnet, bei der Rolf Dieter Brinkmann dem Kritiker vor versammeltem Publikum mit der Anwendung von Waffengewalt gedroht hatte. ${ }^{267}$ Nicht nur Brinkmann, sondern auch Bernhard scheint über die Mitwirkung Reich-Ranickis an dem Gesprächs- und Leseformat „Autoren diskutieren mit ihren Kritikern“, dessen dritte Ausgabe an diesem Abend stattfand, nicht erfreut gewesen zu sein; hatte dieser doch kurz zuvor Ungenach in der ZEIT nicht eben freundlich besprochen und dem Autor im April 1967 attestiert, mit seinem zweiten Roman Verstörung erzählerisch „völlig hilflos“ zu agieren, ja „in einem Ozean von Platitüden und in einem wirren Gerede“ zu „ertrinken“, „das an die Geduld des Lesers außerordentliche und unzumutbare Anforderungen stellt“ ${ }^{\text {268 }}$

263 Marcel Reich-Ranicki: Kritikers Kummer - Kritikers Freud. Ein Gespräch mit Joachim Kaiser. [1993] In: M. R.-R.: Kritik als Beruf (Anm. 17), S. 41-96, hier S. 66.

264 Reich-Ranicki: Der doppelte Boden (Anm. 45), S. 54 u. 63.

265 Ebd., S. 137.

266 Vgl. Manfred Mittermayer: Thomas Bernhard. Eine Biografie. Salzburg, Wien: Residenz 2015, S. 357, bzw. den Kommentar in TBW 7, 261. Holzfällen findet sich, neben „28 anderen Autorinnen und Autoren des 20. Jahrhunderts aus dem deutschen Sprachraum“, außerdem in Harold Blooms 1995 veröffentlichtem Western Canon (vgl. ebd., 272).

267 Auf Brinkmanns, aber auch auf Handkes Attacken sind wohl die folgenden Passagen in ReichRanickis Autobiographie Mein Leben gemünzt: „Die Schmerzen und die Leiden der von mir abgelehnten Schriftsteller sind mir nicht unbekannt, und so muß ich Verständnis für ihre Racheakte und Haßausbrüche haben. Nur scheinen mir manche dieser Ausbrüche die Grenzen des Humanen nun doch überschritten zu haben.“ - „Doch will ich nicht verheimlichen, daß mich die Brutalität mancher gegen mich gerichteter Äußerungen verblüfft hat.“ (ReichRanicki: Mein Leben [Anm. 52], S. 445 u. 447)

268 Marcel Reich-Ranicki: Konfessionen eines Besessenen. In: DIE ZEIT, Nr. 17, 28. 4. 1967; die Rezension findet sich auch in M. R.-R.: Literatur der kleinen Schritte (Anm. 47), S. 266-271, 
Bernhard weigerte sich in Berlin nun zwar, gemeinsam mit Reich-Ranicki und dem Kritiker Rudolf Hartung auf der Bühne Platz zu nehmen; er verzichtete aber darauf, in Brinkmanns am Gestus der Surrealisten geschulten Furor gegen den ,Großkritiker' einzustimmen. ${ }^{269}$ Zeitlebens zeigte Bernhard wenig Interesse, gemeinsam mit anderen als aggressiver Polemiker aufzutreten; ihm war daran gelegen, als alleiniger und selbstermächtigter Provokateur zu agieren.

Später wurde Bernhard und Reich-Ranicki, mit Blick auf ihren Hang zur Agonalität und zum öffentlichkeitswirksamen Dissens, wiederholt ein gemeinsamer Charakterzug attestiert: „Wie der von ihm so hoch geschätzte Thomas Bernhard im Bereich der Literatur hat sich Reich-Ranicki in der Literaturkritik als Übertreibungskünstler inszeniert. “270 Die literaturkritische Praxis Reich-Ranickis zeichne, so der mit ihm befreundete Siegfried Lenz, im Besonderen das Wissen um die „Notwendigkeit zu methodischer Übertreibung“ aus; ${ }^{271}$ er sei, wie Hugo Dittberner prägnant festgehalten hat, „ein Mann des Superlativs“; ; ${ }^{272}$ der Kritikerkollege Reinhard Baumgart attestierte ihm in seinen autobiographischen Erinnerungen eine „populistische Lust an provokativer Grellheit und Wirkung “ ${ }^{\text {273 }}$ - ein Liste der Charakterisierungen, die sich beliebig erweitern ließe.

und wurde außerdem in einen vom Suhrkamp Verlag herausgegebenen Materialien-Band aufgenommen: M. R.-R.: Konfessionen eines Besessenen. In: Über Thomas Bernhard. Hg. v. Anneliese Botond. Frankfurt a. M.: Suhrkamp 1970, S. 93-99; direkt im Anschluss wurde in diesem Band übrigens Handkes Text über Verstörung gedruckt (S. 100-106).

269 Vgl. Fellinger: „Ich bin kein Teppichknüpfer“ (Anm. 97), S. 38.

270 Anz: Werten und Fühlen (Anm. 7), S. 20. Vgl. außerdem ders.: Marcel Reich-Ranicki (Anm. 15), S. 15, wonach Reich-Ranicki in der Verwendung von „Stilmittel[n] der überspitzten Formulierung und der maßlosen Übertreibung“ „einem anderen Komödianten und Übertreibungskünstler, den er nicht zufällig außerordentlich schätzt“, gleiche: „Thomas Bernhard“. Vgl. auch ebd., S. 142: „Die polemische Übertreibung - mit der Absicht zu überzeugen, nicht zu überreden! - soll zur Deutlichkeit beitragen und damit Reaktionen provozieren. [...] Die rhetorische Kunst, mit Worten starke Wirkungen zu erzielen, beherrscht Reich-Ranicki wie kein anderer Kritiker der Gegenwart.“

271 Siegfried Lenz: Der Kritiker bei der Arbeit. In: Literatur und Kritik (Anm. 235), S. 24-32, hier S. 32 .

272 Hugo Dittberner: Der Mann in der Arena. Über Marcel Reich-Ranicki. In: Text + Kritik (1988), H. 100, S. 10-22, hier S. 10.

273 Baumgart: Damals (Anm. 9), S. 196. Eine scharfe Kritik an Reich-Ranickis ,Populismus‘ findet sich bei Helmut Arntzen: Literaturkritik? Annotierte Zitate aus einem Buch von Marcel ReichRanicki. In: Kunstgriffe. Auskünfte zur Reichweite von Literaturtheorie und Literaturkritik. Hg. v. Ulrich Horstmann u. Wolfgang Zach. Frankfurt a. M. u. a.: Lang 1989, S. 27-33, hier S. 32: „Es sind durchweg mit Aplomb vorgetragene Platitüden [sic], die weder für den Autor noch für den Leser etwas erbringen können. [...] So wie Reich-Ranicki Gemeinplätze reiht und Behauptungen als Urteile ausgibt, genauso verfährt ein erheblicher Teil der Leser mit der Literatur. Auch ihr Urteil ist häufig eines aus konventionellen Floskeln und willkürlichen Behauptungen. [...] Reich-Ranickis Kritik ist das, was man so meint. Sie ist das Urteil des Durchschnitts.“ 
Tatsächlich erinnern sein Agieren im literarischen Feld, sowohl was den Drang nach Aufmerksamkeit (bei Beteuerung des Gegenteils) als auch was die Tendenz zu polemischer Zuspitzung betrifft, und seine „permanente[ ] Bereitschaft zum Konflikt“274 an das Selbst- und Wunschbild des „Übertreibungskünstler[s]“ Thomas Bernhard (TBW 8, 478): „Wenn wir unsere Übertreibungskunst nicht hätten, hatte ich zu Gambetti gesagt, wären wir zu einem entsetzlich langweiligen Leben verurteilt“ (TBW 8, 101), lässt der Autor seinen Protagonisten Franz-Josef Murau in Auslöschung. Ein Zerfall (1986) sagen - ein Credo, das auch Bernhard selbst nicht fremd war: „Um etwas begreiflich zu machen“, so eine der meistzitierten Passagen des Buches, „müssen wir übertreiben, [...] nur die Übertreibung macht anschaulich“ (TBW 8, 101). ${ }^{275}$ Der emphatisch-hyperbolische Superlativ, im Positiven wie im Negativen, gehörte bei Bernhard ebenso wie bei Reich-Ranicki zum Standardrepertoire ihrer Rhetorik; dem Kritiker galt die Übertreibung dabei insbesondere als Möglichkeit der Popularisierung, der Wirkung auf ein breiteres Publikum: „Man soll übertreiben, überspitzen, um sich verständlich zu machen. “276 Auch hier kann Peter Handke als Gegenpol gelten: Ein Jahr nach dem Erscheinen von Auslöschung hielt er in einem Gespräch mit Lothar Schmidt-Mühlisch fest, dass ein Schriftsteller „nie grell“ sein dürfe, „ein Dichter übertreibt nie. Es ist ein dummer Spruch von Thomas Bernhard, daß

274 Gerhard Roth: o. T. In: Reich-Ranicki: Kritik als Beruf (Anm. 17), S. 99-101, hier S. 101.

275 In der Bernhard-Forschung hat sich der Begriff durch den folgenden Band verfestigt: Wendelin Schmidt-Dengler: Der Übertreibungskünstler. Studien zu Thomas Bernhard. Wien: Sonderzahl 1986. Vgl. auch Hermann Korte: Dramaturgie der „Übertreibungskunst“. Thomas Bernhards Roman Auslöschung. Ein Zerfall. In: Text + Kritik ( $\left.{ }^{3} 1991\right)$, H. 43, S. 88-103; Tim Reuter: „Vaterland, Unsinn“. Thomas Bernhards (ent-)nationalisierte Genieästhetik zwischen ÖsterreichGebundenheit und Österreich-Entbundenheit. Würzburg: Königshausen \& Neumann 2013, S. 262-286. - Freilich bezeichnen Bernhards Figuren das Übertreiben selbst des Öfteren als ungerechtes, moralisch fragwürdiges Vorgehen, etwa der Erzähler von Der Untergeher (1983): „Wie immer, übertrieb ich auch jetzt und es war mir vor mir selbst peinlich, [...] so, dachte ich, gehe ich immer gegen Andere vor, ungerecht, ja verbrecherisch. An dieser Ungerechtigkeitseigenschaft habe ich immer gelitten, dachte ich." (TBW 6, 133) - Andreas Dorschel: Lakonik und Suada in der Prosa Thomas Bernhards. In: Thomas Bernhard Jahrbuch 2007/2008, S. 215-233, hier S. 228, hat die Vermutung geäußert, der Gestus der „Übertreibung“ sei bei Bernhard (bzw. in Bernhards literarischen Texten) „nichts weiter als ein Trick der Selbstbehauptung, der das knappe Gut Aufmerksamkeit von anderen abzieht und auf den Übertreibenden zieht".

276 Rolf Becker/Hellmuth Karasek: „Ich habe manipuliert, selbstverständlich!“ Kritiker Marcel Reich-Ranicki über seine Rolle im Literaturbetrieb und seinen Abgang von der FAZ. In: Der Spiegel, Nr. 1, 2.1.1989, S. 140-146, hier S. 144. Dazu auch Reich-Ranicki: Entgegnung [1979] (Anm. 237), S. 14: „Nun scheint es mir angebracht, an ein so knappes wie verblüffendes Wort von Auguste Rodin zu erinnern: ,Man soll übertreiben.' [...] Denn wovor sich der Literaturwissenschaftler hüten sollte, das darf sehr wohl der Kritiker: Ähnlich wie der Pamphletist hat er das Recht und bisweilen sogar die Pflicht zu übertreiben und zu überspitzen.“ 
man übertreiben müsse. Ein Dichter muß strukturieren, erkennen, gliedern und ins Offene gehen. “277 Dem Bernhard'schen Konzept des fortwährenden Übertreibens stellt Handke, in affirmativem Bezug auf die Poetik Friedrich Hölderlins und dessen Fragment gebliebene Elegie Der Gang aufs Land. An Landauer, eine ganz andere Vorstellung von Literatur gegenüber. ${ }^{278}$

Wenngleich spät, entwickelte doch auch Bernhard seinerseits eine gewisse Sympathie für Reich-Ranicki. Am 18. Januar 1986 gratulierte er dem Kritiker in einer Postkarte aus Madeira zu einem tags zuvor in der FAZ erschienenen Aufsatz über Erika Mann: „Dem Haßenden muß erlaubt sein, ebenso stark zu lieben: nach Lektüre von ,Th. Manns treue Tochter' beide, das Meisterwerk u. seinen Meister. Vergebung voraussetzend, Thomas Bernhard“. ${ }^{279}$ Zwar bleibt durch die aphoristische Kürze der Nachricht im Dunkeln, ob die Liebe des „Haßenden“, mit dem vermutlich der Briefschreiber selbst gemeint ist, nun Thomas Mann oder dem Adressaten gilt und wofür konkret er um „Vergebung“ bittet; dass Bernhard die freundlichen Zeilen aber gerade an jenem Tag verfasst, an dem er einen seiner berüchtigten Schmähbriefe an Siegfried Unseld schickt - „verlegerische Katastrophe“, „proletarische[r], stumpfsinnige[r] Müll“, „Stupiditätsrekord“280 wirft ein bezeichnendes Licht auf Bernhards Sympathiemanagement, zumal die beiden Postsendungen die Frankfurter Redaktion und den Frankfurter Verlag wohl zur gleichen Zeit erreichten.

Gleichwohl beantwortete Bernhard im Jahr darauf im Gespräch mit Asta Scheib die Frage, ob er ein „Hochgefühl“ verspüre, „wenn Kritiker wie ReichRanicki oder Benjamin Henrichs bewundernd über Sie schreiben“, abschlägig:

Bei Kritiken habe ich nie mehr ein Hochgefühl. Am Anfang ja, weil man diese Dinge alle glaubt. Wenn man aber dreißig Jahre lang dieses Auf und Ab erlebt, dieses Heimzahlen von Schuld, dann durchschaut man die Mechanismen. Da schickt einer seinen Diener und sagt dem: „Da will ich eine negative Kritik.“ So geht das. (TBW 22.2, 336)

277 Lothar Schmidt-Mühlisch: Peter Handke: Ich denke wieder an ein ganz stummes Stück. In: Die Welt, 9. 10.1987.

$278 \mathrm{Zu}$ den Bezügen von Handkes Schreiben zu Hölderlins „Komm, ins Offene, Freund“ vgl. Albes: Erzählen - Argumentieren - Beschreiben (Anm. 189), S. 395, sowie ausführlich Hans Höller: Eine ungewöhnliche Klassik nach 1945. Das Werk Peter Handkes. Berlin: Suhrkamp 2013.

279 Thomas Bernhard an Marcel Reich-Ranicki, 19.1.1986. In: Deutsches Literaturarchiv Marbach, Handschriftensammlung, A: Reich-Ranicki, HS.2003.0002.00153. Bernhard bezieht sich auf den folgenden Aufsatz des Kritikers: Marcel Reich-Ranicki: Thomas Manns treue Tochter. In: Frankfurter Allgemeine Zeitung, 18. 1. 1986. Für die Genehmigung zum Abdruck danke ich Peter Fabjan.

280 Bernhard an Unseld, 19. 1.1986. In: Bernhard/Unseld: Der Briefwechsel (Anm. 151), S. 743. Es handelt sich um Bernhards Polemik gegen die Herausgabe von Marianne Fritz' Roman Dessen Sprache du nicht verstehst. 
Wiederholt hat Handke gegen das Feuilleton der FAZ rebelliert, während Bernhard - der in der Bemerkung über die „Mechanismen“ des Literaturbetriebs Handkes Vorwurf an Reich-Ranicki als Literaturchef der FAZ sekundiert hier vorgibt, selbst positiven Rezensionen von meinungsbildenden Kritikern inzwischen gelassen und abgeklärt gegenüberzustehen. Wohl nicht von ungefähr handelt es sich dabei um jenes Gespräch, in dem Bernhard seine langjährige, 1984 verstorbene Gefährtin Hedwig Stavianicek als ideale Kritikerin seiner Arbeit bezeichnet hat: „Ich hatte nie einen besseren Kritiker als sie. Das ist nicht vereinbar mit einer dummen, öffentlichen Kritik, die gar nicht eindringt.“ (TBW 22.2, 340) Wie in anderen späten Texten des Autors - besonders prägnant in Alte Meister (1985) - wird hier die persönliche Erfahrung des Verlusts eines geliebten Menschen thematisiert, eines Verlusts, der andere Maßstäbe und Konflikte in den Hintergrund treten lässt: „Die Dinge rühren einen gar nicht mehr an danach. Es interessieren einen weder Erfolg noch Mißerfolg, weder Theater noch Regisseure, weder Redakteure noch Kritiker. Es interessiert einen wirklich nichts mehr." (TBW 22.2, 340)

„Der Name Thomas Bernhard fällt nicht, auch der von Reich-Ranicki nicht.“281 Der Satz, den Siegfried Unseld im Sommer 1980, nach einem spannungsreichen Treffen mit Peter Handke, in seinem Reisebericht notiert, verweist auf eine taktische Finte des Autors: auf seine Weigerung, die beiden Kontrahenten, die er zudem jeweils im Bunde mit seinem Verleger sah, beim Namen zu nennen. Es verwundert angesichts des „wechselseitigen Dauer-Beobachtungsverhältnis[ses] “282 zwischen Bernhard und Handke nicht, dass Unseld im gleichen Bericht von seiner Reise nach Salzburg vice versa eine ganz ähnlich geartete Paranoia des Gegenübers festhält: „Eifersüchtig wachte er darüber, wie ich meine Stunden in Salzburg ausfüllte, der

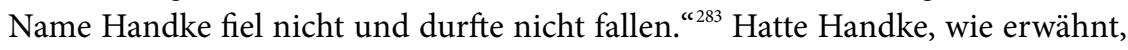
bei der Arbeit an der Lehre der Sainte-Victoire zunächst das Kürzel „MRR“ an den Rand seiner Notizen gesetzt, tilgte er den Namen in der Folge nicht nur in seinem Arbeitsheft, sondern auch aus seinem Sprachgebrauch: Reich-Ranicki als der ,HeWho-Must-Not-Be-Named', der ,You-know-who' der Handke’schen Antipathien. „Diesen Namen werden Sie aus meinem Mund niemals hören. Sie können ihn mir ruhig zehnmal sagen. Das geht zum einen Ohr hinein, zum anderen wieder

281 Unseld: Reisebericht Salzburg, 24--26. Juli 1980. In: Handke/Unseld: Der Briefwechsel (Anm. 6o), S. 414. Vgl. bereits seine Notiz zu einem Gespräch mit Handke am 5. April 1980, auch hier mit Bezug auf Reich-Ranicki: „Es war ja klar, wer gemeint war, obschon er den Namen nicht aussprechen kann.“ (Ebd., S. 40o)

282 Karl Wagner: „Er war sicher der Begabteste von uns allen“. Bernhard, Handke und die österreichische Literatur. Wien: Picus 2010, S. 32.

283 Unseld: Reisebericht Salzburg, 24.-26. Juli 1980. In: Bernhard/Unseld: Der Briefwechsel (Anm. 151), S. 598. 
hinaus“, so Handke im Herbst 1988 zu André Müller. ${ }^{284}$ Kurz zuvor hatte er - die aggressive Schmähung des „übelsten Monstrums, das die deutsche Literaturbetriebsgeschichte je durchkrochen hat " ${ }^{285}$ aus dem Februar 1981 aufgreifend - eine negative Rezension des Kritikers zur „Suada des gemeindummen Monsters von Frankfurt" erklärt, ohne das Monster beim Namen zu nennen; ${ }^{286}$ der Empfänger des Briefes, Alfred Kolleritsch, wusste jedenfalls, wovon (nicht) die Rede war.

Reich-Ranicki setzte derweil auf kleinere Sticheleien, indem er Handke beiläufig in anderen Rezensionen auftreten ließ. In einem 1988 veröffentlichten Artikel zur Entwicklung des Theaters in den Vereinigten Staaten etwa führt der Kritiker seinen Kontrahenten in einer illustren Reihe alternder Dramatiker an:

[W] enn sie etwas älter werden, dann sind sie des unentwegten Trubels und ihres meist etwas unseriösen Geschäfts überdrüssig. Sie verstummen (wie Shakespeare), sie wenden sich der Mystik zu (wie Gogol), sie schießen sich in den Kopf (wie Raimund), sie werden fromm (wie Handke), sie gehen zum Fernsehen (wie Kroetz). ${ }^{287}$

Die Aufzählung, die Reich-Ranicki hier vornimmt, mutet schon auf den ersten Blick recht kurios an, beging doch, um nur dieses eine Beispiel weiter zu verfolgen, Ferdinand Raimund 1836 keineswegs aus Überdruss gegenüber dem Theaterbetrieb Selbstmord, sondern aus Angst, nach dem Biss eines Hundes an Tollwut erkrankt zu sein. Die Liste diente dem Kritiker aber jedenfalls dazu, erneut seiner Überzeugung, Handke habe sich Ende der 1970er Jahre der

284 Müller: Im Gespräch mit Peter Handke (Anm. 112), S. 65. Vgl. auch Federmair: Die Apfelbäume von Chaville (Anm. 218), S. 202: „Scheu wie er ist, hält sich der Autor zurück, vor allem bei direkten Benennungen; den Namen Reich-Ranicki nimmt er nicht einmal im lockeren Gespräch in den Mund, auch nicht Jahrzehnte nach den vorgefallenen Streitigkeiten. " - Handkes Absicht, den Namen Reich-Ranickis demonstrativ zu verschweigen, findet seine Entsprechung in Helmut Heißenbüttels Nachruf bei Lebzeiten (1988) auf den namentlich ausdrücklich nicht genannten Kritiker: „Ich habe versucht, seinen Namen auszusparen, wie ich ihn jetzt ausspare. Das ist bei einem so allgegenwärtigen Schriftsteller nicht so einfach, aber auch wieder nicht so schwer, wie es auf den ersten Blick erscheint." (Heißenbüttel: Nachruf bei Lebzeiten [Anm. 82], S. 27f.) Als komplementäre Strategie kann Handkes Beharren auf der Nennung vergessener, aus dem Fokus medialer Aufmerksamkeit gerückter Personen gelten, etwa in einer kurzen Erzählung aus dem Umfeld der Jugoslawien-Texte: „[I]mmer wieder sei dieser Name erwähnt, damit er sich einpräge über die Aktualitäten hinaus“ (Peter Handke: Die Geschichte des Dragoljub Milanović. Salzburg, Wien: Jung und Jung 2011, S. 13).

285 Handke an Unseld, 25. 2. 1981. In: Handke/Unseld: Der Briefwechsel (Anm. 6o), S. 431.

286 Handke an Kolleritsch, 15. 1. 1987. In: Handke/Kolleritsch: Schönheit ist die erste Bürgerpflicht (Anm. 12), S. 161.

287 Marcel Reich-Ranicki: Ein amerikanisches Welttheater. [1988] In: M. R.-R.: Über Amerikaner. Von Hemingway und Bellow bis Updike und Philip Roth. München: DVA 2004, S. 137-152, hier S. 137. 
,religiösen“ Literatur verschrieben und sei entsprechend „fromm“ geworden, Ausdruck zu verleihen.

Als Handke sich im Januar 1990 von Aix-en-Provence aus erneut zur Montagne Sainte-Victoire aufmacht und dieser Wanderung wenig später eine Epopöe vom Verschwinden der Wege widmet, ist das Gebiet kaum wiederzuerkennen: Ein verheerender Waldbrand hat die Charakteristik der Bergkette tiefgreifend verändert, hat „alles verbrannt, was nur brennbar war, von den Vorbergen über die Zwischenplateaus bis zu den letzten, vereinzelten Krüppelbüschen ganz oben in den Ritzen der sonst unbewachsenen Felswände“. ${ }^{288}$ Angesichts der „bis auf

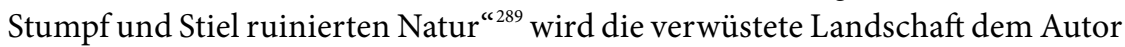
zum Bild für sein eigenes Dasein, für das Verschwinden des Bekannten, für die Nicht-Wiederholbarkeit der vertrauten Wege - mithin zu einer poetologischen Allegorie. Von einer aggressiven Bestie ist in dieser Anderen Lehre der SainteVictoire - so der Nebentitel der Epopöe - keine Spur mehr zu finden; sie wird jedoch anderswo in Handkes Werk wieder auftauchen.

Im Literarischen Quartett nahm Reich-Ranicki einstweilen weiterhin Neuerscheinungen Handkes ins Visier: Nachdem er den Versuch über die Jukebox (1990) als "ganz schwache Literatur" abgekanzelt hatte, ${ }^{290}$ fiel sein Kommentar zum Versuch über den geglückten Tag ein Jahr darauf überraschend positiv und freundlich aus:

Ich muss sagen, es hat mich viel tiefer beeindruckt als die beiden vorangegangenen Versuche von Handke. Was an dem Buch für mich so beeindruckend, so wichtig ist, [...] ist die Übereinstimmung von Gedanklichem und von der Darstellung sinnlicher Eindrücke, der Sprache und des Gedankens. Es ist selten ein Buch da, von dem man sagen kann: Hier ist Form und Inhalt dasselbe. Die Form ist hier der Inhalt, der Inhalt ist hier die Form. Die Sprache und der Gedanke kommen ganz aneinander, und das ist sprachlich von einer Virtuosität, wie es Handke, glaube ich, schon lange nicht war, sehr lange nicht war. ${ }^{291}$

Wüsste man es im Rückblick nicht besser, wäre man versucht, das Lob des Kritikers im Literarischen Quartett als Zeichen einer allmählichen Entspannung der Fehde zu interpretieren.

288 Peter Handke: Epopöe vom Verschwinden der Wege oder Eine andere Lehre der Sainte-Victoire. In: P. H.: Noch einmal für Thukydides. Salzburg, Wien: Residenz 1990, S. 34-38, hier S. 35.

289 Ebd., S. 36.

290 Marcel Reich-Ranicki. In: Das Literarische Quartett. Bd. 1 (Anm. 249), S. 290. Diese Sendung des Literarischen Quartetts ist nicht als Videomitschnitt im Internet verfügbar.

291 Marcel Reich-Ranicki: Peter Handke, Versuch über den geglückten Tag im Literarischen Quartett [ZDF], Sendung Nr. 16, 16.10.1991. In: https://www.youtube.com/watch?v=OsbUjhIAojg (Stand 14. 10. 2020), 01:09:20-01:10:16; vgl. Das Literarische Quartett. Bd. 1 (Anm. 249), S. 428. 


\section{Schnüffeln und Verreißen (Mein Jahr in der Niemandsbucht)}

Der Kritiker als Hund, dem der „Geifer“ fortwährend aus dem Maul tropft ${ }^{292}$ ohne explizit auf die Lehre der Sainte-Victoire Bezug zu nehmen, aktualisierte der Spiegel im Buchmessen-Herbst 1993 Handkes wenig schmeichelhafte MRR-Ikonographie: Das Cover des Magazins vom 4. Oktober zierte, unter dem Titel „Der Verreißer“, Reich-Ranickis Kopf auf dem Körper und mit den Ohren eines Hundes, eben im Begriff, ein Buch zu verschlingen. In der Lehre der Sainte-Victoire hatte Handkes wanderndes Alter Ego der „Dogge von Puyloubier“ durch den Zaun „eine gelbe Pariser Métrofahrkarte“ zugeworfen, „und der Hund verwandelte sich auf der Stelle in einen Marder, die bekanntlich Allesfresser sind, und schlang mein Papier hinunter “ ${ }^{293}$ Hier wie dort, in der fiktionalen Erzählung wie im investigativen Nachrichtenmagazin, handelt es sich um einen Akt der Papyrophagie, der nicht den genüsslichen Verzehr eines Gourmets, sondern den rabiaten Hunger eines nicht eben wählerischen Omnivoren ins Visier nimmt.

Reich-Ranicki konnte für das provokante Cover des Spiegels wenig Verständnis aufbringen: Er fühlte sich an die Bildsprache antisemitischer Hetze erinnert und protestierte in einem, Krisengespräch' mit Volker Hage und Hellmuth Karasek heftig: Es handle sich, so der Karikierte, um „eine Infamie [...] im tief nationalsozialistischen Sinne“; ${ }^{294}$ den Einwand Karaseks, die Vorlage des Titelsujets stamme aus der satirischen Wochenschrift Simplicissimus, ${ }^{295}$ wollte er nicht gelten lassen, vielmehr sah er darin eine schändliche Verunglimpfung der gesamten Kritiker-Profession. Ein literarischer „Allesfresser“ wollte ReichRanicki ebenso wenig sein wie ein „Zerberus“ des Literaturbetriebs, ${ }^{296}$ obgleich

292 Handke: Die Lehre der Sainte-Victoire (Anm. 10), S. 56.

293 Ebd., S. 58 f.

294 Marcel Reich-Ranicki im Gespräch mit Volker Hage und Hellmuth Karasek, Oktober 1993. In: https://www.spiegel.de/video/reich-ranicki-karasek-hage-video-99010556.html (Stand 14. 10. 2020), 01:10-01:20. Vgl. dazu auch Hage/Schreiber: Marcel Reich-Ranicki (Anm. 57), S. 147-149; Steiner: Literatur als Kritik der Kritik (Anm. 29), S. 144, Anm. 20.

295 Vgl. die Abb. in: Simpliccismus 1896-1933. Die satirische Wochenschrift. Hg. v. Reinhard Klimmt u. Hans Zimmermann. Stuttgart: LangenMüller 2018.

296 Diese Funktion hatte Peter Turrini den Kritikern bereits 20 Jahre zuvor in toto zugeschrieben. Siehe Peter Turrini: Kulturkritik. [1974] In: P. T.: Mein Österreich. Reden, Polemiken, Aufsätze. Darmstadt: Luchterhand 1988, S. 27-39, hier S. 29 u. 34. - Auch die Schilderung in Die Lehre der Sainte-Victoire spielt auf die Figur des Zerberus an, wenn Handke aus dem Sechsten Gesang von Dantes Inferno zitiert, in dem das „Untier Zerberus“ auftritt (Dante Alighieri: Die göttliche Komödie. Aus dem Italienischen v. Philaletes. Zürich: Diogenes 1991, S. 39). - Vgl. Handke: Die Lehre der Sainte-Victoire (Anm. 10), S. 58: „und der Stacheldraht zwischen uns, wie im alten Gedicht, wieder als ewiger, vermaledeiter, kalter, schwerer Regen, durch den hindurch ich, geistesgegenwärtig und tagträumend zugleich, den Feind betrachtete“; dazu im Detail Albes: 
er sich, etwa mit Bänden wie Lauter Verrisse, wiederholt selbst als ein solcher inszeniert hatte. Der österreichische Autor, Philosoph und Publizist Franz Schuh hat Reich-Ranicki gerade diesen double speak zum Vorwurf gemacht: „Ein Kritiker, der sich selbst dadurch kenntlich machen will, daß er bildlich sich auf das Zerreißen eines Buches reduziert, ist sehr einprägsam. “ ${ }^{297}$ Reich-Ranicki hatte dem öffentlichkeitswirksamen Bild vom ,Verreißer ' jahrelang zugearbeitet und daraus eine Marke mit starkem Wiedererkennungswert auch jenseits des engeren Literaturbetriebs etabliert; dass er sich nun darüber echauffierte, das von ihm selbst sorgsam genährte Image im Spiegel vorgehalten zu bekommen, trug durchaus Züge der Heuchelei. ${ }^{298}$ Im Zuge des zitierten Gesprächs bezog sich Reich-Ranicki außerdem ein weiteres Mal auf Goethes Rezensenten-Gedicht aus dem Jahr 1774, das mit dem berühmt-berüchtigten Vers „Schlagt ihn tot den Hund! Er ist ein Rezensent “299 endet; er hatte es schon 1991 in der Frankfurter Anthologie als das „dümmste“ Gedicht des „unverbesserliche[n] Vielschreiber[s]“ Goethe bezeichnet. ${ }^{300}$ Der Text galt Reich-Ranicki zeitlebens als unverzeihlicher Lapsus des Klassikers, an den er sich nun angesichts der Handke'schen Allegorie und des aktuellen Spiegel-Covers erneut erinnert fühlte. ${ }^{301}$ Handke wiederum hat Goethes Gedicht noch 2015 im Theaterstück Die Unschuldigen, ich und die Unbekannte am Rand der Landstraße variierend aufgegriffen. ${ }^{302}$

Erzählen - Argumentieren - Beschreiben (Anm. 189), S. 415 f.; Herwig Gottwald: „In wie vielen Zeitungsfotos von Mördern ich mich wiedererkenne!“ Handke und das ,Böse‘. In: Schreiben als Weltentdeckung (Anm. 230), S. 201-213, hier S. $209 \mathrm{f}$.

297 Schuh: All you need is love (Anm. 27), S. 94.

298 Vgl. die Bemerkungen ebd., S. 93 f.

299 Johann Wolfgang Goethe: [Da hatt ich einen Kerl zu Gast]. In: J. W. G.: Sämtliche Werke nach Epochen seines Schaffens. Münchner Ausgabe. Hg. v. Karl Richter in Zusammenarbeit mit Herbert G. Göpfert u. a. Bd. 1.1: Der junge Goethe. 1757-1775. Hg. v. Gerhard Sauder. München: Hanser 1985, S. 223-224, hier S. 224. Die Überschrift „Rezensent“ wurde dem zunächst ohne Titel gedruckten Gedicht erst später hinzugefügt; vgl. Burkhard Moennighoff: Goethes Gedichttitel. Berlin, New York: de Gruyter 2000, S. 75 f.

300 Marcel Reich-Ranicki: Ein Gegner der Meinungsfreiheit. In: Frankfurter Anthologie. Bd. 14. Gedichte und Interpretationen. Hg. v. M. R.-R. Frankfurt a. M., Leipzig: Insel 1991, S. 30-32, hier S. 32.

301 Vgl. ebd., S. 32: „Indem Goethe seine Leser auffordert, die Rezensenten totzuschlagen, entpuppt er sich als ein Anhänger der Todesstrafe [?] und als ein Gegner der Meinungsfreiheit; überdies ist auch der Tatbestand der Volksverhetzung [?] erfüllt." Siehe dazu Porombka: Gemengelagen lesen (Anm. 62), S. 109.

302 Vgl. Peter Handke: Die Unschuldigen, ich und die Unbekannte am Rand der Landstraße. Ein Schauspiel in vier Jahreszeiten. Berlin: Suhrkamp 2015, S. 94: „Jeder Fremde ist ihm lieber als ein-Nachbar [sic]. Auf unsere Nachbarschaftsfeste spuckt er. Nachbar ist ihm gleich Bluthund: ,Schlagt ihn tot, den Hund, er ist ein Nachbar! Er ist gegen die Macht und möchte doch der sein, der das Machtwort spricht.“ 
Danach befragt, wen er in der deutschsprachigen Gegenwartsliteratur besonders schätze, antwortete Reich-Ranicki im Interview mit den Spiegel-Redakteuren Volker Hage und Mathias Schreiber, im selben Heft der Zeitschrift gedruckt, Peter Handke zähle „bestimmt nicht“ dazu. ${ }^{303}$ Dieser arbeitete, mittlerweile nach Chaville bei Paris übersiedelt, in jenem Herbst 1993 intensiv an einer groBen epischen Erzählung, die ein Jahr darauf unter dem Titel Mein Jahr in der Niemandsbucht erscheinen sollte. ${ }^{304}$ Wie schon in Die Lehre der Sainte-Victoire gehen darin narrative und essayistische, autobiographische, poetologische und fiktionale Passagen ineinander über, ergeben eine komplexe und anspielungsreiche Textur. Auf mehr als 1000 Seiten stellt der Band, wie Jan Wiele gezeigt hat, einen „Hybrid aus Chronik, Selberlebensbeschreibung, Tagebuch“ vor ${ }^{305}$ und liegt damit, anderen Büchern Handkes vergleichbar, quer zu den üblichen Gattungsformen. Indem er es im Untertitel als „Märchen aus der neuen Zeit“ ausweist, greift Handke auf die Genrebezeichnung von E. T. A. Hoffmanns Der goldene Topf zurück. Mein Jahr in der Niemandsbucht handelt, in einem komplexen System von Alter-Ego- und Doppelgänger-Figuren, ${ }^{306}$ von der Schreiberexistenz des Gregor Keuschnig. Diesen Namen hatte Handke schon dem Protagonisten der fast zwei Jahrzehnte zuvor erschienenen Erzählung Die Stunde der wahren Empfindung (1975) gegeben.

Was mein Buch von den Vorzeitformen alias der Schimärischen Welt betraf, so dachte ich während meiner Rückfälle, damit falsch aufgehört zu haben, und derart ein Gescheiterter und zugleich endlich an meinem Platz zu sein, und dann wiederum, auf es mein ganzes weiteres Leben bauen zu können, oder wenigstens ein Stück davon. ${ }^{307}$

Zentrale Stationen und Konstellationen der Handke'schen Werkbiographie sind hier und an anderen Stellen des Opus magnum klar wiederzuerkennen: „Die Vorzeitformen“, die Bezeichnung des ersten Kapitels von Langsame Heimkehr, hatte Handke zunächst als Titel des gesamten Buches im Auge gehabt; die in der Niemandsbucht geschilderte Schreibkrise des Gregor Keuschnig ist an jene

303 Volker Hage/Mathias Schreiber: „Kritiker sind einsam“. Marcel Reich-Ranicki über sich selbst und die deutsche Literatur. In: Der Spiegel, Nr. 40, 4. 10. 1993, S. 279-287, hier S. 287.

304 Die Entstehungsgeschichte des Buches rekonstruiert Raimund Fellinger: „Schreiben: Sich zur Ruhe setzen“. Die Entstehung von Mein Jahr in der Niemandsbucht. In: Peter Handke. Freiheit des Schreibens - Ordnung der Schrift. Hg. v. Klaus Kastberger. Unter Mitarb. v. Clemens Özelt. Wien: Zsolnay 2009, S. 133-142.

305 Wiele: Poetologische Fiktion (Anm. 39), S. 206.

306 Vgl. Christoph Parry: Der Prophet der Randbezirke. Zu Peter Handkes Poetisierung der Peripherie in Mein Jahr in der Niemandsbucht. In: Text + Kritik ( $\left.{ }^{6} 1999\right)$, H. 24/24a, S. 51-61; Wiele: Poetologische Fiktion (Anm. 39), S. 216-218.

307 Handke: Mein Jahr in der Niemandsbucht (Anm. 29), S. 404. 
des Autors Handke in den Jahren 1978/1979 angelehnt. ${ }^{308}$ Indem der Ich-Erzähler im Folgenden die Rezeption der Langsamen Heimkehr, die seine „Generationsgenossen“ von ihm abrücken habe lassen, rekonstruiert, wird ein weiteres Mal die Kontroverse mit seinem journalistischen Erzkontrahenten aufgerufen:

Die Besprechungen waren so oder so. Nur einer der Kritiker, der schlaueste und zugleich beschränkteste, und der seine Begrenztheit für Einfachheit ausgab, erschnüffelte etwas und meinte, daß ein Bedürfnis nach Heil, wie es einem der Helden auf die Augenlider drückt, ein verunglücktes Bild sei, und fragte sich, ob auf die Knie zu fallen, wie es im Verlauf der Begebenheiten einem geschah, eine geeignete Haltung zum Denken sei. ${ }^{309}$

Offenkundig werden hier die von Reich-Ranicki gegen Langsame Heimkehr ins Treffen geführten Einwände paraphrasiert und in den Erzähltext eingespeist, ${ }^{310}$ um wenige Seiten später sowohl die Hunde-Episode aus der Lehre der SainteVictoire als auch den Konflikt zwischen Handke und Unseld erneut ins Spiel zu bringen; wiederum bemüht der Autor dabei den Vergleich Reich-Ranickis mit einem Tier. Dieses Mal jedoch konnte, obgleich Namen und Zeitebenen im Zuge einer sanften Fiktionalisierung verfremdet und verschoben sind, von Beginn an kein Zweifel am ,biographischen Schlüssel' der Sätze bestehen: ${ }^{311}$

308 Vgl. Handke/Unseld: Der Briefwechsel (Anm. 60), S. 350 u. 352. Dazu die Dokumentation der Textgenese der Langsamen Heimkehr bei Ines Barner: „Nie wieder will ich Masken sehen“. Zur Entstehung von Peter Handkes Erzählung Langsame Heimkehr (1979). In: Jahrbuch der Deutschen Schillergesellschaft 58 (2014), S. 355-385, bes. S. 357-362, die, im Gegensatz zu früheren Darstellungen, besonders den „große[n] Gestaltungsspielraum lektoralen Mitwirkens“ (S. 380) durch Elisabeth Borchers hervorhebt. Zur Bedeutung der Titel „Vorzeitformen“ und „Schimärische[ ] Welt" im Erzählkontext der Niemandsbucht vgl. Gabriele Feulner: Mythos Künstler. Konstruktionen und Destruktionen in der deutschsprachigen Prosa des 20. Jahrhunderts. Berlin: Erich Schmidt 2010, S. 282 f.; zu Borchers” „Position im Verlagsgefüge“ jetzt Paweł Zajas: Verlagspraxis und Kulturpolitik. Beiträge zur Soziologie des Literatursystems. Paderborn: Fink 2019, S. 196-200.

309 Handke: Mein Jahr in der Niemandsbucht (Anm. 29), S. 405. - Steiner: Literatur als Kritik der Kritik (Anm. 29), S. 153, hat darauf hingewiesen, „daß die Literaturkritik im fiktionalen Kontinuum der Niemandsbucht eine nicht unwesentliche Rolle spielt“. Dazu auch ebd., S. 156-158.

310 Vgl. Reich-Ranicki: Peter Handke und der liebe Gott (Anm. 129): „Viele Kritiker versuchten, ihm noch eine Weile treu zu bleiben und schrieben auch über seine neuen Arbeiten meist kniend, also in einer Position, die weder das Denken noch das Schreiben begünstigt.“ - „Ist das Bedürfnis nach Heil etwas Animalisches? Was soll das bedeuten, daß es auf die Augenlider drückt? [...] Von nun an lesen wir die Erzählung in der Hoffnung, Antworten auf die Fragen zu finden, die schon dieser weihevolle und offensichtlich verunglückte erste Satz aufwirft."

311 Vgl. etwa Thomas Steinfeld: Das Krokodil in meinem Herzen. Ein Prophet des Seßhaften: Peter Handke verbringt ein Jahr in der Niemandsbucht. In: Frankfurter Allgemeine Zeitung, 12. 11. 1994: „Siegfried Unseld, vergiftet' die Gegend, und Marcel Reich-Ranicki kommt vor, doch 
[M]ein Feind in Deutschland, inzwischen der umschmeichelte Vornamensfreund meines ehemaligen Verlegers (aber auch zuvor schon, sooft ich bei diesem eintrat, war mein Stuhl noch von dem anderen stinkheiß gewesen), warf mir, als ich ihm, der überall war und nirgends, dann einmal über den Weg, nein, er war ohne Weg, lief, in seinem Vorbeiteufeln, mit dem Geäug eines wahnsinnigen, zu seinem Leidwesen von seinem Wutobjekt durch einen Zaun abgehaltenen Hundes, hin: ,Na, Herr PelegrinKeuschnig, wie gehen die Geschäfte?' (Wieder einmal war er der Schlaue, nur wußte er nicht, daß auch Keuschnig ein angenommener Name war. Und wie immer verlor er, der sonst bewährte Schnüffler und Reißer, die Fährte bei den Sachen, die zählen, indem diese nämlich beinahe duftlos sind.) ${ }^{312}$

Im Gespräch mit André Müller hat Handke diesen Satz 2007, befragt nach Kontakten mit dem Kritiker, ausdrücklich Reich-Ranicki zugeschrieben: „Ich bin ihm einmal auf der Frankfurter Buchmesse, als ich zum letzten Mal dort war, begegnet. Da ging er an mir vorbei und sagte: ,Herr Handke, wie gehen die Geschäfte? Seither frage ich das auch alle, die mir begegnen. “313

Im Abstand einiger Jahre hat Handke Mein Jahr in der Niemandsbucht als sein Pendant zu Adalbert Stifters Nachsommer bezeichnet, während der 2002 erschienene Band Der Bildverlust nach Aussage des Autors seine Entsprechung in Stifters sperrigem Alterswerk Witiko habe. ${ }^{314}$ An der Kontrolle der Affekte, der Bezähmung emotionaler Gewalten, die in Stifters Texten - allen diesem Ideal inhärenten Brüchen und Gefährdungen zum Trotz - vorgeführt wird, scheitert Handkes AutorProtagonist jedoch: Die „Phantasien der Versöhnung ${ }^{\text {“ } 315}$ werden ein ums andere Mal von der „Bereitschaft zur Entzweiung ${ }^{\text {“316 }}$ unterlaufen; Zorn und Wut über

ihr literarisches Erscheinen soll die Kolporteure beschäftigen“; J. B.: Ein Zank. Schriftsteller gegen Kritiker. In: Süddeutsche Zeitung, 23. 12. 1994: „Handke hat in seinem Roman Mein Jahr in der Niemandsbucht Passagen eingestreut, in denen ein namenloser, aber nur zu allzu [sic] gut erkennbarer Literaturkritiker auf das derbste verunglimpft wird.“

312 Handke: Mein Jahr in der Niemandsbucht (Anm. 29), S. 422.

313 Müller/Handke: „Ein Idiot im griechischen Sinne“ (Anm. 28), S. 56. Vgl. dazu die Beobachtung von Graf: Peter Handke und seine Kritiker (Anm. 72), S. 90, Handke sei „jahrelang mit wirtschaftsnahem Vokabular unterstellt“ worden, „mit seinem Schreiben vor allem Verkaufserfolge anzustreben“.

314 Vgl. Thomas Steinfeld: Ich erzähle von einem Leben, das über mich hinausgeht. [Gespräch mit Peter Handke.] In: Süddeutsche Zeitung, 30.1. 2002; Handke/Hamm: Es leben die Illusionen (Anm. 247), S. 74. - Zu Handkes Stifter-Rezeption vgl. Sabine Schneider: Adalbert Stifter, die Literatur des 20. Jahrhunderts und die methodischen Paradigmenwechsel der Literaturwissenschaft. In: Die Literatur der Literaturtheorie. Hg. v. Boris Previšić. Bern u. a.: Lang 2010, S. 187-199, sowie zuletzt Maria Luisa Roli: „Varianten der Wiederholung“. Peter Handkes Stifter-Rezeption. In: Die tägliche Schrift (Anm. 103), S. 133-152.

315 Handke: Mein Jahr in der Niemandsbucht (Anm. 29), S. 168.

316 Ebd., S. 164 
die Widersacher, die „Bedrohungen und Hindernisse“ ${ }^{\text {317 }}$ des Schreibens, drängen an die Oberfläche der Erzählung; die „Ruhe“, die Keuschnig findet, wenn er in den Rhythmus des Schreibens kommt, ${ }^{318}$ erweist sich stets aufs Neue als fragil.

Gegen Ende des Buches, im ausgreifenden, fast ein Viertel des gesamten Textes einnehmenden Kapitel „Das Jahr“, wird die Situation Deutschlands nach einem verheerenden „Binnenblitzkrieg“ geschildert; dieser habe dem Land zu einer Art von Befreiung verholfen und eine durchaus positiv gezeichnete Regression in einen ursprünglichen Natur-Zustand mit sich gebracht:

In der Tat hatten selbst die deutschen Landschaften andere Züge angenommen, etwa indem zwischen den Hochhäusern auf einmal im Himmel sich Perspektiven zeigten, wo seit Hölderlin nie welche gewesen waren, oder auch, indem zum Beispiel der Fluß Spree in Berlin, bis dahin tümpelhaft und wie gestockt, unversehens ins Strömen kam und über Katarakte und Wasserfälle wieder durch ein Urstromtal rauscht. ${ }^{319}$

Der beschriebene „Ruck nach oben“ betrifft nicht nur den Blick des Erzählers auf die topographische Struktur Deutschlands im Sinne einer Wiedergewinnung landschaftlicher Schönheit, sondern er tangiert auch den Bereich des öffentlichen Sprechens: Es handelt sich, so Keuschnig, um eine Zeit, in der „die Meinungsmacher in den Zeitungen [...] mit ihrer Hirnschwellsprache fürs erste hinter ihren Büroscheiben tonlos allein“ bleiben, also ihr Publikum nicht mehr erreichen. ${ }^{320}$ Sogar Keuschnigs „einstiger Feind, weiter aktiv bei seinem Bücher-Vornehmen und -Ausschnüffeln“, findet „für seine Wortspektakel keine Gaffer mehr“. Der frühere Kontrahent sei nun, aus der Mitte der medialen Aufmerksamkeit gerückt, „zu Gängen [...] in die von ihm verabscheute Natur" verurteilt, „wo ihm [...] aus jeder Blume und jedem Busch nichts als die eigene Fratze entgegenstiert[ ]“. ${ }^{321}$ Der „Landschaftshasser Reich-Ranicki“, wie ihn Ulrich Greiner erst kürzlich apostrophiert hat, ${ }^{322}$ rückt so ein weiteres Mal als böswilliger „Bücher-Vornehme[r]“ in den Fokus des Erzählens; in der märchenhaften Zukunftsvision eines anderen Deutschland, in dem die Brüder Grimm ihre Sammeltätigkeit wieder aufnehmen, in der Novalis als Bildhauer auftritt und Eduard Mörike „sich für sein Pfarrhaus einen Anrufbeantworter

317 Ebd., S. 766.

318 Ebd., S. 879.

319 Ebd., S. 928 f.

320 Ebd., S. 929.

321 Ebd., S. 929 f.

322 Ulrich Greiner: Der Makel der Lesbarkeit. Als Marcel Reich-Ranicki die Deutschstunde fragwürdig fand. In: DIE ZEIT, Nr. 7, 9. 2. 2017, S. 39. 
an [schafft]“, hat der als „Buchseibeiuns“ apostrophierte Kritiker keinen Platz und, vor allem, keine Handlungsmacht mehr. ${ }^{323}$

Wenig überraschend entdeckte Handke, obwohl die Aufnahme im Feuilleton weitgehend positiv verlief, schon in den ersten Rezensionen der Niemandsbucht viel „Unsinniges oder Widersinniges“. 324 Bald nach Erscheinen des Buches war zudem klar, dass Mein Jahr in der Niemandsbucht im Literarischen Quartett diskutiert werden würde. Danach befragt, was er dabei von ReichRanicki erwarte, antwortete Handke am 7. Dezember 1994 im Gespräch mit Christoph Hirschmann: „Ich hoffe, daß er endlich einmal schweigt. Schweigen lernt. “325 Bereits zwei Tage zuvor war im Spiegel ein Interview erschienen, in dem Handke explizit darauf hingewiesen hatte, dass in der Niemandsbucht ein „bekannte[r] Kritiker [...] als Hund vorbeischnüffelt“ ${ }^{326}$ Im Literarischen Quartett vom 15. Dezember gingen die drei Stammdiskutanten, die in dieser Ausgabe von Norbert Miller unterstützt wurden, über die entsprechenden Passagen indes diskret hinwegging. Reich-Ranickis erstem Seitenhieb, das Buch sei gerade deshalb misslungen, weil es einen "typische[n] Handke“ vorstelle, ${ }^{327}$ folgten zahlreiche weitere. Obgleich sich Miller in der Auseinandersetzung mit Karasek und Reich-Ranicki um Differenzierungen bemüht zeigte, kam Letzterer erneut zu einem apodiktischen, Handkes „Märchen“ schroff ablehnenden Urteil: Es handle sich zweifelsfrei um „miserable Literatur“; die „deutsche Kritik“ habe sich jedoch unverständlicherweise „begeistert“ dazu geäußert, ja sie zeichne sich - auch das ein Vorwurf, den Reich-Ranicki bereits anlässlich von Langsame Heimkehr erhoben hatte - durch ein nachgerade „religiöses Verhältnis zum Gegenstand“ aus. ${ }^{328}$ Außerdem sei Thomas Bernhard, wie der Kritiker

323 Handke: Mein Jahr in der Niemandsbucht (Anm. 29), S. 930.

324 Handke an Unseld, 13.11. 1994. In: Handke/Unseld: Der Briefwechsel (Anm. 6o), S. 645.

325 Christoph Hirschmann: Stiller Streß. Handke exklusiv über den Erfolg seines neuen Buches. In: News, Nr. 49, 7.12.1994, S. 130-132, hier S. 131.

326 Volker Hage/Mathias Schreiber: „Gelassen wär’ ich gern“. Der Schriftsteller Peter Handke über sein neues Werk, über Sprache, Politik und Erotik. In: Der Spiegel, Nr. 49, 5. 12. 1994, S. 170-176, hier S. 176.

327 Marcel Reich-Ranicki: Peter Handke, Mein Jahr in der Niemandsbucht im Literarischen Quartett [ZDF], Sendung Nr. 34, 15.12.1994. In: https://www.youtube.com/watch?v=pUkRi-EysoA (Stand 14. 10. 2020), 32:54-32:56, 33:58-34:02 u. 38:55-38:56; vgl. Das Literarische Quartett. Bd. 2 (Anm. 249), S. 250.

328 Reich-Ranicki: Handke, Mein Jahr in der Niemandsbucht (Anm. 327), 38:55-39:0o u. 39:36-39:38; vgl. Das Literarische Quartett. Bd. 2 (Anm. 249), S. 253. - Dazu Steiner: Literatur als Kritik der Kritik (Anm. 29), S. 130, der mit Blick auf die Rezeption von Mein Jahr in der Niemandsbucht festhält: „Fast jede Rezension, positiv wie negativ, geht nicht einfach nur auf das Werk, sondern auf die kritische Debatte ein. Verfechter Handkes rügen die Nörgler, insbesondere aber nehmen die Kritiker diejenigen aufs Korn, die sie für gläubige Adepten halten. Der literarisch 
erneut betont, „viel bedeutender als der ganze Handke“ ${ }^{329}$ Reich-Ranicki und Karasek isolierten in ihren Wortmeldungen ganz bewusst Textstellen aus dem narrativen Kontext des Buches, um Handkes Sprachgestus zu desavouieren und der Lächerlichkeit preiszugeben.

Handkes ausführlichster Selbstkommentar zum abermaligen Auftritt des Kritikers in einem Erzähltext findet sich wenige Tage später, kurz vor Weihnachten 1994, in einem Interview des Autors mit dem Magazin stern. Angesprochen darauf, dass Reich-Ranicki mittlerweile zu einer populären Figur auch der fiktionalen Literatur geworden sei, antwortete Handke: „Bei mir ist er keine Figur, eher eine flüchtige Glossen-Gestalt, so, wie in meinem Manuskript die Tierfiguren an den Rand gezeichnet sind. Ich wollte ein paar Schlenker in der Geschichte haben, damit sie nicht so streng und ausschließlich abläuft. “" ${ }^{330}$ Tatsächlich hatte Handke, folgt man der Auskunft seines Lektors Raimund Fellinger, beim Schreiben Miniaturen von Tieren, u. a. von Bisamratten, an den Rand des Niemandsbucht-Manuskripts gesetzt. ${ }^{331}$ Reich-Ranickis kolportierte Aussage, er ärgere sich weniger darüber, in Handkes Buch vorzukommen, als über den Umstand, dass die ihn betreffenden Passagen „besonders schlecht geschrieben“ seien, ${ }^{332}$ entgegnete dieser wenig konziliant und mit erneutem Rückgriff auf die etablierte MRR-Topik, wobei das animalische Tableau in diesem Fall um Primaten ergänzt wird:

Es ist ja nicht so, wie er das in seiner Affen-Psychologie darstellt. Ich finde es sehr fein und elegant geschrieben, wie er vorkommt. Da kann er drauf stolz sein, daß er so verewigt ist. Er hat einen Riecher für alles, aber da die große Literatur fast keinen Duft hat, hat er keine Witterung für große Literatur. Er lebt nur für diese FernsehWortspektakel für Leute, die gar nicht lesen, sondern Worte nur zum Angaffen finden. Er verwechselt in seiner Literaturkritik-Tätigkeit seine Plattheit mit Klarheit. Und da er ein ungeheures Maulwerk hat, finden zu meinem immerwährenden Erstaunen die Leute daran ihre Belustigung. ${ }^{333}$

angegriffene Marcel Reich-Ranicki z. B. wütet im Literarischen Quartett gegen die angeblichen Verehrer, würdigt aber das Buch selber keines Wortes."

329 Reich-Ranicki: Handke, Mein Jahr in der Niemandsbucht (Anm. 327), 43:10-43:13; vgl. Das Literarische Quartett. Bd. 2 (Anm. 249), S. 255.

330 Michaelsen/Handke: „Ab und zu sticht mich ein Teufelchen“(Anm. 30), S. 126.

331 Vgl. Fellinger: „Schreiben: Sich zur Ruhe setzen“(Anm. 304), S. 139.

332 Zit. nach: Hage/Schreiber: Marcel Reich-Ranicki (Anm. 57), S. 99: „Reich-Ranicki reagierte zunächst souverän und sagte kurz nach Erscheinen der ,Niemandsbucht' in einem Interview: ,Handkes Seitenhiebe schmerzen mich überhaupt nicht, aber - das will ich nicht verheimlichen -, es ärgert mich doch, daß in seinem Buch die gegen mich gerichteten Passagen besonders schlecht geschrieben sind.“

333 Michaelsen/Handke: „Ab und zu sticht mich ein Teufelchen“ (Anm. 30), S. 126. 
Zwar müsse er, so Handke, „der Gerechtigkeit halber sagen“, dass er „im Laufe der 25 Jahre, die ich seine Rezensionen lese, doch zwei, drei vor Augen bekommen habe, die ein Geheimnis von dem Buch mitteilen“, vor dem Hintergrund ihrer gemeinsamen Konfliktgeschichte jedoch werde er ihm „nie [...] auch nur das Kleinste verzeihen können“: „Es ist ja so: In der ,FAZ“ wurde ein Jahrzehnt lang jedes einzelne meiner Bücher zerfleddert wie von Strauchdieben. Und er war der Oberstrauchdieb. “334 Reich-Ranicki habe in den 1980er Jahren als Literaturchef der $F A Z$ auf andere Kritiker eingewirkt, d. h. Verrisse gezielt in Auftrag gegeben. Handkes Bemerkungen sind ein Beispiel dafür, dass Schriftsteller kritische Rezensionen oft „nicht nur dem Individuum des Rezensenten“ zuschreiben, „sondern auch der Institution des Rezensionsorgans“ “335 Handke sah die Rezensionspolitik der FAZ, deren Literaturteil Reich-Ranicki bis 1988 dirigierte, zuallererst als abgekartetes Spiel.

„Erzählen heißt auch Spurenverwischen; die Hunde finden deine Fährte nicht mehr“336 - Handkes im Januar 1983 notierte Hoffnung, man werde sich künftig nicht mehr über den Weg laufen, hatte sich jedenfalls nicht erfüllt. Noch Mitte der 1990er Jahre belauerten sich die beiden Kontrahenten gegenseitig und ließen kaum eine Gelegenheit aus, ihr Missfallen über das Tun und Schreiben des jeweils anderen zu bekunden.

\section{Unversöhnt: letzte Gefechte \\ (In einer dunklen Nacht ging ich aus meinem stillen Haus)}

Im April 1997 folgte die letzte Besprechung eines Handke-Buches im Literarischen Quartett. Ein weiteres Mal klagte Reich-Ranicki darüber, dass sich „zu [s]einem großen Leidwesen“ sowie „zur Schande der deutschen Kritik“ in zahlreichen Rezensionen eine unbotmäßige „Faszination“ für Handkes Bücher offenbare. Diese unkritischen Lobeshymnen zeichneten sich, wie im Fall des aktuellen Romans In einer dunklen Nacht ging ich aus meinem stillen Haus, durch „ehrerbietige Inhaltsangaben“ aus und seien nicht imstande, kritische Distanz

334 Ebd. Zu Handkes langdauernder Kontroverse mit der FAZ vgl. Thomas Anz: Literaturkritisches Argumentationsverhalten. Ansätze zu einer Analyse am Beispiel des Streits um Peter Handke und Botho Strauß. In: Literaturkritik - Anspruch und Wirklichkeit (Anm. 26), S. 415-430, hier S. 417, sowie Kap. III, Abschnitt „Einwenden und Hochhalten: Handkes Rede gegen die Literaturkritik“.

335 Carlos Spoerhase: Ausweitung der literarischen Kampfzone: Was die Geschichte der aufklärerischen Rezensionskultur die aktuelle Reflexion über Literaturkritik lehren könnte. In: Zeitschrift für Germanistik. N. F. 19 (2009), H. 1, S. 171-178, hier S. 175.

336 Handke: Am Felsfenster morgens (Anm. 223), S. 23. 
zu ihrem Gegenstand zu wahren. ${ }^{337}$ Hier klingt jene Anschuldigung nach, die Reich-Ranicki knapp 20 Jahre zuvor in der Rezension von Langsame Heimkehr ins Treffen geführt hatte: Die Kritiker hätten sich, so die bereits zitierte maliziöse Metarezension von 1979, Handkes Buch „meist kniend“ genähert, „also in einer Position, die weder das Denken noch das Schreiben begünstigt“ 338

In der Geschichte des Apothekers von Taxham schildert Handke indes eine deutlich versöhnlichere Hunde-Szene als in der Niemandsbucht: Dem Protagonisten des Romans begegnet auf seinem Weg durch die spanische Steppe, weitab von der Zivilisation, ein „herrenloser Hund“, „der in einem Erdloch lebte und ihn, erst fletschend, dann seine Finger ableckend, eine lange Zeitlang begleitete “ ${ }^{339}$ Auf den von Rezensenten wie Reich-Ranicki formulierten Vorwurf, seine Figuren blieben deshalb blass, weil er die Auskunft darüber, ob sie „jung oder alt, dünn oder dick“ seien, ${ }^{340}$ beharrlich verweigere, lässt Handke den Erzähler des Romans antworten, als dieser sich am Ende doch an einer äußerlichen Beschreibung des Apothekers versucht: „Ich weiß nicht, warum es mir seit jeher widerstrebt hat, Leute, ihre Gesichter, ihre Körper, zu beschreiben, vor allem mit irgendwelchen Eigenheiten, und ich derartige Beschreibungen, wie gekonnt immer, auch mit Mißbehagen lese, so als gehörten sie sich nicht. “341

Wenig überraschend fand Reich-Ranicki daran und an zahlreichen anderen Aspekten von In einer dunklen Nacht ging ich aus meinem stillen Haus wenig Gefallen. Hatte er sich im Literarischen Quartett gleich eingangs über den umständlichen Titel des Romans lustig gemacht, gestand er diesem im Zuge seines launigen Kommentars zwar zu, nicht „so furchtbar schlecht wie die Niemandsbucht“ zu

337 Marcel Reich-Ranicki: Peter Handke, In einer dunklen Nacht ging ich aus meinem stillen Haus im Literarischen Quartett [ZDF], Nr. 48, 25. 4. 1997. In: https://www.youtube.com/watch?v=4qjcY ax9Mwo (Stand 14. 10. 2020), 10:12-10:38; vgl. Das Literarische Quartett. Bd. 2 (Anm. 249), S. 60o. Gerade in den Debatten um Handke sind, wie Anz: Literaturkritisches Argumentationsverhalten (Anm. 334), S. 415 u. 425, gezeigt hat, „Meta-Argumente gehäuft anzutreffen“, d.h. „Aussagen, die sich auf den Zustand und die Funktion der Institution Literaturkritik allgemein beziehen“. Zu Reich-Ranickis Agieren als „Meta-Kritiker“ siehe Dittberner: Der Mann in der Arena (Anm. 272), S. 17.

338 Reich-Ranicki: Peter Handke und der liebe Gott (Anm. 129).

339 Peter Handke: In einer dunklen Nacht ging ich aus meinem stillen Haus. Roman. Frankfurt a. M.: Suhrkamp 1997, S. 235.

340 Reich-Ranicki: Peter Handke und der liebe Gott (Anm. 129).

341 Handke: In einer dunklen Nacht (Anm. 339), S. 30o. Eine überzeugende, weil überaus detailliert am Text argumentierende Interpretation des Romans, die „deutliche Parallelen“ der Erzählanlage „zum mittelalterlichen Epos“ aufzeigt, findet sich in Carstensen: Romanisches Erzählen (Anm. 216), S. 281-295, Zit. S. 286. Das Bekenntnis, „Beschreibungen von Gesichtern“ seien ihm „seit jeher zuwider“ gewesen, findet sich noch in Die Obstdiebin, Handkes wiederholt als ,letztes Epos‘ angekündigtem Prosabuch aus dem Jahr 2017 (Peter Handke: Die Obstdiebin oder Einfache Fahrt ins Landesinnere. Berlin: Suhrkamp 2017, S. 107). 
sein, ${ }^{342}$ kam aber trotzdem zu einem ernüchterten Fazit: „Ich hätte nie freiwillig das Buch gelesen, ich finde es bis zur Seite fünfzig einigermaßen erträglich, was weiter kommt - bitte explodieren Sie nicht - ist meiner Ansicht nach schlechte, gläubige Literatur, sprachlich sehr fragwürdig und furchtbar langweilig. “ ${ }^{343}$ Was seine Ablehnung angeht, erwies sich Reich-Ranicki, aller Transformationen in Handkes Poetik, aller Varianz seiner Erzählverfahren zum Trotz, als ein Meister der Beständigkeit, der die immer gleichen Vorwürfe gegen die Texte des Autors erhob. Ein knappes halbes Jahr nach der Diskussion des Apotheker-Romans im Literarischen Quartett hat Reich-Ranicki in einem Interview mit dem Spiegel als Reprise früherer Kritiken noch einmal auf die ,Langweiligkeit' von Handkes Arbeiten schon Mitte der 1960 Jahre - hier konkret bei der Princetoner Tagung der Gruppe 47 - hingewiesen: „Peter Handke war zuvor durchgefallen mit einem sehr langweiligen Text. Er meldete sich plötzlich und sagte in einem weinerlich-infantilen Ton, die Literatur, die vorgelesen wurde, sei ,Beschreibungsliteratur'. Damit charakterisierte er vor allem seinen eigenen Text. ${ }^{\text {"344 }}$ In diesem Zusammenhang hatte Sigrid Löffler Reich-Ranicki bereits 1990 im Literarischen Quartett - als dieser sich erneut „sehr gelangweilt“ von Handkes Büchern zeigte, ${ }^{345}$ ohne die Kriterien seines Urteils offenzulegen - ans Herz gelegt, dem Autor „mal etwas ganz anderes [zu] verübeln“, anstatt die über Jahrzehnte kaum variierten Vorwürfe bloß zu recyceln. ${ }^{346}$

2007 ist Handke, neuerlich im Gespräch mit André Müller, noch einmal auf die als elementare Bedrohung seiner Autoren-Existenz erlebte Auseinandersetzung mit Reich-Ranicki zu sprechen gekommen: „Früher, als ich so dreissig, vierzig war, da habe ich schon manchmal bösartig losgelegt. Da wollte ich jemanden zwar nicht vernichten, aber weghaben von mir. Aber dann hat der andere, zu Recht, mich vernichten wollen." Auf die Nachfrage Müllers, sich doch genauer zu erklären, erwiderte Handke: „Lassen Sie mich mit diesem Knickerbocker in Frieden! Ich bin froh, dass ich an diesen armen Menschen schon lang nicht mehr denken muss. “ ${ }^{347}$

342 Reich-Ranicki: Handke, In einer dunklen Nacht (Anm. 337), 18:45-18:49; vgl. Das Literarische Quartett. Bd. 2 (Anm. 249), S. 603.

343 Reich-Ranicki: Handke, In einer dunklen Nacht (Anm. 337), 19:26-19:50; vgl. Das Literarische Quartett. Bd. 2 (Anm. 249), S. 603.

344 N. N.: „Mancher Dichter fand es grausam“. Interview mit Marcel Reich-Ranicki über die „Gruppe 47“, ihre Autoren und ihren Gründer. In: Der Spiegel, Nr. 36, 1. 9.1997, S. 214-219, hier S. 215. Auf S. 218 druckte der Spiegel ein Foto Handkes mit dem Untertitel „Tagungsteilnehmer Handke (1966) / Weinerlich-infantiler Ton“.

345 Reich-Ranicki in: Das Literarische Quartett. Bd. 1 (Anm. 249), S. 290.

346 So Sigrid Löffler ebd.

347 Müller/Handke: „Ein Idiot im griechischen Sinne“ (Anm. 28), S. 55. 
Die Fehde hatte durch den allmählichen Rückzug Reich-Ranickis aus der Öffentlichkeit - er feierte 2007 seinen 87. Geburtstag - mit der Zeit an Schärfe eingebüßt, obgleich Handke im zitierten Interview den Topos der versuchten ,Vernichtung' ein weiteres Mal aufgreift und als einschneidende Erfahrung seiner Schreib-Biographie anführt. ${ }^{348}$ Weitere fünf Jahre später, im Oktober 2012, elf Monate vor Reich-Ranickis Tod, zeigte sich Handke in einem weiteren Interview zwar ansatzweise konziliant - „Wollen wir den jetzt seinen Lebensabend ruhig verbringen lassen?" ${ }^{349}$-, rief im gleichen Atemzug aber auch die Schilderung des Kritikers in der Lehre der Sainte-Victoire in Erinnerung, um, der Rhetorik des Textes folgend, das intellektuelle Erbe Reich-Ranickis ante mortem zu „zusammengeschustert[en]“ Exkrementen zu erklären:

Es ist überhaupt kein Problem mehr für mich. Es ist nichts zu versöhnen. Es ist vorbei. Ich bin der, der dies gemacht hat, und er ist der, der das zusammengeschustert hat. Ich glaube, das ist unsterblich, wie ich es in der Lehre der Sainte-Victoire geschrieben habe: Ein paar getrocknete Haufen liegen herum von dem Hund. ${ }^{350}$

Noch 2018, fünf Jahre nach dem Tod des Kritikers, hat Handke in einem Gespräch in der Zeitschrift Freitag Reich-Ranicki gemeinsam mit Joschka Fischer und Daniel Cohn-Bendit zu den „schlimmsten Typen der Nachkriegszeit in Deutschland“ gerechnet. ${ }^{351}$ Ein letztes Mal kommt Handke auf Nachfrage der beiden Journalisten auf das Treffen der Gruppe 47 in Princeton zurück, wo „Pfeifen wie Reich-Ranicki“ über Texte von Uwe Johnson und Günter Grass geurteilt hätten: „Ich hab gedacht: ,Wie lassen sich solche Autoren abkanzeln von so einem Stinker?' [...] Ich finde jetzt nicht mal die Wörter für dieses falsche Ausholen eines falschen Wissenden über die Literatur. “ Das Diktum De mortuis nihil nisi bene scheint hier keine Gültigkeit zu haben; Vergebung wird nicht gewährt: „Reich-Ranicki werde ich nie verzeihen, was er angerichtet hat. “ ${ }^{“ 32} \mathrm{Ja}$, man könnte, als Fazit der lebenslangen „Unversöhnlichkeit“, auf der Handke schon in seinem Brief aus dem Jahr 1976 beharrt hatte, die Bemerkung des Franz-Josef Murau in Thomas Bernhards Auslöschung (1986) anführen, wonach der „Tod eines Menschen“ aus diesem ja „keinen andern“ mache:

348 Anlässlich der Zuerkennung des Düsseldorfer Heinrich-Heine-Preises an Handke im Frühjahr 2006 hatte Reich-Ranicki noch von einer „empörende[n] Beleidigung und Verhöhnung des Dichters Heine“ gesprochen; die Aussage kolportiert Hubert Spiegel: Preis für Peter Handke. Heine wird verhöhnt. In: Frankfurter Allgemeine Zeitung, 27. 5. 2006.

349 Herwig/Michaelsen/Handke: „Ich wäre liebend gern ein Böser“ (Anm. 241), S. 54.

350 Ebd.

351 Jan C. Behmann/Mladen Gladić: „Ich habe keine Schublade“. [Gespräch mit Peter Handke.] In: Freitag, Nr. 34, 23. 8. 2018, https://www.freitag.de/autoren/der-freitag/ich-habe-keine-schublade (Stand 30.10. 2018).

352 Ebd. 
Über einen Toten soll nichts Schlechtes geredet werden, sagen die Leute, es ist geheuchelt und verlogen. Wie kann ich über einen zeitlebens immer scheußlich gewesenen Menschen, der durch und durch ein niederträchtiger Charakter gewesen ist, nach seinem Tod plötzlich behaupten, er wäre kein scheußlicher Mensch, kein niederträchtiger Charakter gewesen, sondern auf einmal ein guter Mensch. Diese Geschmacklosigkeit erleben wir jeden Tag, wenn einer gestorben ist. Wie wir uns nicht scheuen sollten, bei seinem Tode zu sagen, der gute Mensch ist tot, sollten wir uns auch nicht scheuen, zu sagen, der gemeine, der niederträchtige ist tot. (TBW 9, 85)

Eine über die jeweilige Schaffenszeit hinausgehende Bedeutung wollten die beiden Kontrahenten dem anderen jedenfalls nicht zugestehen: „Ich werd' Sie in einem Jahr fragen: Wie war das eigentlich betitelt, das Büchlein von Handke? Da werden Sie sich nicht mal an den Titel erinnern können“, "353 hatte Reich-Ranicki schon Sigrid Löffler im Literarischen Quartett mit Blick auf den Versuch über die Müdigkeit (1990) prophezeit und acht Jahre später am gleichen Ort darüber geklagt, dass Handke „immer noch“ von „manche[n] Leute[n]“ gelesen werde. ${ }^{354}$ Sah der Kritiker Handke als einen Autor, der sich bereits in den 1970er Jahren ,aus der Literatur herausgeschrieben ${ }^{655}$ und seitdem erzählerisch wie intellektuell dürftige „Erbauungsliteratur “ ${ }^{\text {“356 }}$ publiziert habe, hatte dieser Reich-Ranicki schon 1968 vorgeworfen, der „am meisten selbstgerechte deutsche Literaturkritiker“ $\mathrm{zu}$ sein, weil er „statt mit Urteilen nur mit Vorurteilen“ arbeite und zudem keinerlei Sensibilität für innovative, von der Norm und seinen eingeschliffenen Erwartungen abweichende literarische Verfahren aufbringen könne. ${ }^{357}$

Die geschilderte Konfrontation kann auch als Beispiel dafür dienen, „dass Prozesse der literarischen Kommunikation zwischen Kritikern, rezensierten Autoren und anderen Adressaten der Kritik ein Geschehen sind, bei dem Emotionen der Beteiligten eine erhebliche Rolle spielen. ${ }^{358}$ Volker Hage und

353 Reich-Ranicki: Handke, Versuch über die Müdigkeit (Anm. 249), 37:53-38:02; vgl. Das Literarische Quartett. Bd. 1 (Anm. 249), S. 186

354 Reich-Ranicki: Handke, In einer dunklen Nacht (Anm. 337), 10:09-10:12; vgl. Das Literarische Quartett. Bd. 2 (Anm. 249), S. 6oo.

355 Vgl. Michaelsen/Handke: „Ab und zu sticht mich ein Teufelchen“ (Anm. 30), S. 126: „Als ,Das Gewicht der Welt' erschien, schrieb er - ich kann bei ihm das Wort schreiben nur in Anführungszeichen setzen: ,Damit hat sich Peter Handke aus der Literatur herausgeschrieben.' Da er gar keinen Verstand für subtile, sucherische Bücher hat, hätte er nie etwas darüber griffeln dürfen.“

356 Reich-Ranicki: Peter Handke und der liebe Gott (Anm. 129).

357 Handke: Marcel Reich-Ranicki und die Natürlichkeit (Anm. 2), S. 206. Lorenz: Die Öffentlichkeit der Literatur (Anm. 25), S. 195, hat auf die „Anachronismen der Kritik bei Marcel ReichRanicki“ hingewiesen, Wolf: Autonomie und/oder Aufmerksamkeit? (Anm. 4), S. 54, Anm. 44, auf Beispiele einer „antimodernistische[n] Argumentation“.

358 Anz: Werten und Fühlen (Anm. 7), S. 14 
Mathias Schreiber haben Reich-Ranicki eine veritable Dünnhäutigkeit und Sensibilität für die Urteile anderer über seine Person attestiert: „Kaum etwas registriert er so genau wie das, was über ihn gedacht, geschrieben, gesprochen wird. [...] Er ist empfindlich und hat für Kränkungen ein gutes Gedächtnis. Wie so mancher, der gut austeilen kann, zählt er zu den Empfindsamen und Liebesbedürftigen. “ ${ }^{359}$ Ähnliches trifft auch auf den Autor Peter Handke zu. ${ }^{360}$ Während die beiden im Laufe der Jahre ihre argumentativen Waffen schärften und weder vor Reprisen bereits hinlänglich artikulierter Vorwürfe noch vor pointierten Untergriffen und Seitenhieben zurückschreckten, offenbarten sie unwillkürlich auch die eigene Verletzlichkeit - und, mit Hage und Schreiber gesprochen, ein gutes Gedächtnis, was frühere Attacken und Kränkungen betrifft: „Nicht zu übersehen sind in der Beziehung zwischen Kritiker und Autor schließlich jene Emotionen, die zu typischen Merkmalen narzisstischer Syndrome gehören: Unter- oder Überlegenheitsgefühle, schwere Kränkungen mit den damit verbundenen Aggressionen. “361

Die wechselseitige Kritik entzündete sich wiederholt an der Popularität des Gegenübers; beide, Handke wie Reich-Ranicki, waren der Überzeugung, der Ruhm und die Prominenz des anderen beruhe auf einem Missverständnis, sei nicht der Qualität ihrer literarischen bzw. literaturkritischen Arbeiten geschuldet, sondern einer - von weiten Teilen des Literaturbetriebs nicht durchschauten Inszenierung, einer geschickten Selbstvermarktung. Während Handke ReichRanicki zum Vorwurf machte, er bediene mit dem Habitus des,Verreißers' und ,Buch-Vornehmers' vor allem die Erwartungen eines schaulustigen Publikums, ${ }^{362}$ konstatierte der Kritiker ein ums andere Mal, Handkes Erfolg sei zunächst durch

359 Hage/Schreiber: Marcel Reich-Ranicki (Anm. 57), S. 132. Vgl. dazu auch den auf Reich-Ranicki gemünzten Kommentar von Baumgart: Damals (Anm. 9), S. 197: „denn Kritik kann dieser große Kritiker noch weniger ertragen als seine Opfer“.

360 Durzak: Peter Handke und die deutsche Gegenwartsliteratur (Anm. 156), S. 171, hat Handke vorgeworfen, die Rezensionen „einzelne[r] Literaturkritiker, die ihn hier und da unfreundlich in ihren Blättern behandelt hatten“, stets als „Attacken auf ihn als Person“ interpretiert zu haben, „auch wenn das in der Realität nie so intendiert gewesen war“. Vgl. ebd., S. 13: „Ein Verriß ist [...] für ihn immer gleich auch ein persönlicher Angriff, ein Lobpreis ist für ihn nicht irgendein abstraktes Lob über eine literarische Arbeit, sondern zugleich eine moralische Kommunikationsgeste."

361 Anz: Werten und Fühlen (Anm. 7), S. 23.

362 Reich-Ranicki kann wohl als Paradebeispiel jenes Kritikers gelten, den Pierre Bourdieu folgendermaßen beschrieben hat: „Selbst den für ihre Konformität mit den Erwartungen ihres Publikums berüchtigten Kritikern ist durchaus zu glauben, wenn sie versichern, sich nie die Ansichten ihrer Leser zu eigen zu machen; und es darf auch davon ausgegangen werden, daß die Ursache für die Effektivität ihrer Kritiken keineswegs in einer demagogischen Anpassung an den Geschmack des Publikums besteht, sondern in einer objektiven Übereinkunft; sie ermächtigt zu vollkommener Aufrichtigkeit, die notwendig - und damit wirksam - ist, damit einem 
das Image des jungen Provokateurs, später durch den selbst von professionellen Lesern unkritisch affirmierten turn ins Religiös-Raunende bedingt gewesen; die Qualität seiner literarischen Texte habe sich dafür als im Grunde zweitrangig erwiesen. ${ }^{363}$ Die gegenseitige Aversion fußte zwar von Anfang an auf der Unvereinbarkeit ihrer ästhetischen Konzepte und ihrer gänzlich gegensätzlichen Vorstellungen vom Gelingen literarischen Schreibens, sie erhielt aber gerade durch die Überzeugung, der andere sei ein Scharlatan und imposter, der unverdientermaßen im Ruf künstlerischer bzw. intellektueller Brillanz stehe, immer wieder neue Nahrung.

Reich-Ranicki, der zumal aufgrund seiner Popularität und medialen Sichtbarkeit die Aggressionen vieler Autorinnen und Autoren auf sich zog, fand in Handke einen besonders zähen Widersacher; die „individuelle Idiosynkrasie“364 ging dabei weit über das übliche Maß hinaus. „Von Reich-Ranicki kritisiert und missachtet worden zu sein“, habe Handke jedoch, so Dieter Heimböckel, „nicht geschadet“: „Ganz im Gegenteil. Es hat - aus literaturkritischer Perspektive zur Verfestigung einer Position beigetragen, der er durch alle Wandlungen und Windungen hindurch konsequent treu geblieben ist. “365 Tatsächlich ließ gerade der Konflikt der beiden die Unvereinbarkeit ihrer Poetiken sowie ihrer Konzepte und Ideen von Literaturkritik besonders deutlich zutage treten. ${ }^{366}$ „Handke ist ein

geglaubt wird.“ (Pierre Bourdieu: Die Regeln der Kunst. Genese und Struktur des literarischen Feldes. Frankfurt a. M.: Suhrkamp 1999, S. 263)

363 Zum wiederkehrenden Vorwurf, Handke „verdanke seinen literarischen Rang mehr seinen Auftritten und seiner medialen Präsenz als den literarischen Qualitäten der Texte“, vgl. Pfister: Handkes Mitspieler (Anm. 125), S. 280. Der Autor hat sich dagegen wiederholt zur Wehr gesetzt: „Ich weiß nur, daß nirgendwo es genügt hätte oder auch nur einen Anreiz gegeben hätte, einen Schriftsteller zu lancieren, wenn er nur auf dieser Gruppe 47 diese Beschimpfungen von sich gegeben hätte, wie es kolportiert worden ist. So kann kein Schriftsteller sich machen, glaub' ich. Das hätte länger als ein oder zwei Monate nicht gewirkt. Also das seh' ich nicht ganz als eine Entstehung von mir als Schriftsteller. Das hat so eine gewisse Publizität gehabt, die mir noch immer um die Ohren gehauen wird.“ (Manfred Durzak: „Vom Büchner-Preis habe ich sogar geträumt“. Gespräch mit dem Autor Peter Handke. In: Die Welt, 1. 11. 1973)

364 Wolf: Autonomie und/oder Aufmerksamkeit? (Anm. 4), S. 58; vgl. Wagner: Handkes Endspiel (Anm. 4), S. 66.

365 Dieter Heimböckel: Zwischen Elfenbein- und Fernsehturm. Peter Handkes (massen-)mediale Widerspruchsarbeit. In: Schriftsteller-Inszenierungen. Hg. v. Gunter E. Grimm u. Christian Schärf. Bielefeld: Aisthesis 2008, S. 215-230, hier S. 224. Dazu auch Evelyne Polt-Heinzl: Peter Handke. In Gegenwelten unterwegs. Wien: Sonderzahl 2011, S. 11: „Die verstockte Feindschaft Marcel Reich-Ranickis mag Handke in den Anfängen viel Kummer, späterhin vielleicht Groll beschert haben, aber sie sorgte stets für Medienecho und letztlich dafür, daß die Gewichtigkeit dieses Kritikers auch ein wenig zurechtgestutzt wurde.“

366 Zu den gegensätzlichen Positionen von Handke und Reich-Ranicki vgl. Kunz: Sehnsucht nach dem Guten (Anm. 183), S. 68; Wolf: Autonomie und/oder Aufmerksamkeit? (Anm. 4), S. 58; 
mir fremder Autor“, gestand Reich-Ranicki 1990 in einem Interview mit Paul F. Reitze, stellte aber keineswegs seine eigenen Lektüreerwartungen infrage, sondern knüpfte daran zuallererst die Einschätzung, der ungeliebte Schriftsteller sei stets „sehr, sehr überschätzt“ worden. ${ }^{367}$ Dem Erfolg im Feld der Literatur bzw. der Literaturkritik tat die Feindschaft des jeweils anderen indes sowohl für Handke als auch für Reich-Ranicki keinen Abbruch, ja sie fügte ihrem jeweiligen ,Portfolio eine weitere, der medialen Aufmerksamkeit durchaus zuträgliche Facette hinzu.

zu „Reich-Ranickis Literaturbegriff“ jetzt Nicole Kaminski: Literaturkritik ohne Sprachkritik? Theodor Fontane, Alfred Kerr, Karlheinz Deschner, Marcel Reich-Ranicki und Kollegen. Frankfurt a. M.: Lang 2015, S. 175-186.

367 Paul F. Reitze: „Gerecht oder ungerecht - wer weiß das schon?“ [Gespräch mit Marcel ReichRanicki.] In: Die Welt, 1. 6.1990. 


\title{
V „ES SIND AUCH ANDERE SÄTZE MÖGLICH“: PETER HANDKES GEGENMODELLE ZUR ZEITGENÖSSISCHEN LITERATURKRITIK
}

\begin{abstract}
„Aber ich bin kein Kritiker“
Gut zwei Monate nachdem Peter Handke in einem Brief an Siegfried Unseld die intellektuelle Dürftigkeit und Voreingenommenheit vieler Rezensionen seines Debütromans Die Hornissen beklagt hatte, wandte er sich im August 1966 erneut an seinen Verleger, nun jedoch nicht mehr mit der Idee einer groß angelegten Entgegnung, einem „Artikel gegen all diese Kritiker“, „die die Konsumliteratur, zum Beispiel die Romane eines Günter Grass, zur literarischen Norm erheben wollen“, sondern mit dem Plan, selbst als Kritiker zu arbeiten:
\end{abstract}

Und eine Bitte: wäre es, glauben Sie, möglich, daß ich in einer angesehenen Zeitung oder Zeitschrift ab und zu Bücher rezensiere? Selbstverständlich werde ich mich selber dafür interessieren, aber ich dachte, vielleicht wäre es nicht allzu schlimm für Sie, mir dabei irgendwie zu helfen (nicht beim Rezensieren). Es geht mir nicht so sehr um ein Honorar, sondern um die Möglichkeit, meine Meinung von Literatur (ohne Beschimpfungen) zu erklären. Ich möchte nicht klein beigeben. ${ }^{2}$

Obschon er in der Folge keineswegs darauf verzichtete, direkte Antworten auf negative Besprechungen zu lancieren (und von „Beschimpfungen“ nicht dauerhaft Abstand nahm), hat der Autor, immer noch ein Neuling im literarischen Feld, hier ganz offensichtlich etwas anderes im Sinn: Statt auf die Beiträge anderer polemisch zu reagieren, wollte er selbst eine aktive Rolle übernehmen. Handke war bislang, abgesehen von seinen „Bücherecke“-Feuilletons für Radio Steiermark - der letzte von ihm gestaltete Beitrag wurde am 12. September 1966 gesendet $^{3}$-, lediglich mit einer Besprechung von Ror Wolfs Fortsetzung des Berichts in der Wiener Literaturzeitschrift Wort in der Zeit als Rezensent in

1 Peter Handke an Siegfried Unseld, 20. 6. 1966. In: P. H./S. U.: Der Briefwechsel. Hg. v. Raimund Fellinger u. Katharina Pektor. Berlin: Suhrkamp 2012, S. 35.

2 Handke an Unseld, 29. 8. 1966. In: ebd., S. 41.

3 Vgl. Peter Handke: Tage und Werke. Begleitschreiben. Berlin: Suhrkamp 2015, S. 12-16 u. 281-283. Dazu grundlegend die Ausführungen von Alfred Holzinger: Peter Handkes literarische Anfänge in Graz. In: Peter Handke. Hg. v. Raimund Fellinger. Frankfurt a. M.: Suhrkamp 1985, S. 11-24; Adolf Haslinger: Peter Handke. Jugend eines Schriftstellers. Salzburg, Wien: Residenz 1992, S. 84f., 94-99 u. 118-121; Georg Pichler: Die Beschreibung des Glücks. Peter Handke. Eine Biografie. Wien: Ueberreuter 2002, S. 50-60. 
Erscheinung getreten; ${ }^{4}$ nun suchte er mit großer „publizistischer Energie “5 nach neuen Herausforderungen.

Ziel von Handkes Bemühungen war es nicht zuletzt, sich als neuer Autor des Frankfurter Suhrkamp Verlags intensiver (und medial sichtbarer) als bisher auch in die bundesdeutschen Literaturdebatten der Zeit einzubringen. Texte wie die am 12. Juni 1967 im Spiegel gedruckte Besprechung des Sammelbandes Wochenende erfüllten für ihn in der Folge eine doppelte Funktion: Indem er die Autorinnen und Autoren der ,Kölner Schule um Dieter Wellershoff dafür kritisierte, ihre „längst überholten Methoden nicht [zu] erkennen“ und „gedankenlose[ ] Satzformen" ${ }^{\text {" }}$ zu verwenden - er sich also ostentativ von Konkurrenten und Konjunkturen im literarischen Feld distanzierte -, lässt sich der Verriss auch als impliziter Kommentar zu seinen eigenen literarischen Arbeiten, als Argumentation pro domo, ${ }^{7}$ verstehen, zumal die Formulierungen mit Passagen in Handkes poetologischen Reflexionen korrespondieren: „Was läßt diese in Einzelheiten doch recht sensiblen Autoren auf literarische Schemata hereinfallen? Es ist die Schreibmethode, die diese Arbeiten so unergiebig macht. Ergebnisse bleiben deswegen aus, weil die literarische Methode verbraucht ist. ${ }^{\text {" }}$

Der im selben Jahr entstandene Essay Ich bin ein Bewohner des Elfenbeinturms widmet sich gleichfalls der Frage, auf welche Weise literarische Verfahren,Wirklichkeit' modellieren und verarbeiten. Im Zentrum des Textes steht die Forderung nach einer ihre eigenen Methoden reflektierenden und kritisch prüfenden Literatur, als deren Erfüllung er sogleich sein eigenes Schreiben präsentiert. „Die Methode müßte alles bisher Geklärte wieder in Frage stellen, sie müßte zeigen, daß es noch eine Möglichkeit der Darstellung der Wirklichkeit gibt, nein, daß es noch eine Möglichkeit gab: denn diese Möglichkeit ist dadurch, daß sie gezeigt wurde, auch schon verbraucht worden. “9 Nimmt der Schriftsteller Handke für sich in Anspruch, sich stets auf der Suche nach einer weiteren noch möglichen

4 Vgl. Peter Handke: Ror Wolf: Fortsetzung des Berichts. In: Wort in der Zeit 11 (1965), S. 59-6o.

5 Otto Lorenz: Literatur als Widerspruch. Konstanten in Peter Handkes Schriftstellerkarriere. In: Text + Kritik ( $\left.{ }^{5} 1989\right)$, H. 24, S. 8-16, hier S. 9.

6 Peter Handke: Bei Abschied Regen. Über den Sammelband Wochenende. In: Der Spiegel, Nr. 25, 12. 6. 1967, S. 112-113, hier S. 113; auch in: P. H.: Ich bin ein Bewohner des Elfenbeinturms. Frankfurt a. M.: Suhrkamp 1972, S. 191-194.

7 Vgl. Otto Lorenz: Pro domo - Der Schriftsteller als Kritiker. Zu Peter Handkes Anfängen. In: Literaturkritik - Anspruch und Wirklichkeit. DFG-Symposion 1989. Hg. v. Wilfried Barner. Stuttgart: Metzler 1990, S. 399-414, hier S. 400: „Pro domo zu sprechen - das ist, seit Lessing spätestens, die Hauptfunktion der Literaturkritik der Autoren, die selber versuchen, den Resonanzraum für das Wirkungspotential ihrer Texte zu schaffen."

8 Handke: Bei Abschied Regen (Anm. 6), S. 112.

9 Peter Handke: Ich bin ein Bewohner des Elfenbeinturms. [1967] In: P. H.: Ich bin ein Bewohner des Elfenbeinturms (Anm. 6), S. 19-28, hier S. $21 \mathrm{f}$. 
Schreib-Methode zu befinden, spricht der Rezensent Handke den Texten des Wochenende-Bandes die Qualität und ihren Autoren das nötige Problembewusstsein ab. ${ }^{10}$ Schon im Juli 1965 hatte er dem amerikanischen Autor Joseph Hayes entsprechend attestiert, dass ihm beim Schreiben „vor sprachlichem Unverstand“ "die Hand" ausgeglitten sei, ${ }^{11}$ was sich in einer bloßen Reproduktion literarischer Klischees und stereotyper Erzählmuster niedergeschlagen habe:

Wenn etwa eine junge Frau erscheint, deren Gestalt sich in der Beschreibung „zart unter dem enganliegenden Kleid abzeichnet“, dann weiß man bereits, wieviel es geschlagen hat; die Beschreibung des Regens, „der die zarten Linien noch nachzieht“, läßt auch nicht lang auf sich warten; und „das leise Begehren“, das den betrachtenden Mann „ganz erfüllt", steht auf dem nämlichen Blatt. ${ }^{12}$

Hatte er mit Hayes einen „Illustriertenschriftsteller"13 attackiert, wendet sich Handke mit seinen poetologischen Essays und in seiner Besprechung des Wellershoff-Bandes gegen unmittelbare Konkurrenten im literarischen Feld. Hier wie dort richtet sich seine Kritik gegen eine Literatur, die ihm „bekannte Gedanken und Gefühle“ vermittle, „weil die Methoden bekannt sind“. ${ }^{14}$ Es handelt sich dabei um eine Einsicht, die in Handkes literaturtheoretischen wie literaturkritischen Arbeiten der frühen Jahre ganz wesentlich auf den Erkenntnissen der russischen Formalisten beruht, die der junge Autor im Zuge seiner Tätigkeit für die „Bücherecke“ kennen und schätzen gelernt hatte: „Eine neue Form entsteht nicht, um einen neuen Inhalt zum Ausdruck zu bringen“, heißt es bei Viktor Šklovskij, dessen Aufsatzsammlung Theorie der Prosa 1966 in deutscher Übersetzung erschien, „sondern um eine alte Form zu ersetzen, die ihren künstlerischen Wert verloren hat. ${ }^{\text {15 }}$ In seiner Besprechung von Boris Eichenbaums Aufsätzen zur Theorie und Geschichte der Literatur, in denen Šklovskij wiederholt zustimmend zitiert wird, ${ }^{16}$ hat Handke diesen Satz bereits im Oktober 1965, also

10 Vgl. Manfred Mixner: Peter Handke. Kronberg i. Ts.: Athenäum 1977, S. 175.

11 Peter Handke: „Bücherecke“ vom 5. 7.1965. In: P. H.: Tage und Werke (Anm. 3), S. 225-232, hier S. 227.

12 Ebd., S. 228.

13 Ebd.

14 Handke: Ich bin ein Bewohner des Elfenbeinturms (Anm. 9), S. 23.

15 Viktor Šklovskij: Die Beziehungen zwischen den Kunstgriffen des Handlungsaufbaus und den allgemeinen stilistischen Kunstgriffen. [1916] In: V. S.: Theorie der Prosa. Hg. u. aus dem Russischen übersetzt v. Gisela Drohla. Frankfurt a. M.: S. Fischer 1966, S. 28-61, hier S. 35.

16 Es handelt sich dabei um den folgenden, in der „edition suhrkamp“ erschienenen Band: Boris Eichenbaum: Aufsätze zur Theorie und Geschichte der Literatur. Frankfurt a. M.: Suhrkamp 1965. Zu den Korrelationen von Handkes frühen theoretischen Positionen mit jenen des russischen Formalismus vgl. meine Überlegungen in: Peter Handkes epitextuelle Werkpolitik. In: 
noch vor Erscheinen von Theorie der Prosa, als Leitlinie des Blicks auf avancierte Textverfahren hervorgehoben. Liest man Handkes überaus wertschätzende Charakterisierung von Eichenbaums und Šklovskijs theoretischen Arbeiten, so wird rasch deutlich, warum der junge Autor sich für die Methoden der Formalisten begeistern konnte: „Dies ist eins [sic] der wichtigsten Erkenntnisse des Formalismus: daß sprachliche Elemente Eigenwert haben. ${ }^{\text {17 }}$

In seiner Wellershoff-Rezension moniert Handke, dass in den Texten des Bandes aufgrund ihrer erzählerischen Konventionalität „auf nichts [...] aufmerksam gemacht" werde. ${ }^{18}$ Dieser Vorwurf korrespondiert mit der programmatischen Forderung in Ich bin ein Bewohner des Elfenbeinturms, eine neue „Methode“ des Schreibens eröffne zuallererst die Möglichkeit, , aufmerksam zu machen und aufmerksam zu werden“, besitze also das Vermögen, sowohl die Wahrnehmung der Leserinnen und Leser als auch jene des Autors selbst zu schärfen und zu schulen. ${ }^{19}$ Beide Formen des Schreibens über Literatur, die literaturkritische Kommentierung fremder Texte wie die poetologische Selbstreflexion, beziehen bei Handke wichtige Impulse aus den Forschungen der Formalisten, die in den 1910er und 1920er Jahren die ästhetische Revolution der russischen Avantgarde theoretisch flankiert hatten. 1969 erklärte Handke deren Ansätze, die für ihn eine entscheidende Orientierungsmarke darstellten, zur „wichtigste[n], methodisch-literarische[n] Schule, die am Anfang des 20. Jahrhunderts überhaupt entstanden ist“. 20

Handkes Kritik am Wochenende-Band, wonach keiner der Autoren „die Methode als Widerstand“ einsetze, „als sei das Geschichtenerzählen die gegebene, natürliche Art der Vermittlung von Wirklichkeit“,' findet ihre literaturtheoretische Entsprechung in Šklovskijs berühmtem, zunächst 1916 im russischen Original veröffentlichtem Aufsatz Kunst als Kunstgriff (später auch, mit anderem Akzent, als Die Kunst als Verfahren übersetzt ${ }^{22}$ ). Šklovskijs Überzeugung, das „Ziel der Kunst“ müsse die Fähigkeit sein, „uns ein Empfinden für das Ding zu

Paratextuelle Politik und Praxis. Interdependenzen von Werk und Autorschaft. Hg. v. Martin Gerstenbräun-Krug u. Nadja Reinhard. Wien: Böhlau 2018, S. 271-292, bes. S. 276-279 u. 285 f.

17 Peter Handke: „Bücherecke“ vom 11.10.1965. In: P. H.: Tage und Werke (Anm. 3), S. 240-248, hier S. 244.

18 Handke: Bei Abschied Regen (Anm. 6), S. 112.

19 Handke: Ich bin ein Bewohner des Elfenbeinturms (Anm. 9), S. 26; vgl. Lorenz: Pro domo (Anm. 7), S. $408 \mathrm{f}$.

20 Peter Handke im Gespräch mit Friedrich Luft. [1969] In: https://www.youtube.com/watch?v= fMPWoom_gZc (Stand 14.10. 2020), 11:42-11:49.

21 Handke: Bei Abschied Regen (Anm. 6), S. 112.

22 Vgl. Viktor Šklovskij: Die Kunst als Verfahren. [1916] In: Russischer Formalismus. Texte zur allgemeinen Literaturtheorie und zur Theorie der Prosa. Hg. v. Jurij Striedter. München: Fink ${ }^{4} 1988$, S. $3-35$. 


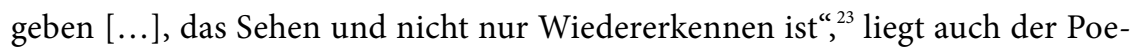
tik und dem literaturkritischen Anforderungskatalog des jungen Peter Handke zugrunde. ${ }^{24}$ Bereits der „Bücherecke“-Feuilletonist führt, wenn er Eichenbaums Darstellung referiert, „die Beschreibung des Regens" als Beispiel an; sie könne in einer modernen Literatur "nicht mehr als Vorspiel zu der Beschreibung eines Liebesszene " dienen. ${ }^{25}$ Die Verbindungen zwischen den von Handke rezipierten literaturtheoretischen Entwürfen des Formalismus und der eigenen Rezensionspraxis sind kaum zu übersehen - geht die Besprechung von Wellershoffs Wochenende-Band doch von der Kritik am „Wettergesetz der Literatur" aus, dem zufolge es, so Handkes pointierte Beobachtung, „bei einem Begräbnis in der Regel regnet ${ }^{\star 26}{ }^{26}$ Friedrich Christian Delius, ein Jahr jünger als Handke und wie dieser einer der vielversprechenden jungen Autoren im literarischen Feld Deutschlands, sollte wenige Jahre später in seiner Berliner Dissertation das Wetter als „Kunstmittel“ im Roman des bürgerlichen Realismus untersuchen. Der Untertitel von Delius' Studie, der neben dem „Kunstmittel“ auch seinen „ideologische[n] Gebrauch“ in den Blick zu nehmen verspricht, deutet jedoch bereits an, dass das Erkenntnisinteresse bei den beiden Schriftstellern sich nicht unbedingt deckte: Dem in der linken Studentenbewegung verwurzelten Delius war es auch um politische, nicht bloß um sprachästhetische Lesarten literarischer Texte zu tun. ${ }^{27}$

Die skizzierten Prinzipien von Handkes Rezensionspraxis gelten dann in ähnlicher Weise auch für das eigene literarische Schreiben: Das formalistische Diktum, ein ästhetisch wertvoller Text zeichne sich durch eine „Komplizierung der Form" und eine damit einhergehende "Verfremdung" der beschriebenen

23 Viktor Šklovskij: Kunst als Kunstgriff. [1916] In: V. S.: Theorie der Prosa (Anm. 15), S. 7-27, hier S. 14.

24 "Analytisches Vokabular" verwendet Handke dabei, so Christoph Bartmann: Suche nach Zusammenhang. Handkes Werk als Prozeß. Wien: Braumüller 1984, S. 129, „,or allem zur Aufdeckung Manier gewordener narrativer Klischees“. Vgl. dazu Lorenz: Pro domo (Anm. 7), S. 410: „Er wollte, mit immer neuen Schreibansätzen, die ,Macht' der im menschlichen Leben tief verwurzelten Automatismen brechen, die Schemata des Lebens kenntlich machen, um sich von ihnen zu befreien."

25 Handke: „Bücherecke“ vom 11. 10. 1965 (Anm. 17), S. 244.

26 Handke: Bei Abschied Regen (Anm. 6), S. 112. Einige Jahre später ist Handke in einem Interview mit Günther Nenning noch einmal auf diesen Aspekt zurückgekommen. Vgl. Günther Nenning: Warum ich jetzt Geschichten schreibe. [Gespräch mit Peter Handke.] In: Neue Freie Presse (1973), H. 4, S. 7: „Da haben Schriftsteller halt das Wochenende beschrieben, und automatisch kam das Klischee, daß die Sonne scheint, daß Autos gewaschen werden, daß es nach Sonnenöl riecht, und einmal war halt eine Liebesgeschichte, eine traurige, da hat's natürlich geregnet. Es hat ja schon Tolstoi gesagt, daß bei trauriger Liebe immer Regen ist in der Literatur. Das ist ein Montieren von Klischees."

27 Friedrich Christian Delius: Der Held und sein Wetter. Ein Kunstmittel und sein ideologischer Gebrauch im Roman des bürgerlichen Realismus. München, Wien: Hanser 1971. 
„Dinge“ aus, „um die Wahrnehmung zu erschweren und ihre Dauer zu verlängern“, ${ }^{28}$ findet sich in den sprachexperimentellen Arbeiten der frühen Jahre nachgerade mustergültig realisiert. Die Kritik des Wellershoff-Sammelbandes im auflagenstarken Spiegel verfolgt durch die enge Verklammerung mit Handkes poetologischen Essays ${ }^{29}$ zudem eine zentrale werkpolitische Agenda des Autors. Die Argumentation der Kritik, die aus vorderhand unscheinbaren Detailbeobachtungen die sprachliche Nachlässigkeit der einzelnen Beiträger - u. a. Peter Opitz und Martin Kurbjuhn - deduziert, entspricht der methodischen Strenge seiner frühen theoretisch-poetologischen Entwürfe, aber auch der literarischen Arbeiten, etwa jener der hermetisch anmutenden Sprechstücke (Weissagung, Selbstbezichtigung etc.) oder einzelner Texte des ,Lyrik'-Bandes Die Innenwelt der Außenwelt der Innenwelt (1969). Hat man in zahlreichen Darstellungen von Handkes Werkentwicklung in den Jahren um 1970 eine erste ,Wende“ ausgemacht, die eine partielle Revision früherer theoretischer Positionen mit sich brachte, so ist eine ähnliche Bewegung auch für Handkes Tätigkeit als Literaturkritiker nachzuvollziehen: In zeitlicher Nähe zur allmählichen Wiedergewinnung traditioneller erzählerischer Verfahren, für die Die Angst des Tormanns beim Elfmeter und Der kurze Brief zum langen Abschied Anfang der $1970 e r$ Jahre wichtige Etappen darstellten, ${ }^{30}$ hat der Autor, wie im Folgenden gezeigt werden soll, auch die Verfahren seines literaturkritischen Schreibens neu ausgerichtet.

Handke war in den ersten Jahren seiner Karriere neben Beiträgen im Spiegel und in der ZEIT, für die er u. a. Berichte über das Berliner Theatertreffen, die „experimenta 3 “ und die Berliner Filmfestspiele verfasste, auch für weitere deutsche Printmedien tätig. Er publizierte nicht nur Rezensionen und Essays in der cineastischen Zeitschrift film - 1967 konstatierte Handke, „daß die Filmkritik hierzulande schon viel weiter fortgeschritten ist als die literarische Kritik“" ${ }^{31}$ was dieses Feld für ihn überaus attraktiv machte -, sondern er besprach, abseits der prominenten Blätter, etwa den Sammelband Rauschgiftesser erzählen

28 Šklovskij: Kunst als Kunstgriff (Anm. 23), S. 14.

29 Aber auch, weil sie eine pointierte Positionierung in den Debatten um einen ,Neuen Realismus vorstellt; vgl. dazu ausführlich Anna Estermann: Vom „bloß sprachlichen“ zu einem „allumfassenden Realismus“. Handkes ,realistic turn` um 1970. In: Schreiben als Weltentdeckung. Neue Perspektiven der Handke-Forschung. Hg. v. A. E. u. Hans Höller. Wien: Passagen 2014, S. $97-134$.

30 Vgl. dazu Hans Höller: „Bruch“ und „Wende“. Zu einer Schreibbiografie Peter Handkes. In: Wende - Bruch - Kontinuum. Die moderne österreichische Literatur und ihre Paradigmen des Wandels. Wien: Praesens 2006, S. 195-209, bes. S. 201-203; Herwig Gottwald/Andreas Freinschlag: Peter Handke. Wien u. a.: Böhlau 2009, S. 25 f.

31 Handke: Ich bin ein Bewohner des Elfenbeinturms (Anm. 9), S. 26. Dazu Gottwald/Freinschlag: Peter Handke (Anm. 30), S. 83. 
für die Münchner Abendzeitung (August 1967) oder den Briefwechsel zwischen Ludwig Wittgenstein und Ludwig von Ficker für die Nürnberger Nachrichten (Dezember 1969). ${ }^{32}$ Viel stärker als Bernhard, der seine Tätigkeit als Redakteur des Demokratischen Volksblatts zum Zeitpunkt seines schriftstellerischen Durchbruchs längst aufgegeben hatte und später nur noch einmal als ,Kritiker auftrat, brachte sich Handke parallel zu seinen ersten literarischen Erfolgen selbst als Rezensent ein. Er erprobte Formen und Möglichkeiten literatur- und filmkritischen Schreibens - freilich stets mit dem Vorbehalt, nicht als Profi oder Sachverständiger in diesem Bereich zu agieren bzw. agieren zu wollen: „Aber ich bin kein Kritiker“, lautet die einschlägige Formel, die der Autor 1967 an das Ende eines offenen Briefs an Henning Rischbieter, den Herausgeber der Zeitschrift Theater heute, gesetzt ${ }^{33}$ und noch 40 Jahre später im Gespräch mit Michael Kerbler rekapituliert hat: „[I]ch bin ja kein Journalist, ich bin auch kein Historiker, ich bin ein Schreiber oder Schriftsteller, wie auch immer Sie das nennen.$^{\text {“ }}{ }^{4}$ Diese Rhetorik der distinktiven Positionierung, der Betonung der Nicht-Zugehörigkeit, ist für Handkes erfolgreiche Durchsetzung im literarischen Feld von entscheidender Bedeutung; nicht als Kritiker wahrgenommen zu werden, war ihm ein großes Anliegen. Gleichwohl spielt die „Arbeit des Rezensierens", die er wiederholt als eine schwierige, ihm bis zu einem gewissen Grad fremde beschrieben hat, ${ }^{35}$ für Handkes Werkpolitik, zumal in den frühen Jahren, eine zentrale Rolle - auch im Sinne einer Verständigung über poetologische Fragen. Dabei zeigt sich erneut, dass die „polemischen Absetzbewegungen" Handkes ${ }^{36}$ in diesem Fall jene von den Methoden der Literaturkritik, stets in Verbindung mit seinen Reflexionen über das eigene Schreiben, über die eigene literarische Praxis stehen.

32 Vgl. Peter Handke: Loch im Kopf. Der Erfolgsautor rezensiert eine Drogen-Dokumentation. In: Abendzeitung, 25. 8.1967 („Wieder einmal zeigt sich, daß man über Rauschgift nicht lesen kann: Man muß es NEHMEN“); ders.: „Ein Buch fürs Leben“. Über die Briefe zwischen Ludwig Wittgenstein und Ludwig von Ficker. In: Nürnberger Nachrichten, 23.12.1969.

Peter Handke: Briefe über Theater (1). In: Theater heute (1967), H. 2, S. 37.

34 ... und machte mich auf, meinen Namen zu suchen. Peter Handke im Gespräch mit Michael Kerbler. Klagenfurt: Wieser 2007, S. 29. Vgl. auch Peter Handke im Gespräch mit Brita Steinwendtner [Ö1, 1987]. In: Im Gespräch. Peter Handke 1987 2012. Interviews mit Wolfgang Hofer, Brita Steinwendtner u. Michael Kerbler. 2 CDs. [Wien]: ORF 2012, CD 1, Track 20, 01:54-02:03: „[M] ir zumindest hilft das Gehen, damit ich die Anschauung wiedergewinne, ohne die ich überhaupt nicht schreiben könnt', sonst wär' ich ein Kritiker oder irgend so ein anderer Heini“.

35 Peter Handke an Hermann Lenz, 7. 10. 1986. In: P. H./H. L.: Berichterstatter des Tages. Briefwechsel. Hg. u. mit einem Nachwort v. Helmut Böttiger, Charlotte Brombach u. Ulrich Rüdenauer. Mit einem Essay v. Peter Hamm. Frankfurt a. M.: Insel 2006, S. 221.

Rolf G. Renner: Peter Handke. Stuttgart: Metzler 1985, S. 24. 


\section{Ein Leseerlebnis beschreiben: Handke rezensiert Hermann Lenz}

Im Zentrum seiner Ambitionen als Rezensent stand bald auch eine Neukonzeption des Genres ,Kritik'. Diese hob sich ganz bewusst von den etablierten Verfahren der Beschreibung und Bewertung von Literatur ab. Sie stellte im Gegenzug die Idee einer „erzählte[n] Lektüre“ in den Mittelpunkt, die auch für seine fiktionalen Texte - etwa für den Kurzen Brief zum langen Abschied (1972), dessen Protagonist Kellers Grünen Heinrich und Fitzgeralds Der große Gatsby liest eine wichtige Rolle spielt; ${ }^{37}$ „daß einer von einem Buch erzählt, was er damit erlebt hat" ${ }^{\prime 38}$ diese Vorstellung hat dem Autor im Laufe der Jahre immer wieder als Ideal und als Leitlinie seines Rezensierens gedient. Er verfolgte dabei, wie er 1972 in der Vorbemerkung zum Essayband Ich bin ein Bewohner des Elfenbeinturms festhält, den Anspruch, über Bücher - aber auch über Filme oder LPs - zu schreiben, „ohne dem Leser mit dem üblichen Rezensions- und Analyseschema jede eigene Erkenntnismöglichkeit gleich mit dem ersten Satz wegzunehmen“. ${ }^{9}$

Die bereits in Handkes „Bücherecke“-Sendung vom 21. Dezember 1964 artikulierten Vorbehalte gegenüber einer konventionellen Literaturkritik, die durch die Automatisierung ihrer Ausdruckmittel zur unproduktiven und „gedankenlos[en] " Routine verkommen sei, ${ }^{40}$ versuchte der junge Autor nun für die Bestimmung eines alternativen Verfahrens der Kritik zu mobilisieren. „Es sind auch andere Sätze möglich“, hatte Handke Ende 1964 als Fazit seiner Ausführungen über die „Bewertungsworte“ der Kritiker vielsagend angekündigt. ${ }^{41}$ Der eingangs zitierte Brief an Unseld vom 29. August 1966 zeigt, dass er es auch in Zukunft nicht bei einem Lamento über den sprachlichen und intellektuellen Zustand der zeitgenössischen Literaturkritik bewenden lassen wollte. Der 1967 in den manuskripten publizierte Lektürebericht Als ich „Verstörung“ von Thomas Bernhard las, von dem noch ausführlicher die Rede sein wird, ist ein prägnantes Beispiel für Handkes bewusst betriebene Distinktion von den Gattungskonventionen der Literaturkritik - ein Beispiel zudem, das Handkes anfängliche Faszination, ja „Hochschätzung“42 für Bernhards Bücher, die sich Anfang der 197oer Jahre

37 Bartmann: Suche nach Zusammenhang (Anm. 24), S. 121.

38 Volker Hage/Mathias Schreiber: „Gelassen wär' ich gern“. Der Schriftsteller Peter Handke über sein neues Werk, über Sprache, Politik und Erotik. In: Der Spiegel, Nr. 49, 5.12. 1994, S. 170-176, hier S. 176.

39 Peter Handke: Vorbemerkung. In: P. H.: Ich bin ein Bewohner des Elfenbeinturms (Anm. 6), S. 7-8, hier S. 7. Vgl. dazu Clemens Özelt: Klangräume bei Peter Handke. Versuch einer polyperspektivischen Motivforschung. Wien: Braumüller 2012, S. $60 \mathrm{f}$.

40 Peter Handke: „Bücherecke“ vom 21. 12.1964. In: P. H.: Tage und Werke (Anm. 3), S. 189-197, hier S. 189.

41 Ebd., S. 190.

42 Hans Höller: Peter Handke. Reinbek b. Hamburg: Rowohlt 2007, S. 36. 
abschwächte und schließlich in deutliche, auch deutlich artikulierte Abneigung überging, anschaulich dokumentiert.

Im Dezember 1973 hat Peter Handke die Veränderung seines Schreibens über Literatur am Beispiel von Hermann Lenz als Entdeckung der Lektüre als Erlebnis beschrieben. „Ohne geübt zu sein“, habe er, so Handke im Abstand von gut acht Jahren, 1965 für das Radio „eine halbwegs geübte Kritik“ zu Lenz’ Roman Die Augen eines Dieners geschrieben, „in der, als ich sie vor kurzem wiederlas, nichts von dem vorkam, was ich damals mit dem Buch erlebt hatte; statt dessen ein Vergleich mit Knut Hamsun, der Zuschlag zu einer vertrauten Literaturart und damit der Zuschlag zur Literatur als etwas Vertrautem. “ ${ }^{43}$ Die souveräne Ordnungsgeste des jungen Rezensenten, der den neu erschienenen Roman mit exemplarischen Texten des Genres verglichen hatte, erscheint dem mittlerweile 31-jährigen Handke im Rückblick verdächtig. Zwar werden bereits in der Besprechung vom Januar 1965 die Reaktionen eines „Lesenden“ beschrieben, den der Roman „aufschreckt“ und „vor den Kopf stößt“; ${ }^{44}$ nichtsdestoweniger habe er, so Handke mit Blick auf seinen frühen Text, seinerzeit die Schilderung der Lektüre als Leseerlebnis vernachlässigt. ${ }^{45}$ „Und trotzdem vergaß ich Hermann Lenz nicht; durch die Jahre erinnerte ich mich immer wieder an das Buch, weniger an die Geschichte und die Einzelheiten darin als an meinen Zustand, während ich es damals gelesen hatte“. ${ }^{46}$ Handke war, wie er 1997 in einer Laudatio auf Lenz gestand, zunächst davon ausgegangen, es handle sich bei dem Autor von Die Augen eines Dieners um einen Österreicher:

Vor über dreißig Jahren habe ich zum ersten Mal, lieber Hermann, ein Buch von Dir gelesen, das waren Die Augen eines Dieners. [...] [I]ch wußte damals nicht, wer dieser Hermann Lenz ist. Die Augen eines Dieners ist ein Roman, der in Österreich spielt, in einer vergangenen Epoche, und ich hielt den Autor - es wurde im Klappentext nicht gesagt wer der Autor war -, als ich seinerzeit, vielleicht 1963, das Buch als

43 Peter Handke: Jemand anderer: Hermann Lenz. [1973] In: P. H.: Als das Wünschen noch geholfen hat. Frankfurt a. M.: Suhrkamp 1974, S. 81-100, hier S. 81. Der erwähnte Rundfunkessay findet sich in Auszügen in Peter Handke: „Bücherecke“ vom 18. 1. 1965. In: P. H.: Tage und Werke (Anm. 3), S. 198-203, hier S. 201 f., jedoch fehlt im „Rundfunkmanuskript [...] eine Seite, auf der P. H. sich mit Hermann Lenz' Roman Die Augen eines Dieners beschäftigte und die man P. H. zusandte, als er 1973 eine Gesamtwürdigung von Hermann Lenz schrieb. Diese Seite hat sich nicht erhalten. “ (Kommentar ebd., S. 201, Anm. ${ }^{*}$ )

44 Handke: „Bücherecke“ vom 18.1.1965 (Anm. 43), S. 201.

45 Vgl. Mixner: Peter Handke (Anm. 10), S. 207: „Gerade das rückt Handke nun in den Vordergrund: was er mit den Büchern von Hermann Lenz erlebt hat [...]. Der Erkenntniswert der Bücher von Hermann Lenz zeigt sich in den Erfahrungen, von denen Handke erzählt, daß er sie beim Lesen gemacht hat."

Handke: Jemand anderer: Hermann Lenz (Anm. 43), S. 81. 
Student, für den österreichischen Rundfunk in Graz, besprechen oder mich seiner annehmen sollte: ich hielt den Autor, Hermann Lenz, für einen Österreicher und dachte, was ist das für ein Österreicher, so einen Österreicher, wie der da schreibt, habe ich noch nie gelesen. ${ }^{47}$

Der junge Autor, der 1972 mit Der kurze Brief zum langen Abschied und Wunschloses Unglück zwei seiner bis heute meistgelesenen Bücher vorgelegt hatte, wandte sich Ende des Jahres brieflich an den bislang kaum beachteten Hermann Lenz, lernte ihn kurz darauf persönlich kennen und setzte sich in der Folge mit Nachdruck für die Verbreitung von dessen literarischem Werk ein, nicht zuletzt durch die Vermittlung an die Verlage Insel bzw. Suhrkamp: Im Februar 1976 bekannte Handke bei einer Lesung in München - einem der wenigen öffentlichen Auftritte des Autors in diesen Jahren -, er, „der ich fast 30 Jahre jünger bin als Hermann Lenz“, sei durchaus „egoistisch stolz“ auf den mittlerweile zum Freund gewordenen "freien Schriftsteller“, den er an diesem Abend vorstellte. ${ }^{48}$ Er hatte mit seinen wiederholten Lektüreempfehlungen, legitimiert durch sein symbolisches Kapital im literarischen Feld, ganz wesentlich dazu beigetragen, Lenz nach Jahrzehnten des Schreibens im Verborgenen einem größeren Publikum bekannt zu machen. ${ }^{49}$ Sein Engagement für Lenz kann geradezu als Paradefall der von Pierre Bourdieu beschriebenen „Konsekrationsmacht“ etablierter Autoren gelten, die

47 Peter Handke: Hermann Lenz, der Epiker des „und“, „bei“ und „mit“. Rede zur Verleihung des Europäischen Literaturpreises. In: P. H.: Mündliches und Schriftliches. Zu Büchern, Bildern und Filmen. 1992-2002. Frankfurt a. M.: Suhrkamp 2002, S. 101-111, hier S. 102. - In der Rundfunksendung hatte es diesbezüglich geheißen: „Es ist dies nicht nur dem Schauplatz nach ein im Grunde österreichischer Roman: die zur Schau getragene Gleichmut, die große Verwundbarkeit im Innern, die Vergangenheitsverhaftung machen den Diener Wasik vertraut lebendig." (Handke: „Bücherecke“ vom 18.1.1965 [Anm. 43], S. 202)

48 Peter Handke: Hermann Lenz, freier Schriftsteller. [1976] In: P. H.: Das Ende des Flanierens. Frankfurt a. M.: Suhrkamp 1980, S. 70-73, hier S. 73. Auf diese Veranstaltung in München geht Handke in seinem Brief an Lenz vom 11.3.1976 ein und bekennt, „,orher meine unheilbaren kleinen Zustände, vor Leuten zu sein“, gehabt zu haben (Handke/Lenz: Berichterstatter des Tages [Anm. 35], S. 97).

49 Zur Beziehung von Handke und Lenz vgl. Helmut Böttiger/Charlotte Brombach/Ulrich Rüdenauer: Sanfte Bewegungen von außen nach innen. Zum Briefwechsel von Peter Handke und Hermann Lenz. In: Handke/Lenz: Berichterstatter des Tages (Anm. 35), S. 427-444, hier S. 442: „Für Hermann Lenz ist die Begegnung mit Peter Handke ein entscheidender Wendepunkt in seinem Leben. Verblüfft notiert er die ersten Anzeichen, wie er in den Literaturbetrieb integriert wird, wie sich die Lesungen häufen, wie Fragen an ihn gestellt werden, wie er Bücher signieren soll. Er findet durch Handke Zugang zu einem literarischen und Freundschafts-Zirkel, der ihm jahrzehntelang verschlossen war." Vgl. den Bericht von Hermann Lenz: Begegnungen mit Peter Handke. In: ensemble. Internationales Jahrbuch für Literatur 8 (1977), S. 154-157. Dazu Höller: Peter Handke (Anm. 42), S. 79 f.; Malte Herwig: Meister der Dämmerung. Peter Handke. Eine Biographie. München: DVA ²010, S. 199-207. 
sich für die „Ausgrabung und Neubewertung“ vordem „zweitrangiger Künstler“ einsetzen, ${ }^{50}$ wobei hier nicht der Ältere für den Jüngeren, sondern der gefeierte Aufsteiger Handke für den lange verkannten poète maudit, gewissermaßen der Sohn für die „literarische[ ] Vaterfigur “51 Lenz eintritt: eine Talentförderung unter umgekehrten Vorzeichen, wie sie etwa auch in Handkes Bemühungen um Franz Nabl zu beobachten ist. ${ }^{52}$

Bezeichnenderweise setzt auch der Briefwechsel der beiden am 21. Dezember 1972 mit der Beschreibung einer Leseszene ein, in der sich der Gestus von Handkes Rezension bereits andeutet:

\section{Lieber Herr Lenz,}

heute bin ich früher aufgewacht und habe dann Ihr Buch „Der Kutscher und der Wappenmaler" zu Ende gelesen. Es war vor dem Fenster ein ganz warmes, fast menschliches Licht, wie es vor allem auf den letzten Seiten Ihres Buches so genau und ergreifend beschrieben ist. Ich war von der Geschichte richtig gerührt, und hoffe, das so sagen zu dürfen. [...] Ihr letztes Buch habe ich Satz für Satz gelesen, weil ich auf jede Einzelheit neugierig war. Einmal dachte ich: „Da kann man sich wirklich auf die Einzelheiten ganz und gar verlassen“ - und das ist sicher ein Zeichen, daß da wirklich ein Schriftsteller arbeitet, und kein bloßer Behaupter. Ich las in dem Buch einen Monat lang, und es hat mir sehr geholfen. Ich halte Sie für einen der wenigen Schriftsteller, bei denen man sich lesend zwar fremd, aber doch ganz zu Hause fühlen kann. ${ }^{53}$

Die Verbindung der literarischen Struktur des Buches mit der konkreten Lektüresituation des lesenden Autors Handke, die Anregung zur langsamen, genauen Lektüre ,Satz für Satz', schließlich das Moment der Selbsterkenntnis des Lesers, dem sich das Buch als ,Hilfestellung' für sein eigenes Leben erweist, und die daraus gewonnene Überzeugung, hier sei nicht ein „Behaupter“, ein auf den Effekt bedachter Poseur am Werk, sondern „wirklich ein Schriftsteller“ - Handke benennt damit in seinem ersten Brief an Lenz im Dezember 1972 Aspekte einer emphatischen Lektürepraxis, die für sein literaturkritisches Schreiben von zentraler Bedeutung waren und seither geblieben sind.

Bald nach Beginn der Korrespondenz mit Lenz stellt Handke diesem in Aussicht, „was über Ihre Arbeit zu schreiben“, er habe allerdings „, seit 3 Jahren nichts Aufsatzähnliches geschrieben, deswegen macht es mir Schwierigkeiten. Aber da es

50 Pierre Bourdieu: Die Regeln der Kunst. Genese und Struktur des literarischen Feldes. Frankfurt a. M.: Suhrkamp 1999, S. 364.

51 Pichler: Die Beschreibung des Glücks (Anm. 3), S. 111.

52 Vgl. exemplarisch Peter Handke: Österreich und die Schriftsteller. In: Literatur im Residenz Verlag. Almanach auf das Jahr 1974. Salzburg: Residenz 1974, S. 57-61, hier S. 6o f.

53 Handke an Lenz, 21.12. 1972. In: Handke/Lenz: Berichterstatter des Tages (Anm. 35), S. 9. 
ein Bedürfnis ist in Ihrem Fall, wird dem nicht auszuweichen sein. " ${ }^{54}$ Tatsächlich hatte Handke nach zahlreichen Rezensionen in den Jahren 1967 bis 1969 seine Tätigkeit als Kritiker Anfang der 1970er Jahre weitgehend eingestellt; nur eine Theaterkritik zu Wolfgang Bauers Magic Afternoon bildete davon eine Ausnahme ${ }^{55}$ während die 1972 in Ich bin ein Bewohner des Elfenbeinturms versammelten Buch- und Filmbesprechungen allesamt bereits in den 196oer Jahren erschienen waren. Seine Arbeit über Hermann Lenz stellte einen Neuansatz als Kritiker dar, der ihm neben den eigenen literarischen Arbeiten offenbar nicht leicht von der Hand ging: „Nun bin ich noch immer nicht soweit mit der Geschichte über H. L., will aber unbedingt Ende September fertig sein“, "56 schreibt er dem Autor des zu rezensierenden Buches im August 1973, kann aber erst am 23. November „froh und erleichtert“ davon berichten, „[m] einen Aufsatz über H. L. [...] seit vorgestern abend fertig “ $z$ u haben. ${ }^{57}$ Die Schreibhaltung als Rezensent, die Handke mit seinem Lektürebericht über Hermann Lenz anvisiert, ist in der abweichenden Bezeichnung der Textsorte in den beiden zitierten Briefen prägnant skizziert: Sie nimmt eine Zwischenstellung zwischen einer „Geschichte über H. L.“ und einem „Aufsatz über H. L.“ ein. „Es wäre schön, wenn man möglichst viele dieser Texte als Geschichten lesen könnte " ${ }^{58}$ hatte Handke schon 1972 in den einleitenden Bemerkungen zum Band Ich bin ein Bewohner des Elfenbeinturms, der u. a. seine Arbeiten über Thomas Bernhard und Gert Jonke enthielt, die von ihm präferierte Rezeption dieser Texte umrissen.

In der schließlich am 22. Dezember 1973 in der Süddeutschen Zeitung publizierten „Einladung, Hermann Lenz zu lesen“59 erinnert Handke sich zunächst an den „Zustand einer wachsenden Ungestörtheit“, in dem er einst Die Augen eines Dieners gelesen habe - ein Zustand, der „aber nicht von außen kam, sondern von dem Buch erst erzeugt wurde ${ }^{\prime 60} .{ }^{60}$ Mit Blick auf seine Rundfunkrezension von 1965 skizziert Handke eine alternative Form der Literaturbeschreibung, die von der Idee einer analytischen Sezierung des Textes Abstand nimmt. Er rückt den Lektüreakt in den Mittelpunkt der Beschreibung, um am Beispiel des aktuellen

54 Handke an Lenz, 15. 2.1973. In: ebd., S. 13.

55 Vgl. Peter Handke: Schwankende Nerven. Über Wolfgang Bauers dramatischen Erstling Magic Afternoon. Zur Nürnberger Inszenierung dieses Bühnenstücks über die Verhaltensweise der Jugend. In: Nürnberger Nachrichten, 24. 4. 1970.

56 Handke an Lenz, 27. 8. 1973. In: Handke/Lenz: Berichterstatter des Tages (Anm. 35), S. 25.

57 Handke an Lenz, 23.11.1973. In: ebd., S. 31.

58 Handke: Vorbemerkung (Anm. 39), S. 8. Handke habe damit, so Höller: Peter Handke (Anm. 42), S. 62, „das Übergängige von Theorie und Literatur“ betonen wollen.

59 So der Untertitel des Essays über Hermann Lenz in der Süddeutschen Zeitung vom 22. 12. 1973, der (ebenso wie der Haupttitel Tage wie ausgeblasene Eier) für die Buchfassung in Als das Wünschen noch geholfen hat (1974) geändert wurde.

60 Handke: Jemand anderer: Hermann Lenz (Anm. 43), S. 81. 
Romans Der Kutscher und der Wappenmaler seine Wertschätzung für Lenz' Literatur im Allgemeinen zu betonen:

Es war gerade eine Jahreszeit wie auf einer Eisscholle, so bodenlos dunkel ringsherum, und manchmal hatte ich Angstzustände, daß mir beim Vorübergehen an einem leeren Zimmer die Ohren stachen, aber sobald ich Der Kutscher und der Wappenmaler las, hörten die Gegenstände um mich herum auf, Vorzeichen des Furchtbaren zu sein, und standen unverrückbar in dem freundlichen elektrischen Licht, in das ich nun wieder aufschauen konnte. Ich bekam vom Lesen ein Kindheitsgefühl: als ob nun endlich alle Vermißten zu Hause wären. Wenn zwischendurch die nächtliche Stille wieder mit Bedeutungen drohte, las ich einfach genauer, Wort für Wort, und die Bedeutungen vergingen; das Buch lenkte mich nicht ab von ihnen, sondern es stärkte mich gegen sie; kaum jemals hatte ich mich so geborgen gefühlt. ${ }^{61}$

Der Rezensent, der die „fremde Rolle“ des Kritikers sowie die damit assoziierten „beliebig verfügbare[n] Begriffe “62 ein Jahr zuvor, in der bereits zitierten Vorbemerkung zu Ich bin ein Bewohner des Elfenbeinturms, demonstrativ von sich gewiesen hatte, führt hier die Verortung des Lesens im Leben exemplarisch vor; die Besprechung erweist sich zuallererst als autobiographischer Lektürebericht:

[I]ch erinnere mich, wie es war, als ich Der Kutscher und der Wappenmaler las, und wie es gewesen ist, als ich das Buch zu Ende las: am frühen Morgen im Stockfinstern aufgewacht, fing ich nach einiger Zeit zu lesen an. Dann war es hell, und die Geschichte vom Kutscher August Kandel, für den der geheimnisvolle Wappenmaler hinter ihm in der Kutsche das andere Leben bedeutete, war aus. Eine tiefgelbe Wintermorgensonne im Zimmer; die Besänftigung; nichts vergessen, dachte ich. ${ }^{63}$

61 Ebd., S. 83 f. Über Handkes Würdigung zeigte sich Lenz erfreut, wie sich aus Handkes Antwortbrief erschließen lässt. Vgl. Handke an Lenz, 30. 12. 1973. In: Handke/Lenz: Berichterstatter des Tages (Anm. 35), S. 35: „Lieber Hermann Lenz, auch mich hat es gefreut, den Aufsatz in der ,Süddeutschen Zeitung zu lesen, sehr, und Ihre Meinung und Beschreibung dazu hat mich richtig glücklich gemacht, ich habe Ihren Brief öfter gelesen und lese ihn immer noch.“

62 Handke: Vorbemerkung (Anm. 39), S. 8. In einem ersten Entwurf der einleitenden Überlegungen, der ausdrücklich „(Keine Überschrift!)“ vorsieht, war noch von „flinken Begriffen“ die Rede, was Handke dann durch „beliebig verfügbaren Begriffen“ ersetzt. Siehe dazu das Faksimile der Korrekturen in: „Was ich schreibe, ist ja nur meine geformte Existenz“. Peter Handke. Eine Ausstellung über Leben und Werk des Schriftstellers. Stift Griffen 1997. Klagenfurt: Kulturinitiative Stift Griffen 1998, S. 50.

63 Handke: Jemand anderer: Hermann Lenz (Anm. 43), S. 84 f. In der Folge schildert Handke auch ein Gespräch mit Lenz, in dem er diesem von der Lektüre seiner Werke berichtet habe: „Ich erzählte, wenn ich sehr lange in einem seiner Bücher gelesen hätte, käme mir gegen Ende darin auf einmal alles selbstverständlich vor, unumstößlich, aber ungezwungen, völlig ruhig, aber 
Beispielgebend für spätere Reflexionen über das Lesen, zumal für die zahlreichen Notate zu diesem Themenkomplex in den Journalbänden, entwirft Handke hier die Idee einer Lektüre, die die Bedeutung eines Buches für den Leser, Autor und Kritiker nicht mittels eines streng analytisch-distanzierten Verfahrens zu ermitteln versucht, sondern ganz wesentlich auf die Vermittlung und Beschreibung eines subjektiven Leseerlebnisses setzt. Ausgehend von dieser grundsätzlichen Überzeugung fand Handke, wie Manfred Mixner anschaulich gezeigt hat, zu „einem eigenständigen essayistisch-literarischen Verfahren“, das „ganz und gar nicht den Normen literaturwissenschaftlicher [und literaturkritischer] Praxis“ entsprach. ${ }^{64}$ Varianten dieses Verfahrens, die er in Reflexionen über das Genre der Kritik wie in eigenen Arbeiten über Literatur erkundet, finden sich etwa in den frühen Essays zu Thomas Bernhards Verstörung (1967) und Gert Jonkes Geometrischem Heimatroman (1969). Das Gravitationszentrum der Beschreibung bildet dabei das „Ereignis des Lesens“; ${ }^{65}$ als Leitbild einer solchen Praxis hatte Handke im Disput mit Peter Hamm bereits 1969 die Idee einer „andere[n], vielleicht den Leser freier lassende[n] Möglichkeit der Kritik $^{\text {“6 }}$ in Aussicht gestellt.

Noch 2005 hat Peter Handke, im Gespräch mit dem österreichischen Journalisten Heinz Sichrovsky, eine der emphatischen Lektüre verpflichtete Literaturkritik gefordert:

Das Schönste an Rezensionen ist, wenn man das Lesen spürt. Nicht das Auseinanderklauben, das Loben, das Tadeln, sondern das Lesen. Nur dann hat ein Rezensent einen Sinn. Auch, wenn er zornig ist. Dann spürt man den zornigen Leser. Aber den Leser muss man spüren, nicht den Rezensenten. ${ }^{67}$

Die „Expedition des Lesens“, 68 von der Handke in Mein Jahr in der Niemandsbucht (1994) schreibt, ist für ihn keine, die auf exakte Instrumente und Karten vertrauen kann. Ebenso wie das Schreiben, das Handke an zahlreichen Stellen

noch mild von der überstandenen Unruhe - und da läse ich nicht mehr, sondern empfände einfach nur Glück. ,Das ist es!' sagte Lenz überrascht und doch selbstbewußt.“ (Ebd., S. 98 f.)

64 Mixner: Peter Handke (Anm. 10), S. 208.

65 Lothar Struck: Der Begleitschreiber. Einige Bemerkungen zum Kritiker und Leser Peter Handke. In: L. S.: Erzähler, Leser, Träumer. Begleitschreiben zum Werk von Peter Handke. Mit einem Vorwort v. Klaus Kastberger. [Klipphausen]: Mirabilis 2017, S. 13-27, hier S. 22.

66 Peter Handke über Peter Handke. In: konkret, Nr. 13, 16.6.1969, S. 51; auch in: Über Peter Handke. Hg. v. Michael Scharang. Frankfurt a. M.: Suhrkamp 1972, S. 314-319.

67 Heinz Sichrovsky: „Ich bin ein konservativer Mensch“. Gespräch mit Peter Handke. In: News, Nr. 39, 29. 9. 2005, S. 144-148, hier S. 146.

68 Peter Handke: Mein Jahr in der Niemandsbucht. Ein Märchen aus der neuen Zeit. Frankfurt a. M.: Suhrkamp 1994, S. 185. 
als gefahrvolle, sich der Planung entziehende „Ein-Mann-Expedition“, 69 als „eine Expedition [...], wie man sie sich abenteuerlicher nicht wünschen kann" ${ }^{\text {“70 }}$ charakterisiert hat, versteht Handke auch das Lesen und die Dokumentation dieser Lektüre als Tätigkeit, die die eigenen Sicherheiten infrage stellt, um nicht in unproduktive Routinen zu verfallen - gerade Letzteres ist ein wiederkehrender Vorwurf des ,Gelegenheitskritikers' Handke an die professionellen Rezensenten in den Redaktionen der Tages- und Wochenzeitungen. Sein Interesse richtet sich, so Manfred Mixner, auf einen „Erkenntniswert“, „der durch die Dimension der Erfahrbarkeit jeder über ein begriffliches Regelsystem gewonnenen Erkenntnis [...] überlegen ist“ .

Dabei will auch der Rezensent Handke nicht von der Vorstellung abrücken, ein Buch so zu lesen, „als könnte es mir“, wie er im 1977 erschienenen Journalband Das Gewicht der Welt über Wolf Solent von John Cowper Powys notiert, „fürs weitere Leben etwas bringen “72 Diesen emphatischen, ausdrücklich nicht-analytischen Begriff von literarischer Lektüre hat der Autor in immer neuen Anläufen festgehalten, skizziert, in kleinen Miniaturen erzählerisch entworfen - nicht zuletzt als Gegenpol zu den ,Bestenlisten' und wertenden Gesten der Literaturkritik: „Die besten sind jene Bücher“, schreibt er in Die Geschichte des Bleistifts (1982), „die einen immer wieder dazu bringen, innezuhalten, aufzuschauen, in die Gegend zu schauen, tief einzuatmen, sich von der Sonne bescheinen zu lassen - auch wenn diese gar nicht scheint ${ }^{\text {“ }}{ }^{73}$ In vielen Fällen steht dabei, wie Roland Borgards treffend formuliert, die Frage im Zentrum, wie es möglich ist, „aus der Erfahrung mit dem Text zu einer neuen Wahrnehmung der Welt [zu] gelangen“.74

69 Peter Handke: Drei Zitterer an der homerischen Quelle. [2015] In: P. H.: Tage und Werke (Anm. 3), S. 165-186, hier S. 185.

70 Peter Handke: Prosa als Hintergrund(aus)leuchten. [2004] In: P. H.: Meine Ortstafeln. Meine Zeittafeln. 1967-2007. Frankfurt a. M.: Suhrkamp 2007, S. 334-340, hier S. 336; so auch in Peter Handke: Gestern unterwegs. Aufzeichnungen November 1987 - Juli 1990. Salzburg, Wien: Jung und Jung 2005, S. 86: „Das Schreiben hat ein Abenteuer zu sein, oder es ist nicht - und es ist mir doch noch fast jedesmal gelungen, mich in solch ein Abenteuer zu verwickeln? verwickeln zu lassen?" - Eine ähnliche Konzeption des Schreibens findet sich, um nur ein Beispiel zu nennen, auch bei Max Frisch: „Schreiben ist ein abenteuerliches Unternehmen, man setzt sich seiner Erfahrung aus“ - „Ich will also, wenn ich ein Stück schreibe und es zur Aufführung gebe, etwas auskundschaften“ (Max Frisch/Dieter E. Zimmer: Noch einmal anfangen können. [1967] In: M. F.: „Wie Sie mir auf den Leib rücken!“ Interviews und Gespräche. Ausgewählt u. hg. v. Thomas Strässle. Berlin: Suhrkamp 2017, S. 67-78, hier S. 69 u. 72).

71 Mixner: Peter Handke (Anm. 10), S. 162.

72 Peter Handke: Das Gewicht der Welt. Ein Journal (November 1975 - März 1977). Salzburg: Residenz 1977, S. 62.

73 Peter Handke: Die Geschichte des Bleistifts. Salzburg, Wien: Residenz 1982, S. 65.

74 Roland Borgards: Sprache als Bild. Handkes Poetologie und das 18. Jahrhundert. München: Fink 2003, S. 32. 
Auf die eine oder andere Weise hat die Maxime, den Gestus des forschenden Lesers jenem des routinierten Rezensenten vorzuziehen, Handkes literaturkritische Praxis über viele Jahrzehnte geprägt - und ihm dazu gedient, sich von anders verfahrenden Zeitgenossen zu distanzieren, ja, so Otto Lorenz, „gegen die Leitprinzipien der anderen zu Felde “ zu ziehen. ${ }^{75}$ In der Korrespondenz mit Hermann Lenz beklagte Handke 1975 zunächst, die „üblichen Rezensionsschemata“ seien ,ja so tötend (geist- und seele-) “76 um kurz darauf sein eigenes Lesen und Rezensieren mit diesem negativen Vorbild abzugleichen: „Ihr Buch habe ich schon vom Verlag gekriegt und lese es gerade noch einmal, mir scheint, zu rezensentenhaft, durch. “"77 Handke betonte wiederholt, nur die „Rolle des Kritikers ${ }^{\text {“78 }}$ einzunehmen, die entsprechende Profession hat er selbst aber nie für sich reklamiert. Karl Wagner hat in diesem Zusammenhang Handkes „Reserve gegenüber der parat stehenden Rolle des Profi-Lesers“ hervorgehoben, „von der er geradezu methodisch Abstand hält" ${ }^{\text {"79 }}$

Wie der Geologe Sorger in Langsame Heimkehr tunlichst vermeidet, sich in seiner forschenden Tätigkeit „als Professioneller“ aufzuspielen, ${ }^{80}$ weil ihm die „Beschreibungs- und Benennungsübereinkünfte“ seiner Wissenschaft stets „fragwürdig " erscheinen, ${ }^{81}$ so distanziert sich Handke davon, ein Literaturkritiker im herkömmlichen Sinne zu sein. „Experten, Profis, Spezialisten“" ${ }^{\text {"2 }}$ sind ihm, wie er ein ums andere Mal betont hat, verdächtig; er könne „den Kritiker“ bestenfalls

75 Lorenz: Pro domo (Anm. 7), S. 409.

76 Handke an Lenz, 14.3.1975. In: Handke/Lenz: Berichterstatter des Tages (Anm. 35), S. 69.

77 Handke an Lenz, 30. 4. 1975. In: ebd., S. 74.

78 Der entsprechende Abschnitt in Ich bin ein Bewohner des Elfenbeinturms (1972) heißt denn auch demonstrativ „In der Rolle des Kritikers“ (S. 191-207).

79 Karl Wagner: Handke als Leser. In: lesen.heute.perspektiven. Hg. v. Eduard Beutner u. Ulrike Tanzer. Innsbruck u. a.: StudienVerlag 2010, S. 140-149, hier S. 146 f. Vgl. Mixner: Peter Handke (Anm. 10), S. 162: „Für ihn ist die Rolle des Kritikers, des Kommentators, des Wohl-oder Übelmeinenden eine fremde Rolle. Er fühlt sich darin nicht wohl, denn das Begriffsrepertoire, dessen er sich dafür bedienen muß, erscheint ihm beliebig verfügbar."

Peter Handke: Langsame Heimkehr. Erzählung. Frankfurt a. M.: Suhrkamp 1979, S. 120.

81 Ebd., S. 18. Vgl. Bartmann: Suche nach Zusammenhang (Anm. 24), S. 231 f.; jetzt auch Ulrich von Bülow: Heidegger-Lektüren. In: Das stehende Jetzt. Die Notizbücher von Peter Handke. Gespräch mit dem Autor und Essays von U. v. B. Marbach a. N.: Deutsche Schillergesellschaft 2018, S. 95-123, hier S. 102: „In Handkes Erzählung Langsame Heimkehr von 1979 sucht die Hauptfigur Valentin Sorger einen grundsätzlich neuen Bezug zur Welt, indem er Landschaftsformen zeichnet und beschreibt. Als Geologe ist er mit den Dimensionen von Raum und Zeit vertraut, allerdings wird ihm die Sprache seiner Wissenschaft zunehmend problematisch, ihre, interesselose' Darstellungsmethode lehnt er als unzulänglich ab. [...] Mit der von ihm geplanten Abhandlung, Über Räume` will er ausdrücklich ,die Übereinkünfte seiner Wissenschaft verlassen."

82 Peter Handke: Die Unschuldigen, ich und die Unbekannte am Rand der Landstraße. Ein Schauspiel in vier Jahreszeiten. Berlin: Suhrkamp 2015, S. 123. 
„spiele[n] “, so Handke 2006 in seiner Laudatio auf Jürgen Becker ${ }^{83}$ Es sei nicht „[s]eine Sache“, „die Poetik, die poetische Methode“ eines Autors „zu umreißen, gar zu definieren“, wie er 2014 in einem Essay über Carlfriedrich Claus und Franz Mon eingesteht: „Im Übrigen könnte ich es auch nicht, habe zwar momentan, unversehens, ruckhaft einen Blick dafür, mehr noch ein Gehör [...]. Doch es fehlen mir die Worte und mehr noch die Begriffe. ${ }^{\text {" }}{ }^{4}$ Gerade daran - an der Unsicherheit der Sprache, der Unverfügbarkeit der entsprechenden Terminologie - hat Handke seine Schwierigkeiten, im Schreiben über Literatur die Anforderung einer konventionellen Vorstellung von Literaturkritik zu erfüllen, wiederholt festgemacht, etwa in einem ausführlichen Gespräch mit Manfred Durzak anlässlich der Verleihung des Georg-Büchner-Preises im Jahr 1973:

Das ist vielleicht schon interessant für eine gewisse Zeit, einen Rezeptionsvorgang zu beschreiben und eine Scheinanalyse vorzunehmen mit einem bestimmten Begriffsmaterial. Aber das würde mich überhaupt nicht bei einem Schriftsteller interessieren. Ich würde es auch als unwahr empfinden, jetzt faktisch nur dauernd den Staub zu analysieren, den der Mann aufgewirbelt hat. Da besteht für mich ein Defekt der Leute, das ist ein sterilisierter Zustand in bezug auf Literatur. Wenn ich dann höre: Ja, der gesellschaftliche Aspekt usw. - das ist für mich ganz etwas anderes. Es ist viel schwieriger, ein Buch zu beschreiben, ohne Rituale und ohne Begriffssystem, das jedem zum Halse heraushängt, der weiß, wie die zustandekommen. ${ }^{85}$

Sein literaturkritisches Verfahren hat Handke demonstrativ als Gegenentwurf zu etablierten Konzepten entwickelt, um - wie es in der Erzählung Nachmittag eines Schriftstellers (1987) heißt - dem „Kreislauf aus Einordnungen und Urteilen“ zu entkommen, „die doch fast nur aus dem Ausspielen des einen gegen den anderen bestanden". ${ }^{86}$ In Opposition dazu hat Handke die Idee einer Literaturkritik entworfen, in deren Zentrum das Erlebnis oder die Erfahrung der Lektüre steht: Es handelt sich dabei, so Mixner, um ein ausdrücklich „poetisches Verfahren

83 Peter Handke: Gurken und Kiefern, Äpfel und Schnee. Laudatio zum Hermann-Lenz-Preis an Jürgen Becker. [2006] In: P. H.: Meine Ortstafeln. Meine Zeittafeln (Anm. 70), S. 272-279, hier S. 273. Vgl. in ähnlicher Weise auch Peter Handke: Josef W. Janker oder Die Selbstverschränkung der Autor-Kreatur. Rede zum Hermann-Lenz-Preis 1999. In: P. H.: Mündliches und Schriftliches (Anm. 47), S. 139-154, hier S. 148.

84 Peter Handke: Eine Ideal-Konkurrenz. [2014] In: P. H.: Tage und Werke (Anm. 3), S. 132-152, hier S. 134 .

85 Manfred Durzak: Für mich ist Literatur auch eine Lebenshaltung. Gespräch mit Peter Handke. [1973] In: M. D.: Gespräche über den Roman. Formbestimmungen und Analysen. Frankfurt a. M.: Suhrkamp 1976, S. 314-343, hier S. 328.

86 Peter Handke: Nachmittag eines Schriftstellers. Erzählung. Salzburg, Wien: Residenz 1987, S. $36 \mathrm{f}$. 
der Kritik, das Handke dazu verhalf, von der Vermittlung von Daten und Fakten in einem Wertungszusammenhang wegzukommen, und an dessen Stelle das Kritisierte in einen Erfahrungszusammenhang zu stellen. ${ }^{487}$ Entsprechend hat Handke 1995 in einer weiteren Laudatio, anlässlich der Verleihung des NicolasBorn-Preises an Arnold Stadler, bemerkt, es sei „vielen Kritiken zu entnehmen, daß der Rezensent das Wissen über den Autor nicht mehr aus dem Lesen bezieht, sondern aus Daten, aus dem Lexikon. ${ }^{\text {(88 }}$

Anhand der bereits zitierten Erzählung Langsame Heimkehr und ihres Protagonisten Valentin Sorger lässt sich exemplarisch zeigen, wie stark das skizzierte Problem auch in Handkes literarische Texte hineinwirkt, speist sich die Skepsis des Geologen Sorger gegenüber den "Beschreibungsmethoden“ seiner Wissenschaft doch ganz wesentlich aus dem Umstand, dass sie es, wie zuletzt Ulrich von Bülow gezeigt hat, nicht ermöglichen, „die eigenen Erfahrungen“ des Forschers auszudrücken. ${ }^{89}$ Während Sorgers Interesse der „Möglichkeit eines ganz verschiedenen Darstellungsschemas der Zeitverläufe in den Landschaftsformen" gilt (und er sich deshalb selbstbewusst in eine Genealogie der „Umdenker“ einschreibt), ${ }^{90}$ sind Handkes Ambitionen auf eine alternative Form der emphatischen Beschreibung von Literatur gerichtet. Wie die Tätigkeit des Geologen, der „von seiner Wissenschaft“ „überzeugt“ ist, „weil sie ihm half, zu fühlen, wo er jeweils war", ${ }^{\text {“91 }}$ zeichnet sich auch das literaturkritische Schreiben Handkes, das im Folgenden genauer in den Blick genommen wird, ganz wesentlich durch eine selbstreflexive, auf das eigene Dasein gerichtete Suchbewegung aus. ${ }^{92}$

87 Mixner: Peter Handke (Anm. 10), S. 176. Dazu auch Karl Wagner: Handkes „Der Roman des Lesens". In: Texttreue. Komparatistische Studien zu einem masslosen Massstab. Hg. v. Jürg Berthold u. Boris Previšić. Bern u. a.: Lang 2008, S. 173-181, hier S. 179: „Es war ihm auch wichtig, seine Rolle als Gelegenheitsrezensent in frühen Jahren von den Gattungserwartungen an eine Buchbesprechung fernzuhalten und sie - zumindest nachträglich - als Geschichte zu präsentieren, mit geradezu primitiv-epischem Signalement [...]." Dies hat Handke auch hämische Kommentare eingetragen, etwa 1993 in einem Bericht der Süddeutschen Zeitung anlässlich der Verleihung der Ehrendoktorwürde der Universität Eichstätt: „Handke liest seine Kollegen so, wie wir Blümelein auf dem Felde beobachten oder die Vögel am Himmel.“ (J. B.: Der poetische Gelehrte. In: Süddeutsche Zeitung, 10. 5. 1993)

88 Peter Handke: Eine gewaltige Sehnsucht. Zu Arnold Stadler. [1995] In: P. H.: Mündliches und Schriftliches (Anm. 47), S. 82-91, hier S. 83.

89 Ulrich von Bülow: Spinoza-Lektüren. In: Das stehende Jetzt (Anm. 81), S. 125-147, hier S. 140.

90 Handke: Langsame Heimkehr (Anm. 80), S. 18.

91 Ebd., S. 12.

92 Siehe dazu etwa, um nur ein Beispiel zu nennen, die Selbstbestimmung Handkes in einem 2000 anlässlich des Todes von H. C. Artmann geführten Interviews: „Er war der perfekte Artist als Poet. Aber meine Position als Poet, wenn ich überhaupt eine habe, ist nicht die des Artisten, sondern die des Forschers. Des Stümpers. Des landwirtschaftlichen Dichters." (Heinz Sichrovsky: 


\section{Abenteuergeschichte der Lektüre: Handke liest Bernhards Verstörung}

Die Idee, von ihm geschätzten Büchern durch die Beschreibung ihrer Lektüre, aber auch durch die bloße Nacherzählung ihrer Fabel literarisch seine Reverenz zu erweisen, ohne sich dabei eines kritisch-analytischen Vokabulars zu bedienen, findet sich bei Handke bereits sehr früh: etwa in dem $1967 \mathrm{im}$ Band Begrüßung des Aufsichtsrats gedruckten Prosatext Der Prozeß (für Franz K.), der Kafkas Roman mit zahlreichen wörtlichen Übernahmen erzählerisch rekapituliert, ohne eine wertende Position außerhalb des ursprünglichen Textes zu etablieren, ${ }^{93}$ oder im ebenfalls 1967 erschienenen Bericht Als ich "Verstörung" von Thomas Bernhard las. Obgleich den beiden Texten ganz unterschiedliche literarische Verfahren zugrunde liegen, dokumentieren sie doch jeweils Handkes Abkehr von den Genrekonventionen literaturkritischer Publizistik, seine Erprobung neuer und idiosynkratischer Formen des Schreibens über Literatur.

Thomas Bernhards zweiter Roman Verstörung erschien am 15. März 1967, die letzte Insel-Publikation des Autors vor seinem Wechsel zu Suhrkamp; Handke bekam ihn wohl kurz darauf vom gemeinsamen Verleger zugeschickt: „Und noch einen Dank: für das Thomas-Bernhard-Buch“, schreibt er am 23. Mai an Siegfried

„Freie Figur unter den Dichtern“. [Gespräch mit Peter Handke.] In: News, Nr. 50, 14. 12. 2000, S. 132)

93 Vgl. Peter Handke: Der Prozeß (für Franz K.). In: P. H.: Begrüßung des Aufsichtsrats. Prosatexte. Salzburg: Residenz 1967, S. 105-122. Der letzte Absatz von Handkes Text etwa ist mit dem letzten Absatz von Kafkas Roman - bis auf minimale Abweichungen, die sich eventuell mit der von Handke verwendeten Ausgabe erklären lassen - identisch: „Aber an K.'s Gurgel legten sich die Hände des einen Herrn, während der andere das Messer ihm ins Herz stieß und zweimal dort drehte. Mit brechenden Augen sah noch K. wie nahe vor seinem Gesicht die Herren Wange an Wange aneinandergelehnt die Entscheidung beobachteten. Wie ein Hund!' sagte er, es war, als sollte die Scham ihn überleben." (Franz Kafka: Der Proceß. Hg. v. Malcolm Pasley. Frankfurt a. M.: S. Fischer 1990 [= F. K.: Schriften Tagebücher Briefe. Kritische Ausgabe], S. 312) - Vgl. zu diesem Text Norbert Gabriel: Peter Handke und Österreich. Bonn: Bouvier 1983, S. 117-123, der dessen Qualität allerdings kritisch beurteilt: „Die Form des hier gegebenen Berichts erinnert in ihrem hilflosen Stil mit der Anhäufung von Partizipien und dem Versuch, möglichst viel in einem Satz zu sagen und die reine Handlung möglichst genau zu verfolgen, an schlechte Zeitungsartikel.“ (ebd., S. 117) Vgl. hingegen die Überlegungen zu Handkes „retelling of Kafka’s novel“ als „counter-version“ bei Frank Pilipp: In Defense of Kafka: The Case of Peter Handke. In: The Legacy of Kafka in Contemporary Austrian Literature. Hg. v. F. P. Riverside: Ariadne Press 1997, S. 117-149, hier S. 123f., sowie Reinhard Urbach: Die Rezeption Franz Kafkas durch die jüngste österreichische Literatur. In: Franz Kafka. Eine Aufsatzsammlung nach einem Symposium in Philadelphia. Hg. u. eingel. v. Maria Luise Caputo-Mayr. Berlin, Darmstadt: Agora 1978, S. 183-193, hier S. 187: „Es ist eine Nacherzählung auf 18 Seiten, keine Inhaltsangabe. Dieser Unterschied ist zu beachten. [...] Handkes Nacherzählung ist keine Kritik des Romans, keine Parodie des Stils, sondern: er nimmt Kafkas Roman zum Anlaß für eine neue Geschichte; eine Geschichte, die nicht mehr erzählt wird, sondern berichtet." 
Unseld, „ich habe es fast in einem Anlauf durchgelesen, war stellenweise ziemlich wütend, ärgerlich, aber schließlich doch fast ,erschlagen'. Das ist doch ein

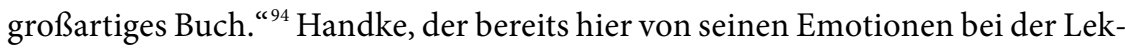
türe des Romans ausgeht („wütend“, „ärgerlich“), beschloss in der Folge, seine Eindrücke ausführlicher festzuhalten und seine Wertschätzung für Bernhards Buch auch öffentlich zum Ausdruck zu bringen. Im September schickte er den offenbar recht kurzfristig entworfenen Text an Alfred Kolleritsch zum Abdruck in den manuskripten. Er habe, so Handke, „[g]estern [...] eine Geschichte [!] über Thomas Bernhards ,Verstörung' geschrieben“:

Du kannst es als eine Art Besprechung machen, obwohl ich gerade den Typ der Besprechung vermeiden wollte, sondern eine Geschichte schreiben, wie ich ein Buch gelesen habe. Ich finde das Buch übrigens ganz außerordentlich, auch wunderbar enervierend. So oder so gehört es in einer österreichischen Literaturzeitschrift erwähnt. ${ }^{95}$

Handke, der sich „fasziniert von der Denk-, vor allem aber von der Sprachwelt des Fürsten Saurau“ zeigt, ${ }^{96}$ beschreibt die Lektüre von Bernhards Roman als „Abenteuergeschichte[ ]“ ${ }^{\text {"97 }}$ des Lesens. Diese beginnt mit der Ankunft des Erzählers auf dem Hauptbahnhof in Hannover; weil er den Bekannten, den er besuchen möchte, telefonisch nicht erreichen kann, nimmt er im Bahnhofscafé Platz: „Ich bestellte etwas zu trinken und las ein wenig in der Zeitung. Ich war recht müde, aber das Buch ließ mir keine Ruhe. ${ }^{\text {"98 }}$ Der Text bietet im weiteren

94 Handke an Unseld, 23.5.1967. In: Handke/Unseld: Der Briefwechsel (Anm. 1), S. 73. Unseld antwortete darauf überraschend ambivalent: „Ich freue mich, daß Sie Bernhards Buch letztlich doch zustimmen können; es ist ja ein Buch, das eher durch seine Schwächen als durch seine Vorzüge fasziniert." (6.6.1967; ebd., S. 75)

95 Peter Handke an Alfred Kolleritsch, 22. 9. 1967. In: P. H./A. K.: Schönheit ist die erste Bürgerpflicht. Briefwechsel. Salzburg, Wien: Jung und Jung 2008, S. 18 f. Vgl. den Erstdruck in Peter Handke: Als ich Verstörung von Thomas Bernhard las. In: manuskripte (1967), H. 21, S. 14-15.

96 Manfred Mittermayer: Thomas Bernhard. Eine Biografie. Salzburg, Wien: Residenz 2015, S. 180.

97 Wagner: Handke als Leser (Anm. 79), S. 146. - Vgl. Hans Höller: Wie die Form der Sprache das Denken des Lesens ermöglicht. Der analytische Charakter von Bernhards Sprache. In: Rhetorik und Sprachkunst bei Thomas Bernhard. Hg. v. Joachim Knape u. Olaf Kramer. Würzburg: Königshausen \& Neumann 2011, S. 81-90, hier S. 81: „Handke hat seine Lektüre von Bernhards Verstörung als ein Abenteuer beschrieben." Peter Hamm zufolge handelte es sich bei Handkes Lektürebericht um „[e]ine ganz wunderbare Rezension“, „die selber ein Stück Literatur war“ (Peter Hamm: „Ich verdanke Ihnen das schönste Hotel meines Lebens“. In: Was reden die Leute. 58 Begegnungen mit Thomas Bernhard. Aufgezeichnet v. Sepp Dreissinger. Salzburg, Wien: Müry Salzmann 2011, S. 14-21, hier S. 19).

98 Peter Handke: Als ich Verstörung von Thomas Bernhard las. [1967] In: P. H.: Ich bin ein Bewohner des Elfenbeinturms (Anm. 6), S. 211-216, hier S. 211. 
Verlauf tatsächlich, wie Handke Kolleritsch in Aussicht stellt, die „Geschichte“ der Lektüre eines Buches: Nach dem ersten Abschnitt, der die Ankunft des Autor-Lesers in Hannover schildert, und einem knappen Hinweis auf die Lektüresituation in der Mitte des Textes - „ich las, wie der Fürst die eigenen Satzmodelle immerfort umkehrte, wie er, sprechend, die Auflösung aller Begriffe möglich machte ${ }^{\text {“99 }}$ - schließt der letzte Absatz den narrativen Rahmen, wobei die Fiktion des Romans und die Lektüre des Erzählers zusehends miteinander verschränkt werden:

Ich war inzwischen aus dem Bahnhofscafé weggegangen und hatte noch einmal angerufen. Wieder meldete sich niemand. Beim Sprechen, sagte der Fürst, könne er wenigstens mißverstanden werden. Es war recht dunkel geworden. Ich ging in einen Park in der Nähe der Hannoverschen Oper und las dort beim Laternenschein weiter. Der Fürst konnte die beiden nicht ins Haus führen, weil alles in Unordnung war. Ich war dann aufgestanden und hatte in einer Gaststätte, zur Musik eines Stehgeigers, weitergelesen. Ich hatte noch einige Male angerufen. Ich hatte etwas getrunken und weitergelesen. Der Fürst war ganz gegen die Wirklichkeit konstruiert. Er erfror von innen heraus. Ich las und las und las ... ${ }^{100}$

Hans Höller hat darauf hingewiesen, ${ }^{101}$ dass der später vom Verlag für die Bewerbung des Romans verwendete letzte Satz von Handkes Rezension auf die Schlusssequenz von Bernhards 1966 in den protokollen, ein Jahr darauf in der Sammlung Prosa veröffentlichter Erzählung Die Mütze anspielt:

Und ich dachte, während ich schrieb, die ganze Zeit immer nur, daß ich mir, wenn ich damit fertig bin, etwas kochen werde, etwas essen, dachte ich, endlich wieder einmal etwas Warmes essen, und ich setzte, weil mir während des Schreibens so kalt geworden war, auf einmal die Mütze auf. Alle haben sie eine solche Mütze auf, dachte ich, alle, während ich schrieb und schrieb und schrieb ... (TBW 14, 34) ${ }^{102}$

99 Ebd., S. 213 (Herv. H. G.).

100 Ebd., S. 216.

101 Höller: Wie die Form der Sprache das Denken des Lesens ermöglicht (Anm. 97), S. 81-83. Handke hat die Formel auch in anderem Zusammenhang als Bild eines intensiven, in sich versunkenen Lesens gebraucht, und zwar in einem Brief an seinen ehemaligen Lehrer Reinhard Musar, in dem er ein Erlebnis aus der Schulzeit beschreibt; „so daß ich dort etwa Charles Dickens las, und las, und las (ein ,wirkliches Lesen' ist doch etwas anderes als ein ,wirklicher Hofrat', auch viel seltener, leider; natürlich auch fruchtbarer)“ (Peter Handke an Reinhard Musar, 1995. In: „Was ich schreibe, ist ja nur meine geformte Existenz" [Anm. 62], S. 31).

102 Dass am Ende von Die Mütze „der Beginn des Schreibaktes der Erzählung selbst beschrieben“ wird, hat Tim Reuter: „Vaterland, Unsinn“. Thomas Bernhards (ent-)nationalisierte Genieästhetik zwischen Österreich-Gebundenheit und Österreich-Entbundenheit. 
Gleichzeitig ist Handkes Lektürebericht eng mit dem Text der Verstörung selbst verwoben; er entwirft keine Perspektive außerhalb des ,besprochenen' Romans, um dessen literarische Machart zu beschreiben, sondern er vollzieht dessen erzählerische Struktur bis ins Detail des Wortbestandes nach: Wenn Handke etwa im vorletzten Satz vom inneren Erfrieren des Fürsten schreibt, nimmt er dabei eine im Roman selbst gebrauchte Formel auf: „Ich erfriere von innen heraus.“ (TBW 2, 161) ${ }^{103}$ Auch die von Handke verwendete Bezeichnung Sauraus als „ganz gegen die Wirklichkeit konstruiert[e]" Figur findet sich bereits in Bernhards Text, wobei es sich dort um eine Selbstcharakterisierung des zusehends dem Wahnsinn anheimfallenden Fürsten handelt: „Ich bin ganz gegen die Wirklichkeit konstruiert" (TBW 2, 178).

Neben jenen Passagen, die konkret dem Akt der Lektüre von Bernhards Verstörung gewidmet sind, besteht Handkes Aufsatz zu großen Teilen aus der Nacherzählung des Romans bzw. aus dem Nachvollzug der Handlung (des Besuchs eines Arztes und seines Sohns bei dem zurückgezogen auf der Burg Hochgobernitz lebenden Fürsten Saurau) im Sinne eines detaillierten Lektüreprotokolls: ${ }^{104}$

Als die beiden auf der Burg ankamen, ging der Blick tatsächlich Hunderte von Kilometern weit. / Sie sahen den Fürsten auf der äußeren Burgmauer, sie trafen ihn auf der inneren. Er begrüßte sie, ohne stehenzubleiben. Sie schlossen sich ihm an. Er setzte sein Selbstgespräch, das er schon den ganzen Tag lang führte, sogleich mit ihnen fort. Dem Fürsten war es in jedem Augenblick natürlich, daß die Welt auseinanderbricht. Er redete immer von sich selber wie von der ganzen Welt und von der ganzen Welt wie von sich selber. Der Vater hatte dem Studenten schon gesagt, der Fürst sei total wahnsinnig, auch die Müllersburschen unten hatten erzählt, daß der Fürst Unglaubliches rede. ${ }^{105}$

Würzburg: Königshausen \& Neumann 2013, S. 258, als in Bernhards CEuvre wiederkehrendes Strukturmuster des Zirkulären beschrieben; Handke greift dieses Muster in seinem Text in Ansätzen auf.

103 Eine ähnliche Stelle findet sich bereits in Bernhards erstem Prosabuch Frost (1963): „Es sei ja nicht kalt“, rekapituliert dort der Famulant eine Aussage des Malers Strauch, „im Gegenteil, aber: ,der Föhn, wissen Sie. Innerlich, verstehen Sie, habe ich gefroren. Man friert innerlich.“ (TBW 1, 25)

104 Vgl. dazu Karl Wagner: „Er war sicher der Begabteste von uns allen“. Bernhard, Handke und die österreichische Literatur. Wien: Picus 2010, S. 34: Als ich „Verstörung“von Thomas Bernhard las ,illustriert zugleich, wie Handke die Zwänge und Rituale der Gattung Buchrezension auszuhebeln trachtet, indem er mit Hilfe einer Nacherzählung eine Analyse zu geben sucht. Sein geradezu Rosegger'scher Titel indiziert eine epische Naivität, die dem Meinungs- und Urteilsterror der Besprechung ein Schnippchen schlagen will [...].“

105 Handke: Als ich Verstörung von Thomas Bernhard las (Anm. 98), S. 212. 
Obschon Handke Kolleritsch vorgeschlagen hatte, er könne den BernhardAufsatz „als eine Art Besprechung“ drucken, zeigt sich deutlich, dass er die Anforderungen an das Genre der Rezension - „de[n] Typ der Besprechung“ hier demonstrativ nicht zu erfüllen gewillt ist, unterlässt er doch bewusst jegliche Wertung, jeden expliziten Hinweis darauf, ob er das Buch für, gut' oder ,schlecht' befinde. Er konzentriert sich vielmehr auf die Schilderung der Erfahrungen bei dessen Lektüre. Wenn Handke zwei Jahre später in einem Aufsatz zu Gert Jonkes Geometrischem Heimatroman im Spiegel hervorhebt, „[d]as Buch“, das er „gerade gelesen habe“, sei „kein sehr gutes Buch, auch kein wertvolles Buch [...] - aber man kann so viele Erfahrungen damit machen, daß man Lust hat, die Erfahrungen zu beschreiben", ${ }^{106}$ ist damit auch die Idee von Handkes Bernhard-Text (sowie zahlreicher weiterer literaturkritischer Arbeiten des Autors) treffend charakterisiert. Sein Aufsatz ist - in Abwandlung eines bereits zitierten Handke-Titels - nicht nur eine Einladung, Thomas Bernhard zu lesen, sondern auch und im Besonderen eine Ermunterung, sich dem Lesen, das es dem Einzelnen ermögliche, „genauer und sensibler existieren [zu] können ", 107 anzuvertrauen.

Handke hebt in Als ich „Verstörung“ von Thomas Bernhard las bestimmte Charakteristika des Romans hervor, um zu zeigen, warum ihm das Buch „keine Ruhe “108 gelassen habe; „der Blick auf die sprachliche Konstruktion“ und die „emphatische Beteiligung des lesenden Ich“ gehen dabei, so Hans Höller, eine für Handkes Schreiben über Literatur signifikante Verbindung ein. ${ }^{109}$ Die entscheidende Qualität des Romans liegt für Handke indes weniger in Bernhards inhaltlicher Radikalität - mit der Ingeborg Bachmann das „Neue“ in dessen Literatur assoziiert hatte ${ }^{110}$ - oder im misanthropischen Pessimismus des Protagonisten, vielmehr in der grammatikalischen Form seiner Sätze. Sie verweisen als "Zeichen seiner Verstörung “"111 auf eine umfassende existentielle Beunruhigung,

106 Peter Handke: In Sätzen steckt Obrigkeit. Über G. F. Jonke: Geometrischer Heimatroman. In: Der Spiegel, Nr. 17, 21. 4. 1969, S. 186-188, hier S. 186; dazu u. a. Lorenz: Pro domo (Anm. 7), S. 409. Ganz in diesem Sinne hatte Handke bereits in seiner ersten gedruckten Rezension, der 1965 in Wort in der Zeit veröffentlichten Besprechung eines Buches von Ror Wolf, begonnen: „,Zwischen Suppe und Mund kann sich vieles ereignen. ' Es ereignet sich in dem Buch so vieles zwischen Suppe und Mund, daß daraus ein Ereignis wird“ (Handke: Ror Wolf [Anm. 4], S. 59).

107 Handke: Ich bin ein Bewohner des Elfenbeinturms (Anm. 9), S. 26.

108 Handke: Als ich Verstörung von Thomas Bernhard las (Anm. 98), S. 211.

109 Höller: Wie die Form der Sprache das Denken des Lesens ermöglicht (Anm. 97), S. 82 f.

110 Ingeborg Bachmann: Watten und andere Prosa (über Thomas Bernhard). In: I. B.: Kritische Schriften. Hg. v. Monika Albrecht u. Dirk Göttsche. München, Zürich: Piper 2005, S. 453-457, hier S. 455.

111 Handke: Als ich Verstörung von Thomas Bernhard las (Anm. 98), S. 214. 
die nicht nur das Verhältnis des Individuums zur Welt, sondern im Besonderen das Problem der sprachlichen Vermittlung dieses Verhältnisses betrifft: „Was er von der Außenwelt erwähnte, war nur ein Zeichen seiner Innenwelt. Der Fürst sprach nicht in Metaphern, sondern in Zeichen. ${ }^{\text {"112 }}$

Wenn Handke die „Empfindlichkeitswörter" und „Qualwörter “"113 des Fürsten hervorhebt - man ist unwillkürlich an Handkes Gedicht Die Reizwörter erinnert, das ebenso 1967 entstand $^{114}$ - und von Sauraus "grammatikalische[m] Irrsinn“ berichtet, der ihn, „wie es bei Schizophrenen üblich ist“, „neue Wörter“ bilden lasse, ${ }^{115}$ zeigt sich außerdem Folgendes: Handke schenkt hier jenen Aspekten von sprachlicher Repräsentation besondere Aufmerksamkeit, die auch im Zentrum seiner eigenen literarischen Arbeiten dieser Jahre stehen - etwa der Erzählung Die Angst des Tormanns beim Elfmeter, an der er Mitte $1968 \mathrm{zu}$ arbeiten beginnt und die 1970 erscheinen wird. Wenn Bernhards Saurau „ganz gegen die Wirklichkeit konstruiert ist " ${ }^{116}$ dann interessiert sich Handke gar nicht primär für das Verhältnis von Realität und Fiktion, dafür, ob es eine Figur wie den Fürsten, in Wirklichkeit' gibt oder geben könnte. Vielmehr stellt er das Moment der literarischen Konstruktion sowie die „Logik der grammatikalischen Modelle“ ${ }^{“ 117}$ in den Mittelpunkt. Erst durch die Irritation, die die sprachliche Form des Romans im Allgemeinen und des „paranoischen Monologs ${ }^{\text {“118 }}$ des Fürsten Saurau im Besonderen auslöse, sei es möglich, den aufmerksamen Leserinnen und Lesern neue Erfahrungen zu vermitteln.

112 Ebd., S. 213.

113 Ebd., S. 212.

114 Vgl. Peter Handke: Die Reizwörter. [1967] In: P. H.: Die Innenwelt der Außenwelt der Innenwelt. Frankfurt a. M.: Suhrkamp 1969, S. 87-91, hier S. 90: „mein Reizwort ist / jedes Wort / jedes Wort / ist ein Reizwort“. - Bereits zuvor gedruckt in: manuskripte 8 (1968), H. 22, S. 16-17; Egoist 4 (1968), H. 1, S. 13-14.

115 Handke: Als ich Verstörung von Thomas Bernhard las (Anm. 98), S. 214.

116 Ebd., S. 216 (Herv. H. G.).

117 Ebd., S. 213.

118 W. G. Sebald: Wo die Dunkelheit den Strick zuzieht. Zu Thomas Bernhard. In: W. G. S.: Die Beschreibung des Unglücks. Zur österreichischen Literatur von Stifter bis Handke. Salzburg, Wien: Residenz 1985, S. 103-114, hier S. 105. Dass sich nicht nur Handke, sondern auch Bernhard in der zweiten Hälfte der 196oer Jahre mit Diskursen der Psychopathologie beschäftigte, zeigt ein Brief an Anneliese Botond vom 19.4.1966, in dem Bernhard auf Leo Navratils kurz zuvor erschienene Studie Schizophrenie und Sprache rekurriert (vgl. Anneliese Botond: Briefe an Thomas Bernhard. Mit unbekannten Briefen von Thomas Bernhard. 1963-1971. Hg. v. Raimund Fellinger. Mattighofen: Korrektur 2018, S. 89). Zu Handkes Rezeption der Psychopathologie vgl. Norbert Christian Wolf: „Die beginnende Schizophrenie“ eines Tormanns. Handkes Erzählung und die Pathographien aus Klaus Conrads Gestaltanalyse des Wahns. In: Schreiben als Weltentdeckung (Anm. 29), S. 165-200. 
„Jede Geschichte von Thomas Bernhard sei“, zitiert Handke im Vorwort zum Band Der gewöhnliche Schrecken (1969) eine eigene Äußerung, „eine Schreckensgeschichte, eine Horror-Geschichte, die aber den Schrecken nicht zu etwas Besonderem, etwas literarisch Genießbarem verniedliche, sondern von ihm als von etwas Gewöhnlichem, Alltäglichem rede. ${ }^{\text {"119 }}$ Handkes Respekt vor dem Nicht-Genießbaren von Bernhards Poetik - er sollte später in das genaue Gegenteil und den Vorwurf allzu großer Bekömmlichkeit umschlagen ${ }^{120}$ - gründet hier ganz wesentlich auf der Wertschätzung eines literarischen Verfahrens: Als Resultat der von Handke beschriebenen literarischen Konstruktionsleistung entstehen Texte, die dem Leser eine neue Form der Erschließung der Welt ermöglichen, wobei, mit John Cages berühmter Lecture on nothing gesprochen, die Struktur des Sprechens und Schreibens nicht nur intellektuell erfassbar, sondern auch emotional erlebbar wird: „Sie haben soeben“, heißt es in Ernst Jandls Cage-Übersetzung, „die Struktur dieses Vortrags erlebt. “121

Erneut korrespondiert hier Handkes literarische Ambition mit den Kriterien seines literaturkritischen Schreibens, wie ein Beispiel aus unmittelbarer zeitlicher Nähe verdeutlichen soll: Wenn er in einer poetologischen Skizze zum Roman Der Hausierer, der wie Bernhards Verstörung 1967 erschien, angibt, er habe die „schemata des schreckens“ im Kriminalroman „wieder erlebbar“ machen wollen, ${ }^{122}$ sind die Parallelen zwischen Handkes Anspruch an seine eigenen Arbeiten und seinen Forderungen an die Texte anderer evident: Hier wie dort geht es nicht nur darum, erzählerische Automatismen und literarische Klischees als „darstellungsschema[ta]“ zu entlarven, sondern auch darum, die „erlebnisschema[ta]“123 bei der Lektüre zu subvertieren, zu unterlaufen und damit sichtbar zu machen.

119 Peter Handke: [Vorwort]. In: Der gewöhnliche Schrecken. Horrorgeschichten. Hg. v. P. H. Salzburg: Residenz 1969, S. [5]. Das Buch enthält u. a. Bernhards Erzählung Midland in Stilfs, die 1971 im gleichnamigen Erzählband erneut abgedruckt wurde, zudem Texte von Peter Bichsel, Elfriede Jelinek, Friederike Mayröcker und zahlreichen weiteren Autorinnen und Autoren.

120 Vgl. etwa Peter Handke: Aber ich lebe nur von den Zwischenräumen. Ein Gespräch, geführt von Herbert Gamper. Zürich: Ammann 1987, S. 93: „Ich möchte jetzt nicht gegen Thomas Bernhard herziehen, aber wenn man liest, wie er seine Suggestionssuade herstellt: da ist überhaupt kein Problem mehr von Erzählen, kein Problem des Gegenstands mehr, vor allem kein Problem eines Übergangs mehr - weder zwischen den Räumen, zwischen einem Raum und dem anderen, noch zwischen den Zeiten, noch zwischen Personen -, weil alles ein rhetorischer Fertigbau ist."

121 John Cage: Silence. Aus dem Amerikanischen v. Ernst Jandl. Frankfurt a. M.: Suhrkamp 1987, S. 12.

122 Peter Handke: Über meinen neuen Roman Der Hausierer. In: Dichten und Trachten 29 (1967), S. 27-29, hier S. 28.

123 Ebd. (Herv. im Orig.). 


\section{„Kritik, die zugleich eine Form der Begeisterung ist": Helmut Färber}

Als Ideal und Vorbild eines Rezensenten gilt Handke bis heute der Filmkritiker Helmut Färber, Jahrgang 1937, den der junge Autor Mitte der 1960er Jahre als versierten Kino-Enthusiasten und subtilen Kommentator kennen und schätzen gelernt hatte: „Helmut Färber, mit seinen Filmkritiken in der Süddeutschen Zeitung und der filmkritik, hat mich, lang ist's her, auf die Sprünge gebracht, Dinge, die einem durch und durch gegangen sind, ,Herzenssachen', statt sie zu analysieren, einfach, oder auch nicht einfach, zu erzählen. ${ }^{“ 124}$ In Färbers Artikeln zum zeitgenössischen Film sah Handke die Idee verwirklicht, wonach die Kritik eines Kunstwerks sich nicht in souveränen Gesten der Wertung und in kulturhistorischen Vergleichen erschöpft, sondern dem Moment des Erlebens von Kunst in möglichst jargonfreiem Duktus - eine zentrale Bedeutung beimisst. 1994 hat Handke sich in seiner Laudatio zur Verleihung des Petrarca-Preises an Färber an den Beginn seiner Faszination für dessen Arbeiten erinnert:

Wer ist Helmut Färber? Beim Lesen bin ich ihm zuerst begegnet als einem Filmkritiker, Mitte der sechziger Jahre [...]. Zu Filmen, gleich welchen, eine solch feine und zugleich bodenständige Sprache zu Gesicht zu bekommen, und das auch noch in einer Tageszeitung, das hat mich damals wachgestoßen, fürs Filmeanschauen, aber auch für das Tun und Schreiben, und ich weiß es, nicht nur mich. ${ }^{125}$

Im Bericht des Kritikers anlässlich eines „Science-Fiction-Filmfestival[s] in Triest“ sei, so Handke, der in extenso aus den Arbeiten Färbers zitiert, „kein einziger Film“ vorgekommen, „dafür der Mond über der Leinwand und vor allem, ausführlich beschrieben, ein Schaufenster in der Triester Innenstadt mit phantastischen Weltraumfiguren, geknetet, händisch, aus Marzipan, samt Nachtbeleuchtung. ${ }^{“ 126}$ Es sind die scheinbaren Nebensächlichkeiten und Begleitumstände der Kunstwahrnehmung, die in Färbers Kritiken wie in Handkes literarischer Poetik (und Literaturkritik) eine wichtige Rolle einnehmen; ihre unprätentiöse Würdigung trägt, wie man seinen Bemerkungen entnehmen kann,

124 Handke: Eine Ideal-Konkurrenz (Anm. 84), S. 152. Zu Handkes Wertschätzung für Färber vgl. Struck: Der Begleitschreiber (Anm. 65), S. 14 f. Im Literaturarchiv Salzburg werden Hefte der Zeitschrift filmkritik aus den 196oer Jahren aufbewahrt, in denen Peter Handke Texte Färbers handschriftlich annotiert hat. Vgl. etwa Peter Handke: Handschriftliche Annotationen zu Helmut Färber: Die Verachtung. La Mépris. In: Filmkritik (1965), H. 3, S. 141-143, hier S. 142. In: Literaturarchiv Salzburg, Bestand: Peter Handke, Sammlung Helmut Färber: „H. F. geht ein auf die Art des anderen (wenn der eine hat)“.

125 Peter Handke: Wie ein Letzter ein Erster; Lob eines „Kritikers“. Zu Helmut Färber. [1994] In: P. H.: Mündliches und Schriftliches (Anm. 47), S. 39-65, hier S. 40.

126 Ebd., S. 43. 
ganz wesentlich zu Handkes Sympathie für die Texte Färbers bei. Dementsprechend habe sich, so Handke weiter, auch Färbers Beschäftigung mit Büchern durch „eine ganze neue, ein Beispiel gebende Art“ ausgezeichnet. ${ }^{127}$ Sie stellte für den jungen, aufstrebenden Autor ein Vorbild dar, das sein eigenes „Tun und Schreiben“"128 nachhaltig geprägt hat.

Während er in seiner - zunächst in den Grazer manuskripten gedruckten Laudatio von 1994 anderen Filmkritikern gegenüber den Vorwurf erhebt, als „Öffentlichkeitsagenten“ mit „lieblose[m] Scharfsinn“ zu agieren, weil ihnen „die eigene Intelligenz so viel mehr gilt als die Gedanklichkeit oder die Denkhaltung " 129 sei Färber hiervon eine wohltuende Ausnahme:

Sein Scharfsinn ist insbesondere einer, der aus dem Enthusiasmus kommt: Hand in Hand mit diesem zeitigt er im Schreiben die so spezifisch Färber'sche Melodie, die Bildlichkeit, die Gegenständlichkeit. Helmut Färber ist ein märchenhafter Filmkritiker und Satz für Satz auch noch etwas anderes. ${ }^{130}$

In seiner Idee, dass „Kritik“ „zugleich eine Form der Begeisterung“ sein könne, ja müsse, wie er noch 2015 in einem langen Essay über Dragan Aleksić, Xaver Bayer und Dag Solstad formuliert, ${ }^{131}$ sah Handke sich bereits am Beginn seiner schriftstellerischen Laufbahn durch die Texte Färbers bestärkt. Dessen Haltung, sich einem Kunstwerk „gewissermaßen geleitschützerisch“ und mit „barmherzi-

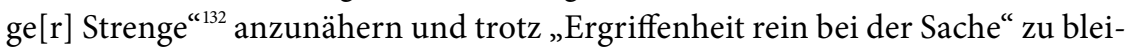
ben, ${ }^{133}$ fungierte für den jungen Rezensenten Handke, der partout kein ,Kritiker sein wollte - bezeichnenderweise setzt Handke den Begriff auch in der gedruckten Laudatio auf Färber in Anführungszeichen -, als Leit- und Vorbild für sein

127 Ebd.

128 Ebd., S. 40.

129 Ebd., S. 45. - Vgl. zu diesen Vorwürfen auch den folgenden, 1986 in der Neuen Zürcher Zeitung erschienenen Essay von Hans Magnus Enzensberger: Rezensentendämmerung. [1986] In: H. M. E.: Mittelmaß und Wahn. Gesammelte Zerstreuungen. Frankfurt a. M.: Suhrkamp 1988, S. 53-60; während Handke in seiner Rede vom „Öffentlichkeitsagenten“ spricht, hat Enzensberger den Typus des „Zirkulationsagenten“ (ebd., S. 56) als Zerrbild des Kritikers skizziert.

130 Handke: Wie ein Letzter ein Erster (Anm. 125), S. 46. Als „Märchen“ hatte Handke im Jahr der Färber-Laudatio auch Mein Jahr in der Niemandsbucht ausgewiesen. Gerade solche Affinitäten im Detail, solche Korrespondenzen zwischen der poetologischen Selbstbeschreibung und der Würdigung von Texten und Verfahren anderer Autoren erweisen sich als elementarer Teil von Handkes vernetzender Werkpolitik.

131 Handke: Drei Zitterer an der homerischen Quelle (Anm. 69), S. 167; in weiterer Folge des Textes deutet Handke freilich wiederum eine „Kritik der begeisterten Kritik“ (ebd., S. 176) an. Zu diesem Text Handkes vgl. auch Struck: Der Begleitschreiber (Anm. 65), S. 23.

132 Handke: Wie ein Letzter ein Erster (Anm. 125), S. 47.

133 Ebd., S. 48. 
Vorhaben, „das Lesen, wie auch immer, weiterzugeben“ ${ }^{134}$ In diesem Sinne hat Handke auch in einer Rede auf seinen langjährigen Freund Alfred Kolleritsch 1978 den Enthusiasmus der Kunstbetrachtung und die kritische, analytische, aufmerksame Würdigung nicht als Gegensätze, sondern nachgerade als einander bedingende Aspekte beschrieben, wobei der Laudator den Ausgezeichneten direkt anspricht: „Die Begeisterung über deine Gedichte schließt nicht die Analyse aus, macht vielmehr erst die Lust zu derselben. “135

Ende der 1960er Jahre war Handke gewillt, diese Haltung der Kunstrezeption und Kunstvermittlung auch in einer eigenen publizistischen Unternehmung zu erproben - einem Zeitschriftenprojekt, dessen Realisierung am Ende allerdings scheitern sollte. Die Dokumente, die aus der Zeit der Konzeption vorliegen, bieten gleichwohl einen aufschlussreichen Einblick in Handkes Überlegungen zur Neuinterpretation der Gattung ,Literatur- und Filmkritik'. Anfang 1969 diskutierte Siegfried Unseld - nicht zuletzt, weil sich die Trennung des Enzensberger'schen Kursbuchs vom Suhrkamp Verlag abzeichnete ${ }^{136}$ - mit verschiedenen Autoren Möglichkeiten eines neuen Periodikums. Am 20. Januar ließ Handke dem Verleger, basierend auf einem Gespräch mit Jürgen Becker, Peter Bichsel, Max Frisch und Martin Walser, einige „Vorschläge“ für das „Projekt der Zeitschrift “137 zukommen. Frisch, der seit den Erfolgen von Stiller (1954), Homo faber (1957) oder Andorra (1961) zu den prominentesten Autoren des Verlags gehörte und auf dessen Einschätzungen Unseld großen Wert legte, hat die Stimmung dieses Gesprächs in einer kurzen Notiz festgehalten, in der er Handkes Habitus dieser Zeit - „nicht provokant, nur abseits“ - prägnant beschreibt:

Peter Handke. Er schweigt wie ein Prinz. Wie er unterdessen einen grossen Eisbecher auslöffelt, kindlich. Ohne Arroganz, wenn er sagt: Das langweilt mich. (Uebrigens langweilt es mich auch; Pläne für eine Zeitschrift.) Seine dunkle Sonnenbrille. Wenn es die Runde nicht überzeugt, was er einmal sagt, lässt er’s schläfrig. Klug wie der junge

134 Handke: Drei Zitterer an der homerischen Quelle (Anm. 69), S. 166.

135 Peter Handke: Der tiefe Atem (Rede zur Petrarca-Preis-Verleihung über den Gedichtband Einübung in das Vermeidbare). [1978] In: P. H.: Das Ende des Flanierens (Anm. 48), S. 137-144, hier S. 137. Dem gemeinsamen Verleger Wolfgang Schaffler hatte Handke die Entscheidung der Jury, den Petrarca-Preis an Kolleritsch zu vergeben, ebenso emphatisch mitgeteilt: „Die Gedichte von Kolleritsch waren für uns alle, nachdem wir alles andere schon mit Griesgrämigkeit und Müdigkeit hatten passieren lassen, ein Ereignis, und wir waren fast selig danach. Das hat die Poesie gemacht.“ (Peter Handke an Wolfgang Schaffler, 5. 4. 1978. In: Süddeutsche Zeitung, 5.7.2003)

136 Vgl. Henning Marmulla: Enzensbergers Kursbuch. Eine Zeitschrift um 68. Berlin: Matthes \& Seitz 2011, S. 199-217.

137 Handke an Unseld, 20.1.1969. In: Handke/Unseld: Der Briefwechsel (Anm. 1), S. 102. Zur Liste der Gesprächsteilnehmer vgl. auch Unseld an Handke, 9. 1. 1969. In: ebd., S. 101. 
Alexander. Nur in der ersten Minute sieht er wie ein Mädchen aus; das Haar. Jürgen Becker, nur wenig älter, begründet noch, warum er nicht daran glaubt. Aussage-Sätze. Später kommt Martin Walser dazu: also Eloquenz, Charme, Temperament, ein Streiter, dadurch altväterlich. Wie Handke während der Besprechung dasitzt: nicht provokant, nur abseits, sleep in, er sässe lieber im Kino, Meinungen schläfern ihn ein ... ${ }^{138}$

Im Gegensatz zu den Ende der 1960er Jahre proliferierenden literatur- und gesellschaftstheoretischen Positionen, für die das Kursbuch oder konkret prominente Beispiele darstellten, sollte das neue Medium, wie Handke in seinem Brief an Unseld vermerkt, einer „subjektivistische[n] Theorie“ verpflichtet sein. Das bedeute für ihn nicht zuletzt den Verzicht auf die Gattung „übliche[r]“ Rezensionen; „vielmehr“ sollten „Literatur und Film als Reiz“ fungieren, „von seinen eigenen Erfahrungen zu schreiben. Eine Theorie, die zugleich die Praxis zeigt, und auch Praxis ist. “139 Ausdrücklich betont Handke dabei seine Forderung, „[d] as Schreiben über etwas“ nicht von der „Literatur“ selbst zu unterscheiden: „Ebenso könnte das Berichten über Film selbst eine Art Film sein, oder ein Fotoroman, eine Fotogeschichte, oder einfach eine gezielte Reproduktion von Bildern aus dem Film, die Einstellungen deutlich machen. Dasselbe Verfahren mit Literatur. “ ${ }^{140}$

Die von Handke skizzierten Überlegungen haben eine Neudefinition dessen, was literatur- und filmkritisches Schreiben sein kann und soll, im Blick, wobei die gesamte Anmutung und Layoutierung der geplanten Zeitschrift, für die es bislang kein „[p] ositives Beispiel“ im Sinne eines Vorbilds gebe, dieser Neuausrichtung entsprechen müsse: „Das wichtigste für mich wäre, daß auch die Anordnung der Beiträge selbst Literatur oder ästhetische Methode ist, weit über das übliche Layout hinaus. Aufmachung und Inhalt dürften nicht mehr getrennt sein!!“141 Das Postulat einer Aufhebung der Grenzen zwischen den

138 Max Frisch/Uwe Johnson: Der Briefwechsel 1964-1983. Hg. v. Eberhard Falcke. Frankfurt a. M.: Suhrkamp 1999, S. 336 f. Die Notiz wurde nicht in das Tagebuch 1966-1971 übernommen, sondern erst postum im Anhang der Briefausgabe veröffentlicht.

139 Handke an Unseld, 20.1. 1969. In: Handke/Unseld: Der Briefwechsel (Anm. 1), S. 102 f. (Herv. H. G.). Interessanterweise hatte Handke eine solche „Synthese der Theorie mit der Praxis“ bereits im Januar 1966 dem Prosaband Zoo oder Briefe nicht über die Liebe des von ihm geschätzten Viktor Šklovskij attestiert (Peter Handke: „Bücherecke“ vom 17. 1. 1966. In: P. H.: Tage und Werke [Anm. 3], S. 258-265, hier S. 264), dessen literaturästhetische Konzepte für den jungen Handke bekanntlich überaus fruchtbar und anregend waren. Die Koinzidenz verweist ein weiteres Mal auf die enge Verzahnung literarischer, poetologischer, kritischer und publizistischer Konzepte und Strategien in Handkes Werkpolitik.

140 Handke an Unseld, 20.1. 1969. In: Handke/Unseld: Der Briefwechsel (Anm. 1), S. 103.

141 Ebd., S. 104. Vgl. ebd., S. 103: „Die Aufmachung wäre keine Aufmachung, sondern gehörte zum Inhalt der Zeitschrift, wäre selber Literatur, oder Ästhetik. Deswegen würde ein üblicher Lay-outer [sic] nicht genügen. Die Anordnung der Arbeit ist Ästhetik.“ 
Gattungen und Kunstsparten, zwischen Theorie und Praxis, zwischen Kunst und Lebenswelt, zwischen Inhalt und Form, das durch doppelte Ausrufungszeichen bekräftigt wird, verweist in diesem für die Ästhetik des frühen Handke überaus aufschlussreichen Dokument nicht zuletzt auf Forderungen und Positionen der historischen Avantgarden.

Im ersten ausführlichen Brief Handkes an Unseld, der das Projekt einer neuen Zeitschrift umreißt, werden Journalisten wie Ernst Wendt, Urs Jenny und Uwe Nettelbeck sowie der zu dieser Zeit noch für Theater heute tätige, erst 24-jährige Botho Strauß als mögliche Mitarbeiter genannt; der Name Helmut Färber fällt einstweilen noch nicht. In den folgenden Wochen und Monaten wurden unter intensiver Beteiligung Handkes Möglichkeiten „eine[r] andere[n] Art des Artikelschreibens ${ }^{\text {"142 }}$ reflektiert, potentielle Beiträger angefragt und in den Diskussionsprozess einbezogen. Auch an Färber wandte Handke sich nun mit der Frage, ob er "grundsätzlich Lust“ habe, „Sachen, Filme, die Sie reizen, in einer möglich [sic] nicht genormten Form, nicht in der üblichen Kritikform zu beschreiben. Ich schreibe Ihnen deswegen, weil ich von Ihrer Art, Filme ohne Normbilder von Filmen zu sehen und zu schildern, oft ziemlich beeindruckt bin. ${ }^{\text {"143 }}$ Die Vorbereitungen einer „neue[n], neuartige[n] Zeitschrift ${ }^{\text {“144 }}$ gerieten in der Folge, wohl auch aufgrund unterschiedlicher Auffassungen der Beteiligten, ${ }^{145}$ ins Stocken: „An die Zeitschrift denke ich, allerdings fühle ich mich dabei ein bißchen isoliert und mutlos“, schreibt Handke am 21. Juli 1969 an Unseld; ${ }^{146}$ und etwa zweieinhalb Monate später: „Es müßte halt jetzt einer kommen, der das Projekt wirklich heftig angeht und sonst wenig im Sinn hat, sodaß er nicht abgelenkt wird. “147 Dass das Zeitschriftenprojekt schließlich scheiterte und auch nicht in anderer Form realisiert wurde ${ }^{148}$ ist wohl auf die divergierenden Konzepte der beteiligten Akteure,

142 Handke an Unseld, 29.3.1969. In: ebd., S. 111.

143 Handke an Färber, 22.3. 1969. Zit. nach ebd., S. 113, Anm. 1 (Herv. H. G.). - Vgl. dazu Handke an Unseld, 17. 4. 1969. In: ebd., S. 117: „Wegen der Zeitschrift habe ich vier Leuten geschrieben, Urs Jenny hat noch nicht geantwortet, dafür aber außer Herrn [Herbert] Linder noch Helmut Färber und Siegfried Schober, die beide in der, Süddeutschen Zeitung ' und in der ,Filmkritik schreiben. Beide interessieren sich recht sehr für das Vorhaben." - Im Siegfried-Unseld-Archiv im DLA Marbach hat sich im Briefwechsel zwischen Jürgen Becker und dem Suhrkamp Verlag eine dreiseitige Skizze Färbers „Gegen und für eine noch nicht existierende Zeitschrift“, die auf den 31.7.1969 datiert ist, erhalten, die für die vorliegende Arbeit jedoch nicht eingesehen werden konnte.

144 Handke an Unseld, 2. 5.1969. In: Handke/Unseld: Der Briefwechsel (Anm. 1), S. 122.

145 Siehe dazu Unseld: Reisebericht München, 11.-13. Juli 1969. In: ebd., S. 123 f.

146 Handke an Unseld, 21. 7. 1969. In: ebd., S. 127.

147 Handke an Unseld, 3.10.1969. In: ebd., S. 140.

148 Vgl. dazu auch die vom ursprünglichen Plan abweichenden Überlegungen, ,eine eigene neue Zeitschrift [zu] machen [...], für Ästhetik“, in Handkes Brief an Unseld vom 19.12.1969. In: ebd., S. 157. 
aber auch auf Probleme bei der Koordination und fehlende zeitliche Ressourcen zurückzuführen, zumal Handke in diesen Monaten des Jahres 1969 intensiv mit der Arbeit an der Erzählung Die Angst des Tormanns beim Elfmeter beschäftigt war; zudem hatte er wiederholt bekundet, für die Position eines „Redakteurs“ der Zeitschrift, also für die operativen Agenden einer solchen Unternehmung, „unfähig“ zu sein und folglich nicht dafür zur Verfügung zu stehen. ${ }^{149}$

Für den gegenwärtigen Zusammenhang ist indes ein weiteres Mal Handkes Doppelstrategie in Bezug auf das Genre der Rezension von Interesse. Während er sich, wie Unseld in einem Reisebericht notiert, im Zuge der Diskussionen über die Konzeption der Zeitschrift mit „ziemlich schlimmen Urteilen“ nicht nur über „Adorno, Marcuse, Habermas“ - also drei zentrale Akteure der Suhrkamp-Intelligenzija -, sondern auch „über die Literaturkritiker“ hervortat, ${ }^{150}$ erprobte er parallel zur Feststellung diverser Defizite der zeitgenössischen Literaturkritik selbst alternative Formen der Besprechung von Büchern, Theaterstücken, Filmen und Musik. Anders als Bernhard hat Handke versucht, sein Unbehagen über die Verfahren der Literaturkritik nicht bloß resignativ zu konstatieren; vielmehr war er stets bestrebt, als Gegenentwurf Möglichkeiten eines anderen „Artikelschreibens" zu erkunden.

\section{„Haben Sie das gehört?“: Wolfgang Bauer, The Beatles, Gert Jonke}

In der Weihnachtsnummer des Kölner Stadt-Anzeigers hatte Handke Ende 1968, also kurz vor Beginn der Planungsphase der Zeitschrift, in Bezug auf das Doppelalbum The Beatles konstatiert, es sei „schwer, zu dem Album was zu sagen; es ist so schön, daß man es nur beschreiben möchte. ${ }^{\text {"151 }}$ Die Episode, in der er vom Kauf des Albums erzählt, kann als Beleg für die Beziehung gelten, die sich Ende der 196oer Jahre ganz selbstverständlich zwischen dem Style der Beatles und der posture des jungen Autors, der sich rasch den Ruf eines, Literatur-Beatles $^{{ }^{152}}$ erarbeitet hatte, herstellen ließ: „Als ich vor ungefähr einem Monat ein Plattengeschäft betrat und zu der Verkäuferin sagte: ,Raten Sie, welche Platte ich möchte', lachte die Verkäuferin und zog auch schon gleichzeitig die Platte heraus. “ ${ }^{153} \mathrm{Ob}$ die Verkäuferin den Schriftsteller Handke, der sich mit seinen

\footnotetext{
149 Handke an Herbert Linder, 29.3. 1969. Zit. nach ebd., S. 113, Anm. 1.

150 Unseld: Reisebericht München, 11.-13. Juli 1969. In: ebd., S. 124.

151 Peter Handke: John Lennon sagte: Revolutionäre sollen sich selber ändern. In: Kölner StadtAnzeiger, 24.12.1968.

152 Vgl. etwa Höller: Peter Handke (Anm. 42), S. 37-46. Zum Kontext vgl. auch Anja Pompe: Peter Handke. Pop als poetisches Prinzip. Köln u. a.: Böhlau 2009.

153 Handke: John Lennon sagte (Anm. 151).
} 
von Beatmusik unterstützten Lesungen einen Namen gemacht hatte, erkannte oder ob sie den jungen Autor nur aufgrund seines Aussehens mit der britischen Band assoziierte, geht aus Handkes Text allerdings nicht hervor. Er ist aufgrund seiner pointierten, gegen schriftstellerisches ,Engagement ' im herkömmlichen Sinn argumentierenden Interpretation von John Lennons Revolution nicht nur eine erneute Provokation gegen die politisch-ästhetischen Dogmen der 68erBewegung, ${ }^{154}$ sondern er stellt auch einen weiteren Versuch Handkes dar, das Schreiben über kulturelle Artefakte neu zu konzipieren. Die Spannung zwischen Beschreibung und Analyse ist dafür, wie schon in anderen Fällen, von konstitutiver Bedeutung.

Wenn Handke in seinem Beatles-Text, der manche Aspekte der früheren Radiofeuilletons Der Rausch durch die Beatles (1964) und Von der Schwierigkeit, einen Schlagertext zu schreiben (1965) aufgreift, ${ }^{155}$ davon schreibt, man müsse auf „die Übergänge zwischen den einzelnen Songs“ achten, ${ }^{156}$ so wird erneut Folgendes deutlich: Die konkrete Wahrnehmungssituation des Rezensenten spielt für Handkes kritisches Schreiben eine zentrale Rolle. Dabei ist die Schilderung des individuellen, subjektiven Kunst- bzw. Hörerlebnisses stets eine Aufforderung, ein Angebot an die Leserinnen und Leser der Rezension, ihre eigenen Erfahrungen mit dem jeweiligen ästhetischen Artefakt, sei es ein Buch, ein Film oder ein Musikstück, zu machen (und diese womöglich selbst mit anderen zu teilen, um ein umfassendes Gespräch über Kunst und ihre Bedeutung zu initiieren bzw.

154 Vgl. ebd. die Passage: „Vor allem wegen des Songs, Revolution', den John Lennon geschrieben hat, sind die Beatles von den Revolutionären, die bis dahin auf die Songs der Beatles hörten, geschmäht worden. In ,Revolution` wird den Revolutionären geraten, erst einmal sich selber zu ändern." - Vgl. dazu schon Handkes Bemerkung im Rundfunkfeuilleton Von der Schwierigkeit, einen Schlagertext zu schreiben (1965): „Die Beatles lehnen soziales oder rassisches oder kulturkritisches Engagement ab. Ihre Lieder sind ganz ohne Attitüde, ohne vorbedachten Weltbezug, ohne Gemeinschaftsfanatismus wie etwa die Songs der amerikanischen Folksinger, die sich betont anti geben. Die Songs der Beatles sind gesellschaftlich durch ihre Wirkung, durch die Fröhlichkeit und die Melancholie, die sie in andern erzeugen. [...] Paul McCartney, der gemeinsam mit John Lennon bei den Beatles die Lieder schreibt, antwortet auf die Frage, was er von den amerikanischen Protestsongs halte, er kenne keine Protestsongs, er kenne nur gute und schlechte Songs." (Peter Handke: Von der Schwierigkeit, einen Schlagertext zu schreiben. [1965] In: protokolle (1973), H. 2, S. 182-186, hier S. 185)

155 Vgl. Peter Handke: Der Rausch durch die Beatles. [1964] In: Ver sacrum. Neue Hefte für Kunst und Literatur 5 (1974), S. 114-117 (hier die wohl falsche Jahresangabe „1965“); Handke: Von der Schwierigkeit, einen Schlagertext zu schreiben (Anm. 154), S. 184-186; Der Rausch durch die Beatles war 1964 das erste „Funkfeuilleton“ für das Radio Steiermark; „das Thema“ hatte sich Handke, so Holzinger: Peter Handkes literarische Anfänge in Graz (Anm. 3), S. 17, „selbst gewählt“, „das Manuskript geriet zu einer emotional gefärbten Verteidigung“ der von ihm verehrten Band. Zum Feuilleton Von der Schwierigkeit, einen Schlagertext zu schreiben vgl. die Bemerkungen ebd., S. 18.

156 Handke: John Lennon sagte (Anm. 151). 
zu perpetuieren). Handkes Rezensionen sind, mehr oder weniger explizit, als Anregungen zu verstehen, die eigene Wahrnehmung zu sensibilisieren - ganz im Sinne jenes emphatisch vorgetragenen Anspruchs, den er 1967 für seine eigenen literarischen Texte formuliert hatte: „sensibler, empfindlicher, genauer zu machen und zu werden“, so heißt es in Ich bin ein Bewohner des Elfenbeinturms, „damit ich und andere auch genauer und sensibler existieren können, damit ich mich mit anderen besser verständigen und mit ihnen besser umgehen kann“. ${ }^{157}$ Auch hier ist die Anregung zum Austausch, zur Verständigung von zentraler Bedeutung.

Ganz in diesem Sinne fordert Handke am Ende seiner Besprechung von Wolfgang Bauers Theaterstück Magic Afternoon, in dem ein analoger Vorgang auf der Bühne stattfindet, ${ }^{158}$ die Leserinnen und Leser dazu auf, sich „,von den Rolling Stones Their Satanic Majesties Request“ anzuhören, „Seite 1, jetzt gleich, die erste Nummer, ,Sing this all together““. „Haben Sie die Platte aufgelegt?“, wendet er sich direkt an die Rezipienten: „So, und jetzt warten Sie auf den Übergang zur zweiten Nummer, ,citadel ' .. / Haben Sie das gehört? ${ }^{\text {“159 }}$ Hatte Handke in den „Regeln für die Schauspieler“, die der Publikumsbeschimpfung (1966) vorangestellt sind, diesen aufgetragen, einen Song der Rolling Stones sowie die „Hitparade von Radio Luxemburg“ anzuhören und im „ersten Beatles-Film“ auf „Ringo Starrs Lächeln“ zu achten, „in dem Augenblick, da er, nachdem er von den andern gehänselt worden ist, sich an das Schlagzeug setzt und zu trommeln beginnt “ ${ }^{\text {, }}{ }^{\text {" }}$ richtet er hier einen Appell an die Leser seiner Theaterkritik: Indem er sie zum Musikhören während der Lektüre , anstiftet' und dabei auch gleich einen „Tip für eine angemessene Rezeptionshaltung " liefert, ${ }^{161}$ versucht Handke, das Erlebnis, das Bauers Stück dem Betrachter ermöglicht, für andere nachvollziehbar zu machen - habe er doch, so Handke, schon seit langer Zeit keinen „theatralischen Vorgang von ähnlicher Schönheit gesehen“: ${ }^{162}$

157 Handke: Ich bin ein Bewohner des Elfenbeinturms (Anm. 9), S. 26.

158 Vgl. dazu Handkes Brief an Kolleritsch, 20.12. 1968. In: Handke/Kolleritsch: Schönheit ist die erste Bürgerpflicht (Anm. 95), S. 23. - Handkes Text erschien zunächst unter dem Titel Wenn Nerven schwanken in der Münchner Abendzeitung vom 30.11./1.12. 1968.

159 Peter Handke: Zu Wolfgang Bauer, Magic Afternoon. [1968] In: P. H.: Ich bin ein Bewohner des Elfenbeinturms (Anm. 6), S. 195-198, hier S. 198.

160 Peter Handke: Publikumsbeschimpfung und andere Sprechstücke. Frankfurt a. M.: Suhrkamp 1966, S. 9; vgl. dazu Hanna Klessinger: Postdramatik. Transformationen des epischen Theaters bei Peter Handke, Heiner Müller, Elfriede Jelinek und Rainald Goetz. Berlin, Boston: de Gruyter 2015, S. 148 f., die die „Regeln für die Schauspieler“ mit der „in den 6oer Jahren diskutierte[n] Camp-Ästhetik“ in Verbindung gebracht hat. Zudem sind Handkes Regeln für die Schauspieler aber auch als ironische Reverenz an Goethes kanonische Regeln für Schauspieler zu verstehen.

161 Lorenz: Pro domo (Anm. 7), S. 409; vgl. dazu auch Pichler: Die Beschreibung des Glücks (Anm. 3), S. $51 \mathrm{f}$.

162 Handke: Zu Wolfgang Bauer, Magic Afternoon (Anm. 159), S. 197 f. 
Unvergeßlich ist mir die Szene von der Uraufführung des Stückes in Hannover, als die zwei männlichen Akteure mitten im ,ernsthaften ' Reden aufhören und auf die Platte horchen, die gerade läuft. Und dann warten sie beide auf die gleiche Stelle in der Nummer, auf den Übergang; sie strecken beide den Arm aus und werden so immer stiller: - jetzt kommt die Stelle, sie seufzen, lassen die Arme sinken. ${ }^{163}$

Um den Leserinnen und Lesern diese subjektive Erfahrung verständlich und nachvollziehbar zu machen, versucht der Rezensent nicht, die künstlerische Qualität von Bauers Stück durch den Vergleich mit kanonischen Vorläufern zu plausibilisieren (obwohl der Name Nestroy fällt) oder durch Floskeln der Theaterkritik zu unterstreichen. Vielmehr ist ihm daran gelegen, seine Begeisterung über die Wahrnehmung der „Vorgänge im Theater“ zu vermitteln. ${ }^{164}$ „Hat noch niemand erlebt“, fragt Handke denn auch wenige Monate später in einem Kommentar zu verschiedenen Inszenierungen seines Kaspar in der Zeitschrift Theater heute, „wie quälend spannend es sein kann, jemandem, der am Niesen ist, aber dann doch nicht niest, zuzuschauen? ${ }^{\text {“165 }}$ Den Lesern einer Kritik eine solche Aufmerksamkeit für scheinbar unbedeutende Gesten, Handlungen und Vorgänge auf der Bühne bzw. auf der Leinwand zu vermitteln, ist ein wesentliches Anliegen von Handkes theater- und filmkritischen Arbeiten der späten 196oer Jahre.

Wer nicht willens oder fähig war, diese konzentrierte und wohlwollende Achtsamkeit für die Details eines Kunstwerks aufzubringen - die in manchem auf Handkes „poetische Arbeit am Abenteuer der Alltagswahrnehmung "166 vorausweist -, löste beim Rezensenten mitunter Phantasien gewalttätigen Einschreitens aus, wie seine zunächst in der Zeitschrift film gedruckte Notiz zu einer „Nachtvorstellung" verdeutlicht:

In der Nacht habe ich mir in der „Lupe“ am Kurfürstendamm wieder Peckinpah’s „Sacramento" (Ride the high country) angeschaut. Auf diesen unendlich schönen, ruhigen und traurigen Film, in dem man aufatmen und schauen konnte, reagierten die linken Nachtvorstellungsbesucher, die blind mit ihren elendblöden, lauten Zicken in die Nachtvorstellung geraten waren, mit besoffenem Grölen, Brüllen und Schreien. Sie waren gar nicht mehr fähig, was zu SEHEN, sie reagierten nur dumpf auf Reizwörter, wie die Meerschweinchen. Mein Wunsch: daß man sie zusammentun würde, die linke Scheiße und die rechte Scheiße, die liberale Scheiße dazu, und eine Bombe drauf schmeißen. ${ }^{167}$

163 Ebd., S. 197.

164 Ebd.

165 Peter Handke: Das Hören und das Sehen. In: Theater heute (1969), H. 2, S. 67.

166 Gottwald/Freinschlag: Peter Handke (Anm. 30), S. 33.

167 Peter Handke: Dummheit und Unendlichkeit. In: film 7 (März 1969), H. 3, S. 10-11, hier S. 11; auch in: P. H.: Ich bin ein Bewohner des Elfenbeinturms (Anm. 6), S. 153-157, hier S. 156. Der 
Sam Peckinpahs „unendlich schöne[m]“ Film hatte Handke bereits zwei Jahre zuvor einen subtilen und vieldeutigen Prosatext gewidmet, der zwar die filmische Szenerie von Sacramento aufgreift und ,nacherzählt', diese aber durch die Einführung einer Erzählerfigur, durch Variationen und Adaptionen im Handlungsverlauf sowie die Verschränkung von fiktionalen und fiktionsbrechenden Passagen verfremdet: „Es war der Schauplatz ein felsiges Gebiet, zur Verfügung gestellt vom Landwirtschaftsministerium der Vereinigten Staaten; die Luft flimmerte, der Wind stieß gelben Sand über die Steine. ${ }^{\text {“168 }}$ Die eigensinnige Prägung des Textes ergibt sich nicht zuletzt daraus, dass die Rezeptionshaltung des Kinobesuchers mit dem Erleben einer innerhalb der Diegese wahrnehmenden Figur amalgamiert wird, wie sich etwa am Beispiel der akustischen Untermalung einzelner Szenen zeigen lässt: „Jetzt verschwanden auch die alten Männer und wurden zu Schatten. Die Musik schwoll an. Als jedoch die Schüsse gefallen waren, brach sie jäh ab. Ich hörte sie erst wieder, nachdem mit gesenktem Haupt der andre alte Mann hinter dem Mais hervorgekommen war. “169 Vonseiten der linken Kulturkritik brachten Handkes Western-Texte ihm den Vorwurf ein, dass er, indem er „Western wie ,Der Galgenbaum' (mit Gary Cooper) oder ,Sacramento' (mit Randolph Scott) minuziös nacherzählt“, diesen „eben jenes befreiende Moment, das sie auf dem Weg vom verhärteten Begriff zum sinnlichen Bild eroberten, wieder raubt ${ }^{\text {“170 }}$ - eine Deutung, die ganz im Widerspruch zu Handkes eigenem Anspruch stand, die Filme gerade durch den erzählerischen Nachvollzug auf neue Weise zugänglich und erlebbar zu machen.

Der polemische Kommentar über das „wie die Meerschweinchen“ bloß auf „Reizwörter“ reagierende, aber am „SEHEN“ scheiternde Kino-Publikum geht, ebenso wie die Besprechung der Uraufführung von Bauers Magic Afternoon, von

Titel des Aufsatzes greift das Motto von Ödön von Horváths Geschichten aus dem Wiener Wald auf. Die Süddeutsche Zeitung druckte Handkes Polemik gegen die Nachtvorstellungsbesucher in der Rubrik „Gehört, gelesen, zitiert“ vollständig ab. Vgl. Peter Handke: Nachtvorstellung. In: Süddeutsche Zeitung, 17.3.1969.

168 Peter Handke: Sacramento (Eine Wildwestgeschichte). In: P. H.: Begrüßung des Aufsichtsrats (Anm. 93), S. 84-92, hier S. 88. Vgl. auch die folgende Passage: „Neben dem Brunnen lag gekrümmt Jim Borasso. Er wurde in dem Film dargestellt von Joel McCrea; der Darsteller des anderen alten Mannes war Randolph Scott.“ (Ebd., S. 92) Vgl. dazu jetzt Anna Estermann: Mit(ge)lesen. Handkes Sacramento (Eine Wildwestgeschichte). In: Die tägliche Schrift. Peter Handke als Leser. Hg. v. Thorsten Carstensen. Bielefeld: transcript 2019, S. 87-108; Herwig Gottwald: Peter Handke und der Western. In: „Das Wort sei gewagt“. Ein Symposium zum Werk von Peter Handke. Hg. v. Attila Bombitz u. Katharina Pektor. Wien: Praesens 2019, S. 60-74.

169 Handke: Sacramento (Anm. 168), S. 92.

170 Peter Hamm: Der neueste Fall von deutscher Innerlichkeit: Peter Handke. In: konkret, Nr. 12, 2. 6. 1969, S. 42-45, hier S. 43. Zu Handkes Konfrontation mit Hamm Ende der 196oer Jahre vgl. Kap. II, Abschnitt „Fronten, Verbündete, Kampfbegriffe“. Auch der zweite von Hamm genannte Text, Der Galgenbaum, erschien im Band Begrüßung des Aufsichtsrats (Anm. 93, S. 55-65). 
der Idee einer ideologiefreien Aufmerksamkeit für die Schönheit theatralischer wie filmischer Vorgänge aus, die der Autor als Kritiker auch den Leserinnen und Lesern seiner Beiträge empfiehlt - sei es durch die Schilderung der eigenen Rezeptionshaltung oder durch die Denunziation der ,blinden' und ,dumpfen Anderen. Mit der Fokussierung zunächst bedeutungslos erscheinender Details der jeweiligen künstlerischen Artefakte erweisen sich Handkes Ausführungen nicht zuletzt auch als pointierte Einsätze in der Auseinandersetzung des Autors mit dem „handelsüblichen Realismus“: ${ }^{171}$

Jemand ruft an, er hat falsch gewählt: In jedem anderen Stück hätte das eine Bedeutung, vielleicht etwas Metaphysisches, in Bauers Stück aber ist das möglich, es ist selbstverständlich, es hat keine Bedeutung über sich hinaus, es ist für sich allein spannend. Das zu bemerken, kann im Theater aufregend sein. ${ }^{172}$

Handkes Rezensionen haben in vielen Fällen den Charakter eines präzisen Erfahrungsreports, suspendieren aber trotzdem nicht die Vorstellung, im Zuge der Schilderung des eigenen subjektiven Erlebens von Theater, Musik und Literatur auch Ansätze zu einer analytischen Kommentierung zu formulieren. Gleichwohl ist eine ausgeprägte „Scheu vor den kulturkritischen Theorie-Ritualen“, die der Autor sich selbst im Vorwort zu Ich bin ein Bewohner des Elfenbeinturms attestiert hat, ${ }^{173}$ den Rezensionen Handkes bis heute abzulesen. Immer wieder hat er, wie 1973 in einer Besprechung von Edward Bonds Komödie Der See, die Gefahr, durch Müdigkeit und Nachlässigkeit „in die Formeln der Theaterkritik“ zu verfallen, explizit thematisiert, ${ }^{174}$ hat seine eigene Praxis des Rezensierens als Abweichung von den etablierten „Kritikerstandards“ definiert. ${ }^{175}$

Wie sehr indes das Vorbild Helmut Färbers Handkes literaturkritisches Schreiben beeinflusste und ihn dazu anregte, seine Prinzipien der Kritik neu zu kalibrieren, lässt sich anhand der am 21. April $1969 \mathrm{im} \mathrm{Spiegel} \mathrm{veröffentlichten} \mathrm{Rezension}$ von Gert Jonkes Geometrischem Heimatroman, der im selben Jahr im Suhrkamp Verlag erschienen war, ${ }^{176}$ nachvollziehen: „Über John Fords Film Lost Patrol schrieb

171 Handke: Zu Wolfgang Bauer, Magic Afternoon (Anm. 159), S. 196 f.

172 Ebd., S. 197.

173 Handke: Vorbemerkung (Anm. 39), S. 7.

174 Peter Handke: Bonds pauschaler Schmerz. In: Der Spiegel, Nr. 50, 10.12.1973, S. 131-134, hier S. 134: „Walter Schmidinger in München ,dagegen' (ja, es ist gegen zwei Uhr in der Nacht, und allmählich gerate ich in die Formeln der Theaterkritik) war als Hatch mehr der Theatertyp des Übergeschnappten, der gerade durch das bewußte, virtuos hintereinandergesetzte Vorzeigen aller Einzelheiten an einem üblichen Übergeschnappten ein Theatertyp blieb.“

175 Lorenz: Pro domo (Anm. 7), S. 399.

176 Hamm: Der neueste Fall von deutscher Innerlichkeit (Anm. 170), S. 44, warf Handke im Juni 1969 vor, „für das Buch eines Freundes Propaganda [zu] mach[en], das er selbst zum Suhrkamp 
ein Kritiker, sehr gute Filme könne man nur beschreiben“, zitiert Handke gleich im ersten Satz seiner Buchbesprechung den von ihm bewunderten Färber. ${ }^{177} \mathrm{Im}$ Abstand eines Vierteljahrhunderts hat er, in der Laudatio zum Petrarca-Preis, Färbers Sentenz über John Ford erneut als „fundamental[es]“ Beispiel für dessen Konzept von Kritik referiert: „,Nur bei einem sehr guten Film hat man Lust, zu beschreiben. Beschreiben ist etwas ganz anderes als Nacherzählen. Und für Leser, die finden, hier sei über einen Film dies und jenes gesagt, aber nicht recht, was er insgesamt ist: Ein schöner Film, den man nicht nur von außen ansehen kann, man kann in ihm herumgehen! “ ${ }^{178}$

An Jonkes Geometrischem Heimatroman, der heute in der Geschichte ostentativer Überschreitungen der Romanform neben Friedrich Achleitners quadratroman (1973), Andreas Okopenkos Lexikon-Roman (1970) und Oswald Wieners die verbesserung von mitteleuropa (1969) einen festen Platz innehat, lobt Handke, dass es dem Autor gelungen sei, die traditionelle Struktur eines literarischen Textes nicht nur intellektuell versteh-, sondern auch erfahr- und erlebbar zu machen: „Mit diesem Buch kann man also Erfahrungen machen. Erfahrungen zu machen, bereitet Vergnügen: Es ist ein vergnügliches Buch. Kein neuer Film von Godard, kein neuer Film von Straub im Kino - man könnte wieder zu lesen anfangen. “179 Jonkes Roman biete die „Chance“, so betont der Rezensent, „nicht nur beim Lesen, sondern auch am Lesen Vergnügen zu haben“; ${ }^{180}$ später setzt Handke die Erfahrung bei der Lektüre des Buches mit einem Bild aus Gustave Flauberts Erzählung Herodias in Beziehung - einem Bild, das bei ihm seit der 1965 publizierten Halbschlafgeschichte ${ }^{181}$ und bis hinein ins Spätwerk als positiver Bezugspunkt literarischen Schreibens auftaucht: „Es könnte einem mit dem Buch ergehen, wie es in einer der Drei Erzählungen Flauberts dem Tyrannen ergeht, der nach den Mühen und Plagen des Tages vor dem Palast verstockt auf

Verlag brachte“. Im Briefwechsel zwischen Handke und Unseld finden sich jedoch keine Hinweise auf eine Vermittlung; im Rückblick hat Handke im Gespräch mit Hamm 2002 Jonke $\mathrm{zu}$ jenen Autoren gerechnet, mit denen in frühen Jahren im Umkreis der Grazer Zeitschrift manuskripte und des Forum Stadtpark „eine Art Freundschaft“ entstanden sei (Peter Handke/ Peter Hamm: Es leben die Illusionen. Gespräche in Chaville und anderswo. Göttingen: Wallstein ${ }^{2} 2008$, S. 143). Anfang 2009 notiert Handke schließlich anlässlich des Todes von Jonke: „,Zu Sätzen aufgetürmte Sinnlosigkeiten?’ - ,Nur Sätze? Überraschend gesprenkelt mit Sinn' (zum Tod von Gert Jonke)“ (Peter Handke: Vor der Baumschattenwand nachts. Zeichen und Anflüge von der Peripherie. 2007-2015. Salzburg, Wien: Jung und Jung 2016, S. 51).

177 Handke: In Sätzen steckt Obrigkeit (Anm. 106), S. 186.

178 Handke: Wie ein Letzter ein Erster (Anm. 125), S. 49.

179 Handke: In Sätzen steckt Obrigkeit (Anm. 106), S. 188.

180 Ebd.

181 Vgl. Peter Handke: Halbschlafgeschichte (Entwurf zu einem Bildungsroman). In: manuskripte (1965), H. 14/15, S. 35-36. 
der Terrasse sitzt: ,Der Mond ging auf. Besänftigung zog in sein Herz. “182 Sei Jonkes Geometrischer Heimatroman auch weder ein „sehr gutes Buch“ noch ein „wertvolles Buch, mit dem Zeitungen um Abonnenten werben“ (womit Handke nicht zuletzt gegen den Jargon der Literaturkritik Stellung bezieht), liege seine Qualität gerade darin, dass man „so viele Erfahrungen damit machen“ könne, „daß man Lust hat, die Erfahrungen zu beschreiben“. ${ }^{183}$

Wie nebenher benennt Handke hier einen zentralen Antrieb seines literaturkritischen Schreibens, nimmt aber überraschenderweise nicht darauf Bezug, dass Jonke selbst in seinem Roman eine Parodie der Kunstkritik vorgelegt hat: Im ersten „Intermezzo“ des Geometrischen Heimatromans, das mit „Vorführung des Künstlers “ überschrieben ist, ${ }^{184}$ präsentiert der Autor zunächst erzählerische Varianten über den tragischen Unfall eines Artisten, der bei der Ausführung seines Kunststücks zu Tode gekommen ist, um nach diversen (auch typographisch experimentellen) Anläufen zur Vermittlung des Geschehens mit dem Hinweis zu schließen, es sei „am besten“, „wenn wir uns an den objektiven und wahrheitsgetreuen Bericht der Presse halten“. ${ }^{185}$ Der nun folgende „BERICHT auf Der Kulturseite einer Zeitung / geschrieben vom Kunstkritiker,

182 Handke: In Sätzen steckt Obrigkeit (Anm. 106), S. 188. In der Übersetzung von Jürgen Rehbein lautet die Passage bei Flaubert: „Der Mond ging auf; ein Gefühl der Ruhe senkte sich in sein Herz.“ (Gustave Flaubert: Herodias. In: G. F.: Drei Erzählungen. Übers. u. hg. v. Jürgen Rehbein. Stuttgart: Reclam 1994, S. 91-133, hier S. 117) Vgl. auch die folgenden Spuren des Flaubert-Zitats in Handkes Werken: „Wenn nach dem Tanzen die Bewegungen abbrechen und nur noch Geräusche und Weggehen sich ereignen: ,Besänftigung zog in sein Herz ““ (Handke: Das Gewicht der Welt [Anm. 72], S. 13); „Am noch taghellen Himmel ging der Mond auf. Ich konnte mir darauf das ,Meer des Schweigens' vorstellen, und Flauberts ,Besänftigung' zog in mein Herz" (Peter Handke: Die Lehre der Sainte-Victoire. Frankfurt a. M.: Suhrkamp 1980, S. 62); „Ja, er war zurückgeschreckt, und fast zugleich, wie im Gegenzug, entfaltete sich in ihm etwas, das mehr war als er und ihn überstieg, allein schon in der Bewegungsart seinem Wegzucken widersprechend, eine so namen- und grenzenlose wie riesenhafte Beseligung, wozu er in der Nacht auf dem Boot ein Satzpaar Gustave Flauberts abwandelte - statt ,Der Mond ging auf / Besänftigung zog in sein Herz؛ : Sie wählte mich / Beseligung zog in sein Herz. “" (Peter Handke: Die morawische Nacht. Erzählung. Frankfurt a. M.: Suhrkamp 2008, S. 139); „Die Augen meines Gegenübers wurden Farbe. Besänftigung zog in mein Herz (noch einmal für Flaubert)“ (Handke: Vor der Baumschattenwand nachts [Anm. 176], S. 225). - Auf die Geschichte dieses Zitats in Handkes Werk verweist bereits Clemens Özelt: Durch die Lupe? Peter Handkes Kurzprosa (Noch einmal für Thukydides, Begrüßung des Aufsichtsrats). In: Schreiben als Weltentdeckung (Anm. 29), S. 73-95, hier S. 86 f. u. 90. - Zu ,auto-intertextuellen Referenzen“ im Werk des Schriftstellers vgl. jetzt auch Oliver Kohns: Werkimmanente Intertextualität bei Peter Handke. Selbstzitat, -fortschreibung, -kommentar und -parodie. In: Die tägliche Schrift (Anm. 168), S. 231-242, Zit. S. 241.

183 Handke: In Sätzen steckt Obrigkeit (Anm. 106), S. 186.

184 G. F. Jonke: Geometrischer Heimatroman. Frankfurt a. M.: Suhrkamp 1969, S. 21.

185 Ebd., S. 29. 
Feuilletonisten und Publizisten Doktor Paul Anton Zierl“, ${ }^{186}$ einer wohl fiktiven Person, dekuvriert den Zynismus konservativer Kulturkritik im Gestus der Parodie, wenn dem durch einen Sturz auf den Rücken verunglückten Artisten etwa zugutegehalten wird, er sei ein Beispiel dafür, dass es „noch Leute mit Rückgrat und Charakter“ gebe. ${ }^{187}$ Die Besprechung der Darbietung bietet dem Journalisten im Grunde nur einen Anlass dafür, gegen „schludernde Scribenten“ ins Feld zu ziehen, die, wie er ausführt, „ihren Dilettantismus und ihr Unvermögen unter den fadenscheinigen Vorwänden einer angeblich ,modernen Richtung “ " zu „verbergen“ trachten. ${ }^{188}$ Ähnlich wie bei Handke, der seine Poetik ganz wesentlich in Auseinandersetzung mit der etablierten Literaturkritik geschärft und profiliert hat, wird in Jonkes Geometrischem Heimatroman die Konfrontation mit dem Kulturbetrieb und dem Jargon des Journalismus in den eigenen literarischen Entwurf integriert. Der Kampf um die Legitimation und Durchsetzung einer avancierten Ästhetik wird nicht (nur) in Paratexten, in nachgetragenen Selbstkommentaren und polemischen Verteidigungen, sondern im Roman selbst ausgetragen.

\section{„,wirklich unorthodox“: Handke über/mit Ödön von Horváth}

Als bewusste Abkehr von traditionellen Formen der Literaturkritik sind auch Handkes „Beschreibungen“ literarischer Texte zu interpretieren. ${ }^{189}$ Der junge Schriftsteller hatte bereits früh seine Sympathie für Ödön von Horváths Bühnenästhetik bekundet, indem er ihr 1968 in einer Umfrage der Zeitschrift Theater heute den Vorrang vor Bertolt Brechts epischem Theater einräumte. Er fand in Horváth einen wichtigen Referenzautor für die Entwicklung seiner eigenen Vorstellung von Theater; die in Theater heute lancierte fundamentale Kritik an Brecht, die dessen Stücke der Trivialität und ästhetischen Konventionalität bezichtigt, ging Hand in Hand mit einem pointierten Hinweis auf die literaturgeschichtliche Bedeutung Horváths, dessen „Unordnung und unstilisierte Sentimentalität“ er Brechts „ergreifenden Weihnachtsmärchen“vorziehe: „Die verwirrten Sätze seiner Personen erschrecken mich, die Modelle der Bösartigkeit, der Hilflosigkeit, der Verwirrungen in einer bestimmten Gesellschaft wer-

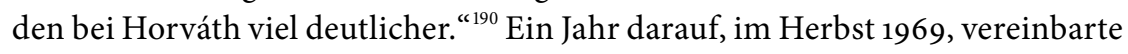

\footnotetext{
186 Ebd., S. 30.

187 Ebd., S. 33.

188 Ebd., S. 30.

189 Unter diesem Begriff sind in Ich bin ein Bewohner des Elfenbeinturms die beiden Texte über Thomas Bernhards Verstörung und Ödön von Horváths Geschichten aus dem Wiener Wald zusammengefasst, deren Beschreibungsverfahren jedoch signifikant voneinander abweichen.

190 Peter Handke: Horváth ist besser. In: Theater heute (1968), H. 3, S. 28. - In Kaspar (1968) erwies er dem Dramatiker zudem mit einem adaptierten Zitat aus Glaube Liebe Hoffnung seine
} 
Handke mit Siegfried Unseld ein Nachwort für eine Neuausgabe der Geschichten aus dem Wiener Wald in der „Bibliothek Suhrkamp“: „In den letzten Tagen habe ich das Nachwort zu Horváth geschrieben“, teilt Handke seinem Verleger sodann Anfang Januar 1970 mit, setzt aber gleich einschränkend hinzu: „ein Nachwort ist es wohl nicht ", 191 was er wenige Tage später noch einmal dezidiert unterstreicht: „Natürlich kann man es nicht als orthodoxes Nachwort bezeichnen, aber gerade die genaue Inhaltsangabe liefert, glaube ich, auch eine Analyse der Form und des Aufbaus, mehr als eine übliche Analyse. “ ${ }^{192}$ Unseld zeigte sich von der „wirklich unorthodox[en]“ Form des Nachworts zwar überzeugt, schlug Handke aber - wohl von der Konsequenz des Textes irritiert - vor, diesem, „wenigstens in ein paar Zeilen, eine wertende Beurteilung von Dir über das Buch ${ }^{193}$ voranzustellen - eine Bitte, der Handke nicht nachkommen sollte, da er der Überzeugung war, seine Wertschätzung für Horváth gehe aus dem ,Nachwort' hinreichend hervor: „Nur was man wirklich liebt, kann man so lang und breit beschreiben. “194

Im Vergleich zu Als ich „Verstörung“ von Thomas Bernhard las verzichtet Handke in seinem Horváth-Aufsatz auf die Etablierung einer Sprecherposition außerhalb der Fiktion des behandelten Textes. Beginnt die ,Beschreibung von Bernhards Roman in der ersten Person Singular („Nachdem ich auf dem Hauptbahnhof in Hannover angekommen war ${ }^{\text {“195 }}$ ) und endet mit dem erneuten Hinweis auf die konkrete Situation der Lektüre („Ich las und las und las ... “96), fällt eine solche ,Rahmenerzählung‘ hier gänzlich weg. „Handke verzichtet als Nacherzähler vollkommen auf eigene Kommentare, ja selbst auf eigene Formulierungen, in denen eine Interpretation zum Ausdruck kommen und den Blick auf Horváths Intentionen verstellen könnte. ${ }^{\text {197 }}$ Der Bezug auf Horváths

Reverenz. - Handkes Einsatz für Horváth trug zur Renaissance und Wiederentdeckung von dessen Werk in deutschen Theatern bei. Bereits zuvor waren führende Akteure des österreichischen Literaturbetriebs für den nach der Zäsur des Dritten Reichs in Vergessenheit geratenen Horváth eingetreten: so etwa Hans Weigel in seiner 1957 publizierten Aufforderung, Ödön von Horváth zu spielen, den mit Handke zwar eine Abneigung gegenüber Bertolt Brecht verband, dies aber weniger aus theaterästhetischen denn aus politisch-ideologischen Gründen. Man müsse, so Weigel, weil Horváth „keiner Schlagzeilen im Kulturteil unserer Presse für würdig erachtet“ werde, ,,außer der Reihe und gegen die Aktualität“ über ihn schreiben (Hans Weigel: Aufforderung, Ödön von Horváth zu spielen. [1957] In: H. W.: Nach wie vor Wörter. Literarische Zustimmungen, Ablehnungen, Irrtümer. Graz u. a.: Styria 1985, S. 313-316, hier S. 313).

191 Handke an Unseld, 9. 1. 1970. In: Handke/Unseld: Der Briefwechsel (Anm. 1), S. 158.

192 Handke an Unseld, 14.1.1970. In: ebd., S. 160.

193 Unseld an Handke, 23.10.1070. In: ebd., S. 161.

194 Handke an Unseld, 8. 2.1970. In: ebd., S. 163.

195 Handke: Als ich Verstörung von Thomas Bernhard las (Anm. 98), S. 211.

196 Ebd., S. 216.

197 Gabriel: Peter Handke und Österreich (Anm. 93), S. 89. 
Geschichten aus dem Wiener Wald besteht im Wesentlichen in einem getreuen Nachvollzug des Prätextes, der sich mit Christoph Bartmann auch als „Hommage" auf das von Handke überaus geschätzte Volkstheaterstück verstehen lässt. ${ }^{198}$ Gleichwohl beansprucht er, wie er im bereits zitierten Brief an Unseld schreibt, mit der Transformation von Horváths Geschichten in einen fortlaufenden Prosatext (wobei er Szenenanweisungen und Figurenreden integriert und durch Streichungen auch inhaltliche Akzente setzt ${ }^{199}$ ), eine „Analyse der Form und des Aufbaus“ ${ }^{200}$ und eine „Beschreibung der Dramaturgie des Stücks“ ${ }^{201}$ vorgenommen zu haben.

Anhand der Paratexte von Totenstille beim Heurigen im 1972 erschienenen Band Ich bin ein Bewohner des Elfenbeinturms lässt sich indes zeigen, dass die Terminologien und die damit assoziierten Gattungsformen in Handkes Schreiben über Literatur keineswegs fest und klar definiert waren. So wird der Begriff der ,Nacherzählung', der in der Titelei der Bibliothek-Suhrkamp-Ausgabe des Horváth-Stücks aufscheint ${ }^{202}$ und den auch Bartmann und Gabriel zur Charakterisierung von Handkes Nachwort verwenden, hier gleichzeitig eingeführt und für nicht passend erklärt: Kündigt die „Vorbemerkung“ von Ich bin ein Bewohner des Elfenbeinturms den Horváth-Text explizit nicht als „Nacherzählung“, sondern als eine „bewußte Auswahl von Sätzen aus dem Stück“ an, „die damit das darin formulierte Bewußtsein kommentieren sollten “, ${ }^{203}$ lautet die Genrebezeichnung im Untertitel des 1972 gedruckten Textes „Versuch einer Analyse mit Hilfe einer Nacherzählung“ (in der Erstausgabe 1970 fehlte diese Angabe noch). ${ }^{204}$ Mag dies auch auf einen Fehler in der Herstellung des Bandes vonseiten des Verlags zurückgehen, verweist die paratextuelle Inkonsistenz doch auch auf eine (produktive, weil der Routine entsagende) Variabilität und generische Flexibilität von Peter Handkes ,Begleitschreiben $:^{605}$ eine Flexibilität, die in enger Beziehung zu den Prinzipien seiner literarischen Poetik und Praxis steht.

198 Bartmann: Suche nach Zusammenhang (Anm. 24), S. 129. Vgl. ebd.: „Je enthusiasmierter die Reaktion auf Literatur, Filme oder Theater ist, desto weiter tritt ein kritisches Vokabular zurück, an dessen Stelle die Beschreibung und Nacherzählung tritt.“

199 Dazu im Detail Gabriel: Peter Handke und Österreich (Anm. 93), S. 88-92.

200 Handke an Unseld, 14. 1.1970. In: Handke/Unseld: Der Briefwechsel (Anm. 1), S. 16o.

201 Handke an Unseld, 8. 2.1970. In: ebd., S. 163.

202 Vgl. Ödön von Horváth: Geschichten aus dem Wiener Wald. Volksstück in drei Teilen mit einer Nacherzählung von Peter Handke. Frankfurt a. M.: Suhrkamp 1970.

203 Handke: Vorbemerkung (Anm. 39), S. 7.

204 Peter Handke: Totenstille beim Heurigen. Versuch einer Analyse mit Hilfe einer Nacherzählung von Ödön von Horváths, Geschichten aus dem Wienerwald. In: P. H.: Ich bin ein Bewohner des Elfenbeinturms (Anm. 6), S. 217-227, hier S. 217. Vgl. in der Erstausgabe P. H.: Totenstille beim Heurigen. In: Horváth: Geschichten aus dem Wiener Wald (Anm. 202), S. 123-137.

205 So lautet nicht nur der Untertitel des 2015 veröffentlichten Bandes Tage und Werke, auch ein Notizheft-Eintrag Handkes aus dem Jahr 1986 nennt den Begriff: „statt ,Kritik‘ sag: ,Begleitschreiben““ 


\section{Keine Axt für das gefrorene Meer in uns: Franz Kafka, Karin Struck}

Nachdem Handke seine Tätigkeit als Autor von Essays und Besprechungen anderer Bücher Anfang der 1970er Jahre zugunsten seiner eigenen literarischen Arbeiten deutlich reduziert hatte, entdeckte er Mitte der 1970er Jahre - wohl auch bestärkt von der positiven Resonanz auf seinen Lenz-Aufsatz - wieder eine gewisse Freude am Rezensieren: „Nach meiner letzten Arbeit bin ich eigentlich in dem Zustand“, teilt er am 8. Januar 1975 dem befreundeten Autor Nicolas Born mit, „daß ich nur noch von anderen schreiben möchte, freilich mit mir als Unterstützung (für die andern). ${ }^{“ 206}$ Bereits einige Monate zuvor, am 1. Juni 1974, hatte Handke einen Beitrag über Franz Kafka in der Frankfurter Allgemeinen Zeitung veröffentlicht; auch dieser beginnt mit einer prägnanten Leseszene (einer Erinnerung an frühere Kafka-Lektüren), die sogleich eine überraschende Wendung nimmt: „Es gab eine Zeit, da las ich die Tagebücher von Kafka, seine Briefe, und auch das, was seine Freunde über ihn geschrieben hatten, nur aus dem Grund noch einmal durch, weil ich herausfinden wollte, ob er vielleicht Pickel gehabt hätte. ${ }^{\text {207 }}$ Noch heute stelle er sich, so Handke, „immer vor, Kafka hätte als Heranwachsender Akne gehabt, schmerzhafte, eiternde Schwellungen im Gesicht und am Hals“, obgleich Freunde wie Max Brod ihn durchwegs als „schön“ bezeichnet hätten. ${ }^{208}$

Im weiteren Verlauf des kurzen Textes setzt Handke sein eigenes Schreiben explizit mit seinen Reflexionen über Kafka in Beziehung, wenn er von seinem Plan berichtet, „eine Geschichte [zu] schreiben, in der jemand, dadurch daß er Akne bekam, alles mit anderen Augen anzuschauen begann. Diese Geschichte sollte ,AKNE` heißen. Das war vor langer Zeit, als meine Welt die Welt Kafkas war

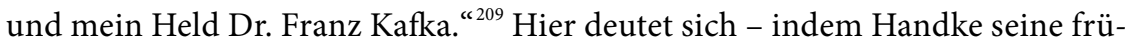
here Identifikation mit Kafkas Literatur einer distanzierteren Haltung zum Zeitpunkt des Niederschrift gegenüberstellt ${ }^{210}$ - bereits die Leitlinie der berühmten

(Peter Handke: Am Felsfenster morgens (und andere Ortszeiten 1982-1987). Salzburg, Wien: Residenz 1998, S. 351). Zur Idee des ,Begleitschreibens' bei Handke vgl. grundlegend Struck: Der Begleitschreiber (Anm. 65), bes. S. $13 \mathrm{f}$.

206 Peter Handke an Nicolas Born, 8. 1.1975. In: N. B., P. H.: Die Hand auf dem Brief. Briefwechsel 1974-1979. In: Schreibheft (2005), H. 65, S. 3-35, hier S. 7. In diesem Brief an Born nennt er u.a. seinen „Aufsatz über die amerikanische Schriftstellerin Patricia Highsmith“, für den er „allerdings 2 Monate gebraucht habe“ (ebd.); er erschien wenige Tage später, am 13.1.1975, unter dem Titel Die privaten Weltkriege der Patricia Highsmith im Spiegel.

207 Peter Handke: Zu Franz Kafka. [1974] In: P. H.: Das Ende des Flanierens (Anm. 48), S. 153-155, hier S. 153 (zuerst, anlässlich von Kafkas 50. Todestag am 3. 6.1974, gedruckt als P. H.: Gewaltiger als alle Handlungen. In: Frankfurter Allgemeine Zeitung, 1. 6.1974).

208 Ebd.

209 Ebd. Vgl. noch Hage/Schreiber/Handke: „Gelassen wär' ich gern“ (Anm. 38), S. 172.

210 Vgl. Handke: Zu Franz Kafka (Anm. 207), S. 153 f.: „Wie habe ich mich in der Scham Kafkas wiedergefunden - nein, nicht wiedergefunden, sondern überhaupt erst einmal entdeckt ... und 
Rede zur Verleihung des Franz-Kafka-Preises im Jahr 1979 an: der Weg von der Wahrnehmung Kafkas als dem „Maßgebende[n]“ der eigenen Poetik zur Einsicht, dass „sich meine Schreib-Versuche von dem Werk Franz Kafkas unterscheiden müssen“ ${ }^{\text {“211 }}$ - ein Weg, der später auch in Attacken gegen den „Ewigen Sohn“212 und „Heiratsschwindler Kafka“"213 münden sollte. Aufschlussreich für den vorliegenden Zusammenhang ist indes der Umstand, dass Handkes poetologische Reflexionen im Kafka-Essay von 1974 erneut von einer Lektüreszene ihren Ausgang nehmen. Weitere Aufsätze (über Thomas Mann und Heimito von Doderer) für das Feuilleton der Frankfurter Allgemeinen Zeitung waren Mitte der 1970er Jahre zwar in Planung, kamen aufgrund des endgültigen Zerwürfnisses zwischen Peter Handke und Marcel Reich-Ranicki aber nicht mehr zustande und wurden auch nicht an anderer Stelle gedruckt. ${ }^{214}$

Handkes 1975 im Spiegel veröffentlichter Verriss von Karin Strucks Roman Die Mutter gehört ebenso in den skizzierten Zusammenhang einer am Lektüreerlebnis orientierten Rezensionspraxis, obgleich er von den wertschätzenden

dann immer wiederentdeckt. Und wie zaghaft, wie ängstlich erscheint mir diese Scham heute wie hochmütig." Gabriel: Peter Handke und Österreich (Anm. 93), S. 134, hat auf „eine Fülle von äußerlichen Merkmalen“ hingewiesen, die in Handkes 1975 bis 1977 entstandenem Journalband Das Gewicht der Welt „mit dem Tagebuch Kafkas übereinstimmen“. Tatsächlich finden sich in diesem Band (unter dem Datum 29.3.1976) mehrere Notate, die eine Kafka-Lektüre belegen und die zugleich poetologische Reflexionen anstellen: „Beim Lesen von Kafkas Tagebuch: ich merke, daß mich seine Klagen und Selbstbezichtigungen nicht mehr interessieren, nur noch seine Beschreibungen“; „Kafka lesen: man muß sich seine Sätze nicht merken (man kann seine Sätze sofort vergessen, das ist das Schöne an ihnen), und sie bleiben doch da, auch wenn man sie vergißt“; „,Ein Jahr müßte ich suchen, bis ich ein wahres Gefühl in mir fände (K.) "' (Handke: Das Gewicht der Welt [Anm. 72], S. 89 f.). In den späteren Journalbänden Die Geschichte des Bleistifts, Phantasien der Wiederholung, Am Felsfenster morgens und Gestern unterwegs, ja noch in Vor der Baumschattenwand nachts wird die Auseinandersetzung mit Kafka weitergeführt. Zur Bedeutung von Kafkas Tagebüchern für Handkes Das Gewicht der Welt siehe die Darstellung in Karlheinz Fingerhut: Drei erwachsene Söhne Kafkas. Zur produktiven Kafka-Rezeption bei Martin Walser, Peter Weiss und Peter Handke. In: Wirkendes Wort 30 (1980), H. 6, S. 384-403, bes. S. 394-399.

211 Peter Handke: Rede zur Verleihung des Franz-Kafka-Preises. [1979] In: P. H.: Das Ende des Flanierens (Anm. 48), S. 156-159, hier S. 156 f. Zur Bedeutung Kafkas für Handkes Selbstverständnis als Autor vgl. bereits Gabriel: Peter Handke und Österreich (Anm. 93), S. 142-148; später Pilipp: In Defense of Kafka (Anm. 93), bes. S. 117-122 u. 143-145; ders.: Peter Handke's coming to terms with Kafka: Die Stunde der wahren Empfindung. In: Modern Austrian Prose. Interpretations and Insights. Hg. v. Paul F. Dvorak. Bd. 1. Riverside: Ariadne Press 2001, S. 107-128; zuletzt die erhellende Studie von Hans Höller: Eine ungewöhnliche Klassik nach 1945. Das Werk Peter Handkes. Berlin: Suhrkamp 2013, S. 91-100.

212 Peter Handke: Phantasien der Wiederholung. Frankfurt a. M.: Suhrkamp 1983, S. 94.

213 Handke: Gestern unterwegs (Anm. 70), S. 288.

214 Vgl. Kap. IV, Abschnitt „Schleichende Eskalation: die 1970er Jahre“. 
Arbeiten über Bauer, Bernhard oder Lenz signifikant abweicht. ${ }^{215}$ Er habe vor, schreibt Handke am 5. Februar 1975 an Nicolas Born, „etwas über Strucks Buch Die Mutter [zu] verfassen“, das ihn jedoch, wie er dem befreundeten Autor gesteht, „Ziemlich abstößt“; und er setzt in Klammern hinzu: „(ich habe seit langem wieder Lust, auch schriftlich, nicht nur so, böse zu sein) ${ }^{“ 216}$ Einen veritablen Verriss hatte Handke tatsächlich schon seit einigen Jahren nicht mehr publiziert. Nach Abschluss der Rezension bat Handke die Redaktion des Spiegels darum, „mit der Veröffentlichung möglichst lang zu warten - sollte es vorher ähnliche Meinungen schon geben, brauchte man mein Manuskript nicht zu drucken. ${ }^{\text {“217 } \mathrm{Da}}$ dem offenbar nicht so war, wurde die Besprechung am 17. März 1975 unter dem Titel Denunziation ohne Wahrnehmung im Spiegel, für den Struck selbst wenige Monate zuvor Franz Innerhofers Schöne Tage rezensiert hatte, ${ }^{218}$ veröffentlicht.

Seinem Verleger kündigte Handke die Rezension betont vorsichtig als „eine bloße Analyse“, „eine Demystifikation“ des Buches an, ${ }^{219}$ nicht zuletzt deshalb, weil der Roman - wie der Großteil von Handkes eigenem Werk - im Suhrkamp Verlag erschienen war und Unseld großen Wert darauf legte, Konflikte zwischen seinen Autorinnen und Autoren zu vermeiden: „Nun ist Karin Struck aber wesentlich offener dafür, eine Schriftstellerin zu sein, als die meisten, die sich so bezeichnen“, fährt Handke im Brief an Unseld fort, will daraus aber gerade keinen Milderungsgrund für die Besprechung ableiten: „So wollte ich es auch herauskommen lassen, aber das erschien mir dann als eine Herablassung ihr gegenüber, die sie nicht benötigt. “220 Im Vergleich zu früheren negativen Urteilen über Bücher von schreibenden Kolleginnen und Kollegen, etwa über den Wellershoff'schen Wochenende-Band, weist Denunziation ohne Wahrnehmung einen anderen methodischen Fokus auf, entzünden sich Handkes Einwände an anderen Aspekten. Zielt die Rezension von Strucks Die Mutter im Sinne seiner theoretischen und kritischen Arbeiten der 1960er Jahre zunächst auf die Reproduktion sprachlicher und narrativer Stereotypen („das Höchstpersönliche als Schema“221), bleibt Handke

215 Mixner: Peter Handke (Anm. 10), S. 208, zufolge stellt Handkes Struck-Rezension „[e]ine sehr präzise Anwendung des aus dem eigenen poetologischen Programm entwickelten kritischen Verfahrens" dar. Vgl. dazu auch Struck: Der Begleitschreiber (Anm. 65), S. 20 f.

216 Handke an Born, 5. 2. 1975. In: Born/Handke: Die Hand auf dem Brief (Anm. 206), S. 9. So auch in Handke an Unseld, 21. 2. 1975. In: Handke/Unseld: Der Briefwechsel (Anm. 1), S. 276: „,Die Mutter hat mich, vor allem beim zweiten Lesen, abgestossen, und so habe ich es auch geschrieben.“

217 Ebd.

218 Vgl. Karin Struck: Für die Arbeit gezeugt. Über Franz Innerhofer: Schöne Tage. In: Der Spiegel, Nr. 50, 9.12.1974, S. 136-139.

219 Handke an Unseld, 21. 2. 1975. In: Handke/Unseld: Der Briefwechsel (Anm. 1), S. 276.

220 Ebd.

221 Peter Handke: Denunziation ohne Wahrnehmung. Über Karin Struck: Die Mutter. In: Der Spiegel, Nr. 12, 17.3. 1975, S. 147-149, hier S. 147; auch in: P. H.: Das Ende des Flanierens (Anm. 48), 
nicht bei dieser Diagnose stehen. Wenn er die erzählerische Faktur des Romans im Zuge einer detaillierten Lektüre unter die Lupe nimmt, erschließt sich ihm zwar Strucks „Schreib-Automatik“; 222 diese ergebe sich aber nicht primär aus einer unreflektierten Verwendung literarischer Modelle, sondern, ganz im Gegenteil, aus einer allzu gewollt inszenierten erzählerischen Konstruktion, die ihre eigene Agenda - die Sensibilisierung für das Schicksal der Protagonistin - „in modischen Satzposen" hintertreibe:

Deklamation bleibt vor allem die in dem Buch ersehnte Bewußtseinslandschaft, die Poesie. Karin Struck verpaßt in ihrer eifervollen Unaufmerksamkeit, die immer sogleich auf Poetisches aus ist und deshalb poesielos bleibt, vielleicht gerade die Momente, da während des definierten Rollenspiels in einer Art von Versprecher kleinwinzig und weltbewegend jene nicht definierte, noch unbekannte Geschichte erscheint, deren Aufspürung und Beschreibung die Arbeit der Literatur wäre. ${ }^{223}$

Handkes Vorwurf besteht demnach nur teilweise darin, dass die Zeichnung der Figuren „literarische[n] Konventionen“ folgt; ${ }^{224}$ vielmehr nimmt er, wie Manfred Mixner gezeigt hat, an der „mangelnde[n] Erfahrbarkeit des Romans“ Anstoß. ${ }^{225}$ Ganz in diesem Sinne schließt die Rezension denn auch mit einer Wendung, die eine der meistzitierten Sentenzen der Literaturgeschichte aufgreift - sie stammt aus Franz Kafkas Brief an Oskar Pollak vom 27. Januar $1904^{226}$ - und gegen Strucks allzu vordergründiges erzählerisches Kalkül ins Spiel bringt:

Das Buch „Die Mutter“ ergrimmt so, weil es pauschal propagiert, poetisch das Leben zu ändern, in jeder Einzelheit jedoch servil von den schon bekannten psychologischen, soziologischen und vor allem poetischen Definitionen des Menschen abhängt. Statt „die Axt für das gefrorene Meer in uns" zu sein (auch dieser Kafka-Satz ist bei Karin Struck zu bloßer Beliebtheit entwürdigt), vermehrt es das Eis in uns und zwischen dir und mir. ${ }^{227}$

S. $49-54$.

222 Handke: Denunziation ohne Wahrnehmung (Anm. 221), S. 149.

223 Ebd.

224 Ebd., S. 147.

225 Mixner: Peter Handke (Anm. 10), S. 209.

226 Vgl. Franz Kafka an Oskar Pollak, 27.1.1904. In: Franz Kafka: Briefe 19oo-1912. Hg. v. HansGerd Koch. Frankfurt a. M.: S. Fischer 1999 (= F. K.: Schriften Tagebücher Briefe. Kritische Ausgabe), S. 36: „Wir brauchen aber die Bücher, die auf uns wirken wie ein Unglück, das uns sehr schmerzt, wie der Tod eines, den wir lieber hatten als uns, wie wenn wir in Wälder vorstoßen würden, von allen Menschen weg, wie ein Selbstmord, ein Buch muß die Axt sein für das gefrorene Meer in uns. Das glaube ich."

227 Handke: Denunziation ohne Wahrnehmung (Anm. 221), S. 149. Zur Kafka-Anspielung in Handkes Struck-Rezension vgl. Gabriel: Peter Handke und Österreich (Anm. 93), S. 124, zur 
In seinen Arbeiten über Bernhard und Lenz hatte Handke die Lektüre als positive Erfahrung in den Mittelpunkt gestellt. Sein entschiedenster Einwand gegen Strucks Roman besteht nun gerade darin, dass dieser - „mit geschlossenen Sinnen “228 - keinen Raum für die individuelle Wahrnehmung des Lesers lasse, ja die Offenheit der ästhetischen Erfahrung behindere. Nicht nur in seinen emphatischen Lektüreberichten folgt Handke der Idee, „das Lesen, wie auch immer, weiterzugeben", 229 sondern auch die kritischen Einwände gegen bestimmte Bücher gehen von den Schwierigkeiten, Herausforderungen und Enttäuschungen bei der Lektüre eines Buches, nicht von einem abstrakten Wertmaßstab aus.

\section{Der Autor als Kritiker: ein Rollenkonflikt?}

In einer Umfrage unter Kritikern des Westdeutschen Rundfunks nannten diese im Jahr 1973, nach ihren Vorbildern und Anregern befragt, Peter Handke immerhin an siebter Stelle, zwischen Jean-Paul Sartre auf Platz sechs und Günter Grass auf Platz acht, noch vor Theodor W. Adorno (neun) und Martin Walser (zehn). Dass zu diesem Zeitpunkt Heinrich Böll den ersten Platz einnahm, während die pole position 15 Jahre später bei einer erneuten Umfrage an Marcel Reich-Ranicki (vor Heinrich Vormweg und Joachim Kaiser) überging, ${ }^{230}$ verweist einerseits auf die Verschiebungen im Renommee der genannten Personen, andererseits auf die zunehmend herausgehobene Position Reich-Ranickis, der sich nach und nach zum ,Literaturpapst' gemausert hatte. Die Nennung Handkes - 1988 scheint er nicht mehr auf - zeigt indes, dass er in der ersten Hälfte der 1970er Jahre als jemand wahrgenommen wurde, der über den engeren Bereich des literarischen Schreibens hinaus auch in literaturkritischen Debatten Entscheidendes und Anregendes beizutragen hatte.

Die Wertschätzung für Handke nicht nur als Schriftsteller, der mit Publikumsbeschimpfung (1966), Kaspar (1968), Die Angst des Tormanns beim Elfmeter (1970) oder Wunschloses Unglück (1972) rasch symbolisches Kapital im literarischen Feld

allg. Produktivität der Kafka'schen Axt-Metapher Katrin Kohl: Poetologische Metaphern. Formen und Funktionen in der deutschen Literatur. Berlin, New York: de Gruyter 2007, S. 190-193. Dazu auch Handkes Notat aus dem März 1988: „Das Kunstwerk, die sanfte Lebensohrfeige (,Backpfeife‘ hin zum Leben) (es muß nicht immer, die Axt für das gefrorene Meer in uns sein)“ (Handke: Gestern unterwegs [Anm. 70], S. 144).

228 Handke: Denunziation ohne Wahrnehmung (Anm. 221), S. 147.

229 Handke: Drei Zitterer an der homerischen Quelle (Anm. 69), S. 166.

230 Die Angaben entnehme ich Wolfgang Albrecht: Literaturkritik. Stuttgart, Weimar: Metzler 2001, S. 76. Ausführliche Informationen zu den beiden Umfragen finden sich in Reinhold Viehoff: Literaturkritik 1973 und 1988. Aspekte des literaturkritischen Wertewandels. In: Literaturkritik Anspruch und Wirklichkeit (Anm. 7), S. 440-459. 
akkumuliert hatte, sondern auch als streitbarer Literatur- und Theaterkritiker brachte gleichwohl ein Problem mit sich: Seit er sich in der zweiten Hälfte der 1960er Jahre mit Texten über Autorinnen und Autoren, über Inszenierungen und Neuerscheinungen hervorgetan hatte, die in meinungsbildenden Medien wie der ZEIT oder dem Spiegel erschienen waren, sah er sich mit dem Vorwurf konfrontiert, er könne als Schriftsteller nicht unvoreingenommen über die Werke anderer Autoren urteilen, weil sich dabei zwangsläufig ein Rollenkonflikt ergebe. Der „zugleich als Kritiker auftretende Schriftsteller“231 sei, wie nicht zuletzt Reich-Ranicki bei verschiedenen Gelegenheiten äußerte, als „Sonntagsjäger der Kritik“ ${ }^{232}$ nicht in der Lage, ausreichend Distanz zum Gegenstand seiner Analyse zu wahren, weil er dabei eine eigene Agenda verfolge und außerdem für Freundschaftsdienste und Gefälligkeitsrezensionen anfälliger sei als ein professioneller Kritiker: „Ein wenig zwielichtig ist es immer, wenn Literaten über die Arbeit anderer Literaten öffentlich urteilen. “233 Als Beispiel für diesen Rollenkonflikt nennt Reich-Ranicki den von ihm eigentlich sehr geschätzten Theodor Fontane, der in seinen literaturkritischen Arbeiten nicht gezögert habe, „die aus seinem eigenen Werk bezogenen Kriterien zur allgemeingültigen Norm zu erheben“: „Mit anderen Worten: Der Romancier kommt hier dem Rezensenten ins Gehege, der - bewußt oder unbewußt - den eigenen epischen Bemühungen Schützenhilfe leistet. “234

Seine Position in den einschlägigen Debatten hat Handke 1969 in einem ausführlichen Fernseh-Gespräch mit Friedrich Luft folgendermaßen umrissen:

231 Lorenz: Pro domo (Anm. 7), S. 404.

232 Marcel Reich-Ranicki: Der doppelte Boden. Ein Gespräch mit Peter von Matt. Zürich: Ammann 1992, S. 18. Die identische Formulierung findet sich in Rolf Becker/Hellmuth Karasek: „Ich habe manipuliert, selbstverständlich!“ Kritiker Marcel Reich-Ranicki über seine Rolle im Literaturbetrieb und seinen Abgang von der FAZ. In: Der Spiegel, Nr. 1, 2.1.1989, S. 140-146, hier S. 143.

233 Reich-Ranicki: Der doppelte Boden (Anm. 232), S. 14. Vgl. dagegen Stefan Neuhaus: Dichter als Kritiker: Schiller und Fontane. In: Große Literaturkritiker. Hg. v. Sigurd Paul Scheichl. Innsbruck u. a.: StudienVerlag 2010, S. 31-41, hier S. 41, der argumentiert, dass etwa „Schiller und Fontane, obwohl oder weil sie in ihrer Doppelfunktion als Autoren und Kritiker agieren, Grundsätzliches zum Verständnis des literaturkritischen Prozesses zu sagen haben. Das bedeutet nicht, dass Autoren die besseren Kritiker sind [...]; aber man kann Autoren nicht, wegen eines möglichen Rollenkonflikts, die literaturkritische Kompetenz absprechen.“ Zum „Schriftsteller als Kritiker“ sowie zur „Verknüpfung der Werkbetrachtung mit der Reflexion der eigenen literarischen Tätigkeit“ vgl. exemplarisch die Überlegungen von Dirk Göttsche: Liebeserklärungen und Verletzungen - Zur Literaturkritik von Martin Walser und Ingeborg Bachmann. In: Literaturkritik - Anspruch und Wirklichkeit (Anm. 7), S. 197-212, Zit. S. 197.

234 Marcel Reich-Ranicki: Theodor Fontane. Der Profi des kritischen Geschäfts. [1971] In: M. R.-R.: Die Anwälte der Literatur. Stuttgart: DVA 1994, S. 120-129, hier S. 127. 
Mir wird dann immer vorgeworfen ... Wenn man das liest, diese kritikähnlichen Erfahrungen oder diese kritischen Bemerkungen - Kritiken kann man das ja nicht nennen -, wird mir vorgeworfen, ich schriebe ja selber und ich könnte das also nur subjektiv sehen oder ich könnte das nur von meiner Art des Machens sehen, und ich finde das eigentlich einen schändlichen Vorwurf. Warum soll ich, weil ich schreibe, weniger sehen oder beschränkter sein in meinem Sehen? Ich will eigentlich nur, wenn ich über Theater oder über Film schreibe, meine Erfahrungen mitteilen und sehen, ob die anderen Leute auch solche ähnlichen Erfahrungen machen können. Ich glaub, man muss da mit dieser Arbeitsteilung zwischen Theorie und Praxis vielleicht versuchen aufzuhören. ${ }^{235}$

Handke, der - wie bereits zitiert - die „Rolle“ des „Kritikers“, „eines Kommentators, eines Wohl- und Übelmeinenden“, 236 stets als eine für ihn „fremde“ wahrnahm, ja sich ostentativ gegen diese Bezeichnung verwahrte und mit dem souveränen „Kritikspiel“ ${ }^{\text {237 }}$ der professionellen Rezensenten lediglich kokettierte, wendet den „schändlichen Vorwurf“ der ,Subjektivität' des Autor-Kritikers hier in eine positive Bestimmung der eigenen Praxis - komme es doch, so Handke, nicht auf eine distanzierte Analyse, sondern auf die Mitteilung ästhetischer „Erfahrungen“" an.

Der Forderung nach einer feinsäuberlichen „Gewaltenteilung zwischen poetologischer Normsetzung, dichterischer Kunstübung und kritischer Vermittlung “ ${ }^{238}$ nach einer „zunftmäßigen Trennung zwischen literarischer Kritik und literarischer Produktion" “239 konnte er jedenfalls wenig abgewinnen, sondern er verstand das Schreiben über die Texte literarischer Zeitgenossen stets als integralen Teil seiner schriftstellerischen Existenz. Was er Mitte der 1980er Jahre im Gespräch mit Herbert Gamper für den Bereich des Sports konstatiert hat, dass nämlich „die Fußballer [...] viel schöner erzählen über ihr Spiel als die meisten Reporter das je können“, hat er in ähnlicher Weise für die Schriftstellerinnen und Künstler festgehalten. Allerdings sei, wie Handke Gamper gegenüber kritisch geäußert hat, zu beobachten, dass sich nicht nur die „Künstler zunehmend so wie die Journalisten“ ausdrückten, „die drüber ihren Diskurs veranstalten“, sondern auch „die Fußballer“ mehr und mehr „wie die Reporter über ihr Spiel“" redeten. ${ }^{240}$

235 Peter Handke im Gespräch mit Friedrich Luft (Anm. 20), 28:32-29:19.

236 Handke: Vorbemerkung (Anm. 39), S. 8.

237 Handke: Gurken und Kiefern, Äpfel und Schnee (Anm. 83), S. 274.

238 Lorenz: Pro domo (Anm. 7), S. 399.

239 Reinhard Baumgart: Damals. Ein Leben in Deutschland. 1929-2003. [München]: Hanser 2003, S. 195.

240 Handke: Aber ich lebe nur von den Zwischenräumen (Anm. 120), S. 258. 
Reich-Ranicki war der Überzeugung, dass es in der Literaturkritik nicht darauf ankomme, „selber dichterisch zu denken, sondern das Dichten und Denken anderer zu erkennen und zu überprüfen, zu zeigen und einzuordnen “. ${ }^{241}$ Walter Benjamin warf er vor, „zu sehr poetischer Denker“ gewesen zu sein, um als „Literaturkritiker“ $\mathrm{zu}$ arbeiten, ${ }^{242}$ während Handke sein Verständnis von Literaturkritik 1984 in einer programmatischen Rede ausdrücklich in dessen Nachfolge gestellt und die Unvereinbarkeit von dichterischem und kritischem Schreiben vehement bestritten hat: „Würde das Wünschen helfen, so wäre folgendes mein Wunsch: eine Wiederholung, eine Erneuerung, eine Wiederbelebung der Haltung Walter Benjamins. “243 Handke bezieht sich hier nicht auf Benjamins Ende der 1920er Jahre intensivierte Agitation für eine politisch engagierte, materialistische Praxis der Kritik, der das „Kunstwerk“ als „blanke Waffe in dem Kampfe der Geister“ dient. ${ }^{244}$ Vielmehr zielt er mit der emphatischen Hoffnung auf eine „Wiederbelebung“ auf eine markante Traditionslinie in der deutschen Literaturkritik ab, die sich von Novalis' im ersten Band des Athenäums skizziertem Ideal des „artistischen Kritikers“, „dessen Arbeiten die Geschichte der Kunst vorbereiten“, ${ }^{245}$ bis ins 20. Jahrhundert verfolgen lässt: $z u$ Benjamins in den ,Dreizehn Thesen' zur ,Technik des Kritikers' im Band Einbahnstraße (1928) formulierter Forderung, die Kritik müsse „in der Sprache der

241 Marcel Reich-Ranicki: Walter Benjamin. Der poetische Denker. [1972] In: M. R.-R.: Die Anwälte der Literatur (Anm. 234), S. 227-236, hier S. $234 \mathrm{f}$.

242 Ebd., S. 235. Zu Reich-Ranickis Vorbehalten gegenüber Benjamin vgl. Franz Schuh: All you need is love. Notizen und Exzerpte zur (Literatur-)Kritik. In: F. S.: Schreibkräfte. Über Literatur, Glück und Unglück. Köln: DuMont 200o, S. 24-114, hier S. 69-71; Christoph Schmitt-Maaß: Kritischer Kannibalismus. Eine Genealogie der Literaturkritik seit der Frühaufklärung. Bielefeld: transcript 2019, S. 134-137.

243 Peter Handke: Einwenden und Hochhalten. Rede auf Gustav Januš. [1984] In: P. H.: Langsam im Schatten. Gesammelte Verzettelungen. 1980-1992. Frankfurt a. M.: Suhrkamp 1992, S. 125-135, hier S. 127. Vgl. zu dieser Rede Kap. III, Abschnitt „Einwenden und Hochhalten: Handkes Rede gegen die Literaturkritik“.

244 Walter Benjamin: Einbahnstraße. In: W. B.: Gesammelte Schriften. Unter Mitwirkung v. Theodor W. Adorno u. Gershom Scholem hg. v. Rolf Tiedemann u. Hermann Schweppenhäuser. Bd. IV.1. Hg. v. Tillman Rexroth. Frankfurt a. M.: Suhrkamp 1972, S. 83-148, hier S. 109. Vgl. dazu Benjamins umfangreiche Vorarbeiten für eine Einleitung zu einem nie realisierten Band mit gesammelten Kritiken; ders.: Zur Literaturkritik. In: W. B.: Gesammelte Schriften. Bd. VI. Hg. v. Rolf Tiedemann u. Hermann Schweppenhäuser. Frankfurt a. M.: Suhrkamp 1985, S. 161-183. Zum Plan dieses Bandes vgl. Uwe Steiner: Walter Benjamin. Stuttgart, Weimar: Metzler 2004, S. 99 f., sowie Michael Opitz: Literaturkritik. In: Benjamin-Handbuch. Leben - Werk - Wirkung. Hg. v. Burkhardt Lindner. Unter Mitarb. v. Thomas Küpper u. Timo Skrandies. Stuttgart, Weimar: Metzler 2006, S. 311-332, hier S. 323 f.

245 [Novalis:] Blüthenstaub. In: Athenäum. Eine Zeitschrift v. August Wilhelm Schlegel u. Friedrich Schlegel. Ersten Bandes Erstes Stück. Berlin: Vieweg 1798, S. 70-106, hier S. 85. 
Artisten reden“, ${ }^{246}$ ebenso wie zu Robert Musils im gleichen Jahr publizierter Bemerkung über Alfred Kerr, wonach „es überhaupt bei allen Unterschieden keine bedeutende Kritik gibt, die nicht Dichtung wäre“; der „Kritikerdichter[ ]“, so Musils Charakterisierung von Kerrs Selbstverständnis, sei ein „Mensch, der aus Dichtung wieder Dichtung, gedichtete Kritik macht“ . ${ }^{247}$ Auf Novalis und Benjamin, insbesondere auf dessen Passagen-Werk, das eine wesentliche Grundlage für die ,Schwellengeschichte‘ Der Chinese des Schmerzes (1983) bildete, hat sich Handke wiederholt berufen, während er für Musil und insbesondere für den Mann ohne Eigenschaften kaum je besondere Sympathie gezeigt hat. ${ }^{248}$

Ohne Handke allzu forciert mit den zitierten Autoren in eine Genealogie der Reflexion über die Grenzen von Literatur und Literaturkritik einordnen zu wollen, ist jedenfalls Folgendes festzuhalten: Auf den Vorwurf, als Kritiker nur seiner eigenen schriftstellerischen Agenda zu folgen, reagierte Handke mit dem Hinweis auf die Blindheiten auch ,professioneller' Rezensenten. Zudem beharrte er darauf, als literarischer Autor eine besondere ästhetische Kompetenz, eine Sensibilität für die Faktur literarischer Texte zu besitzen, an der es den Berufskritikern mitunter mangle. Seine Reflexionen über die Rolle der Kritik im literarischen Feld und ihre Verfahren berühren immer auch die Frage nach den Möglichkeiten , artistischer Kritik', zumal Handke deren zentrale Aufgabe mit Novalis' emphatischer Formulierung - durchaus darin sah, Leitlinien und Orientierungsmarken für die zukünftige „Geschichte der Kunst“ vorzubereiten. Die literaturkritischen Arbeiten Handkes erweisen sich vor diesem Hintergrund

246 Benjamin: Einbahnstraße (Anm. 244), S. 108. Vgl. dazu etwa die Reflexionen über „Elemente einer Theorie des Lesens nach Benjamin“ in Alexander Honold: Der Leser Walter Benjamin. Bruchstücke einer deutschen Literaturgeschichte. Berlin: Vorwerk 8 2000, S. 14-51.

247 Robert Musil: Heute spricht Alfred Kerr. Ein Porträt des berühmten deutschen Kritikers. [1928] In: R. M.: Gesammelte Werke. Hg. v. Adolf Frisé. Bd. II. Reinbek b. Hamburg: Rowohlt 200o, S. 1186-1188, hier S. 1188.

248 Vgl. Karl Wagner: Musil und Handke: kein Vergleich. In: Peter Handke. Freiheit des Schreibens - Ordnung der Schrift. Hg. v. Klaus Kastberger unter Mitarb. v. Clemens Özelt. Wien: Zsolnay 2009, S. 294-305. Spuren dieser Aversion zeigen sich bereits im 1972 publizierten Gedicht Leben ohne Poesie: „Im ,Mann ohne Eigenschaften' bin ich bis zu / dem Satz gekommen / ,Ulrich sah sich den Menschen an' / (Auch ,den Menschen' meinte Musil / verächtlich) / da habe ich vor Ekel nicht weiterlesen können“" (Peter Handke: Leben ohne Poesie. [1972] In: P. H.: Als das Wünschen noch geholfen hat [Anm. 43], S. 9-23, hier S. 13); in der Geschichte des Bleistifts greift Handke die Passage aus dem Mann ohne Eigenschaften noch einmal auf: „Nicht ,Ich sehe mir die Leute an' (so ungefähr Musil), sondern: ,Ich lasse sie, betrachtend, sein' (jedenfalls ist das mein Ideal)“ (Handke: Die Geschichte des Bleistifts [Anm. 73], S. 197). Die Stelle findet sich im 81. Kapitel von Musils Opus magnum: „Ulrich sah sich den Menschen an und wahrte Raum zwischen sich und ihm“ (Robert Musil: Der Mann ohne Eigenschaften. Roman. Hg. v. Adolf Frisé. Bd. 1. Reinbek b. Hamburg: Rowohlt 1981, S. 349). 
auch als kontinuierliche Sondierung des Übergangsbereichs zwischen Literatur und Kritik, zwischen Erzählung und Analyse.

Bereits im Herbst 1989 teilte Handke Hermann Lenz mit, „die letzte Buchbesprechung meines Lebens“ geschrieben zu haben, um diese Ankündigung aber sogleich durch den Nachsatz „(fürs erste die letzte)“ zu relativieren. ${ }^{249}$ Tatsächlich bildet das Schreiben über Bücher und Literatur bis in die unmittelbare Gegenwart einen wesentlichen Teil von Handkes schriftstellerischer Arbeit und ist dabei aufs Engste mit seinem literarischen Schreiben verknüpft. ${ }^{250}$ Er setzt sich einerseits „[k]raft seines berühmten Namens“ für andere Autoren ein (es handelt sich fast durchwegs um Männer), um sie gewissermaßen im Windschatten der Aufmerksamkeit einem größeren Publikum zu präsentieren. ${ }^{251}$ Andererseits reflektiert er im Nachvollzug und in der Beschreibung, fremder ' Erzählverfahren stets auch die eigene Poetik, die eigene ,Schreibregel': Handkes Rezensionen sprechen, mehr oder weniger explizit, immer auch von seinen eigenen Texten, von seiner eigenen Vorstellung von Literatur.

Wenn sich Autorinnen und Autoren über andere Schreibende äußern und deren Texte, sei es kritisch oder zustimmend, in den Blick nehmen, dann sind diese Kommentare, wie Klaus Amann pointiert festgehalten hat, stets unausweichlich „mit dem eigenen Schreiben verbunden“, sind von diesem „nicht zu trennen“: „Wer als Schriftsteller über das Schreiben anderer spricht, gibt, ob er will oder nicht, Auskunft über sein eigenes Schreiben, über das, was er können oder nicht können möchte, womit er kämpft, was er für möglich hält, was ihm geglückt oder misslungen ist. “252 Nicht zuletzt deshalb bieten Peter Handkes ,Begleitschreiben' zu den Texten anderer Schriftstellerinnen und Schriftsteller, seine begeisterten Empfehlungen wie seine mitunter harschen Einwände, auch vielfältige und aufschlussreiche Zugänge zum im engeren Sinne literarischen Werk des Autors.

249 Handke an Lenz, 15.11. 1989. In: Handke/Lenz: Berichterstatter des Tages (Anm. 35), S. 246.

250 Haslinger: Peter Handke (Anm. 3), S. 95, hat in diesem Zusammenhang betont: „Die Rezensionsarbeit brachte Handkes literarischer Entwicklung viel.“

251 Pichler: Die Beschreibung des Glücks (Anm. 3), S. 121. Vgl. dazu Struck: Der Begleitschreiber (Anm. 65), S. 20.

252 Klaus Amann: Das Wie des Was. Vorwort. In: Freund und Feind. Alois Brandstetter u. a. über ihre literarischen Vorbilder, Widersacher und Nebenbuhler. Hg. v. K. A. u. Fabjan Hafner. Wien: Sonderzahl 2006, S. 7-14, hier S. 13. 


\title{
VI „ZEITUNGSG'SCHICHT'LN“: THOMAS BERNHARD ALS LITERATURKRITIKER
}

\author{
Vor eines Dichters Grab: Johannes Freumbichler
}

Als er Thomas Bernhard in den 1950er Jahren kennengelernt habe, so der Wiener Autor Hermann Hakel in erst postum veröffentlichten Aufzeichnungen, sei dieser „ein kleiner Reporter“ gewesen und habe „Salzburg (und Österreich) in kleinen Artikeln“ gelobt; nun, gut dreißig Jahre später, jedoch wage es „[n]iemand“ mehr, „die jetzt nachzudrucken“. Sind Hakels Kommentare zum Werdegang des jungen Schriftstellers auch mit Vorsicht zu genießen, weil sie von einem tiefsitzenden Ressentiment gegenüber dem „dumpfe[n], schwermäulige[n] Wurzelsepp[ ]“ Bernhard zeugen, ${ }^{2}$ machen sie doch auf einen wesentlichen Bruch in der Karriere des 1931 geborenen Autors aufmerksam: Viele Texte, die Bernhard in der ersten Hälfte der 1950er Jahre als Gerichtsberichterstatter, Kulturjournalist, Erzähler, Lyriker und Feuilletonist für Zeitungen und Anthologien verfasst hat, sind nur schwer mit dem späteren Image des streitbaren Polemikers und Provokateurs in Einklang zu bringen, dem - im Gegensatz zum 20 Jahre älteren Hakel - eine weit über den deutschsprachigen Raum hinausreichende Aufmerksamkeit zuteilwurde.

Aus den Worten Hakels, der sich nach dem Zweiten Weltkrieg als Förderer junger Schriftsteller (etwa von Gerhard Amanshauser) hervorgetan hat, ${ }^{3}$ spricht nicht nur - wie aus seinen Bemerkungen zu Peter Handke ${ }^{4}$ - der Missmut eines Außenseiters über den Erfolg eines in seinen Augen überschätzten Autors. Sie rufen, vier Jahre nach Hakels und zwei Jahre nach Bernhards Tod publiziert, auch in Erinnerung, dass Bernhards erste Schreibversuche den Furor und die polemische Energie des späteren Skandalautors kaum erahnen ließen. Sein Weg zum ersten Prosabuch, dem 1963 im Frankfurter Insel Verlag erschienenen Frost, war - gerade im Vergleich mit dem literarischen shooting star Handke - langwierig und mühselig. Erst mit der Zeit gelang es ihm, sich vom restaurativen

1 Hermann Hakel: Dürre Äste. Welkes Gras. Begegnungen mit Literaten. Bemerkungen zur Literatur. Wien: Lynkeus 1991, S. 336.

2 Ebd., S. $334 \mathrm{f}$.

3 Vgl. Gerhard Amanshauser/Hermann Hakel: Die taoistische Powidlstimmung der Österreicher. Briefwechsel 1953-1986. Hg. v. Hans Höller. Weitra: Bibliothek der Provinz 2005; zu Hakels Rolle als Mentor im österreichischen Literaturbetrieb vgl. Evelyne Polt-Heinzl: Die grauen Jahre. Österreichische Literatur nach 1945. Mythen, Legenden, Lügen. Wien: Sonderzahl 2018, S. $143 \mathrm{f}$.

4 Sie finden sich in Hakel: Dürre Äste. Welkes Gras (Anm. 1), S. 347-353, unter dem bezeichnenden Titel „Peter Handkes künstlerische Selbstbefriedigung“. 
Salzburger Kulturbetrieb der Nachkriegsjahre zu emanzipieren. Die ersten Schritte auf diesem Weg lassen sich anhand seiner Tätigkeit als Journalist und Kulturberichterstatter nachvollziehen. Ihr sind die folgenden Überlegungen, die Bernhards frühe Literaturkritik und ihren Nachhall im späteren Werk in den Blick nehmen, gewidmet.

Im konservativen Literaturbetrieb Salzburgs sozialisiert, fand Thomas Bernhard die ersten Taktgeber seines Schreibens und seiner Reflexion über Literatur und Kultur nicht - wie später der knapp zwölf Jahre jüngere Handke - im "großen, dabei so leichtsinnigen Schall“ der Beatles, ${ }^{5}$ sondern in der Riege jener Geistesgrößen, die schon sein Großvater, der Schriftsteller Johannes Freumbichler, in Ehren gehalten hatte. Ende der 1940er Jahre mit einer schweren Lungenerkrankung in einem Sanatorium in Großgmain untergebracht, entdeckte er jene Werke für sich, die ihm sein kurz zuvor verstorbener Großvater als Erbe und Lesestoff hinterlassen hatte. ${ }^{6}$ Seine Familie bat er darum, so berichtet Bernhard im dritten Band der autobiographischen Erzählungen, Der Atem. Eine Entscheidung (1978), ihm „jene Bücher aus dem Bücherkasten meines Großvaters“ ans Krankenbett zu bringen, von denen er wusste, „daß sie im Leben meines Großvaters von allererster Bedeutung gewesen waren“ (TBW 10, $298 \mathrm{f}$.): Werke von William Shakespeare und Adalbert Stifter waren darunter, von Nikolaus Lenau und Miguel de Cervantes, von Michel de Montaigne, Blaise Pascal und Arthur Schopenhauer, aber mit Ausnahme von Charles Péguy und Knut Hamsun offenbar keine Autoren (und schon gar keine Autorinnen), deren Wirken bis ins 20. Jahrhundert, geschweige denn bis zu den Avantgarden der 1910er und 1920er Jahre gereicht hätte:

Meine Bibliothek in meinem Zimmer war schon auf mehrere Dutzend Bücher angewachsen gewesen, ich hatte den Hunger von Hamsun, den Jüngling von Dostojewski und Die Wahlverwandtschaften gelesen und mir, wie mein Großvater das sein ganzes Leben lang praktiziert hatte, zu meiner Lektüre Notizen gemacht. [...] Kaum war ich aufgewacht und hatte wie seit Monaten jeden Morgen die Vorschrift, meine Temperatur zu messen, gewissenhaft erfüllt gehabt, war ich auch schon mit meinen Büchern, meinen engsten und innigsten Freunden, zusammen gewesen. (TBW 10, 306)

5 Peter Handke: Versuch über die Jukebox. Erzählung. Frankfurt a. M.: Suhrkamp 1990, S. 89.

6 Vgl. dazu Bernhard Judex: Der Schriftsteller Johannes Freumbichler. 1881-1949. Leben und Werk von Thomas Bernhards Großvater. Wien u. a.: Böhlau 2006, S. 221-249, sowie ders.: Schreiben in der „Denkkammer“. Thomas Bernhard und das literarische Erbe seines Großvaters Johannes Freumbichler - Überlegungen zur poetischen Genese. In: Thomas Bernhard Jahrbuch 2005/2006, S. 11-33. - Alexander Honold: Bernhards Dämonen. In: Thomas Bernhard eine Einschärfung. Hg. v. Joachim Hoell, A. H. u. Kai Luehrs-Kaiser. Berlin: Vorwerk $8{ }^{2} 1999$, S. 17-25, hier S. 22, schreibt mit Blick auf Bernhards jugendliche Lektüren von einem „angelesene[n], nicht wirklich angeeignete[n] Sammelsurium auf Großvaters Spuren“. 
Während Peter Handke im Versuch über die Jukebox (1990) davon berichtet, er habe die täglich und stundenlang in einem Lokal gehörten Lieder der Beatles anfangs ohne Wissen um deren Interpreten gehört, mit einem „Staunen, das keine Namens-Neugier kannte“", standen Bernhards Anfänge, angeleitet von seinem Großvater, im Zeichen bedeutender Namen und ehrwürdiger Traditionen, die für sein späteres Schreiben - obgleich er sich dabei mitunter auf bloßes name dropping beschränkte ${ }^{8}$ - von zentraler Signifikanz werden sollten: „Alle meine Kenntnisse“, wird er 1975 in Die Ursache. Eine Andeutung, dem ersten Band der autobiographischen Pentalogie, schreiben, „sind zurückzuführen auf diesen für mich in allem lebens- und existenzentscheidenden Menschen, der selbst durch die Schule Montaignes gegangen war, wie ich durch seine Schule gegangen bin.“ (TBW 10, 89) Nicht nur Bernhard selbst, sondern auch seine Protagonisten werden „immer wieder auf herausragende Philosophen und ihre Sätze rekurrieren und sie gewissermaßen als Anlaß des Schreibens in Anspruch nehmen“;” der Großvater steht dabei als Vermittlerfigur, genannt oder ungenannt, im Hintergrund.

In Johannes Freumbichlers Nachlass hat sich eine umfangreiche Sammlung von annähernd 300 Gedichten mit dem Titel Erziehung zu Vernunft und Fröhlichkeit erhalten. Anfang 1946 begonnen, wurde sie Ende Oktober 1948, gut drei Monate vor dem Tod Freumbichlers am 11. Februar 1949, beendet. ${ }^{10}$ Die darin enthaltenen Texte, von denen bislang nur eine kleine Auswahl publiziert vorliegt, waren als Lehrgedichte konzipiert, die der Großvater dem Enkel zu dessen 18. Geburtstag mit auf den Lebensweg zu geben beabsichtigte: „Geliebter

7 Handke: Versuch über die Jukebox (Anm. 5), S. 89. Vgl. dazu Clemens Peck: „Schall und Wahn“. Andere Orte der Erinnerung in Peter Handkes Versuch über die Jukebox. In: High und low. Zur Interferenz von Hoch- und Populärkultur in der Gegenwartsliteratur. Hg. v. Thomas Wegmann u. Norbert Christian Wolf. Berlin, Boston: de Gruyter 2012, S. 97-119; Karl Wagner: Handkes Versuch über die Jukebox. In: Figurationen 14 (2013), H. 1, S. 65-74; Alexander Honold: Der Erd-Erzähler. Peter Handkes Prosa der Orte, Räume und Landschaften. Stuttgart: Metzler 2017, S. 293-325.

8 Vgl. zu diesem Verfahren bei Bernhard Juliane Vogel: Die Gebetbücher des Philosophen. Lektüren in den Romanen Thomas Bernhards. In: Modern Austrian Literature 21 (1988), H. 3/4, S. 173-186. Tobias Heyl: Zeichen und Dinge, Kunst und Natur. Intertextuelle Bezugnahmen in der Prosa Thomas Bernhards. Frankfurt a. M. u. a.: Lang 1995, S. 130, hat darauf hingewiesen, dass in Bernhards Prosa intertextuelle „Markierungen“ überwiegen, „die allein über den Autornamen laufen“.

9 Markus Janner: Der Tod im Text. Thomas Bernhards Grabschriften. Dargestellt anhand von frühen Erzählversuchen aus dem Nachlaß, der Lyrik und der späten Prosa. Frankfurt a. M. u. a.: Lang 2003 , S. 163.

10 Vgl. das Nachwort von Heike Mayer in: Johannes Freumbichler: Erziehung zu Vernunft und Fröhlichkeit. Briefe in Knittelversen für die Jugend von Sechzehn bis Sechzig. Lehrgedicht aus dem Nachlaß, gewidmet dem Enkel Thomas Bernhard. Hg. u. mit einem Nachwort v. H. M. o. O.: Liliom 2003, S. 103-112, hier S. 103. 
Enkelbub, Niclas van Heerlen“, hebt der „Vorspruch“ der Sammlung an und nimmt dabei jenes Pseudonym vorweg, das Bernhard später unter seinen ersten journalistischen Beitrag Vor eines Dichters Grab setzen wird,

im stillen Kämmerlein

Schreib' ich in Reimen dir, arm und holprig, grob und fein,

So wie es in die Feder läuft und ohne viel Bedenken,

Will ich dir väterlich hier Rat auf Ratschlag schenken. ${ }^{11}$

Einzelne Texte der Sammlung werde ich noch genauer in den Blick nehmen, da die konservative, gegen Massen- und Unterhaltungskultur anschreibende Kritik, die in diesen Versen zum Ausdruck kommt - „Drum rat ich dir, mein Sohn, wend' dich dem schönen Buche zu, / Hier findest du das wahre Glück, die selige Ruh'“12 -, in den folgenden Jahren einen wichtigen Bezugspunkt für Bernhards literaturkritische Reflexionen bilden sollte.

Thomas Bernhard hat den Beginn seines Schreibens wiederholt mit der Zäsur des Todes von Johannes Freumbichler, nur zwei Tage nach seinem 18. Geburtstag, in Verbindung gebracht. Ein knappes halbes Jahr danach, im Juli 1949, wurde Bernhard in die Lungenheilanstalt Grafenhof (St. Veit/Pongau) eingewiesen und flüchtete sich dort, wie er in Die Kälte. Eine Isolation (1981) festhält, aus seiner schwierigen gesundheitlichen und familiären Lage mehr und mehr „ins Schreiben“: „[I]ch schrieb und schrieb, ich weiß nicht mehr, Hunderte, Aberhunderte Gedichte, ich existierte nur, wenn ich schrieb“; als Katalysator der Produktivität nennt das autobiographische Ich im Rückblick den Tod des geliebten Großvaters, dem bei aller Tragik auch ein Moment der Befreiung inhärent gewesen sei: „, $[\mathrm{M}]$ ein Großvater, der Dichter, war tot, jetzt durfte ich schreiben, jetzt hatte ich die Möglichkeit, selbst zu dichten, jetzt getraute ich mich, jetzt hatte ich dieses Mittel zum Zweck, in das ich mich mit allen meinen Kräften hineinstürzte " (TBW 10, 331). ${ }^{13}$ Im letzten ausführlichen Interview, das Bernhard der Journalistin Asta Scheib 1987 gegeben hat, weist er noch einmal auf diesen Zusammenhang hin: „Mein Großvater war Schriftsteller. Erst nach seinem Tode habe ich mich getraut, selber zu schreiben." (TBW 22.2, 335)

11 Freumbichler: Erziehung zu Vernunft und Fröhlichkeit (Anm. 10), S. 12.

12 Ebd., S. 38.

13 Vgl. dazu die Deutung in Manfred Mittermayer: Die Stimme des alten Meisters. Zur Figur des Großvaters im literarischen Werk Thomas Bernhards. In: Österreich und andere Katastrophen. Thomas Bernhard in memoriam. Beiträge des Internationalen Kolloquiums an der Universität des Saarlandes vom 10. bis 12. Juni 1999. Hg. v. Pierre Béhar u. Jeanne Benay. St. Ingbert: Röhrig 2001, S. 25-45, hier S. 30 f.

14 Michael Billenkamp: Thomas Bernhard. Narrativik und poetologische Praxis. Heidelberg: Winter 2008, S. 68, hat die Rolle Freumbichlers als Vorbild für das Schreiben seines Enkels 
Das Narrativ von der Befreiung der eigenen Produktivität durch das Ableben des Vorbildes bzw. des Vorfahren gehorcht, ebenso wie andere Erzählsequenzen in Bernhards autobiographischen Arbeiten, einem vielfach erprobten literarischen Muster. ${ }^{15}$ Erst jüngst hat Friedrich Christian Delius in der Erzählung Die Zukunft der Schönheit (2018) mit Blick auf seinen Vater eine ganz ähnliche Konstellation entworfen: Nach dessen Tod habe er, so Delius, rasch die väterliche Schreibmaschine „erobert“ und in der Folge „den Triumph ausgekostet, eine ganz andere Buchstabenmelodie darauf zu spielen als er und auf ihren Tasten mein Glück zu suchen ${ }^{\text {“ }}{ }^{16}$ Steht Delius' Schilderung auch in einem anderen historischen Kontext, weil der 2011 mit dem Georg-Büchner-Preis ausgezeichnete Autor in Die Zukunft der Schönheit vor allem die Abnabelung seiner Generation von der Welt der Väter in den 1960er Jahren versinnbildlicht, gehorcht sie doch einem ähnlichen Strukturprinzip wie Bernhards autobiographische Erzählung: „Mit dem Geräusch des Hackens und Hauens und Tippens jedes einzelnen Buchstabens signalisierte ich der Familie: Jetzt schreibe ich, jetzt führe ich das Wort, jetzt bin ich der Stärkere. ${ }^{\text {“17 }}$ Was bei Delius und in der Kulturtheorie Harold Blooms als anmaßende „Umschrift des Vaters" ${ }^{\text {"18 }}$ firmiert, ist in Bernhards autobiographischem Narrativ um eine Generation nach hinten verschoben. Hier wie dort kreist die Erzählung um das Recht zu schreiben, um das Selbstbewusstsein zum eigenen künstlerischen Ausdruck, das erst mit dem Tod des Vorfahren zur Entfaltung kommen kann.

Die prekäre Gleichzeitigkeit von Befreiung und tiefer Trauer, die in der Autobiographie einprägsam beschrieben wird, hat Bernhard auch in fiktionalen Texten wiederholt verarbeitet: Noch der Musikphilosoph Reger in Alte Meister (1985) wird vom Tod seiner Frau sagen, dieser sei nicht nur sein "größtes Unglück“ gewesen, sondern habe ihn auch „befreit“: „Mit dem Tod meiner Frau bin ich frei geworden, sagte er, und wenn ich sage frei, so meine ich gänzlich frei, zur Gänze frei, vollkommen frei, wenn Sie wissen oder wenigstens ahnen, was das heißt. [...] Der Tod des geliebten Menschen ist ja auch die ungeheuere Befreiung unseres ganzen Systems“ (TBW 8, 186). Die Figur des Großvaters wird dem schreibenden Enkel zeitlebens, im Guten wie im

zudem auf gattungstheoretische Aspekte bezogen: „Bernhards anfängliche Verehrung von Freumbichlers Werk erklärt, dass er sich zunächst mittels Lyrik und kürzeren Erzählungen zu profilieren sucht. Längeren Prosastücken und Romanen, die er zu Beginn seiner Karriere noch ausspart, weil er sich am Werk seines Großvaters nicht messen lassen will, wendet er sich erst zu, als er sich von Freumbichlers Einfluss emanzipiert hat.“

15 Vgl. dazu grundlegend Reinhard Tschapke: Hölle und zurück. Das Initiationsthema in den Jugenderinnerungen Thomas Bernhards. Hildesheim u. a.: Olms 1984.

16 Friedrich Christian Delius: Die Zukunft der Schönheit. Erzählung. Berlin: Rowohlt 2018, S. 56.

17 Ebd.

18 Harold Bloom: Eine Topographie des Fehllesens. Frankfurt a. M.: Suhrkamp 1997, S. 29. 
Schlechten, ${ }^{19}$ als wichtige Orientierungsinstanz dienen, wobei sich Bernhards diesbezügliche Äußerungen stets „zwischen den Polen der Identifikation und der Abgrenzung “ bewegen. ${ }^{20}$ Auch vielen Protagonisten hat er diese Prägung mit auf den Lebensweg gegeben. „Wenn wir von unserem Großvater / nichts als Schopenhauer erben / können wir uns in jedem Fall / glücklich schätzen“" (TBW 20, 24), lässt er etwa den alten Schauspieler in Einfach kompliziert (1986) sagen. Konstellationen wie diese tauchen in Bernhards Prosa- und Theatertexten immer wieder auf. Zahlreiche Bühnenfiguren - etwa Caribaldi in Die Macht der Gewohnheit (1974) oder Bruscon in Der Theatermacher (1984) - tragen charakterliche Züge des Großvaters; der Autor selbst hat bereits im Filmmonolog Drei Tage von 1970 darauf hingewiesen, dass die von ihm gezeichneten „Männerfiguren“ im Grunde immer seinem „Großvater, mütterlicherseits“ ähneln (TBW 22.2, 55). ${ }^{21}$ Wiederholt hat er einzelne Biographeme aus dem Leben Freumbichlers in Texte eingearbeitet, etwa wenn er Schriftsteller- und Gelehrtenfiguren - dem Vorbild seines Großvaters folgend - in eine „alte Pferdedecke“ (TBW 18, 267) eingehüllt am Schreibtisch sitzen lässt. ${ }^{22}$ „Der Großvater schnürte sich mit einem Ledergurt seine Pferdedecke um den Leib und setzte sich an den Schreibtisch“, heißt es in Ein Kind (1982) über Freumbichlers tägliche Schreibexerzitien (TBW 10, 426), die Bernhard im selben Jahr den an seinem Werk verzweifelnden Musikwissenschaftler in Beton nachvollziehen lässt: „Ich stand auf und wickelte mich in die Decke, in die von meinem Großvater mütterlicherseits ererbte Pferdedecke, ich schnürte die Decke mit dem Ledergurt, den ich genauso wie die Decke von meinem Großvater geerbt habe, so fest als möglich $\mathrm{zu}$, so fest, daß ich gerade noch atmen konnte und setzte mich an den Schreibtisch." (TBW 5, 9) Zudem hat die Forschung auf die Übereinstimmung zwischen Formulierungen, die in Die Kälte (1981) dem Großvater in den Mund gelegt werden, und Äußerungen des „Weltverbesserers“im gleichnamigen Theaterstück von 1979 hingewiesen ${ }^{23}$ - und

19 Rudolf Brändle: Zeugenfreundschaft. Erinnerungen an Thomas Bernhard. [1999] Frankfurt a. M.: Suhrkamp 2001, S. 15, spricht vom „prägende[n] und doch abschreckende[n] Vorbild des Großvaters“.

20 Mittermayer: Die Stimme des alten Meisters (Anm. 13), S. 35.

21 Vgl. dazu Uwe Betz: Der Großvater als Dramaturg, Double und Farce. Zur steten Wiedergeburt der Ahnen in Thomas Bernhards Werk. In: Bernhard-Tage Ohlsdorf 1999. „In die entgegengesetzte Richtung“. Thomas Bernhard und sein Großvater Johannes Freumbichler. Materialien. Hg. v. Franz Gebesmair u. Manfred Mittermayer. Weitra: Bibliothek der Provinz [20oo], S. 100-131; Bernhard Judex: Die Persiflage des Geistesmenschen. Thomas Bernhard und die Figur des Großvaters. Konstruktionen biografischer und literarischer Identität. In: Thomas Bernhard. Persiflage und Subversion. Hg. v. Mireille Tabah u. Manfred Mittermayer. Würzburg: Königshausen \& Neumann 2013, S. 189-205.

22 Vgl. Nina Birkner: Vom Genius zum Medienästheten. Modelle des Künstlerdramas im 2o. Jahrhundert. Tübingen: Niemeyer 2009, S. $245 \mathrm{f}$.

23 Vgl. etwa Mittermayer: Die Stimme des alten Meisters (Anm. 13), S. 38. 
diesen intratextuellen Transfer als „Osmose zwischen Autobiografie und literarischem Werk" beschrieben. ${ }^{24}$

Die Person Freumbichlers spielte schließlich auch für den Beginn von Bernhards Tätigkeit als Journalist im Salzburg der 1950er Jahre eine zentrale Rolle. Die Kritiken und Feuilletons, die Bernhard ab 1952 für das Demokratische Volksblatt verfasste, verraten eine starke Affinität zum Weltbild und zur literarischen Ästhetik seines Großvaters. Bereits Bernhards erster, am 12. Juli 1950 im Salzburger Volksblatt gedruckter journalistischer Beitrag widmete sich unter dem Titel Vor eines Dichters Grab dem Andenken Freumbichlers. Ein knapper Monat zuvor, am 19. Juni 1950, war die Erzählung Das rote Licht unter dem Namen „Thomas Fabian“ (also unter dem Familiennamen seines Vormunds) ebenfalls im Salzburger Volksblatt erschienen. ${ }^{25}$ Auch Vor eines Dichters Grab wurde unter einem Pseudonym veröffentlicht: „Niklas van Heerlen“, einer Namensbildung aus dem zweiten Vornamen des Autors und seinem niederländischen Geburtsort. ${ }^{26}$ In der Rubrik „Die Heimat“ gedruckt - gleich über einem Bericht zur Wiedereröffnung des traditionsreichen Café Tomaselli ${ }^{27}$-, schildert das kurze Feuilleton

24 Franz M. Eybl: „Wenn das Werk lacht, weint der Dichter“. Thomas Bernhards poetologische Maskeraden. In: Dichterdarsteller. Fallstudien zur biographischen Legende des Autors im 20. und 21. Jahrhundert. Hg. v. Robert Leucht u. Magnus Wieland. Göttingen: Wallstein 2016, S. $157-174$, hier S. 163 .

25 Vgl. TBW 14, 457-46o. Kurz vor dem Druck seiner ersten literarischen Publikation am 19. 6.1950 wurde Bernhard erneut in die Lungenheilstätte Grafenhof eingeliefert. Vgl. Manfred Mittermayer: Thomas Bernhard. Eine Biografie. Salzburg, Wien: Residenz 2015, S. 81. - Das Salzburger Volksblatt war erst wenige Tage zuvor, am 15.6.1950, erstmals nach Kriegsende wieder erschienen; Grund für die nach 1945 zunächst fehlende Zulassung des Salzburger Volksblatts war die nazistische Vergangenheit der Eigentümerfamilie der Zeitung gewesen. Vgl. https:// www.sn.at/wiki/Salzburger_Volksblatt (Stand 14.10.2020). Das Salzburger Volksblatt diente vielen ehemaligen NS-Autorinnen und -Autoren, denen nach 1945 Publikationsverbote auferlegt worden waren, als willkommene Möglichkeit, Texte zu veröffentlichen: „Im ersten Halbjahr (ab Juni 1950) des Wiedererscheinens des ,Salzburger Volksblatts` war praktisch die gesamte ehemals deutsch-nationale und NS-Schriftsteller-Prominenz mit Textauszügen vertreten. Robert Hohlbaum schrieb einen Nachruf auf Karl Hans Strobl, Bruno Brehm erhielt einen Würdigungsbeitrag, Robert Hohlbaum und Heinrich Zillich wurden als Vortragende in Salzburg begrüßt, [Erwin Guido] Kolbenheyer wurde gefeiert, ohne daß jedoch auf ihre Rolle einige Jahre zuvor eingegangen worden wäre.“ (Karl Müller: Zäsuren ohne Folgen. Das lange Leben der literarischen Antimoderne Österreichs seit den 3oer Jahren. Salzburg: Otto Müller 1990, S. 262)

26 Zu Bernhards Pseudonymen in den frühen 1950er Jahren vgl. Rudolf Habringer: Der Auswegsucher. Über Thomas Bernhards Anfänge als Journalist. In: Thomas Bernhard und Salzburg. 22 Annäherungen. Hg. v. Manfred Mittermayer u. Sabine Veits-Falk. Salzburg: Jung und Jung 2001, S. 31-40, hier S. 32.

27 Vgl. N. N.: Café Tomaselli wird wieder eröffnet. Salzburgs ältestes Kaffeehaus. In: Salzburger Volksblatt, 12.7.1950. 
einen Spaziergang auf dem Friedhof im Salzburger Stadtteil Maxglan; siebzehn Monate zuvor war Freumbichler hier beerdigt worden:

Plötzlich stand ich still. Ich las an einer anscheinend vergessenen Grabstätte den Namen eines stillen Denkers und einzigartigen Dichters, der, wie ich mich erinnerte, vor eineinhalb Jahren hier begraben wurde. Ich dachte sogleich an Leute in Henndorfer Tracht, an Bauern und Bäuerinnen mit gesenktem Haupt, die dem schlichten Sarge langsam folgten. Wieder schmerzte mich der Verlust dieses großartigen Mannes aus dem nahen Henndorf und wie von fern her drangen die Lobgesänge aus seinen Gedichten zu mir, sah ich die Gestalten aus einer unvergänglichen Philomena Ellenhub. Hat man das Grab des Dichters vergessen? (TBW 22.1, 9)

Der Autor dieser Zeilen verzichtet darauf, sich als Enkel des „großartigen Mannes“ zu outen. Später wird er Johannes Freumbichler in weiteren journalistischen Beiträgen, etwa in den Reportagen Hochsommerliches Henndorf (9. Juli 1952) und Hügelwanderung zu zweit (8. Juli 1953), ${ }^{28}$ beiläufig erwähnen, er wird sich bei verschiedenen Gelegenheiten bemühen, „die Erinnerung an Freumbichler lebendig zu halten" ${ }^{29}$ und dabei wiederholt beklagen, dass sein Großvater nicht genügend Aufmerksamkeit und Wertschätzung im literarischen Feld erfahre: Man finde, so heißt es in einem Artikel zu den Salzburger Festspielen 1953, in den hiesigen Buchhandlungen beinahe keine Bände von „österreichischen Autoren“ mehr - „fast keinen Mell, keinen Freumbichler, nichts von Preradović, kaum einen Hofmannsthal, nur mehr den Hemingway und die gute Colette“ (TBW 22.1, 228). ${ }^{30}$

Bernhards nun mit vollem Namen gezeichnete Klage über die mangelnde Präsenz der österreichischen Literatur in den Schaufenstern des Salzburger Buchhandels ist charakteristisch für seinen Blick auf Literatur und Literaturbetrieb dieser Jahre: Zum einen äußert sich darin die tendenzielle Reserviertheit

28 Vgl. zu diesen Texten Christian Klug: Thomas Bernhards Arbeiten für das Salzburger Demokratische Volksblatt 1952 bis 1954. In: Modern Austrian Literature 21 (1988), H. 3/4, S. 135-172, hier S. 139 f.: „In Berichten über seine Wanderungen idealisiert Bernhard die bäuerliche und handwerkliche Sozialstruktur dieser Gegend zu einer Idylle, in die sich Momente kindlicher Wahrnehmung mischen. Dadurch erhalten diese Schilderungen seltsam entrückte, sowohl klischee- als auch märchenhafte Züge." Vgl. dazu ebd., S. 140-144.

29 Billenkamp: Thomas Bernhard (Anm. 14), S. 37

30 Einige Wochen zuvor hatte Bernhard in Wo sind die österreichischen Dichter? bedauert, dass man in den Schaufenstern der Buchhandlungen „zehnmal (und in allen Schattierungen) Cronin, Colette, Lewis, Hemingway usw. - um noch die besseren zu nennen - vorfindet, während unsere Augen nur sehr, sehr selten Kunde von der Existenz eines Franz Nabl oder einer Paula Grogger, um nur zwei Beispiele herauszugreifen, erfahren." (TBW 22.1, 168) Vgl. auch TBW 22.1, 284 . 
des jungen Journalisten gegenüber fremdsprachigen Autorinnen und Autoren - schon Anfang 1952 hatte er die „überseeischen, überwürzten Erzeugnisse“ der ausländischen Literatur kritisiert (TBW 22.1, 15), in der Folge über Veranstaltungen im Salzburger „Amerika-Haus“ aber, wie noch zu zeigen sein wird, auch positiv berichtet. Zum anderen zeigt die Nennung Max Mells in einer Reihe mit Hugo von Hofmannsthal und der im Widerstand aktiven Verfasserin der österreichischen Bundeshymne Paula von Preradović, dass Bernhard in der ersten Hälfte der 1950er Jahre noch wenig „Sensibilität für problematische Kontinuitäten bei den Repräsentanten des zeitgenössischen Kulturbetriebs“ entwickelt hatte. ${ }^{31}$

Max Mell war nicht nur einer der prominentesten Autoren im austrofaschistischen Ständestaat, sondern auch im NS-Literatursystem; er hatte 1938 zum Bekenntnisbuch österreichischer Dichter ein Gedicht zur Feier des ,Anschlusses Österreichs an das Deutsche Reich beigesteuert und in zahlreichen einschlägigen Anthologien publiziert, ${ }^{32}$ was seinem Ansehen in der Zweiten Republik - trotz vehementer Kritik durch Otto Basil und andere in der unmittelbaren Nachkriegszeit $^{33}$ - jedoch kaum abträglich war: Mells Bühnenstück Kriemhilds Rache war in der Saison 1950/1951 die erste österreichische Uraufführung am Wiener Burgtheater (gefolgt von Traube in der Kelter von Richard Billinger, der sich ebenfalls am Bekenntnisbuch beteiligt hatte). ${ }^{34}$ Mit seiner verzeihenden, in Teilen wohl auch unwissend-naiven Haltung stand Bernhard in den 1950er Jahren jedenfalls nicht alleine da, bewegte sich vielmehr im kulturpolitischen Mainstream jener Jahre, die - so die pointierte Formulierung des Historikers Gert Kerschbaumer - den

31 Manfred Mittermayer: „Die brennende hilfesuchende Glut“. Thomas Bernhard als Literaturkritiker in den frühen 1950er Jahren. In: Literatur - Politik - Kritik. Beiträge zur Österreichischen Literatur des 20. Jahrhunderts. Hg. v. Harald Jele u. Elmar Lenhart. Göttingen: Wallstein 2014, S. 204-213, hier S. 213.

32 Vgl. Max Mell: Am Tage der Abstimmung - 10. April 1938. In: Bekenntnisbuch österreichischer Dichter. Hg. v. Bund deutscher Schriftsteller in Österreich. Wien: Krystall 1938, S. 68. - Dazu die Aufstellung in Müller: Zäsuren ohne Folgen (Anm. 25), S. 319-322. Zu Mells Rolle im Dritten Reich vgl. ders.: Die Bannung der Unordnung. Zur Kontinuität österreichischer Literatur seit den dreißiger Jahren. In: Kontinuität und Bruch 1938-1945-1955. Beiträge zur österreichischen Kultur- und Wissenschaftsgeschichte. Hg. v. Friedrich Stadler. Wien, München: Jugend und Volk 1988, S. 181-215, hier S. 184; Ernst Klee: Das Kulturlexikon zum Dritten Reich. Wer war was vor und nach 1945. Frankfurt a. M.: S. Fischer 2009, S. 364. - 1956 lud Bernhard Max Mell zum von ihm gemeinsam mit Elisabeth Effenberger veranstalteten „Forum Hohensalzburg“ ein; ein Auftritt kam aufgrund gesundheitlicher Beschwerden Mells aber nicht zustande.

33 Vgl. Polt-Heinzl: Die grauen Jahre (Anm. 3), S. 37 f.; Daniela Strigl: Spurensicherung auf dem „österreichischen NS-Parnaß“. Otto Basil und die Debatte um Josef Weinheber. In: Otto Basil und die Literatur um 1945. Tradition - Kontinuität - Neubeginn. Hg. v. Volker Kaukoreit u. Wendelin Schmidt-Dengler. Wien: Zsolnay 1998, S. 66-76.

Vgl. Polt-Heinzl: Die grauen Jahre (Anm. 3), S. $91 \mathrm{f}$. 
„kulturellen Rückwärtsgang“"35 eingelegt hatten. Darauf wird im Laufe des vorliegenden Kapitels genauer zurückzukommen sein.

Auch in der Folge hat Bernhard bei verschiedenen Gelegenheiten, freilich mit überschaubarem Erfolg, versucht, die literarische Öffentlichkeit auf Johannes Freumbichler und dessen erzählerisches Werk aufmerksam zu machen. ${ }^{36}$ In einem Artikel über den Dichter aus Henndorf in den Wiener Bücherbriefen - er gab sich auch hier nicht als dessen Enkel zu erkennen - bedauerte er 1957 erneut, dass selbst Menschen, „die sich heute in Österreich mit Literatur beschäftigen, oder vorgeben, das zu tun“, den Namen Freumbichlers noch nie gehört hätten:

Das ist durchaus kein Wunder in einer Zeit, in der man sich das Dichten so leicht macht wie das Nudelwalken, in der man über Stifter verächtlich spricht, ohne ihn gelesen zu haben, in welcher man Proust bewundert (mit Recht bewundert!), ohne ihn gelesen zu haben, in welcher man überhaupt keine Ahnung hat - jedenfalls auf der sogenannten literarischen Seite -, was vor Robert Musil und Hermann Broch passiert ist. Und da ist sehr viel passiert! (TBW 22.1, 573) ${ }^{37}$

Seine andauernde „Erfolgslosigkeit“ habe den Schriftsteller ebenso gequält wie das Bewusstsein „eigene[r] Unzulänglichkeit“; Freumbichler habe, so Bernhard weiter, sowohl „sehr gute“ als auch „sehr schlechte“ Bücher geschrieben, „[v]öllig danebengegangene und einzig dastehende, unwiederholbare poetische Blöcke“ (TBW 22.1, 570 f.). Die tiefe Sympathie für den „außerordentliche[n] Schriftsteller" Freumbichler, der zeitlebens und auch nach seinem Tod vom Literaturbetrieb „bagatellisiert“ und an den Rand gedrängt worden sei (TBW 22.1, 574), wird hier, Mitte der 1950er Jahre, bereits um deutlich kritischere Töne ergänzt. Bernhard Judex hat darauf aufmerksam gemacht, dass das Freumbichler-Porträt

35 Gert Kerschbaumer: Der kalte Krieg gegen die Moderne. In: G. K./Karl Müller: Begnadet für das Schöne. Der rot-weiß-rote Kulturkampf gegen die Moderne. Wien: Verlag für Gesellschaftskritik 1992, S. 117-204, hier S. 121.

36 Zum „Wunsch“ Bernhards, „den Großvater in der Öffentlichkeit wieder bekannter zu machen“, vgl. Judex: Schreiben in der „Denkkammer“ (Anm. 6), S. 28. Bei Siegfried Unseld hat Bernhard sich wiederholt für eine Neuauflage von Freumbichlers Büchern eingesetzt (vgl. Thomas Bernhard/Siegfried Unseld: Der Briefwechsel. Hg. v. Raimund Fellinger, Martin Huber u. Julia Ketterer. Frankfurt a. M.: Suhrkamp 2009, S. 523, 525, 640 u. 717). Der zunächst 1937 im Wiener Zsolnay Verlag veröffentlichte und 1982 bei Ullstein als Taschenbuch gedruckte Roman Philomena Ellenhub erschien jedoch erst 2009 in einer kommentierten Neuauflage im Insel Verlag.

37 Vgl. Michael Billenkamp: Provokation und posture. Thomas Bernhard und die Medienkarriere der Figur Bernhard. In: Mediale Erregungen? Autonomie und Aufmerksamkeit im Literaturund Kulturbetrieb der Gegenwart. Hg. v. Markus Joch, York-Gothart Mix u. Norbert Christian Wolf. Tübingen: Niemeyer 2009, S. 23-43, hier S. 28: „Bernhards Arbeiten aus den 5oer Jahren sind von dem Bestreben gekennzeichnet, das Andenken an den von ihm bewunderten Freumbichler zu bewahren." 
in den Wiener Bücherbriefen nicht als historisch korrekte Darstellung zu verstehen ist, sondern dass sich darin "die biografische Wahrheit mit fiktiven Elementen“ vermischt: Bernhard betreibe, so Judex, „eine geschickte Montage realer biografischer und fiktiv-literarischer Elemente“, „indem er Faktisches poetisch verdichtet und auflädt, frei Erfundenem wiederum den Anschein von Wirklichkeit verleiht" ${ }^{\text {“38 }}$ - ein Darstellungsverfahren, das Bernhard später in seiner autobiographischen Pentalogie sowie in Texten wie Wittgensteins Neffe (1982) perfektioniert hat.

1968 für einen Zeitschriftenbeitrag dazu aufgefordert, über die Landschaft seiner Kindheit zu schreiben, widmete Bernhard lange Passagen des Unsterblichkeit ist unmöglich betitelten Essays dem Andenken seines Großvaters, der ihn in „Naturwissenschaft“, „Geisteswissenschaften“ und „Philosophie“ gleichermaßen eingeführt habe (TBW 22.1, 604). ${ }^{39}$ In Die Kälte (1981) und Ein Kind (1982) schließlich wird er Freumbichler nicht nur als wichtigste Vertrauensperson seiner Kindheit und Adoleszenz würdigen, sondern auch als „erfolglose[n]“ und „verkannte[n] Schriftsteller“ (TBW 10,350) beschreiben, der für ihn in mancherlei Hinsicht ein abschreckendes Beispiel dargestellt habe: ${ }^{40}$ Die „Erfahrung des miterlebten Scheiterns des eigenen familiären Schreibvorfahren“ hat Bernhard, so Hans Höller, mit Sicherheit stark geprägt; ${ }^{41}$ seine Äußerungen über Leben und Werk des Großvaters weisen im Laufe der Zeit zusehends Züge einer Reflexion über das eigene Konzept von Autorschaft auf - dem Schicksal seines Großvaters, nach jahrzehntelangem, selbstzerstörerischem Ringen mit der „Romanarbeit“ im Grunde „völlig unbekannt“ aus dem Leben zu scheiden (TBW 10, 426 u. 468), wollte der Enkel unter allen Umständen entgehen. Als er im Juli 1950 in seinem ersten Beitrag als Kulturjournalist den verwahrlosten Zustand der Grabstätte am Maxglaner Friedhof beklagte, stand Bernhard freilich noch ganz am Beginn seiner literarischen Karriere.

38 Judex: Die Persiflage des Geistesmenschen (Anm. 21), S. $196 \mathrm{f}$.

39 Bernhard Judex: Das „größte politische Dilemma der Geschichte“. Krieg und Nationalsozialismus bei Thomas Bernhard. In: Text + Kritik (42016), H. 43, S. 153-165, hier S. 156, zufolge handelt es sich bei Unsterblichkeit ist unmöglich um einen „im Unterschied zur Autobiografie noch weniger auf ein ästhetisch-poetologisches Konzept hin entworfenen stenogrammartigen Text[ ]“. Mittermayer: Die Stimme des alten Meisters (Anm. 13), S. 27, hat indes auf die „stark ausgeprägte Stilisierungstendenz" auch in diesem frühen autobiographischen Text hingewiesen.

40 Bereits Tschapke: Hölle und zurück (Anm. 15), S. 74, hat auf „ambivalente Züge“ in Bernhards Freumbichler-Bild aufmerksam gemacht. Noch ausführlicher hat diese intrikate Vermengung von „Vaterfigur“ und „Familientyrann“ Judex: Die Persiflage des Geistesmenschen (Anm. 21), S. 190, herausgearbeitet.

41 Hans Höller: „Gewalt auch über ganz Große“. Thomas Bernhards Überwindung der ,Einflussangst'. In: Thomas Bernhard Jahrbuch 2005/2006, S. 65-74, hier S. 68. 
„Ich glaube, da liegen die Wurzeln“: Bernhard als Gerichtsreporter

Thomas Bernhards Tätigkeit für das Demokratische Volksblatt kam um den Jahreswechsel 1951/1952 unter anderem über Carl Zuckmayers Fürsprache beim Chefredakteur der Zeitung und späteren Präsidenten der Salzburger Festspiele, Josef Kaut, zustande. ${ }^{42}$ Neben ersten Veröffentlichungen über die soziale Lage im Salzburg der frühen 1950er Jahre (Menschen ohne Heimat, Mit Retorten und Filter gegen Pantscher und Schicksale am Hauptbahnhof) und über literarische Themen trat Bernhard bald auch mit anonymen Gerichtsreportagen hervor. Die Verfasserschaft einzelner Artikel in der Rubik „Aus dem Gerichtssaal“ ist heute nicht mehr $\mathrm{zu}$ eruieren, lediglich von jenen Beiträgen, die sich gesammelt in einer Mappe im Nachlass des Autors befinden, kann „mit einiger Sicherheit“ angenommen werden, dass sie von Bernhard stammen. ${ }^{43}$

Das Demokratische Volksblatt war nach der Genehmigung durch die amerikanischen Besatzungstruppen im Oktober 1945 gegründet worden und galt als offizielles Organ der Sozialistischen Partei Österreichs. In seinen Reportagen schildert der junge Autor, der sich kaum von „landläufigen Wertvorstellungen und Vorurteilen “ ${ }^{44}$ sowie sprachlichen Konventionen entfernt, Verhandlungen in Salzburger Gerichten: Sittlichkeitsdelikte, kleinere Diebstähle und Wirtshausraufereien machen einen Großteil der Fälle aus und sind weitgehend dem Feld der Kleinkriminalität zuzurechnen: „Die Zehn-Schilling-Fälle des Franzl, die Nachthemdgeschichte der Mariandl oder die Ehrenbeleidigung zwischen Herrn Mayer und Herrn Müller erschüttern nicht die Welt", war sich Bernhard am 28. November 1952 in dem namentlich gezeichneten Feuilleton Prozesse, nichts als Prozesse selbst bewusst (TBW 22.1, 87).

Der Gestus der Berichte erweist sich dabei als ambivalent: Neben Artikeln, die mit komischen Elementen, Übertreibungen und der denunziatorischen Imitation von Dia- und Soziolekten arbeiten, ja die Angeklagten - so Karl-Markus Gauß - „oft einer billigen Pointe wegen“"verraten, ${ }^{45}$ ergreift Bernhard immer wieder vehement Partei für die Delinquenten, kritisiert die Härte von Urteilen und führt Delikte

42 Vgl. Mittermayer: Thomas Bernhard [2015] (Anm. 25), S. 90. Zu den verschiedenen „Versionen, auf welche Weise Thomas Bernhard Mitarbeiter des Demokratischen Volksblatts wurde“, vgl. den Kommentar in TBW 22.1, 706 f., sowie die einander widersprechenden Interviewäußerungen in TBW 22.2, 112 u. 335 f., bzw. in Kurt Hofmann: Aus Gesprächen mit Thomas Bernhard. Wien: Löcker 1988, S. $41 \mathrm{f}$.

43 Habringer: Der Auswegsucher (Anm. 26), S. 33. Vgl. die kommentierte Textsammlung in: Aus dem Gerichtssaal. Thomas Bernhards Salzburg in den 5oer Jahren. Hg. v. Jens Dittmar. Wien: Edition S 1992, sowie jetzt den Kommentar in TBW 22.1, 891-903.

44 Herbert Moritz: Lehrjahre. Thomas Bernhard - vom Journalisten zum Dichter. Weitra: Bibliothek der Provinz 1992, S. 49.

45 Karl-Markus Gauß: Die Legende. In: Süddeutsche Zeitung, 19. 12. 2015. 
auf die prekäre soziale Lage der vor Gericht stehenden Menschen zurück. ${ }^{46}$ Diese sei ihm - so der Autor 1976 in Der Keller. Eine Entziehung, dem zweiten Band der Autobiographie - von seiner Tätigkeit als Lehrling in der Salzburger Scherzhauserfeldsiedlung in den Jahren 1947 bis $1949^{47}$ nur zu gut vertraut gewesen:

Die Richter kannten nicht, was ich kannte, und sie machten sich auch nicht die Mühe, einem Menschenschicksal auf den Grund zu gehen, sie verhandelten eine Sache wie die andere, hielten sich an die Papiere und an die sogenannten unumstößlichen Tatsachen und urteilten ab, ohne den Abgeurteilten zu kennen und ohne die Umwelt des Abgeurteilten zu kennen und ohne seine Geschichte zu kennen und ohne die Gesellschaft zu kennen, die ihn zu einem Verbrecher gemacht hatte, zu welchem er vor Gericht abgestempelt wurde. Die Richter hielten sich beinahe ausschließlich an die Papiere und zerstörten mit ihren brutalen, geistlosen und völlig gefühllosen, ja geistfeindlichen und gefühlsfeindlichen Gesetzen den Menschen, der ihnen vorgeführt wurde. (TBW 10, 119)

Bei mehreren Gelegenheiten hat Bernhard seine Zeit als Gerichtsberichterstatter als wesentlichen Impuls und „unschätzbares Kapital“ für sein literarisches Schreiben bezeichnet. Die Gerichtsreportagen seien ihm, so der Autor $1987 \mathrm{im}$ Gespräch mit Asta Scheib, „später beim Prosaschreiben wieder gegenwärtig geworden“: „Ich glaube, da liegen die Wurzeln.“ (TBW 22.2, 336) ${ }^{48}$

Diese Einschätzung lässt sich einerseits thematisch auf den intensiven Kontakt mit heterogenen sozialen Milieus beziehen: Auf diesen Erfahrungsschatz hat Bernhard, in dessen literarischen Arbeiten (ehemalige) Strafgefangene eine wichtige Rolle spielen, ${ }^{49}$ wiederholt zurückgegriffen: „Was Macht eigentlich ist,

46 Vgl. Moritz: Lehrjahre (Anm. 44), S. 39; ders.: Das Milieu der Gerichtsberichte hat ihn beeinflusst. In: Was reden die Leute. 58 Begegnungen mit Thomas Bernhard. Aufgezeichnet v. Sepp Dreissinger. Salzburg, Wien: Müry Salzmann 2011, S. 44-51, hier S. 47: „Er bewies ein großes soziales Verständnis. In seiner Berichterstattung hat er immer die sozialen Probleme mit anklingen lassen, das war sicher eine Stärke seiner Berichte. Er hat sich damals auch Baracken angesehen und mit Flüchtlingsproblemen beschäftigt. Er war durchaus sozial engagiert, und dies traf sich mit unseren politischen Intentionen."

47 Vgl. dazu die Schilderung in Harald Waitzbauer: Thomas Bernhard in Salzburg. Alltagsgeschichte einer Provinzstadt 1943-1955. Wien u. a.: Böhlau 1995, S. 47-49, sowie Jens Dittmar: Zwischen Paris-Lodron-Straße und Kajetaner Platz. In: Aus dem Gerichtssaal (Anm. 43), S. 13-30, hier S. 22.

$48 \mathrm{Zu}$ Bernhards Tätigkeit als Berichterstatter bei Gericht vgl. Billenkamp: Thomas Bernhard (Anm. 14), S. 52-54; Moritz: Lehrjahre (Anm. 44), S. 32-50. Seine anonym erschienenen Texte lassen, so Moritz, „in ihrer Qualität deutliche Hinweise auf journalistisch oder gar literarisch Außerordentliches vermissen“ (S. 47).

49 Vgl. Mittermayer: Thomas Bernhard [2015] (Anm. 25), S. 92 f. - Neben den Erzählungen Der Zimmerer (1965) und Der Kulterer (1969) etwa in Watten. Ein Nachlaß (1969): Ein Arzt 
und wie man sie ausübt, das kann man dort [i.e. im Gerichtssaal] sehr gut studieren“, so der Autor im Interview mit Peter Hamm (TBW 22.2, 113). Zudem hat er die Vermutung geäußert, seine charakteristische, Übertreibungskunst ' habe sich bereits in diesen Jahren, in den Berichten über Kriminalfälle und Gerichtsurteile, herausgebildet und entwickelt - eine Behauptung freilich, die sich in Teilen als kaum haltbar erweist und dem allgegenwärtigen Hang zur Stilisierung der eigenen Biographie in Bernhards öffentlichen Selbstauskünften geschuldet zu sein scheint. ${ }^{50}$

Andererseits verweisen die Kurzprosabände Ereignisse (1969) und vor allem Der Stimmenimitator (1978) auch formal auf Textverfahren dieser frühen, zuallererst auf „Broterwerb“ ${ }^{\text {“51 }}$ ausgerichteten journalistischen Arbeiten. In vielen Miniaturen des Stimmenimitators geht Bernhard vom Duktus und von den Sujets der Gerichtssaalberichte aus, überführt die Kriminalfälle, Morde und Gewaltdelikte, von denen berichtet wird, aber ein ums andere Mal ins Absurde und Groteske. ${ }^{52}$

überlässt darin dem Mathematiker und Juristen Undt das Geld aus dem Verkauf seiner Besitzungen, das dieser wiederum zur Unterstützung entlassener Häftlinge verwendet. In Meine Preise berichtet Bernhard davon, dass dazu auch eine biographische Entsprechung existiert: Die Preissumme des Franz-Theodor-Csokor-Preises in Höhe von 15.00o Schilling spendete Bernhard 1972 der „Häftlingsfürsorge in Stein“ (TBW 22.2, 432). Zu den Hintergründen und dazu, dass es sich hierbei, im Gegensatz zu anderen Angaben in Meine Preise, wohl nicht um eine literarische Stilisierung handelt, vgl. Mittermayer: Thomas Bernhard [2015] (Anm. 25), S. $244 \mathrm{f}$.

50 Während Bernhard im Gespräch mit Krista Fleischmann behauptet, er habe im Zuge seiner Arbeit für das Demokratische Volksblatt als Reporter auch über schwere Unfälle mit mehreren Toten berichtet und der Zeitung „durch Falschmeldungen und Übertreibungen“ zu höheren Auflagezahlen verholfen (TBW 22.2, 324 f.), hat Herbert Moritz, sein damaliger Vorgesetzter in der Redaktion, betont, „daß Bernhard während seiner ganzen Tätigkeit für das ,Demokratische Volksblatt' nie als Berichterstatter zu einem Unfall oder einer Brandkatastrophe geschickt worden ist" (Moritz: Lehrjahre [Anm. 44], S. 18). In den Gerichtssaalberichten jedoch habe Bernhard „seine Phantasie uferlos schweifen“ lassen und sich „immer weiter von der Wirklichkeit entfernt" (Moritz: Das Milieu der Gerichtsberichte hat ihn beeinflusst [Anm. 46], S. 46). Vgl. dazu auch Bernhards Bemerkungen im Gespräch mit Peter Hamm (TBW 22.2, $112 \mathrm{f}$.).

51 Jens Dittmar: Thomas Bernhard als Journalist beim Demokratischen Volksblatt. In: Bernhard. Annäherungen. Hg. v. Manfred Jurgensen. Bern, München: Francke 1981, S. 15-35, hier S. 16.

52 Vgl. Franz M. Eybl: Thomas Bernhards Stimmenimitator als Resonanz eigener und fremder Rede. In: Kontinent Bernhard. Zur Thomas-Bernhard-Rezeption in Europa. Hg. v. Wolfram Bayer. Wien u. a.: Böhlau 1995, S. 31-43, hier S. 33: „Die epischen Kleinformen - ihre Länge schwankt zwischen vier Druckzeilen und zweieinhalb Druckseiten - berichten im Stil von Anekdoten, Zeitungsmeldungen oder Gerichtssaalberichten von ganz und gar außergewöhnlichen Ereignissen, aber auch vom Schrecken des Gewöhnlichen.“ Dazu auch Till Greite: „Prozesse, nichts als Prozesse“. Thomas Bernhard. Vom Gerichtsberichterstatter zum Fall für die Justiz. In: Recht, sachlich. Hg. v. David Oels, Stephan Porombka u. Eberhard Schütz. Hannover: Wehrhahn 2009, S. 95-102, hier S. 99: „[D]ie Texte imitieren gezielt die ,Stimmen“ von 
Das zeigt sich etwa im mit Sorgfalt überschriebenen Kurzprosatext, an dessen Ende der Delinquent nicht einer psychiatrischen Behandlung überantwortet, sondern, so hat es jedenfalls den Anschein, in die Freiheit entlassen wird:

Ein des Mordes an einer schwangeren Frau angeklagter Postbeamter hat vor Gericht angegeben, er wisse nicht, warum er die Schwangere umgebracht habe, er habe sein Opfer aber so sorgfältig als nur möglich umgebracht. Auf alle Fragen des Gerichtsvorsitzenden hatte er immer nur das Wort sorgfältig gesagt, worauf das Verfahren gegen ihn eingestellt worden ist. (TBW 14, 340)

Der bekannteste Rekurs auf seine Zeit als Gerichtsreporter im Stimmenimitator ist freilich der Text Exempel, in dem die entsprechende Tätigkeit als fordernde Schule des Lebens beschrieben wird: „Der Gerichtssaalberichterstatter ist dem menschlichen Elend und seiner Absurdität am nächsten und er kann diese Erfahrung naturgemäß nur eine kurze Zeit, aber sicher nicht lebenslänglich machen, ohne verrückt zu werden. ${ }^{“ 53}$ Weil ihm im Gericht jeden Tag „das Unglaubliche, ja das Unglaublichste“ begegne, sei er, so heißt es vom Erzähler, „naturgemäß

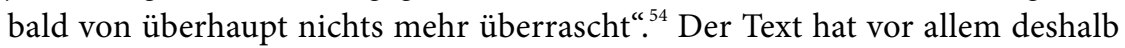
Beachtung gefunden, weil die Tochter des darin namentlich genannten „Oberlandesgerichtsrat[s] Zamponi“ nach der Veröffentlichung des Buches mit einer Klage gedroht hatte. ${ }^{55}$ Sie sah darin das Andenken ihres Vaters Reinulf Zamponi beschädigt, von dem in Bernhards Kurzprosastück zu lesen ist, er habe nach der Verurteilung eines Erpressers „zu zwölf Jahren Kerker und zur Zahlung von acht Millionen Schilling “ plötzlich eine Pistole hervorgeholt und nicht etwa den Straftäter, sondern sich selbst in den Kopf geschossen. ${ }^{56}$ Tatsächlich war Reinulf

Gerichtsreport und journalistischer Meldung, was zum einen auf Bernhards kalkuliertes Spiel mit dem protokollarischen Stil benannter Formen hinweist und zum anderen die bewusste Erprobung unterschiedlicher Stimmen zur Erzeugung einer scheinbaren Authentizität des Faktischen belegt."

53 Thomas Bernhard: Der Stimmenimitator. Frankfurt a. M.: Suhrkamp 1978, S. 29.

54 Ebd.

55 Vgl. dazu und zum Folgenden: Sehr geschätzte Redaktion. Leserbriefe von und über Thomas Bernhard. Hg. v. Jens Dittmar. Wien: Edition S 1991, S. 86-89; Mittermayer: Thomas Bernhard [2015] (Anm. 25), S. 93 f.; Moritz: Das Milieu der Gerichtsberichte hat ihn beeinflusst (Anm. 46), S. 47; sowie den Kommentar in TBW 22.1, $857 \mathrm{f}$.

56 Bernhard: Der Stimmenimitator (Anm. 53), S. 29 f. Der Name von „Staatsanwalt Dr. Zamponi“ findet sich gleich in mehreren anonym erschienenen Gerichtssaalberichten, für die Bernhards Autorschaft angenommen wird (vgl. TBW 22.1, 435, 448 u. 495). Jens Dittmar hat darauf hingewiesen, dass Reinulf Zamponi selbst Beiträge für das Demokratische Volksblatt verfasst hat (vgl. Dittmar: Zwischen Paris-Lodron-Straße und Kajetaner Platz [Anm. 47], S. 16). Auch im Romanprojekt „Schwarzach St. Veit“, einer Vorstufe von Frost, taucht der Name Zamponi auf. Vgl. dazu Martin Huber: Von Schwarzach St. Veit nach Weng. Zur Vorgeschichte von Thomas 
Zamponi 1977, ein Jahr vor der Publikation des Stimmenimitators, eines natürlichen Todes gestorben.

Auf die Nachricht der drohenden Klage reagierte Bernhard im Januar 1979 mit einem offenen Brief an Annelore Lucan-Stood, die Tochter Zamponis, in den Oberösterreichischen Nachrichten, in dem er betonte, keinesfalls eine „Verunglimpfung Ihres Herrn Vaters“ beabsichtigt, vielmehr eine "philosophische Dichtung als Huldigung Ihres Herrn Vaters" geschrieben zu haben:

Sehr geehrte Frau Annelore Lucan-Stood,

in einer der hundertvier freien Assoziationen und Denk-Erfindungen meines Buches Der Stimmenimitator habe ich Ihrem Herrn Vater, dem von mir während meiner Gerichtsreportertätigkeit am Salzburger Landesgericht in den fünfziger Jahren hochgeschätzten und von mir bis heute hochverehrten Staatsanwalt Dr. Zamponi, ein, wie ich glaube, auf längere Dauer standfestes, wenn auch nur dichterischer Denkmal gesetzt. (TBW 22.1, 653)

Es könne sich nur um ein „Mißverständnis“ handeln (TBW 22.1, 654), wenn man sein literarisches Porträt mit einem Verächtlichmachen des angesehenen Juristen gleichsetze. In Absprache mit der Familie des Verstorbenen konnte schließlich eine außergerichtliche Einigung erzielt werden. Diese sah vor, dass in allen weiteren Ausgaben des Textes, auch im 2003 veröffentlichten 14. Band der Werkausgabe, der Name „Zamponi“ durch „Ferrari“ (TBW 14, 248) ersetzt wurde. - In den mitunter skurril anmutenden Fallgeschichten des Stimmenimitators verbindet Bernhard das für seine Prosa insgesamt charakteristische Verfahren des vermittelten Erzählens mit der journalistischen Forderung nach Kürze und Prägnanz. ${ }^{57}$ Nicht nur über die Nennung einzelner Zeitungen, in denen er in der ersten Hälfte der 1950er Jahre gelegentlich Beiträge veröffentlicht hatte (z. B. im Linzer und Salzburger Volksblatt; TBW 14, 90 f. u. 245), werden die Kurzprosatexte mit seiner früheren Tätigkeit als Gerichtsberichterstatter verknüpft.

Bernhards literarischem Durchbruch mit seinem Roman Frost. In: Thomas Bernhard Jahrbuch 2005/2006, S. 35-44.

57 Zum literarischen Verfahren des Bandes vgl. Peter Staengle: „Das könne er nicht.“ Zu Thomas Bernhards Der Stimmenimitator. In: Die kleinen Formen in der Moderne. Hg. v. Elmar Locher. Innsbruck, Wien: StudienVerlag 2001, S. 279-298, sowie Willi Huntemann: Artistik und Rollenspiel. Das System Thomas Bernhard. Würzburg: Königshausen \& Neumann 1990, S. $210 \mathrm{f}$. 


\section{„Kanzlist, Kofferträger und Kunstkritiker“}

In einem Gespräch im Juli 1980 teilte Bernhard seinem Suhrkamp-Verleger Siegfried Unseld zunächst mit, dass er einen vierten Teil der Autobiographie geschrieben habe - und dass er den Die Kälte. Eine Isolation betitelten Band erneut im Salzburger Residenz Verlag publizieren wolle: „Er würde“, notiert Unseld in seinem Reisebericht, „im Laufe von drei Jahren noch drei weitere Teile schreiben. Das Ganze sei eine Einheit. ${ }^{\text {c58 }}$ Schließlich hält Unseld auch die von Bernhard genannten Titel der in Aussicht gestellten Bände fest, ebenso wie die Beteuerung des Autors, nach Die Kälte keine weiteren Bücher mehr im Residenz Verlag zu veröffentlichen, in dem bereits alle bisherigen Teile der Autobiographie gedruckt worden waren:

Das sei nun unwiderruflich der letzte Text bei Residenz, er hatte mir das schon einmal in Wien zugesagt. Er würde die weiteren drei Teile schreiben, Teil V ,Der Gerichtsreporter. Teil VI ,Der Beginn des Schriftstellerischen', Teil VII ,Die erste Kindheit'. Wir veröffentlichen dann 1983 einen Band ,Kindheit und Jugend, er enthält die vier bei Residenz erschienen Teile und drei unveröffentlichten Teile, wobei Teil VII das erste Kapitel werden wird. ${ }^{59}$

Bekanntlich erschien nach Die Kälte nur noch jener Band von Bernhards ,Selberlebensbeschreibung, den er Unseld hier als „Teil VII“ in Aussicht gestellt hatte: Ein Kind wurde 1982 erneut bei Residenz veröffentlicht; ein weiteres Mal hatte sich der Autor als wortbrüchig erwiesen. ${ }^{60}$ Mit Blick auf die als „Teil V“ und „Teil VI“ angekündigten Abschnitte indes lässt sich Folgendes festhalten: Obgleich die autobiographische Pentalogie - so Michael Billenkamp - eine Art von „Berufsautobiografie“ darstellt, weil die „Genese des Berufswunsches Schriftsteller“ darin eine zentrale Rolle spielt, ${ }^{61}$ nahm Bernhard doch davon Abstand, die erzählte Zeit auf die erste Hälfte der 1950er Jahre auszudehnen und den Beginn seiner Publikationstätigkeit sowie die Arbeit als Gerichtsreporter in seine Selbstbiographie aufzunehmen.

„Er begann zu schreiben als Theater- und Prozeßberichter“, hatte Unseld bereits im November 1973 nach einem ausführlichen Gespräch mit Bernhard

58 Unseld: Reisebericht Salzburg, 24.-26. Juli 1980. In: Bernhard/Unseld: Der Briefwechsel (Anm. 36), S. 597.

59 Ebd., S. $597 \mathrm{f}$.

60 Vgl. zu diesem Konfliktfeld Manuela Dressel: Thomas Bernhard und seine Verleger. Wien: danzig \& unfried 2014, S. 95-108; Martin Huber/Manfred Mittermayer: Thomas Bernhard und seine Verlage. Linz: StifterHaus 2007, S. $16 \mathrm{f}$.

61 Billenkamp: Provokation und posture (Anm. 37), S. 34. 
notiert; „schließlich“, so Unseld weiter, „aus Verehrung für Thomas Wolfe und Faulkner, begann er zu schreiben.“ Knapp zwei Jahre vor Erscheinen von Die Ursache (1975), der ersten autobiographischen Erzählung, berichtete Bernhard dem Verleger bei einem Abendessen mit „Meraner Rotwein“ über die Geschichte seiner „ganz und gar unmöglichen Familie“, über „Herkommen“ und „Aufwachsen“, aber auch über die ersten Schritte auf dem Weg zur Autorschaft. ${ }^{62}$ Unselds Notiz aus dem Jahr 1973 ist deshalb beachtenswert, weil Bernhard zwar seine Arbeit als Gerichtssaalreporter bei mehreren Gelegenheiten - und mit einem gewissen Stolz - als wichtige "Schule“ (TBW 22.2, 44) und als Experimentierfeld des literarischen Schreibens bezeichnet, ${ }^{63}$ sich über seine Tätigkeit als Literatur-, Kunst-, Film- und Theaterkritiker im Salzburg der frühen 1950er Jahre aber nie öffentlich geäußert hat. ${ }^{64}$ Die Hinweise auf seine „Zeitungsg'schicht'ln“65 in Interviews und in der autobiographischen Pentalogie beschränken sich auf die Arbeit als Gerichtsreporter und einen im Januar 1952 veröffentlichten Bericht über ein Salzburger Flüchtlingslager (vgl. TBW 22.1, 10-12, bzw. 22.2, 112 u. 336). Wenn in Der Keller (1976) vom Demokratischen Volksblatt die Rede ist, dann nur mit Blick auf „Zustände“ in der Scherzhauserfeldsiedlung, deren unterprivilegierte Bewohner ihm Anfang der 1950er Jahre am Salzburger Gericht als Angeklagte und Zeugen wieder begegnet waren (TBW 10, 119f.).

Diese gezielte Selektion, die durchaus als werkpolitische Intervention im Sinne der Rezeptionssteuerung zu begreifen ist, lässt sich schon früh beobachten: Hatte Bernhard $1954^{66}$ in einem Begleittext zu seiner ersten Publikation im Wiener Jahrbuch Stimmen der Gegenwart noch angeführt, er habe „zuletzt auch als Kunstkritiker einer Tageszeitung " gearbeitet, ${ }^{67}$ wurde diese Informationen zwei Jahre später, als er die Erzählung Der Schweinehüter in dem von Hans Weigel begründeten Periodikum veröffentlichte, bereits ausgespart: Er habe,

62 Unseld: Bericht Thomas Bernhard, 8./9. November 1974 [recte: 1973] Salzburg. In: Bernhard/ Unseld: Der Briefwechsel (Anm. 36), S. 406.

63 Ob sich Bernhards „todesfixierte Schreibweise“ jedoch tatsächlich „der Arbeit als Lokaljournalist und Gerichtsreporter im Salzburg der 1950er Jahre“ „verdankt“, wie Markus Janner: Der Tod im Text (Anm. 9), S. 105, vermutet, scheint mir fraglich. Vgl. auch ebd., S. 112-115.

64 Vgl. Dittmar: Zwischen Paris-Lodron-Straße und Kajetaner Platz (Anm. 47), S. 16 f.: „Wenn von seiner journalistischen Laufbahn die Rede ist, dann ist immer von den Gerichtssaalberichten die Rede."Vgl. auch Klug: Thomas Bernhards Arbeiten (Anm. 28), S. 137, der hervorhebt, dass Bernhard „seine sonstigen journalistischen und literarischen Arbeiten stets verschwiegen hat“.

65 Hofmann: Aus Gesprächen mit Thomas Bernhard (Anm. 42), S. 45.

661952 waren die von ihm eingereichten Gedichte noch abgelehnt worden. Vgl. Evelyne PoltHeinzl: Thomas Bernhard betritt die Wiener Szene oder Über Dissonanzen in Hans Weigels Stimmen der Gegenwart. In: Sprachkunst 46 (2015), H. 1, S. 51-70, hier S. $64 \mathrm{f}$.

67 [Biographische Angaben]. In: Stimmen der Gegenwart 1954. Hg. v. Hans Weigel. Wien: Albrecht Dürer 1954, S. 259. In diesem Band wurde Bernhards Erzählung Großer, unbegreiflicher Hunger gedruckt (ebd., S. 138-143). 
heißt es nun sehr viel ungenauer, „[v] on 1952 bis 1955 als freier Schriftsteller“ gearbeitet. ${ }^{68}$ In einem Mitte 1956 veröffentlichten Heft der Zeitschrift Wort in der Zeit war freilich noch zu lesen, „Thomas Niklas Bernhard“ habe sich „unter anderem als Kanzlist, Kofferträger und Kunstkritiker verschiedener Zeitungen“ verdingt, ${ }^{69}$ wobei die Liste der angeführten Tätigkeiten wohl zuallererst der Lust an der Alliteration und weniger der biographischen Faktenlage geschuldet war. Während er seine Arbeit als Berichterstatter im Salzburger Gericht wiederholt thematisiert, ja ihr eine wichtige Rolle für seine Initiation als Schriftsteller zugeschrieben hat, kommen die namentlich bzw. mit Initialen gezeichneten Beiträge für das Demokratische Volksblatt, später für die Salzburger Nachrichten und die Wiener Wochenzeitung Die Furche in seinen späteren Selbstauskünften nicht mehr vor. So gibt etwa die 1970 im Suhrkamp-Band Über Thomas Bernhard gedruckte „Vita“ des Autors lediglich an, er habe „bis 1955“ als „Gerichtsreporter des sozialistischen Demokratischen Volksblatt [sic] “ gearbeitet. ${ }^{70}$ Von seiner Tätigkeit als Literatur- und Kulturkritiker, als Feuilletonist und Berichterstatter von Lesungen, Volksfesten, Vorträgen, Brauchtumsveranstaltungen, Musik- und Theateraufführungen, ist in diesem von Anneliese Botond herausgegebenen Band nichts zu finden.

Als 1963 mit Frost Bernhards erstes Prosabuch im Frankfurter Insel Verlag erschien, war auf dem Umschlag prominent zu lesen, der Autor habe vier Jahre lang „als Gerichtsberichterstatter" gearbeitet: ${ }^{71}$ eine Information, die sich auch

68 [Biographische Angaben]. In: Stimmen der Gegenwart 1956. Wien, München: Herold 1956, S. 265.

69 Unsere Autoren. In: Wort in der Zeit 2 (1956), H. 6, S. 63-64, hier S. 63. Zu Bernhards wechselnden Angaben vgl. Polt-Heinzl: Thomas Bernhard betritt die Wiener Szene (Anm. 66), S. 68 f., zu seinen Publikationen in den Stimmen der Gegenwart auch Wieland Schmied: Auersbergers wahre Geschichte und andere Texte über Thomas Bernhard. Ein Alphabet. Vorwort v. Hans Höller. Weitra: Bibliothek der Provinz [2014], S. 41 f. - In einem Tagebucheintrag vom 22.7. 1956 notierte Gerhard Fritsch: „Bernhard will sich jetzt Th. Haarlem nennen, in ,Wort in der Zeit ${ }^{`}[\ldots]$ heißt er Thomas Niklas Bernhard über einigen Gedichten. Und in der Biographie ist er schmockant wie nur. Mich stört das; alles Attitüde." (Gerhard Fritsch: Man darf nicht leben, wie man will. Tagebücher. Hg. u. mit einem Nachwort v. Klaus Kastberger. Transkription u. Kommentar: Stefan Alker-Windbichler. Salzburg, Wien: Residenz 2019, S. 46)

70 Vita. In: Über Thomas Bernhard. Hg. v. Anneliese Botond. Frankfurt a. M.: Suhrkamp ${ }^{2} 1970$, S. 142-143, hier S. 142. Auf diese Aufstellung weist auch Habringer: Der Auswegsucher (Anm. 26), S. 33, hin, verzeichnet sie aber sinnwidrig als eine „,on Bernhard verfaßte Vita von 1955“.

71 Thomas Bernhard: Frost. Frankfurt a. M.: Insel 1963, Klappentext. Mit den dort gestreuten Informationen, er sei „als Bibliothekar an einem Kulturinstitut in London“ beschäftigt gewesen und habe sein Studium am Salzburger Mozarteum 1957 „mit einer vergleichenden Arbeit über Bertolt Brecht und Antonin Artaud“ abgeschlossen, etablierte Bernhard mithilfe von Wieland Schmied eine biographische Legende, die in der Folge weiter tradiert wurde. Vgl. dazu Habringer: Der Auswegsucher (Anm. 26), S. 37; Gitta Honegger: Thomas Bernhard. „Was ist 
in der zeitnah publizierten Anthologie Neunzehn deutsche Erzählungen findet ${ }^{72}$ und die in der Folge, wohl ausgehend von diesen ersten Nennungen, zum Standardrepertoire biographischer Abrisse über den Autor gehören sollte. ${ }^{73}$ Diese verlagsseitige Informationsvergabe trug mit Sicherheit dazu bei, dass Bernhard heute als „wohl bekannteste[r] ehemalige[r] Gerichtsreporter[ ] Österreichs ${ }^{\text {( } 74}$ gilt. Bei diversen Gelegenheiten, etwa in einem Gespräch mit Peter von Becker, hat sich der Autor zu seiner Tätigkeit als „Zeitungsreporter" geäußert und darüber bereitwillig Auskunft gegeben. ${ }^{75}$

Der 1989 veröffentlichte, aber bereits Ende der $1950 e r$ Jahre entstandene Text In der Höhe. Rettungsversuch, Unsinn zeigt, dass die Erfahrungen dieser Jahre ihn in seinen frühen Prosaarbeiten stark beeinflusst haben - und ihm mit der Herausgabe des Buches im Residenz Verlag daran gelegen war, diesen Zusammenhang offenzulegen. Im Band In der Höhe, einem „einzige[n] Steinbruch später aufgegriffener oder für immer liegengelassener literarischer Themen und Motive“ ${ }^{16}$ taucht das Demokratische Volksblatt an mehreren Stellen auf: „Freier Mitarbeiter am Demokratischen Volksblatt, lache ich aus mir heraus", heißt es gleich nach wenigen Seiten (TBW 11, 22), bevor die Zeitung in der Folge als „Brotherr[ ]“ des Erzählers bezeichnet (TBW 11, 26) und schließlich auch eine Szene aus dem Gerichtssaal angedeutet wird:

das für ein Narr?““ München: Propyläen 2003, S. 164; Mittermayer: Thomas Bernhard [2015] (Anm. 25), S. 113.

72 Vgl. [Biographische Angaben]. In: Neunzehn deutsche Erzählungen. München: Nymphenburger Verlagshandlung 1963, S. 354.

73 Vgl. etwa N. N.: Thomas Bernhard. In: Grenzverschiebung. Hg. u. mit einem Nachwort v. Renate Matthaei. Köln, Berlin: Kiepenheuer \& Witsch 1970, S. 72.

74 Greite: „Prozesse, nichts als Prozesse“ (Anm. 52), S. 95.

75 Peter von Becker: Bei Bernhard. Eine Geschichte in 15 Episoden. In: Theater 1978. Sonderheft der Zeitschrift Theater heute. Bilanz und Chronik der Saison 77/78, S. 80-87, hier S. 85. - Der Literaturkritiker Hans Haider, der ein Jahr zuvor an der Skandalisierung von Holzfällen als ,Schlüsselroman' federführend beteiligt gewesen war, machte Bernhard 1985 in der Presse die fortwährende Beschwörung seiner Außenseiterposition zum Vorwurf. Zu diesem Narrativ zähle, so Haider, nicht nur „die Entscheidung, nicht mit den wohlgekleideten Bürgerskindern in einer Reihe zur Schule zu gehen“ - womit er auf das zentrale Narrativ von Der Keller (1976) rekurriert -, sondern auch die Betonung „sein[es] Gerichtsberichterstatterdasein[s] im ,Salzburger Volksblatt" (Hans Haider: Die Stigmatisierten steigen auf. In Österreichs literarischer Szene gibt es mehr prominente als gelesene Autoren. In: Die Presse, 23. 8.1985). Es gehört zu den unfreiwillig komischen Effekten von Haiders Polemik, dass er, indem er Bernhards angebliche Nähe zum „sozialdemokratischen Literaturbetrieb“ offenlegen will, das nationalfreiheitliche Salzburger Volksblatt mit dem Demokratischen Volksblatt, der sozialistischen Parteizeitung, verwechselt.

76 Hans Höller: Thomas Bernhard. Reinbek b. Hamburg: Rowohlt 1993, S. 69. Dazu jetzt ausführlich Stefano Apostolo: Thomas Bernhards unveröffentlichtes Romanprojekt Schwarzach St. Veit. Das Konvolut, die Fassungen und ihre Deutung. Mattighofen: Korrektur 2019, S. 167-178. 
bis zwei Uhr mittags im Gerichtssaal: Richtlinienvertreter, Mußmaßungstalent, Perspektivenanheuerer: der Staatsanwalt und der betrügerische Wirtschaftsagent, der ins Zuchthaus muß: die zwei Justizwachebeamten packen ihn, schlagen ihm auf den Kopf und stoßen ihn die Gefangenenhaustreppe hinunter: er hat sich der Welt ganz einfach entzogen (TBW 11, 93)

Ganz am Ende des Textes markiert die Behauptung des Erzählers, wonach „das wichtigste“ sein „Buch“ sei und „nicht das Demokratische Volksblatt" (TBW 11, 106), die Emanzipation des Schriftstellers vom Handwerk des Journalisten. Die Passage verdeutlicht die Diskrepanz zwischen notwendigem Brotberuf und selbst gewählter Berufung: „um fünf Uhr sitze ich an meinem Schreibtisch: das ist mein einziger Triumph“ (TBW 11, 106). Als ihn gleich darauf „der Chefredakteur beim Ärmel“ packt, ihn „auf die Seite“ zieht und ihm „eine Stelle als Lokalredakteur“ anbietet, hat er daran kein Interesse mehr: „nein, / ich habe mich dieser Stadt schon entzogen" (TBW 11, 107).

\section{„zuchtvoll und klar“: Bernhard als Literaturkritiker im Salzburger Demokratischen Volksblatt}

Nachdem sich Thomas Bernhard in seinem ersten journalistischen Artikel vom Juli 1950 im politisch weit rechts stehenden Salzburger Volksblatt dem Andenken seines Großvaters Johannes Freumbichler gewidmet hatte, arbeitete er ab Januar 1952 für das sozialistische Demokratische Volksblatt nicht nur als Gerichtsberichterstatter, sondern auch als Feuilletonist und Kulturredakteur. Auf die bereits genannte Reportage über ein Flüchtlingslager (11. Januar 1952), auf deren Zugehörigkeit zum literarischen Werk er Jahre danach ausdrücklich bestanden hat, ${ }^{78}$ folgte zehn Tage später ein ausführlicher, mit dem Kürzel „Th. B.“ gezeichneter Artikel über die Situation junger Schriftsteller in Österreich - ein Thema, das seine Beiträge im Demokratischen Volksblatt im Lauf der Jahre begleiten sollte:

77 Laut Kommentar der Werkausgabe hat Bernhard den Namen der Zeitung erst 1988 im Zuge der Vorbereitung der Publikation eingefügt. Vgl. TBW 11, 345.

78 Als Reaktion auf die Zusammenstellung einer Werkgeschichte (1981) durch Jens Dittmar klagte Bernhard in einem Gespräch mit Siegfried Unseld, dass jene Texte, die Dittmar „als erste ausgegeben“ habe, „gar nicht die ersten Texte“ gewesen seien: „Er hätte“, so notiert Unseld in seinem Reisebericht, „,in der von Herrn Kaut herausgegebenen ,Demokratischen Zeitung ' [sic] ein Flüchtlingslager besprochen, das sei sein erster Text, aber den habe Herr Dittmar nicht gefunden.“ (Unseld: Reisebericht [Februar 1982]. In: Bernhard/Unseld: Der Briefwechsel [Anm. 36], S. 649) - Vgl. Manfred Mittermayer: Das Salzburg des Thomas Bernhard. Berlin: Edition A. B. Fischer 2017, S. $31 \mathrm{f}$. 
„Sagen Sie, wovon leben heute unsere Dichter?“, fragte neulich eine bekannte Dame. Freilich konnte ich nicht gleich antworten, aber ich hatte Gelegenheit, Bekanntschaft zu machen mit einigen dieser jungen Träger der österreichischen Kultur. Und tatsächlich, sie sind Träger. Jeder einzelne trägt schwer, aber nicht nur Kultur allein, sondern mit größter Ausdauer einen Berg von Alltagssorgen auf seinem Rücken. Die „Kunst“ der kunstbegeisterten Männer und Frauen besteht meist darin, sich von einem Tag zum andern am Leben zu erhalten. Hier ist man oft glücklich bei Wassersuppe und trockenem Brot, mit geflickten Hemden und durchlöcherten Schuhen. (TBW 22.1, 13)

Viele junge Autorinnen und Autoren hausten, so Bernhard, unter unwürdigen Bedingungen; von seinem einstmals romantischen Bild vom Beruf des Schriftstellers habe er sich, so heißt es in dem Junge Dichter in Österreich betitelten Beitrag, verabschieden müssen. ${ }^{79}$ Zudem sei angesichts der schwierigen ökonomischen Situation vieler Kunstschaffender ein veritabler brain drain in die deutschsprachigen Nachbarländer zu beobachten:

[D] eshalb ist es nicht verwunderlich, trotz allen schweren Kämpfen unseres kleinen, wirtschaftlich nicht am besten fundierten Staates, wenn manche, diese ohnehin zähen Künstlernaturen, nach Deutschland oder der nahen Schweiz abwandern, wo man ihnen Brot und Mut gibt. Diese Art des Abschiebens geistig arbeitender Persönlichkeiten, seien es nun Dichter, Schriftsteller, Komponisten, Maler oder Wissenschaftler, die schon zu einer dauernden Einrichtung geworden zu sein scheint, wirft kein gutes Licht auf unser Land und es ist beschämend für uns, daß man die, in der Ferne oftmals zu Ruhm und Anerkennung gelangten Österreicher, später mit Geschrei und Posaunen empfängt. (TBW 22.1, 14)

Umso erstaunlicher sei, dass es weiterhin unbeirrbare Idealisten gebe - die Situation unter den „Dichtern“ bezeichnet Bernhard als besonders schlimm -, die sich neben ihren Brotberufen als „Straßenkehrer und Schneeschaufler“, als „Großküchengehilfen und Kohlenschupfer" noch ihrer Kunst widmeten; ihnen müsse man, so das Plädoyer des erst 20-jährigen Journalisten, der hier ganz offensichtlich auch pro domo spricht, „hilfreich unter die Arme [...] greifen“ (TBW 22.1, 15).

Während Bernhard später aus der Position des privilegierten und ökonomisch abgesicherten Autors vehement gegen jede „Subvention“ und „Förderung künstlerischer Belange“ (TBW 22.2, 269 f.) Stellung bezogen hat, ${ }^{80}$ setzte er sich

79 Vgl. jedoch Moritz: Lehrjahre (Anm. 44), S. 155, der Bernhards Rechercheaufwand stark in Zweifel zieht: „In dieser Philippika für die Jugend, in seiner Beweisführung vor allem, schöpft Bernhard aus eigenem Empfinden und eigenen Erfahrungen mehr als aus objektiven Fakten.“ heißt es weiter: „Ist ja in einem Satz gesagt: Alles abschaffen, was Subvention und Förderung 
im Zuge seiner Arbeit für das Demokratische Volksblatt für die Belange junger, am oder unter dem Existenzminimum lebender Schriftsteller ein, ${ }^{81}$ so etwa im vorweihnachtlich getönten Artikel Bücher warten auf dich! vom 29. November 1952: „Beglückend ist, daß es die junge österreichische Literatur gibt“, heißt es dort. „Sie ist da, in einer unglaublichen Mannigfaltigkeit. Aber sie will, wie alles in der Welt, gehegt und gepflegt werden.“ (TBW 22.1, 89f.) Vier Monate später formulierte Bernhard auf der eigens dafür eingerichteten „Seite unserer Jugend“ erneut eine Apologie seiner Generation. Mit seinem unkonkreten und zur Phrase neigenden Pathos ist das Die Kultur ist nicht stehen geblieben! übertitelte Feuilleton charakteristisch für den Stil des jungen Journalisten:

Die Jugend hat nicht geschlafen! Sie hat gearbeitet und arbeitet mehr denn je. Sie hat es nicht leicht, sie muß einen harten, unerbittlichen Kampf ausstehen und durchhalten. Sie muß Herr werden über den Dünkel, der die Menschen beherrscht, die Ich-Sucht und das Unverständnis gegenüber der neuen Zeit. (TBW 22.1, 142)

Bernhards wiederholte Klage über die Vernachlässigung jüngerer Autorinnen und Autoren bleibt weitgehend unspezifisch, weil er in den einschlägigen Beiträgen meist keine konkreten Namen von förderungswürdigen und -bedürftigen Schriftstellern nennt, und sie geht zudem kaum auf Kosten der Literatur der älteren Generation. Ein Aufbegehren gegen den konservativ-restaurativen Mainstream im Salzburger Kulturbetrieb der Nachkriegszeit wird noch einige Zeit auf sich warten lassen.

Hatte er am 30. Januar 1952 mit dem frühverstorbenen Rudolf Kasparek einen Weggefährten und Freund seines Großvaters als „eigenwillige Dichterpersönlichkeit“

ist. Ich würde nie einem jungen Künstler zehn Schilling geben; gar nichts. Der soll hinaus, und entweder wird er oder nicht. Ich hab's ja auch so g'macht. [...] Ein Schriftsteller, der nur aus sich selber heraus lebt, arbeiten muß, der wird auch was leisten. Aber wenn er weiß, ich brauch' eh nichts tun, weil am Ersten kommt die Rente vom Ministerium oder irgendein Rentenzuschuß - das ist doch alles furchtbar." (TBW 22.2, 270) Vgl. auch Bernhards Kommentar zu seinem Austritt aus der Deutschen Akademie für Sprache und Dichtung im Dezember 1979, in dem er sich ebenfalls gegen den „Subventionsdampf “ wendet, der „zum Himmel stinkt“ (TBW 22.1, 662). Dass Bernhard selbst im Laufe seiner schriftstellerischen Karriere von Zuwendungen durch öffentliche Stellen profitiert hat, verschweigt er indes geflissentlich: „Die Leugnung“ sei, so Honegger: Thomas Bernhard (Anm. 71), S. 97 f., „derart unverschämt, dass er sich damit keineswegs von den anderen absetzt, sondern im Gegenteil sich selbst in ihren Heucheleien und Selbsttäuschungen mit einzubeziehen scheint [...]. Sein Zorn mag sich wohl auch am Selbsterkennen, um nicht zu sagen Selbsthass entzündet haben.“

81 Zu Bernhards „Engagement für Dichterkolleg/innen der jungen Generation“ vgl. auch Janner: Der Tod im Text (Anm. 9), S. 116, zum literaturgeschichtlichen Kontext dieser Thematik das Kapitel „Das Problem mit der Jugend“ in Polt-Heinzl: Die grauen Jahre (Anm. 3), S. 69-78, zu Bernhard bes. S. $75 \mathrm{f}$. 
porträtiert, dem wie Freumbichler die verdiente Wertschätzung zeitlebens verwehrt geblieben sei (TBW 22.1, 16), ${ }^{82}$ wandte er sich - nach Beiträgen zu wissenschaftlichen, sozialen und kulturellen Themen ${ }^{83}$ - erst Ende November 1952 wieder einzelnen Schriftstellern zu. Als Redakteur der sozialistischen Tageszeitung besuchte er u. a. Veranstaltungen und Lesungen, die von der Salzburger Volkshochschule, vom Künstlerbund „Die Silberrose“, im von Walter Seidlhofer gegründeten „Salzburger Lesestudio“ oder im „Amerika-Haus“ angeboten wurden. ${ }^{84}$ Seine Kurzberichte zeichnen sich gerade anfangs durch eine weitgehend undifferenziert-naive Affirmation traditioneller literarischer Ausdrucksformen aus; sie sind, wie Christian Klug gezeigt hat, „arm an Kriterien“, wodurch kaum ein „Hintergrund einer theoretisch reflektierten Ästhetik oder Poetik erkennbar wird“ ${ }^{85}$ Vergleicht man sie mit Handkes frühen Buchrezensionen und Kulturbeiträgen, die er in den Jahren 1964 bis 1966 für das steiermärkische Regionalradio verfasst hat, ${ }^{86}$ dann wird deutlich, dass die Texte des etwa gleichaltrigen Bernhard jene Vertrautheit mit Aspekten moderner Kunsttheorie und mit aktuellen literarästhetischen Fragestellungen, die Handkes Rundfunkfeuilletons auszeichnet, ganz und gar vermissen lassen.

Bernhard lobt in seinen kurzen Berichten über das Salzburger literarische Leben „beschaulich-besinnliche Erzählungen“ (TBW 22.1, 125) sowie „zuchtvoll[e] und klar[e]“ Verse (TBW 22.1, 320), er freut sich über die „schöne besinnliche Stunde“ (TBW 22.1, 121), die Theodor Renzls Mundartgedichte dem Publikum bereitet haben, und die „seelenvollen Strophen“ einer Lyrikerin, die sich nur

82 Zur Beziehung von Bernhard, Freumbichler und Kasparek vgl. Mittermayer: Thomas Bernhard [2015] (Anm. 25), S. 24, 27 u. 74, zu Bernhards Text vgl. Billenkamp: Thomas Bernhard (Anm. 14), S. 55 .

83 Die Beiträge beschäftigten sich u. a. mit dem Fremdenverkehr, den Salzburger Festspielen, einem Konzert der Salzburger Mittelschulen, Volksfesten in München und Salzburg sowie Vorträgen über Afrika, Atomenergie, Höhlenforschung und Gesundheitsvorsorge. Auch in der Folgezeit erschienen neben literatur- und kulturkritischen Artikeln stets auch solche zu populärwissenschaftlichen, medizinischen, volkskundlichen und sozialen Themen mit Titeln wie Lepra ist noch immer unheilbar, Jod verhindert Kropf, Salzburger Tracht in der Residenz, Der Sturm auf den Nanga Parbat oder Alles fährt jetzt Ski!.

84 Vgl. Waitzbauer: Thomas Bernhard in Salzburg (Anm. 47), S. 94 f. u. 127; Mittermayer: Thomas Bernhard [2015] (Anm. 25), S. 94 f.; hierzu und zum Folgenden vgl. bereits meine Ausführungen in: Journalistische Arbeiten. In: Bernhard-Handbuch. Leben - Werk - Wirkung. Hg. v. Martin Huber u. Manfred Mittermayer. Unter Mitarb. v. Bernhard Judex. Stuttgart: Metzler 2018, S. 16-20, hier S. $17 \mathrm{f}$.

85 Klug: Thomas Bernhards Arbeiten (Anm. 28), S. 145; vgl. auch Habringer: Der Auswegsucher (Anm. 26), S. 35: „Eine selbständig entwickelte Ästhetik läßt sich aus den zahlreichen Kritiken allerdings nicht ableiten."

86 Vgl. dazu u.a. Kap. III, Abschnitt „Literaturkritik als ,leeres Geschäft‘: Handkes Vorarbeiten im Radio“. 
manchmal „etwas von der beschwingt-fraulichen Sphäre entfernen“ (TBW 22.1, 113). Die Gedichte der 1913 in Bad Gastein geborenen Maria Zittrauer, die er wiederholt zur Lektüre empfiehlt, rühmt er im März 1953 nicht für ihre literarischen „Mittel“, sondern für den „großen einfachen Ausdruck[ ], der nur einer Frau gegeben sein kann“: „Und weil wir sagen müssen, daß wir glauben, was sie uns sagt“, schließt Bernhard, der hier wie so oft in seinen frühen journalistischen Beiträgen von sich selbst im Plural schreibt, „darum ist sie Dichterin in voller Bedeutung des Wortes.“ (TBW 22.1, 138f.) Etwas mehr als ein Jahr später bescheinigt er Zittrauers neuem Lyrikband Die Feuerlilie, man finde in ihm nicht nur „das Salzburger Land in seiner beruhigenden Vielfalt“, sondern auch „die Größe und Erhabenheit der Berge und das schlichte Empfinden eines starken, von den rauhen Stürmen der Täler entfachten Herzens“; „stark, lebensvoll und echt“ seien die Verse der 1952 mit dem Georg-Trakl-Preis ausgezeichneten Dichterin (TBW 22.1, 370). ${ }^{87}$ Immer wieder stellt Bernhard in seinen literaturkritischen Arbeiten, aber auch in anderen Beiträgen für das Demokratische Volksblatt die Vitalität und Ursprünglichkeit der Natur und des Landlebens - „das unbeschadete Empfinden“" (TBW 22.1, 373) - dem Bereich des Kranken und Künstlichen gegenüber: „Der Blick geht plötzlich wunderbar weit hinaus“, heißt es in der Schilderung eines Ausflugs, den Bernhard nach Oberndorf unternommen hat, „und endlich werden die Wiesen auch grün und man sieht: da krankt auch die Welt nicht mehr." (TBW 22.1, 180)

Wenn er dem Innsbrucker Schriftsteller Walter Rodlauer im Dezember 1952 einige „sehr gute Ansätze“ attestiert (TBW 22.1, 109) oder bei anderer Gelegenheit von einer „starke[n] dichterische[n] Begabung“ spricht (TBW 22.1, 323), ohne diese Einschätzungen näher zu erläutern, dann verweist dies auf die mitunter recht lieblos wirkende Beiläufigkeit vieler Beiträge des jungen Journalisten, aber auch auf den eingeschränkten Raum, der den Lesungsberichten im Demokratischen Volksblatt zur Verfügung stand. Manche Texte Bernhards weisen gerade einmal einen Umfang von 100 Wörtern auf, in dem alle grundlegenden Informationen sowie Angaben zur Publikumsresonanz ${ }^{88}$ Platz finden mussten: Oft war

$87 \mathrm{Zu}$ Bernhards Wertschätzung für Zittrauer vgl. Mittermayer: „Die brennende hilfesuchende Glut“ (Anm. 31), S. 205 f.

88 Vgl., um nur eine Auswahl zu nennen, die folgenden stereotypen Schlusswendungen in Bernhards Lesungsberichten: „Das erschienene Publikum dankte dem jungen Autor für die schöne, besinnliche Stunde mit viel Beifall“ (TBW 22.1, 121); „Das zahlreich erschienene Publikum dankte mit reichem Beifall den Vorlesungen“ (TBW 22.1, 139); „Das Publikum war sehr zahlreich erschienen und unterhielt sich an manchen Stellen. Der Beifall am Ende war liebenswürdig bemessen“ (TBW 22.1, 150); „Die Zuhörer spendeten reichen Beifall“ (TBW 22.1, 270); „Daß nur wenige Menschen der Hunderttausend-Stadt zu dem Autor gefunden haben, beeinträchtigte den angenehmen Erzählerabend in keiner Weise“ (TBW 22.1, 276); „Das Publikum dankte mit reichem, verdientem Beifall“ (TBW 22.1, 282); „Die Zuhörer spendeten reichen 
der „Kunst- oder Literaturkritiker“, so Jens Dittmar, vor allem „ein Reporter, der sich weitgehend auf das Was, Wann und Wo beschränken mußte“ ${ }^{89}$ Christian Klug hat zudem hervorgehoben, dass der Nachwuchsrezensent von der Redaktion des Demokratischen Volksblatts meist „zu den eher zweitrangigen Kulturereignissen geschickt" wurde, ${ }^{90}$ während die attraktiveren kulturellen Termine den arrivierten Kollegen, etwa dem in Bernhards Der Keller (1976) porträtierten Musikkritiker Theodor W. Werner, vorbehalten waren.

Werner, der Musikwissenschaftler aus Hannover, [...] ging nach jedem Konzert an den späteren Nachmittagen mit einer feinsäuberlich mit der Hand geschriebenen Kritik, mit einem kleinen Meisterwerk, wie ich heute weiß, aus der Pfeifergasse über den Mozartplatz und durch die Judengasse und über die Staatsbrücke und in die ParisLodron-Straße in die Zeitungsredaktion des Demokratischen Volksblatts, das seine Gedanken, die immer die außerordentlichsten Gedanken gewesen sind, abdruckte. Er war nichts weniger als ein Musikwissenschaftler und Philosoph, was die Redakteure und die Leser des Demokratischen Volksblatts, der einzigen sozialistischen Tageszeitung in der Stadt, zwar hochgeschätzt, aber niemals begriffen haben. (TBW 10, 197)

Während Bernhard in den autobiographischen Erzählungen davon berichtet, dass er auf Anregung des Großvaters „Novalis, Kleist, Hebel, Eichendorff“, ja "Shakespeare und Stifter" gelesen habe (TBW 10, 284 u. 299), widmen sich viele Artikel im Demokratischen Volksblatt Büchern bzw. Autorinnen und Autoren, die heute kaum mehr bekannt sind, darunter Karoline Brandauer, Alfons Czibulka, Georg Eberl, Eduard C. Heinisch, Loni Seitz-Ransmayr und Kurt Ziesel. Große Teile der von Bernhard rezipierten und besprochenen Literatur, etwa Theodor Renzls Hoamatliab (1951) oder Lorenz Macks Das Glück wohnt in den Wäldern... (1952), dessen „natürliche, wahrhaft menschliche Stimme“ er schätzte (TBW 22.1, 89), sind jener literarischen Strömung der Nachkriegszeit zuzurechnen, die „Bilder der Einheit, der Ruhe, Geborgenheit und Stabilität“ entwarf und den Verfahren und Sujets der literarischen Moderne fern stand. ${ }^{91}$ Hatte Ernst Schönwiese im Salzburg der unmittelbaren Nachkriegszeit die 1935/1936 begründete Zeitschrift

Beifall“ (TBW 22.1, 323); „Die Zuhörer dankten den beiden Vortragenden herzlich“ (TBW 22.1, 326); „Das zahlreich gekommene Publikum dankte Georg Eberl mit herzlichem Applaus“ (TBW 22.1,367) etc.

89 Jens Dittmar: Thomas Bernhard. Reporter. In: Aus dem Gerichtssaal (Anm. 43), S. 259-278, hier S. 276. Billenkamp: Thomas Bernhard (Anm. 14), S. 59, hat außerdem zu bedenken gegeben, dass Bernhards Beiträge im Demokratischen Volksblatt stets ,von den verantwortlichen Redakteuren nachträglich redigiert worden sind" und der Anteil der sprachlichen und inhaltlichen Über- und Umarbeitungen nicht mehr zu ermitteln ist.

90 Klug: Thomas Bernhards Arbeiten (Anm. 28), S. 144.

91 Müller: Die Bannung der Unordnung (Anm. 32), S. 187. 
das silberboot reaktiviert und sich, u. a. mit dem Abdruck von Texten Hermann Brochs, Franz Kafkas und Robert Musils, der „verschüttete[n] Tradition der österreichischen Moderne“ angenommen, ${ }^{92}$ zeigte das Salzburger Lesungsprogramm der 1950er Jahre eine recht deutliche konservative und literarisch biedere Schlagseite. Bernhards Eloge auf Lorenz Macks Roman Das Glück wohnt in den Wäldern... mutet, zumal mit Blick auf die spätere Agitation gegen Natur, Heimat und ländliche Behaglichkeit, in seiner naiven Positivität beinahe kurios an:

Hier wird uns der Wald mit seinen tausend und abertausend Wundern geschildert, mit seinen frühen und späten Wandlungen im Laufe der Jahreszeiten, das Glück und Unglück zweier Liebender, die schließlich - nach den immer wiederkehrenden Enttäuschungen - im Glauben an die Größe und Schönheit des Lebens aufgehen. Größe und Schönheit des Lebens, das kann uns ergreifen, zum Guten stimmen ... Ohne Effekt geschrieben, nur „aus sich selbst gewachsen“, könnte man zu diesem Buch sagen, das uns in dieser Zeit der inneren Unruhe selbst wie eine wunderbare Lichtung im Wald der jungen Literatur dünkt (in dem nicht immer das Glück wohnt), in der wir getrost und liebend ruhen können. (TBW 22.1, 89)

Seine nachträglichen Bemühungen, „diese Jahre umzudeuten und sich als einen frühreifen Querulanten und Skeptiker darzustellen“, stehen zu den überlieferten Texten der ersten Hälfte der $1950 e r$ Jahre in denkbar großem Kontrast. ${ }^{93}$ Bernhards Arbeiten für das Demokratische Volksblatt verraten einige „Unsicherheit in Wertungsfragen“; ${ }^{94}$ zudem sind sie Ausdruck einer nicht nur in Salzburg, sondern in großen Teilen der österreichischen Kulturlandschaft der Nachkriegszeit vor-

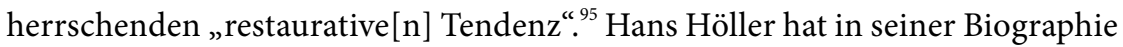
einen Teil der journalistischen Beiträge des Autors als geradezu „unerträglich positiv“ beschrieben. ${ }^{96}$

Kritik an den lesenden Schriftstellerinnen und Schriftstellern übte Bernhard im Demokratischen Volksblatt meist „Vornehm zurückhaltend“997 bzw. in recht allgemeiner Form: „Es gibt viel Spreu unter dem dünngesäten Weizen“ (TBW 22.1, 88). Lediglich in einem kurzen Lesungsbericht vom 2. April 1954 formuliert er

92 Wendelin Schmidt-Dengler: Bruchlinien. Vorlesungen zur österreichischen Literatur 1945 bis 1990. Salzburg, Wien: Residenz 1995, S. 52. Dazu auch Hildemar Holl: Literaturgeschichte Salzburgs von 1945 bis zur Gegenwart. In: Salzburg. Zwischen Globalisierung und Goldhaube. Hg. v. Ernst Hanisch u. Robert Kriechbaumer. Wien u. a.: Böhlau 1997, S. 671-734, hier S. 675 f.

93 Klug: Thomas Bernhards Arbeiten (Anm. 28), S. 137.

94 Polt-Heinzl: Thomas Bernhard betritt die Wiener Szene (Anm. 66), S. 59.

95 Billenkamp: Thomas Bernhard (Anm. 14), S. 57.

96 Höller: Thomas Bernhard (Anm. 76), S. 51.

97 Manfred Mixner: Vom Leben zum Tode. Die Einleitung des Negations-Prozesses im Frühwerk von Thomas Bernhard. In: Bernhard. Annäherungen (Anm. 51), S. 65-97, hier S. 66. 
einen veritablen Verriss, der so harsch ausfällt, dass er auf die Nennung des nur unter Vorbehalt als „Dichter" apostrophierten Autors verzichtet. ${ }^{98}$ Aus den Zeilen spricht freilich weniger die Häme des Polemikers als vielmehr Mitleid mit dem Gast des verunglückten Abends:

In einem Hörsaal der theologischen Fakultät stellte die Salzburger Volkshochschule Mittwoch abends wieder einen „Dichter“ vor. Wir wollen über die gelesenen Verse und über die vorgetragene Prosa den Mantel des Verzeihens breiten, denn auch die Bemühung ist ihre Anerkennung wert. Man muß aber feststellen, daß, wenn die Volkshochschule diesen Weg weitergeht und um jeden Preis Dichter entdecken will, bald niemand mehr in Salzburg ihre „Dichterlesungen“ besuchen wird. Eine gesunde und strenge Auswahl der Lesenden wäre vonnöten. So, wie es jetzt geschieht, tut man mehr gegen als für die Literatur. (TBW 22.1,350)

Die hier als Veranstalter genannte Salzburger Volkshochschule, die ab 1953 auch eine Reihe unter dem Titel „Junge Dichter lesen“ anbot (vgl. TBW 22.1, 121), spielte Anfang der 1950er Jahre eine wichtige Rolle für Bernhards literarische Sozialisation und den Aufbau eines Netzwerkes. Hier knüpfte er Kontakte zu anderen jungen Autorinnen und Autoren, die wie er nach ersten Publikationsmöglichkeiten suchten und am Austausch mit Gleichgesinnten interessiert waren: „Bernhard lernte ich Anfang bis Mitte der fünfziger Jahre auf der Salzburger Volkshochschule kennen“, erinnert sich der ebenfalls 1931 geborene Johann Barth: „Da hat Professor Adalbert Schmidt Vorträge über moderne Gegenwartsliteratur gehalten. Da sind sich Erwin Gimmelsberger, der die Rauriser Literaturtage begründet hat, Thomas Bernhard und ich begegnet. ${ }^{\text {“99 }}$ Deutlich geschickter als sein zeitlebens im Literaturbetrieb isolierter Großvater beteiligte Bernhard sich aktiv am kulturellen Geschehen der Stadt Salzburg und war mit vielen Autorinnen und Autoren, über die er im Demokratischen Volksblatt berichtete, auch persönlich

98 Bei dem Autor handelte es sich, so der Kommentar der Werkausgabe, um den Salzburger Lyriker Emil Lerperger, dessen Band Begnadete Nacht 1954 erschien. Vgl. TBW 22.1, 776.

99 Johann Barth: Er war sich seines Sieges schon gewiss. In: Was reden die Leute (Anm. 46), S. 140-144, hier S. 141. Diente die Volkshochschule einerseits jungen Autorinnen und Autoren als Ort, an dem sie zum ersten Mal an die literarische Öffentlichkeit treten konnten, stand der Name Adalbert Schmidt zugleich für die stillschweigend tolerierten Kontinuitäten zwischen Drittem Reich und Zweiter Republik. Er war Mitglied der NSDAP und der Reichsschrifttumskammer sowie Herausgeber der Anthologie Ostmark-Lyrik (1939) gewesen, nach 1945 hatten seine Arbeiten auf der „Liste der gesperrten Autoren und Bücher" gestanden. 1949 bis 1954 (also in den Jahren, in denen Bernhard ihn kennenlernte) war Schmidt Lektor für Phonetik und Sprecherziehung sowie Mitarbeiter beim Salzburger Volksblatt, schließlich von 1966 bis 1976 Professor für österreichische Literaturgeschichte an der Universität Salzburg. Vgl. dazu Karl Müller: Adalbert Schmidt. In: Internationales Germanistenlexikon. 1800-1950. Hg. v. Christoph König. Bd. 3: R-Z. Berlin, New York: de Gruyter 2003, S. 1616-1618. 
näher bekannt: Ernst Schönwiese war wie Georg Eberl Mitarbeiter des Demokratischen Volksblatts; Gerhard Amanshauser, Georg Eberl, Elisabeth Effenberger oder Thea Manzl, deren Auftritte Bernhard als Kritiker besprach, präsentierten in denselben Lesungsreihen wie er ihre Bücher ${ }^{100}$ bzw. publizierten zeitnah in jenen Anthologien und Sammelbänden, in die auch Bernhards erste Texte aufgenommen wurden (z. B. Hans Weigels Jahrbuch Stimmen der Gegenwart, 1954; Salzburg von A-Z, 1954; Die ganze Welt in meines Herzens Enge, 1955). Gemeinsam mit Elisabeth Effenberger und dem bildenden Künstler Josef Hödlmoser war er an der Gründung und Organisation der im Sommer stattfindenden „Wochen österreichischer Dichtung“ (später: „Forum Hohensalzburg“) beteiligt, bei denen schon im ersten Jahr u. a. Christine Busta, Jeannie Ebner, Marlen Haushofer und Christine Lavant zu Gast waren und 1956 ein geplanter Auftritt von Gottfried Benn nur durch dessen Tod verhindert wurde. ${ }^{101}$ Bernhard trat im Zuge der „Wochen österreichischer Dichtung“ nicht nur als Organisator, ${ }^{102}$ sondern auch als Leser eigener und Rezitator fremder Texte auf und rezensierte 1955 sogar eine Lesung des deutschen Schriftstellers Bernt von Heiseler in den Salzburger Nachrichten ${ }^{103}$ - ein veritabler Interessenkonflikt. 1955 und 1956 nahm er zudem an den als Vernetzungstreffen bekannten Jugendkulturwochen in Innsbruck teil. ${ }^{104}$

Im Rückblick hat Bernhard in diesem Zusammenhang von Erfahrungen der „Degradierung“ und allgegenwärtiger „Rivalität“ gesprochen, die etwa sein Verhältnis zu Gerhard Amanshauser geprägt habe. ${ }^{105}$ Amanshauser hatte 1952, ebenso wie Elisabeth Effenberger, im Rahmen der Verleihung des Georg-Trakl-Preises an Maria Zittrauer einen Anerkennungspreis erhalten, während Bernhard, der ebenfalls Texte eingereicht hatte, nicht zum Zug kam. War der Anerkennungspreis auch mit keiner Geldsumme, sondern lediglich mit der Überreichung einer TraklGesamtausgabe verbunden, bedeutete er doch Aufmerksamkeit, symbolisches

$100 \mathrm{Zu}$ Bernhards ersten eigenen Lesungen in Salzburg vgl. Habringer: Der Auswegsucher (Anm. 26), S. 35 f.; Mittermayer: Das Salzburg des Thomas Bernhard (Anm. 78), S. 36.

101 Vgl. Ursula A. Schneider/Annette Steinsiek: Mengenlehre. Christine Lavant und die „Wochen österreichischer Dichtung“ in Salzburg 1955. In: praesent (2004), S. 59-70; Mittermayer: „Die brennende hilfesuchende Glut“ (Anm. 31), S. $206 \mathrm{f}$.

102 Vgl. Thomas Bernhard an Siegfried Melchinger, 3 Briefe, 1956. In: Deutsches Literaturarchiv Marbach, Handschriftensammlung, A: Melchinger, HS.1999.0010. Bernhard lud den deutschen Theaterkritiker Melchinger am 4.3.1956 brieflich zu einem Vortrag im Rahmen des „Forum Hohensalzburg" ein und kümmerte sich in der Folge auch um organisatorische Belange wie die Unterbringung des Referenten sowie die Vereinbarung von Honoraren und Fahrtspesen.

103 Vgl. Schneider/Steinsiek: Mengenlehre (Anm. 101), S. 63.

104 Vgl. Christina Riccabona/Erika Wimmer/Milena Meller: Die Österreichischen Jugendkulturwochen 1950-1969 in Innsbruck. Innsbruck u. a.: StudienVerlag 2006, S. 47-52 u. 56; dazu auch den Bericht in N. N.: Erfolgreiche junge Schriftsteller. In: Demokratisches Volksblatt, 5. 5. 1955.

105 Hofmann: Aus Gesprächen mit Thomas Bernhard (Anm. 42), S. 88; vgl. auch TBW 22.2, 277. Zur Rivalität zwischen Amanshauser und Bernhard vgl. Moritz: Lehrjahre (Anm. 44), S. 126. 
Kapitel und verbesserte Publikationsmöglichkeiten für seine beiden Kollegen. ${ }^{106}$ Als drei Jahre später die von Hansjörg Graf herausgegebene Anthologie Ahnung und Gestalt (1955) Beiträge aller Trakl-Preisträger versammelte, ${ }^{107}$ waren denn auch Amanshauser und Effenberger darin vertreten, während Bernhard außen vor blieb - der auch 1957 bei seiner nächsten Einreichung nicht erfolgreich war. ${ }^{108}$ Seine Behauptung, er habe „sicher mindestens fünf, sechs Mal beim Trakl-Preis eingereicht, den hat dann immer der Amanshauser gekriegt oder irgendwer" 109 ist wohl übertrieben, wurde der Trakl-Preis doch nicht jährlich, sondern nur zu Jubiläen des Geburts- und Todestages des Lyrikers vergeben (also 1952, 1954, 1957, 1962 usw.).

Es fällt allerdings auf, dass Bernhard - mit Ausnahme von Maria Zittrauer ${ }^{110}$ gerade jene Autorinnen und Autoren, die 1952 mit einer Auszeichnung im Rahmen des Trakl-Preises bedacht wurden (neben Amanshauser und Effenberger war dies der Oberösterreicher Josef Laßl, der einen mit 1000 Schilling dotierten Nebenpreis erhielt), in seinen Lesungsberichten besonders kritisch besprach. Als im März 1953 in der Volkshochschule Gerhard Amanshauser gemeinsam mit Maria Zittrauer auftrat, lobte Bernhard in seinem Artikel für das Demokratische Volksblatt zunächst ausführlich die Lyrik der „Gasteiner Dichterin“, um im kürzeren zweiten Teil seines Textes dem drei Jahre älteren Amanshauser zu bescheinigen, dass seine Gedichte „noch unreif“ und „unbeholfen“ seien: „Denn es genügt nicht, Stimmungen einzufangen - man muß ihrer auch Herr werden. “ (TBW 22.1, 138f.) Drei Wochen später legte er anlässlich einer zweiten Veranstaltung zum Trakl-Preis Elisabeth Effenberger „Selbstkritik, nichts als Selbstkritik!“ ans Herz, weil sie sich mit ihrer „frauliche[n], unselbständige[n] Lyrik“ als „allzu sehr im Kunstgewerblichen des Wortes befangen“ gezeigt habe; Josef Laßl, dessen Roman zwar „nicht schlecht geschrieben“ sei, aber doch nicht habe überzeugen können, wurde nicht eben freundlicher behandelt (TBW 22.1, 149). ${ }^{111} \mathrm{Im}$ Dezember 1953

106 Vgl. Hans Weichselbaum: Im Namen des Dichters. 45 Jahre Georg-Trakl-Preis für Lyrik Geschichte und Dokumentation. Salzburg, Wien: Otto Müller 1998, S. 10-12.

107 Vgl. Ahnung und Gestalt. Salzburger Almanach der Georg-Trakl-Preisträger. Zusammengestellt u. eingeleitet v. Hansjörg Graf. Salzburg: Otto Müller 1955; in der Riege der Preisträger fehlte in Ahnung und Gestalt lediglich Josef Laßl, der, so Schneider/Steinsiek: Mengenlehre (Anm. 101), S. 61, aufgrund seiner NS-Vergangenheit ,ausgeschlossen worden war“.

108 Vgl. Weichselbaum: Im Namen des Dichters (Anm. 106), S. 16.

109 Hofmann: Aus Gesprächen mit Thomas Bernhard (Anm. 42), S. 88.

$110 \mathrm{Vgl}$. schon seinen ersten Bericht über eine Lesung der Autorin im November 1952: „Eine Dichterin, die mitten im Leben steht, und damit umzugehen weiß. Und wie! [...] Man preist sich glücklich, sie im Lande zu haben, bei all der Flut von ,Form'-Produktion, die uns allmählich den Hals zuschnürt. Die Dichterin hat den Trakl-Preis verdient!“ (TBW 22.1, 83)

111 Dass Bernhard seine früheren Urteile auch Jahre später noch präsent waren, zeigt ein Eintrag in Karl Ignaz Hennetmairs Tagebuch vom 2. 2. 1972: „Dann kommt Thomas wieder auf Laßl zu sprechen und sagt, daß er vor 20 Jahren in Salzburg über Dr. Laßls Gedichte und die seiner 
äußerte Bernhard sich schließlich doch konzilianter über Effenberger, deren Verse er nun als „zuchtvoll und klar“ beschrieb; ihre „Gedanken“ hätten, so Bernhard, „manchmal aufhorchen lassen“ (TBW 22.1, 320). Die Rivalität mit Amanshauser indes blieb auch in der Folgezeit bestehen.

Neben Beiträgen über Lesungen österreichischer Autorinnen und Autoren finden sich im Demokratischen Volksblatt auch zahlreiche Artikel Bernhards zur amerikanischen Literatur. Er besuchte regelmäßig Veranstaltungen des 1945 eröffneten und überaus populären "Amerikahauses" am Alten Markt ${ }^{112}$ und berichtete über Abende, bei denen, von Schauspielern wie Heinz Moog oder Helene Thimig gelesen, dem Salzburger Publikum Werke von Clarence Day, Emily Dickinson, Eugene O'Neill, Ezra Pound, William Saroyan, James Thurber und Thornton Wilder vorgestellt wurden. ${ }^{113}$ Das "Amerikahaus" war Teil der amerikanischen Fördermaßnahmen zur „kulturelle[n] Neuorientierung“ in der Besatzungszeit, die großzügige Investitionen „auch in das Buch- und Verlagswesen“ mit sich brachten. ${ }^{114}$ Während er an einer Lesung aus Ernest Hemingways Wem die Stunde schlägt Kritik übte, weil man ,just das unbedeutendste, fleischigste und undichterischste Kapitel" ausgewählt hatte (TBW 22.1, 126), ${ }^{115}$ zeigte er sich am 2. Dezember 1952 über die Präsentation des Romans Schau heimwärts, Engel! von

Freundin eine vernichtende Kritik geschrieben habe. Über Laßl hat Thomas geschrieben: Der macht Gedichte, wie ein anderer eine Spanschachtel macht. Daraufhin haben Dr. Laßl und dessen Freundin Thomas zu sich eingeladen. Sie glaubten, Bernhard wäre ein Unikum, kamen aber zur Überzeugung, daß er eigentlich ein nettes Bürschchen ist. [...] Und jetzt rühmt sich Laßl, daß er mich 20 Jahre kennt, ja, aber wie das damals war, auf das kommt es ja an." (Karl Ignaz Hennetmair: Ein Jahr mit Thomas Bernhard. Das versiegelte Tagebuch 1972. St. Pölten u. a.: Residenz ${ }^{52014}$, S. 95 f.)

112 Vgl. Waitzbauer: Thomas Bernhard in Salzburg (Anm. 47), S. 89: „In der ersten Hälfte der fünfziger Jahre zählt das Amerikahaus in Salzburg zu den populärsten amerikanischen Einrichtungen in Österreich. Allein von Jänner bis August 1950 werden über 300.000 Besucher gezählt." Die Veranstaltungen des „Amerikahauses“ fanden zum Teil auch im Wiener Saal des Mozarteums statt; im August 1954 übersiedelte die Einrichtung in ein Gebäude an der Ecke Münzgasse-Griesgasse (vgl. ebd., S. 90 f.).

113 Vgl. Bernhard Judex/Manfred Mittermayer: Literatur. In: Bernhard-Handbuch (Anm. 84), S. 373-380, hier S. 376 f.: "Wichtige Vertreter der angloamerikanischen Literatur hatte Bernhard bereits während seiner Tätigkeit als Journalist im Salzburg der 1950er Jahre kennengelernt, als das Kulturleben der Stadt noch von den US-Alliierten mitgeprägt wurde. Überhaupt ist Bernhards Tätigkeit als Kulturredakteur und Verfasser von Feuilletons hinsichtlich seiner Lektüre-Biographie nicht zu unterschätzen, lernte er doch dadurch zahlreiche Autoren namentlich kennen, die durch Übersetzungen auf den deutschsprachigen Buchmarkt kamen."

114 Müller: Zäsuren ohne Folgen (Anm. 25), S. 258.

115 Dort heißt es weiter: „Die kaum heißblütige Liebesszene im Rahmen des spanischen Bürgerkrieges, zwischen dem schönen Mädchen Marie und dem kraftstrotzenden jungen Mann aus dem westlichen Kontinent, heuschoberhaft anmutend, erreichte denn auch nicht die erhoffte Wirkung." (TBW 22.1, 126) 
Thomas Wolfe begeistert. Im Sinne jenes emphatischen Künstlerideals, das auch seinen 1954 im Salzburger Hotel Pitter gehaltenen Vortrag über Arthur Rimbaud prägt, ${ }^{116}$ charakterisiert er Wolfe als ,unaufhörlich Anklagende[n], Suchende[n], Verbitterte[n], nach Wahrheit Ringende[n] ohne Ausweg“ (TBW 22.1, 93).

Thomas Wolfe sollte für Bernhard zeitlebens ein wichtiger Autor bleiben. In der 1957 unter dem Titel Ein Wort an junge Schriftsteller veröffentlichten - und wohl im Kontext der Innsbrucker Jugendkulturwochen entstandenen ${ }^{117}$ - Polemik gegen seine Altersgenossen erwies er ihm gemeinsam mit Dylan Thomas und Walt Whitman als Verfasser „neuer, gewaltiger Poesien“ seine Reverenz und stellte ihn den feigen, auf „Krankenversicherungen und Stipendien, Preise und Förderungsprämien“" schielenden Autoren seiner Generation gegenüber (TBW 22.1, 566). Noch Mitte der 1970er Jahre nannte er Wolfe im Gespräch mit Peter Hamm als ersten Autor, der ihn „wirklich fasziniert“ habe; Schau heimwärts, Engel! sei ein Buch gewesen, „wo ich mir gedacht hab', das ist so großartig, und der, der das schreibt, ist so ungeheuer vital und jung und gescheit" (TBW 22.2, 104). ${ }^{118}$

Bereits im ersten Bericht über Wolfes Roman im Rahmen der Lesung im "Amerikahaus" entwirft Bernhard ein Bild bedingungsloser Autorschaft ohne Konzessionen an einen literarischen ,Betrieb; das Ideal einer künstlerischen Existenz, die aller Unbill des Lebens trotzt, der alle finanziellen und moralischen Rücksichten fremd sind und die nur sich selbst und der Kunst Rechenschaft abzulegen bereit ist. ${ }^{119}$ Ein ums andere Mal beschreibt er in den folgenden Jahren den Künstler als einen mit der Welt „Ringenden“ (TBW 22.1, 414): Die Zeichnungen Oskar Kokoschkas charakterisiert er im Sommer 1956 in der Wiener Furche in diesem Sinne als „abgründig und leidenschaftlich“, „ungehemmt geben sie Zeugnis von den Fieberträumen und Finsternissen der Menschen. Jedes Blatt ist ein Stück Leben, das nach einem Stück Brot verlangt." (TBW 22.1, 418) Den hungrig durch die Straßen streunenden, von der Gesellschaft ausgestoßenen Künstler setzt er ein Jahr darauf im Wort an junge Schriftsteller (1957) den schwächlichen „pragmatisierten Dichtern“ und „pragmatisierten Lyrikern“ als Ideal entgegen (TBW 22.1, 567), um sich im gleichen Atemzug selbst in eine Reihe mit Charles Baudelaire, Charles Péguy, Paul Verlaine und Walt Whitman

116 Vgl. dazu ausführlicher meinen Beitrag: Journalistisches, Reden, Interviews. In: BernhardHandbuch (Anm. 84), S. 270-278, hier S. 270 f.

117 Vgl. Mittermayer: Thomas Bernhard [2015] (Anm. 25), S. $102 \mathrm{f}$.

118 Vgl. noch das 1980 im Spiegel gedruckte Gespräch mit Hellmuth Karasek und Erich Böhme: „Ich liebe Wittgenstein und Thomas Wolfe, das sind Sachen, die mich über Jahrzehnte brüderlich begleiten, die liebe ich innigst bis ans Lebensende und über den Tod hinaus, wie das so schön heißt." (TBW 22.2, $174 \mathrm{f}$.)

$119 \mathrm{Zu}$ Bernhards „Künstler-Reflexionen“ in den journalistischen Arbeiten vgl. Janner: Der Tod im Text (Anm. 9), S. 117 f. - Höller: Thomas Bernhard (Anm. 76), S. 48, hat diese nicht zuletzt mit dem Vorbild seines Großvaters Johannes Freumbichler in Verbindung gebracht. 
sowie den skandinavischen Nobelpreisträgern Knut Hamsun und Frans Eemil Sillanpää zu stellen. ${ }^{120}$ Im Demokratischen Volksblatt war von derlei Anmaßung indes noch wenig zu bemerken.

\section{Verschweigen und Verzeihen: Bernhard und der „NS-Parnaß“}

Gerhard Amanshauser habe ihm, so Hermann Hakel in seinen Lebenserinnerungen, Mitte der 1950er Jahre von einem ,jungen, absonderlichen Autor" namens Thomas Bernhard erzählt und ihm einige von dessen Gedichten zur Prüfung vorgelegt: „Nun, die Verse waren schlecht, weinheberisch, sentimentale Naturduselei“, ja „banale Zeitschriften- oder Sonntagsbeilage-Gedichte für die deutsche Familie“. Wenige Jahre später jedoch sei Bernhards literarische Formensprache plötzlich „modern geworden“ und Carl Zuckmayer habe öffentlich „erklärt, daß dieser junge Autor die größte lyrische Hoffnung sei“. ${ }^{121}$ Zwischen den beiden Lektüren Hakels liegt ein entscheidender Schritt in Bernhards schriftstellerischer Entwicklung. Ton und Sujet seines lyrischen Schaffens haben sich auf dem Weg von den ersten Veröffentlichungen im Münchner Merkur im April und Juni 1952 über gelegentliche Beiträge in Zeitungen, Zeitschriften und Anthologien bis hin zu den drei in renommierten Verlagen gedruckten Bänden Aufder Erde und in der Hölle (1957), In hora mortis (1958) und Unter dem Eisen des Mondes (1958) deutlich gewandelt. ${ }^{122}$ Bereits in einer 1955 in den Salzburger Nachrichten gedruckten Kritik hatte sich Hansjörg Graf darüber erfreut gezeigt, dass Bernhard seine epigonalen „Jugendsünden“ allmählich zurückgelassen habe, ja dass sich, bei aller gebotenen Vorsicht, der „Durchbruch seiner dichterischen Begabung“ abzeichne. ${ }^{123}$

120 Vgl. weiter TBW 22.1, 567: „Die Bücher, die ihr schreibt, sind langweilig, sie sind aus Papier, eure Sprache ist erlogen [...], sie brüskiert die Sprache Hölderlins, Whitmans, Brechts [...]. Es ist, als hättet ihr gar nichts erlebt, als lebtet ihr nur aus den Büchern der alten Vetter, als stopftet ihr euch zum Frühstück, Mittagessen und Nachtmahl mit den schwindsüchtigen Rilkes und seiner bleichen Verwandtschaft den Magen voll“. Mit großer Geste entwickelt Bernhard seine Philippika, die - wie viele literarische Scheltreden - damit operiert, Autoren der literarischen Tradition gegeneinander auszuspielen. Hier funktioniert dies v. a. über die Frage des sozialen Status und Habitus der Schriftsteller. Während er Hamsun, Whitman oder den kurz zuvor verstorbenen Gottfried Benn für sich und seine Konzeption von Autorschaft zu vereinnahmen sucht, ist es der in höchsten Kreisen verkehrende und von reichen Gönnerinnen unterstützte Rilke, den er als Negativbeispiel anführt. Die Funktion der literarischen Polemik besteht hier ganz klassisch vor allem auch in Traditions- und Kanonbildung - und in deren Gegenteil.

121 Hakel: Dürre Äste. Welkes Gras (Anm. 1), S. $334 \mathrm{f}$.

122 Zur Entwicklung von Bernhards Lyrik vgl. Axel Diller: Das vergessene Werk. Thomas Bernhards Lyrik. In: Text + Kritik ( $\left.{ }^{4} 2016\right)$, H. 43, S. 66-91.

123 H.[ansjörg] G.[raf]: Skepsis und Erwartung. In: Salzburger Nachrichten, 27. 7.1955. 
Wenn Hakel dem jungen Autor Thomas Bernhard attestiert, sich in seinen Gedichten „weinheberisch“ gebärdet zu haben, dann verweist diese beiläufige Notiz aber auch auf einen Zusammenhang jenseits von Bernhards eigener schriftstellerischer Entwicklung. Der Wiener Lyriker Josef Weinheber, geboren 1892, hatte Mitte der 1930er Jahre mit Gedichtbänden wie Adel und Untergang (1934) und Wien wörtlich (1935) Anerkennung im österreichischen literarischen Feld gefunden, engagierte sich allerdings schon früh in der nationalsozialistischen Bewegung. 1938 war Weinheber einer der prominentesten Beiträger des Bekenntnisbuchs österreichischer Dichter, mit dem die „führenden nationalen Dichter Österreichs“, so das Vorwort des Wiener Schriftstellers und Verlegers Max Stebich, den ,Anschluss` Österreichs an das Deutsche Reich feierten: „Österreich / ist durch die Tat des Führers und Reichskanzlers / Adolf Hitler / heimgekehrt in das Deutsche Reich. / Die nationalen Dichter der Ostmark / neigen sich / freudig bewegt vor dieser Vollendung. " ${ }^{24}$ Weinhebers im Bekenntnisbuch ab- und in vielen NS-Anthologien nachgedruckter Hymnus auf die Heimkehr endet mit einer begeisterten Anrufung Adolf Hitlers: „Deutschland, ewig und groß, / Deutschland, wir grüßen dich! / Führer, heilig und stark, / Führer, wir grüßen dich! / Heimat, glücklich und frei, / Heimat, wir grüßen dich! “ ${ }^{125}$ Im Dritten Reich stand Weinheber auf der „Gottbegnadeten-Liste“ der wichtigsten und bevorzugt zu behandelnden Kulturschaffenden. ${ }^{126}$ Gegen Ende des Zweiten Weltkriegs, am 8. April 1945, nahm er sich angesichts der heranrückenden Roten Armee im niederösterreichischen Kirchstätten das Leben.

In der Folge entwickelten sich heftige Diskussionen über die Rolle Weinhebers im Nationalsozialismus und über die Frage, wie nun mit seinem literarischen Erbe umzugehen sei. In den Jahren 1947 und 1948 wurde in der katholisch-konservativen Zeitschrift Der Turm und ihrem progressiven, betont anti-nazistischen Pendant, dem von Otto Basil herausgegebenen PLAN, intensiv um die Deutung Weinhebers gerungen. Die „Bruchlinien der unmittelbaren Nachkriegszeit“ kamen dabei, so Daniela Strigl, nur zu deutlich zum Vorschein. ${ }^{127}$ Als 1950 ein

124 Max Stebich: [Vorwort]. In: Bekenntnisbuch österreichischer Dichter (Anm. 32), S. 7-8, hier S. $7 \mathrm{f}$.

125 Josef Weinheber: Hymnus auf die Heimkehr. In: ebd., S. 113-116, hier S. 116. Nachgedruckt u. a. in: Ostmark-Lyrik. Gesammelt u. hg. v. Adalbert Schmidt. Wien, Leipzig: Adolf Luser 1939, S. 83-86; Heimkehr ins Reich. Großdeutsche Dichtung aus Ostmark und Sudetenland. 1866-1938. Hg. v. Heinz Kindermann. Leipzig: Reclam 1939, S. 325-327.

$126 \mathrm{Zu}$ seiner Rolle im NS-Kulturbetrieb vgl. Klee: Das Kulturlexikon zum Dritten Reich (Anm. 32), S. 588.

127 Strigl: Spurensicherung (Anm. 33), S. 68. Vgl. ebd.: „Josef Weinheber galt einerseits als die Symbolfigur der politisch Gestrauchelten, andererseits als der Übervater der österreichischen Lyrik, in seiner Kunst auch anerkannt von den meisten seiner politischen Kritiker." Unmittelbar nach dem Zweiten Weltkrieg setzten sich prominente Schriftsteller - darunter mit Franz Theodor 
Erinnerungsbuch an den „Paradelyriker des Dritten Reichs“ ${ }^{\text {128 }}$ erschien, versammelte es Beiträge vieler prominenter Akteure im NS-Kulturbetrieb - etwa von Bruno Brehm, Maria Grengg, Robert Hohlbaum, Mirko Jelusich und Friedrich Schreyvogl, aber auch von den Philologen Heinz Kindermann, Josef Nadler und Adalbert Schmidt. Der von Heinrich Zillich herausgegebene Band knüpfte nicht nur personell, sondern auch mit dem Titel Bekenntnis zu Josef Weinheber ostentativ an die Tradition des Bekenntnisbuchs von 1938 an. ${ }^{129}$

Thomas Bernhard hob die Gedichte Weinhebers bereits im Dezember 1952 anlässlich der Präsentation des im Salzburger Pfad Verlag erschienenen Bandes Die schöne Stadt positiv hervor (vgl. TBW 22.1, 91). „O Salzburg, schöne Stadt! So frauenfein / und männerhart wie du will keine scheinen“, heißt es dort in Weinhebers Hymne An Salzburg, die zunächst 1941 in der Anthologie Das Flügelroß veröffentlicht wurde: „Es klingt der Stein. Es eifert in den Steinen / ein derbes Deutsch, ein

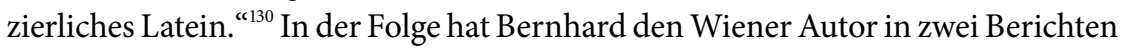
für das Demokratische Volksblatt erwähnt (vgl. TBW 22.1, 147 u. 270), ohne dabei die Diskussionen um Weinhebers Person einige Jahre zuvor bzw. dessen Rolle als poeta laureatus der Nationalsozialisten - er war mit Abstand der am meisten in NS-Anthologien gedruckte österreichische Dichter ${ }^{131}$ - zur Sprache zu bringen.

In der am 8. Juni 1953 publizierten Streitschrift Wo sind die österreichischen Dichter? beklagt Bernhard, dass in den Schaufenstern der Salzburger Buchhandlungen vornehmlich englisch- und französischsprachige Literatur zu finden sei, während man „nur sehr, sehr selten Kunde von der Existenz eines Franz Nabl oder einer Paula Grogger“ erhalte (TBW 22.1, 168). Der Vergleich, den der junge

Csokor, Theodor Kramer und Alexander Lernet-Holenia solche mit einem ganz unterschiedlichen biographischen und ästhetischen Background - für Weinheber ein: „Deutlich getrennt wurden somit Weinhebers politisches Engagement für den Nationalsozialismus und seine Qualitäten als Dichter: Als solcher wurde er von österreichischen Autoren der Nachkriegszeit aller Couleur in Schutz genommen und hochgeschätzt.“ (Roland Innerhofer: „In der Tat brauchen wir nur dort fortzufahren, wo uns die Träume eines Irren unterbrochen haben“. Kontinuitäten in der österreichischen Literatur von der Ersten zur Zweiten Republik. In: Poetologien deutschsprachiger Literatur 1930-1960. Kontinuitäten jenseits des Politischen. Hg. v. Moritz Baßler, Hubert Roland u. Jörg Schuster. Berlin, Boston: de Gruyter 2016, S. 105-117, hier S. 110)

128 Strigl: Spurensicherung (Anm. 33), S. 66.

129 Vgl. Bekenntnis zu Josef Weinheber. Erinnerungen seiner Freunde. Hg. v. Heinrich Zillich. Salzburg: Akademischer Gemeinschaftsverlag 1950. Zu diesem Band vgl. Strigl: Spurensicherung (Anm. 33), S. 7o f.; Polt-Heinzl: Die grauen Jahre (Anm. 3), S. 51-53.

130 Josef Weinheber: An Salzburg (Für ein Salzburger Dichterbuch, 1941). In: Die schöne Stadt. Ein lyrischer Spaziergang. Hg. v. Eligius Scheibl. Salzburg: Pfad 1952, S. 11.

131 Vgl. Müller: Zäsuren ohne Folgen (Anm. 25), S. 319-322. In Müllers Auswertung der Veröffentlichungen in NS-Anthologien belegt Josef Weinheber mit 33 Publikationen vor Karl Springenschmid (26), Bruno Brehm, Robert Hohlbaum (beide 25) und Erna Blaas (21) den ersten Platz. 
Rezensent in der Folge anstellt, mutet mehr als fragwürdig an, zieht man in Betracht, dass Grogger und Nabl im NS-Literaturbetrieb durchaus hatten reüssieren können: ${ }^{132}$ „Es scheint auf den allerersten Blick, als wären unserer Dichter, unsere wirklichen Dichter, ausgestorben. Als hätte man ihre Bücher auf einem allgemeinen Scheiterhaufen (wie schon einmal) verbrannt." (TBW 22.1, 168) Als er drei Tage später in einer kurzen Notiz im Demokratischen Volksblatt jubiliert, weil die Buchhandlung Höllrigl als Reaktion „auf unseren montägigen Artikel“ den österreichischen Autorinnen und Autoren ein eigenes Schaufenster gewidmet hatte, konstatiert der Journalist: „Man hat sie also nicht samt und sonders verbrannt." (TBW 22.1, 171) Bernhard wusste also, so hat es den Anschein, durchaus über die Bücherverbrennung am Salzburger Residenzplatz Bescheid, identifizierte mit Grogger und Nabl aber gerade die falschen Opfer des fünfzehn Jahre zuvor vom Salzburger Lehrer und Schriftsteller Karl Springenschmid organisierten Autodafés. Was hier als Einspruch gegen das „Übersehen[ ] der österreichischen Werke“ auftritt (TBW 22.1, 168), ist im Grunde Ausdruck einer fatalen Indifferenz, die Bernhards Schreiben über belastete Autorinnen und Autoren in toto kennzeichnet. Indem er die Buchhändler dazu auffordert, die „oft ahnungslosen Käufer" mit mehr Nachdruck auf die österreichische Literatur hinzuweisen (TBW 22.1, 169), erweist er sich selbst als in gewisser Hinsicht ahnungslos. ${ }^{133}$

Literatur- und ideologiegeschichtlich sind Bernhards kulturjournalistische Anfänge jener spezifisch österreichischen ,Restauration' zuzurechnen, die das kulturelle Klima der Nachkriegszeit nachhaltig prägte. Hatte Otto Basil schon im ersten Heft des PLAN im Oktober 1945 unter dem Titel Vom österreichischen NSParnaß jene "großen und kleinen Schwätzer“ angeklagt, die sich als dienstbare Kollaborateure des NS-Regimes erwiesen hatten, ${ }^{134}$ geriet diese kritische Position in den folgenden Jahren rasch „unter die Räder des restaurativen Kulturbetriebs“ ${ }^{135}$

132 Vgl., um nur wenige Beispiele zu nennen, Paula Grogger: Haussegen. In: Bekenntnisbuch österreichischer Dichter (Anm. 32), S. 46; Franz Nabl: Von der Einheit des deutschen Volkskörpers. In: Heimkehr ins Reich (Anm. 125), S. 203. Dazu auch die Verzeichnisse in Müller: Zäsuren ohne Folgen (Anm. 25), S. 319-329. Zu Nabls Verhalten im Dritten Reich vgl. Klaus Amann: Franz Nabl - Politischer Dichter wider Willen? Ein Kapitel Rezeptions- und Wirkungsgeschichte. In: K. A.: Die Dichter und die Politik. Essays zur österreichischen Literatur nach 1918. Wien: Edition Falter/Deuticke 1992, S. 152-168.

133 Vgl. auch die folgenden Überlegungen in Wo sind die österreichischen Dichter?, in denen höchst unklar bleibt, welche „vergangene[ ] Zeit“ hier nun gemeint ist: „Dem heutigen Durchschnittsleser, der vielfach ein willenloses Opfer der vergangenen Zeit geworden ist, kann man nicht allein Schuld an dieser ,Krise‘ geben, denn er sieht seit Jahren nicht anderes mehr als eine Flut von ausländischen Titeln, Autorennamen und Massenprodukten, deren Daseinsberechtigung nur in den seltensten Fällen erwiesen scheint." (TBW 22.1, 169)

134 Otto Basil: Vom österreichischen NS-Parnaß. In: PLAN 1 (1945), H. 1, S. 72-76, hier S. 72.

135 Strigl: Spurensicherung (Anm. 33), S. 76. Vgl. dazu auch Klaus Amann: Zahltag. Der Anschluß österreichischer Dichter an das Dritte Reich. [1988] Bodenheim: Philo ${ }^{2} 1996$, S. 208 f. 
Nach einem „kurze[n] Zeitfenster“ in der unmittelbaren Nachkriegszeit, „in dem Aufklärung über die NS-Verbrechen explizit gefordert wurde“ und diese strenge Haltung auch für den Literatur- und Kultursektor galt, ${ }^{136}$ konnten politisch belastete Autorinnen und Autoren nach Amnestieregelungen und der Entschärfung einschlägiger Gesetze ab 1948/1949 wieder weitgehend ungehindert in (Salzburger) Verlagen veröffentlichen, wurden zu Lesungen eingeladen und von offiziellen Stellen mit Preisen und Ehrungen bedacht. Klaus Amann hat dieses kulturelle Klima am Beispiel der Vergabepolitik von Literaturpreisen folgendermaßen umrissen:

Österreichische Literaturpreise wurden unmittelbar nach dem Krieg nicht, was ja durchaus im Bereich des Denkbaren läge - und was auch für ein neues staatliches und kulturelles Selbstbewußtsein Signalfunktion hätten haben können -, als Instrument der Wiedergutmachung oder als Anreiz zur Heimholung der vertriebenen und emigrierten Autoren verwendet. Ganz im Gegenteil. [...] Repräsentative österreichische Literaturpreise gingen denn auch in großem Umfang gerade an jene Autoren, die entweder bereits unter dem Austrofaschismus oder unter dem Nationalsozialismus oder unter beiden Systemen gefördert und ausgezeichnet worden waren. ${ }^{137}$

In dieser kultur- und gesellschaftspolitischen Situation erwies sich Bernhard insofern als „Kind der Zeit“ ${ }^{138}$ als sich der einschlägige Autorenmix im Salzburg der 1950er Jahre auch in seinen Rezensionen findet - die damit die „,ideologische Spannbreite des damaligen Lesungs-Angebots ${ }^{\text {“139 }}$ idealtypisch abbilden: Erna Blaas, Gertrud Fussenegger, Linus Kefer, Franz Tumler, Kurt Ziesel oder Ilse Ringler-Kellner, die 1938 im Bekenntnisbuch Hitlers Mutter dafür gedankt hatte, „unserem Volk“ den „Heiland“ geboren zu haben, ${ }^{140}$ stehen in Bernhards Kritiken

136 Polt-Heinzl: Die grauen Jahre (Anm. 3), S. 42.

137 Klaus Amann: Men for all Seasons. Österreichische Literaturpreisträger der fünfziger Jahre. In: K. A.: Die Dichter und die Politik (Anm. 132), S. 219-222, hier S. 220 f. Amann nennt als Preisträger der 1950er Jahre u. a. Erna Blaas, Gertrud Fussenegger, Franz Karl Ginzkey, Paula Grogger, Robert Hohlbaum, Max Mell und Franz Nabl. Vgl. dazu auch Sigurd Paul Scheichl: Vergessene. Träger des Großen Österreichischen Staatspreises in den $50 e r$ Jahren. In: Literatur in Österreich von 1950 bis 1965. Walter Buchebner Tagung 1984. Hg. v. Wendelin Schmidt-Dengler. Mürzzuschlag: Walter Buchebner Gesellschaft [1984], S. 75-91, sowie Müller: Die Bannung der Unordnung (Anm. 32), S. 183.

138 Joachim Hoell: Thomas Bernhard. München: dtv 200o, S. 52; vgl. Billenkamp: Thomas Bernhard (Anm. 14), S. 57.

139 Mittermayer: „Die brennende hilfesuchende Glut“ (Anm. 31), S. 208.

140 Ilse Ringler-Kellner: An die Mutter des Führers. In: Bekenntnisbuch österreichischer Dichter (Anm. 32), S. 85. Bernhards Lesungsbericht nimmt sich durchwegs positiv aus: „Es war ein glücklicher Gedanke der Volkshochschule, die böhmische Lyrikerin Ilse Ringler-Kellner zu einer Lesung einzuladen." (TBW 22.1, 161) Die Veranstaltung im März 1953 wurde sinnfälligerweise von Adalbert Schmidt, selbst prominenter Akteur im NS-Wissenschaftsbetrieb, moderiert. 
unkommentiert neben Schriftstellern, die erst nach 1945 zu schreiben begonnen hatten (z. B. Erwin Gimmelsberger) oder wie Jakob Haringer 1938 ins Exil geflohen waren. Immer wieder hat er in seinen Beiträgen für das Demokratische Volksblatt , auch Personen gewürdigt, die minder- bis schwerbelastete Anhänger des NS-Regimes waren “, ${ }^{\text {"141 }}$ war sich der Vergangenheit der entsprechenden Autorinnen und Autoren aber wohl oft nicht bewusst. Im Bestreben, ihre Spuren zu verwischen, waren nicht wenige ehemalige Nationalsozialisten im Literatur- und Kulturbetrieb sehr erfolgreich; viele in den 1950er Jahren erschienene Anthologien und Zeitschriften unterließen vorsorglich biographische Angaben zur Periode des Dritten Reichs. Dahinter steckte, so Karl Müller, der sich so ausführlich wie kaum jemand anderer mit dieser Thematik befasst hat, durchaus „Methode: Auf gleiche oder ähnliche Weise wurde nach 1945 auch in Salzburg mit den Biographien etlicher Künstler verfahren, um sie weiterhin/wieder als unbefleckte Leitfiguren einer konservativen Kultur einsetzen zu können. ${ }^{\text {“142 }}$

Jene Schriftsteller, die „das Dritte Reich durch ihre hervorragenden Fähigkeiten zur Mimikry unbeschadet und teilweise geehrt und geachtet überstanden" hatten, ${ }^{143}$ wurden in Bernhards literaturkritischen und feuilletonistischen Texten im Demokratischen Volksblatt nicht enttarnt und angeklagt, sondern stillschweigend geduldet: „Ihre Sprache ist einfach und melodiös“, heißt es etwa über Erna Blaas' Gedichtband Die Lieder der Mutter, ,die liedhaften Strophen sind empfindsame Musik und von der Anrufung bis zum Siedlerhaus wölbt sich der Bogen der fraulichen Sehnsucht, der mütterlichen Schwermut und der Daseinsfreude eines von der Zeit geläuterten Menschen." (TBW 22.1, 380) Klingt hier, im Verweis auf die allmähliche ,Läuterung' des lyrischen Ichs, das Wissen um die Vergangenheit der Schriftstellerin an? Acht Jahre zuvor war Blaas' gesamtes Werk vom österreichischen Unterrichtsministerium gesperrt und auf die „Liste der verbotenen Autoren und Bücher" gesetzt worden; 1957 indes sollte Blaas den Georg-TraklPreis erhalten, 1969 den Adalbert-Stifter-Preis des Landes Oberösterreich und 1970 den Ehrenring der Stadt Salzburg. Und Ironie der Geschichte: 1965 wurde ihr der Professorentitel von jenem Ministerium ehrenhalber verliehen, das 20 Jahre zuvor ihre Bücher auf den antinazistischen Index gesetzt hatte. ${ }^{144}$

Auch die 1955 von Bernhard gemeinsam mit Elisabeth Effenberger und Josef Hödlmoser veranstalteten „Wochen österreichischer Dichtung“ weisen das

141 Polt-Heinzl: Thomas Bernhard betritt die Wiener Szene (Anm. 66), S. $58 \mathrm{f}$.

142 Müller: Zäsuren ohne Folgen (Anm. 25), S. 270.

143 Anton Thuswaldner: Österreichische Verhältnisse. In: Deutschsprachige Gegenwartsliteratur. Wider ihre Verächter. Hg. v. Christian Döring. Frankfurt a. M.: Suhrkamp 1995, S. 108-119, hier S. $115 \mathrm{f}$.

144 Zu Blaas' Werdegang vgl. Müller: Die Bannung der Unordnung (Anm. 32), S. 185 f. u. 194-196; ders.: Zäsuren ohne Folgen (Anm. 25), S. 267-270. 
charakteristische Nebeneinander von ehemaligen Nationalsozialisten und politisch unbelasteten Autorinnen und Autoren auf: Gerhard Amanshauser, Christine Lavant und Wieland Schmied lasen ebenso bei der von Bernhard mitorganisierten Reihe wie Ingrid Teuffenbach, die nach dem ,Anschluss' Hymnen auf Adolf Hitler und die HJ veröffentlicht hatte. Im Vergleich zu den parallel stattfindenden „Internationalen Ferienkursen für deutsche Sprache und Germanistik“ war das Angebot der „Wochen österreichischer Dichtung“ aber geradezu progressiv, hatte die Konkurrenz doch in diesem Sommer Richard Billinger, Franz Karl Ginzkey und Karl Heinrich Waggerl, alle drei Beiträger des Bekenntnisbuchs, zu Gast. ${ }^{145}$

Diese intrikate Situation im Salzburger Literatur- und Verlagsleben der $1950 e r$ Jahre lässt sich anhand der in diesem Zeitraum erschienenen Anthologien und Sammelbände prägnant veranschaulichen. Schon im 1951 im Otto Müller Verlag veröffentlichten Almanach Der Pegasus stehen mit Erna Blaas, Hans Deißinger und Karl Heinrich Waggerl ${ }^{146}$ nicht nur drei Beiträger des Bekenntnisbuchs neben Autoren wie Carl Zuckmayer oder Alois Grasmayr, der im Dritten Reich zeitweilig wegen Wehrkraftzersetzung inhaftiert gewesen war; im namentlich nicht gezeichneten „Vorwort“ des Bandes ist, als Nachhall des Vokabulars der völkischen Germanistik, auch noch von den „spezifische[n] Stammeseigenschaften“ der Salzburger Schriftsteller die Rede. ${ }^{147}$ Zehn Jahre zuvor war, ebenfalls in Salzburg, das von Heinrich Zillich herausgegebene Kunstjahrbuch Das Flügelroß erschienen, in das neben Texten von Bruno Brehm, Max Mell, Josef Friedrich Perkonig und Karl Springenschmid auch Arbeiten von Blaas, Deißinger und Waggerl aufgenommen wurden. ${ }^{148}$ Der Pegasus von 1951 war in Teilen eine Reprise des Flügelrosses von 1941, nur war die Gruppe der Autorinnen und Autoren nun politisch heterogener, und der Titel hatte vom Deutschen ins Lateinische zurückgefunden.

Ähnliches trifft auf den 1952 im Salzburger Pfad Verlag gedruckten Lyrikband Die schöne Stadt (herausgegeben von Eligius Scheibl) zu, der neben Gedichten von Georg Trakl und dem 1942 im brasilianischen Exil verstorbenen Stefan

145 Vgl. Schneider/Steinsiek: Mengenlehre (Anm. 101), S. 60.

146 Die drei genannten Autoren traten gemeinsam am 24. Jänner 1941 bei einer Lesung der „Deutschen Arbeitsfront“ im Mozarteum auf. Vgl. Gert Kerschbaumer: Faszination Drittes Reich. Kunst und Alltag der Kulturmetropole Salzburg. Mit einem Vorwort v. Gerhard Amanshauser. Salzburg: Otto Müller 1988, S. 265; dort allg. zu Waggerls Rolle im NS-Kulturbetrieb S. 264-267.

147 N. N.: Vorwort. In: Der Pegasus. Salzburger Dichteralmanach 1952. Salzburg: Otto Müller 1951, S. [6]-[7], hier S. [6].

148 Vgl. Das Flügelroß. Erstes Kunstjahrbuch des Reichsgaues Salzburg. Hg. v. Heinrich Zillich. Salzburg: Bergland-Buch 1941. Im Vorwort von Heinrich Zillich heißt es: „Denn in unserer Zeit, da sich das Reich sieghaft erneuert, wissen die schöpferischen Menschen aus der Tiefe der Werkbeauftragung, daß ihr Dichten, den Baumzweigen gleich, einem einzigen Wurzelstamm entsprießt und sich, obgleich tausendfach verschieden, unverwandt ergänzt." (Ebd., S. 7) 
Zweig auch Texte zahlreicher ehemaliger Nationalsozialisten enthielt, darunter erneut Blaas, Deißinger und Waggerl, darüber hinaus Franz Karl Ginzkey, Max Mell und Josef Weinheber. In Bernhards Bericht von der Präsentation des Bandes im Rahmen der Salzburger Buchwoche stehen Weinheber und Deißinger kommentarlos neben dem Exilanten Haringer. Die in der Anthologie versammelten Gedichte seien zwar formal nicht immer „vollendet“, aber, so Bernhards beschwichtigende, die historischen Verwerfungen großzügig ignorierende Schlussformel, „letzten Endes sind wir, die Salzburger nämlich, doch bei Georg Trakl zu Hause“ (TBW 22.1, 91). Eine Fortsetzung des Bandes unter dem Titel Das schöne Land war in Planung, wurde aber nicht realisiert - Bernhard berichtete am 7. Oktober 1953 im Demokratischen Volksblatt, dass dafür Texte von Richard Billinger, Hans Carossa, Paula Grogger, Franz Tumler, Josef Weinheber und Linus Kefer, dem ehemaligen Leiter der Reichsschrifttumskammer im Gau Oberdonau, vorgesehen waren.

Die im großen und ganzen glücklich gewählte Auswahl erfreute die Anwesenden, stimmte sie heiter und nachdenklich und erweckte vor allem den Eindruck, daß die Lyrik, in unserer Zeit mehr und mehr in den Hintergrund gedrängt, durchaus nicht ausgestorben ist. Dem Herausgeber kann man nur für seine Tatkraft danken und ihn würdigen, indem man ihm Mut zuspricht, das schon so weit gereifte Werk vollenden zu können. (TBW 22.1, 270)

Ab Anfang der 1950er Jahre fanden sich viele österreichische Autorinnen und Autoren, die zwischen 1938 und 1945 in NS-Anthologien aufgeschienen waren, wieder in Almanachen und Sammelwerken, ohne dass diese Kontinuität von den Herausgebern oder Verlegern kommentiert worden wäre. ${ }^{149}$ Als am 18. Jänner 1957 in den Berichten und Informationen des Österreichischen Forschungsinstituts für Wirtschaft und Politik Thomas Bernhards polemisches Wort an junge Schriftsteller erschien, in dem er seine schreibenden Altersgenossen des Opportunismus und der ökonomischen Korrumpierbarkeit bezichtigte, stand auf der folgenden Seite eine ausführliche Buchkritik von Bruno Brehm, einem der führenden Akteure im NS-Literaturbetrieb. ${ }^{150}$ Und noch 1972 nennt der von

149 Vgl. etwa den von Heinz Kindermann herausgegebenen Band Heimkehr ins Reich. Großdeutsche Dichtung aus Ostmark und Sudetenland (1939), in dem u. a. Texte von Richard Billinger, Erna Blaas, Hans Deißinger, Gertrud Fussenegger, Franz Karl Ginzkey, Linus Kefer, Max Mell, Franz Nabl, Ilse Ringler-Kellner, Karl Heinrich Waggerl, Josef Weinheber und Kurt Ziesel enthalten waren - allesamt Namen, die auch in Bernhards journalistischen Beiträgen der Jahre 1952 bis $1955 \mathrm{zu}$ finden sind.

150 Thomas Bernhard: Ein Wort an junge Schriftsteller. In: Berichte und Informationen des Österreichischen Forschungsinstituts für Wirtschaft und Politik 12 (18.1.1957), Nr. 548, S. 14; Bruno Brehm: Aus der Nachkriegszeit. In: ebd., S. 15. - Einer Aufstellung von Klaus Amann: 
Erich Landgrebe herausgegebene Band Dichtung aus Salzburg Bernhard im alphabetischen Inhaltsverzeichnis zwischen Rudolf Bayr und Erna Blaas, ${ }^{151}$ ist in ihm ein Beitrag von Karl Heinrich Waggerl ebenso enthalten wie zwei Texte des erst 1943 geborenen Bodo Hell, der in diesem Jahr den Rauriser Literaturpreis erhielt.

Für das charakteristische Nebeneinander von politisch belasteten Autoren einer älteren und aufstrebenden Schriftstellern einer neuen Generation gibt der Salzburger Otto Müller Verlag ein anschauliches Beispiel ab. Obschon dessen Gründer und Leiter Otto Müller im Dritten Reich politisch verfolgt worden war, nahm er bald nach dem Krieg prominente Autoren des NS-Kulturbetriebs wie Karl Heinrich Waggerl wieder in sein Verlagsprogramm auf und publizierte bereits 1948 Hans Sedlmayrs modernekritische Streitschrift Verlust der Mitte. ${ }^{152}$ 1956 erschien bei Otto Müller sowohl Gerhard Fritschs Moos auf den Steinen als auch der letzte Band der von Josef Nadler seit 1953 edierten Weinheber-Werkausgabe. Im Münchner Merkur rezensierte Bernhard am 16. Februar 1955 die ersten vier Bände der Ausgabe, deren Herausgeber Nadler - ein zentraler Akteur der völkischen Germanistik ${ }^{153}$ - er zur „aufrechte[n] Arbeit“ gratuliert (TBW 22.1, 401). In seiner Besprechung liest man den zeittypischen, im Kontrast zu späteren Bernhard-Texten jedoch erstaunlichen Satz: „Und darum sei über den Menschen, über die brennende hilfesuchende Glut, Verzeihen gebreitet, denn jeder hat notwendig, einen Teil wenigstens vergessen zu bekommen." (TBW 22.1, 399) ${ }^{154} \mathrm{Mehr}$ als zwei Jahrzehnte später wird Bernhard in Meine Preise Weinheber, gemeinsam mit Anton Wildgans, beiläufig als „Wiener Vorstadt-Hölderlin“ bezeichnen, in dem die spezifisch österreichische „dilettantische Auffassung von Dichtung [...] ihr Ideal gefunden“ habe (TBW 22.2, 422). Von seiner einstigen Begeisterung für ein Werk, das sich - wie es im Münchner Merkur heißt - durch „Gemüt und Österreichertum und Deutschtum“ gleichermaßen auszeichne (TBW 22.1, 399), ist hier nichts mehr zu lesen.

Literaturbetrieb in der ,Ostmark' (1938-1945). Vermessungen eines unerforschten Gebietes. In: K. A.: Die Dichter und die Politik (Anm. 132), S. 113-128, hier S. 120 f., zufolge war Brehm der am häufigsten in nationalsozialistischen Empfehlungslisten für Literatur genannte österreichische Autor.

151 Vgl. Dichtung aus Salzburg. Hg. v. Erich Landgrebe. Wien: Kremayr \& Scheriau 1972, S. 215-217.

152 Vgl. Holl: Literaturgeschichte Salzburgs (Anm. 92), S. 680 f.

153 Vgl. Kerschbaumer: Der kalte Krieg gegen die Moderne (Anm. 35), S. 121: „Nadler, der 1945 außer Dienst gestellt worden war, entwickelte sich zu einer Leit- und Identifikationsfigur für das sich neu formierende politische Lager aus ehemaligen Nationalsozialisten, Großdeutschen und Feigenblattliberalen, für den Verband der Unabhängigen. "Vgl. dazu auch Polt-Heinzl: Die grauen Jahre (Anm. 3), S. 49-51.

154 Es ist jedoch anzumerken, dass die von Josef Nadler und Hedwig Weinheber, der Witwe des Autors, betreute Werkausgabe „alle politisch kompromittierenden Gedichte vorsorglich nicht enthielt“ (Polt-Heinzl: Thomas Bernhard betritt die Wiener Szene [Anm. 66], S. 59). 


\section{„Traumfabrik“ und „Ro-Ro-Ro-Kost“: Kino und Taschenbuch}

Obschon es sich bei Bernhards Gerichtssaalreportagen und den für andere Sparten des Demokratischen Volksblatts verfassten Texten im Grunde um getrennte Bereiche seiner journalistischen Tätigkeit handelt - die nicht zuletzt durch die Differenz Anonymität vs. Onymität markiert sind -, gehen die Themen manchmal auch ineinander über. Der Ende November 1952 veröffentlichte Beitrag Prozesse, nichts als Prozesse ist im Gegensatz zu den Gerichtsberichten mit den Initialen „Th. B.“ gezeichnet, greift aber doch ein juristisches Thema auf. ${ }^{155}$ Darin kolportiert der 21-jährige Journalist, dass die Kriminalität unter Jugendlichen als „Folge der Flut von verabscheuungswürdiger Literatur, die in großen Mengen an allen Ecken und Enden angeboten wird“, zu begreifen sei: „Beinahe jeder Jugend-Schöffengerichtsprozeß endet mit der Feststellung, daß die Ursache des Verbrechens in den Gossenromanen und Schundfilmen zu suchen ist. Und trotz Jugendschutz- und Schundgesetzen ist man nicht in der Lage (oder will man es nicht sein?), diese Anleitungen zum Verbrechen zu beseitigen." (TBW 22.1, 87) Jene „reißerische[n] Filmprodukte aus unserem und dem überseeischen Kontinent" (TBW 22.1, 87), denen Bernhard in Prozesse, nichts als Prozesse die Verantwortung für die steigende Kriminalität unter Jugendlichen zuschiebt, kannte er nicht nur vom Hörensagen. In Freumbichlers Lehrgedichten Erziehung zu Vernunft und Fröhlichkeit, die er seinem Enkel als Trost und Leitlinie für das Leben gewidmet hatte, ist ein Vorwurf zu lesen, der dem jungen Rezensenten bei Urteilen wie diesem womöglich noch in den Ohren gehallt hat:

Du machst mir manchmal bange Sorg', ich weiß nicht, was mir ahnt,

Ich seh dich niemals einsam sitzen, ein Buch in deiner Hand.

Du trägst ins Kino deine Groschen, zu dieser Afterkunst,

Ergötzt dich in der Traumfabrik, dem lächerlichen Schwindeldunst.

An diesem ausgefallenen, jämmerlichen Konservenleben,

Das schlaue Geldsackkrämer euch zur Verdummung geben. ${ }^{156}$

Freumbichlers etwas holprige Ermahnung legt nahe, dass Bernhard sich durchaus für das Kino als Kunstform und Freizeitbeschäftigung begeistern konnte - aber wohl stets mit schlechtem Gewissen gegenüber dem strengen Großvater, handelte es sich diesem zufolge doch um eine „Afterkunst“, für deren Genuss man sich zu schämen hatte. Als der Chefredakteur des Demokratischen Volksblatts, Josef Kaut, im Dezember 1952 über Bernhards erste Lesung an der Volkshochschule

$155 \mathrm{Zu}$ diesem Text vgl. Greite: „Prozesse, nichts als Prozesse“ (Anm. 52), S. 98, sowie zuletzt Mittermayer: Das Salzburg des Thomas Bernhard (Anm. 78), S. $32 \mathrm{f}$.

156 Freumbichler: Erziehung zu Vernunft und Fröhlichkeit (Anm. 10), S. 38. 
berichtete, lobte er nicht nur seine „wohlgeformte, zarte Lyrik“, „duftig in den Farben und fast durchwegs von einem nachdenklich-melancholischen Untergrund“, sondern er verteidigte das „Werk des jungen Autors“ auch gegen jene, „die gerne in Reden und Artikeln über die Jugend klagen, die sich angeblich nur für Fußball und Gangsterfilme interessiert “. ${ }^{157}$ Interesse für Gangsterfilme und Lyrik scheinen bei Thomas Bernhard in der ersten Hälfte der 1950er Jahre freilich keineswegs ein Widerspruch gewesen zu sein.

Von März 1953 bis April 1954 war der Journalist und Schriftsteller Bernhard auch als Filmkritiker für das Demokratische Volksblatt tätig und stellte den Leserinnen und Lesern der Zeitung in Salzburger Kinos gezeigte Filme in meist kurzen Notizen vor. ${ }^{158}$ Weil die Filmkritiken, was ihren Umfang angeht, sehr beschränkt waren, gingen Bernhards Texte oft kaum darüber hinaus, den Inhalt der Filme kurz zu skizzieren, die wichtigsten Schauspielerinnen und Schauspieler zu nennen und einige persönliche Anmerkungen einzustreuen, was den Artikeln oft eher den Anschein humoriger Glossen als jenen eingehender Besprechungen verleiht. So heißt es am 27. März 1953 über den im Maxglaner Kino gezeigten Streifen Die Liebe des Korsaren (orig. Caribbean, USA 1952, Regie: Edward Ludwig):

Vor 200 Jahren: Pirat gegen Pirat, Messer gegen Messer. Der eine raubt die Tochter des anderen. Gut 9o Kilogramm Muskelfleisch werden zur Befreiung ausgeschickt. Der Erfolg ist sicher. Dazwischen Feste auf der Insel und Mondscheinstunden auf dem Meeresstrand. Ein Film, wie wir ihn uns mit 15 Jahren gewünscht hätten. Im übrigen gute Aufnahmen, taugliche Regie und ein schlichter Beitrag zur Beilegung des Rassenproblems. Arlene Dahl und John Payne spielen - wie es im Buch steht. (TBW 22.1, 348)

Mit jenen Kritiken, die Peter Handke eineinhalb Jahrzehnte später für die Zeitschrift film verfassen sollte, ${ }^{159}$ haben Bernhards Beiträge im Demokratischen

157 J.[osef] K.[aut]: Dichterlesung Thomas Bernhard. In: Demokratisches Volksblatt, 19.12.1952.

158 Vgl. Waitzbauer: Thomas Bernhard in Salzburg (Anm. 47), S. 94 f. Dass Bernhard, wie sich Johann Barth: Er war sich seines Sieges schon gewiss (Anm. 99), S. 141f., erinnert, auch „Mitarbeiter für Filmkritik“ bei den Salzburger Nachrichten war, ist bisher nicht mit konkreten Textbelegen dokumentiert. Folgt man Barth, so müsste diese Tätigkeit bis in die 196oer Jahre hinein gereicht haben; lediglich „Monate später“ nämlich sei Bernhards Frost (1963) erschienen. In einem erneuten Abdruck des Gesprächs mit Johann Barth wurde Bernhards Tätigkeit für die Salzburger Nachrichten nicht mehr in das direkte zeitliche Umfeld von Frost datiert (vgl. Johann Barth: Es war eine Berufskrankheit. In: Immer noch Frost. 26 Betrachtungen zu Thomas Bernhards erstem Roman. Hg. v. Sepp Dreissinger. Wien: Album 2019, S. 44-47, hier S. 46).

159 Vgl. dazu Rolf G. Renner: Der Kinogeher. Peter Handke und der Film. In: Peter Handke. Poesie der Ränder. Hg. v. Klaus Amann, Fabjan Hafner u. Karl Wagner. Wien u. a.: Böhlau 2006, S. 201-214. 
Volksblatt nur wenig gemein. Während in Handkes Kritiken immer auch grundlegende Fragen filmischer Ästhetik (Kameraführung, literarisches vs. filmisches Erzählen, ,Natürlichkeit' vs. ,Künstlichkeit', Repräsentation außerfilmischer Wirklichkeit etc.) und soziologische Aspekte des Kinos verhandelt werden ${ }^{160}$ erweist sich Bernhard in seinen Texten als nicht eben versierter Cineast. Wohl auch bedingt durch die Vorgaben einer Regionalzeitung ${ }^{161}$ formulieren sie landläufige und stereotype Beobachtungen zu den besprochenen Filmen, etwa wenn dem Hollywood-Film Trommeln in der Nacht (orig. Savage Drums, USA 1951, Regie: William Berke) am 16. September 1953 bescheinigt wird, dass darin „keine einzige Aufnahme“ „echt“ sei:

Eine Anzahl (scheinbar) schöner Frauen flimmert vorüber, es wird geschossen, schlecht getanzt und Wein getrunken - und alles innerhalb einer öden, zum Gähnen anregenden „Handlung“, die einmal zeigt, wie schwer es heutzutage ist, ein handfestes Drehbuch-Manuskript auf den Tisch zu bekommen. (TBW 22.1, 249)

Die Bandbreite der Urteile reicht von recht allgemeiner Zustimmung - „Erlebnis sondergleichen“ (TBW 22.1, 283), , gut und sehenswert“ (TBW 22.1, 296), ,[e]iner der wenigen Filme“, die „gut sind und Geschmack beweisen“ (TBW 22.1, 347), „eine unterhaltsame Filmgeschichte für den Sonntag" (TBW 22.1, 351) - bis hin zu deutlicher Kritik, wenn von „geballte[r] Rührseligkeit“ (TBW 22.1, 252) oder "grausige[r] Geschmacksverwirrung" (TBW 22.1, 264) die Rede ist. In Franz Antels Kaiserwalzer (1953), einem Paradebeispiel der kulturellen Restauration nach 1945, sieht Bernhard zwar einzelne hervorragende „schauspielerische[ ] Leistungen“, kann dem Film ansonsten aber wenig Positives abgewinnen, „weicht der Streifen“ doch, so seine ernüchterte Feststellung, „kaum von dem guten vorhergegangenen Dutzend Liebesfilmen der monarchischen Erzherzoge ab“ (TBW 22.1, 252). Antels nächstes Werk, Die süßesten Früchte (1954), führte bei Bernhard schließlich zu noch größerer Verstimmung: „Dieser geschmacklose Mischmasch, der sich in uralten schlechten Witzen erschöpft, kann selbst dem standhaftesten Kinobesucher den Saft hochgehen lassen." (TBW 22.1, 360) Für manche Filme findet er in seinen Kurzkritiken zwar freundliche Worte - „eine wirkliche Filmkomödie“, „die sich sehen lassen kann“

160 Vgl. etwa Peter Handke: Probleme werden im Film zu einem Genre. In: film 6 (August 1968), H. 8, S. 10; ders.: Vorläufige Bemerkungen zu Landkinos und Heimatfilmen. In: film 6 (November 1968), H. 11, S. 10 u. 37; ders.: Augsburg im August: trostlos. In: film 7 (Januar 1969), H. 1, S. 30-32; ders.: Dummheit und Unendlichkeit. In: film 7 (März 1969), H. 3, S. $10-11$.

161 Vgl. Dittmar: Thomas Bernhard als Journalist (Anm. 51), S. 29, wonach „analytische Kritik in einer Zeitung wie dem Demokratischen Volksblatt gar nicht erwünscht" gewesen sei. 
Goetz' Hokuspokus (1953) muss er aber abschließend doch konstatieren: „Nach gemäßem Abstand über Hokuspokus nachzudenken, ist nicht ratsam. “ (TBW 22.1, 271) Bernhards Reserviertheit gegenüber dem Medium war nicht zuletzt auf die Qualität der von ihm rezipierten Streifen zurückzuführen, der sich die „Tagesschreiberei“ des Salzburger Journalisten mitunter anpasst. ${ }^{162}$

Nur selten hat sich Bernhard einem Film etwas ausführlicher gewidmet; William Wylers Carrie (1953) sticht dabei besonders hervor: „Einer der besten Filme der letzten Jahre, vielleicht des letzten Jahrzehnts überhaupt, hat jetzt den Weg zu uns gefunden“, schreibt er am 16. September 1953 über die USamerikanische Produktion. Carrie schildere „die Geschichte eines großen Menschenschicksals“, das „fern von allem Klischee“ jeden „wahren Menschen erschüttern“ müsse (TBW 22.1, 248). Die beiden Schauspieler Laurence Oliver und Jennifer Jones hebt Bernhards besonders lobend hervor, ihre „Darstellung“ werde künftig „einmalig in der Filmgeschichte dastehen“. Es handle sich, so das Fazit, um ein „Meisterwerk“, einen „Film, der von jedem besucht werden soll, dem das Leben, so wie es ist, wertvoll erscheint ..." (TBW 22.1, 248). Der rhetorische Überschwang verrät freilich ebenso wie seine negativen Filmkritiken, dass Bernhard zu diesem Zeitpunkt kein ausdifferenziertes Sensorium für filmische Ästhetik aufwies. Noch stärker als andere Textsorten für das Demokratische Volksblatt erwecken seine Kinokritiken den Eindruck „journalistischer Dutzendware“ ${ }^{163}$

Thomas Bernhards Veröffentlichungen im Demokratischen Volksblatt vom 28. November 1953 indes verweisen erneut auf das Erbe des Nationalsozialismus im Kulturbetrieb dieser Jahre, auf die oft stillschweigende Akzeptanz der Kontinuitäten zwischen NS-Zeit und Zweiter Republik. Er besprach an diesem Tag den im Stadtkino gezeigten „Veit-Harlan-Film“ Das unsterbliche Herz, von dem er zwar angibt, er sei schon „alt“, dessen konkretes Erscheinungsjahr 1939 er jedoch verschweigt (TBW 22.1, 319). Harlan hatte sich im Dritten Reich mit Propagandafilmen wie dem antisemitischen Machwerk Jud Süß (1940) hervorgetan und zählte bis zuletzt „zu den politisch verläßlichsten Regisseuren des NS-Regimes“. ${ }^{164}$ Im Abstand von 14 Jahren konnte Bernhard dem Unsterblichen Herzen dessen ungeachtet „nur Bewunderung entgegenbringen“ (TBW 22.1, 319). Im April 1951 hatte die Aufführung von Veit Harlans aktuellem Film Unsterbliche

162 Michael Töteberg: Höhenflüge im Flachgau. Drei Anläufe, dreimal abgestürzt: die Vorgeschichte des Autors Thomas Bernhard. In: Text + Kritik ( $\left.{ }^{3} 1991\right)$, H. 43, S. 3-10, hier S. 4.

163 Höller: Thomas Bernhard (Anm. 76), S. 51. Klug: Thomas Bernhards Arbeiten (Anm. 28), S. 149, führt die vielerorts zu beobachtenden „sprachliche[n] Unebenheiten“ in Bernhards Texten auch auf den „zeitlichen Druck journalistischer Tagesproduktion“ zurück.

164 Oliver Rathkolb: Führertreu und gottbegnadet. Künstlereliten im Dritten Reich. Wien: ÖBV 1991, S. 224. Zu Veit Harlans Rolle im Nationalsozialismus vgl. ebd., S. 221-224; Klee: Das Kulturlexikon zum Dritten Reich (Anm. 32), S. 196 f.; sowie den Kommentar in TBW 22.1, 769. 
Geliebte (nach Theodor Storms Novelle Aquis submersus) in Salzburg noch zu wütenden Protesten von jüdischen Displaced Persons - darunter angeblich auch Simon Wiesenthal - geführt. ${ }^{165}$ Zwei Jahre später meldete Bernhard gegen eine Aufführung von Harlans 1939 veröffentlichtem Film Das unsterbliche Herz, an dessen Drehbuch der Österreicher Richard Billinger mitgearbeitet hatte, keinerlei Bedenken an. „Kurzum“, beschließt er seine wenige Zeilen umfassende Rezension: „Ein Film, der auch weiterhin zu den besten zählen wird, die man zu zeigen hat." (TBW 22.1, 319) Am selben Tag erschien im Demokratischen Volksblatt ein ausführlicher Bericht Bernhards über das Salzburger Heimatwerk, das unter der Leitung von Tobi Reiser „jahraus, jahrein das Bodenständige wachhält und längst Vergessenes wieder ans Tageslicht trägt“; im Rahmen des vom Heimatwerk veranstalteten Salzburger Adventsingens werde auch Karl Heinrich Waggerl „aus seinen Christkindlgeschichten lesen und bestimmt eine echte Weihnachtsstimmung hervorzaubern“" (TBW 22.1, 317). Mit Harlan, Reiser und Waggerl finden sich in Bernhards Veröffentlichungen vom 28. November 1953 gleich drei Personen, die im Nationalsozialismus als willfährige Künstler reüssiert hatten und in der Gunst der Machthaber gestanden waren. ${ }^{166}$

Während Bernhard sich mit Blick auf politisch belastete Kunstschaffende nachsichtig erwies - oder nicht das Wissen mitbrachte, die einschlägigen Akteure und Institutionen historisch einzuordnen -, zeigte er sich Phänomenen der Unterhaltungskultur gegenüber von Anfang an sehr reserviert; wiederholt führte er in seinen Kritiken den Vorwurf, zu sehr auf das Kommerzielle zu schielen, ins Treffen. ${ }^{167}$ Den Arbeiten von Elisabeth Effenberger etwa bescheinigte er im April 1953, sie seien „allzu sehr im Kunstgewerblichen des Wortes befangen“, weil sie sich

165 Vgl. Waitzbauer: Thomas Bernhard in Salzburg (Anm. 47), S. 76.

166 Vgl. Oliver Rathkolb: Tobi Reiser und der Nationalsozialismus. Salzburg: Salzburg Museum 2016, der im Detail zeigt, auf welche Weise Reisers Tätigkeit im Dritten Reich „system- und herrschaftsstabilisierend gewirkt hat" (S. 38). Zu Bernhards Verhältnis zu Waggerl vgl. Karl Müller: „Wir sind eben Bestien, die sich gegenseitig in Schach halten.“ - „Das Leben ist ein Prozeß, den man verliert.“ Karl Heinrich Waggerl und Thomas Bernhard im Vergleich. In: Thomas Bernhard Jahrbuch 2003, S. 13-33; zu Waggerls Karriere nach 1945 ders.: Zur (Dis-)Kontinuität österreichischer Literatur seit den zoer Jahren: Karl Heinrich Waggerl (1897-1973). Ein Erfolgsautor der 5oer Jahre. In: Literatur in Österreich (Anm. 137), S. 52-74. - Ob Waggerl tatsächlich „trotz seiner Nähe zum Nationalsozialismus“ der „erfolgreichste“ Autor im Salzburg der Nachkriegszeit war, wie Adolf Haslinger: Literatur. In: Salzburger Kulturlexikon. Hg. v. A. H. u. Peter Mittermayr. Salzburg u. a.: Residenz 2001, S. 25-29, hier S. 27, vermutet, oder nicht gerade aufgrund der Übereinstimmung seiner einstigen Gesinnung mit jener des Publikums, wäre zu diskutieren.

$167 \mathrm{Zu}$ Bernhards Klage angesichts der „Überfremdung und Trivialisierung des Buchmarktes“vgl. Habringer: Der Auswegsucher (Anm. 26), S. 35, der die wiederkehrende Argumentation des jungen Rezensenten, seine „Option für den Erbauungscharakter von Literatur“, als „reine Apologie der Vormoderne" kritisiert. 
„nicht greifbare[r] Motive[ ]“ bedienten und zudem „jedes wesentlich tiefere[ ] Empfinden[ ]" vermissen ließen (TBW 22.1, 149); Erich Landgrebe ließ er ein knappes Jahr später wissen, die von ihm vorgestellte Geschichte sei „routiniert und effektvoll in höchstem Maße“ gewesen, während er die am selben Abend präsentierten Arbeiten von Georg Eberl für die „volkstümlichsten und echtesten“ der Lesung hielt - und diese beiden Superlative ausdrücklich als Lob verstand (TBW 22.1, 336). Bernhard operiert in seinen Literatur- und Theaterkritiken der Jahre 1952 bis 1954 oft mit der Gegenüberstellung von ,Echtem', Einfachem' und ,Wahrem' auf der einen und ,Künstlichem' auf der anderen Seite, wobei mit Letzterem der Vorwurf einer Orientierung am Kommerziellen und allzu Bekömmlich-Trivialen einhergeht: „Irgendwie weiß der Autor, wie man ein Stückchen schneidert“, heißt es etwa am 1. Juni 1954 in den Salzburger Nachrichten über Jochen Huths Lustspiel Die vier Gesellen. „Es ist Konfektion, präsentiert sich sehr anspruchslos, aber es paßt." (TBW 22.1, 382)

In diesen Zusammenhang fügt sich auch der am 5. Oktober 1953 im Demokratischen Volksblatt veröffentlichte Artikel über die im Juni 1950 gestartete Taschenbuchreihe des Rowohlt Verlags: „Es ist noch keine drei Jahre her, als auf dem deutschen Büchermarkt die kleinen scheckigen und verblüffend billigen Büchlein des Ernst-Rowohlt-Verlages erschienen." (TBW 22.1, 267) Unter dem Titel Die Ro-Ro-Ro-Kost schmeckt nicht mehr? echauffiert sich Bernhard über die "geschmacklose Aufmachung“ der neuen Taschenbücher, mit der man offenbar "dem Schundroman Konkurrenz machen“ wolle, zeigt sich in weiterer Folge des Berichts aber erfreut darüber, dass „der Absatz der billigen Kleinbuchreihe“ gegenwärtig stocke: „Der Leser legt heute auch wieder Wert auf eine gediegene Ausstattung des Buches" (TBW 22.1, 267f.), ja:

Die Leser wollen die Ro-Kost nicht mehr. Daß aber jetzt vielleicht die Zeit angebrochen ist, in der man auf das Äußere (vom Inneren zu reden, lassen wir uns noch eine Weile Zeit!) des Buches Wert legt, auf die Beständigkeit, verbunden mit gutem Geschmack, das ist auf alle Fälle erfreulich, ist einer der Lichtblicke unserer Zeit. (TBW 22.1, 268 f.) $)^{168}$

168 Zur Geschichte der „rororo“-Taschenbuchreihe vgl. Daniela Völker: Das Buch für die Massen. Taschenbücher und ihre Verlage. Marburg: Tectum 2014, S. 81-104. - Zu den Diskussionen um das Medium des Taschenbuchs in den 1950er Jahren vgl. u. a. Patrick Rössler: Pro(roro)vokation - die bunten Farben des Massengeschmacks. Der Rowohlt-Verlag und das frühe deutsche Taschenbuch. In: Neue Perspektiven der deutschen Buchkultur in den $50 e r$ Jahren des 20. Jahrhunderts. Ein Symposion. Hg. v. Günter Häntzschel. Wiesbaden: Harrassowitz 2003, S. 119-154; David Oels: Rowohlts Rotationsroutine. Das moderne Taschenbuch in Deutschland und der rasante Aufstieg des Rowohlt-Verlags nach 1945. In: Solitäre und Netzwerker. Akteure des kulturpolitischen Konservativismus nach 1945 in den Westzonen Deutschlands. Hg. v. Erhard Schütz u. Peter Uwe Hohendahl. Essen: Klartext 2009, S. 185-208. 
Wie in anderen Fällen liegt auch hier der Verdacht nahe, dass Bernhard für seinen Bericht über die Konjunkturen des Taschenbuchmarktes kaum eingehende Recherchen angestellt hat; ob er, wie es im Artikel heißt, tatsächlich „Gespräche[ ] mit deutschen Verlegern“ (TBW 22.1, 268) geführt hat oder diese nicht vielmehr aus zweiter oder dritter Hand kolportiert, bleibt unklar. Wenige Tage später, am 16. November 1953, musste das Demokratische Volksblatt jedenfalls eine Erwiderung des Rowohlt Verlags veröffentlichen, weil Bernhard, so Herbert Moritz, mit falschen Zahlen hantiert hatte und von einem Rückgang der Absatzzahlen nicht die Rede sein konnte. ${ }^{169}$

Mit seinen Vorbehalten gegenüber der Aufmachung und dem Marketingkonzept der neuen Taschenbuchreihen - 1952 waren u. a. die Verlage S. Fischer und List dem Vorbild Rowohlts gefolgt ${ }^{170}$ - konnte Bernhard im konservativen österreichischen Literaturbetrieb dieser Zeit auf Zustimmung zählen, etwa vonseiten Hans Weigels, der noch 1959 als Beitrag zur „Diskussion über das Problem der Taschenbücher“ der Überzeugung war, ${ }^{171}$ dass die „TB-Seuche“ mittlerweile „einen erschreckenden Umfang angenommen“ habe. ${ }^{172}$ Obschon sich Weigels Rekonstruktion der Rolle des Taschenbuchs im Literatursystem der Nachkriegszeit deutlich subtiler und fundierter ausnimmt als jene Bernhards, stimmt er mit dem jungen Autor doch darin überein, dass „die gewaltige Problematik der industriellen TB-Erkrankung“ nicht zuletzt in der mangelnden „Rücksicht auf übermaterielle Werte“ bestehe: „[G]eistige und künstlerische Werte" würden in der Diskussion über das Taschenbuch auf unbotmäßige Weise „mit industriellen Mitteln vermengt ${ }^{“ .}{ }^{173}$ Weigel koppelt das Taschenbuch Schritt für Schritt mit verschiedenen medizinischen Termini, wenn er vom „TB-infizierten Verlagswesens“, von „TB-Erkrankung“, „TB-Seuche“ und „TB-Epidemie“ schreibt, wobei seine Wortschöpfungen mit der gängigen Abkürzung für die Tuberkulose (TB bzw. TBC) spielen, einer gerade in den Kriegs- und Nachkriegsjahren grassierenden Lungenerkrankung. „Die TB-Epidemie verhält sich zum regulären Buchwesen“, so Weigels abschließende Wendung, wie der Film zum Theater“:

Bedenklich, wie bei der Theater-Film-Beziehung, ist auch bei der TB-Infektion, daß allenthalben mit dem Gegner zusammengearbeitet wird, statt daß man auf reinliche

169 Vgl. Moritz: Lehrjahre (Anm. 44), S. 159.

170 Vgl. Rössler: Pro(roro)vokation (Anm. 168), S. 149-154.

171 Hans Weigel: Die TB-Seuche. Das große Geschäft mit den kleinen Büchern. [1959] In: H. W.: Nach wie vor Wörter. Literarische Zustimmungen, Ablehnungen, Irrtümer. Graz u. a.: Styria 1985, S. 222-229, hier S. 222.

172 Ebd., S. 224.

173 Ebd., S. 228. 
Scheidung sähe. Erhebend und ermutigend aber bleibt als Fazit des Vergleichs die Gewißheit, daß die mechanisch-industrielle Zelluloid-Inflation das lebendige Theater nicht zum Tod verurteilt hat - so besteht begründete Hoffnung, daß auch das echte Buch allen TB-Herden zum Trotz weiterleben wird. ${ }^{174}$

Ob es sich dabei um Krankheitsherde oder aber um Herden im Sinne einer Vielzahl einfältiger Lebewesen handelt, bleibt in der Schwebe - beide Lesarten treffen Weigels Intention wohl gleichermaßen. Die Vorstellung, dass das ,Echte sich gegen das bloß kommerziell Erfolgreiche behaupten müsse, ist auch in Bernhards Literaturkritik der 1950er Jahre ein zentrales, immer wieder ins Spiel gebrachtes Narrativ.

Über Taschenbücher sollte sich Bernhard auch dann noch despektierlich äußern, ${ }^{175}$ als seine Texte längst in entsprechenden Bänden des Suhrkamp Verlags gedruckt und beworben wurden und sein Werk nicht zuletzt deshalb zusehends höhere Auflagezahlen erreichte. ${ }^{176}$ „Er hasse Taschenbücher und finde es auch unnötig, daß seine Bücher im Taschenbuch erscheinen“, notiert Siegfried Unseld im Februar 1982 nach einem krisenhaften Gespräch mit dem Autor in Palma de Mallorca. ${ }^{177}$ Bernhard räumte, abseits der hochwertigen leinengebundenen Erstausgaben seiner Prosaarbeiten, stets den kartonierten, mit einem Schutzumschlag versehenen Ausgaben der „Bibliothek Suhrkamp“ den Vorrang ein und nahm die Verwertung seiner Texte in den Taschenbuchreihen des Verlags lediglich billigend in Kauf. ${ }^{178}$

174 Ebd., S. 228 f.

175 Als Unseld Gehen für die erste Tranche der neuen Reihe „suhrkamp taschenbuch“ einplante, war Bernhard davon zunächst nicht eben angetan, fand die Gestaltung des Bandes aber schließlich doch „sehr gelungen“ (Bernhard an Unseld, 1.11. 1971. In: Bernhard/Unseld: Der Briefwechsel [Anm. 36], S. 248). - Zur Erstausgabe von Gehen im „suhrkamp taschenbuch“vgl. jetzt Catherine Marten: Bernhards Baukasten. Schrift und sequenzielle Poetik in Thomas Bernhards Prosa. Berlin, Boston: de Gruyter 2018, S. 258-267.

176 Allein Suhrkamp, so die Auskunft seines langjährigen Verlegers, hatte Anfang des 21. Jahrhunderts bereits mehr als 1,5 Millionen Bücher von Thomas Bernhard verkauft. Vgl. Siegfried Unseld: Bruchstücke einer großen Rebellion. In: Der Spiegel, Nr. 45, 4. 11. 2002, S. 194-195, hier S. 195 .

177 Unseld: Reisebericht [13./14. 2. 1982]. In: Bernhard/Unseld: Der Briefwechsel (Anm. 36), S. 649.

$178 \mathrm{Zu}$ Bernhards Favorisierung der „Bibliothek Suhrkamp“ vgl. Marten: Bernhards Baukasten (Anm. 175), S. 243-249. Vgl. allerdings auch Judex/Mittermayer: Literatur (Anm. 113), S. 373, die darauf hinweisen, dass Bernhard die „Zitate der von ihm erwähnten Dichter und Denker keineswegs aus philologisch hochwertigen Editionen“ bezog, „sondern eher aus günstig erworbenen Ausgaben, etwa Taschenbuch-Anthologien und Rowohlt-Monographien, wie sie in seiner Bibliothek zu finden waren“. 


\section{Alte Zöpfe, neue Pferde}

Einer der Texte der Sammlung Erziehung zu Vernunft und Fröhlichkeit, die Johannes Freumbichler in den Jahren 1946 bis 1948 zusammengestellt hat, trägt den Titel Das Neue, das Neueste. Er liefert freilich keine Ermunterung an den Enkel, sich, zumal nach dem Zivilisationsbruch des Zweiten Weltkriegs, einen dezidiert neuen, eigenständigen Weg zu suchen, sondern präsentiert eine eindringliche Warnung vor den Marktschreiern des ,Neuen':

Das Neue, das Neueste, mein Junge, möchtest du stets hören,

Und möchtest dein Gemüt mit diesem Rauschgift dir betören?

Sei auf der Hut vor diesem Neuen! Mit viel Geschrei

Wird es tagtäglich uns verkündet: „Ihr lieben Leut' herbei, herbei!“(179

Freumbichler assoziiert die Idee des ,Neuen' in der Folge vor allem mit dem Umwälzungspathos der Nationalsozialisten: Das „ganze Elend“ der jüngsten Vergangenheit sei „aus diesem Neuen [...] sturmflutartig über uns gekommen“, und es seien, so heißt es weiter, gerade die „Spießgesellen des Neuen“, die nach den Urteilen der Nürnberger Prozesse nun ,alle schmählich hangen“. ${ }^{180}$ Nicht das Neue - im Sinne einer radikalen Abnabelung von der Gewaltgeschichte der vergangenen Jahrzehnte - ist in Freumbichlers Augen das Gebot der Stunde, sondern die Rückbesinnung auf eine ländliche und bodenständige Lebensweise: „Die kühle, alte Weisheit unsrer Bauern kann allein uns besser betten“, sie sei „das einzige Mixtum positum, gegen diese Pest, dies Neue ${ }^{\text {“ }}{ }^{181}$ Freumbichlers ein wenig krudes Lehrgedicht schließt mit der nochmaligen Anrede an den „liebe[n] Enkel“, um diesem am Ende noch eine ewige „Weisheit" mit auf den Weg zu geben: „Erlösung, ist geweissagt, kommt einem Volke nur aus dem Bauerntum. ${ }^{\text {“182 }}$ Bei der Lektüre von Bernhards frühen (kultur-)journalistischen Texten gewinnt man den Eindruck, der junge Autor habe sich von dieser Lehre des Großvaters, von der vehementen Ermahnung, dem Neuen stets zu misstrauen,

179 Freumbichler: Erziehung zu Vernunft und Fröhlichkeit (Anm. 10), S. 50.

180 Ebd.

181 Ebd., S. 51. Mittermayer: Die Stimme des alten Meisters (Anm. 13), S. 32, hat darauf hingewiesen, dass die „konkreten zeitgeschichtlichen Phänomene“ in Freumbichlers Gedichten „keine politische Erklärung“ erfahren, sondern „auf die fatalen Auswirkungen einer materialistischareligiösen Moderne zurückgeführt“ werden.

182 Freumbichler: Erziehung zu Vernunft und Fröhlichkeit (Anm. 10), S. 51. Zur Deutung der Aspekte dieses Lehrgedichts vgl. Manfred Mittermayer: „Aufzuwachen und ein Haus zu haben. “ Thomas Bernhards „Heimatkomplex“ in frühen und frühesten Texten. In: Ferne Heimat - Nahe Fremde. Bei Dichtern und Nachdenkern. Hg. v. Eduard Beutner u. Karlheinz Rossbacher. Würzburg: Königshausen \& Neumann 2008, S. 186-202, hier S. 188 f. 
erst allmählich lösen können, als habe die Warnung des Großvaters noch länger in seinen Ohren geklungen.

Dem bildenden Künstler Josef Hödlmoser bescheinigte Bernhard in einem Artikel vom 22. Juli 1953, man habe es bei ihm mit einer „eigenwilligen, von den verschiedenen Kunst-Strömungen und -Seuchen noch nicht angegriffenen Persönlichkeit zu tun“ (TBW 22.1, 219); dem in diesen Tagen ebenfalls auf der Salzburger Festung ausstellenden Bildschnitzer Lois Lindner attestierte er im folgenden Absatz, ein „ruhende[r] Pol“ zu sein: „verwurzelt in der Tradition, aber dem Neuen voll aufgeschlossen“ (TBW 22.1, 220). Wenn Bernhard sich in diesen Jahren über den Zusammenhang von Überlieferung und Gegenwart, von Tradition und ,Neuem', d. h. zum Verhältnis des Bestehenden zu seiner Überschreitung äußert, flüchtet er nicht selten in rhetorische Floskeln und Allgemeinplätze: „Auch der Städter kann nur bestehen, wenn er neben dem Neuen immer wieder auch das Alte pflegt“, heißt es etwa im November 1953 in einem Bericht zum besinnlichen Salzburger Advent: „Jedes Land hat seine Vergangenheit, seine Lieder und Tänze, Spiele und Trachten, und nur aus dem Althergebrachten können wir, oft vom Wege abgekommen, neue wirkliche Impulse schöpfen." (TBW 22.1, 317) ${ }^{183}$

Mit dem „Neuen“, das Bernhard hier recht vage im Blick hat, sind freilich kaum die internationalen Avantgardebewegungen dieser Jahre gemeint; Salzburg lag in den frühen 1950er Jahren abseits jener Auf- und Umbrüche, die das Etablierte und Gewohnte im Gestus der Provokation zurückwiesen und die Institutionen und Statthalter der Tradition infrage stellten: Im jenem Jahr, in dem John Cages ikonisches Musikstück 4'33" in der Maverick Concert Hall in Woodstock uraufgeführt wurde (29. April 1952), erschien im Demokratischen Volksblatt Bernhards heiter-harmlose Erzählung von einer Radioübertragung der Salzburger Festspiele (vgl. TBW 22.1, 51-54). Gesendet wurde die Uraufführung von Richard Strauss' Die Liebe der Danae, die musikalische Leitung hatte jener Clemens Krauss inne, der schon die für den Sommer 1944 geplante Premiere der Oper hätte dirigieren sollen, die infolge des Attentats auf Adolf Hitler abgesagt wurde. ${ }^{184}$ Und eine Woche bevor H. C. Artmann in Wien seine Acht-Punkte-Proklamation des poetischen Actes präsentierte (5. April 1953), ${ }^{185}$ besprach Bernhard

183 Vgl. dazu Moritz: Lehrjahre (Anm. 44), S. 71, sowie den kritischen Kommentar von Klug: Thomas Bernhards Arbeiten (Anm. 28), S. 144: „Bernhard wird diesen Gemeinplatz vom Alten und Neuen auch in seinen Kulturberichten wiederholen, dabei aber keinerlei Zweifel daran lassen, zu welcher Seite er den Ausschlag zu geben gedenkt: zur Tradition und althergebrachten Ordnung, aus welcher das Neue bruchlos als Aktualisierung des Immergleichen hervorzugehen habe."

184 Zu Krauss' Rolle im Dritten Reich vgl. Rathkolb: Führertreu und gottbegnadet (Anm. 164), S. $106-113$.

185 Vgl. Gerhard Rühm: Vorwort. In: Die Wiener Gruppe. Achleitner, Artmann, Bayer, Rühm, Wiener. Texte, Gemeinschaftsarbeiten, Aktionen. Hg. u. mit einem Vorwort v. G. R. Reinbek b. 
im Demokratischen Volksblatt eine Lesung von Elisabeth Effenberger und Josef Laßl, die, so der Rezensent, mit „liebenswürdig bemessen[em]“ Beifall geendet habe (TBW 22.1, 150). Während die sich allmählich neu formierende Wiener Literaturszene an radikalen künstlerischen Verfahren arbeitete und Anschluss an die internationale Avantgarde suchte, ${ }^{186}$ attestierte er Effenberger, „frauliche Gedichte geschrieben zu haben, und gab ihr als Rat auf den Weg: „Dichten heißt Arbeiten, nicht basteln!“ (TBW 22.1, 149) Davon, dass Laßl einige Jahre zuvor noch als Redakteur des Völkischen Beobachters gearbeitet hatte ${ }^{187}$ ist in Bernhards Lesungsbericht nichts zu lesen. Er offenbart die ästhetische und ideologische Indifferenz eines jungen Rezensenten, der erst in den folgenden Jahren Anschluss an avanciertere Strömungen im österreichischen literarischen Feld finden sollte.

Bernhard fordert in mehreren Beiträgen für das Demokratische Volksblatt zwar vehement Aufmerksamkeit für die Werke einer jungen Generation von Autorinnen und Autoren (zu der er nicht zuletzt selbst gehört); er geht aber zunächst, so Christian Klug, von einem „Handlungssystem“ aus, „in welchem die Jungen sich um die Anerkennung der Alten bemühen, statt spezifisch neue Wertmaßstäbe zu entwickeln“: „Nicht das Neue als bestimmte Negation des Alten ist erwünscht, sondern der kontinuierliche, bruchlose, bewahrende Anschluß an eine bestimmte Tradition. ${ }^{“ 188}$ Während der Prosa- und Theaterautor Bernhard später „rebellische[ ] Söhne“ in den Fokus seiner Texte gerückt hat, „die gegen die Tradition vorgehen und das Alte auflösen wollen “', 189 kann sich der Journalist zu Beginn zu solch radikalen Gesten noch nicht durchringen.

Immer wieder ist in seinen publizistischen Arbeiten der frühen 1950er Jahre von der „große[n] Verantwortung gegenüber unseren großen Geistern der Geschichte" die Rede; erst der Anspruch, ihnen gerecht werden zu können, bilde die Legitimation für die „künstlerisch Schaffenden des jungen Österreich“ (TBW 22.1, 143), so Bernhard im Aufsatz Die Kultur ist nicht stehen geblieben! vom April

Hamburg: Rowohlt 1967, S. 5-36, hier S. 9 f.; zur genaueren Datierung siehe Klaus Kastberger: Acte und Akten. Konrad Bayer und die Archive der Avantgarde. In: Konrad Bayer: Texte, Bilder, Sounds. Hg. v. Thomas Eder u. K. K. Wien: Zsolnay 2015, S. 15-33, hier S. 22.

186 Vgl. dazu etwa Klaus Kastberger: Wien 50/60. Eine Art einzige österreichische Avantgarde. In: Schluß mit dem Abendland! Der lange Atem der österreichischen Avantgarde. Hg. v. Thomas Eder u. K. K. Wien: Zsolnay 200o, S. 5-26; Daniela Strigl: Ihr Auftritt, bitte! Sprachingenieure als Entertainer. In: verschiedene sätze treten auf. Die Wiener Gruppe in Aktion. Hg. v. Thomas Eder u. Juliane Vogel. Wien: Zsolnay 2008, S. 9-28. Zu Bernhards Verhältnis zur Wiener Gruppe vgl. Billenkamp: Thomas Bernhard (Anm. 14), S. $374 \mathrm{f}$.

187 Vgl. Schneider/Steinsiek: Mengenlehre (Anm. 101), S. 61.

188 Klug: Thomas Bernhards Arbeiten (Anm. 28), S. 15of. Vgl. dazu auch Töteberg: Höhenflüge im Flachgau (Anm. 162), S. 6: „Bernhards Zeitungsartikel erscheinen wie die Aufsätze eines Musterschülers. Ein junger Mann, nicht aufmüpfig, sondern traditionsbewußt.“

189 Judex: Schreiben in der „Denkkammer“ (Anm. 6), S. 29. 
1953. ${ }^{190}$ Während in der Kunsttheorie der Moderne, wie Boris Groys gezeigt hat, die „Abwertung der bestehenden kulturellen Werte“ ein „notwendiger Aspekt des innovatorischen Gestus“ ist, ${ }^{191}$ stand der junge Kulturjournalist diesem Konzept anfangs noch denkbar fern. In seinen Feuilletons, Veranstaltungsberichten und volkskundlichen Reportagen sieht er die zentrale Qualität eines Kunstwerks eben nicht in der „negativen Anpassung an die kulturelle Tradition“ ${ }^{192}$ sondern in deren entschiedener Fortschreibung: „Zweifellos“ zählte er, so Michael Billenkamp mit Blick auf Bourdieus Unterscheidung von ,Orthodoxie` und ,Häresie, ${ }^{\text {(193 }, z u ~}$ Beginn seiner schriftstellerischen Laufbahn eher zur Gruppe der Bewahrer als zu den Häretikern. “ ${ }^{194}$ In einem Bericht über eine Vortragsreihe der Salzburger Volkshochschule vom 23. April 1954 fallen Sätze, die für Bernhards damaliges Verständnis von kultureller Genealogie bezeichnend sind. Es sei, wie der junge Rezensent in etwas altväterlichem Gestus formuliert,

gerade heute von unabschätzbarer Wichtigkeit, die großen Geister der Vergangenheit in ein neues Licht zu rücken, und jeden einzelnen von uns mit ihrem Fundament vertraut zu machen. Erst wenn wir einigermaßen die Bedeutung und den Geist der Geschichtsträger erfaßt haben, können wir den entscheidenden Schritt in die Gegenwart und in die Zukunft unternehmen. (TBW 22.1, 362)

Bereits im März 1953 hatte Bernhard jedoch anlässlich einer Lesung von Rudolf Bayr - mit dem er mehr als zwei Jahrzehnte später ein Fernsehinterview führen sollte - auch eine kritischere Perspektive auf die „Geister der Vergangenheit“ angedeutet. ${ }^{195}$ Die von Bayr vorgetragenen Texte seien "geschöpft aus

190 Laut Klug: Thomas Bernhards Arbeiten (Anm. 28), S. 148, handelt es sich dabei um einen recht „seltsame[n] Essay, in dem unausgewiesene Tatsachenbehauptungen, Gegenwartsdeutungen und autobiographische, nur die eigene Person betreffende Äußerungen kunterbunt durcheinander laufen".

191 Boris Groys: Über das Neue. Versuch einer Kulturökonomie. München: Hanser 1992, S. 63.

192 Ebd., S. 19.

193 Vgl. Pierre Bourdieu: Die Regeln der Kunst. Genese und Struktur des literarischen Feldes. Frankfurt a. M.: Suhrkamp 1999, S. 329; ders.: Das literarische Feld. Kritische Vorbemerkungen und methodologische Grundsätze. In: P. B.: Kunst und Kultur. Kunst und künstlerisches Feld. Schriften zur Kultursoziologie 4. Hg. v. Franz Schultheis u. Stephan Egger. Berlin: Suhrkamp 2015, S. 309-337, hier S. 316; dazu Christine Magerski: Theorien der Avantgarde. Gehlen Bürger - Bourdieu - Luhmann. Wiesbaden: Verlag für Sozialwissenschaften 2011, S. $85 \mathrm{f}$.

194 Billenkamp: Thomas Bernhard (Anm. 14), S. 372 f. Vgl. auch ders.: Provokation und posture (Anm. 37), S. 28: „Bernhard betritt die literarische Bühne [...] nicht, wie es das Spätwerk [...] vermuten [lässt], als Revolutionär und provokanter Avantgardekünstler, sondern er sieht seine künstlerische Heimat in der Nähe der orthodoxen Bewahrer heimatlicher Dichtung.“

195 Vgl. zu diesem Text Mittermayer: „Die brennende hilfesuchende Glut“ (Anm. 31), S. 207, der zudem darauf hinweist, dass Bayr - ebenso wie Josef Laßl - „in jungen Jahren“ als 
dem unendlichen Reichtum der großen Vorbilder, die mit Namen aufzuzählen nicht notwendig erscheint“. Allerdings bemerkt Bernhard auch, „daß das in der Tradition Verwurzelte, das Festgebundene, obwohl immer neu Reifende, zugleich auch eine große, nicht zu unterschätzende Gefahr für den Autor, und im übertragenen Sinn, für die gesamte Entwicklung in sich birgt“ (TBW 22.1, 133). Auf diese Einsicht, in der sich leise andeutet, was Bernhard 1970 im Filmmonolog Drei Tage als „ununterbrochenes Zur-Wehr-Setzen“ (TBW 22.2, 63) gegen Kanon und Tradition beschreiben wird, folgt nun jedoch wieder jene stereotype Berichterstatterrhetorik, die in den Lesungskritiken allenthalben festzustellen ist und die die zuvor angedeutete Problematik abschließend wohlig einhegt: „Rudolf Bayr als Erzähler zu hören, als besinnlich Heiteren und mit dem Wesen des Kindhaften Vertrauten, ist durchaus vergnüglich. [...] Das Publikum dankte dem Autor herzlich für seine Lese-Stunde.“ (TBW 22.1, 133 f.) Während Herbert Moritz in Bernhards Text über Rudolf Bayr einen „wichtigen Anstoß zum Diskurs über Traditionalismus und Eklektizismus“ erkennt, ${ }^{196}$ bleibt die Vorstellung einer hinderlichen, ja gefährlichen Tradition doch „konturlos, ohne Konsequenz und als Warnung vollkommen abstrakt“. Er „erkennt in der Traditionsgebundenheit nicht das grundsätzliche Problem der österreichischen Literatur der Nachkriegszeit", ${ }^{197}$ sondern sieht darin nur ein individuelles Problem des Autors Bayr, dessen „intellektuelle“ Literatur sich eben $z u$ stark am „unendlichen Reichtum der großen Vorbilder“ orientiere (TBW 22.1, 133) - ein Kritikpunkt, den er ein halbes Jahr später anlässlich einer Lesung von Alfons Czibulka - „allzu stark im Traditionellen verankert“ (TBW 22.1, 276) - wiederholen sollte.

Erst allmählich zeigen die im Demokratischen Volksblatt veröffentlichten Beiträge Bernhards eine ideologie- wie kulturgeschichtlich signifikante Entwicklung, die - parallel zum eigenen literarischen Schreiben - vom Paradigma der Fortschreibung und Bewahrung im Kontext einer „konservativen Neuerungsscheu“198 hin zur Idee eines Bruchs mit der Tradition, zur Überwindung des Bestehenden führt. Sein „mühsamer, aber steter Prozeß der Emanzipation aus der geistigen und künstlerischen Enge ${ }^{\text {“199 }}$ geht mit einer maßgeblichen „Weiterentwicklung“

„Kulturredakteur beim Völkischen Beobachter" gearbeitet hat.

196 Moritz: Lehrjahre (Anm. 44), S. 108.

197 Klug: Thomas Bernhards Arbeiten (Anm. 28), S. 146.

198 Holl: Literaturgeschichte Salzburgs (Anm. 92), S. 691.

199 Habringer: Der Auswegsucher (Anm. 26), S. 38. Dazu auch Holl: Literaturgeschichte Salzburgs (Anm. 92), S. 675: „So wurde auch in Salzburg nicht der Grundstein für Neues, für die Wiedererringung der Moderne gelegt, die im deutschen Sprachraum 12 bzw. 7 Jahre lang ausgesperrt gewesen war, sondern man wählte die Kontinuität, das Vertraute, das Anknüpfen an die Regionalliteratur der dreißiger Jahre.“ 
seines „Kunstbegriffs“ einher, ${ }^{200}$ die sich gerade anhand der allmählichen Schärfung des Blicks auf das Verhältnis von, Altem' und ,Neuem' nachvollziehen lässt. Seine essayistischen Beiträge nähern sich im Laufe der 1950er Jahre mehr und mehr der Vorstellung an, die literarische Tradition mit dem eigenen Schreiben nicht fortzuführen, sondern herauszufordern. Nicht zuletzt daran lässt sich, so Hans Höller, zeigen, „welch entscheidende künstlerische Wendung Bernhard im Verlauf dieses Jahrzehnts vollzogen hat “ ${ }^{201}$

Erst mit der Zeit entwickelt er dabei ein Sensorium für jene Unterscheidung, die schon Georg Lukács als interne Differenzierung im Feld des ,Neuen herausgearbeitet hat: jene zwischen dem „wesentlich Neuen“, das sich später als das „historisch Entscheidende[ ]“ erweisen wird, und dem - wie es in Lukács” Essay Schriftsteller und Kritiker von 1939 heißt - bloßen „Fetisch“ und „Schlagwort des Neuen“. ${ }^{202}$ Hatte Freumbichler das ,Neue“ im Grunde ausschließlich mit diesem „Fetisch“ in eins gesetzt und seinem Enkel diese Deutung mit auf den Weg gegeben, wurde Bernhard - zumal als er die Tätigkeit als Kritiker zugunsten des eigenen Schreibens und des Studiums am Salzburger Mozarteum aufgab - mehr und mehr bewusst, dass die Durchsetzung im literarischen Feld mit einem Bruch mit den „bereits anerkannten Vorläufer[n]“ ${ }^{203}$ einhergehen musste. Die Anwärter im literarischen Feld müssen sich, so Pierre Bourdieu, all dem verweigern, „was in ihren Augen einen ,alten Zopf“ darstellt“, um durch die forcierte Zurückweisung ihre eigene, neue Position distinktiv zu bestimmen $^{204}$ - eine Einsicht, die sich bei Bernhard erst allmählich durchgesetzt hat, wofür nicht zuletzt seine mit den Jahren intensivierten Beziehungen zur Wiener Literaturszene wichtig waren: „Es wird immer schwieriger“, schreibt er am 13. Juni 1958 an seinen Freund Gerhard Fritsch, „,in der Literatur bleiben zu können. Man muß doch immer mit einem neuen Pferd in die ,Aschenbahn jagen. Das alte zieht nicht mehr recht, bei niemand. ${ }^{“ 205}$ Und er setzt, nachdem

200 Mixner: Vom Leben zum Tode (Anm. 97), S. 71. Mixner hat dies auch explizit mit Bernhards eigenen schriftstellerischen Ambitionen in Verbindung gebracht: „Zusammenfassend kann man sagen, daß Bernhard in seinem Frühwerk bis zum Erscheinen des Romans ,Frost' 1963 nur mit großer Anstrengung aus einem naiven und epigonalen Kunstverständnis zu einem Schreibverfahren gefunden hat, das es ihm ermöglicht, seine subjektive Bewußtseinserfahrung zu objektivieren." (Ebd., S. 93)

201 Höller: Thomas Bernhard (Anm. 76), S. 49.

202 Georg Lukács: Schriftsteller und Kritiker. [1939] In: G. L.: Schriften zur Literatursoziologie. Hg. v. Heinz Maus u. Friedrich Fürstenberg. Neuwied, Berlin: Luchterhand ${ }^{4} 1970$, S. 198-212, hier S. $209 \mathrm{f}$.

203 Bourdieu: Die Regeln der Kunst (Anm. 193), S. 379.

204 Ebd.

205 Thomas Bernhard an Gerhard Fritsch, 13. 6. 1958. In: T. B./G. F.: Der Briefwechsel. Hg. v. Raimund Fellinger u. Martin Huber. Mattighofen: Korrektur 2013, S. 19. 
er zwischenzeitlich konstatiert hatte, „Dichten“ sei „sicher das Schwierigste“, ja „mindestens so schwer, wie zehn Kinder gleichzeitig an verschiedenen Orten zu erhalten und zu betreuen" (eine Verlegenheit, in die Bernhard nie kommen sollte), hinzu: „Und dann, heraus, neu, völlig verwandelt. Das beschäftigt mich die ganze Zeit. “206 Diese spektakuläre Verwandlung sollte ihm erst fünf Jahre später, mit dem Erscheinen von Frost, gelingen.

Hieß es 1953 in einem Artikel zur Salzburger Buchwoche noch, die Dichtung sei gerade deshalb nicht „ausgestorben“, weil sich das ,Neue“ „an das vertraute Alte" anschließe (TBW 22.1,311), zeigt sich in späteren Texten - etwa in Ein Wort an junge Schriftsteller (1957) - bereits jener polemische Gestus, der ab Mitte der 1960er Jahre im Zusammenspiel von Provokation und Innovation zum spezifischen „Erkennungszeichen“ ${ }^{207}$ des Autors werden sollte. Texte wie die Erzählung Ein junger Schriftsteller (1965), in der sich ein Autor „fast drei Jahrzehnte“ „die Welt und die Atmosphäre um sie herum als eine höchst sinnvolle vorsetzen“ hat lassen, um sich ihr schließlich zu verweigern (TBW 14, 368), können als narrative Inszenierung bzw. literatursoziologisch als, Selbstobjektivierung ${ }^{\text {(208 }}$ der eigenen Entwicklung gelesen werden. In diesem Zusammenhang ist Bernhards aggressive Rhetorik gegen Österreich und die restaurativen Tendenzen im österreichischen Kulturbetrieb auch als autoreflexiver Kommentar gedeutet worden, als „Selbstdistanzierung von der einstmals naiv reproduzierten Heimat-Ideologie“ ${ }^{209}$ bzw. als „Polemik des Autors gegen sich selbst“ ${ }^{210}$ „Es schien mir beim Lesen von Thomas Bernhard oftmals so, daß diese Sätze übriggebliebene Negationen waren“, so Arnold Stadler in seiner Abrechnung mit Bernhard zugunsten des von ihm favorisierten Adalbert Stifter, „Reaktionen auf Zurückweisungen früherer Affirmationen, von einem ursprünglichen Ja-Sagen, das niemand hören wollte. “211

206 Ebd., S. 19 f.

207 Vgl. Pierre Bourdieu: Das literarische Feld. In: P. B.: Kunst und Kultur (Anm. 193), S. 339-447, hier S. 392.

208 Vgl. Bourdieu: Die Regeln der Kunst (Anm. 193), S. 54 f. Dazu auch Kap. VII, Abschnitt „Zwischen ,Geisteskunst' und ,Selbstkorrektur': Szenen prekärer Autorschaft“; Kap. IV, Abschnitt „,ekelhaft ekelhaft ekelhaft': Kritiken auf der Bühne“.

209 Töteberg: Höhenflüge im Flachgau (Anm. 162), S. 9.

210 Klug: Thomas Bernhards Arbeiten (Anm. 28), S. 137. Vgl. auch ders.: Thomas Bernhards Theaterstücke. Stuttgart: Metzler 1991, S. 8: „Bernhards spätere Attacken gegen alles Österreichische, gegen Provinzialismus und trügerische Selbstgewißheit richten sich [...] unausgesprochen auch gegen Vorstellungen, die sein eigenes Denken jahrelang bestimmt haben. Die Heftigkeit seiner Angriffe muß“, so Klug, „nicht zuletzt auf das Gefühl zurückgeführt werden, betrogen und ideologisch verführt worden zu sein.“

211 Arnold Stadler: Mein Stifter. Porträt eines Selbstmörders in spe und fünf Photographien. Köln: DuMont 2005, S. 160. 
In Auslöschung. Ein Zerfall (1986) schließlich wird Franz-Josef Murau seinem Schüler Gambetti die Maxime vermitteln, man müsse „nach und nach gegen alles sein“, ja im Zuge der „allgemeinen Vernichtung, die wir im Auge haben“, auch und vor allem „das Alte auflösen, um es am Ende ganz und gar auslöschen zu können für das Neue“:

Das Alte muß aufgegeben werden, vernichtet werden, so schmerzhaft der Prozeß auch ist, um das Neue zu ermöglichen, wenn wir auch nicht wissen können, was denn das Neue sei, aber daß es sein muß, wissen wir, Gambetti, habe ich zu diesem gesagt, es gibt kein Zurück. Natürlich haben wir, wenn wir so denken, alles Alte gegen uns und also haben wir Alles gegen uns, Gambetti, habe ich zu diesem gesagt. Das darf uns aber nicht hindern, unsere Idee, das Alte gegen das von uns gewünschte Neue einzutauschen, zunichte zu machen. (TBW 9, 166)

In den Jahren seiner Tätigkeit für das Demokratische Volksblatt scheint Bernhard eine solche Vorstellung noch einigermaßen fremd gewesen zu sein, und er befand sich dabei im österreichischen Kulturbetrieb in guter Gesellschaft, war das Paradigma des „Anschlusses an die Tradition“, so Sigurd Paul Scheichl, doch „in den 5oer Jahren das vorherrschende “. 212 Mit seinem Lob für das Salzburger Heimatwerk vom 30. Oktober 1953, „aus der Tradition heraus Neues und Stilvolles zu schaffen“ (TBW 22.1, 289), stand Bernhard keineswegs allein. Zu einer stärker individuellen Positionierung, die mit der polemischen Distanzierung von der Tradition und ihren (regionalen) Statthaltern einherging, fand er erst im Lauf der folgenden Jahre.

\section{„Was in den guten Jungen nur gefahren sein mag?“: erste Polemiken}

Bernhards Veröffentlichungen im Demokratischen Volksblatt kamen Ende Mai 1954 mit einem Artikel über den bildenden Künstler Arno Lehmann vorläufig zu einem Ende; im Juni und Juli folgten zunächst drei Theaterkritiken in den Salzburger Nachrichten, bevor dann eine Lücke von gut viereinhalb Monaten festzustellen ist. Erst am 24. und 25. November 1954 erschienen drei Artikel aus dem Kulturressort im Demokratischen Volksblatt, am 4. und 20. Dezember zwei letzte Feuilletons zur Weihnachtszeit, bevor Bernhard seine Tätigkeit für die sozialdemokratische Zeitung endgültig aufgab. Bei verschiedenen Gelegenheiten hat er darüber berichtet, dass der Wunsch der Redaktion, er möge in die SPÖ eintreten, zum Bruch geführt habe: „Ich hätte dort zur Partei gehen sollen, bin auch dazugegangen, aber nach drei Tagen hab' ich mir gedacht, daß ich da, weil

212 Scheichl: Vergessene (Anm. 137), S. 79. 
es ja von vornherein nicht meine Richtungssache war, nicht richtig handle, und bin dann weggegangen“, so Bernhard 1977 im Gespräch mit Peter Hamm (TBW 22.2, 115). ${ }^{213}$ Im Anfang der $1980 e r$ Jahre verfassten, aber erst 2009 veröffentlichten Prosatext Meine Preise hat Bernhard seinen Austritt aus der „Sozialistischen Partei“, „,in welche ich allerdings tatsächlich kurz zuvor eingetreten war“, als Beispiel seiner grundlegenden Abneigung gegenüber „Parteien und Vereinigungen“ angeführt (TBW 22.2, 430). Zu einer regelmäßigen Mitarbeit in einer Zeitungsredaktion kam es in der Folge nicht mehr. Im Laufe des Jahres 1955 veröffentlichte er vereinzelte Beiträge im Münchner Merkur (über Josef Weinheber), im Linzer Volksblatt (über Venedig), in den Salzburger Nachrichten (über eine Lesung Bernt von Heiselers) und in der Wiener Wochenzeitung Die Furche, für die er vor allem über Kunstausstellungen berichtete ${ }^{214}$ - eine Aufgabe, die er auch 1956 noch gelegentlich übernahm (vgl. TBW 22.1, 399-419).

Als Auftakt einer selbstbewussteren und betont provokativen Publikationspraxis kann sein Angriff auf das Salzburger Landestheater in der Furche vom 3. Dezember 1955 gelten, der unter dem Titel Salzburg wartet auf ein Theaterstück gedruckt wurde. ${ }^{215}$ Hatte Bernhard noch 1952 spekuliert, dass womöglich ein hiesiger Schauspieler „den verwaisten ,Ifflandring ' tragen“ werde (TBW 22.1, 81), und die „Überschwemmung unserer Theater mit amerikanischen, französischen und englischen Bühnenwerken" beklagt (TBW 22.1, 15), zielt seine Polemik nun gerade auf die ästhetische Rückständigkeit und provinzielle Beschränktheit des dortigen Programms:

213 Vgl. auch Hofmann: Aus Gesprächen mit Thomas Bernhard (Anm. 42), S. 43 f.: „Eines Tages komm' ich hin, da sagt der [Josef] Kaut: ,Also jetzt geht das nimmer so, jetzt müssen wir zur Partei gehen. Also, ich mein', so eine sozialistische Zeitung und nichts, das gibt's nicht.' [...] Ich hab' mir gedacht, ist mir ganz wurscht, jetzt geh' ich halt zur Partei. Und vorgepickt die Mitgliedsmarken gleich auf ein halbes Jahr, dort an Ort und Stelle, und hab' das alles unterschrieben, und damit war die G'schicht erledigt. Ich bin heimgegangen und hab' mir nachher gedacht, was hat denn jetzt eigentlich g'macht? [...] Und ich weiß genau, am nächsten Tag oder am übernächsten hab' ich das Parteibuch genommen, hab' einen Brief g'schrieben [...]. Ich hab' das eingeschrieben aufgegeben und dann g'schrieben, eigentlich halte ich vom Sozialismus nichts und so, und hiermit schick' ich das mit, das war ein Blödsinn. Ich schick' das wieder zurück, und die G'schicht' hat sich. Dann hab' ich mich nicht mehr hingeh'n getraut zum Kaut, und da waren natürlich meine ganzen neunzig Schilling am Tag hin. Es war alles aus. Da hab' ich dann, ich glaub zehn, fünfzehn Jahr, keinen Kontakt mehr g'habt. War dort Schluß." Zu Bernhards Abschied aus der Redaktion vgl. Moritz: Lehrjahre (Anm. 44), S. $166 \mathrm{f}$.

214 Im Zuge seiner Tätigkeit für die Furche kam Bernhard auch mit Friedrich Heer in Kontakt, der als Kulturredakteur für die Wochenzeitung arbeitete. Vgl. Renate Langer: Hitlerbild und Kreuz. Nationalsozialismus und Katholizismus bei Thomas Bernhard. In: Thomas Bernhard Jahrbuch 2007/2008, S. 21-35, hier S. 32.

215 Vgl. dazu und zum Folgenden Gschwandtner: Journalistische Arbeiten (Anm. 84), S. 18 f. 
Wir warten. Wir warten noch immer darauf, daß das Salzburger Landestheater endlich einmal ein Theaterstück herausbringt, das in den Kulturspalten diskutabel ist. Seit zwei Jahren warten wir auf das entsprechende Stück und auf die entsprechende Inszenierung, und das Unbehagen wird mit jedem Theatersemester größer. Bald wird auch der letzte Hoffnungsschimmer geschwunden sein und die Bretter rechts der Salzach, die Bretter dieses einzigartigen österreichischen Kammertheaters, werden nur noch ein Rummelplatz des Dilettantismus sein. (TBW 22.1, 411)

In der Zeit abseits der Salzburger Festspiele sinke das im Landestheater angebotene Programm auf das „Niveau einer Bauernbühne“ herab; dem „wenn auch nicht immer kulturfreundlichen, so doch durchaus nicht kulturfeindlichen“ Publikum der Stadt setzte man „nichts als sauer gewordene Schlagobersmärchen“ vor: „Dieses Haus krankt an chronischer Phantasielosigkeit und an einem unnachahmlichen Mißmut.“ (TBW 22.1, 411f.) Die unverhohlene Kritik am Spielplan des Landestheaters hatte sich gut eineinhalb Jahre zuvor in einem Bericht für die Salzburger Nachrichten (24. Mai 1954) bereits sanft angedeutet. Bernhard hatte darin eine Aufführung von Hubert Marischkas Operette Walzerkönigin als „süße Windbäckerei mit Schlagobersschaum“ abqualifiziert (TBW 22.1, 377), ansonsten aber einen noch deutlich weniger aggressiven Ton angestimmt. Mit anhaltender Kritik hatte sich das Landestheater schon in den Jahren zuvor konfrontiert gesehen: Ende der 1940er, Anfang der 1950er Jahre wurde die Programmgestaltung des Hauses und die künstlerische Qualität der Inszenierungen in der Salzburger Presse wiederholt kontrovers diskutiert; der 1951 neu berufene Intendant Peter Stanchina indes wies nach seinem Amtsantritt ein ums andere Mal auf die prekäre finanzielle Lage des Theaters und die damit einhergehenden Beschränkungen hin. ${ }^{216}$

Im Dezember 1955 empfahl der zum Polemiker gereifte Bernhard Stanchina nun - wohl unter dem Eindruck seines kurz zuvor begonnenen Studiums am Mozarteum - „als letzte Medizin“ „ein Lexikon der Theaterliteratur, darin Namen stehen wie Williams, Faulkner, Eliot, Miller, Andres [?] und alle die österreichischen Dichter, deren Werke jenseits der Grenzen wesentlich wurden“ (TBW 22.1, 412). Die Attacke zog nicht nur verwunderte bis erboste Reaktionen nach sich, wie die des Journalisten Kurt Kutschera, der im Salzburger Volksblatt fragte, was „in den guten Jungen nur gefahren sein mag“, 217 sondern auch einen Gerichtsprozess wegen übler Nachrede, der erst 1959 nach mehreren Instanzen mit einem Vergleich endete. ${ }^{218}$ In einer 1969 in der Zeitschrift Theater heute publizierten

216 Vgl. ausführlich Waitzbauer: Thomas Bernhard in Salzburg (Anm. 47), S. 122-127.

217 Hans Kutschera: Thomas Bernhard „furchte“. In: Salzburger Volksblatt, 7. 12. 1955. Vgl. den Kommentar in TBW 22.1, 787.

218 Vgl. Sehr geschätzte Redaktion (Anm. 55), S. 9-16; Mittermayer: Thomas Bernhard [2015] (Anm. 25), S. $98 \mathrm{f}$. 
Stellungnahme erneuerte Bernhard seine 1955 in der Furche geäußerte Kritik am Salzburger Landestheater, wiederholte seine damaligen Argumente gegen „Schwachsinn“, „Schweinerei“ und „kopflose[n] Mimenunrat“ (TBW 22.1, 608) und rekapitulierte die daraus resultierende gerichtliche Auseinandersetzung. Indem er den Erscheinungszeitpunkt seines Furche-Artikels in das Jahr 1949 vorverlegte - „ich bin nichts als achtzehn gewesen“ (TBW 22.1, 608) -, modifizierte er seine intellektuelle Biographie und stilisierte sich wie bei anderen Gelegenheiten zum frühreifen journalistischen Rebellen. Nun klagte nicht das Landestheater, sondern der Verlag und die Chefredaktion der Furche, weil Bernhard sie in seinem Beitrag für Theater heute als „damals beste[ ] Wochenzeitung Österreichs bezeichnet hatte, „die heute allerdings nurmehr noch als eine Quadratur des perversen katholisch-nazistischen Stumpfsinns herauskommt" (TBW 22.1, 608). Auch dieses Gerichtsverfahren, dessen Akten den Beschuldigten als "Thomas Bernhard, Journalist und Theaterkritiker“ auswiesen, ${ }^{219}$ endete mit einem Vergleich.

Bis Mitte der 1950er Jahre sei Bernhard, so Gitta Honegger, „der brave Bub gewesen, der Not und Krankheit überwunden hatte, ein junger einheimischer Schriftsteller, dessen Geschichten und Gedichte von liebevoller Beobachtung des heimischen Milieus zeugten“; doch nun „stellte sich der Enkel - das offiziell verhätschelte lokale Nachwuchstalent - gegen den gemütlichen Provinzialismus einer beliebten lokalen Institution“.220 Der mit ihm befreundete Komponist und Dirigent Rudolf Brändle war Jahrzehnte später der Überzeugung, die im Lauf der Zeit gewonnene „Schreibroutine“ habe Bernhard allmählich seine „Macht“ als Journalist und Kritiker bewusst gemacht und ihn zu seiner „polemisch überspitzte[n] Attacke" gegen das Salzburger Landestheater angestachelt; zugleich hat Brändle diese rabiate publizistische Intervention aber auch mit Bernhards „erfolglose [m] Vorsingen ein Jahr zuvor an eben diesem Theater" in Verbindung gebracht, die Polemik also, jedenfalls zum Teil, als persönliche Retourkutsche interpretiert. $^{221}$

Dass Bernhards neu gewonnenes Selbstbewusstsein im Sprechen über Literatur und Kultur und sein zunehmender Hang zur Provokation nicht allseits auf Zustimmung stießen, zeigt ein im November 1957 in den Salzburger Nachrichten veröffentlichter Bericht über eine gemeinsam mit Gerhard Fritsch abgehaltene Lesung:

219 Zit. nach Bernhard/Unseld: Der Briefwechsel (Anm. 36), S. 16o, Anm. 3; zur Ehrenbeleidigungsklage gegen Bernhard vgl. die Korrespondenz ebd., S. 157-169.

220 Honegger: Thomas Bernhard (Anm. 71), S. 8of.

221 Brändle: Zeugenfreundschaft (Anm. 19), S. 89. 
Jeder fruchtbare Non-Konformismus in Ehren, besonders in einer kulturbeflissenen Zeit wie der unseren! Aber Rilke einen ,nicht sehr bedeutsamen Dichter ${ }^{`}$ zu nennen oder Jüngers Marmorklippen als ,Papierblumenästhetik‘ abzutun, hat damit nichts mehr zu tun, wenn auch in diesen Urteilen etwas Richtiges getroffen sein mag. Das ist reine Überheblichkeit, nicht zu sagen Dünkel. ${ }^{222}$

Als er zwei Jahre später, im November 1959, in der Monatsschrift Morgen alle Schriftstellerinnen und Schriftsteller seiner Generation als „Epigonen“ denunzierte, die „in den Kaffeehäusern bei lebendigem Leib vermodern“ und sich gegenseitig ,in den Spalten der schmutzigsten, witzlosesten und unbedeutendsten Zeitungsblätter der Welt“ „beweihräuchern“ (TBW 22.1, 577), fühlten sich H. C. Artmann, Gerald Bisinger, Jeannie Ebner, Elfriede Gerstl und Kurt Klinger zu einer öffentlichen Erwiderung und Zurechtweisung des Provokateurs herausgefordert. ${ }^{223}$ Konnte Bernhard zu diesem Zeitpunkt auch noch keine eigenen literarischen Texte vorweisen, die diese Überheblichkeit tatsächlich hätten rechtfertigen können, fand er im Laufe der zweiten Hälfte der 1950er Jahre doch zu einem charakteristischen Gestus des Sprechens über die Literatur seiner Kollegen und Kontrahenten, in dem der Sound der späteren Polemiken, seine umfassende „Rhetorik der Bezichtigung “, 224 bereits anklingt.

\section{„Ich kann kein Buch besprechen": Absagen und Stellvertretungen (Alte Meister, Auslöschung)}

Im Zuge seiner Tätigkeit für das Demokratische Volksblatt in der ersten Hälfte der 1950er Jahre habe Bernhard, so sein einstiger Vorgesetzter in der Redaktion, Herbert Moritz, „Routine im Schreiben“ und „Sicherheit im Auftreten und Selbstgefühl“ gewonnen. ${ }^{225}$ Mit der Zeit habe sich der junge Autor sogar „zu einem recht gewichtigen und wohl auch ein wenig gefürchteten Kritiker in den lokalen

222 O. Sch.: Thomas Bernhard und Gerhard Fritsch. In: Salzburger Nachrichten, 14. 11. 1957. - Es war womöglich diese Lesung, nach der sich Bernhard ernüchtert an seine Wiener Freundin Jeannie Ebner wandte: „Mir hat er ganz am Anfang, nach einer Lesung in Salzburg, geschrieben, daß Kritiken immer der gleiche Käse sind und daß letztendlich die Dichtung die Bartwische der Literatur und der Redaktionsstuben zum Teufel fegt." (Maria Fialik: Eine Bombenreklame. Gespräch mit Jeannie Ebner, Schriftstellerin. In: M. F.: Der Charismatiker. Thomas Bernhard und seine Freunde von einst. Wien: Löcker 1992, S. 17-47, hier S. 35).

223 Vgl. dazu den Kommentar in TBW 22.1, $806 \mathrm{f}$.

224 Manfred Mittermayer: Lächerlich, charakterlos, furchterregend. Zu Thomas Bernhards Rhetorik der Bezichtigung. In: Rhetorik und Sprachkunst bei Thomas Bernhard. Hg. v. Joachim Knape u. Olaf Kramer. Würzburg: Königshausen \& Neumann 2011, S. 25-44.

225 Moritz: Lehrjahre (Anm. 44), S. $167 \mathrm{f}$. 
Kulturkreisen, ja zu einem zeitweise geradezu meinungsbildenden Kommentator entwickelt“. ${ }^{226}$ Trotzdem scheint Bernhard, was das literaturkritische Schreiben im engeren Sinn angeht, ab Mitte der 1950er Jahre wenig Interesse an der Rolle des „gefürchteten Kritiker[s]“ gehabt zu haben. ${ }^{227}$ Die Polemiken gegen das Salzburger Landestheater (1955) und gegen den Opportunismus seiner schreibenden Kolleginnen und Kollegen (Ein Wort an junge Schriftsteller, 1957; Junge Köpfe, 1959) folgen zwar grundsätzlich einer Rhetorik des radikalen Verrisses, wenn die sachliche Gegenrede vom polemischen Furor überlagert wird, aber sie widmen sich nicht einzelnen Autorinnen und Autoren, sondern allgemeinen Entwicklungen und Missständen. Der Bericht zu einer Lesung Bernt von Heiselers in den Salzburger Nachrichten vom 8. September 1955 war für lange Zeit der letzte im engeren Sinn literaturkritische Kommentar. In einem Brief vom 23. April 1956 ist zwar davon die Rede, Bernhard habe Gerhard Fritschs Roman Moos auf den Steinen für eine Münchner Zeitung besprochen - vermutlich für den Münchner Merkur, in dem er 1955 Weinhebers Gedichte rezensiert hatte -; ;28 ein Text Bernhards über den ersten Roman seines langjährigen Freundes ließ sich bislang jedoch nicht ermitteln.

In der Folge erhob es Bernhard zu seiner Maxime, „auf Aufforderungen der journalistischen gemeinen ebenso essaiistischen gemeineren Umwelt überhaupt nicht zu reagieren“, worunter wohl auch Rezensionsanfragen zu verstehen sind. Er müsse sich, so Bernhard am 28. Juli 1969 an Siegfried Unseld, den „Platz am Schreibtisch“ für die „eigenen Gedanken fortwährend frei [...] machen“ und das Schreiben „allein für mich“ reservieren: „Ist Ihnen nie aufgefallen, dass ich weder Artikel noch Essays etcetera veröffentliche, während es doch soviel Geld eintragen würde etcetera. ${ }^{\text {“229 }}$ Von Zeitschriftenredaktionen wie jener des Merkur dazu aufgefordert, neben lyrischen Texten, fiktionalen Prosaformen oder Skizzen aus Theaterstücken gerne auch ein „Wort zur Zeit“ oder „mutige Wahrheiten“ zum „Kulturbetrieb“ einzusenden, ${ }^{230}$ hat Bernhard meist ausweichend bis

226 Ebd., S. 163.

227 Klaus Gmeiner, Bernhards Studienkollege am Salzburger Mozarteum, hat zum Habitus Bernhards in diesen Jahren festgehalten: „Kollegen wurden kritisiert, oft fielen harte zynische Urteile. Auch die Damen und Herren Professores wurden ätzend analysiert. Ich will nicht verschweigen, dass auch ich oft Zielscheibe seines Sarkasmus war.“ „Selbstkritik“ jedoch sei Bernhard „fremd“ gewesen (Klaus Gmeiner: „Hic Buzli, Bazli, Bali - Ich bin der Zauberer Kemikali“. In: Was reden die Leute [Anm. 46], S. 32-35, hier S. 33 u. 35).

228 Vgl. Bernhard an Fritsch, 23. 4. 1956. In: Bernhard/Fritsch: Der Briefwechsel (Anm. 205), S. 8: „Die Besprechung von ,Moos' ist nach München abgegangen. Ich hoffe, daß sie bald kommt -“. Dazu Apostolo: Thomas Bernhards unveröffentlichtes Romanprojekt (Anm. 76), S. 52.

229 Bernhard an Unseld, 28. 7. 1969. In: Bernhard/Unseld: Der Briefwechsel (Anm. 36), S. 118 f.

230 Hans Paeschke an Thomas Bernhard, 25. 5. 1975. In: Deutsches Literaturarchiv Marbach, Handschriftensammlung, D: Merkur, HS.NZ80.0003. 
abwehrend reagiert. Ebenso dürfte er Einladungen, sich erneut als Literaturkritiker zu betätigen, wiederholt zurückgewiesen haben, wie Karl Ignaz Hennetmair, Bernhards langjähriger Vertrauter und Kompagnon, in seinem Tagebuch des Jahres 1972 festgehalten hat: Der Autor war dabei, so hat es in Hennetmairs launiger Schilderung jedenfalls den Anschein, nicht zuletzt in Sorge um seine literarische Reputation, die er durch das ,niedere' Handwerk der Literaturkritik potentiell beschädigt sah:

Um 10 Uhr 30 traf ich in Nathal bei Thomas mit der Post ein. Ein eingeschriebener Brief aus Frankfurt war auch dabei. Den öffnete Thomas sofort und las laut: Du kennst meine Sendung „Welt des Buches“... Ohne den Brief ganz zu Ende zu lesen, zerriß ihn Thomas und sagte: Der will schon wieder, daß ich ein Buch bespreche. [...] Jetzt habe ich dem [Janko von] Musulin schon einmal abgesagt, der müßte doch endlich begreifen, daß ich das nicht mache. Ich sagte: Wenn er deine Bücher kennt und begriffen hat, dann muß er doch wissen und begreifen, daß deine bisherige Arbeit eine Buchbesprechung ausschließt. Ja, sagte Thomas, aber der begreift nicht einmal, wie schlecht er selbst ist. Ich kann kein Buch besprechen, alles kann ich machen, nur das nicht. Eher könnte ich auf das Welser Volksfest als Hutschenschieber gehen, das würde mir weniger schaden, als wenn ich ein Buch bespräche. Und ganz leise und verschmitzt fügte Thomas hinzu: Stell dir vor, eintausend Schilling hat er mir dafür geboten. Und nach einer kurzen Pause sagte er ganz laut: Und um hunderttausend Schilling würde ich mir schaden, wenn ich das machen würde. ${ }^{231}$

Eine Woche später sei Janko von Musulin sogar persönlich nach Ohlsdorf gekommen, woraus Hennetmair in seinen erst lange nach Bernhards Tod publizierten Aufzeichnungen eine etwas träge, weil im Grunde pointenlose Szene entfaltet:

Musulin fragte Thomas, ob er das Buch schon gelesen habe. Thomas sagte nein, denn er werde es nicht besprechen. Wieso, fällt dir nichts ein? fragte Musulin. Thomas sagte, daß er so etwas überhaupt nicht mache, es tue ihm leid, aber er bespreche kein Buch. Er kann kein Buch besprechen, er könnte es höchstens vernichten, sagte ich zu Musulin. Ich dachte, „Ein Faß voll Leben“ wäre was für ihn, sagte Musulin. Thomas griff zum Fensterbrett und legte das Buch von Christy Brown ${ }^{[232]}$ vor Musulin hin. Da hast du es, sagte er zu Musulin. Das Buch war noch in der Zellophanhülle, und Musulin sagte, du hast es ja noch nicht einmal angeschaut. Weil ich es nicht bespreche,

231 Hennetmair: Ein Jahr mit Thomas Bernhard (Anm. 111), S. 420 (Eintrag v. 2. 10. 1972).

232 Down All the Days (1970), ein Roman des irischen Autors Christy Brown, erschien 1972 in deutscher Übersetzung unter dem Titel Ein Faß voll Leben im Scherz-Verlag. 
gehört es auch nicht mir, deswegen habe ich es nicht geöffnet, sagte Thomas. Das kannst du aber behalten, sagte Musulin. Jetzt gehört es mir, jetzt öffne ich es, sagte Thomas und entfernte die Hülle. ${ }^{233}$

Weder das von Musulin vorgeschlagene Buch des irischen Autors Brown noch irgendein anderes literarisches Werk sollte Bernhard in den folgenden Jahren rezensieren. Auf Siegfried Unselds Vorschlag, zu Ludwig Hohls Band Vom Erreichbaren und Unerreichbaren in der „Bibliothek Suhrkamp“ ein Nachwort zu verfassen, ging er Anfang 1972 zwar zunächst ein, ${ }^{234}$ zog seine Zusage aber kurz darauf ohne nähere Begründung zurück: „[I]ch werde nicht über Hohl schreiben.“235 Auf eine von den Bremer Nachrichten veranstaltete Umfrage, welche Veröffentlichungen der aktuellen Buchsaison er zur Lektüre empfehlen könne, bekundete er im Dezember 1976, „kein einziges seit 1975 erschienenes Buch gelesen“ zu haben und deshalb auch „kein solches Buch empfehlen“ zu können: „[A]ber wenn die Pensées des Pascal erst nach 1975 erschienen wären, was nicht der Fall ist, würde ich die Pensées empfehlen." (TBW 22.1, 615) Lediglich für einen 1987 bei Suhrkamp gedruckten Auswahlband mit Gedichten von Christine Lavant sollte Bernhard eine Ausnahme von seiner sonstigen Regel machen, keine Texte über andere Autorinnen und Autoren zu schreiben. Sein Nachwort zu dem in der „Bibliothek Suhrkamp“ veröffentlichten Lyrikband umfasste freilich nur eine „Notiz“ von zehn Zeilen - und es kann kaum als ernsthafter literaturkritischer Kommentar zu Lavants Werk gelten:

Dieses Buch dokumentiert die Chronologie der Christine Lavant, die bis zu ihrem Tod weder Ruhe noch Frieden gefunden hat und die in ihrer Existenz durch sich selbst gepeinigt und in ihrem christlich-katholischen Glauben zerstört und verraten war; es ist das elementare Zeugnis eines von allen guten Geistern mißbrauchten Menschen als große Dichtung, die in der Welt noch nicht so, wie sie es verdient, bekannt ist. Diese Auswahl folgt nur meinem Verstand, keinem andern. ${ }^{236}$

233 Hennetmair: Ein Jahr mit Thomas Bernhard (Anm. 111), S. 441 (Eintrag v. 9. 10. 1972).

234 Vgl. ebd., S. 74 (Eintrag v. 27. 1. 1972): „Dann erzählt mir Thomas noch von einem zweiten Brief, den er heute bekommen hat. Vom Verleger Unseld! Zwei Zeilen. Unseld ersucht mich, das ihm versprochene Nachwort für Ludwig Holl (oder ähnlicher Name) zu schreiben. Nur ganz kurz. Ich sage: Bist du wahnsinnig, das Nachwort bekommt er nicht! Du wirst doch nicht von deinen Grundsätzen abgehen, das hast du doch noch nie gemacht.“

235 Bernhard an Unseld, 3. 2. 1972. In: Bernhard/Unseld: Der Briefwechsel (Anm. 36), S. 258. Später nahm sich Handke des Schweizer Autors an und hielt u. a. 1980 die Rede zur Verleihung des Petrarca-Preises an Hohl. Vgl. Peter Handke: Ein Gruß an Ludwig Hohl. In: P. H.: Das Ende des Flanierens. Frankfurt a. M.: Suhrkamp 1980, S. 162-163.

236 Thomas Bernhard: Notiz. In: Christine Lavant: Gedichte. Hg. v. T. B. Frankfurt a. M.: Suhrkamp 1987, S. [91]. 
Während Peter Handke seine Reflexionen über die Bewertungs- und Beschreibungsverfahren der Literaturkritik stets mit eigenen Proben kritischen Schreibens flankiert hat, wurde es um den Kritiker Thomas Bernhard ab Mitte der 1950er Jahre also auffallend ruhig. Er polemisierte zwar in Briefen und öffentlichen Statements regelmäßig gegen andere Schriftstellerinnen und Schriftsteller - etwa gegen den „absoluten Kleinbürgerschmarren“ Martin Walsers ${ }^{237}$ oder die „grauenhaft[en]“ Theaterstücke Rolf Hochhuths (TBW 22.2, 175) -, aber er tat dies nicht in einer Buchbesprechung oder in einem ausführlicheren Kommentar zu einem konkreten Werk. Das Genre der Literaturkritik, das ganz wesentlich die argumentative Rückbindung des eigenen Urteils an bestimmte Kriterien erfordert, spielte in Bernhards Euvre keine Rolle mehr.

Peter Handke hat seinen Entschluss, „kein Kritiker“ (mehr) sein zu wollen, ${ }^{238}$ vor allem mit seiner Abscheu gegenüber dem „Urteilen und Meinen“ bzw. dem "Meinen und Urteilen“239 begründet und dies in Die Geschichte des Bleistifts (1982) mit einem von Georges Simenon entliehenen anaphorischen Mantra bekräftigt: „,Ich urteile nicht. Ich werde nicht urteilen. Ich werde nie wieder urteilen.' (Simenon)“. ${ }^{240}$ In Arbeiten über die Texte anderer Schriftstellerinnen und Schriftsteller hat Handke wiederholt betont, auf ein Urteil verzichten $\mathrm{zu}$ wollen, so etwa in seiner Laudatio auf John Berger im Zuge der Verleihung des Petrarca-Preises 1991: „Und selbstverständlich urteile ich damit nicht, sondern zeige zwei Möglichkeiten, von Menschendingen zu erzählen, feiere die eine nicht auf Kosten, sondern mit Hilfe der anderen, freue mich, Leser, gerade an solcher Zweistimmigkeit. “241 Bernhards Distanzierung vom Handwerk des Kritikers hingegen erklärt sich nicht aus solch skrupulösem Zögern vor dem Urteil, vielmehr resultiert es aus einer peniblen Imagekontrolle, die den Anschein vermeiden

237 Bernhard an Unseld, 3. 11. 1985. In: Bernhard/Unseld: Der Briefwechsel (Anm. 36), S. 739. Diesen Brief hat er jedoch nicht abgeschickt; in dem tatsächlich versendeten Schreiben vom 26.11.1985 ist aber immer noch von einem ,schauerliche[n] Walserbuch“ zu lesen (ebd., S. 738). Gemeint ist damit Martin Walsers Roman Brandung (1985). Sigurd Paul Scheichl: Die Omnipräsenz der Literaturkritik. In: Große Literaturkritiker. Hg. v. S. P. S. Innsbruck u. a.: StudienVerlag 2010, S. 11-30, hier S. 13, zufolge hat man es hier zwar „durchaus mit einem literaturkritischen Urteil zu tun, das die Abwertung mit einem rudimentären sozialen Argument begründet“: „Gerade bei solcher ,Literaturkritik' müssen wir freilich auch die Situation bedenken, in der sie artikuliert wird: Walser war beim Publikum wie im Suhrkamp Verlag ein Konkurrent Bernhards, was zur Schärfe der Äußerung nicht weniger beigetragen haben mag als die ganz unterschiedlichen ästhetischen Positionen."

238 Peter Handke: Briefe über Theater (1). In: Theater heute (1967), H. 2, S. 37.

239 Peter Handke: Gestern unterwegs. Aufzeichnungen November 1987-Juli 1990. Salzburg, Wien: Jung und Jung 2005, S. 435 u. 510.

240 Peter Handke: Die Geschichte des Bleistifts. Salzburg, Wien: Residenz 1982, S. 123.

241 Peter Handke: Wir-Erzähler und Ich-Erzähler: Zu John Berger. [1991] In: P. H.: Langsam im Schatten. Gesammelte Verzettelungen. 1980-1992. Frankfurt a. M.: Suhrkamp 1992, S. 156-166, hier S. 163. 
will, er habe etwas ,für Geld' bzw. im Auftrag einer Redaktion geschrieben: Das Rezensieren von Büchern sei für die Kritiker, so Bernhard in den von Kurt Hofmann aufgezeichneten Gesprächen, ,ein ganz primitives, lebenserhaltendes, familienerhaltendes G'schäft“ “242 Nicht von ungefähr bediente er sich für seine publizistischen Interventionen mit Vorliebe der Gattung des Leserbriefs bzw. des offenen Briefs, weil hier die Aktion ganz vom Schreibenden selbst ausgeht. ${ }^{243}$ In öffentlichen Äußerungen zur Gegenwartsliteratur beschränkte Bernhard sich meist auf abschätzige Kommentare und pauschale Diffamierungen.

Gleichwohl sind Spuren eines (literatur)kritischen Gestus in zahlreichen Werken des Autors zu entdecken: Schon die Protagonisten früher Prosatexte - etwa in Das Verbrechen eines Innsbrucker Kaufmannssohns (1965) - rühmen sich ihres „Scharfsinn[s]“, der „alles“ einer „in fast allen Fällen tödlichen Kritik“ unterwirft (TBW 14, 69), laborieren aber auch an dem Umstand, selbst „dauernd kritischer Beobachtung ausgeliefert" zu sein und zugleich "dauernd kritisch beobachtend“ ihr Umfeld in den Blick zu nehmen (Zwei Erzieher, 1966; TBW 14, 12). Im Anfang der 1980er Jahre verfassten, aber erst 1986 publizierten Opus magnum Auslöschung. Ein Zerfall lässt Bernhard mit Franz-Josef Murau einen literaturaffinen Privatgelehrten auftreten, der seinem einzigen Schüler Gambetti auf langen Spaziergängen durch Rom die deutschsprachige Literatur und Philosophie näherbringt: Gleich zu Beginn erinnert er sich daran, Gambetti „fünf Bücher" ans Herz gelegt zu haben, um diese ,auf das aufmerksamste und mit der in seinem Fall gebotenen Langsamkeit zu studieren": Neben Romanen von Jean Paul (Siebenkäs), Franz Kafka (Der Prozeß) und Hermann Broch (Esch oder Die Anarchie) trägt er ihm Robert Musils Novelle Die Portugiesin zur Lektüre auf - und „Amras von Thomas Bernhard“ (TBW 9, 7). Als fünftes Buch von Muraus Leseliste war im Typoskript der Auslöschung anfangs noch Adalbert Stifters Witiko angeführt; erst kurz vor der Publikation tilgte Bernhard den Buchtitel mit schwarzem Filzstiff ${ }^{244}$ und ersetzte ihn durch seine eigene, 1964 erschienene Erzählung Amras, die er bei mehreren Gelegenheiten als sein literarisch gelungenstes Werk bezeichnet hat. ${ }^{245}$

242 Hofmann: Aus Gesprächen mit Thomas Bernhard (Anm. 42), S. 49.

243 Vgl. dazu Clemens Götze: „Mit allen Anzeichen der Empörung“. Thomas Bernhard als Leserbriefschreiber. In: Text + Kritik (42016), H. 43, S. 52-65; Gschwandtner: Journalistisches, Reden, Interviews (Anm. 116), S. 275-277.

244 Vgl. das Faksimile der Typoskript-Seite in TBW 9, 549; vgl. zur Korrektur der Textstelle auch den Kommentar in TBW 9, 538 u. 544, sowie Markus Kreuzwieser: Epochendialoge. Noch einmal: Adalbert Stifter und die Gegenwartsliteratur unter besonderer Berücksichtigung der Stifter-Lektüre Thomas Bernhards. In: ide. Informationen zur Deutschdidaktik 29 (2005), H. 1, S. 82-95, hier S. 93.

245 Vgl. TBW 22.2, 121 f.: „Am liebsten war mir immer Amras. [...] Da ist mir was gelungen, ohne das ganz genau zu erfassen, dieser Schwebezustand zwischen Naivität, Pubertät und doch ganz hohem Geistesniveau, dieses ganzen Zustands, nicht? Das ist wie eine Prosa-Seilbahn, würde ich 
Franz-Josef Murau publiziert, wie er betont, regelmäßig „in den verschiedensten Zeitungen und Zeitschriften nicht nur in Frankfurt und Hamburg, auch in Mailand und Rom“, wobei sich der Gelehrte, so legen es die verstreuten Hinweise nahe, vor allem als Musikkritiker betätigt, hat er doch zuletzt einen „kurze[n] Aufsatz über Leoš Janáček“ im Corriere della Sera veröffentlicht (TBW 9, 16 f.). Später erinnert er sich daran, einst in Brüssel „etwas über Pascal“ und „über Marias Gedichte“, d. h. über die Lyrik Ingeborg Bachmanns, geschrieben zu haben (TBW 9, 404): „Auch über den von mir so geliebten Bohuslav Martinů habe ich einen kleinen Aufsatz dort oben im vierten Stock geschrieben, den Aufsatz aber gleich wieder weggeworfen." (TBW 9, $404 \mathrm{f}$.)

Den Gestus des abwägenden Kritikers veranschaulicht Murau indes schon auf den ersten Seiten des Buches, wenn er im Gespräch mit Gambetti einen Satz aus Schopenhauers Die Welt als Wille und Vorstellung zunächst im Original und dann in italienischer Übersetzung rezitiert, um seinem Schüler zu verdeutlichen, „wie schwer sich die Waagschale auf der mit meiner linken Hand vorgetäuschten deutschen Waagschale senkte, während sie sozusagen auf der italienischen mit meiner rechten Hand in die Höhe schnellte" (TBW 9, $8 \mathrm{f}$.); die Praxis des Abwägens und kritischen Prüfens im Wechsel der beiden Sprachen scheint für ihn zuallererst ein „Spiel“ zu sein:

Zu meinem und zu Gambettis Vergnügen sagte ich mehrere Schopenhauersche Sätze zuerst in Deutsch, dann in meiner eigenen italienischen Übersetzung und legte sie sozusagen für alle Welt, aber vor allem für Gambetti, deutlich sichtbar auf die Waagschale meiner Hände und entwickelte daraus mit der Zeit ein von mir auf die Spitze getriebenes Spiel, das schließlich mit Hegelsätzen und mit einem Kantaphorismus endete. Leider, sagte ich zu Gambetti, sind die schweren Wörter nicht immer die gewichtigsten, wie die schweren Sätze nicht immer die gewichtigsten sind. Mein Spiel hatte mich bald erschöpft. (TBW 9, 9)

Wie andere Figuren in Bernhards Spätwerk ist Murau nicht darauf angewiesen, mit Zeilenhonoraren für publizistische Arbeiten seinen Lebensunterhalt zu finanzieren, weil er durch das Vermögen seiner Familie ökonomisch abgesichert ist. Als wohlhabender Privatgelehrter hat er, was die Gegenstände seiner Beschäftigung angeht, freie Hand. Das unterscheidet ihn ganz wesentlich vom einstigen Kulturjournalisten Thomas Bernhard im Salzburg der 1950er Jahre, der meist zu den „eher zweitrangigen“ Veranstaltungen geschickt wurde ${ }^{246}$ - und für den die Tätigkeit als Kritiker seinen täglichen Broterwerb bedeutete.

sagen. Und dieses Seil sehe ich heute nicht mehr und sähe es sehr gern. Amras ist also schlafwandlerisch richtig, glaube ich."

246 Klug: Thomas Bernhards Arbeiten (Anm. 28), S. 144. 
Ebenso unabhängig von allen ökonomischen Rücksichten ist der pensionierte Musikphilosoph und Musikkritiker Reger in Alte Meister (1985). Gleich eingangs wird er von seinem Adlatus Atzbacher als „Musikwissenschaftler im eigentlichsten Sinne des Wortes“ vorgestellt; „mit allen diesen musikfeuilletonistischen Schwätzern, wie sie hier tagtäglich in den Tageszeitungen ihren Geschwätzschmutz ausbreiten“, sei er, so Atzbacher, „nicht zu vergleichen“: „Seit über dreißig Jahren schreibt Reger seine Kritiken für die Times, diese kleinen musikphilosophischen Aufsätze, die eines Tages sicher in einem Buch gesammelt erscheinen werden. " (TBW 8, 14) (247 $^{24}$ seiner Heimat Wien sei der mittlerweile 82-Jährige beinahe unbekannt und genieße nicht die ihm gebührende Wertschätzung: „Davon, daß Reger für die Times seine Musikkritiken schreibt, weiß in Österreich niemand, höchstens ein paar Leute wissen davon“; während man hierzulande Reger kaum wahrnehme, wisse man „in London und in England und selbst in den Vereinigten Staaten“, „um was für eine Kapazität es sich bei Reger handelt" (TBW 8, 14 f.). ${ }^{248}$

Von der außerordentlichen „Qualität“ seiner „Kritiken für die Times“, für die er bereits „seit vierunddreißig Jahren“ schreibe (TBW 8, 19), ist Reger selbst überzeugt, von der gängigen Praxis des Schreibens über Kunst im Feuilleton und in den Wissenschaften aber ganz und gar nicht: Die „Kunsthistoriker“ denunziert er als „Kunstvernichter“, die „so lange über die Kunst“ geschwätzt haben“: „Wenn wir einem Kunsthistoriker zuhören, wird uns übel, sagte er, indem wir einem Kunsthistoriker zuhören, sehen wir, wie die Kunst, die er beschwätzt, vernichtet wird, mit dem Geschwätz des Kunsthistorikers schrumpft die Kunst und wird vernichtet." (TBW 8, 23 f.) Er selbst charakterisiert sich in der Folge als universell gebildeter Kritiker, der sein Urteilsvermögen besonders im Vergleich der einzelnen Kunstsparten (Musik, bildende Kunst, Literatur) geschult, dem sein ,Amt' aber zugleich die Freude am Erlebnis der Kunst nach und nach vergällt habe:

Wehe, Sie lesen eindringlicher, Sie ruinieren sich alles, was Sie lesen. Es ist ganz gleich, was Sie lesen, es wird am Ende lächerlich und ist am Ende nichts wert. Hüten Sie

247 Atzbachers Bemerkung verweist nicht zuletzt auf die Dichotomie von ephemerem, schnell der Vergessenheit anheimfallendem Tagesjournalismus auf der einen und beständiger Buchpublikation auf der anderen Seite.

248 Die folgende Schilderung von Regers Position im gesellschaftlichen Abseits erinnert nur zu deutlich an Bernhards eigene Stilisierung zum Außenseiter des Literaturbetriebs: „Nur Leute wie Reger, die man an einer einzigen Hand abzählen kann in diesem fürchterlichen Land, überstehen diesen Zustand der Herabsetzung und des Hasses, der Unterdrückung und der Ignoration, der allgemeinen geistesfeindlichen Gemeinheit, der hier in Österreich überall herrscht, nur Leute wie Reger, die einen großartigen Charakter haben und tatsächlich einen scharfen unbestechlichen Verstand." (TBW 8, 15 f.) 
sich vor dem Eindringen in Kunstwerke, sagte er, Sie verderben sich alles und jedes, selbst das Geliebteste. Schauen Sie ein Bild nicht lang an, lesen Sie ein Buch nicht zu eindringlich, hören Sie ein Musikstück nicht mit der größten Intensität, Sie ruinieren sich alles und damit das Schönste und das Natürlichste auf der Welt. (TBW 8, 44)

Der Gestus der radikalen Kritik, dem sich Reger im Feld der Kunstbetrachtung verschrieben hat, korrespondiert mit einem unbarmherzigen und kalten Blick auf alle Phänomene der Welt, was ihn, wie er nun gegen Ende seines Lebens erkennen muss, ins „Unglück“ gestürzt hat: „Zerlegungs- und Zersetzungsmechanismus, sagte Reger, das ist es, das ich mir angewöhnt habe schon in frühen Jahren, ohne zu wissen, daß das mein Unglück ist." (TBW 8, 141) ${ }^{249}$ Von seinen buchlangen Invektiven gegen Adalbert Stifter, Martin Heidegger, Anton Bruckner und jene Alten Meister, die in den Räumen des Wiener Kunsthistorischen Museums ausgestellt sind, bleibt schließlich eine recht dürftige Essenz, die den Leerlauf seiner polemischen Attacken offenbart: „Die Maler malen Mist, die Komponisten komponieren Mist, die Schriftsteller schreiben Mist, sagte er." (TBW 8, 131) Seine „Kunststückchen für die Times“ (TBW 8, 171) und seine mündlich vorgebrachten Invektiven gegen bildende Kunst, Philosophie, Musik und Literatur rechnen längst nicht mehr mit der Vermittlung an ein Publikum - seine Zuhörer Irrsigler und Atzbacher sind im Grunde bloß Staffage -; vielmehr verleihen sie einzig und allein seiner allumfassenden Misanthropie Ausdruck, die sich seit dem tragischen Tod seiner Frau noch verstärkt hat.

Adalbert Stifter als „schlechter Schriftsteller“, der einen „fürchterlichen Stil“ geschrieben habe, „der noch dazu grammatikalisch unter jeder Kritik“ sei; ein „auf den längsten Strecken seiner Prosa [...] unerträglicher Schwätzer“, der sich eines „stümperhaften und, was das Verwerflichste ist, schlampigen Stil[s] “ bedient habe; „der langweiligste und verlogenste Autor, den es in der deutschen Literatur gibt“; seine Literatur „vollgestopft mit schiefen Bildern und falschen, verqueren Gedanken“ (TBW 8, 46 f.). - Was die „heutigen österreichischen Schriftsteller[ ]“ publizierten, weise sie nicht nur als „schamlos und ruhmsüchtig“ aus, sondern sei ganz grundsätzlich „Mist“ und „widerwärtig-sentimentale Epigonenliteratur“; ihre Bücher gehörten „nicht in die Buchhandlungen, sondern gleich auf den Misthaufen“ (TBW 8, 136 f.). - Was Bernhard seinen Protagonisten Reger in Alte Meister vorbringen lässt, kann nicht im engeren Sinne als Literaturkritik gelten. ${ }^{250}$

249 Vgl. Harald Gschwandtner: Thomas Bernhards ,Radikalität'. Versuch einer kultursoziologischen Lesart. In: Das Radikale. Gesellschaftspolitische und formal-ästhetische Aspekte in der Gegenwartsliteratur. Hg. v. Stephanie Willeke, Ludmila Peters u. Carsten Roth. Berlin u. a.: LIT 2017, S. 235-261, bes. S. 235-237.

250 Marcus Hahn: Geschichte und Epigonen. ,19. Jahrhundert' / ,Postmoderne', Stifter / Bernhard. Freiburg i. Br.: Rombach 2003, S. 426, zufolge präsentieren Bernhards Figuren einen zusehends 
Die Polemiken, die seine Figuren formulieren, sind arm an ästhetischen Kategorien, sie schielen nur zu deutlich auf Aufmerksamkeit durch Provokation, und sie lassen kaum auf eine differenzierte Auseinandersetzung mit den jeweiligen Büchern und Schriftstellern schließen. Sie weisen zudem ähnliche Charakteristika auf wie die Schmähreden des Autors Bernhard. ${ }^{251}$ Nicht von ungefähr hat man Reger als dessen „Sprachrohr“252 bezeichnet, eine Deutung, der Bernhard durch die Erwähnung seines Protagonisten in einem Leserbrief an die Wiener Presse - „würde auch der Österreichagitator und Moralist Reger in meinem Buch Alte Meister sagen“ (TBW 22.1, 682) - bewusst zugearbeitet hat. Hier wie dort, im Bereich der Fiktion wie in jenem des öffentlichen Statements, wird - mit Franz Schuh gesprochen - eine pauschale „Politik durch Urteilen ${ }^{\text {“253 }}$ betrieben. So vehement und forciert Bernhard im Verbund mit den von ihm in Szene gesetzten literarischen Figuren auch auftritt, können diese Invektiven doch kaum der Literaturkritik zugerechnet werden; für ihre apodiktischen Urteile ist zuallererst eine „Gebärde der Abwehr“, ${ }^{254}$ nicht die eingehende und abwägende Prüfung des ins Visier genommenen Objekts kennzeichnend.

„seriellen Verdammungsdiskurs, der ab einem bestimmten Punkt keine logische Konsistenz mehr wahren kann“.

251 Wenn Bernhard etwa in einem 1986 mit Werner Wögerbauer geführten Interview Thomas Mann als „kleinbürgerliche[n]“, „scheußliche[n]“ und „ungeistige[n]“ Schriftsteller bezeichnet (TBW 22.2, 289), arbeitet er sich nur am Image des attackierten Autors ab, leistet aber keinerlei analytische Arbeit an literarischen Texten.

252 Wolfram Bayer: Das Gedruckte und das Tatsächliche. Realität und Fiktion in Thomas Bernhards Leserbriefen. In: Thomas Bernhard. Beiträge zur Fiktion der Postmoderne. Londoner Symposion. Hg. v. Wendelin Schmidt-Dengler, Adrian Stevens u. Fred Wagner. Frankfurt a. M. u. a.: Lang 1997, S. 1-23, hier S. 9.

253 Franz Schuh: Thomas Bernhard, ein alter Meister. In: Alte Meister, Schufte, Außenseiter. Reflexionen über österreichische Literatur nach 1945. Hg. v. Manfred Müller. Wien: Sonderzahl 2005, S. 171-190, hier S. 179.

254 Ebd., S. 18 o. 


\title{
VII REZENSIONEN, DIE KEINE SIND: KRITIK UND SELBSTKRITIK BEI THOMAS BERNHARD
}

\author{
Vorgeschichten einer Polemik: Bernhard vs. Bruno Kreisky
}

So ausführlich sich Thomas Bernhard in der ersten Hälfte der 1950er Jahre als Literatur-, Film- und Theaterkritiker für verschiedene Zeitungen betätigt hatte, so abrupt kam seine Arbeit als Rezensent in der Folge zum Erliegen. Während der Eintritt Peter Handkes ins literarische Feld und sein Aufstieg zu einem der prägenden Autoren des Suhrkamp Verlags mit dem beständigen Schreiben über Bücher anderer Schriftstellerinnen und Schriftsteller einherging, ist der Fall bei Bernhard ganz anders gelagert. Der gefeierte Prosa- und Theaterautor der 196oer und 1970er Jahre brachte sich, ganz im Gegensatz zu Handke, nicht mehr als Rezensent in zeitgenössische Literaturdebatten ein. Erst Anfang der 1980er Jahre trat er erneut mit einer Buchkritik an die Öffentlichkeit - und löste mit ihr, weil er darin den österreichischen Bundeskanzler mit polemischer Verve attackierte, sogleich einen veritablen Skandal aus. Bei dem von Bernhard besprochenen Buch handelte es sich um einen Anfang 1981 anlässlich des 70. Geburtstags von Bruno Kreisky zusammengestellten Band mit Fotografien von Konrad R. Müller und Texten der beiden Schriftsteller Gerhard Roth und Peter Turrini. ${ }^{1}$ Die Rezension wurde am 26. Januar 1981 in der Wiener Wochenzeitschrift profil unter dem Titel Der pensionierte Salonsozialist als ,Gastkommentar' veröffentlicht. Eine Woche darauf teilte Bernhard seinem Verleger Siegfried Unseld mit, er habe „[n]ach dreissig Jahren [...] wieder einmal eine Buchbesprechung veröffentlicht, die bei mir bestellt worden ist[,] und prompt eine Menge aufgescheucht. “2 Auch wenn Bernhard die Zeitspanne zwischen seiner letzten Buchkritik und dem Verriss des Kreisky-Bandes etwas übertreibt - seine Besprechung der Weinheber-Werkausgabe war im Februar 1955, also vor 26 Jahren, im Münchner Merkur erschienen ${ }^{3}$-, war ihm doch bewusst, dass er sich mit Der pensionierte Salonsozialist auf ein publizistisches Terrain begab, das er eigentlich vor langer Zeit hinter sich gelassen hatte.

1 Vgl. Bruno Kreisky. Fotografiert v. Konrad R. Müller. Texte v. Gerhard Roth u. Peter Turrini. Berlin, Wien: Nicolai/Forum 1981.

2 Thomas Bernhard an Siegfried Unseld, 3. 2. 1981. In: T. B./S. U.: Der Briefwechsel. Hg. v. Raimund Fellinger, Martin Huber u. Julia Ketterer. Frankfurt a. M.: Suhrkamp 2009, S. 619.

3 In den folgenden Monaten veröffentlichte Bernhard zwar noch einen Bericht über eine Lesung Bernt von Heiselers in den Salzburger Nachrichten (8. 9.1955), die vielzitierte Polemik Salzburg wartet auf ein Theaterstück in der Wiener Furche (3.12.1955) sowie einzelne Artikel über Kunstausstellungen, aber keine formale „Buchbesprechung“ mehr; vgl. dazu den Kommentar in TBW 22.1, 785-788. 
So steht der,Gastkommentar' im profil denn auch weniger in der Tradition seiner frühen journalistischen Tätigkeit für Zeitungen in Salzburg, Linz und Wien, sondern ist, rein thematisch, zuallererst dem Bereich politischer Provokation und der Auseinandersetzung Bernhards mit der österreichischen Sozialdemokratie zuzurechnen. Um den werkgeschichtlichen Status von Der pensionierte Salonsozialist zu bestimmen, soll deshalb zunächst die Vorgeschichte des Textes rekapituliert werden, um anschließend die spezifisch literaturkritische Ambition des Artikels zu erkunden.

Der Konflikt Bernhards mit dem sozialistischen Bundeskanzler Bruno Kreisky, dem längstdienenden Regierungschef der Zweiten Republik, reichte zum Zeitpunkt des polemischen,Gastkommentars' bereits einige Jahre zurück: Im Mai 1976 hatte er einen offenen Brief in der Wiener Presse an Kreisky gerichtet, um auf die skandalöse Behandlung, die ihm vonseiten des österreichischen Botschafters in Lissabon zuteilgeworden war, aufmerksam zu machen. ${ }^{4}$ Botschafter Heinz Weinberger hatte sich Bernhards Bericht zufolge despektierlich über Person und Werk des Autors geäußert und ihn bei mehreren Gelegenheiten als einen "destruktiven, schrecklichen Kerl“ bezeichnet (TBW 22.1, 648). ${ }^{5}$ „In aller Bescheidenheit und naturgemäß auch Betroffenheit“ wandte er sich deshalb mit der Frage an den Bundeskanzler, ob es denn „die Aufgabe eines österreichischen Botschafters im Ausland“ sein könne, einen angesehenen, vom deutschen Goethe-Institut eingeladenen Autor „im Ausland lächerlich“ zu machen (TBW 22.1, 649). Bernhard forderte den Regierungschef coram publico dazu auf, sich seines Protestes anzunehmen und der Verunglimpfung seiner Person Einhalt zu gebieten. Eine (öffentliche) Reaktion Kreiskys ist nicht belegt; womöglich bedeutete gerade ihr Ausbleiben für Bernhard eine Kränkung, interpretierte er sie als mangelnde Wertschätzung, die er dem Politiker in den folgenden Jahren nicht mit gleicher Münze, sondern mit dem Furor des Nachtragenden - sowohl in Statements in eigenem Namen als auch in fiktionalen Texten - zurückzahlen sollte.

Bernhards erste Attacke ließ nicht lange auf sich warten: Sein Kommentar zum Nationalfeiertag des Jahres 1977, ist, ohne den Namen des Politikers explizit zu nennen, unter anderem auf Bruno Kreisky, insbesondere aber auf die seit

4 Vgl. dazu den Kommentar in TBW 22.1, 852-855; Manfred Mittermayer: Thomas Bernhard. Eine Biografie. Salzburg, Wien: Residenz 2015, S. 289 f.; Sehr geschätzte Redaktion. Leserbriefe von und über Thomas Bernhard. Hg. v. Jens Dittmar. Wien: Edition S 1991, S. 71-80. Vgl. die Bemerkungen in Kurt Hofmann: Aus Gesprächen mit Thomas Bernhard. Wien: Löcker 1988, S. 100.

5 Weinberger hat dieser Darstellung öffentlich widersprochen; vgl. den Leserbrief an die Presse vom 11. 6.1976: „Nachdrücklich möchte ich feststellen, daß ich den Ausdruck, destruktiver, schrecklicher Kerl' nie gebraucht und Herrn Bernhard auch nicht, wie er mir unterstellt, öffentlich lächerlich gemacht habe." (Sehr geschätzte Redaktion [Anm. 4], S. 79) 
Herbst 1971 bestehende SPÖ-Alleinregierung gemünzt. ${ }^{6}$ Der Salzburger Residenz Verlag hatte aufgrund von rechtlichen Bedenken davon Abstand genommen, Bernhards Anmerkungen über „das Land meiner Eltern“, „das geliebte, genauso gehaßte Österreich“ (TBW 22.1, 617), in die von Jochen Jung herausgegebene Anthologie Glückliches Österreich. Literarische Besichtigungen eines Vaterlands (1978) aufzunehmen. Der Autor publizierte sie deshalb am 17. Februar 1978 unter dem Titel Die Kleinbürger auf der Heuchelleiter in der Hamburger ZEIT, dem neben der Frankfurter Allgemeinen Zeitung wichtigsten Organ für Bernhards Polemiken außerhalb seines Heimatlandes: „Die brutalen, skrupellosen Kleinbürger", heißt es dort,

die in den letzten Jahrzehnten mit Leichtigkeit auf der Heuchelleiter in diesem Land in die Höhe und bis in das Parlament und auf den Ballhausplatz [i. e. der Sitz des Bundeskanzlers Bruno Kreisky (1970-1983)] und in die Hofburg [i. e. der Sitz des Bundespräsidenten Rudolf Kirchschläger (1974-1986)] gekommen sind, haben es mit dem von Natur aus gleichmütigen und in sich gleichgültigen Volke leicht. (TBW 22.1, 618) ${ }^{7}$

Bernhards Polemik wendet sich zunächst gegen die „stickige Atmosphäre der Geistfeindlichkeit und der Gefühlsroheit“ in Österreich, gegen „Stumpfsinn und Niedertracht“ (TBW 22.1, 617). Sie bedient in der Folge aber auf bedenkliche Weise Ressentiments gegenüber der parlamentarischen Demokratie, greift neben den damals an der Spitze des politischen Systems stehenden Personen auch die demokratischen Institutionen per se an. Der österreichische Nationalrat, so heißt es in Bernhards Wutrede - die sich, wie andere öffentliche Statements des Autors, durch einen „offensive[n] Verzicht auf Differenzierung“8 auszeichnet - , sei

6 Mit der Nationalratswahl vom 10. Oktober 1971 hatten die Sozialisten unter Kreisky erstmals die absolute Mehrheit an Sitzen im Parlament erreicht, beim vier Jahre später abgehaltenen Urnengang wurde diese mit leichten Zugewinnen bestätigt.

7 Der Text wurde in Auszügen in einem Sonderheft der Zeitschrift Theater heute abgedruckt. Siehe Peter von Becker: Bei Bernhard. Eine Geschichte in 15 Episoden. In: Theater 1978. Sonderheft der Zeitschrift Theater heute. Bilanz und Chronik der Saison 77/78 (1978), S. 80-87, hier S. 84; dort mit dem Hinweis versehen: „Sein Beitrag für eine Österreich-Anthologie wurde vom Salzburger Residenz Verlag abgelehnt.“ (Ebd.)

8 Andreas Dorschel: Lakonik und Suada in der Prosa Thomas Bernhards. In: Thomas Bernhard Jahrbuch 2007/2008, S. 215-233, hier S. 226. Einem „konkreten Gespräch“ über politische Themen, etwa über die Person Kreiskys, habe sich Bernhard, so Viktor Hufnagl, stets verwehrt (Viktor Hufnagl: Sie hat sich total in den Thomas verknallt. In: Was reden die Leute. 58 Begegnungen mit Thomas Bernhard. Aufgezeichnet v. Sepp Dreissinger. Salzburg, Wien: Müry Salzmann 2011, S. 100-105, hier S. 103). 
ein luxuriöser und kostspieliger, lebensgefährlicher Wurstelprater, und die Regierung ist eine ebenso teure Dummköpfelotterie. Wenn der Vorhang des Staates aufgeht, sehen wir an jedem österreichischen Tag (und also auch am Nationalfeiertag) ein Lustspiel für Marionetten. (TBW 22.1, 618)

Wenn der Autor hier die politischen Akteure als „Marionetten“ und ihren Wirkungsbereich als Theaterszenerie beschreibt (und damit nicht zuletzt den Unernst des Geschehens betont), greift er zum einen den seit der Antike tradierten und in der Literatur vielfach ausgestalteten Topos von der Welt als Bühne auf; in Shakespeares Versen aus der 1603 uraufgeführten Komödie As You Like It, "All the world's a stage, / And all the men and women merely players“, hat er wohl den berühmtesten Ausdruck gefunden. ${ }^{9}$ Für Bernhards Poetik ist die Ineinssetzung von politisch-gesellschaftlicher Wirklichkeit und theatraler Inszenierung von zentraler Bedeutung; immer wieder hat er damit operiert, Vorgänge des öffentlichen Lebens, insbesondere der institutionellen Repräsentation, als theatralische Handlungen zu beschreiben: „Die Welt ist“, heißt es in Bernhards zweitem Roman Verstörung (1967), „tatsächlich eine Probebühne, auf der ununterbrochen geprobt wird“; die „Menschen“ seien, so der Fürst Saurau, „nichts als Schauspieler, die uns etwas vormachen“ (TBW 2, 146). „Mein erster Theaterbesuch“, erinnert sich das autobiographische Ich im Band Ein Kind (1982) an die Zeit in Seekirchen Mitte der 193oer Jahre, „war mein erster Kirchenbesuch" (TBW 10, 456 f.) - auch in Bernhards Auseinandersetzung mit Bruno Kreisky taucht der Topos einer theatralisch organisierten Wirklichkeit noch weitere Male auf. ${ }^{10}$

Zum anderen aber spielt die pauschale Kritik an der politischen Praxis, an ihren Institutionen und Akteuren aber auch anti-demokratischen Vorurteilen und Einstellungen in die Hände - ein Umstand, der Bernhard den Vorwurf einer totalitären Schreib- und Geisteshaltung eingebracht hat. ${ }^{11}$ Sind es in früheren

9 William Shakespeare: As You Like It / Wie es euch gefällt. Englisch / Deutsch. Übers. u. hg. v. Herbert Geisen u. Dieter Wessels. Stuttgart: Reclam 1981, S. 74.

10 Vgl. dazu umfassend Tim Reuter: „Vaterland, Unsinn“. Thomas Bernhards (ent-)nationalisierte Genieästhetik zwischen Österreich-Gebundenheit und Österreich-Entbundenheit. Würzburg: Königshausen \& Neumann 2013, S. 174-180. Vgl. dazu, um nur ein weiteres Beispiel unter vielen zu nennen, die Schilderung der Rückkehr Franz-Josef Muraus nach Wolfsegg in Auslöschung (1986): „Das Theatralische des Vorgangs an der Orangerie war mir auf einmal deutlich geworden, daß ich einem Theater zuschaue, in welchem Gärtner mit Kränzen und Buketten agieren. Die Hauptfigur in diesem Theater aber fehlt, habe ich gleichzeitig gedacht, und ebenso, das eigentliche Schauspiel kann erst anfangen, wenn ich auftrete, sozusagen der Hauptdarsteller, welcher aus Rom herbeigeeilt kommt für dieses Trauerspiel." (TBW 9, 250)

11 Schon Heinz F. Schafroth kritisierte 1977 Bernhards seiner Meinung nach sowohl ästhetisch als auch ideologisch bedenkliche „totalitäre Sprache“ (Heinz F. Schafroth: Die unmögliche und 
Texten vor allem Bernhard'sche Protagonisten, die sich abschätzig über Demokratie und Parlament äußern - etwa der Maler Strauch in Frost (1963), der die „Demokratie“ als den „größte[n] Schwindel“ bezeichnet und seiner anarchistisch grundierten „Abscheu gegen den Staat“ Ausdruck verleiht (TBW 1, 282 u. 324) -, , bedient sich hier der Autor selbst dieses bedenklichen Repertoires.

Im Juni 1979 attackierte Bernhard in einem Leserbrief an die ZEIT den langjährigen Bundeskanzler als einen „Salzkammergut- und Walzertito“, der sich zwar mit der Lektüre Robert Musils brüste - Kreisky hatte wiederholt den Mann ohne Eigenschaften als sein ,Lieblingsbuch ${ }^{\text {genannt }}{ }^{13}-$, im Grunde aber nur noch die „Rolle des alternden, selbstgefälligen Staatsclowns“ spiele:

die skeptische Hoffnung. Thomas Bernhard und Wolfgang Koeppen: Nachdenklicher Rückgriff auf die Jugend. In: Die Weltwoche, 19. 1. 1977). - Im Zuge der Diskussionen um Bernhards Kreisky-Rezension im profil konstatierte der ORF-Intendant Wolf In der Maur, an dem „Jargon“, den Bernhard verwende, seien „sowohl die Weimarer Republik als auch die erste österreichische Republik zugrunde gegangen“, ja er bezeichnete in einem Statement in den Salzburger Nachrichten Bernhards Polemik gegen Kreisky als „epigonale[n] Stürmer-Artikel“, setzte sie also explizit mit der Rhetorik der nationalsozialistischen Hetzpresse in eins (zit. nach: Sehr geschätzte Redaktion [Anm. 4], S. 124 u. 130). - Der deutsche Autor Herbert Rosendorfer hat Bernhard gar einen „Kryptofaschist[en]“ genannt (zit. nach der O-Ton-Sammlung in: Thomas Bernhard - eine Einschärfung. Hg. v. Joachim Hoell, Alexander Honold u. Kai Luehrs-Kaiser. Berlin: Vorwerk $8{ }^{2} 1999$, S. 31).

12 Vgl. etwa Sauraus umfassende Ablehnung staatlicher Organisation in Verstörung (1967): „Meine Lieblingswortzusammenstellung in letzter Zeit, lieber Doktor, ist: Der Staat ist morsch. Alles ist nichts, sage ich zu Huber: die Roten sind nichts und die Schwarzen sind nichts, die Monarchie ist natürlich nichts und die Republik ist natürlich nichts." (TBW 2, 103 f.) - Siehe dazu auch die Äußerung des Musikphilosophen Reger in Alte Meister (1985): „Und überall dieses ekelerregende Demokratiegefasel! [...] An der Spitze unseres Staates stehen Politiker als Staatenmörder, sagte er, das ist die Wahrheit. Jeder Kanzler und jeder Minister ist ein Staatenmörder und damit auch ein Landesmörder, sagte Reger, und geht der Eine, kommt der Andere, sagte Reger, geht der eine Mörder als Kanzler, kommt schon der andere Kanzler als Mörder, geht der eine Minister als Staatenmörder, kommt schon der andere." (TBW 8, 133f.) Wenn Reger in der Folge die österreichischen Politiker als „Demokratiemißbraucher“ (TBW 8, 134) bezeichnet, deutet sich allerdings an, dass die Polemik sich weniger gegen das demokratische System an sich, sondern vor allem gegen dessen Akteure richtet.

13 Vgl. Wolfgang Petritsch: Bruno Kreisky. Die Biografie. St. Pölten, Salzburg: Residenz 2010, S. 54, 67 u. 193 f. - Es wird kolportiert, Kreisky habe im skandinavischen Exil, „kaum des Schwedischen mächtig, damit angefangen, einige Kapitel Musil zu übersetzen“ (Rolf Schneider: Das revolutionäre Fragment. Über Robert Musil: Gesammelte Werke. In: Der Spiegel, Nr. 24, 12. 6.1978, S. 211-213, hier S. 211). Vgl. noch ein Interview mit Schneider aus dem Jahr 2013: „Bruno Kreisky, was kaum jemand weiß ist [sic], hat während seines Exils angefangen, Robert Musil ins Schwedische zu übertragen.“ (Adelbert Reif: „Das Identische und das Andersartige“. Gespräch mit Rolf Schneider. In: Der Standard, 2.3. 2013) Zu Schneiders Beschäftigung mit Musil vgl. jetzt Marion Schmaus: Literarische Rezeption. In: Robert-Musil-Handbuch. Hg. v. Birgit Nübel u. Norbert Christian Wolf. Berlin, Boston: de Gruyter 2016, S. 825-854, bes. S. $839-841$. 
Seit vielen Jahren behauptet unser Bundeskanzler Kreisky bei jeder ihm passend erscheinenden Gelegenheit, er kenne Robert Musil wahrscheinlich besser als irgendein anderer Zeitgenosse, weil er glaubt, das beweise sein hohes Geistesniveau, aber es beweist doch nur, daß er ein Kleinbürger ist. (TBW 22.1, 655) (14 $^{14}$

Der Autor reagierte mit seinem Brief an die Wochenzeitung auf ein seines Erachtens „blödsinniges Feuilleton“ über Kreisky, das kurz zuvor im ZEITmagazin gedruckt worden war; „und das hab’ ich halt widerlegt“, so Bernhard im Gespräch mit André Müller, „und geschrieben, daß er ein alter seniler Pimpf ist“ (TBW 22.2, 509) ${ }^{15}$ Erst nachdem sich Bernhard bei Müller beklagt hatte, dass der Leserbrief „in der Versenkung verschwunden“ und wohl aus Rücksicht auf Kreisky „nicht gedruckt“ worden sei (TBW 22.2, 158), rang sich die Hamburger Zeitung zur Veröffentlichung der Polemik gegen den österreichischen „Abonnementbundeskanzler“ (TBW 22.1, 655) durch.

In der Schlusswendung seines Leserbriefs bringt Bernhard einen Aspekt ins Spiel, der in seinen späteren Attacken gegen Bruno Kreisky eine wichtige Rolle spielen sollte: den Vorwurf, die Politik, die der Sozialdemokrat und seine Partei verfolgten, sei von der ursprünglichen Idee des Sozialismus längst abgewichen. Bernhard überführt seine ohne genauere Argumente auskommende Diagnose in ein Bild aus dem ihm wohlbekannten Lebensmittelhandel:

Der Kommis Kreisky, ein echter Nestroy, also eine Figur der Weltliteratur, wenn auch wahrscheinlich nicht der Weltgeschichte, behauptet, er führe einen phantastischen Laden, während er doch ganz genau weiß, daß er bankrott ist und daß die Regale leer sind. Nicht ein einziges Sackerl echten unverfälschten Sozialismus ist nicht einmal mehr in der untersten Lade. (TBW 22.1, 656)

Knapp eineinhalb Jahre später, im November 1980, entwarf Bernhard ${ }^{16}$ im Gespräch mit der ORF-Journalistin Krista Fleischmann spaßeshalber den Plan für „ein Weltstück“, in dem neben zahlreichen anderen prominenten Protagonisten

14 Zu Kreiskys Verwurzelung im intellektuellen Großbürgertum und seiner dadurch (sowie durch seine jüdische Herkunft) erschwerten Karriere in der Sozialistischen Partei vgl. Oliver Rathkolb: Die paradoxe Republik. Österreich 1945 bis 2010. Innsbruck, Wien: Haymon 2011, S. 134 f.

Dieser Teil des Gesprächs mit André Müller, dessen gekürzte Version in der ZEIT vom 29. 6. 1979 gedruckt wurde (vgl. TBW 22.2, 150-163), wurde erst nach Bernhards Tod im folgenden Band publiziert: André Müller: Im Gespräch mit Thomas Bernhard. Weitra: Bibliothek der Provinz 1992, S. 33-87. Vgl. den Kommentar in TBW 22.2, 490-511.

16 Die Datierung des Gesprächs, das erst am 11.2.1981, also erst nach Bernhards Rezension des Kreisky-Bandes, ausgestrahlt wurde, folgt dem Kommentar in TBW 22.2, 514, bzw. der Angabe in: Thomas Bernhard - Eine Begegnung. Gespräche mit Krista Fleischmann. Wien: Edition S 1991, S. 8. 
auch „der kleine Kreisky“ auftreten sollte; die Bühne der globalen Politik und jene des Theaters werden dabei, wie so oft bei Bernhard, zusammengeführt, um aus der Konfrontation der beiden Sphären komische Effekte zu gewinnen:

Der Papst und der Ronald Reagan und der Breschnew, das ist so wie der Bronner und der Farkas und der Wehle, auf etwas kleinerer Stufe. [...] Es spielen ja immer alle Mächtigen sehr gut zusammen. Heut ist es der Carter, der Reagan und der Wojtyła. Und dann war's einmal der Duce und der Hitler und der Franco. Jede Zeit hat ihre anderen Hauptdarsteller. Und dann kommt einmal so eine Evita Péron oder was, so eine Liz Taylor auf der Weltbühne halt. [...] Ist alles ein großes Theater. Oder der böse Khomeini, der tritt dann von rechts, tritt der auf, und der kleine Kreisky von hinten, nicht, „die Pferde sind gesattelt“, ist doch alles ganz lustig. (TBW 22.2, 222 f.)

Bernhard setzte die Idee einer umfassenden „Menschheitskomödie“ (TBW 19, 103), in der unter anderem Julius Caesar, Winston Churchill, Napoleon Bonaparte, Madame de Staël und Albert Einstein auftreten, zwischenzeitlich im Bühnenstück Der Theatermacher (1984) in Szene. Im März 1988 nahm er sie in einer Zuschrift an die ZEIT noch einmal auf - und zwar im Konzept eines Stücks für diverse Persönlichkeiten des öffentlichen Lebens, in dem Kreisky "den großen Dubiosus “ (TBW 22.1, 695) spielen sollte. Indem Bernhard dem imaginierten Theaterstück den Titel Glückliches Österreich gab, verknüpfte er seinen humoristischen Text mit der bereits zitierten Polemik gegen Kreisky von 1977, der man die Aufnahme in den gleichnamigen Residenz-Band (Glückliches Österreich, 1978) verweigert hatte. Sein imaginiertes Stück und die Bedingungen seiner dramaturgischen Ausarbeitung entwirft Bernhard als veritable Massenveranstaltung für das „fantastischste[ ] aller Theaterensembles“" TBW 22.1, 698):

Leider sind so viele Mitspieler in meinem Glücklichen Österreich, daß ich sie hier nicht aufzählen kann, aber es sind mehr als dreihundert, ich glaube dreihundertneunundzwanzig, aber die wichtigsten habe ich ja schon genannt. Waldheim, Kreisky, dazu kommen noch Vranitzky, Herr Mock und der Papst, der sich bereit erklärt hat, die Endproben mitzumachen, und glauben Sie mir, der Papst war schon dreimal hier und hat seine Rolle ausgezeichnet gespielt. (TBW 22.1, 695 f.) ${ }^{17}$

17 Vgl. zu diesem fiktiven Stück die Überlegungen von Nicolas Pethes: „glauben Sie mir“. Die Ausweitung der literarischen Kampfzone in Thomas Bernhards Interviews, Briefen, Preisreden und Feuilletonbeiträgen. In: Text + Kritik ( $\left.{ }^{4} 2016\right)$, H. 43, S. 126-139, hier S. 138: „Was fängt man an mit einer ironischen Pointe, die sich selbst so deutlich als solche ausstellt, dass man nicht mehr sicher sein kann, ob diese Ausstellung nicht selbst ironisch ist? Was mit der Ankündigung eines Theaterstücks in einem Leserbrief, das offensichtlich fiktiv, als Fiktion aber ja gerade doch wieder Literatur und nicht etwa Gegenstand eines sachlichen Schreibens ist?“ 
Auch abgesehen von solchen literarischen Fingerübungen, die stärker dem unernsten Fabulieren als der politischen Polemik zuzurechnen sind, rückte Bruno Kreisky in den $1980 e r$ Jahren gemeinsam mit seiner Partei, der SPÖ, zusehends ins Visier von Thomas Bernhards publizistischen Attacken. Der Politiker wurde, wie Alfred Pfabigan gezeigt hat, immer mehr zum „Verdichtungspunkt von Bernhards Österreichkritik“ ${ }^{18}$ Die „schon auf die tödliche Länge an der Macht befindliche Regierung “ bestehe - so der Autor am 2. Februar 1981, also kurz vor Halbzeit der vierten Kreisky-Regierung, der dritten mit absoluter Mehrheit der Sozialisten, in einem Brief an Gerhard Ruiss - „nur aus Dummköpfen, Banausen und brutalen Bossen“" (TBW 22.1, 668). ${ }^{19}$

Die Angriffe Bernhards auf den ,katholisch-nationalsozialistischen' Komplex in Österreich - etwa in Die Ursache (1975), dem ersten Band der Autobiographie $^{20}$ - wurden mit der Zeit durch jene gegen den Sozialismus bzw. dessen vermeintliche Fehlinterpretation und Verfälschung durch die zeitgenössische Politik ergänzt. In seinem 1978 veröffentlichten Theaterstück Immanuel Kant lässt Bernhard seine Titelfigur darüber räsonieren, dass die Gesellschaft einerseits „Selbstmord / begangen“ habe, „indem sie den Weg des Sozialismus gegangen ist“, andererseits sei dies aber nur dadurch zustande gekommen, dass sie „den Sozialismus / vollkommen mißverstanden“ habe: „Ich bin Sozialist“, so Kant, „der wahre der tatsächliche Sozialist / alles Andere ist ein Irrtum“ (TBW 17, 110). Die Attacken gegen den „sogenannte[n] Sozialismus“ (TBW 19, 164) und die Sozialdemokratie, die sich sowohl in öffentlichen Statements des Autors als auch in den Äußerungen seiner Prosa-Erzähler und Bühnenfiguren finden, sollten in den

18 Alfred Pfabigan: Motive und Strategien der Österreichkritik des Thomas Bernhard. In: Thomas Bernhard. Gesellschaftliche und politische Bedeutung der Literatur. Hg. v. Johann Georg Lughofer. Wien u. a.: Böhlau 2012, S. 35-48, hier S. 43.

19 Sein Brief an Gerhard Ruiss, den Geschäftsführer der IG Autoren, wenige Tage nach der Publikation von Der pensionierte Salonsozialist verfasst, wurde zunächst gekürzt in einem Band zum „Ersten österreichischen Schriftstellerkongress“ gedruckt - Bernhard hatte die Teilnahme daran entschieden abgelehnt (vgl. TBW 22.1, 665-667) - und erst nach dem Tod des Autors vollständig veröffentlicht (vgl. den Kommentar in TBW 22.1, 867).

20 In Die Ursache ist u. a. von der „katholisch-nationalsozialistische[n] Atmosphäre“ in Salzburg die Rede (TBW 10, 77). - Die Verbindung der beiden Adjektive findet sich bereits in einem Brief Bernhards aus dem Sommer 1972. Im Nachhall des Salzburger ,Notlicht-Skandals‘ um die Uraufführung von Der Ignorant und der Wahnsinnige konstatiert er in einem Schreiben an Siegfried Unseld, dass aus den Leitartikeln der „schauerliche[n] Provinzpresse“, die „ihren faulen Bottich voll Gemeinheit und Niedertracht, Heuchelei und Erbärmlichkeit über mich und meine Schauspieler und Peymann ausschüttet“, peu à peu eine „infame Geistesgeschichte des österreichischen nationalen katholisch-nazistischen Stumpfsinns“ entstehe (Bernhard an Unseld, 19. 8. 1972. In: Bernhard/Unseld: Der Briefwechsel [Anm. 2], S. 297). - Zu seinen schulischen Erfahrungen in Salzburg im Spannungsfeld von „Hitlerbild“ und „Kreuz“vgl. auch das 1975 geführte Gespräch mit Rudolf Bayr über den Band Die Ursache (TBW 22.2, 75). 
folgenden Jahren vor allem in diesem Spannungsfeld operieren: zwischen dem Einwand gegen die politische Bewegung an sich und dem Vorwurf an dessen gegenwärtige Interpretation, die als bloßer „Pseudosozialismus“ (TBW 9, 506) einen Abfall von der eigentlichen Lehre darstelle. Auch in der Anfang der 1980er Jahre entstandenen, aber erst 1986 als letzte umfangreiche Prosaarbeit Bernhards publizierten Auslöschung spricht der zentrale Protagonist Franz-Josef Murau in diesem Sinne vom „gigantischsten aller politischen Mißbräuche“ (TBW 9, 94), der den von ihm - so hat es jedenfalls den Anschein - eigentlich in Ehren gehaltenen Sozialismus besudelt habe:

Bis jetzt habe ich immer geglaubt, dieser sogenannte Sozialismus sei eine harmlose, vorübergehende politische Nervenkrankheit, hatte ich zu Gambetti gesagt, aber in Wahrheit und tatsächlich ist er tödlich. Ich meine den heute herrschenden Sozialis$m u s$, der nur geheuchelt ist, Gambetti, den verlogenen, den impertinent vorgetäuschten, das sollten Sie wissen. Wie diese heutigen Sozialisten keine tatsächlichen sind, sondern geheuchelte, verlogene, vorgetäuschte. Dieses Jahrhundert hat es zustande gebracht, das Ehrenwort Sozialismus in einer Weise in den Schmutz zu ziehen, daß es geradezu zum Erbrechen ist, hatte ich zu Gambetti gesagt. Die an den tatsächlichen Sozialismus gedacht und an ihn geglaubt haben für die Ewigkeit, würden sich im Grab umdrehen, wenn sie sehen könnten, was ihre widerwärtigen Nachfolger aus ihm gemacht haben. (TBW 9, 93)

Hatte Bernhard seinen Verleger im Herbst 1972 zum Wahlerfolg des Sozialdemokraten Willy Brandt „beglückwünsch[t]“, weil damit nicht nur Deutschland, sondern „das ganze darauf ausgerichtete Europa“ einen neuen „Geburtstag“ gefeiert habe, ${ }^{21}$ ja noch 1981 die Wahl des Sozialisten François Mitterand als „Jubeltag für ein neues Frankreich“ wohlwollend zur Kenntnis genommen, ${ }^{22}$ polemisierte Bernhard mit der Zeit immer heftiger vor allem gegen die österreichische Sozialdemokratie: „Kein Wort ist mir ekelhafter geworden, als das Wort Sozialismus, wenn ich denke, was aus diesem Begriff gemacht worden ist“ (TBW 6, 40), so der Erzähler im 1983 gedruckten Prosatext Der Untergeher:

Der Staat sei bankrott, sagte ich, dazu schüttelte sie den Kopf, die Regierung sei korrupt, sagte ich, die Sozialisten, die jetzt schon dreizehn Jahre an der Macht seien, hätten diese Macht bis zum äußersten ausgenützt und den Staat vollkommen ruiniert. [...] Und auf das Wort Sozialismus, sagte ich, fallen vor allem die Österreicher immer noch herein, obwohl jeder weiß, daß das Wort Sozialismus seinen Wert verloren

21 Bernhard an Unseld, 22. 11. 1972. In: Bernhard/Unseld: Der Briefwechsel (Anm. 2), S. 325. 
hat. Die Sozialisten sind keine Sozialisten mehr, sagte ich, die heutigen Sozialisten sind die neuen Ausbeuter, alles verlogen! sagte ich zur Wirtin [...]. (TBW 6, 107f.)

Die Verwischung der Grenzen zwischen fiktionalen Texten und Statements des Autors in eigenem Namen ist ein zentrales Charakteristikum von Bernhards Poetik; sie führte, so Clemens Götze, zu einer komplexen „Vernetzung von Interview, Leserbrief, öffentlicher Rede und literarischem Text “23 Am Beispiel der gleich in mehreren Genres geäußerten Pauschalkritik am politischen System Österreichs und seinen Akteuren lässt sich diese spezifische Textstrategie Bernhards exemplarisch nachvollziehen. ${ }^{24}$ Auf stilistischer Ebene weisen die auktorialen Statements in öffentlichen Debatten eine signifikante Nähe zur fiktionalen Rollenprosa bzw. zur Figurenrede in den Theaterstücken auf; dieses rhetorische Verfahren, das Nicolas Pethes zuletzt als komplexes „Fiktionalitätsspiel“ beschrieben hat, ${ }^{25}$ sollte sich mit der Zeit zu Bernhards Markenzeichen, zu einer „unverwechselbare[n] Handschrift“ entwickeln..$^{26}$ Gerade im Kontext seiner offen oder verdeckt autobiographischen Schreibprojekte näherten sich der Duktus des Leserbriefschreibers und Feuilletonisten Bernhard und die Sprechweisen seiner Protagonisten auf bemerkenswerte Weise an, so dass es mitunter „nahezu unmöglich“ scheint, „signifikante Unterschiede zwischen seinen Prosatexten und den öffentlichen Äußerungen [...] auszumachen “ ${ }^{27}$ In Bernhards Spiel mit diversen Genres schriftstellerischer Artikulation werden dabei thematische und stilistisch-performative Elemente „wie fertige Versatzstücke von Text zu Text weitergereicht ${ }^{\star 28}$ - ein Verfahren, das in der öffentlichen

23 Clemens Götze: „Die Redereien und Selbstdarstellungen hasse ich“. Thomas Bernhards Interviewkunst. In: Echt inszeniert. Interviews in Literatur und Literaturbetrieb. Hg. v. Torsten Hoffmann u. Gerhard Kaiser. Paderborn: Fink 2014, S. 239-256, hier S. 241.

24 Hierzu und zum Folgenden vgl. bereits Harald Gschwandtner: Journalistisches, Reden, Interviews. In: Bernhard-Handbuch. Leben - Werk - Wirkung. Hg. v. Martin Huber u. Manfred Mittermayer. Unter Mitarb. v. Bernhard Judex. Stuttgart: Metzler 2018, S. 270-278.

25 Pethes: „glauben Sie mir“ (Anm. 17), S. 133.

26 Michael Billenkamp: Thomas Bernhard. Narrativik und poetologische Praxis. Heidelberg: Winter 2008, S. 183.

27 Ebd., S. 385. Vgl. Manfred Mittermayer: Lächerlich, charakterlos, furchterregend. Zu Thomas Bernhards Rhetorik der Bezichtigung. In: Rhetorik und Sprachkunst bei Thomas Bernhard. Hg. v. Joachim Knape u. Olaf Kramer. Würzburg: Königshausen \& Neumann 2011, S. 25-44, hier S. 39 f.; Clemens Götze: „Die Ursache bin ich selbst!“ Thomas Bernhards inszenierte Autorschaft am Beispiel seiner (Film-)Interviews. In: Thomas Bernhard. Gesellschaftliche und politische Bedeutung der Literatur (Anm. 18), S. 357-371, hier S. $366 \mathrm{f}$.

28 Wolfram Bayer: Das Gedruckte und das Tatsächliche. Realität und Fiktion in Thomas Bernhards Leserbriefen. In: Thomas Bernhard. Beiträge zur Fiktion der Postmoderne. Londoner Symposion. Hg. v. Wendelin Schmidt-Dengler, Adrian Stevens u. Fred Wagner. Frankfurt a. M. u. a.: Lang 1997, S. 1-23, hier S. 7. Vgl. auch Franz M. Eybl: „Wenn das Werk lacht, weint der 
Rezeption ein enormes Provokations- und Irritationspotential entfaltet hat: "Ich schreibe prinzipiell nur Dinge, die ich selbst empfinde“, wird Bernhard im Oktober 1988 in einem seiner letzten öffentlichen Statements äußern und damit frühere Stellungnahmen konterkarieren: „Da ist alles autobiographisch. Wer mich kennt, der weiß das auch. “ ${ }^{29}$

In Bernhards letztem, 1988 am Burgtheater uraufgeführtem Theaterstück Heldenplatz findet sich mit Robert Schusters elegisch-aggressivem ,Monolog ${ }^{\text {(30 }}$ schließlich jene charakteristische Passage, in der - im Gestus bewusster Provokation - gar eine Ununterscheidbarkeit nazistischer und sozialistischer Ideologie postuliert wird:
dieser größenwahnsinnige Republikanismus
und dieser größenwahnsinnige Sozialismus
der mit Sozialismus schon seit einem halben Jahrhundert
nichts mehr zu tun hat
was die Sozialisten hier in Österreich aufführen
ist ja nichts als verbrecherisch
aber die Sozialisten sind ja keine Sozialisten mehr
die Sozialisten heute sind im Grunde nichts anderes
als katholische Nationalsozialisten (TBW 20, 285 f.)

Als besonders hellsichtige Kommentierungen eines politischen Systems und seiner historischen Filiationen können diese Zeilen, ebenso wie manche publizistische Invention, die Bernhard unter eigenem Namen lanciert hat, kaum gelten - man denke etwa an den in einem Leserbrief angestrengten Vergleich von Franz Vranitzkys Kulturverständnis mit „Metternich, Stalin und Hitler“ (TBW 22.1, 680). Die Forschung hat darauf hingewiesen, dass sich in Bernhards „Denken und Schreiben“, trotz seiner vielfältigen Bezüge zu realhistorischen und tagespolitischen Ereignissen, weder einlässliche Analysen des Status quo

Dichter“. Thomas Bernhards poetologische Maskeraden. In: Dichterdarsteller. Fallstudien zur biographischen Legende des Autors im 20. und 21. Jahrhundert. Hg. v. Robert Leucht u. Magnus Wieland. Göttingen: Wallstein 2016, S. 157-174, hier S. 163.

29 Conny Bischofsberger: Herr Bernhard: Was haben Sie gegen Österreich? In: Kurier, 14. 10. 1988.

30 Christian Klug: Thomas Bernhards Theaterstücke. Stuttgart: Metzler 1991, S. 11, hat darauf hingewiesen, dass die Bezeichnung des ,Monologischen` für die Sprechakte von Bernhards Theaterstücken bis zu einem gewissen Grad irreführend ist, weil die langen Reden einzelner Figuren „nicht nur in der Gegenwart anderer Figuren statt[finden]“, sondern diese auch ,voraus[setzen]“: „Die Reden von Bernhards Theaterfiguren können nur unter der (überaus problematischen) Voraussetzung sinnvoll als monologische bezeichnet werden, daß ein qualitativer Maßstab gelingender Kommunikation vorausgesetzt wird, der in Bernhards Konversationen unterschritten würde.“ 
noch ernsthafte Versuche finden, sich konstruktiv in politische Debatten einzubringen. ${ }^{31}$

Schusters Äußerungen in Heldenplatz stellen den skandalträchtigen ${ }^{32}$ Endpunkt einer langen Reihe von Bemerkungen dar, in denen Bernhard und seine Figuren ihre Attacken gegen den Gewaltkomplex von Kirche und Nazismus zusehends um den Sozialismus erweitert hatten: Bereits in der Ursache hatte der autobiographische Erzähler konstatiert, dass sich in Salzburg „selbst die, die sich Sozialisten nennen“, durch „nationalsozialistische und katholische Züge" (TBW 10, 80) auszeichneten; in der Folge dehnte Bernhard seine wiederholten Angriffe auf Institutionen politischer Organisation und gesellschaftlicher Disziplinierung mehr und mehr auf den Bereich des Sozialismus bzw. der Sozialdemokratie aus. Veranschaulicht er in der Ursache den Zusammenhang von Katholizismus und Nationalsozialismus noch anhand konkreter, mentalitäts- und institutionengeschichtlich durchaus belastbarer Beispiele, verlieren seine Angriffe in späteren Auslassungen zusehends an Evidenz und analytischer Plausibilität. ${ }^{33}$

In Auslöschung bezeichnet Franz-Josef Murau nicht nur den „Nationalsozialismus“ als „das größte österreichische Übel neben dem Katholizismus“ (TBW 9, 347), ${ }^{34}$ sondern er setzt die beiden wiederholt und ausdrücklich auch mit der zeitgenössischen Interpretation des Sozialismus in eins:

31 Reuter: „Vaterland, Unsinn“ (Anm. 10), S. 173; Bernhard liefere, so Reuter weiter, „auch keine alternativen Modelle zur Verbesserung oder Überwindung der bestehenden Verhältnisse“ (ebd., S. 174).

32 Dazu die prägnante Schilderung in Robert Weninger: Wien: Heldenplatz. Viel Ärger um Thomas Bernhard. In: R. W.: Streitbare Literaten. Kontroversen und Eklats in der deutschen Literatur von Adorno bis Walser. München: C. H. Beck 2004, S. 118-132.

33 Vgl. etwa die Wutrede des Schauspielers Bruscon im Theatermacher (1984), die den Konnex von Sozialismus und Nationalsozialismus explizit herstellt: „Gleich mit wem wir reden / es stellt sich heraus / es ist ein Dummkopf / gleich wem wir zuhören / es stellt sich heraus / es ist ein Analphabet / sie seien sozialistisch / sagen sie / und sind doch nur nationalsozialistisch / sie seien katholisch / sagen sie / und sind doch nur nationalsozialistisch / sie seien Menschen sagen sie / und sind nur Idioten" (TBW 19, 139).

34 Vgl. auch TBW 9, 228 f.: „So war ich, obwohl die nationalsozialistische Ära längst vorbei war, doch nationalsozialistisch erzogen worden, gleichzeitig katholisch, also mit einer sich auf den heranwachsenden Menschen grausam und entsetzlich auswirkenden österreichischen Machtmischmethode. Das katholisch-nationalsozialistische Element, die katholisch-nationalsozialistischen Erziehungsmethoden sind aber die in Österreich normalen, die üblichen, die am meisten verbreiteten und wirken sich also überall ungehemmt auf dieses ganze letzten Endes nationalsozialistisch-katholische Volk verheerend und grausam aus. [...] Katholizismus und Nationalsozialismus haben sich in diesem Volk und in diesem Land immer die Waage gehalten und einmal war es mehr nationalsozialistisch, einmal mehr katholisch, aber niemals nur eines von beidem. Der österreichische Kopf ist immer nur nationalsozialistisch-katholisch.“ 
Zuerst dieser gemeine und niederträchtige Nationalsozialismus und dann dieser gemeine und niedrige und verbrecherische Pseudosozialismus, habe ich zu Gambetti auf dem Pincio gesagt, dachte ich jetzt an der offenen Gruft. Diese nationalsozialistische und pseudosozialistische Zerstörung und Vernichtung unseres österreichischen Vaterlandes in Zusammenarbeit mit dem österreichischen Katholizismus, von welchem für dieses Österreich immer nur Unheil ausgegangen ist. [...] Dieses um alles betrogene österreichische Volk, habe ich zu Gambetti gesagt, dem in den letzten Jahrhunderten auf die infamste Weise der Verstand ausgetrieben worden ist von Katholizismus, Nationalsozialismus und Pseudosozialismus, Gambetti, habe ich zu Gambetti gesagt, dachte ich jetzt. (TBW 9, 506)

Bereits zuvor hatte Murau, auf dem Familiensitz in Wolfsegg eingetroffen, das Begräbnis seiner Eltern und seines Bruders imaginiert, die bei einem Autounfall ums Leben gekommen sind. Wenn er dabei nicht nur die „Erzbischöfe“ und „die Gauleiter und die SS-Obersturmbannführer und Blutordenträger“ hinter den Särgen hergehen lässt, sondern auch beschreibt, dass „unser nationalsozialistischkatholisches Volk“, das an der Trauerfeier teilnimmt, „die nationalsozialistischen Böller“ abfeuert, und darüber sinniert, ob „während der ganzen Zeremonie unsere nationalsozialistisch-katholische Sonne“ scheinen oder „der nationalsozialistisch-katholische Regen" auf die Gäste niederprasseln werde (TBW 9, 348), wird deutlich: Muraus Tiraden ist, neben ihrem Verweis auf die verheerende Gewaltgeschichte des 20. Jahrhunderts, auch ein Moment ironischer Selbstbezüglichkeit eigen. ${ }^{36}$ Derart literarisch durchgearbeitete, in ihrer Bezichtigungsrhetorik heißlaufende Passagen haben im Spätwerk Bernhards den Charakter von ,Selbstpastiches, wie sie Gérard Genette exemplarisch beschrieben hat: Der späte Bernhard ist geradezu ein Paradefall für einen Autor, der „seinen Idiolekt betont, indem er dessen typische Merkmale häuft oder übertreibt", was von geneigten Leserinnen und Lesern als „ironisches Selbstpastiche, oder, wie man geläufiger sagt, als ,Parodie seiner selbst', beurteilt“ wird. ${ }^{37}$ Aus der Überdrehung

35 Vgl. Renate Langer: Hitlerbild und Kreuz. Nationalsozialismus und Katholizismus bei Thomas Bernhard. In: Thomas Bernhard Jahrbuch 2007/2008, S. 21-35, hier S. 27; dort umfassender zur „enge[n] Verflechtung von Katholizismus und Nationalsozialismus“ (ebd., S. 23) in Bernhards Werk.

36 Vgl. die folgende Passage aus Alte Meister (1985), in der sich der Musikphilosoph Reger über Gemälde im Wiener Kunsthistorischen Museum ereifert: „Betrachten Sie doch einmal einen gutgemalten Kopf hier längere Zeit, am Ende ist es doch nur ein katholischer, so Reger. Selbst das Gras auf diesen Gemälden wächst als ein katholisches und selbst die Suppe in den holländischen Suppenschüsseln ist nichts als die katholische Suppe." (TBW 8, 190)

37 Gérard Genette: Palimpseste. Die Literatur auf zweiter Stufe. Frankfurt a. M.: Suhrkamp 1993, S. 168. - Vgl. dazu bereits Willi Huntemann: Artistik und Rollenspiel. Das System Thomas Bernhard. Würzburg: Königshausen \& Neumann 1990, S. 212 f., der auf die Technik der 
und Übertreibung der polemischen Rhetorik - wenn sogar der Witterung eine nazistische Prägung zugeschrieben wird - ergibt sich dabei einerseits die „Einsicht in die Austauschbarkeit" der verwendeten Begriffe und attackierten Institutionen, andererseits geht, so Hans Höller, mit Muraus „manichäischer Entlarvung der Welt“ stets auch die „Selbstentlarvung des manichäischen Subjekts“ einher. ${ }^{38}$ Entsprechend ist die Tendenz zum ,Selbstpastiche“ in Bernhards Spätwerk sowohl als Ausdruck der ästhetischen Stagnation als auch als konsequente Weiterentwicklung und Perfektionierung eines literarischen Verfahrens interpretiert worden.

Bernhards Attacken gegen Bruno Kreisky müssen stets vor der skizzierten Folie, also angesichts seiner insistierenden, wenngleich kaum analytisch belastbaren Beschäftigung mit ,Sozialismus' und ,Pseudosozialismus', in den Blick genommen werden. An der Person des Bundeskanzlers entzündeten sich die Polemiken des Autors wohl deshalb besonders heftig, weil er sich in der Bevölkerung großer Beliebtheit und allgemeiner Anerkennung erfreute: Bernhard „schlug“, so Wendelin Schmidt-Dengler, gerne und mit besonderer Lust „dort zu, wo ein Konsensmaximum zu vermuten war“ “ 39 Dieses „Konsensmaximum“ forderte den Autor in besonderer Weise heraus und schürte seine Bereitschaft, als erklärter Non-Konformist vehement Einspruch zu erheben: Im Gespräch mit Krista Fleischmann hat Bernhard dies 1986 in nachgerade aphoristischer Kürze festgehalten: „Man soll immer dort hingehen, wo ein Kontrast ist.“ (TBW 22.2, 324) Auch seine einmalige Rückkehr als (Literatur-)Kritiker stand unter diesem Zeichen, feierte man 1981 doch nicht nur ein rundes Jubiläum des Politikers Kreisky, sondern auch die seit mehr als einem Jahrzehnt andauernde, Ära Kreisky‘

„Selbstimitation“ bei Bernhard hinweist: „Bernhards Schreiben ist, insoweit sich die Komik aus der Form-Inhalt-Relation herleitet, selbstparodistisch, Bernhard ist sein eigener ,Stimmenimitator' und damit das Gegenstück zum Stimmenimitator in der gleichnamigen Geschichte, der sein Publikum durch die Vielzahl der von ihm imitierten Stimmen verblüfft." Huntemann veranschaulicht diese Tendenz im Spätwerk des Autors u. a. anhand der Dramolette in den Bänden Der deutsche Mittagstisch und Claus Peymann kauft sich eine Hose und geht mit mir essen, aber auch am Beispiel anderer Prosa- und Theaterarbeiten. - Zum, Selbstpastiche` bei Bernhard vgl. Marcus Hahn: Geschichte und Epigonen. ,19. Jahrhundert' / ,Postmoderne', Stifter / Bernhard. Freiburg i. Br.: Rombach 2003, S. 461-465, der von einer „radikalen Hyperbolisierung des eigenen Textverfahrens" spricht (ebd., S. 465).

38 Hans Höller: Auslöschung als Comédie humaine der österreichischen Geschichte. In: H. H.: Der unbekannte Thomas Bernhard. Mattighofen: Korrektur 2014, S. 95-106, hier S. 104.

39 Wendelin Schmidt-Dengler: „... das fortgeschrittenste Land ohne es zu wissen“. Unbewusster Avantgardismus aus Österreich. Hg. v. Michael Rohrwasser. Innsbruck u. a.: StudienVerlag 2009, S. 69. Dazu bereits ders.: Der Übertreibungskünstler. Studien zu Thomas Bernhard. Wien: Sonderzahl 1986, S. 102: „Wo der Konsens am größten, ist Bernhards Lust zum Schelten am größten, ob Kreisky, ob Canetti, ob die Akademie für Sprache und Dichtung - immer dort, wo das Wohlwollen und die Einigung eine Plattform des Redens ermöglicht, entfernt sich Bernhard unter wüster Beschimpfung." 


\section{Politische Polemik als Literaturkritik (Gerhard Roth, Peter Turrini)}

Anfang 1981 - die vierte Regierung Kreisky war seit gut eineinhalb Jahren im Amt - beauftragte die Zeitschrift profil Bernhard damit, eine Rezension über eine Festschrift zum 70. Geburtstag des Bundeskanzlers zu verfassen. Die Besprechung wurde vier Tage nach dem Jubiläum, am 26. Januar 1981, veröffentlicht: ein von der Zeitschrift provozierter, jedenfalls bewusst in Kauf genommener Skandal, war zu diesem Zeitpunkt Bernhards Aversion gegen Kreisky doch allseits bekannt, seine Reaktion auf diese Publikation folglich absehbar. ${ }^{40}$ Die Kulturredaktion des profil hatte zunächst nicht damit gerechnet, Bernhard für eine Besprechung des Bandes gewinnen zu können; über Vermittlung des Residenz-Verlegers Wolfgang Schaffler hatte man jedoch, wie sich Horst Christoph erinnert, „wenig Mühe“, ihm „das Vorhaben schmackhaft zu machen“. Als Bernhards Text dann vorlag, entwickelten sich in der Redaktion heftige Diskussionen darüber, ob er in dieser Form gedruckt werden könne; man einigte sich schließlich darauf, in einem distanzierenden Nachsatz zu betonen, dass es zum journalistischen Ethos des Blattes zähle, abweichenden Meinungen und Positionen Gehör zu verschaffen. ${ }^{41}$

Bernhard zeichnet in seiner Rezension nicht nur den österreichischen Kanzler als „renitent gewordene[n] Spießbürger" und „längst der Lächerlichkeit anheimgefallene[n] alte[n], am eigenen Murren würgende[n] sture[n] Sozimonarch[en] “ (TBW 22.1, 623 f.), sondern er wendet sich - im Sinne einer doppelten Adressierung seiner Polemik - auch gegen die prominenten Verfasser des Buches: Gerhard Roth und Peter Turrini, beide etwas mehr als zehn Jahre jünger als Bernhard (also aus der Generation Handkes), aber bereits als wichtige Autoren der österreichischen Literatur anerkannt, seien ein Beispiel dafür, „wie schwachsinnig und charakterlos unsere jungen opportunistischen Schriftsteller heute sind“ (TBW 22.1, 624). Sein Urteil trifft demnach sowohl den Gegenstand des besprochenen Bandes, Bruno Kreisky, als auch dessen Verfasser. Die zunehmende Antipathie

40 Vgl. Sehr geschätzte Redaktion (Anm. 4), S. 109; Pfabigan: Motive und Strategien der Österreichkritik (Anm. 18), S. 45; zu den Hintergründen Mittermayer: Thomas Bernhard [2015] (Anm. 4), S. 332-334, sowie den Kommentar in TBW 22.1, 826-830 u. $858 \mathrm{f}$. Dazu auch die Bemerkungen in Petritsch: Bruno Kreisky (Anm. 13), S. 289 f., der auf eine als Reaktion auf Bernhards Polemik gezeichnete Karikatur hinweist: „Manfred Deix interpretierte in einer großartig-hintergründigen Karikatur die publizistische Kontroverse als politische Fronleichnamsprozession. Während Kreisky unter einem Baldachin - begleitet von den beiden Ministranten Gerhard (Roth) und Peter (Turrini) - über die Felder getragen wird, schlägt ein sichtlich betrunkener Thomas Bernhard beim Kreisky-Marterl, auf das die Prozession zusteuert, sein (poetisches) Wasser ab.“

41 So die Rekonstruktion von Horst Christoph: Chronik eines Eklats. In: profil, Nr. 6, 7. 2. 2011, S. 97. 
gegenüber der Sozialdemokratie verbindet sich dabei mit dem Vorwurf an die Schriftsteller Roth und Turrini, der Politik als willfährige Handlanger zu dienen und damit die Idee künstlerischer Autonomie zu verraten. ${ }^{42}$ Wie in den frühen publizistischen Inventionen Ein Wort an junge Schriftsteller (1957) und Junge Köpfe (1959) entzündet sich der polemische Furor nicht primär an der Ablehnung bestimmter literarästhetischer Positionen, sondern an den Autorschaftsund Lebensentwürfen der attackierten Schriftsteller. Hatte Bernhard schon Mitte der 1950er Jahre andere Autoren als vor der „Partei“ kapitulierende „Handlanger“ geschmäht, für die „Bücklinge“ und „Kratzfuß“ zum selbstverständlichen Repertoire ihres künstlerischen Habitus gehörten (TBW 22.1, 566 f.), richtet sich seine Kritik auch hier im Besonderen gegen das seiner Meinung nach unterwürfige Einvernehmen der Literaten mit den politischen Machthabern. Weil es im literarischen Feld zum Ethos des autonomen, selbstbestimmten Schriftstellers gehört, „Ansprüche oder Forderungen weltlicher Mächte zu übergehen, ja sie im Namen ihrer eigenen Grundsätze und Werte zu bekämpfen“, ${ }^{43}$ wiegen die Vorwürfe des Rezensenten besonders schwer.

Bernhards Vorhaltungen gewinnen gerade dadurch an Schärfe, dass man Gerhard Roth und Peter Turrini in der öffentlichen Wahrnehmung gemeinhin ebenfalls zu den unbequemen Schriftstellern des Landes rechnete, deren Texte nicht selten kontrovers rezipiert wurden. ${ }^{44}$ Bernhard attackierte damit, das darf an dieser Stelle nicht vergessen werden, unmittelbare Konkurrenten im Kampf um mediale Aufmerksamkeit: Der dreizehn Jahre jüngere Turrini hatte mit der 1971 uraufgeführten rozznjogd kurz nach Bernhards erstem abendfüllenden Stück Ein Fest für Boris (1970) als neuer, innovativer und durch seine rohe Bühnenästhetik provozierender Autor am Theater reüssiert. ${ }^{45}$ Mit den Aufführungen von sauschlachten (1972) in den Münchner Kammerspielen und am Wiener Volkstheater gelang es ihm wenig später, die in ihn gesetzten Hoffnungen zu

42 Vgl. Nina Birkner: Vom Genius zum Medienästheten. Modelle des Künstlerdramas im 20. Jahrhundert. Tübingen: Niemeyer 2009, S. 243; Billenkamp: Thomas Bernhard (Anm. 26), S. 363. Auf Annotationen in Bernhards Rezensionsexemplar des Kreisky-Bandes verweist der Kommentar in TBW 22.1, 827.

43 Pierre Bourdieu: Das literarische Feld. In: P. B.: Kunst und Kultur. Kunst und künstlerisches Feld. Schriften zur Kultursoziologie 4. Hg. v. Franz Schultheis u. Stephan Egger. Berlin: Suhrkamp 2015, S. 339-447, hier S. 352.

44 Vgl. exemplarisch Nicholas J. Meyerhofer: Peter Turrini as political writer. In: I am too many people. Peter Turrini, playwright, poet, essayist. Hg. v. Jutta Landa. Riverside: Ariadne Press 1998, S. 30-43. - Rathkolb: Die paradoxe Republik (Anm. 14), S. 333, nennt Turrini neben Bernhard und Elfriede Jelinek als Beispiel einer prononciert „österreichkritische[n] Literatur“.

45 Dazu u.a. Wendelin Schmidt-Dengler: Peter Turrinis rozznjogd als Initialzündung. In: Peter Turrini, Schriftsteller. Kämpfer, Künstler, Narr und Bürger. Mit einer Rede Peter Turrinis. Hg. v. Klaus Amann. St. Pölten, Salzburg: Residenz 2007, S. 74-83. 
bestätigen. Turrini, Jahrgang 1944, den Bernhard von seiner Zeit am Kärntner ,Tonhof' Ende der 1950er Jahre als adoleszenten Dichter kannte, ihn damals aber nie ernst genommen, ja verspottet hatte, ${ }^{46}$ war es gelungen, den Generationenunterschied zu Bernhard, was seine Karriere am Theater anging, beinahe zu überwinden und aufzuholen. Zudem trat Turrini im Laufe der 1970er Jahre wiederholt mit Äußerungen über seinen Kollegen an die literarische Öffentlichkeit, die dem derart adressierten, für Kritik an seiner Person überaus sensiblen Autor ${ }^{47}$ nicht verborgen bleiben konnten.

Im Herbst 1974 etwa bemängelte Turrini in der Zeitschrift Neues Forum Bernhards indifferente, weil bloß pauschale Gesellschaftskritik, die ihre Zuständigkeit für konkrete politische und soziale Fragen von sich weise und stattdessen darauf schiele, die Erwartung des Literaturmarktes und der an derlei Aspekten kaum interessierten Literaturkritik zu erfüllen - Vorwürfe, die an die Kontroversen zwischen Peter Handke und Peter Hamm bzw. Hans Christoph Buch Ende der 1960er Jahre erinnern. ${ }^{48}$ Wie so oft zeigt sich auch hier eine gewisse Phasenverschiebung der literarischen bzw. literaturpolitischen Debatten in der Bundesrepublik Deutschland und in Österreich:

Man soll kritisch sein, sehr kritisch sogar, aber niemals konkret. Ein Autor, der schlicht und einfach hinschreibt, in Chile werden täglich fünfzig Menschen ermordet, hat schon verloren. Seine Aussage ist viel zu banal. [...] Wie man es richtig macht, zeigt uns der Spitzenläufer Thomas Bernhard. Er schreibt: Die Natur ist einerseits das Natürlichste, andererseits das Unnatürlichste. Oder: Wir leben in einer Zeit, in der die Forderungen der Gemeinen erfüllt werden. Oder: Die Welt, die Welt ist so entstellt. Jeder dieser Sätze beschäftigt mindestens zwanzig Kritiker, vier germanistische Institute, achtzehn Seminare, sieben Tagungen und 315 neurotische Backfische. Der Mann ist ein genialer Dichter, er hat einen genialen Marktinstinkt. ${ }^{49}$

46 Vgl. Klaus Amann: Peter Turrinis Bei Einbruch der Dunkelheit. Ein Stück über den „Tonhof“? Mit einem Seitenblick auf Thomas Bernhards Holzfällen. Eine Erregung. In: Peter Turrini, Schriftsteller (Anm. 45), S. 155-178, hier S. 160 u. 165 f.; dazu auch Maria Fialik: Eine Bombenreklame. Gespräch mit Jeannie Ebner, Schriftstellerin. In: M. F.: Der Charismatiker. Thomas Bernhard und die Freunde von einst. Wien: Löcker 1992, S. 17-47, hier S. 21.

47 Wieland Schmied: Auersbergers wahre Geschichte und andere Texte über Thomas Bernhard. Ein Alphabet. Vorwort v. Hans Höller. Weitra: Bibliothek der Provinz [2014], S. 32, zufolge war Bernhard ein Schriftsteller „,on höchst empfindlicher Natur“.

48 Vgl. Kap. II, Abschnitt „Fronten, Verbündete, Kampfbegriffe“.

49 Peter Turrini: Kulturkritik. [1974] In: P. T.: Mein Österreich. Reden, Polemiken, Aufsätze. Darmstadt: Luchterhand 1988, S. 27-39, hier S. 37. Zu den Angriffen Turrinis gegen Bernhard vgl. Jutta Landa: Realistisch oder experimentell. Frontenbildungen in der österreichischen Literatur der sechziger und siebziger Jahre. In: Konflikte - Skandale - Dichterfehden in der österreichischen Literatur. Hg. v. Wendelin Schmidt-Dengler. Berlin: Schmidt 1995, S. 215-224, hier S. 218. 
Gerade der Vorwurf, Bernhard schreibe im Grunde Literatur für Kritiker und Germanisten, für Feuilletonredaktionen und Universitäten, stand in scharfem Widerspruch zu dessen Selbstverständnis bzw. zu jenem Bild, das er von sich in der Öffentlichkeit kolportiert sehen wollte, war Bernhard doch darauf aus, Leser wie Kritiker mit seinen Texten fortwährend „zu provozieren“ (TBW 22.2, 275) und eben nicht deren Erwartungshaltung zu befriedigen. Seiner „Verachtung“ des „Seziertum[s] in den Operationssälen der Literatur" hat er ein ums andere Mal Ausdruck verliehen.$^{50}$ Dass Turrini ihn nun ausgerechnet als Zulieferer bekömmlicher Interpretationsobjekte attackierte, wog vor diesem Hintergrund besonders schwer.

Ein Jahr darauf wiederholte und verschärfte Turrini seine Attacke gegen Bernhard in einem Interview für die Kärntner Kulturzeitschrift Brücke noch einmal, wobei er die Kritik an seinem Kontrahenten erneut mit dessen Präsenz in der „Literaturkritik“ und auf den „Kulturseite[n]“ verknüpft:

Ich rede ja mit Leuten und möchte eine Antwort haben. Ich schreie ja nicht in Literaturbücher hinein, um irgendwo abgedruckt zu werden. Das ist ja auch der Unterschied zwischen einem politisch engagierten Literaten, der ich sein möchte, und einem an der Kunst an sich interessierten Literaten. Und genau dieser Mangel an Antwort auf der ganzen Ebene am Theater und auch in der Literaturkritik ist auch eine Erklärung dafür, warum ich zum Fernsehen gegangen bin, von dem sich ja die meisten Kritiker und Literaturfexen ohnehin höhnisch abwenden und sagen: ,Das ist ja so etwas Triviales, da brauchen wir uns kaum über eine Viertelspalte damit zu beschäftigen. ' Viel wichtiger ist es, wenn der Thomas Bernhard wieder einmal einen Wald gefunden hat, wo die Borkenkäfer herumrennen: das ist viel elementarer für die Kulturseite. Gerade dort gehöre ich aber nicht hin, in diesen Wald, aus dem keine Antwort kommt, nur Borkenkäfer. Ich gehöre ganz woanders hin. ${ }^{51}$

50 Bernhard an Joseph Breitbach, 28.6.1966. In: Bernhard/Unseld: Der Briefwechsel (Anm. 2), S. 46, Anm. 5. Im konkreten Fall handelt es sich hier um ein von Bernhard besuchtes Seminar an der Universität München, das sich unter der Leitung von Werner Vordtriede mit Amras beschäftigt hatte und von dem der Autor, wie er in einem Brief an Gerhard Fritsch schreibt, im Juni 1966 „nichts als schauerliche Eindrücke“ mitgebracht habe (Thomas Bernhard an Gerhard Fritsch, 26. 6. 1966. In: T. B./G. F.: Der Briefwechsel. Hg. v. Raimund Fellinger u. Martin Huber. Mattighofen: Korrektur 2013, S. 57).

51 Günther Nenning: Werkstättengespräch mit Peter Turrini. [1975] In: Turrini Lesebuch. Stücke, Pamphlete, Filme, Reaktionen etc. Ausgew. u. bearb. v. Ulf Birbaumer. Wien u. a.: Europaverlag 1978, S. 343-352, hier S. 350 f. - Turrinis Rede vom Borkenkäfer spielt auf Bernhards 1974 am Wiener Burgtheater uraufgeführtes Theaterstück Die Jagdgesellschaft an: „Tatsache ist / daß der Borkenkäfer / alles hier / alles mit dem Jagdhaus Zusammenhängende / zerstört / zerfrißt / alles" (TBW 15, 363). 
1978 ließ Bernhard den einst verlachten Buben und nunmehrigen Rivalen Turrini im Kurzprosaband Der Stimmenimitator als „gelernte[n] Möbeltischler“ auftreten, „der durch die Bekanntschaft mit einem ursprünglich begabten Komponisten“ - die Bemerkung weist auf die Abrechnung mit dem früheren Mäzen und Freund Gerhard Lampersberg in Holzfällen (1984) voraus - „auf die Literatur gekommen“ sei, jedoch „,aus Verzweiflung über seine Verkennung an seinem zweiundzwanzigsten Geburtstag“ Selbstmord begangen habe (TBW 14, 274). Die fiktionale Miniatur Bernhards bringt den Konkurrenten nicht nur um sein Leben, sondern auch um seinen künstlerischen Erfolg. ${ }^{52}$

Anfang der 1980er Jahre waren Peter Turrini und Gerhard Roth, der eben den ersten Band seines großen Romanzyklus Die Archive des Schweigens (1980-1991) vorgelegt hatte, als Akteure einer (auch politisch) progressiven österreichischen Literatur etabliert. Dass sie sich für die Arbeit an der Festgabe für Kreisky zur Verfügung gestellt hatten, verweist nicht zuletzt auf das Ansehen, das der sozialistische Bundeskanzler bei vielen Autoren und Kunstschaffenden in Österreich genoss. ${ }^{53}$ Umso mehr reizte Bernhard die Denunziation der beiden Schriftsteller als Handlanger der Politik, als heteronome Künstler, die ex negativo seine eigene Unkorrumpierbarkeit, die eigene autonome Position im literarischen Feld unterstreichen sollte. $^{54}$

52 Der Hinweis darauf in Amann: Turrinis Bei Einbruch der Dunkelheit (Anm. 46), S. 166.

53 Vgl. Petritsch: Bruno Kreisky (Anm. 13), S. 286-289, der u. a. Stellungnahmen von Gerhard Roth und Peter Henisch zitiert.

54 Dazu und zur Problematisierung einer solchen „polemische[n] Sicht“ auf den Gegensatz Autonomie/Heteronomie vgl. Pierre Bourdieu: Die Regeln der Kunst. Genese und Struktur des literarischen Feldes. Frankfurt a. M.: Suhrkamp 1999, S. 349-353, Zit. S. 350 f. - Roth ist auf Bernhards Angriff in seinem im Februar 1989 in der Neuen Rundschau veröffentlichten Nekrolog zurückgekommen. Vgl. Gerhard Roth: Der Menschenfeind, der der Alpenkönig war. Nachruf auf Thomas Bernhard. In: Neue Rundschau (1989), H. 2, S. 187-189, hier S. 188: „Er war ein unerbittlicher Kritiker, was ich auch selbst zu spüren bekam.“ Dazu ausführlich Ralf Georg Bogner: Drei Distanzierungen. Die Nachrufe von H. C. Artmann, Elfriede Jelinek und Gerhard Roth auf Thomas Bernhard. In: Die Lebenden und die Toten. Beiträge zur österreichischen Gegenwartsliteratur. Hg. v. Markus Knöfler, Peter Plener u. Péter Zalán. Budapest: ELTE 200o, S. 251-263. - Im Zuge der Diskussionen um Heldenplatz setzte sich Roth im Oktober 1988, so Oliver Bentz: Thomas Bernhard - Dichtung als Skandal. Würzburg: Königshausen \& Neumann 2000, S. 92, gemeinsam mit Barbara Frischmuth, Josef Haslinger, Elfriede Jelinek, Michael Scharang, Peter Turrini (!) und Gernot Wolfgruber u. a. mit einem Aufruf in der Volksstimme für Bernhard ein. Noch 1999 war er freilich der Überzeugung, dass Bernhard „Kreisky als Politiker lächerlich falsch eingeschätzt hat, wie ich überhaupt den Eindruck habe, dass er es sich mit der Politik in der Ablehnung aus einer Position der Stammtisch-Häme zu leicht machte“ (Gerhard Roth: Thomas Bernhard. Der lebendige Tote. [1999] In: G. R.: Portraits. Frankfurt a. M.: S. Fischer 2012, S. 83-92, hier S. 85 f.). 
Zielt Der pensionierte Salonsozialist vorderhand auf eine provokative „Dekonstruktion des Bundeskanzlers “55 als „Halbseidensozialist“ und „rosaroter Beschwichtigungsonkel“ (TBW 22.1, 622) ab, folgt Bernhards ,Gastkommentar doch in Ansätzen auch einem literaturkritischen Impetus, indem er die Geste der Huldigung und somit die Darstellungsverfahren der beiden Autoren einer strengen Prüfung unterzieht. Das „kuriose Buch“ sei „miserabel geschrieben“ und sollte, so Bernhard, eigentlich „nur in ausgesuchten Devotionalienhandlungen verkauft werden“ (TBW 22.1, 621f.):

Nicht nur die Sprache stelzt durch das ganze provinziell-pompös-aufgeschranzte Buch, auch der Kanzler. Und wenn er nicht stelzt, so sitzt er gespreizt oder reckt, während er geht, seinen Kopf in die Unendlichkeit. Dann zeigt er sich wieder müde und abgespannt von den Mühen des Weltenlaufs, wie große Männer, die Weltgeschichte machen, halt so sind - und dann wieder leutselig wie ein Hutschenschleuderer. (TBW 22.1, 623)

Auf Johannes Mario Simmels populären Roman Der Stoff, aus dem die Träume sind - nicht von ungefähr auf ein Buch der Unterhaltungsliteratur! - anspielend, konstatiert Bernhard pointiert eine „fantastisch authentisch[e]“ Entsprechung von Form und Inhalt: „Andererseits ist in dem Buch alles wahr, es ist ganz aus dem Stoff, aus dem unser Kanzler ist.“ (TBW 22.1, 622) Der Rezensent arbeitet sich am Image Kreiskys und an den etablierten Formeln, in denen über den Kanzler gesprochen wird, gleichermaßen ab: So greift er das Anfang der 1970er Jahre geprägte Wort vom ,Sonnenkönig' Kreisky auf, ${ }^{56}$ um es angesichts des im Jubiläumsband gedruckten Bildmaterials zum „Höhensonnenkönig im Pensionisten-Look“ zu verschärfen (TBW 22.1, 622) - ihm ist es um die Verspottung des Politikers ebenso zu tun wie um die Denunziation der beiden Autoren.

\section{„ein wirklicher Dichter“: Kreisky verteidigt Handke}

Obgleich auf Umwegen, so ist doch auch für die skizzierten Polemiken gegen Bruno Kreisky die Konkurrenz zwischen Thomas Bernhard und Peter Handke von Interesse, äußerte sich doch Letzterer nach seiner Rückkehr nach Österreich Ende der 1970er Jahre in mehreren Interviews betont positiv über Kreisky. „Von keinem Politiker, außer vom Kreisky, hab’ ich jemals eine Antwort gekriegt

55 Clemens Götze: „Mit allen Anzeichen der Empörung“. Thomas Bernhard als Leserbriefschreiber. In: Text + Kritik ( $\left.{ }^{4} 2016\right)$, H. 43, S. 52-65, hier S. 55.

56 Vgl. dazu Petritsch: Bruno Kreisky (Anm. 13), S. 198. 
auf das, was ich geschrieben habe. ${ }^{\text {57 }}$ Der Bundeskanzler nahm Handke schon in den Debatten, die im Mai und Juni 1975 auf die polemischen Bemerkungen des Autors zum Jubiläum des österreichischen Staatsvertrags folgten, in Schutz. Leserinnen und Leser der Kleinen Zeitung hatten sich über Handkes Ausführungen, die zunächst im ORF gesendet worden waren, erbost gezeigt: „Der Staatsvertrag wurde von unsereinem eher als sportliches Ereignis aufgenommen, das man neugierig verfolgt, solange es im Fernsehen übertragen wird“, heißt es in Handkes Fernsehbeitrag, der unter dem Titel Wirkliche Mächte in Österreich am 18. Mai 1975 in der Kleinen Zeitung gedruckt wurde: ${ }^{58}$

Aber wenn man abschaltet, ist man in seiner eigenen Welt wieder ganz verriegelt. Diese eigene Welt war Österreich, in dem man sich auch ohne Russen und Engländer besetzt fühlte, von den Besatzungsmächten der materiellen Not, der Herzenskälte der Religion, der Gewalttätigkeit von Traditionen, der brutalen Gespreiztheit der Obrigkeit, die mir nirgends fetter und stumpfsinniger erschien als in Österreich. ${ }^{59}$

57 Sigrid Löffler: „Als Schreibender krepiert man fast“. Gespräch mit Peter Handke. In: profil, 27. 4.1981, S. 58-6o, hier S. 6o. Vgl. Gerhard Neureiter: Was man vom Fernsehen kennt, das kennt man nicht. SN-Interview mit dem Dichter der Festspielpremiere Über die Dörfer, Peter Handke, zur Politik. In: Salzburger Nachrichten, 21. 8. 1982, worin Handke angibt, „manchmal mit Bruno Kreisky gesprochen“ zu haben: „Aber so ist es wahrscheinlich einigen Schriftstellern, auch Malern, ergangen. So ganz ungezwungen, daß er mich gefragt hat, ob man nicht eine Stunde reden könnte. Da habe ich auch vielfältige Eindrücke gewonnen, als Bilder und als Sätze." So könnte Bernhards - freilich bereits vor Handkes zitierten Interviewaussagen getätigte - Bemerkung über Kreiskys Verhältnis zu österreichischen Kulturschaffenden in Der pensionierte Salonsozialist auch auf seinen Konkurrenten Handke gemünzt werden: „Mit den großen Künstlern und Denkern auf du, heißt es ununterbrochen, aber es sind dann doch nur die Kleinkünstler und die Kleindenker, deren Hände er schüttelt.“ (TBW 22.1, 621)

58 Der Text wurde 1980, leicht verändert, als Persönliche Bemerkungen zum Jubiläum der Republik in den Band Das Ende des Flanierens aufgenommen.

59 Peter Handke: Persönliche Bemerkungen zum Jubiläum der Republik. [1975] In: P. H.: Das Ende des Flanierens. Frankfurt a. M.: Suhrkamp 1980, S. 56-59, hier S. 56. Im 1977 publizierten Journalband Das Gewicht der Welt greift Handke die Formulierung aus dem letzten zitierten

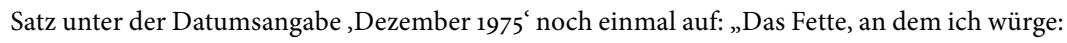
Österreich“ (Peter Handke: Das Gewicht der Welt. Ein Journal (November 1975 - März 1977). Salzburg: Residenz 1977, S. 21); siehe dazu Peter Handke an Alfred Kolleritsch, 3. 3. 1977. In: P. H./A. K.: Schönheit ist die erste Bürgerpflicht. Briefwechsel. Salzburg, Wien: Jung und Jung 2008, S. 103. - Fast vierzig Jahre später findet sich der Begriff in einer Interviewpassage Handkes über Thomas Bernhard, die sich in weiterer Folge zur Abrechnung mit dem einst geschätzten Kollegen entwickelt: „Als junger Schreiber hat mir Thomas Bernhard ja gut getan, wie er da als Österreicher mit einem Spieß das fette Land durchstieß. Die ersten zwei, drei Bücher waren wie eine Erlösung für mich. Aber allmählich hat es angefangen, mich abzustoßen und zu erzürnen." (Julia Encke: Schimpfen ist ein Ausdruck von Hilflosigkeit. [Gespräch mit Peter Handke.] In: Frankfurter Allgemeine Sonntagszeitung, Nr. 41, 11. 10. 2015, S. 53) 
Nicht die Freude über die Unterzeichnung des Staatsvertrags am 15. Mai 1955 und die ,Befreiung' von den alliierten Besatzungsmächten steht in Handkes Reflexionen im Mittelpunkt. Seine Erinnerung an das Zwangssystem des „Brauchtum[s]“, die „Fachidiotie“ der Universitätsprofessoren und den „Eigendünkel“, der ihm bei jedem späteren Besuch aus den österreichischen Tageszeitungen „entgegen[ge]brutzelt“ sei, ${ }^{60}$ ergänzt Handke im zweiten Teil seines Textes um positivere Bilder seines Heimatlandes. Sie bleiben allerdings nicht frei von Ambivalenzen und eignen sich in ihrer Betonung von „Distanz“ und „Befremdung“ kaum für die Feier politischer Jubiläen, die zumal in den ersten Jahrzehnten der Zweiten Republik nicht dazu angetan waren, sich (selbst-)kritischen Fragen zu stellen:

Ich bin kein Revolutionär, von dem man sagt, er müsse sich im Volk bewegen „wie ein Fisch im Wasser“. Aber ich spüre doch beim Schreiben immer mehr diese Notwendigkeit, dem Land, ohne das ich ja nicht das wäre, was ich schlecht oder recht geworden bin, möglichst nahe zu sein und dem sogenannten Volk, von dem ich ja ein Teil bin; dabei doch die Distanz und nötige Befremdung bewahrend, ohne die man über ein Land nicht gerecht schreiben kann. ${ }^{61}$

Die Betrachtungen des seit 1966 im Ausland (zunächst in Düsseldorf, später in Berlin, Kronberg/Taunus und Paris) lebenden Autors, der sich bereits ein Jahr zuvor im Almanach des Residenz Verlags über den „hysterische[n] Patriotismus eines kleinen Landes" geäußert hatte, ${ }^{62}$ bleiben zwiespältig - und boten diverse Angriffsflächen für erboste Patrioten. Handkes Ausführungen changieren zwischen kritischen Kommentaren zum politisch-gesellschaftlichen Klima und zur Ökonomisierung des österreichischen Kulturerbes einerseits und einer durchaus freundlichen Erinnerung an seine Herkunft und die Bewohner des Landes andererseits:

Wenn ich jetzt in Österreich bin, fühle ich manchmal ein schönes Einsinken in dieses Land, fühle mich fast optimistisch, als einer unter anderen, höre sogar manchmal die Kirchenglocken mit Freude und schüttle mich doch, wenn die Welt im Fernsehen wie eine amerikanisierte Lipizzaner-Show erscheint, wenn Soldaten zu Tode geschunden werden, wenn im slowenischen Kärnten zweisprachige Ortstafeln umgeworfen werden usw. / Beides gehört zu Österreich. / Ich liebe Österreich ... nicht, denn ein Land kann man nicht lieben, höchstens Menschen. Aber Liebesgefühle zu Menschen sind

60 Handke: Persönliche Bemerkungen zum Jubiläum der Republik (Anm. 59), S. 57.

61 Ebd., S. 58.

62 Peter Handke: Österreich und die Schriftsteller. In: Literatur im Residenz Verlag. Almanach auf das Jahr 1974. Salzburg: Residenz 1974, S. 57-61, hier S. 57. 
unfrei in einem Land oder Staat, in dem man sich unfrei fühlt, weil es noch so viele geheime Besatzungsmächte gibt. Und ich habe Lust, durch meine Arbeit die mörderische Gewalt dieser doch eigentlichen Besatzungsmächte vermindern zu helfen; das kann man allerdings nicht mit einem Staatsvertrag erreichen. ${ }^{63}$

Gerade die Verweigerung der Heimat-Liebe, so differenziert sie hier auch vorgebracht wird, sollte sich - wie im Zuge anderer österreichischer Literaturskandale - als Stein des Anstoßes erweisen. ${ }^{64}$ In den folgenden Wochen entwickelte sich auf der Leserbriefseite der Kleinen Zeitung eine heftige Debatte, an der auch zahlreiche prominente Akteure des politischen und literarischen Lebens teilnahmen. Handkes „Art von Verbundenheit und Verpflichtung“ sei ihm, so Bruno Kreisky in einer Zuschrift an die Zeitung vom 6. Juni 1975, „ungleich lieber als jene, die sich durch bloße Nachahmung bei uns üblicher Lebensformen und Bräuche kundtut “ ${ }^{65}$ Zuvor hatten Leserbriefschreiber Handke unter anderem vorgeworfen, seine Ausführungen erinnerten „an das Gegreine eines vom Ruhm maßlos verwöhnten Einzelkindes“; ${ }^{66}$ er sei unehrenhaft „ins Ausland“ geflüchtet, „um von der Position des arrivierten Autors gebündelte Blitze des Zornes“ aus Paris in die Heimat „zu schleudern“67 - ein beliebtes Muster der Denunziation von Künstlerinnen und Künstlern, die ihren Lebensmittelpunkt außerhalb ihres Herkunftslands haben: Sie hätten, so will es dieses Narrativ, durch ihre ,Flucht' ins Ausland das Recht verwirkt, sich über Missstände in der Heimat zu echauffieren.

63 Handke: Persönliche Bemerkungen zum Jubiläum der Republik (Anm. 59), S. 58 f.

$64 \mathrm{Zu}$ diesem Aspekt in Handkes Werk vgl. exemplarisch Karl Wagner: „[...] wenn dir nicht ein Traum von ihr genügt.“ Peter Handke, Heimatsucher. In: Ferne Heimat - Nahe Fremde. Bei Dichtern und Nachdenkern. Hg. v. Eduard Beutner u. Karlheinz Rossbacher. Würzburg: Königshausen \& Neumann 2008, S. 203-213; Christoph Parry: Von Ahnen und Enklaven. Staat und Heimat bei Peter Handke. In: Text + Kritik (2015), Sonderbd. „Österreichische Gegenwartsliteratur", S. 71-82. - Zu dieser Thematik bei Bernhard vgl. z. B. Renate Langer: „Erde, Erbe, was war das immer?" Thomas Bernhards Heimatkomplex. In: Thomas Bernhard und Salzburg. 22 Annäherungen. Hg. v. Manfred Mittermayer u. Sabine Veits-Falk. Salzburg, Wien: Jung und Jung 2001, S. 41-48; Manfred Mittermayer: „Aufzuwachen und ein Haus zu haben.“ Thomas Bernhards „Heimatkomplex“ in frühen und frühesten Texten. In: Ferne Heimat - Nahe Fremde (Anm. 64), S. 186-202.

65 Bruno Kreisky: Wahr ist, was einer denkt. In: Kleine Zeitung, 8. 6.1975.

66 Rudolf E. Kellermayr: Vom Ruhm verwöhnt. In: Kleine Zeitung, 31. 5. 1975. In anderen Leserbriefen ging diese Einschätzung gar mit medizinischen Diagnosen einher: „Peter Handke ist der Typ des milieugeschädigten, neurasthenischen Kindes, das deshalb Schwierigkeiten mit sich, der Umwelt und der Schule hatte. Diese Schwierigkeiten im eigenen familiären Bereiche und die daraus resultierenden Kettenreaktionen werden heute noch der Umwelt und der Schule angelastet." (Matthias Offner: Dann wäre Handke ein großer Dichter ... In: Kleine Zeitung, 31. 5. 1975) Für den Hinweis auf die Leserbrief-Materialien danke ich Christoph Kepplinger-Prinz.

67 Heinz Stritzl: Amoklauf gegen Österreich. In: Kleine Zeitung, 5. 6.1975. 
Waren Anfang Juni 1975 bereits Humbert Fink und Gerhard Roth für Handke eingetreten, ${ }^{68}$ hatte das Wort des Bundeskanzlers in dieser Leserbriefdebatte nun natürlich besonderes Gewicht:

Warum ich mich melde, wo ich doch eigentlich gar nicht in mehr Streit verwickelt sein möchte, als ich es schon bin? Weil Peter Handke ein wirklicher Dichter ist, einer von denen, die selten kommen. Und sie sollen wie jeder das Recht haben zu schreiben, was sie für wahr halten - und wahr ist halt nach Bernanos, was einer denkt. ${ }^{69}$

Literaturfunktionäre wie Reinhard Federmann, der Generalsekretär des österreichischen P. E. N.-Clubs, oder Rudolf Henz, der Präsident des österreichischen Kunstsenats, hatten vehement gegen Handkes Äußerungen protestiert. ${ }^{70}$ Auf Kreiskys Statement für Handke folgte wiederum eine Reihe weiterer Leserbriefe, in denen man es etwa für befremdlich hielt, dass „der hochverehrte Herr Bundeskanzler“ sich für das „von ,linker“ Hand aufgezogene[ ] Flaschenkind der extremen Linken, Herrn Peter Handke“, so sehr „ins Zeug“ legte. ${ }^{71}$ (Die „extremen Linken“, die Handke längst als einen von ihnen abgeschrieben hatten, weil er als zu eigensinnig und politisch ,unzuverlässig‘ galt, waren über diese Zuschreibung wohl wenig erfreut.) Kreisky nahm, das darf nicht vergessen werden, in dieser Causa eine Position ein, die durchaus das Potential hatte, ihn bei weniger kunstsinnigen Wählerinnen und Wählern Stimmen zu kosten.

Jedenfalls war es einer interessierten Öffentlichkeit nicht verborgen geblieben, wie selbstverständlich der Politiker Kreisky den Schriftsteller Handke Mitte der 1970er Jahre in einer aufgeheizten Kontroverse mit persönlichem Einsatz verteidigte $^{72}$ - und Thomas Bernhard hatte für derlei Allianzen ein besonders feines Sensorium. Ein Foto der beiden, das wenige Wochen nach Bernhards Polemik im Zuge eines Interviews mit Handke im profil erschien, trug die Bildunterschrift

68 Vgl. Humbert Fink: Von Urangst befallen ... In: Kleine Zeitung, 1. 6. 1975; Gerhard Roth: Die Wehleidigkeit der Antworten. In: Kleine Zeitung, 3. 6. 1975.

69 Kreisky: Wahr ist, was einer denkt (Anm. 65).

70 Vgl. dazu die Dokumentation im Katalog: „Was ich schreibe, ist ja nur meine geformte Existenz“. Peter Handke. Eine Ausstellung über Leben und Werk des Schriftstellers. Stift Griffen 1997. Klagenfurt: Kulturinitiative Stift Griffen 1998, S. 70. Zu Henz’ andauernder „offene[r] Feindschaft“ gegenüber Handke vgl. Evelyne Polt-Heinzl: Peter Handke. In Gegenwelten unterwegs. Wien: Sonderzahl 2011, S. 12 f., sowie dies.: Die grauen Jahre. Österreichische Literatur nach 1945. Mythen, Legenden, Lügen. Wien: Sonderzahl 2018, S. 178; zu den Debatten um Handkes Beitrag Malte Herwig: Meister der Dämmerung. Peter Handke. Eine Biographie. München: DVA ${ }^{2} 2010$, S. 209 f.

71 Karl-Ernst Halder: Freibrief für Schmähungen? In: Kleine Zeitung, 15. 6. 1975.

72 Petritsch: Bruno Kreisky (Anm. 13), S. 290, berichtet in seiner Kreisky-Biographie sogar davon, dass Handke im März 1979, „wenige Wochen vor der Nationalratswahl“, dem Kanzler geschrieben und seiner Hoffnung auf dessen Wahlerfolg Ausdruck verliehen habe. 
„Autor Handke, Bewunderer Kreisky“"73 Im gleichen Jahr stellte Kreisky den Roman Der Zögling Tjaž von Florjan Lipuš, den Handke gemeinsam mit Helga Mračnikar ins Deutsche übersetzt hatte, ${ }^{74}$ im Wiener Museum des 20. Jahrhunderts vor - nicht nur eine „Geste für das tatsächlich mehrsprachige Österreich“, ${ }^{75}$ sondern auch eine Geste der Wertschätzung für Handkes Tätigkeit als Übersetzer und Literaturvermittler.

Im März 1985, knapp zwei Jahre nach Kreiskys Ausscheiden aus dem Amt des Bundeskanzlers, sollte die Wiener Presse gar ein amikales Gespräch zwischen ihm und Handke veröffentlichen, das dem leidenschaftlichen Zeitungsleser Bernhard mit Sicherheit nicht verborgen blieb. ${ }^{76}$ Als das Interview mit dem Altkanzler erschien, fand sich Handke gerade in eine heftige mediale Auseinandersetzung verstrickt, die sich aus einem ,nächtlichen Vorfall' mit einer Polizeistreife auf dem Salzburger Universitätsplatz und der folgenden Berichterstattung darüber entsponnen hatte. In einer ausführlichen Stellungnahme in profil beklagte Handke, dass "hierzulande das Wort ,Künstler ' zugleich als Schmähwort“ verwendet werde: „, [I]ch kenne kein anderes Land in Europa, wo, durch die Zunahme der nichtsnutzigen, unbefriedigten, unerotischen Berufe, das Kleinbürgertum so frech geworden ist, daß es sich erlauben kann, alles zu

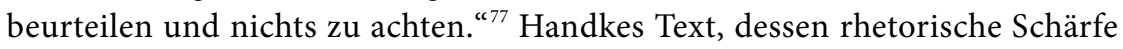
mitunter an Thomas Bernhards Tiraden erinnert, gehört zu den politisch brisantesten Einmischungen des Autors im österreichischen Kontext. Kreiskys Nachfolger als Bundeskanzler, Fred Sinowatz, wird darin namentlich genannt; dieser gebe sich zwar als „Freund der Künstler“ aus, eine jüngst von ihm getätigte Aussage zum Verhältnis von Politik und Literatur jedoch sei „würdig, unter die dümmsten Sätze aufgenommen zu werden, welche seit der Nacht der Zeiten von Menschen mit Zungen im Maul gesprochen worden sind“ ${ }^{78}$ Was Handke und andere Autoren Kreisky stets zugutehielten, nämlich seine Affinität zur Literatur, wollte er dem deutlich weniger weltmännisch auftretenden Sinowatz nicht zugestehen: „[W]ir werden uns von solch machthabenden, geistfeindlichen

73 Löffler/Handke: „Als Schreibender krepiert man fast“ (Anm. 57), S. 58.

74 Vgl. Florjan Lipuš: Der Zögling Tjaž. Roman. Deutsch von Peter Handke zusammen mit Helga Mračnikar. Salzburg, Wien: Residenz 1981.

75 Petritsch: Bruno Kreisky (Anm. 13), S. 289.

76 Vgl. „Man kann gar nichts mehr sagen“. Peter Handke mit Bruno Kreisky, unvergessen, über Literatur und Politik. In: Die Presse, 16./17.3. 1985. Im selben Jahr erschien eine ausführlichere, gleichwohl ebenfalls gekürzte Fassung: Peter Handke/Bruno Kreisky: Von der Abwesenheit des Unglücks. In: Peter Handke. Die Arbeit am Glück. Hg. v. Gerhard Melzer u. Jale Tükel. Königstein i. Ts.: Athenäum 1985, S. 11-24.

77 Peter Handke: Eine andere Rede über Österreich. [1985] In: P. H.: Langsam im Schatten. Gesammelte Verzettelungen. 1980-1992. Frankfurt a. M.: Suhrkamp 1992, S. 64-73, hier S. 69. Ebd., S. 71. 
Staatsmännlein nicht davon abbringen lassen, dieses Land Österreich zu lieben, und dieses Volk zu lieben, das heißt die vielen Vereinzelten, welche ohne Gruppenzwang leben, ohne Meutendrang, Zotenhang, Grinsgeselligkeit. “"79

Noch im „einzigen Politiker, der mir einmal nahgekommen war und jetzt nach seiner Entmachtung auf seinem Altenteil saß“, jenem „Politiker, den ich wie keinen geachtet hatte" ${ }^{80}$ von dem Handkes Alter Ego Gregor Keuschnig in Mein Jahr in der Niemandsbucht (1994) erzählt, ohne seinen Namen zu nennen, könnte man eine Reverenz des Autors an den 1990 verstorbenen Kreisky vermuten. Mehr als ein Jahrzehnt darauf hat er im Gespräch mit dem Journalisten Michael Kerbler den einstigen Bundeskanzler als eine positive Ausnahme im politischen Feld Österreichs beschrieben: Er habe, so Handke, „nie einen Staatsmann bewundert“, lediglich zu Kreisky „vielleicht“ „eine Zuneigung“ gefasst, „Ende der siebziger, Anfang der achtziger Jahre, aber das war auch eine Epoche, wo alles im Aufbruch war". 81

Ganz deutlich klaffen die Bilder, die Thomas Bernhard und Peter Handke von Bruno Kreisky gezeichnet haben, auseinander: Während Bernhard der Umstand, dass viele Autorinnen und Autoren Kreisky als einen der Kunst und der Literatur gewogenen, für ihre Kritik am Status quo aufgeschlossenen Politiker schätzten und öffentlich für ihn eintraten, zu immer heftigeren Attacken reizte, weil er diesem Konsens misstraute und nicht als einer von vielen gelten wollte, verlieh Handke seiner Achtung für Kreisky wiederholt Ausdruck. Dass Kreisky ausgerechnet als „Bewunderer“ seines schärfsten Konkurrenten im literarischen Feld galt, dürfte Bernhards Sympathie für den Politiker nicht eben gesteigert haben. ${ }^{82}$

79 Ebd., S. $71 \mathrm{f}$.

80 Peter Handke: Mein Jahr in der Niemandsbucht. Ein Märchen aus der neuen Zeit. Frankfurt a. M.: Suhrkamp 1994, S. 126 f. u. 132. - Sehr viel weniger begeistert zeigte sich Handke von anderen sozialdemokratischen Politikern; vgl. etwa seine Äußerung in Heinz Sichrovsky: Peter Handke: Ich bin ein Attentäter. In: H. S.: Einblicke. Begegnungen und Porträts. Wien: Jugend \& Volk 1990, S. 169-174, hier S. 169: „Ich habe einmal mit Finanzminister Ferdinand Lacina über Literatur gesprochen und dabei das Ausmaß der Verformung begriffen: Da existiert nur das Lustige, das Kritisch-Politische. Für alles, was jenseits von Nestroy und Karl Kraus stattfindet, für Raimund, für Grillparzer, die ich liebe, ist im Denken der lebenslangen Roten Falken kein Raum.“

81 ... und machte mich auf, meinen Namen zu suchen. Peter Handke im Gespräch mit Michael Kerbler. Klagenfurt: Wieser 2007, S. 54.

82 Vgl. dazu die Ausführungen zur „Konkurrenzsituation“ der beiden Autoren, ,in die persönliche Animositäten eingespeist und im journalistischen Echo mit entsprechenden Halleffekten wiedergegeben und so verschärft werden“, in Karl Wagner: „Er war sicher der Begabteste von uns allen“. Bernhard, Handke und die österreichische Literatur. Wien: Picus 2010, S. 32: „Es ist eine kleine Welt für große Konkurrenten, die durch ein wechselseitiges Dauer-Beobachtungsverhältnis nicht größer wird.“ - Polt-Heinzl: Die grauen Jahre (Anm. 70), S. 198, hat darauf hingewiesen, dass „die neue Kulturpolitik der Kreisky-Ära“ auch zu einer „institutionellen Gründungswelle“ 


\section{The Return of the Critic oder: Ausweitung der Kampfzone}

Es ist fraglich, ob Bernhard mit seiner Rezension des Kreisky-Bandes tatsächlich beabsichtigte, sich „als Kritiker [... zu profilieren“, wie Clemens Götze vermutet. ${ }^{83}$ Vielmehr übertrug Bernhard hier - von einer in Österreich breitenwirksamen Zeitschrift dazu aufgefordert - den bereits in anderen Genres erprobten Gestus polemischen Schreibens in die Gattung der Buchrezension, ohne sich besonders um deren spezifische darstellerische Verfahren zu kümmern. Der Auftrag der profil-Redaktion bot demnach lediglich den Anlass des Schreibens, ohne dass Bernhard seine etablierte „Rhetorik der Bezichtigung ${ }^{\text {“ } 84}$ wesentlich an die Konventionen der Gattung angepasst hätte, zumal er ja selbst in Zweifel zog, „der richtige Besprecher“ $z u$ sein (TBW 22.1, 621). Die Rezensionsanfrage fungierte im Grunde als Trigger für die Abfassung einer polemischen Intervention, zu deren öffentlichkeitswirksamer Lancierung Bernhard bislang vor allem Leserbriefe bzw. offene Briefe genutzt hatte. Der Vergleich mit einem im Februar 1981, also in unmittelbarer zeitlicher Nähe zur Kreisky-Polemik, im Wiener Journal publizierten Leserbrief über Franz Stelzhamer legt die Vermutung nahe, dass Bernhards Rezension der hagiographischen Kreisky-Festgabe weniger darauf abzielte, ihren Verfasser nach langer Abstinenz wieder als Literaturkritiker zu positionieren. ${ }^{85}$ Es folgten auch keine weiteren Versuche Bernhards in dieser Richtung. Das Genre der Besprechung bot sich vielmehr bei dieser konkreten Gelegenheit als öffentlichkeitswirksames, die Aufmerksamkeit eines größeren Publikums garantierendes Medium für seine Attacke gegen Kreisky an.

Am 23. März 1981 meldete sich Bernhard, dessen Rezension vielfältige Leserreaktionen - etwa vom jungen Michael Häupl - hervorgerufen hatte, ${ }^{86}$ erneut in profil zu Wort. Er behauptete nun in einer Zuschrift an die Redaktion, dass „Mitglieder der Sozialistischen Partei Österreichs, die hier in meiner Umgebung leben und die mir namentlich bekannt sind“, „das von mir besprochene Buch“ über den

im Literaturbetrieb führte, „die eine Vielzahl bis heute wirksamer Einrichtungen schuf“, etwa die IG Autoren, die Grazer Autorenversammlung oder den Ingeborg-Bachmann-Preis.

Götze: „Mit allen Anzeichen der Empörung“ (Anm. 55), S. 55. Es bleibt überdies unklar, warum Götze die Rezension selbst als ,Leserbrief‘ einordnet (vgl. ebd., S. 54 f.).

84 Mittermayer: Lächerlich, charakterlos, furchterregend (Anm. 27), S. 25.

85 Bernhard echauffierte sich in der Zuschrift an das Wiener Journal über die falsche Schreibung des „Von mir hochverehrten“ Autors Franz Stelzhamer (mit zwei statt mit einem „m“). Aus diesem Lapsus deduziert Bernhard in der Folge die „Dummheit und Scheinheiligkeit“ der gesamten Zeitschrift (TBW 22.1, 670). Laut Bayer: Das Gedruckte und das Tatsächliche (Anm. 28), hier S. 3, „entzünden“ sich Bernhards Leserbriefe oft „an Geringfügigkeiten“, um sich zu „apodiktischen Pauschalverdammungen hochzuschrauben“.

86 Vgl. Mittermayer: Thomas Bernhard [2015] (Anm. 4), S. 333 f., sowie den Kommentar in TBW 22.2, $828 \mathrm{f}$. 
SPÖ-Kanzler „seit einiger Zeit unaufgefordert“ zugeschickt bekämen (TBW 22.1, 671). Indem Bernhard diesen - vermutlich fingierten ${ }^{87}$ - Anlass dazu nutzte, um den Band abermals als „stupide[s] Machwerk“ und „schauerlichen Bilderroman aus der Jetztzeit“ zu schmähen und dessen Distribution zu einer „neuerlichen Geschmacklosigkeit“ zu erklären (TBW 22.1, 671), erhält sein Leserbrief den Charakter einer polemischen Nachschrift, einer Re-Rezension, die die provokative Kraft des ersten Schlags erneuern sollte. ${ }^{88}$ Der Verleger des kritisierten Bandes, Dieter Beuermann, jedoch antwortete mit einer souveränen Geste, die sonst in der Öffentlichkeit angegriffenen Autorinnen und Autoren vorbehalten ist - nämlich mit dem Verweis auf den durch Bernhards Verriss bewirkten Gewinn an medialer Aufmerksamkeit für das von ihm in Umlauf gebrachte Buch: „Bisher“ seien „,von unserem Kreisky-Titel 10 ooo Exemplare gedruckt“ worden, man hoffe allerdings, „mit Hilfe weiterer Besprechungen und Leserbriefe von Thomas Bernhard diese Zahl noch erheblich steigern zu können." (TBW 22.1, 869)

Auf solche Weise mit seinen eigenen Waffen attackiert, antwortete Bernhard im Feld der fiktionalen Prosa: In Beton, ein Jahr nach der Kreisky-Rezension im Suhrkamp Verlag erschienen, zieht der namenlos bleibende Protagonist, der fortwährend am ersten Satz einer musikwissenschaftlichen Studie über Felix Mendelssohn Bartholdy scheitert, über die „perversen Schauermärchen vom Ballhausplatz“ her, „wo ein gemeingefährlich gewordener Kanzler seinen Ministeridioten ebenso gemeingefährliche Befehle gibt“ (TBW 5, $72 \mathrm{f}$.):

Ich verlasse ja ein vollkommen ruiniertes Land, ein widerwärtiges Staatsgebilde, vor welchem einem an jedem Morgen graust. Zuerst haben es die sogenannten Konservativen ausgebeutet und weggeworfen, jetzt die sogenannten Sozialisten. Ein renitenter Dummkopf, als alter Kanzler größenwahnsinnig, unberechenbar, gemeingefährlich.

(TBW 5, 93)

Über den Begriff der ,Renitenz', den er bereits zuvor gegen Kreisky ins Treffen geführt hatte (vgl. TBW 22.1, 623), verknüpft Bernhard das Genre der Rezension mit der fiktionalen Prosa: Die Figur führt gewissermaßen die Agenda ihres Autors fort. ${ }^{89}$ Siegfried Unseld hatte im Vorfeld der Publikation von Beton zu

87 Jedenfalls verwehrte sich Dieter Beuermann, der Leiter der Nicolaischen Verlagsbuchhandlung, in der das Buch erschienen war, am 6.4.1981 in einem Leserbrief an profil gegen Bernhards Behauptung, da sie „schlicht falsch“ sei (TBW 22.1, 869).

88 Einige Wochen später erschienen im stern Notizen von Niklas Frank über ein Gespräch mit Bernhard, in dem dieser Kreisky erneut attackierte und als „blindwütige[n] alte[n] Narr[en]“ bezeichnete (Niklas Frank: Ansichten eines unverbesserlichen Weltverbesserers. In: stern, Nr. 24, 4. 6.1981, S. 160-162, hier S. 162).

89 Mit Huntemann: Artistik und Rollenspiel (Anm. 37), S. 193, ist indes zu betonen, dass die „Vorstellung, außerhalb seiner Texte spreche der Autor in eigener Person, in ihnen durch erfundene 
bedenken gegeben, dass sich aus der Erwähnung des Kanzlers womöglich rechtliche Probleme ergeben könnten. Bernhard schwächte die inkriminierte Stelle in der Folge zwar geringfügig ab, veränderte die Passage aber bereits in der zweiten Auflage wieder auf eine schärfere Formulierung. ${ }^{90}$ Ein Jahr später lässt Bernhard den Erzähler von Der Untergeher darüber räsonieren, „daß der Kanzler ein gemeiner, durchtriebener, gefinkelter Mann sei, der den Sozialismus nur als ein Vehikel für seine perversen Machtgelüste mißbraucht habe“ (TBW 6, 107):

Kein Wort ist mir ekelhafter geworden, als das Wort Sozialismus, wenn ich denke, was aus diesem Begriff gemacht worden ist. Überall ist dieser hundsgemeine Sozialismus unserer hundsgemeinen Sozialisten, die den Sozialismus gegen das Volk ausnützen, es mit der Zeit so gemein gemacht haben, wie sie selbst sind. Überall, wohin wir auch schauen heute, ist dieser tödliche Gemeinsozialismus zu sehen, zu fühlen, alles hat er durchdrungen. (TBW 6, 40 f.) ${ }^{91}$

Figuren“, als "naiv“ gelten muss und den ludischen Charakter des Zusammenspiels fiktionaler und faktualer Genres bei Bernhard verkennt. Am Beispiel der Kreisky-Polemiken ist zu zeigen, dass Textstrategien und Angriffsobjekte aus früheren autornahen Statements später in fiktionalen Prosatexten bewusst aufgegriffen werden - ein Verfahren, das bei Bernhard auch in die entgegengesetzte Richtung zu beobachten ist; am offensichtlichsten und prominentesten dort, wo er in einem Leserbrief vom September 1985 explizit auf Aussagen des „Österreichagitator[s] und Moralist[en] Reger in meinem Buch Alte Meister" rekurriert (TBW 22.1, 682). Vgl. dazu Götze: „Mit allen Anzeichen der Empörung“ (Anm. 55), S. 59 ff.

$90 \mathrm{Zu}$ den Veränderungen der Kreisky-Passage zwischen Typoskript, Erstausgabe und zweiter Auflage vgl. den Kommentar in TBW 5, 142 f. u. 147 (dort ein Faksimile der Typoskriptseite), sowie den Brief von Unseld an Bernhard, 16. 2.1982. In: Bernhard/Unseld: Der Briefwechsel (Anm. 2), S. 655.

91 In diesem Kontext wiegt es besonders schwer, wenn der Bernhard (gerade seit dem HolzfällenSkandal) nicht eben wohlgesinnte Literaturkritiker Hans Haider 1985 in der Wiener Presse konstatiert, Bernhard dränge sich auf, „als Leitfossil der vergangenen 15 Jahre sozialdemokratischen Literaturbetriebs untersucht zu werden“: „Zeigen sich bei ihm doch Formen gesellschaftlichen Wesens ähnlich wie im andersartig, im politisch organisierten Überbau. Das Ziel hieß Aufstieg zu Macht, doch einmal erworben, ist sie nicht mehr als Selbstzweck, Spiel gegen andere Mächtige, Überleben im Sacro Egoismo. / Bernhard gleicht manchen, die in seiner Zeit die Sozialdemokratie in Verruf gebracht haben, aufs Haar. Das sozial stigmatisierte Kind will hinauf und zielt nach dem Aristokratischen." (Hans Haider: Die Stigmatisierten steigen auf. In Österreichs literarischer Szene gibt es mehr prominente als gelesene Autoren. In: Die Presse, 23. 8.1985) Haider rückt Bernhard also in die Nähe jener "Nadelstreifensozialisten“ (TBW 22.1, 680), als die der Autor Politiker wie Bruno Kreisky und Franz Vranitzky denunziert hatte (vgl. auch TBW 22.1, 621). Zur Rolle Haiders im Skandal um Holzfällen vgl. Franz Schuh: All you need is love. Notizen und Exzerpte zur (Literatur-)Kritik. In: F. S.: Schreibkräfte. Über Literatur, Glück und Unglück. Köln: DuMont 200o, S. 24-114, hier S. 60 f. 
Kreisky hingegen verlor über Bernhards Attacken lange Zeit kein Wort - erst anlässlich der Uraufführung von Heldenplatz 1988 äußerte er sich in einem Telefoninterview mit der Kronen Zeitung, wobei er die Aufrichtigkeit des Autors in Zweifel zog. ${ }^{92}$

Auch Bernhards Angriffe gegen Roth und Turrini finden ihre Entsprechung und Erweiterung in den Invektiven fiktionaler Figuren und Sprechinstanzen: In Holzfällen etwa echauffiert sich der Erzähler über die vielerorts praktizierte „verabscheuungswürdige Staatsanbiederungskunst als Literatur“ (TBW 7, 157), über jene Autorinnen und Autoren zumal, die als „absolut niederträchtige Staatspfründnerexistenzen“ (TBW 7, 158) den "gemeine[n] und verlogene[n] Weg des Staatsopportunismus" beschreiten (TBW 7, 161). Während die schreibenden Kolleginnen und Kollegen in Holzfällen durch Decknamen vorderhand nicht mehr eindeutig zu identifizieren sind - für Insider waren und sind sie es bekanntlich sehr wohl -, boten Rezension und Leserbrief Bernhard die Möglichkeit, die Polemik direkt und unverstellt ad hominem zu richten. Die Besprechung des Kreisky-Bandes in der Zeitschrift profil übernahm bei sich bietender Gelegenheit die Funktion einer initialen Provokation, ansonsten spielte das Genre der Literaturkritik in Bernhards Ensemble polemischer Einmischungen - ganz im Gegensatz zu Handkes publizistischer Praxis - aber keine wesentliche Rolle mehr.

\section{Bernhard als Kritiker seiner selbst (Korrektur)}

Während sich Bernhards literaturkritische Ambitionen ab Mitte der 1950er Jahre auf die referierte Kreisky-Episode beschränkten, taucht in seinen Äußerungen zur Literaturkritik neben deren pauschaler Verunglimpfung auch das Motiv der ,Selbstrezension' auf. Gemeint ist damit weder die von Gérard Genette beschriebene Idee, einem Buch durch Kommentare des Verfassers zu einer „relevanten Lektüre" zu verhelfen, ${ }^{93}$ noch sollte, wie Friedrich Schiller dies im Zuge der Uraufführung der Räuber 1782 in Szene gesetzt hat, ${ }^{94}$ die anonyme Selbstrezension den Austausch von Literatur und Literaturkritik im öffentlichen Raum (und damit

92 Vgl. Christoph: Chronik eines Eklats (Anm. 41), S. 97, und Bentz: Thomas Bernhard - Dichtung als Skandal (Anm. 54), S. 78 f.; dazu auch Petritsch: Bruno Kreisky (Anm. 13), S. 290, der leider ohne Nennung einer Quelle - den Wortlaut von Kreiskys Kommentar zitiert: „Bernhard ist ein schrecklicher Raunzer. Ich habe ja gewisse Sachen von ihm gelesen, da war er immer souverän - als Raunzer. In Wirklichkeit ist der Bernhard ein Kleinbürger.“

93 Gérard Genette: Paratexte. Das Buch vom Beiwerk des Buches. Mit einem Vorwort v. Harald Weinrich. Frankfurt a. M.: Suhrkamp 2001, S. 10.

94 Vgl. Thomas Wegmann: Der Dichter als „Letternkrämer“? Zur Funktion von Paratexten für die Organisation von Aufmerksamkeit und Distinktion im literarischen Feld. In: Das achtzehnte Jahrhundert 36 (2012), H. 2, S. 238-249, hier S. 242 f., sowie Nina Birkner: Die Theaterkritik 
die positive Resonanz auf das Werk) simulieren. Das von Bernhard skizzierte Konzept der Selbstrezension geht, unabhängig von einem möglichen Publikum sowie ohne Bindung an die traditionellen Medien der Literaturkritik, vielmehr davon aus, dass nur der Autor selbst in der Lage sei, die Defizite eines von ihm verfassten Textes schonungslos und präzise aufzuzeigen und zu beschreiben. Bernhards Koketterie mit der Möglichkeit der Selbstrezension ist im Grunde ein Spiel mit der Vorstellung, externe Kommentatoren aus dem Gespräch über das literarische Werk auszuschließen - und damit die Herrschaft über Wert und Unwert, über Gelingen und Scheitern des Kunstwerks selbst in der Hand zu haben.

Weil er, so Bernhard im 1977 geführten, jedoch erst postum publizierten ,Nachtgespräch“ mit Peter Hamm, „noch nie eine Kritik, ganz wurscht welche, gelesen“ habe, „die nicht ein totales Mißverständnis gewesen wäre“, ja weil trotz mancher „richtige[n] Andeutung“ alle Rezensenten „immer daneben“ gelegen hätten, sei er auf die Idee verfallen, sich selbst um eine adäquate literaturkritische Kommentierung seines Schreibens zu kümmern: „Ich könnt' sie selbst schreiben, ja, ich könnt' selbst Kritiken über meine Sachen schreiben." (TBW 22.2, 129) Auf Hamms Nachfrage, ob es sich denn dabei um „[k]ritische Kritiken“ handeln würde, antwortet Bernhard mit einem Gemeinplatz skrupulöser Autorschaft: „Ja sicher, ja, das wär' interessant. Es ist niemand so kritisch mit allen meinen Sachen wie ich. Ich könnte so vorgehen gegen mich, wie ich gegen meine Figuren. Absolut." Statt durch Rezensionen und wissenschaftliche Aufsätze unberufener Geister erneut „lauter Mißverständnisse“ zu befördern, sei ihm an einem „Zurechtrücken“ gelegen, das er allerdings nur selbst bewerkstelligen könne (TBW 22.2, 129). Peter Handke hat sich, knapp zehn Jahre später, in ähnlicher Weise geäußert: „Ich könnte ja selber bessere Abhandlungen über meine Sachen, denk ich oft, also stichhaltigere verfassen als die meisten, weitaus das meiste was ich drüber lese." Wie Bernhard attestiert sich auch Handke im Gespräch mit Herbert Gamper die Fähigkeit zu einer „fruchtbaren Selbstkritik“; zögerlich, aber doch bestimmt vergleicht er sie bei dieser Gelegenheit mit der „selbstkritischen Haltung gegenüber dem Dichterberuf“, wie sie Goethe im Torquato Tasso exemplarisch gestaltet habe. ${ }^{95}$

als Instrument der Selbstpositionierung betrachtet - Friedrich Schillers Rezeptionspraxis und die Schaubühne. In: Germanisch-Romanische Monatsschrift 61 (2011), H. 4, S. 395-406.

95 Peter Handke: Aber ich lebe nur von den Zwischenräumen. Ein Gespräch, geführt von Herbert Gamper. Zürich: Ammann 1987, S. 226. Vgl. auch die folgenden beiden Notate in Peter Handke: Die Geschichte des Bleistifts. Salzburg, Wien: Residenz 1982, S. 143 f.: „Selbstkritik: In die Leere, in die ich schaute und Fülle phantasierte, trat ein wirklicher Mensch, der mich störte (erst in der Selbstkritik habe ich auch die Empfindung, zu denken)“ - „Schönheit und Trostlosigkeit werden verbunden durch Kritik. Deswegen müßte mein Schreiben kritischer sein (der starke Atem der Selbstkritik)“. 
Der Vorstellung, der einzig geeignete Kritiker eigener literarischer Arbeiten zu sein, ist eine doppelte, auf den ersten Blick widersprüchliche Konzeption von Autorschaft eingeschrieben: Sie entwirft den Schriftsteller zunächst als „oberste und einzige Instanz" ${ }^{\text {“96 }}$ für eine angemessene Bewertung eines von ihm verfassten Textes, geht also von einer starken, vom Urteil keines Ausstehenden abhängigen Position des Autors aus. Gleichwohl hat Bernhard die Selbstrezension im Gespräch mit Peter Hamm im Zusammenhang einer ausgeprägten Unzufriedenheit mit einem abgeschlossenen Schreibprojekt ins Spiel gebracht. Die Idee, die eigenen Texte so kritisch wie niemand anderer zu prüfen, entstehe, so Bernhard, gerade dann, wenn ihm „wieder nicht gelungen“ sei, „das zu machen, was ich eigentlich wollte“ (TBW 22.2, 129). Bernhard hat diese Einschätzung, seinem sonstigen Hang zur selbstbewussten Hybris zum Trotz, noch im letzten ausführlichen Interview, das er 1987 mit Asta Scheib geführt hat, artikuliert:

Man kann nie zu Papier bringen, was man sich denkt oder vorgestellt hat. Das geht zum größten Teil mit der Übertragung aufs Papier verloren. Was man liefert, ist nur ein schwacher, lächerlicher Abklatsch dessen, was man sich vorgestellt hat. (TBW $22.2,340$ f.)

Bei Bernhard verschränken sich zwei Dimensionen der beständigen Selbstkritik, der fortwährenden Beteuerung eigener Unzulänglichkeit: Zum einen nimmt er den Prozess der Niederschrift, der Verwandlung von Ideen in eine schriftliche Form, in den Blick, um zu zeigen, dass die schriftliche Form stets hinter der ursprünglichen gedanklichen Konstruktion zurückbleibt; zum anderen greift er das Problem in seinen poetologischen Reflexionen noch umfassender auf, wenn er die Möglichkeit einer sprachlichen Repräsentation erlebter Realität in einem literarischen Text ganz grundsätzlich in Zweifel zieht.

Den Topos von der Unverfügbarkeit der - mit Adalbert Stifters Nachkommenschaften gesprochen - ,wirklichen Wirklichkeit ${ }^{97}$ dessen weitverzweigte Geschichte in Literatur und bildender Kunst hier nicht rekapituliert werden kann, hat Bernhard nicht nur in vereinzelten Selbstauskünften, ${ }^{98}$ sondern auch in zahlreichen Erzähltexten in Stellung gebracht. In der autobiographischen Pentalogie

96 Götze: „Mit allen Anzeichen der Empörung“ (Anm. 55), S. 62.

97 Vgl. Adalbert Stifter: Nachkommenschaften. In: A. S.: Nachkommenschaften. Späte Erzählungen. Hg. u. mit einem Nachwort v. Karl Wagner. Salzburg, Wien: Jung und Jung 2012, S. 5-84, hier S. 43 u. passim.

98 Vgl. etwa Bernhards Rede zur Verleihung des Georg-Büchner-Preises 1970: „Was wir veröffentlichen, ist nicht identisch mit dem, was ist" (TBW 22.2, 34); Bernhards Schreiben folgt, so Christoph Kappes: Schreibgebärden. Zur Poetik und Sprache bei Thomas Bernhard, Peter Handke und Botho Strauß. Würzburg: Königshausen \& Neumann 2006, S. 235, ganz grundsätzlich einer „repräsentationskritischen Poetologie[ ]“. 
ist er als die entscheidende Herausforderung einer ,Selberlebensbeschreibung beständig präsent. „Alles Mitgeteilte kann nur Fälschung und Verfälschung sein, also sind immer nur Fälschungen und Verfälschungen mitgeteilt worden. [...] Wir beschreiben einen Gegenstand und glauben, wir haben ihn wahrheitsgemä $\beta$ und wahrheitsgetreu beschrieben, und müssen feststellen, es ist nicht die Wahrheit" (TBW 10, 135), heißt es dementsprechend in Der Keller (1976).$^{99}$ Fünf Jahre später hat Bernhard im vierten Band der Autobiographie, Die Kälte (1981), sein Misstrauen gegenüber der Vermittlungsleistung von Sprache in Bezug auf eine biographische „Wahrheit“ noch einmal unterstrichen:

Die Sprache ist unbrauchbar, wenn es darum geht, die Wahrheit zu sagen, Mitteilung zu machen, sie läßt dem Schreibenden nur die Annäherung, immer nur die verzweifelte und dadurch auch nur zweifelhafte Annäherung an den Gegenstand, die Sprache gibt nur ein gefälschtes Authentisches wider, das erschreckend Verzerrte, sosehr sich der Schreibende auch bemüht, die Wörter drücken alles zu Boden und verrücken alles und machen die totale Wahrheit auf dem Papier zur Lüge. (TBW 10, 364)

Rainald Goetz hat, in einer der hellsichtigsten Besprechungen von Die Kälte, von den „selbstinquisitorischen Zweifeln“ in Bernhards autobiographischen Bänden gesprochen. ${ }^{100}$ In dem 1981 bei den Salzburger Festspielen uraufgeführten Theaterstück Am Ziel bringt die dominante Mutter, die gemeinsam mit ihrer Tochter die Ankunft eines jungen Dramatikers erwartet, das Problem der Unverfügbarkeit auf die folgende Formel: „Wenn wir einen Menschen schildern / und wir denken wir schildern ihn so wie er ist / so haben wir ihn ganz falsch geschildert / er ist nicht so wie wir ihn schildern" (TBW 18, 317). Gerade am Beispiel seiner selbstbiographischen Texte hat sich die Bernhard-Philologie - und insbesondere die an der Lebensgeschichte des Autors orientierte Forschung - mit dem „schwierige[n] Verhältnis von Realität und literarischer Wiedergabe“ in dessen

99 Vgl. dazu etwa Reinhard Tschapke: Hölle und zurück. Das Initiationsthema in den Jugenderinnerungen Thomas Bernhards. Hildesheim u. a.: Olms 1984, S. 148 f. Billenkamp: Thomas Bernhard (Anm. 26), S. 301, hat in diesem Zusammenhang auf eine Veränderung im Laufe von Bernhards autobiographischem Projekt hingewiesen: „Geht es ihm in den ersten Bänden noch explizit um die wirklichkeitsgetreue Darstellung, um die Schilderung von Wahrheit und Authentizität sowie eine intensive Ursachenforschung, so distanziert sich Bernhard in den nachfolgenden Bänden von diesem Vorhaben und behauptet, dass Wahrheit in der Literatur oder in der Kunst ohne Fälschung und Verfälschung nicht darstellbar sei." Vgl. dazu ebd., S. 297-302, sowie die Überlegungen von Till Greite: „Prozesse, nichts als Prozesse“. Thomas Bernhard. Vom Gerichtsberichterstatter zum Fall für die Justiz. In: Recht, sachlich. Hg. v. David Oels, Stephan Porombka u. Eberhard Schütz. Hannover: Wehrhahn 2009, S. 95-102, hier S. 99, wonach „authentisches Sprechen bei Bernhard immer schon auf schwankendem Grund steht“.

100 Rainald Goetz: „Wahr ist nur, was nicht paßt“. Über Thomas Bernhards Die Kälte. In: Der Spiegel, Nr. 18, 27.4.1981, S. 229-232, hier S. 229. 
Werk beschäftigt und dabei entscheidende Einsichten in Bernhards Produktionsästhetik gewonnen. ${ }^{101}$

Den Zweifel an der Fähigkeit, mit einer literarischen oder wissenschaftlichen Schrift der (nicht zuletzt emotionalen) Komplexität des Lebens gerecht werden zu können, hat Bernhard sowohl in fiktionalen Texten als auch in paratextuellen Kommentaren zum Ausdruck gebracht; für mehrere Bücher des Autors stellen „die Unmöglichkeit, die Wahrheit zu sagen“ (TBW 22.1, 610), und der Skrupel davor, es trotzdem zu tun, zentrale Motive dar. ${ }^{102}$ Der Roman Korrektur (1975) ist in diesem Zusammenhang ein besonders prägnantes Beispiel, weil das geschilderte Problem hier die Grenze zwischen Leben und Werk transzendiert: Das Spiel mit dem Titelwort „Korrektur“ begleitet zunächst die Entstehung des Textes, insbesondere die Korrespondenz mit Siegfried Unseld, es prägt aber auch die Zuspitzung des erzählten Konflikts im Buch selbst. Wenn gegen Ende des Romans gar von der „Korrektur der Korrektur der Korrektur der Korrektur“ (TBW 4, 317) die Rede ist, greift die rhetorische Figur die wechselvolle Textgenese von Korrektur ironisch auf; außerdem verweist die heißlaufende Genetivkonstruktion auf die Krise des Protagonisten Roithamer, der seine Studie auf der Suche nach intellektueller Perfektion durch fortwährende Kürzungen am Ende gänzlich tilgt.

Im Sommer 1972 hatte Bernhard, aktuell von den publizistischen, schließlich auch juristischen Nachwehen des Salzburger ,Notlichtskandals' in Beschlag genommen, ${ }^{103}$ seinem Verleger Unseld mitgeteilt, er werde nicht zu einer Aufführung von Der Ignorant und der Wahnsinnige nach Berlin reisen können, weil er damit beschäftigt sei, „die ,Korrektur“ [zu] korrigieren““ ${ }^{104}$ Der Titel von Bernhards

101 Mittermayer: Thomas Bernhard [2015] (Anm. 4), S. 282. Vgl. u. a. Manfred Mittermayer: „Der Wahrheitsgehalt der Lüge“. Thomas Bernhards autobiographische Inszenierungen. In: Spiegel und Maske. Konstruktionen biographischer Wahrheit. Hg. v. Bernhard Fetz u. Hannes Schweiger. Wien: Zsolnay 2006, S. 79-94; Olaf Kramer: Wahrheit als Lüge, Lüge als Wahrheit. Thomas Bernhards Autobiographie als rhetorisch-strategisches Konstrukt. In: Rhetorik und Sprachkunst bei Thomas Bernhard (Anm. 27), S. 105-122; an einem konkreten Beispiel hat dies Martin Huber: „beinahe alles falsch“? Dichtung und Wahrheit in Thomas Bernhards Meine Preise. In: Text + Kritik ( $\left.{ }^{4} 2016\right)$, H. 43, S. 10-28, durchgespielt.

102 Vgl., um nur ein weiteres Beispiel zu nennen, die folgende Passage aus $J a$ (1978): „Aber alles zu Schreibende muß immer wieder von vorne angefangen und immer wieder aufs neue versucht werden, bis es wenigstens einmal annähernd, wenn auch niemals zufriedenstellend glückt. Und ist es noch so aussichtslos und ist es noch so fürchterlich und so hoffnungslos, es sollte doch immer wieder, wenn wir einen Gegenstand haben, der uns immer wieder und immer wieder mit der größten Hartnäckigkeit peinigt und nicht mehr in Ruhe läßt, probiert werden." (TBW 13, 34 f.)

103 Dazu die Chronik von Karl Ignaz Hennetmair: Ein Jahr mit Thomas Bernhard. Das versiegelte Tagebuch 1972. St. Pölten u. a.: Residenz ${ }^{5} 2014$, bes. S. 254-369. Vgl. die Zusammenfassung in Mittermayer: Thomas Bernhard [2015] (Anm. 4), S. 221-225.

104 Bernhard an Unseld, 11. 8. 1972. In: Bernhard/Unseld: Der Briefwechsel (Anm. 2), S. 293. 
Romanprojekt hatte schon einige Monate zuvor festgestanden; die Publikation des Buches verzögerte sich in den folgenden Jahren jedoch ein ums andere Mal. Mehrmals musste der Erscheinungstermin verschoben werden, weil der Autor sein Manuskript - auch aus taktischen Gründen, um den Verleger finanziell unter Druck zu setzen - nicht aus der Hand geben wollte. Erst im September 1975 konnte das Buch ausgeliefert werden. ${ }^{105}$

Er habe, so Bernhard am 18. Oktober 1972, bei der Arbeit am Roman „die grösste Anstrengung mit dem grösstmöglichen Glücksfall einer ununterbrochenen Angespanntheit [...] vereinigen können", ${ }^{106}$ der Abschluss des Projekts schien zu diesem Zeitpunkt, geht man nach Bernhards brieflichen Auskünften, durchaus absehbar. Noch im Juli 1974 musste Unseld nach einem Treffen mit dem Autor aber zähneknirschend dessen "großen Drang zur Perfektion“ vermerken, der ihn erneut von der Übergabe des Manuskripts abgehalten habe. ${ }^{107}$ Zuvor hatte Bernhard im März des Jahres seinem Verleger mitgeteilt, gegenwärtig „an der vierten Dimension der ,Korrektur“ “ zu arbeiten - „die ,Korrektur wird seit Monaten einer nochmaligen Korrektur unterzogen“; ; ${ }^{108}$ er befand es im Mai dennoch als „nicht richtig“, das Buch zum jetzigen Zeitpunkt zu veröffentlichen. ${ }^{109}$ Die Publikation des Romans im Herbst 1975 wurde schließlich vom zeitgleichen Erscheinen von Die Ursache. Eine Andeutung, dem ersten Band der Bernhard'schen Autobiographie, im Salzburger Residenz Verlag überschattet der Beginn eines Konflikts zwischen Bernhard und Unseld, der bis zum Tod des Autors mal schwelen, mal lodern sollte. ${ }^{10}$

Was der von Bernhard überaus geschätzte Henry James ${ }^{111}$ in der 1893 erschienenen Erzählung The Middle Years als „Ideal“ des gealterten Schriftstellers Dencombe,

105 Zur Entstehungsgeschichte des Romans vgl. ausführlich den Kommentar in: TBW 4, 321-343; zum Verhältnis von Autor und Verleger in diesem Prozess Manuela Dressel: Thomas Bernhard und seine Verleger. Wien: danzig \& unfried 2014, S. 74-85.

106 Bernhard an Unseld, 18. 10. 1972. In: Bernhard/Unseld: Der Briefwechsel (Anm. 2), S. 301.

107 Unseld: Chronik, Juli 1974. In: ebd., S. 441.

108 Bernhard an Unseld, 25.3.1974. In: ebd., S. 422.

109 Bernhard an Unseld, 30. 5. 1974. In: ebd., S. 431.

110 Dazu Dressel: Thomas Bernhard und seine Verleger (Anm. 105), S. 88-110; Bernhard Sorg: Der Berechnende und der Geduldige. Ein Schriftsteller und sein Verleger. In: Text + Kritik ( ${ }^{4}{ }_{2016)}$, H. 43 , S. 41-51.

111 Vgl. die entsprechende Stelle im Filmmonolog Drei Tage (1970; TBW 22.2, 63), aber auch die von Unseld notierte Bemerkung Bernhards über sein Stück Vor dem Ruhestand (1979), an dessen Beginn ein Motto von Henry James steht: „Das Stück sei so ruhig wie ein Strindberg-Stück, ein Traumspiel in gewisser Weise, es sei, so Bernhard, eine Mischung aus Strindberg und Henry James.“ (2.4.1979, Bernhard/Unseld: Der Briefwechsel [Anm. 2], S. 556) Bereits 1968 hatte Bernhard in seiner nicht gehaltenen Dankesrede zur Verleihung des Anton-Wildgans-Preises James in einer Reihe mit Alexander Blok und Ludwig Wittgenstein genannt (vgl. TBW 22.2, 28). In Ritter, Dene, Voss (1984) geben die beiden Schwestern die Aussage ihres Vaters wieder, „,von 
eines „leidenschaftliche[n] Korrigierer[s]“, entworfen hat - „im Geheimen zu veröffentlichen und dann den veröffentlichten Text zum eigenen Vergnügen einer

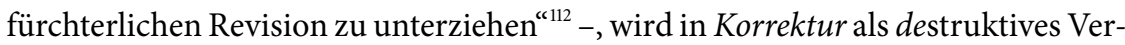
fahren der Textproduktion auf die Spitze getrieben. Ist es in anderen Erzähltexten, etwa in Beton (1982), die störende Umgebung, die die schriftliche Fixierung einer „Geistesarbeit“ vermeintlich sabotiert, ja diese in letzter Konsequenz „zuerst zerstört und dann endgültig vernichtet“ (TBW 5, 8 u. 10), führt Bernhard in Korrektur am Beispiel des Architekten Roithamer die Radikalisierung einer autodestruktiven Schreibbewegung vor Augen, an deren Ende die ultimative ,Selbstkorrektur' steht: der Suizid; denn die „eigentliche wesentliche Korrektur“ kann, wie der Erzähler den Protagonisten zitiert, nur durch den „Selbstmord“ vollzogen werden (TBW 4, 286). ${ }^{113}$ Willi Huntemann hat darauf hingewiesen, dass sich eine ganz ähnlich gelagerte Konstellation bereits im Ende der 1950er Jahre entstandenen, aber erst 1989 im Residenz Verlag publizierten Text In der Höhe. Rettungsversuch, Unsinn findet: „Sie streichen sich selbst weg“, heißt es dort in einer Passage, ohne dass klar wird, um wen es sich bei den am Gespräch beteiligten Personen handelt, „wenn Sie aus dem Manuskript noch etwas wegstreichen, Sie streichen sich aus, heraus, vollkommen weg, im Lauf der Jahre haben Sie sich ganz konsequent aus Ihrem Manuskript herausgestrichen, totgestrichen haben Sie sich, einfach totgestrichen“ (TBW 11, 41). ${ }^{114}$ Auch hier wird der Korrekturprozess als für den Korrigierenden letztlich letaler Vorgang geschildert. ${ }^{115}$ Autoikonoklasmus und Autodafé sind in Bernhards Prosawerk - man denke etwa an den Maler Strauch in Frost, der seine

Henry James“ abzustammen, „nicht von unseren Eltern“ (TBW 19, 230 u. 255); wie in Drei Tage erscheint der Romancier hier als eine Art Erzieher und Initiationshelfer. - Zu Bernhards Bezügen zu Henry James vgl. Tobias Heyl: Zeichen und Dinge, Kunst und Natur. Intertextuelle Bezugnahmen in der Prosa Thomas Bernhards. Frankfurt a. M. u. a.: Lang 1995, S. 150-154, der James' Roman Die Madonna der Zukunft (1875) als ,Prätext' für Bernhards Debüt Frost (1963) ausmacht. Dazu jetzt Andreas Gößling: Frost. In: Bernhard-Handbuch (Anm. 24), S. 37-46, hier S. 40 f.

112 Henry James: Die mittleren Jahre. Erzählung. Aus dem Englischen übertragen u. mit einem Nachwort v. Walter Kappacher. Salzburg, Wien: Jung und Jung 2015, S. 29 f.

113 Dazu Andreas Gößling: Thomas Bernhards frühe Prosakunst. Entfaltung und Zerfall eines ästhetischen Verfahrens in den Romanen Frost - Verstörung - Korrektur. Berlin, New York: de Gruyter 1987, S. 323; Wilhelm Voßkamp: „Auslöschung“. Zur Selbstreflexion des Bildungsromans im 20. Jahrhundert bei Thomas Bernhard. In: Literatur und Demokratie. Festschrift für Hartmut Steinecke zum 6o. Geburtstag. Hg. v. Aldo Allkemper u. Norbert Otto Eke. Berlin: Erich Schmidt 200o, S. 231-244, hier S. 239 f.; Anne Thill: Die Kunst, die Komik und das Erzählen im Werk Thomas Bernhards. Textinterpretationen und die Entwicklung des Gesamtwerks. Würzburg: Königshausen \& Neumann 2011, S. 214 f.; zuletzt auch Stefano Apostolo: Thomas Bernhards unveröffentlichtes Romanprojekt Schwarzach St. Veit. Das Konvolut, die Fassungen und ihre Deutung. Mattighofen: Korrektur 2019, S. 12-16.

114 Vgl. Huntemann: Artistik und Rollenspiel (Anm. 37), S. 37 f., Anm. 57.

115 Laut Hahn: Geschichte und Epigonen (Anm. 37), S. 446, handelt es sich dabei um ein umfassendes „Verfahren des Weg- oder Totstreichens“. 
Bilder „verheizt“ (TBW 1, 35 u. 139) - auf fatale Weise mit der Option des Suizids verknüpft; die selbstkritische, ja selbstquälerische Korrektur rückt dem Korrigierenden schließlich buchstäblich zu Leibe.

\section{Zwischen „Geisteskunst" und "Selbstkorrektur“: Szenen prekärer Autorschaft (Korrektur, Am Ortler)}

110 Jahre vor der Publikation von Korrektur, am 18. August 1865, teilte Adalbert Stifter seinem Verleger Gustav Heckenast mit, er sei sich bewusst, dass „stetes Verbessern" des Manuskripts auf das Erscheinen des Witiko äußerst ungünstige Auswirkungen habe; trotz seiner gegenwärtigen „Verzweiflungsstimmung“ über den Zustand des Textes müsse demnach bald „ein Abschluß gemacht werden “ ${ }^{116}$ Er trage zwar, wie er Heckenast schreibt, nach wie vor "das glühende Verlangen“ in sich, „durch weitere Feile und durch weiteres Austragen im Gemüthe“ die „Hoheit des Inhaltes und der Gestaltung“ zu verbessern, sei sich aber bewusst, dass er die Abgabe der nächsten Tranche der historischen „Erzählung “117 nicht mehr weiter hinauszögern dürfe: „In einer Woche ungefähr wird die Handschrift an dich abgehen. "118 Stifters Briefe, die in den folgenden Wochen meist gesundheitliche, aber auch konzeptionelle Gründe für ausbleibende Postsendungen, d.h. erneute Verschiebungen des Abgabedatums anführen, ähneln jenen Bernhards zwar nicht im Ton - „Ich bin in der lezten Durchsicht, und brauche noch 10 Tage. Diese Tage warte doch noch in Güte und Liebe “119 - , aber doch in den Argumenten, die für die Verzögerung genannt werden: Hier wie dort hat der Text noch nicht eine den Autor zufriedenstellende Form erreicht. Einen Teil des Manuskripts zum zweiten Band des Witiko habe er, so Stifter im Januar 1866, „ganz neu gemacht“, weil ihm die ursprüngliche Fassung „völlig farblos und wesenlos vor[gekommen] “ sei; ${ }^{120}$ wenig später kündigt er Heckenast die Zusendung der nächsten Blätter mit folgender Bemerkung an: „Die Sache ist ganz neu

116 Adalbert Stifter an Gustav Heckenast, 18. 8. 1865. In: Adalbert Stifter: Sämmtliche Werke. Bd. 21: Briefwechsel 5. Mit Benutzung der Vorarbeiten v. Adalbert Horcicka hg. v. Gustav Wilhelm. Reichenberg: Kraus 1928, S. $16 \mathrm{f}$.

117 Wie Peter Handke verweigerte auch Adalbert Stifter seinen umfangreichsten Prosaarbeiten, Der Nachsommer und Witiko, demonstrativ die Bezeichnung „Roman“ und wies sie stattdessen peritextuell als „Erzählungen“ aus; vgl. etwa Peter Handke: Die morawische Nacht. Erzählung. Frankfurt a. M.: Suhrkamp 2008. Dazu grundlegend Werner Michler: Teilnahme. Epos und Gattungsproblematik bei Peter Handke. In: Peter Handke. Poesie der Ränder. Hg. v. Klaus Amann, Fabjan Hafner u. Karl Wagner. Wien u. a.: Böhlau 2006, S. 117-134.

118 Stifter an Heckenast, 18. 8. 1865. In: Stifter: Sämmtliche Werke. Bd. 21 (Anm. 116), S. 18.

119 Stifter an Heckenast, 24. 9.1865. In: ebd., S. 23 f.

120 Stifter an Heckenast, 22.1.1866. In: ebd., S. 135. 
gearbeitet worden, das Alte war klägliches Zeug. “121 Die beständige Selbstkritik des Autors forderte ihn zu immer neuen Überarbeitungen heraus; diese haben, um eine Bemerkung von Ernst Osterkamp aufzugreifen, nicht unwesentlich zur „stilistischen Verkauztheit ${ }^{\text {“122 }}$ des Witiko beigetragen. Und: Es waren gerade diese Ankündigungen von „Neuschrift", „Umänderung“ und „Ausfeilung “, ${ }^{123}$ die die Verleger Stifters und Bernhards, Gustav Heckenast und Siegfried Unseld, im 19. wie im 20. Jahrhundert gleichermaßen der Verzweiflung nahe brachten.

Bernhard, dessen Protagonist Reger in Alte Meister (1985) zähneknirschend eingestehen muss, mit dem „Provinzdilettant[en]“ Stifter ,verwandt“ zu sein (TBW 8, 47 u. 62), ${ }^{124}$ inszeniert im und um den zehn Jahre davor erschienenen Roman Korrektur eine Problematik, die einige ihrer Parameter mit den Schreibund Überarbeitungsnöten Stifters teilt, verschiebt diese aber durch Zuspitzung und Radikalisierung noch stärker ins Existentielle, ins Existenzbedrohende. Im Gewand der Fiktion reflektiert Bernhard nicht nur den wechselvollen Entstehungsprozess des Buchs selbst, ${ }^{125}$ sondern er stellt den Drang zum fortwährenden Korrigieren ganz allgemein ins Zentrum der Romanhandlung. Der Erzähler der Korrektur schildert, gestützt auf den Nachlass seines Freundes Roithamer, den Prozess der Bearbeitung eines Manuskripts als unabschließbare bzw. nur mit der vollständigen Durchstreichung des Werks, seiner Vernichtung, zu bewerkstelligende Destruktionsbewegung. ${ }^{126}$ Er fasst den Entschluss, durch die „sogenannte

121 Stifter an Heckenast, 4. 2. 1866. In: ebd., S. 148.

122 Ernst Osterkamp: Ist da ein Mensch? Was geschieht, wenn man dem eigenen Lieblingsbuch, dem Nachsommer, untreu wird und Adalbert Stifters Witiko liest. In: Frankfurter Allgemeine Zeitung, 5.8.2017.

123 Stifter an Heckenast, 6.10.1865. In: Stifter: Sämmtliche Werke. Bd. 21 (Anm. 116), S. 28.

124 Zur „unerhörte[n] Nähe und Verwandtschaft“ zwischen Bernhard und Stifter vgl. Arnold Stadler: Mein Stifter. Porträt eines Selbstmörders in spe und fünf Photographien. Köln: DuMont 2005, S. 164 u. passim; zu Bernhards Polemiken gegen Stifter außerdem Markus Kreuzwieser: Epochendialoge. Noch einmal: Adalbert Stifter und die Gegenwartsliteratur unter besonderer Berücksichtigung der Stifter-Lektüren Thomas Bernhards. In: ide. Informationen zur Deutschdidaktik 29 (2005), H. 1, S. 82-95; Stefan Krammer: Bernhards unsanftes Gesetz. Ein Stifterexperiment. In: Thomas Bernhard Jahrbuch 2005/2006, S. 75-85.

125 Vgl. den Kommentar in TBW 4, 321: „[D]er Blick in die Verlagskorrespondenz zeigt, daß die im Roman thematisierten Fragen nicht beliebig gewählt wurden, sondern in entscheidenden Punkten - von den Schwierigkeiten mit dem Verfassen einer Schrift, insbesondere deren Beginn und Abschluß, bis zur richtigen Verwendung von Textfragmenten - frappante Parallelen zur Entstehungsgeschichte aufweisen." Bernhard habe die Entstehung und Überarbeitung des Romans seinem Verleger gegenüber „mit Sätzen“ beschrieben, „die direkt aus dem Roman zu stammen scheinen“" (TBW 4, 335).

126 Gößling: Thomas Bernhards frühe Prosakunst (Anm. 113), S. 314, hat darauf hingewiesen, dass - aller Korrektur-Rhetorik Bernhards zum Trotz - der Roman neben „semantische[n] und syntaktische[n] Irregularitäten“ auch eine Reihe ,inhaltlicher Widersprüche“ aufweist; dies führe, so Gößling, zur Frage, ,inwieweit solch unkontrolliertes Zerbersten des Fiktionsgefüges 
letztwillige Verfügung“ dazu ermächtigt, den Nachlass Roithamers „zu sichten und zu ordnen " und zudem , auch gleich über diese Beschäftigung zu schreiben“ (TBW 4, 7); der Roman stellt gewissermaßen das Protokoll dieser Aufarbeitung dar. Wie nicht selten bei Bernhard sind es in Korrektur der Tod eines Menschen und die Notwendigkeit, sich mit dessen Hinterlassenschaft auseinanderzusetzen, die am Beginn der Handlung stehen; bereits in der Erzählung Ungenach (1968) ist dies der Fall, in Watten. Ein Nachlaß (1969) auch im Untertitel angedeutet, und noch in Auslöschung. Ein Zerfall (1986) steht Franz-Josef Murau vor der Herausforderung, sich nach dem Unfalltod seiner Eltern und seines Bruders mit der materiellen wie ideellen Hinterlassenschaft der Familie beschäftigen zu müssen - erst die unumgängliche Aufarbeitung der Vergangenheit setzt den Erzähltext in Gang. ${ }^{127}$

Zentraler Gegenstand der archivarischen Recherche in Korrektur ist Roithamers Studie Über Altensam und alles, was mit Altensam zusammenhängt, mit besonderer Berücksichtigung des Kegels, deren Universalitätsanspruch - eben „alles“ zu erfassen, „was mit Altensam zusammenhängt“ - bereits im Titel deutlich wird. Der Nachlassbefund, den der Erzähler in der Folge fragmentarisch erstellt, erhellt den zerrütteten Geisteszustand des Autors Roithamer; andererseits tritt dabei aber auch jener charakteristische Redaktionsprozess zutage, in dem ,Vernichtung und ,Vollendung' auf hintersinnige Weise miteinander korrespondieren. Auf der Reise zum Begräbnis seiner Schwester, „auf der Überfahrt von Dover auf den Kontinent“ (TBW 4, 76), habe Roithamer begonnen, die umfangreiche Studie über seinen Herkunftsort und das für seine Schwester entworfene Kegel-Bauwerk erneut zu korrigieren: „Ich hatte das Manuskript aus der Reisetasche herausgenommen und sofort gesehen, es ist alles falsch in meinem Manuskript, daß ich nicht nur Teile falsch beschrieben habe, daß ich alles falsch beschrieben habe, denn es ist das Entgegengesetzte, so Roithamer." (TBW 4, 312 f.) Der Autor der Studie habe diese, wie der Erzähler zu erkennen glaubt, „durch die rücksichtsloseste und dadurch vollkommenste Korrektur“ allerdings nicht „vernichtet“,

sondern zu einer gänzlich neuen Studie gemacht, denn die Zerstörung der Studie durch seine Hand, durch seinen scharfen, mit der Studie am rücksichtslosesten verfahrenden Verstand, war doch nur gleichbedeutend mit der Erschaffung einer völlig neuen Studie, er hatte solange die Studie korrigiert, bis nicht, wie er geglaubt hat, die Studie vernichtet gewesen, sondern eine neue Studie entstanden war. (TBW 4, 76)

und schließlich auch semantischer und syntaktischer Strukturen den ästhetischen Rang des offensichtlich, nach längerer konzentrierter Vorbereitung, in größter Hast produzierten [...] Romans gefährdet“. Dazu auch Bernhard Judex: Thomas Bernhard. Epoche - Werk - Wirkung. München: C. H. Beck 2010, S. 76.

127 Hahn: Geschichte und Epigonen (Anm. 37), S. 436, spricht in diesem Zusammenhang vom allgegenwärtigen „Alpdruck der Hinterlassenschaften“ in Bernhards Euvre. 
Er sei überzeugt, so der Erzähler, der sich die apodiktische Rhetorik des Verstorbenen rasch zu eigen macht, dass Roithamer durch „die totale Korrektur seiner Studie“, die „Von ihm nicht vernichtet, sondern vollendet worden“ sei, den Charakter der Studie ,in einem infamen Korrekturprozeß in sein Gegenteil verkehrt“ habe, ja diese im Zuge der nochmaligen Bearbeitung „erst zur vollendeten Studie geworden“ sei (TBW 4, 77). Zwar könne „[j]ede Korrektur“ mit „Zerstörung, Vernichtung“ gleichgesetzt werden, sie berge aber auch das Potential, dass, „durch die Vernichtung des alten, ein völlig anderes, neues Manuskript entsteht" (TBW 4, 313). Die Perfektionierung der intellektuellen Substanz des Geschriebenen ${ }^{128}$ steht dabei in einem Spannungsverhältnis zum Abbruch der Anstrengungen als Krönung der Unternehmung, sei es doch, so Roithamer zweideutig, „das Höchste“, „kein neues [Manuskript] mehr entstehen zu lassen, nichts mehr zu korrigieren, zu vernichten“ (TBW 4, 313). Ob das ideale Ende des Korrekturvorgangs hier die Vollendung der Schrift im Sinne eines endgültigen, nicht mehr korrekturbedürftigen Textes oder aber im Gegenteil die vollständige Vernichtung aller Textstufen meint, bleibt in der Schwebe.

Die Erkenntnis der Unzulänglichkeit des schriftlichen Ausdrucks führt in Bernhards Roman, „wenn der Zeitpunkt für eine solche Korrektur ist“, zur radikalen Kürzung des Textes: „[D]ann korrigiere ich und dann korrigiere ich das Korrigierte“, wie der Erzähler seinen Freund zitiert, „und das Korrigierte korrigiere ich dann wieder undsofort“ (TBW 4, 285). Die Studie, in der „alles, was Roithamer jemals gedacht hat, in der konzentriertesten und in der ihm entsprechendsten Weise" vorliegt (TBW 4, 157), wird, mit Henry James gesprochen, einer „fürchterlichen Revision“ unterzogen; „eine endgültige Form“ der Studie wird dabei, wie im Fall von James' „Korrigierer" Dencombe, nie erreicht. ${ }^{129}$ Aus einer ursprünglich 80o-seitigen Niederschrift habe Roithamer zunächst eine „Zweite dreihundert Seiten lange Fassung“ erstellt, aus der wiederum eine „Achtzigseitenfassung“ hervorgegangen sei, die Roithamer „auf der Fahrt von London nach Altensam“ erneut zu korrigieren begonnen habe, „indem er, wie er glaubte, diese letzte kürzeste Fassung auch noch einmal kürzen und eine noch kürzere Fassung hatte herstellen wollen“; aus dem „über achthundert Seiten umfassenden Material“ seien schließlich, „wie ich aus seinen Korrekturen ersehen kann“, am Ende „nurmehr noch zwanzig oder dreißig Seiten“ übrig

128 Wie Thill: Die Kunst, die Komik und das Erzählen (Anm. 113), S. 211, gezeigt hat, entspricht diese „Form des Korrigierens“ in Korrektur ganz allgemein Bernhards „Prinzip des durch ständiges Zerdenken immer präziser werdenden Denkens“. Vgl. dazu auch Kappes: Schreibgebärden (Anm. 98), S. 190: „Es ist immer eine Korrektur des Geschriebenen vonnöten hinsichtlich eines differierenden Moments, eines von der Beschreibung Unberücksichtigten, Nicht-Erkannten und Nicht-Gesagten, eine Korrektur, zu der Texte Bernhards in fortlaufenden Wiederholungen ansetzen, die sie aber nie vollständig zu leisten imstande sind.“ 
geblieben (TBW 4, 157 f.). ${ }^{130}$ Die Selbstkorrektur als Ausdruck radikaler Skepsis greift vom Schreiben am Ende auf das Leben über: Schreckt Roithamer vor der letzten Konsequenz seines Tuns, der „eigentliche[n] Korrektur“ (TBW 4, 286), d.h. dem Selbstmord, zunächst zurück, ist in der Erzählzeit des Romans, der mit dem Bericht über den "Selbstmord meines Freundes Roithamer" einsetzt (TBW 4, 7), bereits klar, dass er auch diesen Schritt vollzogen hat - ohne jedoch seinen schriftlichen Nachlass zu vernichten und ihn damit vor dem Zugriff der Nachwelt zu bewahren. ${ }^{131}$

In der Figur Roithamers stilisiert Bernhards Korrektur die Monomanie einer künstlerisch-intellektuellen Praxis, wobei die Wiederholungsstruktur des Textes und sein hyperbolisch-superlativischer Gestus durchaus komische Effekte zeitigen. Zugleich verweist die tragische Geschichte des Architekten aber auch auf die Entstehung jenes Buches, in dem diese Geschichte erzählt wird - etwa auf das Problem des Abschlusses eines kreativen Prozesses. Es liegt deshalb nahe, den Roman mit Andreas Gößling auch und im Besonderen als „Selbstreflexion“ eines „ästhetischen Verfahrens“ zu begreifen. ${ }^{132}$ Die geschilderte „Gewalt gegen das zu Korrigierende ${ }^{\text {"133 }}$ ist, zieht man die Textgenese von Korrektur in Betracht, eminent poetologisch aufgeladen: Sie stellt jenen Modus permanenter Selbstkritik ins Zentrum, den Bernhard auch für seine eigene literarische Praxis reklamiert hat. „[E]s ist immer der gleiche Vorgang“, so Bernhard im Dezember 1969 in einem Brief an seine Lektorin Anneliese Botond in Bezug auf Das Kalkwerk (1970), „das Buch ist fertig und zerfällt dann plötzlich in der Nacht, die Trümmer liegen vor mir und ich habe wieder mein Vergnügen daran. “134 Im 1971 publizierten Prosatext Am Ortler. Nachricht aus

130 Dazu Gößling: Thomas Bernhards frühe Prosakunst (Anm. 113), S. 298 f. Roithamer versuche, so Gößling weiter, das Manuskript „dadurch zu retten, daß er alles Disparate tilgt, die Zeichen mehr und mehr verdichtet; aber dieser Prozeß, einmal begonnen, gerät sogleich außer Kontrolle: Mehr und mehr Elemente lösen sich als disparat ab, stärker und stärker muß er verdichten, um das System zu retten“ (ebd., S. 304). - Vgl. auch Hans Höller: Wie die Form der Sprache das Denken des Lesens ermöglicht. Der analytische Charakter von Bernhards Sprache. In: Rhetorik und Sprachkunst bei Thomas Bernhard (Anm. 27), S. 81-90, hier S. 88, sowie Heyl: Zeichen und Dinge (Anm. 111), S. 125.

131 Vgl. dazu Billenkamp: Thomas Bernhard (Anm. 26), S. 204: „Mit jedem Revidieren des von ihm Geschriebenen korrigiert Roithamer auch sich selbst. Den finalen Schritt, der darin besteht, die Aufzeichnungen nach der letzten Überarbeitung zu verbrennen, vollzieht er entgegen seiner ursprünglichen Planung nicht mehr.“

132 Gößling: Thomas Bernhards frühe Prosakunst (Anm. 113), S. 305.

133 Thill: Die Kunst, die Komik und das Erzählen (Anm. 113), S. 211.

134 Thomas Bernhard an Anneliese Botond, 7.12.1969. In: Anneliese Botond: Briefe an Thomas Bernhard. Mit unbekannten Briefen von Thomas Bernhard. 1963-1971. Hg. v. Raimund Fellinger. Mattighofen: Korrektur 2018, S. 170; zuerst gedruckt in: Text + Kritik ( $\left.{ }^{4} 2016\right)$, H. 43 , S. $5-6$. 
Gomagoi erläutert der Erzähler - er arbeitet seit langer Zeit an einer meteorologischen Studie - das Problem künstlerischer Perfektionierung am Beispiel seines Bruders: Dieser beginne immer wieder aufs Neue mit der Erarbeitung eines Kunststücks; er entwickle seine Kunst „bis zu dem Grade ihrer Vollkommenheit“, der aber „gleichzeitig der Grad ihrer Auflösung, ihres Zerfalls“ sei (TBW 14, 171). Das geschilderte Problem betrifft beide Brüder gleichermaßen: Während der eine am Ausdruck seiner „Körperkunst“ (TBW 14, 172) feilt, arbeitet der andere an einer wissenschaftlichen Studie, die zwar „immer wieder eine noch viel kompliziertere Arbeit“, aber „doch immer wieder die gleiche über die Luftschichten“" (TBW 14, 168) sei. Wiederholung und Überbietung des bereits Geleisteten stehen ständig in einem prekären, an der psychischen Substanz der Brüder nagenden Verhältnis. „Ursache aller Schriften, Zweifel über ihr Thema, du verstehst, alles anzweifeln, alles aus der Finsternis herausrecherchieren und anzweifeln und vernichten. Alles. Ohne Ausnahme. Schriften sind zu vernichtende Schriften." (TBW 14, 172) Als zentrale Herausforderung beschreibt der Artist die „Schwierigkeit“, die Ergebnisse des eigenen Tuns - als Wissenschaft oder als artistic research - „zu zeigen oder zu veröffentlichen, ohne augenblicklich Selbstmord machen zu müssen“. Kunst und wissenschaftliche Forschung folgen, so vermittelt es das Schicksal der beiden Brüder, im Grunde ähnlichen Prinzipien: „Körperkunst“ und „Geisteskunst“ stehen jeweils im Spannungsfeld von Vollendung und Vernichtung, und die „Hölle der Veröffentlichung“ (TBW 14, 172) trägt dazu einen wesentlichen Teil bei. ${ }^{135}$

In Äußerungen wie diesen sind die Grundkoordinaten des Schreibprojekts Korrektur, das Bernhard über insgesamt vier Jahre verfolgt hat, im Kern angelegt. Der fertiggestellte Roman überschreitet in der Folge zwar die im Brief an Botond umrissene Konstellation deutlich, weil er den Protagonisten an seiner drastischen Selbstkorrektur auch physisch zugrunde gehen lässt, macht den Bezug zu seiner Entstehungsgeschichte aber keineswegs unsichtbar, sondern stellt ihn im Spiel mit der „Korrektur der Korrektur der Korrektur der Korrektur“ (TBW 4, 317) ostentativ aus. Pierre Bourdieus Idee der „Selbstobjektivierung“, ${ }^{136}$ die der französische Soziologie anhand von Gustave Flauberts Éducation sentimentale entworfen hat, geht von ähnlichen Voraussetzungen aus: „Im Schreiben einer Geschichte, die die seine [i. e. Flauberts] hätte sein können, negiert er, daß diese Geschichte eines Scheiterns die Geschichte desjenigen ist, der sie schreibt. ${ }^{\text {137 }}$ Bezogen auf

135 Vgl. Huntemann: Artistik und Rollenspiel (Anm. 37), S. 21, der bei den beiden Brüdern eine „Angst vor der Entäußerung ihrer Produkte“ feststellt. Dazu auch die Überlegungen in Kappes: Schreibgebärden (Anm. 98), S. 65 f, sowie zum Motiv der „Veröffentlichungsqual“ bei Bernhard die Notizen von Schmied: Auersbergers wahre Geschichte (Anm. 47), S. 148-150.

136 Bourdieu: Die Regeln der Kunst (Anm. 54), S. 55.

137 Ebd., S. 57. 
die Genese des Romans, ließe sich die Figur Roithamers, der die Selbstkorrektur schließlich auch an Leib und Leben vollzieht, als negative, Objektivierung von Bernhards gelingender Schriftstellerexistenz verstehen. ${ }^{138}$ Während Roithamer am Abschluss der Studie, d.h. an seinen eigenen Ambitionen und Ansprüchen, scheitert, publiziert sein Autor Bernhard aller Überarbeitungsnöte und aller Verzögerungen zum Trotz ein (in der Erstausgabe) immerhin 363 Seiten dickes Buch, seinen bis dahin umfangreichsten Roman, im renommiertesten Literaturverlag des deutschsprachigen Raums. Im Gegensatz zu seinem Protagonisten scheitert Thomas Bernhard nicht, sondern bringt sein Buchprojekt erfolgreich zum Abschluss.

In den Prosatexten Die Billigesser (1980) und Der Untergeher (1983) hat Bernhard dieses Sujet bzw. dieses Strukturprinzip erneut aufgenommen. ${ }^{139} \mathrm{Im}$ Untergeher heißt es über den ehemaligen Klaviervirtuosen und nunmehrigen Selbstmörder Wertheimer, er habe ein Buch

veröffentlichen wollen, aber dazu ist es nicht gekommen, weil er sein Manuskript immer wieder geändert hat, so oft und so lange geändert, bis von dem Manuskript nichts mehr dagewesen ist, die Veränderung seines Manuskripts war nichts anderes, als das völlige Zusammenstreichen des Manuskripts, von dem schließlich nichts als der Titel Der Untergeher übriggeblieben ist. (TBW 6, 50) ${ }^{140}$

Dass man diese Zeilen in einem Buch liest, das den Titel Der Untergeher und die Verfasserangabe „Thomas Bernhard“ trägt, verweist - wie auch im Fall von Korrektur - nur zu deutlich auf die Überlegenheit des Autors gegenüber seiner scheitenden Figur.

138 Vgl. dazu auch meine Überlegungen in: Thomas Bernhards, Radikalität'. Versuch einer kultursoziologischen Lesart. In: Das Radikale. Gesellschaftspolitische und formal-ästhetische Aspekte in der Gegenwartsliteratur. Hg. v. Stephanie Willeke, Ludmila Peters u. Carsten Roth. Berlin u. a.: LIT 2017, S. 235-261, hier S. 239 f. Ohne Bezug auf Bourdieu hat schon Klug: Thomas Bernhards Theaterstücke (Anm. 30), S. 3, festgestellt, „das Schreiben“ habe Bernhard als „einzigartige[s] Medium der Selbstanalyse und der Objektivierung der eigenen Schwierigkeiten mit dem Existieren“ gedient.

139 Siehe schon die einschlägige Passage in Bernhards zweitem Roman Verstörung (1967) über einen schreibenden Industriellen: „Er arbeite Tag und Nacht, schreibe und vernichte das Geschriebene wieder, schreibe wieder und wieder und vernichte wieder und nähere sich seinem Ziel.“ (TBW 2, 46)

140 Vgl. dazu Christoph Bartmann: Vom Scheitern der Studien. Das Schriftmotiv in Bernhards Romanen. In: Text + Kritik ( $\left.{ }^{3} 1991\right)$, H. 43, S. 22-29, hier S. 24, sowie Huntemann: Artistik und Rollenspiel (Anm. 37), S. 47 f., der in Wertheimers „Perfektionismus“ eine „Reminiszenz an Roithamers Korrektur-Problematik" erkennt. 
Vom „Streben nach eigener Billigung“

(Der Untergeher, Der Theatermacher)

Darüber hinaus lassen sich gewisse Parallelen zwischen dem in Korrektur geschilderten architektonischen und dem als Schilderung vorliegenden Schreibprojekt feststellen, denn beide - das Kegelbauwerk selbst und das Buch über das Kegelbauwerk - definieren sich ganz wesentlich über die Differenz zu Akteuren und Institutionen der jeweiligen Felder. Roithamers Anspruch, „,etwas [zu] bauen, das noch kein Mensch gebaut hat“ (TBW 4, 238), nämlich „sein Kegelwerk, welches bis dahin niemals hatte ausgeführt werden können“ (TBW 4, 42), richtet sich ausdrücklich gegen das Misstrauen und den Unverstand der „sogenannten Fachleute“ (TBW 4, 43), gegen die Ablehnung des „Fachgesindel[s]“ (TBW 4, 186). Zudem verschafft die Konstruktion des Kegels als „nie dagewesenes Bauwerk“"141 seinem Architekten gerade deshalb die „höchste Befriedigung“ (TBW 4, 238), weil er mit dieser doppelt superlativischen „höchsten Höchstleistung[ ]“ (TBW 4 , 35) den common sense in einem Land überschritten habe, das, so Roithamer, „alle Anzeichen von Geistesschwäche“ (TBW 4, 27) zeige. Nicht etwa das Urteil der „Baufachleute[ ]“ bzw. „der sogenannten Architektenwelt“ (TBW 4, 43) bestätigt das Gelingen des Projekts, vielmehr die feste Überzeugung Roithamers, den Kegel „ganz gegen das Bauen der anderen, ganz gegen die Vorschriften und auch Vorstellungen der anderen“ (TBW 4, 99) errichtet zu haben: Roithamers Kegel ist, so Roland Innerhofer, ein „Zeichen der Souveränität“: „Durch die Errichtung des Bauwerks, für das es in der Tradition kein Beispiel gibt, das sich an keine konventionellen Vorgaben hält, will der Erbauer seine eigene Identität erlangen: nicht durch Erinnerung an die Vergangenheit, sondern durch die Antizipation der Zukunft. “142

Roithamers „totale Rücksichtslosigkeit“ gegenüber ästhetischen Konventionen und sozialen Erwartungen, die der Erzähler und Nachlassbearbeiter beharrlich hervorhebt, geht, wie David Roberts gezeigt hat, mit der „totale[n] Bejahung der eigenen Entwicklung“ einher. ${ }^{143}$ Nur er selbst, keine kritische Instanz von außen, bestimmt über das Glücken seiner Studie wie über den Wert seiner

141 David Roberts: Korrektur der Korrektur? Zu Thomas Bernhards Lebenskunstwerk Korrektur. In: Bernhard. Annäherungen. Hg. v. Manfred Jurgensen. Bern, München: Francke 1981, S. 199-213, hier S. 212; Hahn: Geschichte und Epigonen (Anm. 37), S. 425, schreibt Roithamer das Konzept eines „originalitätsästhetischen Innovationismus“ zu.

142 Roland Innerhofer: Der Kegel als Held. Zu Thomas Bernhards Korrektur. In: Ein Zoll Dankfest. Texte für die Germanistik. Konstanze Fliedl zum 6o. Geburtstag. Hg. v. Susanne Hochreiter u. a. Würzburg: Königshausen \& Neumann 2015, S. 193-200, hier S. 193 f.; vgl. ebd., S. 194 f.: „Der Roithamer'sche Kegel ist eine gebaute Utopie, die sich aus der radikalen Opposition zu aller Überlieferung definiert."

143 Roberts: Korrektur der Korrektur? (Anm. 141), S. 204. 
architektonischen Innovation; „nicht des Geldes wegen, nicht des Ruhmes wegen, nicht aus Eitelkeit“, sondern - wie es in Adalbert Stifters Erzählung Nachkommenschaften heißt, deren Ton und Sujet in mancherlei Hinsicht auf Bernhards Literatur vorausweist - aufgrund des „[S]treben[s] nach eigener Billigung “ ${ }^{144}$ Auch Peter Handke hat in seinen Journalbänden und anderen Genres darüber reflektiert, auf welche Weise ein Schriftsteller als „Selbstmaßregler “145 fungieren könne, ja müsse; „sich selber Maß und Regeln [zu] geben“, hält er im Januar 1988 in einem Notat fest, ${ }^{146}$ sei ein entscheidendes Pensum eines Schreibens abseits gängiger Vorstellungen, das er - und hier schließt sich der Kreis - wiederholt als bewusste und provokante Abkehr von den Erwartungshaltungen der Literaturkritik entworfen hat.

In öffentlichen Statements hat Bernhard regelmäßig auf einer signifikanten Alterität seines Werks beharrt und eine Stellung als „Außenseiter der Literaturgeschichte ${ }^{\text {"147 }}$ für sich beansprucht: Er habe, so der Autor 1979 im Gespräch mit André Müller, „das Gefühl“, „,etwas zu machen, was mir keiner nachmacht, nicht nur bei uns, sondern auf der ganzen Welt nicht“ (TBW 22.2, 160), um zwei Jahre später darauf zu pochen, „nie ein Vorbild gehabt“ zu haben: „Ich hab’ immer nur ich selber sein wollen und hab' immer nur so geschrieben, wie ich selber gedacht hab, und dadurch bin ich in die Gefahr, von irgendso [sic] einem Vorbild aufgesaugt zu werden, gar nie gekommen." (TBW 22.2, 192) Das Selbstverständnis des Autors und jenes seines Protagonisten Roithamer treffen sich in

144 Stifter: Nachkommenschaften (Anm. 97), S. 34. Zur Nähe der Nachkommenschaften zur Literatur Bernhards vgl. die Bemerkungen in Martina Kurz: Bild-Verdichtungen. Cézannes Realisation als poetisches Prinzip bei Rilke und Handke. Göttingen: Vandenhoeck \& Ruprecht 2003, S. 357, Anm. 34: „Der Perfektionismus Roderers [in Stifters Nachkommenschaften] treibt diesen so weit, daß er sich ein Blockhaus in den Wald setzt, um von dort aus ungestört sein Objekt durch ein Fenster kontrollieren zu können; das Gebäude bietet ihm die Gewähr, beständig seine künstlerischen Hervorbringungen mit dem realen Vorbild in kritischer Absicht zu konfrontieren. Diese Unerbittlichkeit verbindet Roderer nicht nur mit Cézanne, sondern hat offensichtlich in Thomas Bernhards Roithamer im Roman ,Korrektur' einen späten Nachfahren gefunden. Roithamer sucht nicht nur seiner Schwester ein vollendetes, gleichfalls der Natur abgerungenes Bauwerk $[\ldots]$ zu errichten, sondern zeichnet sich überdies durch seine mit derselben Konsequenz betriebene dichterische Produktivität aus [...]." Vgl. jedoch die gegensätzliche Position bei Hahn: Geschichte und Epigonen (Anm. 37), S. 451.

145 So der Titel eines kurzen Aufsatzes über Karl Philipp Moritz. Vgl. Peter Handke: Der Selbstmaßregler. Zu Karl Philipp Moritz. [1993] In: P. H.: Mündliches und Schriftliches. Zu Büchern, Bildern und Filmen. 1992-2002. Frankfurt a. M.: Suhrkamp 2002, S. 37-38, hier S. 38: „Kaum jemand ist in einem Buch so streng mit sich selber umgegangen wie Karl Philipp Moritz mit sich als Anton Reiser“; er habe sich, so Handke, durch „eine fast schaurige Härte, nein, Schärfe gegen sich selbst" ausgezeichnet (ebd., S. 37).

146 Peter Handke: Gestern unterwegs. Aufzeichnungen November 1987 - Juli 1990. Salzburg, Wien: Jung und Jung 2005, S. 83.

147 Götze: „Die Redereien und Selbstdarstellungen hasse ich“ (Anm. 23), S. 252. 
diesem Punkt, legen doch beide nachdrücklich Wert auf die Distinktion gegenüber Zeitgenossen und Konventionen - eine Pose, die nicht zuletzt dazu dient, sich gegen Kritik zu immunisieren.

Roithamers fataler Solipsismus erkennt nur das eigene Urteil an. Mit dem Bericht von der intellektuellen Selbstbehauptung des Architekten entwirft Bernhards Korrektur auch die Emanzipation seines Protagonisten von den Urteilen und Einschätzungen Außenstehender, ist dieser doch trotz der offensichtlichen Schwierigkeiten seiner Unternehmung "gar nicht daran interessiert, daß andere seinen Kegel, sein Baukunstwerk in Augenschein nahmen“" (TBW 4, 43). Sätze wie dieser fungieren im Roman als Postulate jener radikalen Unabhängigkeit, die Bernhard auch für sich selbst in Anspruch genommen und etwa in der Korrespondenz mit Siegfried Unseld des Öfteren pointiert festgehalten hat: „Die Ergebnisse sind wichtig, sonst nichts", schreibt er im November 1977 nach Abschluss des Manuskripts von $\mathrm{Ja}(1978),{ }^{148}$ um knapp drei Jahre später die absolute Konzentration auf sich selbst und den eigenen Maßstab erneut zu betonen: "Ich freue mich über eine gelungene Arbeit, das ist alles. ${ }^{\text {" }{ }^{149}}$

Unselds Vorschlag, ein „Vorexemplar“ des Romans Korrektur „einem ganz kleinen Kreis unter den Rezensenten " zur Verfügung zu stellen, ${ }^{150}$ hatte Thomas Bernhard im Herbst 1973 entschieden abgelehnt, „weil mich die Kritiker überhaupt nicht, und die berühmtesten am allerwenigsten interessieren. ${ }^{\text {" } 151}$ Nicht das Urteil der professionellen Leser sollte der Maßstab für das Gelingen seiner nächsten großen Prosaarbeit - im Übrigen des letzten als „Roman“ ausgewiesenen Buches ${ }^{152}$ - sein, sondern die Überzeugung des Autors, sich durch die

148 Bernhard an Unseld, 22. 11. 1977. In: Bernhard/Unseld: Der Briefwechsel (Anm. 2), S. 527. Vgl. ebd.: „Ich denke, es ist eine Prosa geworden, die mich ,glücklich' macht ..."

149 Bernhard an Unseld, 15.9.1980. In: ebd., S. 605.

150 Unseld an Bernhard, 29. 8.1973. In: ebd., S. 388.

151 Bernhard an Unseld, 13. 9. 1973. In: ebd., S. 391.

152 Während Verstörung (1967), Das Kalkwerk (1970) und Korrektur (1975) in den jeweiligen Erstausgaben peritextuell als „Roman“ ausgewiesen werden, fehlt diese Gattungsbezeichnung schon im Prosadebüt Frost (1963) sowie bei allen späteren umfangreichen Prosabänden wie Holzfällen. Eine Erregung (1984) oder Auslöschung. Ein Zerfall (1986). Der Untergeher (1983) heißt zwar auf dem Schutzumschlag der Erstausgabe „Roman“, in der Titelei fehlt der Terminus jedoch. In der Bernhard-Forschung, etwa auch im aktuellen Bernhard-Handbuch, werden die fünf längeren Prosatexte von Beton (1982) bis Auslöschung (1986) meist unkommentiert als „Romane“ bezeichnet, während andere ohne traditionelle Gattungsbezeichnung gedruckte Bücher wie Ja (1978) und Die Billigesser (1980) den „Erzählungen“ zugeschlagen werden. - Heyl: Zeichen und Dinge (Anm. 111), S. 135, zufolge „erwecken Bernhards Texte den Anschein, sich jeder Klassifikation in Gattungen zu entziehen“; er greift aber deutlich zu kurz, in Bernhards „sehr eigenwillige[n] Gattungszuschreibungen“" „lediglich ein Spiel mit paratextuellen Konventionen“ (ebd.) zu sehen. Laut Billenkamp: Thomas Bernhard (Anm. 26), S. 398, macht es Bernhards „virtuose Handhabung biografischer Faktizität und fiktionaler Narration [...] schwierig[,] seine 
erneute Bearbeitung des nur vermeintlich „perfekten Körper[s] des Manuskripts “153 seiner eigenen Idealvorstellung von Literatur zumindest angenähert zu haben. Anstatt „den Maulaffen zwischen Hamburg und München“154 Gehör zu schenken, zähle für ihn, so Bernhards vielfach variiertes Unabhängigkeitsnarrativ, nur sein eigener Maßstab; schließlich sei, wie er im bereits zitierten Gespräch mit Peter Hamm betont hat, „niemand so kritisch mit allen meinen Sachen“ wie er selbst (TBW 22.2, 129).

Wie in anderen Fällen Bernhard'scher Apodiktik wich die Praxis jedoch deutlich vom postulierten Programm ab. Aller suggestiven Rhetorik zum Trotz zeigte sich der Autor - das belegen zahlreiche Berichte von Freunden und Weggefährten - keineswegs unberührt von der literaturkritischen Rezeption seines Werks: „Er hat sicher alle Kritiken gelesen“, bestätigt etwa Hilde Spiel, „hat sich sicher furchtbar gekränkt über die schlechten und die, in denen er mißverstanden wurde. “ 155 "Ich lese sie“, gestand Bernhard, angesprochen auf die Rezensionen seiner Bücher und Theaterstücke, 1976 im Münchner Merkur:

Is' ja blöd zu sagen, das interessiert mich nicht. Ich lese alles, was mir irgendwie erreichbar ist, mach' mir ein Bild. Bin ja net aus Granit oder gehörlos. Ich bin sehr vital, Gott sei Dank, aber auch ein empfindsamer Mensch ... (TBW 22.2, 86)

„[J]eder Verriß und jede schlechte Kritik“ hätten ihm, so Rudolf Brändle, den Bernhard Ende der 1940er Jahre als Patient der St. Veiter Lungenheilanstalt kennengelernt hatte und mit dem er weiterhin freundschaftlich verbunden war, „furchtbar wehgetan“. ${ }^{156}$ Auch sein langjähriger Freund und Weggefährte Wieland Schmied, der bei der Vermittlung von Frost (1963) an den Insel Verlag eine wichtige Rolle spielte, hat den Autor als in dieser Hinsicht „sehr empfindsam“ beschrieben: „[D]ie Resonanz seines Schaffens, vor allem die darüber in den Medien publizierte Meinung“, habe ihm stets "große Pein“ bereitet. ${ }^{157}$ Noch im letzten ausführlichen Interview mit Asta Scheib hat Bernhard 1987 auf die Frage, ob er sich über Verrisse seiner Bücher ärgere, geantwortet: „Ja. Ich falle auch heute noch in jede Grube“, um kurz darauf relativierend hinzuzufügen: „Es trifft mich, aber es stört mich in meiner Arbeit nicht mehr.“ (TBW 22.2, 336 f.)

Prosa gattungsspezifisch zu verorten“. - Eine umfassendere Studie zu Bernhards literarischer ,Gattungspolitik' steht einstweilen noch aus.

153 Bernhard an Unseld, 25.3.1974. In: Bernhard/Unseld: Der Briefwechsel (Anm. 2), S. 423.

154 Bernhard an Unseld, 7.5.1979. In: ebd., S. 561.

155 Krista Fleischmann: Hilde Spiel. In: K. F.: Thomas Bernhard - Eine Erinnerung. Interviews zur Person. Wien: Edition S 1992, S. 141-150, hier S. 146.

156 Krista Fleischmann: Rudolf Brändle. In: ebd., S. 39-50, hier S. 48.

157 Schmied: Auersbergers wahre Geschichte (Anm. 47), S. 149. 
Dieser Übergang von tiefer Betroffenheit zu abgeklärter und souveräner Duldung stellte für Bernhard - aber auch für Handke - eine zentrale Herausforderung dar. Handkes Mitte der 1970er Jahre in Das Gewicht der Welt notierte Sentenz „Was andere über mich sagen, dulde ich, ohne daß es mich betrifft“ ist für beide Autoren eher als vergeblich repetiertes Mantra zu verstehen denn als Beschreibung einer tatsächlich konsequenten Abwendung. ${ }^{158}$

Die Bemerkung des Erzählers von Der Untergeher (1983), der kurz zuvor durch Suizid aus dem Leben geschiedene Pianist Wertheimer habe „unter einem ununterbrochenen künstlerischen Bestätigungszwang“ gelitten (TBW 6, 96), kann wohl auch als selbstreflexiver Kommentar seines Autors Thomas Bernhard gelesen werden: „Wertheimer war immer wichtig zu wissen, was die Leute über ihn denken“, heißt es von dem gescheiterten Künstler, während der sehr viel erfolgreichere, international gefeierte Pianist Glenn Gould darauf „nicht den geringsten Wert" gelegt habe (TBW 6, 79). ${ }^{159}$ Der auf die positive Resonanz der „sogenannten Umwelt" bedachte (TBW 6, 79), ja von ihr abhängige Wertheimer fungiert in Der Untergeher als abschreckendes Beispiel des scheiternden Künstlers, dem der selbstbestimmte, nur seinen eigenen Maßstäben gehorchende Klaviervirtuose Glenn Gould als Wunschbild gegenübersteht: „Glenn war stark“, heißt es in Übereinstimmung mit Harold Blooms Theorie schriftstellerischer Kreativität, „Wertheimer war unser Schwächster“ (TBW 6, 29).$^{160}$ Bloom hat in seiner begriffsprägenden Studie zur Einflussangst bekanntlich die grundlegende Unterscheidung von ,starken' und ,schwachen' Künstlern etabliert, wobei nur der starke Künstler in der Lage sei, der Übermacht der Überlieferung im „Kampf des Künstlers gegen die Kunst“ eine eigenständige, individuelle Position entgegenzusetzen. ${ }^{161}$ Wenn Bloom in seiner 1973 unter dem Titel The Anxiety of

158 Handke: Das Gewicht der Welt (Anm. 59), S. 186.

159 Ein von Sepp Dreissinger zusammengestellter Band mit Erinnerungen von Freunden, Weggefährten, Kollegen u.v. a. trägt den bezeichnenden Titel Was reden die Leute. 58 Begegnungen mit Thomas Bernhard (Anm. 8).

160 Siehe auch die Bemerkung des Erzählers an einer späteren Stelle des Textes: „Die schwachen Charaktere werden immer auch nur schwache Künstler, sagte ich mir, Wertheimer bestätigt das unmißverständlich, dachte ich.“ (TBW 6, 78) Zu Korrespondenzen zwischen Bernhard und Bloom vgl. Ingeborg Hoesterey: Visual Art as Narrative Structure. Thomas Bernhard's Alte Meister. In: Modern Austrian Literature 21 (1988), H. 3/4, S. 117-122, bes. S. 118 u. 120; Hahn: Geschichte und Epigonen (Anm. 37), S. 383 f. u. 453 ff.; Jörg Robert: Wir sind ja diese Verwandtschaft ... Unheimliche Tradition und ,Herkunftskomplex' in Thomas Bernhards Roman Alte Meister. In: Euphorion 105 (2011), H. 4, S. 443-464, bes. S. 451-453, 457 u. 463; Gschwandtner: Thomas Bernhards ,Radikalität' (Anm. 138), S. 237 f.

161 Harold Bloom: Einflußangst. Eine Theorie der Dichtung. Basel, Frankfurt a. M.: Stroemfeld 1995, S. 12. Vgl. dazu mit Blick auf Bernhards Werk Hans Höller: „Gewalt auch über ganz Große“. Thomas Bernhards Überwindung der ,Einflussangst'. In: Thomas Bernhard Jahrbuch 2005/2006, S. 65-74. 
Influence publizierten Arbeit die rücksichts- und skrupellose Aneignung der Tradition zur „Formel jedes starken Dichters“ erklärt, ${ }^{162}$ finden die Reflexionen des Literaturtheoretikers ihre Entsprechung in Bernhards fiktionalen Texten, die das Künstlertum im Spannungsfeld von Scheitern und Triumph verorten. ${ }^{163}$ Die selbstquälerischen Reflexionen der beiden Brüder in Am Ortler kennzeichnet nicht nur die Angst, den eigenen Ansprüchen nie genügen zu können, sondern auch die Scham, öffentlich „etwas zu zeigen, das man ist“ (TBW 14, 172) - und darauf nicht das gewünschte wertschätzende Feedback zu erhalten. Der „Kunststückeangst“ des einen Bruders steht die „Wissenschaftsangst“ des anderen gegenüber (TBW 14, 173); der Künstler befindet sich am Ende der Erzählung „in dem Innsbrucker Vorort Büchsenhausen in einer Anstalt“ - sein Bruder muss bezweifeln, ob „er jemals wieder auftreten wird“ (TBW 14, 189).

Am prägnantesten hat Bernhard den Bestätigungszwang, unter dem viele seiner Protagonisten leiden, in der Figur des Schauspielers Bruscon im 1985 uraufgeführten Stück Der Theatermacher entworfen. Bruscon ist eine tragische, ja beinahe bemitleidenswerte Existenz, ein Schauspieler, der längst nicht mehr auf den großen Bühnen auftritt, den seine Tournee, seine trostlose Never Ending Tour, vielmehr durch Mattighofen, Gaspoltshofen, Ried im Innkreis, Zwicklett und Utzbach führt. Nicht das distinguierte Publikum städtischer Theater besucht die Vorstellungen seines Bühnenstücks Das Rad der Geschichte, sondern das von ihm zutiefst verachtete „Landpack“ (TBW 19, 188). - „Was ist dein Vater / was ist dein Vater" (TBW 19, 160), fordert er seine Tochter Sarah wiederholt dazu auf, ihm, dem abgehalfterten Mimen, seinen künstlerischen Rang zu bestätigen. Als Sarah, die gemeinsam mit ihrer Mutter und ihrem Bruder Bruscons bescheidenes Ensemble bildet, nur „Herr Bruscon“ antwortet, wirft er ihr vor, ein „[u]nverschämtes Mädchen“ und ein „Antitalent“ zu sein; er dulde „keine Widerrede / und keine Gehorsamsverweigerung" (TBW 19, 16o f.). Erst als sie auf die erneute Frage "Also / was ist dein Vater" unwillig und, wie es in der Regieanweisung heißt, „widerstrebend“ repliziert, er sei „, [d]er größte Schauspieler / aller Zeiten“, ist Bruscon einigermaßen zufriedengestellt:

$\mathrm{Na}$ also

Das wollte ich hören

Schließlich ist es mir heute

noch nicht gesagt worden (TBW 19, 161 f.)

162 Bloom: Einflußangst (Anm. 161), S. 71; Höller: „Gewalt auch über ganz Große“ (Anm. 161), S. 70, spricht mit Bloom von der "radikalen kritischen Aneignung“ der „Tradition“ bei Bernhard.

1631995 nahm Harold Bloom Bernhards Holzfällen neben 28 anderen deutschsprachigen Autoren des 20. Jahrhunderts in seinen Band The Western Canon auf. Vgl. Mittermayer: Thomas Bernhard [2015] (Anm. 4), S. 375 f. 
Gleich darauf gibt er freimütig die psychologische Notwendigkeit dieser erzwungenen Bestätigung, seine emotionale Bedürftigkeit preis; sie wirft ein bezeichnendes Licht auf die bloß prätendierte Unabhängigkeit vom Urteil anderer:

\author{
Da ihr selbst \\ nicht auf die Idee kommt \\ mir zu sagen \\ wer ich bin \\ muß es erzwungen werden \\ Ich habe keine andere Wahl mein Kind (TBW 19, 162)
}

Nicht um Erkenntnis durch die kritische Vermittlung zwischen Selbst- und Fremdbild ist es Bruscon zu tun. Der Schauspieler ist von den Lobesworten seiner Familienmitglieder abhängig, selbst wenn ihm diese den Wunsch nur widerwillig und nicht aus eigenem Antrieb erfüllen. ${ }^{164}$ Bruscons Begehr richtet sich nicht mehr auf die differenzierte Auseinandersetzung mit seiner künstlerischen Praxis, mit der er womöglich in einen produktiven Dialog treten könnte, sondern er gibt sich mit der routinierten Bestätigung durch seine Verwandten, von deren Urteil er doch eigentlich wenig hält, zufrieden: „Auch wenn er die Replik erzwingen muss“, so Stefan Krammer, der sich intensiv mit kommunikativen Machtkonstellationen in Bernhards Dramen beschäftigt hat, „scheint das Ritual in seiner Iterabilität und Zitathaftigkeit ein probates Mittel zu sein, sich seiner superlativischen Stellung gewahr zu werden. Wichtig ist dabei aber, dass diese im wiederholten Sprechakt immer wieder von Neuem bestätigt wird. “165 So erweist sich die Figur des Bruscon nicht nur als „witzige Selbstparodie der Kunstprogrammatik Bernhards “ ${ }^{166}$ sondern

164 Zur hierarchischen Struktur der Figurenkonstellation vgl. Judex: Thomas Bernhard (Anm. 126), S. 92 f.; Stefan Krammer: Der Theatermacher. In: Bernhard-Handbuch (Anm. 24), S. 246-250, hier S. 246, zufolge zeigt das Stück „eine hegemoniale Männlichkeit, die innerhalb familiärer Strukturen aufrechterhalten wird“: „In dieser spezifischen Konstellation wird ein problematisches Familiensystem deutlich, das dem Vater scheinbar das Recht dazu gibt, Frau und Kinder auf sein Lebensziel zu verpflichten."

165 Stefan Krammer: Figurationen der Macht. Rhetorische Strategien in Thomas Bernhards Dramen. In: Rhetorik und Sprachkunst bei Thomas Bernhard (Anm. 27), S. 91-103, hier S. 98. Zur „Gewalt asymmetrischer Kommunikation“ bei Bernhard vgl. Eva Marquardt: Gegenrichtung. Entwicklungstendenzen in der Erzählprosa Thomas Bernhards. Tübingen: Niemeyer 1990, S. 27, sowie Verena Ronge: Frauenfiguren im dramatischen Werk Thomas Bernhards. Zur Subversion des Bildes der sprach(macht)losen Frau. In: Text + Kritik ( $\left.{ }^{4} 2016\right)$, H. 43 , S. 200-212.

166 Hans Höller: Thomas Bernhard. Reinbek b. Hamburg: Rowohlt 1993, S. 126; vgl. dazu auch Nicholas J. Meyerhofer: The Laughing Sisyphus. Reflections on Bernhard as (Self-)Dramatist in Light of His Der Theatermacher. In: Modern Austrian Literature 21 (1988), H. 3/4, S. $107-115$. 
auch als schonungslose und fatale Karikatur des Künstlers und seiner „Sehnsucht nach Anerkennung “ ${ }^{167}$ Wie es für den erst gegen Ende seiner Karriere mit Ehrungen überhäuften Schriftsteller Moritz Meister in Über allen Gipfeln ist Ruh (1981) eine andauernde Kränkung darstellt, einst „fünfunddreißig Jahre ohne Echo“ geblieben zu sein (TBW 18, 225), steht auch das Selbstbild Bruscons in einer offensichtlichen Abhängigkeit vom Urteil und von der Bestätigung anderer.

Hier wie dort, in der Fiktion der Erzähl- und Theatertexte wie in der Praxis als Schriftsteller, verschränken sich „Selbstkritik und Narzißmus “168 auf prekäre Weise, und sie stehen dabei nur auf den ersten Blick in Widerspruch zueinander. Bernhards Groll gegen die „Dummheit der Beurteiler“, ${ }^{169}$ denen er die Eignung und Zuständigkeit für die Kommentierung seiner Texte meist grundsätzlich abspricht, erweist sich vor diesem Hintergrund als hochgradig ambivalent. „Nur wenige soziale Individuen“, hat Pierre Bourdieu in diesem Zusammenhang betont, „hängen so sehr wie die Künstler [...] in dem, was sie sind, und in ihrem Bild von sich selbst von der Vorstellung ab, die sich die anderen von ihnen machen. ${ }^{\text {“170 }}$ Dass Bernhard diese Abhängigkeit wiederholt negiert hat, spricht nicht gegen Bourdieus Deutung, ja sie lässt sich vielmehr als Beleg dafür anführen, wie sehr die Prätention interesselosen Handelns für Autorinnen und Autoren am autonomen Pol des literarischen Feldes wichtig ist für deren schriftstellerisches selffashioning; ${ }^{171}$ anderen Maßstäben als den eigenen $\mathrm{zu}$ folgen, gilt dort als Zeichen der Schwäche und Heteronomie. Auch komische Szenen, wie jene in Minetti (1976), in der der titelgebende Schauspieler davon berichtet, „in der Nähe von Folkestone / von einem Gastwirt / in den Ärmelkanal geworfen worden“ zu sein, worauf er, „[a]ngeklammert an eine Wochenendausgabe der TIMES“, aus dem Wasser gerettet werden musste, weshalb er der Zeitung buchstäblich „[s] eine weitere Existenz“ „verdanke“ (TBW 17, 38), haben indirekt teil an der beständigen Reflexion über die Beziehung von Kunst, Kritik und Öffentlichkeit in Bernhards

167 Mittermayer: Thomas Bernhard [2015] (Anm. 4), S. 14.

168 Markus Scheffler: Kunsthaß im Grunde. Über Melancholie bei Arthur Schopenhauer und deren Verwendung in Thomas Bernhards Prosa. Heidelberg: Winter 2008, S. 324.

169 Bernhard an Unseld, 17. 12. 1981. In: Bernhard/Unseld: Der Briefwechsel (Anm. 2), S. 644.

170 Pierre Bourdieu: Künstlerische Konzeption und intellektuelles Kräftefeld. In: P. B.: Kunst und Kultur (Anm. 43), S. 7-49, hier S. 17. - Vgl. dazu auch Georg Franck: Ökonomie der Aufmerksamkeit. Ein Entwurf. München, Wien: Hanser 1998, S. 140: „Auch wenn es denen, die sich zum Gang in die Öffentlichkeit entschließen, nicht nur und nicht vorrangig um das Selbstwertgefühl geht, hängt ihre Selbstwertschätzung fortan vom Kurswert ihres persönlichen Kapitals ab.“

171 Die „Betonung der künstlerischen Autonomie“ hat Michael Billenkamp: Provokation und posture. Thomas Bernhard und die Medienkarriere der Figur Bernhard. In: Mediale Erregungen? Autonomie und Aufmerksamkeit im Literatur- und Kulturbetrieb der Gegenwart. Hg. v. Markus Joch, York-Gothart Mix u. Norbert Christian Wolf. Tübingen: Niemeyer 2009, S. 23-43, hier S. 35, zum „Leitgedanken“ von Bernhards „öffentliche[r] Selbstinszenierung“ erklärt. 
Werk. Der an die Zeitung geklammerte, in seinem Überleben von ihr abhängige Schauspieler wirkt wie eine Parodie des bei Bernhard vielfach thematisierten und in Szene gesetzten Verhältnisses.

„Die Anerkennung, daß er öffentlich bemerkt wird, das war ihm sicher das Wichtigste“, erinnert sich Anfang der 1990er Jahre Franz Josef Altenburg an Bernhards Sensibilität für die Wahrnehmung seines Schreibens und Auftretens in der Öffentlichkeit. ${ }^{172}$ In diesem Sinne hat der auf seine Unabhängigkeit von kritischen Instanzen pochende Autor in Meine Preise schließlich selbst eingestanden, „zur totalen Selbstbeurteilung [...] nicht fähig“ zu sein (TBW 22.2, 410); der „absolut selbstkritische[ ] Zustand als Geisteszustand“, von dem in Wittgensteins Neffe die Rede ist (TBW 13, 265), ist vor diesem Hintergrund mehr ein Wunschbild starker, autonomer Autorschaft denn eine adäquate Beschreibung einer konkreten schriftstellerischen Praxis. Katrin Kohl hat in einer hellsichtigen Studie gezeigt, dass die prätendierte Absage an das Publikum und dessen Bewertungsmaßstäbe für das Autorschaftsmodell vieler Schriftstellerinnen und Schriftsteller eine eminente Herausforderung darstelle: „Wenn nicht die Orientierung am Publikum, sondern ausschließlich die ,inneren' Gesetze des Dichtens und des Kunstwerks als treibende Kraft fungieren sollen, so stehen die Strategien und Wirkmechanismen des Ruhms in Spannung zum Anspruch und zur Bestimmung des Dichters“, weil das Schielen auf „öffentliche[ ] Anerkennung“ bis zu einem gewissen Grad in Widerspruch zur Ablehnung jeglicher "Selbstvermarktung" steht. ${ }^{173}$ In Bernhards poetologischen Kommentaren gerät die Vorstellung, es genüge im Grunde, „von einem Buch nur 1 Exemplar gedruckt“ zu sehen, ${ }^{174}$ mit der Idee des universellen ,Ausstrahlens in Konflikt: „Wenn Sie glauben, Sie schreiben ein Buch, Sie schreiben's nur für sich, und das liest die Omi und der Opa und irgendein blöder Germanist, na, das wäre zu wenig. Ausstrahlen, und zwar nicht nur weltweit, sondern universell." (TBW 22.2, 320)

Das Konzept der ,Selbstkritik' oder der ,Selbstrezension', das nicht zuletzt das arbeitsteilige System des Literaturbetriebs infrage und stattdessen den Autor selbst als Instanz der Beurteilung in den Mittelpunkt stellt, bildet

172 Krista Fleischmann: Franz Josef und Christa Altenburg. In: K. F.: Thomas Bernhard - Eine Erinnerung (Anm. 155), S. 111-122, hier S. 118.

173 Katrin Kohl: Poetologische Metaphern. Formen und Funktionen in der deutschen Literatur. Berlin, New York: de Gruyter 2007, S. 513. Vgl. Huntemann: Artistik und Rollenspiel (Anm. 37), S. 27, der mit Blick auf Bernhards Figuren Folgendes festgehalten hat, was bis zu einem gewissen Grad auch auf den Autor selbst bezogen werden kann: „Sie verachten zwar die Gesellschaft und ziehen sich in die Isolation zurück, sind aber zugleich auf sie als Publikum angewiesen, insofern sie sich mit ihrer Kunst mitteilen wollen." - Zum Problem der Erfüllung von Publikumserwartungen für „Verfechter eines autonomen Hierarchisierungsprinzips“ vgl. Bourdieu: Das literarische Feld (Anm. 43), S. 348.

174 Becker: Bei Bernhard (Anm. 7), S. 84. 
gleichwohl einen wichtigen Aspekt von Bernhards werkpolitischer Agenda. Nur er kann verlässlich über Gelingen und Scheitern Auskunft geben; das „Kulturgeschwätz deutscher Feuilletonisten“, das auch Bernhards schärfster Konkurrent Handke ein ums andere Mal beklagt hat ${ }^{175}$ kann dafür nicht als Richtschnur dienen.

175 André Müller: Im Gespräch mit Peter Handke. Weitra: Bibliothek der Provinz 1993, S. 54 f. 


\section{KRAFT DURCH FEINDE: EINE ART EPILOG}

Können Einwände, die in der Literaturkritik formuliert werden, für Autorinnen und Autoren positive, zur Revision ihres Schreibens anregende Effekte haben? Marcel Reich-Ranicki, Handkes Erzfeind und der wohl prominenteste Kritiker im deutschsprachigen literarischen Feld nach 1945, hat dies wiederholt in Zweifel gezogen und eine entsprechende Wirkung als potentielle ,Schwäche der Schriftsteller identifiziert. Autoren seien, so Reich-Ranicki 1984 im Almanach des Residenz Verlags, „weder lenkbare noch erziehbare Wesen“, ja: „Wenn sich ein Schriftsteller von einem Kritiker erziehen läßt, dann lohnt es sich nicht, diesen Schriftsteller zu erziehen. “1 Dieter E. Zimmer, über viele Jahre Literaturredakteur der ZEIT, hat in einer Festschrift zu Reich-Ranickis 6o. Geburtstag ganz ähnliche Überlegungen angestellt:

Ich glaube nicht an die erzieherische Wirkung von Kritik, es sei denn in nebensächlichen, peripheren Punkten. Es ist eine Illusion, zu denken, Kritik könne einen Autor erziehen. [...] Ein erziehbarer Autor ist einer, der die Kritik wirklich verdient und in dem Maß, in dem seine Erziehung voranschreitet, wohl verstärkt auf sich ziehen wird. [...] Denn daß er erziehbar ist, heißt, daß seine ganz eigene Stimme doch nicht stark und fest genug war. Unmöglich sich vorzustellen, Kafka oder Proust oder Joyce hätten sich durch Kritik beeinflussen lassen; hätten sie es, wären ihre Namen heute vergessen. ${ }^{2}$

Solch pädagogischen Einfluss haben Thomas Bernhard und Peter Handke ebenso entschieden von sich gewiesen, wenngleich sich der Gestus der Zurückweisung bei den beiden Autoren doch recht unterschiedlich ausnimmt: „Dass die Kritiker an Verblödung leiden, ist kein Grund, den Schritt in der eingeschlagenen Richtung,

1 Marcel Reich-Ranicki: Erst die Poesie, dann die Theorie. In: Was Kritiker gerne läsen. Literaturalmanach 1984. Hg. v. Jochen Jung. Salzburg, Wien: Residenz 1984, S. 99-101, hier S. 99. Vgl. dazu auch seine Äußerungen in Marcel Reich-Ranicki: Der doppelte Boden. Ein Gespräch mit Peter von Matt. Zürich: Ammann 1992, S. 56 u. 78: „Schriftsteller lassen sich nicht erziehen. Und wenn sie sich erziehen lassen, dann lohnt es sich nicht.“ - „Meist haben meine Kritiken, wenn es um die Autoren selber geht, nicht viel genützt - und das ist gut so. Die Autoren lassen sich ja nicht erziehen." In dieselbe Richtung gehen die Aussagen in Rolf Becker/Hellmuth Karasek: „Ich habe manipuliert, selbstverständlich!“ Kritiker Marcel Reich-Ranicki über seine Rolle im Literaturbetrieb und seinen Abgang von der FAZ. In: Der Spiegel, Nr. 1, 2.1. 1989, S. 140-146, hier S. 146: „Überspitzt gesagt: Wenn sich ein Schriftsteller von einem Kritiker erziehen läßt, dann lohnt es sich nicht, ihn zu erziehen."

2 Dieter E. Zimmer: Notizen zur Psychologie des Verreißens und Verrissenwerdens. In: Literatur und Kritik. Aus Anlaß des 6o. Geburtstages von Marcel Reich-Ranicki hg. v. Walter Jens. Stuttgart: DVA 1980, S. 120-132, hier S. 126. 
gleich in welcher Richtung, zu verlangsamen“, 3 schreibt Bernhard im November 1970 - seine Rede zur Verleihung des Georg-Büchner-Preises hatte kurz zuvor für geteiltes Echo im Feuilleton gesorgt - an Siegfried Unseld, um diese Beteuerung in der Folge ein ums andere Mal zu wiederholen. Er bekomme, so Bernhard 1977 im Gespräch mit dem Kulturjournalisten Peter von Becker, zwar „regelmäßig eine Wut“ bei der Lektüre von Kritiken, „weil sowieso immer alles falsch ist“, aus der Fassung könnten sie ihn, wie er versichert, aber schon lange nicht mehr bringen: „Ich bin mir meiner Sache vollkommen sicher. ${ }^{\text {" }}$ Im kurz darauf erschienenen Band Der Atem. Eine Entscheidung (1978) hält denn auch der autobiographische Erzähler im Zuge seines Berichts fest, dass „auf das Kopfschütteln, gleich auf welcher Seite und mag sie sich als die kompetenteste ansehen, keinerlei Rücksicht genommen" werden könne (TBW 10, 265) - es liegt nahe, in diesem antizipierten „Kopfschütteln“ auch das Urteil mancher Literaturkritiker zu vermuten.

Alle „Kritiker-Warnungen, die sein Werk von Anfang an begleiten“, habe Bernhard, so Ulrich Greiner, stets „in den Wind“ geschlagen. Er sei nachgerade trotzig „bei immer denselben Konstellationen“ geblieben, „die er in der immer selben kreisenden, bohrenden, auf äußere Geschehnisse mehr und mehr verzichtenden Sprache abhandelt. “5 Dass diese prätendierte Sicherheit und Souveränität durchaus zwiespältig war, weil Bernhard sich um die Rezeption seiner Texte stets besorgt zeigte und ihn manche Verrisse tatsächlich „furchtbar“ schmerzten, wurde im letzten Kapitel bereits ausführlich geschildert. ${ }^{6}$ Es geht dabei nicht zuletzt um den von Georg Franck in seiner Ökonomie der Aufmerksamkeit hervorgehobenen Umstand, dass die „Rolle, die wir im anderen Bewußtsein spielen“, ein integraler „Bestandteil unseres Selbstbildes“ ist. ${ }^{7}$ Für das Verhältnis von Literatur und Literaturkritik heißt das, dass die Selbstbilder, die Autorinnen und Autoren von sich selbst und ihrem Schreiben entwerfen, nicht ohne die Rollen, die sie im „Bewußtsein“ der Rezensenten spielen, auskommen, sondern stets in Korrespondenz zu diesen stehen - so vehement Erstere dies auch von sich weisen.

3 Thomas Bernhard an Siegfried Unseld, 4. 11.1970. In: T. B./S. U.: Der Briefwechsel. Hg. v. Raimund Fellinger, Martin Huber u. Julia Ketterer. Frankfurt a. M.: Suhrkamp 2009, S. 200.

4 Peter von Becker: Bei Bernhard. Eine Geschichte in 15 Episoden. In: Theater 1978. Sonderheft der Zeitschrift Theater heute. Bilanz und Chronik der Saison 77/78 (1978), S. 80-87, hier S. 85.

5 Ulrich Greiner: Die Tortur, die Thomas Bernhard heißt: Korrektur und Die Ursache. [1975] In: U. G.: Der Tod des Nachsommers. Aufsätze, Porträts, Kritiken zur österreichischen Gegenwartsliteratur. München, Wien: Hanser 1979, S. 65-72, hier S. 65.

6 Krista Fleischmann: Hilde Spiel. In: K. F.: Thomas Bernhard - Eine Erinnerung. Interviews zur Person. Wien: Edition S 1992, S. 141-150, hier S. 146. - Vgl. Kap. VII, Abschnitt „Vom ,Streben nach eigener Billigung ““.

7 Georg Franck: Ökonomie der Aufmerksamkeit. Ein Entwurf. München, Wien: Hanser 1998, S. 24. "Angemessener Umgang mit der Aufmerksamkeit anderer zählt“, so Franck, „zum Schwierigsten, was uns Menschen aufgegeben ist.“ (Ebd., S. 219) 
Abschließend soll nun der Frage nachgegangen werden, ob und auf welche Weise die Konfrontation mit der Kritik für die beiden Autoren Bernhard und Handke auch als Motor der Produktivität fungierte. Die in Pierre Bourdieus Kultursoziologie formulierte Einsicht, dass jede Positionierung im literarischen Feld ihren „distinktiven Wert“ aus der „Abgrenzung zu den bestehenden Positionierungen “ bezieht, ${ }^{8}$ ist dafür von entscheidender Bedeutung - bürgen doch im Fall der beiden Autoren gerade die pointierten Gegnerschaften, die öffentlich oder privat ausgetragenen Konflikte und Fehden, für die Individualität und Unverwechselbarkeit ihres künstlerischen Schaffens. Sie sind zudem für die Lenkung und Verstärkung von Aufmerksamkeit im Hallraum der Medien von nicht zu unterschätzender Bedeutung. Im fortwährenden und bisweilen mit harten Bandagen geführten „Kampf um Anerkennung“ spielen „Distinktions-“ bzw. „Erkennungszeichen“, die den einzelnen Akteur unverwechselbar machen, ${ }^{9}$ eine zentrale Rolle; die Auseinandersetzungen mit der Literaturkritik, aber auch die eigenen literaturkritischen Entwürfe sind elementarer Teil dieses Kampfes im literarischen Feld.

Verrisse und kritisches Feedback führten bei Bernhard, folgt man seinen einschlägigen Stellungnahmen, ganz dezidiert nicht zur Korrektur des von ihm verfolgten Kurses. Vielmehr bestärken sie sein literarisches (bzw. in einem umfassenderen Sinn: sein werkpolitisches) Projekt, für das die Irritation, das Vor-den-Kopf-Stoßen ${ }^{10}$ des Publikums ein wesentlicher Bestandteil war: „Die Welt will unterhalten sein“, lässt er den gealterten Schauspieler Minetti im gleichnamigen, 1976 uraufgeführten Stück konstatieren, „aber sie gehört verstört / verstört verstört“ (TBW 17, 31). Bernhards Idee von Autorschaft gewinnt ihr ästhetisches Potential ganz wesentlich daraus, „Reaktionen wie Widerstand oder Ausgrenzung“ zu provozieren, um diesen „Effekt“ des Agierens in der öffentlichen Sphäre gezielt für sich zu nutzen; ${ }^{11}$ das Image des unangepassten, mit seinem Werk stets auf Unverständnis stoßenden Künstlers wird im Sinne eines quod erat demonstrandum bestätigt; der Autor erlangt, so will es diese (auto-)biographische Legende, Kraft und Motivation gerade aus der Ablehnung seiner schärfsten Feinde.

8 Pierre Bourdieu: Das literarische Feld. Kritische Vorbemerkungen und methodologische Grundsätze. In: P. B.: Kunst und Kultur. Kunst und künstlerisches Feld. Schriften zur Kultursoziologie 4. Hg. v. Franz Schultheis u. Stephan Egger. Berlin: Suhrkamp 2015, S. 309-337, hier S. 313.

9 Pierre Bourdieu: Die Regeln der Kunst. Genese und Struktur des literarischen Feldes. Frankfurt a. M.: Suhrkamp 1999, S. 253 f.

10 Schon in der Erzählung Am Ortler (1971) ist vom radikalen „Vordenkopfstoßen“ (TBW 14, 183) die Rede, und Franz-Josef Murau schließlich betont in Auslöschung (1986), er sei ,in [s] einen Vordenkopfstoßmitteln nicht wählerisch“ (TBW 9, 241).

11 Pierre Bourdieu: Das literarische Feld. In: P. B.: Kunst und Kultur (Anm. 8), S. 339-447, hier S. 367 . 
Ohne den Groll zu erwähnen, den ihm negative Kritiken im Laufe der Jahre beschert haben, beschreibt Thomas Bernhard 1986 im Fernsehinterview mit Krista Fleischmann, dass er aus Angriffen gegen seine Person stets neue Kräfte gewonnen habe: „Ich bin immer froh, wenn wer auf mich hinhaut, weil ich dann dreifach zurückhauen kann, und das macht einen ja stark. Sonst würde man ja an einem totalen Muskelschwund leiden - jetzt körperlich und auch geistig gesehen" (TBW 22.2, 312). Mit jener spielerischen Ironie, die sein Spätwerk und insbesondere die Interviews der 1980er Jahre prägt, ${ }^{12}$ hat Bernhard dies in weiterer Folge des Gesprächs mit Fleischmann sogar auf Erfahrungen frühester Kindheit zurückgeführt:

Wer existiert, muß ja irgendwann hinhauen. Sie müssen sich als Kind ja auch schon wehren. Kriegen S' so ein Kinderspielzeug ins Wagerl geworfen, und wenn Sie das nicht oft genug der Mutter oder dem Vater, den lästigen Leuten ins Gesicht schmeißen, als Kind, geh'n S' schon unter, kriegen S' Rachitis, und fertig ist es. Das behalten wir halt bei, als Methode. (TBW 22.2, 312)

Indem Bernhard, sieht man vom offensichtlichen Unernst der zitierten Passage ab, das Beharren auf dem Eigenen zu einem zentralen Moment im Prozess künstlerischer Kreativität erklärt, nimmt er ein Motiv auf, das sich auch in zahlreichen fiktionalen Texten des Autors - und in der Kulturtheorie Harold Blooms ${ }^{13}$ - findet: Nur der starke Künstler (bzw. Forscher) sei in der Lage, sich gegen die literarische (bzw. wissenschaftliche) Tradition wie gegen die Forderungen und Zumutungen seiner Schreibgegenwart zu behaupten und den eigenen Weg beharrlich weiter zu verfolgen. So heißt es von einem der Protagonisten der 1978 veröffentlichten Erzählung $J a$, er gehöre zu jenen Menschen, „die aus sich selbst und also allein aus ihrem Talent oder aus ihren Talenten nichts machen können, weil er ein schwacher Mensch gewesen war“ - ganz im Gegensatz zu „den starken, die nur allein und immer nur ganz allein ihre Talente entwickeln und in höchste

12 Vgl. dazu etwa Nicolas Pethes: „glauben Sie mir“. Die Ausweitung der literarischen Kampfzone in Thomas Bernhards Interviews, Briefen, Preisreden und Feuilletonbeiträgen. In: Text + Kritik ( $\left.{ }^{4} 2016\right)$, H. 43, S. 126-139, hier S. 126 f. Sind bereits die Interviews der 1970er Jahre von assoziativen Wortspielen und „Kalauer[n]“ geprägt (Peter Hamm, zit. nach: TBW 22.2, 486), betreibt Bernhard in den späteren Gesprächen noch intensiver einen „kompromißlosen Abbau des Auratischen" (Wendelin Schmidt-Dengler: Vorwort. In: Von einer Katastrophe in die andere. 13 Gespräche mit Thomas Bernhard. Hg. v. Sepp Dreissinger. Weitra: Bibliothek der Provinz 1992, S. 13-18, hier S. 17), indem er die existentielle Dimension des Todes in humoristisch-komische Bilder überführt: „Ich red’ ja über den Tod wie ein anderer über a Semmel.“ (TBW 22.2, 155)

13 Vgl. Harold Bloom: Einflußangst. Eine Theorie der Dichtung. Frankfurt a. M.: Stroemfeld 1995, S. 9: „Ich beschäftige mich nur mit starken Dichtern, bedeutenderen Gestalten, die genug Ausdauer haben, mit ihren starken Vorläufern sogar bis auf den Tod zu ringen.“ 
Höhen entwickeln können“ (TBW 13, 88). Die Betonung ihrer intellektuellen und sozialen Unabhängigkeit ist sowohl für Bernhards, Geistesmenschen - es handelt sich durchwegs um Männer, die die Frauen in ihrer Umgebung nicht als gleichwertige Gesprächspartnerinnen verstehen - als auch für seine eigene auktoriale posture von entscheidender Bedeutung. ${ }^{14}$

Die Konzepte künstlerischer und wissenschaftlicher Produktivität, die der Autor in fiktionalen Texten wie in poetologischen Selbstauskünften entworfen hat, gehen von einem notwendigen und „ununterbrochene[n] Zur-Wehr-Setzen“ gegen Tradition und Überlieferung aus; „gerade die Autoren, die für mich am wichtigsten sind“, so Bernhard im 1970 von Ferry Radax produzierten Filmmonolog Drei Tage, seien gleichzeitig seine „größten Gegner oder Feinde“:

Der Henry James - ein ständiges Zur-Wehr-Setzen. Meistens kommt man sich lächerlich vor gegen diese Leute, dann darf man aber nicht arbeiten ... Aber nach und nach bekommt man Gewalt, auch über ganz Große ... und man kann sie niederdrücken ... / Man kann sich über die Virginia Woolf oder über Forster erheben, und dann muß ich schreiben. (TBW 22.2, 63)

Nicht nur Bernhards Figuren haben es zu ihrer Maxime erhoben, gegen die kanonisierten Akteure der Geistes- und Literaturgeschichte „mit der größten Grobheit und Roheit“, „[m]it der größten Kühnheit und gleichzeitig Unverschämtheit" vorzugehen (TBW 9, $121 \mathrm{f}$.), um in diesem Widerstreit ihre intellektuelle und künstlerische Eigenständigkeit zu beweisen. Auch der Autor selbst hat sein Schreiben als Auflehnung gegen das Bestehende, gegen das Vorbildliche der kulturellen Tradition wie gegen die Tendenzen und Moden der Gegenwart, ${ }^{16}$ verstanden; er hat sich selbst zum Außenseiter stilisiert, dessen kreative

14 Dazu die exemplarische Untersuchung von Michael Billenkamp: Provokation und posture. Thomas Bernhard und die Medienkarriere der Figur Bernhard. In: Mediale Erregungen? Autonomie und Aufmerksamkeit im Literatur- und Kulturbetrieb der Gegenwart. Hg. v. Markus Joch, York-Gothart Mix u. Norbert Christian Wolf. Tübingen: Niemeyer 2009, S. $23-43$.

15 Im Almanach des Residenz Verlags wurde die Passage 1974 unter dem bezeichnenden Titel Meine größten Gegner erneut abgedruckt. Vgl. Thomas Bernhard: Meine größten Gegner. In: Literatur im Residenz Verlag. Almanach auf das Jahr 1974. Salzburg: Residenz 1974, S. 26-28. Dazu die einschlägigen Lektüren dieses Bernhard-Textes von Manfred Mittermayer: Thomas Bernhard. Stuttgart, Weimar: Metzler 1995, S. 2-5, und Hans Höller: „Gewalt auch über ganz Große“. Thomas Bernhards Überwindung der ,Einflussangst‘. In: Thomas Bernhard Jahrbuch 2005/2006, S. 65-74.

16 Zu dieser „doppelten“ Distinktion, von „der literarischen Tradition zum einen“ und von „den Zeitgenossen zum anderen“, vgl. Marcus Hahn: Geschichte und Epigonen. ,19. Jahrhundert‘ / ,Postmoderne', Stifter / Bernhard. Freiburg i. Br.: Rombach 2003, S. 427 f. 
Energie $^{17} \mathrm{zu}$ nicht unwesentlichen Teilen aus streitbarer Konfrontation und polemischer Abgrenzung von anderen Akteuren im literarischen Feld resultiere: "Seine Arbeit", heißt es in einem 1959 von Bernhard selbst verfassten und in der Monatsschrift Morgen veröffentlichten Porträt, ,verrichtet er mit Energie, mit Zähigkeit und mit Gleichgültigkeit gegenüber seinen Feinden." (TBW 22.1, 577)

„Sie haben es fertiggebracht", schreibt Anneliese Botond am 1. Mai 1967 an Bernhard über dessen zweiten Roman Verstörung, „sich mit diesem Buch, über das alle Kritiker [...] mit Messern und mit Zähnen und Krallen hergefallen sind und noch herfallen werden, als grosser Autor zu etablieren. ${ }^{(18}$ Seine „Würde als Autor" sei, so die Lektorin, auf den ersten Artikel des deutschen Grundgesetzes anspielend, weiter, von den Verrissen des Buches „unangetastet": Unwillen und Unfähigkeit der Kritiker, sich auf die poetische Faktur des Romans einzulassen, sei vielmehr ein Auftrag an den Autor, seinen Weg beharrlich weiter zu verfolgen:

Sie selber werden zu Ende denken müssen, was die Kritiker Ihnen schuldig geblieben sind, und so werden Sie, nicht die Kritiker, herausfinden, ob tatsächlich - was mich am meisten beschäftigt, worüber ich mir aber noch nicht im klaren bin - in der Art zu schreiben, die Ihnen die liebste ist, in der Denksprache (um es verkürzt so auszudrücken), von der Sache selbst her eine Unmöglichkeit liegt. ${ }^{19}$

Botonds Brief, am Tag der Arbeit des Jahres 1967 geschrieben, ist Solidaritätsadresse und Ansporn zu weiteren literarischen Unternehmungen zugleich. Es war gerade diese Mischung aus persönlicher Anteilnahme, emotionaler Rückendeckung und professioneller Unterstützung, die Bernhard an Botond so sehr schätzte: „Sie gehen allein in eine Richtung“, schreibt die Lektorin dem Autor wenige Monate später, „in die Ihnen das Gros vermutlich nur notgedrungen folgen wird“. ${ }^{20}$ Botond sekundiert Bernhard in seiner Skepsis gegenüber der Literaturkritik, indem sie nicht die Kritiker, sondern den Autor selbst darüber urteilen lässt, ob es sich bei seiner „Art zu schreiben“ um eine „Unmöglichkeit" handelt.

„Er hat den Widerstand gebraucht, und er ist am Widerstand, der ihm entgegengetreten ist, den er zu überwinden hatte, an dem ist er sicherlich gewachsen,

17 Die in der Erzählung Ungenach (1968) beschworene „ungeheure Energie gegen das Gemeine, Voraussetzungslose, Niederträchtige, Niedrige, gegen den Menschenunsinn und gegen die Menschenbrutalität" (TBW 12, 21), kehrt später in Statements des Autors, die seine eigene Situation als Schriftsteller betreffen, wieder.

18 Anneliese Botond an Thomas Bernhard, 1.5.1967. In: Anneliese Botond: Briefe an Thomas Bernhard. Mit unbekannten Briefen von Thomas Bernhard. 1963-1971. Hg. v. Raimund Fellinger. Mattighofen: Korrektur 2018, S. 111.

19 Ebd.

20 Botond an Bernhard, 19. 8.1967. In: ebd., S. 127. 
und er hat diesen Widerspruch provoziert", so Bernhards langjähriger Freund und Weggefährte Wieland Schmied. ${ }^{21}$ Die Überzeugung, „praktisch eh alle gegen [s]ich“ zu haben und mit seiner Literatur fast ausschließlich auf Ablehnung gestoßen zu sein (TBW 22.2, 272), ${ }^{22}$ der er in diversen Genres und mitunter sprachlich virtuos Ausdruck verliehen hat, ist für Bernhards Modell von Autorschaft von zentraler Bedeutung. In einem Ende 1980 verfassten Brief an Gerhard Ruiss, der kurz darauf auch öffentlich gedruckt wurde, hat Bernhard diese Frontstellung pointiert festgehalten:

[M]eine Existenz als Schriftsteller in Österreich, das meine natürliche Heimat ist, war von Anfang an von bösartiger Verleumdung und Ignoration begleitet gewesen und immer sind auf Perioden gehässiger Verleumdung solche der totalen Ignoration gefolgt und da ich meine Landsleute kenne, wird sich auch in Zukunft daran nichts ändern, die Verleumdung wird eine noch größere sein, die Ignoration eine totalere, ich kenne die Situation jetzt schon über drei Jahrzehnte, solange schreibe und veröffentliche ich. (TBW 22.1, 665)

Immer wieder hat Bernhard diese pauschale, auf konkrete Beispiele bewusst verzichtende Diagnose auch auf das Verhältnis von Literatur und Literaturkritik bezogen; die beklagte „Verleumdung“ schließt nicht zuletzt die Rezeption seines literarischen Werks in Tages- und Wochenzeitungen, insbesondere durch österreichische „Inkompetenzschmierer“ (TBW 19, 107), mit ein. Er habe sich jedoch, so Bernhard im zitierten Brief an Gerhard Ruiss, mittlerweile „mit der totalen Geistlosigkeit dieser Gesellschaft abgefunden und hege nicht einmal mehr den geringsten Vorwurf“, denn er wolle seine „Arbeit fortsetzen und mich nicht durch die Übermacht des Stumpfsinns, der hier herrscht, schwächen lassen“ (TBW 22.1, 666). Wenn der eigenwillige Physiognomiker Koller im ebenfalls 1980 erschienenen Prosaband Die Billigesser doziert, „der Geistesmensch“ müsse „schon im Augenblick der Geburt den Kampf gegen die Masse aufnehmen“, weil er „naturgemäß immer die Masse und also unvermeidbar, pathetisch ausgedrückt, die ganze Menschheit gegen sich" habe (TBW 13, 162), wird das Konzept des einsamen, der Feindschaft seiner gesamten Umwelt ausgesetzten Solitärs freilich auch ironisch unterlaufen; im Gestus der hyperbolischen Stilisierung wird die

21 Krista Fleischmann: Wieland Schmied. In: K. F.: Thomas Bernhard - Eine Erinnerung (Anm. 6), S. 9-22, hier S. 20.

22 Auch viele Figuren Bernhards entdecken - so etwa in der Erzählung Der Wetterfleck (1971) mit paranoider Aufmerksamkeit „[ [ü]berall“ Zeichen des Hasses gegen sich (TBW 14, 156); diese Konstellation findet sich ebenso in Selbstauskünften des Autors Bernhard: „die Feinde sind überall“ (TBW 22.1, 667). - Brigitte Prutti: Festzertrümmerungen. Thomas Bernhard und seine Preise. Bielefeld: Aisthesis 2012, S. 129, hat in Bernhards einschlägigen Statements ein nicht zu unterschätzendes „paranoide[s] Moment“ ausgemacht. 
Aggression des Intellektuellen angesichts einer geistlosen Gesellschaft lächerlich, sie unterminiert ihren Anspruch auf Validität und Seriosität selbst.

Dieses Changieren zwischen apodiktischem Ernst und spielerischer Selbstdistanzierung ist für Bernhards streitbare Werkpolitik - zumal dort, wo sie an der Schnittstelle von Fiktionalität und Faktualität operiert - generell kennzeichnend. Wie am Beispiel von Frost gezeigt wurde, ${ }^{23}$ gehorchen auch seine Kommentare zur Literaturkritik nicht nur einer "Rhetorik der Bezichtigung “, 24 sondern auch einer Rhetorik der Übertreibung und Stilisierung - wurde der Schriftsteller Bernhard doch keineswegs nur von missgünstigen Feinden, hartherzigen Türhütern und stumpfsinnigen Lesern in seiner Entwicklung gehemmt, seine Karriere vielmehr von freundlichen Förderern, umsichtigen Redakteuren, Lektoren und Verlegern sowie ihm freundlich gesinnten Kritikern begleitet und unterstützt. Literarisch produktiv wird die Distanzierung von den Urteilen der Kritik indes auf zwei Ebenen: Zunächst dienen die Erwiderungen und polemischen Gegendarstellungen, seien sie privat oder öffentlich, der Selbstbestätigung im Dissens, wirken dem literarischen „Muskelschwund“ (TBW 22.2, 312) entgegen. Aber selbst dort, wo Bernhard wortmächtig betont, „meiner Arbeit zuliebe mit meinen Feinden nichts zu tun haben“ zu wollen (TBW 22.1, 667), bringt diese Beteuerung einen Text hervor, hält also den Konflikt und das Schreiben gleichermaßen wie ein Schwungrad in Bewegung.

Sowohl Bernhard als auch Handke haben davon berichtet, sich ihrer „Sache“25 durch die Zurückweisung kritischer Urteile sicherer und klarer geworden zu sein: Gerade der "polemische Stil, mit dem Kritiker ein Urteil vertreten“, ${ }^{26}$ forderte Handke dazu heraus, selbst pointiert Stellung zu beziehen, um die Prinzipien seines Schreibens - wie er es 2009 in einem Interview formuliert hat - „aus einem Gegenstoß heraus ${ }^{\text {“27 }}$ zu verteidigen. Die selbstbewusste Reaktion auf Jakov Linds Besprechung der Hornissen aus dem Jahr 1966, die den programmatischen Titel

23 Dazu Kap. III, Abschnitte „,vollkommen humorlos und blöd‘: Bernhard und die Literaturkritik“ und „,vom peinlichsten Lob bis zum bösartigsten Verriß': Bernhard liest Rezensionen“.

24 Manfred Mittermayer: Lächerlich, charakterlos, furchterregend. Zu Thomas Bernhards Rhetorik der Bezichtigung. In: Rhetorik und Sprachkunst bei Thomas Bernhard. Hg. v. Joachim Knape u. Olaf Kramer. Würzburg: Königshausen \& Neumann 2011, S. 25-44.

25 Etwa im Brief von Peter Handke an Alfred Kolleritsch, 14.11.1969. In: P. H./A. K.: Schönheit ist die erste Bürgerpflicht. Briefwechsel. Salzburg, Wien: Jung und Jung 2008, S. 33: „Aber ich bin meiner Sache, nicht meiner selbst, ziemlich sicher, wenn ich sehe, was die andern so machen."

26 Gerhard Pfister: Handkes Mitspieler. Die literarische Kritik zu Der kurze Brief zum langen Abschied, Langsame Heimkehr, Das Spiel vom Fragen, Versuch über die Müdigkeit. Bern u. a.: Lang 2000, S. 278.

27 Klaus Kastberger/Elisabeth Schwagerle: „Es gibt die Schrift, es gibt das Schreiben.“ Peter Handke im Gespräch. In: Peter Handke. Freiheit des Schreibens - Ordnung der Schrift. Hg. v. Klaus Kastberger unter Mitarb. v. Clemens Özelt. Wien: Zsolnay 2009, S. 11-30, hier S. 13: „Ich möchte nur nicht auftreten als aggressiver Schreibender. [...] Meine ganze Existenz ist eine 
Wenn ich schreibe trägt, ist dafür ein frühes charakteristisches Beispiel: „Was Jakov Lind sagt, sagt er halt. Den Fortgang der Literatur wird er nicht aufhalten. ${ }^{\text {28 }}$ Bei Bernhard wie bei Handke führte die negative Aufnahme ihrer Bücher in Teilen des Feuilletons zudem, wenn man ihren entsprechenden Aussagen Glauben schenken darf, dazu, den eingeschlagenen künstlerischen Weg mit noch größerer Beharrlichkeit weiter zu verfolgen: Es gebe, so Handke 1973 im Interview mit dem Journalisten Christian Schultz-Gerstein, „bestimmte Arten von Verrissen oder böseren Beschreibungen - die spornen mich an“. ${ }^{29}$ Ebenfalls 1973, im Jahr der Verleihung des renommierten Büchner-Preises, hat Handke in einem ausführlichen Gespräch mit Manfred Durzak die Möglichkeit einer produktiven Anverwandlung kritischer Reaktionen umrissen:

Sie haben vorhin schon mal gefragt, ob ich von Rezensionen oder irgendwelchen Analysen beeinflußt werde. Ich glaube das schon. In der letzten Zeit hab ich mir vorgenommen: wenn jetzt wirklich was Geduldiges erscheint, dann will ich das genau lesen, weil ich selber auch ziemlich ratlos bin [...]. Deswegen les ich doch ziemlich genau, was da geschrieben steht und überprüf es mit meinen eigenen manchmal relativ vagen Befürchtungen und Unsicherheiten. Und wenn etwas scharf und bedenklich ist, dann tut's mir eigentlich ganz wohl: das spornt mich dann an, das gibt mir dann aus einer gewissen Apathie heraus, die sich sicherlich einstellt durch eine, wie Sie sagen, Kanonisierung, wieder ein Gefühl von Lebendigkeit, innerhalb des Sich-als-Schriftsteller-Fühlens. ${ }^{30}$

In einem 1975 mit Heinz Ludwig Arnold geführten Gespräch hat Handke kritischen Rezensionen zudem das Potential eingeräumt, ihn in Zeiten eigener Unsicherheit

Verteidigung. Aus der Verteidigung heraus bin ich ein guter Angreifer. Ohne Anlass war ich nie Angreifer. Ich komme immer aus einem Gegenstoß heraus."

28 Peter Handke: Wenn ich schreibe. In: Akzente 13 (1966), H. 5, S. 467. Dazu Kap. II, Abschnitt „Ein Buch ,rehabilitieren'?“.

29 Christian Schultz-Gerstein: Erinnerungen für die Zukunft. Ein Gespräch mit dem diesjährigen Büchnerpreisträger Peter Handke. In: DIE ZEIT, Nr. 43, 19.10.1973.

30 Manfred Durzak: Für mich ist Literatur auch eine Lebenshaltung. Gespräch mit Peter Handke. [1973] In: M. D.: Gespräche über den Roman. Formbestimmungen und Analysen. Frankfurt a. M.: Suhrkamp 1976, S. 314-343, hier S. 329. - Mehr als ein Vierteljahrhundert später hat Handke in einem Essay in der Wiener Tageszeitung Der Standard eine wichtige Unterscheidung zwischen verschiedenen kritischen Positionen getroffen: „In-Frage-Stellen: Ja! Für jedes künstlerische Schaffen ist das fruchtbar und gut. Was aber die Journalisten jetzt machen [in der Berichterstattung zur Uraufführung von Die Fahrt im Einbaum] und zusammenschnüren, das ist kein In-Frage-Stellen, vielmehr Abschaffensdrang.“ (Peter Handke: „Laßt mein Stück in Frieden!“ Kurzer Brief an die „Edelfedern“ des Journalismus. In: Der Standard, 20./21.3. 1999; erneut abgedruckt in: Lieber Peymann, Großfürst der Schnürböden. Dichter schreiben an den Burgtheaterdirektor. In: Die Presse, 14. 3. 2010) 
auf Probleme seines Schreibens aufmerksam zu machen: „Es gibt gewisse Kritiken, die mir zeigen: Aha, ich bin in der Gefahr, so hinzutrudeln. Das Maß ist so schwer zu erreichen, dieses Maß zwischen dem ICH, das man ist, und den anderen; daß man da ein Gleichgewicht findet, ist höllisch schwer - das hat vielleicht nur Goethe erreicht. “ ${ }^{31}$ Das Ideal eines produktiv wütenden Kritikers, das Handke in weiterer Folge entwirft, ist freilich ambivalent, gestehen Autorinnen und Autoren eine solche polemische Intervention for the good of all doch meist nur sich selbst $\mathrm{zu}$, reagieren auf entsprechende Verrisse selbst aber überaus sensibel und verstehen die dort formulierten Einwände weniger auf der Sach- als auf der Beziehungsebene:

Und wenn Sie als Kritiker mal wirklich eine existenzielle Wut kriegen, dann werden Sie natürlich nicht nur einen sogenannten Verriß schreiben, sondern Sie werden versuchen, von Grund auf zu beschreiben, nicht nur was da an dem Buch, sondern an einer bestimmten Lebensauffassung Ihnen mißfällt, was Sie als Pose, Theatralik und als Getue ansehen. Und das wird den oder die dann vielleicht im Schreiben vernichten, aber es wird sie oder ihn noch mehr dazu bringen können, seine Positionen ganz zu überdenken oder irgendwie eine Art Gleichgewicht herzustellen. Und in dem Sinne empfinde ich auch gewisse Kritiken als Korrektur. Ich brauche das auch. ${ }^{32}$

Im Herbst 1977 nahmen zahlreiche Rezensenten Handkes kurz zuvor veröffentlichten ersten Journalband Das Gewicht der Welt mehr als nur reserviert auf. Ulrich Greiner etwa warf dem Autor in der Frankfurter Allgemeinen Zeitung vor, radikal „ichbezogen“ und „selbstherrlich“ zu sein, ${ }^{33}$ Reich-Ranicki äußerte sich nur zwei Tage später im selben Medium nachgerade despektierlich über Handkes aktuelles Buch: Es dokumentiere, so der Kritiker, „den Verfall eines Talents, dessen Größenwahn jegliche Selbstkontrolle ausgeschaltet hat “ ${ }^{34}$ Mogens Mohn, Rezensent der linken Monatsschrift konkret, fühlte sich bei der Lektüre von Das Gewicht der Welt gar an seine Diarien „aus der Primaner-Zeit“ erinnert, hielt sich jedoch zugute, derart „Größenwahnsinnig-Pubertäres“ aus der eigenen Feder längst „verbrannt“ $z u$ haben. ${ }^{35}$

Anfang 1978 trat Siegfried Unseld mit dem Vorschlag an Handke heran, „parallel zum Taschenbuch“ - das bei Residenz erschienene Buch sollte als

31 Heinz Ludwig Arnold: Gespräch mit Peter Handke. [1975] In: Text + Kritik ( $\left.{ }^{3} 1976\right)$, H. 24/24a, S. $15-37$, hier S. 36 .

32 Ebd.

33 Ulrich Greiner: Peter Handke und das Glücksgefühl, eine Flasche Mineralwasser anschauen zu können. In: Frankfurter Allgemeine Zeitung, 11.10.1977; unter dem Titel Ein routinierter Narziß auch in U. G.: Der Tod des Nachsommers (Anm. 5), S. 92-97, hier S. 93.

34 Marcel Reich-Ranicki: Deutsche Literatur 1977. Ein Überblick aus Anlaß der Frankfurter Buchmesse. In: Frankfurter Allgemeine Zeitung, 13.10.1977.

35 Mogens Mohn: Nicht mehr mit Simmel allein. In: konkret (1977), H. 12, S. 37-38, hier S. 37. 
Paperback-Ausgabe in den Suhrkamp Verlag übernommen werden -, „selbstverständlich in einem gesonderten Band, den Kampf mit der Kritik aufzunehmen“" ${ }^{36}$ Unselds Vorschlag, man könne auf diese Weise „Kritiker Kritiker kritisieren lassen“, ${ }^{37}$ um damit „andere kritische Kriterien“ ins Spiel zu bringen, ${ }^{38}$ konnte der Autor allerdings wenig abgewinnen. Einen „Kommentarband“ ${ }^{39}$ oder einen „Kritikeraufsatz“ hielt er in seinen beiden Antwortbriefen an Unseld ausdrücklich nicht für die geeignete Form der Erwiderung: „Vielleicht kann ich statt dessen fürs Taschenbuch eine kurze, unpolemische Vorbemerkung hinzufügen zumal ich inzwischen, durch viele Reaktionen (und deren Intensität) bestärkt, meiner (jedenfalls dieser) Sache recht sicher geworden bin. “40 Handke wollte die Verteidigung seiner Poetik demnach nicht anderen Kritikern übertragen (sollten diese ihm auch wohlgesinnt $\operatorname{sein}^{41}$ ), sondern selbst, „bestärkt“ durch den Zuspruch vieler Leserinnen und Leser, aber auch angestachelt durch das Unverständnis weiter Teile der Literaturkritik, tätig werden: „Habe ich“, heißt es in der im Laufe der vorliegenden Studie bereits zitierten Notiz aus der Geschichte des Bleistifts (1982), deren Niederschrift in diese Zeit fällt, „nicht seit jeher erst gegen die anderen gewußt, wer ich bin?“" ${ }^{42}$ Im „Universum“ des literarischen Feldes, „in dem“ - mit Pierre Bourdieu gesprochen - „existieren differenzieren

36 Siegfried Unseld an Peter Handke, 6. 1. 1978. In: P. H./S. U.: Der Briefwechsel. Hg. v. Raimund Fellinger u. Katharina Pektor. Berlin: Suhrkamp 2012, S. 333.

37 Ebd.

38 Unseld an Handke, 30. 1. 1978. In: ebd., S. 335.

39 Handke an Unseld, 3. 2.1978. In: ebd., S. 338.

40 Handke an Unseld, 17. 1. 1978. In: ebd., S. 334. Zugleich hat Handke in diesen Jahren auch seine Verletzlichkeit im Hinblick auf negative Kritiken betont, so etwa in einem 1979 auf Englisch geführten Interview: „I believe that to receive no encouragement but to be portrayed always as an enemy is very, very damaging to this good creative impulse which a writer needs. This creative impulse is the most valuable thing which one can have; that is all I know." (June Schlueter: An Interview with Peter Handke. [1979] In: Studies in $20^{\text {th }}$ Century Literature 4 (1980), H. 1, S. 63-73, hier S. 72)

41 Er habe, so Handke wenig später, durchaus „sehr schöne, herzerwärmende, d. h. genau teilnehmende Kritiken“ von Das Gewicht der Welt gelesen, was an seiner Ablehnung des ,Begleitbandes‘ aber allem Anschein nach wenig änderte (Handke an Unseld, 3. 2. 1978. In: ebd., S. 338). Zu den positiven Rezensionen zählte etwa die Besprechung von Sigrid Löffler: Die Wahrnehmungshölle des Peter Handke. In: profil, Nr. 39, 27.9. 1977, S. 53-54; auch der einst scharfe Handke-Kritiker Hans Christoph Buch zeigte sich angesichts von Das Gewicht der Welt überraschend freundlich: „Kein Zweifel: diese Aufzeichnungen aus den Jahren 1975 bis 1977, eine Mischung aus Arbeitsjournal und intimem Tagebuch, gehören zum Besten und Schönsten, was derzeit in deutscher Sprache zu lesen ist." (Hans Christoph Buch: Der vollkommene Schauspieler. Über Peter Handke: Das Gewicht der Welt. In: Der Spiegel, Nr. 37, 5.9.1977, S. 197-201, hier S. 197)

42 Peter Handke: Die Geschichte des Bleistifts. Salzburg, Wien: Residenz 1982, S. 156. 
heißt ${ }^{43}$ ist die Bestimmung des eigenen Schreibens ganz wesentlich davon geprägt, es als Gegenentwurf zum bereits Vorhandenen, zu bereits etablierten ästhetischen Verfahren und zu Erwartungshaltungen von Publikum und Kritik gleichermaßen, zu positionieren.

Drei werkbiographische ,Szenen' sollen zentrale Aspekte der Arbeit zum Abschluss ein letztes Mal anekdotisch in den Blick rücken: „Einmal freute Philip Kobal sich innig über seine Feinde", heißt es im 1998 veröffentlichten Salzburger Journal Am Felsfenster morgens, das Aufzeichnungen aus den Jahren 1982 bis 1987 enthält, über den Protagonisten der großen Erzählung Die Wiederholung (1986), „sie dienten ihm als Erkenntnismittel“; ${ }^{44}$ und kurz zuvor in Die Geschichte des Bleistifts (1982), mit dem Pathos dieser Jahre, das in den Bänden der Tetralogie Langsame Heimkehr seinen Ausdruck gefunden hat: „In jedem noch so dummbösen Angriff, der einem entgegengebracht wird, steckt ein guter Satz für die ewige Erzählung “ ${ }^{45}$ Wiederholt hat Peter Handke geäußert, dass ihn selbst hämische Rezensionen seiner Bücher, an denen zumal Ende der 1970er, Anfang der 1980er Jahre kein Mangel herrschte, dazu ermuntert hätten, sein im zeitgenössischen Kontext hochgradig eigensinniges Schreibprojekt umso überzeugter weiterzuführen: Er zweifle zwar ständig an sich selbst und dem Gelingen seiner erzählerischen Arbeit: „Aber das Seltsame ist, daß ich gerade, wenn man mich niedermacht, am ehesten weiß, wer ich bin. Sonst weiß ich das nicht. ${ }^{“ 46}$ Wenn die Figur der Nova im 1981 veröffentlichten und im Jahr darauf in der Salzburger Felsenreitschule uraufgeführten Stück Über die Dörfer am Beginn ihres großen Schlussmonologs ankündigt, sie könne nur „im Widerstand“ so „reden, wie ich reden werde “ ${ }^{\text {“ }}{ }^{7}$ ist damit - verkleidet in der Fiktion der Bühne - auch ein Grundprinzip von Handkes streitbarer Poetik formuliert. Nicht von ungefähr hat Handke im Dezember 2019 Passagen aus Über die Dörfer in seine Rede anlässlich der Verleihung des Literaturnobelpreises aufgenommen.

Das Wort „Talschaft“ “48 ein „altes, übliches Wort für eine Gegend aus einer Mehrzahl von Tälern“, sei ihm, so Handke im Essay Über Lieblingswörter (1991), gerade dadurch „ans Herz gewachsen“, „daß ein geschätzter Kritiker es dann

43 Bourdieu: Die Regeln der Kunst (Anm. 9), S. 253.

44 Peter Handke: Am Felsfenster morgens (und andere Ortszeiten 1982-1987). Salzburg, Wien: Residenz 1998, S. 155.

45 Handke: Die Geschichte des Bleistifts (Anm. 42), S. 229.

46 André Müller: Im Gespräch mit Peter Handke. Weitra: Bibliothek der Provinz 1993, S. 90.

47 Peter Handke: Über die Dörfer. Dramatisches Gedicht. Frankfurt a. M.: Suhrkamp 1981, S. 96.

48 Der Begriff findet sich in Peter Handke: Die Wiederholung. Frankfurt a. M.: Suhrkamp 1986, S. 147 f. u. 152. Handke hat die Verwendung des Wortes in seinem Erzähltext selbst explizit thematisiert: „Wenn ich jetzt die Augen schließe, öffnet sich vor mir ein weltentferner [sic], von dem leeren fjordblauen See bestimmter, von den Gebirgen geschützter, von den Moränenwellen 
lachhaft fand, in seinen Augen fast so verstiegen wie ,Kelchschaft “ ${ }^{49}$ Zwar habe ihn Benjamin Henrichs' Rezension der Wiederholung zunächst gekränkt, nicht zuletzt, weil dieser einst ein "getreuer Leser und Kritiker“ seiner Bücher gewesen sei, wie der Autor 1987 im Gespräch mit Heinz-Norbert Jocks bekannt hat. ${ }^{50}$ Der 1991 in der ZEIT gedruckte Text Über Lieblingswörter legt freilich nahe, dass Handke bald darauf nicht mehr gewillt war, sich durch einen Einwand wie diesen irritieren zu lassen, sondern, ganz im Gegenteil, den ihm „ans Herz gewachsen[en] “ Begriff der „Talschaft“ desto selbstbewusster weiter zu verwenden. In Mein Jahr in der Niemandsbucht (1994) hat Handke das Wort demonstrativ wieder aufgenommen, wenn es von Filip Kobal, der hier als literarische Figur erneut auftaucht, heißt, er sei „für sein nächstes Volksbuch zurückgekehrt in unsere gemeinsame Talschaft", um es mehr als 600 Seiten später noch einmal in den Erzähltext einzuspeisen:

Sonst regnete es im Frühjahr eine Zeitlang so stark, daß einige der ehemaligen Bäche, ohne die es ja nie zu dem ziemlich unübersichtlichen Netz von Talschaften, oft geradezu Schluchten und Schründen, in der Vororte-Landschaft gekommen wäre, aus der Kanalisation traten $[\ldots] . .^{51}$

am Boden vielfach abgeteilter Fluchtraum, für den kein Wort so treffend ist wie das eingangs gebrauchte ,Talschaft."“ (Ebd., S. 148)

49 Peter Handke: Über Lieblingswörter. [1991] In: P. H.: Langsam im Schatten. Gesammelte Verzettelungen. 1980-1992. Frankfurt a. M.: Suhrkamp 1992, S. 14-15, hier S. 15. Gemeint ist die Rezension der Wiederholung von Benjamin Henrichs: Der Evangelimann. Glücksmärchen, Wanderpredigt, Lesefolter: Die Wiederholung - Peter Handkes neues Buch. In: DIE ZEIT, Nr. 41, 3. 10. 1986: „Der Erzähler sieht nicht, er ,gewahrt'; er denkt nicht, er ,bedenkt'; wenn er zurückdenkt, dann nicht an Kindheit, sondern an ,Kindschaft'; wenn er zurückblickt, dann nicht ins Tal, sondern in die ,Talschaft. (Die ,Kelchschaft' immerhin erspart er seinem Leser.) “ Vgl. dazu Thorsten Carstensen: Romanisches Erzählen. Peter Handke und die epische Tradition. Göttingen: Wallstein 2013, S. $12 \mathrm{f}$.

50 Heinz-Norbert Jocks: Ein Märtyrer unter Erzählzwang. Sonntagnachmittag eines Autors. Bei Peter Handke in Salzburg. In: Stuttgarter Zeitung, 28.3.1987.

51 Peter Handke: Mein Jahr in der Niemandsbucht. Ein Märchen aus der neuen Zeit. Frankfurt a. M.: Suhrkamp 1994, S. 159 u. 788. Zwei Jahre darauf ist Handke im Reisebericht Sommerlicher Nachtrag zu einer winterlichen Reise erneut auf den Begriff „Talschaft“ zurückgekommen und hat ihn dort als geographischen Fachterminus ausgewiesen. Vgl. Peter Handke: Sommerlicher Nachtrag zu einer winterlichen Reise. Frankfurt a. M.: Suhrkamp 1996, S. 64. - Zu Handkes „Selbstzitaten“ vgl. Herwig Gottwald: Von Namen, Augenblicksgöttern und Wiederholungen. Handkes Umgang mit dem Mythischen. In: Peter Handke. Poesie der Ränder. Hg. v. Klaus Amann, Fabjan Hafner u. Karl Wagner. Wien u. a.: Böhlau 2006, S. 135-153, hier S. 146, sowie zuletzt Oliver Kohns: Werkimmanente Intertextualität bei Peter Handke. Selbstzitat, -fortschreibung, -kommentar und -parodie. In: Die tägliche Schrift. Peter Handke als Leser. Hg. v. Thorsten Carstensen. Bielefeld: transcript 2019, S. 231-242. 
Handkes trotzige Wiederaufnahme des von Benjamin Henrichs maliziös herausgegriffenen Wortes erinnert an Jean Cocteaus vielzitierten Rat an junge Künstler, gerade jene Aspekte ihres Schaffens zu kultivieren und weiterzuentwickeln, die von den Kritikern am schärfsten attackiert werden, weil diese ihre Individualität, ihr Eigenes ausmachten. ${ }^{52}$

In Mein Jahr in der Niemandsbucht lässt Handke sein Alter Ego Gregor Keuschnig, einen Wiedergänger aus der Stunde der wahren Empfindung (1975), auf dem Nachhauseweg „einen Bogen vorbei an dem tagsüber in die Garage gesperrten Nachbarshund" machen, um sich „von dem massigen Tier, das dabei in einem fort das Stahltor ansprang, gründlich an- und ausbrüllen zu lassen ${ }^{\alpha, 53}$ bevor er, zu Hause angelangt, mit dem Schreiben beginnt: „Der erste Satz hernach, nicht vorbedacht, führte mich gleich weit zu der Waldbucht hinaus, und jetzt erst kann ich dorthin zurückkehren. ${ }^{\text {" } 54}$ Es ist nicht gänzlich abwegig, diese Passage auch als Anspielung auf die konfliktreiche Beziehung Handkes zu Reich-Ranicki zu lesen, zumal der autornahe Erzähler der Niemandsbucht die Verknüpfung von Hund und übelwollendem Kritiker, die Handke in der Lehre der Sainte-Victoire etabliert hatte, gleich an zwei Stellen des Buches aktualisiert, wenn er ReichRanicki als „wahnsinnigen“ Köter auftreten lässt. ${ }^{55}$ Sich von Zeit zu Zeit (von Hundeartigen oder Kritikern) aus- und anbellen zu lassen, scheint in dieser Lesart dem Schreibprojekt des Autors gar nicht zu schaden.

Während der Schriftsteller und Philosoph Manès Sperber der Überzeugung war, man solle im Sinne der Souveränität „seinem Feind die Gunst der erwiderten Feindschaft vorenthalten ${ }^{\text {“ }}{ }^{56}$ haben Thomas Bernhard und Peter Handke ihre Feindschaften, und nicht zuletzt jene zur Literaturkritik und zu einzelnen Literaturkritikern, sorgsam gepflegt, ja auf dem Übelwollen der Gegner geradezu insistierend bestanden: „Ich und meine Arbeit haben so viele Feinde, wie Österreich Einwohner hat", so Bernhard 1982 in seinem Beitrag zu jenem Almanach, in dem auch Sperbers sehr viel friedfertigere Maxime abgedruckt wurde (TBW 22.1, 625). Teil dieser mehr imaginierten als tatsächlich bestehenden Front der Feinde sind für Bernhard immer auch die Journalisten und Kritiker. Er war stets bemüht, sich von den Urteilen der Rezensenten unbeeindruckt zu zeigen, und machte jenen Schriftstellern, die sich von einer „kleine[n] positive[n]

52 Dazu Susanne Winter: Jean Cocteau und die Schwierigkeit zu sein. In: Leben als Kunstwerk. Künstlerbiographien im 20. Jahrhundert. Hg. v. Christopher F. Laferl u. Anja Tippner. Bielefeld: transcript 2011, S. 59-84, hier S. 81 f.; Robert Schediwy: Rückblick auf die Moderne. Wien, Berlin: LIT 2014, S. $21 \mathrm{f}$.

53 Handke: Mein Jahr in der Niemandsbucht (Anm. 51), S. $741 \mathrm{f}$.

54 Ebd., S. 742.

55 Ebd., S. 422.

56 Manès Sperber: Meine Feinde. In: Mein(e) Feind(e). Literaturalmanach 1982. Hg. v. Jochen Jung. Salzburg, Wien: Residenz 1982, S. 121-125, hier S. 125. 
Zeitungsbesprechung“, von „ein paar dumme[n] lobende[n] Erwähnungen, im Kurier oder in der Presse“ (TBW 7, 63), geschmeichelt fühlten, dies wiederholt zum Vorwurf.

Thomas Bernhard und Peter Handke haben ein ums andere Mal auf der Unabhängigkeit ihres Schreibens von der positiven wie negativen Rezeption vonseiten der Literaturkritik bestanden; ihre Selbstaussagen changieren dabei zwischen dem Ideal gleichmütigen Ignorierens und der Vorstellung, gerade aus dem Widerspruch und der Ablehnung bestimmter Teile des Feuilletons neuen Antrieb und neue Kraft zum Schreiben zu gewinnen. Eine von Handke unter dem Datum des 21. Juni 1976 - zwei Tage vor seiner brieflichen Abrechnung mit ReichRanicki - notierte Sentenz hält die angestrebte Autonomie und Souveränität des Autors pointiert fest und kann dabei für Bernhard und Handke gleichermaßen gelten: „Ich bin nur kritisierbar innerhalb der Idee, die ich von mir selber habe “. ${ }^{\text {. }}$

57 Peter Handke: Das Gewicht der Welt. Ein Journal (November 1975 - März 1977). Salzburg: Residenz 1977, S. 198. 


\section{DANKSAGUNG}

"Ich sagte ja selber einmal zum Fuhrmann“, heißt es in Thomas Bernhards 1969 veröffentlichtem Prosatext Watten. Ein Nachlaß, „die ganzen Tage, Jahre sind nichts als eine einzige Kapitulation vor diesem Papierhaufen, geehrter Herr, die Frage sei nur noch, wann diesen Haufen verbrennen. “- Daran, dass ich im Lauf der Jahre vor dieser Dissertation nicht kapituliert habe, haben viele Menschen einen gewichtigen Anteil, waren Wegbereiter und Wegbegleiterinnen, Mutmacher und aufmerksame Gesprächspartnerinnen. Zunächst sind die beiden Betreuer dieser Arbeit, Norbert Christian Wolf und Werner Michler, zu nennen; für ihre langjährige Unterstützung des Projekts an der Universität Salzburg bin ich ihnen zu großem Dank verpflichtet. Für die freundliche, faire und überaus konstruktive Abhaltung der Defensio meiner Doktorarbeit am Fachbereich Germanistik der Universität Salzburg danke ich Herwig Gottwald und Ulrike Tanzer sehr herzlich.

Eine wichtige Basis meiner Dissertation konnte ich bei insgesamt drei Aufenthalten am Deutschen Literaturarchiv in Marbach/Neckar erarbeiten. Meine dortigen Recherchen wurden im Januar/Februar 2013 durch ein SuhrkampStipendium gefördert sowie im Juli/August 2013 durch die Marbacher Sommerschule ermöglicht. Für Hilfestellungen und Beratung vor Ort danke ich Anna Kinder stellvertretend für alle Mitarbeiterinnen und Mitarbeiter des Archivs sehr herzlich. Johannes Kempf war in Marbach ein guter Freund und großzügiger Gastgeber.

Von 2016 bis 2019 war ich an der Universität Salzburg in das Doktoratskolleg „Ästhetische Kommunikation“ eingebunden. Der Austausch mit meinen Kommilitoninnen und Kommilitonen hat mir für meine Arbeit manchen weiterführenden Hinweis gegeben. Meine Senior-Scientist-Stelle an der Universität Salzburg wurde von 2016 bis 2018 vom Referat „Kultur und Wissenschaft“ des Landes Salzburg gefördert. Im September 2018 hat mir ein Forschungsstipendium der Thomas-Bernhard-Privatstiftung einen wichtigen Schritt auf dem Weg zum Abschluss der Dissertation sowie einen dreiwöchigen Aufenthalt in Ottnang am Hausruck ermöglicht. Von Oktober bis Dezember 2018 schließlich hat ein großzügiges Stipendium der Literar-Mechana mir die Zeit gegeben, der Arbeit den (fast) letzten Schliff zu verleihen.

Im Rahmen von Tagungen und Workshops in Bayreuth, Innsbruck, Marbach, Neuchâtel, Paderborn, Salzburg und Zadar konnte ich erste Ergebnisse meiner Forschungen zu Thomas Bernhard und Peter Handke vorstellen. Die ThomasBernhard-Tage in St. Veit/Pongau waren für mich ein wichtiges Diskussionsforum, ihre langjährigen Organisatorinnen und Kuratoren (Hilde Brandstetter, Richard Donauer, Hans Höller, Martin Huber, Bernhard Judex, Renate Langer, Manfred Mittermayer) Ansprechpartner und freundliche Helferinnen. Zudem 
haben die Veranstaltungen und Gespräche am interuniversitären Schwerpunkt „Wissenschaft und Kunst“ den Blick auf das Thema meiner Dissertation geschärft und ihr neue Impulse verliehen. Die Plattform „HANDKE online“ bot stets eine verlässliche Anlaufstelle zum Werk des Autors; Christoph Kepplinger-Prinz und Katharina Pektor danke ich in diesem Zusammenhang für vielfältige Hilfe und die Bereitstellung von Materialien.

Für die Genehmigung zum „Ein- und Ausschauhalten bei den Sie interessierenden Briefen“ sowie für die Einwilligung, drei bis dato unpublizierte Briefe an Marcel Reich-Ranicki für meine Arbeit zu verwenden, danke ich Peter Handke sehr herzlich. Raimund Fellinger vom Suhrkamp Verlag hat es mir ermöglicht, in den Beständen des DLA Marbach die Korrespondenz und die Notatbände von Peter Handke einzusehen. Anny und Peter Fabjan danke ich ganz besonders für die Gastfreundschaft in Ottnang und für die Erlaubnis, bislang unveröffentlichte Briefe von Thomas Bernhard hier abdrucken zu dürfen.

Neben meinen beiden Betreuern hatten am Salzburger Fachbereich Germanistik auch Uta Degner, Daniel Ehrmann, Anna Estermann, Herwig Gottwald, Paul Keckeis, Arturo Larcati, Marlen Mairhofer, Gertraud Mitterauer und Clemens Peck stets ein offenes Ohr, waren aufmerksame Ansprechpartnerinnen und freundliche Begleiter meines Schreibens. Uta Degner, Günther Eisenhuber, Hannes Karl Wallner und Katharina Zeppezauer-Wachauer haben Teile der Arbeit gegengelesen und dabei den einen oder anderen Fehler ausgebügelt: vielen lieben Dank dafür!

Magdalena Stieb hat lange Jahre die Arbeit an der Dissertation begleitet und mich immer wieder aufs Neue zum Weiter- und Fertigschreiben angespornt. Lina Maria Zangerl hat meine Zweifel vor der Einreichung zerstreut, mich in meiner Unternehmung bestärkt und ist mir in Zeiten wiederkehrender Desperation zur Seite gestanden.

Abschließend möchte ich meiner Familie und meinen Eltern, Anneliese und Peter Gschwandtner, mit ganzem Herzen für ihre Unterstützung und ihre Geduld in all den Jahren meines Studiums und meiner Arbeit an der Promotion danken. 


\title{
X BIBLIOGRAPHIE
}

\author{
Primärliteratur und Quellen
}

Thomas Bernhard

Werkausgabe

Werke. 22 Bde. Hg. v. Martin Huber u. Wendelin Schmidt-Dengler. Frankfurt a. M., Berlin:

Suhrkamp 2003-2015. [mit der Sigle „TBW“, Band- und Seitenzahl ausgewiesen]

Bd. 1: Frost. Hg. v. Martin Huber u. Wendelin Schmidt-Dengler. Frankfurt a. M.:

Suhrkamp 2003.

Bd. 2: Verstörung. Hg. v. Martin Huber u. Wendelin Schmidt-Dengler. Frankfurt a. M.:

Suhrkamp 2003.

Bd. 3: Das Kalkwerk. Hg. v. Renate Langer. Frankfurt a. M.: Suhrkamp 2004.

Bd. 4: Korrektur. Hg. v. Martin Huber u. Wendelin Schmidt-Dengler. Frankfurt a. M.:

Suhrkamp 2005.

Bd. 5: Beton. Hg. v. Martin Huber u. Wendelin Schmidt-Dengler. Frankfurt a. M.:

Suhrkamp 2006.

Bd. 6: Der Untergeher. Hg. v. Renate Langer. Frankfurt a. M.: Suhrkamp 2006.

Bd. 7: Holzfällen. Hg. v. Martin Huber u. Wendelin Schmidt-Dengler. Frankfurt a. M.:

Suhrkamp 2007.

Bd. 8: Alte Meister. Hg. v. Martin Huber u. Wendelin Schmidt-Dengler. Frankfurt a. M.:

Suhrkamp 2008.

Bd. 9: Auslöschung. Hg. v. Hans Höller. Frankfurt a. M.: Suhrkamp 2009.

Bd. 10: Die Autobiographie. Hg. v. Martin Huber u. Manfred Mittermayer. Frankfurt a. M.: Suhrkamp 2004.

Bd. 11: Erzählungen I. Hg. v. Martin Huber u. Wendelin Schmidt-Dengler. Frankfurt a. M.: Suhrkamp 2004.

Bd. 12: Erzählungen II. Hg. v. Hans Höller u. Manfred Mittermayer. Frankfurt a. M.:

Suhrkamp 2006.

Bd. 13: Erzählungen III. Hg. v. Hans Höller u. Manfred Mittermayer. Frankfurt a. M.:

Suhrkamp 2008.

Bd. 14: Erzählungen. Kurzprosa. Hg. v. Hans Höller, Martin Huber u. Manfred

Mittermayer. Frankfurt a. M.: Suhrkamp 2003.

Bd. 15: Dramen I. Hg. v. Manfred Mittermayer u. Jean-Marie Winkler. Frankfurt a. M.:

Suhrkamp 2004.

Bd. 16: Dramen II. Hg. v. Manfred Mittermayer u. Jean-Marie Winkler. Frankfurt a. M.:

Suhrkamp 2005.

Bd. 17: Dramen III. Hg. v. Martin Huber u. Bernhard Judex. Berlin: Suhrkamp 2010. 
Bd. 18: Dramen IV. Hg. v. Bernhard Judex u. Manfred Mittermayer. Frankfurt a. M.: Suhrkamp 2007.

Bd. 19: Dramen V. Hg. v. Martin Huber, Bernhard Judex u. Manfred Mittermayer. Berlin: Suhrkamp 2011.

Bd. 20: Dramen VI. Hg. v. Martin Huber u. Bernhard Judex. Berlin: Suhrkamp 2012.

Bd. 21: Gedichte. Hg. v. Raimund Fellinger. Berlin: Suhrkamp 2015.

Bd. 22/I u. II: Journalistisches, Reden, Interviews. Hg. v. Wolfram Bayer, Martin Huber u. Manfred Mittermayer. Berlin: Suhrkamp 2015.

\section{Zusätzlich verwendete Einzelausgaben}

Frost. Frankfurt a. M.: Insel 1963.

Ungenach. Erzählung. Frankfurt a. M.: Suhrkamp 1968.

Der Stimmenimitator. Frankfurt a. M.: Suhrkamp 1978.

Einfach kompliziert. Frankfurt a. M.: Suhrkamp 1986.

(Hg.) Christine Lavant: Gedichte. Frankfurt a. M.: Suhrkamp 1987.

In der Höhe. Rettungsversuch, Unsinn. Salzburg, Wien: Residenz 1989.

Erzählungen. Mit einem Kommentar v. Hans Höller. Frankfurt a. M.: Suhrkamp 2001 (= Suhrkamp BasisBibliothek, Bd. 23).

Meine Preise. Frankfurt a. M.: Suhrkamp 2009.

Der Wahrheit auf der Spur. Reden, Leserbriefe, Interviews, Feuilletons. Hg. v. Wolfram Bayer, Raimund Fellinger u. Martin Huber. Berlin: Suhrkamp 2011.

Heldenplatz. Mit einem Kommentar v. Martin Huber. Berlin: Suhrkamp 2012 (= Suhrkamp BasisBibliothek, Bd. 124).

Argumente eines Winterspaziergängers. Und ein Fragment zu Frost: Leichtlebig. Mit dem Faksimile des Leichtlebig-Typoskripts. Hg. v. Raimund Fellinger u. Martin Huber. Berlin: Suhrkamp 2013.

Berlin, 17. November 1968. Autoren diskutieren mit ihren Kritikern. Thomas Bernhard diskutiert mit Rudolf Hartung. Mattighofen: Korrektur 2017.

\section{Unselbstständig erschienene Texte}

[Biographische Angaben]. In: Stimmen der Gegenwart 1954. Hg. v. Hans Weigel. Wien: Albrecht Dürer 1954, S. 259.

Ein Wort an junge Schriftsteller. In: Berichte und Informationen des Österreichischen Forschungsinstituts für Wirtschaft und Politik 12 (18.1.1957), Nr. 548, S. 14.

Der Zimmerer. In: Erfundene Wahrheit. Deutsche Geschichten seit 1945. Hg. v. Marcel Reich-Ranicki. München: Piper 1965, S. 477-493.

An der Baumgrenze. In: Dichtung aus Salzburg. Hg. v. Erich Landgrebe. Wien: Kremayr \& Scheriau 1972, S. 147-155. 
In der Finsternis wird alles deutlich. In: Jemand der schreibt. 57 Aussagen. Hg. v. Rudolf de le Roi. München: Hanser 1972, S. 64-67.

Meine größten Gegner. In: Literatur im Residenz Verlag. Almanach auf das Jahr 1974. Salzburg: Residenz 1974, S. 26-28.

Ein Antwortbrief. In: Mein(e) Feind(e). Literaturalmanach 1982. Hg. v. Jochen Jung. Salzburg, Wien: Residenz 1982, S. 28.

Notiz. In: Christine Lavant: Gedichte. Hg. v. Thomas Bernhard. Frankfurt a. M.: Suhrkamp 1987, S. [91].

Brief an Anneliese Botond, 7. 12.1969. In: Text + Kritik (42016), H. 43, S. 5-6.

\section{Briefwechsel}

Bernhard, Thomas/Hennetmair, Karl Ignaz: Ein Briefwechsel. 1965-1974. Kommentiert v. Peter Bader in Zusammenarb. mit K. I. H. Weitra: Bibliothek der Provinz 1994.

Bernhard, Thomas/Unseld, Siegfried: Der Briefwechsel. Hg. v. Raimund Fellinger, Martin Huber u. Julia Ketterer. Frankfurt a. M.: Suhrkamp 2009.

Bernhard, Thomas/Fritsch, Gerhard: Der Briefwechsel. Hg. v. Raimund Fellinger u. Martin Huber. Mattighofen: Korrektur 2013.

Botond, Anneliese: Briefe an Thomas Bernhard. Mit unbekannten Briefen von Thomas Bernhard. 1963-1971. Hg. v. Raimund Fellinger. Mattighofen: Korrektur 2018.

\section{Interview- und Gesprächsbände}

Hofmann, Kurt: Aus Gesprächen mit Thomas Bernhard. Mit Photographien v. Sepp Dreissinger u. Emil Fabjan u. einer Vorbemerkung des Verlags. Wien: Löcker 1988. Thomas Bernhard - Eine Begegnung. Gespräche mit Krista Fleischmann. Wien: Edition S 1991.

Von einer Katastrophe in die andere. 13 Gespräche mit Thomas Bernhard. Hg. v. Sepp Dreissinger. Weitra: Bibliothek der Provinz 1992.

Fialik, Maria: Der Charismatiker. Thomas Bernhard und die Freunde von einst. Wien: Löcker 1992.

Fleischmann, Krista: Thomas Bernhard - Eine Erinnerung. Interviews zur Person. Wien: Edition S 1992.

Müller, André: Im Gespräch mit Thomas Bernhard. Weitra: Bibliothek der Provinz 1992. „Sind sie gern böse?“ Ein Nachtgespräch zwischen Thomas Bernhard und Peter Hamm im Hause Bernhard in Ohlsdorf 1977. Berlin: Suhrkamp 2011.

Was reden die Leute. 58 Begegnungen mit Thomas Bernhard. Aufgezeichnet v. Sepp Dreissinger. Fotografien v. S. D. u. Johann Barth. Salzburg, Wien: Müry Salzmann 2011. Immer noch Frost. 26 Betrachtungen zu Thomas Bernhards erstem Roman. Hg. v. Sepp Dreissinger. Wien: Album 2019. 


\section{Interviews und Reportagen in Zeitungen und Zeitschriften}

Rumler, Fritz: Alpen-Beckett und Menschenfeind. In: Der Spiegel, Nr. 32, 31. 7. 1972, S. 98. Becker, Peter von: Bei Bernhard. Eine Geschichte in 15 Episoden. In: Theater 1978. Sonder-

heft der Zeitschrift Theater heute. Bilanz und Chronik der Saison 77/78 (1978), S. 80-87. Frank, Niklas: Ansichten eines unverbesserlichen Weltverbesserers. In: stern, Nr. 24, 4. 6. 1981, S. 160-162.

Rambures, Jean-Louis de: Thomas Bernhard im Gespräch mit Le Monde. In: Spectaculum 39. Sechs moderne Theaterstücke. Frankfurt a. M.: Suhrkamp 1984, S. 242-245.

Seibert, Ingrit: Mußmaßungen über Thomas B. In: Das Magazin (Juli/August 1985), Nr. 718, S. $42-52$.

Bischofsberger, Conny: Herr Bernhard: Was haben Sie gegen Österreich? In: Kurier, 14.10.1988.

Sichrovsky, Heinz: Thomas Bernhard. Der letzte Akt. In: H. S.: Einblicke. Begegnungen und Porträts. Wien: Jugend \& Volk 1990, S. 162-168.

Hofmann, Kurt: „Ich bin nur mehr kurz da“. Thomas Bernhard in seinem letzten Gespräch. In: Der Spiegel, Nr. 5, 29. 1.1990, S. 161-170.

\section{Peter Handke}

\section{Einzelausgaben}

Die Hornissen. Roman. Frankfurt a. M.: Suhrkamp 1966.

Publikumsbeschimpfung und andere Sprechstücke. Frankfurt a. M.: Suhrkamp 1966.

Begrüßung des Aufsichtsrats. Prosatexte. Salzburg: Residenz 1967.

Der Hausierer. Roman. Frankfurt a. M.: Suhrkamp 1967.

Kaspar. Frankfurt a. M.: Suhrkamp 1968.

(Hg.) Der gewöhnliche Schrecken. Horrorgeschichten. Salzburg: Residenz 1969.

Deutsche Gedichte. Frankfurt a. M.: Euphorion 1969.

Die Innenwelt der Außenwelt der Innenwelt. Frankfurt a. M.: Suhrkamp 1969.

Prosa, Gedichte, Theaterstücke, Hörspiele, Aufsätze. Frankfurt a. M.: Suhrkamp 1969.

Die Angst des Tormanns beim Elfmeter. Frankfurt a. M.: Suhrkamp 1970.

Der kurze Brief zum langen Abschied. Frankfurt a. M.: Suhrkamp 1972.

Ich bin ein Bewohner des Elfenbeinturms. Frankfurt a. M.: Suhrkamp 1972.

Wunschloses Unglück. Erzählung. Salzburg: Residenz 1972.

Als das Wünschen noch geholfen hat. Frankfurt a. M.: Suhrkamp 1974.

Das Gewicht der Welt. Ein Journal (November 1975 - März 1977). Salzburg: Residenz 1977.

Langsame Heimkehr. Erzählung. Frankfurt a. M.: Suhrkamp 1979.

Das Ende des Flanierens. Frankfurt a. M.: Suhrkamp 1980.

Die Lehre der Sainte-Victoire. Frankfurt a. M.: Suhrkamp 1980. 
Kindergeschichte. Frankfurt a. M.: Suhrkamp 1981.

Über die Dörfer. Dramatisches Gedicht. Frankfurt a. M.: Suhrkamp 1981.

Die Geschichte des Bleistifts. Salzburg, Wien: Residenz 1982.

Der Chinese des Schmerzes. Frankfurt a. M.: Suhrkamp 1983.

Phantasien der Wiederholung. Frankfurt a. M.: Suhrkamp 1983.

Die Wiederholung. Frankfurt a. M.: Suhrkamp 1986.

Gedicht an die Dauer. Frankfurt a. M.: Suhrkamp 1986.

Nachmittag eines Schriftstellers. Erzählung. Salzburg, Wien: Residenz 1987.

Versuch über die Müdigkeit. Frankfurt a. M.: Suhrkamp 1989.

Noch einmal für Thukydides. Salzburg, Wien: Residenz 1990.

Versuch über die Jukebox. Erzählung. Frankfurt a. M.: Suhrkamp 1990.

Abschied des Träumers vom Neunten Land. Eine Wirklichkeit, die vergangen ist: Erinnerung an Slowenien. Frankfurt a. M.: Suhrkamp 1991.

Versuch über den geglückten Tag. Ein Wintertagtraum. Frankfurt a. M.: Suhrkamp 1991.

Langsam im Schatten. Gesammelte Verzettelungen. 1980-1992. Frankfurt a. M.: Suhrkamp 1992.

Mein Jahr in der Niemandsbucht. Ein Märchen aus der neuen Zeit. Frankfurt a. M.: Suhrkamp 1994.

Eine winterliche Reise zu den Flüssen Donau, Save, Morawa und Drina oder Gerechtigkeit für Serbien. Frankfurt a. M.: Suhrkamp 1996.

Sommerlicher Nachtrag zu einer winterlichen Reise. Frankfurt a. M.: Suhrkamp 1996.

In einer dunklen Nacht ging ich aus meinem stillen Haus. Roman. Frankfurt a. M.: Suhrkamp 1997.

Am Felsfenster morgens (und andere Ortszeiten 1982-1987). Salzburg, Wien: Residenz 1998. Mündliches und Schriftliches. Zu Büchern, Bildern und Filmen. 1992-2002. Frankfurt a. M.: Suhrkamp 2002.

Wunschloses Unglück. Erzählung. Mit einem Kommentar v. Hans Höller unter Mitarb. v. Franz Stadler. Frankfurt a. M.: Suhrkamp 2003.

Gestern unterwegs. Aufzeichnungen November 1987 - Juli 199o. Salzburg, Wien: Jung und Jung 2005.

Spuren der Verirrten. Frankfurt a. M.: Suhrkamp 2006.

Meine Ortstafeln. Meine Zeittafeln. 1967-2007. Frankfurt a. M.: Suhrkamp 2007.

Die morawische Nacht. Erzählung. Frankfurt a. M.: Suhrkamp 2008.

Ein Jahr aus der Nacht gesprochen. Salzburg, Wien: Jung und Jung 2010.

Der Große Fall. Erzählung. Berlin: Suhrkamp 2011.

Die Geschichte des Dragoljub Milanović. Salzburg, Wien: Jung und Jung 2011.

Versuch über den Stillen Ort. Berlin: Suhrkamp 2012.

Die Unschuldigen, ich und die Unbekannte am Rand der Landstraße. Ein Schauspiel in vier Jahreszeiten. Berlin: Suhrkamp 2015.

Tage und Werke. Begleitschreiben. Berlin: Suhrkamp 2015. 
Vor der Baumschattenwand nachts. Zeichen und Anflüge von der Peripherie 2007-2015.

Salzburg, Wien: Jung und Jung 2016.

Die Obstdiebin oder Einfache Fahrt ins Landesinnere. Berlin: Suhrkamp 2017.

Das zweite Schwert. Eine Maigeschichte. Berlin: Suhrkamp 2020.

\section{Unselbstständig erschienene Texte}

Halbschlafgeschichte (Entwurf zu einem Bildungsroman). In: manuskripte (1965), H. 14/15,

S. 35-36.

Ror Wolf: Fortsetzung des Berichts. In: Wort in der Zeit 11 (1965), H. 3, S. 59-6o.

Beschreibungsimpotenz. Zur Tagung der Gruppe 47 in USA. In: konkret (1966), H. 6 , S. $32-33$.

Bitte kein Pathos! In: Abend-Zeitung [München], 22./23.10.1966.

Für eine neue Literatur. In: Gruppe 47. Die Polemik um die deutsche Gegenwartslitera-

tur. Eine Dokumentation. Hg. v. Horst Ziermann. Frankfurt a. M.: Wolter Editionen 1966, S. 51-54.

Pantoffeln. [Leserbrief] In: Der Spiegel, Nr. 22, 23.5.1966.

Wenn ich schreibe. In: Akzente 13 (1966), H. 5, S. 467.

Als ich Verstörung von Thomas Bernhard las. In: manuskripte (1967), H. 21, S. 14-15.

Betr.: Sie küßten und sie trennten sich. [Leserbrief] In: konkret (1967), H. 10, S. 62.

Briefe über Theater (1). In: Theater heute (1967), H. 2, S. 37.

Ich höre Grandma Moses. In: Sprache im technischen Zeitalter (1967), H. 22, S. 170.

Loch im Kopf. Der Erfolgsautor rezensiert eine Drogen-Dokumentation. In: Abend-Zeitung

[München], 25. 8.1967

Über meinen neuen Roman Der Hausierer. In: Dichten und Trachten 29 (1967), S. 27-29. Charakter-Studie. [Leserbrief] In: Der Spiegel, Nr. 4, 22.1.1968.

Horváth ist besser. In: Theater heute (1968), H. 3, S. 28.

John Lennon sagte: Revolutionäre sollen sich selber ändern. In: Kölner Stadt-Anzeiger, 24.12. 1968.

Marcel Reich-Ranicki und die Natürlichkeit. In: manuskripte (1968), H. 22, S. 40-41.

Probleme werden im Film zu einem Genre. In: film 6 (August 1968), H. 8, S. 10.

Totgeborene Sätze. Kunst als Ware. In: DIE ZEIT, Nr. 49, 6.12.1968.

Vorläufige Bemerkungen zu Landkinos und Heimatfilmen. In: film 6 (November 1968),

H. 11, S. 10 u. 37.

Wenn Nerven schwanken. In: Abend-Zeitung [München], 30.11./1.12.1968.

Ah, Gibraltar! Die 19. Internationalen Filmfestspiele Berlin 1969. In: DIE ZEIT, Nr. 28 , 11.7.1969.

Augsburg im August: trostlos. In: film 7 (Januar 1969), H. 1, S. 30-32.

Das Hören und das Sehen. In: Theater heute (1969), H. 2, S. 67.

Dummheit und Unendlichkeit. In: film 7 (März 1969), H. 3, S. 10-11. 
„Ein Buch fürs Leben“. Über die Briefe zwischen Ludwig Wittgenstein und Ludwig von Ficker. In: Nürnberger Nachrichten, 23.12.1969.

In Sätzen steckt Obrigkeit. Über G. F. Jonke: Geometrischer Heimatroman. In: Der Spiegel, Nr. 17, 21. 4.1969, S. 186-188.

Nachtvorstellung. In: Süddeutsche Zeitung, 17.3.1969.

Peter Handke über Peter Handke. In: konkret, Nr. 13, 16. 6.1969, S. 51.

Verdrängt das Kino das Theater? Das Elend des Vergleichens. In: protokolle (1969), S. $228-236$.

[Vorwort]. In: Der gewöhnliche Schrecken. Horrorgeschichten. Hg. v. Peter Handke. Salzburg: Residenz 1969, S. [5].

Namen als Beweise. In: Das große Eierbuch. Hg. v. Ulrich Raschke u. Heinz Jacobi. Frankfurt a. M.: Euphorion 1970, [unpag.].

Peter Handke und der Monteur. In: DIE ZEIT, Nr. 20, 15.5.1970.

Schwankende Nerven. Über Wolfgang Bauers dramatischen Erstling Magic Afternoon. Zur Nürnberger Inszenierung dieses Bühnenstücks über die Verhaltensweise der Jugend. In: Nürnberger Nachrichten, 24. 4.1970.

Totenstille beim Heurigen. In: Ödön von Horváth: Geschichten aus dem Wiener Wald. Volksstück in drei Teilen mit einer Nacherzählung von Peter Handke. Frankfurt a. M.: Suhrkamp 1970, S. 123-137.

Das Umfallen der Kegel von einer bäuerlichen Kegelbahn. [1969] In: Verteidigung der Zukunft. Deutsche Geschichten seit 1960. Hg. v. Marcel Reich-Ranicki. München: Piper 1972, S. 358-368.

Bonds pauschaler Schmerz. In: Der Spiegel, Nr. 50, 10.12.1973, S. 131-134.

Tage wie ausgeblasene Eier. Einladung, Hermann Lenz zu lesen. In: Süddeutsche Zeitung, 22./23. 12. 1973 .

Von der Schwierigkeit, einen Schlagertext zu schreiben. [1965] In: protokolle (1973), H. 2, S. 182-186.

Der Rausch durch die Beatles. [1964] In: Ver sacrum. Neue Hefte für Kunst und Literatur 5 (1974), S. 114-117.

Gewaltiger als alle Handlungen. In: Frankfurter Allgemeine Zeitung, 1. 6.1974.

Österreich und die Schriftsteller. In: Literatur im Residenz Verlag. Almanach auf das Jahr 1974. Salzburg: Residenz 1974, S. 57-61.

Das Umfallen der Kegel von einer bäuerlichen Kegelbahn. [1969] In: Verteidigung der Zukunft. Deutsche Geschichten seit 196o. Hg. v. Marcel Reich-Ranicki. München, Zürich: Piper ${ }^{2} 1975$, S. 358-368.

Denunziation ohne Wahrnehmung. Über Karin Struck: Die Mutter. In: Der Spiegel, Nr. 12, 17.3.1975, S. 147-149.

Die privaten Weltkriege der Patricia Highsmith. In: Der Spiegel, Nr. 3, 13. 1. 1975, S. 88-93. Wirkliche Mächte in Österreich. In: Kleine Zeitung, 18.5.1975.

Gegen den tiefen Schlaf. Nicolas Borns zweiter Roman: Die erdabgewandte Seite der Geschichte. In: DIE ZEIT, Nr. 42, 8.10.1976. 
Von einem redelustigen Gottesvolk. Über Klaus Hoffer: Halbwegs. Bei den Bieresch I. In: Der Spiegel, Nr. 26, 25. 6.1979, S. 176-179.

Zu Franz Michael Felder. In: Franz Michael Felder: Aus meinem Leben. Mit einer Vorbemerkung v. Peter Handke u. einem Nachwort v. Walter Methlagl. Salzburg, Wien: Residenz 1985, S. 5-6.

Am Felsfenster, morgens. In: manuskripte 27 (Oktober 1987), H. 97, S. 3-9.

Im Wortlaut: Peter Handkes ,Auftritt' in Princeton und Hans Mayers Entgegnung. [1966]

In: Text + Kritik ( $\left.{ }^{5} 1989\right)$, H. 24, S. 17-20.

„Laßt mein Stück in Frieden!“ Kurzer Brief an die „Edelfedern“ des Journalismus. In: Der Standard, 20./21.3.1999.

Brief an Wolfgang Schaffler, 5. 4.1978. In: Süddeutsche Zeitung, 5.7. 2003.

Brief an Klaus Hoffer, 27.3. 1979. In: manuskripte (2012), H. 198, S. 75.

Eine Ideal-Konkurrenz. Zum Briefwechsel zwischen Carlfriedrich Claus und Franz Mon. In: Sinn und Form 66 (2014), H. 5, S. 581-592.

\section{Briefwechsel}

Born, Nicolas/Handke, Peter: Die Hand auf dem Brief. Briefwechsel 1974-1979. In: Schreibheft (2005), H. 65, S. 3-35.

Handke, Peter/Lenz, Hermann: Berichterstatter des Tages. Briefwechsel. Hg. u. mit einem Nachwort versehen v. Helmut Böttiger. Frankfurt a. M.: Insel 2006.

Handke, Peter/Kolleritsch, Alfred: Schönheit ist die erste Bürgerpflicht. Briefwechsel. Salzburg, Wien: Jung und Jung 2008.

Handke, Peter/Unseld, Siegfried: Der Briefwechsel. Hg. v. Raimund Fellinger u. Katharina Pektor. Berlin: Suhrkamp 2012.

\section{Interview- und Gesprächsbände}

Handke, Peter: Aber ich lebe nur von den Zwischenräumen. Ein Gespräch, geführt von Herbert Gamper. Zürich: Ammann 1987.

Müller, André: Im Gespräch mit Peter Handke. Weitra: Bibliothek der Provinz 1993.

Noch einmal vom Neunten Land. Peter Handke im Gespräch mit Jože Horvat. Klagenfurt, Salzburg: Wieser 1993.

... und machte mich auf, meinen Namen zu suchen. Peter Handke im Gespräch mit Michael Kerbler. Klagenfurt u. a.: Wieser 2007 (= Gehört gelesen, Bd. 1).

Handke, Peter/Hamm, Peter: Es leben die Illusionen. Gespräche in Chaville und anderswo. Göttingen: Wallstein ${ }^{2} 2008$.

Im Gespräch. Peter Handke 1987-2012. Interviews mit Wolfgang Hofer, Brita Steinwendtner u. Michael Kerbler. 2 CDs. [Wien]: ORF 2012.

Peter Handke im Gespräch mit Hubert Patterer und Stefan Winkler. Graz: Edition Kleine Zeitung 2012. 
Handke, Peter/Oberender, Thomas: Nebeneingang oder Haupteingang? Gespräche über 50 Jahre Schreiben fürs Theater. Berlin: Suhrkamp 2014 (= suhrkamp spectaculum).

Das stehende Jetzt. Die Notizbücher von Peter Handke. Gespräch mit dem Autor und Essays von Ulrich von Bülow. Marbach a. N.: Deutsche Schillergesellschaft 2018 (= marbacher magazin, Bd. 161).

\section{Interviews und Reportagen in Sammelbänden, Zeitungen und Zeitschriften}

Dornbacher, Rolf: Absage an das Publikum. AZ-Gespräch mit dem Schriftsteller Peter Handke. In: Abend-Zeitung [München], 25./26.6.1966.

Bock, Hans Bertram: „Ich wollte immer Kommunist werden“. AZ-Gespräch mit dem Beat-Autor Peter Handke. In: Abend-Zeitung [München], 8./9.7.1967.

Sander, Hartmut/Tomayer, Horst: Subversive Dialoge. Peter Handke über Berliner Subkultur. In: Abend-Zeitung [München], 1. 8.1969.

Brandt, Elke: Peter Handke antwortet. Wieder „richtiges“ Theater und „richtige“ Geschichten schreiben. In: Rheinischer Merkur, 8. 8.1969.

Bloch, Peter-André: Peter Handke. In: Der Schriftsteller und sein Verhältnis zur Sprache. Dargestellt am Problem der Tempuswahl. Eine Dokumentation zu Sprache und Literatur der Gegenwart. Gespräche und Werkanalysen einer Arbeitsgruppe des Deutschen Seminars der Universität Basel. Hg. v. P.-A. B. Bern, München: Francke 1971, S. 170-178.

Müller, Andreas: Das Schreiben ist unglaublich sinnlich. Die AZ stellt Autoren der Gegenwart vor: Peter Handke. In: Abend-Zeitung [München], 22.7.1971.

Hohler, Franz: Ist Ihnen oft langweilig? Fragen an Peter Handke. [24.5.1972] In: F. H.: Fragen an andere. Bern: Zytglogge 1973, S. 19-39.

Linder, Christian: Die Ausbeutung des Bewußtseins. Gespräch mit Peter Handke. In: Frankfurter Allgemeine Zeitung, 13.1.1973.

Schultz-Gerstein, Christian: Erinnerungen für die Zukunft. Ein Gespräch mit dem diesjährigen Büchnerpreisträger Peter Handke. In: DIE ZEIT, Nr. 43, 19.10.1973.

Durzak, Manfred: „Vom Büchner-Preis habe ich sogar geträumt“. Gespräch mit dem Autor: Peter Handke. In: Die Welt, 1.11.1973.

Nenning, Günther: Warum ich jetzt Geschichten schreibe. [Gespräch mit Peter Handke.] In: Neue Freie Presse (1973), H. 4, S. 7.

Nenning, Günther: „Schreiben, intensiv wie im Traum!“ [Gespräch mit Peter Handke.] In: Neue Freie Presse (1974), H. 8, S. 7.

Durzak, Manfred: Für mich ist Literatur auch eine Lebenshaltung. Gespräch mit Peter Handke. [1973] In: M. D.: Gespräch über den Roman. Formbestimmungen und Analysen. Frankfurt a. M.: Suhrkamp 1976, S. 314-343.

Arnold, Heinz Ludwig: Gespräch mit Peter Handke. [1975] In: Text + Kritik ( $\left.{ }^{3} 1976\right)$, H. 24/24a, S. 15-37. [gekürzt auch in: DIE ZEIT, Nr. 11, 5.3.1976, S. 36.] [erneut in: H. L. A.: Gespräche mit Autoren. Frankfurt a. M.: S. Fischer 2012, S. 463-498.] 
Bock, Hans Bertram: Im Taumel der Fremdheit. Interview mit dem Schriftsteller Peter Handke. In: Nürnberger Nachrichten, 27./28. 8.1977.

Schlueter, June: An Interview with Peter Handke. [1979] In: Studies in $20^{\text {th }}$ Century Literature 4 (1980), H. 1, S. 63-73.

Fleischmann, Krista/Handke, Peter: Ein Gespräch über das Schreiben und die Kindergeschichte. In: Die Rampe (1981), H. 2, S. 7-15.

Löffler, Sigrid: „Als Schreibender krepiert man fast“. [Gespräch mit Peter Handke.] In: profil, 27. 4.1981, S. 58-6o.

Hage, Volker: Die Fiktion ist nötig. [Gespräch mit Peter Handke, März 1972.] In: V. H.: Die Wiederkehr des Erzählers. Neue deutsche Literatur der siebziger Jahre. Frankfurt a. M. u. a.: Ullstein 1982, S. 111-121.

Neureiter, Gerhard: Was man vom Fernsehen kennt, das kennt man nicht. SN-Interview mit dem Dichter der Festspielpremiere Über die Dörfer, Peter Handke, zur Politik. In: Salzburger Nachrichten, 21. 8.1982.

Poßarnig, Renate: „Ich möchte nicht verehrt werden“. [Gespräch mit Peter Handke.] In: stern, Nr. 40, 30. 9. 1982.

Hoghe, Raimund: „Unsereiner hat keine Gemeinde“. Ein Besuch bei Peter Handke auf dem Mönchsberg in Salzburg. In: DIE ZEIT, Nr. 44, 29.10.1982, S. 70.

Schmidt-Mühlisch, Lothar: Macht der stinkenden Fäulnis. Wider die Abtreibung der Kultur - Ein Welt-Gespräch mit Peter Handke. In: Die Welt, 27.7.1984.

„Man kann gar nichts mehr sagen“. Peter Handke mit Bruno Kreisky, unvergessen, über Literatur und Politik. In: Die Presse, 16./17.3.1985.

Handke, Peter/Kreisky, Bruno: Von der Abwesenheit des Unglücks. In: Peter Handke. Die Arbeit am Glück. Hg. v. Gerhard Melzer u. Jale Tükel. Königstein i. Ts.: Athenäum 1985, S. 11-24.

Gamper, Herbert: Die Natur bestärken. Gespräch mit Peter Handke über Aischylos, das Übersetzen, das Schreiben. In: Die Presse, Literaricum, 16./17. 8. 1986.

Löffler, Sigrid: Der Mönch auf dem Berge. [Gespräch mit Peter Handke.] In: profil, Nr. 47, 17.11. 1986, S. $98-102$.

Jocks, Heinz-Norbert: Ein Märtyrer unter Erzählzwang. Sonntagnachmittag eines Autors. Bei Peter Handke in Salzburg. In: Stuttgarter Zeitung, 28.3.1987.

Löffler, Sigrid: „Mein Fluch. Mein Glanz.“ Ein Besuch bei Peter Handke. In: Süddeutsche Zeitung, 28./29.3.1987.

Schmidt-Mühlisch, Lothar: Peter Handke: Ich denke wieder an ein ganz stummes Stück. In: Die Welt, 9.10.1987.

Kurtz, Ulrich: „Das sind die Sachen, die mich zum Schreiben bringen“. Peter Handke im Gespräch. In: Das Goetheanum. Wochenschrift für Anthroposophie 67 (24.1.1988), H. 4, S. 21-25.

Funcke, Konrad: Wir müssen fürchterlich stottern. Die Möglichkeit der Literatur Gespräch mit dem Schriftsteller Peter Handke. In: Süddeutsche Zeitung, 23. 6. 1988. 
Müller, André: Wer einmal versagt im Schreiben, hat für immer versagt. [Gespräch mit Peter Handke.] In: DIE ZEIT, Nr. 10, 3.3.1989, S. 77-79.

Sichrovsky, Heinz: Peter Handke: Ich bin ein Attentäter. In: H. S.: Einblicke. Begegnungen und Porträts. Wien: Jugend \& Volk 1990, S. 169-174.

Karasek, Hellmuth/Winkler, Willi: „Der Alltag ist schändlich leblos“. Spiegel-Gespräch mit dem österreichischen Schriftsteller Peter Handke über sein verändertes Leben. In: Der Spiegel, Nr. 16, 16. 4.1990, S. 220-234.

Becker, Peter von: „Ich mag die Menschen nicht anfassen beim Schreiben ... “ [Gespräch mit Peter Handke.] In: Theater 1992. Das Jahrbuch der Zeitschrift Theater heute (1992), S. 11-21.

Hage, Volker/Schreiber, Mathias: „Gelassen wär’ ich gern“. Der Schriftsteller Peter Handke über sein neues Werk, über Sprache, Politik und Erotik. In: Der Spiegel, Nr. 49, 5. 12. 1994, S. $170-176$.

Hirschmann, Christoph: Stiller Streß. Handke exklusiv über den Erfolg seines neuen Buches. In: News, Nr. 49, 7.12.1994, S. 130-132.

Michaelsen, Sven: „Ab und zu sticht mich ein Teufelchen“. [Gespräch mit Peter Handke.] In: stern, Nr. 52, 22.12.1994, S. 124-130.

Winkler, Willi: Ich bin nicht hingegangen, um mitzuhassen. Peter Handke antwortet seinen Kritikern. In: DIE ZEIT, Nr. 6, 2. 2. 1996, S. 47-48.

Reiter, Wolfgang/Seiler, Christian: „Nackter, blinder, blöder Wahnsinn“. [Gespräch mit Peter Handke.] In: profil, Nr. 12, 18.3.1996, S. 80-83.

Sichrovsky, Heinz: „Freie Figur unter den Dichtern“. [Gespräch mit Peter Handke.] In: News, Nr. 50, 14.12. 2000, S. 132.

Steinfeld, Thomas: Ich erzähle von einem Leben, das über mich hinausgeht. [Gespräch mit Peter Handke.] In: Süddeutsche Zeitung, 30.1. 2002.

Sichrovsky, Heinz: „Ich bin ein konservativer Mensch“. [Gespräch mit Peter Handke.] In: News, Nr. 39, 29. 9. 2005, S. 144-148.

Jocks, Heinz-Norbert: Geglückte Tage, unterwegs. Im Gespräch: Peter Handke erzählt vom Reisen allein, von Nomaden und Nesträubern. In: Freitag, Nr. 42, 21. 10. 2005, S. 3.

Greiner, Ulrich: Ich komme aus dem Traum. ZEIT-Gespräch mit dem Schriftsteller Peter Handke über die Lust des Schreibens, den jugoslawischen Krieg und das Gehen in den Wäldern. In: DIE ZEIT, Nr. 6, 2. 2. 2006, S. 53-54.

Sichrovsky, Heinz: Die Wut eines Dichters. [Gespräch mit Peter Handke.] In: News, Nr. 37, 14.9. 2006, S. 198-201.

Katz-Logar, Rosina: „Literatur ist wie ein Schlager“. [Gespräch mit Peter Handke.] In: Kleine Zeitung, 17.5.2007.

Müller, André: „Ein Idiot im griechischen Sinne“. [Gespräch mit Peter Handke.] In: Die Weltwoche, Nr. 35, 30. 8. 2007, S. 52-57.

Eichel, Christine: „Der Zorn verraucht, das Feuer bleibt.“ [Gespräch mit Peter Handke.] In: Cicero online, Februar 2008, https://www.cicero.de/kultur/\%3Fder-zorn-verrauchtdas-feuer-bleibt\%3F/23293 (Stand 20.12. 2014). 
Kastberger, Klaus/Schwagerle, Elisabeth: „Es gibt die Schrift, es gibt das Schreiben.“ Peter Handke im Gespräch. In: Peter Handke. Freiheit des Schreibens - Ordnung der Schrift. Hg. v. Klaus Kastberger. Unter Mitarb. v. Clemens Özelt. Wien: Zsolnay 2009 (= Profile, Bd. 16), S. 11-30.

Katz-Logar, Rosina: „Jeder, wie er blind ist“. [Gespräch mit Peter Handke.] In: Kleine Zeitung, 15. 8. 2009.

Weinzierl, Ulrich: „Serbien soll Weltmeister werden“. [Gespräch mit Peter Handke.] In: Welt am Sonntag, Nr. 24, 13. 6.2010, S. 68.

Müller, André: Peter Handke. [2007] In: A. M.: „Sie sind ja wirklich eine verdammte Krähe!“ Letzte Gespräche und Begegnungen. Mit einem Vorwort v. Elfriede Jelinek. München: LangenMüller 2011, S. 69-89.

Böhm, Gero von: Peter Handke. [2008] In: G. v. B.: Begegnungen. Menschenbilder aus drei Jahrzehnten. München: Collection Rolf Heyne 2012, S. 585-591.

Herwig, Malte/Michaelsen, Sven: „Ich wäre liebend gern ein Böser“. [Gespräch mit Peter Handke.] In: Süddeutsche Zeitung Magazin, Nr. 42, 19. 10. 2012, S. 52-57.

Nüchtern, Klaus: „Ich kann nicht realistisch über Frauen schreiben“. [Gespräch mit Peter Handke.] In: Falter, Nr. 49, 5. 12. 2012, S. 26-29.

Petsch, Barbara: „Herr, verzeih ihnen nicht!“ [Gespräch mit Peter Handke.] In: Die Presse, Spectrum, 13.9. 2014.

Encke, Julia: Schimpfen ist ein Ausdruck von Hilflosigkeit. [Gespräch mit Peter Handke.]

In: Frankfurter Allgemeine Sonntagszeitung, Nr. 41, 11. 10. 2015, S. 53.

Sichrovsky, Heinz: Der König der Niemandsbucht. [Gespräch mit Peter Handke.] In: News, Nr. 2, 16.1. 2016, S. 84-89.

Behmann, Jan C./Gladić, Mladen: „Ich habe keine Schublade“. [Gespräch mit Peter Handke.] In: Freitag, Nr. 34, 23. 8. 2018, https://www.freitag.de/autoren/der-freitag/ ich-habe-keine-schublade (Stand 30.10. 2018).

Greiner, Ulrich: „Spielen Sie jetzt Tribunal?“ [Gespräch mit Peter Handke.] In: DIE ZEIT, Nr. 48, 21. 11. 2019, S. 61-62.

\section{Texte anderer Autorinnen und Autoren, Lebenszeugnisse, Quellen}

Amanshauser, Gerhard/Hakel, Hermann: Die taoistische Powidlstimmung der Österreicher. Briefwechsel 1953-1986. Hg. v. Hans Höller. Weitra: Bibliothek der Provinz 2005.

Bachmann, Ingeborg: Watten und andere Prosa (über Thomas Bernhard). In: I. B.: Kritische Schriften. Hg. v. Monika Albrecht u. Dirk Göttsche. München, Zürich: Piper 2005, S. 453-457.

Basil, Otto: Vom österreichischen NS-Parnaß. In: PLAN 1 (1945), H. 1, S. $72-76$.

Bauer, Wolfgang: Manche Künstler sind Dichter. In: 25 Jahre Residenz Verlag. Zeitgenössische Literatur. Literatur für Zeitgenossen. Almanach für Literatur und Kunst 1981. Salzburg, Wien: Residenz 1981, S. 29-34. [auch in: W. B.: Werke in sieben Bänden. Hg. 
v. Gerhard Melzer. Bd. 6: Kurzprosa, Essays und Kritiken. Mit einem Nachwort v. Rolf Schwendter. Graz, Wien: Droschl 1997, S. 97-99.]

Baumgart, Reinhard: Damals. Ein Leben in Deutschland 1929-2003. [München]: Hanser 2003.

Bender, Hans/Canetti, Elias: Briefwechsel. 1963-199o. Hg. v. Hans Georg Schwark u. Walter Hörner. Aachen: Rimbaud 2016.

Bernard, Emile: Erinnerungen an Paul Cézanne, 1904-1906. [1907] In: Gespräche mit Cézanne. Hg. v. Michael Doran. Deutsch v. Jürg Bischoff. Zürich: Diogenes 1982, S. 68-106.

Boehlich, Walter: Autodafé. In: Kursbuch (November 1968), Nr. 15, Kursbogen [unpag.]. Brändle, Rudolf: Zeugenfreundschaft. Erinnerungen an Thomas Bernhard. [1999] Frankfurt a. M.: Suhrkamp 2001.

Brandstetter, Alois: Selig sind die Feindseligen, fertig sind die Friedfertigen. In: Mein(e) Feind(e). Literaturalmanach 1982. Hg. v. Jochen Jung. Salzburg, Wien: Residenz 1982, S. 29-32.

Brecht, Bertolt: Über das Zerpflücken von Gedichten. [1937/1939] In: B. B.: Werke. Große kommentierte Berliner und Frankfurter Ausgabe. Hg. v. Werner Hecht u. a. Bd. 22: Schriften 2. Teil I. Berlin u. a.: Aufbau/Suhrkamp 1993, S. 453-454.

Brehm, Bruno: Aus der Nachkriegszeit. In: Berichte und Informationen des Österreichischen Forschungsinstituts für Wirtschaft und Politik 12 (18.1.1957), Nr. 548, S. 15.

Buch, Hans Christoph: Von der möglichen Funktion der Literatur. Eine Art Metakritik. In: Kursbuch (1970), H. 20, S. 42-52.

Buch, Hans Christoph: Kritische Wälder. Essays - Kritiken - Glossen. Reinbek b. Hamburg: Rowohlt 1972.

Cage, John: Silence. Aus dem Amerikanischen v. Ernst Jandl. Frankfurt a. M.: Suhrkamp 1987.

Canetti, Elias: Wortanfälle. In: Jemand der schreibt. 57 Aussagen. Hg. v. Rudolf de le Roi. München: Hanser 1972, S. 68-72.

Canetti, Elias: Der Beruf des Dichters. In: DIE ZEIT, Nr. 7, 6. 2.1976, S. 35-36.

Canetti, Elias: Das Gewissen der Worte. Essays. München: dtv 1978.

Canetti, Elias: Rede zur Verleihung des Nabl-Preises der Stadt Graz im Jahr 1975. In: Über Franz Nabl. Aufsätze, Essays, Reden. Hg. v. Kurt Bartsch, Gerhard Melzer u. Johann Strutz. Graz u. a.: Styria 1980, S. 177-179.

Canetti, Elias: Aufzeichnungen 1973-1984. München, Wien: Hanser 1999.

Canetti, Elias: Das Buch gegen den Tod. Mit einem Nachwort v. Peter von Matt. München: Hanser 2014.

Canetti, Elias: Ich erwarte von Ihnen viel. Briefe 1932-1994. Hg. v. Sven Hanuschek u. Kristian Wachinger. München: Hanser 2018.

Dante Alighieri: Die göttliche Komödie. Aus dem Italienischen v. Philaletes. Zürich: Diogenes 1991. 
Delius, Friedrich Christian: Der Held und sein Wetter. Ein Kunstmittel und sein ideologischer Gebrauch im Roman des bürgerlichen Realismus. München: Hanser 1971.

Delius, Friedrich Christian: Als die Bücher noch geholfen haben. Biografische Skizzen. Berlin: Rowohlt 2012.

Delius, Friedrich Christian: Die Zukunft der Schönheit. Erzählung. Berlin: Rowohlt 2018. Dittberner, Hugo: Der Mann in der Arena. Über Marcel Reich-Ranicki. In: Text + Kritik (1988), H. 100, S. 10-22.

Enzensberger, Hans Magnus: Mittelmaß und Wahn. Gesammelte Zerstreuungen. Frankfurt a. M.: Suhrkamp 1988.

Flaubert, Gustave: Herodias. In: G. F.: Drei Erzählungen. Übers. u. hg. v. Jürgen Rehbein. Stuttgart: Reclam 1994, S. 91-133.

Freumbichler, Johannes: Erziehung zu Vernunft und Fröhlichkeit. Briefe in Knittelversen für die Jugend von Sechzehn bis Sechzig. Lehrgedicht aus dem Nachlaß, gewidmet dem Enkel Thomas Bernhard. Hg. u. mit einem Nachwort v. Heike Mayer. o. O.: Liliom 2003. Frisch, Max: Öffentlichkeit als Partner. Frankfurt a. M.: Suhrkamp 1967.

Frisch, Max: Aus dem Berliner Journal. Hg. v. Thomas Strässle unter Mitarb. v. Margit Unser. Berlin: Suhrkamp 2014.

Frisch, Max: „Wie Sie mir auf den Leib rücken!“ Interviews und Gespräche. Ausgewählt u. hg. v. Thomas Strässle. Berlin: Suhrkamp 2017.

Frisch, Max/Johnson, Uwe: Der Briefwechsel 1964-1983. Hg. v. Eberhard Falcke. Frankfurt a. M.: Suhrkamp 1999.

Fritsch, Gerhard: „Man darf nicht leben, wie man will“. Auszüge aus den Tagebüchern 1956-1964. In: Gerhard Fritsch. Schriftsteller in Österreich. Hg. v. Stefan Alker u. Andreas Brandtner. Wien: Sonderzahl 2005, S. 237-260.

Fritsch, Gerhard: Man darf nicht leben, wie man will. Tagebücher. Hg. u. mit einem Nachwort v. Klaus Kastberger. Transkription u. Kommentar: Stefan Alker-Windbichler. Salzburg, Wien: Residenz 2019.

Goethe, Johann Wolfgang: Sämtliche Werke nach Epochen seines Schaffens. Münchner Ausgabe. Hg. v. Karl Richter in Zusammenarb. mit Herbert G. Göpfert u. a. Bd. 1.1: Der junge Goethe. 1757-1775. Hg. v. Gerhard Sauder. München: Hanser 1985.

Hakel, Hermann: Dürre Äste. Welkes Gras. Begegnungen mit Literaten. Bemerkungen zur Literatur. Wien: Lynkeus 1991.

Hamann, Johann Georg: Sämtliche Werke. Hg. v. Josef Nadler. Bd. II: Schriften über Philosophie / Philologie / Kritik. 1758-1763. Wien: Thomas-Morus-Presse 1950.

Hamm, Peter: Der Großkritiker. Literaturkritik als Anachronismus. In: Kritik - von wem / für wen / wie. Eine Selbstdarstellung deutscher Kritiker. Hg. v. P. H. München: Hanser 1968, S. 20-39.

Hamm, Peter: ,Kritik muß sein. Vorbemerkung. In: Kritik - von wem / für wen / wie. Eine Selbstdarstellung deutscher Kritiker. Hg. v. P. H. München: Hanser 1968, S. 7-10. Hamm, Peter: Versäumte Solidarität. Eine Erwiderung auf Peter Handkes Aufsatz „Totgeborene Sätze“. In: DIE ZEIT, Nr. 50, 13.12.1968. 
Hamm, Peter: Nackte Schauspieler, stummes Stück. In: Neues Forum 16 (März 1969), H. $183 /$ I, S. $183-184$.

Hamm, Peter: Der neueste Fall von deutscher Innerlichkeit: Peter Handke. In: konkret, Nr. 12, 2. 6. 1969, S. 42-45.

Hamm, Peter: Der Dramaturgie dritter Teil oder das denkfaule Genie. In: konkret, Nr. 14, 30.6.1969.

Hamm, Peter: Handke entdeckt sich selbst. In: Neues Forum 17 (März 1970), H. 195/I, S. $253-255$.

Hamm, Peter: Peter Handke und kein Ende. Stationen einer Annäherung. Göttingen: Wallstein 2017 (= Edition Petrarca).

Heinrichs, Hans-Jürgen: Wo nichts ist, kann nichts vergeudet werden. Gesellschaft und Obszönität, Lust und Schreiben, Männer und Frauen: Elfriede Jelinek im Gespräch. In: Frankfurter Rundschau, 4.3.200o.

Heißenbüttel, Helmut: Nachruf bei Lebzeiten. In: Text + Kritik (1988), H. 100, S. 26-28. Hennetmair, Karl Ignaz: Ein Jahr mit Thomas Bernhard. Das versiegelte Tagebuch 1972. St. Pölten u. a.: Residenz ${ }^{5} 2014$.

Homer: Ilias. Übersetzung, Nachwort u. Register v. Roland Hampe. Stuttgart: Reclam 1979. Horváth, Ödön von: Geschichten aus dem Wiener Wald. Volksstück in drei Teilen mit einer Nacherzählung von Peter Handke. Frankfurt a. M.: Suhrkamp 1970.

Hütter, Frido: „Ich schulde so vielen so vieles“. Nobelpreisträgerin Elfriede Jelinek über die Hoffnung auf Rückkehr zur Normalität und den Zusammenhang von Text und Musik. In: Kleine Zeitung, 10. 10. 2004.

James, Henry: Die mittleren Jahre. Erzählung. Aus dem Englischen übertragen u. mit einem Nachwort v. Walter Kappacher. Salzburg, Wien: Jung und Jung 2015.

Januš, Gustav: Gedichte. 1962-1983. Aus dem Slowenischen v. Peter Handke. Frankfurt a. M.: Suhrkamp 1983.

Jonke, G. F.: Geometrischer Heimatroman. Frankfurt a. M.: Suhrkamp 1969.

Kafka, Franz: Der Proceß. Hg. v. Malcolm Pasley. Frankfurt a. M.: S. Fischer 1990 (= F. K.: Schriften Tagebücher Briefe. Kritische Ausgabe).

Kafka, Franz: Briefe 1900-1912. Hg. v. Hans-Gerd Koch. Frankfurt a. M.: S. Fischer 1999 (= F. K.: Schriften Tagebücher Briefe. Kritische Ausgabe).

Karsunke, Yaak: Uralte Binsenwahrheiten. In: Kritik - von wem / für wen / wie. Eine Selbstdarstellung deutscher Kritiker. Hg. v. Peter Hamm. München: Hanser 1968, S. 45-48. Kinder, Hermann: Schweine-Bande. In: Text + Kritik (1988), H. 10o, S. 30-36.

Kraus, Karl: Es zieht! In: Die Fackel (2. 8.1916), H. 431-436, S. 109.

Lenz, Hermann: Begegnungen mit Peter Handke. In: ensemble. Internationales Jahrbuch für Literatur 8 (1977), S. 154-157.

Lenz, Siegfried: Der Kritiker bei der Arbeit. In: Literatur und Kritik. Aus Anlaß des 60. Geburtstages von Marcel Reich-Ranicki hg. v. Walter Jens. Stuttgart: DVA 198o, S. 24-32. Lipuš, Florjan: Der Zögling Tjaž. Roman. Deutsch v. Peter Handke zusammen mit Helga Mračnikar. Salzburg, Wien: Residenz 1981. 
Mann, Golo/Reich-Ranicki, Marcel: Enthusiasten der Literatur. Ein Briefwechsel. Aufsätze und Portraits. Hg. v. Volker Hage. Frankfurt a. M.: S. Fischer 2000.

Menasse, Eva: Vienna. Roman. Köln: Kiepenheuer \& Witsch 2005.

Muschg, Adolf: Ein Brief. In: Akzente 13 (1966), H. 5, S. 478-479.

Musil, Robert: Briefe 1901-1942. Mit Briefen von Martha Musil, Alfred Döblin, Efraim Frisch u. a. Hg. v. Adolf Frisé. Unter Mithilfe v. Murray G. Hall. Reinbek b. Hamburg: Rowohlt 1981.

Musil, Robert: Der Mann ohne Eigenschaften. Roman. Hg. v. Adolf Frisé. Bd. 1: Erstes und Zweites Buch. Reinbek b. Hamburg: Rowohlt 1981.

Musil, Robert: Gesammelte Werke. Hg. v. Adolf Frisé. Bd. II: Prosa und Stücke. Kleine Prosa, Aphorismen. Autobiographisches. Essays und Reden. Kritik. Reinbek b. Hamburg: Rowohlt 2000.

Nabl, Franz: Charakter. Der Schwur des Martin Krist. Dokument. Frühe Erzählungen. Hg. v. Peter Handke. Salzburg: Residenz 1975.

Nenning, Günther: Werkstättengespräch mit Peter Turrini. [1975] In: Turrini Lesebuch. Stücke, Pamphlete, Filme, Reaktionen etc. Ausgew. u. bearb. v. Ulf Birbaumer. Wien u. a.: Europaverlag 1978, S. 343-352.

Novalis: Blüthenstaub. In: Athenäum. Eine Zeitschrift v. August Wilhelm Schlegel u. Friedrich Schlegel. Ersten Bandes Erstes Stück. Berlin: Vieweg 1798, S. 70-106.

Puff-Trojan, Andreas: „Vielleicht sind ja doch die Alpen schuld“. Gespräch mit Elfriede Jelinek. In: Frankfurter Rundschau, 13.10. 2004.

Rakusa, Ilma: Langsamer! Gegen Atemlosigkeit, Akzeleration und andere Zumutungen. Graz, Wien: Droschl ${ }^{5} 2008$.

Ransmayr, Christoph: Die Verbeugung des Riesen. Vom Erzählen. Frankfurt a. M.: S. Fischer 2003.

Reich-Ranicki, Marcel/Rühmkorf, Peter: Der Briefwechsel. Hg. v. Christoph Hilse u. Stephan Opitz. Göttingen: Wallstein 2015.

Reif, Adelbert: „Das Identische und das Andersartige“. Gespräch mit Rolf Schneider. In: Der Standard, 2.3.2013.

Richter, Hans Werner: Briefe. Hg. v. Sabine Cofalla im Auftrag der Stiftung Preußische Seehandlung und der Textkritischen Arbeitsstelle der Freien Universität Berlin. München, Wien: Hanser 1997.

Roth, Gerhard: Die Wehleidigkeit der Antworten. [Leserbrief] In: Kleine Zeitung, 3. 6. 1975. Roth, Gerhard: Der Menschenfeind, der der Alpenkönig war. Nachruf auf Thomas Bernhard. In: Neue Rundschau (1989), H. 2, S. 187-189.

Roth, Gerhard: o. T. In: Marcel Reich-Ranicki: Kritik als Beruf. Drei Gespräche, ein kritisches Intermezzo und ein Porträt. Hg. v. Peter Laemmle. Frankfurt a. M.: S. Fischer 2002, S. 99-101.

Roth, Gerhard: Portraits. Frankfurt a. M.: S. Fischer 2012.

Roth, Gerhard/Turrini, Peter: Bruno Kreisky. Fotografiert v. Konrad R. Müller. Berlin, Wien: Nicolai/Forum 1981. 
Rühmkorf, Peter: Tabu I. Tagebücher 1989-1991. Reinbek b. Hamburg: Rowohlt 1995.

Rühmkorf, Peter: In meinen Kopf passen viele Widersprüche. Über Kollegen. Mit Dichterporträts von F. W. Bernstein. Hg. v. Susanne Fischer u. Stephan Opitz. Göttingen: Wallstein 2012.

Schneider, Peter: Die Mängel der gegenwärtigen Literaturkritik. In: Neue deutsche Hefte (1965), H. 107, S. 98-123.

Schneider, Peter: Die Phantasie im Spätkapitalismus und die Kulturrevolution. In: Kursbuch (1969), H. 16, S. 1-37.

Shakespeare, William: As You Like It / Wie es euch gefällt. Englisch / Deutsch. Übers. u. hg. v. Herbert Geisen u. Dieter Wessels. Stuttgart: Reclam 1981.

Sperber, Manès: Meine Feinde. In: Mein(e) Feind(e). Literaturalmanach 1982. Hg. v. Jochen Jung. Salzburg, Wien 1982, S. 121-125.

Stadler, Arnold: Mein Stifter. Porträt eines Selbstmörders in spe und fünf Photographien. Köln: DuMont 2005.

Stifter, Adalbert: Sämmtliche Werke. Bd. 21: Briefwechsel 5. Mit Benutzung der Vorarbeiten v. Adalbert Horcicka hg. v. Gustav Wilhelm. Reichenberg: Kraus 1928.

Stifter, Adalbert: Nachkommenschaften. Späte Erzählungen. Hg. u. mit einem Nachwort v. Karl Wagner. Salzburg, Wien: Jung und Jung 2012.

Turrini, Peter: Mein Österreich. Reden, Polemiken, Aufsätze. Darmstadt: Luchterhand 1988. Unseld, Siegfried: Die Aufgaben des literarischen Verlegers. In: S. U.: Der Autor und sein Verleger. Vorlesungen in Mainz und Austin. Frankfurt a. M.: Suhrkamp 1978, S. 9-64. Unseld, Siegfried: Bruchstücke einer großen Rebellion. In: Der Spiegel, Nr. 45, 4. 11. 2002, S. 194-195.

Walser, Martin: Tagtraum, daß der Kritiker ein Schriftsteller sei. In: Kritik - von wem / für wen / wie. Eine Selbstdarstellung deutscher Kritiker. Hg. v. Peter Hamm. München: Hanser 1968, S. 11-14.

Walser, Martin: „Ich bin ihm nahe“. Es gab Zerwürfnisse und Versöhnungen. Am Ende siegt die Dankbarkeit. In: DIE ZEIT, Nr. 40, 26. 9. 2013, S. 55.

Die Wiener Gruppe. Achleitner, Artmann, Bayer, Rühm, Wiener. Texte, Gemeinschaftsarbeiten, Aktionen. Hg. u. mit einem Vorwort v. Gerhard Rühm. Reinbek b. Hamburg: Rowohlt 1967.

\section{Anthologien}

Bekenntnisbuch österreichischer Dichter. Hg. v. Bund deutscher Schriftsteller in Österreich. Wien: Krystall 1938.

Gesänge der Ostmark. Ein Dichtergruß. Hg. v. Bund der deutschen Schriftsteller Österreichs. Leipzig: Reclam 1938.

Heimkehr ins Reich. Großdeutsche Dichtung aus Ostmark und Sudetenland. 1866-1938. Hg. v. Heinz Kindermann. Leipzig: Reclam 1939 (= Deutsche Literatur. Sammlung 
literarischer Kunst- und Kulturdenkmäler in Entwicklungsreihen. Reihe Politische Dichtung, Bd. 10).

Ostmark-Lyrik. Gesammelt u. hg. v. Adalbert Schmidt. Wien, Leipzig: Adolf Luser 1939. Das Flügelroß. Erstes Kunstjahrbuch des Reichsgaues Salzburg. Hg. v. Heinrich Zillich.

Salzburg: Bergland-Buch 1941.

Bekenntnis zu Josef Weinheber. Erinnerungen seiner Freunde. Hg. v. Heinrich Zillich.

Salzburg: Akademischer Gemeinschaftsverlag 1950.

Der Pegasus. Salzburger Dichteralmanach 1952. Salzburg: Otto Müller 1951.

Die schöne Stadt. Ein lyrischer Spaziergang. Hg. v. Eligius Scheibl. Salzburg: Pfad 1952.

Salzburg von A-Z. Gesammelt u. hg. v. Josef Kaut. Salzburg, Wien: Alpen-Verlag 1954.

Stimmen der Gegenwart 1954. Hg. v. Hans Weigel. Wien: Albrecht Dürer 1954.

Ahnung und Gestalt. Salzburger Almanach der Georg-Trakl-Preisträger. Zusammengestellt u. eingeleitet v. Hansjörg Graf. Salzburg: Otto Müller 1955.

Die ganze Welt in meines Herzens Enge. Anthologie junger Salzburger Lyrik. Salzburg: Pfad 1955.

Stimmen der Gegenwart 1956. Wien, München: Herold 1956.

Neunzehn deutsche Erzählungen. München: Nymphenburger Verlagshandlung 1963.

Erfundene Wahrheit. Deutsche Geschichten seit 1945. Hg. v. Marcel Reich-Ranicki. München: Piper 1965.

Der gewöhnliche Schrecken. Horrorgeschichten. Hg. v. Peter Handke. Salzburg: Residenz 1969.

Grenzverschiebung. Hg. u. mit einem Nachwort v. Renate Matthaei. Köln, Berlin: Kiepenheuer \& Witsch 1970.

Dichtung aus Salzburg. Hg. v. Erich Landgrebe. Wien: Kremayr \& Scheriau 1972. Jemand der schreibt. 57 Aussagen. Hg. v. Rudolf de le Roi. München: Hanser 1972.

Verteidigung der Zukunft. Deutsche Geschichten seit 1960. Hg. v. Marcel Reich-Ranicki. München: Piper 1972.

Literatur im Residenz Verlag. Almanach auf das Jahr 1974. Salzburg: Residenz 1974.

Verteidigung der Zukunft. Deutsche Geschichten seit 1960. Hg. v. Marcel Reich-Ranicki. München, Zürich: Piper ${ }^{2} 1975$.

Verteidigung der Zukunft. Deutsche Geschichten 1960-1980. Hg. v. Marcel Reich-Ranicki. München: dtv 1980.

25 Jahre Residenz Verlag. Zeitgenössische Literatur. Literatur für Zeitgenossen. Almanach für Literatur und Kunst 1981. Salzburg, Wien: Residenz 1981.

Mein(e) Feind(e). Literaturalmanach 1982. Hg. v. Jochen Jung. Salzburg, Wien: Residenz 1982.

Was Kritiker gerne läsen. Literaturalmanach 1984. Hg. v. Jochen Jung. Salzburg, Wien: Residenz 1984. 


\section{Archivbestände}

Thomas Bernhard an Siegfried Melchinger, 3 Briefe, 1956. In: Deutsches Literaturarchiv Marbach, Handschriftensammlung, A: Melchinger, HS.1999.0010.

Thomas Bernhard an Marcel Reich-Ranicki, 2 Briefe, 1965/1986. In: Deutsches Literaturarchiv Marbach, Handschriftensammlung, A: Reich-Ranicki, HS.2003.0002.00153.

Peter Handke: Handschriftliche Annotationen zu Helmut Färber: Die Verachtung. La Mépris. In: Filmkritik (1965), H. 3, S. 141-143. In: Literaturarchiv Salzburg, Bestand: Peter Handke, Sammlung Helmut Färber.

Peter Handke an Marcel Reich-Ranicki, 3 Briefe, 1975-1976. In: Deutsches Literaturarchiv Marbach, Handschriftensammlung, A: Reich-Ranicki, HS.2003.0002.00240.

Peter Handke an Wolfgang Schaffler, Briefkonvolut. In: Literaturarchiv Salzburg, Archiv des Residenz Verlags.

Hans Paeschke an Thomas Bernhard, 12 Briefe, 1964-1978. In: Deutsches Literaturarchiv Marbach, Handschriftensammlung, D: Merkur, HS.NZ8o.ooo3.

\section{Literatur- und Kulturtheorie}

Adorno, Theodor W.: Noten zur Literatur. Hg. v. Rolf Tiedemann. Frankfurt a. M.: Suhrkamp 1981.

Barthes, Roland: Am Nullpunkt der Literatur. Objektive Literatur. Aus dem Französischen v. Helmut Scheffel. Hamburg: Claassen 1959.

Barthes, Roland: Mythen des Alltags. Deutsch v. Helmut Scheffel. Frankfurt a. M.: Suhrkamp 1964.

Benjamin, Walter: Gesammelte Schriften. Unter Mitwirkung v. Theodor W. Adorno u. Gershom Scholem hg. v. Rolf Tiedemann u. Hermann Schweppenhäuser. Bd. IV.1. Hg. v. Tillman Rexroth. Frankfurt a. M.: Suhrkamp 1972.

Benjamin, Walter: Gesammelte Schriften. Unter Mitwirkung v. Theodor W. Adorno u. Gershom Scholem hg. v. Rolf Tiedemann u. Hermann Schweppenhäuser. Bd. VI. Hg. v. Rolf Tiedemann u. Hermann Schweppenhäuser. Frankfurt a. M.: Suhrkamp 1985.

Bloom, Harold. Einflußangst. Eine Theorie der Dichtung. Aus dem amerikanischen Englisch v. Angelika Schweikhart. Basel, Frankfurt a. M.: Stroemfeld/Nexus 1995.

Bloom, Harold: Eine Topographie des Fehllesens. Aus dem Englischen v. Isabella Mayr. Frankfurt a. M.: Suhrkamp 1997.

Bourdieu, Pierre: Satz und Gegensatz. Über die Verantwortung des Intellektuellen. Aus dem Französischen v. Ulrich Raulff u. Bernd Schwibs. Berlin: Wagenbach 1989.

Bourdieu, Pierre: Rede und Antwort. Aus dem Französischen v. Bernd Schwibs. Frankfurt a. M.: Suhrkamp 1992.

Bourdieu, Pierre: Soziologische Fragen. Aus dem Französischen v. Hella Beister u. Bernd Schwibs. Frankfurt a. M.: Suhrkamp 1993. 
Bourdieu, Pierre: Praktische Vernunft. Zur Theorie des Handelns. Aus dem Französischen v. Hella Beister. Frankfurt a. M.: Suhrkamp 1998.

Bourdieu, Pierre: Die Regeln der Kunst. Genese und Struktur des literarischen Feldes. Übersetzt v. Bernd Schwibs u. Achim Russer. Frankfurt a. M.: Suhrkamp 1999.

Bourdieu, Pierre: Kunst und Kultur. Zur Ökonomie symbolischer Güter. Schriften zur Kultursoziologie 4. Hg. v. Franz Schultheis u. Stephan Egger. Aus dem Französischen v. Hella Beister. Berlin: Suhrkamp 2014 (= P. B.: Schriften, Bd. 12.1).

Bourdieu, Pierre: Kunst und Kultur. Kunst und künstlerisches Feld. Schriften zur Kultursoziologie 4. Hg. v. Franz Schultheis u. Stephan Egger. Aus dem Französischen v. Bernd Schwibs, Achim Russer, Michael Tillmann, Hella Beister, Wolfgang Fietkau, Bernd Dieckmann u. Stephan Egger. Berlin: Suhrkamp 2015 (= P. B.: Schriften, Bd. 12.2).

Certeau, Michel de: Kunst des Handelns. Aus dem Französischen übersetzt v. Ronald Voullié. Berlin: Merve 1988.

Eichenbaum, Boris: Aufsätze zur Theorie und Geschichte der Literatur. Frankfurt a. M.: Suhrkamp 1965.

Franck, Georg: Ökonomie der Aufmerksamkeit. Ein Entwurf. München, Wien: Hanser 1998 (= Edition Akzente).

Genette, Gérard: Palimpseste. Die Literatur auf zweiter Stufe. Aus dem Französischen v. Wolfram Bayer u. Dieter Hornig. Frankfurt a. M.: Suhrkamp 1993.

Genette, Gérard: Paratexte. Das Buch vom Beiwerk des Buches. Mit einem Vorwort v. Harald Weinrich. Aus dem Französischen v. Dieter Hornig. Frankfurt a. M.: Suhrkamp 2001.

Greenblatt, Stephen: Was ist Literaturgeschichte? Mit einem Kommentar v. Catherine Belsey. Aus dem Englischen v. Reinhard Kaiser u. Barbara Naumann. Frankfurt a. M.: Suhrkamp 2000.

Groys, Boris: Über das Neue. Versuch einer Kulturökonomie. München: Hanser 1992. Jakobson, Roman: Poetik. Ausgewählte Aufsätze 1921-1971. Hg. v. Elmar Holenstein u. Tarcisius Schelbert. Frankfurt a. M.: Suhrkamp 1979.

Lukács, Georg: Schriften zur Literatursoziologie. Hg. v. Heinz Maus u. Friedrich Fürstenberg. Neuwied, Berlin: Luchterhand ${ }^{4} 1970$.

Meizoz, Jérôme: Die posture und das literarische Feld. Rousseau, Céline, Ajar, Houllebecq. In: Text und Feld. Bourdieu in der literaturwissenschaftlichen Praxis. Hg. v. Markus Joch u. Norbert Christian Wolf. Tübingen: Niemeyer 2005 (= Studien und Texte zur Sozialgeschichte der Literatur, Bd. 108), S. 177-188.

Šklovskij, Viktor: Theorie der Prosa. Hg. u. aus dem Russischen übersetzt v. Gisela Drohla. Frankfurt a. M.: Fischer 1966.

Striedter, Jurij (Hg.): Russischer Formalismus. Texte zur allgemeinen Literaturtheorie und zur Theorie der Prosa. München: Fink ${ }^{4} 1988$. 


\section{Forschungsliteratur}

Albes, Claudia: Erzählen - Argumentieren - Beschreiben. Zur Theorie und Interpretation moderner Prosatexte am Beispiel von Peter Handkes Lehre der Sainte-Victoire. Trier: Wissenschaftlicher Verlag Trier 2013 (= Schriftenreihe Literaturwissenschaft, Bd. 87). Albrecht, Wolfgang: Literaturkritik. Stuttgart, Weimar: Metzler 2001.

Alker, Stefan: Das Andere nicht zu kurz kommen lassen. Werk und Wirken von Gerhard Fritsch. Wien: Braumüller 2007 (= Wiener Arbeiten zur Literatur, Bd. 23).

Althaus, Thomas (Hg.): Kleinbürger. Zur Kulturgeschichte des begrenzten Bewußtseins. Tübingen: Attempto 2001.

Amann, Klaus: Die Dichter und die Politik. Essays zur österreichischen Literatur nach 1918. Wien: Edition Falter/Deuticke 1992.

Amann, Klaus: Zahltag. Der Anschluß österreichischer Dichter an das Dritte Reich. [1988] Bodenheim: Philo ${ }^{2} 1996$.

Amann, Klaus: Das Wie des Was. Vorwort. In: Freund und Feind. Alois Brandstetter u. a. über ihre literarischen Vorbilder, Widersacher und Nebenbuhler. Hg. v. K. A. u. Fabjan Hafner. Wien: Sonderzahl 2006, S. 7-14.

Amann, Klaus: Peter Turrinis Bei Einbruch der Dunkelheit. Ein Stück über den „Tonhof“? Mit einem Seitenblick auf Thomas Bernhards Holzfällen. Eine Erregung. In: Peter Turrini, Schriftsteller. Kämpfer, Künstler, Narr und Bürger. Mit einer Rede Peter Turrinis. Hg. v. K. A. St. Pölten, Salzburg: Residenz 2007, S. 155-178.

Amann, Klaus/Hafner, Fabjan/Wagner, Karl (Hg.): Peter Handke. Poesie der Ränder. Wien u. a.: Böhlau 2006 (= Literaturgeschichte in Studien und Quellen, Bd. 11).

Anz, Thomas: Literaturkritisches Argumentationsverhalten am Beispiel des Streits um Peter Handke und Botho Strauß. In: Literaturkritik - Anspruch und Wirklichkeit. DFG-Symposion 1989. Hg. v. Wilfried Barner. Stuttgart: Metzler 1990 (= Germanistische Symposien. Berichtsbände, Bd. XII), S. 415-430.

Anz, Thomas: Marcel Reich-Ranicki. München: dtv 2004.

Anz, Thomas: Werten und Fühlen. Zur Rationalität und Emotionalität literaturkritischer Kommunikation - am Beispiel von Marcel Reich-Ranicki. In: Literaturkritik heute. Tendenzen - Traditionen - Vermittlung. Hg. v. Heinrich Kaulen u. Christina Gansel. Göttingen: V\&R unipress 2015, S. 13-25.

Apostolo, Stefano: Thomas Bernhards unveröffentlichtes Romanprojekt Schwarzach St. Veit. Das Konvolut, die Fassungen und ihre Deutung. Mattighofen: Korrektur 2019.

Arntzen, Helmut: Literaturkritik? Annotierte Zitate aus einem Buch von Marcel Reich-

Ranicki. In: Kunstgriffe. Auskünfte zur Reichweite von Literaturtheorie und Literaturkritik. Festschrift für Herbert Mainusch. Hg. v. Ulrich Horstmann u. Wolfgang Zach. Frankfurt a. M. u. a.: Lang 1989, S. 27-33.

Bandeili, Angela: Rolf Dieter Brinkmann und Peter Handke um '68. Der Skandal als Akt der Revolte? In: Skandalautoren. Zu repräsentativen Mustern literarischer Provokation 
und Aufsehen erregender Autorinszenierung. Bd. 2. Hg. v. Andrea Bartl u. Martin Kraus. Würzburg: Königshausen \& Neumann 2014 (= Konnex, Bd. 10), S. 53-67.

Barner, Ines: „Nie wieder will ich Masken sehen“. Zur Entstehung von Peter Handkes Erzählung Langsame Heimkehr (1979). In: Jahrbuch der deutschen Schillergesellschaft 58 (2014), S. 355-385.

Barner, Wilfried: Zwischen unübersichtlichem Überfluß und unverhoffter „friedlicher Revolution“. Literarisches Leben im Westen. In: Geschichte der deutschen Literatur von den Anfängen bis zur Gegenwart. Bd. XII: Geschichte der deutschen Literatur von 1945 bis zur Gegenwart. Hg. v. W. B. München: C. H. Beck 22006, S. 797-813.

Barthofer, Alfred: King Lear in Dinkelsbühl. Historisch-Biographisches zu Thomas Bernhards Theaterstück Minetti. In: Maske und Kothurn 23 (1977), S. 159-172.

Bartmann, Christoph: Suche nach Zusammenhang. Handkes Werk als Prozeß. Wien: Braumüller 1984.

Bartmann, Christoph: Das Gewicht der Welt - revisited. In: Text + Kritik (51989), H. 24, S. 34-41.

Bartmann, Christoph: Vom Scheitern der Studien. Das Schriftmotiv in Bernhards Romanen. In: Text + Kritik ( $\left.{ }^{3} 1991\right)$, H. 43, S. 22-29.

Bätschmann, Oskar: Ausstellungskünstler. Kult und Karriere im modernen Kunstsystem. Köln: DuMont 1997.

Bauer, Werner M.: Die deutschsprachige Literatur Österreichs nach 1945. In: Literaturgeschichte Österreichs von den Anfängen im Mittelalter bis zur Gegenwart. Hg. v. Herbert Zeman. Graz: Akademische Druck- und Verlagsanstalt 1996, S. 511-563.

Bayer, Wolfram: Das Gedruckte und das Tatsächliche. Realität und Fiktion in Thomas Bernhards Leserbriefen. In: Thomas Bernhard. Beiträge zur Fiktion der Postmoderne. Londoner Symposion. Hg. v. Wendelin Schmidt-Dengler, Adrian Stevens u. Fred Wagner. Frankfurt a. M. u. a.: Lang 1997, S. 1-23.

Bentz, Oliver: Thomas Bernhard - Dichtung als Skandal. Würzburg: Königshausen \& Neumann 2000 (= Epistemata. Reihe Literaturwissenschaft, Bd. 337).

Betz, Uwe: Der Großvater als Dramaturg, Double und Farce. Zur steten Wiedergeburt der Ahnen in Thomas Bernhards Werk. In: Bernhard-Tage Ohlsdorf 1999. „In die entgegengesetzte Richtung". Thomas Bernhard und sein Großvater Johannes Freumbichler. Materialien. Hg. v. Franz Gebesmair u. Manfred Mittermayer. Weitra: Bibliothek der Provinz [2000], S. 100-131.

Billenkamp, Michael: Thomas Bernhard. Narrativik und poetologische Praxis. Heidelberg: Winter 2008 (= Beiträge zur neueren Literaturgeschichte, Bd. 259).

Billenkamp, Michael: Provokation und posture. Thomas Bernhard und die Medienkarriere der Figur Bernhard. In: Mediale Erregungen? Autonomie und Aufmerksamkeit im Literatur- und Kulturbetrieb der Gegenwart. Hg. v. Markus Joch, York-Gothart Mix u. Norbert Christian Wolf. Tübingen: Niemeyer 2009 (= Studien und Texte zur Sozialgeschichte der Literatur, Bd. 118), S. 23-43. 
Birkner, Nina: Vom Genius zum Medienästheten. Modelle des Künstlerdramas im 20. Jahrhundert. Tübingen: Niemeyer 2009 (= Studien zur deutschen Literatur, Bd. 192).

Birkner, Nina: Die Theaterkritik als Instrument der Selbstpositionierung betrachtet Friedrich Schillers Rezeptionspraxis und die Schaubühne. In: Germanisch-Romanische Monatsschrift 61 (2011), H. 4, S. 395-406.

Blasberg, Cornelia: Peter Handke und die ewige Wiederkehr des Neuen. In: Literaturwissenschaftliches Jahrbuch. N. F. 38 (1997), S. 185-204.

Bode, Georg Heinrich: Geschichte der Hellenischen Dichtkunst. Zweiter Band: Geschichte der Lyrischen Dichtkunst der Hellenen bis auf Alexandros den Grossen. Erster Theil: Ionische Lyrik, nebst Abhandlungen über die ältesten Kultus- und Volkslieder und über die Tonkunst der Hellenen. Leipzig: Köhler 1838.

Bogner, Ralf Georg: Drei Distanzierungen. Die Nachrufe von H. C. Artmann, Elfriede Jelinek und Gerhard Roth auf Thomas Bernhard. In: Die Lebenden und die Toten. Beiträge zur österreichischen Gegenwartsliteratur. Hg. v. Markus Knöfler, Peter Plener u. Péter Zalán. Budapest: ELTE 2000 (= Budapester Beiträge zur Germanistik, Bd. 35), S. 251-263.

Bohn, Volker: „Später werde ich über das alles Genaueres schreiben“. Peter Handkes Erzählung Wunschloses Unglück aus literaturtheoretischer Sicht. In: GermanischRomanische Monatsschrift 26 (1976), S. 356-379.

Bohrer, Karl Heinz: Mit Dolchen sprechen. Der literarische Hass-Effekt. Berlin: Suhrkamp 2019.

Borgards, Roland: Sprache als Bild. Handkes Poetologie und das 18. Jahrhundert. München: Fink 2003.

Bossinade, Johanna: Moderne Textpoetik. Entfaltung eines Verfahrens. Mit dem Beispiel Peter Handke. Würzburg: Königshausen \& Neumann 1999.

Botond, Anneliese (Hg.): Über Thomas Bernhard. Frankfurt a. M.: Suhrkamp 1970.

Böttiger, Helmut: Nach den Utopien. Eine Geschichte der deutschsprachigen Gegenwartsliteratur. Wien: Zsolnay 2004.

Böttiger, Helmut: Die Gruppe 47. Als die deutsche Literatur Geschichte schrieb. München: DVA 2012.

Böttiger, Helmut/Brombach, Charlotte/Rüdenauer, Ulrich: Sanfte Bewegungen von außen nach innen. Zum Briefwechsel von Peter Handke und Hermann Lenz. In: Peter Handke/ Hermann Lenz: Berichterstatter des Tages. Briefwechsel. Hg. u. mit einem Nachwort versehen v. Helmut Böttiger. Frankfurt a. M.: Insel 2006, S. 427-444.

Breuer, Ulrich: Parasitenfragen. Medienkritische Argumente in Peter Handkes Serbienreise. In: Mediensprache - Medienkritik. Hg. v. U. B. u. Jarmo Korhonen. Frankfurt a. M. u. a.: Lang 2001 (= Finnische Beiträge zur Germanistik, Bd. 4), S. 285-303.

Brokoff, Jürgen: „Ich wäre gern noch viel skandalöser“. Peter Handkes Texte zum Jugoslawien-Krieg im Spannungsfeld von Medien, Politik und Poesie. In: Peter Handke. Stationen, Orte, Positionen. Hg. v. Anna Kinder. Berlin, Boston: de Gruyter 2014, S. 17-37. 
Brunkhorst, Martin: Minetti oder Beckett und Bernhard. In: Beckett und die Literatur der Gegenwart. Hg. v. M. B., Gerd Rohmann u. Konrad Schoell. Heidelberg: Winter 1988, S. $175-189$.

Bülow, Ulrich von: Die Tage, die Bücher, die Stifte. Peter Handkes Journale. In: Peter Handke. Freiheit des Schreibens - Ordnung der Schrift. Hg. v. Klaus Kastberger. Unter Mitarb. v. Clemens Özelt. Wien: Zsolnay 2009 (= Profile, Bd. 16), S. 237-252.

Bülow, Ulrich von: Heidegger-Lektüren. In: Das stehende Jetzt. Die Notizbücher von Peter Handke. Gespräch mit dem Autor und Essays von U. v. B. Marbach a. N.: Deutsche Schillergesellschaft 2018, S. 95-123.

Bülow, Ulrich von: Spinoza-Lektüren. In: Das stehende Jetzt. Die Notizbücher von Peter Handke. Gespräch mit dem Autor und Essays von U. v. B. Marbach a. N.: Deutsche Schillergesellschaft 2018, S. 125-147.

Carstensen, Thorsten: Romanisches Erzählen. Peter Handke und die epische Tradition. Göttingen: Wallstein 2013.

Carstensen, Thorsten (Hg.): Die tägliche Schrift. Peter Handke als Leser. Bielefeld: transcript 2019.

Carstensen, Thorsten: „Ich muß zu Meinesgleichen!“ Lesen, Ahnenkult und Autorschaft bei Peter Handke. In: Die tägliche Schrift. Peter Handke als Leser. Hg. v. T. C. Bielefeld: transcript 2019, S. 9-40.

Christians, Heiko: Der Roman vom Epos. Peter Handkes „Poetik der Verlangsamung“. In: Hofmannsthal. Jahrbuch zur europäischen Moderne 10 (2002), S. 357-389.

Cofalla, Sabine: Die Gruppe 47. Dominante soziale Praktiken im literarischen Feld der Bundesrepublik Deutschland. In: Text und Feld. Bourdieu in der literaturwissenschaftlichen Praxis. Hg. v. Markus Joch u. Norbert Christian Wolf. Tübingen: Niemeyer 2005 (= Studien und Texte zur Sozialgeschichte der Literatur, Bd. 108), S. 353-369.

Cramer, Sibylle: Literaturkritik. In: Machen - Erhalten - Verwalten. Aspekte einer performativen Literaturgeschichte. Hg. v. Burckhard Dücker. Göttingen: Wallstein 2016, S. $61-68$.

Czernin, Franz Josef: Marcel Reich-Ranicki. Eine Kritik. Göttingen: Steidl 1995.

DeMeritt, Linda C.: Handkes Antigeschichten. Der Kriminalroman als Subtext in Der Hausierer und Die Angst des Tormanns beim Elfmeter. In: Experimente mit dem Kriminalroman. Ein Erzählmodell in der deutschsprachigen Literatur des 20. Jahrhunderts. Hg. v. Wolfgang Düsing. Frankfurt a. M. u. a.: Lang 1993, S. 185-203.

Demetz, Peter: On Marcel Reich-Ranicki. In: German Literature, Jewish Critics. The Brandeis Symposium. Hg. v. Stephen D. Dowden u. Meike G. Werner. Rochester: Camden House 2002, S. 289-302.

Diller, Axel: Das vergessene Werk. Thomas Bernhards Lyrik. In: Text + Kritik ( $\left.{ }^{4} 2016\right)$, H. 43 , S. 66-91.

Diller, Axel/Mittermayer, Manfred: Rezeption der Prosa im deutschen Sprachraum. In: Bernhard-Handbuch. Leben - Werk - Wirkung. Hg. v. Martin Huber u. M. M. Unter Mitarb. v. Bernhard Judex. Stuttgart: Metzler 2018, S. 478-483. 
Dinter, Ellen: Gefundene und erfundene Heimat. Zu Peter Handkes zyklischer Dichtung: Langsame Heimkehr. 1979-1981. Köln, Wien: Böhlau 1986 (= Kölner germanistische Studien, Bd. 22).

Dittmar, Jens (Hg.): Thomas Bernhard. Werkgeschichte. Frankfurt a. M.: Suhrkamp 1981.

Dittmar, Jens: Thomas Bernhard als Journalist beim Demokratischen Volksblatt. In: Bernhard. Annäherungen. Hg. v. Manfred Jurgensen. Bern, München: Francke 1981, S. $15-35$.

Dittmar, Jens (Hg.): Thomas Bernhard. Werkgeschichte. Aktualisierte Neuausgabe 1990. Frankfurt a. M.: Suhrkamp ${ }^{2} 1990$.

Dittmar, Jens (Hg.): Sehr geschätzte Redaktion. Leserbriefe von und über Thomas Bernhard. Wien: Edition S 1991.

Dittmar, Jens (Hg.): Aus dem Gerichtssaal. Thomas Bernhards Salzburg in den $50 e r$ Jahren. Wien: Edition S 1992.

Donnenberg, Josef: Thomas Bernhards Zeitkritik und Österreich. In: Literarisches Kolloquium Thomas Bernhard. Materialien. Hg. v. Johann Lachinger u. Alfred Pittertschatscher. Weitra: Bibliothek der Provinz 1994, S. 53-72.

Döring, Jörg: Peter Handke beschimpft die Gruppe 47. Mit einem autobiographischen Nachwort v. Helmut Schanze. Siegen: universi 2019.

Dorschel, Andreas: Lakonik und Suada in der Prosa Thomas Bernhards. In: Thomas Bernhard Jahrbuch 2007/2008, S. 215-233.

Dressel, Manuela: Thomas Bernhard und seine Verleger. Wien: danzig \& unfried 2014.

Durzak, Manfred: Peter Handke und die deutsche Gegenwartsliteratur. Narziß auf Abwegen. Stuttgart: Kohlhammer 1982 (= Sprache und Literatur, Bd. 108).

Eder, Thomas/Vogel, Juliane (Hg.): verschiedene sätze treten auf. Die Wiener Gruppe in Aktion. Wien: Zsolnay 2008 (= Profile, Bd. 15).

Estermann, Anna: „statt ,Bild‘ sag auch ,Traum, ,Illusion‘, ,Ganz-Sein`, ,Mit-Sein`...“. Handkes ganz weltliche „Religion“ der Bilder. In: „Verwandeln allein durch Erzählen“. Peter Handke im Spannungsfeld von Theologie und Literaturwissenschaft. Hg. v. Jan-Heiner Tück u. Andreas Bieringer. Freiburg i. Br. u. a.: Herder 2014, S. 175-194.

Estermann, Anna: Vom „bloß sprachlichen“ zu einem „allumfassenden Realismus“. Handkes, realistic turn' um 1970. In: Schreiben als Weltentdeckung. Neue Perspektiven der Handke-Forschung. Hg. v. A. E. u. Hans Höller. Wien: Passagen 2014 (= Passagen Literaturtheorie), S. 97-134.

Estermann, Anna: Mit(ge)lesen. Handkes Sacramento (Eine Wildwestgeschichte). In: Die tägliche Schrift. Peter Handke als Leser. Hg. v. Thorsten Carstensen. Bielefeld: transcript 2019, S. 87-108.

Eybl, Franz M.: Thomas Bernhards Stimmenimitator als Resonanz eigener und fremder Rede. In: Kontinent Bernhard. Zur Thomas-Bernhard-Rezeption in Europa. Hg. v. Wolfram Bayer. Wien u. a.: Böhlau 1995, S. 31-43.

Eybl, Franz M.: „Wenn das Werk lacht, weint der Dichter“. Thomas Bernhards poetologische Maskeraden. In: Dichterdarsteller. Fallstudien zur biographischen Legende des 
Autors im 20. und 21. Jahrhundert. Hg. v. Robert Leucht u. Magnus Wieland. Göttingen: Wallstein 2016, S. 157-174.

Eyckeler, Franz: Reflexionspoesie. Sprachskepsis, Rhetorik und Poetik in der Prosa Thomas Bernhards. Berlin: Erich Schmidt 1995 (= Philologische Studien und Quellen, Bd. 133).

Federmair, Leopold: Die Apfelbäume von Chaville. Annäherungen an Peter Handke. Salzburg, Wien: Jung und Jung 2012.

Fellinger, Raimund: „Schreiben: Sich zur Ruhe setzen“. Die Entstehung von Mein Jahr in der Niemandsbucht. In: Peter Handke. Freiheit des Schreibens - Ordnung der Schrift. Hg. v. Klaus Kastberger. Unter Mitarb. v. Clemens Özelt. Wien: Zsolnay 2009 (= Profile, Bd. 16), S. 133-142.

Fellinger, Raimund: Thomas Bernhard als Menschenfänger? In: Text + Kritik ( $\left.{ }^{4} 2016\right)$, H. 43, S. 7-9.

Fellinger, Raimund: „Ich bin kein Teppichknüpfer“. In: Berlin, 17. November 1968. Autoren diskutieren mit ihren Kritikern. Thomas Bernhard diskutiert mit Rudolf Hartung. Mattighofen: Korrektur 2017, S. 35-39.

Ferk, Janko: Bauer Bernhard. Beamter Kafka. Dichter und ihre Zivilberufe. Wien u. a.: Styria premium 2015.

Feulner, Gabriele: Mythos Künstler. Konstruktionen und Dekonstruktionen in der deutschsprachigen Prosa des 20. Jahrhunderts. Berlin: Erich Schmidt 2010 (= Philologische Studien und Quellen, Bd. 222).

Fingerhut, Karlheinz: Drei erwachsene Söhne Kafkas. Zur produktiven Kafka-Rezeption bei Martin Walser, Peter Weiss und Peter Handke. In: Wirkendes Wort 30 (1980), H. 6, S. 384-403.

Freinschlag, Andreas: Der kokette Künstler. Überlegungen zum Habitus und zur Poetik Peter Handkes. In: Medien der Autorschaft. Formen literarischer (Selbst-)Inszenierung von Brief und Tagebuch bis Fotografie und Interview. Hg. v. Lucas Marco Gisi, Urs Meyer u. Reto Sorg. München: Fink 2013, S. 215-226.

Fuest, Leonhard: Kunstwahnsinn irreparabler. Eine Studie zum Werk Thomas Bernhards. Frankfurt a. M. u. a.: Lang 2000 (= Beiträge zur Literatur und Literaturwissenschaft des 20. Jahrhunderts, Bd. 20).

Gabriel, Norbert: Peter Handke und Österreich. Bonn: Bouvier 1983 (= Abhandlungen zur Kunst-, Musik- und Literaturwissenschaft, Bd. 334).

Gamper, Herbert: Thomas Bernhard. München: dtv 1977.

Gesellschaft für Exilforschung: Nachrichtenbrief 1984 bis 1993 mit Gesamtregister. Bd. 1. Redaktion: Ernst Loewy. München u. a.: Saur 1995.

Gilcher-Holtey, Ingrid: 1968. Eine Zeitreise. Frankfurt a. M.: Suhrkamp 2008.

Görtz, Franz Josef: Hier spukt natürlich Beckett. Thomas Bernhard und die Kritik. In: Text + Kritik (1974), H. 43, S. 36-44.

Gößling, Andreas: Thomas Bernhards frühe Prosakunst. Entfaltung und Zerfall eines ästhetischen Verfahrens in den Romanen Frost - Verstörung - Korrektur. Berlin, New 
York: de Gruyter 1987 (= Quellen und Forschungen zur Sprach- und Kulturgeschichte der germanischen Völker, Bd. 88 [212]).

Gößling, Andreas: Frost. In: Bernhard-Handbuch. Leben - Werk - Wirkung. Hg. v. Martin Huber u. Manfred Mittermayer. Unter Mitarb. v. Bernhard Judex. Stuttgart: Metzler 2018, S. 37-46.

Göttsche, Dirk: Liebeserklärungen und Verletzungen - Zur Literaturkritik von Martin Walser und Ingeborg Bachmann. In: Literaturkritik - Anspruch und Wirklichkeit. DFG-Symposion 1989. Hg. v. Wilfried Barner. Stuttgart: Metzler 1990 (= Germanistische Symposien. Berichtsbände, Bd. XII), S. 197-212.

Gottwald, Herwig: Mythos und Mythisches in der Gegenwartsliteratur. Studien zu Christoph Ransmayr, Peter Handke, Botho Strauß, George Steiner, Patrick Roth und Robert Schneider. Stuttgart: Heinz 1996 (= Stuttgarter Arbeiten zur Germanistik, Bd. 333).

Gottwald, Herwig: Einladung, Peter Handke zu lesen. Erfahrungen eines Germanisten. In: ide. Informationen zur Deutschdidaktik 25 (2001), H. 4, S. 27-37.

Gottwald, Herwig: Von Namen, Augenblicksgöttern und Wiederholungen. Handkes Umgang mit dem Mythischen. In: Peter Handke. Poesie der Ränder. Hg. v. Klaus Amann, Fabjan Hafner u. Karl Wagner. Wien u. a.: Böhlau 2006 (= Literaturgeschichte in Studien und Quellen, Bd. 11), S. 135-153.

Gottwald, Herwig: „In wie vielen Zeitungsfotos von Mördern ich mich wiedererkenne!“ Handke und das ,Böse`. In: Schreiben als Weltentdeckung. Neue Perspektiven der Handke-Forschung. Hg. v. Anna Estermann u. Hans Höller. Wien: Passagen 2014 (= Passagen Literaturtheorie), S. 201-213.

Gottwald, Herwig: Peter Handke und der Western. In: „Das Wort sei gewagt“. Ein Symposium zum Werk von Peter Handke. Hg. v. Attila Bombitz u. Katharina Pektor. Wien: Praesens 2019 (= Österreich-Studien Szeged, Bd. 15), S. 60-74.

Gottwald, Herwig/Freinschlag, Andreas: Peter Handke. Wien u. a.: Böhlau 2010 (= UTB basics).

Götze, Clemens: „Die eigentliche Natur und Welt ist in den Zeitungen“. Geschichte, Politik und Medien im dramatischen Spätwerk Thomas Bernhards. Marburg: Tectum 2009.

Götze, Clemens: Der geehrte Autor und die Kunst der Invektive. Zu Thomas Bernhards Meine Preise. In: Studia austriaca 20 (2012), S. 55-84.

Götze, Clemens: „Die Ursache bin ich selbst!“ Thomas Bernhards inszenierte Autorschaft am Beispiel seiner (Film-)Interviews. In: Thomas Bernhard. Gesellschaftliche und politische Bedeutung der Literatur. Hg. v. Johann Georg Lughofer. Wien u. a.: Böhlau 2012, S. 357-371.

Götze, Clemens: „Die Redereien und Selbstdarstellungen hasse ich“. Thomas Bernhards Interviewkunst. In: Echt inszeniert. Interviews in Literatur und Literaturbetrieb. Hg. v. Torsten Hoffmann u. Gerhard Kaiser. Paderborn: Fink 2014, S. 239-256.

Götze, Clemens: „Ein Autor ist etwas ganz und gar erbärmliches und lächerliches“. Autorschaft als Inszenierung bei Thomas Bernhard. In: Theorien und Praktiken der 
Autorschaft. Hg. v. Matthias Schaffrick u. Marcus Willand. Berlin, Boston: de Gruyter 2014 (= spectrum Literaturwissenschaft, Bd. 47), S. 419-437.

Götze, Clemens: Ichwerdung als dichterischer Selbstentwurf. Thomas Bernhards , literarische' Inszenierung. In: Subjektform Autor. Autorschaftsinszenierungen als Praktiken der Subjektivierung. Hg. v. Sabine Kyora. Bielefeld: transcript 2014, S. 69-82.

Götze, Clemens: „Mit allen Anzeichen der Empörung“. Thomas Bernhard als Leserbriefschreiber. In: Text + Kritik ( $\left.{ }^{4} 2016\right)$, H. 43, S. 52-65.

Graf, Werner: Peter Handke und seine Kritiker. Zu Motiven der Rezeption von Gegenwartsliteratur. In: Literatur für Leser 27 (2004), H. 2, S. 89-101.

Greite, Till: „Prozesse, nichts als Prozesse“. Thomas Bernhard. Vom Gerichtsberichterstatter zum Fall für die Justiz. In: Recht, sachlich. Hg. v. David Oels, Stephan Porombka u. Eberhard Schütz. Hannover: Wehrhahn 2009 (= Non Fiktion. Arsenal der anderen Gattungen, Bd. 3), S. 95-102.

Gschwandtner, Harald: „Fontane hat das vielleicht noch gekonnt“. Familiennarrativ und Gattungspolemik bei Peter Handke. In: Familie und Identität in der Gegenwartsliteratur. Hg. v. Goran Lovrić u. Marijana Jeleč. Frankfurt a. M. u. a.: Lang 2016, S. 199-218.

Gschwandtner, Harald: [Rez. zu:] Jan-Heiner Tück, Andreas Bieringer (Hg.): „Verwandeln allein durch Erzählen“. Peter Handke im Spannungsfeld von Theologie und Literaturwissenschaft. In: Salzburger Theologische Zeitschrift 20 (2016), H. 2, S. 289-292.

Gschwandtner, Harald: Thomas Bernhards ,Radikalität. Versuch einer kultursoziologischen Lesart. In: Das Radikale. Gesellschaftspolitische und formal-ästhetische Aspekte in der Gegenwartsliteratur. Hg. v. Stephanie Willeke, Ludmila Peters u. Carsten Roth. Berlin u. a.: LIT 2017 (= Literaturwissenschaft, Bd. 8), S. 235-261.

Gschwandtner, Harald: Journalistische Arbeiten. In: Bernhard-Handbuch. Leben - Werk Wirkung. Hg. v. Martin Huber u. Manfred Mittermayer. Unter Mitarb. v. Bernhard Judex. Stuttgart: Metzler 2018, S. 16-20.

Gschwandtner, Harald: Journalistisches, Reden, Interviews. In: Bernhard-Handbuch. Leben - Werk - Wirkung. Hg. v. Martin Huber u. Manfred Mittermayer. Unter Mitarb. v. Bernhard Judex. Stuttgart: Metzler 2018, S. 270-278.

Gschwandtner, Harald: Peter Handkes epitextuelle Werkpolitik. In: Paratextuelle Politik und Praxis. Interdependenzen von Werk und Autorschaft. Hg. v. Martin GerstenbräunKrug u. Nadja Reinhard. Wien: Böhlau 2018, S. 271-292.

Gschwandtner, Harald: Von Kollegen und Diktatoren. Bernhard, Jelinek und die literarische Konkurrenz. In: Elfriede Jelinek und Thomas Bernhard. Intertextualität - Korrelationen - Korrespondenzen. Hg. v. Bastian Reinert u. Clemens Götze. Berlin, Boston: de Gruyter 2019 (= Untersuchungen zur deutschen Literaturgeschichte, Bd. 154), S. 71-85.

Gschwandtner, Harald: „Meine Sehnsucht ist, das Dramatische mehr zu episieren“. Zum Erzählerischen in Peter Handkes Theaterstücken. In: Entwicklungen der Dramatik und Formen des Theaters in Österreich seit den 1960er Jahren. Hg. v. Sieglinde Klettenhammer u. Wolfgang Wiesmüller. Innsbruck: innsbruck university press 2020 (= Innsbrucker Beiträge zur Kulturwissenschaft. Germanistische Reihe, Bd. 93), S. 45-64. 
Gutknecht, Christoph (Hg.): Lauter Worte über Worte. Runde und spitze Gedanken über Sprache und Literatur. München: C. H. Beck 1999.

Habringer, Rudolf: Der Auswegsucher. Über Thomas Bernhards Anfänge als Journalist. In: Thomas Bernhard und Salzburg. 22 Annäherungen. Hg. v. Manfred Mittermayer u. Sabine Veits-Falk. Salzburg: Jung und Jung 2001, S. 31-40.

Hackl, Wolfgang: Kein Bollwerk der alten Garde - keine Experimentierbude. Wort in der Zeit (1955-1965). Eine österreichische Literaturzeitschrift. Innsbruck: Institut für Germanistik 1988 (= Innsbrucker Beiträge zur Kulturwissenschaft, Bd. 35).

Hackl, Wolfgang: „Kollegial bis zur Selbstverleugnung“. Gerhard Fritsch als Redakteur und Herausgeber von Literaturzeitschriften. In: Gerhard Fritsch. Schriftsteller in Österreich. Hg. v. Stefan Alker u. Andreas Brandtner. Wien: Sonderzahl 2005, S. 205-222.

Hackl, Wolfgang: Zwischen Theaterereignis und Theaterbluff. Handkes Publikumsbeschimpfung und sein Anfang als Dramatiker. In: „Das Wort sei gewagt“. Ein Symposium zum Werk von Peter Handke. Hg. v. Attila Bombitz u. Katharina Pektor. Wien: Praesens 2019 (= Österreich-Studien Szeged, Bd. 15), S. 148-162.

Hafner, Fabjan: Peter Handke. Unterwegs ins Neunte Land. Wien: Zsolnay 2008.

Hafner, Fabjan: Zwischen Herkunft und Ankunft. Peter Handke übersetzt. In: Peter Handke. Freiheit des Schreibens - Ordnung der Schrift. Hg. v. Klaus Kastberger. Unter Mitarb. v. Clemens Özelt. Wien: Zsolnay 2009 (= Profile, Bd. 16), S. 73-86.

Hage, Volker: Warum nicht wie Balzac? Peter Handkes Die Geschichte des Bleistifts und Phantasien der Wiederholung. In: The German Quarterly 63 (1990), H. 3/4, S. 412-420. Hage, Volker: Episches Lebensgefühl. Peter Handkes Notatbücher. In: Spätmoderne und Postmoderne. Beiträge zur deutschsprachigen Gegenwartsliteratur. Hg. v. Paul Michael Lützeler. Frankfurt a. M.: S. Fischer 1991, S. 117-130.

Hage, Volker/Schreiber, Mathias: Marcel Reich-Ranicki. Köln: Kiepenheuer \& Witsch 1995. Hahn, Marcus: Geschichte und Epigonen. ,19. Jahrhundert` / ,Postmoderne', Stifter / Bernhard. Freiburg i. Br.: Rombach 2003 (= Cultura, Bd. 35).

Hanuschek, Sven: Elias Canetti. Biographie. München, Wien: Hanser 2005.

Haslinger, Adolf: Peter Handke. Jugend eines Schriftstellers. Salzburg, Wien: Residenz 1992. Haslinger, Adolf: „Achtung, Hornissen!“ Zu Peter Handkes früher Prosa. In: Peter Handke. Die Langsamkeit der Welt. Hg. v. Gerhard Fuchs u. Gerhard Melzer. Graz: Droschl 1993, S. 95-113.

Haslinger, Adolf: Literatur. In: Salzburger Kulturlexikon. Hg. v. A. H. u. Peter Mittermayr. Salzburg u. a.: Residenz 2001, S. 25-29.

Haslinger, Adolf: In treusorgender Ironie. In: Peter Handke/A. H.: Einige Anmerkungen zum Da- und zum Dort-Sein. Ehrendoktorat an Peter Handke durch die Universität Salzburg. Salzburg, Wien: Jung und Jung 2004, S. 13-34.

Heimböckel, Dieter: Zwischen Elfenbein- und Fernsehturm. Peter Handkes (massen-) mediale Widerspruchsarbeit. In: Schriftsteller-Inszenierungen. Hg. v. Gunter E. Grimm u. Christian Schärf. Bielefeld: Aisthesis 2008, S. 215-230. 
Heinrici, Sandra: Maskenwahnsinn. Darstellungsformen des Wahnsinns im europäischen Theater des 20. Jahrhunderts. Bonn: Bouvier 2008 (= Junges Forum Literatur, Bd. 2). Heinz, Jutta: Cézanne-Erlebnisse bei Rainer Maria Rilke und Peter Handke. Ansätze zu einer literarischen Phänomenologie. In: Hofmannsthal. Jahrbuch zur europäischen Moderne 21 (2013), S. 367-389.

Herwig, Malte: Meister der Dämmerung. Peter Handke. Eine Biographie. München: DVA 2010

Heyl, Tobias: Zeichen und Dinge, Kunst und Natur. Intertextuelle Bezugnahmen in der Prosa Thomas Bernhards. Frankfurt a. M. u. a.: Lang 1995 (= Münchner Studien zur literarischen Kultur in Deutschland, Bd. 24).

Hoell, Joachim: Thomas Bernhard. München: dtv 2000.

Hoell, Joachim/Honold, Alexander/Luehrs-Kaiser, Kai (Hg.): Thomas Bernhard - eine Einschärfung. Berlin: Vorwerk $8{ }^{2} 1999$.

Hoesterey, Ingeborg: Visual Art as Narrative Structure. Thomas Bernhard's Alte Meister. In: Modern Austrian Literature 21 (1988), H. 3/4, S. 117-122.

Hofer, Stefan: Funktion - Peter Handke. In: Systemtheoretische Literaturwissenschaft. Begriffe - Methoden - Anwendungen. Hg. v. Niels Werber unter Mitarb. v. Maren Lickhardt. Berlin, New York: de Gruyter 2011, S. 135-146.

Holl, Hildemar: Literarisches Leben in Salzburg 1945-1955. In: Befreit und besetzt. Stadt Salzburg 1945-1955. Hg. v. Erich Marx. Salzburg: Magistrat der Landeshauptstadt Salzburg 1996, S. 163-168.

Holl, Hildemar: Literaturgeschichte Salzburgs von 1945 bis zur Gegenwart. In: Salzburg. Zwischen Globalisierung und Goldhaube. Hg. v. Ernst Hanisch u. Robert Kriechbaumer. Wien u. a.: Böhlau 1997 (= Geschichte der österreichischen Bundesländer seit 1945), S. $671-734$

Höller, Hans: Thomas Bernhard. Reinbek b. Hamburg: Rowohlt 1993.

Höller, Hans: Selbstporträts des Künstlers als alter Mann. Zu typischen Figuren bei Thomas Bernhard, Franz Grillparzer und Adalbert Stifter. In: Bernhard-Tage Ohlsdorf 1999. „In die entgegengesetzte Richtung“. Thomas Bernhard und sein Großvater Johannes Freumbichler. Materialien. Hg. v. Franz Gebesmair u. Manfred Mittermayer. Weitra: Bibliothek der Provinz [2000], S. 201-214.

Höller, Hans: Geschichtsbewusster Kosmopolitismus. Peter Handkes Raum-Poetik. In: Der Dichter als Kosmopolit. Zum Kosmopolitismus in der neuesten österreichischen Literatur. Hg. v. Patricia Broser u. Dana Pfeiferová. Wien: Praesens 2003, S. 51-66.

Höller, Hans: „Gewalt auch über ganz Große“. Thomas Bernhards Überwindung der ,Einflussangst'. In: Thomas Bernhard Jahrbuch 2005/2006, S. 65-74.

Höller, Hans: „Bruch“ und „Wende“. Zu einer Schreibbiographie Peter Handkes. In: Wende Bruch - Kontinuum. Die moderne österreichische Literatur und ihre Paradigmen des Wandels. Hg. v. Renata Cornejo u. Ekkehard W. Haring. Wien: Praesens 2006, S. 195-209.

Höller, Hans: Peter Handke. Reinbek b. Hamburg: Rowohlt 2007. 
Höller, Hans: Wie die Form der Sprache das Denken des Lesers ermöglicht. Der analytische Charakter von Bernhards Sprache. In: Rhetorik und Sprachkunst bei Thomas Bernhard. Hg. v. Joachim Knape u. Olaf Kramer. Würzburg: Königshausen \& Neumann 2011, S. 81-90.

Höller, Hans: Eine ungewöhnliche Klassik nach 1945. Das Werk Peter Handkes. Berlin: Suhrkamp 2013.

Höller, Hans: Der unbekannte Thomas Bernhard. Mattighofen: Korrektur 2014.

Holzinger, Alfred: Peter Handkes literarische Anfänge in Graz. In: Peter Handke. Hg. v. Raimund Fellinger. Frankfurt a. M.: Suhrkamp 1985, S. 11-24.

Honegger, Gitta: Thomas Bernhard. „Was ist das für ein Narr?“ München: Propyläen 2003. Honold, Alexander: Bernhards Dämonen. In: Thomas Bernhard - eine Einschärfung. Hg. v. Joachim Hoell, A. H. u. Kai Luehrs-Kaiser. Mit Photos v. Erika Schmied, Sepp Dreissinger u. Erich Hinterholzer. Berlin: Vorwerk $8{ }^{2}$ 1999, S. 17-25.

Honold, Alexander: Der Leser Walter Benjamin. Bruchstücke einer deutschen Literaturgeschichte. Berlin: Vorwerk 82000.

Honold, Alexander: Der Erd-Erzähler. Peter Handkes Prosa der Orte, Räume und Landschaften. Stuttgart: Metzler 2017.

Huber, Alexander: Versuch einer Ankunft. Peter Handkes Ästhetik der Differenz. Würzburg: Königshausen \& Neumann 2005 (= Epistemata. Reihe Literaturwissenschaft, Bd. 531).

Huber, Martin: Von Schwarzach St. Veit nach Weng. Zur Vorgeschichte von Thomas Bernhards literarischem Durchbruch mit seinem Roman Frost. In: Thomas Bernhard Jahrbuch 2005/2006, S. 35-44.

Huber, Martin: Was war der „Skandal“ an Heldenplatz? Zur Rekonstruktion einer österreichischen Erregung. In: Thomas Bernhard. Gesellschaftliche und politische Bedeutung der Literatur. Hg. v. Johann Georg Lughofer. Wien u. a.: Böhlau 2012, S. 129-136.

Huber, Martin: „beinahe alles falsch“? Dichtung und Wahrheit in Thomas Bernhards Meine Preise. In: Text + Kritik (42016), H. 43, S. 10-28.

Huber, Martin/Mittermayer, Manfred: Thomas Bernhard und seine Verlage. Linz: StifterHaus 2007 .

Huntemann, Willi: Artistik und Rollenspiel. Das System Thomas Bernhard. Würzburg: Königshausen \& Neumann 1990 (= Epistemata. Reihe Literaturwissenschaft, Bd. 63). Innerhofer, Roland: Der Kegel als Held. Zu Thomas Bernhards Korrektur. In: Ein Zoll Dankfest. Texte für die Germanistik. Konstanze Fliedl zum 6o. Geburtstag. Hg. v. Susanne Hochreiter u. a. Würzburg: Königshausen \& Neumann 2015, S. 193-200.

Innerhofer, Roland: „In der Tat brauchen wir nur dort fortzufahren, wo uns die Träume eines Irren unterbrochen haben“. Kontinuitäten in der österreichischen Literatur von der Ersten zur Zweiten Republik. In: Poetologien deutschsprachiger Literatur 1930-1960. Kontinuitäten jenseits des Politischen. Hg. v. Moritz Baßler, Hubert Roland u. Jörg Schuster. Berlin, Boston: de Gruyter 2016 (= Untersuchungen zur deutschen Literaturgeschichte, Bd. 146), S. 105-117. 
Janner, Markus: Der Tod im Text. Thomas Bernhards Grabschriften. Dargestellt anhand von frühen Erzählversuchen aus dem Nachlaß, der Lyrik und der späten Prosa. Frankfurt a. M. u. a.: Lang 2003 (= Regensburger Beiträge zur deutschen Sprach- und Literaturwissenschaft, $\mathrm{Bd} .85)$.

Jaumann, Herbert: Literaturkritik. In: Reallexikon der deutschen Literaturwissenschaft. Neubearbeitung des Reallexikons der deutschen Literaturgeschichte. Bd. II: H-O. Hg. v. Harald Fricke. Berlin, New York: de Gruyter 2007, S. 463-468.

Jens, Walter (Hg.): Literatur und Kritik. Aus Anlaß des 6o. Geburtstages von Marcel Reich-Ranicki. Stuttgart: DVA 1980.

Joch, Markus/Wolf, Norbert Christian: Feldtheorie als Provokation der Literaturwissenschaft. Einleitung. In: Text und Feld. Bourdieu in der literaturwissenschaftlichen Praxis. Hg. v. M. J. u. N. C. W. Tübingen: Niemeyer 2005 (= Studien und Texte zur Sozialgeschichte der Literatur, Bd. 108), S. 1-24.

John-Wenndorf, Carolin: Der öffentliche Autor. Über die Selbstinszenierung von Schriftstellern. Bielefeld: transcript 2014.

Judex, Bernhard: Schreiben in der „Denkkammer“. Thomas Bernhard und das literarische Erbe seines Großvaters Johannes Freumbichler - Überlegungen zur poetischen Genese. In: Thomas Bernhard Jahrbuch 2005/2006, S. 11-33.

Judex, Bernhard: Der Schriftsteller Johannes Freumbichler. 1881-1949. Leben und Werk von Thomas Bernhards Großvater. Wien u. a.: Böhlau 2006 (= Literatur und Leben, Bd. 69).

Judex, Bernhard: Thomas Bernhard. Epoche - Werk - Wirkung. München: C. H. Beck 2010. Judex, Bernhard: Die Persiflage des Geistesmenschen. Thomas Bernhard und die Figur des Großvaters. Konstruktionen biografischer und literarischer Identität. In: Thomas Bernhard. Persiflage und Subversion. Hg. v. Mireille Tabah u. Manfred Mittermayer. Würzburg: Königshausen \& Neumann 2013, S. 189-205.

Judex, Bernhard: Das „größte politische Dilemma der Geschichte“. Krieg und Nationalsozialismus bei Thomas Bernhard. In: Text + Kritik ( $\left.{ }^{4} 2016\right)$, H. 43, S. 153-165.

Judex, Bernhard/Mittermayer, Manfred: Literatur. In: Bernhard-Handbuch. Leben - Werk Wirkung. Hg. v. Martin Huber u. M. M. Unter Mitarb. v. B. J. Stuttgart: Metzler 2018, S. $373-380$.

Jürgens, Dirk: Das Theater Thomas Bernhards. Frankfurt a. M. u. a.: Lang 1999 (= Historisch-kritische Arbeiten zur deutschen Literatur, Bd. 28).

Kaminski, Nicole: Literaturkritik ohne Sprachkritik? Theodor Fontane, Alfred Kerr, Karlheinz Deschner, Marcel Reich-Ranicki und Kollegen. Frankfurt a. M.: Lang 2015 (= Frankfurter Forschungen zur Kultur- und Sprachwissenschaft, Bd. 20).

Kappes, Christoph: Schreibgebärden. Zur Poetik und Sprache bei Thomas Bernhard, Peter Handke und Botho Strauß. Würzburg: Königshausen \& Neumann 2006 (= Epistemata. Reihe Literaturwissenschaft, Bd. 559). 
Kastberger, Klaus: Wien 50/60. Eine Art einzige österreichische Avantgarde. In: Schluß mit dem Abendland! Der lange Atem der österreichischen Avantgarde. Hg. v. Thomas Eder u. K. K. Wien: Zsolnay 2000 (= Profile, Bd. 5), S. 5-26.

Kastberger, Klaus: Lesen und Schreiben. Peter Handkes Theater als Text. In: Die Arbeit des Zuschauers. Peter Handke und das Theater. Hg. v. K. K. u. Katharina Pektor. Salzburg, Wien: Jung und Jung 2012, S. 35-48.

Kastberger, Klaus: Acte und Akten. Konrad Bayer und die Archive der Avantgarde. In: Konrad Bayer: Texte, Bilder, Sounds. Hg. v. Thomas Eder u. K. K. Wien: Zsolnay 2015 (= Profile, Bd. 22), S. 15-33.

Kaulen, Heinrich: „Die Aufgabe des Kritikers“. Walter Benjamins Reflexionen zur Theorie der Literaturkritik 1929-1931. In: Literaturkritik - Anspruch und Wirklichkeit. DFGSymposion 1989. Hg. v. Wilfried Barner. Stuttgart: Metzler 1990 (= Germanistische Symposien. Berichtsbände, Bd. XII), S. 318-336.

Kerschbaumer, Gert: Faszination Drittes Reich. Kunst und Alltag der Kulturmetropole Salzburg. Mit einem Vorwort v. Gerhard Amanshauser. Salzburg: Otto Müller 1988.

Kerschbaumer, Gert/Müller, Karl: Begnadet für das Schöne. Der rot-weiß-rote Kulturkampf gegen die Moderne. Wien: Verlag für Gesellschaftskritik 1992 (= Beiträge zu Kulturwissenschaft und Kulturpolitik, Bd. 2).

Kerschner, Julia: Autodidaktik, Artistik, Medienpraktik. Erscheinungsweisen des Dilettantismus bei Karl Philipp Moritz, Carl Einstein und Thomas Bernhard. Göttingen: V\&R unipress 2016 (= Palaestra. Untersuchungen zur europäischen Literatur, Bd. 344).

Kiesel, Helmuth: Geschichte der literarischen Moderne. Sprache - Ästhetik - Dichtung im zwanzigsten Jahrhundert. München: C. H. Beck 2004.

Kiesel, Helmuth: Verklärung und Heilszuversicht. Peter Handkes Über die Dörfer. In: „Verwandeln allein durch Erzählen“. Peter Handke im Spannungsfeld von Theologie und Literaturwissenschaft. Hg. v. Jan-Heiner Tück u. Andreas Bieringer. Freiburg i. Br. u. a.: Herder 2014, S. 55-68.

Klee, Ernst: Das Kulturlexikon zum Dritten Reich. Wer war was vor und nach 1945. Frankfurt a. M.: S. Fischer 2009.

Klessinger, Hanna: Postdramatik. Transformationen des epischen Theaters bei Peter Handke, Heiner Müller, Elfriede Jelinek und Rainald Goetz. Berlin, Boston: de Gruyter 2015 (= Studien zur deutschen Literatur, Bd. 209).

Klimmt, Reinhard/Zimmermann, Hans (Hg.): Simpliccismus 1896-1933. Die satirische Wochenschrift. Stuttgart: LangenMüller 2018.

Klug, Christian: Thomas Bernhards Arbeiten für das Salzburger Demokratische Volksblatt 1952 bis 1954. In: Modern Austrian Literature 21 (1988), H. 3/4, S. 135-172.

Klug, Christian: Thomas Bernhards Theaterstücke. Stuttgart: Metzler 1991.

Kohl, Katrin: Poetologische Metaphern. Formen und Funktionen in der deutschen Literatur. Berlin, New York: de Gruyter 2007. 
Kohns, Oliver: Werkimmanente Intertextualität bei Peter Handke. Selbstzitat, -fortschreibung, -kommentar und -parodie. In: Die tägliche Schrift. Peter Handke als Leser. Hg. v. Thorsten Carstensen. Bielefeld: transcript 2019, S. 231-242.

Korte, Hermann: Dramaturgie der „Übertreibungskunst“. Thomas Bernhards Roman Auslöschung. Ein Zerfall. In: Text + Kritik ( $\left.{ }^{3} 1991\right)$, H. 43, S. 88-103.

Kramer, Olaf: Wahrheit als Lüge, Lüge als Wahrheit. Thomas Bernhards Autobiographie als rhetorisch-strategisches Konstrukt. In: Rhetorik und Sprachkunst bei Thomas Bernhard. Hg. v. Joachim Knape u. O. K. Würzburg: Königshausen \& Neumann 2011, S. 105-122. Kramer, Olaf: Der Übertreibungskünstler als Geschäftsmann. Ein Brief Thomas Bernhards an Siegfried Unseld. In: Briefkultur. Texte und Interpretationen - von Martin Luther bis Thomas Bernhard. Hg. v. Jörg Schuster u. Jochen Strobel. Berlin, Boston: de Gruyter 2013, S. 381-393.

Krammer, Stefan: Bernhards unsanftes Gesetz. Ein Stifterexperiment. In: Thomas Bernhard Jahrbuch 2005/2006, S. 75-85.

Krammer, Stefan: Figurationen der Macht. Rhetorische Strategien in Thomas Bernhards Dramen. In: Rhetorik und Sprachkunst bei Thomas Bernhard. Hg. v. Joachim Knape u. Olaf Kramer. Würzburg: Königshausen \& Neumann 2011, S. 91-103.

Krammer, Stefan: Maskeraden der Männlichkeit. Bernhards subversives Geschlechtertheater. In: Thomas Bernhard. Persiflage und Subversion. Hg. v. Mireille Tabah u. Manfred Mittermayer. Würzburg: Königshausen \& Neumann 2013, S. 175-186.

Krammer, Stefan: Der Theatermacher. In: Bernhard-Handbuch. Leben - Werk - Wirkung. Hg. v. Martin Huber u. Manfred Mittermayer. Unter Mitarb. v. Bernhard Judex. Stuttgart: Metzler 2018, S. 246-250.

Kreuzwieser, Markus: Epochendialoge. Noch einmal: Adalbert Stifter und die Gegenwartsliteratur unter besonderer Berücksichtigung der Stifter-Lektüren Thomas Bernhards. In: ide. Informationen zur Deutschdidaktik 29 (2005), H. 1, S. 82-95.

Kunz, Tanja Angela: Sehnsucht nach dem Guten. Zum Verhältnis von Literatur und Ethik im epischen Werk Peter Handkes. Paderborn: Fink 2017 (= Ethik - Text - Kultur, Bd. 12).

Kurz, Martina: Bild-Verdichtungen. Cézannes Realisation als poetisches Prinzip bei Rilke und Handke. Göttingen: Vandenhoeck \& Ruprecht 2003 (= Palaestra. Untersuchungen zur europäischen Literatur, Bd. 315).

Landa, Jutta: Realistisch oder experimentell. Frontenbildungen in der österreichischen Literatur der sechziger und siebziger Jahre. In: Konflikte - Skandale - Dichterfehden in der österreichischen Literatur. Hg. v. Wendelin Schmidt-Dengler, Johann Sonnleitner u. Klaus Zeyringer. Berlin: Erich Schmidt 1995 (= Philologische Studien und Quellen, Bd. 137), S. 215-224.

Langer, Renate: „Erde, Erbe, was war das immer?“ Thomas Bernhards Heimatkomplex. In: Thomas Bernhard und Salzburg. 22 Annäherungen. Hg. v. Manfred Mittermayer u. Sabine Veits-Falk. Salzburg, Wien: Jung und Jung 2001, S. 41-48.

Langer, Renate: Hitlerbild und Kreuz. Nationalsozialismus und Katholizismus bei Thomas Bernhard. In: Thomas Bernhard Jahrbuch 2007/2008, S. 21-35. 
Lethen, Helmut: Die Staatsräte. Elite im Dritten Reich: Gründgens, Furtwängler, Sauerbruch, Schmitt. Berlin: Rowohlt 2018.

Lettau, Reinhard (Hg.): Die Gruppe 47. Bericht - Kritik - Polemik. Ein Handbuch. Neuwied, Berlin: Luchterhand 1967.

Linstead, Michael: Outer World and Inner World. Socialisation and Emancipation in the works of Peter Handke, 1964-1981. Frankfurt a. M. u. a.: Lang 1988 (= Europäische Hochschulschriften. Reihe I: Deutsche Sprache und Literatur, Bd. 1024).

Löffler, Susanna: „Ich bin ja ein musikalischer Mensch“. Thomas Bernhard und die Funktion der Musik in seinem literarischen Werk. Wien u. a.: Böhlau 2018 (= Wiener Musikwissenschaftliche Beiträge, Bd. 28).

Lorenz, Otto: Literatur als Gespräch. Zur Aufgabe der Literaturkritik heute. In: Text + Kritik (1988), H. 100, S. 100-106.

Lorenz, Otto: Literatur als Widerspruch. Konstanten in Peter Handkes Schriftstellerkarriere. In: Text + Kritik ( $\left.{ }^{5} 1989\right)$, H. 24, S. 8-16.

Lorenz, Otto: Pro domo - Der Schriftsteller als Kritiker. Zu Peter Handkes Anfängen. In: Literaturkritik - Anspruch und Wirklichkeit. DFG-Symposion 1989. Hg. v. Wilfried Barner. Stuttgart: Metzler 1990 (= Germanistische Symposien. Berichtsbände, Bd. XII), S. $399-414$.

Lorenz, Otto: Die Öffentlichkeit der Literatur. Fallstudien zu Publikationskontexten und Publikationsstrategien. Wolfgang Koeppen - Peter Handke - Horst-Eberhard Richter. Tübingen: Niemeyer 1998 (= Studien und Texte zur Sozialgeschichte der Literatur, Bd. 66).

Löwenstein, Sascha: Poetik und dichterisches Selbstverständnis. Eine Einführung in Rainer Maria Rilkes frühe Dichtungen (1884-1906). Würzburg: Königshausen \& Neumann 2004.

Luckscheiter, Christian: Das Blau des Himmels über dem Hôtel Terminus. Peter Handke und der Nachkrieg. In: Peter Handke. Stationen, Orte, Positionen. Hg. v. Anna Kinder. Berlin, Boston: de Gruyter 2014, S. 39-55.

Magenau, Jörg: Princeton 66. Die abenteuerliche Reise der Gruppe 47. Stuttgart: KlettCotta 2016.

Magerski, Christine: Theorien der Avantgarde. Gehlen - Bürger - Bourdieu - Luhmann. Wiesbaden: Verlag für Sozialwissenschaften 2011.

Markolin, Caroline: Die Großväter sind die Lehrer. Johannes Freumbichler und sein Enkel Thomas Bernhard. Salzburg: Otto Müller 1988.

Marmulla, Henning: Enzensbergers Kursbuch. Eine Zeitschrift um 68. Berlin: Matthes \& Seitz 2011.

Marmulla, Henning: Veränderung um 68. Enzensberger, die anderen und Peter Handke. In: Peter Handke. Analyse du temps. Hg. v. Mireille Calle-Gruber, Ingrid Holtey u. Patricia Oster-Stierle. Paris: Presses Sorbonne Nouvelle 2018, S. 227-238. 
Marquardt, Eva: Gegenrichtung. Entwicklungstendenzen in der Erzählprosa Thomas Bernhards. Tübingen: Niemeyer 1990 (= Untersuchungen zur deutschen Literaturgeschichte, Bd. 54).

Marten, Catherine: Bernhards Baukasten. Schrift und sequenzielle Poetik in Thomas Bernhards Prosa. Berlin, Boston: de Gruyter 2018 (= Studien zur deutschen Literatur, Bd. 217).

Martus, Steffen: Werkpolitik. Zur Literaturgeschichte kritischer Kommunikation vom 17. bis ins 2o. Jahrhundert. Mit Studien zu Klopstock, Tieck, Goethe und George. Berlin, New York: de Gruyter 2007 (= Historia Hermeneutica Series Studia, Bd. 3).

Matt, Peter von: Grandeur und Elend literarischer Gewalt. Die Regeln der Polemik. In: P. v. M.: Das Schicksal der Phantasie. Studien zur deutschen Literatur. München: dtv 1996, S. 35-42.

Maurer, Stefan: Wolfgang Kraus und der österreichische Literaturbetrieb nach 1945. Wien u. a.: Böhlau 2020 (= Literaturgeschichte in Studien und Quellen, Bd. 30).

Mayer, Heike: Bauer und Dichter. Johannes Freumbichler und sein Lehrgedicht Erziehung $z u$ Vernunft und Freundlichkeit. In: Johannes Freumbichler: Erziehung zu Vernunft und Fröhlichkeit. Briefe in Knittelversen für die Jugend von Sechzehn bis Sechzig. Lehrgedicht aus dem Nachlaß, gewidmet dem Enkel Thomas Bernhard. Hg. u. mit einem Nachwort v. H. M. o. O.: Liliom 2003, S. 103-112.

Meis, Verena: Bernhard und das Theater der 1970er und 1980er Jahre. In: Bernhard-Handbuch. Leben - Werk - Wirkung. Hg. v. Martin Huber u. Manfred Mittermayer. Unter Mitarb. v. Bernhard Judex. Stuttgart: Metzler 2018, S. 302-306.

Melzer, Gerhard/Pechmann, Paul (Hg.): Sprachmusik. Grenzgänge der Literatur. Wien: Sonderzahl 2003.

Meyerhofer, Nicholas J.: The Laughing Sisyphus. Reflections on Bernhard as (Self-)Dramatist in Light of His Der Theatermacher. In: Modern Austrian Literature 21 (1988), H. 3/4, S. 107-115.

Meyerhofer, Nicholas J.: Peter Turrini as political writer. In: I am too many people. Peter Turrini, playwright, poet, essayist. Hg. v. Jutta Landa. Riverside: Ariadne Press 1998, S. $30-43$.

Michaelis, Rolf: Ohrfeigen für das Lieblingskind. Peter Handke und seine Kritiker. Eine Beispielsammlung. In: Text + Kritik ( $\left.{ }^{3} 1976\right)$, H. 24/24a, S. 80-96. [auch in: Text + Kritik ( $\left.{ }^{4} 1978\right)$, H. 24/24a, S. 115-131.]

Michalzik, Peter: Unseld. Eine Biographie. München: btb 2003.

Michel, Sascha: Einleitung [zu Marcel Reich-Ranicki: Über Literaturkritik]. In: Texte zur Theorie der Literaturkritik. Hg. v. S. M. Stuttgart: Reclam 2008, S. 240-243.

Michel, Sascha (Hg.): Texte zur Theorie der Literaturkritik. Stuttgart: Reclam 2008.

Michler, Werner: Teilnahme. Epos und Gattungsproblematik bei Peter Handke. In: Peter Handke. Poesie der Ränder. Hg. v. Klaus Amann, Fabjan Hafner u. Karl Wagner. Wien u. a.: Böhlau 2006 (= Literaturgeschichte in Studien und Quellen, Bd. 11), S. 117-134. 
Mittermayer, Manfred: Thomas Bernhard. Stuttgart, Weimar: Metzler 1995 (= Sammlung Metzler, Bd. 291).

Mittermayer, Manfred: Die Stimme des alten Meisters. Zur Figur des Großvaters im literarischen Werk Thomas Bernhards. In: Österreich und andere Katastrophen. Thomas Bernhard in memoriam. Beiträge des Internationalen Kolloquiums an der Universität des Saarlandes vom 10. bis 12. Juni 1999. Hg. v. Pierre Béhar u. Jeanne Benay. St. Ingbert: Röhrig 2001 (= Beiträge zur Robert-Musil-Forschung und zur neueren österreichischen Literatur, Bd. 15), S. 25-45.

Mittermayer, Manfred: Thomas Bernhards Poetik der Ambivalenz. In: Thomas Bernhard Jahrbuch 2004, S. 163-173.

Mittermayer, Manfred: „Der Wahrheitsgehalt der Lüge“. Thomas Bernhards autobiographische Inszenierungen. In: Spiegel und Maske. Konstruktionen biographischer Wahrheit. Hg. v. Bernhard Fetz u. Hannes Schweiger. Wien: Zsolnay 2006 (= Profile, Bd. 13), S. 79-94.

Mittermayer, Manfred: Thomas Bernhard. Frankfurt a. M.: Suhrkamp 2006 (= Suhrkamp BasisBiographie, Bd. 11).

Mittermayer, Manfred: „Aufzuwachen und ein Haus zu haben.“ Thomas Bernhards „Heimatkomplex“ in frühen und frühesten Texten. In: Ferne Heimat - Nahe Fremde. Bei Dichtern und Nachdenkern. Hg. v. Eduard Beutner u. Karlheinz Rossbacher. Würzburg: Königshausen \& Neumann 2008, S. 186-202.

Mittermayer, Manfred: „Das schönste Theater der Welt“. Thomas Bernhard und Salzburg. In: „Österreich selbst ist nichts als eine Bühne“. Thomas Bernhard und das Theater. Hg. v. Martin Huber u. M. M. Wien: Brandstätter 2009, S. 9-29.

Mittermayer, Manfred: Lächerlich, charakterlos, furchterregend. Zu Thomas Bernhards Rhetorik der Bezichtigung. In: Rhetorik und Sprachkunst bei Thomas Bernhard. Hg. v. Joachim Knape u. Olaf Kramer. Würzburg: Königshausen \& Neumann 2011, S. 25-44.

Mittermayer, Manfred: „Nur die Verstellung rettet mich zeitweise“. Ausgangspunkte einer Biographie über Thomas Bernhard. In: Leben als Kunstwerk. Künstlerbiographien im 20. Jahrhundert. Hg. v. Christopher F. Laferl u. Anja Tippner. Bielefeld: transcript 2011, S. 85-109.

Mittermayer, Manfred: „Die brennende hilfesuchende Glut“. Thomas Bernhard als Literaturkritiker in den frühen 1950er Jahren. In: Literatur - Politik - Kritik. Beiträge zur Österreichischen Literatur des 2o. Jahrhunderts. Hg. v. Harald Jele u. Elmar Lenhart. Göttingen: Wallstein 2014, S. 204-213.

Mittermayer, Manfred: Thomas Bernhard. Eine Biografie. Salzburg, Wien: Residenz 2015. Mittermayer, Manfred: Das Salzburg des Thomas Bernhard. Photographien: Angelika Fischer. Berlin: Edition A. B. Fischer 2017.

Mittermayer, Manfred: „Auf dem Totenbett eine Komödie schreiben“. Thomas Bernhards Verwandlung der Welt in eine Theaterbühne. In: Entwicklungen der Dramatik und Formen des Theaters in Österreich seit den 196oer Jahren. Hg. v. Sieglinde Klettenhammer 
u. Wolfgang Wiesmüller. Innsbruck: innsbruck university press 2020 (= Innsbrucker Beiträge zur Kulturwissenschaft. Germanistische Reihe, Bd. 93), S. 27-43.

Mixner, Manfred: Peter Handke. Kronberg i. Ts.: Athenäum 1977.

Mixner, Manfred: Vom Leben zum Tode. Die Einleitung des Negations-Prozesses im Frühwerk von Thomas Bernhard. In: Bernhard. Annäherungen. Hg. v. Manfred Jurgensen. Bern, München: Francke 1981, S. 65-97.

Mixner, Manfred: Das Forum Stadtpark Graz und der ORF - eine Erinnerung an Alfred Holzinger. In: Literatur in Graz seit 1960 - das Forum Stadtpark. Wien, Köln: Böhlau 1989 (= Walter-Buchebner-Literaturprojekt, Bd. 2), S. 13-20.

Moennighoff, Burkhard: Goethes Gedichttitel. Berlin, New York: de Gruyter 2000.

Moritz, Herbert: Lehrjahre. Thomas Bernhard - vom Journalisten zum Dichter. Weitra: Bibliothek der Provinz 1992.

Moser, Doris: Der Ingeborg-Bachmann-Preis. Börse, Show, Event. Wien u. a.: Böhlau 2004 (= Literaturgeschichte in Studien und Quellen, Bd. 9).

Moser, Doris: Feldspieler und Spielfelder. Vom Gewinnen und Verlieren beim IngeborgBachmann-Wettbewerb. In: Mediale Erregungen? Autonomie und Aufmerksamkeit im Literatur- und Kulturbetrieb der Gegenwart. Hg. v. Markus Joch, York-Gothart Mix u. Norbert Christian Wolf. Tübingen: Niemeyer 2009, S. 189-203.

Moysich, Helmut: Rück mir auf den Leib, Du stille Welt. Poetisch-existentielle Verwandtschaften zwischen Peter Handke und Heimito von Doderer. In: Die tägliche Schrift. Peter Handke als Leser. Hg. v. Thorsten Carstensen. Bielefeld: transcript 2019, S. 163-177. Müller, Karl: Zur (Dis-)Kontinuität österreichischer Literatur seit den 3oer Jahren: Karl Heinrich Waggerl (1897-1973). Ein Erfolgsautor der 5oer Jahre. In: Literatur in Österreich von 1950 bis 1965 . Walter Buchebner Tagung 1984. Hg. v. Wendelin SchmidtDengler. Mürzzuschlag: Walter Buchebner Gesellschaft [1984], S. 52-74.

Müller, Karl: Die Bannung der Unordnung. Zur Kontinuität österreichischer Literatur seit den dreißiger Jahren. In: Kontinuität und Bruch 1938-1945-1955. Beiträge zur österreichischen Kultur- und Wissenschaftsgeschichte. Hg. v. Friedrich Stadler. Wien, München: Jugend und Volk 1988, S. 181-215.

Müller, Karl: Zäsuren ohne Folgen. Das lange Leben der literarischen Antimoderne Österreichs seit den zoer Jahren. Salzburg: Otto Müller 1990.

Müller, Karl: Adalbert Schmidt. In: Internationales Germanistenlexikon. 180o-1950. Hg. v. Christoph König. Bd. 3: R-Z. Berlin, New York: de Gruyter 2003, S. 1616-1618. Müller, Karl: „Wir sind eben Bestien, die sich gegenseitig in Schach halten.“- „Das Leben ist ein Prozeß, den man verliert." Karl Heinrich Waggerl und Thomas Bernhard im Vergleich. In: Thomas Bernhard Jahrbuch 2003, S. 13-33.

Müller, Karl: Die Theaterkonzepte Thomas Bernhards und Elfriede Jelineks im Vergleich. In: Thomas Bernhard Jahrbuch 2004, S. 91-116.

Müller, Karl Otfried: Geschichte der griechischen Literatur bis auf das Zeitalter Alexanders. Nach der Handschrift des Verfassers hg. v. Eduard Müller. Erster Band. Breslau: Josef Max und Komp. 1841. 
Neuhaus, Stefan: Dichter als Kritiker: Schiller und Fontane. In: Große Literaturkritiker. Hg. v. Sigurd Paul Scheichl. Innsbruck u. a.: StudienVerlag 2010, S. 31-41.

Nickel, Gunther: Krise der Literaturkritik. Historische Dimensionen eines aktuellen Themas. In: Kaufen! statt Lesen! Literaturkritik in der Krise? Im Auftrag der Deutschen Literaturkonferenz hg. v. G. N. Göttingen: Wallstein 2006, S. 5-19.

Niefanger, Dirk: Rolf Dieter Brinkmanns Poetik der Selbstinszenierung. In: Medialität der Kunst. Rolf Dieter Brinkmann in der Moderne. Hg. v. Markus Fauser. Bielefeld: transcript 2011, S. 65-82.

Oels, David: Rowohlts Rotationsroutine. Das moderne Taschenbuch in Deutschland und der rasante Aufstieg des Rowohlt-Verlags nach 1945. In: Solitäre und Netzwerker. Akteure des kulturpolitischen Konservativismus nach 1945 in den Westzonen Deutschlands. Hg. v. Erhard Schütz u. Peter Uwe Hohendahl. Essen: Klartext 2009, S. 185-208. Opitz, Michael: Literaturkritik. In: Benjamin-Handbuch. Leben - Werk - Wirkung. Hg. v. Burkhardt Lindner. Unter Mitarb. v. Thomas Küpper u. Timo Skrandies. Stuttgart, Weimar: Metzler 2006, S. 311-332.

Özelt, Clemens: Klangräume bei Peter Handke. Versuch einer polyperspektivischen Motivforschung. Wien: Braumüller 2012 (= Zur neueren Literatur Österreichs, Bd. 25). Özelt, Clemens: Durch die Lupe? Peter Handkes Kurzprosa (Noch einmal für Thukydides, Begrüßung des Aufsichtsrats). In: Schreiben als Weltentdeckung. Neue Perspektiven der Handke-Forschung. Hg. v. Anna Estermann u. Hans Höller. Wien: Passagen 2014, S. 73-95.

Pape, Walter: „Mich interessiert nur mein Körper und mein Kopf und sonst gar nichts“. Erzählerische und autobiographische Subjektivität bei Thomas Bernhard. In: Geschichte und Vorgeschichte der modernen Subjektivität. Hg. v. Reto Luzius Fetz, Roland Hagenbüchle u. Peter Schulz. Bd. 2. Berlin, New York: de Gruyter 1998, S. 1174-1197.

Parry, Christoph: Der Prophet der Randbezirke. Zu Peter Handkes Poetisierung der Peripherie in Mein Jahr in der Niemandsbucht. In: Text + Kritik ( $\left.{ }^{6} 1999\right)$, H. 24/24a, S. 51-61.

Parry, Christoph: Von Ahnen und Enklaven. Staat und Heimat bei Peter Handke. In: Text + Kritik (2015), Sonderbd. „Österreichische Gegenwartsliteratur“, S. 71-82.

Peck, Clemens: „Schall und Wahn“. Andere Orte der Erinnerung in Peter Handkes Versuch über die Jukebox. In: High und low. Zur Interferenz von Hoch- und Populärkultur in der Gegenwartsliteratur. Hg. v. Thomas Wegmann u. Norbert Christian Wolf. Berlin, Boston: de Gruyter 2012 (= Studien und Texte zur Sozialgeschichte der Literatur, Bd. 130), S. 97-119.

Perram, Garvin H. C.: Peter Handke. The Dynamics of the Poetics and the Early Narrative Prose. Frankfurt a. M. u. a.: Lang 1992 (= Europäische Hochschulschriften. Reihe I: Deutsche Sprache und Literatur, Bd. 1298).

Pethes, Nicolas: „glauben Sie mir“. Die Ausweitung der literarischen Kampfzone in Thomas Bernhards Interviews, Briefen, Preisreden und Feuilletonbeiträgen. In: Text + Kritik (42016), H. 43, S. 126-139.

Petritsch, Wolfgang: Bruno Kreisky. Die Biografie. St. Pölten, Salzburg: Residenz 2010. 
Pfabigan, Alfred: Thomas Bernhard. Ein österreichisches Weltexperiment. Wien: Sonderzahl 2009.

Pfabigan, Alfred: Motive und Strategien der Österreichkritik des Thomas Bernhard. In: Thomas Bernhard. Gesellschaftliche und politische Bedeutung der Literatur. Hg. v. Johann Georg Lughofer. Wien u. a.: Böhlau 2012, S. 35-48.

Pfabigan, Alfred: „Gespräch nennen Sie das?"Anmerkungen zu den Interviews des Thomas Bernhard. In: Text + Kritik ( $\left.{ }^{4} 2016\right)$, H. 43, S. 92-106.

Pfister, Gerhard: Handkes Mitspieler. Die literarische Kritik zu Der kurze Brief zum langen Abschied, Langsame Heimkehr, Das Spiel vom Fragen, Versuch über die Müdigkeit. Bern u. a.: Lang 2000.

Pfohlmann, Oliver: Kleines Lexikon der Literaturkritik. Marburg: LiteraturWissenschaft.de 2005.

Pfohlmann, Oliver: Literaturkritik in der Bundesrepublik. In: Literaturkritik. Geschichte Theorie - Praxis. Hg. v. Thomas Anz u. Rainer Baasner. München: C. H. Beck ${ }^{4} 2007$, S. $160-191$.

Pfohlmann, Oliver: Literatur- und Theaterkritik. In: Robert-Musil-Handbuch. Hg. v. Birgit Nübel u. Norbert Christian Wolf. Berlin, Boston: de Gruyter 2016, S. 414-429.

Pichler, Georg: Die Beschreibung des Glücks. Peter Handke. Eine Biographie. Wien: Ueberreuter 2002

Pilipp, Frank: In Defense of Kafka: The Case of Peter Handke. In: The Legacy of Kafka in Contemporary Austrian Literature. Hg. v. F. P. Riverside: Ariadne Press 1997 (= Studies in Austrian Literature, Culture, and Thought), S. 117-149.

Pilipp, Frank: Peter Handke’s coming to terms with Kafka: Die Stunde der wahren Empfindung. In: Modern Austrian Prose. Interpretations and Insights. Hg. v. Paul F. Dvorak. Bd. 1. Riverside: Ariadne Press 2001 (= Studies in Austrian Literature, Culture, and Thought), S. 107-128.

Podlasiak, Marek: Das Geistesduo - Thomas Bernhard und Bernhard Minetti. In: Im Wechselspiel der Kulturen. Festschrift für Karol Sauerland. Hg. v. Maria Gierlak, Małgorzata Klentak-Zabłocka u. Leszek Żyliński. Toruń: Wydawnictwo Uniwersytetu Mikołaja Kopernika 2001, S. 95-103.

Polt-Heinzl, Evelyne: Der Kalte Krieg schreibt Literaturgeschichte oder der Mythos vom langen Schweigen der Literatur zum Nationalsozialismus. In: Kalter Krieg in Österreich. Literatur - Kunst - Kultur. Hg. v. Michael Hansel u. Michael Rohrwasser. Wien: Zsolnay 2010 (= Profile, Bd. 17), S. 123-137.

Polt-Heinzl, Evelyne: Peter Handke. In Gegenwelten unterwegs. Wien: Sonderzahl 2011. Polt-Heinzl, Evelyne: Thomas Bernhard betritt die Wiener Szene oder Über Dissonanzen in Hans Weigels Stimmen der Gegenwart. In: Sprachkunst 46 (2015), H. 1, S. 51-70.

Polt-Heinzl, Evelyne: Die grauen Jahre. Österreichische Literatur nach 1945. Mythen, Legenden, Lügen. Wien: Sonderzahl 2018.

Pompe, Anja: Peter Handke. Pop als poetisches Prinzip. Köln u. a.: Böhlau 2009 (= Literaturgeschichte in Studien und Quellen, Bd. 15). 
Porombka, Stephan: Gemengelagen lesen. Plädoyer für einen kulturwissenschaftlichen Umgang mit Literaturkritik. In: Zeitschrift für Germanistik. N. F. 15 (2005), H. 1, S. 109-121.

Prutti, Brigitte: Festzertrümmerungen. Thomas Bernhard und seine Preise. Bielefeld: Aisthesis 2012.

Pütz, Peter: Peter Handke. Frankfurt a. M.: Suhrkamp 1982.

Pütz, Peter: Peter Handkes „Elfenbeinturm“. In: Text + Kritik (51989), H. 24, S. 21-29.

Pütz, Susanne: „Das Literarische Quartett“ - Elite-Show oder Show-Elite. In: Arbeitshefte Bildschirmmedien (1990), H. 21, S. 16-63.

Radax, Ferry: Thomas Bernhard und der Film. In: Literarisches Kolloquium Thomas Bernhard. Materialien. Hg. v. Johann Lachinger u. Alfred Pittertschatscher. Weitra: Bibliothek der Provinz 1994, S. 200-211.

Rathkolb, Oliver: Führertreu und gottbegnadet. Künstlereliten im Dritten Reich. Wien: ÖBV 1991.

Rathkolb, Oliver: Die paradoxe Republik. Österreich 1945 bis 2010. Innsbruck, Wien: Haymon 2011.

Rathkolb, Oliver: Tobi Reiser und der Nationalsozialismus. Zusatzrecherchen: Petra Mayrhofer. Salzburg: Salzburg Museum 2016.

Raulet, Gérard: Einbahnstraße. In: Benjamin-Handbuch. Leben - Werk - Wirkung. Hg. v. Burkhardt Lindner. Unter Mitarb. v. Thomas Küpper u. Timo Skrandies. Stuttgart, Weimar: Metzler 2006, S. 359-373.

Rebien, Kristin: Gruppe 47: Literature, politics, and the political economy of postwar publishing. In: German Life and Letters 62 (2009), H. 4, S. 448-464.

Reiter, Andrea: „Die Bachmann [...] war halt eine gescheite Frau. Eine seltsame Verbindung, nicht?" Das Bild der Frau in Thomas Bernhards Prosa. In: Die Rampe (1992), H. 2, S. 17-43.

Renner, Rolf G.: Peter Handke. Stuttgart: Metzler 1985 (= Sammlung Metzler, Bd. 218).

Renner, Rolf G.: Der Kinogeher. Peter Handke und der Film. In: Peter Handke. Poesie der Ränder. Hg. v. Klaus Amann, Fabjan Hafner u. Karl Wagner. Wien u. a.: Böhlau 2006 (= Literaturgeschichte in Studien und Quellen, Bd. 11), S. 201-214.

Reulecke, Anne-Kathrin: Die Lehre der Sainte-Victoire. Poetologie in einer medialen Welt. In: Text + Kritik ( $\left.{ }^{6} 1999\right)$, H. 24, S. 62-79.

Reulecke, Anne-Kathrin: Geschriebene Bilder. Zum Kunst- und Mediendiskurs in der Gegenwartsliteratur. München: Fink 2002.

Reuter, Tim: „Vaterland, Unsinn“. Thomas Bernhards (ent-)nationalisierte Genieästhetik zwischen Österreich-Gebundenheit und Österreich-Entbundenheit. Würzburg: Königshausen \& Neumann 2013 (= Film, Medium, Diskurs, Bd. 44).

Riccabona, Christina/Wimmer, Erika/Meller, Milena: Die Österreichischen Jugendkulturwochen 1950-1969 in Innsbruck. Innsbruck u. a.: StudienVerlag 2006. 
Robert, Jörg: Wir sind ja diese Verwandtschaft ... Unheimliche Tradition und ,Herkunftskomplex' in Thomas Bernhards Roman Alte Meister. In: Euphorion 105 (2011), H. 4, S. 443-464.

Roberts, David: Korrektur der Korrektur? Zu Thomas Bernhards Lebenskunstwerk Korrektur. In: Bernhard. Annäherungen. Hg. v. Manfred Jurgensen. Bern, München: Francke 1981, S. 199-213.

Roli, Maria Luisa: „Varianten der Wiederholung“. Peter Handkes Stifter-Rezeption. In: Die tägliche Schrift. Peter Handke als Leser. Hg. v. Thorsten Carstensen. Bielefeld: transcript 2019, S. 133-152.

Ronge, Verena: Frauenfiguren im dramatischen Werk Thomas Bernhards. Zur Subversion des Bildes der sprach(macht)losen Frau. In: Text + Kritik ( $\left.{ }^{4} 2016\right)$, H. 43, S. 200-212.

Rössler, Patrick: Pro(roro)vokation - die bunten Farben des Massengeschmacks. Der Rowohlt-Verlag und das frühe deutsche Taschenbuch. In: Neue Perspektiven der deutschen Buchkultur in den 5oer Jahren des 20. Jahrhunderts. Ein Symposion. Hg. v. Günter Häntzschel. Wiesbaden: Harrassowitz 2003, S. 119-154.

Rovagnati, Gabriella: Studien zur österreichischen Literatur: Von Nestroy bis Ransmayr. Frankfurt a. M.: Lang 2016 (= Beiträge zur Text-, Überlieferungs- und Bildungsgeschichte, Bd. 5).

Rüffer, Ulrich: Benjamins Programm der Kritik. In: Walter Benjamin. Profane Erleuchtung und rettende Kritik. Hg. v. Norbert W. Bolz u. Richard Faber. Würzburg: Königshausen \& Neumann ${ }^{2} 1985$, S. 34-40.

Scharang, Michael (Hg.): Über Peter Handke. Frankfurt a. M.: Suhrkamp 1972.

Schediwy, Robert: Rückblick auf die Moderne. Wien, Berlin: LIT 2014.

Scheffler, Markus: Kunsthaß im Grunde. Über Melancholie bei Arthur Schopenhauer und deren Verwendung in Thomas Bernhards Prosa. Heidelberg: Winter 2008 (= Beiträge zur neueren Literaturgeschichte, Bd. 252).

Scheichl, Sigurd Paul: Nicht Kritik, sondern Provokation. Vier Thesen über Thomas Bernhard und die Gesellschaft. In: Annali. Studi Tedeschi 22 (1979), H. 1, S. 101-119.

Scheichl, Sigurd Paul: Vergessene. Träger des Großen Österreichischen Staatspreises in den 5oer Jahren. In: Literatur in Österreich von 1950 bis 1965. Walter Buchebner Tagung 1984. Hg. v. Wendelin Schmidt-Dengler. Mürzzuschlag: Walter Buchebner Gesellschaft [1984], S. 75-91.

Scheichl, Sigurd Paul: Polemik. In: Reallexikon der deutschen Literaturwissenschaft. Neubearbeitung des Reallexikons der deutschen Literaturgeschichte. Bd. III. Hg. v. Jan-Dirk Müller. Berlin, New York: de Gruyter 2007, S. 117-120.

Scheichl, Sigurd Paul: Die Omnipräsenz der Literaturkritik. In: Große Literaturkritiker. Hg. v. S. P. S. Innsbruck u. a.: StudienVerlag 2010, S. 11-30.

Schlösser, Hermann: „Milchegel an den Zitzen der Kunst“. Autoren als Gegner der Literaturwissenschaft. In: Konflikte - Skandale - Dichterfehden in der österreichischen Literatur. Hg. v. Wendelin Schmidt-Dengler, Johann Sonnleitner u. Klaus Zeyringer. Berlin: Erich Schmidt 1995 (= Philologische Studien und Quellen, Bd. 137), S. 280-290. 
Schmaus, Marion: Literarische Rezeption. In: Robert-Musil-Handbuch. Hg. v. Birgit Nübel u. Norbert Christian Wolf. Berlin, Boston: de Gruyter 2016, S. 825-854.

Schmidt-Dengler, Wendelin: Franz Nabl und die Literaturgeschichte. In: Über Franz Nabl. Aufsätze, Essays, Reden. Hg. v. Kurt Bartsch, Gerhard Melzer u. Johann Strutz. Graz u. a.: Styria 1980, S. 9-27.

Schmidt-Dengler, Wendelin: Der Übertreibungskünstler. Studien zu Thomas Bernhard. Wien: Sonderzahl 1986.

Schmidt-Dengler, Wendelin: Drei Naturen: Bernhard, Jandl, Handke - Destruktion, Reduktion, Restauration. In: Zeit ohne Manifeste? Zur Literatur der siebziger Jahre in Österreich. Hg. v. Friedbert Aspetsberger u. Hubert Lengauer. Wien: Österreichischer Bundesverlag 1987, S. 150-165.

Schmidt-Dengler, Wendelin: Vorwort. In: Von einer Katastrophe in die andere. 13 Gespräche mit Thomas Bernhard. Hg. v. Sepp Dreissinger. Weitra: Bibliothek der Provinz 1992, S. 13-18.

Schmidt-Dengler, Wendelin: Bruchlinien. Vorlesungen zur österreichischen Literatur 1945 bis 1990. Salzburg, Wien: Residenz 1995.

Schmidt-Dengler, Wendelin: Kontinuität, Tradition und Neubeginn. Zu Otto Basil. In: Otto Basil und die Literatur um 1945. Tradition - Kontinuität - Neubeginn. Hg. v. Volker Kaukoreit u. W. S.-D. Wien: Zsolnay 1998 (= Profile, Bd. 2), S. 7-36.

Schmidt-Dengler, Wendelin: Literaturwissenschaft und Literaturkritik. In: Literaturkritik. Theorie und Praxis. Hg. v. W. S.-D. u. Nicole Katja Streitler. Innsbruck, Wien: StudienVerlag 1999, S. 11-25.

Schmidt-Dengler, Wendelin: Peter Turrinis rozznjogd als Initialzündung. In: Peter Turrini, Schriftsteller. Kämpfer, Künstler, Narr und Bürger. Mit einer Rede Peter Turrinis. Hg. v. Klaus Amann. St. Pölten, Salzburg: Residenz 2007, S. 74-83.

Schmidt-Dengler, Wendelin: „... das fortgeschrittenste Land ohne es zu wissen“. Unbewusster Avantgardismus aus Österreich. Hg. v. Michael Rohrwasser. Innsbruck u. a.: StudienVerlag 2009 (= Österreich - Zweite Republik. Befund, Kritik, Perspektive, Bd. 12).

Schmidt-Dengler, Wendelin: Bruchlinien II. Vorlesungen zur österreichischen Literatur 1990 bis 2008. St. Pölten, Wien: Residenz 2012.

Schmied, Wieland: Auersbergers wahre Geschichte und andere Texte über Thomas Bernhard. Ein Alphabet. Vorwort v. Hans Höller. Weitra: Bibliothek der Provinz [2014]. Schmitt-Maaß, Christoph: Kritischer Kannibalismus. Eine Genealogie der Literaturkritik seit der Frühaufklärung. Bielefeld: transcript 2019 (= Lettre).

Schneider, Sabine: Adalbert Stifter, die Literatur des 20. Jahrhunderts und die methodischen Paradigmenwechsel der Literaturwissenschaft. In: Die Literatur der Literaturtheorie. Hg. v. Boris Previšić. Bern u. a.: Lang 2010 (= Sammlung Variations, Bd. 10), S. $187-199$.

Schneider, Ursula A./Steinsiek, Annette: Mengenlehre. Christine Lavant und die „Wochen österreichischer Dichtung“ in Salzburg 1955. In: praesent (2004), S. 59-70. 
Schuh, Franz: Schreibkräfte. Über Literatur, Glück und Unglück. Köln: DuMont 2000.

Schuh, Franz: Thomas Bernhard, ein alter Meister. In: Alte Meister, Schufte, Außenseiter. Reflexionen über österreichische Literatur nach 1945. Hg. v. Manfred Müller. Wien: Sonderzahl 2005, S. 171-190.

Schütte, Uwe: Auf der Spur der Vergessenen. Gerhard Roth und seine Archive des Schweigens. Köln u. a.: Böhlau 1997 (= Literatur und Leben. N. F., Bd. 50).

Schütte, Uwe: Thomas Bernhard. Köln u. a.: Böhlau 2010 (= UTB Profile).

Schwencke, Olaf (Hg.): Kritik der Literaturkritik. Stuttgart u. a.: Kohlhammer 1973.

Schwens-Harrant, Brigitte: Literaturkritik. Eine Suche. Innsbruck u. a.: StudienVerlag 2008 (= Angewandte Literaturwissenschaft, Bd. 2).

Sebald, W. G.: Die Beschreibung des Unglücks. Zur österreichischen Literatur von Stifter bis Handke. Salzburg, Wien: Residenz 1985.

Sebald, W. G.: Unheimliche Heimat. Essays zur österreichischen Literatur. Salzburg, Wien: Residenz 1991.

Sexl, Martin: Literatur als Bildkritik. Peter Handke und die Jugoslawienkriege der 199oerJahre. In: Kriegsdiskurse in Literatur und Medien nach 1989. Hg. v. Carsten Gansel u. Heinrich Kaulen. Göttingen: V\&R unipress 2011, S. 89-106.

Sorg, Bernhard: Kunst ja, Politik nein. Thomas Bernhard in Österreich. In: Metamorphosen des Dichters. Das Selbstverständnis deutscher Schriftsteller von der Aufklärung bis zur Gegenwart. Hg. v. Gunter E. Grimm. Frankfurt a. M.: S. Fischer 1992, S. 302-311.

Sorg, Bernhard: Der Berechnende und der Geduldige. Ein Schriftsteller und sein Verleger. In: Text + Kritik ( $\left.{ }^{4} 2016\right)$, H. 43, S. 41-51.

Spoerhase, Carlos: Ausweitung der literarischen Kampfzone: Was die Geschichte der aufklärerischen Rezensionskultur die aktuelle Reflexion über Literaturkritik lehren könnte. In: Zeitschrift für Germanistik. N. F. 19 (2009), H. 1, S. 171-178.

Sprengel, Peter: Der Authentizitätsdiskurs der literarischen Moderne. Von Heinrich Heine bis Hubert Fichte, mit einem einleitenden Exkurs zum „Literarischen Quartett“. In: Das Authentische. Referenzen und Repräsentationen. Hg. v. Ursula Amrein. Zürich: Chronos 2009, S. 53-65.

Srienc, Dominik: „Aber das Schreiben war Existenz non plus ultra“. Peter Handke, der Bleistift und der Versuch über die Müdigkeit. In: Peter Handke. Stationen, Orte, Positionen. Hg. v. Anna Kinder. Berlin, Boston: de Gruyter 2014, S. 153-171.

Staengle, Peter: „Das könne er nicht.“ Zu Thomas Bernhards Der Stimmenimitator. In: Die kleinen Formen in der Moderne. Hg. v. Elmar Locher. Innsbruck, Wien: StudienVerlag 2001, S. 279-298.

Steiner, Uwe C.: Literatur als Kritik der Kritik. Die Debatte um Peter Handkes Mein Jahr in der Niemandsbucht und die Langsame Heimkehr. In: Gegenwartsliteratur. Wider ihre Verächter. Hg. v. Christian Döring. Frankfurt a. M.: Suhrkamp 1995, S. 127-169.

Steiner, Uwe: Walter Benjamin. Stuttgart, Weimar: Metzler 2004 (= Sammlung Metzler, Bd. 350 ). 
Stocker, Günther: Bernhard und die literarische Landschaft Österreichs der 1950er und 196oer Jahre. In: Bernhard-Handbuch. Leben - Werk - Wirkung. Hg. v. Martin Huber u. Manfred Mittermayer. Unter Mitarb. v. Bernhard Judex. Stuttgart: Metzler 2018, S. 296-301.

Streitler, Nicole: Musil als Kritiker. Bern u. a.: Lang 2006 (= Musiliana, Bd. 12).

Strigl, Daniela: Spurensicherung auf dem „österreichischen NS-Parnaß“. Otto Basil und die Debatte um Josef Weinheber. In: Otto Basil und die Literatur um 1945. Tradition Kontinuität - Neubeginn. Hg. v. Volker Kaukoreit u. Wendelin Schmidt-Dengler. Wien: Zsolnay 1998 (= Profile, Bd. 2), S. 66-76.

Strigl, Daniela: Platzanweiser im circus maximus? Traum und Wirklichkeit der Literaturkritik. In: Literatur und Kritik (2001), H. 353/354, S. 24-30.

Strigl, Daniela: Seher, Emphatiker, Gnostiker. Literaturkritik und Literaturtheorie. In: Germanistik und Literaturkritik. Zwischenbericht zu einer wunderbaren Freundschaft. Hg. v. Primus-Heinz Kucher u. Doris Moser. Wien: Praesens 2007 (= Stimulus 2006), S. 35-48.

Strigl, Daniela: Ihr Auftritt, bitte! Sprachingenieure als Entertainer. In: verschiedene sätze treten auf. Die Wiener Gruppe in Aktion. Hg. v. Thomas Eder u. Juliane Vogel. Wien: Zsolnay 2008 (= Profile, Bd. 15), S. 9-28.

Strigl, Daniela: Alles muss man selber machen. Biographie, Kritik, Essay. Graz, Wien: Droschl 2018 (= Grazer Vorlesungen zur Kunst des Schreibens, Bd. 1).

Struck, Lothar: Erzähler, Leser, Träumer. Begleitschreiben zum Werk von Peter Handke. Mit einem Vorwort v. Klaus Kastberger. [Klipphausen]: Mirabilis 2017.

Svandrlik, Rita: Das Zusammenwirken von Lust und Unlust beim Lesen von Elfriede Jelinek und Thomas Bernhard. In: Figurationen 15 (2014), H. 2, S. 83-98.

Tabah, Mireille: Geschlechterdifferenz im Werke Thomas Bernhards. Ansätze zu einer feministischen Interpretation. In: Thomas Bernhard Jahrbuch 2002, S. 133-144.

Tabah, Mireille: Weiblichkeitsimages bei Thomas Bernhard. In: ide. Informationen zur Deutschdidaktik 29 (2005), H. 4, S. 51-59.

Terhorst, Christel: Peter Handke. Die Entstehung literarischen Ruhms. Die Bedeutung der literarischen Tageskritik für die Rezeption des frühen Peter Handke. Frankfurt a. M. u. a.: Lang 1990 (= Europäische Hochschulschriften. Reihe 1: Deutsche Sprache und Literatur, Bd. 1206).

Thill, Anne: Die Kunst, die Komik und das Erzählen im Werk Thomas Bernhards. Textinterpretationen und die Entwicklung des Gesamtwerks. Würzburg: Königshausen \& Neumann 2011 (= Epistemata. Reihe Literaturwissenschaft, Bd. 738).

Thornton, Thomas K.: Die Thematik von Selbstauslöschung und Selbstbewahrung in den Werken von Peter Handke. Frankfurt a. M. u. a.: Lang 1983 (= Europäische Hochschulschriften. Reihe 1: Deutsche Sprache und Literatur, Bd. 659).

Thuswaldner, Anton: Österreichische Verhältnisse. In: Deutschsprachige Gegenwartsliteratur. Wider ihre Verächter. Hg. v. Christian Döring. Frankfurt a. M.: Suhrkamp 1995, S. 108-119. 
Thuswaldner, Gregor: „Morbus Austriacus“. Thomas Bernhards Österreichkritik. Wien: Braumüller 2011 (= Zur neueren Literatur Österreichs, Bd. 23).

Tommek, Heribert: Der lange Weg in die Gegenwartsliteratur. Studien zur Geschichte des literarischen Feldes in Deutschland von 1960 bis 200o. Berlin, Boston: de Gruyter 2015 (= Studien und Texte zur Sozialgeschichte der Literatur, Bd. 140).

Töteberg, Michael: Die Dürre der Theaterlandschaft. Polemische Anmerkungen, gestützt auf Zahlen, Daten und Statistiken. In: Text + Kritik (1988), Sonderbd. „Bestandsaufnahme Gegenwartsliteratur", S. 61-66.

Töteberg, Michael: Höhenflüge im Flachgau. Drei Anläufe, dreimal abgestürzt: die Vorgeschichte des Autors Thomas Bernhard. In: Text + Kritik ( $\left.{ }^{3} 1991\right)$, H. 43, S. 3-10.

Treichel, Hans-Ulrich: Auslöschungsverfahren. Exemplarische Untersuchungen zur Literatur und Poetik der Moderne. München: Fink 1995.

Tschapke, Reinhard: Hölle und zurück. Das Initiationsthema in den Jugenderinnerungen Thomas Bernhards. Hildesheim u. a.: Olms 1984 (= Germanistische Texte und Studien, Bd. 22).

Ulmer, Judith S.: Geschichte des Georg-Büchner-Preises. Soziologie eines Rituals. Berlin, New York: de Gruyter 2006.

Ulrich, Anne: „Ich bin kein Redner und ich kann überhaupt keine Rede halten“. Thomas Bernhard und seine Preise. In: Rhetorik und Sprachkunst bei Thomas Bernhard. Hg. v. Joachim Knape u. Olaf Kramer. Würzburg: Königshausen \& Neumann 2011, S. 45-62.

Urbach, Reinhard: Die Rezeption Franz Kafkas durch die jüngste österreichische Literatur. In: Franz Kafka. Eine Aufsatzsammlung nach einem Symposium in Philadelphia. Hg. u. eingel. v. Maria Luise Caputo-Mayr. Berlin, Darmstadt: Agora 1978, S. 183-193. Vellusig, Robert: Thomas Bernhards Gesprächs-Kunst. In: Thomas Bernhard. Beiträge zur Fiktion der Postmoderne. Londoner Symposion. Hg. v. Wendelin Schmidt-Dengler, Adrian Stevens u. Fred Wagner. Frankfurt a. M. u. a.: Lang 1997, S. 25-46.

Viehoff, Reinhold: Literaturkritik 1973 und 1988. Aspekte des literaturkritischen Wertewandels. In: Literaturkritik - Anspruch und Wirklichkeit. DFG-Symposion 1989. Hg. v. Wilfried Barner. Stuttgart: Metzler 1990 (= Germanistische Symposien. Berichtsbände, Bd. XII), S. 440-459.

Vogel, Juliane: Die Gebetbücher des Philosophen. Lektüren in den Romanen Thomas Bernhards. In: Modern Austrian Literature 21 (1988), H. 3/4, S. 173-186.

Vogel, Juliane: Apfelgarten und Geschichtslandschaft. Fallszenarien bei Thomas Bernhard und Peter Handke. In: Was der Fall ist. Casus und lapsus. Hg. v. Inka Mülder-Bach u. Michael Ott. Paderborn: Fink 2014 (= Anfänge), S. 187-199.

Völker, Daniela: Das Buch für die Massen. Taschenbücher und ihre Verlage. Marburg: Tectum 2014 (= Studien zu Literatur und Film der Gegenwart, Bd. 9).

Voßkamp, Wilhelm: „Auslöschung“. Zur Selbstreflexion des Bildungsromans im 20. Jahrhundert bei Thomas Bernhard. In: Literatur und Demokratie. Festschrift für Hartmut Steinecke zum 6o. Geburtstag. Hg. v. Aldo Allkemper u. Norbert Otto Eke. Berlin: Erich Schmidt 2000, S. 231-244. 
Wagner, Karl: Handkes Arbeit am 19. Jahrhundert. Roman- und Realismuskritik. In: Die Dinge und die Zeichen. Dimensionen des Realistischen in der Erzählliteratur des 19. Jahrhunderts. Für Helmut Pfotenhauer. Hg. v. Sabine Schneider u. Barbara Hunfeld. Würzburg: Königshausen \& Neumann 2008, S. 403-412.

Wagner, Karl: Handkes „Der Roman des Lesens“. In: Texttreue. Komparatistische Studien zu einem masslosen Massstab. Hg. v. Jürg Berthold u. Boris Previšić. Bern u. a.: Lang 2008, S. 173-181.

Wagner, Karl: „[...] wenn dir nicht ein Traum von ihr genügt.“ Peter Handke, Heimatsucher. In: Ferne Heimat - Nahe Fremde. Bei Dichtern und Nachdenkern. Hg. v. Eduard Beutner u. Karlheinz Rossbacher. Würzburg: Königshausen \& Neumann 2008, S. 203-213.

Wagner, Karl: Handkes Endspiel. Literatur gegen Journalismus. In: Mediale Erregungen? Autonomie und Aufmerksamkeit im Literatur- und Kulturbetrieb der Gegenwart. Hg. v. Markus Joch, York-Gothart Mix u. Norbert Christian Wolf. Tübingen: Niemeyer 2009 (= Studien und Texte zur Sozialgeschichte der Literatur, Bd. 118), S. 65-76.

Wagner, Karl: Musil und Handke: kein Vergleich. In: Peter Handke. Freiheit des Schreibens - Ordnung der Schrift. Hg. v. Klaus Kastberger. Unter Mitarb. v. Clemens Özelt. Wien: Zsolnay 2009 (= Profile, Bd. 16), S. 294-305.

Wagner, Karl: „Er war sicher der Begabteste von uns allen“. Bernhard, Handke und die österreichische Literatur. Wien: Picus 2010 (= Wiener Vorlesungen im Rathaus, Bd. 150).

Wagner, Karl: Handke als Leser. In: lesen.heute.perspektiven. Hg. v. Eduard Beutner u. Ulrike Tanzer. Innsbruck u. a.: StudienVerlag 2010, S. 140-149.

Wagner, Karl: Weiter im Blues. Studien und Texte zu Peter Handke. Bonn: Weidle 2010. Wagner, Karl: Handke und die Gruppe 47. In: Zwischen Aufbegehren und Anpassung. Poetische Figurationen von Generationen und Generationserfahrung in der österreichischen Literatur. Hg. v. Joanna Drynda. Frankfurt a. M. u. a.: Lang 2012 (= Posener Beiträge zur Germanistik, Bd. 32), S. 121-132.

Wagner, Karl: Handkes Versuch über die Jukebox. In: Figurationen 14 (2013), H. 1, S. 65-74. Wagner, Karl: Holzfällen als Selbstdemontage. Eine Lektüre nach den Skandalen. In: Thomas Bernhard. Persiflage und Subversion. Hg. v. Mireille Tabah u. Manfred Mittermayer. Würzburg: Königshausen \& Neumann 2013, S. 107-117.

Wagner, Karl: Echo. (Nach-)Hall: Beckett, Bernhard, Handke. In: Ein Zoll Dankfest. Texte für die Germanistik. Konstanze Fliedl zum 6o. Geburtstag. Hg. v. Susanne Hochreiter u. a. Würzburg: Königshausen \& Neumann 2015, S. 227-244.

Wagner, Karl: Der Popstar im Elfenbeinturm. Kontexte zu Handkes ,Auftritt' in Princeton. In: Dichterdarsteller. Fallstudien zur biographischen Legende des Autors im 20. und 21. Jahrhundert. Hg. v. Robert Leucht u. Magnus Wieland. Göttingen: Wallstein 2016, S. 175-190.

Wagner, Karl: Peter Handkes Moderne(kritik). In: Die tägliche Schrift. Peter Handke als Leser. Hg. v. Thorsten Carstensen. Bielefeld: transcript 2019, S. 153-161. 
Wagner-Egelhaaf, Martina: Peter Handke - eine Skandalgeschichte. In: Autorschaften im Spannungsfeld von Religion und Politik. Hg. v. Christian Sieg u. M. W.-E. Würzburg: Ergon 2014, S. 97-118.

Waitzbauer, Harald: Thomas Bernhard in Salzburg. Alltagsgeschichte einer Provinzstadt 1943-1955. Wien u. a.: Böhlau 1995.

„Was ich schreibe, ist ja nur meine geformte Existenz“. Peter Handke. Eine Ausstellung über Leben und Werk des Schriftstellers. Stift Griffen 1997. Klagenfurt: Kulturinitiative Stift Griffen 1998.

Wegmann, Nikolaus/Reiber, Cornelius: Deutsche Literatur. Die Gruppe 47 in Princeton. In: Sprache und Literatur 43 (2012), H. 110, S. 50-65.

Wegmann, Thomas: Der Dichter als „Letternkrämer“? Zur Funktion von Paratexten für die Organisation von Aufmerksamkeit und Distinktion im literarischen Feld. In: Das achtzehnte Jahrhundert 36 (2012), H. 2, S. 238-249.

Weichselbaum, Hans: Im Namen des Dichters. 45 Jahre Georg-Trakl-Preis für Lyrik Geschichte und Dokumentation. Salzburg, Wien: Otto Müller 1998.

Weiss, Walter: Thomas Bernhard - Peter Handke. Parallelen und Gegensätze. In: Literarisches Kolloquium Thomas Bernhard. Materialien. Hg. v. Johann Lachinger u. Alfred Pittertschatscher. Weitra: Bibliothek der Provinz 1994, S. 14-29.

Weninger, Robert: Streitbare Literaten. Kontroversen und Eklats in der deutschen Literatur von Adorno bis Walser. München: C. H. Beck 2004.

Wiele, Jan: Poetologische Fiktion. Die selbstreflexive Künstlererzählung im 20. Jahrhundert. Heidelberg: Winter 2010 (= Beiträge zur neueren Literaturgeschichte, Bd. 278).

Winkler, Jean-Marie: Bernhard als Anti-Mozart. Einige Thesen zum Stück Der Ignorant und der Wahnsinnige als Kontrafaktur der Zauberflöte. In: Bernhard-Tage Ohlsdorf 1996. Materialien. Hg. v. Franz Gebesmair u. Alfred Pittertschatscher. Weitra: Bibliothek der Provinz [1998], S. 206-218.

Winter, Susanne: Jean Cocteau und die Schwierigkeit zu sein. In: Leben als Kunstwerk. Künstlerbiographien im 2o. Jahrhundert. Hg. v. Christopher F. Laferl u. Anja Tippner. Bielefeld: transcript 2011, S. 59-84.

Wittkowski, Joachim: Das souveräne Bekenntnis zu sich selbst. Notizen zu einem ,Fall‘ der bundesdeutschen Literaturkritik. In: Text + Kritik (1988), H. 100, S. 59-65.

Wittstock, Uwe: Die Demokratisierung der Literaturkritik. In: Marcel Reich-Ranicki: Kritik als Beruf. Drei Gespräche, ein kritisches Intermezzo und ein Porträt. Hg. v. Peter Laemmle. Frankfurt a. M.: S. Fischer 2002, S. 135-138.

Wittstock, Uwe: Marcel Reich-Ranicki. Die Biografie. München: Blessing 2015.

Wittstock, Uwe: Ich liebe die Form der Rezension, aber es ist falsch, sie zum Fetisch zu machen. Literaturkritik in Nachrichtenmagazinen. In: Transformationen literarischer Kommunikation. Kritik, Emotionalisierung und Medien vom 18. Jahrhundert bis heute. Hg. v. Jörg Schuster, André Schwarz u. Jan Süselbeck. Berlin, Boston: de Gruyter 2017 (= spectrum Literaturwissenschaft/spectrum Literature, Bd. 58), S. 87-96. 
Wolf, Norbert Christian: Der „Meister des sachlichen Sagens“ und sein Schüler. Zu Handkes Auseinandersetzung mit Goethe in der Filmerzählung Falsche Bewegung. In: Peter Handke. Poesie der Ränder. Hg. v. Klaus Amann, Fabjan Hafner u. Karl Wagner. Wien u. a.: Böhlau 2006 (= Literaturgeschichte in Studien und Quellen, Bd. 11), S. 181-199.

Wolf, Norbert Christian: Autonomie und/oder Aufmerksamkeit? Am Beispiel der medialen Erregungen um Peter Handke. Mit einem Seitenblick auf Marcel Reich-Ranicki. In: Mediale Erregungen? Autonomie und Aufmerksamkeit im Literatur- und Kulturbetrieb der Gegenwart. Hg. v. Markus Joch, York-Gothart Mix u. N. C. W. Tübingen: Niemeyer 2009 (= Studien und Texte zur Sozialgeschichte der Literatur, Bd. 118), S. $45-63$.

Wolf, Norbert Christian: High and Low. Mediale Dominanzbildungen bei Peter Handke. In: Der neue Wettstreit der Künste. Legitimation und Dominanz im Zeichen der Intermedialität. Hg. v. Uta Degner u. N. C. W. Bielefeld: transcript 2010, S. 77-97.

Wolf, Norbert Christian: „Die beginnende Schizophrenie“ eines Tormanns. Handkes Erzählung und die Pathographien aus Klaus Conrads Gestaltanalyse des Wahns. In: Schreiben als Weltentdeckung. Neue Perspektiven der Handke-Forschung. Hg. v. Anna Estermann u. Hans Höller. Wien: Passagen 2014 (= Passagen Literaturtheorie), S. 165-200.

Wolf, Norbert Christian: Pop, Ästhetik und Politik 1969 - und ihr Nachspiel: Handke gegen/mit Jelinek. In: Literatur - Politik - Kritik. Beiträge zur Österreichischen Literatur des 20. Jahrhunderts. Hg. v. Harald Jele u. Elmar Lenhart. Göttingen: Wallstein 2014, S. 141-151.

Zajas, Paweł: Verlagspraxis und Kulturpolitik. Beiträge zur Soziologie des Literatursystems.

Paderborn: Fink 2019 (= Schriftenreihe des Instituts für russisch-deutsche Literaturund Kulturbeziehungen an der RGGU Moskau, Bd. 21).

Zelle, Carsten: Parteinahme für die Dinge. Peter Handkes Poetik einer literarischen Phänomenologie (am Beispiel seiner Journale, 1975-1982). In: Euphorion 97 (2003), H. 1, S. 99-117.

Zimmer, Dieter E.: Notizen zur Psychologie des Verreißens und Verrissenwerdens. In: Literatur und Kritik. Aus Anlaß des 6o. Geburtstages von Marcel Reich-Ranicki hg. v. Walter Jens. Stuttgart: DVA 1980, S. 120-132.

\section{Rezensionen, Presseberichte, Journalistisches}

A. H.: Thomas Bernhards „Frost“ der Einsamkeit. In: Salzburger Nachrichten, 21. 12.1963. B. S.: Peter Handkes Drinnen- und Draußenwelt. In: Theater heute (1969), H. 7, S. 4. Becker, Rolf/Karasek, Hellmuth: „Ich habe manipuliert, selbstverständlich!“ Kritiker Marcel Reich-Ranicki über seine Rolle im Literaturbetrieb und seinen Abgang von der FAZ. In: Der Spiegel, Nr. 1, 2.1.1989, S. 140-146. 
Beer, Otto F.: Endspiel im Salzburgischen. In: Süddeutsche Zeitung, 17./18. 8. 1963.

Beer, Otto F.: Der innere Frost. In: Neues Österreich, 7. 9.1963.

Boeck, Johann A.: Die bitteren Träume. In: Die Furche, 19.10.1963.

Buch, Hans Christoph: Tot und sauber aufgeräumt. Über Peter Handke: Der Hausierer.

In: Der Spiegel, Nr. 52, 18.12.1967, S. 118-120.

Buch, Hans Christoph: Der vollkommene Schauspieler. Über Peter Handke: Das Gewicht der Welt. In: Der Spiegel, Nr. 37, 5.9.1977, S. 197-201.

Christoph, Horst: Chronik eines Eklats. In: profil, Nr. 6, 7. 2. 2011, S. 97.

Das Literarische Quartett. Gesamtausgabe aller 77 Sendungen von 1988 bis 2001. 3 Bde. Berlin: Directmedia 2006.

Eisenreich, Herbert: Irrsinn im Alpenland. Über Thomas Bernhard: Verstörung. In: Der Spiegel, Nr. 19, 1. 5.1967, S. 164-166.

Finne, Rainer: Wer liest Handke? Eine literarisch-ökonomische Gesamtinszenierung. In: Deutsches Allgemeines Sonntagsblatt, 30.12.1994.

Fink, Humbert: Auf der Spur des Malers Strauch. Thomas Bernhards Debüt als Erzähler. In: Deutsche Zeitung und Wirtschaftszeitung, 24./25. 8.1963.

Fink, Humbert: Von Urangst befallen ... [Leserbrief] In: Kleine Zeitung, 1. 6.1975.

Gauß, Karl-Markus: Vorort-Vermessung und Reiseroman. In: profil, Nr. 46, 14.11.1994, S. $86-88$.

Gauß, Karl-Markus: Die Legende. In: Süddeutsche Zeitung, 19. 12. 2015.

Goetz, Rainald: „Wahr ist nur, was nicht paßt“. Über Thomas Bernhards Die Kälte. In: Der Spiegel, Nr. 18, 27. 4.1981, S. 229-232.

Görtz, Franz Josef: Wallfahrt eines Propheten. Peter Handkes Die Lehre der Sainte-Victoire. In: Frankfurter Allgemeine Zeitung, 16.12.1980.

H.[ansjörg] G.[raf]: Skepsis und Erwartung. In: Salzburger Nachrichten, 27.7.1955.

Greiner, Ulrich: Peter Handke und das Glücksgefühl, eine Flasche Mineralwasser anschauen zu können. In: Frankfurter Allgemeine Zeitung, 11. 10.1977.

Greiner, Ulrich: Der Tod des Nachsommers. Aufsätze, Porträts, Kritiken zur österreichischen Gegenwartsliteratur. München, Wien: Hanser 1979.

Grn [i.e. Ulrich Greiner]: Marcel Reich-Ranicki geht und bleibt. In: DIE ZEIT, Nr. 1, 30.12. 1988.

Greiner, Ulrich: Der Makel der Lesbarkeit. Als Marcel Reich-Ranicki die Deutschstunde fragwürdig fand. In: DIE ZEIT, Nr. 7, 9. 2. 2017.

Hage, Volker: Das Zittern der Gräser. In: Der Spiegel, Nr. 45, 7.11. 1994, S. 242-243.

Hage, Volker/Schreiber, Mathias: „Kritiker sind einsam“. Marcel Reich-Ranicki über sich selbst und die deutsche Literatur. In: Der Spiegel, Nr. 40, 4. 10.1993, S. 279-287.

Haider, Hans: Die Stigmatisierten steigen auf. In Österreichs literarischer Szene gibt es mehr prominente als gelesene Autoren. In: Die Presse, 23. 8. 1985.

Haider, Hans: Die kleine Fehlbarkeit des Literaturpapstes? [Gespräch mit Marcel ReichRanicki.] In: Die Presse, 16. 8.1994.

haku: „Frost“ überm Pongau. In: Salzburger Volksblatt, 21./22.12.1963. 
Halder, Karl-Ernst: Freibrief für Schmähungen? [Leserbrief] In: Kleine Zeitung, 15. 6. 1975. Haller, Bernt: Eine bürgerliche Publikumsbelustigung. Peter Handke liest im Hamburger „Neuen Kunstzentrum Literatur“. In: Süddeutsche Zeitung, 24./25. 5. 1967.

Hasselblatt, Dieter: Was man heute Literatur nennt. In: Saarbrücker Zeitung, 9./10. 7. 1966. Henrichs, Benjamin: Thomas Bernhard oder: Todes Leid und Lust. In: DIE ZEIT, Nr. 20, 10. 5. 1974 .

Henrichs, Benjamin: Der Evangelimann. Glücksmärchen, Wanderpredigt, Lesefolter: Die Wiederholung - Peter Handkes neues Buch. In: DIE ZEIT, Nr. 41, 3.10.1986.

Hieber, Jochen: Staunen und Raunen. Peter Handkes neuer Roman und die deutsche Literaturkritik. In: Frankfurter Allgemeine Zeitung, 19.1.1995.

Hildebrand, Alexander: Wie schwer fällt mir ein Wort. Thomas Bernhard als Lyriker. In: Wiesbadener Kurier, 21.9.1974.

Ignée, Wolfgang: Handkes Nicht-Buch. In: Christ und Welt, 10.10.1967.

J. B.: Der poetische Gelehrte. In: Süddeutsche Zeitung, 10.5.1993.

J. B.: Ein Zank. Schriftsteller gegen Kritiker. In: Süddeutsche Zeitung, 23. 12.1994. Jacobs, Jürgen: Lehren von der großen Harmonie des Daseins. Der Schriftsteller Peter Handke auf dem Weg zum Landschaftsmaler. In: Kölner Stadt-Anzeiger, 2. 10. 1980. Jenny, Urs: Ein Messias der Natur. In: Der Spiegel, Nr. 41, 8.10.1979, S. 247-249.

Kaiser, Joachim: Räuber: dumm. Philoktet: schlecht. SDS: denkfaul. Handke: was? In: DIE ZEIT, Nr. 25, 20.6.1969.

Kaiser, Joachim: Über einen Satz des Kritikers Marcel Reich-Ranicki. In: Text + Kritik (1988), H. 100, S. 23-24.

Karasek, Hellmuth: Handke, wo ist dein Stachel? In: Süddeutsche Zeitung, 25./26. 6. 1966. Karasek, Hellmuth: Was mir bleibt. Über zehn Titel in dreizehn Jahren „Literarisches Quartett“. In: Der Tagesspiegel, 14.12. 2001.

J.[osef] K.[aut]: Dichterlesung Thomas Bernhard. In: Demokratisches Volksblatt, 19. 12. 1952. J.[osef] K.[aut]: Junge Salzburger Lyrik. In: Demokratisches Volksblatt, 5. 5. 1955.

Kellermayr, Rudolf E.: Vom Ruhm verwöhnt. [Leserbrief] In: Kleine Zeitung, 31. 5.1975.

Kesting, Marianne: Mord und Verfolgung. Ein umfunktionierter Kriminalroman von

Peter Handke. In: DIE ZEIT, Nr. 17, 24. 4.1970.

Kreisky, Bruno: Wahr ist, was einer denkt. [Leserbrief] In: Kleine Zeitung, 8. 6.1975.

Kuby, Erich: Ach ja, da liest ja einer. In: Der Spiegel, Nr. 19, 12. 5. 1966, S. 154-165.

Kutschera, Hans: Thomas Bernhard „furchte“. In: Salzburger Volksblatt, 7.12.1955.

Laßl, Josef: Thomas Bernhard: Frost. In: Österreichischer Rundfunk. Radio Salzburg,

8. 2.1964 [Rundfunkmanuskript im Siegfried-Unseld-Archiv].

Laßl, Josef: Das Zucken der leblosen Dinge. In: Oberösterreichische Nachrichten, 14. 5. 1966. Lind, Jakov: Zarte Seelen, trockene Texte. In: Der Spiegel, Nr. 29, 11. 7. 1966, S. 79.

Löffler, Sigrid: Die Wahrnehmungshölle des Peter Handke. In: profil, Nr. 39, 27. 9. 1977, S. $53-54$.

Löffler, Sigrid: Erdforschung. In: profil, Nr. 41, 6.10.1980, S. 61. 
Löffler, Sigrid: Die versalzene Suppe und deren Köche. Über das Verhältnis von Literatur, Kritik und Öffentlichkeit. In: Literaturkritik. Theorie und Praxis. Hg. v. Wendelin Schmidt-Dengler u. Nicole Katja Streitler. Innsbruck, Wien: StudienVerlag 1999, S. 27-39.

Lüdke, W. Martin: Der heilige Handke? Peter Handkes erzählende Poetik Die Lehre der Sainte-Victoire. In: Frankfurter Rundschau, 25.10.1980.

Lütge, Jürgen: Nein zu Handke. In: Münchner Merkur, 9. 7.1966.

Meister, Helga: Enttäuschte Erwartungen. In: Düsseldorfer Nachrichten, 1.10.1966.

Mohn, Mogens: Nicht mehr mit Simmel allein. In: konkret (1977), H. 12, S. 37-38.

Müller, André: Das Schreien. Über Marcel Reich-Ranicki. In: A. M.: „Sie sind ja wirklich eine verdammte Krähe!" Letzte Gespräche und Begegnungen. Mit einem Vorwort v. Elfriede Jelinek. München: LangenMüller 2011, S. 160-168.

N. N.: Café Tomaselli wird wieder eröffnet. Salzburgs ältestes Kaffeehaus. In: Salzburger Volksblatt, 12.7.1950.

N. N.: Erfolgreiche junge Schriftsteller. In: Demokratisches Volksblatt, 5. 5. 1955.

N. N.: Ankündigung einer neuen Zeitschrift. In: Kursbuch 1 (10. 6.1965), H. 1, S. 1-2.

N. N.: Handke: Unerschrocken naiv. In: Der Spiegel, Nr. 22, 25. 5. 1970, S. 174-19o.

N. N.: Geheim-Werk von Peter Handke. In: Der Spiegel, Nr. 37, 8. 9. 1980, S. 184.

N. N.: „Mir soll der Mund verboten werden“. Marcel Reich-Ranicki über seine Popularität, sein Selbstverständnis und die Vorwürfe gegen ihn. In: Süddeutsche Zeitung, 17. 6. 1994.

N. N.: „Mancher Dichter fand es grausam“. Interview mit Marcel Reich-Ranicki über die „Gruppe 47“, ihre Autoren und ihren Gründer. In: Der Spiegel, Nr. 36, 1. 9.1997, S. $214-219$.

O. Sch.: Thomas Bernhard und Gerhard Fritsch. In: Salzburger Nachrichten, 14.11. 1957.

Offner, Matthias: Dann wäre Handke ein großer Dichter ... [Leserbrief] In: Kleine Zeitung, 31.5.1975.

Osterkamp, Ernst: Ist da ein Mensch? Was geschieht, wenn man dem eigenen Lieblingsbuch, dem Nachsommer, untreu wird und Adalbert Stifters Witiko liest. In: Frankfurter Allgemeine Zeitung, 5. 8.2017.

Pack, Claus: Bewältigung des Vergangenen. In: Die Presse, 13.7.1963.

Raddatz, Fritz J.: Die Bilanz von Princeton. [1966] In: Die Gruppe 47. Bericht - Kritik Polemik. Ein Handbuch. Hg. v. Reinhard Lettau. Neuwied, Berlin: Luchterhand 1967, S. $241-247$.

Radisch, Iris: Vorhang zu! Meine Jahre mit Marcel Reich-Ranicki im „Literarischen Quartett“. In: DIE ZEIT, Nr. 40, 26. 9. 2013.

Razumovsky, Andreas: Mist, Most. Bernhard gegen Löcker. In: Frankfurter Allgemeine Zeitung, 18.11.1988.

Reich-Ranicki, Marcel: Literatur der kleinen Schritte. Deutsche Schriftsteller heute. München: Piper 1967.

Reich-Ranicki, Marcel: Konfessionen eines Besessenen. In: DIE ZEIT, Nr. 17, 28. 4. 1967. 
Reich-Ranicki, Marcel: War es ein Mord? Martin Walsers Zimmerschlacht in München inszeniert von Fritz Kortner. In: DIE ZEIT, Nr. 50, 15.12.1967.

Reich-Ranicki, Marcel: Alfred Polgars sanfte Gewalt. Eine neue Auswahl seiner Prosa aus vier Jahrzehnten. In: DIE ZEIT, Nr. 24, 15. 6.1968.

Reich-Ranicki, Marcel: Finstere Wollust aus Österreich. Die Erzählungen des Thomas Bernhard. In: DIE ZEIT, Nr. 43, 25.10. 1968.

Reich-Ranicki, Marcel: Leichen im Ausverkauf. In: DIE ZEIT, Nr. 51, 19.12.1969.

Reich-Ranicki, Marcel: Lauter Verrisse. Mit einem einleitenden Essay. München: Piper 1970.

Reich-Ranicki, Marcel: Die Angst des Peter Handke beim Erzählen. In: DIE ZEIT, Nr. 37, 15. 9. 1972.

Reich-Ranicki, Marcel: ... aber ein Poet war er doch. Zum Tod des Rolf Dieter Brinkmann. In: Frankfurter Allgemeine Zeitung, 28. 4. 1975.

Reich-Ranicki, Marcel: Der Dichter der aggressiven Resignation. In: Frankfurter Allgemeine Zeitung, 19.6.1976.

Reich-Ranicki, Marcel: Unser junger Handke und die alte Hedwig. In: Frankfurter Allgemeine Zeitung, 9.10.1976.

Reich-Ranicki, Marcel: Deutsche Literatur 1977. Ein Überblick aus Anlaß der Frankfurter Buchmesse. In: Frankfurter Allgemeine Zeitung, 13.10.1977.

Reich-Ranicki, Marcel: Entgegnung. Zur deutschen Literatur der siebziger Jahre. Stuttgart: DVA 1979.

Reich-Ranicki, Marcel: Peter Handke und der liebe Gott. Zu der Erzählung Langsame Heimkehr. In: Frankfurter Allgemeine Zeitung, 17.11. 1979.

Reich-Ranicki, Marcel: Der Kaiser ist nackt oder: Über den Herbst unserer Bücher. In: Frankfurter Allgemeine Zeitung, 17.10.1980.

Reich-Ranicki, Marcel: Entgegnung. Zur deutschen Literatur der siebziger Jahre. Erweiterte Neuausgabe. Stuttgart: DVA 1981.

Reich-Ranicki, Marcel: Gibt es eine neue Innerlichkeit? In: Frankfurter Allgemeine Zeitung, 6.6.1981.

Reich-Ranicki, Marcel: Erst die Poesie, dann die Theorie. In: Was Kritiker gerne läsen. Literaturalmanach 1984. Hg. v. Jochen Jung. Salzburg, Wien: Residenz 1984, S. 99-101.

Reich-Ranicki, Marcel: Lauter Verrisse. Mit einem einleitenden Essay. Erweiterte Neuausgabe. Stuttgart: DVA 1984.

Reich-Ranicki, Marcel: Lauter Lobreden. Stuttgart: DVA 1985.

Reich-Ranicki, Marcel: Thomas Bernhards Bolero. Österreichs großer Einzelgänger wird von Buch zu Buch besser: Holzfällen. Eine Erregung. In: Frankfurter Allgemeine Zeitung, 22.9.1984.

Reich-Ranicki, Marcel: Thomas Manns treue Tochter. In: Frankfurter Allgemeine Zeitung, 18.1.1986.

Reich-Ranicki, Marcel: Nichts als Literatur. Aufsätze und Anmerkungen. Stuttgart: Reclam 1990. 
Reich-Ranicki, Marcel: Thomas Bernhard. Aufsätze und Reden. Mit Fotografien v. Barbara Klemm. Zürich: Ammann 1990.

Reich-Ranicki, Marcel: Ein Gegner der Meinungsfreiheit. In: Frankfurter Anthologie. Bd. 14. Gedichte und Interpretationen. Hg. v. M. R.-R. Frankfurt a. M., Leipzig: Insel 1991, S. 30-32.

Reich-Ranicki, Marcel: Der doppelte Boden. Ein Gespräch mit Peter von Matt. Zürich: Ammann 1992.

Reich-Ranicki, Marcel: Die Anwälte der Literatur. Stuttgart: DVA 1994.

Reich-Ranicki, Marcel: Mein Leben. Stuttgart: DVA ${ }^{3} 1999$.

Reich-Ranicki, Marcel: Kritik als Beruf. Drei Gespräche, ein kritisches Intermezzo und ein Porträt. Hg. v. Peter Laemmle. Frankfurt a. M.: S. Fischer 2002.

Reich-Ranicki, Marcel: Über Amerikaner. Von Hemingway und Bellow bis Updike und Philip Roth. München: DVA 2004.

Reitze, Paul F.: „Gerecht oder ungerecht - wer weiß das schon?“ [Gespräch mit Marcel Reich-Ranicki]. In: Die Welt, 1.6.1990.

Schäble, Gunter: Vom Himmel durch die Welt zur Helle. In: Der Spiegel, Nr. 5o, 8. 12. 1980, S. 213-216.

Schafroth, Heinz F.: Die unmögliche und die skeptische Hoffnung. Thomas Bernhard und Wolfgang Koeppen: Nachdenklicher Rückgriff auf die Jugend. In: Die Weltwoche, 19.1.1977.

Scheffel, Helmut: An der Erfahrungsgrenze. Die Hornissen - Der erste Roman von Peter Handke. In: Frankfurter Allgemeine Zeitung, 15.3.1966.

Schmidt-Mühlisch, Lothar: Rolle rückwärts aus einer hellen, heiteren, scharfen Unterhaltung. In: Die Welt, 6.9.1984.

Schneider, Rolf: Das revolutionäre Fragment. Über Robert Musil: Gesammelte Werke. In: Der Spiegel, Nr. 24, 12. 6.1978, S. 211-213.

Schober, Siegfried: Schriftsteller intim. Nicolas Born: Die erdabgewandte Seite der Geschichte. In: Der Spiegel, Nr. 41, 4.10.1976, S. 230-231.

Schonauer, Franz: Marcel Reich-Ranicki: Literarisches Leben in Deutschland. In: Neue deutsche Hefte (1965), H. 108, S. 161-167.

Schultz, Uwe: Die Suche nach dem reinen Augenblick. Peter Handke: Die Lehre der SainteVictoire. In: Hannoversche Allgemeine Zeitung, 11. 10. 1980.

Spiegel, Hubert: Preis für Peter Handke. Heine wird verhöhnt. In: Frankfurter Allgemeine Zeitung, 27.5.2006.

Steinfeld, Thomas: Das Krokodil in meinem Herzen. Ein Prophet des Seßhaften: Peter Handke verbringt ein Jahr in der Niemandsbucht. In: Frankfurter Allgemeine Zeitung, 12.11.1994.

Stolz, Hermann: Böses Ende. [Leserbrief] In: Der Spiegel, Nr. 24, 8. 6.1970.

Stritzl, Heinz: Amoklauf gegen Österreich. [Leserbrief] In: Kleine Zeitung, 5. 6. 1975.

Struck, Karin: Für die Arbeit gezeugt. Über Franz Innerhofer: Schöne Tage. In: Der Spiegel, Nr. 50, 9.12.1974, S. 136-139. 
Tauber, Reinhold: Ein Talent macht Pause. Ein „Journal“ läßt erkennen: Peter Handke tritt auf der Stelle. In: Oberösterreichische Nachrichten, 5.10.1977.

Ude, Karl: Gefährliche Wirklichkeiten. Peter Handke las in der Jungen Akademie. In: Süddeutsche Zeitung, 6.7.1967.

Weigel, Hans: Aufforderung, Ödön von Horváth zu spielen. [1957] In: H. W.: Nach wie vor Wörter. Literarische Zustimmungen, Ablehnungen, Irrtümer. Graz u. a.: Styria 1985, S. 313-316.

Weigel, Hans: Die TB-Seuche. Das große Geschäft mit den kleinen Büchern. [1959] In: H. W.: Nach wie vor Wörter. Literarische Zustimmungen, Ablehnungen, Irrtümer. Graz u. a.: Styria 1985, S. 222-229.

Werth, Wolfgang: Schreibmuster. Peter Handkes Erstlingsroman Die Hornissen. In: DIE ZEIT, Nr. 25, 17. 6. 1966.

Wickenburg, Erik G.: Gratuliert, provoziert, zensiert? Neuer Bernhard-Eklat. In: Die Welt, 4. 2.1981.

wj: Thomas Bernhard: Frost. In: Österreichisches Kulturwort. Zeitschrift für Kultur und Wissen (Februar 1964), [unpag.].

Zimmer, Dieter E.: Gruppe 47 in Princeton. In: DIE ZEIT, Nr. 19, 6. 5.1966.

\section{Fernsehsendungen, Audiovisuelle Medien, Webpages}

Audioaufzeichnung der Tagung der Gruppe 47 in Princeton. [1966] https://german.princeton. edu/department/about/resources/gruppe-47-recordings (Stand 14.10.2020).

Interview: Peter Handke im Gespräch mit Friedrich Luft. [1969] https://www.youtube. $\mathrm{com} /$ watch?v=fMPWoom_gZc (Stand 14.10.2020).

Norbert Beilharz: Die Feuer- und die Wasserprobe. Gespräch mit Thomas Bernhard, Saarländischer Rundfunk 1978. https://www.youtube.com/watch?v=oktFW5KOFjM (Stand 14.10.2020).

Literarisches Quartett, Zweites Deutsches Fernsehen [ZDF], Sendung Nr. 7, 12.10.1989. https://www.youtube.com/watch?v=DC9sROSoPoo (Stand 14.10. 2020).

Literarisches Quartett, Zweites Deutsches Fernsehen [ZDF], Sendung Nr. 16, 16. 10.1991. https://www.youtube.com/watch?v=OsbUjhIAojg (Stand 14.10.2020).

Interview: Marcel Reich-Ranicki im Gespräch mit Volker Hage und Hellmuth Karasek. [1993] https://www.spiegel.de/video/reich-ranicki-karasek-hage-video-99010556.html (Stand 14.10.2020).

Literarisches Quartett, Zweites Deutsches Fernsehen [ZDF], Sendung Nr. 34, 15.12.1994. https://www.youtube.com/watch?v=pUkRi-EysoA (Stand 14.10.2020).

Literarisches Quartett, Zweites Deutsches Fernsehen [ZDF], Sendung Nr. 48, 25. 4. 1997. https://www.youtube.com/watch?v=4qjcYax9Mwo (Stand 14.10.2020).

Onlineplattform „Handke online“, FWF-Forschungsprojekt (Klaus Kastberger, Christoph Kepplinger-Prinz, Katharina Pektor). http://handkeonline.onb.ac.at (Stand 14. 10. 2020). 
Salzburg Wiki, Eintrag „Salzburger Volksblatt“. https://www.sn.at/wiki/Salzburger_ Volksblatt (Stand 14.10.2020).

Stichwörter zur oberösterreichischen Literaturgeschichte, Projekt des Stifter-Hauses Linz (Redaktion und Konzeption: Petra-Maria Dallinger, Martin Huber, Bernhard Judex, Klaus Kastberger, Manfred Kern, Manfred Mittermayer, Daniela Strigl). https://stifterhaus.at/ forschung/stichwoerter-zur-ooe-literaturgeschichte/ (Stand 14.10.2020). 


\section{PERSONENREGISTER}

In das Personenregister wurden nur jene Namen aufgenommen, die im Fließtext bzw. in Fußnoten in eigenständigen syntaktischen Zusammenhängen angeführt sind; reine Literaturverweise wurden nicht für das Register berücksichtigt.

A

Achleitner, Friedrich 88, 257

Achternbusch, Herbert 79

Adorno, Theodor W. 48, 54, 251, 266

Albes, Claudia 182, 187

Aleksić, Dragan 131, 247

Alexijewitsch, Swetlana 9

Altenburg, Franz Josef 70, 394

Amann, Klaus 271, 309, 312

Amanshauser, Gerhard 273, 301-303, 305, 311

André, Klaus 110

Antel, Franz 316

Anz, Thomas 13, 156

Arghezi, Tudor 123

Arnold, Heinz Ludwig 160, 405

Artaud, Antonin 291

Artmann, H. C. 86, 88, 238, 323, 333

\section{B}

Bachmann, Ingeborg 29, 138f., 243, 339

Baier, Lothar 48

Barner, Ines 207

Barth, Johann 300, 315

Barthes, Roland 39, 54, 124, 147 f., 152

Barthofer, Alfred 105

Bartmann, Christoph 261

Basil, Otto 281, 306, 308

Bätschmann, Oskar 186

Baudelaire, Charles 304

Bauer, Wolfgang 14, 19, 132, 232, 253-256, 264

Baumgart, Reinhard 45, 51, 57, 117 f., 125 , 194, 198, 217

Bayer, Konrad 25, 88, 145
Bayer, Xaver 131, 247

Bayr, Rudolf 84, 313, 325 f., 350

Becker, Jurek 176, 190

Becker, Jürgen 153, 237, 248-250

Becker, Peter von 292, 398

Beckett, Samuel $99 \mathrm{f}$.

Beer, Otto F. 89, 91

Beilharz, Norbert 102

Bender, Hans 100

Benjamin, Walter 22, 24, 54, $137 \mathrm{f}$., $269 \mathrm{f}$.

Benn, Gottfried 301, 305

Berger, John 337

Berke, William 316

Bernanos, Georges 366

Bernard, Émile $185 \mathrm{f}$.

Beuermann, Dieter 370

Bezzel, Chris 55

Bichsel, Peter 189, 245, 248

Billenkamp, Michael 276, 289, 298, 325, 375, 388, 393

Billinger, Richard 281, $311 \mathrm{f}$., 318

Birkner, Nina 108

Bisinger, Gerald 333

Blaas, Erna 307, 309-313

Bloch, Ernst 54, 189

Blöcker, Günther 83

Blok, Alexander 377

Bloom, Harold 197, 277, 390 f., 400

Boeck, Johann A. 91

Boehlich, Walter 50, 100

Böhme, Erich 72, 104, 304

Böll, Heinrich 266

Bond, Edward 256

Borchers, Elisabeth 207

Borgards, Roland 235 
Born, Nicolas 19, 44, 118 f., 262, 264

Borns, Nicolas 166

Botond, Anneliese 19, 37 f., 91, 244, 291, 383 f., 402

Bourdieu, Pierre 14, 23, 25, 27, 29, 31, 53, $57,65,81,106,124,126,167,217,230,325$, $327,384,393,399,407$

Brandauer, Karoline 298

Brändle, Rudolf 72, 278, 332, 389

Brandstetter, Alois 13

Brandt, Willy 351

Braun, Karlheinz 112

Brecht, Bertolt 52, 54, 63, 86, 135, 192, 259 f., 291, 305

Brehm, Bruno 279, 307, $311 \mathrm{f}$.

Breitbach, Joseph 360

Breschnew, Leonid 349

Brinkmann, Rolf Dieter 96, 98, 163 f., $197 \mathrm{f}$.

Broch, Hermann 282, 299, 338

Brod, Max 262

Bronner, Gerhard 349

Brown, Christy 335

Bruckner, Anton 341

Buch, Hans Christoph 58-60, 146, 148, 359, 407

Burger, Hermann 190

Busta, Christine 301

Butor, Michel 39

C

Caesar, Gaius Julius 349

Cage, John 245, 323

Canetti, Elias 98-102, 132, 161f., 356

Carossa, Hans 312

Carter, Jimmy 349

Casanova, Nicole 84

Celan, Paul 139, 192

Cervantes, Miguel de 274

Cézanne, Paul 179, 181, 185 f., 387

Cheever, John 19

Chotjewitz, Peter O. 174

Christoph, Horst 357
Churchill, Winston 349

Claus, Carlfriedrich 237

Cocteau, Jean 410

Cohn-Bendit, Daniel 53, 215

Colette, Sidonie-Gabrielle Claudine 280

Cooper, Gary 255

Courths-Mahler, Hedwig 166, 171

Cronin, A. J. 280

Csokor, Franz Theodor 307

Czernin, Franz Josef 155

Czibulka, Alfons 298, 326

\section{D}

Dahl, Arlene 315

Dante Alighieri 182, 204

Day, Clarence 303

Deißinger, Hans $311 \mathrm{f}$.

Deix, Manfred 357

Delacroix, Eugène $185 \mathrm{f}$.

Delius, Friedrich Christian 6o, 125, 176, 225, 277

Demetz, Peter $146,165 \mathrm{f}$.

Demokrit von Abdera 187

Dickens, Charles 241

Dickinson, Emily 303

Dinter, Ellen 187

Dittberner, Hugo 190, 198

Dittmar, Jens 287, 293, 298

Doderer, Heimito von 88, 164 f., 263

Donnenberg, Josef 94

Döring, Jörg 144

Dorschel, Andreas 199

Dostojewski, Fjodor M. 88, 274

Dreissinger, Sepp 85, 390

Duras, Marguerite 19

Durzak, Manfred 16, 39, 61, 160, 177, 217, 237, 405

\section{E}

Eberl, Georg 298, 301, 319

Ebner, Jeannie 301, 333

Edschmid, Kasimir 132 
Effenberger, Elisabeth 281, 301-303, 310, 318,324

Eich, Günter 192

Eichenbaum, Boris 151, 223-225

Eichendorff, Joseph von 298

Eichholz, Armin 84

Einstein, Albert 349

Eisendle, Helmut 132

Eisenreich, Herbert $36-38$

Eliot, T. S. 18,331

Elsner, Gisela 174

Encke, Julia 46

Ensor, James 106

Enzensberger, Hans Magnus 48, 53, 100, $176,192,247 \mathrm{f}$.

Epikur 79

Eschstruth, Nataly von 171

Eybl, Franz M. 64

\section{$\mathbf{F}$}

Fabjan, Peter 196, 200

Färber, Helmut 246 f., 250, $256 \mathrm{f}$.

Farkas, Karl 349

Faulkner, William 290, 331

Federmair, Leopold 188

Federmann, Reinhard 366

Federspiel, Jürg 190

Felder, Franz Michael 19, 177

Fellinger, Raimund 211

Fichte, Hubert 46, 174

Ficker, Ludwig von 227

Fink, Humbert 94, 366

Fischer, Joschka 53, 215

Fitzgerald, F. Scott 228

Flaubert, Gustave 257 f., 384

Fleischmann, Krista 70, 74, 85, 116, 286, 294, 348, 356, 400

Fleißer, Marieluise 192

Fontane, Theodor 197, 267

Ford, John $256 \mathrm{f}$.

Forster, Georg 401

Franck, Georg 14, 42, 70, 398

Franco, Francisco 349
Frank, Niklas 370

Freumbichler, Johannes 66, 89, 274-28o, 282 f., 293, 296, 304, 314, 322, 327

Fries, Fritz Rudolf 190

Frisch, Max 14, 63, 192, 235, 248

Frischmuth, Barbara 96, 361

Frisé, Adolf 145

Fritsch, Gerhard 92, 291, 313, 327, 332, 334, 360

Fritz, Marianne 74, 200

Fröhlich, Hans J. 190

Frühwald, Wolfgang 101

Fussenegger, Gertrud 309, 312

G

Gabriel, Norbert 239, 261, 263

Gamper, Herbert 79, 132, 268, 373

Ganghofer, Ludwig 176

Ganz, Bruno 111

Gauß, Karl-Markus 17, 284

Genette, Gérard 22, 24, 36, 150, 355, 372

Gerstl, Elfriede 333

Gimmelsberger, Erwin 300, 310

Ginzkey, Franz Karl 309, $311 \mathrm{f}$.

Gmeiner, Klaus 334

Godard, Jean-Luc 54, 257

Goethe, Johann Wolfgang 31, 64, 68, 133, $197,205,253,274,373,406$

Goetz, Curt 317

Goetz, Rainald 375

Gogol, Nikolai W. 202

Gold, Käthe 111, 116

Görtz, Franz Josef $175 \mathrm{f}$.

Gößling, Andreas 380, 383

Gottwald, Herwig 17

Götze, Clemens 352, 369

Gould, Glenn 390

Grabbe, Christian Dietrich 91

Graf, Hansjörg 302, 305

Graf, Werner 158

Grasmayr, Alois 311

Grass, Günter 41, 44, 46, 55, 58, 144, 176, $194,215,221,266$ 
Greenblatt, Stephen 23

Green, Julien 123

Greiner, Ulrich 10, 130, 209, 398, 406

Grengg, Maria 307

Grillparzer, Franz 19, 368

Grimm, Jacob 209

Grimm, Wilhelm 209

Grogger, Paula 280, 307-309, 312

Groys, Boris 58, 325

Guevara, Ernesto Che 59

Gutknecht, Christoph 14

\section{H}

Habermas, Jürgen 251

Habringer, Rudolf 291, 318

Hacker, Friedrich 124

Hage, Volker 118, 155, 204, 206, $216 \mathrm{f}$.

Hahn, Marcus 341, 378, 381, 386

Hahn, Ulla 173

Haider, Hans 292, 371

Hakel, Hermann 273, $305 \mathrm{f}$.

Hamann, Johann Georg 10

Hamm, Peter 16, 34, 51-55, 59 f., 85, 108, 147 f., 194, 234, 240, 255-257, 286, 304, 330, 359, 373 f., 389

Hamsun, Knut 88, 229, 274, 305

Handke, Amina 68

Hanuschek, Sven 161

Haringer, Jakob 310, 312

Harlan, Veit $317 \mathrm{f}$.

Härtling, Peter 165

Hartung, Rudolf 96-98, 198

Haslinger, Adolf 39, 41, 271, 318

Haslinger, Josef 361

Häupl, Michael 369

Haushofer, Marlen 301

Hawthorne, Nathaniel 19

Hayes, Joseph 223

Hebel, Johann Peter 298

Heckenast, Gustav $379 \mathrm{f}$.

Heer, Friedrich 330

Hegel, Georg Wilhelm Friedrich 339

Heidegger, Martin 113, 341
Heimböckel, Dieter 218

Heine, Heinrich 13, 27, 215

Heinisch, Eduard C. 298

Heinrici, Sandra 105

Heiseler, Bernt von 301, 330, 334, 343

Heißenbüttel, Helmut 160, 174, 184, 202

Hell, Bodo 313

Hemingway, Ernest 280, 303

Henisch, Peter 361

Hennetmair, Karl Ignaz 36, 100, 302, 335

Henrichs, Benjamin 83, 200, $409 \mathrm{f}$.

Henz, Rudolf 366

Herwig, Malte 80, 134

Hesse, Hermann 192

Heyl, Tobias 275, 378, 388

Highsmith, Patricia 19, 262

Hildesheimer, Wolfgang 192

Hirschmann, Christoph 210

Hitler, Adolf 306, 309, 311, 323, 349, 353

Hochhuth, Rolf 337

Hödlmoser, Josef 301, 310, 323

Hofer, Brigitte 85

Hoffer, Klaus 19

Hofmann, Kurt 89, 338

Hofmannsthal, Hugo von 161, $280 \mathrm{f}$.

Hohl, Ludwig 336

Hohlbaum, Robert 279, 307, 309

Hohler, Franz 15

Hölderlin, Friedrich 91, 200, 209, 305, 313

Höller, Hans 180, 241, 243, 283, 299, 304, $327,356,391$

Höllerer, Walter 45, 51, 57, 79, 141

Holzinger, Alfred 125, 162, 252

Homer 189

Honegger, Gitta 295, 332

Honold, Alexander 274

Horváth, Ödön von 255, 259-261

Hrabal, Bohumil 123

Huber, Alexander 188

Huchel, Peter 192

Hufnagl, Viktor 345

Huntemann, Willi 66, 355 f., 378, 384 f., 394

Huth, Jochen 319 


\section{I}

Iffland, August Wilhelm 330

In der Maur, Wolf 35, 347

Innerhofer, Franz 264

Innerhofer, Roland 386

Inoue, Iasushi 19

J

Jaccottet, Philippe 19

Jacobs, Jürgen 182

Jakobson, Roman 116, 151

James, Henry 377 f., 382, 401

Janáček, Leoš 339

Jandl, Ernst 86, 245

Janner, Markus 290

Januš, Gustav 19, 133, 138-140

Jaumann, Herbert 30

Jean Paul 289, 338

Jelinek, Elfriede 86 f., 111, 166, 245, 358, 361

Jelusich, Mirko 307

Jenny, Urs 89, 170, 174, 250

Jens, Walter $45 \mathrm{f}$., 51, 57, 141, 174

Joch, Markus 27

Jocks, Heinz-Norbert 117, 409

Johannes Paul II. 349

Johnson, Uwe 46, 192, 215

Jones, Jennifer 317

Jonke, Gert 19, 232, 234, 243, 256-259

Joyce, James 104, 397

Judex, Bernhard $282 \mathrm{f}$.

Jung, Jochen 143, 345

Jünger, Ernst 333

Jungk, Peter Stephan 19

\section{K}

Kafka, Franz 55, 97, 160 f., 176, 183, 197, 239, 262 f., 265 f., 299, 338, 397

Kaiser, Joachim 45, 51, 57, 87, 141, 266

Kant, Immanuel 75, 101, 339, 350

Karasek, Hellmuth 42 f., 54, 72, 104, 195, 204, 210 f., 304
Karsunke, Yaak 52

Kaschnitz, Marie Luise 192

Kasparek, Rudolf 295

Kastberger, Klaus 8o

Kathrein, Karin 83

Kaut, Josef 284, 293, 314, 330

Kefer, Linus 309, 312

Keller, Gottfried 228

Kepplinger-Prinz, Christoph 365

Kerbler, Michael 227, 368

Kerr, Alfred 114-116, 270

Kerschbaumer, Gert 281

Kerschner, Julia 72

Kesting, Marianne 6of.

Khomeini, Ruhollah 349

Kindermann, Heinz 307, 312

Kirchschläger, Rudolf 345

Kirsch, Sarah 191

Kleist, Heinrich von 91, 156, 298

Klessinger, Hanna 106, 253

Klinger, Kurt 333

Klug, Christian 32, 296, 298, 317, $324 \mathrm{f}$., 328, 353, 385

Koeppen, Wolfgang 164f., 190, 192

Kohl, Katrin 394

Kokoschka, Oskar 304

Kolbenheyer, Erwin Guido 279

Kolleritsch, Alfred 117, 119, 131, 145, 202, 240 f., 243, 248, 253, 363, 404

Kramberg, Karl Heinz 96

Kramer, Theodor 307

Krammer, Stefan 392

Kraus, Karl 54, 116, 368

Kraus, Wolfgang 92, 102

Krauss, Clemens 323

Krauß, Werner 105

Kreisky, Bruno 343-350, 356 f., 361-363, 365-372

Kroetz, Franz Xaver 136, 202

Krolow, Karl 192

Krüger, Horst 165

Kuby, Erich 43

Kurbjuhn, Martin 226

Kutschera, Kurt 331 
$\mathbf{L}$

Lacina, Ferdinand 368

Lampersberg, Gerhard 35 f., 361

Landgrebe, Erich 312, 319

Laßl, Josef 92, $302 \mathrm{f}$., $324 \mathrm{f}$.

Lavant, Christine 301, 311, 336

Lechner, Hans 95

Lehmann, Arno 329

Lenau, Nikolaus 91, 274

Lenin, Wladimir I. 54

Lennon, John 54, 252

Lenz, Hermann 19, 67 f., 120, 132, 139, 163, 165, 168, 174, 229-234, 236, 262, 264, 266, 271

Lenz, Siegfried 165, 191, 198

Lernet-Holenia, Alexander 307

Lerperger, Emil 300

Lessing, Gotthold Ephraim 27, 222

Levi-Strauss, Claude 54

Lewis, Sinclair 280

Lind, Jakov 56-58, 404f.

Linder, Herbert $250 \mathrm{f}$.

Lindner, Lois 323

Linhartová, Vĕra 123

Lipuš, Florjan 367

Löffler, Sigrid 17, 142, 194, 214, 216, 407

Lorenc, Kito 19

Lorenz, Otto 33, 127, 148, 155, 178, 216

Lucan-Stood, Annelore 288

Lüdke, W. Martin 177, 194

Ludwig, Edward 315

Luft, Friedrich 267

Lukács, Georg 46, 86, 108, 327

Luther, Martin 114

\section{M}

Mack, Lorenz $298 \mathrm{f}$.

Magenau, Jörg 57

Malcolm X 54

Mann, Erika 200

Mann, Golo 161

Mann, Thomas 70, 161, 200, 263, 342

Manzl, Thea 301
Mao Zedong 54, 60

Marcuse, Herbert 54, 251

Marischka, Hubert 331

Marlitt, Eugenie 171

Martinů, Bohuslav 339

Martus, Steffen 24

Marx, Karl 54, 65

Matt, Peter von 27 f., 6o, 193, 197

Mayer, Hans 45, 57, 141, 165

Mayröcker, Friederike 19, 86, 245

McCartney, Paul 252

McCrea, Joel 255

Meister, Ernst 139

Melchinger, Siegfried 301

Mell, Max 28of., 309, 311 f.

Menasse, Eva 80

Mendelssohn Bartholdy, Felix 370

Metternich, Klemens Wenzel Lothar von 353

Michaelis, Rolf 41, 174

Michaelsen, Sven 176

Michler, Werner 135

Miller, Arthur 331

Miller, Norbert 210

Milošević, Slobodan 9

Minetti, Bernhard 104-107, 110 f., 393, 399

Mitterand, François 351

Mittermayer, Manfred 21, 71, 283, 322

Mixner, Manfred 234f., 237, 264f., 327

Mock, Alois 349

Mohn, Mogens 406

Monet, Claude 185

Mon, Franz 237

Montaigne, Michel de $274 \mathrm{f}$.

Moog, Heinz 303

Mörike, Eduard 209

Moritz, Herbert 285 f., 320, 326, 333

Moritz, Karl Philipp 387

Mozart, Wolfgang Amadeus 73, 103

Mračnikar, Helga 367

Müller, André 16, 30, 71, 178, 184, 194, 202, 208, 214, 348, 387

Müller, Hans 95

Müller, Karl 307, 310 
Müller, Konrad R. 343

Müller, Otto 313

Musar, Reinhard 241

Muschg, Adolf 57, 176

Musil, Robert 82, 114-116, 195, 270, 282, 299, 338, $347 \mathrm{f}$.

Musulin, Janko von $335 \mathrm{f}$.

\section{N}

Nabl, Franz 67, 161-163, 177, 280, 307-309, 312

Nabl, Ilse 162

Nadler, Josef 307,313

Napoleon Bonaparte 349

Navratils, Leo 244

Nenning, Günther 156, 225

Nestroy, Johann Nepomuk 254, 348, 368

Nettelbeck, Uwe 250

Neuhaus, Stefan 267

Niefanger, Dirk 164

Nossack, Hans Erich 192, 196

Novalis 209, 269 f., 298

0

Okopenko, Andreas 257

Oliver, Laurence 317

O'Neill, Eugene 91, 303

Opitz, Michael 22

Opitz, Peter 226

Osterkamp, Ernst 380

\section{P}

Pack, Claus 92

Paeschke, Hans 334

Pascal, Blaise 274, 336, 339

Patterer, Hubert 9

Pavese, Cesare 121-123

Pavlović, Miodrag 19

Pawlow, Iwan P. 188

Payne, John 315

Peckinpah, Sam $254 \mathrm{f}$.
Péguy, Charles 274, 304

Perkonig, Josef Friedrich 311

Perón, Evita 349

Perram, Garvin H. C. 155

Pethes, Nicolas 352

Petritsch, Wolfgang 366

Peymann, Claus 56, 109

Pfabigan, Alfred 350

Pfister, Gerhard 24, 47

Pfohlmann, Oliver 59

Piontek, Heinz 55

Pissarro, Camille 185

Piwitt, Hermann Peter 42, 142

Polgar, Alfred 174

Pollak, Oskar 265

Polt-Heinzl, Evelyne 368

Porombka, Stephan 156

Poulet, Georges 40

Pound, Ezra 303

Powys, John Cowper 235

Preradović, Paula von $280 \mathrm{f}$.

Propp, Vladimir 121

Proust, Marcel 40, 282, 397

Prutti, Brigitte 99, 403

Pütz, Peter 182

\section{R}

Radax, Ferry 84, 100, 401

Raddatz, Fritz J. 42, 45

Raimund, Ferdinand 202, 368

Rakusa, Ilma 81

Rambures, Jean-Louis de 85

Ransmayr, Christoph 34

Rathkolb, Oliver 318, 358

Raulet, Gérard 138

Razumovsky, Andreas 93

Reagan, Ronald 349

Rehbein, Jürgen 258

Reich-Ranicki, Marcel 17, 25, 37, $45 \mathrm{f}$., 51 f., 54,56 f., 61, 67, 83, 96, 98, 135, 137, 141-164, 166-18o, 182-184, 188, 190-204, 206-219, 263, 266 f., 269, 397, $406,410 \mathrm{f}$. 


\author{
Reinig, Christa 184 \\ Reiser, Tobi 318 \\ Reiss, Hans 102 \\ Reitze, Paul F. 219 \\ Renzl, Theodor 296, 298 \\ Reulecke, Anne-Kathrin 181, 186 \\ Reuter, Tim 354 \\ Richter, Hans Werner 40, 44, 46 f., 142 \\ Rilke, Clara 133 \\ Rilke, Rainer Maria 133, 305, 333 \\ Rimbaud, Arthur 91, 304 \\ Ringler-Kellner, Ilse 309, 312 \\ Rischbieter, Henning 104, 127, 129, 227 \\ Robbe-Grillet, Alain 39 \\ Roberts, David 386 \\ Rodin, Auguste 199 \\ Rodlauer, Walter 297 \\ Roi, Rudolf de le 100 \\ Ronnefeld, Peter 76, 91 \\ Rosegger, Peter $176 \mathrm{f} ., 242$ \\ Rosendorfer, Herbert 347 \\ Roth, Gerhard 137, 161, 343, 357 f., 361, \\ 366, 372 \\ Roth, Joseph 197 \\ Rühm, Gerhard 88 \\ Rühmkorf, Peter 20, 161 \\ Ruiss, Gerhard 350, 403
}

\section{S}

Saroyan, William 303

Sartre, Jean-Paul 266

Saussure, Ferdinand de 47

Schäble, Gunter 178

Schädlich, Hans Joachim 190

Schaefer, Camillo 72

Schaffler, Wolfgang 162, 248, 357

Scharang, Michael 361

Scheck, Denis 61

Scheffel, Helmut 39 f., 117, 147

Scheib, Asta 200, 276, 285, 374, 389

Scheibl, Eligius 311

Scheichl, Sigurd Paul 329, 337

Schiller, Friedrich 158, 267, 372
Schlösser, Hermann 132

Schmidinger, Walter 256

Schmidt, Adalbert 300, 307, 309

Schmidt-Dengler, Wendelin 15, 356

Schmidt-Mühlisch, Lothar $138 \mathrm{f} ., 199$

Schmied, Wieland 196, 291, 311, 359, 389, 403

Schneider, Rolf 347

Schober, Siegfried 118 f., 250

Schonauer, Franz 146, 188

Schönwiese, Ernst 298, 301

Schopenhauer, Arthur 101, 274, 278, 339

Schostack, Renate 190

Schreiber, Mathias 155, 206, 217

Schreyvogl, Friedrich 307

Schuh, Franz 14, 24, 205, 342

Schultz-Gerstein, Christian 405

Schünemann, Peter $92 \mathrm{f}$.

Schwagerle, Elisabeth 80

Scott, Randolph 255

Sebald, W. G. 182

Sedlmayr, Hans 88, 313

Seidlhofer, Walter 296

Seitz-Ransmayr, Loni 298

Selby, Hubert 174

Shakespeare, William 105 f., 110, 202, 274, 298, 346

Sichrovsky, Heinz 234

Sieburg, Friedrich 51, 153

Sillanpää, Frans Eemil 305

Simenon, Georges 337

Simmel, Johannes Mario 362

Sinowatz, Fred 367

Šklovskij, Viktor 151, 223 f., 249

Solstad, Dag 131, 247

Sperber, Manès 410

Spiel, Hilde 389

Spinoza, Baruch de 181

Springenschmid, Karl 307 f., 311

Stadler, Arnold 238, 328

Staël, Madame de 349

Stalin, Josef 353

Stanchina, Peter 331

Starr, Ringo 253 
Stavianicek, Hedwig 72, 201

Stebich, Max 306

Steiner, Uwe C. 210

Stelzhamer, Franz 369

Stewart, James 179

Stifter, Adalbert 19, 79, 156, 208, 274, 282, $298,328,338,341,374,379$ f., 387

Stiller, Klaus 48

Stocker, Günther 90

Storm, Theodor 318

Straub, Jean-Marie 257

Strauß, Botho 168, 250

Strauss, Richard 323

Strigl, Daniela 49, 306

Strindberg, August 377

Strobl, Karl Hans 279

Struck, Karin 19, 183, 263-266

T

Taylor, Liz 349

Terhorst, Christel 16

Teuffenbach, Ingrid 311

The Beatles 251-253, $274 \mathrm{f}$.

The Rolling Stones 253

Thill, Anne 382

Thimig, Helene 303

Thomas, Dylan 304

Thornton, Thomas K. 182

Thurber, James 303

Tolstoi, Lew N. 80, 225

Töteberg, Michael 114

Trakl, Georg 91, 99, 301, $311 \mathrm{f}$.

Tranströmer, Tomas 19

Tschapke, Reinhard 283

Tumler, Franz 309, 312

Turrini, Peter 83, 204, 343, 357-361, 372

\section{U}

Unseld, Siegfried 15, 21, 30, 37-40, 43, 55 f., 61, 63, 66, 82 f., 92 f., 97, 99, 105, 109 f., 142, 156, 167, 169 f., 175-177, 181, 190-193, 200 f., 207, 221, 228, 240,
248-251, 257, 26o f., 264, 282, 289 f., 293, $321,334,336,343,350,370$ f., 376 f., 38 o, $388,398,406 \mathrm{f}$.

\section{V}

Velikić, Dragan 19

Verlaine, Paul 304

Vordtriede, Werner 360

Vormweg, Heinrich 48, 266

Vranitzky, Franz 349, 353, 371

\section{W}

Waggerl, Karl Heinrich 311-313, 318

Wagner, Christian 19

Wagner, Karl 68, 77, 142, 150, 236

Waldheim, Kurt 349

Walser, Martin 43, 81, 154, 176, 184, $191 \mathrm{f}$., 248 f., 266, 337

Wang, Cilli 103

Warhol, Andy 54

Weber, Max 124

Webern, Anton 35

Wehle, Peter 349

Weigel, Hans 260, 290, 301, $320 \mathrm{f}$.

Weinberger, Heinz 344

Weinheber, Hedwig 313

Weinheber, Josef 305-307, 312 f., 330, 334, 343

Weiss, Peter 46, 192

Wellershoff, Dieter 44, 222-224, 226, 264

Wendt, Ernst 250

Werner, Theodor W. 298

Werth, Wolfgang 55, 96

Wessely, Paula 111, 116

Whitman, Walt $304 \mathrm{f}$.

Wiele, Jan 206

Wiener, Oswald 88, 96, 145, 257

Wiesenthal, Simon 318

Wilder, Thornton 303

Wildgans, Anton 313

Williams, Tennessee 331

Winkler, Stefan 9 
Winkler, Willi 135

Wittgenstein, Ludwig 86, 148, 227, 304, 377

Wittgenstein, Paul 74

Wögerbauer, Werner 64, 70, 86, 342

Wolf, Norbert Christian 27, 216

Wolf, Ror 33, 221, 243

Wolfe, Thomas 88, 290, 304

Wolfgruber, Gernot 361

Wondratschek, Wolf 190

Woolf, Virginia 401

Wyler, William 317
Z

Zamponi, Reinulf $287 \mathrm{f}$.

Ziermann, Horst 47

Ziesel, Kurt 298, 309, 312

Zillich, Heinrich 279, 307, 311

Zimmer, Dieter E. 397

Zittrauer, Maria 297, $301 \mathrm{f}$.

Zuckmayer, Carl 88 f., 92, 94, 284, 305, 311

Zweig, Stefan 312 